\title{
POLITÉCNICA
}

Tribunal nombrado por el Magfco. y Excmo. Sr. Rector de la Universidad Politécnica de Madrid, el día de $20 \ldots .$.

Presidente

Vocal

Vocal

Vocal

Secretario

Suplente

Realizado el acto de defensa y lectura de la Tesis el día de de $201 . . .$. en la E.T.S. Arquitectura.

CALIFICACIÓN:

EL PRESIDENTE

LOS VOCALES

EL SECRETARIO 
Departamento de Urbanística Y ordenación territorial

Escuela Técnica Superior de Arquitectura de Madrid

Universidad Politécnica de Madrid

\section{METODOLOGÍA PARA REHABILITACIÓN DE GRANDES CENTROS COMERCIALES, MEDIANTE EL ANÁLISIS DEL CONTEXTO Y LA SOSTENIBILIDAD URBANA.}

TESIS DOCTORAL

Jorge Carretero Monteagudo

Arquitecto.

Director: Ester Higueras García.

Dra Arquitecta y Prof. Titular

año 2017 



\section{0.- RESUMEN E ÍNDICES}

\section{ABSTRACT:}

The studio of both the urban and architectural features, as well as the retrofitting means of application on a shopping mall, was the parting point to evaluate the sustainability of large surface shopping malls. In the current thesis, a methodology aimed to evaluate the efficacy of the retrofitting means of application on malls was developed, considering four families of retrofitting means: Eco efficient refurbishment of the mall building towards the reduction of energy consumption and the improvement of its installations, insertion of green elements and other measures to improve the environmental quality, insertion of uses, and a family of retrofitting means applied in the urban area surrounding the mall, if the impact of this last one towards urban sustainability is critical. Both the shopping mall building features and facts concerning two different urban scales were considered (wide urban scale, and nearby surrounding). Eight cases were analyzed according this methodology: Three located in the urban background of the city of Sao Paulo (Shopping Light, Shopping Eldorado and Aricanduva), Three located in Madrid (ABC Serrano, La Vaguada and Parquesur), and two located in the background of the Suburban U.S.A. (Mall of America and Belmar). The result of this study, was the establishment of a criteria to focus the operations of any retrofitting program applied on a shopping mall towards some facts related to sustainability. Being the final conclusions, the affirmation that is important to consider various means of retrofitting simultaneously on the shopping mall, as well as to consider the wide urban scale to be retrofitted, in order to achieve a relevant improvement towards sustainability. Specially in cases of shopping malls located in low density suburban areas.

\section{RESUMEN:}

El estudio de las características urbanas y arquitectónicas, y las posibles medidas de rehabilitación para los centros comerciales de gran tamaño, fueron el punto de parida para evaluar la sostenibilidad medioambiental y urbana de los mismos. En la presente tesis, se desarrolló una metodología de evaluación de cara al análisis de las medidas de rehabilitación que pudieran aplicarse sobre un centro comercial. Se consideraron cuatro familias de medidas: Rehabilitación ecoeficiente del centro hacia la reducción del consumo de energía y las instalaciones, inserción de elementos verdes para mejorar las cualidades medioambientales, inserción de usos en el centro, y una familia de medidas re rehabilitación aplicadas sobre el entorno urbano, si la situación de este último es crítica de cara a la sostenibilidad urbana. En el estudio, se consideraron tanto las características del edificio del centro comercial en sí, como las relacionadas con dos escalas urbanas relacionadas al mismo (escala urbana amplia y cercana). Ocho casos de centros comerciales fueron analizados: Tres en el contexto urbano de Sao Paulo (Shopping Light, Shopping Eldorado y Aricanduva), tres en el contexto urbano de Madrid ( $A B C$ Serrano, La Vaguada y Parquesur) y tres en el contexto de la Norteamérica suburbana (Mall of America and Belmar). El resultado del estudio permitió establecer un 
criterio para orientar las operaciones de rehabilitación de centros comerciales hacia ciertos ámbitos de la sostenibilidad. Las conclusiones finales del estudio fueron que es importante considerar varias medidas de rehabilitación de forma simultánea, a la vez que considerar la en escala urbana global para lograr una mejora relevante de cara a la sostenibilidad. Esto último especialmente en centros comerciales ubicados en entornos periféricos de baja densidad.

\section{KEYWORDS:}

Methodology, Sustainability, Retrofitting, Malls, Urban. 


\section{ÍNDICE}

1.- INTRODUCCIÓN.

Pg-1

1.1.- VISTA GENERAL

Pg-1

1.2.- PREGUNTAS E HIPÓTESIS

$\mathrm{Pg}-2$

\section{2.- PRIMERA PARTE DEL ESTADO DEL ARTE: CONCEPTOS A SER} CONSIDERADOS.

$\mathrm{Pg}-4$

\section{1.- DEFINICIÓN DE CENTRO COMERCIAL ACOTACIÓN} TERMINOLÓGICA.

$\mathrm{Pg}-4$

2.2.1.- Definición semántica

$\mathrm{Pg}-4$

2.1.2.- Centro Comercial, concepto

$\mathrm{Pg}-4$

2.1.3.- Centro comercial conceptos asociados y partes que lo componen

Pg-6

2.2.- EL CONCEPTO DE SOSTENIBILIDAD Y SUS PILARES

2.2.1.- El Pilar del medio ambiente

$\mathrm{Pg}-8$

2.2.2.- El pilar de la economía

$\mathrm{Pg}-8$

2.2.3.- El pilar social

Pg-11

2.2.4.- El pilar de la cultura

Pg-12

2.2.5.- El enfoque hacia la rehabilitación

2.4.- INTRODUCCIÓN A LA REHABILITACIÓN URBANÍSTICA.

2.4.1.- La rehabilitación urbanística de áreas de baja densidad en Norteamérica, el New Urbanism

2.5.1.- Los ámbitos relacionados con la sostenibilidad.

2.5.2.- Los ámbitos relacionados con el urbanismo y la

2.6.- UNIT RESUME, THE CONCEPTS TOWARDS THE REASEARCH QUESTIONS AND HYPOTHESES

\section{SEGUNDA PARTE DEL ESTADO DEL ARTE, ANÁLISIS HISTÓRICO, FUNCIONAL Y FORMAL DEL CENTRO COMERCIAL, PROBLEMÁTICA Y REHABILITACIÓN DE LOS MISMOS.}

\section{1.- GÉNESIS E HISTORIA DEL CENTRO COMERCIAL}

3.1.1.- El nacimiento del comercio, edad antigua preclásica

3.1.2.- El comercio y sus tipologías de edificio comercial en la antigüedad clásica (Grecia y Roma)

3.1.3.- El comercio y sus tipologías edificatorias en la Edad Media y la Edad Moderna Temprana. 
3.1.4.- Los edificios comerciales de la llustración, los prototipos de zona comercial cubierta

3.1.5.- Revolución Industrial. Primeros prototipos de centro

3.1.6.- 1900-1950, suburbanización e implantación del modelo

moderno. Implantación de las nuevas centralidades periféricas.

3.1.7.- Segunda Mitad del Siglo XX, consolidación definitiva del modelo periférico del suburb, expansión de la ciudad hacia la periferia.

3.1.8- Génesis del centro comercial de periferia, Segunda Mitad del Siglo XX.

3.1.9.- 1980-2010, Época actual, crisis económica, y medioambiental, los problemas de la ciudad extensiva.

3.2.- EL MARCO URBANO DE LOS CENTROS COMERCIALES.

3.4.- ASPECTOS FUNCIONALES, FORMALES Y PROYECTUALES DE LOS CENTROS COMERCIALES

3.4.1.- Características de proyecto a escala urbana y de entorno

3.4.2.- Características de proyecto a escala de edificio.

Pg-61

3.5.- LAS TIPOLOGÍAS DE EDIFICIO DE CENTRO COMERCIAL EN RELACIÓN AL CONTEXTO URBANO, ANÁLISIS FUNCIONAL Y FORMAL

3.5.1.- Centro Comercial en Altura

3.5.2.- Centro Comercial en superficie

3.5.3.- Centralidades comerciales, en superficie

3.6.- LA PROBLEMÁTICA ACTUAL DE LOS CENTROS COMERCIALES COMO PUNTO DE PARTIDA, CASOS ILUSTRATIVOS

3.6.1.- La problemática medioambiental de los centros comerciales.

3.6.2.- La problemática económica de los centros comerciales.

3.6.3.- La problemática social de los centros comerciales.

Pg-73

Pg-78

3.6.4.- La problemática urbanística de los centros comerciales.

Pg-79

3.6.5.- La problemática arquitectónica y de proyecto de los centros comerciales.

Pg-80

\section{7.- LA VISIÓN PROSPECTIVA EN LA PROBLEMÁTICA DE LOS} CENTROS COMERCIALES

3.8.- ESTADO DEL ARTE EN LOS MÉTODOS E IDEAS DE REHABILITACIÓN DE CENTROS COMERCIALES

3.8.1.- Rehabilitación ecológica o ecoeficiente.

3.8.2.- Rehabilitación para reinauguración comercial, o adaptación al mercado imperante. 
3.8.3.- Reforma dotacional o cambio de uso.

Pg-96

3.8.4.- Modificación o reestructuración del edificio del centro comercial para otros usos.

\section{4.-ESTABLECIMIENTO DE LAS PAUTAS DE LA METODOLOGÍA.}

4.1.- ÁMBITO DE TRABAJO DE LA METODOLOGÍA, ACOTACIÓN.

4.2.- FUNDAMENTOS DE LAS METODOLOGÍAS DE EVALUACIÓN Y PROCEDIMIENTOS.

4.2.1.- Metodología, pasos e inclusión de tipos de estudios.

Pg-104

\section{3.- BASES DE LA METODOLOGÍA DE ANÁLISIS}

Pg-106

4.3.1.- Fundamentos básicos

Pg-106

4.3.2.- Resumen de los ámbitos a considerar como base de la metodología, establecimiento del criterio.

4.3.3.- Establecimiento de la escala de medición dentro de la metodología.

4.3.4.- Gráfico final metodológico, Rosa de la Rehabilitación Sostenible

Pg-106

Pg-109

Pg-110

4.4.- ÍNDICE DE LA METODOLOGÍA, DESARROLLO DE LA MISMA

4.4.1.- Fundamentos de la analítica en los factores de la metodología.

$\operatorname{Pg}-112$

Pg-116

4.5.- FASE 0, RECOGIDA DE DATOS CUANTITATIVOS

Pg-117

4.6.- FASE 1: ANÁLISIS DEL CONTEXTO URBANO

Pg-121

4.7.- FASE 2: ANÁLISIS DE RELACIONES ENTRE CENTRO COMERCIAL Y ENTORNO URBANO

4.8.- FASE 3: ANÁLISIS DEL EDIFICIO DEL CENTRO COMERCIAL.

4.10.- QUCK REFFERENCE GUIDE TO METHODOLOGY

Pg-180

4.10.1.- Methodology basics

Pg-180

4.10.2.- Shopping mall data Analytics

Pg-182

4.10.3.- Questionnaire of the retrofitting rose graph.

Pg-188

4.11.- THE OPTIMAL CASE OF RETROFITTING

Pg-199

4.12- INTRODUCCIÓN AL ESTUDIO DE CASOS.

Pg-206

4.12.1.-Centros comerciales globales, estado actual

Pg-206

4.13.- SELECCIÓN DE CASOS DE ESTUDIO PROFUNDIZADO MADRIDSAO PAULO-NORTEAMÉRICA

4.13.1.- Justificación de la elección de São Paulo. 
4.13.2.- Justificación de la elección de Madrid, y casos a considerar.

4.13.3.- Justificación de la elección de la Norteamérica suburbana, y casos a considerar.

4.14.- RELACIONES URBANAS ENTRE LOS CENTROS Y SU ENTORNO INMEDIATO, PRIMER ACERCAMIENTO A LA REALIDAD DE LOS CASOS DE ESTUDIO

4.15.- FUENTES A CONSIDERAR PARA EL ESTUDIO DE CASOS

4.15.1.- Análisis y recogida de datos cuantitativos.

Pg-224

4.15.2.- Estudios cuantitativos y cualitativos sobre plano.

Pg-225

4.16- JUSTIFICATION OF THE CASES TO BE STUDIED, RESUME OF THE UNIT

\section{5.- ESTUDIO DE CASOS.}

Pg-229

5.1.- CASO 1: SHOPPING LIGHT

Pg-229

5.2.- CASO 2: SHOPPING ELDORADO

Pg-254

5.3.- CASO 3: SHOPPING ARICANDUVA

Pg-280

5.4.- CASO 4: ABC SERRANO

Pg-303

5.5.- CASO 5: LA VAGUADA

Pg-327

5.6.- CASO 6: PARQUESUR

Pg-350

5.7.- CASO 7: BELMAR

Pg-373

5.8.- CASO 8: MALL OF AMERICA

Pg-397

5.9.- CASE STUDY CONCLUSSIONS

5.9.1.- Retrofitting measures of application criteria according to shopping mall urban background

Pg-418

Pg-421

\section{6.- CONCLUSSIONS}

Pg-427

6.1.- INTRUDUCTION TO CONCLUSIVE COMPARATIVE ANALYSIS

Pg-427

6.1.1.- Establishment of the theoretical retrofitting operations to be applied for each center

6.1.2.- Parameters and thresholds of relevance

Pg-429

6.1.3.- The final conclusions establishment

Pg-430

6.2.- THE EFFECTS OF THE THEORETICAL RETROFITTING OPERATIONS

6.2.1.- Calculus performed, and their results for each case

6.2.2 Analysis of the effects of retrofitting measures

Pg-430

6.2.3.- Retrofitting means put in together, resume and dimension of the improvements achieved 
6.2.4.- Retrofitting results considering the cases by urban background

6.3.- FINAL CONCLUSSIONS, RESPONSES TO HYPOTHESES AND RESERCH QUESTIONS.

6.3.1.- Response to the research question.

6.3.2.- Response to the hypothesis 1

6.3.3.- Response to the hypothesis 2 .

Pg-446

6.3.4.- Response to the hypothesis 3.

Pg-446

6.3.5.- Epilogue, final conclusion.

Pg-447

6.4.- RESUMEN DE LAS CONCLUSIONES.

6.4.1.- Introducción a las conclusiones, las medidas de

6.4.3.- Aplicación de las medidas de rehabilitación sobre los casos

Pg-450

6.4.4.- Efectos de las medidas de reforma puestos en común, y relevancia de las mismas.

Pg-455

6.5.- CONCLUSIONES FINALES, PREGUNTAS DE INVESTIGACIÓN E HIPÓTESIS.

6.5.1 Respuesta a la pregunta de investigación.

Pg-458

6.5.2.- Respuesta a la hipótesis 1

Pg-459

6.5.3.- Respuesta a la hipótesis 2

Pg-460

6.5.4.- Respuesta a la hipótesis 3

Pg-460

6.6.- ANÁLISIS RETROSPECTIVO, FORTALEZAS Y DEBILIDADES DE LA METODOLOGÍA Y DE LA INVESTIGACIÓN.

6.6.1.- Limitaciones de la investigación

Pg-461

6.6.2.- Fortalezas del método empleado.

6.7.- FUTUROS TRABAJOS DE INVESTIGACIÓN A PARTIR DE LA PRESENTE TESIS 
METOdOLOGÍA PARA REHABILITACIÓN DE GRANDES CENTROS COMERCIALES, MEDIANTE EL ANÁLISIS DEL CONTEXTO Y LA SOSTENIBILIDAD URBANA.

ANEXO 1: GRÁFICOS RESUMEN ESTUDIO CASOS. (inglés)

ANEXO 2.- ESTADO DEL ARTE EN METODOLOGÍAS DE ANÁLISIS

AMBIENTAL, FUNDAMENTOS Y TIPOS DE ANALÍTICA.

Pg-490

ANEXO 3.- ÍNDICE DE FIGURAS

Pg- 495

Agradecimientos

Pg-509 


\section{1.- INTRODUCCIÓN.}

\section{1.- VISTA GENERAL}

El objetivo de la presente investigación, es el análisis del tema de la rehabilitación de los centros comerciales céntricos y periféricos. Concepto que resulta ser de interés, debido a que en los últimos años del siglo XX y principios del Siglo XXI, esta tipología de edificio experimentó una época dorada de expansión, al mismo tiempo que las ciudades se expandían hacia las periferias aledañas. La crisis global reciente, junto con un incremento en la toma de conciencia medioambiental relacionado con la arquitectura y la ciudad, pusieron esta tipología de edificio en cuestión, a la vez que también fue cuestionado el urbanismo de nueva construcción, baja densidad y expansión, dónde nació la tipología del centro comercial moderno tal y cómo se conoce.

En la actualidad la crisis del modelo de ciudad suburbano, ha derivado en nuevas corrientes de urbanismo que apuestan por la sostenibilidad en las otras facetas que la componen, y la rehabilitación, reestructuración o readaptación de la edificación existente en lugar de la construcción de nuevos desarrollos en territorios naturales (Planes de rehabilitación de barrios vulnerables, New Urbanism...). Esto también ha afectado a los centros comerciales, y el resultado es que muchos ejemplares de gran superficie han caído en completo desuso debido a la saturación de mercado, y éstos se han reformado considerando los preceptos anteriormente mencionados. El resultado ha sido la consolidación de entornos urbanos relativamente complejos, sustituyendo el centro comercial de gran superficie. (Belmar, Boca Raton, Cottonwood...)

En este contexto, el autor de la presente tesis optó por clasificar y evaluar las posibles maneras de rehabilitar un centro comercial, para de este modo dar una visión de cómo se podría acometer una reforma de este tipo de edificios de imagen y formalización característica, teniendo un solo objetivo en mente: la meta de la ciudad sostenible.

De este modo, la presente investigación va a tener la siguiente estructura básica:

En primer lugar van a definirse los términos intervinientes en lo que es el tema a abordar, realizándose un estudio de estado de la cuestión sobre el tema de la sostenibilidad, la rehabilitación de edificios, y los centros comerciales. Analizando también la historia de los mismos, sus características, su problemática y las escuelas de y métodos para su rehabilitación de acuerdo a la sostenibilidad.

En Segundo lugar, va a elaborarse una metodología de análisis de los factores que tienen que considerarse para la rehabilitación de los centros comerciales, todo ello de cara a la sostenibilidad urbana y medioambiental. Va a considerarse cuatro ámbitos: (eficiencia energética, cualidades medioambientales, mezcla de usos, y rehabilitación recomendada en el entorno urbano, antes que sobre el propio centro). Cada uno de estos ámbitos va a ser desglosado en tres medidas de rehabilitación, en los cuales se va a establecer una puntuación de 0 a 10, en función del estado actual del centro. A cuanta mayor puntuación en el baremo, menos recomendable y/o preferente va a ser la medida de rehabilitación de cara a la mejora 
de la sostenibilidad urbana y medioambiental del centro comercial. Cada una de estas medidas de rehabilitación, y la puntuación en las mismas, van a establecerse mediante un cuestionario relativo al estado actual del centro.

En tercer lugar, van a analizarse ocho casos de centros comerciales de gran superficie en tres contextos urbanos diferentes, (Sao Paulo, Madrid y la América suburbana), se va a aplicar la metodología propuesta en la tesis.

Finalmente, y de cara a aclarar las conclusiones y la pregunta de investigación, van a considerarse diferentes medidas de rehabilitación teóricas en cada uno de los ocho centros comerciales analizados, para ver así las posibilidades de las mismas y sus efectos de cara a una mejora de la calidad ambiental y de la complejidad y actividad urbana. Estas operaciones de rehabilitación aplicadas van a basarse en la optimización de las instalaciones, el incremento de superficies verdes sobre la cubierta y la parcela del centro comercial, y la adición de usos no comerciales. Todo ello dentro del centro comercial analizado. Este apartado será utilizado para valorar de manera cuantitativa los efectos de una posible rehabilitación de cara a los objetivos de la tesis (la mejora de la sostenibilidad de los centros comerciales). Siendo en ningún momento considerado como una maniobra de proyecto.

Los efectos logrados a rasgos generales, es que los centros comerciales precisan de diferentes medidas de rehabilitación dependiendo del caso, y el contexto urbano. En los centros comerciales de contexto céntrico, la rehabilitación a considerar debería de estar enfocada generalmente en la mejora de las condiciones medioambientales, y en los casos periféricos las mejoras deben de centrarse en la inserción de usos, sobre todo si el entorno es de baja complejidad urbana y mezcla de usos. No obstante, es importante considerar, que la rehabilitación de un centro comercial exclusivamente no va a solucionar los problemas de insostenibilidad urbana. Esto se agrava incluso más en las zonas de baja densidad, con una configuración basada en el uso masivo de medios motorizados. Otra faceta a considerar, es que los programas de rehabilitación que abarcan más ámbitos y facetas son más eficaces que los que abarcan una faceta exclusivamente.

\section{2.- PREGUNTAS E HIPÓTESIS.}

En base a lo estudiado en el apartado, se estableció la siguiente pregunta de investigación para la presente tesis: ¿La rehabilitación de los centros comerciales, tanto en el ámbito urbanístico, como en el medioambiental, traería consigo una mejora relevante del medio ambiente urbano?.

Considerando las siguientes hipótesis derivadas:

1: Se puede lograr una mejora en la revitalización del área urbana amplia, a través de la alteración del centro comercial y su parcela, mediante diferentes técnicas de rezonificación, adición o alteración de usos. 
2: La aplicación de una única técnica de rehabilitación resultará insuficiente para poder producir una reducción relevante del impacto ambiental. se hará necesaria la aplicación de varias técnicas de manera simultánea

3: La aplicación de estas técnicas, independientemente del alcance, va a resultar insuficiente, ya que para que se produzca una reducción relevante del impacto ambiental a escala de la ciudad, hay que aplicar las técnicas de rehabilitación sobre el conjunto urbano que lo rodea, resultando de importancia la definición de la escala de la intervención. 


\section{2: PRIMERA PARTE DEL ESTADO DEL ARTE: CONCEPTOS A SER CONSIDERADOS.}

\section{1.- DEFINICIÓN DE CENTRO COMERCIAL ACOTACIÓN TERMINOLÓGICA.}

\subsection{1.- Definición semántica.}

El centro comercial es el tema en el que se centrará la presente tesis doctoral. Tal y como se concibe de manera general hoy en día, es una tipología edificatoria de reciente génesis y configuración. A grandes rasgos, el término centro comercial se estructura en base a dos criterios, y cada uno de ellos viene a significar lo siguiente de acuerdo al Diccionario de la Real Academia Española de la Lengua.

Centro: Entre las muchas definiciones que aparecen, las más cercanas a nuestro concepto a analizar es: "7. Lugar dónde parten o dónde convergen acciones particulares coordenadas". "8. Punto donde habitualmente se reúnen los miembros de una sociedad o corporación" Siendo sin duda la más distintiva la de "16: Lugar en el que se desarrolla más intensamente una actividad determinada" ${ }^{1}$.

Comercial: De entre sus significados, La definición más acorde al concepto estudiado es "Perteneciente al comercio y a los comerciantes"2.

De este modo, uniendo los dos términos semánticos, la definición de centro comercial, sería básicamente la de "Lugar en que se desarrolla más intensamente una actividad perteneciente al comercio y a los comerciantes". Y de esta manera, en base a este concepto se ha consolidado una tipología edificatoria, con unas características funcionales y formales destinadas a cumplir las funciones especificadas en la definición descrita anteriormente.

\subsection{2.- Centro Comercial, concepto:}

El Centro Comercial, es un edificio que hace el papel de "Lugar en que se desarrolla más intensamente una actividad perteneciente al comercio y a los comerciantes". y ese lugar requiere de unas características adaptadas a este uso.

El International Council of Shopping Centers, profundizó en la definición de centro comercial, acuñando en el año 2004, dos conceptos que entre sí son muy parecidos: Estos dos conceptos son Shopping Center y Mall. El "Shopping Center", "consiste en una instalación comercial, que cuenta con galerías cerradas, flanqueadas por tiendas. Normalmente esta instalación tiene aparcamientos en la misma parcela que pueden ser en superficie o en altura"13. El Mall, aunque tipológicamente hablando sea un elemento arquitectónico muy parecido al shopping center, en características funcionales y formales, para definirlo hay que considerar otros conceptos más relacionados con la gestión económica. De este modo, el International Council of Shopping

\footnotetext{
${ }^{1}$ Real Academia Española (2001). Diccionario de la Lengua Española, Vigésima primera edición, Pág. 323

${ }^{2}$ Real Academia Española(2001). Diccionario de la Lengua Española, Vigésima primera edición, Pág. 365

${ }^{3}$ ICSC (2004). Incluido en artículo "The Impact Of Shopping Mall Upon the Future of Urban Planning in Greater Amman por Samer Abu-Ghazalah", Ali Abu-Ghanimeh, et al.
} 
Centers define el término "Mall" como "Una serie de tiendas cuya fundación y gestión SE DEBE A LA ACCIÓN DE UNA ENTIDAD GESTORA QUE TAMBIÉN ES LA PROPIETARIA DE LAS MISMAS, el dimensionado del conjunto de tiendas se hace en relación al potencial de mercado de la zona a la que sirve ${ }^{\prime \prime 3}$. De este modo, se puede sacar en conclusión que la diferencia entre el centro comercial y el Mall, es la presencia de la empresa gestora.

No obstante, la presente tesis doctoral va a centrarse en lo que es la tipología edificatoria, que a efectos formales y funcionales, es prácticamente igual tanto para un centro comercial gestionado de manera independiente (Shopping Center) como para uno que cuenta con administración centralizada (Mall). De manera que esta distinción no va a resultar relevante para la presente tesis, ya que su estudio requiere considerar temas de economía o gestión.

En la actualidad, el concepto de Centro comercial, a efectos de imagen tipológica arquitectónica, es normalmente asociado con un edificio de mayor o menor tamaño y altura, cuyo espacio interior está configurado en base a una o varias galerías o plazas de grandes dimensiones, que pueden ser abiertas o cerradas, en cuyos flancos se dispone de gran cantidad de tiendas o expositores cuya función primordial es la de despachar o exponer género de diferentes tipos. Pero no obstante, este conjunto comercial normalmente trata de ser atractivo, cómodo y potente de cara al espectador, como se explicará en capítulos posteriores.

Por otra parte, fuera de lo que es la imagen, la gestión del centro comercial, puede o no correr a cargo de una empresa gestora, que se encarga de fijar las condiciones de alquiler de los locales para las tiendas. A su vez, esta empresa, en el caso de que la haya, para mantener en activo el negocio, optará a su vez por diferentes estrategias de atracción, tales como la presencia de una empresa locomotora que atraiga compradores al centro, a la vez que diferentes maniobras publicitarias o de servicios.

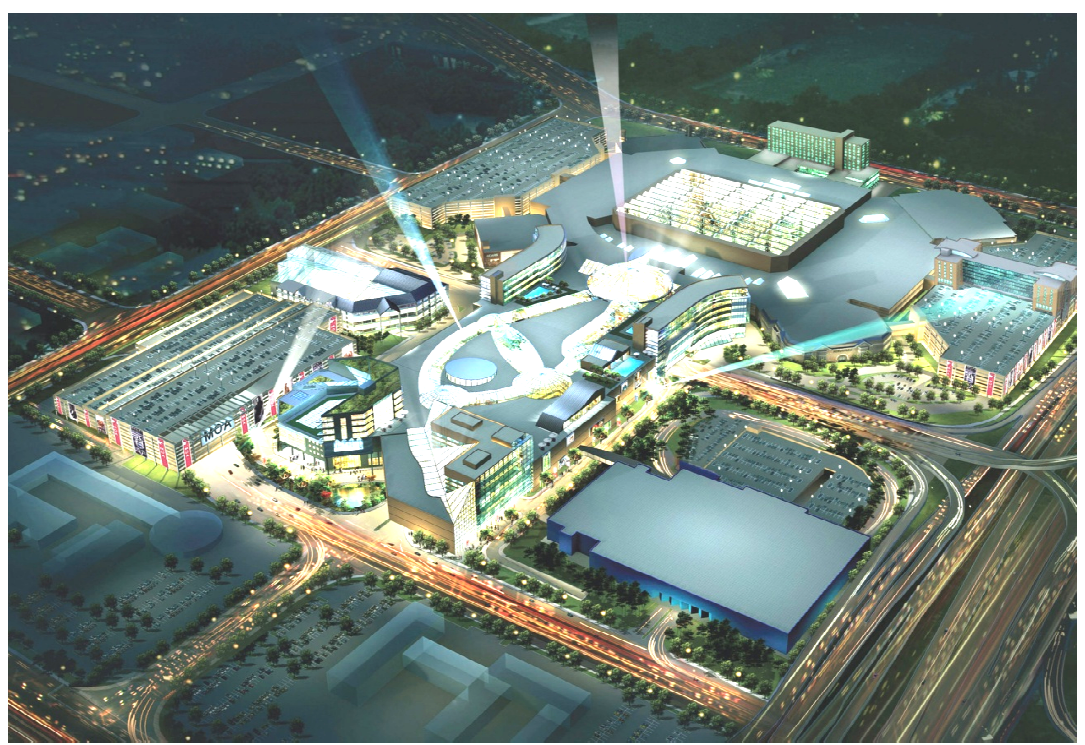

Figura 2.1.1 Renderizado de Mall of America y su futura ampliación, ejemplo de centro comercial de gran tamaño. Fuente: Star Tribune 


\subsection{3.- Centro comercial, conceptos asociados y partes que lo componen.}

La tipología edificatoria del centro comercial, a primera vista es muy compleja, tanto en su proyecto como en su gestión debido a que dentro de ella interviene una amplia variedad de factores, relacionados con las actividades que van a tener lugar en su interior. A día de hoy, los centros comerciales suelen incorporar dentro de su edificación una gran variedad de usos, todo ello con el fin de ampliar la oferta de cara al comprador y así tener mayores beneficios.

Harvard Proyect on the City, en cuyo artículo "Shopping" (Publicado en el libro Mutaciones en el año 2000) enuncia el tema de la actividad comercial en sí, como muy propensa a la interacción con otras actividades ajenas, derivando esta interacción en la creación de tipologías edificatorias.

De este modo, dentro de los centros comerciales, cada actividad presente va a tener un espacio asociado, dimensionado y proyectado de acuerdo a su función, hecho que hace de la tipología del centro comercial una tipología compleja tanto funcional como formalmente. De este modo es necesario explicar las partes del centro comercial, tanto en el ámbito de lo funcional, como de lo formal, viendo las interacciones de la misma con la actividad comercial. Las partes que componen un centro comercial son básicamente las siguientes:

Galería: Espacio de distribución y estancia del centro, es la parte más importante del mismo ya que garantiza el flujo de compradores.

Empresa Locomotora: Esto consiste básicamente en un negocio de gran volumen comercial, cuyo papel principal es el de ser un elemento atrayente de clientela para el centro.

Tiendas en alquiler: Las tiendas son otra de las partes importantes del centro, pues es el lugar en el que se realizan los intercambios comerciales. Su gestión se basa en el alquiler a una gestora si es de tipo mall con empresa gestora, o es propiedad del comerciante, si es un shopping center autogestionado.

Área de restauración o Food Court: Zona dentro del centro dedicada principalmente al ocio o la restauración, como actividad complementaria a las compras.

Aparcamientos: Zona de estacionamiento para los vehículos de los compradores y trabajadores del centro, se diseñan para suplir una gran demanda.

Otros usos complementarios: Usos complementarios o ajenos a la venta de género o la restauración, cuyo fin es ampliar la oferta de actividades del centro de cara al comprador, pueden ser más o menos lucrativos.

Espacios de Servicio: Aunque estos espacios no son lucrativos, disponen de las instalaciones necesarias para el funcionamiento del centro.

Estos conceptos serán explicados de manera más detallada en el capítulo dedicado a las características formales, proyectuales y funcionales del centro. De este modo, una vez definido el objeto de estudio de la presente tesis, se enunciará el otro concepto de importancia para la misma, que es el de la rehabilitación sostenible. 
A posteriori se explicarán las repercusiones de los centros comerciales sobre los pilares de la sostenibilidad y el ámbito del urbanismo.

No obstante, para entender el espacio y la proyección de los centros comerciales, es necesario aclarar dos conceptos muy ligados a la arquitectura de los mismos.

Jerde Transfer: Esta maniobra de proyecto y concepción espacial, está referenciada al Arquitecto Norteamericano Jon Jerde. El motivo de esto, era que susodicho arquitecto en sus proyectos de arquitectura comercial, trataba de ofrecer a los visitantes del centro, una experiencia urbana, creada a través de un decorado artificial, el cual no podía corresponderse con el lugar, debido a que el espacio comercial en cuestión no tenía conexión con la ciudad

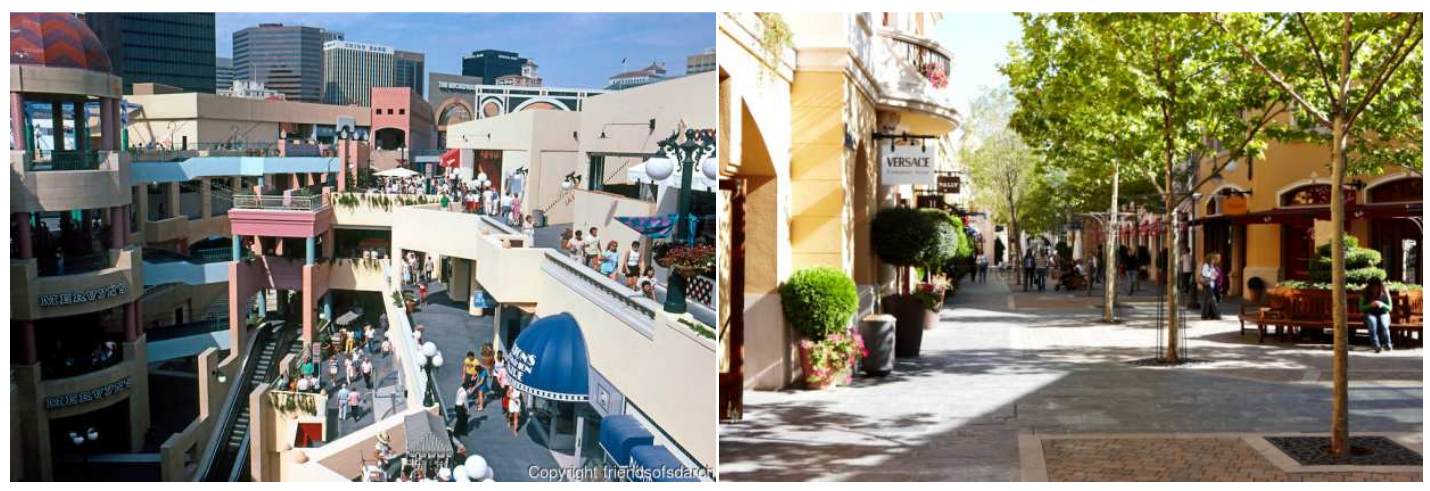

Figura 2.1.2 Imagen urbana en una galería comercial proyectada por Jon Jerde, y ejemplo de Jerde Transfer en el centro comercial de Las Rozas Village. Fuente: Friendsofsdarch ,Secretos de Madrid

Gruen Transfer: Esta idea, hace referencia al Arquitecto Austriaco Victor Gruen, quien, ideó los primeros centros comerciales de la historia (Northland y Southdale) como entes centralizados que pudieran ser representativos para una extensa área urbana. En esos edificios se debían de ofrecer las máximas comodidades posibles, siendo el resultado edificaciones cerradas sobre sí mismas con unos espacios muy característicos. El perfeccionamiento de estas ideas, y su uso con fines comerciales, trajo consigo la consideración de ciertas maniobras de proyección e imagen arquitectónica, que se plasmaron en la concepción del interior del centro comercial como un espacio completamente cerrado de grandes dimensiones, confuso en sus recorridos, en el cual cobra importancia que el visitante fije la vista en los bienes de consumo expuestos, y otros efectos psicológicos ligados a sonidos y colores, como refuerzo de la imagen del centro comercial.
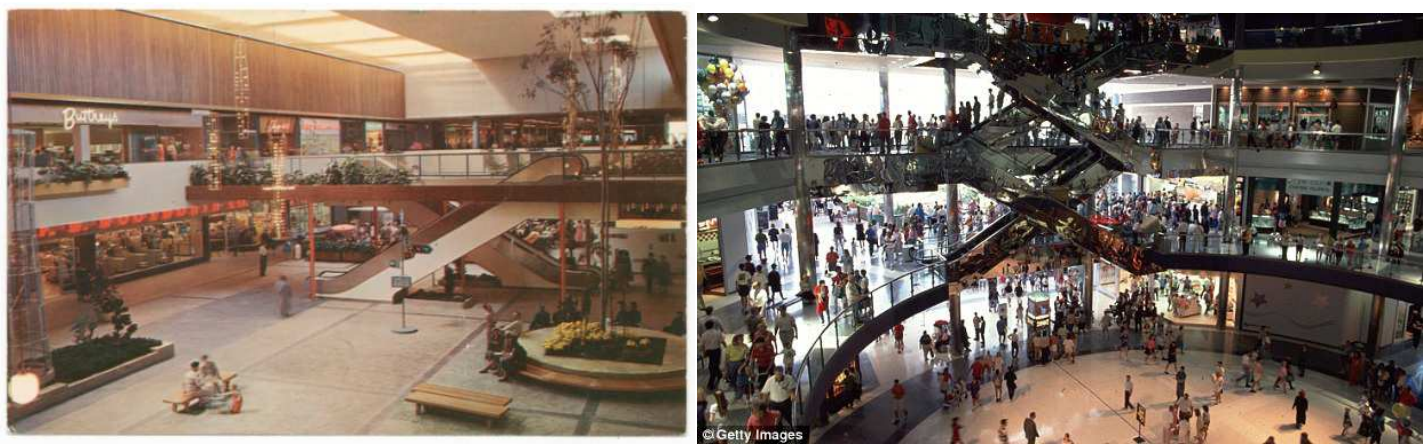

Figura 2.1.3 Interior del centro comercial Southdale, y Mall of America, identidad entre los espacios interiores en los dos casos. Fuente: Minnesota Hystorical Society, Getty images 


\section{2.- EL CONCEPTO DE SOSTENIBILIDAD Y SUS PILARES.}

Una vez acotado el concepto sobre el que se va a trabajar, En la presente tesis doctoral, se plantea el análisis de una "rehabilitación sostenible" sobre los centros comerciales.

La idea de la "rehabilitación sostenible", responde íntegramente a la intervención sobre un elemento urbanístico o arquitectónico de mayor o menor tamaño, con el objetivo de adaptarlo de acuerdo a los preceptos del desarrollo sostenible. No obstante, la primera parte de esta exposición del tema, será enunciar los dos conceptos por separado, de "sostenibilidad" y "rehabilitación" para a posteriori dar referencias sobre rehabilitación sostenible, más cercanas al tema de la tesis.

Para establecer un inicio en el tema: respecto al término de "sostenibilidad", su origen hay que remontarlo a la doctora y ex Primera Ministra de Noruega, Gro Harlem Bruntland, Quién en 1987, encabezó una comisión exponiendo ante la Asamblea General de las Naciones Unidas, el problema que suponía el hecho de que el desarrollo social y tecnológico, había supuesto una degradación del medio ambiente. En esa comisión fue realizado un informe, llamado "Nuestro Futuro Común" (Our Common Future), en el que se acuñó el término de "sostenibilidad", siendo su base el respeto al medio ambiente, sin negar o comprometer el desarrollo social y tecnológico anteriormente citado. Por consiguiente aparece el término "Desarrollo Sostenible", y se describe como "aquel que satisface las necesidades del presente sin comprometer las necesidades de las futuras generaciones ${ }^{\prime 4}$ José Manuel Naredo recoge esta definición en la introducción de su artículo "El Origen, el uso y el contenido del término Sostenible" ${ }^{5}$.

No obstante, el concepto de sostenibilidad, para considerarlo de manera correcta, hay que referenciarlo a tres pilares fundamentales, establecidos por las naciones unidas, a partir de las pautas del Informe Bruntland, que son la economía, la sociedad y el medio ambiente, más un cuarto pilar propuesto a posteriori por la Organización Mundial de Ciudades en el año 2010, que es el de la cultura. No obstante, debido a los requerimientos de conocimiento sociológico de los cuales el autor carece, este último pilar se considerará de manera somera y siempre fuertemente relacionado con el resto de los pilares anteriores, haciendo alguna que otra citación a este concepto en los capítulos donde proceda.

\subsection{1.- El Pilar del medio ambiente.}

El pilar relacionado con el ámbito del medio ambiente, es en el que se centrará principalmente esta tesis. Y pone como base el hecho de que el desarrollo debe de ser compatible con las capacidades del planeta para asimilar los impactos medioambientales, así como el hecho de evitar el uso de recursos que no pueden ser regenerados por el planeta. Siendo esto además

\footnotetext{
${ }^{4}$ Comisión de las Naciones Unidas, Bruntland G. H. (1987). Informe de la Comisión Mundial sobre el Medio Ambiente y el Desarrollo, Informe Nuestro Futuro Común, También conocido como Informe Bruntland.

${ }^{5}$ Naredo J. M. (1997). Sobre el Origen, el uso y el contenido del término Sostenible.
} 
un problema de primer orden para la concepción de la ciudad sostenible, ya que la configuración urbanística y arquitectónica de la mayoría de las ciudades actuales, no propicia hábitos sostenibles de vida. Antes de pasar al tema de los centros comerciales, resulta prioritario aclarar el tema de la insostenibilidad urbana, y los posibles métodos que hay para paliarla.

Salvador Rueda, enuncia que en el medio urbano actual, los recursos empleados para su funcionamiento son degradados, considerando la capacidad recuperativa de la naturaleza que rodea la ciudad o incluso la que está presente dentro de la misma. Esto al final resulta en un despilfarro de recursos. El autor establece una ecuación entre energía consumida en la ciudad (E) y complejidad urbana $(\mathrm{H})$, y la propuesta para paliar este problema es reducir el consumo de energía a través del cambio de modelo urbano de manera evolutiva en el tiempo ${ }^{6}$, considerando los medios pertinentes en materias de gestión, rehabilitación y hábitos de vida. (Figura 2.2.1)

Salvador Rueda en una conferencia realizada en el COAM el 19 de febrero de 2016, a la que el autor de la tesis asistió. Expone el tema del impacto inevitable que generan los sistemas complejos sobre los más sencillos (ciudad sobre naturaleza), insistiendo en la necesidad de reducir este impacto en la medida de lo posible. también este autor enunció el tema de la ciudad sostenible y su concepción y proyecto, considerando las diferentes facetas intervinientes de forma equilibrada. Esta tesis buscará la adaptación del edificio de centro comercial como parte de la ciudad, de cara a estos objetivos expuestos.

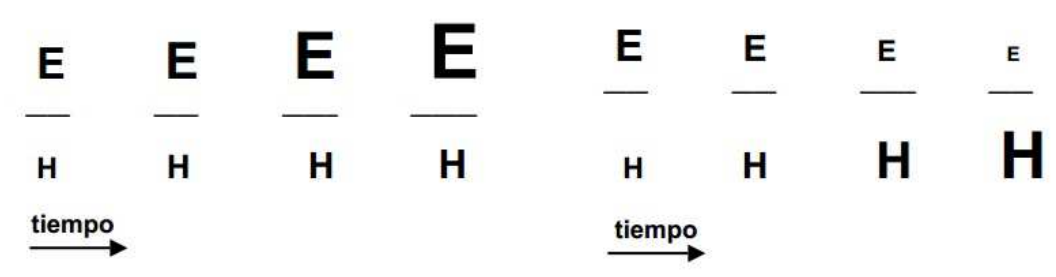

Figura 2.2.1 Ecuación de la sostenibilidad urbana en el tiempo, Izquierda, Evolución en la ciudad actual, Derecha evolución propuesta por Salvador Rueda Fuente y autoría: Salvador Rueda, Un Nuevo Urbanismo para una ciudad más Sostenible

Dando un paso más adelante en este tema, relacionado con la sostenibilidad urbana, se presenta el concepto de "complejidad urbana", De acuerdo a la Agencia del Medio Ambiente de Barcelona, este concepto es un índice cuantitativo, que indica la mezcla de usos y la existencia de interacciones sobre un área urbana determinada. Las zonas céntricas de las ciudades, suelen ser entornos urbanos complejos, debido a la gran diversidad de actividades presentes (Viviendas, oficinas, tiendas, dotaciones, ocio...) que generan interacciones. Mientras que las áreas zonificadas por usos y de poca densidad dentro de las ciudades, suelen ser ejemplos de zonas de baja complejidad urbana.

Atender a la complejidad, es importante para acometer una correcta operación de rehabilitación en el ámbito de lo sostenible, buscando siempre la mejora en este indicador, ya

\footnotetext{
${ }^{6}$ Rueda S. (2005). Un Nuevo Urbanismo para una ciudad más Sostenible, I Encuentro de Redes de Desarrollo Sostenible y de Lucha contra el Cambio Climático.
} 
que de acuerdo a Salvador Rueda, una ciudad de mayor complejidad, va a resultar más respetuosa a efectos de los pilares de la sostenibilidad.

Una vez enunciados los conceptos generales a tratar de la sostenibilidad urbana, va a ser necesario dar un paso adelante en conceptos más concretos y afines al trabajo que se está realizando. Los centros comerciales al tratarse de edificios va a ser necesario un acercamiento al tema del impacto ambiental generado por la edificación.

Margarita de Luxan, en un gráfico, analiza los impactos que tienen los edificios sobre el Medio Ambiente, en relación a las diferentes fases del ciclo de vida de los mismos, estando el mayor impacto en el proceso de fabricación de los elementos constructivos y en segundo lugar en el de instalaciones y equipos. Concepto que sin duda debe de ser tenido en cuanta a la hora de acometer una rehabilitación, ya que ésta va a requerir de nuevos materiales e instalaciones. (Figura 2.2.2)

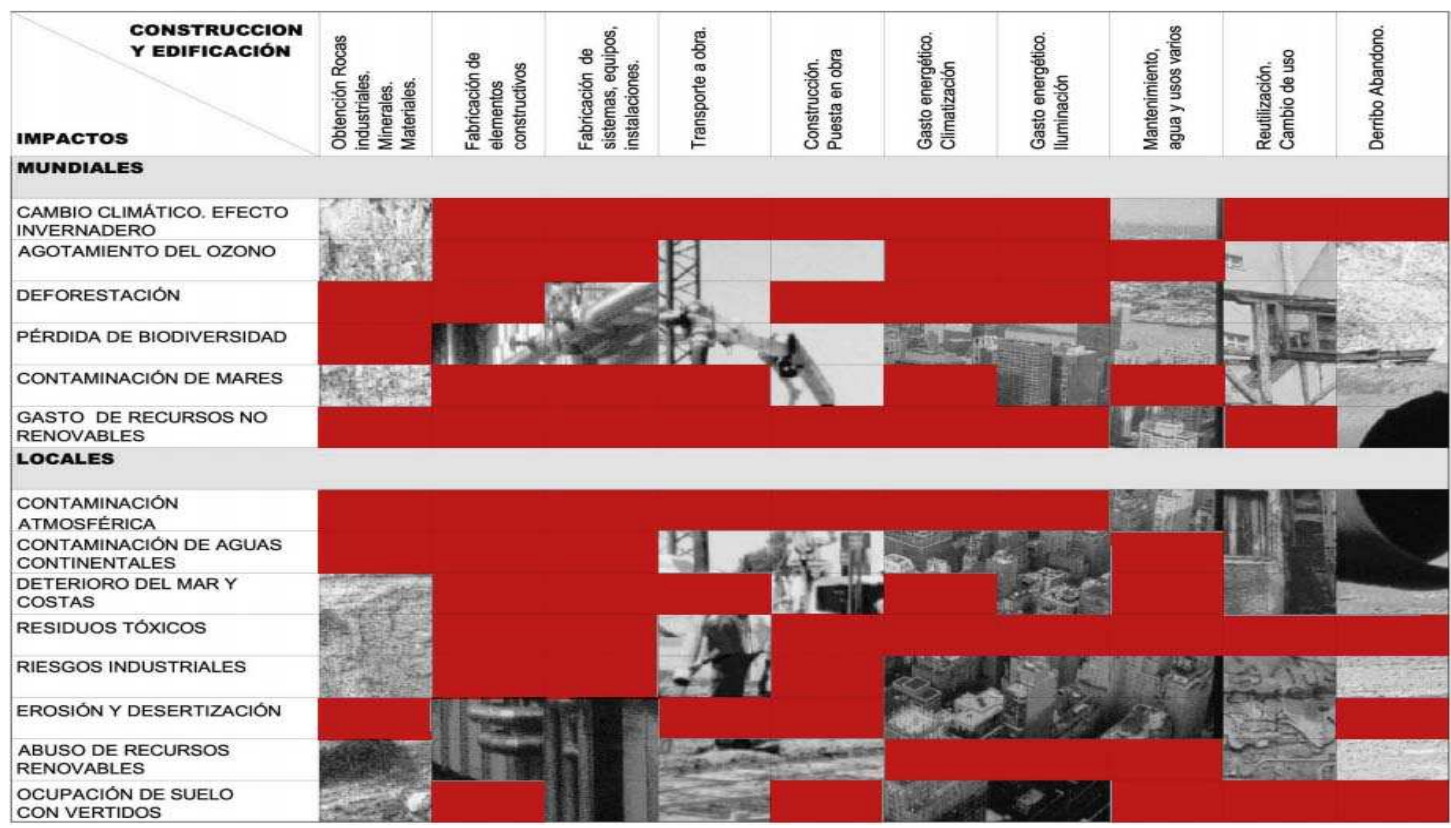

Figura 2.2.2 Impacto medioambiental de la edificación en todas sus fases del ciclo de vida. Fuente y autoría: Margarita de Luxan

Sin embargo, esta autora centra sus estudios en la edificación residencial, esto está muy justificado ya que la mayoría de los edificios de una ciudad son de este tipo. No obstante, en el tema de edificación, los centros comerciales trabajan otro tipo de superficies y sistemas constructivos.

De manera paralela, Mariano Vázquez Espí, en el artículo "Reducción de la Insostenibilidad Mediante la Rehabilitación Urbana", enuncia los problemas ambientales de la construcción, dando balances de energía empleada en la construcción, y polución emitida en relación con las obras en los edificios. Coincide en que la medida de edificación que garantizará el menor coste de combustible, es la rehabilitación ecoeficiente (La que en sus conceptos de proyecto incluya la reducción del consumo energético y de emisiones) a cien años de durabilidad (Figura 1.23) ${ }^{7}$.

\footnotetext{
${ }^{7}$ Vazquez Espí M. (2010). Reducción de la Insostenibilidad Mediante la Rehabilitación Urbana.
} 


\section{Consumos anuales de combustibles según estrategias de sustitución \\ Total $=($ Fabricación $[+$ demolición $])+$ Uso $\left(\mathrm{MJ} / \mathrm{m}^{2}\right)$

\begin{tabular}{|c|c|c|c|}
\hline $\begin{array}{c}\text { Nueva planta } \\
\text { a } \mathbf{3 0} \text { años }\end{array}$ & $\begin{array}{c}\text { Nueva planta } \\
\text { a } \mathbf{5 0} \text { años }\end{array}$ & $\begin{array}{c}\text { Rehabilitación } \\
\text { a } \mathbf{1 0 0} \text { años }\end{array}$ & $\begin{array}{c}\text { Rehabilitación } \\
\text { ecológica } \\
\text { a } \mathbf{1 0 0} \text { años }\end{array}$ \\
$\begin{array}{c}383=133+250 \\
\mathbf{1 0 0} \%\end{array}$ & $\begin{array}{c}330=80+250 \\
\mathbf{8 6} \%\end{array}$ & $\begin{array}{c}280=15+250 \\
\mathbf{7 3} \%\end{array}$ & $\begin{array}{c}203=15+188 \\
\mathbf{5 3} \%\end{array}$ \\
\hline
\end{tabular}

Figura 2.2.3 Consumos relativos de combustibles de acuerdo al modelo de intervención sobre en entorno urbano edificado. Fuente y autoría: Mariano Vázquez Espí.

Estos estudios también están centrados en los edificios de viviendas, siendo de importancia para la presente tesis el concepto que es planteado a rasgos generales.

Como conclusión a esto, en relación con los centros comerciales, la sostenibilidad es un tema muy importante, debido a que estos edificios tienen aparentemente un impacto ambiental muy elevado, al requerir del uso de grandes cantidades de energía, agua y recursos materiales para su funcionamiento. De los estudiado por el presente autor, la mayoría de los documentos relacionados con la rehabilitación de centros comerciales profundizan en el tema de la economía, las características espaciales, el comportamiento urbano o las instalaciones energéticamente eficientes.

\subsection{2.- El pilar de la economía}

El pilar de la sostenibilidad relacionado con el ámbito de la economía, tiene como preceptos y objetivos la garantía de la viabilidad económica del desarrollo. Una acción en sí es sostenible de acuerdo a este pilar, cuando esta deriva en una cantidad mayor o menor de beneficios para el promotor de la misma, pudiendo ser estos ser utilizados en el refuerzo de la propia actividad económica, o en el mantenimiento y mejora del medio de cara a cualquiera de los otros pilares de la sostenibilidad.

Donella H. Meadows, en el informe Los límites del Crecimiento (The Limits to the Growth), exponen la importancia de no sustentar el crecimiento económico a costa de la degradación medioambiental, algo que en al año 1972 se veía inevitable, al no considerar el presente informe los avances tecnológicos. De este modo, se plantea como alternativa un crecimiento estancado en la economía ${ }^{8}$. José Manuel Naredo, Afirma que el término de Sostenibilidad muchas veces se ha relacionado con el desarrollo económico, estableciendo que esa similitud ha llegado a una falta de comprensión del término. ${ }^{2}$

En muchas áreas incluidas dentro del panorama mercantil mundial actual, los centros comerciales tienen problemas económicos debido a su obsolescencia y la saturación de su

\footnotetext{
${ }^{8}$ D. Meadows, Et al. (1972). The Limits to Growth.
} 
respectivo mercado. De este modo, toda operación que esté ligada al desarrollo sostenible aplicada sobre un centro comercial, debe de estar enfocada en hacerlos de nuevo económicamente viables, intentando en todo momento que los beneficios de susodicha actividad nunca se generen a costa de la degradación de los otros pilares de la Sostenibilidad (medio ambiente, sociedad y cultura).

Este pilar, aunque no es el que se tratará más a fondo en la presente tesis, para muchos autores, (Fillion And Hammond, Jacob Jonathan Davis, Dunham Jones Elen, Michael C. Polentz. Clayton B. Gantz. Manatt, Phelps \& Phillips, Abrudan Ioanna, Nicoleta. Davija Dan, Cristian...) la rehabilitación en el ámbito de lo económico, es un tema de especial importancia que resulta ser primordial. Esto se debe a que la inversión monetaria necesaria tanto para construir, como para rehabilitar un centro comercial es muy cuantiosa. El tema de la rehabilitación económica de los centros comerciales, se basa en la consideración de una serie de operaciones materiales y/o de gestión, encaminadas a la reinclusión del centro comercial en el mercado y la garantía de su viabilidad económica dentro del mismo; y es un tema de importancia para posteriores líneas y trabajos de investigación.

\subsection{3.- El pilar social.}

El pilar relacionado con el ámbito de lo social se basa principalmente en el hecho de que las acciones tomadas y relacionadas, deben de un modo u otro garantizar la cohesión social, y de esta manera estar enfocadas hacia la consecución de ciertos objetivos comunes dentro de la comunidad en la que las medidas han sido aplicadas. En ese sentido los centros comerciales actuales son lugares proyectados principalmente hacia la economía de la compra-venta y la función social está limitada a los posibles efectos que el intercambio comercial de productos pudiera tener hacia la comunidad en la que se asienta el centro. Es importante considerar para el estudio de la función social del centro comercial, que la actividad del mismo y sus mayores o menores repercusiones sociales, va a estar limitada a los horarios de apertura y cierre de los mismos.

Para la presente tesis doctoral, el tema social va a ser considerado, ya que algunos de los indicadores que tratará tienen mucho que ver de manera directa e indirecta con el tema social, y sin duda, la aplicación de una o varias medidas.

\subsection{4.- El pilar de la cultura.}

En referencia al pilar de la cultura, su estudio está más ligado a temas de sociología o política. Eso no significa en absoluto que sea ajeno al tema de los centros comerciales. Pues el uso continuado de los mismos ha generado en la población unos determinados hábitos culturales. Y sin duda la rehabilitación de los mismos va a alterar los hábitos anteriormente mencionados. No obstante, aunque este pilar se va a mencionar cuando sea necesario dentro de la presente tesis, su estudio en profundidad no va a ser considerado, siendo el estudio de la cultura como 
pilar de la sostenibilidad en referencia al tema de los centros comerciales, un tema de investigación para futuros trabajos de investigación.

\subsection{5.- El enfoque hacia la rehabilitación.}

Para cerrar el tema introductorio a lo que es el concepto de la sostenibilidad, y su posible relación con el tema de los centros comerciales y la rehabilitación de los mismos se llega a la conclusión parcial de que cualquier operación sobre entornos urbanos que busque de una forma u otra la sostenibilidad, debe de considerar cualquier tipo de mejora en referencia a los cuatro pilares anteriormente mencionados. Haciendo esta hincapié en unos u otros, dependiendo del caso. De este modo, el estudio de la sostenibilidad de manera integral abarcando todos los campos, es un asunto de gran dificultad, debido a la gran cantidad de temáticas y ámbitos diferenciados que intervienen dentro de la misma, siendo además un agravante, la complejidad intrínseca de los mismos.

De este modo, cada tipología de ciudad va a requerir de una acción diferente, para ejecutar una mejora relacionada con el ámbito de lo sostenible. Esta mejora debe de estar enfocada o bien en mejorar los efectos neutros para hacerlos beneficiosos, o bien paliar los efectos hostiles que el funcionamiento de los tipologías urbanas genera sobre los pilares de la sostenibilidad.

Muchas veces se tiende a asociar la densificación de las ciudades, a la mejora en la sostenibilidad. Michael Jenks expone en el libro Dimmensions of the Sustainable City, que aunque cierto es que la alta densidad juega un papel fundamental en lo que es la consecución de la ciudad sostenible de bajo consumo energético, debido a la viabilidad en la implantación del transporte público y la interacción, la elevada densidad siempre acarreará consigo serios problemas medioambientales derivados de la congestión ${ }^{9}$.

No obstante para entender la temática de la presente tesis, todavía es necesario acercarse a otro concepto, que es el de la rehabilitación.

\section{3.- EL CONCEPTO DE REHABILITACIÓN}

El concepto de rehabilitación en su significado semántico está muy ligado a la intención de recuperar algo en referencia a un estado determinado, o modificarlo para restituirlo. Esta palabra está muy ligada a muchos ámbitos de diferentes campo de estudio, tales como la medicina, la preservación del patrimonio, el arte, la arquitectura y el urbanismo. No obstante la presente tesis al estar enfocada en temas de edificación y urbanismo, el concepto de rehabilitación que se va a utilizar, va a ser el relacionado con la construcción, la arquitectura y el urbanismo.

\footnotetext{
${ }^{9}$ Jenks M., Jones C. (2010). Dimmensions of the Sustainable City.
} 
En el ámbito de la arquitectura y la edificación, el concepto de rehabilitación generalmente hace referencia a la actuación arquitectónica sobre una edificación ya construida, la cual puede ser modificada o alterada de acuerdo a la finalidad de su intervención. El objetivo de toda obra de rehabilitación, siempre es la recuperación de una edificación, a través de la mejora en alguna faceta arquitectónica, estructural o de instalaciones dentro de la edificación a intervenir, y por consiguiente es necesario que toda obra de rehabilitación siempre busque esta mejora.

Para establecer la definición semántica de rehabilitación en el plano de la arquitectura de manera exacta, va a ser necesario recurrir al campo de la construcción y la obra. La definición establecida por el Ministerio de Fomento es la siguiente:

Obra de rehabilitación: Es obra mayor que, a diferencia con la anterior, no da lugar a la construcción de un nuevo edificio sino que se actúa sobre los ya construidos todo ello con independencia de que haya habido o no demoliciones parciales. Puede ser de dos tipos:

-Obra de ampliación: Cuando se aumenta la superficie ya construida incorporando nuevos elementos estructurales. Este incremento puede realizarse de forma vertical sin aumentar la superficie ocupada sobre el terreno (Ej. añadiendo una nueva planta) o bien horizontalmente, y en tal caso sí existe superficie a añadir en el terreno.

-Obra de reforma y/o restauración: Cuando no varía la superficie construida pero el edificio sufre modificaciones que afectan a algún elemento estructural ó se implante alguna dotación previamente inexistente. ${ }^{10}$

No obstante, la presente tesis, va a considerar la rehabilitación de una manera más en relación con los usos y con el urbanismo, y esta consistirá en el conjunto de operaciones de mejora e inserción de nuevos usos a una determinada realidad urbana o arquitectónica, todo ello a través de la alteración material de la realidad, se englobarán las obras de recuperación, rehabilitación, reestructuración, consolidación y reforma, siempre y cuando el fin último de las mismas, sea devolver el elemento a intervenir a su estado original. Requiriendo toda acción de las anteriormente mencionadas de una intención, y por consiguiente de su respectivo proyecto.

La Rehabilitación, además de ser de aplicación para los edificios, también puede serlo a escala urbana. En ese caso, estamos hablando de rehabilitación, revitalización o regeneración urbana.

En relación a esto cabe citar a José María Yagüe, que asemeja el concepto de la rehabilitación a los espacios urbanos, buscando además de la reforma física mediante la obra, una recuperación de nuevos usos e interacciones, o la inserción de otros para asíllevar a cabo una mejora del espacio urbano, y la vitalidad de la ciudad. Entonces es cuando aparece el concepto de Revitalización urbana. ${ }^{11}$

Sin embargo, un proyecto integral de rehabilitación o revitalización urbana, muchas veces incluye muchas de las obras anteriormente mencionadas por el Ministerio de Fomento, y de

\footnotetext{
${ }^{10}$ Ministerio de Fomento, (2003): Nota Metodológica de Construcción de Edificios.

${ }^{11}$ Yagüe J. M. (2010): Revitalización vs Rehabilitación.
} 
este modo, para este tipo de operación se aplica este término, ya que la idea y la intención de proyecto es regenerar la ciudad a su estado original antes de su degradación o alteración.

La presente tesis doctoral, va a enfocar cualquier operación de rehabilitación sobre cualquier centro comercial, con el fin de lograr una revitalización o mejora del espacio urbano.

Uniendo el tema de la sostenibilidad, anteriormente mencionado, al de la rehabilitación, se puede sacar en conclusión que la rehabilitación sostenible en el tema de la arquitectura, la edificación y el urbanismo, consistiría básicamente en la aplicación de una serie de medidas materiales sobre un edificio o área urbana, siempre enfocadas a lograr una recuperación en cualquiera de los cuatro pilares de la sostenibilidad anteriormente mencionados, siempre y cuando la formalización y el funcionamiento del edificio, haya supuesto un empeoramiento de los mismos anteriormente.

Margarita de Luxan afirma que "rehabilitar una edificación de viviendas dotándola de aislamiento y actualizando las carpinterías y las instalaciones, va a suponer un ahorro energético del $60 \%$ aproximadamente frente a la construcción de un nuevo edificio". ${ }^{12}$ Esto, aunque está referenciado a edificios de viviendas, que poco tienen que ver constructivamente con los centros comerciales, es una justificación más que suficiente para considerar el tema de la rehabilitación de los mismos.

De este modo, el fundamento de esta tesis va a centrarse en analizar las deficiencias respecto a la sostenibilidad de diferentes casos de centros comerciales y sus respectivos entornos urbanos, todo ello de acuerdo al criterio de la sostenibilidad, haciendo hincapié en los pilares de la misma anteriormente mencionados. El objetivo es establecer un criterio lo más amplio posible, para considerar que medidas de rehabilitación son recomendadas o eficaces para un centro comercial X. Se evitará en todo momento la realización de un proyecto para un caso concreto.

Debido al enfoque claramente urbanístico de esta tesis, hace falta profundizar aún más en el marco conceptual, hacia un concepto aún más complejo, que es el de la Rehabilitación Urbanística Sostenible.

\section{4.- INTRODUCCIÓN A LA REHABILITACIÓN URBANÍSTICA, Y CONCEPTOS.}

Como último acercamiento al núcleo de la temática de la tesis, cabe destacar la idea de la rehabilitación medioambiental urbanística, la cual tiene que ser explicada en sus conceptos, debido a que esta va a jugar un papel fundamental en esta tesis al ser aplicada en algunos casos sobre los centros comerciales.

Al añadir el concepto de la "urbanística" en el tema de la "rehabilitación sostenible", ya dejamos claro que la rehabilitación va a abarcar una dimensión más extensa que la de un edificio a escala pormenorizada, en este caso, los conceptos de análisis y proyecto (si los

\footnotetext{
${ }^{12}$ De Luxan M. (2009). Posibilidades y Resultados de la Rehabilitación Sostenible.
} 
hubiera) van a abarcar una dimensión que va a englobar varios elementos urbanos, haciéndose especial hincapié en unos u otros ámbitos que dependerán de la finalidad del proyecto.

José María Yagüe, como se comentó en el anterior capítulo, mencionaba la importancia de dirigir la rehabilitación de la ciudad, hacia la revitalización de la misma, haciendo hincapié la presente tesis en este tema. En cambio este autor se centra en lo que son los centros de las ciudades antiguas o los barrios céntricos, áreas de la ciudad, que a pesar de que en muchos casos necesitan operaciones de revitalización, no son la únicas áreas de la ciudad en las que estas operaciones pueden llevarse a cabo.

Ester Higueras, también considera la rehabilitación y la revitalización de las ciudades consolidadas. Cita también las cualidades de la rehabilitación, y expone como base teórica de la rehabilitación los tres pilares de la sostenibilidad, describe la rehabilitación ecológica de la siguiente manera: La Rehabilitación ecológica es aquella donde la prioridad se centra en buscar el cierre de ciclos ecológicos urbanos en agua, materia orgánica, energía, y residuos ${ }^{13}$. También menciona como casos de buen hacer los proyectos URBAN, que consisten en iniciativas de la Unión Europea, para la ejecución de una rehabilitación urbanística sobre un barrio con problemas de exclusión social.

José Fariña, enuncia que las operaciones de rehabilitación van a ser más necesarias en las zonas periféricas urbanas de baja densidad, debido a que estas precisan de grandes cantidades de energía para su funcionamiento ${ }^{14}$. Remarcando la idea de que los medios de transporte motorizados han supuesto la expansión de la ciudad de manera dispersa, anulando las capacidades regenerativas de grandes cantidades de espacios verdes. También hace mención a la sustitución de los supermercados como alternativa a los espacios de reunión tradicionales. Tipología que está englobada en el contexto de la ciudad dispersa, que Fariña describe como la de mayor impacto ambiental ${ }^{15}$.

Centrándose generalmente en el confort ambiental, Leonardo Marqués Monteiro, realiza un estudio comparativo analizando las diferentes tipologías de tejido urbano, y volúmenes edificados para la ciudad de Sao Paulo, en relación a sus capacidades para la captación solar, se intenta establecer la forma óptima a efectos de ahorro energético, a su vez, también este autor, considera la reducción de la superficie de la ciudad de Sao Paulo, a través de la densificación ${ }^{16}$.

Los autores mencionados con anterioridad, a pesar de que centran su atención en diferentes partes, o aspectos de la ciudad, todos confluyen en un objetivo común, que es el de la regeneración medioambiental de la ciudad, a través de la rehabilitación material y la revitalización, No obstante, la característica primordial es que en todos los casos expuestos se actúa sobre la ciudad ya construida, y se intenta de algún modo la recuperación de algunas características de la misma, antes de su degradación, evitando a toda costa su demolición. No obstante, todavía quedan varios conceptos por aclarar, ya que el término de rehabilitación

\footnotetext{
${ }^{13}$ Higueras E. (2013). La Rehabilitación Ecológica Y Bioclimática De La Ciudad Consolidada.

${ }^{14}$ Fariña J. (2013). Ciudad Sostenible, Rehabilitación Arquitectónica y Regeneración Urbana.

${ }^{15}$ Fariña J. (2005.) La explosión de la ciudad.

${ }^{16}$ Marqués Monteiro L. (2013) Environmental Urban Design in Central Areas of Sao Paulo. Seminario La Ciudad Solar.
} 
urbana es muchas veces utilizado de una manera muy generalista. Es importante considerar el tipo de proyecto que va a llevarse a cabo.

De este modo, todavía queda por considerar otro modelo de rehabilitación urbana, que es el que generalmente siguen las corrientes norteamericanas, tales como las relacionadas con Ellen Dunham Jones, o el New Urbanism.

\subsection{1.- La rehabilitación urbanística de áreas de baja densidad en Norteamérica, el New Urbanism}

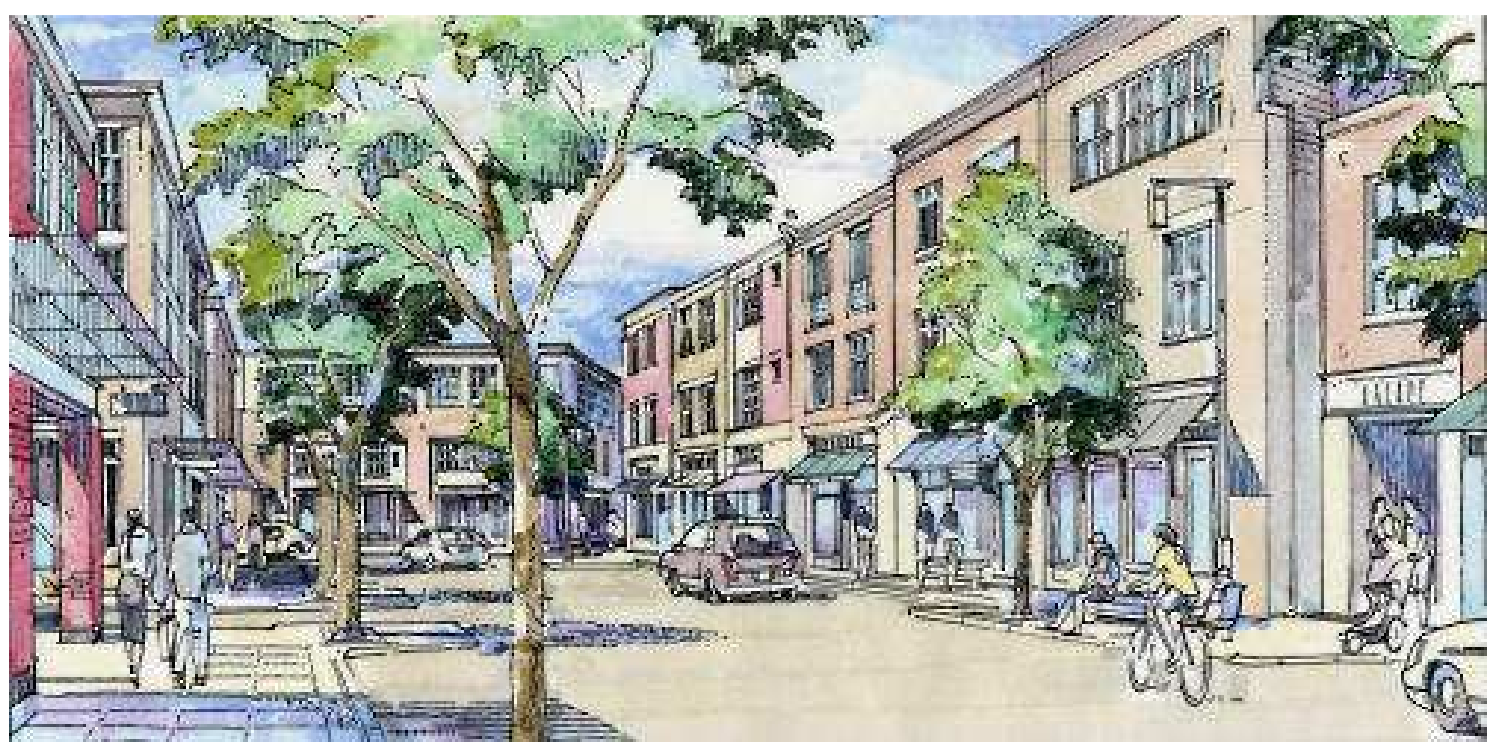

Figura 2.4.1: Imagen Conceptual ligada al movimiento del New Urbanism. Fuente: hesisprep2014

La corriente del New Urbanism, nace en Estados Unidos tras la puesta en crisis del modelo de ciudad de gran superficie norteamericano, compuesto por viviendas unifamiliares, alta zonificación y baja densidad (Suburb), proponiendo como alternativa para crear ciudad, la reconsideración de los conceptos urbanos de los centros consolidados de la ciudades americanas, antes de la expansión y zonificación de la misma que aconteció en la segunda mitad del Siglo XX.

El New Urbanism, surge en el año 1979, promovido por un agente promotor privado llamado Robert S. Davis. Quien en un proyecto inmobiliario, consideró los conceptos urbanísticos tipológicos de los núcleos urbanos norteamericanos anteriores a la expansión urbana de posguerra. Buscando de esta manera un entorno urbano complejo, con actividad a pie de calle, a la par que adaptado a la movilidad y a la escala peatonal. Intentando evitar las externalidades negativas que el desarrollo urbanístico de tipo suburb acarreaba consigo. (ocupación masiva de suelo con edificios e infraestructuras, espacio urbano sin actividad, segregación, zonificación de usos, consumo de combustibles invertidos en desplazamientos...). De este modo el primer proyecto que podría ser considerado como ligado a esta corriente, es el complejo urbano de Seaside (Figura 2.4.2), construido en el año 1981 en la costa de Florida, como la rehabilitación de un frente marítimo. 


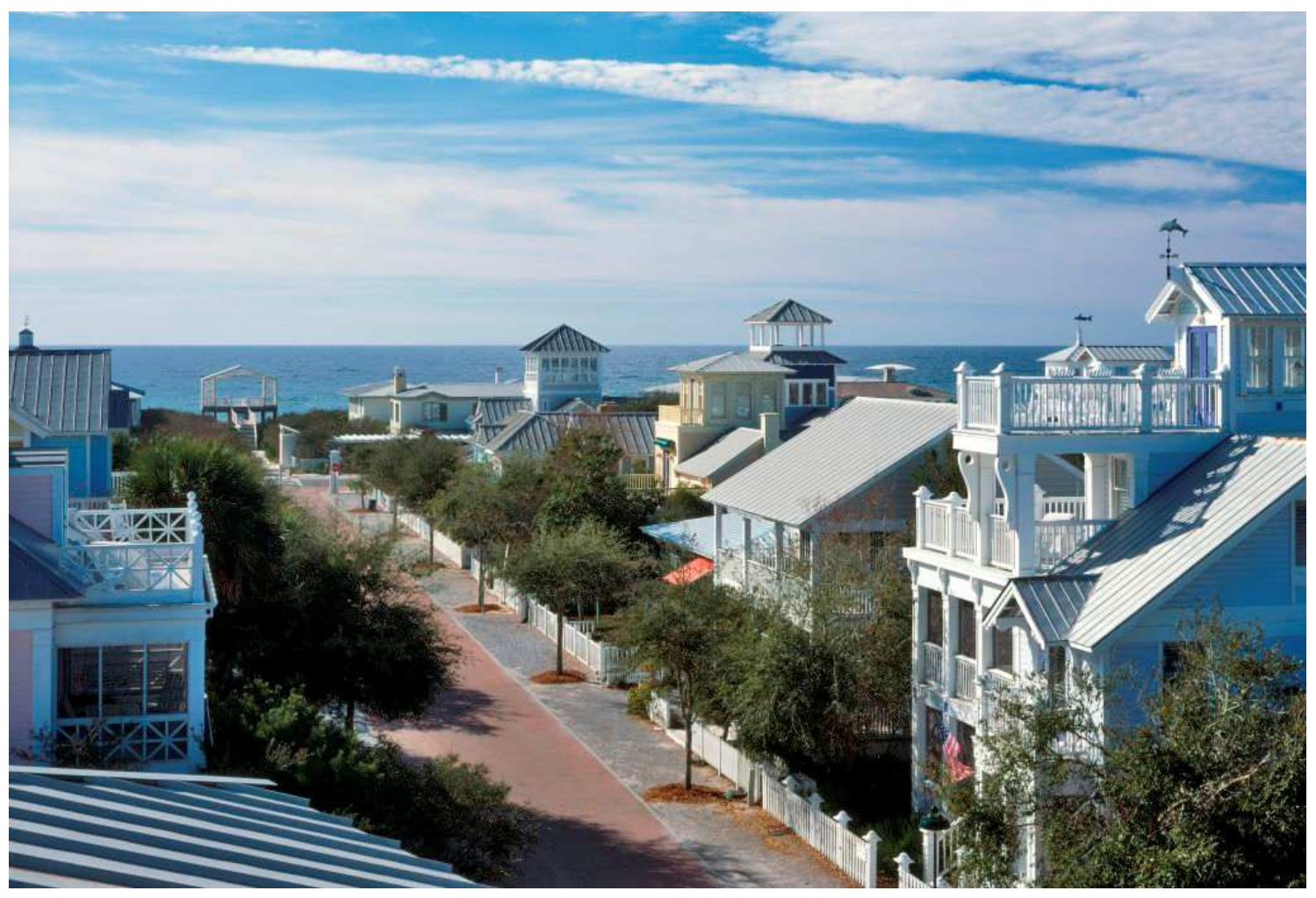

Figura 2.4.2 Imagen de una calle de Seaside Fuente: Ron Beitler

Leigh Gallagher en el Libro The End of the Suburbs, considera como principales causas de esta crisis, la segregación de la familia tradicional hacia nuevas formas de familia (Solteros, parejas sin hijos), el rechazo paulatino hacia el coche particular debido a la congestión y al creciente coste de los combustibles, además del aumento de la demanda de vivienda urbana en los centros de las ciudades, especialmente motivada por las personas jóvenes del país, que buscan otros modos de vida más económicos en coste y tiempo de desplazamiento. No obstante, el autor remarca que los suburbs no van a desaparecer del todo, simplemente, sino que van a reducirse en población, transformándose algunos en zonas degradadas que van a precisar de rehabilitación ${ }^{17}$.

El documental The End of Suburbia, Oil Depletion and Collapse of the American Dream, analiza el auge y la caída de los suburbs dejando claro que la expansión de los mismos se ha producido debido a la difusión de la energía y los combustibles fósiles a precios asequibles, e incluso bajos. Enuncia que la caída de este modelo urbano será debida principalmente a las crisis energéticas que acarrearán el encarecimiento de los mismos debido a la escasez.

No obstante, el modelo norteamericano de ciudad de tipo suburb, será analizado en profundidad en posteriores capítulos.

Como se mencionó anteriormente, la corriente del New Urbanism, propone la recuperación de la ciudad norteamericana consolidada para los nuevos crecimientos urbanos, considerando de cara a los mismos, la densificación y la mezcla de usos, como paso hacia una ciudad más

\footnotetext{
${ }^{17}$ Gallhagher L. (2013). The End of the Suburbs.
} 
sostenible. Esto ha llevado consigo, a la aparición de nuevas tipologías urbanas en Estados Unidos y de vivienda.

No obstante hay que considerar que las operaciones de rehabilitación urbana ecoeficiente en Estados Unidos, son realizadas muchas veces, primando el enfoque a escala pormenorizada sobre los edificios o las calles, en lugar de la escala integral de barrio, que se considera en segundo plano. Resulta de gran importancia la sustitución y mejora de los cerramientos y aislantes, la renovación de las instalaciones y electrodomésticos, o la instalación de sistemas de energías renovables en las viviendas. Siendo estas operaciones financiadas desde la iniciativa privada de asociaciones o empresas. Muchas veces estas operaciones tienen un fuerte peso comercial, considerando a los afectados por el programa de rehabilitación como clientes del mismo.

Generalmente, las acciones urbanísticas que ha considerado la corriente del New Urbanism, han consistido en la construcción de un nuevo crecimiento urbano a nueva planta; o la densificación y sustitución de una zona urbana de baja densidad, retomando conceptual, formal y estéticamente los elementos y características tipológicas del centro urbano complejo de la ciudad densa norteamericana, como maniobra de "rehabilitación" sostenible. En estas intervenciones se consideran formas urbanas más complejas, densificadas y de menor consumo de energía, además de dar importancia a la vitalidad del espacio público.

A pesar de que las operaciones de rehabilitación del New Urbanism han obtenido buenos resultados a efectos de eficiencia energética urbana tras su materialización, en comparación con el estándar estadounidense. Estas acciones han sido criticadas por las siguientes razones:

1: Las ciudades creadas bajo el modelo del New Urbanism en sus comienzos, no resultaron ser más que la creación de otro modelo más de desarrollo periférico de suburb anglosajón, que continuaba ocupando grandes cantidades de suelo. Pues muchas veces la tipología predominante era la de la vivienda unifamiliar con tiendas en las plantas bajas, y de este modo la dependencia de sus habitantes en el transporte motorizado privado no parece acabar de resolverse, este modelo tuvo que ser depurado y mejorado.

2: Los desarrollos del New Urbanism nacieron de intereses inmobiliarios, y de intentos de crear comunidades teóricamente controladas. Esto derivó hacia un nuevo modelo de ciudad que ignora por completo la realidad urbana en la que se asienta, siendo en algunos casos elitista y excluyente. (Comunidades de Celebration o Seaside).

3: Al ignorar la situación de cuidad periférica que los rodea, muchas veces los desarrollos del New Urbanism, pasan a transformarse en los centros urbanos de grandes extensiones de suburbio periférico, cuyos habitantes se ven obligados a usar el vehículo privado. Esto conlleva consigo el colapso de las vías rodadas de la nueva intervención, las cuales con la idea de garantizar espacios urbanos con tráfico más calmado, no están adaptadas a la fuerte demanda de tránsito y aparcamiento proveniente de las zonas aledañas de baja densidad.

4: El uso y la vitalidad urbana, están limitados exclusivamente a las áreas dentro de la intervención del New Urbanism. Se crea una nueva realidad urbana encapsulada dentro de unos límites.

No obstante, estas operaciones de rehabilitación parte de la premisas de la cultura norteamericana, que en lo referente a rehabilitación urbana considera como primordial la 
viabilidad del proyecto para conseguir financiación, y sobre todo la participación y aprobación de los implicados en el proceso, ya que estos adquieren la condición de clientes del plan o proyecto de mejora. De este modo, toda rehabilitación urbana que se ejecuta en Estados Unidos, considera al propietario o al gestor como el agente principal que propiciará la transformación del inmueble, o de la zona urbana, si los propietarios son varios. Resulta primordial la gestión del proceso en su totalidad, además de la garantía del beneficio y la amortización de la inversión.

Sin embargo, muchas de las intervenciones que engloba esta corriente, muchas veces se fundamentan en la demolición o sustitución del tejido urbano existente, o bien la adición de usos mediante edificación. de manera que no sería correcto considerar estas operaciones urbanísticas como una rehabilitación.

\subsection{2.- Conclusiones del capítulo, terminología conclusiva}

La conclusión a este capítulo, va a ser una exposición de términos creada específicamente para este trabajo, la cual ha sido redactada por el autor de la presente tesis, sintetizando los conceptos analizados de otros autores. Esto servirá para establecer el criterio por el cual nos referiremos a las diferentes intervenciones.

Rehabilitación urbana: Hace referencia a una intervención sobre un medio físico urbano degradado. A primera vista en la definición, el objetivo es buscar la reforma de la edificación yo la infraestructura para retornar al estado original antes de su degradación. Ejemplo de ello, son las intervenciones para restaurar los barrios históricos, las cuales se realizan generalmente conservando la estructura urbana, y ejecutando acciones para reparar la edificación volviéndola a su estado original antes de la degradación por antigüedad. Esta definición resulta insuficiente para el alcance de la presente tesis doctoral. Siendo considerado este concepto para la misma, como una operación de remodelación material de un barrio, en el que aún conservándose en mayor o menor medida el estado original de la edificación y/o su infraestructura; en ella intervienen muchos más factores, los cuales no siempre tienen que ver con la edificación en sí y sus características materiales: tales como la recuperación o mejora de la economía, la calidad ambiental o la cohesión social, en ese caso el concepto tiende a confundirse con otros tales como la revitalización o la rehabilitación sostenible. Lo que hay que tener en claro, es que cualquier operación material aplicada sobre un conjunto urbano, su infraestructura o su edificación ya existente, con el objetivo de paliar los efectos de una degradación $\mathrm{X}$ sufrida en el mismo en cualquier ámbito, ya sea material o no, podrá ser considerado como rehabilitación urbana.

Rehabilitación urbana sostenible: Hará referencia a una intervención destinada a la reforma en cualquiera de los tres pilares de la sostenibilidad, mediante medios físicos y constructivos sobre la edificación o la infraestructura de un área urbana degradada a efectos de los mismos. buscando una recuperación ligada a los mismos antes de su degradación. Es importante considerar que toda intervención relacionada con el pilar del medio ambiente dentro de la ciudad, buscando la mejora de las cualidades medioambientales, es considerada como una 
rehabilitación medioambiental, ya que se tratan de recuperar cualidades del medio ambiente y el ecosistema, las cuales fueron anuladas cuando la ciudad se materializó. Ejemplos de rehabilitación sostenible pueden ser cualquier intervención sobre un barrio, que busque la viabilidad económica o la dinamización social a través de la revitalización, o cualquier intervención ecológica que busque mejorar en medio ambiente.

Revitalización urbana: Hace referencia a una intervención sobre un medio urbano degradado, para retomar la vitalidad y la actividad urbana que existía en la zona, antes del supuesto abandono o degradación de la misma, muchas veces el proyecto de revitalización urbana va ligado a la rehabilitación sostenible en el ámbito de los pilares de lo social y lo económico, ya que se espera una mejora en esos mismos pilares a través de la revitalización urbana.

Vitalización urbana: Este concepto va a estar referenciado a la inserción de actividad o vitalidad a través de diversas intenciones dentro de un medio urbano, con el fin de lograr una mejoría en el mismo. Se debe de considerar que el medio en su estado original carece de vitalidad, haya o no experimentado una degradación. Ejemplos de vitalización urbana son las acciones de la corriente del New Urbanism, ya que buscan la sustitución de un modelo de ciudad poco complejo, por otro de mayor complejidad, a través de la adición de edificios e infraestructura, o la sustitución de los mismos.

Una vez establecido el estado de la cuestión en referencia a la rehabilitación urbanística, concluyendo la explicación de los conceptos e ideas principales, el siguiente paso es establecer los ámbitos de estudio de la presente tesis doctoral.

\section{5.- LOS ÁMBITOS DE TRABAJO DE LA PRESENTE TESIS}

Explicadas las bases introductorias de la temática de la presente tesis doctoral, además de diferentes casos de estudio anteriores. Para concluir el capítulo introductorio de la misma, se van a establecer los ámbitos de estudio de la misma, los cuales van a ser analizados en mayor o menor medida.

\subsection{1.- Los ámbitos relacionados con la sostenibilidad.}

Debido al enfoque hacia la sostenibilidad de los estudios de la presente tesis, va a ser fundamental establecer de inicio como áreas de estudio, los tres pilares de la sostenibilidad. Se explicará a su vez el hincapié que se va a hacer en unos o en otros. De este modo, se establecen tres ámbitos de estudio que van a ser:

ÁMBITO 1.- Pilar de la economía: Aunque este pilar va a ser mencionado constantemente debido a su importancia, el estudio del mismo en la presente tesis va a ser somero debido a la falta de conocimientos del autor en el tema de la revitalización económica de los centros comerciales. Siendo el mismo de interés para trabajos posteriores de investigación 
ÁMBITO 2.- Pilar social: Este pilar resulta importante, ya que muchas rehabilitaciones urbanísticas buscan de un modo u otro la cohesión social. En este pilar se va a hacer hincapié en la presente tesis, como concepto a ser considerado de manera somera, siendo su estudio en profundidad tema para futuros trabajos de investigación.

ÁMBITO 3.- Pilar Medioambiental: Este pilar, está relacionado con los temas de la ecología en la edificación (Disminución del impacto medioambiental y cierre de ciclos bióticos en su entorno). Para la presente tesis, este tema es de gran importancia, ya que va a fundamentar las hipótesis expuestas, de manera que va a ser estudiado en mayor profundidad. Dentro del mismo se va a considerar el ahorro energético, la reducción de emisiones, o la posibilidad de realizar una mejora en el medio ambiente urbano.

\subsection{2.- Los ámbitos relacionados con el urbanismo y la arquitectura.}

la rehabilitación de un centro comercial, independientemente de sus propósitos, es una operación en el ámbito de la arquitectura, que bien puede plantearse en la escala del edificio de manera individualizada, o bien en la escala urbana. La importancia de estos pilares reside en el hecho de que toda intervención sobre el edificio del centro comercial muchas veces va a suponer una alteración en su arquitectura, ya sea por el cambio de los espacios, los volúmenes, las funciones o las instalaciones. de este modo, respecto a este tema se va a tocar dos ámbitos:

ÁMBITO 4: Ámbito urbanístico: Este ámbito, que es el que engloba el comportamiento del centro comercial a efectos de funciones e interacciones urbanas, y su papel dentro de la ciudad. Este tema va a ser de interés para la presente tesis, y su estudio va a realizarse en profundidad, debido al enfoque urbanístico de las medidas de rehabilitación que van a considerase.

ÁMBITO 5: Ámbito arquitectónico y de proyecto: Este ámbito al ser muy amplio es necesario especificar que temas van a tratarse en la tesis. Generalmente este ámbito está referenciado a las cualidades espaciales y arquitectónicas de lo que es el edificio del centro comercial en sí. El tema que está ligado a la arquitectura como arte, expresión artística y experiencia espacial no forma parte del núcleo de la tesis y su estudio va a ser muy somero, al igual que la configuración formal de los espacios interiores en planta. No obstante, la presente tesis si va a considerar como importantes los programas de usos y superficies internas del edificio del centro comercial, al ser de gran importancia en el tema de la función del mismo ligado a los usos urbanos. También como parte del estudio medioambiental, se van a considerar las características constructivas del edificio, y sus programas de instalaciones, comportamiento bioclimático, energías renovables y luz natural.

De este modo, establecidos los ámbitos de enfoque de la presente tesis de manera concisa, (medioambiental, urbanístico y de usos) el siguiente capítulo es el acercamiento al objeto de análisis de la presente tesis, que es el centro comercial, analizando su génesis, sus conceptos, su problemática y su estado actual. 


\section{6.- UNIT RESUME, THE CONCEPTS TOWARDS THE REASEARCH QUESTIONS AND HYPOTHESES.}

Shopping malls, as considered nowadays, are supposed to be buildings with strong impact in both urban interactions and sustainability, as being conceived as a building with the single use to offer a large amount of commercial services.

The headline of the following thesis, is the study of the retrofitting of the shopping malls, considering the features of the urban environment, as well as to evaluate how sustainable can be a mean of retrofitting. To start with the main issue of this thesis, this unit was focused on the analysis of the concepts related to the sustainable retrofitting of shopping malls. The comprehension of them is the criteria to establish the parting point for the following thesis, (research question and hypotheses).

In a resumed view, the concepts to study as a preview of the thesis are the following ones:

-Shopping Mall: Consists in a large commercial building aimed to shopping activity, consisting is a central gallery with shops at one, or both sides. Is important to consider that any shopping mall needs to have a management company which owns and lease all the facilities within. If there is there is no management company, the complex is called shopping center, in which the property of the stores belongs to their shopkeepers.

To understand the working of a shopping mall, is important to consider the following concepts related:

Leasable shops: Dwellings aimed to commercial uses, owned and leased by the shopping mall manager to shopkeepers. Some of these dwelling can be aimed to restaurants or leisure, being composed by this way a Food Court.

Galleries: Large size spaces aimed to the transit of shopping mall customers, some are even aimed to the stay of them. Some can be focused too as parks or another sorts of amusement complexes.

Anchor: Large sized commercial dwelling, which are leased to an influent commercial company, as an attraction for customers.

Other facilities: Shopping malls need space for installations, as well as other non commercial facilities aimed to customers or management. (Parking lots, management offices, hotels...)

In the projection of a shopping mall, there are two concepts of importance to be considered:

Jerde Transfer: This concept related to North American architect Jon Jerde, consists in the creation of an urban environment or experience, in an enclosed area isolated from urban reality as a maneuver to mitigate the "no place" experience the shopping mall supposes.

Gruen Transfer: This concept related to the architect Victor Gruen, Consists in the creation of an isolated inner space in which the visitor is forced to focus its sight in the stores of the 
shopping mall. Can be done using some architectural maneuvers, such as the creation of intricate and large scale spaces, the usage of reflective materials, and other psychological effects.

-Sustainability: The concept of sustainability was established By Gro Brunthland in 1987, and it consists of developing societies, without harming the environment, or the life conditions of its people. The sustainability consists in three pillars which are economy, society and environment; and one considered sometimes that is culture. Furthermore, any development, to be considered as sustainable, have to be economically reliable, supporting also the social and community engagement, without harming environment.

-Retrofitting: Related to architecture and buildings, this concept consists in the alteration of a building in order to insert in it new features, or to improve the existent ones. These operations can be also applied in an urban area, in major or minor scale, being considered as urban retrofitting. Nowadays, the urban retrofitting consider as primal the concepts of sustainability.

-Sustainable retrofitting: This concept is related to any retrofitting operation or work applied on a building or an urban area (urban sustainable retrofitting). The aim is the recuperation or the reinforcement of any concept related to any pillar of sustainability formerly stated.

To sum up, as being the concepts established, the following research question was established:

- Would the retrofitting of shopping malls carry on a relevant improvement towards urban environment and sustainability?.

Being the following hypotheses resulting from the question:

- Is possible an improvement of the revitalization of a wide urban area, throughout the alteration of the shopping mall building and plot, considering different techniques of rezoning, and insertion of uses.

- The application of a single retrofitting mean is going to be insufficient to get a relevant improvement towards urban sustainability, is required the application of various means simultaneously.

- The retrofitting of a shopping mall is not going to be enough to produce a reduction of the environmental impact in the scale of the whole city. this supposes is going to be necessary the retrofitting on a whole urban area, being important the definition of the scale of the intervention.

The next unit to develop, is the state of the art in sustainable retrofitting, considering the history of the typology of the shopping mall, its problems related to sustainability, and the retrofitting means of application on it. 


\section{3.- SEGUNDA PARTE DEL ESTADO DEL ARTE, ANÁLISIS HISTÓRICO, FUNCIONAL Y FORMAL DEL CENTRO COMERCIAL, PROBLEMÁTICA Y REHABILITACIÓN DE LOS MISMOS.}

\section{1.- GÉNESIS E HISTORIA DEL CENTRO COMERCIAL}

Como se enunció en el capítulo 1.1 La tipología de centro comercial y su materialización, es muy compleja, teniendo mucho que ver una gran cantidad de procedimientos, actividades e ideas que fueron consideradas. La génesis de esta tipología arquitectónica como es concebida en la actualidad, está muy asociada a una gran cantidad de factores tanto en el campo de lo urbano, como en el campo de lo arquitectónico. La explicación de la génesis y el nacimiento de esta tipología edificatoria, se va a fundamentar en la explicación del contexto tanto histórico, como urbanístico y arquitectónico, para a continuación describir varios casos representativos de cada época, con sus aportaciones a la materialización del centro comercial como es conocido actualmente.

\subsection{1.- El nacimiento del comercio, Edad Antigua Preclásica.}

El nacimiento del intercambios de recursos data de la época en la cual el hombre pasó del nomadismo prehistórico al sedentarismo del neolítico, con esto nace una cultura en la que es importante la gestión y obtención de recursos.

En las cultura, tanto rural como urbana de las primeros asentamientos, el comercio comenzó a expandirse a través del trueque de excedentes, que una región o asentamiento podía producir, a cambio de productos deficitarios dentro de la misma. Esta tónica se mantuvo durante prácticamente toda la Edad Antigua Preclásica, siendo la tónica general de comercio incluso en las posteriores grandes civilizaciones preclásicas. No obstante hay que considerar el hecho de que algunas de estas civilizaciones consiguieron desarrollar un tipo de comercio que usaba como moneda, elementos hechos con materiales de valor normalizados (Oro, Plata, gemas...). A pesar del poco nivel tecnológico, en esta época el comercio estaba muy extendido tanto por tierra, como por mar, y prácticamente todos los núcleos urbanos de cierto tamaño contaban con al menos una calle o plaza, siempre cercana a la ruta comercial terrestre o fluvial. En la que era posible el intercambio de bienes y materias primas. En ese lugar se colocaban tenderetes para el intercambio, o bien estaba próxima a las casas de los artesanos, desde las cuales también se realizaban intercambios.

\subsection{2.- El comercio y sus tipologías de edificio comercial en la Antigüedad Clásica (Grecia y Roma)}

A pesar de que el comercio era una actividad muy considerada durante la Edad Antigua, y existían espacios públicos en las poblaciones adecuados a este fin. Cabe destacar por otra parte, que el comercio asociado directamente a edificios abiertos al público no se dio hasta el nacimiento de las culturas clásicas. En éstas, el sistema económico tenía una base económica 
vinculada fuertemente al comercio que se ejercía en el mar Mediterráneo. Y esta posición privilegiada suponía el movimiento de grandes cantidades y tipologías de materiales y recursos, que llevó incluso a la necesidad de acuñar moneda y generar circulación fiduciaria. De este modo, la Cultura Griega, iba a necesitar unos espacios más aptos para un comercio más avanzado. $Y$ en base a esto, la idea fue el intento de centralizar el comercio dentro de las ciudades, buscando para ello un punto estratégico dentro de la misma que estaba pensado para todo tipo de actividades lúdicas y comerciales. Ese punto era el ágora, y consistía en una plaza abierta de mayores o menores dimensiones que contenía dentro de ella o en los laterales los edificios administrativos, comerciales y en menor medida, religiosos. De todos estos edificios, para el caso del presente trabajo, cabe destacar la Stoa, que consistía en un mero pórtico abierto hacia el lado de la plaza, pensado para proteger a los usuarios de la misma frente a las inclemencias del tiempo. Dentro de este edificio se realizaba gran cantidad de actividades, una de ellas el comercio. Debido a que a veces se colocaban puestos comerciales dentro de ellos en los días de mercado. En épocas tardías de la civilización griega, algunas de estas ágoras o plazas, fueron rodeadas de stoas por todos sus lados, formando de este modo una tipología de edificio singular, llamada Stoa Basilea, predecesor de la basílica romana.

La Civilización Romana, con una estructura social más compleja, contaba ya con un sistema monetario muy consolidado, en el que era muy importante el uso de moneda acuñada, además de la racionalización legal de la economía. De este modo, esta cultura fue la primera que construyó edificios de gran tamaño pensados para el comercio ex profeso. Un ejemplo de estos edificios son las basílicas, que ligadas a los centros neurálgicos urbanos de los foros, contenían espacios pensados exclusivamente para discutir asuntos relacionados con el comercio, además de subastas y otras transacciones bajo una legalidad vigente. No obstante También en esa época se construyeron espacios cubiertos con el fin exclusivo del comercio como actividad. De estos prototipos de mercados cabe destacar el Mercado de Trajano, construido en el Siglo II como zona de comercio asociada a un foro. Este complejo contaba con 150 tiendas cubiertas además de los respectivos espacios para comerciantes ambulantes, pero lo más importante de este complejo, era el hecho de que se introdujo una administración encargada de imponer condiciones y normas a los comerciantes para utilizar las susodichas instalaciones. El propósito de la creación de esta administración, era la de obtener beneficios por la explotación del mercado, a la vez que evitar conflictos entre usuarios.

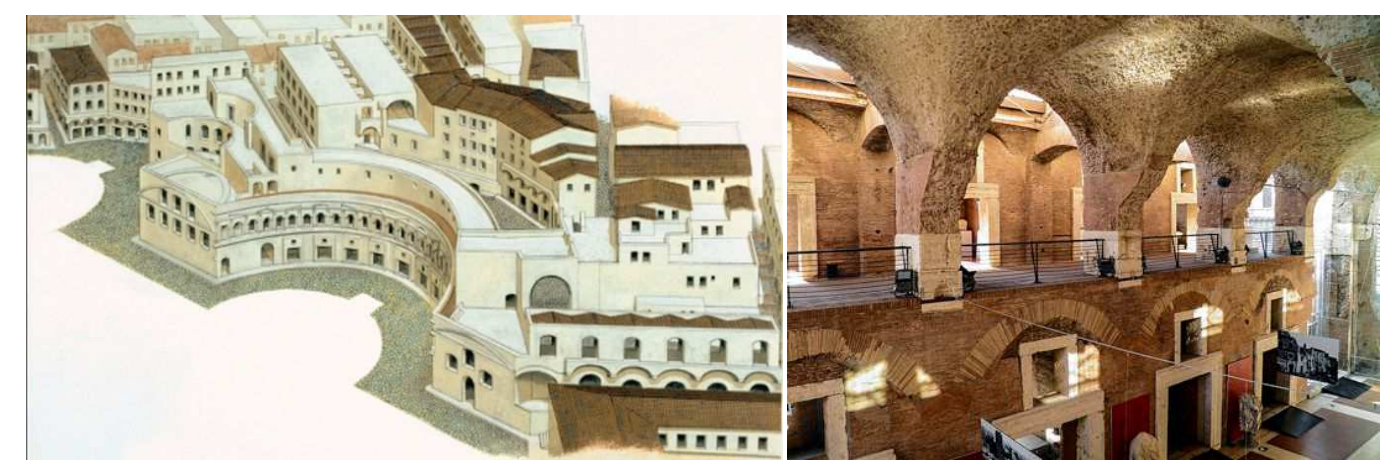

Figura 3.1.1 Imagen del mercado de Trajano y detalle de las tiendas. Se piensa que este complejo es el primer centro comercial integrado y abierto al público de la historia Fuente: Realm Of Hystory, Carole Raddato. 


\subsection{3.- El comercio y sus tipologías edificatorias en la Edad Media y la Edad Moderna Temprana.}

La caída del imperio romano, supuso la caída en Europa del sistema monetario vigente. No obstante las culturas orientales seguían manteniendo un comercio muy consolidado, con lo que era necesario seguir contando con estructuras comerciales para el intercambio de bienes. En este marco surgen los bazares y zocos. Que consistían en una o varias calles y plazas angostas cubiertas por techos y flanqueadas por locales también cubiertos y cerrados destinados a actividades comerciales diversas. Estos zocos y bazares también contaban con administración y horario de apertura, y algunos llegaron a ser de un tamaño tan considerable, que se constituían a sí mismos como auténticas ciudades cubiertas con fines comerciales, a las cuales los mercaderes acudían de muy lejos ex profeso a realizar allí sus transacciones debido al fuerte reconocimiento que estos adquirieron a lo largo y ancho del mundo. Algunos ejemplos de este tipo de centros comerciales de importante índole son el Bazar de Isfahán, EI Gran Bazar de Teherán con sus casi diez kilómetros de calles, y el gran Bazar de Estambul.

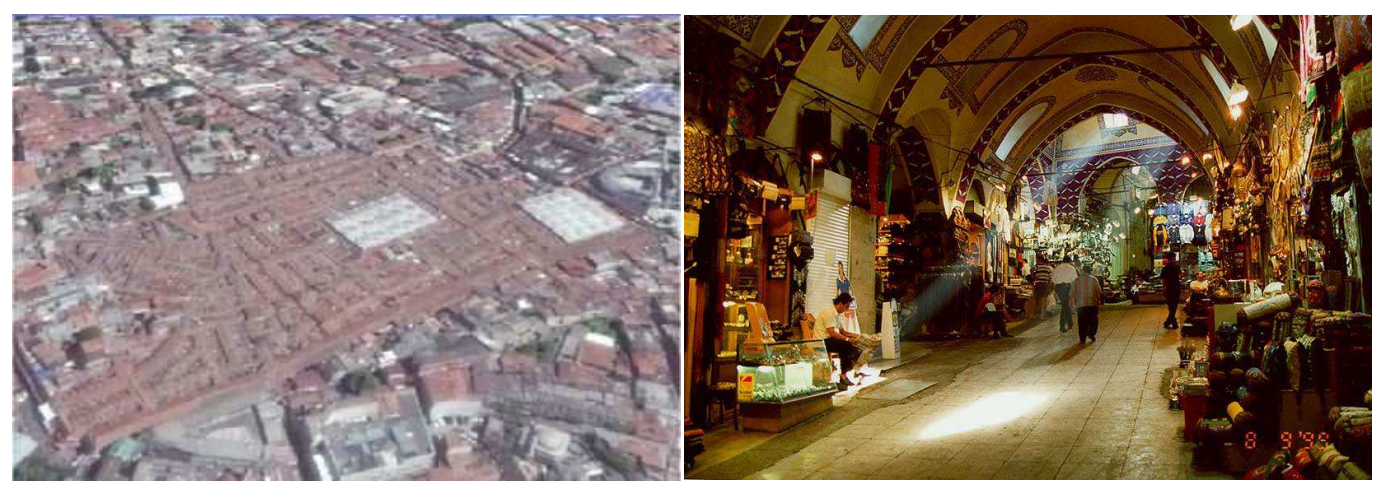

Figura 3.1.2 Vista del Bazar de Estambul e Interior del Bazar de Teherán.Fuente: Google, Iran Review

Por contraste, en Europa, al implantarse el sistema económico-social del feudalismo, el comercio pasó a ser una actividad minoritaria, que se basaba en intercambio de recursos por trueque y que estaba limitada al ámbito comarcal. Esto era debido al proceso de ruralización y a la falta de circulación fiduciaria. El lugar donde se realizaban los intercambios eran las ferias, que eran eventos públicos destinados al intercambio que se celebraban en fechas concretas, en esas fechas las autoridades competentes daban ciertas ventajas fiscales a los comerciantes y mercaderes durante un período de tiempo limitado, quienes atraídos por estas facilidades acudían desde diferentes puntos cercanos o lejanos, para ofrecer sus productos al mejor postor. Estas fechas solían coincidir con las fiestas patronales de la localidad anfitriona. En el tema arquitectónico, debido al desinterés por el comercio a gran escala, este tipo de evento nunca tuvo asociado un tipo de edificio ad hoc, de manera que las construcciones de la feria se limitaban una serie de tenderetes y carromatos móviles apostados en el lindero del camino de acceso a la población anfitriona siempre en las cercanías de la entrada a la misma.

Más tarde durante la Baja Edad Media y el principio de la edad moderna, el comercio volvió a ser una actividad a tener en cuenta debido a la consolidación de los reinos centralizados, y el consiguiente desarrollo de las ciudades, y la nueva clase burguesa urbana. De esta manera, las 
autoridades asignaron un espacio libre de gran tamaño dentro de la ciudad congestionada para que los comerciantes colocasen allí sus tenderetes móviles, apareciendo así la plaza del mercado en la cual se celebraban todo tipo de eventos además de los comerciales. Alrededor de esta plaza los comerciantes locales dispusieron sus tiendas, y estas más adelante derivaron en la creación de soportales para proteger a los usuarios de la plaza mientras hacían los intercambios pertinentes. De esta manera, a finales del S XIV, prácticamente todas las ciudades de Europa contaban con al menos una plaza de mercado. Y esto fue en aumento, ya que con las primeras colonizaciones tras la llegada a América de Cristóbal Colón, la actividad comercial fue ganando importancia debido al interés de las clases pudientes en los productos provenientes de las colonias lejanas a la capital, añadiendo además en el plano político la creación de estructuras gubernamentales más complejas que comenzaron a acuñar moneda para intercambios de recursos para facilitar la actividad comercial a una escala mayor. Estas transformaciones fueron las causantes de que muchas plazas de mercado fuesen mejoradas o habilitadas para satisfacer la creciente demanda. Pero no será hasta mediados del SXVIII (1785), cuando nacieron los primeros mercados cubiertos en Occidente, prototipo de los mercados, galerías y centros comerciales actuales.

Mientras tanto en oriente, aún estando la actividad comercial muy extendida, las tipologías arquitectónicas asociadas al comercio estaban basadas en calles con bajos comerciales y plazas de mercado muy similares a las de las civilizaciones preclásicas, No obstante, se construyeron espacios destinados al comercio ex profeso, y algunos de estos contaban con edificios permanentes adaptados a las necesidades comerciales. Estas tipologías no evolucionaron hasta bien entrado el SXIX.

\subsection{4.- Los edificios comerciales de la llustración, los prototipos de zona comercial cubierta.}

En el Siglo XVIII, entramos en la época de la llustración, esto implica una consolidación total de los estados, y unos cambios drásticos en la sociedad, y por consiguiente en las economías, dónde además de eliminarse todas las trabas económicas por desplazamiento de mercancías, se empiezan a plantear las ideas del liberalismo competitivo frente al sistema económico del Antiguo Régimen basado en el mercantilismo y los gremios. Por ello, el comercio va ganando terreno en las ciudades, pasando a ser una actividad de primera importancia. Esto conllevó una mejora considerable de los espacios arquitectónicos destinados a este tipo de actividades, naciendo en este siglo los prototipos de mercados cubiertos y galerías de los siglos XIX, que posteriormente serán a su vez los prototipos de los grandes almacenes y centros comerciales del SXX. Estos edificios surgieron debido a la creciente demanda de la actividad comercial, una demanda que los soportales en las calles de la ciudad y las plazas de mercado no son capaces de asimilar. Se hace necesario un control más estricto del comercio, y por consiguiente una tipología arquitectónica más atractiva para esta actividad, para ello, surgen edificios que partiendo de la base de la plaza o calle comercial y su relación con la ciudad, buscan la comodidad relativa de los compradores a la vez que la centralización y control de los comercios que se hallaban dispersos por la ciudad. A continuación citaremos los ejemplos más relevantes de este tipo de edificio, como muestra de esta nueva tipología de espacio comercial. 
Oxford Covered Market: Fue construido en 1774 por orden de las autoridades estatales para eliminar los tenderetes de las calles de Oxford, este edificio consistía un complejo formado por varias hileras de edificios con tiendas a cota de suelo, $y$ almacenes $u$ otras instalaciones en la segunda planta. Pero lo más característico eran las calles entre los edificios se cubrían con una cubrición de madera y tejas. Edificio de tipología similar a los zocos, Un precedente de este caso de mercado cubierto es el Marché des Enfants Rouges en París, abierto en el Siglo XVII, con ideas similares.
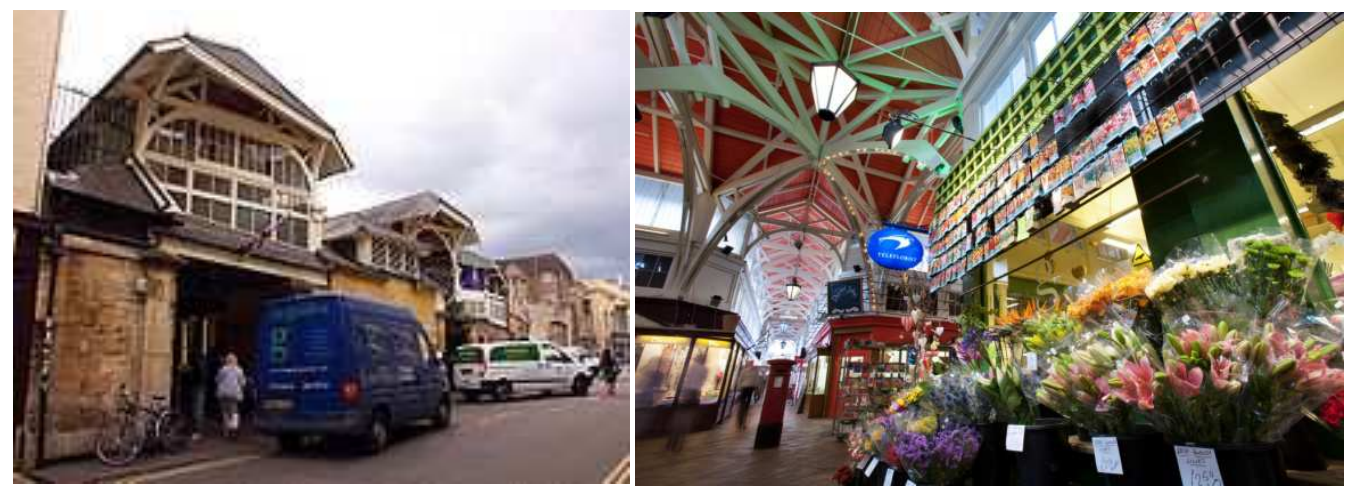

Figura 3.1.3.- Oxford Covered Market. Funte: Wikipedia, Wikimedia Commons

La aportación de este ejemplo en la consolidación de la tipología de centro comercial actual, fue la creación del primer mercado cubierto en Europa, basado en galerías de gran tamaño, en lugar de calles estrechas como los zocos.

Gostini Dvor, San Petersburgo: Fue construido en 1785, Este edificio es uno de los prototipos más tempranos de galería o centro comercial. Consistía en un edificio de manzana cerrada de dos alturas, que contenía tiendas en ambas plantas abiertas al comprador. Este edificio contenía una gran plaza comercial privada a cielo abierto, en la cual se colocaban todo tipo de comercios. Las galerías disponían además de mobiliario y decoración, creando en ambos lugares un ambiente exclusivo retirado de la calle a los visitantes del centro. La propiedad de este centro recaía sobre una empresa privada, quien se encargaba de gestionar las transacciones y del mantenimiento en el interior del edificio.
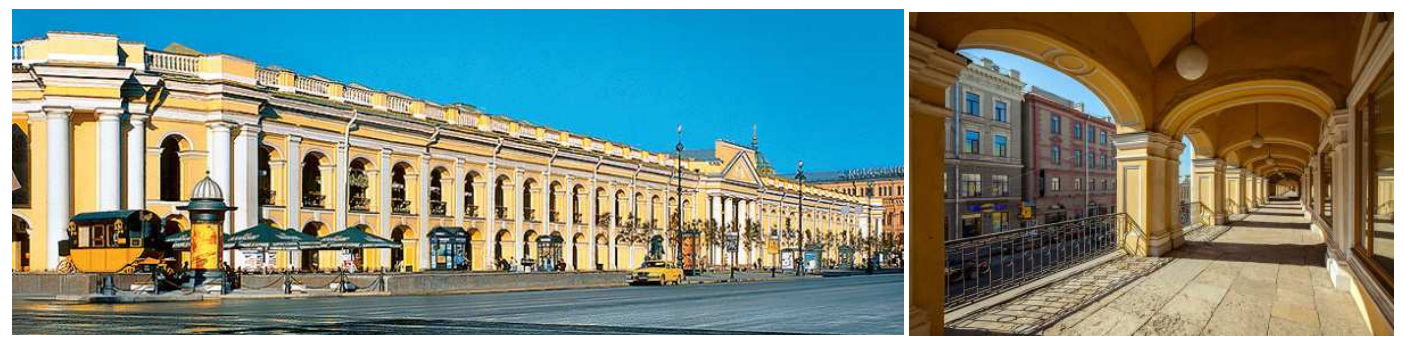

Figura 3.1.4: Fachada y arcadas de Gostini Dvor. Fuente: saint-petersburg.com

La aportación de este caso a la tipología actual, fue la creación de una instalación comercial basada en galerías, que ya contaba con espacios urbanos asociados intrínsecamente a su función. 


\subsection{5.- Revolución Industrial. Primeros prototipos de centro comercial integral, arcadas, galerías y mercados.}

Tras la Revolución Francesa, acudimos en toda Europa y Norteamérica a un cambio radical en las estructuras de poder, y por consiguiente de la economía. El Absolutismo Monárquico, junto con la esclavitud legal son abolidos, y se sustituye la antigua economía basada en gremios, por otro modelo económico de libre mercado y libre competencia más ligado a los sistemas de gobierno liberales que relevaron a las monarquías. Entramos en la época Industrial, durante la cual se producen fuertes innovaciones en el campo de la tecnología que traen consigo una mejora indiscutible en los medios de producción industrial, junto a una mejora de las infraestructuras de comunicación con la aparición de los medios de transporte mecanizados. Por esta razón, la industria junto con el comercio experimentan un fuerte ascenso en la sociedad, que hace que infinidad de personas emigren de las zonas rurales a las urbanas en busca de una vida mejor. $Y$ debido a esto comienzan a aparecer nuevos movimientos sociales que reivindican una mejora de las condiciones de vida, que tardarían aún tiempo en llegar. Las estructuras aristocráticas de poder, son asimiladas al sistema liberal, y aparecen en las ciudades la figura del burgués adinerado y poderoso, como contraste a la miseria y el hacinamiento en el cual vive la clase trabajadora ya sea urbana o rural.

Los edificios en el mundo industrializado ligados al comercio en esta época, marcan la consolidación de los modelos anteriores del siglo XVIII mencionados anteriormente. Cabe destacar el factor crucial que supone descubrimiento del hierro como material de construcción por Labrouste, Le Duc o Paxton. Factor importante para la concepción de estos edificios comerciales, debido que la construcción con este tipo de material muy resistente a flexión permitía la materialización de grandes cubriciones en poco tiempo, de manera que era posible salvar muchos metros de luz con una cantidad escasa de material. Lo que suponía carta blanca para los constructores de instalaciones comerciales a la hora de crear amplios espacios interiores con unas condiciones relativas de confort, en contraste con los espacios cerrados, limitados y angostos de los bazares, arcadas y soportales de tiempos pasados.

Otro factor a destacar, es también la capacidad de adaptación de estas nuevas tipologías comerciales a los diferentes estratos de la sociedad, cada vez mas definidos.

En las zonas más pobres de la ciudad, aunque siguieron conservándose las tipologías de arcadas y soportales, el modelo de edificio con función comercial íntegra fue el de el mercado público, que ubicado en las cercanías de las instalaciones de transporte, se encargaba de suplir la demanda de bienes de consumo de las clases medias y bajas de la sociedad. Este edificio consistía básicamente en una cubrición de metal y vidrio bajo la cual se colocaban las tiendas en un único nivel de circulación, este edificio contaba además con sus zonas de almacenaje.

En los centros burgueses de las ciudades, surgen dos nuevas tipología de instalación comercial más asociadas a la riqueza de sus compradores. Una son las galerías comerciales, en las que haremos especial hincapié ya que son las predecesoras de los centros comerciales de periferia. Estos edificios íntegramente para el comercio consistían en una calle central amplia cubierta por una cubrición metálica y de vidrio en cuyas cotas accesibles al peatón se disponían tiendas de considerable nivel económico, los niveles de circulación podrían ser uno o varios. La 
administración corría por cargo de una empresa privada que alquilaba los locales a los comerciantes, de una forma muy similar a los centros comerciales actuales. La segunda tipología íntegramente comercial asociada a las clases pudientes, es la de los grandes almacenes, que consisten en una única tienda de gran tamaño y varias alturas en la cual están disponibles para la compra, productos de diversa índole, estos almacenes siguen siendo propiedad de una empresa. Esta tipología fue posterior, y adquirió gran protagonismo en el Siglo XX.

El interés de analizar las galerías más profundamente, es debido a que el tema principal de este trabajo es el análisis del centro comercial actual, y las galerías son un claro precedente del mismo, por ello a continuación citaremos una serie de galerías representativas que claramente sirvieron de precedente en la consolidación formal de la tipología de centro comercial actual.

Burlington Arcade, Londres 1819, calle comercial cubierta por una cubrición de vidrio, disponía de mobiliario urbano. Prototipo de galería comercial europea. La aportación de este caso al modelo de centro comercial actual, fue la concepción del espacio para las compras como un lugar para el recreo y el paseo.

Westminster Arcade, Providence RI, E.E.U.U. 1819, Este caso es un claro ejemplo de protocentro comercial en cuanto a características formales, Consistía en una pareja de edificios comerciales de dos alturas más bajo, con un espacio central intermedio cubierto, las cotas accesibles para los peatones eran tres, y había una serie de escaleras metálicas para comunicar los niveles en altura y pasarelas que salvaban las distancias entre galerías a través del espacio vacío central. Las aportaciones más relevantes de este caso, fueron el tratamiento del mismo como edificio exento, la inclusión de varias cotas de circulación para aumentar la capacidad de espacio alquilable del edificio, utilizando la menor cantidad de superficie de parcela, y la disposición de una fachada con fines representativos para el edificio. Esta galería, fue la que definió el arquetipo para este tipo de edificación comercial en las ciudades de Norteamérica.
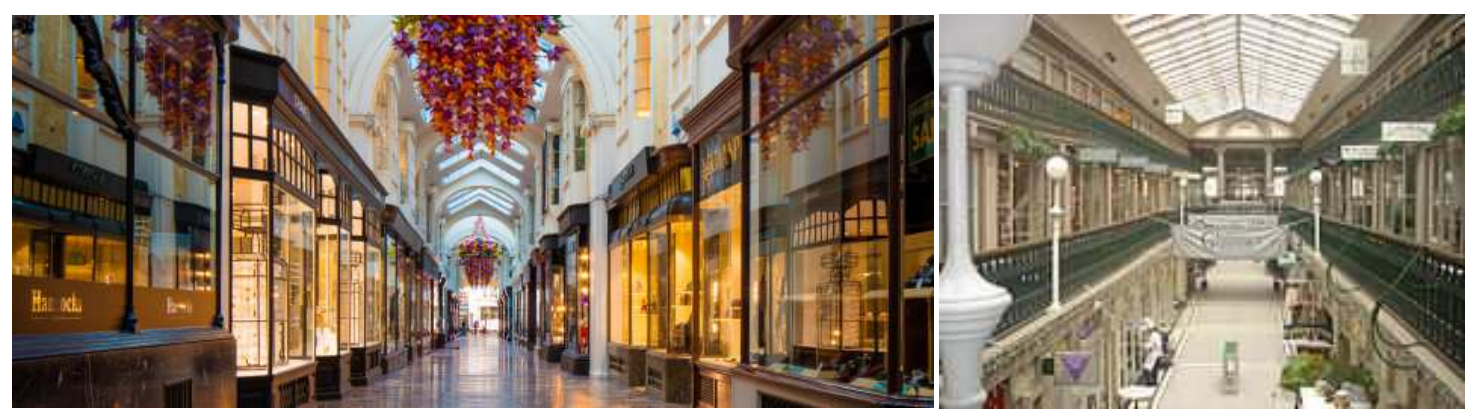

Figura 3.1.5.- Interiores de Burlington y Westminster Arcade. Fuente: Polytech, Wikipedia

Galería Vittorio Emmanuelle, Milán 1870, Esta galería comercial siguió la corriente dictada por la Burlington Arcade, es decir, la idea de cubrir una calle comercial con una cubrición metálica, transformando el espacio de compras en un lugar para el esparcimiento. Sin embargo la relevancia y aportación principal de este caso reside en el aumento de escala de la calle, junto al aumento de complejidad en la planta del edificio, al añadir una segunda calle también cubierta, perpendicular a la principal, formándose de esta manera un esquema básico con forma de cruz. La intersección entre las dos galerías, fue tratada colocando una plaza de gran escala cubierta por una cúpula de acero y vidrio. Las aportaciones de este ejemplo de galería al centro comercial actual, fue el aumento de escala de las galerías, junto a la inclusión de 
plazas centrales de reunión en el interior del centro comercial, las galerías comerciales se conciben como auténticas zonas de reunión. Este complejo, al utilizar una imagen característica llamativa, comienza a considerar en su programa las bases de lo que se conocerá a posteriori como la Jerde Transfer, iniciándose a su vez los inicios de la Gruen Tranfer. No obstante, estas ideas son conceptos definidos de manera reciente en los últimos años del Siglo XX.

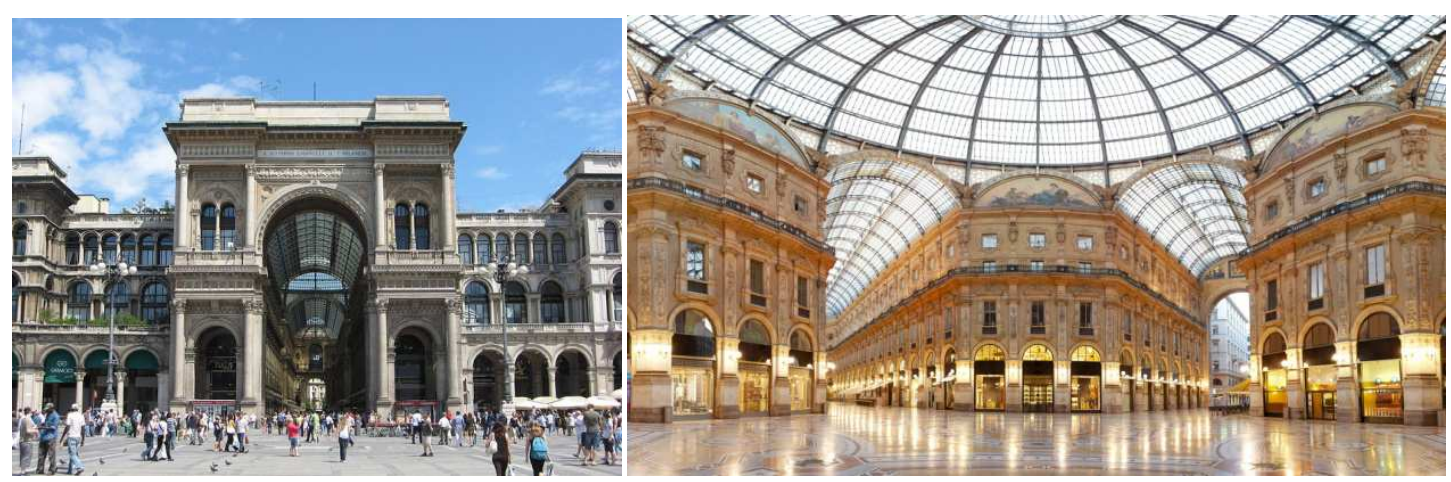

Figura 3.1.6. Fachada e interior de la Galería Vittorio Emmanuelle. Fuente: deviajeporitalia.com. Tecnaria

Cleveland Arcade, Cleveland OH, E.E.U.U 1890. Esta galería comercial, siguiendo el ejemplo de la Westminster Arcade, pero con cinco alturas de galerías. dio un paso adelante en cuanto a temas de confort se refiere, ya que fue el primer edificio comercial de grandes dimensiones en el cual se cerró completamente la galería central al exterior, creando de esta manera un ambiente estanco y acondicionado en la totalidad del espacio interior del edificio. Este interés por buscar el confort máximo se debió a la necesidad de proteger lo máximo posible a los compradores del duro clima del Medio Oeste Americano, Con temperaturas Máximas veraniegas de 40 $\mathrm{C}$ y temperaturas mínimas invernales de $-20 \circ \mathrm{C}$.

La aportación más relevante al concepto actual de centro comercial. Fue por una parte, la inclusión del espacio interior de gran tamaño aclimatado para la tipología comercial, y Por otra parte, la incorporación de servicios ajenos a la adquisición de bienes de consumo, tales como restaurantes, cafeterías u hoteles, apareciendo de esta manera el característico Food Court, o zona de restauración de los centros comerciales modernos.
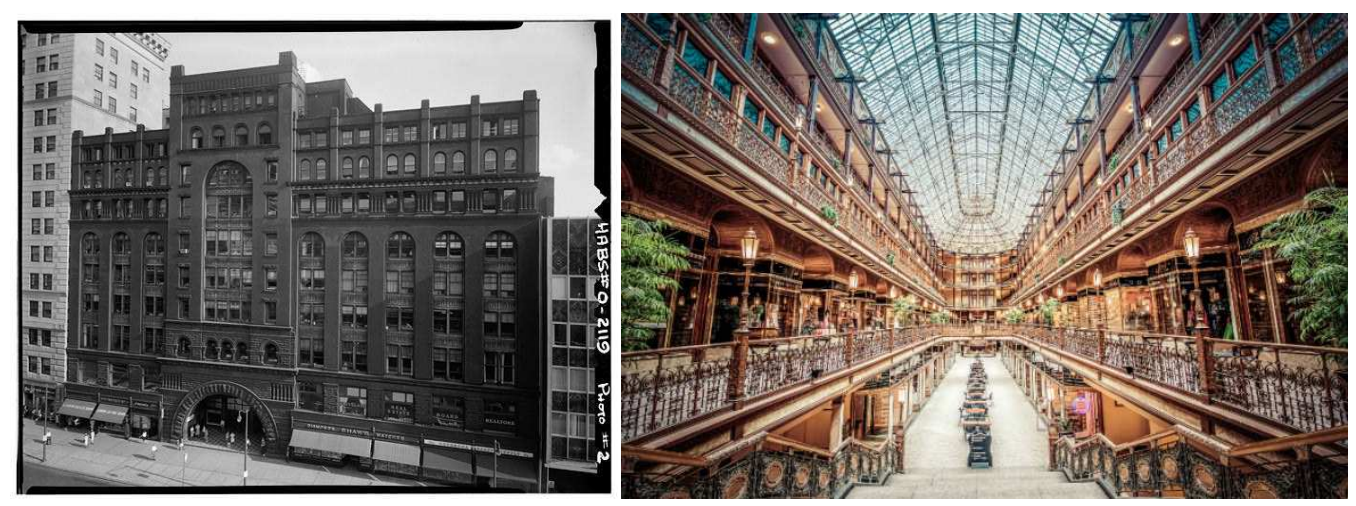

Figura 3.1.7. Fachada e interior de Cleveland Arcade. Fuente: theclevelandarcade.com, Cleveland Area History

No obstante, es de espacial interés, remarcar el hecho de que todas estas instalaciones comerciales se construyeron en contextos de centro de ciudad consolidada. Se hará necesario un cambio en la concepción de la ciudad a escala urbana y tipológica hacia la baja densidad, 
para que todavía se consolide la tipología de instalación comercial de gran superficie en planta y ubicación periférica.

\subsection{6.- 1900-1950, suburbanización e implantación del modelo moderno. Implantación de las nuevas centralidades periféricas.}

Durante el Siglo XIX, y los inicios del Siglo XX, la situación en las zonas urbanas del Reino Unido al igual que en el resto de Europa y Norteamérica, era crítica en cuanto a condiciones de habitabilidad y salubridad. Como respuesta a estos problemas, surgen iniciativas tanto por parte de particulares de abandonar la ciudad, y asentar su vivienda en zonas rurales o periurbanas, como de las administraciones locales de intentar mejorar las condiciones de vida de las zonas urbanas. De este modo asistimos al nacimiento del suburbio anglosajón actual, que fue concebido en sus orígenes desde estas dos iniciativas.

Desde las administraciones públicas, el objetivo era descongestionar las ciudades de personas que emigraban del campo, entre otras muchas acciones de ensanche, dotación y rehabilitación infraestructural. Los ayuntamientos dispusieron barrios especiales para emigrantes rurales en las periferias de las ciudades. Estos barrios buscaban ser lo menos densos posibles como contrapartida al hacinamiento del centro de la ciudad, teniendo siempre en cuenta la limitada capacidad de movilidad de sus habitantes, que necesitaban del transporte público para recorrer largas distancias. De este modo, el resultado fue la construcción de enormes hileras de casas de baja densidad adosadas con jardines de tamaño mínimo. Esta iniciativa en principio resolvió el problema de la congestión dando a los emigrantes una vivienda en unas condiciones relativamente salubres. Pero las condiciones de vida en estos barrios no resultaban en absoluto atractivas, debido a que se intentó resolver el problema reduciendo la densidad, dando como resultado barriadas interminables y monótonas de casas adosadas iguales con una seria carencia de equipamientos dotacionales o de recreo.

Por parte de iniciativas privadas, cabe destacar la decisión de las clases más pudientes de la burguesía urbana, que ante las malas condiciones de habitabilidad de la ciudad, emigraron al campo próximo a la ciudad buscando una nueva vida basada en los ideales románticos de la vida en el campo, y la identidad del habitante de la vivienda como "amo y señor de su propio feudo". De esta manera, estas personas adineradas generaron así su propio modelo de ciudad, intentando recopilar las ventajas de la vida en el campo, con las ventajas de la vida en la ciudad. La composición de estas ciudades, consistía en parcelas de medio a gran tamaño, comunicadas mediante calles con estructura orgánica. En estas parcelas los burgueses edificaron viviendas de gran tamaño, que disponían de grandes jardines muy decorados. A pesar de su gran tamaño, estos barrios disponían de estación de ferrocarril, no obstante, al igual que los barrios de descongestión periféricos, estos apenas tenían dotaciones. Esto en principio no resultaba ser un problema, debido a que prácticamente todos los habitantes del barrio podían disponer de automóvil privado (Un lujo de primer orden en aquella época). Esta situación se mantuvo hasta después de la primera guerra mundial, cuando las escasas clases medias empezaron a tener cierto poder adquisitivo. 
Durante el período de Entreguerras, el suburbio experimentó ciertos cambios. Nos encontramos en una época de cierta bonanza económica con un consiguiente aumento del poder adquisitivo de las personas, junto a un aumento de las clases medias. Esto supondrá a escala urbana un aumento y mutación de los barrios de las periferias, especialmente los habitados a las personas ajenas a las clases altas de la aristocracia o la burguesía. A ras de estos acontecimientos nace el modelo de suburbio de clase media actual, un híbrido entre los suburbios de las clases pudientes y los barrios periféricos de descongestión del siglo XIX. La similitud entre el nuevo suburbio de clase media y el de clase alta, radica principalmente en el hecho de que la vida de las personas que habitaban los lujosos suburbios de clase alta, se consolidó como un "modelo y sueño de vida" para las clases de menor poder adquisitivo. De este modo, los promotores de este tipo de barrios intentaron construir un producto lo mas similar posible a lo demandado por estas clases. Con la crucial diferencia, de que al estar destinados a personas con un poder adquisitivo menor, las viviendas, al igual que las parcelas tuvieron que hacerse de un tamaño mucho menor que en los suburbios de clase alta, manteniéndose únicamente los conceptos, la estructura y la imagen urbana. Estas viviendas fueron adquiridas en principio por las personas con suficiente nivel adquisitivo para pagarse el coste de las casas y los trayectos de ida y vuelta al centro de la ciudad para ir a trabajar; con esto, los ideales románticos del suburbio de clase alta se extienden a los suburbios de las clases medias, creándose un modelo de ciudad disperso que fue exportado a las ciudades de Estados Unidos y Australia. Reinterpretándose las ideas del suburbio de acuerdo a su contexto.

En Gran Bretaña, además de lo explicado con anterioridad, el suburbio fue concebido principalmente como un intento de acercar la ciudad a la naturaleza de manera privada y controlada. Se toma como referente el modo de vida tradicional de retiro asociado a las villas rurales y castillos de la nobleza. Considerando de este modo los ideales del romanticismo, a la par que rechazar el liberalismo industrial capitalista y sus ciudades contaminadas. La privacidad y la identidad son conceptos de gran importancia para los habitantes del suburbio. debido a que la idea primordial, es a grandes rasgos el abandono de los estresantes y contaminados centros urbanos, para practicar el ejercicio del control total sobre su territorio y su vivienda dentro de la naturaleza.

En Estados Unidos, y en menor grado Canadá, el ideal de la vida del suburbio está muy ligado a un único concepto similar al de Gran Bretaña, pero este está aún más radicalizado: Para los americanos, la consolidación del suburbio, es sinónimo del sueño de reclamar el territorio para consolidarse una identidad política, y de esta manera definir un lugar al que pertenecer. Siendo estos preceptos las bases del posterior "Sueño Americano". Por esa razón, es obvio que en Estados Unidos, tras la expansión de este ideal, el índice de vivienda en propiedad sea mucho mayor que en Inglaterra, y esto se debe al factor que brinda la oportunidad de tener una vivienda propia como parte de un sueño de superación e identidad. Esto desembocará a la larga en la creación de comunidades cerradas con identidad propia. Pero a pesar de ello partícipes de la realidad urbana ajena. Es por estas razones por las cuales comienza a consolidarse consolida el suburbio como un símbolo de la propia cultura americana.

En Australia los suburbios tienen también la connotación de identidad política, pero esta difiere con respecto de la estadounidense o la británica. En lugar de la idea de reclamar el 
territorio, la identidad en estos casos se basa en una cultura de la colonización del territorio con fines productivos, muy ligada a espacios de gran extensión con gran escasez de habitantes.

Basándose en estos preceptos ideológicos antes mencionados, surgieron corrientes en el campo del urbanismo experimental tanto en Gran Bretaña, como en Europa y en Estados Unidos. Ebenezer Howard en $1902^{18} 19$ propuso crear ciudades íntegras de nueva planta basadas en anillos circulares concéntricos, con un centro de actividades en el anillo central. Estos anillos estarían conectados entre sí por grandes vías radiales centralizadas. Para solventar el problema de las largas distancias entre puntos, Howard propuso un sistema de transporte entre los diferentes puntos mediante estructuras ferroviarias y autobuses. Las edificaciones en estas ciudades serían principalmente de dos alturas, quedando entre ellas grandes cantidades de espacio libre ajardinado. Este modelo de ciudad fue concebido como Ciudad Jardín.

Frank Lloyd Wright en 1932 también diseñó un modelo de ciudad expansivo basándose en la idea de que cada habitante debía disponer de un acre de parcela como territorio privado, Broadacre Mile City ${ }^{2}$. El resultado fue en una ciudad con una gran cantidad de espacio libre, cuyo elemento integrador con la naturaleza sería su enorme extensión de terreno libre entre calles y edificios. Para salvar las distancias, Wright propuso un sistema de vehículos individuales bastante avanzado e inconcebible para su época.

En España, como refugio a la congestión de las ciudades. Arturo Soria ${ }^{20}$ de 1892 a casi 1932 , propone la creación de una ciudad lineal basada en una única calle central de gran anchura que contiene instalaciones ferroviarias en el centro de la calzada, a los lados de esa calle se dispondrían las parcelas de gran superficie ajardinada con las viviendas en el interior de las mismas.

De este modo, en la primera mitad del siglo XX, asistimos a una época de grandes cambios en la historia, que marcan el principio de la sociedad en el ámbito de lo comercial tal y como la conocemos ahora. Todo comienza con la consolidación final y definitiva del modelo liberal capitalista, pasando por las dos Guerras Mundiales, y finalmente la división del mundo en dos grandes bloques. El hecho más importante durante esta época, es sin duda el tímido crecimiento de las clases medias, junto con la inserción del vehículo particular a una escala más generalizada.

En esta época, las instalaciones comerciales, comienzan a interesarse por los barrios periféricos, manteniendo por supuesto su tienda principal en el centro, las tiendas de nueva construcción, basándose en los conceptos de las arcadas y las galerías anteriores, comenzarán a adaptarse a las nuevas necesidades de los clientes pertenecientes a las clases burguesas. buscando para ello una mejora tanto de la imagen de la tienda, como del entorno del lugar. Los nuevos complejos de tiendas que se construirán, buscarán nuevas estrategias para crear el ambiente más agradable posible de cara al cliente. Tales como la recreación de ambientes añorados con carácter festivo, o la inclusión de calles y plazas de aparcamiento. Cabe destacar

\footnotetext{
${ }^{18}$ Howard E. (1902). Ciudades Jardín del Mañana.

${ }^{19}$ Benévolo L. (2002). Historia de la Arquitectura Moderna.

${ }^{20}$ Navascués Palacio P. (1969). La Ciudad Lineal de Arturo Soria.
} 
también, que las nuevas tiendas de alta categoría se construirán en las proximidades de los barrios residenciales de las clases pudientes. Esto supone el primer acercamiento del comercio fuera del centro de la ciudad, y por consiguiente el nacimiento de los primeros prototipos, y las pautas que guiarán la consolidación del centro comercial no céntrico como tipología arquitectónica.

Todas estas modificaciones en la tipología comercial surgen en los Estados unidos de América, que en esta época cuenta con una población cuyo poder adquisitivo es superior al de los ciudadanos de una Europa, que en esta época se encuentra maltrecha por las diferencias sociales y las sucesivas guerras devastadoras. En este continente se mantienen las tipologías heredadas del siglo XIX de mercados, galerías y grandes almacenes, sin sufrir apenas cambio alguno. Los casos siguientes, son algunos ejemplos de primeros prototipos de centros comerciales periféricos, que incluyen los conceptos anteriormente mencionados, y las aportaciones en la consolidación definitiva de la tipología.

Finalmente asistimos al nacimiento de una nueva idea urbana que será la guía para la concepción de los centros comerciales periféricos modernos, esta será denominada como centralidad periférica, y concebirá la dotación comercial desde otro enfoque diferente a los anteriormente estudiados. Se buscará la creación de una zona comercial con actividad centralizada y baja densidad, acorde con las características urbanas de su contexto periférico. No obstante, mas adelante con la popularización del vehículo privado en los años 50 , que propició aún más la expansión de la ciudad, obligó a que la tipología de centralidad periférica fuese readaptada a otras necesidades. Asistimos al inicio de la concepción de la ciudad desde la zonificación de la misma en zonas monofuncionales, una idea importante a ser considerada para el estudio del contexto en el que se engloban los centros comerciales periféricos.

A continuación se exponen varios ejemplos de centralidades periféricas con función comercial.

Roland Park, Baltimore MD 1907, E.E.U.U.: Consiste en una hilera de tiendas de gama alta con una acera de gran ancho asociada a las mismas, la aportación de este modelo reside en la idea de reservar espacios urbanos exentos a la edificación para el mero uso comercial.

Lake View Store, Duluth MN 1915, y Market Square, Lake Forest IL 1916, E.E.U.U.: Ambos casos corresponden a una Hilera de tiendas de alta categoría a dos alturas, de manera similar a Roland Park, teniendo estos un espacio urbano perimetral reservado. Sin embargo la aportación principal de estos casos, es el espacio urbano que se reserva para plazas de aparcamiento de uso exclusivo de los compradores.

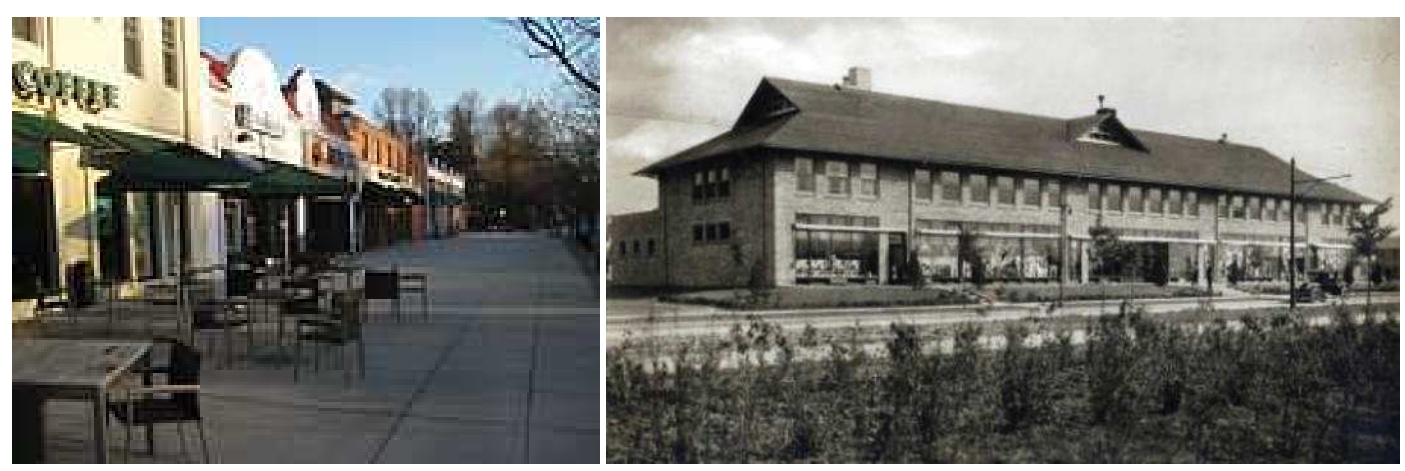

Figura 3.1.8. Roland Park y Lake View Store. Fuente:Wikipedia, Duluth Budgeteer 
Country Club Plaza: Kansas City KN 1923, E.E.U.U.: Este ejemplo es sin duda uno de los más característicos de prototipo de centro comercial de periferia. Siguiendo la línea del Market Square mencionado anteriormente, el Country Club Plaza da un paso adelante, concibiéndose este como un complejo comercial de tamaño considerable cuyos elementos básicos son hileras de tiendas con sus espacios urbanos y aparcamientos asociados íntegramente al conjunto urbano. Todos estos edificios de hileras de tiendas están conectados entre sí mediante grandes avenidas que cuentan con vías de tráfico rodado para conectar la plazas de aparcamiento, a la vez que con recorridos peatonales que unen los espacios estancia cercanos a las tiendas. Otro rasgo característico que cabe destacar en la arquitectura de este complejo comercial, que concibe las fachadas de los edificios con una estética relacionada con diversas arquitecturas del mundo mediterráneo; este complejo al estar destinado al ocio, el fin único de este procedimiento era el mero hecho de crear un decorado para satisfacer la necesidad de los compradores de ver algo diferente a lo que estaban acostumbrados a ver en su vida cotidiana, adaptando un estilo histórico que no es habitual en Estados Unidos debido a las lagunas históricas. De esta manera aparece la arquitectura del decorado como elemento de atracción y publicidad del centro comercial. La aportación de este caso, es que por primera vez asistimos a la creación de un complejo comercial integrado multifuncional, en el que se contemplan todas las necesidades del habitante de la periferia, y se consolida la imagen publicitaria del centro a través de la idea del decorado, se consolida la idea de la Jerde Transfer, al crear un espacio con una imagen urbana característica, pero aislada de la realidad.
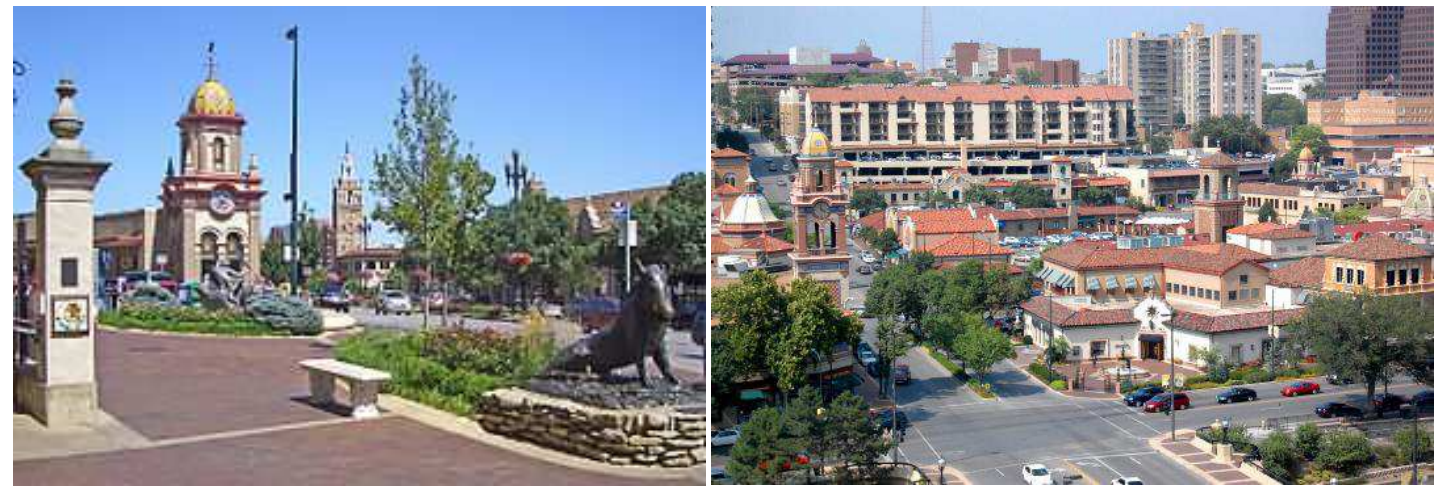

Figura 3.1.9. Country Club Plaza. Fuente: Internet

Highland Park: TX 1931, E.E.U.U.: Este centro siguiendo el ejemplo del Country Club Plaza, intenta crear un entorno aislado del mundo exterior, utilizando como barrera las hileras de tiendas, cuyas entradas se realizan desde un espacio interior que contiene las plazas, avenidas y algunos aparcamientos, dejando los restantes en las zonas exteriores. Los aparcamientos se duplican y se disponen más cerca de las tiendas. La aportación de este caso a la tipología de centro comercial actual es que se busca una Idea de instalación comercial cerrada en sí misma, que evita el contacto con el mundo exterior, idea del espacio urbano destinado a la función comercial, que no interfiere con el resto de funciones de la ciudad. ${ }^{21}$

\footnotetext{
${ }^{21}$ Richard A. Feinberg and Jennifer Meoli (1991) A Brief History of the Mall, Estados Unidos, - Advances in Consumer Research Volumen 18, eds. Rebecca H. Holman and Michael R. Solomon, Provo, UT : Association for Consumer Research, Páginas: 426-427.
} 


\subsection{7.- Segunda Mitad del Siglo XX, consolidación definitiva del modelo periférico del suburb, expansión de la ciudad hacia la periferia.}

Para explicar las razones del contexto en el cual se generó la tipología edificatoria estudiada en el presente trabajo, se hace necesario ahondar en la historia de los suburbios o barrios periféricos de baja densidad, como el otro de los condicionantes que propició la forma del centro comercial periférico actual.

Tras la segunda Guerra mundial, la ciudad americana comienza a expandirse desde los centros consolidados hacia la periferia, ocupando enormes extensiones de terreno libre. Esto fue debido a la demanda de viviendas unifamiliares por parte del público en general.

Sandford Kwinter y Daniela Fabricius, en el libro Mutaciones (2000) (pg 484-648), hablan de los factores de cambio que llevaron a la mutación de la ciudad americana hacia su concepción actual, y estos autores asocial este cambio en parte a un desarrollo condicionado por una variedad de factores sociales, gubernamentales y económicos. ${ }^{22}$

En el caso de la ciudad americana, que es el contexto en el que nació el centro comercial actual, los factores de cambio surgieron tras el fin de la Segunda Guerra Mundial. Recién acabado el conflicto, muchas fábricas de mecánica y contratistas militares, a la vez que empresas petroleras, se encuentran ante una situación de excedente de artículos, debido a falta de demanda. De este modo, aprovechando el tirón de los nuevo artículos de consumo, las empresas de mecánica, deciden orientar su producción hacia la automoción, y los gobiernos viendo en ello una buena oportunidad de reactivación de la economía y desarrollo, ofrecen subsidios para esta transformación, y propician a través de la legalidad, el nuevo desarrollo de esta industria emergente.

Esto supuso en Estados Unidos una bajada drástica de los precios de los automóviles, electrodomésticos y combustibles, de manera que mucha gente perteneciente a las clases medias, (que en esa época estaban en aumento), pudo adquirir fácilmente un vehículo particular, lo que implica que cada vez más personas adquieren la capacidad de poder moverse grandes distancias en relativamente poco tiempo, y así mas y mas familias buscarán vivienda en las afueras huyendo de los centros congestionados.

Otras empresas destinadas a fines bélicos, también se adaptaron, y aprovechando la fuerte demanda de vivienda, los constructores de barracones, tomando como ejemplo la base militar de Oak Ridge, ponen su tecnología de construcción rápida y de bajo coste al servicio de esta demanda, de modo que se genera además un excedente considerable en la oferta de viviendas de nueva planta.

Por otro lado las petroleras, debido a la fuerte demanda de vehículos, a la abundancia de recursos y a los subsidios por parte del estado bajaron también los precios de sus productos refinados.

Frente a esta transformación las autoridades de obras públicas también pusieron de su parte para incentivar este nuevo negocio creando una nueva tipología de vía urbana e interurbana, readaptando el innovador modelo de la Autobahn alemana (Carretera desdoblada con dos

\footnotetext{
${ }^{22}$ Koolhas R., Harvard Proyect on the City, Boeri S., Kwinter S., Tazi N., Ulbrich Obrist H. (2000) Mutaciones.
} 
carriles por sentido) a la creciente necesidad de infraestructura debido al aumento de vehículos. Con esto nace la tipología de autopista moderna, esencial para el desarrollo de los crecimientos periféricos dispersos, y los centros comerciales dentro de su contexto, que se vio beneficiada por la Ley de Autopistas Interestatales de 1956 y por consiguiente se expandió en muy poco tiempo a lo largo y ancho del territorio estadounidense. Adquiriendo esta obra de infraestructura la función de ser el elemento planificador de un nuevo modelo de ordenación del territorio centrado en potenciar la expansión de las ciudades a través de la construcción de zonas urbanas de poca densidad. El resultado de todas estas operaciones en el ámbito urbanístico, fue la expansión acelerada de un nuevo modelo de ciudad basado en la funcionalidad y en las infraestructuras.

Como agravante de este efecto, hay que remarcar la mejora de las telecomunicaciones cuyo efecto más visible en la época, fue la aparición del televisor que rápidamente fue adquirido por las nuevas clases medias estadounidenses. Utilizando este medio, las empresas pudieron publicitar más fácilmente sus productos, aumentando el interés del ciudadano medio en la adquisición de nuevos productos, entre los cuales estaban incluidos los bienes inmobiliarios construidos recientemente en los nuevos suburbios. Las empresas comerciales destinadas a la venta, también se beneficiaron de esta situación, y este movimiento de personas a la periferia fue el incentivo para que los vendedores se trasladasen al suburbio debido a la incipiente necesidad de adquisición de los bienes de consumo por parte de las nuevas clases medias que los habitaban.

De este modo, en Estados Unidos, presenciamos el aumento de las clases medias, y gracias a los cambios acontecidos, y guiados por los preceptos ideológicos de la identidad y superación del Sueño Americano que termina de consolidarse. Estas optarán por abandonar los congestionados y peligrosos núcleos urbanos, para adquirir una vivienda en los nuevos y extendidos barrios periféricos buscando una vida más tranquila y en armonía con la naturaleza.

Así, la demanda de vivienda en el suburbio periférico es cada vez de mayor envergadura, y en consonancia con estos hechos, asistimos a una dispersión de la ciudad, que desde el núcleo central, se expande descontroladamente ocupando grandes superficies de terreno. En este sentido, se consolida de manera definitiva la idea de la ciudad de gran extensión, cuya calificación zonal estará marcada por la zonificación de la misma en áreas homogéneas destinadas exclusivamente a un único uso. Aparece el llamado fenómeno del Sprawl (Dispersión de la ciudad y ocupación masiva del territorio por parte de la misma). Asistiendo también a un cambio de concepto en el espacio urbano, que en estos nuevos crecimientos es concebido de manera integral desde el punto de vista del uso prioritario del vehículo particular, cuya pertenencia y propiedad por parte de los habitantes de la ciudad va en aumento. De este modo, los nuevos crecimientos periféricos ignorarán el papel del espacio urbano como punto de encuentro y relación entre los vecinos.

Con este fenómeno, el número de vehículos privados comienza a ascender, y esto supone la aparición en la trama urbana de grandes infraestructuras destinadas al uso y circulación de los vehículos particulares. Harvard Project on the City ${ }^{5}$, Gallhager Leight ${ }^{23}$ o en el documental The End Of Suburbia, Oil Depletion and Collapse of the American Dream (2004) se explica que el

\footnotetext{
${ }^{23}$ Gallhagher L. (2013)The End of the Suburbs.
} 
factor que propició y desencadenó el desarrollo de las áreas suburbanas de gran extensión y baja densidad, fue principalmente el bajo coste del petróleo y otros artículos de consumo relacionados con la vida en el suburbio. Poniendo más tarde de manifiesto la necesidad de retomar otros modelos de ciudad frente al incremento de los costes del combustible fósil.

Esta situación de crecimiento, se mantuvo hasta prácticamente la época actual, En los años Sesenta ese modelo se exportará a Europa, y comenzará a crecer de manera exponencial a partir de esa época. En España el crecimiento de este tipo de barrios se dio principalmente $A$ partir de los años noventa, teniendo mucho éxito. Esto coincide a su vez con la época en la cual en Estados Unidos se consolidan las ideas del New Urbanism, y el modelo de ciudad periférica y dispersa comienza a ser cuestionado.

A día de hoy, el crecimiento de suburbios a lo largo y ancho del mundo todavía es un hecho real. Y en la actualidad, la ciudad de gran extensión, y las tipologías comerciales ligadas a la misma es algo que ya está expandido en todo el mundo. Como se mencionó anteriormente, el éxito del modelo urbano de gran expansión, se basa en la demanda de los ciudadanos, que buscan vivir en una ciudad descongestionada más cercana a la naturaleza y que a la vez de identidad a sus propietarios.

\subsection{8- Génesis del centro comercial de periferia, Segunda Mitad del Siglo XX,}

Una vez definidas y comprendidas las pautas que condicionaron el nacimiento de los centros comerciales periféricos, se explicará a través de la asimilación de estos conceptos, el nacimiento de estos centros.

A efectos de análisis histórico de los centros comerciales, Esta época histórica es sin duda la más importante en lo referente a la génesis de los mismos, debido a que por fin asistimos en los Estados Unidos de América al nacimiento de los primeros centros comerciales integrales de periferia, como se conocen actualmente.

Frente a la constante expansión de la ciudad, el comercio también se unió al susodicho fenómeno emergente. La emigración de las personas de clase media a la periferia suponía un pérdida muy considerable de posibles compradores en los comercios céntricos. Y por ello, era necesario hacer que la gente que se mudaba no perdiera en ningún momento el interés en la adquisición de bienes de consumo, cuya demanda estaba en alza. En los primeros años de la expansión de los suburbios (años 40), el comercio se trasladó a la periferia ubicándose en fila a los lados de las principales vías de comunicación, todo ello con el mero propósito de que las personas durante sus desplazamientos diarios para ir a trabajar, pasasen delante de las tiendas. Esto trajo consigo la aparición de interminables calles flanqueadas exclusivamente por equipamientos comerciales, llamadas "Shopping Strips" o "Miracle Miles". Este modelo, cumplió sus objetivos de una manera satisfactoria en cuanto al tema de atraer compradores, sin embargo esta atracción trajo consigo serios problemas de tráfico en las vías principales, debido a que se dobló la cantidad de vehículos, ya que se juntaron los que iban de paso a su trabajo, con los que iban a comprar. Por si esto fuera poco, los vehículos parados y estacionados frente a las tiendas junto a las maniobras de aparcamiento y los peatones que cruzaban la carretera para ir a otra tienda diferente, agravaron aún más los problemas de tráfico. El resultado fue catastrófico a efectos de tráfico, de manera que las "shopping strips" llegaron a ser unos puntos negros en cuanto a fluidez y seguridad vial se refiere. Estos 
problemas se solventaron creando aparcamientos en las partes traseras de las tiendas a la vez que vías alternativas que ofrecieran mejores condiciones de tráfico, pero esto solucionó solamente en parte los problemas de tráfico. Sin llegar a crear un espacio agradable para el comercio. De este modo, los comerciantes de mayor envergadura de negocio decidieron optar por otro modelo diferente a la vez que arriesgado. ${ }^{24}$

Los comerciantes de grandes almacenes en su interés por desplazarse al suburbio, adquirieron terrenos de gran extensión alejados del centro buscando el precio más bajo. En estos terrenos construirían una tienda satélite de gran tamaño, llegando a igualar e incluso superar en superficie construida a las tiendas principales de la compañía ubicadas en el centro, con esto además adaptaron sus comercios a un factor emergente, que era el de la adquisición de artículos en cantidades mayores por parte de los nuevos consumidores de los suburbios. Para evitar los problemas de congestión en el viario público, se dispusieron de plazas de aparcamiento en los alrededores, destinando grandes partes de la parcela a ese uso. Con esto aparecerán los primeros hipermercados y las tiendas especializadas de gran tamaño. El riesgo de estas intervenciones, residía en el alto coste de inversión que suponía la adquisición del terreno, la construcción y puesta en funcionamiento de esta gran cantidad de metros cuadrados para uso comercial desconocidas hasta la fecha. A todo ello hay que añadir la abismal diferencia de densidad de población de los suburbios con respecto a los centros urbanos consolidados, de manera que debido a este factor crucial, puede darse el caso de que el número de compradores no sea tan grande como en el centro debido las características intrínsecas del suburbio (Poca densidad y largas distancias). Y si el número de compradores es insuficiente, no se amortizan las pérdidas que supone la construcción y el mantenimiento de esta tienda satélite de gran tamaño, lo que implica que la empresa pierde dinero y va a la quiebra.

En algunos casos esta predicción se cumplió, Pero la mayoría de estas intervenciones tuvieron éxito, atrayendo a personas incluso desde diversos puntos de la ciudad. De esta manera se centraliza el comercio nuevos barrios creados ex profeso para ello, ya que otras muchas tiendas aprovecharon el tirón para construir sus hipermercados satélite al lado de los anteriores, generando polígonos comerciales. Que más adelante derivará en el concepto actual de centro comercial como se conoce actualmente. Una tipología edificatoria de gran superficie y poca altura, en la que los inversores concentrarán dentro de un mismo edificio, una serie de tiendas de diversos tamaños y volúmenes de comercio, junto con servicios de diversa índole ajenos al comercio. Entre las tiendas dispuestas en el nuevo centro, es habitual la presencia de uno o varios hipermercados, que como estaban teniendo éxito en la época, estos servirían de elemento atrayente de cara al usuario de la nueva centralidad, (concepto de empresa locomotora).

De los casos de nuevos centros comerciales integrados por una parte cabe destacar el caso del centro comercial Park Forest en Illinois, 1947 en el cual el objetivo del proyecto consistía en la creación de una centralidad comercial ubicada en un barrio periférico, que consistiría en una serie de hipermercados y edificios de tiendas, ubicados en torno a un espacio abierto y aislado

\footnotetext{
${ }^{24}$ Gruen V. (1973). Centers For The Urban Environment.
} 
meramente peatonal. Los bordes de la parcela y demás áreas anexas al conjunto comercial servirían para disponer las plazas de aparcamiento.

Por otra parte, y partiendo de la idea de centralización, el arquitecto Vienés Victor Gruen, en un artículo de la revista Progressive Architecture del año $1952^{25},{ }^{26}$, da una visión de lo que son los centros comerciales actuales. Gruen, para paliar la falta de usos y la dispersión presente en los suburbs norteamericanos propone la creación de nuevas centralidades con gran cantidad de servicios urbanos, en los entornos de gran extensión y baja densidad, teniendo como objetivo la reducción del consumo energético derivado de los desplazamientos y la recuperación del espacio cívico. estas pautas también vienen recogidas en el libro "Centers for the Urban Development" redactado por el mismo autor, y su estudio de arquitectura. Como resultado de esto, nace una nueva tipología edificatoria, buscando la creación de una centralidad con gran variedad de funciones que a su vez sirviera de punto de encuentro cívico para la comunidad.

Gruen tomará como referencia las ideas de las galerías cubiertas europeas y los hipermercados, para más adelante proyectar un espacio polivalente pensado para el comercio, incluyendo dentro del mismo otras actividades sociales aparte del comercio (encuentros, conciertos, ferias...). Apareciendo de esta manera el centro comercial de Northland en Seattle, en 1950, con una anatomía similar a Park Forest, con la diferencia de que en este centro se incluirían soportales y zonas cubiertas para uso cívico, y más tarde el centro comercial de Southdale Mall en Edina, Minnesota, en 1956, que será el primer centro comercial periférico con variedad de funciones y tiendas que cuenta con plazas y galería cubiertas y cerradas en su totalidad.

La idea que Gruen persiguió en la concepción de los centros comerciales. Estaba encaminada, a evitar la gran cantidad de desplazamientos que implicaría la dispersión de los equipamientos a lo largo y ancho de la ciudad en la que el operaba, es decir, el suburbio norteamericano. Y a su vez presentar una alternativa más viable a los polígonos de contenedores especializados, que estaban en auge en la Norteamérica de esos años. Por ello basándose en esta idea, Gruen plantea una tipología de edificio multifuncional centralizado que además de ofertar servicios de adquisición de bienes de consumo como objetivo primordial, debe de ofertar una gran cantidad de servicios orientados a diversas funciones de la vida ajenas al comercio, tales como lugares de actos y encuentros de reunión. Por si esto no fuera suficiente, este centro debería concebirse además como un lugar óptimo para el esparcimiento y la actividad, en el cual la comodidad de los usuarios es objetivo prioritario y por ello es conveniente aclimatar los interiores de los centros multifuncionales, creando un ambiente aislado del exterior con amplios espacios en el cual las actividades sociales puedan desarrollarse sin problemas. Además este centro debía de tener suficiente aparcamiento para todos los visitantes, de manera que se dispuso de un gran número de plazas de aparcamiento al aire libre que ocupaban mucho espacio. En cuanto a las dimensiones del edificio y su organización funcional, Victor Gruen describe claramente unas pautas de dimensionado basadas en datos cuantitativos como receta del centro comercial ideal.

1:Toma cuarenta hectáreas cuadradas de terreno (Ilano, si es posible).

\footnotetext{
${ }^{25}$ Oficina Ecosistema Urbano (Junio de 2015). Reinventarse o Morir, la Transformación de los Centros Comerciales bajo el Nuevo Paradigma Económico/Urbano.

${ }^{26}$ Equipo Plataforma Urbana (Agosto 2012). La idea del mall cerrado cumple 60 años y prepara su jubilación
} 
2: Rodéalos con 500.000 consumidores que no tengan acceso a ningún otro equipamiento comercial.

3: Prepara el terreno central y cúbrelo con 1.000.000 de metros cuadrados en edificios.

4: Rellena los edificios anteriormente dispuestos con comerciantes de primera categoría que vendan artículos de calidad a precios seductoramente bajos.

5: Dispón de 10.000 plazas de aparcamiento en el exterior y asegúrate de hacerlas accesibles desde las infrautilizadas autopistas de primer rango, que vienen de todas partes.

6: Acaba el centro, decorándolo con algunas plantas en macetas, lechos de flores variadas, un poco de escultura y sírvelo muy caliente al cliente. ${ }^{27}$

Siguiendo estos preceptos, Victor Gruen proyectó el primer centro comercial periférico de espacio aclimatado en 1956, en Edina, una pequeña ciudad de Minnesota (Estados Unidos). Cuyas características funcionales y formales responden a las que citaremos más adelante para los centros comerciales.

Este modelo resultó muy exitoso a la vez que rompedor, y paulatinamente, muchos inversores fueron construyendo el suyo propio, valiéndose de empresas locomotoras (Tiendas de gran envergadura, que por su atractivo o volumen de comercio atraen compradores al centro comercial en su conjunto), para atraer clientes y así amortizar la inversión. llevándose esta tipología también a los centros consolidados de las ciudades. Sin embargo, durante el proceso de difusión acontecido en los años venideros las funciones ajenas al comercio fueron relevadas a un segundo plano, interesando solamente la disposición de locales destinados a tiendas, ya que estos generaban un mayor beneficio al inversor. Esto supuso la orientación de los futuros nuevos centros hacia la temática exclusiva de la compra-venta de bienes de consumo, perdiéndose por el camino la función social propuesta por Victor Gruen.
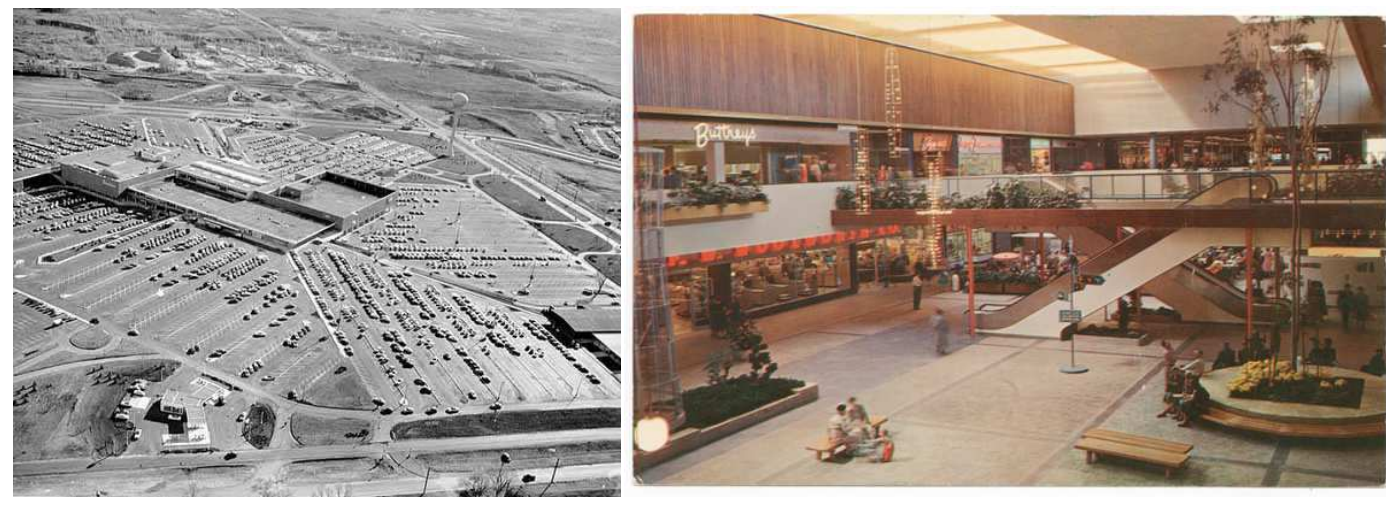

Figura 3.1.10. Exterior e interior de Southdale, el primer centro comercial con concepto actual de la historia. Fuente: MNopedia, Minnesota Hystorical Society

\subsection{9.- 1980-2010, Época actual, crisis económica, y medioambiental, los problemas de la ciudad extensiva.}

En estos años asistimos al final de la Guerra fría. Y la casi completa dominación del mundo por los sistemas de gobierno democráticos neoliberales. A su vez aparece, un desarrollo tecnológico muy alto, sobre todo en el ámbito de la las telecomunicaciones. Se consolida definitivamente la sociedad de consumo y del bienestar en algunos países. A su vez, el modelo económico neoliberal comienza a cuestionarse por ciertos grupos sociales. Asistiendo a su vez

\footnotetext{
${ }^{27}$ Extracto de Victor Gruen "Receta para el centro comercial ideal", recopilado en el libro Mutaciones, (2000). En el capítulo Shopping escrito por "Harvard Project on The City". (Página 162).
} 
durante estos últimos años al nacimiento de una conciencia proteccionista del medio ambiente en alza, que es una intención de toma de conciencia frente a la degradación medioambiental que el planeta lleva sufriendo desde el inicio del desarrollo tecnológico en el Siglo XIX.

En esta época, la tipología de centro comercial se encuentra sometida a las reglas de una sociedad cambiante cuyo nivel de vida de sus miembros va en aumento. La democratización absoluta del vehículo particular para todos los estratos de la sociedad, permite que cada vez más personas accedan a los centros y otras centralidades comerciales ajenas al centro urbano. $Y$ es debido a esta razón por la cual los centros comerciales multi-funcionales de periferia comienzan a aparecer en todo tipo de entornos rurales y urbanos, incluidos los centros de las grandes ciudades. Además, debido al aumento del nivel de vida a escala globalizada, la tipología de centro comercial comienza a exportarse a lo largo y ancho del mundo, de modo que a principios de los años noventa, prácticamente todas las ciudades del mundo desarrollado o en vías de desarrollo tienen al menos un centro comercial de las características antes citadas. El creciente aumento de la demanda por parte de la sociedad, hace que los inversores guiados por el pretexto de aumentar el aforo y volumen de comercio para garantizar el éxito de la inversión del centro comercial, comiencen a construir centros comerciales cada vez de mayor tamaño buscando de este modo hacer enormes complejos comerciales atrayentes a escala extraterritorial, que incluyan el máximo número de tiendas, hipermercados y actividades lucrativas posibles. De este modo aparece el concepto de "Regional y Super Regional Mall", Que consiste en un centro comercial con las características espaciales dictadas por Victor Gruen, pero sus significativas diferencias, radican por una parte en su gran tamaño, que puede englobar en los casos más extremos hasta cientos de miles de metros cuadrados construidos, y por otra parte en la gran cantidad de actividades dentro de los mismos (mayoritariamente lucrativas). Estas características son consecuencia de la intención de abarcar la mayor capacidad posible de actividades de mercado ligados al comercio y el ocio dentro de un solo edificio, utilizando ambas como elemento atrayente. $Y$ de este modo un centro comercial de gran tamaño, perfectamente puede incluir en un solo complejo, varios hipermercados, otros varios centenares de tiendas de alquiler, junto con una inmensa variedad de espacios de ocio de diversos tamaños y funciones, tales como una gran cantidad de restaurantes y cafeterías variadas, salas de cine, parques de atracciones o acuáticos, e incluso hoteles. Lo que hace que el uso del centro comercial ya se consolide definitivamente como en una ciudad destinada al ocio, pero con fines meramente lucrativos. Este tipo de centro se ha exportado de una manera muy satisfactoria en los últimos años, y donde más éxito está teniendo, es en los países petroleros del Oriente Medio, y en los centros financieros urbanos de los países emergentes del Este de Asia. En Europa, Sudamérica y Japón, la tipología de "Regional Mall" se ha introducido de manera bastante satisfactoria. Es en esta época, cuándo se consolidan y se definen las ideas de la Jerde Transfer, y la Gruen Transfer.

A continuación citaremos algunos ejemplos de Super Regional Mall más relevantes, incluyendo ejemplares en estado de deterioro.

Mall of America, 1992, Bloomington, Estados Unidos: Este centro de gran tamaño, es el más importante del mundo debido a que es la instalación comercial que más compradores recibe al año en el mundo (40 millones de personas). También fue pionero, ya que fue el primero que 
incluyó en su programa un enorme parque de ocio cubierto. Su superficie construida es de $230.000 \mathrm{~m}^{2}$ y tiene prevista una ampliación de $500.000 \mathrm{~m}^{2}$, contiene 520 locales comerciales y un parque cubierto.

West Edmonton Mall, 1981, Edmonton, Este centro de gran tamaño es el mayor de Norteamérica y el quinto del mundo en superficie útil $(493.000 \mathrm{~m} 2)$. Contiene 800 locales comerciales, parque acuático, pista de hielo e incluso una zona educativa. Sin embargo este centro recibe 28,2 millones de visitantes al año, poco más de la mitad del Mall of America.

Dubai Mall, 2009, Dubai, Emiratos Árabes, Con sus 1.124.000 de metros cuadrados construidos, esta instalación comercial es la mayor del mundo en cuanto a superficie construida, Además de una gran variedad de tiendas de gran lujo, el centro contiene un hotel de 250 habitaciones, 1200 locales, 22 salas de cine, 14.000 plazas de aparcamiento, una pista de hielo e incluso acuario.
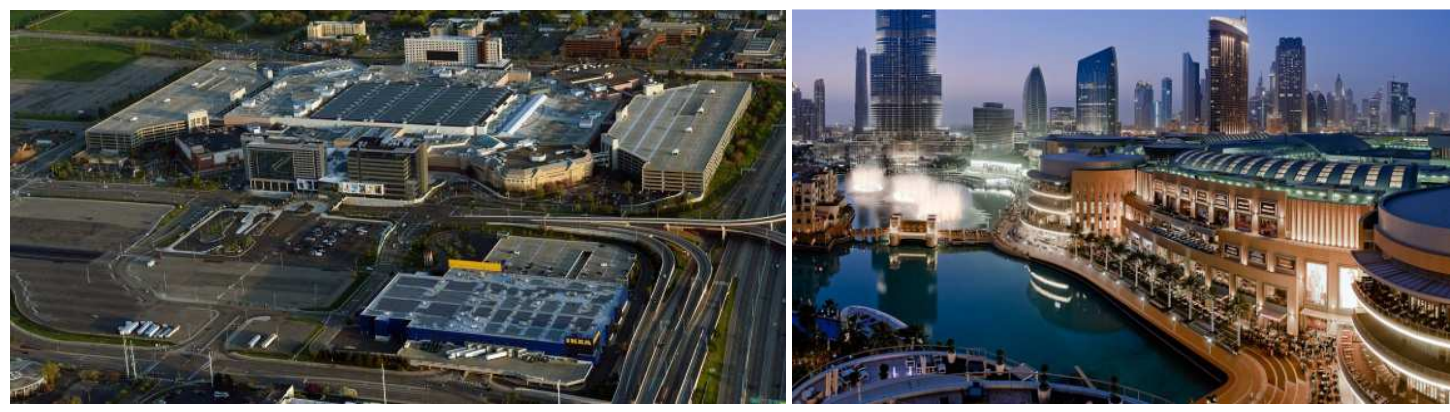

Figura 3.1.11. Mall of America y Dubai Mall Fuente: Internet, Google.

Golden Resources, 2004 Beijing, China, Este centro comercial de gran tamaño ubicado en el centro de Beijing, es el tercero del mundo en cuanto a tamaño construido, No obstante, aunque no está en estado de decadencia, este centro no ha tenido mucho éxito debido a los elevados precios de los locales, que normalmente suelen pertenecer a multinacionales europeas o americanas. Siendo sus principales clientes los turistas que tienen un nivel de rentas mayor que la media de China.

New South China Mall, Donghuan, China 2005, Este centro, es el segundo mayor complejo comercial del mundo en cuanto a metros cuadrados construidos $(890.000 \mathrm{~m} 2)$, y el primero en cuanto a número de locales alquilables (1500 locales) Contiene además varios parques de atracciones y zonas de relax, que copian lugares emblemáticos del mundo. Sin embargo al ubicarse en una zona habitada por inmigrantes de la china continental que buscan trabajo en las fábricas del sur, el centro no dispone de suficiente demanda local, de manera que el centro tras su inauguración oficial, rápidamente se fue abandonando por falta de interés de los compradores hasta quedar prácticamente vacío, solo el $1 \%$ de la superficie está alquilada, quedando el $99 \%$ de los comercios como un espacio vacío y sin uso, a la espera de ser alquilado en un corto espacio de tiempo. No obstante, este centro actualmente está abierto debido a los beneficios del parque de atracciones, que ha resultado ser el único negocio exitoso en el centro. 


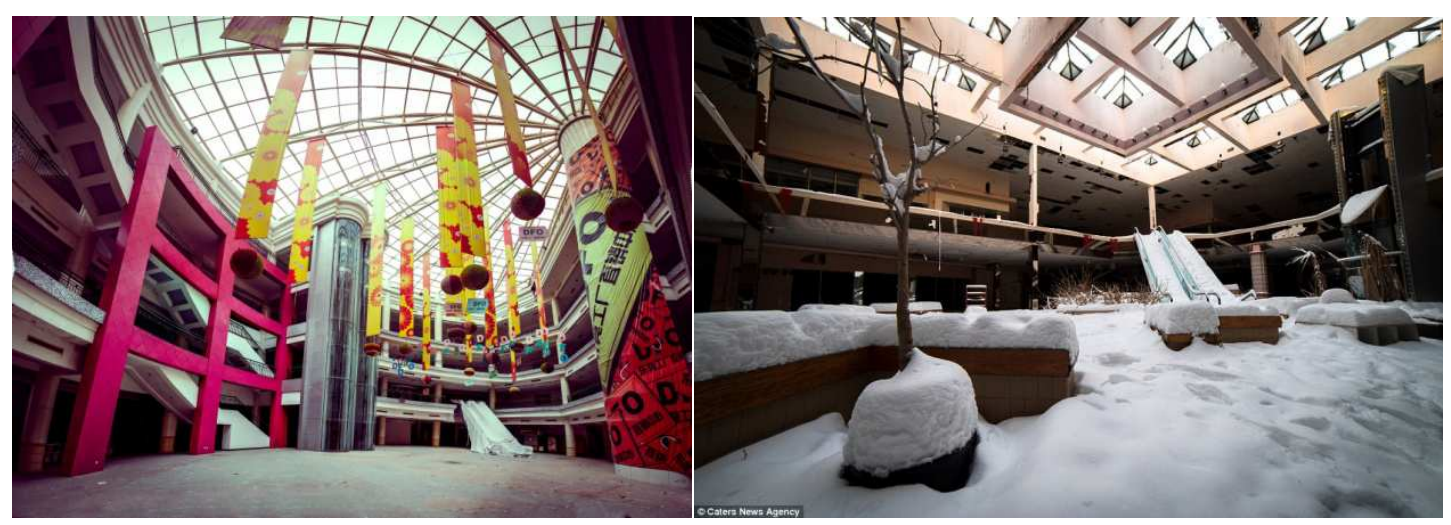

Figura 3.1.12. New South China Mall y Rolling Acres, Ejemplos de centros comerciales en desuso o Dead Malls. Fuente: UberPickleMonkey, Caters News Agency.

Actualmente, estamos asistiendo a un cambio en la tendencia comercial, propiciado en parte por la altísima oferta de centros comerciales existentes, y en parte por la crisis económica. No obstante, antes de la realización de cualquier análisis a fondo de la rehabilitación de los centros comerciales, se va a hacer necesario explicar en primer lugar las ideas y conceptos intervinientes en el proyecto y materialización de un centro comercial, para sentar las bases de lo que más adelante va a ser la problemática, que ha supuesto la expansión y el desarrollo de los mismos respecto a los pilares de la sostenibilidad.

Otra contra tendencia en lo que es el centro comercial, es el aparente traslado de tiendas especializadas de gran contenedor de la periferia (big box retailer), hacia los centros de las ciudades. Un ejemplo de este hecho, es la tienda Media Markt de Goya, en el centro de Madrid. La cual y ha obtenido un éxito relevante debido al negocio de las compras de internet al actuar como punto de recogida. Ejerciendo este local un gran poder de atracción, al poseer la misma cantidad de género que cualquier otra tienda Media Markt de la periferia, a pesar de los problemas relacionados con una superficie menor de tienda, la ausencia de un aparcamiento a escala masiva y una regulación estricta para la carga y descarga de género.

No obstante, la relevancia de este caso para la presente tesis, es que se hace evidente una posible reversión del proceso de suburbanización de los grandes almacenes, que aconteció en la primera mitad del Siglo XX. Este proceso, como se contó anteriormente dio lugar a los Hipermercados (big box retailer) y estos posteriormente a los centros comerciales periféricos (Shopping Mall).
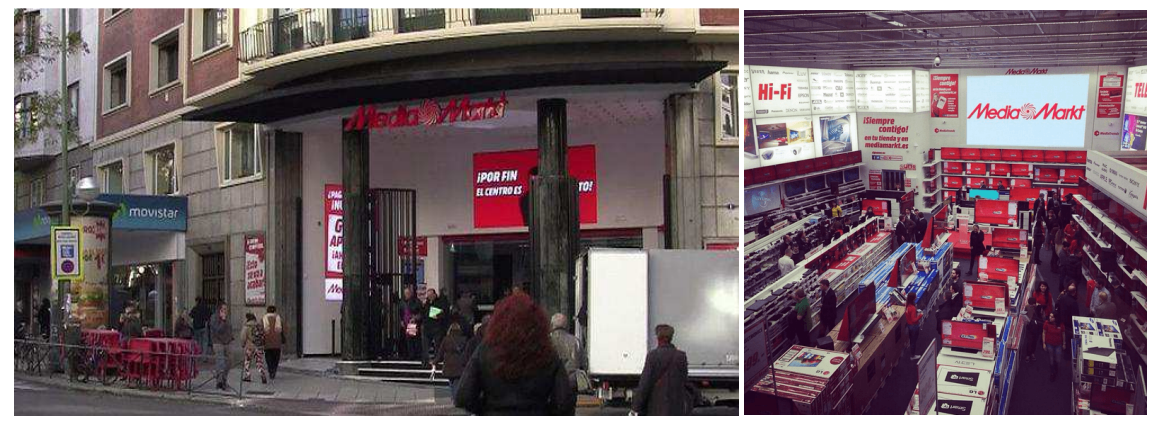

Figura 3.1.13. Media Markt Goya. Fuente: ABC, Zonaretiro.com 
A continuación se muestra en la siguiente gráfica, un resumen de la evolución de los centros comerciales. (Figura 3.1.14)
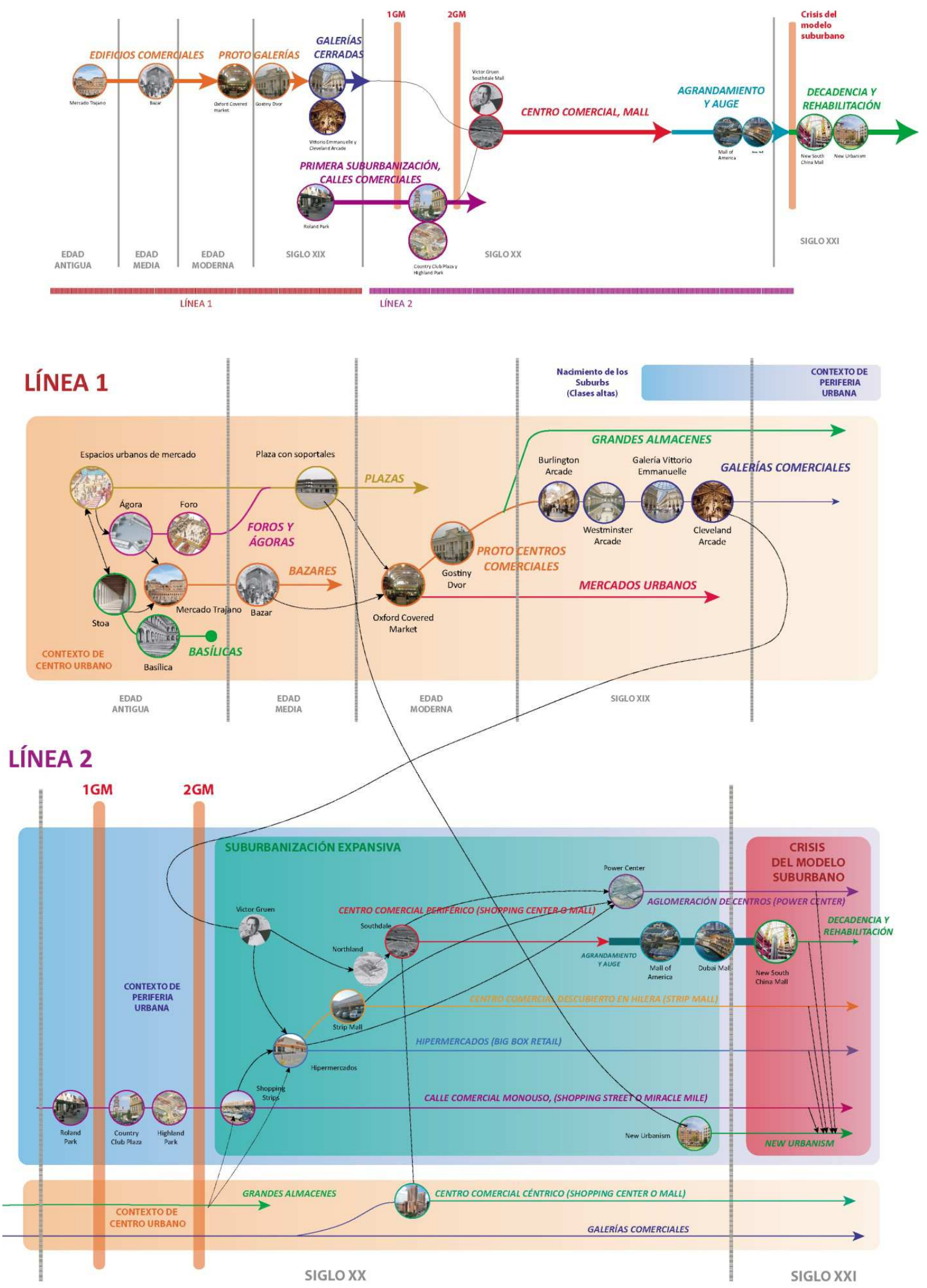

Figura 3.1.14. Gráfico temporal de la evolución de los centros comerciales. Fuente: Elaboración propia 


\section{2.- EL MARCO URBANO DE LOS CENTROS COMERCIALES.}

A efectos de planificación, un centro comercial puede encuadrarse en varios contextos urbanos tipológicamente diferentes. Este tema, va a resultar introductorio, teniendo como función enunciar el contexto urbano en el que un centro puede ubicarse. Siendo un punto de especial interés, el hecho de que el centro comercial en sí, va a adaptar su estructura funcional y formal, a las características del barrio en el que va a ubicarse. Para la presente tesis doctoral van a fundamentarse dos ámbitos urbanísticos, que van a ser el céntrico y el periférico, considerándose a su vez los centros expandidos que están comprendidos dentro de los contextos urbanos céntricos los cuales van a ser diferenciados en relación a sus características.

\subsection{1- El contexto urbano Céntrico o centro expandido.}

En esta tesis, el contexto urbano céntrico, va a estar referenciado generalmente a los barrios consolidados dentro de lo que se consideraría el centro de la ciudad (Centros históricos y, o administrativos, ensanches tempranos de ciudades...). Siendo requisito para que un barrio sea considerado como céntrico, que cumpla ciertos requisitos de densidad, mezcla de usos e interacción con su contexto urbano, siguiendo de un modo u otro la estructura de la ciudad tradicional previa a la suburbanización ocurrida en la segunda mitad del Siglo XX. Otro requisito para que un barrio sea considerado como céntrico es que a su vez que este esté integrado dentro de lo que es el núcleo central, histórico o administrativo de la ciudad, existiendo una potente interacción.

De este modo, Aunque en esta tesis se van a considerar los barrios céntricos como contexto para algunos casos, el estudio de los mismos es muy complejo, ya que en su consolidación han intervenido muchos factores que pueden variar dependiendo del barrio en sí, siendo muy complicado el establecimiento de un modelo de actuación genérico que pudiera definir todos los casos de barrio céntrico. De manera que el estudio de los factores intervinientes en la consolidación de un barrio céntrico, es un asunto que debe de ser estudiado de manera concreta para casos particulares, cuyas variables van a diferir dependiendo del barrio que estemos estudiando. No obstante en este tipo de barrios, debido a la complejidad de usos y a la densidad, existe interacción entre los elementos, de manera que la función social del espacio libre va a estar presente. Como zona específica de este contexto urbano, caben destacar los centros expandidos, que aunque son áreas que más o menos comparten las características urbanísticas de los centros, su localización respecto al centro urbano es excéntrica, o estan en la periferia próxima del mismo.

Las características del contexto urbano céntrico a grandes rasgos son las siguientes:

-Densidad de población de media a elevada (80 viviendas por hectárea o más) ${ }^{28}$.

-Gran volumen edificado $\left(7 \mathrm{~m}^{3} \text { de edificación, por } \mathrm{m}^{2} \text { de superficie, o mayor }\right)^{1}$.

-Interacción mayor o menor entre los elementos que componen el barrio, que pueden o no dotar al espacio público de una función social. (Por lo menos un $50 \%$ de fachadas activas)

${ }^{28}$ Rueda S. (2010), Plan de Indicadores de sostenibilidad urbana de Vitoria Gastéiz. 
-Mayor o menor mezcla de usos. (Ningún uso específico deberá de exceder el $70 \%$ de la superficie total del área edificada)

-Comunicación e interacción del barrio con otras zonas de la ciudad. (Existencia de transporte público y recorridos peatonales)

No obstante, en la presente tesis más adelante van a describirse las características del contexto urbano céntrico más a fondo, a través de la utilización de indicadores y otros factores de interés.

\subsection{2- El contexto urbano periférico}

Los barrios que son considerados como periféricos en la presente tesis, van a hacer referencia a los denominados "Bedroom Suburb", o "Suburb", y similares. Estos barrios básicamente se caracterizan por ser crecimientos urbanos generalmente dispersos y de poca densidad, los cuales a efectos de usos están radicalmente zonificados en el mayor de los casos. También en estas zonas urbanas predominan las tipologías edificatorias de poca altura, con grandes espacios no edificados a su alrededor. La consolidación de esta estructura urbana acarrea un incremento en las distancias entre edificios, propiciándose el uso del vehículo particular; hecho que hace que el proyecto de la infraestructura relacionada con este uso, ya sea para la circulación o el estacionamiento, juegue un papel crucial tanto en el diseño del plan urbano, como en los proyectos de las parcelas y edificaciones dentro del mismo.

De este modo podría afirmarse que la tipología de suburbio periférico de poca densidad, o "suburb", a diferencia de los crecimientos céntricos, en cuya consolidación intervinieron varios factores, es una tipología urbanística que nació en los Estados Unidos de América a mediados del Siglo XX debido la democratización del vehículo particular. Lo que acarrea consigo el hecho de que en el diseño del espacio urbano, se prime la circulación de los vehículos sobre otros asuntos, de manera que la función social del espacio libre como espacio de reunión va a limitarse a los espacios privados de los inmuebles, no existiendo esta en el espacio público debido a la escasa interacción entre los elementos.

A día de hoy, los suburb anglosajones ya empiezan a ser cuestionados como una manera de crear ciudad nada viable, especialmente por parte de los grupos e investigadores afines a la corriente de la rehabilitación urbana en Norteamérica (New Urbanism), que propone como solución la densificación y mezcla de usos dentro de las periferias. El libro de Leigh Gallhager, The end of the suburbs ${ }^{29}, y \mathrm{El}$ documental The End Of Suburbia, Oil Depletion and Collapse of the American Dream (2004), alerta del hecho de que los barrios periféricos de poca densidad, son extremadamente vulnerables a la escasez de energía o combustibles fósiles, y de este modo estos pasarán a transformarse en los barrios marginales del futuro, siendo estos paulatinamente abandonados, a medida que los precios de los combustibles fósiles se incrementen, y las reservas de los mismos se agoten, entre otros factores que también van a propiciar su desaparición (preferencia nuevos modos de vida más ligados a los centros urbanos, falta de demanda de vivienda unifamiliar, aparición de otras formas de familia...)

En definitiva, las características predominantes de los barrios de tipo "suburb", o crecimiento periférico poco denso son las siguientes, tomando como base la referencia de Richard Harris y

\footnotetext{
${ }^{29}$ Gallhagher L. (2013)The End of the Suburbs.
} 
Peter Larkham en Changing Suburbs, Foundation, Form And Function (1999) ${ }^{30}$, y los escritos de Ellen Dunham Jones, en Retrofitting Suburbia $(2011)^{31}$.

-Baja densidad de población, derivada del uso de tipologías edificatorias de poca altura y la parcelación a tamaños relativamente grandes en relación con la tipología de edificio (grandes retranqueos), que propician la dispersión de las edificaciones a lo ancho del territorio. Densidad de viviendas no mayor a 30 por hectárea.

-Importancia del vehículo particular a la hora de diseñar el espacio urbano, propiciada principalmente por la dependencia de los habitantes en el mismo, inviabilidad para la implantación del transporte público.

-Infraestructura de tráfico rodado, muy jerarquizada y concebida de acuerdo a su uso y función, que principalmente es de alta capacidad y predominancia del tráfico rodado.

-Zonificación por usos, que trae consigo una división del territorio en zonas homogéneas de gran tamaño y un solo uso.

-Predominancia del espacio privado, frente a la función pública, hecho que se ve propiciado por el desinterés en el espacio público debido a la falta de interacción.

-Concepción de los edificios y unidades urbanas como elementos aislados, esto se agrava con la concepción del entorno y la funcionalidad desde el punto de vista del uso mayoritario del vehículo particular.

Este capítulo en relación con el contexto urbano periférico ha realizado un análisis introductorio, citando las características más generalistas y relevantes. A posteriori, se va a realizar un estudio más a fondo del contexto urbano periférico a través de indicadores, que nos servirá para definir de manera rigurosa las cualidades de esta tipología de barrio.

No obstante, una vez enunciado e introducido el contexto urbano urbanos que caracterizan los barrios periféricos de poca densidad o suburbs, se procederá a explicar las cualidades y los defectos de este tipo de planeamiento urbano desde el punto de vista de los tres pilares de la sostenibilidad (Sostenibilidad económica, social y medioambiental), ya que estos son la referencia constante del trabajo de investigación.

\section{3.- EL PROCESO DE PROYECTO Y FUNDACIÓN DE UN CENTRO COMERCIAL.}

Aunque el proceso de fundación de un centro comercial no es el tema central de la tesis, la comprensión del mismo será importante, ya que nos ayudará a comprender la problemática de los mismos, considerando también para temas posteriores de la presente tesis, el hecho que muchos de los factores considerados durante el proceso pueden fundamentar muchos de los puntos que deberían de ser tratados a la hora de acometer cualquier tipo de rehabilitación funcional de una instalación comercial. Espacialmente, si se trata de un comercio, cuya

\footnotetext{
${ }^{30}$ Harris R. (1999). Changing Suburbs, Foundation Form And Function.

${ }^{31}$ Dunham Jones E. Williamson J. (2011). Retrofitting Suburbia, Urban Solutions For Redesigning Suburbs.
} 
edificación ocupa una gran superficie, como las estudiadas en esta tesis doctoral, cuya materialización y puesta en funcionamiento es un proceso complejo y costoso, que requiere una gran cantidad de recursos tanto económicos como materiales. Hecho que se agrava incluso más, cuando se trata de acometer una rehabilitación sobre este tipo de instalaciones.

La idea de proyecto del centro comercial se basa la centralización un número de comercios en un único punto. El método de proyecto de estos edificios es totalmente funcional, y engloba el manejo de cifras que tienen que ver con la oferta y la demanda entre otros factores. A pesar de esto, hay que destacar los centros comerciales como se conocen hoy en día, parten de las ideas de Victor Gruen aplicadas en Southdale en 1956, quien en el proyecto de centro comercial incluía otras funciones sociales aparte del comercio, Sin embargo, la evolución de estos centros, ha ido hacia la función exclusivamente comercial, debido al constante interés de los dueños por generar el máximo número de beneficios.

De este modo, de acuerdo a Francisco A. Queipo Blanco ${ }^{32}$. Los pasos para la fundación de un centro comercial son los siguientes, estas fases aunque serán enunciadas y explicadas en el presente trabajo, el estudio a fondo de las mismas es muy extenso, y este puede ser tema de posteriores trabajos de investigación.

(...) Primera fase, Estudio de la factibilidad de la operación comercial: esta fase está basada principalmente en el análisis y estudio previo del potencial y los factores externos de la zona en la que se va a asentar el centro comercial, en esta fase se estudiarán de manera pormenorizada los factores del lugar de implantación, el potencial comercial, la presencia e influencia de la competencia, las características urbanísticas de la infraestructura, estimando a su vez un tanteo del coste de la operación comercial. La adquisición del terreno puede realizarse de manera previa a esta fase.

(...) Segunda fase, Estudios del concepto y la imagen: El objetivo de esta fase, es principalmente considerar el objetivo económico y de proyecto que se pretende centrándonos en lo que va a ser el edificio del centro comercial exclusivamente, todo ello dentro del contexto estudiado con anterioridad. El resultado de esta fase, será un pre dimensionado del centro comercial, en el que se tanteará el número de locales y empresas locomotora, los flujos, la imagen y la primera fase del proyecto.

(...) Tercera fase, Análisis financiero y de costes: Una vez definidos los objetivos y las dimensiones del centro, se estudiarán los factores económicos en referencia a la materialización y gestión del mismo, tales como el coste de los alquileres, la financiación de las obras, los presupuestos, la rentabilidad...

(...) Cuarta fase, Proyecto y merchandising: Esta fase gira en torno a lo que es el proyecto en sí edificio del centro comercial, estando incluidos los pasos inmediatamente previos a la construcción del centro comercial, tales como contratas de construcción y proyectos arquitectónicos. También es en esta fase cuando la gestora del centro comercial define la imagen corporativa para el centro, estableciendo el paso previo a la presentación del centro de cara al público.

\footnotetext{
${ }^{32}$ Queipo F. (1992). Planificación, Análisis, Concepto de Centros Comerciales
} 
(...) Quinta Fase, Estudio jurídico: En esta fase, que es la que cierra el proceso de proyecto del centro comercial, se estudian y se definen los estatutos corporativos de la posterior gestión del centro, así como los seguros, y por supuesto los derechos y los deberes de los comerciantes en la adquisición, propiedad o alquiler de locales.

(...) Sexta fase, Comercialización: Esta fase que la que corresponde a la fase previa a la materialización del centro comercial, y en ella la empresa gestora establece las tarifas de propiedad o alquiler de los locales, para a posteriori y paulatinamente firmar y negociar los contratos con las empresas arrendatarias o propietarias de los locales, poniendo especial interés en la contrata de las empresas locomotora.

(...) Séptima fase, Contratación y obras: Esta fase del proceso de fundación del centro comercial, corresponde con los pasos de la materialización y construcción física del edificio, las instalaciones y la infraestructura necesaria para el funcionamiento, en esta fase se realizan los pagos del material y la construcción del edificio, siendo esta la más costosa económicamente.

(...) Octava fase, Pilotaje de locales: En esta fase los locales son entregados a las empresas que los han adquirido, asumiendo estas empresas los costes y las obras de decoración y adaptación de los mismos de cara al cliente. A su vez se tramitan las licencias de apertura y las autorizaciones pertinentes de cara a la administración.

(...) Novena fase, Publicidad y relaciones públicas: En esta fase el centro comercial ya está listo para su inauguración oficial. No obstante, como paso previo a este acontecimiento, es necesario considerar la publicidad del centro de cara a los futuros compradores, así como planificar las necesidades de los comerciantes. Una vez considerados estos factores, el centro comercial es inaugurado, iniciándose así su negocio.

(...) Décima fase, gestión, planificación y control: Esta fase es la relacionada con la gestión del negocio del centro en las fases posteriores a la inauguración del mismo. Durante la gestión del negocio de un centro comercial, es necesaria la supervisión de los beneficios, gastos y condicionantes, así como el análisis de la evolución del negocio y la preparación de diferentes estudios de prospectiva económica y escenarios de futuro.

Una vez comprendidas las fases de la fundación de un centro comercial, Francisco A. Queipo Blanco, realiza un acercamiento hacia lo que es el proyecto arquitectónico y económico del centro comercial en sí, enunciando en una lista los factores que deben de ser considerados y estudiados durante el proceso de proyecto, organizándolos en familias de indicadores en referencia a un tema de análisis. Los temas de análisis y los respectivos indicadores a analizar propuestos por el autor son los siguientes, siendo la autoría de los mismos propiedad exclusiva de Francisco A. Queipo ${ }^{1}$. (Planificación, Análisis, Concepto de Centros Comerciales, Páginas 16 a 27):

\section{(...)}

PRIMER TEMA DE ANÁLISIS: POBLACIÓN Y POTENCIAL DISPONIBLE.

1.1.- Zona de atracción.

1.2.- Características socioeconómicas.

1.3.- Influencia del Sector primario, Secundario y Terciario. 
1.4.- Población pasada, presente y futura.

1.5.- Características de la población, edades y empleos.

1.6.- Renta Per Cápita.

1.7.- Gastos por persona.

1.8.- Potencial de ventas disponible.

1.9.- Gastos totales.

1.10.- Potencial suburbano.

1.11.- Objetivos de venta.

1.12.- Programa comercial recomendado.

1.13.- Grandes superficies.

1.14.- Alimentación especializada.

1.15.- Equipamiento del hogar.

1.16.- Vestido y calzado.

1.17.- Otros comparativos.

1.18.- Prestatarios de servicios.

1.19.- Restauración.

1.20.- Servicios del automóvil.

1.21.- Servicios de Ocio.

SEGUNDO TEMA DE ANÁLISIS: CARACTERÍSTICAS DEL EMPLAZAMIENTO.

2.1.- Situación y Límites.

2.2.- Superficie.

2.3.- Características urbanísticas.

2.4.- Dotaciones urbanísticas.

2.5.- Datos registrales.

2.6.- Análisis de localización.

2.7.- Análisis de accesibilidad.

2.8.- Situación frente a la competencia actual y/o futura.

2.9.- Características de la implantación.

2.10.- Equilibrio del entorno exterior.

2.11.- Actividades urbanas.

2.12.- Vínculo espacial.

TERCER TEMA DE ANÁLISIS: ENTORNO FÍSICO Y URBANÍSTICO.

3.1.- Situación urbana, periurbana, exterior...

3.2.- Desarrollo futuro del área.

3.3.- Desarrollo de visibilidad.

3.4.- Desarrollo de accesibilidad peatonal o rodada.

3.5.- Accesos inmediatos/locales/regionales.

3.6.- Topografía del área.

3.7.- Transportes públicos y privados.

3.8.- Distribución del tráfico.

3.9.- Frecuentación posible.

3.10.- Principios de acceso al centro.

CUARTO TEMA DE ANÁLISIS: ACCESIBILIDAD/NUEVAS INFRAESTRUCTURAS.

4.1.- Accesos lejanos/medios/inmediatos.

4.2.- Entradas a la ciudad/enlaces con cinturones o rondas. 
4.3.- Accesos inmediatos/orientación/señalización.

4.4.- Remodelación del viario y/o nuevas infraestructuras.

4.5.- Distribución del tráfico interior/periférico/sub periférico.

4.6.- Entradas y salidas (al periférico/ a los aparcamientos).

4.7.- Aparcamiento en superficie/búsqueda.

4.8.- Aparcamiento en altura, subidas/búsquedas/bajadas.

4.9.- Cruces y prioridades.

4.10.- Explotación de aparcamientos.

4.11.- Transportes públicos.

QUINTO TEMA DE ANÁLISIS: APARCAMIENTOS.

5.1.- Frecuencia de clientela: diaria, semanal quincenal y mensual.

5.2.- Medios de transporte: peatonal, en vehículo propio, en vehículo público.

5.3.- Tráfico generado en horas punta y valle, en lunes, martes, miércoles, jueves, viernes, sábado y domingo.

5.4.- Necesidades de estacionamiento y duración media de la visita.

5.5.- Otros tráficos: oficinas y hoteles.

5.6.- Dimensionado del aparcamiento.

5.7.- Concepto del aparcamiento: entradas y salidas, rampas de subida y bajada, visibilidad y señalización, orientación y comodidad, distancia de la plaza a la entrada, facilidad de manejo, toma de decisiones (binaria).

5.8.- Circulaciones: sentido único, derechas y cruces, doble sentido, izquierdas.

5.9.- Explotación: Apertura de plantas y orden de prioridades respecto a los días de la semana.

SEXTO TEMA DE ANÁLISIS: CONCEPTO COMERCIAL.

6.1.- Vocación del centro: posicionamiento e imagen, distinción/diferenciación.

6.2.- Objetivos comerciales.

6.3.- Tamaño e intención: (regional/local/súper regional/comunitario...).

6.4.- Que satisfaga las necesidades y carencias de la zona: suma global de la oferta del centro comercial, adecuada a la demanda de la zona que origina interés.

6.5.- Factor diferencial.

6.6.- Plan de Merchandising: masas y mezcla comercial, alternativas.

6.7.-Niveles de desarrollo.

6.8.-Tipología de locales, cantidad, fachadas, proporción.

6.9.- Factores humanos: Percepción, visualización, conducta y ambiente.

6.10.-Factores psicológicos: Respuesta emocional.

6.11.- Factores de sensibilidad: Modelo social heterogéneo.

6.12.- Desarrollo básico de un concepto, etapas: zonificación de funciones, espacios arquitectónicos, circulación y forma, respuesta al contexto y cubierta del edificio.

SÉPTIMO TEMA DE ANÁLISIS: MASAS COMERCIALES, POLOS Y EJES.

7.1.- Grandes superficies: tamaño, posición y radio de acción.

7.2.- Medianas superficies: tamaño, posición y radio de acción.

7.3.- Polos y ejes: localización, ejes creados, tensiones endógenas y elementos exógenos.

7.4.- Áreas de especialización: puntos calientes y puntos fríos.

7.5.- Otros: posicionamiento sobre la competencia actual y la previsible futura.

OCTAVO TEMA DE ANÁLISIS: CIRCULACIONES BÁSICAS HITOS Y JERARQUÍAS. 
8.1.- Circulaciones exógenas: clientes peatones a entradas, clientes motorizados a aparcamientos, clientes de servicios públicos a paradas y entradas, camiones de distribución a zonas de carga y descarga, otras circulaciones exógenas.

8.2.- Circulaciones endógenas: Clientes peatonales en galería o mall, clientes de aparcamientos en circulaciones de transición y galería o mall, clientes de servicios públicos en mall, otros visitantes del centro en mall, usuarios de zonas de carga y descarga en pasillos de servicio.

8.3.- Circulaciones básicas: flujos peatonales de acuerdo a incidencia comercial, claridad, entendimiento, orientación, equilibrio, rutas peatonales: orígenes y destinos, rutas para las diferentes tipologías y clases de carros de compra.

8.4.- Hitos: elementos focalizadores, fuentes relacionadas con áreas de descanso, y esculturas relacionadas con medios mecánicos.

8.5.- Jerarquía: de acuerdo con circulaciones e hitos, grados de anchura de los ejes de flujo, ejes horizontales y verticales de circulación.

\section{NOVENO TEMA DE ANÁLISIS: GALERÍA O MALL, TIPOLOGÍA Y VOLUMETRÍA.}

9.1.- Mall, eje conductor: proyección del mismo a nivel de usuarios visitantes y clientes que van a descubrir/conocer/usar el futuro centro comercial.

9.2.- Circulación forma y espacio: los requisitos que debe cumplir este planteamiento son: fácil orientación de las personas, optimización de los recorridos, atracción del espacio, interés y curiosidad del mismo, visualización de distintos niveles y de las comunicaciones.

9.3.- Luz natural: Iluminación natural, iluminación artificial, dimensiones y proporciones, ambiente requerido en cada zona.

9.4.- Objetivos a cubrir: irrigación óptima, equilibrio de flujos y recorridos, grado de confort, intercambios de nivel, integración de niveles, integración de medios físicos y mecánicos, superficies y líneas de fachada, circulaciones y forma, espacios y referencias.

9.5.- Composición en planta: secuencia, aparcamiento o calle. y entre las diferentes tipologías y de espacios del mall.

9.6.- Composición en volumen.

DÉCIMO TEMA DE ANÁLISIS: MERCHANDISING Y PROGRAMA COMERCIAL.

10.1.- Mezcla comercial, merchandising: técnica que ayuda a planificar y distribuir las superficies de venta, Fórmula para satisfacer las demandas de los consumidores y rentabilizar las inversiones de promotores y comerciantes. Distinguir el merchandising de productos de locales y la distribución de usos.

10.2.- Planos de merchandising: locales, tipologías: equilibrio delante/detrás/izquierda y derecha, tamaños, cantidad, estudio de rentas, estimación de ventas, flexibilidades.

10.3.- Marketing de comercio en base los productos en venta en los locales: Hipermercado, equipamiento del hogar y de la persona, ocio...

\section{UNDÉCIMO TEMA DE ANÁLISIS: SEGUIMIENTO DE LA RENTABILIDAD, Y ETAPAS.}

11.1.- Superficie de zonas comunes.

11.2.- Gastos de explotación y mantenimiento de zonas comunes.

11.3.- Coste inicial de construcción de zonas comunes.

11.4.- Financiación de zonas comunes.

11.5. - Ingresos derivados del uso de zonas comunes.

11.6.- Seguimiento de la puesta en marcha de zonas comunes. 
11.7.- Seguimiento de la construcción, funcionamiento, conservación y adaptación de las zonas comunes a lo largo de los años. (1er año, de $2^{\circ}$ a $4^{\circ}$ año, 5 año, y $10^{\circ}$ año de cara a la posible renovación o ampliación).

11.8.- Superficie de zonas privadas.

11.9.- Ventas y alquileres de las zonas privadas.

11.10.- Coste inicial de construcción de zonas privadas.

11.11.- Financiación de las zonas privadas.

11.12.- Ingresos derivados del uso de las zonas privadas.

11.13. - Seguimiento de la puesta en marcha de las zonas privadas.

11.14.- Seguimiento de la construcción, funcionamiento, conservación y adaptación de las zonas privadas a lo largo de los años. (1er año, de $2^{\circ}$ a 4 o año, 5o año, y $10^{\circ}$ año de cara a la posible renovación o ampliación). $\left(^{33}\right)$

De este modo, los indicadores establecidos por Queipo antes mencionados serán agrupados en cuestión a los cinco ámbitos de interés de la presente tesis doctoral.

Ámbito social: Se agruparán bajo este ámbito, los indicadores relacionados generalmente con la población, su nivel de vida y la configuración socioeconómica del barrio al que va a servir el centro comercial.

Ámbito económico: Se agruparán bajo este ámbito los indicadores que hacen referencia tanto a la gestión económica del centro, como a los estudios de las bases y prospectiva económica del negocio exclusivamente.

Ámbito medioambiental: Se agruparán bajo este ámbito los indicadores que hacen referencia al estudio de las condiciones medioambientales de la zona en la que se va a situar el centro, o las posibles medidas en beneficio del medio ambiente.

Ámbito urbanístico: Se agruparán bajo este ámbito los indicadores que hacen referencia a las relaciones del centro comercial con el contexto urbano, en base a la infraestructura.

Ámbito proyectual: Hace referencia a los indicadores y conceptos relacionados con el proyecto, dimensionado y materialización de lo que es exclusivamente el centro comercial en sí.

De este modo, se realizaron las siguientes tablas de análisis, desglosando los indicadores de Francisco Queipo ${ }^{1}$ de acuerdo a los ámbitos anteriormente mencionados, que corresponden a los de estudio de la presente tesis doctoral. El objetivo es analizar en que conceptos se centra un proyecto de centro comercial. (Figura 3.3.1):

(S) SOCIAL - (E) ECONÓMICO - (M) MEDIOAMBIENTAL - (U) URBANÍSTICO - (P) PROYECTUAL

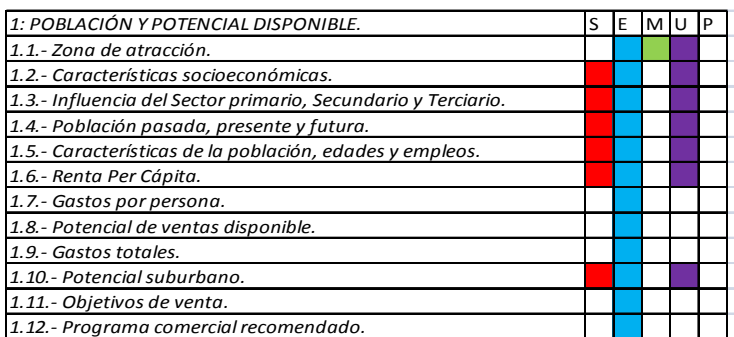

1.12.- Programa comercial recomendado.

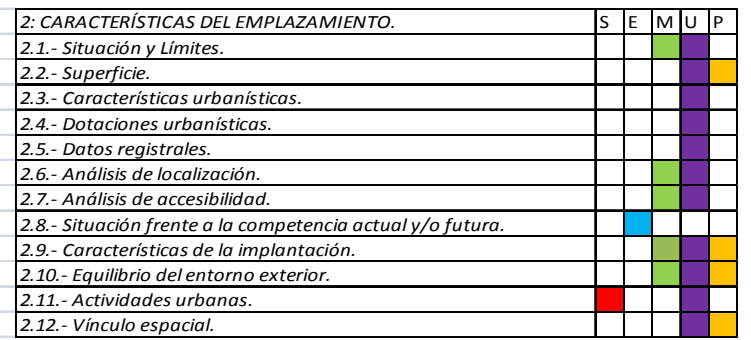




\begin{tabular}{|l|c|c|c|c|c|}
\hline 3: ENTORNO FÍSICO YURBANÍSTICO. & S & E & M & U & P \\
\hline 3.1.- Situación urbana, periurbana, exterior... & & & & & \\
\hline 3.2.- Desarrollo futuro del área. & & & & & \\
\hline 3.3.- Desarrollo de visibilidad. & & & & & \\
\hline 3.4.- Desarrollo de accesibilidad peatonalo rodada. & & & & & \\
\hline 3.5.- Accesos inmediatos/locales/regionales. & & & & & \\
\hline 3.6.- Topografía del área. & & & & & \\
\hline 3.7.- Transportes públicos y privados. & & & & & \\
\hline 3.8.- Distribución del tráfico. & & & & & \\
\hline 3.9.- Frecuentación posible. & & & & & \\
\hline 3.10.- Principios de acceso al centro. & & & & & \\
\hline
\end{tabular}

\begin{tabular}{|c|c|c|}
\hline 5: APARCAMIENTOS. & \begin{tabular}{l|l}
$S$ & $E$ \\
\end{tabular} & \begin{tabular}{|l|l}
$U$ & $P$ \\
\end{tabular} \\
\hline 5.1.- Frecuencia de clientela. & & \\
\hline 5.2.- Medios de transporte. & & \\
\hline 5.3.- Tráfico generado en horas punta y valle. & & \\
\hline 5.4.- Necesidades de estacionamiento. & & \\
\hline 5.5.- Otros tráficos: oficinas y hoteles. & & \\
\hline 5.6.- Dimensionado del aparcamiento. & & \\
\hline 5.7.- Concepto del aparcamiento. & & \\
\hline 5.8.- Circulaciones. & & \\
\hline 5.9.- Explotación. & & \\
\hline
\end{tabular}

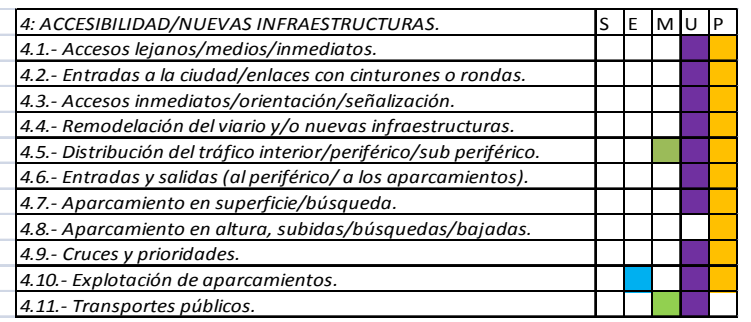

\begin{tabular}{|l|l|l|l|l|l|}
\hline 7: MASAS COMERCIALES, POLOS YEJES. & S & E & M & U & P \\
\hline 7.1.- Grandes superficies. & & & & & \\
\hline 7.2.- Medianas superficies. & & & & & \\
\hline 7.3.- Polos y ejes. & & & & & \\
\hline 7.4.- Áreas de especialización. & & & & & \\
\hline 7.5.- Otros. & & & & & \\
\hline
\end{tabular}

\begin{tabular}{|l|c|c|c|c|c|}
\hline 9: GALERÍA O MALL, TIPOLOGÍA Y VOLUMETRÍA. & S & E & M & U & P \\
\hline 9.1.- Mall, eje conductor. & & & & & \\
\hline 9.2.- Circulación forma y espacio. & & & & & \\
\hline 9.3.- Luz natural. & & & & & \\
\hline 9.4.- Objetivos a cubrir. & & & & & \\
\hline 9.5.- Composición en planta. & & & & & \\
\hline 9.6.- Composición en volumen. & & & & & \\
\hline
\end{tabular}

\begin{tabular}{|c|c|c|c|c|}
\hline 1: SEGUIMIENTO DE LA RENTABILIDAD, Y ETAPAS. & & & & \\
\hline 11.1.- Superficie de zonas comunes. & & & & \\
\hline 11.2.- Gastos de explotación y mantenimiento de zonas comunes. & & & & \\
\hline 11.3.- Coste inicial de construcción de zonas comunes. & & & & \\
\hline 11.4.- Financiación de zonas comunes. & & & & \\
\hline 11.5.- Ingresos derivados del uso de zonas comunes. & & & & \\
\hline 11.6.- Seguimiento de la puesta en marcha de zonas comunes. & & & & \\
\hline 11.7.- Seguimiento de zonas comunes & & & & \\
\hline 11.8.- Superficie de zonas privadas. & & & & \\
\hline 11.9.- Ventas y alquileres de las zonas privadas. & & & & \\
\hline 11.10.- Coste inicial de construcción de zonas privadas. & & & & \\
\hline 11.11.- Financiación de las zonas privadas. & & & & \\
\hline 11.12.- Ingresos derivados del uso de las zonas privadas. & & & & \\
\hline 11.13.- Seguimiento de la puesta en marcha de las zonas privadas. & & & & \\
\hline 11.14.- Seguimiento de zonas privadas & & & & \\
\hline
\end{tabular}
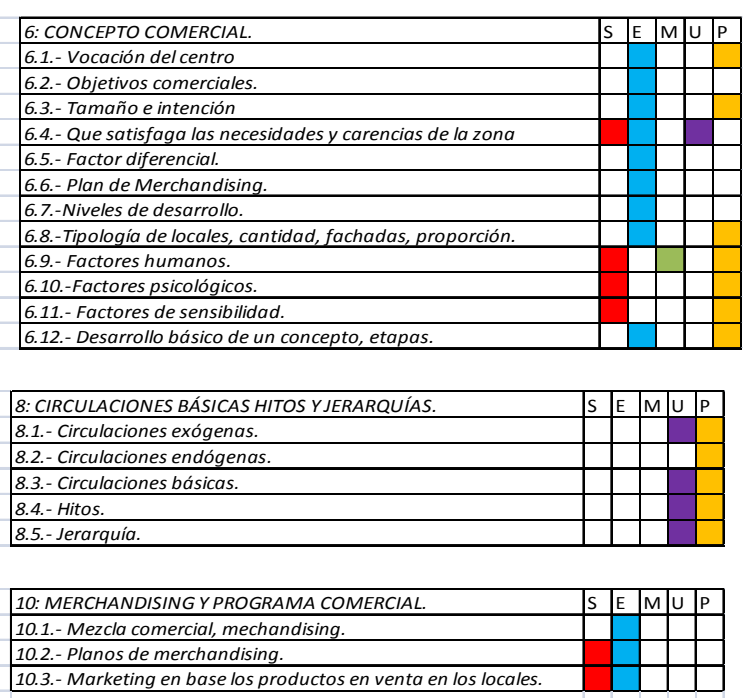

Figura 3.3.1. Desglose por ámbitos de los factores de análisis del proceso de proyecto del centro comercial realizados por el autor Francisco Queipo Blanco. Fuente: Elaboración propia a partir de datos de Francisco Queipo.

Como se puede ver, los indicadores de Queipo Blanco ${ }^{1}$ hacen un fuerte hincapié en el tema del proyecto arquitectónico, y el tema económico. A este gráfico es necesario que se le añadan más factores a considerar en la fase de proyecto. Aunque el medio ambiente no es considerado muy a fondo, hay una gran cantidad de factores en los cuales se hace necesaria su consideración.

Analizando estos preceptos de proyecto a efectos de sostenibilidad, se puede decir que el proyecto de los centros comerciales en la época de su auge, aunque consideraba muy a fondo el pilar de la viabilidad económica. Los pilares relacionados con la cohesión social o el medio ambiente eran considerados secundarios. Otra faceta importante, es que este análisis considera de manera somera para la fase de proyecto, temas que son muy importantes, tales como la gestión del centro comercial una vez abierto, la prospectiva, o los contingencias de cara al cese de la actividad del mismo. 
Por consiguiente, para que un proyecto de centro comercial pueda ser considerado como sostenible, es necesario que considera a partes iguales, preceptos que tengan que ver con los tres pilares de la sostenibilidad. El autor propone que al presente análisis de Queipo Blanco se le añadan los siguientes factores a determinadas facetas:

1: POBLACIÓN Y POTENCIAL DISPONIBLE:

-Indicadores de exclusión y desigualdad social.

-Datos de clasificación de tipos de familias y modos de vida.

-Fotografía de la sociología predominante y/o secundaria.

-Índice de desarrollo humano.

\section{2: CARACTERÍSTICAS DEL EMPLAZAMIENTO:}

-Crecimientos urbanos previstos.

\section{3: ENTORNO FÍSICO Y URBANÍSTICO:}

- Huellas de carbono y ecológica de área urbana, y centro comercial previsto.

-Impacto ambiental del nuevo centro comercial previsto.

-Biocapacidad del área.

-Análisis paisajístico.

-Reservas y características hídricas.

-Análisis climático, temperaturas, hidrología y soleamiento.

\section{4: ACCESIBILIDAD, NUEVAS INFRAESTRUCTURAS:}

-Estudio de Impacto ambiental de la accesibilidad peatonal, rodada y por transporte público.

\section{5: APARCAMIENTOS:}

-Análisis y plan de impacto ambiental del aparcamiento sobre el suelo y el medio ambiente.

-Proyecto de gestión de aguas pluviales en aparcamiento

-Proyecto de gestión de polución y residuos en aparcamiento.

-Plan de gestión de medios de transporte de bajo consumo y emisiones. (vehículos eléctricos y ciclos).

\section{6: CONCEPTO COMERCIAL:}

-Estudio de impacto ambiental de los productos vendidos.

9: GALERÍA O MALL:

-Zonas verdes y arbolado.

-Comportamiento bioclimático de las galerías.

-Posibilidades y gestión de las mismas para usos no comerciales.

Añadiéndose a su vez los nuevos apartados:

11:GESTIÓN DEL FUNCIONAMIENTO DEL CENTRO COMERCIAL:

-Balance económico de beneficios-pérdidas.

-Marco y plan jurídico.

-Planes laborales y de empleo.

-Consumo y gestión de energía.

-Consumo y gestión de aguas.

-Consumo y gestión de recursos materiales.

-Plan de ahorro energético.

-Plan de energías renovables. 
-Gestión de residuos y emisiones.

-Plan estratégico prospectivo a escala económica, social, medioambiental y urbanística.

12: CESE DE ACTIVIDAD:

-Impacto social del cese de actividad.

-Impacto económico del cese de actividad.

-Plan de rehabilitación, ampliación o rezonificación de la parcela.

-Impacto ambiental de la demolición del centro.

-Adaptación de los espacios a usos no comerciales.

Aunque el proceso de la fundación de los centros comerciales, no es el tema de investigación principal de esta tesis, muchos de los pasos y temas de análisis comprendidos dentro del mismo, pueden ser de utilidad más adelante, a la hora de considerar las pautas para consolidar una metodología de aplicación para la rehabilitación de los centros comerciales, o bien analizar las ya existentes, que son los temas principales de la presente tesis doctoral. Además, el análisis de los conceptos de proyecto, nos van a ayudar a sentar las bases para otros indicadores que pudieran ser de utilidad más en adelante.

\section{4.- ASPECTOS FUNCIONALES, FORMALES Y PROYECTUALES DE LOS CENTROS COMERCIALES.}

Una vez enunciado y explicado el proceso de proyecto, se procederá a explicar el resultado edificado del centro comercial. La importancia de este tema se debe al carácter arquitectónico de la presente tesis doctoral. Además de la necesidad de comprender las características de la tipología edificatoria a rehabilitar o reestructurar, para analizar o ejecutar una operación de este tipo de manera correcta. Como se mostro en el anterior capítulo, el centro comercial es una tipología edificatoria muy compleja, en cuyo proceso de proyecto entran en juego infinidad de factores que deben de ser considerados para garantizar la viabilidad económica del mismo, que de manera dual, es la principal finalidad de la tipología edificatoria de estudio en la presente tesis. De este modo, la descripción proyectual y arquitectónica de un centro comercial resulta ser de interés para la presente tesis doctoral, ya que la comprensión de la misma, nos va a ayudar a reforzar la problemática inherente respecto de los mismos.

Como efecto de la cantidad de factores a considerar en el proceso de proyecto, en el plano arquitectónico, un centro comercial debe de cumplir con unos preceptos arquitectónicos y espaciales predeterminados de antemano, que van a derivar en un espacio tanto interior como exterior, que en todos los casos siempre va a cumplir en mayor o menor medida algunas de las características de proyecto citadas a continuación.

\subsection{1.- Características de proyecto a escala urbana y de entorno.}

El edificio del centro comercial, es una tipología arquitectónica de cualidades formales, funcionales y espaciales muy definidas. para la formalización del mismo, Victor Gruen dio una fórmula para el centro comercial ideal, antes de la realización del proyecto de Southdale. 
1:Toma cuarenta hectáreas cuadradas de terreno (Ilano, si es posible).

2: Rodéalos con 500.000 consumidores que no tengan acceso a ningún otro equipamiento comercial.

3: Prepara el terreno central y cúbrelo con 1.000.000 de metros cuadrados en edificios.

4: Rellena los edificios anteriormente dispuestos con comerciantes de primera categoría que vendan artículos de calidad a precios seductoramente bajos.

5: Dispón de 10.000 plazas de aparcamiento en el exterior y asegúrate de hacerlas accesibles desde las infrautilizadas autopistas de primer rango, que vienen de todas partes.

6: Acaba el centro, decorándolo con algunas plantas en macetas, lechos de flores variadas, un poco de escultura y sírvelo muy caliente al cliente. ${ }^{33}$

De acuerdo a lo estipulado por Gruen, podemos sacar en claro, que en primer lugar el dimensionamiento del edificio se hace considerando escalas urbanas de gran amplitud: El centro comercial al estar pensado para la actividad comercial a gran escala, se hace necesaria la materialización de un edificio que sea capaz de copar una gran cantidad de nichos de mercado a través del ofrecimiento de una amplia oferta comercial. Para la materialización correcta de una instalación que sea capaz de lograr este fin, es necesario englobar un área urbana o territorial de gran tamaño, que considere en su interior una gran cantidad de compradores dispuestos a suplir sus necesidades de adquisición de bienes de consumo en lo que será el centro comercial, siendo de gran importancia el estudio de cualquier interacción urbana presente en la zona de influencia. Victor Gruen, al proyectar los centros comerciales en los años 50 y 60, los consideraba muchas veces los como sustitutos del centro urbano. Y de este modo, en los mismos se debían de incluir todas las funciones que pudieran ser de utilidad a una comunidad de mayor o menor tamaño, no solo a efectos de actividad comercial sino también a efectos de actividad dotacional.

En segundo lugar, la Importancia de la infraestructura urbana en el funcionamiento del mismo: El anterior capítulo puso de manifiesto la necesidad de considerar la infraestructura como una parte importante del proyecto del centro comercial. Esta afirmación viene fundamentada por la característica anteriormente mencionada, que es la consideración de la gran escala urbana para el dimensionado del centro. Como efecto de este concepto de proyecto, el centro comercial va a generar un gran movimiento tanto de personas como de materiales dentro del contexto urbano en el que está emplazado, y para que estos flujos operen de manera correcta, se precisa del uso de grandes infraestructuras, tanto de nueva planta como existentes, que faciliten la llegada de los compradores a la instalación comercial, y de este modo se garanticen los flujos de personas hacia el centro, asegurando de esta manera la llegada de compradores.

En tercer lugar, cobra importancia la búsqueda de lugares representativos para su emplazamiento: El emplazamiento del centro en un lugar representativo de la ciudad, siempre va a ser un factor favorable para el desarrollo de su negocio, ya que este tipo de lugares resultan atrayentes para las personas que viven o visitan la ciudad, y de este modo, el centro comercial explotará esta oportunidad, buscando compradores entre los visitantes de la parte representativa, a través del ofrecimiento de actividades.

\footnotetext{
${ }^{33}$ Victor Gruen "Receta para el centro comercial ideal", recopilado en el libro Mutaciones, (2000). Capítulo Shopping escrito por "Harvard Project on The City". (Página 162)
} 
y por último, también se busca la diferenciación del entorno en el que está emplazado, arquitectura de la publicidad: El centro comercial, aunque en su proceso de proyecto considera las características del entorno en el que está emplazado, ignora por completo la integración en el mismo, o la mimetización, enfocando su imagen estética y arquitectónica en una diferenciación radical respecto de su entorno. Esta finalidad busca reforzar el carácter de elemento atrayente de cara a las personas, a través de la creación de una imagen característica y diferenciadora, la cual muchas veces se basa en la negación de los preceptos urbanísticos y arquitectónicos del entorno. En este sentido, el centro comercial de cara al exterior, recoge muchos de los conceptos arquitectónicos de Venturi, o de las iglesias de la Roma Contra Reformista del Siglo XVI. Es decir, la presencia del edificio en la ciudad a través de la diferenciación de imagen del mismo, como elemento para su auto publicitación. El estudio exhaustivo de las similitudes entre los centros comerciales, y la arquitectura de Venturi o la Roma Contra reformista, puede ser un futuro tema de investigación.

\subsection{2.- Características de proyecto a escala de edificio.}

En primer lugar, para proyectar un centro comercial, es muy importante proyectar y dimensionar el edificio para albergar una gran cantidad de usos de diversa índole, además de considerar un aforo para una gran cantidad de público, garantizando en todo momento su comodidad. Aparte de esto, es importante el ofrecimiento de la variedad de servicios y productos buscando el fin de copar el mayor número de nichos de mercado. Como resultado de esto, un centro comercial en su proyecto incluirá una gran cantidad de espacios de diferentes características, distribución, dimensiones, y dinamismo, orientados a cada una de las funciones que va a albergar. Los usos que un centro comercial alberga en su interior son los siguientes:

Galería: La galería de un centro comercial es sin duda la parte más importante del mismo, ya que es el espacio de distribución entre las tiendas de cara al público, el que regula los flujos, y por consiguiente el más frecuentado por los compradores, esta galería puede ser de una o varias plantas, y contar con sistemas de elevación mecánicos, locales, o espacios estancia para los compradores. A veces, algunas de estas galerías pueden contener espacios de ocio lucrativos para la empresa gestora, si se dan ciertas condiciones de tamaño. Las galerías pueden estar pensadas desde el punto de vista dinámico, para asegurar el flujo de compradores, o bien pueden ser espacios estancia estáticos que hacen la función de servir de lugar de estancia para determinados tipos de locales (restauración y ocio).

Empresa Locomotora: A efectos de terminología de centros comerciales, la empresa locomotora consiste en un negocio de gran tamaño, volumen comercial y cierta reputación entre los compradores, cuyo papel principal es el de ser el principal elemento atrayente de clientela para el centro. A la vez que esta juega un papel en el apoyo a la financiación de la fundación del centro comercial. Las empresas locomotoras en un centro comercial juegan un papel de gran importancia, y de este modo normalmente ocupan los locales de mayor superficie, estando estas dispuestas de manera estratégica para garantizar los flujos de compradores a través de las galerías. La explotación de las empresas locomotoras, además de 
resultar muy lucrativa para el centro, su mantenimiento es de gran importancia debido al efecto atrayente que generan estos negocios.

Tiendas en alquiler: Las tiendas dentro del centro comercial, normalmente se ubican en los laterales de las galerías. Siendo estas otra de las partes importantes del centro. La gestión de estos locales se basa en el alquiler de los mismos a diferentes cadenas de tiendas o propietarios. Que pagarán sus alquileres, y adaptarán sus horarios de apertura a los del centro. La explotación de las tiendas en alquiler es una actividad muy lucrativa para el centro comercial.

Área de restauración o Food Court: Los centros comerciales muchas veces incluyen una zona dentro sus galerías dedicada principalmente al ocio o la restauración como actividad complementaria a las compras. De este modo este término hace referencia a la galería, plaza, o zona del centro en la que los locales son ocupados por restaurantes. La inserción de este tipo de instalación tiene la función de ampliar la oferta del centro comercial de cara a los compradores, ofertando servicios complementarios a la venta de género. L explotación del área de restauración siempre va a resultar lucrativa.

Aparcamientos: Los aparcamientos de un centro comercial cumplen la función de servir como estacionamiento para los vehículos de los compradores y trabajadores del centro, estos normalmente se diseñan para suplir una gran demanda, ya que la facilidad y comodidad de estacionamiento es un elemento atrayente de clientes para el centro. Los aparcamientos de un centro pueden colocarse en superficie, en sótanos bajo el centro comercial, o en edificios anexos al centro. La gestión de este espacio puede ser lucrativo o no, dependiendo de si al comprador se le cobra o no una tasa por el uso de la mismo.

Otros usos lúdicos complementarios: Algunos centros comerciales pueden tener asociados usos complementarios o ajenos a la venta de género o la restauración, que pueden ser o no lucrativos. Estos usos están destinados generalmente a ampliar la oferta de actividades del centro de cara al comprador. Pueden ser parques de atracciones, guarderías, oficinas de correos o burocráticas e incluso hoteles.

Espacios de Servicio: El funcionamiento del centro comercial, precisa de ciertos espacios de uso y servicio que deben de estar presentes en el edificio, los cuales a pesar de no ser lucrativos, resultan fundamentales. Se considerarán como espacios de servicio los almacenes, zonas de carga, pasillos de servicio y salas de máquinas.

En segundo lugar, otra característica formal y de proyecto del centro comercial es la intención de crear un espacio interior aislado, confuso y de grandes dimensiones, pensado para que el espectador quede desorientado y sin referencias una vez dentro de él, esta visión introspectiva del centro comercial también puede ser un factor a considerar de cara al refuerzo de su concepción como espacio de compras. Un centro comercial, a efectos de proyecto de espacio interior, va a buscar de un modo u otro generar un espacio aislado y de potente imagen, que centre la atención del comprador, para conseguir este fin, va a ser necesaria la inserción del espectador dentro del espacio interior del centro, a partir de una serie de transiciones espaciales bruscas y agresivas, que buscan la "preparación" del visitante para el nuevo espacio 
comercial, para una vez dentro de él, centrar la atención en el mismo. A esta inserción espacial se la llama "Gruen Transfer", (Efecto Gruen), y su finalidad es el desvío de la atención del espectador a través de la utilización de diferentes mecanismos arquitectónico-espaciales tales como circulaciones complejas en su recorrido, espacio interior cuya asociación con la forma exterior del centro resulta muy difícil, recorridos confusos, espacio interior de gran escala tanto en altura como en desarrollo, aislamiento total del espacio interior respecto al exterior para evitar distracciones en los compradores, uso de materiales y acabados específicos con tal de crear efectos psicológicos, visión centrada del comprador hacia los locales comerciales... El término "Gruen Transfer" hace referencia al arquitecto Victor Gruen, debido a que este arquitecto en sus proyectos de espacio comercial buscaba la creación de este espacio aislado centrador de la atención del visitante, como factor asegurador del incremento de las ventas del centro comercial.

En tercer lugar, cobra importancia el dimensionamiento de las instalaciones adaptado a una gran cantidad de público: Como se menciono con anterioridad, el centro comercial en su papel de gran nodo de actividad comercial, ocio y servicios en la escala urbana de gran amplitud, debe de considerar en el dimensionamiento de su espacio la capacidad para albergar a un gran número de compradores. Victor Gruen dimensiono el espacio del centro "en un millón de metros cuadrados para veinte mil personas". Es decir, cincuenta metros cuadrados por comprador.

En cuarto lugar, la Mitigación del efecto del No Lugar, a través de la creación de ambientes escénicos, arquitectura de la escenografía, creación de un lugar a través de una imagen potente y representativa: Los centros comerciales al tratarse de una arquitectura muy introspectiva, muchas veces generan de cara al exterior y a su interior la sensación del No Lugar descrita por Augé (Los no lugares son espacios arquitectónicos anodinos basados en la mera funcionalidad, los cuales niegan cualquier interacción o parecido con su entorno inmediato $)^{34}$. Este efecto que se corrobora en la anteriormente explicada negación de las características del lugar a nivel proyectual, que es necesaria para realizar la transición espacial entre el espacio interior y exterior (Gruen Transfer), como agravante de este hecho, hay que remarcar el hecho de que todos los centros comerciales a lo largo y ancho del mundo tienen características similares en su concepción espacial y arquitectónica. A pesar de esto, esta preocupación por concebir las galerías de los centros comerciales como no lugares, a través de sus correspondientes transiciones espaciales y elección de materiales específicos, ha creado una imagen característica espacial que es muy reconocible, y que se repite en prácticamente todos los centros comerciales del planeta. Algunos centros para mitigar esta sensación del no lugar tratan de reproducir escenografías de lugares que pueden o no corresponderse con los autóctonos del entorno en el que está emplazado el centro comercial.

Por último, la Importancia de los recorridos, y búsqueda de continuidad en los mismos: Como se menciono anteriormente, la comodidad de los visitantes es un factor clave para asegurar las ventas de un centro comercial, la cual puede lograrse a través de la materialización de instalaciones, Sin embargo el espacio interior representativo del centro comercial al ser de tipo dinámico, resulta de gran importancia asegurar la continuidad y la facilidad de recorrido

\footnotetext{
${ }^{34}$ AUGÉ MARC (1992): "Los No Lugares, Espacios Del Anonimato". Gedisa. 125 Páginas
} 
dentro del mismo, para de esta manera asegurar el flujo constante de compradores. Normalmente esta continuidad se consigue a través de la visibilidad amplia pero parcial del espacio, las grandes dimensiones del mismo, y los mecanismos elevadores que aseguran el flujo de peatones entre las diferentes alturas (Escaleras mecánicas).

Una vez explicadas las características proyectuales, funcionales y formales del centro comercial, el siguiente paso será definir la problemática de los mismos, como elemento motivador para la consideración de la rehabilitación de los mismos.

\section{5.- LAS TIPOLOGÍAS DE EDIFICIO DE CENTRO COMERCIAL EN RELACIÓN AL CONTEXTO URBANO, ANÁLISIS FUNCIONAL Y FORMAL.}

Una vez definido el contexto urbano, el proceso de proyecto y las características arquitectónicas de la tipología urbanística que será el objeto de estudio en la presente tesis doctoral, además del proceso de proyecto de la misma y sus factores, el siguiente paso es comenzar a definir las tipologías edificatorias que van a ser objeto de estudio en la presente tesis. Antes de comenzar a explicar las tipologías existentes de centro comercial, es de importancia remarcar el hecho de que todo centro comercial, al tratarse de una pieza dentro de un contexto urbano amplio, va a tender a adaptarse a los condicionantes del entorno urbano, asumiendo el edificio las facetas funcionales del mismo, ya sea tanto en el contexto urbano céntrico como en el periférico.

A continuación se explican las tipologías de centro comercial, calificándolas en dos grandes grupos de acuerdo a su edificación, de manera que tenemos los centros comerciales en altura y superficie. Esta calificación fue realizada por el autor, tomando como base en las clasificaciones del International Council Of Shopping Centers, además de las definiciones establecidas por Victor Gruen.

\subsection{1.- Centro Comercial en Altura.}

Esta tipología de centro comercial está muy ligada a los contextos urbanos céntricos, y básicamente consiste en un edificio destinado a uso comercial, el cual debido a las limitaciones de superficie de la parcela, se ha hecho necesario materializarlo en altura para albergar todo el programa necesario. En este tipo de centros los edificios comerciales ocupan la mayor parte de la parcela, cuando no en su totalidad, estando reservado el escaso espacio libre a espacios estancia o parte de los aparcamientos. En el interior del centro el espacio está distribuido en base a galerías y patios, cobrando gran importancia los mecanismos elevadores destinados a salvar las deficiencias de altura. Para la presente tesis doctoral, van a considerarse como centros comerciales en altura, todos aquellos que superen las cinco plantas. 

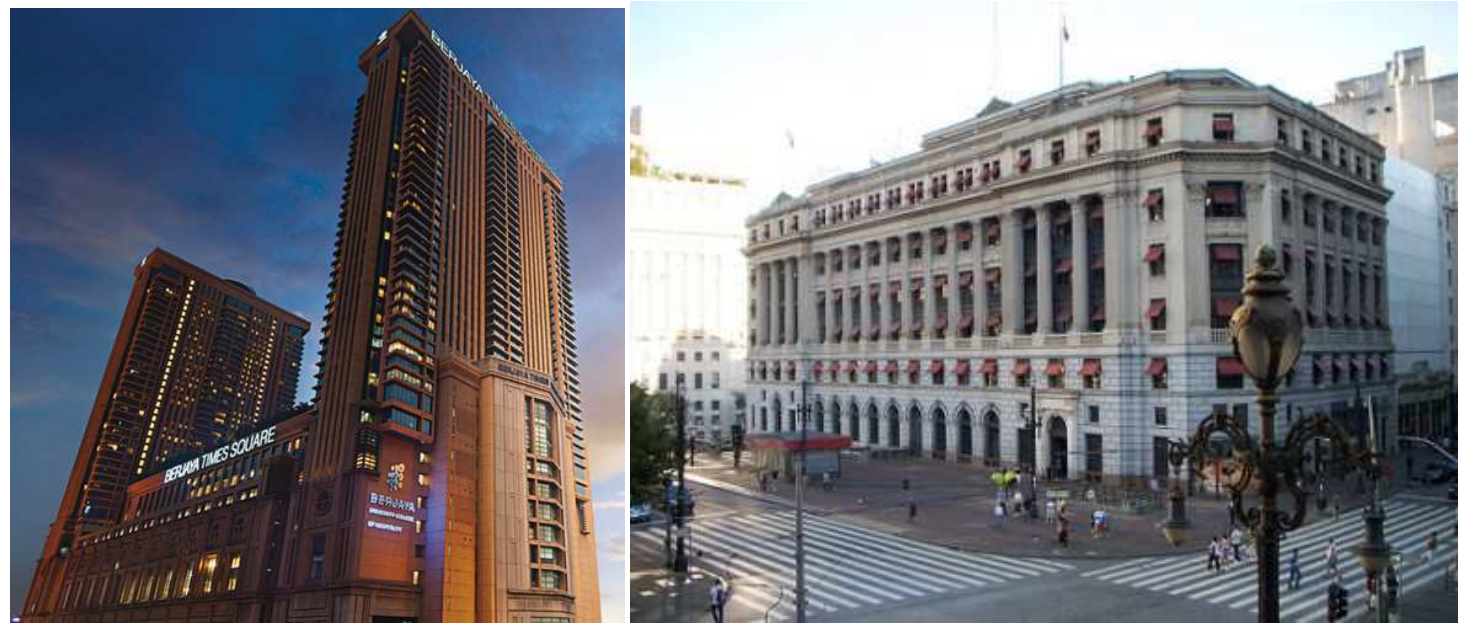

Figura 3.5.1: Berjaya Times Square y Shopping Light, ejemplos de centros comerciales en altura. Fuente: Internet: sonicsteamsauna, Eu Quero Trabalho.

\subsection{2.- Centro Comercial en superficie.}

El centro comercial en superficie es el tema en el que se hará hincapié en la presente tesis, siendo su caracterización algo más compleja, debido a que a la hora de materializar un centro comercial en superficie, el grado de libertad en el proyecto es mayor debido a la disponibilidad de terreno. de este modo, dentro de las tipologías de centro comercial en superficie tenemos estas categorías:

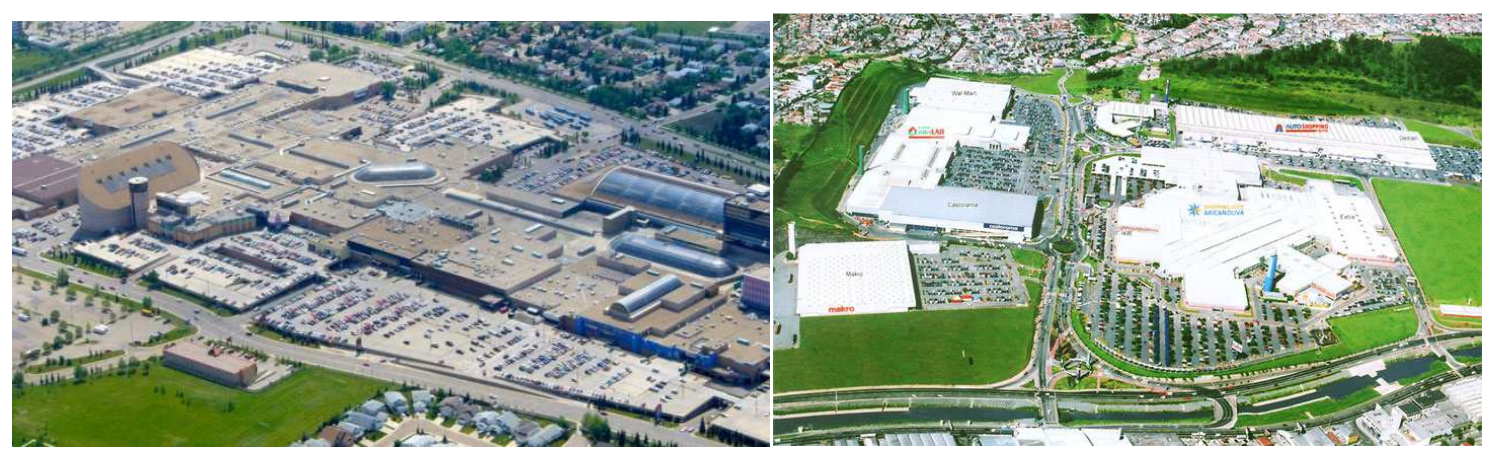

Figura 3.5.2: West Edmonton y Aricanduva, ejemplos de centros comerciales en superficie Fuente: Internet: paNOW, SkyscraperCity.

\section{Hipermercado o "Big Box Retail"}

Como tipología de centro comercial en superficie, esta es a efectos de proyecto la más sencilla. Pues ésta consiste básicamente en una única tienda de grandes dimensiones mayor de $2500 \mathrm{~m} 2$, (algunos llegan a superar los 10.000m2), dentro de un único edificio de gran superficie que no precisa de galerías o espacios de comunicación.

Buscando mejores condiciones de tráfico, los hipermercados tenderán a establecerse en las proximidades de grandes vías de comunicación, incorporando a su vez dentro de la parcela otros tráficos de carácter secundario que dan servicio a los aparcamientos y a las plataformas de almacenaje y suministro. Los aparcamientos de este tipo de instalaciones comerciales 
pueden ser en superficie, materializándose como enormes explanadas de asfalto con o sin cubriciones, subterráneos o emplazados dentro de otro edificio exento anejo al edificio central del hipermercado. (Dependiendo de la disponibilidad de suelo).

Los primeros hipermercados nacieron en Estados Unidos, como otro intento diferente de acercar los grandes almacenes que tenían negocios en él centro, al contexto de los extrarradios periféricos, suponiendo esto una idea innovadora para la época (años 50).

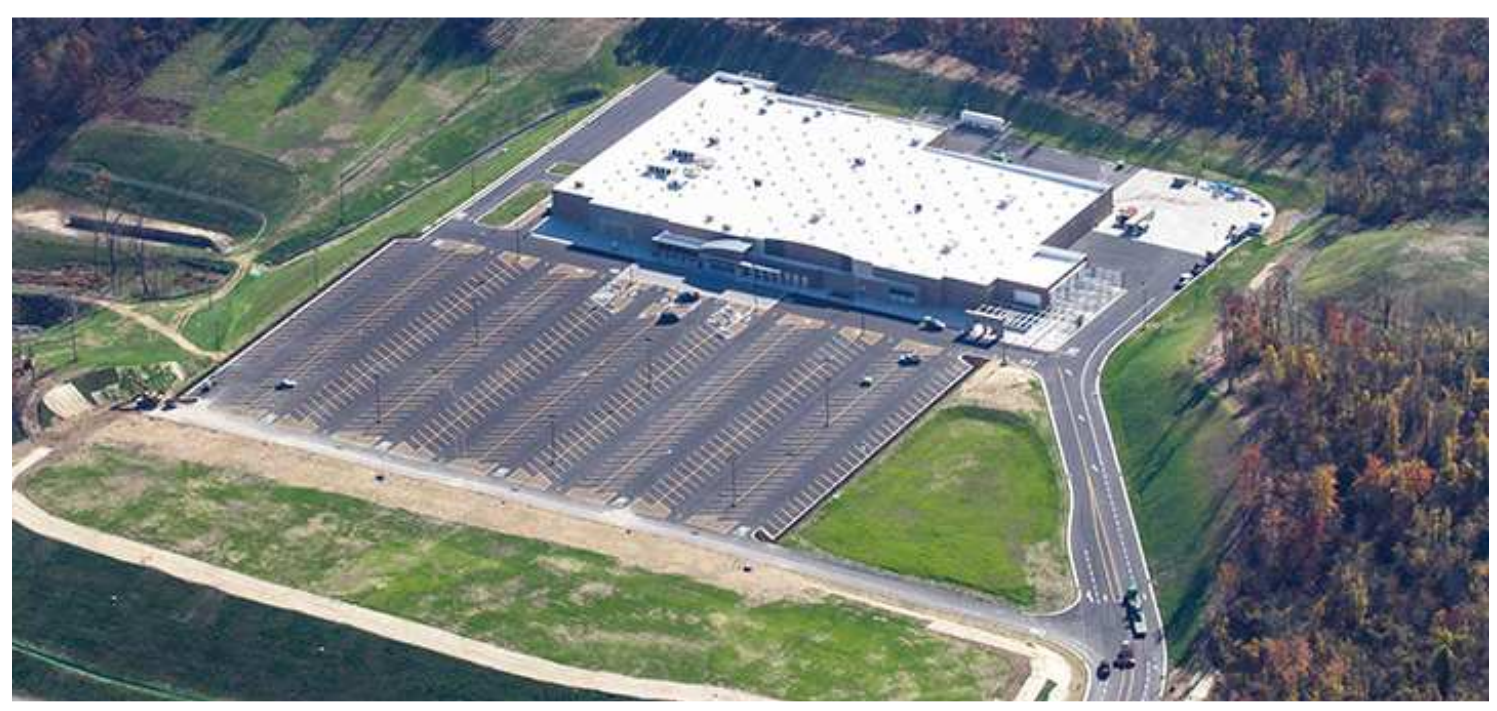

Figura 3.5.3: Ejemplo de big box retailer o hipermercado. Fuente: clevelandconstruction

Centro comercial en hilera o "Strip Mall".

Este tipo de centro comercial, en su proyecto básicamente trata de aunar las características de las calles comerciales con las del hipermercado, siendo esta tipología una de los predecesoras del centro comercial como se conoce actualmente. Este tipo de centralidad comercial básicamente se materializa como una hilera de tiendas, delante de las cuales se colocan unos soportales, que hacen la vez de espacio de distribución de los recorridos en el edificio, y estos a su vez están abiertos a los espacios de aparcamiento del centro, los cuales habitualmente son dispuestos en superficie. Los Strip Mall, o centros comerciales en hilera pueden tener empresa locomotora. 


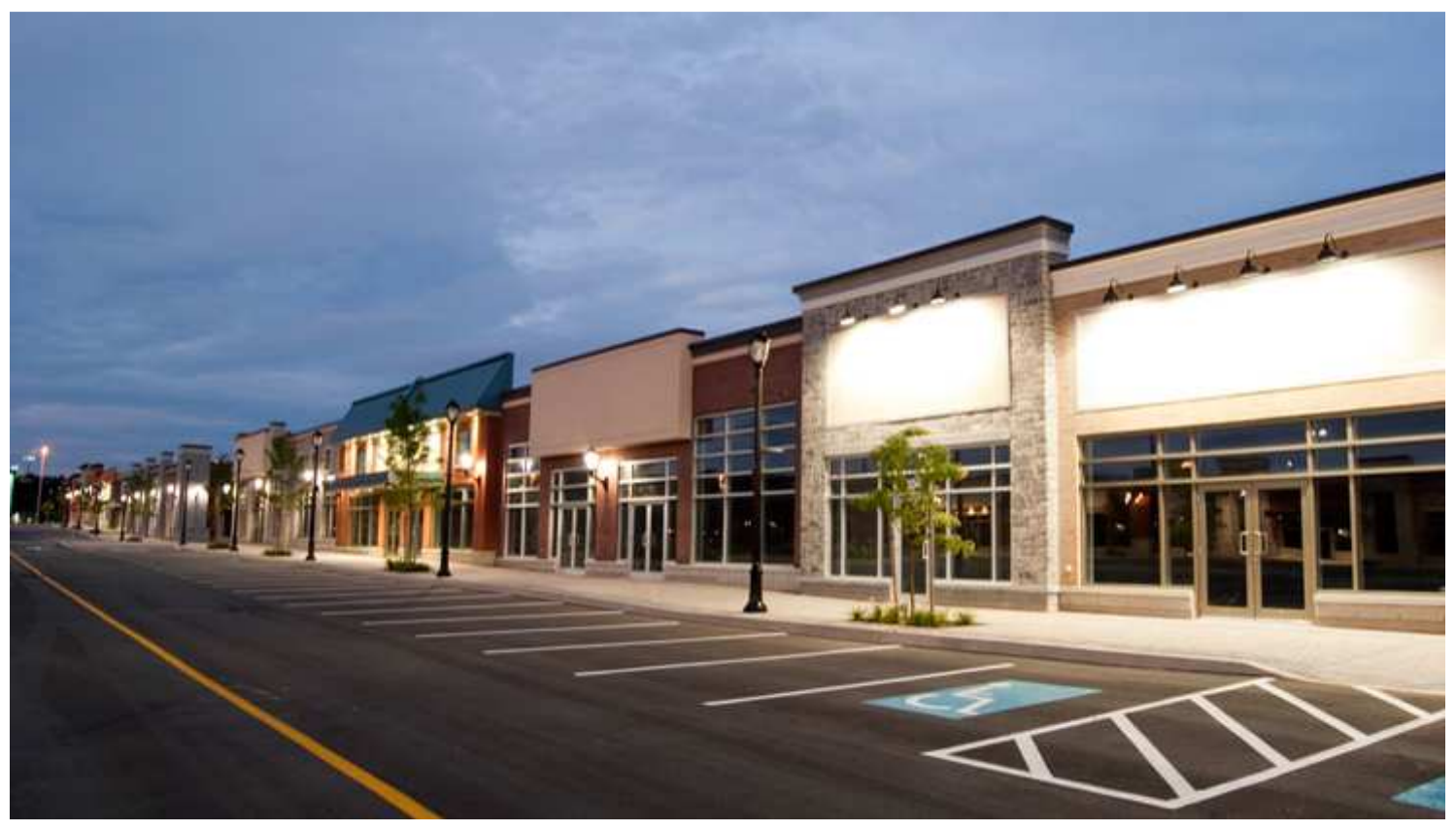

Figura 3.5.4: Ejemplo de strip mall Fuente: lukas-construction

Centro comercial de galería cubierta o "Shopping Mall".

El centro comercial de periferia o "Shopping Mall", es sin duda la tipología de centro comercial de desarrollo en superficie más compleja, pues dentro de ella intervienen muchos factores de usos e interacciones que deben de ser consideradas. Estos edificios consisten en un enorme edificio de una o varias plantas que se articula en base a una red de calles y plazas cubiertas, las cuales distribuyen la circulación de compradores entre los locales de diferentes superficies y tamaños, destinados principalmente al uso terciario comercial. El acceso a los locales la mayoría de las veces se realiza a través de una calle o plaza que puede estar o no cubierta o aclimatada. En los espacios libres de la periferia del edificio del centro comercial, es dónde se ubican los aparcamientos, y su estructura puede estar concebida en base a explanadas de gran superficie pavimentadas con asfalto, aparcamientos subterráneos bajo el centro o la parcela, o también edificios de aparcamientos dispuestos en los alrededores del centro. 


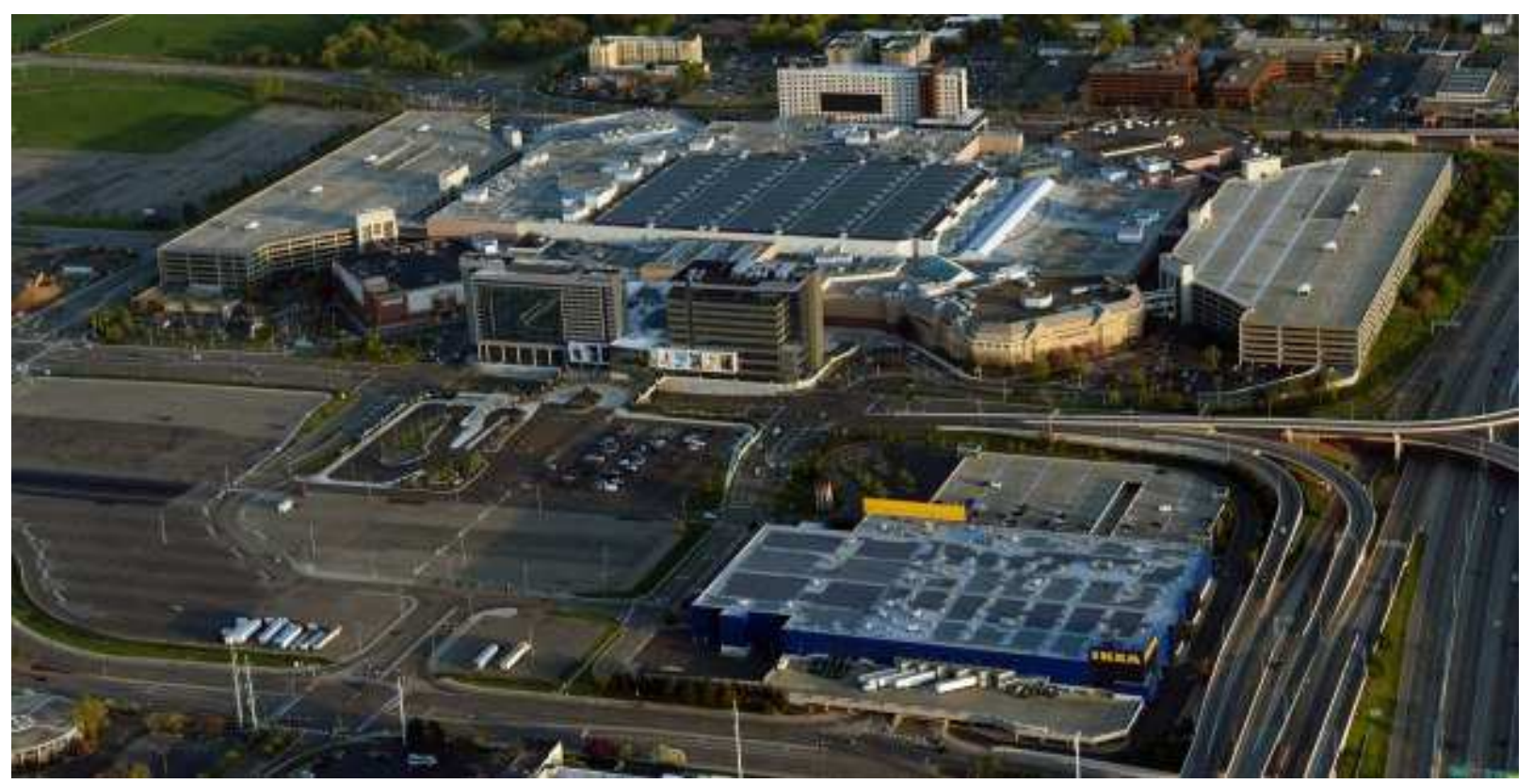

Figura 3.5.5: Mall of America, Ejemplo de shopping mall periférico (Pioneer Press)

\subsection{3.- Centralidades comerciales, en superficie.}

Este tipo de conjuntos urbanísticos, se forman en base a la yuxtaposición de varios elementos de los anteriormente mencionados, formando una centralidad centrada en la actividad comercial, la cual puede tener una mayor o menor presencia en el entorno urbanístico dependiendo de su tamaño y características.

\section{Calle De Tiendas o "Shopping Strip y Miracle Mile"}

Esta tipología de centralidad comercial periférica básicamente se compone de una serie de edificios comerciales dispuestos a lo largo de una carretera, calle o cruce. los cuales pueden contar o no con aparcamientos. Esta tipología de centralidad comercial materializó los primeros modelos de comercio en los barrios periféricos de baja densidad, en forma de hileras de tiendas planificadas (Finales del Siglo XIX y primera mitad del Siglo XX), como en forma de aglomeración de comercios a lo largo de una carretera (Mediados del Siglo XX), estando su desarrollo ha estado muy ligado a la evolución de la tipología de centro comercial periférico en los primeros años de su consolidación. 


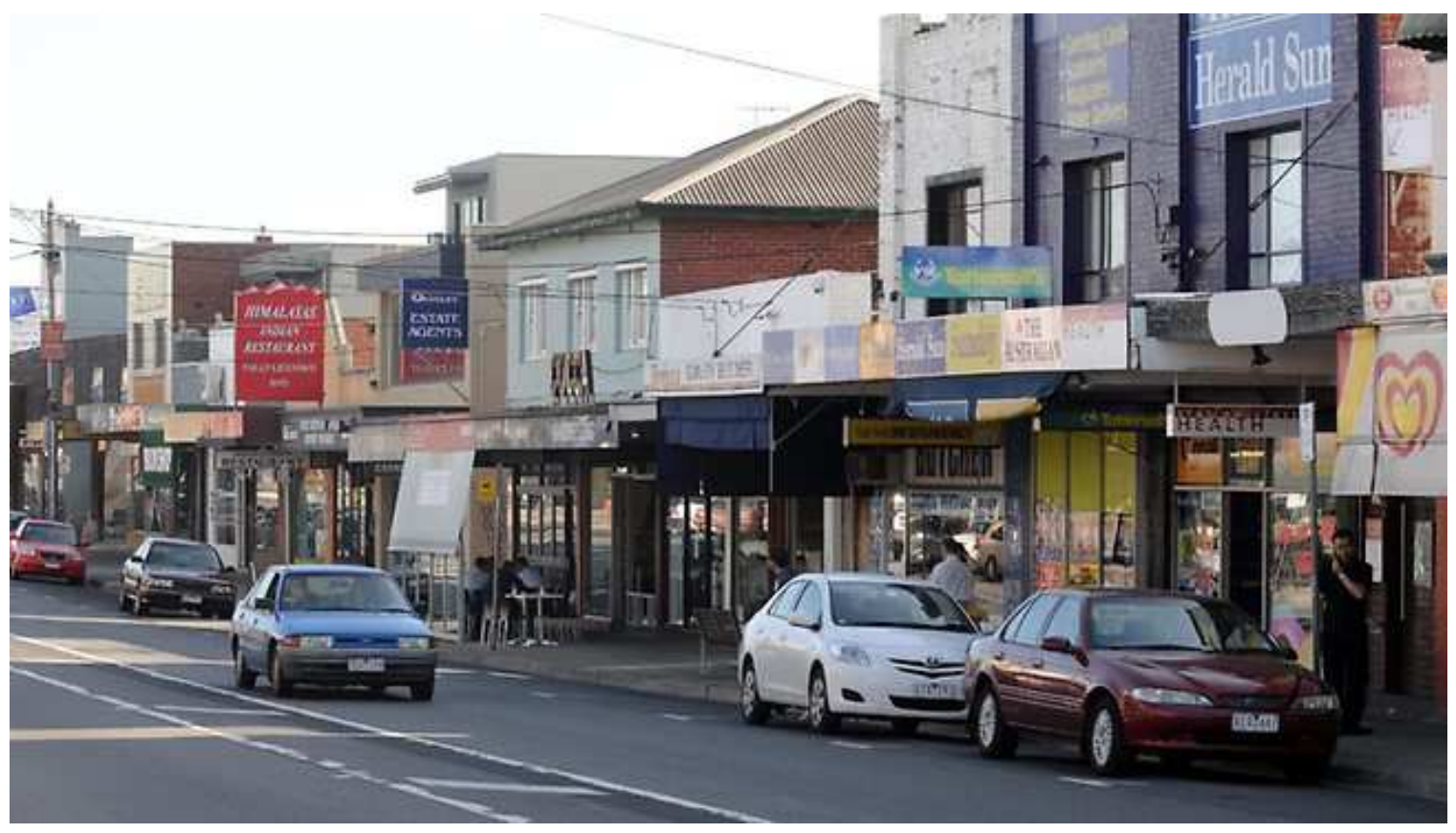

Figura 3.5.6 Ejemplo de Shoppping Strip Fuente: resources3.news.com.au

Aglomeración de edificios comerciales o "Power Center"

Esta tipología comercial es el resultado de la yuxtaposición de una serie de hipermercados y o centros comerciales en superficie, formando el conjunto de los mismos un complejo comercial de gran superficie e infinidad de servicios. En este complejo existen las grandes superficies de aparcamiento, y estas pueden ser individuales y asociadas a cada centro, o bien comunes a todo el complejo, ubicándose las mismas en un espacio común a todos los locales que componen la centralidad comercial.

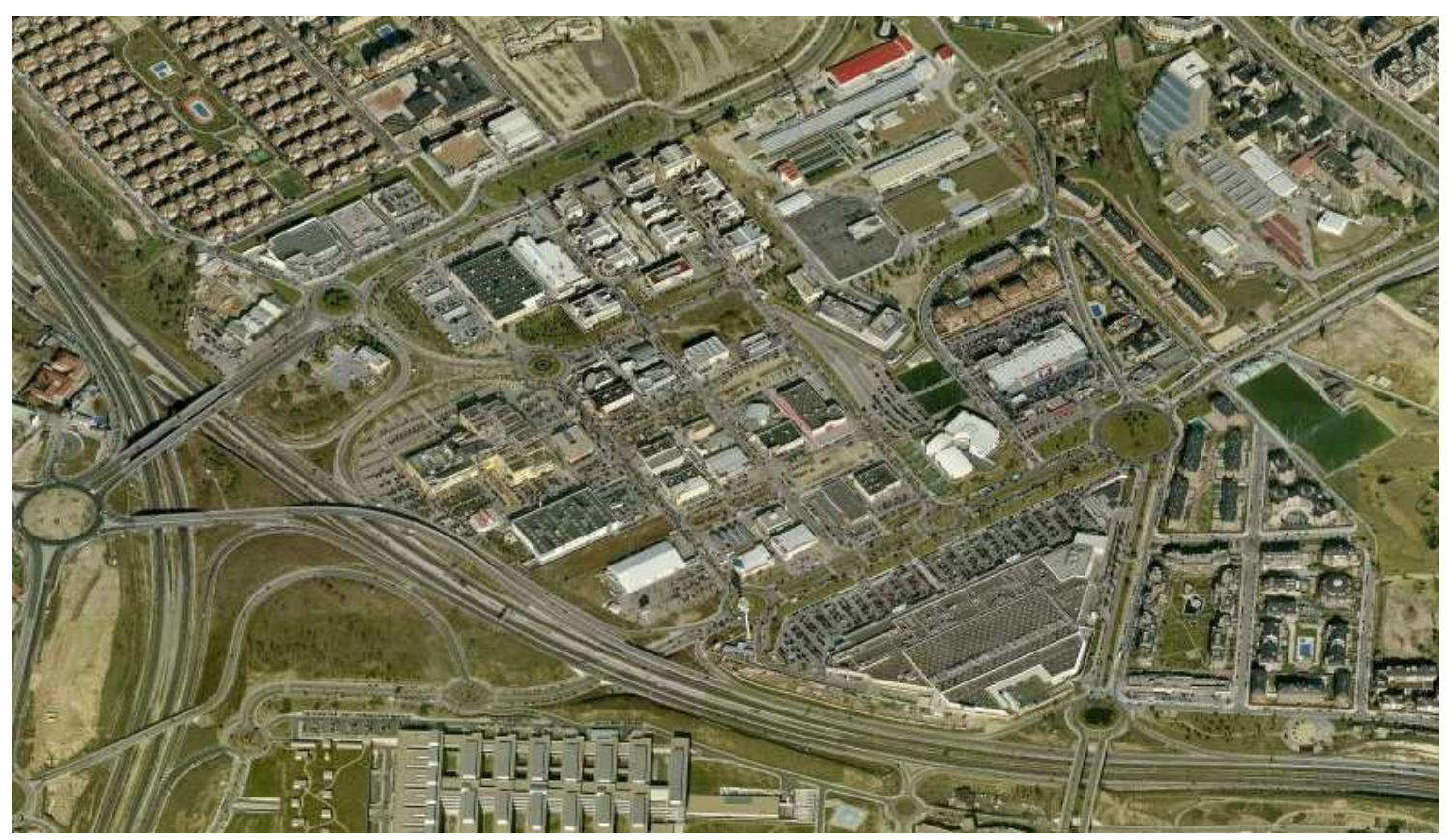

Figura 3.5.7 El Carralero, Ejemplo de Power Center. Fuente: bing maps. 


\section{6.- LA PROBLEMÁTICA ACTUAL DE LOS CENTROS COMERCIALES COMO PUNTO DE PARTIDA, CASOS ILUSTRATIVOS.}

Los centros comerciales de gran tamaño, que son el objeto de investigación de la presente tesis, han generado impacto dentro de nuestras ciudades a efectos de sostenibilidad, especialmente los que están relacionados con la periferia. Para la realización de un análisis enfocado en las medidas de rehabilitación sostenible que pudieran ser de aplicación sobre un centro comercial, tanto a escala urbana como arquitectónica, se va a hacer necesaria la comprensión de la problemática que la tipología edificatoria de centro comercial de gran superficie ha generado en nuestras ciudades, enfocándola desde el punto de vista de los pilares de la sostenibilidad y el plano urbanístico-arquitectónico. No obstante, esta tesis aunque mencionará todos los pilares de la sostenibilidad, va a centrar su atención en el tema del urbanismo, y el medio ambiente. Siendo el estudio exhaustivo de los centros comerciales y su problemática en el ámbito de los otros dos pilares de la sostenibilidad, o del proyecto arquitectónico, posibles tema de futuras actividades de investigación.

A rasgos generales y como anotación introductoria, la oficina Ecosistema Urbano en el artículo "Reinventarse o Morir, la Transformación de los Centros Comerciales bajo el Nuevo Paradigma Económico/Urbano" estipula que "El concepto de centro comercial, como lo entendemos y experimentamos actualmente, podría tener los días contados" ${ }^{\prime \prime 35}$. En el mismo artículo, se hacen amplias referencias al origen y a la problemática de los centros haciendo los autores del artículo un debate sobre las causas de la decadencia de los centros comerciales basado en estos puntos:

"1. Los más grandes, increíbles y novedosos 'shopping malls' se han venido realizado en las nuevas "Américas" del mundo; es decir en China, Emiratos Árabes, Malasia, etc.

2. Los centros existentes en Europa y Estados Unidos sufren una crisis que, lejos de ser exclusivamente económica, va más allá de la actual recesión. Es una crisis estructural del modelo, una crisis que probablemente es debida al fin del efecto novedad, así como a la existencia de un contexto distinto y nuevos modelos de negocio que son posibles a través de la compra online. Hoy el escenario económico es distinto; la competencia entre los centros más antiguos y obsoletos y los recién construidos es atroz e internet multiplica su actividad comercial cada año, restando negocio al comercio físico.

3. La obsolescencia es una parte fisiológica de la vida de todo objeto y por tanto la capacidad de innovar y de buscar nuevas oportunidades es imprescindible para la supervivencia. Los centros comerciales, por su enorme éxito económico, no han tenido la necesidad de replantearse ni cuestionar su modelo, de innovar o de incorporar programas, ideas o cambios para adquirir una identidad propia. Este exitoso negocio ha engrasado una maquinaria económica que ha clonado el mismo modelo sin dejar espacio para el cuestionamiento: ¿por

\footnotetext{
35 Oficina Ecosistema Urbano: (Junio de 2015) "Reinventarse o Morir, la Transformación de los Centros Comerciales bajo el Nuevo Paradigma Económico/Urbano".
} 
qué repensar un modelo que es altamente rentable y funciona en contextos y culturas distintas?" 36.

De este modo, aunque este texto dicta a grandes rasgos la problemática de actualidad de los centros comerciales, para la presente tesis se hace necesario profundizar aún más en la misma.

\subsection{1.- La problemática medioambiental de los centros comerciales.}

El tema del impacto de los centros comerciales a efectos medioambientales va a ser un tema de gran importancia para la presente tesis doctoral, ya que su comprensión correcta es fundamental para acometer de manera correcta una rehabilitación de lo que es el edificio del centro en sí, cuya aplicación resultara en una mejora en el ámbito de lo medioambiental. Roger Sánchez del Río, en el artículo Impacto Medioambiental de los Centros Comerciales: de Gran Vía a Xanadú, publicado por Mercasa, define la el impacto medioambiental en cuatro dimensiones que son: agua y suelo, biodiversidad, calidad del aire y transporte, más una quinta que se insertará en la presente tesis doctoral que es la eficiencia energética. Estas áreas van a ser las que van a ser estudiadas para calificar la problemática medioambiental en la presente tesis, siendo consideradas en el capítulo del análisis de indicadores una vez se hayan obtenido los datos referidos a los centros comerciales.

Agua y suelo: Esta dimensión va a referenciarse tanto al consumo de agua del centro comercial en sí, como al impacto del edificio en lo que es la regeneración del agua en el terreno. Un centro comercial al ser un edificio, su materialización supone la neutralización de las capacidades ambientales del terreno, entre las que se encuentra la absorción de agua para la regeneración de los acuíferos, problema que se ve agravado cuando la superficie de un centro comercial cobra grandes dimensiones. A la vez que también resultan muy problemáticas en este aspecto las grandes superficies asfaltadas, debido a que la caída de agua de lluvia sobre las mismas, va a ser responsable del arrastre de contaminantes hacia el terreno. También, a efectos de funcionamiento, un centro comercial requiere de unas grandes cantidades de agua, especialmente en los locales destinados a las zonas de restauración.

Biodiversidad: El estudio de esta dimensión, hace referencia al estudio, tanto del impacto del centro comercial sobre lo que es la biodiversidad en sí. El estudio realizado por Roger Sánchez del Río, establece dentro de esta dimensión el ruido generado por el transporte, y la cantidad de arbolado presente dentro del centro comercial. La superficie arbolada va a servir de cara a las cualidades regenerativas medioambientales.

No obstante, para el estudio de la problemática medioambiental del centro comercial sobre la biodiversidad, se hace necesario en primer lugar considerar varios impactos ambientales. El primero, va a consistir en la desnaturalización parcial o completa del suelo que la materialización del edificio del centro comercial acarrea consigo, debido a que las superficies edificadas son difícilmente compatibles con la biodiversidad. Este impacto es prácticamente irreversible, ya que para recuperar la biodiversidad original que al terreno tenía antes de la construcción del centro, se va a hacer necesaria la demolición del mismo en su totalidad, generando esta otro impacto ambiental muy severo. El segundo punto que se debe de 
considerar dentro de la problemática medioambiental a efectos de biodiversidad, es la ligada a las externalidades que la actividad del centro genera sobre los seres vivos, siendo de espacial importancia el ruido generado por el tráfico, y la expulsión de gases que pudieran resultar nocivos.

Calidad del aire: El estudio de esta dimensión, está asociada a las emisiones de gases que resultan perniciosos para la atmósfera (efecto invernadero, destrucción de ozono, toxicidad...) teniendo estos a su vez consecuencias sobre la biodiversidad y el medio ambiente en general. El centro comercial en su funcionamiento, va a generar este tipo de gases, ya sean debidos al tráfico que se genera en el acceso al edificio, $\mathrm{o}$ al funcionamiento de las diferentes instalaciones que se encuentran en su interior, la expulsión de estos gases con creces va a mermar la calidad del aire, y resulta importante hacer que el centro comercial se valga de medios alternativos para el transporte y el mantenimiento de su infraestructura que no generen esos gases. Para la presente tesis se van a considerar la emisión de gases perniciosos para el medio ambiente, como un factor de gran relevancia de estudio.

Transporte: Esta dimensión está relacionada con el impacto ambiental que genera el transporte hacia lo que es el centro comercial. En ese tema, se debe de considerar el tipo de transporte más recurrente a la hora de acceder al centro comercial, debido a que como regla general, el mayor impacto medioambiental lo van a producir los medios de transporte motorizados particulares. De este modo, este impacto va a ser crítico, para el caso de los centros comerciales cuya estructura viaria, conexión y enfoque a efectos de transporte y accesibilidad esté enfocado hacia el uso del vehículo privado. Respecto a este tema, como ya se mencionó anteriormente, las tipologías urbanas de baja densidad y escasa interacción entre las áreas y elementos urbanos, ya sea debido a barreras o a distancias, van a agravar este problema.

Eficiencia energética: La eficiencia energética es sin duda una dimensión muy importante a tener en cuenta, ya que los centros comerciales tienen un fuerte impacto en el uso de la misma. El consumo de energía en los centros comerciales, muchas veces viene sustentado por la utilización de los sistemas, tanto de iluminación, como de aclimatación artificial dentro del edificio. No obstante, la mayor o menor utilización que tendrán estas medidas, en muchos aspectos va a estar fundamentada por la morfología del edificio, a la vez que la configuración espacial del mismo, tanto en lo referente a espacio interior, como en lo referente a morfología y ubicación de los diferentes huecos. No obstante, muchas veces en el proyecto de los centros comerciales, el factor bioclimático no es tenido en cuenta, y esto se traduce muchas veces en huecos mal dimensionados o orientados en referencia a las cuestiones climáticas, siendo también un factor relevante que generalmente en un centro comercial, una gran cantidad del espacio interior del edificio no cuenta con luz natural. Estos factores no van sino a incrementar el consumo de energía, debido a las necesidades de aclimatación o iluminación.

Para concluir, es una realidad que los edificios comerciales al igual que el resto de edificios independientemente de su uso, van a acarrear consigo un impacto ambiental. Dentro de los edificios de tipo comercial, los ejemplares que van a suponer un mayor impacto ambiental van a ser los centros comerciales ubicados en la periferia de las grandes ciudades, que ocupen una enorme superficie de terreno, su accesibilidad esté limitada al vehículo particular, y su 
envolvente sea inadecuada para el clima en el que están dispuestos. Habiendo en el mundo infinidad de casos que cumplen estas condiciones negativas.

\subsection{2.- La problemática económica de los centros comerciales.}

A efectos de economía, los centros comerciales, en la actualidad están experimentando crecimiento o pérdidas de acuerdo al contexto económico en el que están ubicados.

El tema de la economía de los centros comerciales, resulta de gran importancia a la hora de acometer cualquier tipo de rehabilitación de un centro comercial, siendo un tema recurrente en los escritos y publicaciones relacionados con la rehabilitación de los centros comerciales. Desgraciadamente, este tema no pudo ser considerado a fondo para la metodología, ya que el autor carece del conocimiento necesario para gestionar una revitalización económica. No obstante, esto no solamente es tema de interés para futuros trabajos de investigación, sino que cualquier operación de rehabilitación a acometer sobre un centro comercial deberá de ir acompañada de un estudio económico de la misma.

De este modo, resulta de gran importancia hacer un estudio del estado de la cuestión de la rehabilitación económica de los centros comerciales, como refuerzo en la comprensión de la problemática actual de los centros comerciales.

Para enunciar el tema de la sostenibilidad económica, se va a hacer necesario en primer lugar entender cómo funciona a grandes rasgos una actividad cualquiera a lo largo del tiempo. De manera que va a ser necesaria la introducción del concepto de ciclo de vida económico.

El concepto del Ciclo de vida de una actividad productiva o económica, es una readaptación del concepto del ciclo de vida de un ser vivo, al ámbito de las actividades económicas, productivas y los negocios, realizado en el año 1965 por el profesor de la Universidad de Harvard Theodore Levitt. De este modo, al igual que un ser vivo, las actividades económicas pasan por diferentes fases antes de caer en declive y resultar improductivas. La duración de este ciclo de vida y sus diferentes fases depende de la actividad en sí, y su concepto puede ser asimilado para la caracterización del conjunto de las actividades económicas dentro de una región concreta de mayor o menor tamaño, o bien puede ser adaptado a una actividad en concreto.

El estudio del ciclo de vida resulta fundamental para el presente trabajo, pues en primer lugar, el estado en el que se encuentra el centro comercial en sí, nos dará la pauta básica para elegir el tipo de intervención a considerar para el mismo. En segundo lugar, este es la base para entender el por qué del declive de los centros comerciales, que muchas veces supone el inicio de la mayoría de las operaciones de rehabilitación.

De este modo la curva del ciclo de vida básica relacionada con el negocio de un centro comercial, es como la de cualquier otra actividad económica: José Miguel Fernández Güell describe las fases de la curva del ciclo de vida la siguiente manera: 


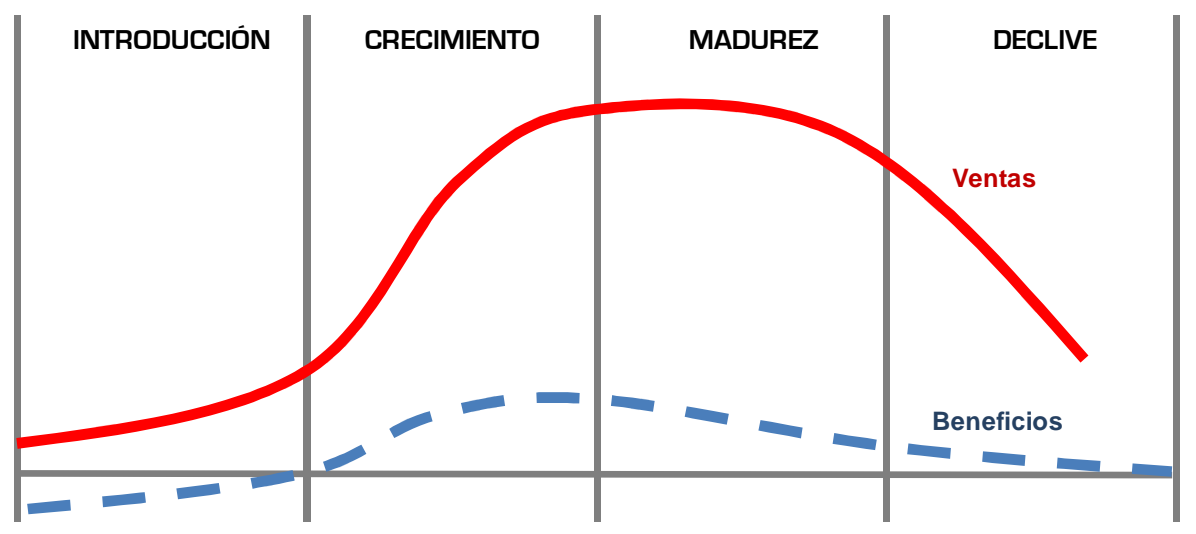

Figura 3.6.1.- Curva de Ciclo de Vida. Elaboración propia a partir de datos de José Miguel Fernández Güell.

1: Introducción: En esta etapa aparece una actividad productiva en el mercado antes de que haya demanda efectiva. Características: Las ventas son escasas y el movimiento comercial es muy lento. Tecnología cambiante y énfasis en conseguir nuevos cliente; las barreras de entrada (Costes de inicio y financiación de actividad)son bajas y las cuotas de mercado cambian con facilidad.(...)

2: Crecimiento o despegue: (...) La demanda se acelera y el mercado total se amplía rápidamente. Características: Crecimiento rápido; los clientes comienzan a alinearse con los productores; decrece el número de nuevos clientes; la tecnología se difunde más ampliamente; las cuotas de mercado comienzan a estabilizarse; aumentan las barreras de entrada.(...)

3: Madurez: En esta etapa la demanda se uniforma y crece en su mayor parte solo al ritmo de la reposición de productos. Características: los clientes se alinean con los productores; la tecnología y las cuotas de mercado se estabilizan; aumentan los costes de entrada; se amplían las líneas de productos; el mercado experimenta precios bajos.(...)

4: Declive: En la última etapa, los productos del sector empiezan a perder atractivo para el consumidor y las ventas decaen. Características: cae la demanda; decrecen los competidores; las líneas de productos se estrechan; aparecen los productos sustitutivos; las empresas actúan enérgicamente para mantener la cuota de mercado. ${ }^{36}$

De este modo, una vez comprendido el concepto del ciclo de vida y sus respectivas fases, podremos realizar un acercamiento mas al tema de los centros comerciales y el ciclo de vida de esta actividad e particular, como paso previo a la comprensión del tema de la problemática económica de los centros comerciales.

Los autores Abrudan loanna Nicoleta and Davija dan Crhistian, para el ciclo de vida de la actividad comercial, establecen cuatro fases, cuyas repercusiones más inmediatas están relacionadas con el tema económico. Lo que estos autores comentan, fue contrastado y comparado con lo anteriormente mencionado escrito por José Miguel Fernández Güell, pudiéndose establecer de esta manera los siguientes pasos relativos al ciclo de vida de un centro comercial.

\footnotetext{
${ }^{36}$ Fernández Güell J. M. (1997). Planificación Estratégica De Ciudades. Página 194
} 
Lanzamiento e innovación: Esta fase es la que comprende el estado de negocio del centro comercial inmediatamente después de su fundación e inauguración, por lo que es la primera del proceso de ciclo de vida. Como se explicó anteriormente en el capítulo de la fundación de los centros comerciales (3.3), el centro es fundado dentro del territorio porque la explotación del mercado relacionado con el comercio resulta viable, ya sea por la falta de comercio en la zona, o por la presentación del mismo como una idea innovadora. En esta fase, la administración del centro comercial buscará captar nuevos clientes, y los beneficios de la misma suelen ser generalmente bajos, a pesar de la creciente ocupación del negocio. Esto se debe, a que es necesario cubrir la alta inversión que ha supuesto el proceso de fundación, construcción y desarrollo del centro comercial (explicados anteriormente).

Etapa de crecimiento y desarrollo: Ésta etapa del ciclo de vida del centro comercial comienza una vez la actividad del mismo se ha consolidado, y éste es insertado dentro de su mercado correspondiente de manera exitosa. En esta fase, el centro comercial ya comienza a tener beneficios gracias al número de compradores, y esto atrae a su vez a mas comerciantes, los cuales se interesarán en tener su actividad comercial dentro del centro, y así, el porcentaje de ocupación de los locales es elevado. Por consiguiente los beneficios de la empresa gestora del centro comercial comienzan a aumentar, y si el negocio resulta exitoso dentro de la zona, comenzará a atraer a otras empresas competidoras, que también desarrollarán su centro comercial a partir de los huecos de mercado.

Etapa de madurez: Esta fase está caracterizada principalmente por una gran presencia de centros comerciales en la zona de mercado, lo que acarrea consigo que habrá una alta competitividad entre ellos. En esta fase, la afluencia de clientes comienza a decrecer, y esto acarrea consigo un menor volumen de ventas. Por consiguiente la tasa de crecimiento de los beneficios, tanto de la gestora del centro comercial como de los comerciantes asentados en el mismo se estanca, cuando no decrece, y de este modo, los propietarios de los negocios que están dentro del centro se plantean el abandono una vez hayan expirado sus contratos. Esto marca el inicio de la pérdida de atractivo que el centro comercial, el cual ya comienza a experimentar un menor volumen de ingresos debido a su obsolescencia. En esta fase, la empresa gestora intentará que los comerciantes no abandonen el centro comercial, ofreciendo unas tasas de alquiler más bajas, y los comerciantes tratarán a toda costa de mantener su afluencia de cliente a través de nuevos métodos de marketing.

Etapa de declive: Esta fase comienza cuando ya la competencia y la oferta de centros comerciales en la zona es tan elevada, que el volumen de mercado comienza a decrecer. Durante esta etapa, los comerciantes afincados en el centro comienzan a abandonarlo, y el espacio alquilable se queda vacío. De este modo, la empresa gestora al no poder cobrar ni alquileres ni remuneraciones de los comerciantes afincados en el centro, la empresa gestora comienza a entrar en pérdida económica.

De este modo, la etapa de declive del centro comercial, indiscutiblemente marca el final del ciclo de vida del mismo.

A día de hoy, el declive de los centros comerciales, se da generalmente en lugares en los que la oferta de este tipo de instalaciones es muy elevada; y de este modo, la excesiva competencia, 
junto a la escasez de nichos de mercado, hacen que muchas instalaciones de este tipo dejen de ser una inversión rentable.

A todo esto hay que añadir, que el éxito económico de los centros comerciales durante su historia moderna (desde su fundación por Victor Gruen hasta la actualidad), no ha propiciado en absoluto ninguna adaptación o innovación de los centros comerciales, siendo además un factor importante de su declive, la repetición constante de los mismos. Por poner un ejemplo, En Estados Unidos en 1990, año en el que la tipología del centro comercial alcanza su apogeo económico, se abrieron 140 centros comerciales de nueva planta ${ }^{1}$.

A todo esto, hay que tener en cuenta que los nuevos modelos de negocio (Compra por internet) le han quitado negocio a los centros comerciales, al tratarse de una alternativa más innovadora. Actualmente, tiendas que habitualmente estaban en zonas periféricas o centros comerciales se están trasladando a los centros de las ciudades, motivados en gran medida por estos cambios en el mercado; ya sea como puntos de recogida de artículos para compras en internet, o como maniobra de acercamiento al centro. (Media Markt Goya en Madrid).

Enunciado esto, presentaremos un esquema del ciclo del estado de los centros comerciales dentro de la curva del ciclo de vida en referencia a diferentes regiones del mundo. El cual estará basado en el análisis de A.T. Kearney realizado en 2013, que considera los mercados emergentes para invertir en centros comerciales:

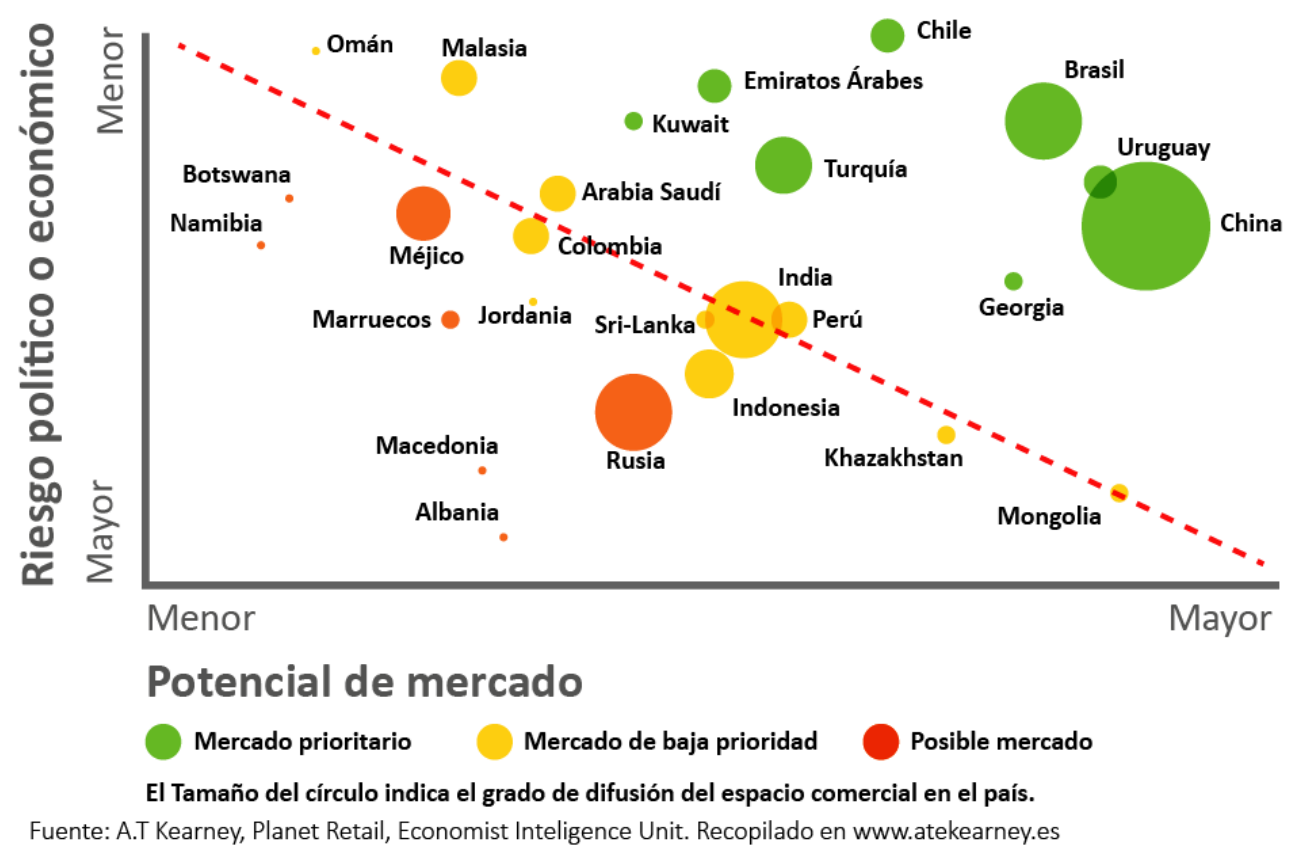

Los cuales fueron agrupados en zonas continentales por el autor de la presente tesis: 


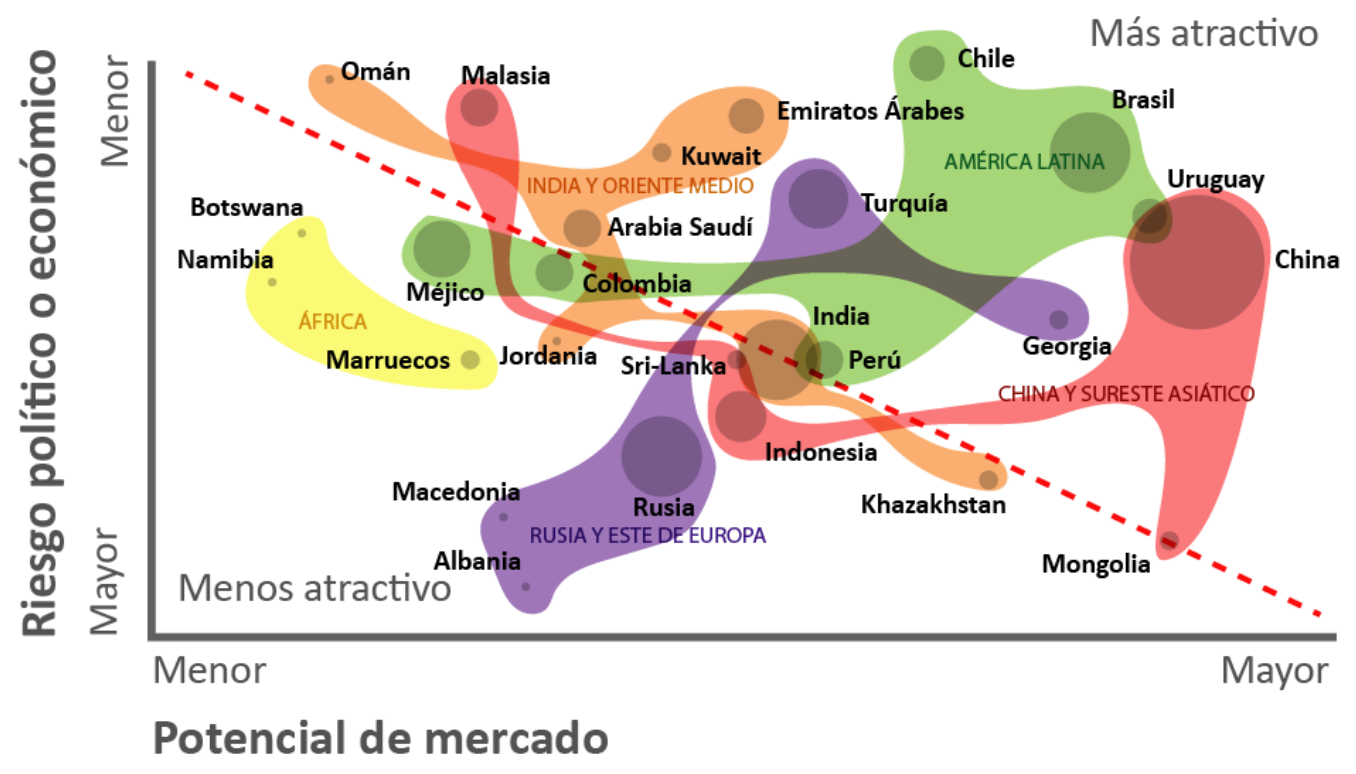

Fuente: A.T Kearney, Planet Retail, Economist Inteligence Unit. Elaboración propia

Figura 3.6.2 Esquemas de potencial de mercado según geografía. Fuente:Elaboración propia a partir de datos de A.T. Kearney

Pudiendo a partir de estos datos, sacar una gráfica del ciclo de vida para los diferentes mercados globales:

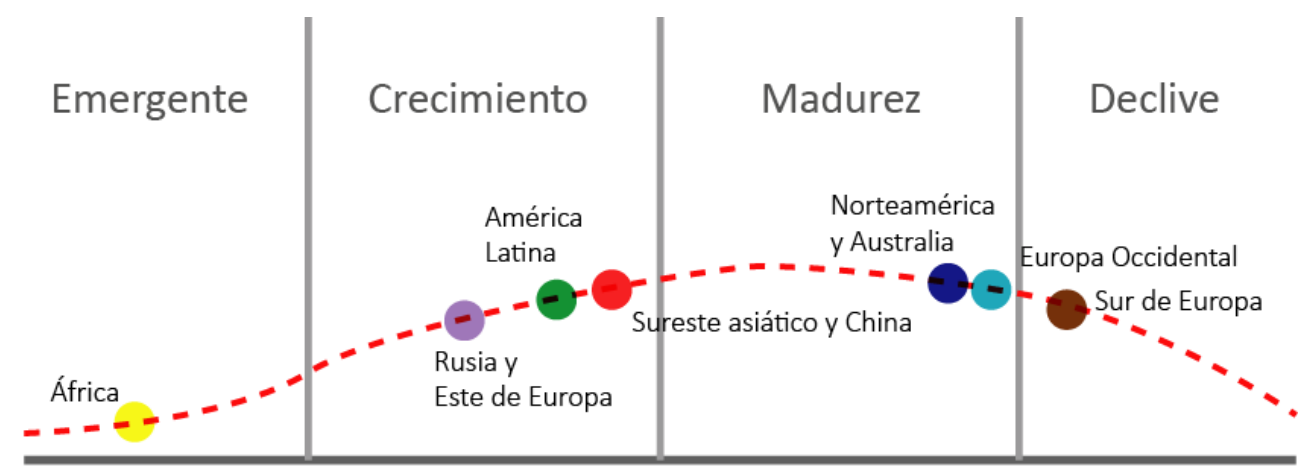

Fuente: Fernandez Guell, Euromonitor International, A.T. Kearney. Elaboracion Propia

Figura 3.6.3 Curva ciclo vida centros comerciales según localización geográfica Fuente: Elaboración propia a partir de datos de A.T. Kearney y Fernández Güell.

Como muestra la gráfica, el negocio de los centros comerciales, en los países emergentes está en mayor o menor etapa de crecimiento, habiendo alcanzado su madurez, muy cercana a su declive en los países desarrollados, donde la oferta de este tipo de instalaciones es mayor. De este modo, aunque esta actividad económica puede mantenerse a largo plazo en los países emergentes, para el caso de los países desarrollados, se van a hacer necesarias las intervenciones, independientemente del tipo que sean, para ir poco a poco reflotando en un punto más o menos anterior al declive esta actividad económica.

El interés por el conocimiento del proceso de ciclo de vida de un centro comercial se debe al hecho de que la rehabilitación de un centro comercial a grandes rasgos, supone una operación arquitectónica o urbanística, cuyo fin último es adaptar el centro comercial y su estado actual, a las exigencias comerciales o de uso presentes en el entorno, ya sea a nivel urbano o de 
mercado. Todo ello mediante la adaptación del contenedor físico del centro comercial a las nuevas exigencias del mercado, con el fin último del mantenimiento, o la prolongación del nivel de negocio dentro de una fase lucrativa. En el caso de que el centro comercial esté en fase de declive, o madurez muy prolongada, la propiedad del centro comercial buscará retornar a una fase del ciclo de vida que en cuanto a volumen de negocio se refiere, pudiera resultar lucrativa, o bien transformar lo que es la instalación en sí de manera drástica, para introducir en él negocios que lo sitúen en una fase de mercado emergente. De este modo, la comprensión de las diferentes fases de volumen de negocio y estado, dentro del ciclo de vida de un centro comercial nos dará sin lugar a dudas una pauta directora de primer orden que nos orientará a elegir la metodología de rehabilitación que debe de ser aplicada sobre el mismo.

De este modo, las operaciones de rehabilitación cuya aplicación es conveniente para un centro comercial en estado de declive, no serán en absoluto las mismas que deberían de ser aplicadas sobre un centro comercial en estado emergente, $u$ otros estados en los que el volumen de negocio sea boyante para el propio centro en sí. No obstante, la metodología que se estudiará en esta tesis, va a responder a las necesidades urbanísticas y medioambientales, considerando las necesidades económicas de manera muy somera debido a la carencia de conocimiento en este aspecto del autor para analizar el tema en profundidad. La consideración de las necesidades económicas puede ser un futuro tema de tesis.

\subsection{3.- La problemática social de los centros comerciales.}

Para entender la problemática social de los centros comerciales, va a ser necesaria la realización de un análisis más a fondo de la cuestión.

El centro comercial, es un elemento urbano, cuya materialización va a tener consecuencias en lo que es el ámbito urbano, en referencia a las pautas sociales de la zona en la que se sitúe. La problemática social de los centros comerciales, generalmente va a darse tanto en lo referente al ámbito interno, como al ámbito externo.

Ámbito interno: El centro comercial, como ya se menciono anteriormente, es un elemento arquitectónico destinado generalmente a la actividad comercial intensiva. La cual mueve grandes cantidades de capital debido a las necesidades de compra de bienes de consumo variados por parte de las personas. Sena İzgi, Reyhan Ateş y Cem Soyer, mencionan em su artículo, "Negative Effects of Shopping Malls", diferentes aspectos negativos de esta actividad comercial intensiva em el ámbito de lo social. Los autores del anteriormente mencionado artículo remarcan como principales problemas sociales inherentes al centro comercial los siguientes:

- Efectos negativos sobre las personas discapacitadas (Sena izgi, Reyhan Ateş y Cem Soyer, "Negative Effects of Shopping Malls" 2010, pg7): Los autores del artículo, hacen referencia a que los centros comerciales, debido al alejamiento, y a las grandes distancias entre los elementos que los componen, acarrean consigo dificultades de accesibilidad para las personas discapacitadas, también en muchos casos de centros comerciales, las instalaciones y recorridos no están preparados ni pensados para este tipo de personas. 
-Efectos negativos en el comportamiento (Sena Izgi, Reyhan Ateş y Cem Soyer, "Negative Effects of Shopping Malls" 2010, pg10): aunque en la presente tesis no se va a estudiar a fondo este tema, resulta importante su mención, pues el mismo además de tener repercusiones en el pilar de lo social, también tiene mucho que ver con el cuarto pilar de la sostenibilidad que es el de la cultura. Los autores anteriormente mencionados, enuncian que los centros comerciales y su actividad intensiva, a la vez que la enorme oferta que ofrecen, acarrean consigo efectos psicológicos y pautas de comportamiento sobre las personas, además de la materialización de una cultura propia centrada en estas instalaciones de tipo comercial, la cual incita a los clientes del centro a adquirir artículos. Este hecho es problemático de cara a las personas que tienen adicción por las compras. Estos problemas pueden venir derivados de su diseño arquitectónico (Efecto Gruen o "Gruen Transfer"), siendo la principal causa, la gran oferta de artículos y la publicidad intensiva de la que gozan.

Ambito externo: Los centros comerciales, al ser unas piezas de gran presencia y actividad, su materialización sin duda va a suponer una alteración de las pautas sociales em el entorno urbano en el que se emplazan, y en la ciudad. Como efectos problemáticos de cara al exterior podemos remarcar:

-Efectos en la estructura socioeconómica urbana: El centro comercial debido a su gran volumen de negocio, y a la alta oferta de productos, muchas veces resulta ser un elemento perjudicial de cara a otras formas de negocio de menor tamaño y capacidad, las cuales quiebran al no poder competir con el centro comercial. De manera que la construcción de un centro comercial muchas veces va a suponer um desplazamiento de esta actividad hacia el mismo. No obstante, puede generar empleo en gran número, ya sea permanente o temporal, pero es de gran importancia atender al desplazamiento y a las alteraciones en la actividad comercial derivadas de la apertura del mismo, para así evitar o mitigar la destrucción de empleo derivada del cese de actividad de los comercios que no pueden competir con el centro.

-Inviabilidad en la función de sustituto del espacio urbano de reunión: Cierto es que el centro comercial debido a su ingente potencial de actividad comercial, es un lugar en el que confluyen grandes cantidades de personas. Sin embargo, su función está generalmente enfocada al comercio, y de este modo, aunque es un espacio relativamente abierto, su propiedad es completamente privada. De este modo, la actividad de um centro va a estar limitada a los horarios comerciales, y todo evento colectivo o individual que se realize en el interior del centro comercial, siempre tiene que estar permitido por la dirección del mismo, que es la única propietaria del espacio de reunión interno. La consideración del centro comercial como espacio de reunión para la ciudad es un problema, ya que es un factor que desmotiva a las autorides urbanísticas de cara a la consideración del espacio estancia dentro de la ciudad como punto de reunión social. Siendo buena prueba de ello, que en la actualidad existen comunidades y contextos urbanos que carecen de espacio urbano público, o no está proyectado de forma adecuada; y por consiguiente, el centro comercial se ha consolidado como suplente del mismo para satisfacer las necesidades de encuentro social entre los habitantes de la comunidad. Siendo además una evidencia que debido a la diferencias conceptuales y urbanísticas, un centro comercial nunca podrá ser um sustituto del espacio público de reunión, al ser este una propiedad privada que tiene como fin la actividad comercial.

\subsection{4.- La problemática urbanística de los centros comerciales.}


La explicación de la problemática urbanística y arquitectónica de los centros comerciales, básicamente sería un resumen de los defectos explicados en los capítulos 2.2, y 2.4. No obstante en este capítulo se va a realizar un recordatorio de los defectos anteriormente mencionados:

El centro comercial de primeras es un elemento con gran presencia en la ciudad. De este modo, como ya se mencionó en el capítulo de la descripción funcional y formal, un centro comercial va a actuar de un modo u otro respecto de su entorno urbano. De este modo, la problemática urbanística básicamente tendría su raíz en la fuerte influencia que este elemento tiene respecto de su entorno. En primer lugar, el centro comercial va a suponer dentro de la ciudad un polo de actividad económica, que podría resultar en el anteriormente mencionado desplazamiento de la actividad comercial, propiciándose de este modo el cese de la actividad comercial en otras zonas, con la consecuente degradación urbanística. En segundo lugar, y como efecto secundario de esta influencia, el centro comercial va a acarrear consigo un incremento en los tráficos hacia sí mismo, pudiendo derivar esto en problemas de tráfico por congestión de las vías. Efecto que se ve agravado si el transporte privado es el único medio de transporte viable para el acceso al centro comercial, hecho que suele ser muy habitual en los centros comerciales que son proyectados a nivel urbano como elementos aislados, o en los ubicados en contextos urbanos de escasa densidad y actividad urbana (suburbios norteamericanos). El tercer punto de la problemática, es exclusivo de los centros comerciales de gran superficie y uso único, y este está muy ligado con la zonificación urbana. De manera que un centro comercial que cumple con los rasgos anteriormente mencionados, de entrada va a suponer la utilización de una gran cantidad de superficie para un único uso, lo que puede agravar los problemas derivados de la zonificación, es decir, el distanciamiento entre las partes de la ciudad, o la pérdida de complejidad dentro de la misma. A todo esto hay que añadir, que la actividad de un centro comercial está limitado al horario de apertura de las tiendas, de manera que un centro comercial es un punto frío en las horas en los que está cerrado.

\subsection{5.- La problemática arquitectónica y de proyecto de los centros comerciales.}

En este aspecto, la problemática del centro comercial muchas veces deriva de su planteamiento como elemento aislado, derivado de su uso generalmente centrado en el comercio a escala masiva. De este modo, un centro comercial se va a materializar como un edificio pensado para negar de manera rotunda las características del entorno, ofreciendo este un ambiente cerrado exclusivo (Efecto Gruen). Esto generalmente deriva en la creación de un "no lugar" tanto dentro del centro como en las afueras del mismo. Se debe de considerar también que esta predominancia de la función comercial, junto con el planteamiento de proyecto introspectivo, ha hecho que todos los centros comerciales sean prácticamente iguales en todos los lugares del mundo; siendo considerandos los ambientes ajenos al centro, cuando en el proyecto se tiene la intención de generar un decorado. A todo esto hay que añadir que generalmente los centros comerciales tampoco se proyectan considerando los rasgos climáticos de la zona en la que se encuentran. 
De este modo, una vez expuesta la problemática actual de los centros comerciales, se realizará un análisis de prospectiva para reforzar este estudio, el cual se concluirá con un análisis DAFO como resumen final de la problemática.

\section{7.- LA VISIÓN PROSPECTIVA EN LA PROBLEMÁTICA DE LOS CENTROS COMERCIALES.}

Una vez enunciada la problemática actual, desde los pilares de la sostenibilidad, como refuerzo del tema de la problemática de los centros comerciales va a realizarse un estudio de factores que pudieran afectar al funcionamiento de los centros comerciales. Este estudio va a incluir tanto las fortalezas, como las debilidades anteriormente mencionadas en los anteriores capítulos relacionados con la problemática a actual. A Esta recopilación de fortalezas y debilidades, se va a incluir un estudio de factores de cambio, que va a considerar tanto los factores que acontecerán a corto plazo, como los relacionados com la visión prospectiva, es decir los factores a medio y largo plazo. Este análisis, va a estar referenciado em todo momento con las tres dimensiones de la sostenibilidad, y será concluido con una tríada de análisis DAFO, que mostrará las relaciones entre los factores tanto internos como externos.

\subsection{1.- Factores internos.}

La recopilación de factores internos referenciado com los centros comerciales, va a considerarse en base al anterior capítulo de la problemática, estableciéndose de este modo las siguientes fortalezas y debilidades.

FORTALEZAS.

Dimensión medioambiental:

-Viabilidad para la implantación de líneas de transporte colectivo: esto es debido a la capacidad de las vías anejas, y al gran movimiento de personas que los centros comerciales generan. (Mitiga de manera positiva el incremento radical del número de vehículos, los problemas de tránsito y la congestión de las vías)

Dimensión económica:

-Gran movimiento de capitales: debido al gran volumen de ventas que un centro comercial puede generar. (Mitiga de manera positiva la negación de crédito)

-Gran oferta de productos disponible en comercios especializados: que permite al centro comercial la explotación de numerosos nichos y ámbitos de mercado. (Hace al centro adaptarse a los cambios en los hábitos de consumo, y a la influencia de las modas)

Dimensión Social: 
-Creación de empleo en cantidades notables: debido a que el centro comercial precisa de un gran número de trabajadores para su funcionamiento. (Mitiga de manera positiva el agravamiento de la crisis)

-Creación de empleos estables: algunos de los empleos generados por el centro comercial, son estables y adecuadamente pagados debido a la potencia del negocio. (Mitiga de manera positiva el agravamiento de la crisis y la pérdida de poder adquisitivo de la población)

-Revitalización económica de zonas: un centro comercial, puede propiciar la revitalización económica y de actividad de una zona en decadencia urbana debido a la creación de empleo y actividad anteriormente mencionada.

Dimensión urbanístico-arquitectónica:

-Creación de un importante nodo de actividad: el centro comercial debido a su potencial en la actividad del comercio, sin lugar a dudas va a resultar ser un elemento atrayente de personas.

-Incentivo para el desarrollo: la actividad económica de un centro comercial, puede acarrear consigo nuevos desarrollos urbanísticos en sus inmediaciones, o ayudar en la revitalización de una área urban determinada. (Propicia de manera positiva la aparición de nuevos modelos urbanos, y la implantación de programas de rehabilitación)

\section{DEBILIDADES:}

Dimensión Medioambiental:

-Alta ocupación de suelo: el centro comercial, como todos los edificios, el centro en su materialización va a anular las capacidades del terreno a efectos de biodiversidad y asimilación de agua, este hecho se agrava cuando la zona edificada del centro comercial ocupa una gran superficie.

-Alto impacto ambiental por emisiones: El centro comercial debido al funcionamiento de sus instalaciones genera emisiones de gases perniciosos. (Agrava de manera negativa el cambio climático)

-Alto impacto ambiental por residuo sólido: Los bienes de consumo vendidos en los centros comerciales, habitualmente vienen acompañados de embalajes y artículos desechables que incrementan los residuos sólidos. (Agrava los problemas de suelo y asimilación de aguas)

-Alto impacto ambiental por consumo de energía: El funcionamiento del centro comercial, supone un alto consumo de energía, pues las condiciones de iluminación y aclimatamiento exigidas precisan del uso a gran escala de sistemas de iluminación y aclimatamiento artificiales. Este impacto se agrava con un planteamiento de proyecto inadecuado a efectos bioclimáticos.

Dimensión Económica: 
-Influencia de las modas: el centro comercial, es una instalación cuyo fundamento es la venta de productos a los clientes, de manera que tiene que resultar atractivo para el personal, tanto en el género disponible, como en su imagen corporativa y arquitectónica. La problemática de esto, es que las cuestiones anteriormente mencionadas vienen muchas veces influenciadas por las tendencias, y generalmente la adaptación a las mismas supone un fuerte desembolso monetario.

-Alto coste económico de fundación y mantenimiento: La obra de materialización un centro comercial es un proceso costoso que requiere una gran inversión monetaria. Además, el coste monetario del funcionamiento del mismo es también muy elevado debido a la gran cantidad de equipos y de personal que el centro comercial requiere para su funcionamiento.

Dimensión Social:

-Agravamiento de conductas adictivas en compradores compulsivos: debido a la gran cantidad de artículos disponible en el centro, junto a su proyección como espacio por y para el consumo de artículos (Gruen Transfer). (Agrava de manera negativa el alto impacto ambiental por residuos sólidos)

-Muchos de los empleos generados son precarios o inestables: El centro comercial, aunque genera mucho empleo, esto tiene como contrapartida, que una gran parte del mismo es temporal, o precario. (Propicia de manera negativa la pérdida de poder adquisitivo de la población, la reducción del tiempo de ocio, el estancamiento poblacional y los problemas políticos en países en crisis, a la vez se niegan o no se propician los empreos estables)

- Casos de inadaptación a personas con movilidad reducida: aunque ahora los centros comerciales están tratando de adaptar los espacios a este tipo de personas, la concepción de muchos de sus espacios todavía resulta dificultosa para las personas con movilidad reducida.

-Fuerte competencia hacia otros modelos de mercado: el centro comercial, debido a su gran volumen de ventas y oferta disponible, tiende a absorber hacia sí mismo una ingente cantidad del mercado disponible. Transformándose los centros comerciales en un fuerte competidor desleal respecto a otras formas de comercio que no disponen de los recursos que tiene el centro.

Dimensión Urbanístico Arquitectónica:

-Agravamiento de problemas de tránsito urbano: El nodo creado a partir del centro comercial, puede derivar en problemas de tráfico debido al incremento de los desplazamientos, sobre todo si el transporte predominante es de tipo particular. (Propicia de manera negativa la congestión de las vías urbanas)

-Proyección de la edificación sin considerar el entorno: El centro comercial es proyectado generalmente siguiendo pautas de pura economía y mercado, esto deriva en edificaciones aisladas y normalizadas que no consideran el entorno.

-Espacios anodinos y agresivos: las formas arquitectónicas utilizadas derivan en espacios que no difieren entre los centros, en los cuales se potencian ciertas actividades a través de las 
formas y la estética. (Propicia de manera negativa el agravamiento de conductas adictivas en compradores compulsivos)

-Idea de zonificación: El centro comercial, si se proyecta en superficie va a suponer el uso de una gran cantidad de espacio urbano para una sola función. (Retrasa de manera negativa la aparición de nuevos modelos urbanos)

\subsection{2.- Factores externos.}

Para el análisis de los factores externos, va a resultar ser necesaria la consideración de los diversos factores de cambio que pudieran afectar de manera directa o indirecta. El establecimiento de estos factores de cambio, se realizó por fuentes propias, recopilando diversas facetas de actualidad, o mediante la realización de una síntesis de la problemática anteriormente mencionada. Se escogerán exclusivamente los factores que pudieran tener un impacto medio o alto sobre el negocio de los centros comerciales.

De este modo, los factores de cambio serán considerados respecto a los tres pilares de la sostenibilidad, mas el ámbito urbanismo, no considerando el ámbito del proyecto o la arquitectura intrínseca del centro, ya que no es de interés para la presente tesis. De este modo se establecieron estos factores de cambio:

Dimensión social:

Problemas políticos en países en crisis: La actual crisis económica en muchos países del mundo ha llevado a la desacreditación total o parcial de las actuales formas políticas ligadas a las democracias liberales. Contra tendencia: Recuperación de la credibilidad política.

Estancamiento y decrecimiento poblacional: En amplias regiones del mundo se está produciendo un envejecimiento de la población debido a las bajas tasas de natalidad, hecho que sin duda se ha agravado con la crisis económica. Contra tendencia: Incremento del número de nacimientos, propiciado por el final de la crisis.

Reducción del tiempo de ocio: La radicalización de la sociedad competitiva a nivel global, puede acarrear consigo el encarecimiento de las condiciones laborables en el sentido del alargamiento de la jornada laboral. Contra tendencia: Estancamiento de la jornada laboral en número de horas, o reducción de la misma.

Estabilización política en países económicamente emergentes: La estabilización económica de los países en vías de desarrollo, frente a su apertura al mercado global, ha propiciado la aparición de formas de gobierno estables. Contra tendencia: Perpetuación de la inestabilidad política y los conflictos en los países en desarrollo. 
Precarización del mercado laboral: La Crisis ha propiciado una severa precarización de las condiciones laborables en los países más afectados por la misma, esto se ha visto agravado por el alto índice de desempleo. Contra tendencia: mejora de las condiciones laborales.

Dimensión económica:

Agravamiento de la crisis y la deuda: La actual crisis económica basada en la economía especulativa ha acarreado consigo el colapso de las economías de bastantes países, los cuales ven inviable su recuperación a corto o medio plazo. Contra tendencia: Recuperación económica de los países afectados por la crisis.

Pérdida de poder adquisitivo: El encarecimiento de las condiciones laborales en los países afectados por la crisis, y el aumento del desempleo, ha acarreado consigo un descenso del poder adquisitivo de la población media, siendo un agravante de este hecho la inflación. Contra tendencia: Mejora de las condiciones laborales a efectos de salarios.

Negación de crédito: La crisis económica ha supuesto el endeudamiento de una gran cantidad de organismos de gestión monetaria tanto públicos como privados, los cuales para hacer frente a este endeudamiento, han optado por la negación del crédito monetario. Contra tendencia: Reactivación del crédito monetario.

Cambio en los hábitos de consumo: La aparición y difusión de nuevos modelos de comercio en zonas ajenas al centro comercial, va a suponer siempre la alteración o el desplazamiento de los nichos de mercado fuera de lo que es el negocio del centro. Hecho que se ve agravado por los cambios en las preferencias de los compradores. Contra tendencia: Perpetuación de la hegemonía del centro comercial en la actividad de venta de artículos.

Incremento de la oferta de centros comerciales: Los nichos de mercado de gran potencial siempre van a atraer a una gran cantidad de empresas dispuestas a sacar beneficios del mismo. De acuerdo a la ley de la oferta y la demanda, el incremento de la oferta, puede derivar en una caída de los precios, además de una fuerte competencia, que sin duda se va a traducir en pérdida de beneficios para el centro comercial. Contra tendencia: Regulación de la competencia, o estabilización de la oferta de centros comerciales.

Aparición de países económicamente emergentes: Algunos países del mundo, están consolidando su presencia económica en el panorama mundial, estableciéndose como potencias económicas de mayor o menor orden. Contra tendencia: Expansión de la crisis a los países emergentes, o recesión económica en los mismos.

Dimensión medioambiental:

Cambio climático: Actual cambio climático producido por el efecto invernadero entre otros factores. Contra tendencia: Mitigación del cambio climático por la estabilización de los gases de efecto invernadero.

Aparición de tecnologías más eficientes: El progreso científico y tecnológico trae consigo una mejora en la eficacia de los aparatos tecnológicos a efectos de consumo de energía y requerimientos. Contra tendencia: Estancamiento del desarrollo debido a la crisis. 
Implantación de energías renovables: En el panorama de la energía, se van implantando formas de transformación de la misma para consumo, que no requieren de recursos agotables. Contra tendencia: fin de las políticas de incentivación de energías renovables.

Difusión de programas de rehabilitación de centros comerciales: Este factor de cambio hace referencia a la inserción de programas de rehabilitación o reestructuración, centrados en la corrección de las obsolescencias y deficiencias en los edificios de los centros comerciales. Estos programas bien pueden venir de fuentes públicas o privadas. Contra tendencia: Desinterés en la rehabilitación de los edificios de los centros comerciales, bien por éxito, o bien por abandono.

Consideración de la rehabilitación de los centros comerciales como un caso ejemplar: El edificio de un centro comercial al ser un elemento con una enorme presencia en la ciudad, la rehabilitación del mismo, puede ser concebida como un caso ejemplar de cara a una muestra de rehabilitación urbana. Contra tendencia: Desinterés en la rehabilitación de los edificios comerciales.

Incremento radical del número de vehículos: Este factor de cambio está ligado al incremento desmesurado del uso del vehículo particular y su uso preponderante frente a otras formas de transporte. Contra tendencia: aparición de nuevas formas de transporte como sustitutivo del vehículo particular.

Dimensión Urbanística y arquitectónica:

Congestión de vías urbanas: la generalización del vehículo particular en las ciudades de gran población, ha conllevado consigo la congestión de las vías debido a la ocupación de las mismas por parte de los vehículos. Contra tendencia: Solución de los problemas de tráfico, mediante la inserción de otros métodos de transporte.

Aparición de nuevos modelos urbanos: La problemática actual de las ciudades, ha motivado a los organismos y entes implicados en el proceso del diseño urbano, a optar por modelos de ciudades que resulten más benignos para los habitantes. Contra tendencia: Perpetuación de los modelos existentes como metodología de planificación de ciudades.

El siguiente paso es establecer las matrices relacionados con el impacto y la certidumbre, estableciéndose de esta manera los factores a considerar a corto, medio o largo plazo. EI recuadro rojo indica los factores de se deben de considera de cara a la planificación prospectiva (medio y largo plazo), los factores de bajo impacto, pero no de baja certidumbre para el presente trabajo quedan excluidos. (Figura 3.7.1) El factor de nivel de certidumbre, refleja la mayor o menor certeza, en la cual los factores de cambio enunciados anteriormente pueden ocurrir. Cuánto más alto es el nivel de certidumbre, mayor es la posibilidad de que el factor de cambio se manifieste. El impacto a lo que hace referencia es a la capacidad de cambio del factor sobre el ámbito analizado. 


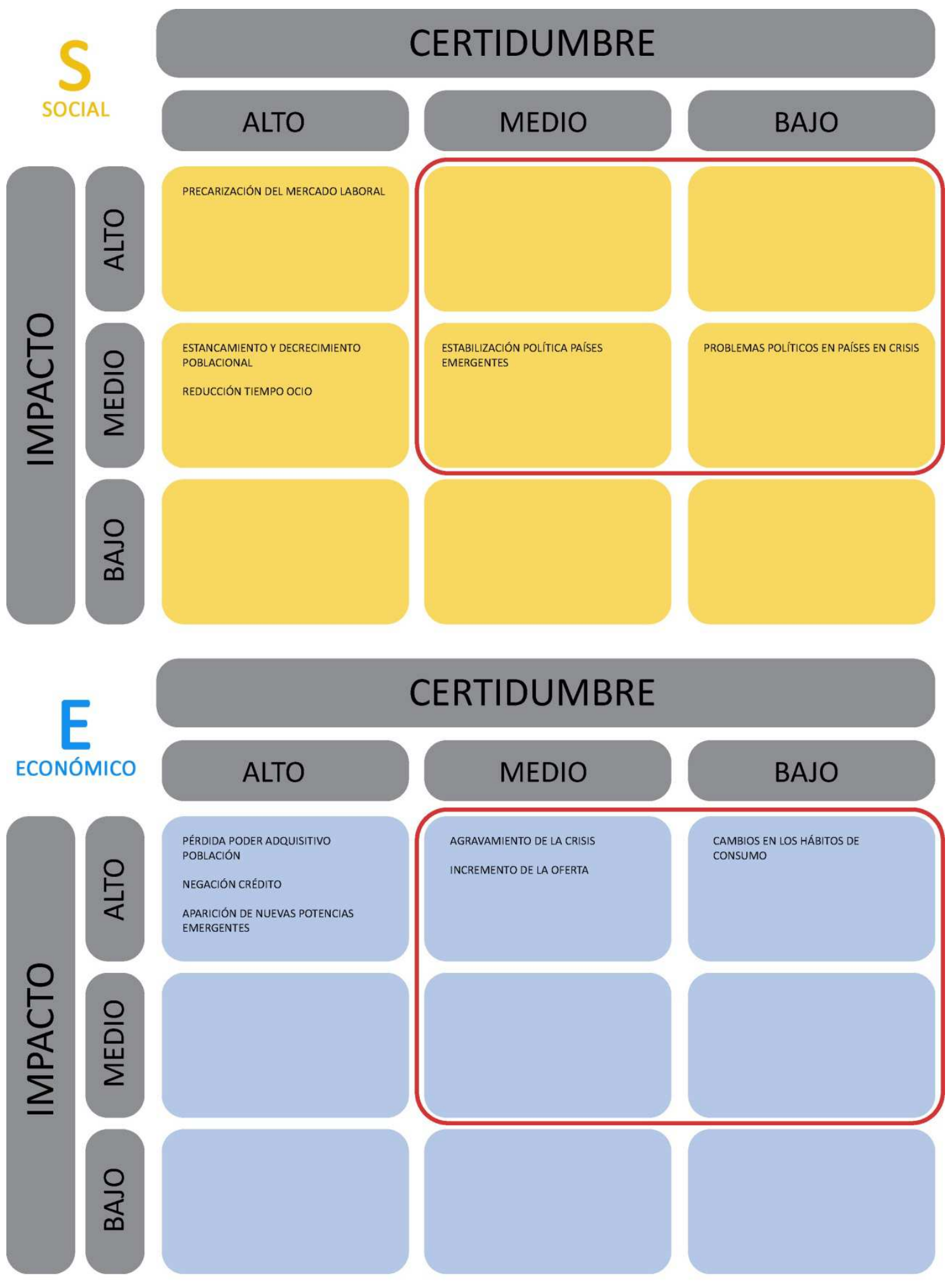




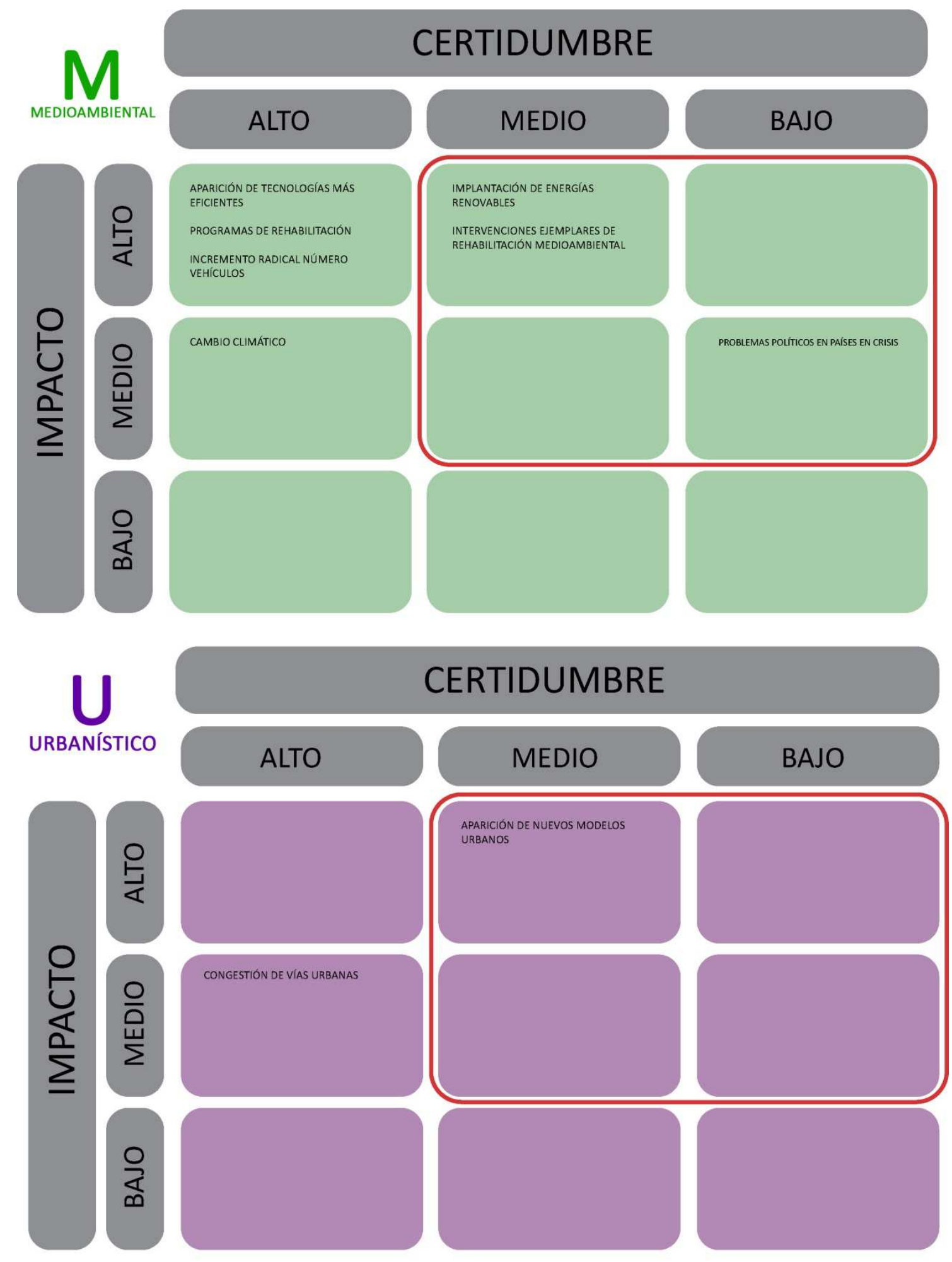

Figura 3.7.1: Matriz certidumbre-impacto de los factores de cambio. Fuente: Elaboración propia

De este modo, una vez enunciados los factores de cambio respecto a la actividad de los centros comerciales, estos van a ser considerados de la siguiente manera, en base a su 
impacto positivo o negativo: De este modo tenemos la siguiente clasificación, enunciada por José Miguel Fernández Güell:

-Amenaza: Factor externo de cambio que en el caso de establecerse, va a acarrear consigo efectos negativos.

-Oportunidad: Factor externo de cambio que en el caso de establecerse, va a acarrear consigo efectos positivos.

De este modo, la clasificación de los factores de cambio como amenazas y oportunidades es la siguiente, de acuerdo al criterio del autor:

Amenazas sociales:

-Problemas políticos en países en crisis. (Afecta la estabilización de países emergentes y propicia el estancamiento poblacional)

-Estancamiento y decrecimiento poblacional.

-Reducción del tiempo de ocio.

Oportunidades sociales:

-Estabilización política de países emergentes.

Amenazas económicas:

-Agravamiento de la crisis. (Destruye empleos estables, detiene la revitalización económica de zonas urbanas, propicia los empreos precarios e inestables y la pérdida de poder adquisitivo de la población).

-Pérdida poder adquisitivo. (Propicia con efectos negativos el agravamiento de la crisis)

-Negación crédito. (Agudiza negativamente el agravamiento de la crisis y detiene los programas de rehabilitación)

-Cambio en los hábitos de consumo.

-Incremento de la oferta. (Propicia el cambio en los hábitos de consumo)

Oportunidades económicas:

-Aparición países emergentes.

Amenazas medioambientales:

-Cambio climático. (Agudiza alto impacto ambiental por emisiones y consumos de energía) -Incremento radical del número de vehículos. (Agrava cambio climático) 
Oportunidades medioambientales:

-Aparición de tecnologías más eficientes. (Mitiga cambio climático y mejora la implantación de energías renovables)

-Implantación de energías renovables. (Reduce el alto impacto ambiental por emisiones y consumos de energía)

-Programas de rehabilitación. (Incluyen programas de implantación de energías renovables, solucionan los problemas de inadaptación a personas con mobilidad reducida y favorecen la viabilidad en la implantación de transporte colectivo)

-Pueden ser casos ejemplares para la rehabilitación medioambiental. (Facilita la viabilidad de programas de rehabilitación)

Amenazas Urbanísticas:

-Congestión de las vías urbanas. (Agrava de forma negativa los problemas medioambientales por emisiones)

Oportunidades urbaníticas:

-Aparición de nuevos modelos urbanos. (Propicia la aparición de programas y casos ejempleres de rehabilitación medioambiental)

y una vez establecidos, estos factores de cambio son ubicados en el esquema DAFO, considerando las diferentes relaciones entre ellos. Figura (3.7.2) 


\section{SOCIAL}

AGRAVAMIENTO DE CONDUCTAS ADICTIVAS EN COMPRADORES COMPULSIVOS

EMPLEOS PRECARIOS O INESTABLES

CASOS DE INADAPTACIÓN A PERSONAS DE MOVILIDAD REDUCIDA

COMPETENCIA FUERTE HACIA OTROS MODELOS DE COMERCIO

CREACIÓN DE GRAN CANTIDAD DE PUESTOS DE TRABAJO

EMPLEOS ESTABLES

REVITALIZACIÓN ECONÓMICA DE ZONAS URBANAS
PROBLEMAS POLITICOS EN PAÍSES EN CRISIS

ESTANCAMIENTO Y DECRECIMIENTO POBLACIONAL (*)

REDUCCIÓN TIEMPO OCIO (*)

PRECARIZACIÓN DEL MERCADO LABORAL (*)

ESTABILIZACIÓN POLÍTICA PAÍSES EMERGENTES

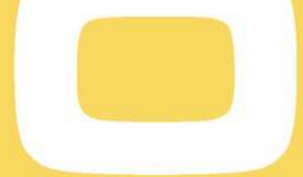

\section{ECONÓMICO}

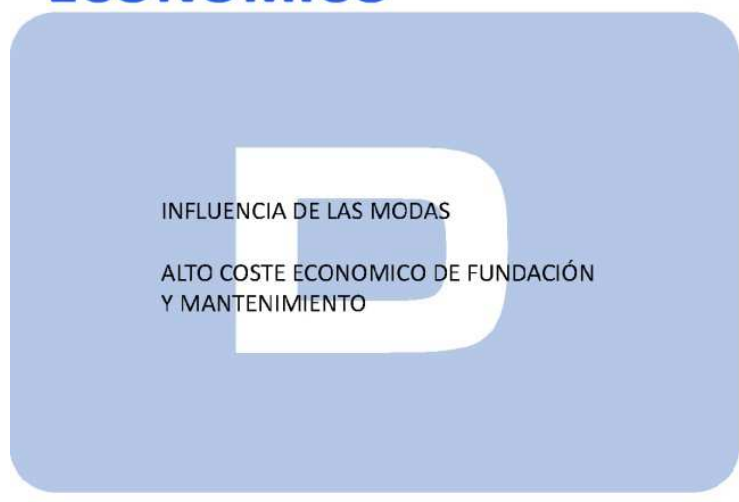

AGRAVAMIENTO DE LA CRISIS

CAMBIO HABITOS CONSUMO

PERDIDA PODER ADQUISITIVO POBLACIÓN (*)

NEGACIÓN CREDITO (*)

INCREMENTO DE LA OFERTA $\left({ }^{*}\right)$

GRAN MOVIMIENTO DE CAPITALES

GRAN OFERTA DE PRODUCTOS A LA VENTA

APARICIÓN DE NUEVAS POTENCIAS EMERGENTES (*) 


\section{MEDIOAMBIENTAL}

ALTO CONSUMO DE SUELO Y PROBLEMAS

DE ASIMILACIÓN DE AGUA

ALTO IMPACTO AMBIENTAL POR EMISIONES

ALTO IMPACTO AMBIENTAL POR RESIDUO SÓLIDO

ALTO IMPACTO AMBIENTAL POR CONSUMO DE ENERGÍA

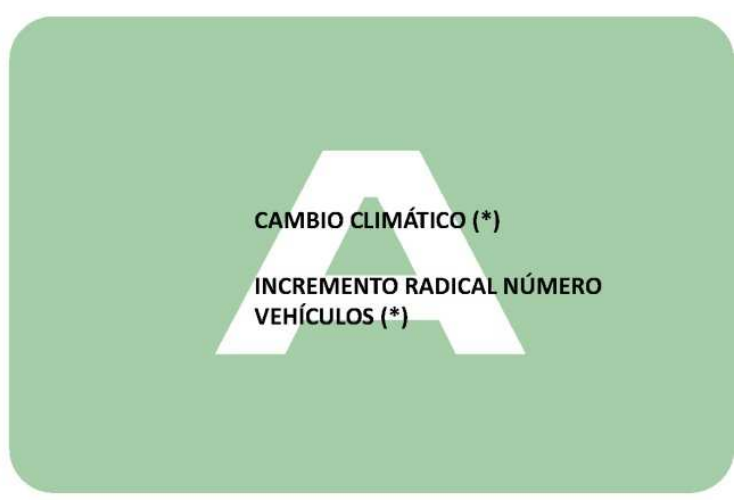

VIABILIDAD PARA LA IMPLANTACIÓN DE LÍNEAS DE TRANSPORTE COLECTIVO

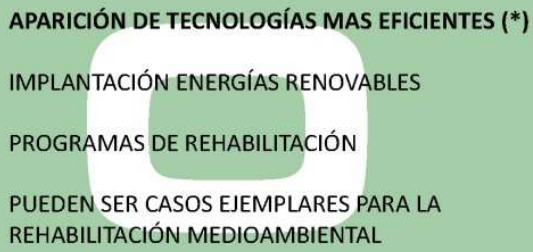

\section{URBANÍSTICO}

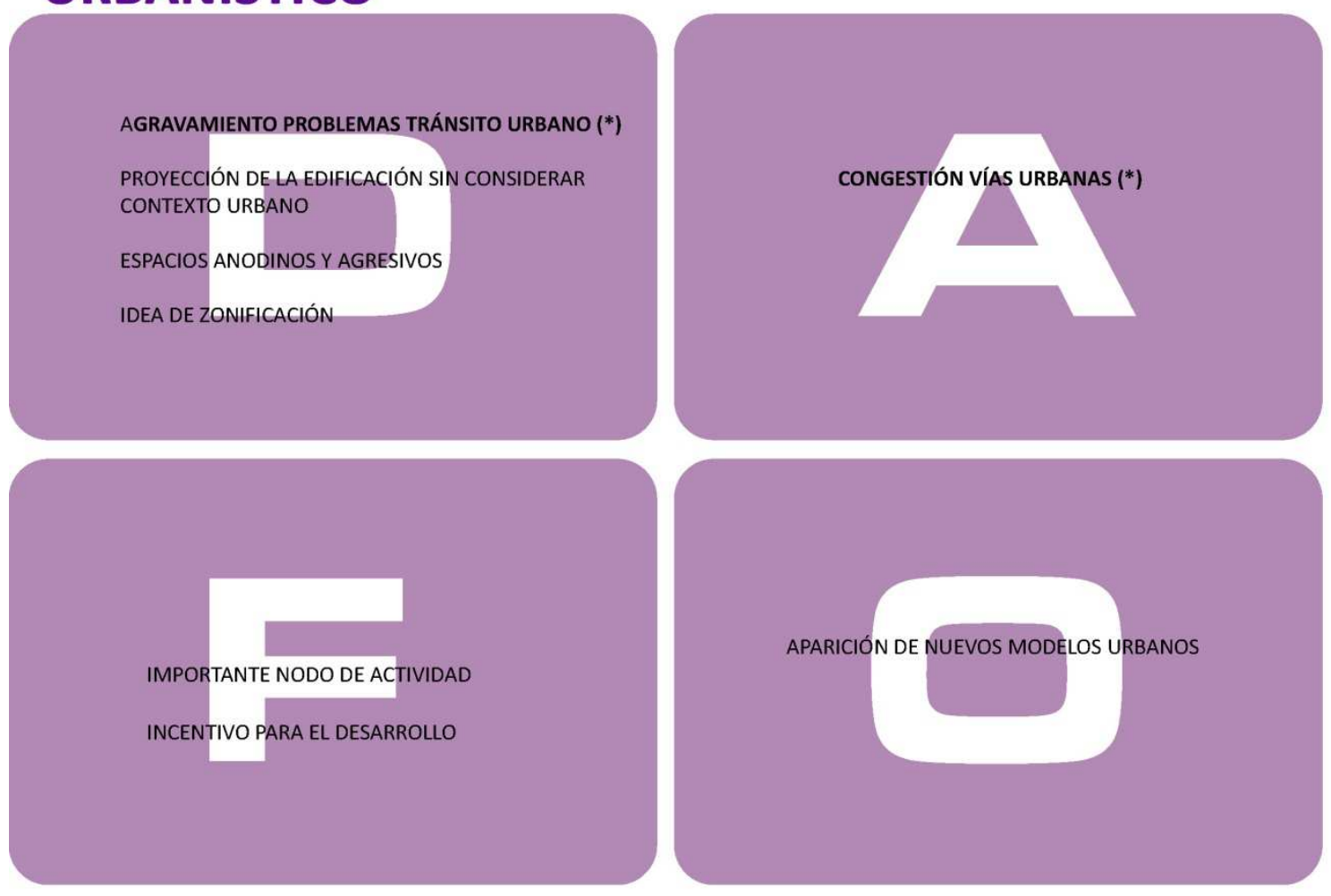

Figura 3.7.2: Análisis DAFO, IMPORTANTE: los factores a considerar a corto plazo vienen marcados en negrita y con un asterisco. Fuente: Elaboración propia. 
Por consiguiente, una vez considerados estos factores de cambio, y comprendidos como base de las acciones a tomar, el siguiente paso va a ser la consideración de los métodos de rehabilitación que pudieran ser de aplicación para lo que son los centros comerciales.

\section{8.- ESTADO DEL ARTE EN LOS MÉTOdOS E IDEAS DE REHABILITACIÓN DE CENTROS COMERCIALES.}

Una vez estudiadas las debilidades y las fortalezas de los centros comerciales, se procederá a la realización de un estudio relacionado con las ideas de rehabilitación que han sido de aplicación para el caso de los centros comerciales. Estas ideas proyectuales van a referirse siempre a lo que es la propiedad del centro comercial en sí, considerando cual pudiera ser de aplicación respecto de la curva de ciclo de vida de un centro comercial, ya que las operaciones de rehabilitación generalmente se aplican para prolongar una de sus fases, o para insertar el centro en otra diferente emergente.

De este modo, se va a realizar un recorrido de las ideas e intenciones que fundamentan las operaciones de rehabilitación presentes aplicadas sobre centros comerciales de manera genérica, este es el primer paso en el desarrollo de la metodología analítica. Por consiguiente para la presente tesis, se hace necesario explicar estas operaciones, con sus intenciones fundamentadas, (sin llegar en ningún momento al proyecto). El marco en este análisis, van a ser los pilares de la sostenibilidad. (Economía, Medio ambiente, Sociedad) considerándose al mismo nivel los ámbitos del urbanismo y la arquitectura. Por otra parte, las operaciones de rehabilitación van a localizarse dentro de la curva del ciclo de vida del centro comercial, e fundamento, es ver para que fase de la actividad comercial está enfocada la misma.

\subsection{1.- Rehabilitación ecológica o ecoeficiente.}

Este idea de rehabilitación consiste básicamente en acometer obras sobre el centro comercial, para hacerlo más benigno de acuerdo a temas de ecología (Menor consumo de energía y agua, generación de energía limpia, mayor eficiencia energética, capacidades ambientales que propicien la regeneración del suelo y la salubridad del aire...). El propósito que guía a tomar la decisión de este modelo de rehabilitación, aunque generalmente es el de acometer mejoras medioambientales; éste también puede tener cierto fundamento social, al presentar a la sociedad un caso ejemplar de comercio sostenible, e incluso un fundamento económico, ya que este respeto por el medio ambiente puede otorgar al centro comercial en sí un valor añadido en ciertos modelos sociales. Este modelo de rehabilitación para centros comerciales va a ser considerado para la presente tesis, ya que su comprensión resulta ser de mucha importancia para el enfoque medioambiental de la misma. Esta idea puede ser considerada como rehabilitación, ya que su finalidad implica reponer de manera parcial las condiciones naturales en el entorno, antes de la materialización del centro. (La reposición total de las condiciones naturales en la parcela del centro es posible, pero requiere de la demolición del centro, y es un proceso muy lento y costoso). 
La rehabilitación ecológica o ecoeficiente, generalmente se aplica sobre centros comerciales que generan beneficios, debido a que las obras asociadas suelen ser relativamente costosas, y no generan lucro directo para el centro comercial.

A continuación se muestran las fases del ciclo de vida en la que se considera la rehabilitación medioambiental, junto a la idea respecto de los cuatro pilares de análisis de la presente tesis doctoral. (Figura 3.8.1)
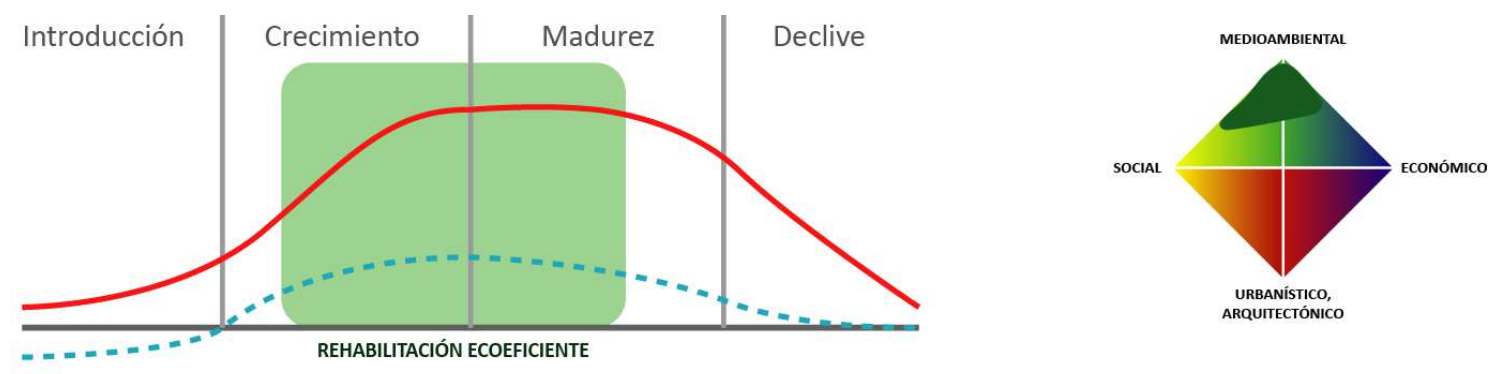

Fuente: Fernandez Guell, Elaboracion Propia

Figura 3.8.1.- Rehabilitación ecoeficiente, ubicación en curva de ciclo de vida, y enfoque respecto a los tres pilares de la sostenibilidad y el urbanismo. (Elaboración Propia)

Para la presente tesis doctoral, se considerarán como ejercicios de rehabilitación ecológica o ecoeficiente los siguientes:

-La inserción de dispositivos centrados en la generación de energía, utilizando fuentes renovables o no contaminantes, independientemente de la tipología de los mismos.

-La readaptación de los cerramientos, los huecos, la iluminación y las instalaciones, buscando en todo momento el ahorro energético.

-La inserción tanto sobre el edificio del centro comercial como en la parcela del mismo, de elementos verdes o asimiladores de dióxido de carbono y fijación de partículas nocivas, independientemente de su tipología.

Ejemplo de centros comerciales que han sufrido este tipo de rehabilitación son La Vaguada, Shopping Eldorado o Parquesur.

\subsection{2.- Rehabilitación para reinauguración comercial, o adaptación al mercado imperante.}

Esta idea de rehabilitación para centros comerciales, basa sus fundamentos en temas meramente económicos, fundamentando cada operación de rehabilitación sobre el centro comercial en la adaptación del mismo a las exigencias del mercado, o la búsqueda de una diferenciación que pudiera otorgar al centro un valor añadido, todo ello a través de la construcción. Esto puede ser considerado como rehabilitación, ya que el fin es recobrar el potencial económico del centro antes de la caída de sus ingresos.

Como operaciones dentro del proceso de rehabilitación, pueden incluirse la reconversión de los locales, la ampliación del centro comercial, la reforma del interior o el exterior del mismo 
para dar una nueva imagen, o la adición de usos complementarios ajenos al comercio, con tal de ampliar a lo que es la oferta comercial del centro. No obstante, la pauta directora en esta idea de rehabilitación, es que cada obra tenida en cuenta siempre debe de buscar la aportación de beneficios económicos bien sea a corto, largo o medio plazo de acuerdo a las exigencias de cada caso. Estas operaciones de rehabilitación, las acomete generalmente la dirección del centro, cuando este llega a la fase de madurez muy avanzada e incluso declive dentro de la curva del ciclo de vida, siendo esto generalmente consecuencia de la fuerte competencia, la cual a en este contexto generalmente es muy elevada. De manera coyuntural, un centro puede realizar una reforma encaminada en la adaptación al mercado, durante la fase de crecimiento tardía o madurez temprana, esto se da generalmente en contextos en los que las tendencias de mercado cambian rápidamente.

Este modelo de rehabilitación, aunque su aplicación resulta ser muy efectiva para muchos casos de centros comerciales en estado de declive, y la viabilidad económica es uno de los pilares de la sostenibilidad, para la presente tesis no va a ser considerado, ya que muchas veces necesita estar enfocado desde el punto de vista del proyecto, al ser requisito indispensable la realización de estudios muy concretos sobre el mercado presente en la zona del centro comercial.

Por otra parte, para la elaboración de una metodología eficiente de rehabilitación de centros comerciales, enfocando las pautas de actuación y el dimensionado de las mismas de acuerdo a la actividad económica, se requiere de un conocimiento exhaustivo del mercado que rige este tipo de actividades económicas, careciendo el autor de la presente tesis de dicho conocimiento. No obstante, la creación de una metodología de rehabilitación económica de centros comerciales de gran tamaño en declive, es sin duda un tema de tesis de gran interés y útil aplicación, tanto para los contextos económicos de declive en la actividad de los centros comerciales, como para los contextos económicos en los que la actividad de los centros comerciales es un mercado emergente. No obstante, en el tema de del estado actual de los centros comerciales, ya se enunció la problemática económica de los mismos.

A continuación se muestran las fases del ciclo de vida en la que se considera la rehabilitación económica, junto a la idea respecto de los cuatro pilares de análisis de la presente tesis doctoral. (Figura 3.8.2)
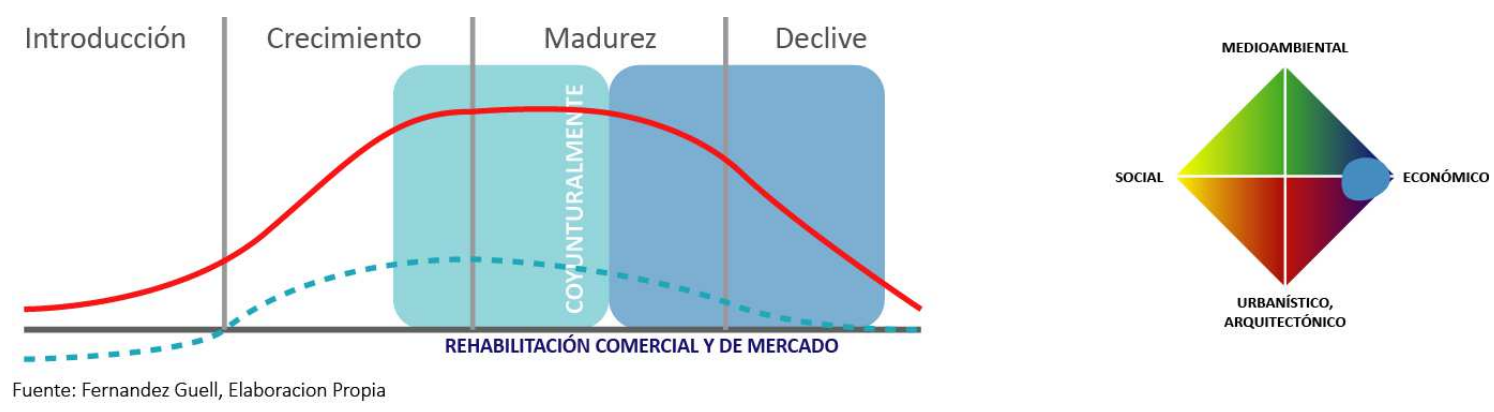

Figura 3.8.2.- Rehabilitación económica, ubicación en curva de ciclo de vida, y enfoque respecto a los tres pilares de la sostenibilidad y el urbanismo. Fuente: Elaboración Propia

De este modo, se considerarán como ejercicios de rehabilitación económica para un centro comercial los siguientes ejercicios: 
-Reestructuración de la superficie alquilable, ya sea por adición, reducción o redistribución de locales dentro del centro comercial.

-Readaptación de la imagen comercial del centro, mediante reformas en la decoración o imagen arquitectónica tanto en el exterior como en el interior.

-Reestructuración de la distribución interior del centro, insertando galerías o modificando las ya existentes.

-Inserción de usos lucrativos, complementarios a la actividad comercial (puestos, mercados parques de atracciones...) dentro del centro, ya sea mediante la redistribución del espacio, la ampliación del centro o la inserción de los mismos en galerías o locales ya existentes o de nueva construcción.

Muchos centros comerciales han considerado este tipo de rehabilitación con fines económicos, siendo de lejos la más recurrente a la hora de rehabilitar un centro coemrcial. Algunos Ejemplos son ABC Serrano, Parquesur, Mall of America o Planetocio.

\subsection{3.- Reforma dotacional o cambio de uso.}

Cuando un centro cesa completamente su actividad comercial debido a la falta de beneficios, o se encuentra próximo a su cierre. Este puede transformarse a efectos de uso. Esta idea de rehabilitación aplicada sobre centros comerciales consiste básicamente en un cambio de los usos que el edificio comercial pudiera albergar en su interior. Estos usos, normalmente son diferentes al uso comercial que el centro albergaba antes de su cese, y estos pueden tener 0 no fines lucrativos. Esta operación de rehabilitación se acomete sobre centros comerciales en estado de abandono, o de manera parcial sobre zonas dentro del propio centro, cuya actividad comercial ha cesado, buscando que la inserción del uso dotacional pueda otorgar a su vez un valor añadido al centro comercial. Esta rehabilitación puede tener repercusiones en los tres ámbitos de la sostenibilidad, y su estudio va a ser considerado para la presente tesis doctoral, ya que sus repercusiones son muy influyentes en el tema de la rehabilitación urbanística desde el punto de la sostenibilidad.

A continuación se muestran las fases del ciclo de vida en la que se considera la rehabilitación dotacional, junto a la idea principal respecto de los cuatro pilares de análisis de la presente tesis doctoral. (Figura 3.8.3)

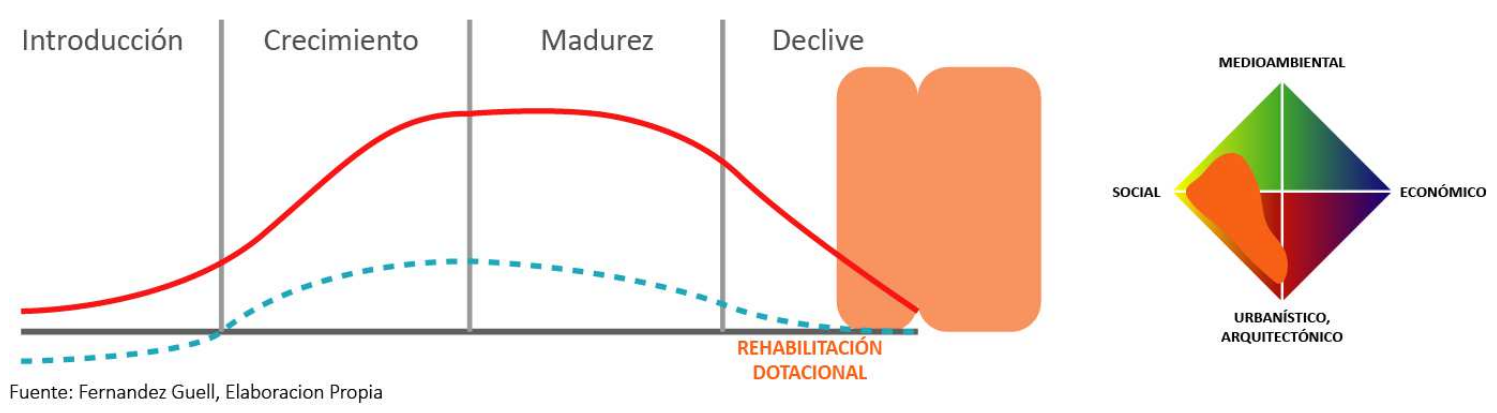


Figura 3.8.3.- Cambio de uso, ubicación en curva de ciclo de vida, y enfoque respecto a los tres pilares de la sostenibilidad y el urbanismo. Fuente: Elaboración Propia.

Para la presente tesis doctoral, van a considerarse como ejercicios de reforma dotacional:

-El cambio de uso de los espacios del centro de manera total o parcial, hacia usos ajenos al comercio que pudieran ser lucrativos (oficinas, fábricas...), alterando principalmente la estructura interior del centro comercial, modificando mínimamente lo que es la configuración volumétrica del edificio.

-El cambio de uso del centro comercial hacia un uso dotacional o no lucrativo, de manera total o parcial, alterándose la estructura interior, modificando mínimamente lo que es la configuración volumétrica del edificio.

Ejemplo de centro comercial rehabilitado para el cambio de uso, sin alterar apenas la forma es Crestwood Court Mall en San Luis, Misouri.

\subsection{4.- Modificación o reestructuración del edificio del centro comercial para otros usos.}

Esta operación de reestructuración del centro construido de forma total o parcial, para la adaptación del mismo a otros usos, o la inclusión de otros nuevos dentro del mismo. Esta rehabilitación puede acometerse tanto desde la escala urbana, a partir de la ejecución de un plan parcial a escala de ciudad o a escala de parcela. En la que está incluida la modificación de la parcela del centro comercial y su estructura urbana, bien para la división de la misma en otras de menor tamaño, o a apertura de nuevas vías de comunicación a través de la misma. Este tipo de reforma aplicada a los centros comerciales, normalmente viene motivada por un cambio radical en lo que es el centro comercial en sí y su estructura, hacia otro tipo de forma urbana, y una operación de cambio de cambio en la parcela del centro comercial, normalmente trae consigo unas modificaciones muy severas en lo que es el edificio del centro comercial.

Por otra parte el edificio de un centro comercial también puede ser alterado en su volumen edificado, para la adaptación del edificio a nuevos usos complementarios. Este modelo de rehabilitación, que normalmente viene precedido por un plan parcial u otra iniciativa urbanística similar, consiste en la modificación del volumen edificado del centro comercial a través de la agregación, recolocación o sustracción de volumen edificado de acuerdo a los criterios del proyecto concreto para el centro a ser rehabilitado, considerando unos u otros usos para las nuevas edificaciones.

La modificación de la edificación de los centros comerciales es una práctica muy recurrida por el movimiento del New Urbanism, y su fundamento de acción se basa en eliminar los problemas derivados de la falta de complejidad y vida urbana en los centros comerciales de gran tamaño, transformando estos en zonas con características tipológicas y funcionales más acordes con los centros urbanos de las ciudades consolidadas, a través de la disposición de nuevas edificaciones. (Figura 3.8.4) 


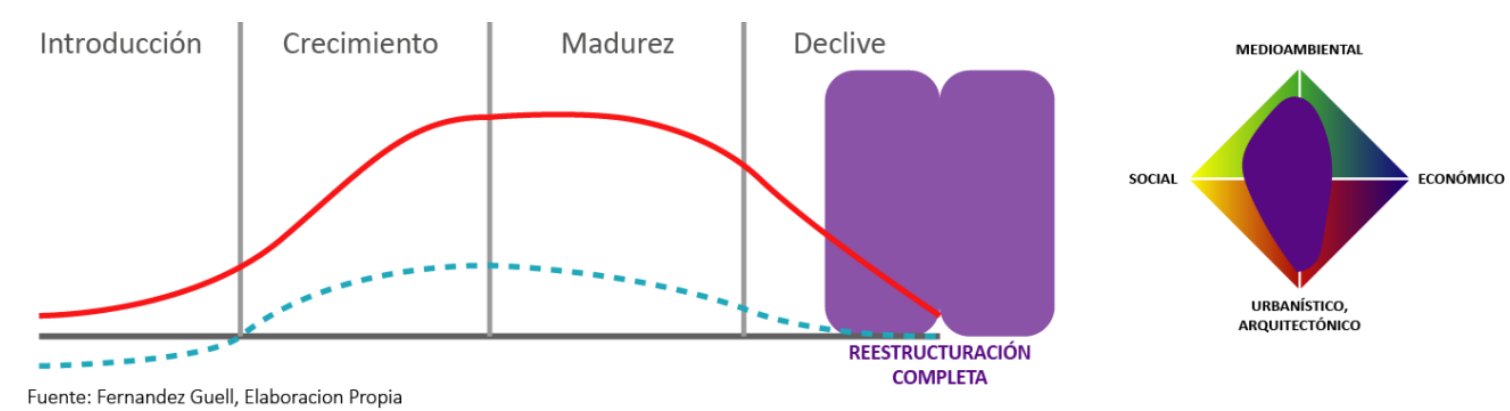

Figura 3.8.4.- Inserción de usos, ubicación en curva de ciclo de vida, y enfoque respecto a los tres pilares de la sostenibilidad y el urbanismo. Fuente: Elaboración Propia

Para la presente tesis doctoral van a considerarse como operaciones de modificación o reestructuración del centro comercial para otros usos:

-La sustitución parcial o completa de los edificios o alas del centro comercial, para la construcción de otros edificios nuevos, o la restitución de los mismos.

-La creación y ejecución de un nuevo plan parcial urbano para la parcela del centro.

-La inserción de calles, plazas o avenidas en la parcela del centro comercial, que fueran de uso público.

-La inserción de usos ajenos al comercio, o ligados al mismo a través de la materialización de nuevas edificaciones, las cuales pueden estar sobre el edificio del centro comercial, anejas, o sustituyendo los edificios del propio centro.

De este modo, una vez mencionadas las diferentes maniobras de rehabilitación de centros comerciales, junto con sus respectivas ideas, se podrá proceder a estudiar más a fondo el tema de la rehabilitación de centros comerciales, que es el tema principal de la presente tesis, estableciendo en primer lugar, que tipos de ámbitos pueden ser considerados para la rehabilitación de centros comerciales.

No obstante, estas metodologías de rehabilitación han sido enunciadas en este capítulo de una manera bastante genérica a modo de estado del arte. Por consiguiente, las que serán establecidas para la metodología, van a estar referenciadas a lo que son los ámbitos que nos interesan para esta tesis. Acotando aún más el ámbito de estudio mediante la selección y el descarte de los ámbitos de estudio, fijando ya el campo definitivo en el que va a estar encuadrada la metodología de estudio de la presente tesis doctoral.

Un ejemplo de centro comercial reestructurado urbanísticamente, es Belmar.

\section{9.- STATE OF THE ART, A RESUMED VIEW.}

In the first chapter of this unit, the origins of the shopping mall were analyzed in the history. Is thought Trajan Market, built in 2nd century, to be the first proto shopping mall in the history, as being a complex of stores with galleries and management company. Another historical examples of proto shopping malls are Minor Asia bazaars of the Middle age, such as the one in 
Teheran or Istanbul. Being the evolution of this typology the galleries and covered markets of 18th century, such as Gostiny Dvor or Oxford Covered Market.

During the 19th century and the first years of 20th, the usage of the metallic materials and glass to make roofs, as well as the intention of doing a representative space for buying goods with presence in the city, consolidated the first ideas of the shopping mall. Two cases of relevance are the Vittorio Emmanuelle Gallery in Milan, or the Cleveland Arcade in Cleveland which was even conceived as a completely enclosed space protected from climate harnesses.

At the same time, the suburban city were developing, and this supposed the displacement of the large commercial buildings to the new suburban outskirts of the city. This ended in the opening of new commercial complexes composing from rows of stores, which included parking plots and private plazas within. (Country Club Plaza and Highland park).

The most relevant step done in history, and the one which supposed the beginning of the modern shopping mall as conceived nowadays, was the massive sprawling process happening during the second half of the 20th century, and the location of the department stores owners in these new areas appearing by this way the Big Box Retailers. In this background, the Viennese architect Victor Gruen, with the idea of centralizing all the uses of a city in a building in order to avoid unnecessary displacements, conceived the first modern enclosed suburban shopping mall in history (Southdale in Edina, MN).

After of opening of Southdale, the suburban shopping malls resulted to be successful, and shopping investors considered the investment in this new building typology abroad the whole world. However the social uses were removed from the mall program as well as the buildings were built bigger and bigger, to catch more market gap as possible. the result of this process are the so called Super Regional Malls (West Edmonton Mall, Mall of America...).

However, nowadays the typology of the shopping mall is in crisis, especially in the places where the market of the shopping mall is overexploited (North America and Europe). This have supposed mall owners to invest in other regions of the world, especially in the developing countries of Asia, supposing this the enclosure of a lot of shopping malls due to the lack of business.

This have lead into some architecture and urbanism currents to consider the retrofitting of the dead malls, turning them into complex urban areas, these current use to consider the ideas of sustainability in their projects.

The process of project of a shopping mall considers as basic step, a wide and deep analysis of the features of the urban area the shopping mall is thought for, as well as the features of the economy of the area related to shopping activity. In this analysis becomes important the usage of the existent infrastructure, the location in a representative/strategic point in the city, as well as the offering of all sorts of services and a powerful image of the shopping mall to catch customers.

The result of this project process is the creation of a building aimed entirely to commercial activity. This building is going to have their respective impacts towards sustainability, as well as 
others in the city where located. The problems attaining the shopping malls are explained in the next paragraphs.

Related to the pillar of environmental sustainability, a shopping mall is going to suppose some severe impacts. At first, the massive usage of large surfaces in plan to materialize the shopping mall is going to suppose the removal of the natural capabilities to regenerate water, as well as soil properties. In addition, if the transportation of the urban surroundings is based on private means, the interaction the mall is going to generate can result in heavy traffic that will carry on a harsh environmental impact on air quality and biodiversity.

Related to the pillar of sustainable economy, the author of the current thesis lacks of the knowledge to make a deep analysis into it. From the analysis done, can be stated, that is important to consider a shopping mall can displace the economical activity. Is even more important related to economy of shopping malls to consider they can be an inefficient activity, if not located correctly or being the activity in the last steps their economical life cycle. This means the economical revitalization is important for any shopping mall retrofitting.

Related to the pillar of sustainability and society, as said before, a shopping mall can produce a drastic change in the urban structure with their subsequent impact in society. To make an appointment, some shopping malls are conceived to be the substitute of the public squares in some urban areas. This results to be unreliable, as shopping malls are conceived as enclosed spaces with private ownership. Other problem related to society, is the impact the shopping mall image has on certain kinds of people with psychological disorders towards the acquisition of goods.

Related to urbanism: at first, the shopping mall activity, can translate into problems related to traffic and urban mobility if located in an area where uses are zoned, and the predominant mean of transportation is private vehicle. In addition a large surface is used for a single use. being also this activity, the reason because a displacement of commercial activity can happen. However, this displacement can be used to revitalize urban areas.

Related to architecture, both the outer and inner space of a shopping mall can be considered as a no place, as being almost the same in image and configuration in all climates and countries of the world. This is headed by the ideas of the Gruen Transfer. To solve this idea of no place, shopping malls owners consider the artificial creation of a both fictional and attractive place (Jerde Transfer).

To solve these problems, the architectural and urban currents aimed to sustainability, have considered different retrofitting means. The means applied are these ones:

Ecological or eco efficient retrofitting: The operations applied on the shopping mall are aimed in the achieving of minor environmental impact, or the insertion of green capabilities into it. This retrofitting current does not suppose direct incomes for the shopping mall, as well as the works are expensive. This retrofitting operation is applied on shopping malls during the firstmedium steps of the life cycle. 
Retrofitting aimed in the re opening, or the economical revitalization: The measures applied for the mall in this retrofitting family, are aimed entirely to the adaptation of the shopping mall to the new market requirements or evolution, so this retrofitting is going to produce direct incomes. the works applied can consider a variation of the leasable surface, the enlargement of the mall, or even a change of its external or internal image. This retrofitting idea is considered during the last steps of the shopping mall cycle, and the aim is to prolong its activity according to the evolution of the market.

Change of use: this retrofitting operation is applied for shopping malls nearby its enclosure or dead malls. this consists in the total or partial turning of the shopping mall building into a non commercial facility, such as a public amenity without altering so much the structure of the building.

Building complete restructuration: this retrofitting, generally applied for dead malls, consists in the alteration of the building of the shopping mall, and its urban plot structure. The idea is to turn it a new urban area with new buildings and uses. These new uses are supposed to be located onto, between or replacing the shopping mall.

To sum up, once the background and genesis of the shopping mall, as well as problems and retrofitting applied to solve them, the next step is the establishment of the methodology of analysis to evaluate the adequacy of the retrofitting measures. 


\section{4.-ESTABLECIMIENTO DE LAS PAUTAS DE LA METODOLOGÍA}

\section{1.- ÁMBITO DE TRABAJO DE LA METOdOLOGÍA, ACOTACIÓN.}

Una vez concluido el estado del arte, el primer paso introductorio para el establecimiento de la metodología, es acotar de manera definitiva el ámbito en el que se va a centrar la misma.

La presente tesis doctoral se centra en lo que es la rehabilitación de los centros comerciales, considerándose la valoración de las diferentes técnicas anteriormente mencionadas en base a las características del centro comercial y su entorno urbano. Resumiendo el capítulo anterior, y reordenando los métodos de rehabilitación de los centros comerciales de acuerdo a los pilares de la sostenibilidad, tendríamos los siguientes modelos, los cuales van a resultar la base de la posterior metodología de análisis.

De este modo, una vez enunciado el objeto en el que se centra la metodología, el siguiente paso es acotar respecto a los cinco ámbitos que fueron considerados en todos los capítulos del estado del arte. A continuación se exponen los ámbitos, y sus diferentes métodos de rehabilitación asociados, explicando en cada uno de ellos si a efectos de metodología este va a ser considerado o descartado de manera total o parcial.

Pilar medioambiental.

En este ámbito van a abarcarse todas las operaciones de reforma que pudieran suponer una mejora a efectos medioambientales, este pilar va a ser considerado en su totalidad para la presente tesis, debido a la fuerte componente de la misma en temas de medio ambiente urbano, respecto al pilar del medio ambiente tenemos estos modelos de rehabilitación medioambiental:

Rehabilitación Ecoefiente: Esta rehabilitación va a hacer referencia a todas las acciones que tienen como fin una mejora en lo que es la eficiencia del edificio del centro comercial en relación con el medio ambiente. Este campo de la rehabilitación va a considerar todo lo relacionado con el ahorro energético o de aguas, la eficiencia energética, y la suplencia o generación de energía dentro del centro mediante fuentes renovables. Este modelo de rehabilitación va a ser considerado para la metodología de análisis.

Rehabilitación Verde o medioambiental: Este modelo de rehabilitación va a referirse a lo relacionado con la mejora de las prestaciones medioambientales del centro comercial de cara a la asimilación de aguas respecto del terreno, o la asimilación de gases de efecto invernadero o nocivos mediante el uso de vegetación. Contribuyendo de esta manera a la mejora del medio ambiente urbano. Este modelo de rehabilitación va a ser considerado para la metodología de análisis.

Pilar social.

El análisis de la rehabilitación social a escala urbana, muchas veces se fundamenta en otros factores ajenos a lo que es la reforma o rehabilitación mediante la construcción en el tema de la arquitectura (factores sociológicos, o de economía social). De manera que en la presente tesis doctoral no se va a considerar este tema al completo. No obstante muchas veces una 
rehabilitación social a escala de barrio, puede venir fundamentada por la reutilización de una edificación concreta en estado de abandono, o la revitalización de la misma, de manera que los cambios de uso de los centros comerciales van a considerarse dentro de la rehabilitación social. De este modo, para la presente tesis de va a estudiar el modelo de rehabilitación dotacional o de cambio e inserción de usos desde el punto de vista del cambio, o la inserción de usos, realizándose las reformas pertinentes de cara al interior del mismo, sin alterar, o alterando de forma total o parcial la forma original del centro comercial.

Pilar económico.

Aunque la economía resulta importante a la hora de acometer cualquier tipo de rehabilitación, ya que para ese fin se precisa de disponer de fondos económicos. No obstante, el estudio de las medidas económicas de rehabilitación es un tema de gran complejidad, en el que se precisa del manejo de conocimientos en el plano económico que el autor de la presente tesis no posee. Aún así, en el estudio de casos se van a hacer constantes menciones hacia la economía de los centros comerciales, y sus condiciones económicas, las cuales van a moderar en mayor o menor medida el alcance de las aplicaciones de rehabilitación.

Metodologías de rehabilitación asociadas a la actividad económica de un centro, son todas aquellas destinadas a la mejora de las condiciones económicas del mismo, (Ampliación de espacio comercial, mejora en la oferta de actividades...). A pesar de ello, es importante considerar que una gran parte de las reformas que se acometen en los centros comerciales, tienen como finalidad la mejora de la economía del mismo.

Ámbito urbanístico.

Este temar va a resultar de importancia, debido a la fuerte componente de la presente tesis en relación con el tema de la rehabilitación urbana. Respecto a este pilar, la metodología va a considerar la posibilidad de plantear actuaciones concretas sobre el entorno urbano, si estas pudieran suponer una mejora en la eficacia medioambiental de lo que es el centro comercial en relación con su entorno.

Ámbito arquitectónico-proyectual.

El tema del proyecto arquitectónico de los centros comerciales, en referencia a las cualidades de su espacio, aunque resulta de gran interés, es un tema que no va a ser considerado en la metodología, debido al enfoque urbanístico y medioambiental de la tesis.

Las reformas que se acometen sobre el edificio en este ámbito, pueden ser cualquiera relacionada con la alteración del espacio interior o exterior del mismo mediante la reestructuración o adición de elementos, o cualquier cambio de decoración e imagen con un objetivo concreto.

De este modo, el alcance de la metodología de rehabilitación de la presente tesis ya queda definido. Esta se va a centrar generalmente en el ámbito de lo medioambiental y lo urbanístico, considerando sus respectivos métodos de rehabilitación como base de la metodología de análisis para la rehabilitación de los centros. En posteriores capítulos, esta metodología va a 
ser desarrollada y definida. El próximo capítulo estará centrado en el estado del arte en el tema de las metodologías de análisis.

\section{2.- FUNDAMENTOS DE LAS METODOLOGÍAS DE EVALUACIÓN Y PROCEDIMIENTOS.}

Un paso importante para la definición de la metodología, es la definición de las estrategias existentes de metodologías de rehabilitación, evaluación y homologación existentes, enfocadas en el objetivo de la reducción del impacto medioambiental. La importancia de este estudio reside principalmente en el interés de establecer un modelo que nos servirá para sentar las bases en la búsqueda de un modelo para la metodología que desarrollará la presente tesis doctoral.

\subsection{1.- Metodología, pasos e inclusión de tipos de estudios.}

El tipo estándar de metodología de estudio ambiental, de cara al análisis de la eficiencia energética y la aplicación de medidas centradas en su mejora, básicamente centra su modus operandi en cinco pasos que son el análisis de campo y recogida de datos, la conversión de la realidad en datos operables, la síntesis de los datos mediante operaciones, la homologación de los mismos en base a baremos establecidos por la propia metodología, y finalmente la proposición de medidas de mejora, si se diera el caso. No obstante cada metodología puede variar, en el hecho de que una u otra puede hacer mayor o menor hincapié en paso u otro en particular. Los pasos anteriormente mencionados se explican con más detalle en los siguientes apartados. Estos pasos de un modo u otro siempre van a incluir uno o varios pasos de los elaborados por Canter y Sadler, (ANEXO 2) van a ser los que rijan las fases de la presente metodología a desarrollar.

1: Recogida de datos: La finalidad de esta fase consiste básicamente en la toma de datos del proyecto a considerar para su homologación o rehabilitación. Esta toma de datos puede ser mediante estudio de campo, encuestas, análisis de documentación relacionada, u otros medios centrados en la adquisición de información.

2: Introducción de los datos en la metodología, abstracción de la realidad: esta segunda fase básicamente consiste en la transformación y abstracción de la realidad urbana o arquitectónica, a través de la puesta de valores a lo visto en la fase de recogida de datos. Todo esto es realizado mediante un criterio basado bien en cantidades numéricas o baremos. Estas abstracciones de la realidad es lo que a efectos metodológicos se considera como indicadores. Cuya elección o baremo va a sentar las bases de la metodología. Esta fase de operación pude estar realizada total o parcialmente de manera simultánea a la fase de recogida de datos.

3: Síntesis entre valores de indicadores: Esta tercera fase consiste en la ponderación de todos los datos recogidos en las fases de análisis, y los valores establecidos para los diferentes indicadores. Para su baremo, comparación y cálculo, de acuerdo a uno o varios criterios establecidos por la metodología de análisis. Es de especial importancia establecer las 
relaciones entre los diferentes valores de los indicadores, que bien pueden ser comparativas o matemáticas; enfocando los cálculos hacia la obtención de uno u varios valores representativos que serán el resultado final sintetizado del análisis de la realidad urbana o arquitectónica.

4: Homologación y evaluación de los resultados: Una vez que los datos de síntesis relacionados con el objeto en cuestión ya han sido obtenidos, el siguiente paso la calificación de los mismos de acuerdo a un baremo ya definido de antemano, o estipulado en la propia metodología, que dará una visión general del objeto a analizar, que bien puede ser positiva o negativa.

5: Proposición de medidas de mejora: En el caso de que el resultado en la fase de homologación sea desfavorable, puede ser de importancia el establecimiento de una o varias medidas de mejora, cuya aplicación física sin duda va a alterar tanto los datos de los indicadores, como el resultado final de cara a una segunda fase de homologación. Es necesario que las medidas de mejora que se consideren para el elemento analizado en cuestión por la metodología, estén enfocadas hacia la obtención de resultados favorables de cara a una segunda aplicación de la metodología de estudio, con su correspondiente síntesis y homologación de los resultados. No obstante, la proposición de medidas de mejora también puede estar aplicada de manera simultánea a la fases de introducción de datos o síntesis de resultados.

En la siguiente tabla, se situarán los métodos de estudio enunciados por Canter y Sadler, y citados por Luis García Leyton (ANEXO 2) en relación a las fases establecidas en este apartado, se marcarán las fases en las que cada método de estudio hace especial hincapié. Se debe de tener en cuenta que cualquiera de los métodos de Canter y Sadler es compatible con todas las fases, siendo una evidencia el uso constante de los mismos a lo largo de todo el proceso de estudio ambiental (Figura 4.2.1).

\begin{tabular}{|c|c|c|c|c|c|}
\hline & $\begin{array}{c}\text { FASE } 1 \\
\text { RECOGIDA DATOS }\end{array}$ & $\begin{array}{c}\text { FASE 2 } \\
\text { INTRODUCCIÓN } \\
\text { DATOS } \\
\end{array}$ & $\begin{array}{c}\text { FASE } 3 \\
\text { SÍNTESIS }\end{array}$ & $\begin{array}{c}\text { FASE } 4 \\
\text { HOMOLOGACIÓN }\end{array}$ & $\begin{array}{c}\text { FASE } 5 \\
\text { PROPOSICIÓN DE } \\
\text { MEDIDAS }\end{array}$ \\
\hline \multicolumn{6}{|l|}{ (1) Métodos Analógicos } \\
\hline \multicolumn{6}{|l|}{ (2) Listas de chequeo } \\
\hline \multicolumn{6}{|l|}{ (3) Listas enfocadas a decisiones } \\
\hline \multicolumn{6}{|c|}{ (4) Análisis ambiental coste-beneficio } \\
\hline \multicolumn{6}{|c|}{ (5) Opinión de expertos } \\
\hline \multicolumn{6}{|l|}{ (6) Sistemas expertos } \\
\hline \multicolumn{6}{|l|}{ (7) índices e indicadores } \\
\hline \multicolumn{6}{|l|}{ (8) Pruebas de laboratorio } \\
\hline \multicolumn{6}{|l|}{ (9) Evaluación de paisajes } \\
\hline \multicolumn{6}{|l|}{ (10) Revisión bibliográfica } \\
\hline \multicolumn{6}{|l|}{ (11) Balances de materia } \\
\hline \multicolumn{6}{|l|}{ (12) Matrices de interacción } \\
\hline \multicolumn{6}{|l|}{ (13) Monitorización } \\
\hline \multicolumn{6}{|l|}{ (14) Estudio de campo } \\
\hline \multicolumn{6}{|l|}{ (15) Estudio de redes } \\
\hline \multicolumn{6}{|l|}{ (16) Superposición de mapas } \\
\hline \multicolumn{6}{|l|}{ (17) Fotografía y fotomontajes } \\
\hline \multicolumn{6}{|l|}{ (18) Modelización cualitativa } \\
\hline \multicolumn{6}{|l|}{ (19) Modelización cuantitativa } \\
\hline \multicolumn{6}{|l|}{ (20) Evaluación de riesgo } \\
\hline \multicolumn{6}{|l|}{ (21) Construcción de escenarios } \\
\hline (22) Extrapolación de tendencias & & & & & \\
\hline
\end{tabular}

Figura 4.2.1: Relación entre métodos de estudio y fases, remarcando en las que se hace especial hincapié. Fuente: Elaboración propia a partir de datos de Canter y Sadler. 
De este modo, en base al análisis realizado, la metodología que guiará la presente tesis doctoral, va a estar basada en la abstracción de datos, el análisis científico y la homologación en base a un baremo relativo. Esto va a explicarse en los posteriores capítulos, siendo desarrollado un estado de la cuestión referente a metodologías en el ANEXO 2 de la presente tesis.

Una vez enunciados los tipos, pasos y procedimientos de las metodologías de análisis medioambiental, el siguiente paso en el estudio, es el establecimiento de la metodología que se aplicará al análisis de los casos de estudio de centro comercial en la presente tesis.

\section{3.- BASES DE LA METODOLOGÍA DE ANÁLISIS.}

una vez acotados y definidos los ámbitos de estudio que van a ser estudiados sobre los centros comerciales, el siguiente tema es definir las bases y procedimientos de la metodología de análisis.

\subsection{1.- Fundamentos básicos}

Este apartado resulta ser de gran importancia, ya que en él se explican de manera resumida cuales van a ser las pautas y fundamentos de la metodología de la presente tesis.

A grandes rasgos, esta metodología al basarse en la analítica, se centra en el establecimiento de una fotografía actual de lo que es el centro comercial en cuestión y su entorno urbano. La cual va a obtenerse a partir del análisis de ciertos factores muy relacionados con los ámbitos de análisis estudiados en el estado del arte, fundamentando los métodos de rehabilitación más adecuados. Se establecerán preferencias y recomendaciones de cara a una supuesta y futura rehabilitación.

Esta fotografía va a presentarse como un gráfico orientativo circular de sectores, el cual va a ser descrito con exactitud tanto en contenidos como en gradación en los siguientes capítulos.

A grandes rasgos, éste es el fundamento de la metodología, que será de aplicación a todos los centros de manera universal, realizándose en la presente tesis un estudio de casos ligado a varios centros comerciales.

Pero el primer paso en el establecimiento de la metodología, y en la composición del gráfico orientativo de aplicación universal de la misma, es la consideración de los ámbitos más genéricos que van a componer su estructura. En el apartado 3.1 de la presente tesis, ya se acotaron las líneas de rehabilitación que serían de aplicación para el estudio de la rehabilitación sostenible de los centros comerciales. Las seleccionadas a partir de los ámbitos de estudio en el estado del arte se explican en el próximo capítulo.

\subsection{2.- Resumen de los ámbitos a considerar como base de la metodología, establecimiento del criterio.}


Este capítulo explica, los tipos de rehabilitación que van a llevarse a cabo en cada parte del gráfico. Estableciéndose en primer lugar campos más genéricos de rehabilitación, que se dividirán en operaciones o medidas más concretas e intrínsecamente relacionadas.

Es necesario concretar de manera precisa que campos genéricos y medidas de rehabilitación van a ser incluidas en el gráfico de la metodología, para de esta manera ofrecer una visión orientativa a los agentes que hicieran uso de la metodología.

\section{A: Rehabilitación de tipo ecoeficiente sobre el centro comercial}

Este campo de rehabilitación, va a centrarse en la reducción de los consumos energéticos y la adaptación bioclimática del edificio del centro, su forma y la configuración de sus espacios, siendo planteado el análisis del mismo y las medidas de rehabilitación en relación al impacto ambiental. En la analítica de esta medida de rehabilitación, van a intervenir los estados actuales de las instalaciones del centro, la presencia de energías renovables en el mismo, y el comportamiento de la forma, los espacios y las características constructivas del edificio, centrándose en lo respectivo a los consumos energéticos y el clima del centro. Esta línea de rehabilitación está muy relacionado con el pilar del medio ambiente, y básicamente va a considerar estas operaciones o medidas de reforma.

A1: Instalaciones poco emisivas: Esta operación de reforma va a considerar el cambio, la sustitución o la adecuación de las instalaciones del centro comercial hacia un modelo que genere una menor cantidad de emisiones o tenga un impacto medioambiental menor. No van a considerarse para este apartado las instalaciones destinadas al aprovechamiento de la energía solar, sino las de calefacción, iluminación, aclimatación y refrigeración, midiéndose la eficacia de las mismas y su rendimiento.

A2: Medidas activas: Este campo de reforma, va a hacer referencia a las medidas relativas al aprovechamiento de la irradiación solar y otras energías renovables para la generación de energía, o la suplencia de la demanda de la misma por parte del edificio. También van a considerarse las medidas tecnológicas o activas pensadas para la reducción del consumo energético del mismo centro comercial, es decir, las que requieran energía para su funcionamiento.

A3: Medidas pasivas: Este campo de reforma va a estar directamente relacionado con la adaptación y el diseño del edificio del centro comercial, todo ello exclusivamente respecto a las características de su clima. (forma en planta, la ubicación de sus huecos, la orientación de las fachadas, la adaptación de los espacios interiores a las características climáticas) Se considerarán además las medidas destinadas a la reducción del consumo energético, que no requieran de energía o medios para su funcionamiento presentes en el edificio del centro comercial.

B: Rehabilitación de tipo verde o medioambiental

Esta línea de rehabilitación, muy en relación con el pilar del medio ambiente, está orientada generalmente hacia la reducción del impacto del centro comercial sobre el agua, el suelo y 
asimilación de gases nocivos presentes en la atmósfera en que se asienta. Las operaciones que se considerarán para este modelo de reforma van a ser las siguientes:

B1: Zonas Verdes: La reforma en este campo está directamente relacionada con la presencia de superficies verdes o arboladas, tanto dentro del centro comercial y su parcela, como en el entorno urbano que lo rodea, se considerará para este modelo de reforma, la capacidad asimilativa de las zonas verdes, su ubicación y sus dimensiones.

B2: Superficie asimiladora de agua: La reforma en este campo está relacionada con la capacidad de asimilación de agua en el centro comercial y su entorno. Se considerará como base y fundamento para esta reforma, la presencia de superficie permeable y adaptada, a lo que es la recuperación de agua por parte del suelo.

B3: Tratamiento de isla de calor: La reforma en este aspecto está orientada al análisis de la isla de calor en el entorno del centro, y la cuantificación y cualificación de las medidas que pudieran existir para la mitigación del efecto mencionado anteriormente.

C: Rehabilitación de tipo dotacional o de uso

Esta línea de rehabilitación va a enfocarse en la realización de un cambio de uso en lo que es el centro en sí, bien sea sin alterar la forma exterior del mismo, o alterándola de manera total o parcial. Esta línea de rehabilitación está muy en relación con el ámbito de lo urbanístico, y hasta cierto punto también en relación con el pilar social de la sostenibilidad. Se considerará el estado actual del centro comercial, y sus carencias de usos, siendo el tema la analítica de los usos ajenos al comercio.

C1: Uso residencial: Esta medida de reforma está centrada en la presencia o inclusión de usos residenciales tanto en la parcela del centro, como en sus alrededores, especificando si fuese necesaria una reforma en la inclusión de estos usos.

C2: Uso Terciario no comercial o productivo: Esta medida de reforma está centrada en la presencia o inclusión de usos terciarios, bien sea ligados a actividades económicas no comerciales o secundarias. Se incluirá tanto la parcela del centro, como sus alrededores, especificando si fuese necesaria una reforma en la inclusión de estos usos.

C3: Uso Dotacional: Esta medida de reforma está centrada en la presencia o inclusión de actividades ligadas a servicios administrativos, dotacionales o asistenciales. Se incluirá tanto la parcela del centro, como sus alrededores, especificando si fuese necesaria una reforma en la inclusión de estos usos.

D: Reestructuración urbana por fallos del entorno urbano:

Este campo, está relacionado directamente con las actuaciones que deberían de ser consideradas sobre el entorno urbano en relación con lo que es el centro y su parcela. Si las carencias del centro en el análisis, predominan en este sector del gráfico, significa que para producir una mejora en el medio ambiente urbano relacionado con el centro comercial, los esfuerzos y medidas de rehabilitación o reestructuración deben de aplicarse de manera preferente sobre el entorno urbano del centro comercial. 
D1: Transporte eficiente: Esta medida de reforma va a estar orientada hacia la analítica de la eficiencia del transporte a efectos medioambientales, con el fin de ponderar si existe o si fuera necesario un transporte público eficaz en el consumo de energía.

D2: Densidad: Esta medida de reforma va a tener su punto de partida y fundamento en la adecuación de la densidad de cara al consumo eficiente de energía y suelo dentro del área urbana en la que está ubicado el centro comercial.

D3: Seguridad y paseabilidad: Esta medida de reforma va a considerar el análisis del entorno urbano, desde el punto de vista de que este pudiera resultar más o menos agradable para el peatón. Deberán de considerarse también la accesibilidad del mismo (pasos adecuados para todo tipo de peatones) y la seguridad.

De este modo, a efectos de composición del gráfico, cada una de las medidas de rehabilitación seleccionadas, van a componer los diferentes sectores dentro del gráfico.

\subsection{3.- Establecimiento de la escala de medición dentro de la metodología.}

Una vez escogidos los ámbitos que conforman el gráfico de sectores de la metodología, el siguiente paso es el establecimiento del baremo y el criterio de gradación que se establecerá dentro del mismo.

Como primer paso, los sectores de las medidas de reformas que se establecieron con anterioridad, van a ser divididos en diez partes de forma radial, que van a establecer el estado actual del centro de cara a la conveniencia y eficacia de la medida de rehabilitación, siendo el 0 la puntuación más baja, y el diez la puntuación más alta. De este modo, cuando un sector de medida de reforma de cara al análisis da una puntuación baja, significa que el centro comercial en lo referente a las cualidades de la medida de reforma, se encuentra lejos de la eficiencia medioambiental requerida, y va a hacer falta intervenir en ese aspecto de manera prioritaria. En oposición, un sector que tenga una puntuación alta, significa que el centro comercial, en lo conveniente a las cualidades de esta medida, cumple con las exigencias requeridas a efectos de eficiencia medioambiental o de usos, y su intervención va a ser menos prioritaria.

No obstante, a su vez dentro del gráfico también es importante establecer un criterio de jerarquía a efectos de relevancia, para ver la prioridad entre las medidas que pudieran ser consideradas. De este modo dentro del gráfico se van a establecer tres áreas de relevancia:

Umbral de mínimos (2 puntos sobre 10): este umbral se estableció en la puntuación de 2 puntos dentro del gráfico de sectores, si el estado de uno de los ámbitos de rehabilitación no supera este umbral, significa que el estado a efectos de este ámbito se encuentra muy lejos de lo que es la eficacia requerida a efectos medioambientales, y la intervención de rehabilitación dentro del mismo debería de ser prioritaria hasta que el estado de la misma supere esta puntuación mínima a corto plazo. Una vez superada esta puntuación, la continuación en la rehabilitación en ese campo, debería de ser planteada a medio o largo plazo. 
Umbral de óptimos (8 puntos sobre 10): este umbral se estableció en la puntuación de 8 puntos dentro del gráfico de sectores, si alguno de los ámbitos de rehabilitación supera esta puntuación, eso significa que a efectos de eficiencia medioambiental y urbanística el ámbito supera con creces el mínimo, y la intervención en ese campo de la rehabilitación no va a resultar prioritaria en absoluto, siendo viable la continuación de la misma sólo cuando todos los demás campos de rehabilitación hayan igualado o superado esta puntuación óptima, o como actividad complementaria a otras operaciones.

Paradigma Verde (10 puntos o más sobre 10): Este umbral, que se estableció en la presente tesis en los 10 puntos y superior, hace referencia a que el estado actual del centro comercial de cara al campo de la rehabilitación concerniente, a efectos medioambientales, está muy por encima del óptimo. De este modo, se han superado con creces los objetivos medioambientales, con lo que no va a ser necesario aplicar medidas en ese campo. Siendo esta medida nada prioritaria.

\subsection{4.- Gráfico final metodológico, Rosa de la Rehabilitación Sostenible}

Una vez se establecieron los baremos de puntuación y los umbrales, éstos fueron recogidos y agrupados en un gráfico circular, en el cual los ámbitos de rehabilitación quedaron establecidos en sectores circulares dentro del gráfico, quedando las puntuaciones relativas a estos ámbitos de rehabilitación, como círculos ordenados del centro a la circunferencia exterior, sobre estos círculos concéntricos se aplicaron los umbrales anteriormente mencionados, quedando como resultado el gráfico de ROSA DE REAHBILITACIÓN SOSTENIBLE. (Figura 3.3.1)

\section{(A) ECOEFICIENTE}

\section{(A3)}

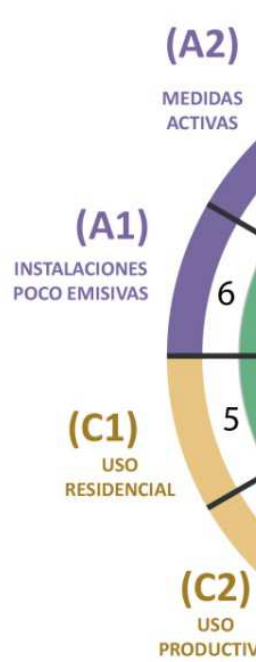
PASIVAS

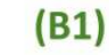

ZONAS ZONAS
VERDES$$
\text { (B2) }
$$

SUPERFICIE ASIMILADORA AGUA

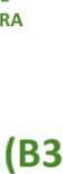

(B3)

TRATAMIENTO ISLA CALOR

SEGURIDAD Y PASEABILIDAD (D2)
(B) MEDIOAMBIENTAL
UMBRALES

2 puntos: Umbral de mínimos, Rehabilitación prioritaria 8 puntos: Situación Óptima, Rehabilitación nada prioritaria 10 puntos: Paradigma verde

ZONAS E INTERVALOS 0-2 puntos: rehabilitación muy prioritaria

2-8 puntos: rehabilitación de prioridad de media a moderada

8-10 puntos: rehabilitación no prioritaria.

\section{(C3)}

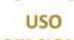
DOTACIONAL

\section{(D1)}

TRANSPORTE
EFICIENTE

\section{(D) ENTORNO URBANO}

Figura 4.3.1: Gráfico de la Rosa de Rehabilitación Sostenible. Fuente: Elaboración propia. 
Este gráfico tiene como objetivo dar una visión del estado actual del centro comercial, viendo en que facetas de la rehabilitación se puede hacer un mayor o menor hincapié para lograr una mejora. Entre los diferentes umbrales establecidos se establecieron tres zonas de prioridad:

Zona Z1: Zona de alta prioridad de intervención (0 a 2 puntos sobre 10): Si el estado de la faceta de rehabilitación analizada se encuentra en esta zona, significa que las operaciones en la misma deben de ser prioritarias hasta que tras la rehabilitación, el estado de la misma iguale o supere el umbral de mínimos a efectos de eficiencia medioambiental.

Zona Z2: Zona de prioridad media de intervención ( 2 a 8 puntos sobre 10): Esta área intersticial que se encuentra entre los dos umbrales, indica que el estado del centro comercial actualmente en lo referente a la medida de reforma de cara a la calidad medioambiental, ha superado el mínimo de la zona de alta prioridad, pero todavía no ha superado el óptimo, las medidas que puntúen en este margen deberán de ser prioritarias en segundo margen.

En esta zona, se recomienda intervenir en primer lugar sobre los aspectos que se encuentran más cercanos al mínimo, tratando en todo momento de que estos estén más o menos igualados, con la media relativa al campo general de rehabilitación. Aún así, las medidas de reforma que se encuentren en puntuaciones cercanas al mínimo, van a representar operaciones de rehabilitación costosas, que requerirán de muchos medios para que el centro logre tener una cierta calidad medioambiental.

Zona Z3: Zona óptima de baja prioridad (8 a 10 puntos sobre 10): Las medidas de rehabilitación que en puntuación superen la zona óptima (8 puntos), significa que a efectos de eficacia medioambiental cumplen con los objetivos establecidos, y no necesitan de ser intervenidas en esa medida. No obstante, los centros en ese aspecto de la rehabilitación estudiada siempre pueden mejorar si se interviene, pero en el caso de hacerlo, estas intervenciones deberían de considerarse como no prioritarias.

Es importante considerar, que para esta metodología, la puntación de la misma está considerada de acuerdo a frecuencias relativas. El motivo de esto, es debido a la falta de datos acerca de ciertos ámbitos del centro comercial, (sobre todo los relativos a las instalaciones y la ecoeficiencia), y la complejidad que supone realizar una ponderación en valores absolutos, de los efectos que estas medidas pudieran tener de cara al tema del impacto ambiental y su reducción. De este modo, la ponderación de las puntuaciones para la valoración de los cuestionarios, fue estimada de manera cualitativa en base al tamaño en superficie del ámbito que abarca la cuestión en sí. Se valorará como factor primordial para la ponderación en el cálculo de la rehabilitación de tipo medioambiental, las superficies en planta y los tamaños relativos de huella de carbono entre centro y área urbana. Siendo el factor de ponderación para los usos, las superficies construidas de los ámbitos a tratar (centro comercial, entorno urbano próximo y entorno urbano global). En los cuestionarios relacionados con el entorno urbano, se considerarán como primordiales los factores a los que la medida de rehabilitación hace referencia, teniendo mayor puntuación lo relativo a las características del entorno urbano del centro comercial. 
Esta metodología en sus etapas finales del análisis va a considerar un baremo de tipo relativo tendente a la cualificación, en lugar de la cuantificación absoluta, además de que no fue posible establecer de manera rigurosa una ponderación de los efectos medioambientales entre las diferentes medidas de rehabilitación propuestas, debido a la ausencia de datos, y el desconocimiento del autor en valorar los efectos reales de impacto medioambiental de manera precisa y concreta.

A todo ello hay que añadir, que el establecimiento de factores de ponderación globales entre las diferentes medidas aplicadas, no va a ser posible, ya que las superficies de los centros y sus instalaciones, a la vez que la configuración y comportamiento de los entornos urbanos, sus programas de transporte y usos van a diferir. El establecimiento de estos factores de manera real entre medidas de rehabilitación para esta metodología en los centros comerciales analizados puede ser tema de futuros trabajos de investigación.

No obstante, de cara a las conclusiones de esta tesis, se valorarán algunas de las medidas de rehabilitación de la rosa de rehabilitación de forma cuantitativa, y se realizará un estudio de medias aritméticas entre las medidas de rehabilitación para los centros comerciales, con el objetivo dar una visión estimativa de la mayor o menor eficacia de las medidas de rehabilitación propuestas. Para el cálculo de la mejora medioambiental de cada una de las medidas propuestas de forma rigurosa y real, va a ser necesario un estudio más exhaustivo, y más ligado a temas de proyecto sobre un centro comercial en concreto.

\section{4.- ÍNDICE DE LA METODOLOGÍA, DESARROLLO DE LA MISMA:}

Una vez establecidos a grandes rasgos el núcleo de la analítica metodológica de la presente tesis doctoral, el siguiente tema es explicar los diferentes pasos que va a ser considerados, para obtener el resultado en el gráfico enunciado en el tema anterior, que nos indicará las medidas de rehabilitación más adecuadas para el caso del centro comercial.

la metodología de análisis de la presente tesis doctoral, va a considerar cuatro grandes fases, en las cuales se van a establecer diferentes sub fases que van a marcar los procedimientos de operación, o los datos que deben de ser recopilados para la aplicación de la metodología.

De este modo, las cuatro grandes fases van a ser:

FASE 0: Recogida de datos cuantitativos.

FASE 1: Análisis del contexto urbano del centro comercial.

FASE 2: Análisis de relaciones entre centro comercial y entorno urbano.

FASE 3: Análisis del edificio del centro comercial.

FASE 4: Aplicación de indicadores, y baremos a través de preguntas clave. Resolución de las medidas en el gráfico de la metodología. 
FASE 5: Establecimiento de posibles medidas de mejora de cara a la prospectiva de acuerdo a escenarios.

De este ,modo, la metodología va a seguir esta línea de actuación, de acuerdo a los pasos anteriormente mencionados, siendo muy habitual dentro del procedimiento de la misma, la mezcla entre temas.

FASE 0: RECOGIDA DE DATOS CUANTITATIVOS.

OC.- TABLA DE DATOS DEL CENTRO COMERCIAL.

C1: SUPERFICIE CENTRO COMERCIAL TOTAL (Unidad: metros cuadrados)

C2: SUPERFICIE TOTAL DE LA PARCELA DEL CENTRO (Unidad: metros cuadrados)

C3: SUPERFICIE EN PLANTA DEL EDIFICIO DEL CENTRO COMERCIAL (Unidad: metros cuadrados)

C4: NÚMERO DE VISITANTES SEMANAL. (Unidad: personas)

C5: ÍNDICE DE ATRACCIÓN DEL CENTRO.

C6: SUPERFICIE DE USO EN EL CENTRO DE TIPO RESIDENCIAL: (Unidad: metros cuadrados)

C7: SUPERFICIE DE USO EN EL CENTRO DE TIPO PRODUCTIVO: (Unidad: metros cuadrados)

C8: NÚMERO DE INSTALACIONES EN EL CENTRO DE TIPO DOTACIONAL O ASISTENCIAL: (Unidad: número de locales)

OU.- TABLA DE DATOS DEL ENTORNO URBANO.

U1: POBLACIÓN DE ÁREA URBANA ASIGNADA A CENTRO COMERCIAL: (Unidad: personas)

U2: DENSIDAD DE POBLACIÓN EN EL DISTRITO DEL CENTRO COMERCIAL: (Unidad: Habitantes por hectárea y metro cuadrado)

U3: SUPERFICIE DEL ENTORNO URBANO DE PARTIDA: (Unidad: Hectáreas y metros cuadrados)

FASE 1: ANÁLISIS DEL CONTEXTO URBANO.

1A: ESTABLECIMIENTO DEL ÁREA DE INFLUENCIA DEL CENTRO COMERCIAL : (Análisis cuantitativo, unidad metros lineales y superficies en metros cuadrados).

1B: DELIMITACIÓN SOBRE PLANO DEL ÁREA DE INFLUENCIA: (Análisis gráfico sobre plano).

1C: SUBDIVISIÓN DEL ÁREA DE INFLUENCIA EN ÁREAS HOMOGÉNEAS Y DELIMITACIÓN DE ZONAS VERDES (Análisis sobre plano y cuantitativo, unidad: metros cuadrados). 
1D: PORCENTAJE DE OCUPACIÓN DE LA EDIFICACIÓN: (Análisis cuantitativo y sobre plano, unidad: metros cuadrados):

1E: SUPERFICIE OCUPADA, Y EDIFICADA MEDIA TOTAL: (Análisis cuantitativo y sobre plano, Unidad: Metros cuadrados).

1F: ESTABLECIMIENTO DE LAS TIPOLOGÍAS DE TEJIDO EN BASE A LA MORFOLOGÍA URBANA: (Análisis cualitativo sobre plano).

1G.- ÍNDICE GLOBAL DE DENSIDAD.

1H: SUPERFICIE EDIFICADA DE CADA ÁREA HOMOGÉNEA. (Análisis cuantitativo, unidad, Metros cuadrados construidos).

1I: ESTABLECIMIENTO DE PORCENTAJES DE USO DENTRO DE LOS TEJIDOS HOMOGÉNEOS: (Análisis sobre plano y estimativo).

1J: CONTEO DE LOS USOS DENTRO DEL CONTEXTO URBANO. (Análisis cuantitativo, Unidad, Metros cuadrados de uso.).

1K: ÍNDICE GLOBAL DE MEZCLA DE USOS.

1L: CONTEO DEL NÚMERO DE DOTACIONES DENTRO DEL CONTEXTO URBANO, DENTRO DEL ÁREA DE DOTACIONES (Análisis cuantitativo, unidad número de dotaciones)

1M: PRESENCIA E INFLUENCIA DE ELEMENTOS POSITIVOS Y NEGATIVOS: (Análisis sobre plano). 1N: ZONAS DE ACTIVIDAD: (Análisis sobre plano).

10: ÁREAS ARBOLADAS Y VERDES, DENTRO DEL ÁREA URBANA DEL CENTRO: (Análisis sobre plano y cuantitativo, unidad: metros cuadrados).

1P.- DELIMITACIÓN DE RECORRIDOS A CENTRO, DENTRO DEL ÁREA URBANA: (Análisis sobre plano).

1Q.- HUELLA DE CARBONO DEL ÁREA URBANA: (Análisis cuantitativo, unidad, toneladas anuales de dióxido de carbono emitidas).

1R.- CAPACIDAD ABSORCIÓN DE LOS ELEMENTOS VERDES EN ÁREA URBANA: (Análisis cuantitativo, unidad, toneladas anuales de dióxido de carbono asimiladas).

1S: DELIMITACIÓN DE ÁREAS EN FUNCIÓN DE LA RECUPERACIÓN DE AGUAS EN ÁREA URBANA (análisis sobre plano y cuantitativo, unidad metros cuadrados).

FASE 2: ANÁLISIS DE RELACIONES ENTRE CENTRO COMERCIAL Y ENTORNO URBANO.

2A: DELIMITACIÓN DE ÁREA PRÓXIMA: (Análisis sobre plano). 
2B: SUPERFICIE TOTAL EDIFICADA EN ÁREA PRÓXIMA: (Análisis cuantitativo, unidad: metros cuadrados).

2C: USOS EN ÁREA PRÓXIMA: (Análisis sobre plano y cuantitativo, unidad: metros cuadrados).

2D: FACHADAS ACTIVAS EN ÁREA PRÓXIMA (Análisis sobre plano).

2E: TIEMPOS DE LLEGADA DESDE LOS PUNTOS EN ÁREA A CENTRO COMERCIAL MEDIANTE TRANSPORTE PÚBLICO: (Análisis cuantitativo y sobre plano, unidad: minutos).

2F: TIEMPOS DE LLEGADA DESDE LOS PUNTOS EN ÁREA A CENTRO COMERCIAL MEDIANTE TRANSPORTE PRIVADO: (Análisis cuantitativo y sobre plano, unidad: minutos).

2G: ÁREA URBANA CUBIERTA POR EL TRANSPORTE PÚBLICO. (Análisis sobre plano y cuantitativo, unidad metros cuadrados).

FASE 3: ANÁLISIS DEL EDIFICIO DEL CENTRO COMERCIAL.

3A: DELIMITACIÓN DE ÁREAS EN FUNCIÓN DE LA RECUPERACIÓN DE AGUAS (Análisis sobre plano y cuantitativo, unidad: metros cuadrados).

3B: USOS DENTRO DEL EDIFICIO DEL CENTRO (Análisis sobre plano y cuantitativo, unidad: metros cuadrados).

3C: DELIMITACIÓN DE ÁREAS VERDES EN CENTRO COMERCIAL. (Análisis sobre plano y cuantitativo, unidad: metros cuadrados).

3D: ABSORCIÓN DE LAS ÁREAS VERDES EN CENTRO COMERCIAL. (Análisis cuantitativo, unidad toneladas de $\mathrm{CO} 2$ anuales)

3E: ANÁLISIS BIOCLIMÁTICO DEL CENTRO COMERCIAL RESPECTO A CLIMA, DIAGRAMA DE GIVONI

3F: CALIFICACIÓN ENERGÉTICA DEL CENTRO COMERCIAL. (análisis cuantitativo, van a extraerse datos de consumo energético, y emisiones del centro)

3G: USO DE FUENTES DE ENERGÍA LIMPIAS.

3H ESPACIOS CON LUZ NATURAL (Análisis sobre plano y cuantitativo, Unidad Metros cuadrados, porcentaje.)

3I FORMA DE LA EDIFICACIÓN: (Análisis cualitativo de la forma del edificio del centro comercial, sobre plano).

3J: PAVIMENTOS Y CUBIERTAS EN RELACIÓN A LA INCIDENCIA DE LA IRRADIACIÓN SOLAR. (Análisis sobre plano y cuantitativo).

FASE 4: CUESTIONARIOS DE LA METODOLOGÍA, APLICACIÓN DE INDICADORES Y BAREMOS. 


\section{A.- REHABILITACIÓN ECOEFICIENTE.}

A1.- Cuestionario referenciado a rehabilitación hacia instalaciones poco emisivas.

A2.- Cuestionario referenciado a inserción de medidas activas.

A3.- Cuestionario referenciado a inserción de medidas Pasivas.

4B.- REHABILITACIÓN MEDIOAMBIENTAL.

B1.- Cuestionario referenciado a rehabilitación mediante zonas verdes.

B2.- Cuestionario referenciado a inserción de superficie asimiladora de agua.

B3.- Cuestionario referenciado a tratamiento de isla de calor.

4C.- REHABILITACIÓN POR USOS.

C1.- Cuestionario referenciado a inserción de uso residencial.

C2.- Cuestionario referenciado a inserción de usos productivos, y terciarios no comerciales.

C3.- Cuestionario referenciado a inserción de instalaciones dotacionales y asistenciales.

4C.- REHABILITACIÓN DE ENTORNO URBANO.

C1.- Cuestionario referenciado a la inserción de medios de transporte eficientes.

C2.- Cuestionario referenciado a la rehabilitación por corrección de la densidad en área urbana.

C3.- Cuestionario referenciado a mejora de la seguridad y la paseabilidad en el área urbana.

4D.- CUESTIONARIO REFERENTE A LA ACTIVIDAD DEL CENTRO.

FASE FINAL: GRÁFICO DE LA ROSA DE REHABILITACIÓN SOSTENIBLE

las puntuaciones obtenidas en el cuestionario, van a definir el gráfico de la rosa de rehabilitación sostenible.

\subsection{1.- Fundamentos de la analítica en los factores de la metodología.}

Una vez establecidos los factores, el siguiente tema es explicar en profundidad, cual va a ser el procedimiento de análisis en cada uno de los factores mencionados, así como que datos deben de ser tenidos en cuenta, y cómo operar con ellos de cara al análisis conclusivo. Como se mencionó anteriormente, cada análisis que va a realizarse, y cada dato obtenido va a estar relacionado con el estado actual del centro comercial, siendo estos la base de la pauta que determinará las relaciones más adecuadas y eficientes para cada caso.

No obstante, algunos de los datos requeridos pueden no estar disponibles para el análisis, en ese caso, se establecerán unas pautas de ponderación a partir de otros datos obtenidos, o un 
procedimiento alternativo para su obtención, basado en el análisis de casos similares. El fin último es poder aplicar la metodología, aún careciendo de datos.

\section{5.- FASE 0, RECOGIDA DE DATOS CUANTITATIVOS.}

Esta fase, aunque es la primera en ser mencionada en el orden de la metodología, se caracteriza por su aplicación constante a lo largo de todo el proceso de la misma. Consiste básicamente, en la obtención de los datos cuantitativos y numéricos necesarios de partida acerca del centro comercial y su entorno urbano, los cuales van a fundamentar los baremos y el conteo que será realizado para las facetas de análisis de posteriores fases.

Los datos que fueran a ser recogidos acerca del centro comercial y su entorno, van a ir recogidos en los siguientes índices numerados, los cuales van a ir recogidos en tablas de análisis.

\section{TABLA DE DATOS DEL CENTRO COMERCIAL (C)}

La primera tabla de análisis que va a ser realizada, va a ser mencionada, va a ser la que está relacionada con el centro comercial en cuestión, esto se debe a que muchos de los datos de esta tabla van a resultar ser de gran relevancia a la hora de delimitar y establecer el entorno urbano del centro, considerando a su vez el hecho, de que el centro comercial es el objeto de análisis de la metodología.

De este modo, la tabla de datos respectiva al centro comercial va a incluir los siguientes índices:

ÍNDICE C1: SUPERFICIE CENTRO COMERCIAL TOTAL (Unidad: metros cuadrados): Este dato va a referirse a la superficie construida total del centro comercial, incluyendo galerías, servicios y comercio, excluyendo aparcamientos. Este dato va a resultar de gran importancia, y puede obtenerse por fuentes oficiales, o bien estimando la superficie ocupada en planta del centro comercial y multiplicarla por el número de plantas.

ÍNDICE C2: SUPERFICIE TOTAL DE LA PARCELA DEL CENTRO (Unidad: metros cuadrados): Este dato va a referirse a la superficie total de la parcela en la que está ubicado el centro comercial, la cual considerará además de la superficie ocupada en planta por el edificio del centro, la superficie de aparcamientos, aceras y jardines que lo rodean, siempre dentro de la unidad catastral.

ÍNDICE C3: SUPERFICIE EN PLANTA DEL EDIFICIO DEL CENTRO COMERCIAL (Unidad: metros cuadrados): Este dato va a referirse a la superficie ocupada en planta del centro comercial, en este dato se incluirán voladizos y galerías abiertas.

ÍNDICE C4: NÚMERO DE VISITANTES SEMANAL. (Unidad: personas): Este dato se obtendrá por fuentes oficiales, y se buscará obtener el número de compradores semanal por centro, siendo 
de importancia cualquier conteo relacionado con el número de compradores. Si el dato obtenido es el mensual o el anual, para la presente tesis se considerará que en un mes hay 4,8 semanas y un año tiene 52,14 semanas.

En el caso de no ser posible la obtención de estos datos, el autor propone un baremo orientativo para esta cantidad basado en los datos obtenidos a partir de la dirección del centro comercial Shopping Light en el centro de Sao Paulo. Este baremo está desarrollado en visitantes por metro cuadrado de centro, y para obtener el número de visitantes se multiplicará éste por la superficie del centro comercial a considerar. Los datos son los siguientes, se precisa operar con todos los decimales, debido a que las superficies de los centros comerciales son números muy elevados: En el caso de centros comerciales de periferia próxima, los números de compradores fueron establecidos algo más reducidos que en los centros céntricos debido a su ubicación en zonas menos concurridas, al igual que los ubicados en las periferias. En estos últimos además se debe de considerar, que el número de compradores va a concentrarse los fines de semana, teniendo mucha menos afluencia entre semana, debido a que está ubicados en zonas apartadas de la ciudad, tales como ciudades dormitorio o centralidades exclusivamente comerciales. (Figura 4.5.1).

\begin{tabular}{|c|}
\hline Ratio semanal visitantes \\
\hline Lunes a viernes: 1 comprador $/ \mathrm{m} 2$ \\
\hline Sábado: 0,83 comprador $/ \mathrm{m} 2$ \\
\hline Domingo: 0,27 comprador $/ \mathrm{m} 2$ \\
\hline
\end{tabular}

Figura 4.5.1.- Número de estimado personas visitantes de un centro comercial de acuerdo a la superficie del mismo, en referencia a los días. Fuente: Shopping Light, Elaboración Propia.

No obstante, estos datos también habrá que ponderarlos, en función al estado del centro y su presencia. Para esto se utilizarán estos factores, los cuales van a multiplicarse por los números expresados en la figura 5.5.1. Los factores que rigen esta ponderación, fueron hallados en base a estimaciones de visitas de otros casos de centros comerciales. Se cogieron los valores de las visitas mensuales de Shopping Aricanduva (3,4-4,5 millones por semana, baremo de 1,6 compradores por metro cuadrado y semana) o los de Mall of America (30-40 millones de visitas anuales, que da un baremo cercano a los 2,7 compradores por metro cuadrado y semana, considerando las zonas originarias del centro comercial antes de las ampliaciones $\left(270.000 \mathrm{~m}^{2}\right)$. como caso contrario está New Souh China Mall, que aunque el parque de atracciones es visitado, las galerías raramente son visitadas por cien personas al día. Estos baremos fueron comparados con la media de Shopping Light. Aún así, este baremo no es preciso, ya que además de que no fue posible obtener datos concretos de los centros analizados, el número de visitas tiene un margen extremadamente amplio entre meses. Para establecer el criterio anteriormente mencionado, fue necesario una investigación cualitativa del estado del centro.

-Centro comercial de gran importancia a escala mundial de primer orden: Multiplicar valores por 1,5 .

-Centro comercial de gran importancia a escala nacional o mundial de segundo orden, o en área turística concurrida: Multiplicar valores por 1

-Centro comercial de gran importancia a escala urbana, ponderación más habitual: Multiplicar valores por 0,8 . 
-Centro comercial en periferia, de importancia regional o en entorno de baja densidad: Multiplicar valores por 0,5 .

-Centro comercial en decadencia: Multiplicar valores por 0,05.

ÍNDICE C5: ÍNDICE DE ATRACCIÓN DEL CENTRO: El centro comercial, en referencia a su área urbana, es un elemento de jerarquía de primer orden. No obstante, es necesario ponderar la influencia del mismo, con respecto a un área urbana más amplia, debido a su función como polo de atracción a una escala amplia. De este modo, este índice se va a medir en una escala del 0 al 5, en función del número de compradores semanal. Este baremo también es poco preciso, y se consideró haciendo una interpolación a partir de las visitas semanales de Shopping Light (75.000) como centro comercial medianamente frecuentado, Mall of America como centro comercial muy frecuentado (762.000), y New South China Mall en sus años de abandono (estimado en menos de 1000 personas por semana).

Índice 0: inferior a 1000 visitantes por semana.

Índice 1: de 1000 a 5000 visitantes por semana.

Índice 2: de 5000 a 20.000 visitantes por semana.

Índice 3: de 20.000 a 150.000 visitantes por semana.

Índice 4: de 150.000 a 300.000 visitantes por semana.

Índice 5: Más de 300.000 visitantes por semana.

ÍNDICE C6: SUPERFICIE DE USO EN EL CENTRO DE TIPO RESIDENCIAL: (Unidad: metros cuadrados): La superficie residencial en el centro, va a incluir todo el espacio no comercial, de tipo residencial (viviendas) que pudiera haber en la parcela del centro, incluyendo los hoteles. Este dato, va a hacerse patente generalmente en operaciones de rehabilitación urbanística aplicadas sobre los centros, y puede obtenerse a partir de fuentes oficiales de los centros comerciales, o bien midiendo sobre plano.

ÍNDICE C7: SUPERFICIE DE USO EN EL CENTRO DE TIPO PRODUCTIVO: (Unidad: metros cuadrados): Esta superficie va a comprender el espacio productivo de uso industrial o terciario no comercial, que pudiera dar servicio a visitantes (oficinas de alquiler). Este factor bien puede obtenerse a partir de fuentes oficiales de los centros comerciales, o bien midiendo sobre plano. En este factor se excluirán las oficinas de administración del centro, ya que éstas no están abiertas al público, y por lo tanto no generan servicio alguno.

ÍNDICE C8: NÚMERO DE INSTALACIONES EN EL CENTRO DE TIPO DOTACIONAL O ASISTENCIAL: (Unidad: número de locales): Este dato va a comprender la cantidad de locales dentro del centro comercial, que está destinada a usos no comerciales ligados al uso urbano público dotacional. (Centros sociales, oficinas de la administración). Este espacio, aunque en principio no va a resultar tan lucrativo como las tiendas, puede darle al centro una cierta complejidad de usos. Este factor bien puede obtenerse a partir de fuentes oficiales de los centros comerciales, o bien analizando sobre plano. Estas dotaciones pueden ser o de titularidad pública o privada.

A partir de la metodología anteriormente explicada, se tomarán los datos de partida del centro comercial en la tabla del anexo a esta unidad:

TABLA DE DATOS DEL ENTORNO URBANO (U). 
Esta tabla de datos, aunque hace referencia a un entorno más general y de mayor escala, se menciona en segundo lugar, debido al hecho de que muchos de los datos de partida para el análisis urbano tienen su punto de partida en varias de las características de los centros comerciales anteriormente mencionadas. El análisis del entorno urbano va a ser un punto clave para la metodología, ya que nos va a servir para establecer las relaciones entre lo que es el centro comercial y su entorno, buscando de esta manera la rehabilitación más adecuada para cada caso.

De este modo, la tabla para el análisis del entorno urbano va a incluir los siguientes datos cuantitativos.

ÍNDICE U1: POBLACIÓN DE ÁREA URBANA ASIGNADA A CENTRO COMERCIAL: (Unidad: personas): Este dato va a obtenerse a partir de los metros cuadrados del centro comercial (Índice C1), aplicando para ello el segundo y tercer paso de la fórmula del centro comercial ideal de Victor Gruen: (Rodea el centro con 500.000 consumidores que no tengan acceso a ningún otro equipamiento comercial y prepara el terreno central cubriéndolo con 1.000.000 de metros cuadrados en edificios.). De este modo, la proporción de espacio edificado para el centro comercial es de aproximadamente dos metros cuadrados por persona residente en el entorno urbano aledaño, para obtener la población asignada al centro, se dividirá la superficie total del centro entre dos, y ese número serán las personas que habitarán en el área de influencia.

ÍNDICE U2: DENSIDAD DE POBLACIÓN EN EL DISTRITO DEL CENTRO COMERCIAL: (Unidad: Habitantes por hectárea y metro cuadrado): Este factor va a considerar la densidad media de población del distrito en el que está ubicado el centro. Este dato es muy relevante en el estudio de la zona urbana del centro y puede obtenerse a partir de fuentes urbanísticas.

Sin embargo, a veces estos índices de densidad no pueden ajustarse a la realidad, sobre todo si hay presencia de amplias áreas verdes o sin edificación, que hacen que este índice disminuya. En el caso de que esto ocurriera, este índice deberá de ser corregido recogiéndose en primer lugar el número total de habitantes del mismo, para a continuación dividirlo entre la superficie edificada exclusivamente, dentro del distrito.

ÍNDICE U3: SUPERFICIE DEL ENTORNO URBANO DE PARTIDA: (Unidad: Hectáreas y metros cuadrados): Una vez obtenidas la población del área urbana y la densidad, el siguiente paso es establecer la superficie del entorno urbano, que nos servirá para delimitar el área en el posterior análisis sobre plano, para obtener este dato, hay que dividir la población del área asignada (U1) entre la densidad (U2) para así obtener la superficie del área asignada al centro. Dentro de este área, no se incluirá el centro comercial, ya que este dato ha sido calculado en función a datos de población, y esta instalación en principio no está enfocada en la habitabilidad y el uso residencial. Salvo que el centro comercial cuente con viviendas, que en ese caso serán incluidas en el área.

Con los datos obtenidos del anterior análisis, se cumplimentarán las tablas de datos de partida. (Figura 4.5.2). 


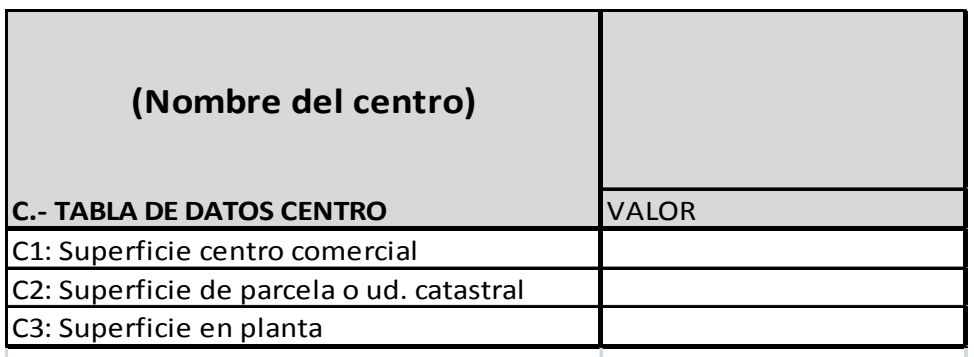

\begin{tabular}{|l|l|}
\hline C4: Superficie de zonas verdes & Valor \\
\hline C4.1: pradera & \\
\hline C4.2: hierba de gran altura o huerto & \\
\hline C4.3: vegetación arbustiva intensiva & \\
\hline C4.4: vegetación arbórea caduca & \\
\hline C4.5: vegetación arbórea perenne & \\
\hline
\end{tabular}

\begin{tabular}{|l|l|}
\hline C5: Número de visitantes & Valor \\
\hline Lunes a Viernes & \\
\hline Sábado & \\
\hline Domingo & \\
\hline TOTAL SEMANAL & \\
\hline
\end{tabular}

\begin{tabular}{|l|l|}
\hline C6: ÍNDICE DE ATRACCIÓN & \\
\hline & \\
\hline C7: Superficie residencial & \\
\hline C8: Superficie de uso productivo & \\
\hline C9: Número de instalaciones dotacionales & \\
\hline
\end{tabular}

\begin{tabular}{|l|l|}
\hline U.- TABLA DE DATOS ENTORNO URBANO & VALOR \\
\hline U1: Población asignada a centro & \\
\hline U2: Densidad de población & \\
\hline U3: Superficie de entorno urbano & \\
\hline
\end{tabular}

Figura 4.5.2.- Tabla de datos de partida (Elaboración Propia).

\section{6.- FASE 1: ANÁLISIS DEL CONTEXTO URBANO.}

En esta fase de análisis sobre plano, y cuantitativo, se van a realizar diferentes análisis sobre plano, que van a considerar lo que es el entorno urbano, de cara al gráfico conclusivo, y por consiguiente a las posibilidades de rehabilitación que pudieran ser consideradas.

De este modo, cada factor de análisis irá numerado, y los que pudieran influir en el establecimiento de la metodología de análisis, van a ir ponderados en base al gráfico de cinco ejes, considerando el estado actual del mismo.

De este modo, los factores que van a considerarse para el análisis del entorno urbano van a ser los siguientes:

1A: eSTABLECIMIENTO DEL ÁREA DE INFLUENCIA DEL CENTRO COMERCIAL : (Análisis cuantitativo, unidad metros lineales y superficies en metros cuadrados).

En esta fase de análisis sobre plano, plano de la zona urbana que rodea el centro comercial, se va a trazar un área base de influencia, basada en la capacidad y el tamaño del centro comercial, 
de acuerdo a las pautas dictadas por Victor Gruen. Este factor ya fue con anterioridad recogido en el ÍNDICE U1, de la tabla de análisis de datos cuantitativos del medio urbano (3.5.2). Esa superficie, será aproximadamente la que tendrá el área de influencia del centro comercial, la cual será establecida considerando los siguientes pasos:

-En primer lugar, a partir de un punto sobre la parcela del centro comercial, va a trazarse una circunferencia cuya superficie sea la de la zona de influencia de Gruen, (ÍNDICE U1) de la tabla de datos cuantitativos urbanos, más la superficie de la parcela del centro comercial (ÍNDICE C2) de la tabla de datos cuantitativos del centro comercial ( $\mathrm{sup}=\mathrm{U} 1+\mathrm{C} 2)$. En base a la superficie anteriormente calculada, se va a establecer el radio de la circunferencia que marcará el primer acercamiento a la zona de influencia del centro.

Radio $=\sqrt{ }$ (superficie/ $\pi$ ).

También, este área de partida puede establecerse en otras formas, mientras se adapten de mejor manera al entorno urbano. Siendo posible una reducción del área, si el analista lo considerara, siempre y cuando esto estuviese justificado.

1B: DELIMITACIÓN SOBRE PLANO DEL ÁREA DE INFLUENCIA: (Análisis gráfico sobre plano).

Una vez hallado el radio, el siguiente tema a considerar será aplicar la morfología del entorno urbano, la cual va a alterar la circunferencia de la zona de influencia estableciéndose de esta manera la delimitación definitiva. Para la delimitación del área de influencia del centro es importante considerar:

Morfología urbana: toda manzana, que contenga un edificio o conjunto de edificios que se encuentre dentro del área de influencia de manera parcial, va a ser incluida en su totalidad, no obstante si se trata de un espacio estancia, esta va a ser excluida en su totalidad. Los bordes del área de influencia van a ser siempre calles o espacios estancia.

Sendas: Para la presente tesis doctoral, se van a considerar como sendas, las vías urbanas transitables de gran capacidad que están integradas dentro del tejido urbano, y que estas a su vez no supongan una barrera para la circulación de los tráficos, tanto peatonales como rodados, que la atraviesen de manera transversal, ejemplos de senda para esta fase de análisis van a ser las calles de jerarquía viaria de primer orden, las avenidas, los bulevares y las autopistas elevadas que confluyan en el centro, cuya presencia no suponga una obstrucción de los tránsitos transversales (autopistas elevadas sobre pilares).

Las sendas urbanas van a influir en el área de influencia, en la manera que esta va a expandirse en la dirección de la misma, hasta un máximo de 500m, abarcando la zona de influencia solo las manzanas en contacto con la senda dentro de este radio.

Barreras: Se van a considerar como barreras, todo elemento urbano, transitable o no longitudinalmente, cuya presencia suponga una obstrucción en los tránsitos transversales a la misma dentro del tejido urbano, debido a que estas no pueden ser transitadas si no es mediante pasos. Ejemplos de barreras son los ríos, los acantilados, los solares de gran tamaño vacíos o las autopistas y vías de tren a nivel de suelo. 
Las barreras van a influir en la zona de influencia, en el sentido de que estas van a acortarla de manera parcial, considerándose dentro del área solo las zonas cercanas a los pasos que esta pudiera tener, siempre y cuando estén incluidas dentro de la zona de influencia de $1 \mathrm{~km}$ a la redonda.

Elementos que tengan interacción con el centro: En el contexto urbano del centro comercial, a veces, pueden haber elementos urbanos que tienen una fuerte relación de interacción de funcionamiento con lo que es el centro comercial en sí, debido a complementariedad de funciones, estos elementos deben de ser considerados en la zona de influencia, independientemente de si se encuentran dentro de la zona de influencia básica de 1 kilómetro a redonda o no. Ejemplos de elementos interactivos son las instalaciones de transporte de cualquier tipo, siempre y cuando estas tengan una fuerte relación con el centro, y estén a una distancia relativamente cercana.

Los elementos interactivos van a ser incluidos dentro de la zona de influencia, considerando un corredor desde el centro hasta el elemento interactivo en cuestión, que incluirá las manzanas próximas al mismo.

1C: SUBDIVISIÓN DEL ÁREA DE INFLUENCIA EN ÁREAS HOMOGÉNEAS Y DELIMITACIÓN DE ZONAS VERDES (Análisis sobre plano y cuantitativo, unidad: metros cuadrados). Una vez establecida el área total, el siguiente paso, es la división de la misma en áreas homogéneas de acuerdo a su tejido, excluyendo en la selección de las mismas los espacios verdes o libres de gran tamaño, los cuales van a ser delimitados también en este paso, y estudiados con más profundidad en el apartado $1 \mathrm{~N}$. Este análisis se realizará tanto sobre plano remarcando las áreas. Se medirá la superficie en planta de cada una de las áreas homogéneas en metros cuadrados.

1D: PORCENTAJE DE OCUPACIÓN DE LA EDIFICACIÓN, Y METROS CUADRADOS OCUPADOS POR ZONA HOMOGÉNEA: (Análisis cuantitativo y sobre plano, unidad: metros cuadrados):

Este dato, indicará en porcentaje la proporción de superficie en planta ocupada por la edificación, respecto al área a analizar. La obtención de ese dato se realizará mediante un análisis sobre plano, y deberá de ser incluido en la lista al tratarse de un dato de referencia. Para susodicho análisis se van a seguir los siguientes pasos:

1. En primer lugar, se marcarán las zonas urbanas homogéneas dentro del área urbana de influencia del centro (1C).

2. El siguiente paso será el establecimiento de un área cuadrada, de la dimensión que el autor estime conveniente, siendo condición obligatoria que describa de manera precisa el tejido urbano. Se eligió el área cuadrada como unidad referente del análisis de superficie de tejidos, con la intención de facilitar y simplificar los cálculos en esta operación, en la medida de lo posible.

3. En tercer lugar, se marcará la superficie ocupada por la edificación y será medida en metros cuadrados. El porcentaje se obtendrá dividiendo la superficie ocupada, entre la superficie total de área cuadrada establecida por el analista. 
4. En el caso de haber varios tipos de zona homogénea, el porcentaje final será la media entre los porcentajes de las diferentes zonas.
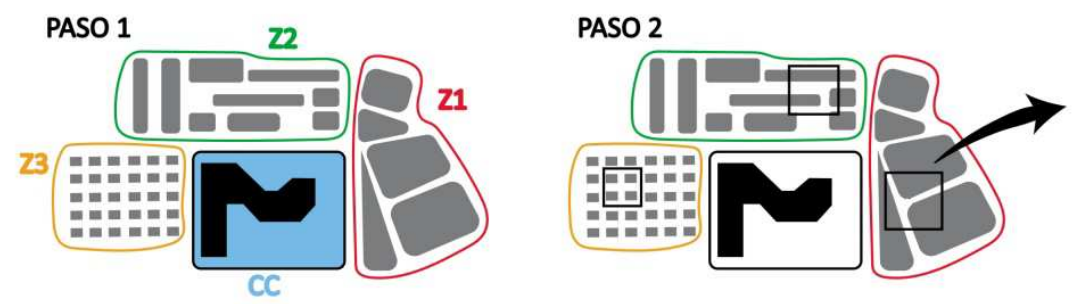

PASO 3-4

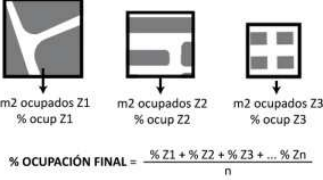

Figura 4.6.1.- Esquema de análisis de tejidos urbanos. Fuente: Elaboración Propia.

Una vez estimado el porcentaje de ocupación para cada zona homogénea, a partir del área

1E: ALTURA MEDIA DE LA EDIFICACIÓN EN ÁREA DE INFLUENCIA DEL CENTRO: (Análisis cuantitativo y sobre plano, Unidad: Número de plantas).

Este dato, indicará el número medio de plantas de la edificación dentro de la zona de influencia del centro comercial. para la obtención de ese dato, se buscará una media total entre las alturas predominantes de las diferentes zonas homogéneas, siguiendo el siguiente procedimiento:

1. En primer lugar, se marcarán los edificios y manzanas por número de alturas dentro del área urbana cuadrada de análisis de cada zona homogénea.

2. En segundo lugar, se marcará el porcentaje de superficie de superficies en referencia a las diferentes alturas establecidas, considerando como total el área ocupada por la edificación.

2. la altura final de la zona homogénea, será la suma de las alturas de la edificación, multiplicadas por sus respectivos porcentajes.

Altura media $=$ Al. edif. $1 * \%$ ocup alt. edif $1+\ldots .+$ Al. edif. $n * \%$ ocup alt $n$. edif $n$.

Esta media total, siempre será redondeada hacia el número natural más cercano, sin decimales se establecerá un número de plantas para cada zona homogénea.

1F: ESTABLECIMIENTO DE LAS TIPOLOGÍAS DE TEJIDO EN BASE A LA MORFOLOGÍA URBANA: (Análisis cualitativo sobre plano).

Una vez que el área de influencia ha sido establecida, el siguiente análisis es el relacionado con la caracterización de los diferentes tejidos urbanos dentro de la misma. Este análisis va a establecerse en base a tres grados de densidad y se realizará sobre plano urbano en base a los siguientes pasos:

En primer lugar, dentro del área de influencia establecida anteriormente sobre plano (1A), se van a marcar las diferentes tipologías de tejido urbano, buscando las zonas homogéneas de manera cualitativa, en estas áreas se incluirán los espacios intersticiales entre los edificios y las calles, siempre que estén dentro del área homogénea. 
Seguidamente, dentro de estas áreas de tejido homogéneo, va a estimarse un porcentaje ocupado para cada tejido urbano, siguiendo los pasos que van del apartado 1 al 3 , del factor 1D. (Figura 4.6.1)

pero en lugar de utilizar la media global, se establecerá este dato de manera independiente por tejido urbano.

El siguiente paso es establecer el número de plantas por área, considerando para cada una, la altura de edificación mayoritaria. de forma similar a lo establecido en el factor 1D, pero individual a cada tejido urbano tipológico.

Una vez esto estas dos variables estén definidas para cada tejido definido, el siguiente paso será insertar cada tejido en tabla de calificación por superficie ocupada y altura, que toma sus base de la analítica de tejidos dictada por Kevin Lynch. En la que se relaciona la ocupación del terreno con la altura de la edificación (Figura 4.6.2).

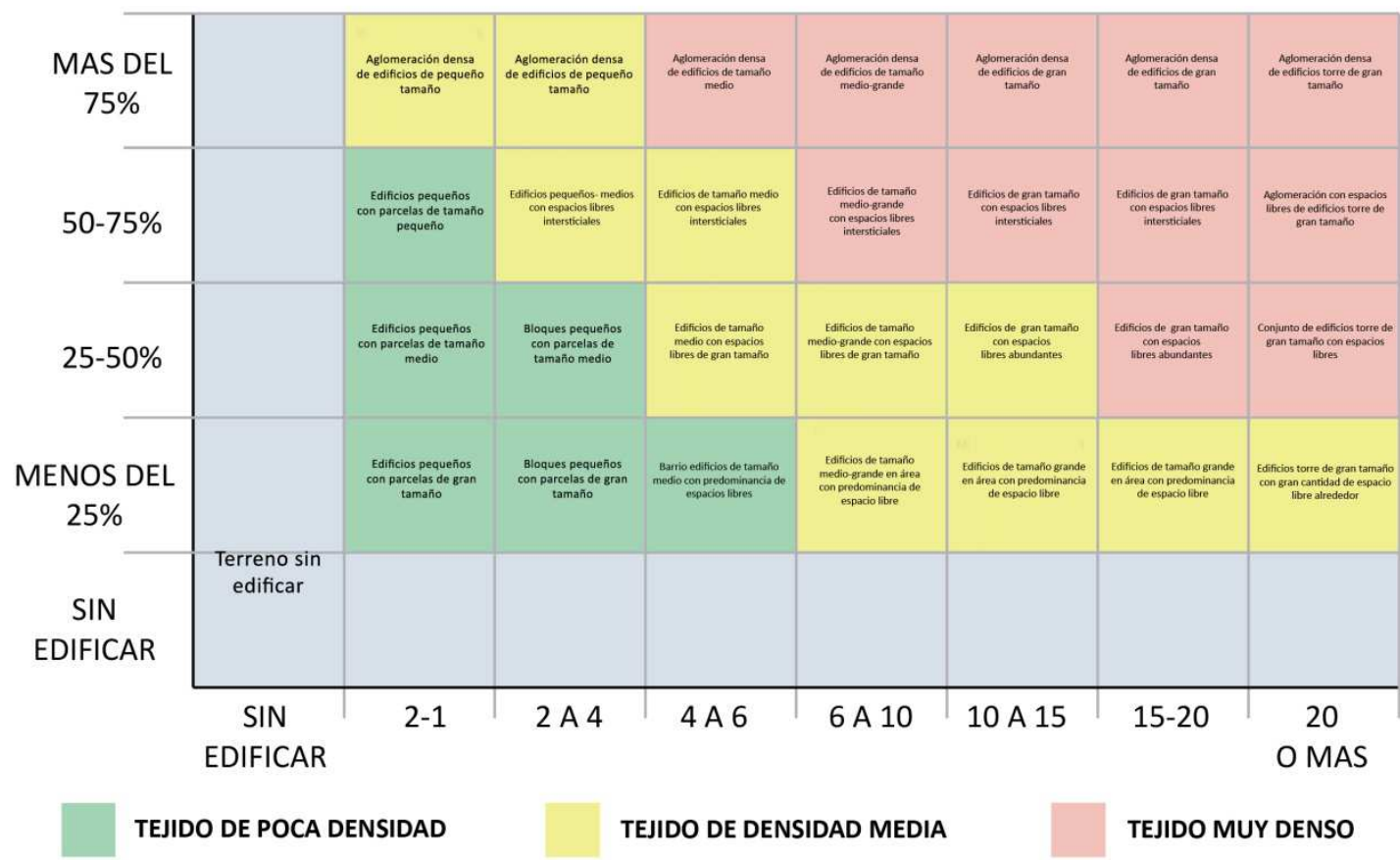

Figura 4.6.2.- Clasificación de tejidos por densidad. Fuente: Elaboración Propia a partir de datos de Kevyn Lynch.

De acuerdo a esta tabla, clasificaremos los tejidos en tres diferentes grados de densidad, que van a ser la poca densidad, la densidad media y la densidad alta.

Es de importancia indicar en cada tejido, tanto el número de plantas como el porcentaje de ocupación de la edificación, para el análisis en posteriores pasos de la metodología, siendo este análisis una base para más adelante caracterizar el tejido urbano que rodea el centro comercial.

1G.- ÍNDICE GLOBAL DE DENSIDAD. 
De cara al cuestionario de la metodología, y como dato conclusivo del análisis de las tipologías de tejido urbano, se calculará el índice global de densidad, considerando los resultados obtenidos a partir de la tabla anterior de densidades. Se procederá de la siguiente manera:

1.- Se clasificarán las zonas homogéneas de acuerdo al criterio de la tabla anteriormente establecida.

2.- Se sumarán las superficies totales de las zonas homogéneas analizadas, de acuerdo a las densidades obtenidas. Para así obtener las superficies totales de los tejidos de acuerdo al criterio de densidad establecido anteriormente. Se obtendrán tres resultados que serán los totales de áreas de zona homogénea obtenidos de acuerdo a la densidad. Se obtendrá el porcentaje total del tejido poco denso, de densidad media, o denso en relación al área total.

3.- Se obtendrá el porcentaje de los totales de cada área en relación con el área urbana total. 4.- Se hallará el índice global de densidad aplicando la siguiente fórmula que considerará índices de densidad parciales de acuerdo al siguiente criterio.

-área poco densa: índice de 1.

-área de densidad media: índice de 2

-área densa: índice de 3.

El índice de densidad global es el resultado de la siguiente fórmula:

(1* \% total del área del tejido poco denso en área urbana $+2 * \%$ total del área del tejido densidad media en área $+3 * \%$ total del área del tejido denso en área).

1H: SUPERFICIE EDIFICADA DE CADA ÁREA HOMOGÉNEA. (Análisis cuantitativo, unidad, Metros cuadrados construidos).

Una vez establecidas las áreas homogéneas en función de las plantas y la ocupación, el siguiente paso es establecer la superficie construida total para cada área homogénea establecida en 1C. multiplicando la superficie total establecida en el anterior apartado, por los porcentajes establecidos para cada área en $1 G$, y a posteriori multiplicando el área ocupada de la edificación por el número de alturas por zona homogénea en el mismo apartado.

\section{1: ESTABLECIMIENTO DE PORCENTAJES DE USO DENTRO DE LAS ZONAS HOMOGÉNEAS} ESTABLECIDAS: (Análisis sobre plano y estimativo).

El conocimiento de los usos urbanos en la zona del centro comercial, va a ser primordial a la hora de enfocar la rehabilitación de manera correcta. IMPORTANTE: Para la presente tesis, en el análisis posterior de la mezcla de usos, se van a considerar dos bloques de usos, el uso residencial, y el uso no residencial, que comprenderá los usos tanto comerciales como productivos.

Con el área de influencia delimitada, y los tejidos calificados en base a su densidad y compacidad, el siguiente paso es establecer zonas de uso en un nuevo análisis sobre plano.

No obstante, se debe de tener en cuenta, que en muchos casos no van a existir datos que ofrezcan una medición exhaustiva de la mezcla de usos, de modo que para la presente tesis doctoral, se van a estimar los porcentajes de uso para cada tejido urbano homogéneo establecido (1C), pudiéndose considerar varias tipologías tipo en base al uso. 
Los usos que se van a estudiar en esta tesis son los siguientes, se dividirá cada zona homogénea (1C) en porcentajes con la siguiente clasificación:

-Uso residencial, (residencias de cualquier tipo y viviendas).

-Uso no residencial: Este para la presente tesis, va a comprender dos subtipos de usos, que son los siguientes:

-Productivo, (Actividades terciarias e industriales, Para este apartado, se incluirán dentro de este ámbito la superficie de instalaciones dotacionales, ya que generan actividad).

-Comercial, (Actividades de compra y venta de género).

El uso comercial, aunque no va a contarse para esta tesis en metros cuadrados de superficie, su estudio va a ser importante de cara al establecimiento de las zonas urbanas complejas.

Para el establecimiento de los porcentajes por tejido, se realizó una caracterización genérica de las tipologías de tejido urbano en base al uso.

1: Áreas urbanas zonificadas de un solo uso: Este tipo de zonas van a ser las que van a estar enfocadas generalmente a un uso exclusivo, siendo predominante una sola función dentro del mismo (más de un $80 \%$ Aproximadamente). Dentro de áreas urbanas zonificadas tenemos tres tipologías con sus respectivos ejemplos en base al uso:

Uso Residencial:

A: Áreas zonificadas de función predominantemente residencial: este tipo de áreas va a comprender zonas de baja mezcla se usos, en las que la función residencial va a ser la predominante. Algunos ejemplos guía de zonas predominantemente residenciales son los siguientes (van a tener más de un $80 \%$ de su uso centrado en la función residencial):

- Barrios compuestos íntegramente por vivienda unifamiliar (Suburbs anglosajones, urbanizaciones de chalets individuales o adosados, ensanches periféricos de vivienda unifamiliar...).

-Urbanizaciones o conjuntos de viviendas cerrados y de acceso restringido con un vallado periférico sin fachadas activas, o de presencia extremadamente minoritaria. (Condominios cerrados, urbanizaciones valladas...).

-Colonias o bloques del movimiento moderno y similares (Hof, Siedlung, Unidades de habitación).

-Polígonos residenciales de bloques exentos o aglomerados sin fachadas activas (Barrios residenciales de las ciudades del Bloque del Este, aglomeraciones de edificios de apartamentos zonificados, polígonos de viviendas...).

Uso no residencial:

B: Áreas zonificadas de función predominantemente productivo: este tipo de áreas va a comprender zonas de baja mezcla se usos, en las que la función terciaria, ya sea de servicios en general privados o institucionales, va a ser la predominante. También dentro de este tipo de 
áreas van a considerarse las destinadas mayoritariamente a la función industrial o de la energía y el transporte, ya sean manufacturas o talleres.

Algunos ejemplos guía de zonas predominantemente productivas son los siguientes, estas zonas tienen más de un $80 \%$ de uso productivo:

-Ciudades o centros administrativos enfocados íntegramente en la actividad empresarial o de negocios. (Centros financieros de ciudades norteamericanas, parques empresariales...).

-Grandes aglomeraciones de edificios dotacionales urbanos o institucionales (Campus universitario, grandes instalaciones destinadas a usos de la administración).

-Polígonos o aglomeraciones, en las que predominan los almacenes de vendedores mayoristas.

-Polígonos industriales ligados íntegramente al sector secundario manufacturero, o de cualquier tipo de procesado de materias primas.

C: Áreas zonificadas de función íntegramente comercial: Este tipo de zonas están centradas en las instalaciones relacionadas con la venta, la adquisición y el intercambio de género al por menor. Aunque no se van a contar para la presente tesis, es necesario tenerlas en cuenta para la delimitación y acotación de los usos que son de interés. El estudio de las zonas comerciales respecto a los centros comerciales puede ser tema de futuros trabajos de investigación

Ejemplas de zonas comerciales zonificadas son estos casos, las cuales van a considerarse a, teniendo como mínimo un $80 \%$ de uso comercial.

Estas zonas son:

-Centros comerciales de gran tamaño.

-Mercados urbanos de gran tamaño.

-Hileras o conjuntos de edificios de único uso comercial de mayor o menor tamaño.

2: Áreas urbanas complejas con mezcla de usos: Este tipo de áreas, van a corresponder a las que tienen mezcla de usos de manera contraria a las áreas zonificadas explicadas con anterioridad (El uso residencial, o el no residencial no copa más del $80 \%$ del espacio ocupado total en una única unidad catastral). Debido a que en algunos casos es difícil saber con exactitud el número de metros cuadrados de cada uso. Para este tipo de áreas, será necesario establecer un conteo estimado, que puede realizarse de múltiples maneras: bien a partir de fuentes oficiales, bien mediante el estudio de casos de barrios similares, o bien mediante un estudio de campo o visual centrado en un trozo arquetípico dentro del tejido.

Una vez establecidas las áreas de uso dentro del área de influencia, el siguiente paso, es el conteo estimado de los metros cuadrados de actividad.

1J: CONTEO DE LOS USOS DENTRO DEL CONTEXTO URBANO. (Análisis cuantitativo, Unidad, Metros cuadrados de uso.). 
Una vez que se han estimado los porcentajes de uso dentro del contexto urbano, el siguiente paso es el conteo total de los mismos de cara al análisis de la rehabilitación por usos del centro comercial. Para la realización del mismo, van a utilizarse los porcentajes estimativos del apartado anterior (1I), los cuales van a ser multiplicados por los metros cuadrados construidos totales de cada área homogénea $(1 \mathrm{H})$. estableciéndose para cada zona homogénea un desglose de usos en metros cuadrados de acuerdo al siguiente criterio:

- Metros cuadrados de uso RESIDENCIAL.

-Metros cuadrados de uso NO RESIDENCIAL, este va a desglosarse en dos sub usos:

-Uso productivo.

-Uso comercial. (servirán para establecer grado de complejidad, añadiendo metros cuadrados a los usos no residenciales)

Una vez que los usos se han desglosado por zonas, el paso final para este apartado, será el cálculo de la relación total de los mismos respecto a la superficie total del área de influencia del centro. Se realizará la suma total de las superficies relacionadas con cada uso en todas las áreas homogéneas calculadas anteriormente, y por otra parte se sumarán todas las superficies edificadas totales de cada área homogénea. Finalmente se estimará el porcentaje global de ocupación de cada uso, dividiendo el total de metros cuadrados por uso, entre la superficie edificada total.

1K: ÍNDICE GLOBAL DE MEZCLA DE USOS.

De cara al cuestionario de la metodología, y como dato conclusivo del análisis de de usos de los tejidos urbanos, se calculará el índice global de mezcla de usos, de manera similar al de densidad. Se procederá de la siguiente manera:

1.- Se hallarán los porcentajes de uso residencial o no residencial por área homogénea, de manera independiente.

2.- En cada área, se establecerá un índice parcial de mezcla de usos, de acuerdo a la siguiente tabla, que ponderará los porcentajes entre los usos residencial y no residencial:

-Si el uso residencial o el no residencial copa más del $80 \%$ del área total edificada, se asignará un índice de 0.

-Si el uso residencial o el no residencial copa menos del $80 \%$ del área total edificada, se asignará un índice de 1.

3.- Se multiplicarán los índices de mezcla de usos, por los porcentajes que ocupa el área homogénea, respecto a la superficie total del área urbana, siendo luego estos resultados sumados para hallar el índice global de mezcla de usos, de acuerdo a esta fórmula:

(Índice de mezcla de usos de zona $1 * \%$ de ocupación de zona $1+$ Índice de zona $2 * \%$ de ocupación de zona $2+\ldots .+$ IÍndice de zona $\mathrm{n} *$ \% de ocupación de zona $\mathrm{n}$ ).

1L: CONTEO DEL NÚMERO DE DOTACIONES DENTRO DEL CONTEXTO URBANO, DENTRO DEL ÁREA DE DOTACIONES (Análisis cuantitativo, unidad número de dotaciones) 
Para este análisis, en primer lugar va a considerarse independientemente de la superficie urbana asignada al centro (1A), un radio de aproximadamente 1000 metros (20 minutos caminando) desde el lindero de la parcela del centro comercial en lo que será considerado como Área de Dotaciones. Una vez establecida este área, van a contarse las instalaciones dotacionales dentro de la misma, no considerando los metros cuadrados de cada una. En la presente tesis se van a considerar como dotaciones:

-Edificios o locales públicos ligados a la administración provincial o estatal, o a algunas de sus funciones.

-Instalaciones dotacionales públicas o concertadas, ya sean sanitarias, educativas o asistenciales.

-Edificios o instalaciones religiosas de cualquier tipo.

-Asociaciones de vecinos o locales ligados al tercer sector.

1M: PRESENCIA E INFLUENCIA DE ELEMENTOS POSITIVOS Y NEGATIVOS: (Análisis sobre plano).

En este apartado, dentro de la zona de influencia, van a considerarse elementos que en relación al centro, van a afectar de manera positiva o negativa su funcionamiento, todo ello desde el punto de vista del efecto de atracción o repulsión que estos pudieran generar de cara a la afluencia de clientes.

A: Elementos positivos en área: Para la presente tesis doctoral, van a considerarse como elementos positivos, todos aquellos que puedan atraer posibles clientes al centro comercial. Se van a considerar como elementos positivos:

-Hitos o atracciones turísticas.

-Avenidas o zonas de la ciudad con mucha actividad, siendo preferible que estén en contacto con el centro, ya que son polo de atracción.

-Centros financieros o dotacionales y administrativos de primer orden.

- Instalaciones de transporte de primera jerarquía (estaciones centrales de tren, metro o autobús, intercambiadores o grandes puntos de trasbordo en transporte urbano, aeropuertos...).

B: Elementos negativos en área: Esta caracterización, hace referencia principalmente a los elementos cuyo funcionamiento va a suponer una amenaza para la continuidad de la actividad del centro comercial, en el sentido de que estos van a hacer efecto de repulsión de cara a los posibles clientes del centro comercial. Se van a considerar como elementos negativos:

-Zonas dentro del contexto urbano que generen efecto repulsión o sean evitadas por los viandantes, tales como áreas peligrosas o insalubres.

1N: ZONAS DE ACTIVIDAD: (Análisis sobre plano).

la actividad en la zona resulta un factor de importancia a la hora de estudiar la interacción urbana de la misma. En este apartado van a estudiarse la actividad, además de los puntos fríos 
y calientes de la zona, indicando en el mapa las interacciones que estas pudieran tener con el centro de la siguiente manera:

\section{1: Actividad diurna:}

Como zonas de alta intensidad durante el día, van a considerarse las calles en las que se centrará la actividad diaria, tales como centros de oficinas comerciales e institucionales además de las dotaciones y las zonas aledañas a las calles con fachadas activas. Va a ser importante marcar las fachadas activas (fachadas con presencia de comercios y otras actividades diferentes a la mayoritaria en la zona de uso establecida en $1 \mathrm{C}$.).

Como zonas de baja intensidad durante el día van a considerarse las calles de zonas exclusivamente residenciales (1C-1A). debido a que estas áreas tienen poca actividad durante el día.

\section{2: Actividad nocturna:}

Como zonas de alta intensidad durante la noche, van a considerarse los espacios de ocio nocturno, o las calles con fachadas activas.

Como zonas de baja intensidad nocturna, van a considerarse las calles ubicadas en áreas de escasa complejidad urbana, que corresponderán íntegramente a las áreas de un solo uso, marcadas en el apartado (1C-1).

10: ÁREAS ARBOLADAS Y VERDES, DENTRO DEL ÁREA URBANA DEL CENTRO: (Análisis sobre plano y cuantitativo, unidad: metros cuadrados).

1: Una vez los tejidos están estudiados, el siguiente paso es remarcar en el plano las superficies verdes existentes en el área, indicando su superficie. Como superficies verdes van a considerarse:

-Parques y jardines de uso público.

-Parques y jardines de uso privado.

-Calles con arbolado.

-Bordes de ciudad y espacio periurbano.

-Cubiertas verdes tanto intensivas como extensivas.

En primer lugar, es importante contar el número de metros cuadrados total en planta de las áreas verdes, independientemente de la vegetación que estas pudieran tener, en lo que se considerará como SUPERFICIE VERDE NETA.

2: Una vez delimitadas estas zonas verdes, el siguiente paso es considerar las diferentes capas y tipologías de vegetación van a aparecer dentro de la superficie verde neta fijada anteriormente, para este análisis se han establecido cuatro categorías: 
-Praderas o vegetación extensiva: hierbas o plantas herbáceas de escasa altura (no más de $50 \mathrm{~cm})$.

-Vegetación arbustiva extensiva: hierbas de gran altura (mayor a $50 \mathrm{~cm}$ ), o arbustos leñosos de pequeño tamaño y baja altura (no más de $30 \mathrm{~cm}$ ).

-Vegetación arbustiva intensiva: arbustos leñosos o árboles de pequeño tamaño.

-Vegetación arbórea caduca: todo tipo de árboles y vegetación leñosa de gran tamaño, que mudan sus hojas.

-Vegetación arbórea perenne: todo tipo de árboles y vegetación leñosa de gran tamaño, que no muda sus hojas.

Esta delimitación va a resultar fundamental para la analítica de las capacidades de fijación de dióxido de carbono, que se estudiará más adelante. (Apartado 1J).

1P.- DELIMITACIÓN DE RECORRIDOS A CENTRO, DENTRO DEL ÁREA URBANA: (Análisis sobre plano).

En este apartado van a establecerse diferentes recorridos desde diferentes puntos representativos en los límites del área establecida, hasta la entrada del edificio del centro comercial. las entradas a los aparcamientos y áreas sin edificar circundantes, aunque van a influir en los recorridos, no van a ser consideradas como entradas al centro, de manera que el recorrido a través de estas áreas hasta la entrada del edificio del centro va a ser incluido.

1Q.- HUELLA DE CARBONO DEL ÁREA URBANA: (Análisis cuantitativo, unidad, toneladas anuales de dióxido de carbono emitidas).

Para la estimación de la huella de carbono del área urbana, se va a realizar estimando una huella general para toda el área, que se va a estimar de esta manera.

Como primer paso se considerará en primer lugar el cálculo de la huella de carbono para el distrito en su totalidad. Partiendo de la huella de carbono estándar por habitante del país en el que está ubicado el centro comercial. Multiplicando esta huella de carbono, por el número de habitantes del área de influencia (ÍNDICE U1, Apartado 0), hallaremos la huella de carbono total para el área de influencia.

1R.- CAPACIDAD ABSORCIÓN DE LOS ELEMENTOS VERDES EN ÁREA URBANA: (Análisis cuantitativo, unidad, toneladas anuales de dióxido de carbono asimiladas).

Este análisis está muy relacionado con el referido al apartado 1G, y es de gran importancia para establecer la rehabilitación necesaria en cada área urbana.

De este modo, la capacidad de absorción de los árboles, va a ser considerada para el presente estudio, de acuerdo a los estudios de diferentes autores. Tales como los realizados por KL Getter, Carbajal Micaela o Manuel Figueroa Clemente. 
El Abstract del artículo Carbon Sequestration Potential of Extensive Green Roofs de KL Getter es el siguiente, y en él se explican las propiedades absorbentes de dióxido de carbono de las cubiertas verdes extensivas, que nos servirán para establecer la capacidad de absorción de las mismas.

"Two studies were conducted with the objective of quantifying the carbon storage potential of extensive green roofs. The first was performed on eight roofs in Michigan and four roofs in Maryland, ranging from 1 to 6 years in age. All 12 green roofs were composed primarily of Sedum species, and substrate depths ranged from 2.5 to $12.7 \mathrm{~cm}$. Aboveground plant material was harvested in the fall of 2006. On average, these roofs stored $162 \mathrm{~g} \mathrm{C} \cdot \mathrm{m}^{-2}$ in aboveground biomass. The second study was conducted on a roof in East Lansing, MI. Twenty plots were established on 21 April 2007 with a substrate depth of $6.0 \mathrm{~cm}$. In addition to a substrate only control, the other plots were sown with a single species of Sedum (S. acre,S. album, S. kamtshaticum, or S. spurium). Species and substrate depth represent typical extensive green roofs in the United States. Plant material and substrate were harvested seven times across two growing seasons. Results at the end of the second year showed that aboveground plant material storage varied by species, ranging from $64 \mathrm{~g} \mathrm{C} \cdot \mathrm{m}^{-2}$ (S. acre) to $239 \mathrm{~g} \mathrm{C} \cdot \mathrm{m}^{-2}$ (S. album), with an average of $168 \mathrm{~g} \mathrm{C} \cdot \mathrm{m}^{-2}$. Belowground biomass ranged from $37 \mathrm{~g} \mathrm{C} \cdot \mathrm{m}^{-2}$ (S. acre) to 185 $\mathrm{g} \mathrm{C} \cdot \mathrm{m}^{-2}$ (S. kamtschaticum) and averaged $107 \mathrm{~g} \mathrm{C} \cdot \mathrm{m}^{-2}$. Substrate carbon content averaged 913 $\mathrm{g} \mathrm{C} \cdot \mathrm{m}^{-2}$, with no species effect, which represents a sequestration rate of $100 \mathrm{~g} \mathrm{C} \cdot \mathrm{m}^{-2}$ over the 2 years of this study. The entire extensive green roof system sequestered $375 \mathrm{~g} \mathrm{C} \cdot \mathrm{m}^{-2}$ in aboveand belowground biomass and substrate organic matter". ${ }^{37}$

De lo que se extrae que una cubierta verde intensiva asimila hasta 0,0003 toneladas de carbono, estableciendo una relación entre valores entre el carbono absorbido con el $\mathrm{CO} 2$ absorbido por otras plantas herbáceas, se pudo establecer una relación aproximada de 0,001 toneladas por cada metro cuadrado de cubierta verde.

Por otra parte, Micaela Carbajal en su artículo describe las cualidades absorbentes de las diferentes plantas presentes en los diferentes cultivos de la región de Murcia, estableciendo los siguientes valores de absorción totales para las siguientes plantas ${ }^{38}$ :

\footnotetext{
${ }^{37}$ Kristin L. Getter, D. et al. (2009) Carbon Sequestration Potential of Extensive Green Roofs. Lansing, Michigan; Departments of Horticulture and Geography, Michigan State University, and Department of Crop and Soil Sciences, W.K. Kellogg Biological Station, Hickory Corners. Abstract Environ. Sci. Technol. 43 (19), pp 7564-7570 DOI: 10.1021/es901539x Copyright @ 2009 American Chemical Society.

${ }^{38}$ Carvajal, Micaela. (2011). "Investigación Sobre La Absorción Del Co2 Por Los Cultivos Más Representativos De La Región De Murcia". CSIC, Revista Horticultura, año XXVIII. n. 294. (pág. 18-31).
} 


\begin{tabular}{|l|r|r|r|r|}
\hline & $\begin{array}{l}\text { CO2 por } \\
\text { planta (gr) }\end{array}$ & $\begin{array}{l}\text { Densidad } \\
\text { plantas por m2 }\end{array}$ & $\begin{array}{l}\text { Total gramos } \\
\text { asimilados por } \\
\text { m2 }\end{array}$ & $\begin{array}{l}\text { Total toneladas } \\
\text { asimiladas por } \\
\text { m2 }\end{array}$ \\
\hline Tomatera & 1590 & 2 & 3180 & 0,00318 \\
\hline Pimiento & 1029 & 2,2 & 2263,8 & 0,0022638 \\
\hline Sandía & 1489 & 0,4 & 595,6 & 0,0005956 \\
\hline Melón & 802 & 1 & 802 & 0,000802 \\
\hline Cogollo & 55,4 & 15 & 831 & 0,000831 \\
\hline Lechuga & 129,8 & 6,5 & 843,7 & 0,0008437 \\
\hline Brócoli Parthenon & 210,4 & 3,5 & 736,4 & 0,0007364 \\
\hline Brócoli Naxos & 238,7 & 3,5 & 835,45 & 0,00083545 \\
\hline Coliflor & 342,5 & 3,5 & 1198,75 & 0,00119875 \\
\hline Alcachofa & 1854 & 0,7 & 1297,8 & 0,0012978 \\
\hline Avena & 10,63 & 128 & 1360,64 & 0,00136064 \\
\hline Cebada & 13 & 100 & 1300 & 0,0013 \\
\hline Trigo & 11 & 125 & 1375 & 0,001375 \\
\hline Albaricoquero & 84498 & 0,0204 & 1723,7592 & 0,001723759 \\
\hline Ciruelo & 40777 & 0,057 & 2324,289 & 0,002324289 \\
\hline Melocotonero & 49771 & 0,057 & 2836,947 & 0,002836947 \\
\hline Nectarina & 46644 & 0,057 & 2658,708 & 0,002658708 \\
\hline Uva de mesa & 23315 & 0,082 & 1911,83 & 0,00191183 \\
\hline
\end{tabular}

Figura 4.6.3.- Capacidades absorción especies de plantas (Micaela Carbajal).

Figueroa Clemente y Susana Redondo Gómez, también analiza la absorción de diferentes especies de plantas, estableciendo el siguiente listado:

Pinus halepensis (Pino carrasco) $48.870 \mathrm{~kg} . \mathrm{CO} 2$ año

Pinus pinea (Pino piñonero) $27.180 \mathrm{~kg} . \mathrm{CO} 2$ año

Melia azederach (Melia) $5.969 \mathrm{~kg} . \mathrm{CO2}$ año = 10.373 coches día

Quercus ilex (Encina) 5.040 kg.CO2 año

Qercus suber (Alcornoque) 4.537 kg.CO2 año

Gleditsia triacanthos $802 \mathrm{~kg}$. CO2 año = 1.619 coches día

Jacaranda ovalifolia (Jacaranda) $1.832 \mathrm{~kg} . \mathrm{CO} 2$ año $=1.405$ coches día

Ulmus minor(Olmo) $762 \mathrm{~kg}$. C.O2 año $=1.320$ coches día

Brachichiton populneum 957 kg.C.O2 año = 1.274 coches día

Citrus aurantium(Naranjo) $555 \mathrm{~kg} . \mathrm{CO} 2$ año $=762$ coches día

Olea europae (Olivo) $570 \mathrm{~kg} . \mathrm{CO} 2$ año

Populus alba (Alamo) $498 \mathrm{~kg} . \mathrm{CO} 2$ año $=831$ coches día

Platanus $x$ hispanica(Platano) 478 kg.CO2 año $=792$ coches día

Cupresus sempervirens $385 \mathrm{~kg} . \mathrm{CO} 2$ año $=629$ coches día

Laurus noviles $384 \mathrm{~kg} . \mathrm{CO} 2$ año $=526$ coches día

Cercis siliquastrum(Arbol del amor) 19 kg.CO2 año = 33 coches día

Prunus cerasifera (Ciruelo japonés 17 kg.CO2 año $=26$ coches día

Catalpa bignonoides(Catalpa) $11 \mathrm{~kg} . \mathrm{CO} 2$ año = 38 coches día

\section{ARBUSTOS}

Viburnun tinus (Durillo) $46 \mathrm{~kg} . \mathrm{CO} 2$ año $=77$ coches día

Chamaerops humlis(Palmito) $40 \mathrm{~kg}$.CO2 año $=63$ coches día

Nerium oleander $31 \mathrm{~kg} . \mathrm{CO} 2$ año $=49$ coches día

Arbutus unedo $28 \mathrm{~kg}$. CO2 año $=47$ coches día

Lantana cámara $6 \mathrm{~kg} . \mathrm{CO} 2$ año $=10$ coches día 
Ligustrum ovalifolium(Aligustre) 1,3 kg.CO2 año = 2 coches día

Myrtus communis(Mirto) 0,6 kg.CO2 año = 0,9 coches día

Pistacea lentiscus(Lentisco) 0,2 kg.CO2 año = 0,5 coches día

(Paspalum paspalodes(Grama) 1,5 kg.CO2 año ${ }^{39}$

Para establecer la absorción por superficie de elemento verde, se establecieron los siguientes datos a partir de la ponderación de la capacidad de absorción de estas especies, y la cantidad de ejemplares que pudieran haber en un metro cuadrado.

De este modo, los datos de absorción por cada metro cuadrado de superficie verde definida en el apartado $1 \mathrm{G} 2$, se establecieron los siguientes valores para la presente tesis. Estos valores van en Toneladas de dióxido de carbono asimiladas por año.

-Pradera o superficie de césped o cubiertas verdes extensivas: 0,0013 $\mathrm{T} \mathrm{CO}^{2} / \mathrm{m}^{2}$ Anuales asimiladas.

-Vegetación arbustiva extensiva, parterres de plantas herbáceas o Huertos urbanos: 0,002 T $\mathrm{CO}^{2} / \mathrm{m}^{2}$ Anuales asimiladas.

-Vegetación arbustiva intensiva, áreas y parterres de arbustos leñosos, cubiertas verdes intensivas (1 ejemplar que asimila 0,035 T CO2 por metro cuadrado): 0,035 T CO $/ \mathrm{m}^{2}$ Anuales asimiladas.

-Superficie arbolada de vegetación de hoja caduca: 0,15 ejemplares que asimilan 1 T CO2 por metro cuadrado): 0,15 $\mathrm{T} \mathrm{CO}^{2} / \mathrm{m}^{2}$ Anuales asimiladas.

-Superficie arbolada de vegetación de hoja perenne (0,15 ejemplares que asimilan 15 T CO2 por metro cuadrado) : 2,25 T CO${ }^{2} / \mathrm{m}^{2}$ Anuales asimiladas.

El último paso, que nos permitirá hallar la absorción total del entorno urbano, consistirá en multiplicar cada una de las tipologías superficies verdes establecidas en el área urbana (1N2), por las cualidades de absorción anteriormente establecidas. El resultado de este análisis será la suma total de todas las toneladas de dióxido de carbono absorbidas por la totalidad de las áreas verdes en el entorno urbano.

Una vez que se han hallado los factores relacionados con el entorno urbano del centro comercial, el siguiente paso es hallar los que regulan las relaciones entre el centro y sus alrededores.

1S: DELIMITACIÓN DE ÁREAS EN FUNCIÓN DE LA RECUPERACIÓN DE AGUAS EN ÁREA URBANA (análisis sobre plano y cuantitativo, unidad metros cuadrados).

\footnotetext{
${ }^{39}$.Figueroa C. et mal. (2009): Ciudad Y Cambio Climático, 707 Medidas Para Luchar Contra El Cambio Climático Desde La Ciudad. 
En esta parte del análisis, van a establecerse tanto la ubicación sobre plano, como las superficies, de las áreas dentro del área urbana, en función de la capacidad y favorabilidad de los mismos para la recuperación de aguas. Para este apartado van a considerarse las siguientes superficies.

-Superficies favorables de cara la recuperación de aguas: este tipo de superficies, son las que de un modo u otro, van a contribuir al mantenimiento del ciclo del agua, o reduzcan el gasto de la misma por parte del centro. Van a considerarse dentro de este apartado:

- Pavimentos urbanos adaptados a la permeabilidad del suelo.

-Superficies verdes, arboladas, o solares sin edificación.

-Cubiertas aljibe.

-Cubiertas o pavimentos, cuyo desagüe de pluviales confluya en un aljibe para consumo de agua del propio centro comercial.

-Huertos urbanos

-Cubiertas verdes de cualquier tipo.

-Superficies desfavorables de cara la recuperación de aguas: este tipo de superficies son las que van a alterar de manera negativa el funcionamiento del ciclo de agua; bien sea porque evitan la captación de agua por parte del suelo, o bien porque favorecen la contaminación de las misma, debido a agentes contaminantes o vertidos de pluviales poco ecológicos. Van a considerarse como superficies desfavorables:

-Pavimentos impermeables de cualquier tipo.

-Zonas con contaminación en el terreno, o vertidos de basuras.

-Superficies edificadas que no cuenten con sistemas de recogida de pluviales.

Este análisis va a establecerse tanto en metros cuadrados en bruto, como en porcentajes respecto a la superficie total del área urbana.

\section{7.- FASE 2: ANÁLISIS DE RELACIONES ENTRE CENTRO COMERCIAL Y ENTORNO URBANO.}

Una vez estudiados los factores en relación a lo que es la escala urbana más amplia, el siguiente paso es el estudio también sobre plano y cuantitativo, de lo que es el área próxima al centro comercial, y la demarcación, abstracción y cuantificación de las relaciones entre lo que es el centro comercial, y el entorno urbano que lo rodea.

2A: DELIMITACIÓN DE ÁREA PRÓXIMA: (Análisis sobre plano).

Para la delimitación de lo que es el área próxima al centro comercial, van a marcarse sobre plano las manzanas al completo, en un área de 100 metros a partir de la línea de la parcela en la que está el centro comercial.

2B: SUPERFICIE TOTAL EDIFICADA EN ÁREA PRÓXIMA: (Análisis cuantitativo, unidad: metros cuadrados). 
Para calcular este factor sobre plano, se va a multiplicar la superficie ocupada por la edificación en planta de las manzanas marcadas en el paso 2A por la altura media de la edificación en área cercana al centro (1E), siendo este dato ponderado al alza o a la baja, en el caso de que los alrededores del centro tengan alturas de edificación que difieran mucho de las del resto del entorno urbano, no van a marcarse en este índice las zonas verdes. Este dato es de gran importancia para hallar la superficie estimada de usos en el entorno de los centros comerciales.

Los datos de superficie total del área ocupada de las manzanas, puede obtenerse midiendo sobre plano, y el número de plantas, puede obtenerse de sacarse de los datos del análisis urbano (1E).

2C: USOS EN ÁREA PRÓXIMA: (Análisis sobre plano y cuantitativo, unidad: metros cuadrados).

Dentro de las manzanas que han sido remarcadas dentro del área próxima (2B), van a marcarse sobre plano los usos, de manera similar a lo estudiado en los apartados $1 \mathrm{l}$ y $1 \mathrm{~J}$, estableciéndose dentro de la superficie construida total, los siguientes usos:

-Metros cuadrados residenciales.

-Metros cuadrados de uso productivo.

-Metros cuadrados de uso comercial. (servirán para establecer grado de complejidad)

2D: FACHADAS ACTIVAS EN ÁREA PRÓXIMA (Análisis sobre plano).

En este análisis, se van a marcar sobre plano las fachadas de los edificios que en planta baja ofrezcan servicios que propicien actividad durante parte del día o en su totalidad. este tipo de usos son generalmente :

- Locales comerciales minoristas.

- Actividades de ocio.

- Actividades institucionales o asistenciales.

Además se estimará un porcentaje de lo que son las fachadas activas respecto del total, dividiendo la longitud total de fachadas activas, entre el total de todas las fachadas.

2E: TIEMPOS DE LLEGADA DESDE LOS PUNTOS EN ÁREA A CENTRO COMERCIAL MEDIANTE TRANSPORTE PÚBLICO: (Análisis cuantitativo y sobre plano, unidad: minutos).

Para este análisis, van a marcarse puntos en los extremos del área urbana establecida en el apartado 1B, y se van a calcular los tiempos de llegada estimados hasta la puerta del centro comercial siguiendo este procedimiento:

1: Medición de distancias: se van a medir las distancias entre el punto asignado y la entrada del centro comercial en metros, considerando en el recorrido las diferentes opciones de transporte público disponibles para ir al centro.

2: Clasificación de los recorridos dentro del trayecto en función al medio de transporte: dentro del trayecto, va a considerarse cada uno de los tramos del recorrido total en función del medio de transporte que va a ser utilizado para cubrirlo, (A pie, metro, tren, autobús) 
3: Cálculo final del tiempo de recorrido: El resultado de este cálculo, va a ser el tiempo invertido en el trayecto en función al medio de transporte indicado en el apartado anterior para este cálculo, van a establecerse en primer lugar los tiempos empleados en el recorrido de acuerdo al medio de transporte. Debido a que los tiempos de llegada son difíciles de prever, ya que intervienen muchos factores no estudiados en esta tesis, habiendo muchos de ellos aleatorios. Para establecer una cierta favorabilidad para los medios de transporte, ambos fueron considerados con el máximo rendimiento y velocidad posibles. Para el transporte público, se eliminaron los tiempos de espera, y el transporte privado fue considerado en su velocidad, con las vías sin problemas de tráfico. No obstante, cuando se analicen los recorridos en transporte público, van a quitarse los tiempos de espera para el análisis cuantitativo, salvo que se traten de trasbordos. Sin embargo, esto va a justificarse en el capítulo relacionado al efecto, para cada centro comercial.

De este modo la fórmula para calcular el tiempo invertido en el desplazamiento es :

Tiempo trayecto $=(D 1 / V 1)+(D 2 / V 2)+\ldots(D n / V n)$

D: Distancia del trayecto en medio de transporte.

V: Velocidad del medio de transporte, en metros por minuto

De este modo, se ilustra la siguiente tabla orientativa de velocidades:

Peatón: $50 \mathrm{~m} / \mathrm{min}$ (aprox $3 \mathrm{~km} / \mathrm{h}$ ).

Autobús urbano: $410 \mathrm{~m} / \mathrm{min}$ (aprox $25 \mathrm{~km} / \mathrm{h}$ ).

Metro o tranvía urbano: $500 \mathrm{~m} / \mathrm{min}$ (aprox $30 \mathrm{~km} / \mathrm{h}$ )

Tren o Autobús interurbano, en vía rápida: $1300 \mathrm{~m} / \mathrm{min}(80 \mathrm{~km} / \mathrm{h})$.

Respecto a tiempos de espera, estos dependen del medio de transporte y la línea, con lo que deben de consultarse en fuentes oficiales de compañías de transporte, para los trayectos caminando o en bicicleta, los tiempos de espera van a considerarse siempre nulos.

2F: TIEMPOS DE LLEGADA DESDE LOS PUNTOS EN ÁREA A CENTRO COMERCIAL MEDIANTE TRANSPORTE PRIVADO: (Análisis cuantitativo y sobre plano, unidad: minutos).

los tiempos empleados en trayectos en transporte privado, van a calcularse de manera similar a los tiempos en transporte público, mediante el siguiente procedimiento:

1: Se marcarán los recorridos más cortos mediante el uso del vehículo particular desde los mismos puntos que fueron marcados para el caso del transporte público (2E), se medirán las distancias de estos recorridos, y se clasificará el tipo de velocidad de acuerdo a la calle por la que se circule, no se van a considerar paradas, y se va a cubrir el trayecto en su totalidad con el mismo medio de transporte.

2: Se calcularán los tiempos de recorrido de acuerdo a la siguiente fórmula, considerando los siguientes factores:

Tiempo trayecto $=(D 1 / V 1)+(D 2 / V 2)+\ldots(D n / V n)$

D: Distancia del trayecto en medio de transporte. 
V: Velocidad del medio de transporte, en metros por minuto

Las velocidades del trayecto en vehículo privado, son las siguientes:

Peatón: $50 \mathrm{~m} / \mathrm{min}$ (aprox $3 \mathrm{~km} / \mathrm{h}$ ).

Circulación congestionada: $150 \mathrm{~m} / \mathrm{min}$ (aprox $15 \mathrm{~km} / \mathrm{h}$ )

Circulación motorizada en vía urbana libre: $660 \mathrm{~m} /$ minuto (aprox $40 \mathrm{~km} / \mathrm{h}$ ).

Circulación motorizada a velocidad elevada (autopistas, carreteras principales interurbanas): $1333 \mathrm{~m} / \mathrm{min}$ (aprox $80 \mathrm{~km} / \mathrm{h}$ ).

No obstante, en muchas áreas, pueden obtenerse los tiempos de trayecto medios, consultando fuentes relacionadas con el tráfico de las vías (Datos oficiales de direcciones de tráfico, aplicaciones de navegación de GPS, Google Maps ${ }^{t m}$...).

2G: ÁREA URBANA CUBIERTA POR EL TRANSPORTE PÚBLICO. (Análisis sobre plano y cuantitativo, unidad metros cuadrados).

Para estimar el área cubierta por el transporte público en la zona de influencia del centro comercial, van a marcarse las paradas de la red de transporte público presentes en el área en primer lugar, independientemente de su naturaleza, para a continuación establecer a partir de ellas un radio de $\mathbf{2 0 0}$ metros cuadrados que va a ser la zona de influencia de la misma. A posteriori, se realizará la suma total de la superficies que abarcan las zonas de influencia de las paradas de transporte público, en metros cuadrados.

\section{8.- FASE 3: ANÁLISIS DEL EDIFICIO DEL CENTRO COMERCIAL.}

3A: DELIMITACIÓN DE ÁREAS EN FUNCIÓN DE LA RECUPERACIÓN DE AGUAS (Análisis sobre plano y cuantitativo, unidad: metros cuadrados).

En esta parte del análisis, van a establecerse tanto la ubicación sobre plano, como las superficies, de las áreas de la parcela y las cubiertas el edificio del centro comercial en función de la capacidad y favorabilidad de los mismos para la recuperación de aguas. Para este apartado van a considerarse las siguientes superficies.

-Superficies favorables de cara la recuperación de aguas: este tipo de superficies, son las que de un modo u otro, van a contribuir al mantenimiento del ciclo del agua, o reduzcan el gasto de la misma por parte del centro. Van a considerarse dentro de este apartado:

- Pavimentos urbanos adaptados a la permeabilidad del suelo.

-Superficies verdes, arboladas, o solares sin edificación.

-Cubiertas aljibe.

-Cubiertas o pavimentos, cuyo desagüe de pluviales confluya en un aljibe para consumo de agua del propio centro comercial.

-Huertos urbanos

-Cubiertas verdes de cualquier tipo. 
-Superficies desfavorables de cara la recuperación de aguas: este tipo de superficies son las que van a alterar de manera negativa el funcionamiento del ciclo de agua; bien sea porque evitan la captación de agua por parte del suelo, o bien porque favorecen la contaminación de las misma, debido a agentes contaminantes o vertidos de pluviales poco ecológicos. Van a considerarse como superficies desfavorables:

-Pavimentos impermeables de cualquier tipo.

-Zonas con contaminación en el terreno, o vertidos de basuras.

-Superficies edificadas que no cuenten con sistemas de recogida de pluviales.

Este análisis va a establecerse tanto en metros cuadrados en bruto, como en porcentajes respecto a la superficie total de parcela.

3B: USOS DENTRO DEL EDIFICIO DEL CENTRO (Análisis sobre plano y cuantitativo, unidad: metros cuadrados).

Este análisis, va a estar centrado principalmente en el desglose aproximado o riguroso de los usos de interés para la presente tesis (1I), dentro de lo que es el edificio del centro comercial. Para el análisis, se van a delimitar exclusivamente los siguientes usos, los cuales van a ser establecidos tanto en metros cuadrados útiles, como en porcentajes respecto al total edificado.

-Espacio productivo,

-Espacio residencial, hoteles o viviendas integradas dentro del complejo.

-Conteo de instalaciones dotacionales.

Este análisis va a establecerse tanto en metros cuadrados en bruto, como en porcentajes, salvo el conteo de dotaciones, que se hará en número de instalaciones.

3C: DELIMITACIÓN DE ÁREAS VERDES EN CENTRO COMERCIAL. (Análisis sobre plano y cuantitativo, unidad: metros cuadrados).

Este dato va a incluir la superficie total verde presente en la parcela del centro comercial, esto quiere decir, cualquier superficie que incluya elementos vegetales, y que pudiera tener relevancia a efectos de asimilación de dióxido de carbono. En el conteo de este factor, van a excluirse las superficies verdes que pudieran ubicarse dentro del edificio del centro comercial, (parques cubiertos o invernaderos) ya que estos no contribuyen en la asimilación del dióxido de carbono del ambiente urbano. No obstante, se van a considerar las superficies verdes que pudieran estar en las cubiertas de los edificios, o bajo una marquesina. Siempre y cuando este espacio no forme parte del interior aclimatado del centro. Estas zonas verdes van a categorizarse de la siguiente manera:

3C1 -Praderas o vegetación extensiva: hierbas o plantas herbáceas de escasa altura (no más de $50 \mathrm{~cm})$.

3C2 -Vegetación arbustiva extensiva: hierbas de gran altura (mayor a $50 \mathrm{~cm}$ ), o arbustos leñosos de pequeño tamaño y baja altura (no más de $30 \mathrm{~cm}$ ).

3C3 -Vegetación arbustiva intensiva: arbustos leñosos o árboles de pequeño tamaño. 
3C4 -Vegetación arbórea caduca: todo tipo de árboles y vegetación leñosa de gran tamaño, que mudan sus hojas.

3C5 -Vegetación arbórea perenne: todo tipo de árboles y vegetación leñosa de gran tamaño, que no muda sus hojas.

3D: ABSORCIÓN DE LAS ÁREAS VERDES EN CENTRO COMERCIAL. (Análisis cuantitativo, unidad toneladas de $\mathrm{CO} 2$ anuales)

Para el cálculo de la absorción de las superficies verdes dentro del centro comercial, se va a utilizar el mismo criterio de absorción definido en el apartado $1 Q$ del análisis, multiplicándose las superficies verdes del centro por los siguientes valores relacionados con la absorción.

-Pradera o superficie de césped o cubiertas verdes extensivas: 0,0013 $\mathrm{T} \mathrm{CO}^{2} / \mathrm{m}^{2}$ Anuales.

-Vegetación arbustiva extensiva, parterres de plantas herbáceas o Huertos urbanos: 0,002 T $\mathrm{CO}^{2} / \mathrm{m}^{2}$ Anuales.

-Vegetación arbustiva intensiva, áreas y parterres de arbustos leñosos, cubiertas verdes intensivas (1 ejemplar que asimila 0,035 T CO2 por metro cuadrado): 0,035 T CO $/ \mathrm{m}^{2}$ Anuales.

-Superficie arbolada de vegetación de hoja caduca: 0,15 ejemplares que asimilan 1 T CO2 por metro cuadrado): $0,15 \mathrm{~T} \mathrm{CO}^{2} / \mathrm{m}^{2}$ Anuales.

-Superficie arbolada de vegetación de hoja perenne (0,15 ejemplares que asimilan 15 T CO2 por metro cuadrado) : 2,25 $\mathrm{T} \mathrm{CO}^{2} / \mathrm{m}^{2}$ Anuales.

El último paso, que nos permitirá hallar la absorción total de dióxido de carbono por parte del las áreas verdes del, consistirá en la suma total de todas las toneladas de dióxido de carbono absorbidas por la totalidad de las áreas verdes en el entorno urbano. El cual se desglosará de la siguiente manera:

- Capacidad de absorción de la parcela del centro comercial.

-Capacidad de absorción del edificio del centro comercial.

3E ANÁLISIS BIOCLIMÁTICO DEL CENTRO COMERCIAL RESPECTO A CLIMA, DIAGRAMA DE GIVONI

El siguiente paso es el análisis de la adaptación y conveniencia de las instalaciones y las medidas pasivas del centro comercial en sí, respecto de su clima.

Para este análisis, en primer lugar se va a realizar u obtener el diagrama de Givoni respecto del clima del centro comercial. Una vez realizado, van a enumerarse todas las medidas activas, pasivas e instalaciones de aclimatación que estuvieran presentes en el edificio del centro comercial, para más tarde ver si estas son convenientes o no respecto a lo estipulado en el diagrama de Givoni. Este estudio es importante, para ver si las medidas de aclimatación van a ser eficaces. 
3F: CALIFICACIÓN ENERGÉTICA DEL CENTRO COMERCIAL. (análisis cuantitativo, van a extraerse datos de consumo energético, y emisiones del centro)

Para ejecutar una simulación energética del centro comercial, pueden utilizarse diversos programas destinados a tal efecto, no obstante el objetivo de la realización de la simulación energética, es obtener una estimación del consumo energético del centro comercial, en relación a sus características volumétricas o bioclimáticas.

la elección del método o el programa a utilizar, para la realización de la simulación energética del mismo dependerá del autor del estudio. (Ecotect, Design Builder, Calener, C3e, Ce3x, Cerma, datos de otras metodologías de evaluación...)

No obstante, de este presente análisis, deben de extraerse dos datos a considerar para la aplicación de la metodología, que son los siguientes:

-Consumo global de energía primaria.

-Emisiones globales anuales de dióxido de carbono.

Siendo obligatorio para la presente metodología, la obtención de la calificación energética de acuerdo a la normativa europea para edificios, que califica estos datos en relación a un baremo que va desde la A (más favorable), a la G (Menos desfavorable).

Es importante remarcar el hecho de que no existe un criterio fijo universal que relacione las cantidades de energía o dióxido de carbono, con los grados de la calificación anteriormente mencionados, pues estos dependen directamente de las características del clima, la forma del edificio, el año de construcción y el uso del mismo entre otros factores. De manera que será necesario el uso de programas de calificación oficiales, de acuerdo a la zona en la que nos ubiquemos.

Esta tesis al tener alcance universal, es necesario tener en cuenta el hecho de que muchos países del mundo, o bien carecen de criterio de evaluación oficial, o bien utilizan otras metodologías de evaluación completamente diferentes a la europea. En este caso, será necesario extrapolar los datos que pudieran obtenerse de la analítica en relación baremo europeo, de manera más o menos estimada.

Para la analítica de los casos de centro comercial de la presente tesis, va a utilizarse el programa Ce $3 \mathrm{x}$, a partir de un modelo estimativo, pero pueden utilizarse otros programas para la realización del mismo, siempre y cuando se extrapolen los datos obtenidos, al criterio europeo de calificación energética, que fue el escogido para la metodología de la presente tesis.

\section{G: USO DE FUENTES DE ENERGÍA LIMPIAS.}

En este apartado, van a obtenerse datos del centro sobre el uso de energías limpias dentro del mismo. En el caso de que esto no fuera posible, se podrá realizar una estimación cuantitativa acerca del uso de las mismas, o consultar fuentes oficiales relacionadas con la ciudad en la que está ubicado el centro, en este apartado van a obtenerse dos resultados: 
-Porcentaje de energía relativo al ahorro energético o a la consecución de calorías de cara al establecimiento de la temperatura de confort mediante el uso de medidas solares activas.

-Porcentaje de energía de consumo del centro suplida por fuentes de energía renovables.

Como energías renovables van a considerarse para el presente trabajo, la eólica, la geotérmica, la solar fototérmica o fotovoltaica, y todas las formas de hidroeléctrica.

3H ESPACIOS CON LUZ NATURAL (Análisis sobre plano y cuantitativo, Unidad Metros cuadrados, porcentaje.)

Este factor a tener en cuenta, va a estar relacionado con la disponibilidad de luz natural de los espacios interiores del centro comercial. Para el análisis de este factor en primer lugar se van a marcar sobre todas las plantas del centro comercial los espacios de acuerdo al siguiente criterio:

-Espacios con alta disponibilidad de luz natural: Se van a marcar en este apartado los espacios interiores que cuentan con un acceso de luz natural, que es capaz de iluminar el espacio sin necesidad de iluminación artificial, o un uso marginal de la misma.

-Espacios con disponibilidad media de luz natural: Este apartado hace referencia a los espacios en los que a pesar de que cuentan con un acceso de luz natural, éste lo ilumina de manera parcial o escasa, predominando el uso de iluminación artificial. Estos espacios para el posterior conteo van a computarse de manera parcial, debido a que estos aunque disponen de luz natural, ésta no es suficiente para iluminar el espacio; No obstante, esta si puede jugar un papel en el consumo energético.

-Espacios sin luz natural: Se van a marcar los espacios que no disponen de ninguna entrada de luz natural.

Una vez marcados estos espacios sobre el plano del centro, se va a computar el total de los metros cuadrados de los diferentes espacios con luz natural de la siguiente manera:

Total $=(\mathrm{ALN}) * 1+(\mathrm{MLN}) * 0,5$

Siendo:

- (ALN) Superficie total de espacios con alta disponibilidad de luz natural.

- (MLN) Superficie total de espacios con disponibilidad media de luz natural.

También será de importancia, la obtención del porcentaje de lo que es el total de los espacios con luz natural del centro, respecto a la superficie total del centro comercial. Dividiendo el total de espacios con luz natural, entre la superficie total construida del centro comercial.

3I FORMA DE LA EDIFICACIÓN: (Análisis cualitativo de la forma del edificio del centro comercial, sobre plano). 
El estudio de la forma del edificio del centro comercial respecto al clima, es un factor a considerar de cara a la rehabilitación sostenible y ecoeficiente de la edificación. Esto se debe al hecho, de que la adaptación de la forma del edificio tanto en planta como en volumen, a las características del clima, es el principio de la eficacia de muchas de las medidas pasivas de aclimatación y ahorro energético.

Para la realización de este análisis cualitativo sobre la planta y el volumen del edificio del centro comercial, se van a tomar en los datos establecidos por Victor Olgyay, para el planeamiento y el proyecto de la edificación con criterio bioclimático, realizándose un resumen de criterios de forma para la presente tesis doctoral, y otros que pudieran ser considerados por el autor de la tesis, que considerará todas las regiones establecidas por olgyay.

Región fría:

-Orientación de la fachada principal del edificio entre los 200 oeste, y los 40 을 este, de azimut, considerando 0 o como la orientación sur.

-Planta con proporciones de volumen básico entre los lados de relación entre 1:1,1 y 1:1,3.

-Asoleo garantizado.

-Protección de los vientos N, NO y O en hemisferio norte, y S, SO y O en Hemisferio Sur.

-Volumen compacto y distribución del edificio en varias plantas.

-Menor superficie de fachada posible.

-Colores de medios a oscuros de fachada.

Región templada:

-Orientación de la fachada principal del edificio entre los 15을 oeste, y los $45 \circ$ este, de azimut, considerando 0 como la orientación sur.

-Planta con proporciones de volumen básico entre los lados de relación 1:1,6 y 1:2,4.

-Asoleo Garantizado sólo durante el invierno.

-Protección de los vientos N, NO y O en hemisferio norte, y S, SO y O en Hemisferio Sur, sólo durante el invierno.

-Volumen no excesivamente distendido o fragmentado.

-Menor superficie de fachada posible.

-Colores de fachada medios.

Región cálida seca:

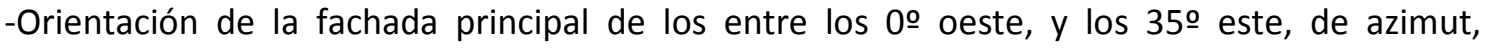
considerando 0 o como la orientación sur.

-Planta con proporciones de volumen básico entre los lados de relación 1:1,3 y 1:1,6

-Inclusión de un patio interior, preferiblemente en orientación norte.

-Evitar asoleo excesivo, especialmente durante el verano.

-Volumen compacto y con el menor desarrollo en altura posible.

-Menor superficie de fachada posible.

-Colores de fachadas fríos y claros.

Región cálida húmeda: 
-Orientación de la fachada principal de los entre los 5o oeste, y los 15으 este, de azimut, considerando 0 o como la orientación sur.

-Planta con proporciones de volumen básico entre los lados de relación 1:1,7 y 1:3

-Inclusión de cubiertas protectoras de la irradiación solar.

-Evitar asoleo excesivo.

-Volumen preferiblemente abierto o fragmentado, y permeable al viento, siempre que este se encuentre cubierto.

-Fachadas protegidas de la irradiación solar.

-Colores de fachada de medios a claros. ${ }^{40}$

De este modo, una vez establecido el criterio, el siguiente paso, es analizar cualitativamente la planta y el volumen del edificio, considerando los elementos urbanos anexos en el caso de ser necesario. En todo momento se comprobará si se cumplen o no las pautas dictadas por Olgyay en relación al clima en el que está ubicado el centro comercial.

\section{J: PAVIMENTOS Y CUBIERTAS EN RELACIÓN A LA INCIDENCIA DE LA IRRADIACIÓN SOLAR.} (Análisis sobre plano y cuantitativo).

Para este análisis, van a recogerse las superficies de cubierta y parcela del centro comercial en su totalidad, las cuales van a ser divididas de acuerdo a la recepción de la luz solar y la acumulación de la misma. La importancia de este análisis radica en el estudio de los efectos de las superficies del centro comercial de cara al efecto de isla térmica.

Para este análisis, van a dividirse las superficies de cubierta y espacio no ocupado dentro de la parcela del centro comercial en su totalidad, de acuerdo a este criterio.

-Superficies receptoras de radiación solar: en esta categorización, van a considerarse todas las superficies que son propensas a la absorción de la irradiación: Para esta tesis van a considerarse estas superficies:

-Pavimentos o superficies asfaltadas.

-Pavimentos o superficies construidas de hormigón de colores oscuros o medios.

-Pavimentos o superficies construidas tratadas con materiales oscuros.

-Superficies de repulsión de radiación solar: en esta categoría, van a considerarse las superficies, que debido a su naturaleza de materiales o colores van a repeler la irradiación solar debido a su composición: Para esta tesis van a considerarse como estas superficies:

-Pavimentos, superficies o áreas construidas con materiales de colores claros, independientemente de su naturaleza.

-Pavimentos o superficies con cualquier tipo de cobertura vegetal.

-Áreas de tierra o solares sin impermeabilizar.

-Áreas que cuentan con arbolado.

De este modo, este tipo de superficies van a ser marcadas, y para este factor, van a sacarse tanto las superficies totales receptoras de radiación solar, como las repelentes, estimándose además el porcentaje de cada una de ellas respecto de la superficie total de cubierta más

\footnotetext{
${ }^{40}$ Olgyay, Victor (Edición de 2008, original:1963), "Arquitectura y Clima". Barcelona, Editorial Gustavo Gili. ISBN: 978-84-252-1488-2.
} 
espacio de parcela, que deberá de coincidir con la suma de superficie receptora, y superficie de repulsión.

\section{9.- CUESTIONARIO DE LA METODOLOGÍA.}

Una vez que se han analizado las diferentes escalas del centro comercial, el siguiente paso es la síntesis de los datos de cara al gráfico conclusivo para el centro comercial en cuestión, de este modo, los datos van a sintetizarse de acuerdo a una serie de preguntas relacionadas con el tipo de rehabilitación.

Cada pregunta establecida en el siguiente baremo, va a tener una serie de respuestas, que van a puntuar de la siguiente manera en el gráfico conclusivo, y cada una de sus áreas estudiadas. A continuación, se explica de manera gráfica el sistema de puntuación.

(poner imagen del gráfico conclusivo y explicación gráfica de la puntuación)

\section{A.- REHABILITACIÓN ECOEFICIENTE:}

Este campo de medidas de rehabilitación, es el que va a considerar lo que es la adaptación del edificio del centro comercial exclusivamente, de cara a lo que es la reducción del consumo energético y las emisiones del mismo a efectos de impacto medioambiental. Se analizarán tanto las instalaciones mecánicas, como la adaptación de lo que es el centro en sí al clima y la disponibilidad de energías renovables. La consideración de este apartado, es importante para lograr un centro comercial de bajo impacto ambiental.

A1.- Instalaciones poco emisivas:

Este apartado del esquema, va a estar relacionado de manera directa, con las emisiones de las instalaciones de acondicionamiento mecánicas del centro comercial. Es decir, las que requieran de fuentes de energía para su correcto funcionamiento. Este apartado, es preciso analizarlo, debido a que estas instalaciones en su funcionamiento van a generar emisiones de dióxido de carbono de manera directa o indirecta, siendo un agravante de este hecho, la presente utilización masiva de este tipo de instalaciones por parte de los centros comerciales. Se va a analizar tanto la adaptación bioclimática de las mismas, como su estado y las emisiones.

Cuestión A1.1.- ¿El centro cuenta con instalaciones que no son necesarias de acuerdo a lo estipulado en el diagrama de Givoni?.

La justificación de esta pregunta, viene dada en base a la intención de buscar la necesidad, y la idoneidad de las instalaciones del centro comercial respecto a su clima correspondiente. El centro comercial ecológicamente sostenible, solamente deberá poseer instalaciones mecánicas (convencionales en el esquema de Givoni), si en alguna época del año estas son necesarias, de acurdo a lo estipulado en el diagrama de Givoni. De este modo, para este análisis va a estudiarse el diagrama de Givoni, considerando exclusivamente las áreas: 10 (humidificación), 11 (instalaciones de refrigeración) y 12 (instalaciones de calefacción). (Figura 3.9.1) 


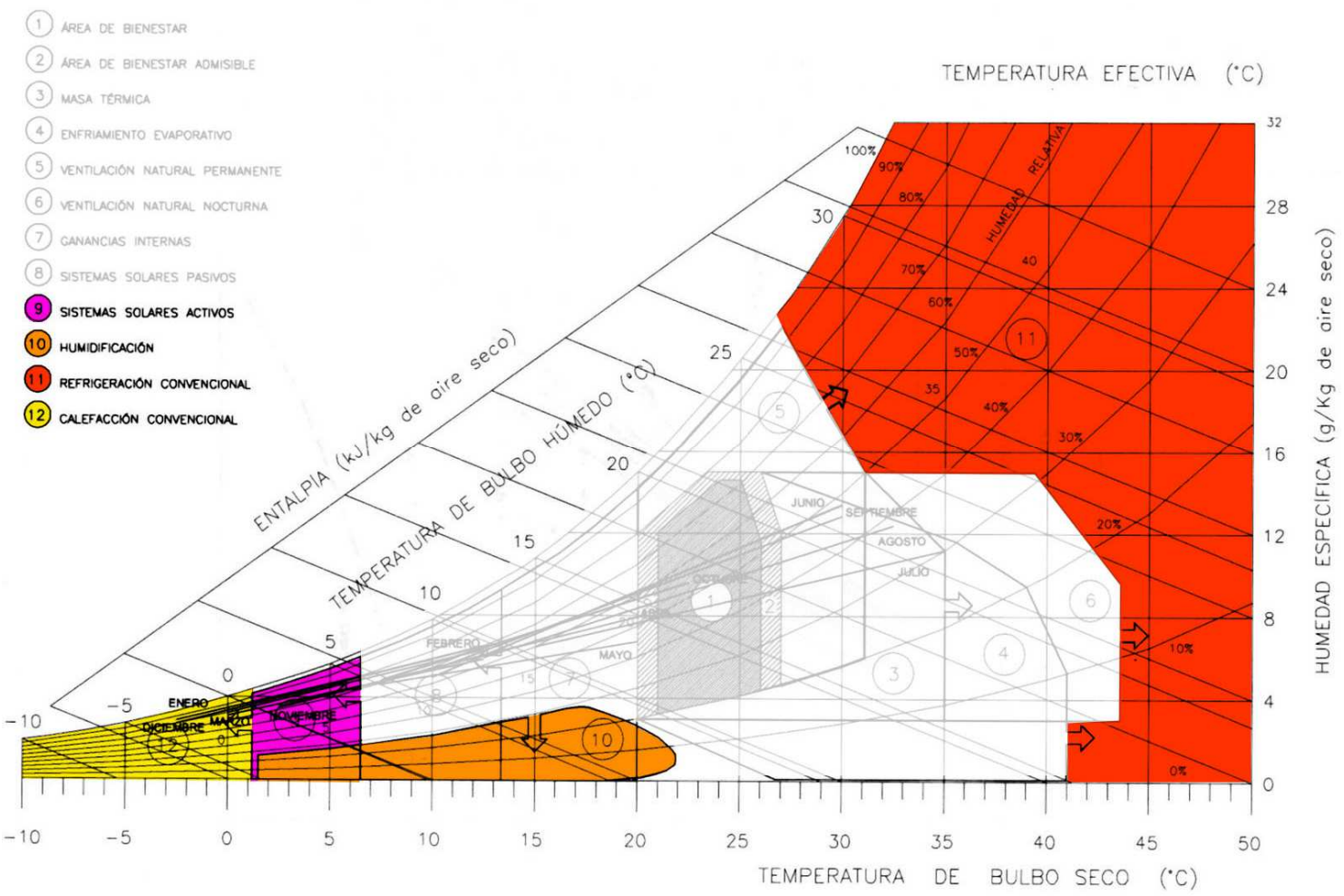

Figura 4.9.1: Áreas del diagrama de Givoni concernientes a este apartado. Fuente: Javier Neila, Ester Higueras.

-Respuesta 1: El centro comercial posee instalaciones que no corresponden a lo aconsejado en el diagrama de Givoni, o carece de las que establece, esta respuesta puntuará como to a la medida de reforma.

-Respuesta 2: El centro comercial no posee instalaciones no requeridas por el diagrama de Givoni, esta respuesta puntuará con +1 a la medida de reforma.

Cuestión A1.2.- ¿Las instalaciones del centro generan unas emisiones de dióxido de carbono superiores a la media?

Como se dijo con anterioridad, En los centros comerciales, al igual que en la mayoría de los edificios, el dióxido de carbono emitido, es en gran parte debido al uso de las instalaciones mecánicas. De este modo, es importante conocer las emisiones derivadas de su funcionamiento, para de esta manera poder definir una línea de actuación eficaz de cara a su reducción.

El criterio con el que esta pregunta va a ser respondida, va a basarse en las calificaciones obtenidas mediante el programa CE3X, a partir de un modelo estimativo lo más parecido posible con la realidad. Para el resultado, el CE3X ponderará las emisiones, de acuerdo a la calificación general de las mismas, obteniendo así el dióxido de carbono por metro cuadrado y año, que emite el conjunto de las instalaciones del centro comercial y su correspondiente calificación media, que irá de la $\mathrm{A}$ (menores emisiones) a la $\mathrm{G}$ (mayores emisiones). 
-Respuesta 1: Las instalaciones del centro comercial han obtenido una calificación energética desfavorable a efectos de emisiones (F-G). La respuesta puntúa con +0

-Respuesta 2: Las instalaciones del centro comercial han obtenido una calificación energética media-baja a efectos de emisiones (E). La respuesta puntúa con +1

-Respuesta 3: Las instalaciones del centro comercial han obtenido una calificación energética media a efectos de consumo de emisiones (D). La respuesta puntúa con +2

-Respuesta 3: Las instalaciones del centro comercial han obtenido una calificación energética favorable a efectos de emisiones $(B-C)$. La respuesta puntúa con +3

-Respuesta 4: El centro comercial en instalaciones ha obtenido una calificación máxima en emisiones (A). La respuesta puntúa con un +4

Cuestión A1.3.- ¿ ¿as instalaciones del centro se encuentran en un estado de obsolescencia?

La obsolescencia de las instalaciones de un centro comercial, generalmente es causa de un rendimiento menor en sus prestaciones de cara a la aclimatación del mismo, conllevando esto una mayor cantidad de emisiones. En esta pregunta, para considerar una instalación como obsoleta, va a establecerse una vida útil de veinte años ${ }^{41}$.

-Respuesta 1: Las instalaciones del centro comercial tienen más de quince años. La respuesta puntúa con +0 .

-Respuesta 2: Las instalaciones del centro comercial tienen menos de quince años. La respuesta puntúa con +1 .

Cuestión A1.4.- ¿Las instalaciones del centro tienen un consumo energético superior a la media?.

Esta cuestión es de importancia, debido a que es la que va a ponderar la eficiencia energética de las instalaciones, y su capacidad para generar las condiciones de confort dentro del centro comercial. Se buscará en todo momento el menor consumo de energía como garante de la eficiencia energética, que siempre lleva consigo una reducción de las emisiones de manera indirecta, sobre todo si para suplir la demanda de energía del centro se utilizan fuentes de energía contaminantes.

-Respuesta 1: Las instalaciones del centro comercial han obtenido una calificación energética desfavorable a efectos de consumo de energía (F-G). La respuesta puntúa con +0

\footnotetext{
${ }^{41}$ E.A.P.E. Domínguez, Samuel (2010): Curso De Patologías En La Edificación, Junta de Extremadura, Universidad de Sevilla . http://fomento.gobex.es/fomento/live/informacionciudadano/Arquitectura/Documentacion/patologiaclimatizacion.pdf
} 
-Respuesta 2: Las instalaciones del centro comercial han obtenido una calificación energética media-baja a efectos de consumo de energía (E). La respuesta puntúa con +1

-Respuesta 3: Las instalaciones del centro comercial han obtenido una calificación energética media a efectos de consumo de energía (D). La respuesta puntúa con +2

-Respuesta 4: Las instalaciones del centro comercial han obtenido una calificación energética favorable a efectos de consumo de energía (B-C). La respuesta puntúa con +3

-Respuesta 5: El centro comercial en instalaciones ha obtenido una calificación máxima en emisiones (A). La respuesta puntúa con un +4

\section{A2.- Medidas activas:}

Para esta pregunta, van a considerarse como medidas activas de acondicionamiento bioclimático, todas las medidas mecánicas que sirvan para el acondicionamiento del centro, las cuales no demanden energía para su funcionamiento. También se considerarán como medidas activas, cualquier instalación que sirva para generar energías renovables o de muy bajas emisiones, o las enfocadas en la reutilización de la energía del centro. Estas instalaciones juegan un papel muy importante en la consolidación del centro comercial ecológicamente sostenible y de bajas emisiones, y de este modo es necesario que se analicen las capacidades de las mismas.

Cuestión A2.1.- ¿Qué porcentaje de las calorías necesarias para lograr la temperatura de confort se logra mediante sistemas activos?

El uso de los sistemas activos para conseguir las condiciones de confort de un centro comercial, juega un papel de gran importancia a la hora de lograr la reducción de las emisiones de dióxido de carbono. Esto se debe, a que muchas veces los sistemas activos pueden ser una alternativa ecológicamente limpia a las instalaciones mecánicas convencionales, para lograr las condiciones de confort. Para esta cuestión, van a definirse porcentajes que van a considerar en mayor o menor medida la contribución energética del uso de estos sistemas para lograr la temperatura de confort.

-Respuesta 1: El centro comercial no posee medidas activas para el establecimiento de la temperatura de confort, esta respuesta puntúa como +o

-Respuesta 2: El centro comercial posee medidas activas que suplen hasta el $10 \%$ de la demanda de energía para el establecimiento de la temperatura de confort, esta respuesta puntúa como +1

-Respuesta 3: El centro comercial posee medidas activas que suplen hasta el $30 \%$ de la demanda de energía para el establecimiento de la temperatura de confort, esta respuesta puntúa como +2 
-Respuesta 4: El centro comercial posee medidas activas que suplen hasta el 50\% de la demanda de energía para el establecimiento de la temperatura de confort, esta respuesta puntúa como +3

-Respuesta 5: El centro comercial posee medidas activas que suplen más del $70 \%$ de la demanda de energía para el establecimiento de la temperatura de confort, esta respuesta puntúa como +4

Cuestión A2.2.- ¿Qué porcentaje de la demanda energética se logra a partir de fuentes de energía renovable?

Al igual que cualquier edificio, un centro comercial, de manera inevitable va a demandar energía para el funcionamiento de sus instalaciones. Siendo una realidad el hecho de que muchas fuentes de energía generan gran cantidad de contaminantes aéreos o terrestres. De este modo, es de importancia considerar la naturaleza de las fuentes que van a ser utilizadas para suplir esta demanda. Considerando como benigno de cara al medio ambiente la utilización de energías que no generen contaminación de ningún tipo, o que la generen de manera reducida. Esta cuestión se considerará en base a porcentajes que ponderarán la cantidad de energía de consumo del centro, procedente de fuentes renovables.

-Respuesta 1: El centro comercial no posee medidas activas para el establecimiento de la temperatura de confort, esta respuesta puntúa como +0

-Respuesta 2: El centro comercial posee medidas activas que suplen hasta el $10 \%$ de la demanda de energía para el establecimiento de la temperatura de confort, esta respuesta puntúa como +1

-Respuesta 3: El centro comercial posee medidas activas que suplen hasta el 30\% de la demanda de energía para el establecimiento de la temperatura de confort, esta respuesta puntúa como +2

-Respuesta 4: El centro comercial posee medidas activas que suplen más del $50 \%$ de la demanda de energía para el establecimiento de la temperatura de confort, esta respuesta puntúa como +3

-Respuesta 5: El centro comercial posee medidas activas que suplen más del $70 \%$ de la demanda de energía para el establecimiento de la temperatura de confort, esta respuesta puntúa como +4

Cuestión A2.3.- ¿El centro cuenta con las medidas y dispositivos necesarios para su aclimatación de acuerdo a lo estipulado en el diagrama de Givoni para sistemas solares activos?. 
La adecuación de los sistemas solares activos de cara a la aclimatación del centro, siempre va a estar justificada por el clima en el que se encuentra. De este modo, es importante estudiar esta adecuación bioclimática, para poder ver la eficacia real de estos sistemas de cara a la aclimatación mediante dispositivos de impacto ambiental nulo o reducido. De este modo, para este estudio va a estudiarse el diagrama de Givoni del clima en el que está ubicado el centro, considerando dentro del mismo si los sistemas activos que posee el centro son los que establece este diagrama. En este análisis van a considerarse las áreas 9 (Sistemas solares activos), y 10 (humidificación).

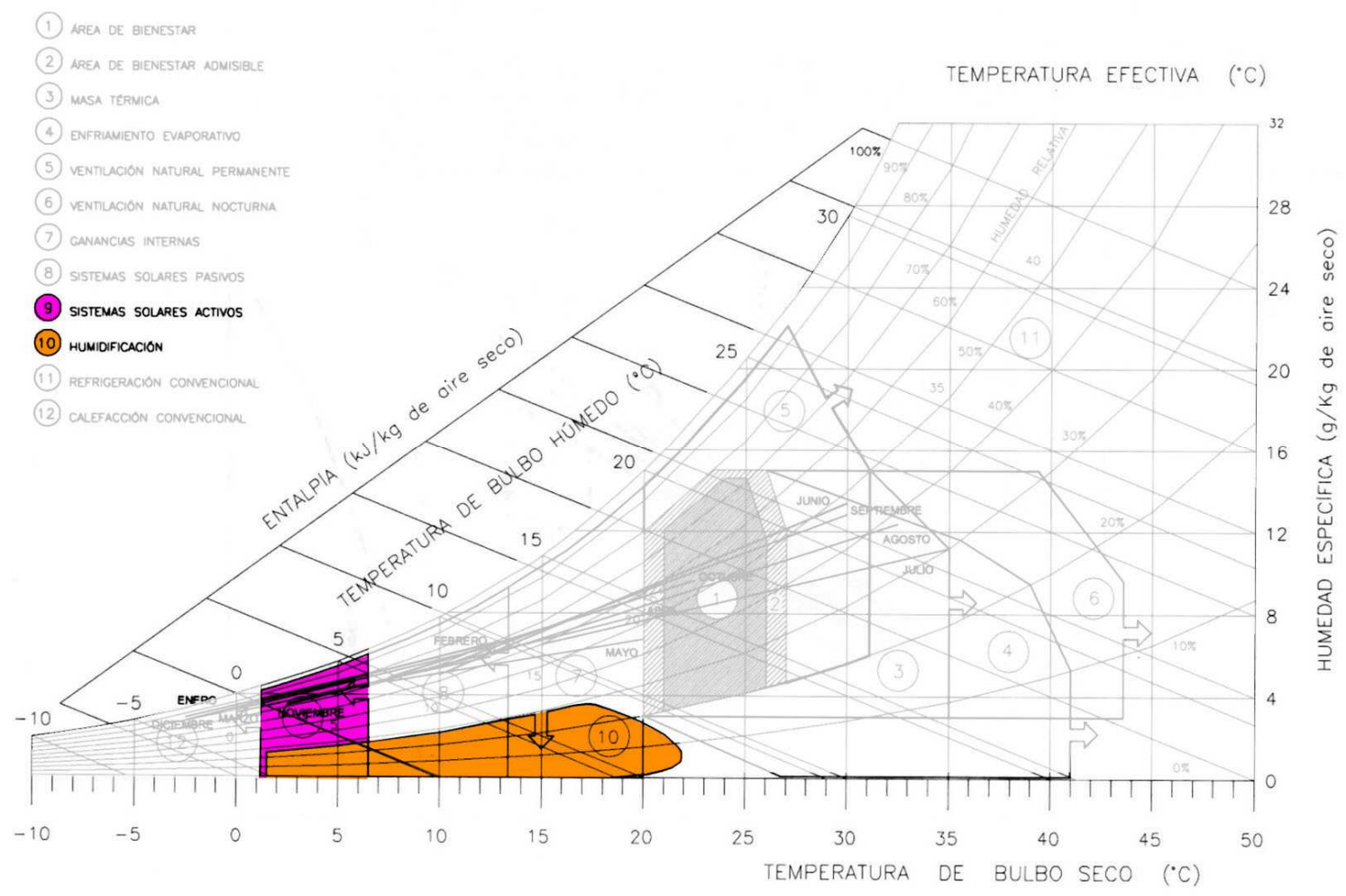

Figura 4.9.2: Áreas del diagrama de Givoni concernientes a este apartado. Fuente: Javier Neila, Ester Higueras.

-Respuesta 1: El centro comercial no posee ninguna instalación activa que corresponda a lo aconsejado en el diagrama de Givoni respectivo (Figura 3.9.2), esta respuesta puntuará como +O a la medida de reforma.

-Respuesta 2: El centro comercial posee algunas instalaciones activas requeridas por el diagrama de Givoni, esta respuesta puntuará con +1 a la medida de reforma.

-Respuesta 3: El centro comercial posee todo tipo de instalaciones activas adaptadas a cada zona del diagrama de Givoni en relación con la pregunta (Figura 3.9.1), esta respuesta puntuará con un +2 a la medida de reforma.

\section{A3.- Medidas pasivas:}

El estudio de las medidas pasivas va a referenciarse generalmente a la adecuación bioclimática del edificio del centro comercial, estudiando en este apartado las características y adaptación 
de sus sistemas constructivos, huecos y cerramientos, sin contar en ningún momento con las instalaciones que este pudiera tener. La justificación de este estudio, se fundamenta en el hecho de que la base del ahorro energético en la edificación, empieza con la adaptación del edificio al clima a partir de la configuración de sus espacios exteriores e interiores, así como el correcto control de las pérdidas y las ganancias de energía del acondicionamiento del mismo a través de los cerramientos.

A3.1.- ¿El centro comercial tiene una forma adecuada en volumen a las condiciones climáticas?:

El estudio de la volumetría del edificio en relación al clima es una cuestión de gran importancia para el estudio bioclimático de los centros comerciales y otros edificios. Esto se debe al hecho, de que para proyectar un edificio con criterio bioclimático, las decisiones de cara a la consideración de las medidas pasivas de acondicionamiento, deben de ser establecidas en las fases más tempranas del proyecto (anteproyecto o proyecto básico) mediante la adaptación de lo que es la planta y el volumen del futuro edificio con respecto al clima en el que está ubicado. Esto es debido a que la forma del edificio va a condicionar en gran medida la eficacia de las medidas pasivas a efectos de acondicionamiento, siendo además patente el hecho de que resulta muy complicado alterar el volumen de un edificio ya construido.

De este modo, Para responder a esta pregunta, se va a tomar la volumetría y la forma en planta del centro comercial, y se va a comparar con lo establecido para las edificaciones por Victor Olgyay para cada zona climática del planeta.

\section{REGIÓN FRÍA}

-Orientación de la fachada principal del edificio entre los 20 o oeste, y los 40 o este, de azimut, considerando 0 o como la orientación sur, o norte en el Hemisferio Sur.

-Planta con proporciones de volumen básico entre los lados de relación entre 1:1,1 y 1:1,3.

-Asoleo garantizado.

-Protección de los vientos $N$, NO y O en hemisferio norte, y S, SO y O en Hemisferio Sur.

-Volumen compacto y distribución del edificio en varias plantas.

-Menor superficie de fachada posible.

-Colores de medios a oscuros de fachada.

\section{REGIÓN TEMPLADA}

-Orientación de la fachada principal del edificio entre los 150 oeste, y los 45 este, de azimut, considerando 0 o como la orientación sur, o norte en el Hemisferio Sur.

-Planta con proporciones de volumen básico entre los lados de relación 1:1,6 y 1:2,4.

-Asoleo Garantizado sólo durante el invierno.

-Protección de los vientos $N, N O$ y $O$ en hemisferio norte, y $S$, SO y O en Hemisferio Sur, sólo durante el invierno.

-Volumen no excesivamente distendido o fragmentado.

-Menor superficie de fachada posible.

-Colores de fachada medios.

\section{REGIÓN CÁLIDA SECA}


-Orientación de la fachada principal de los entre los 0 o oeste, y los 350 este, de azimut, considerando 0 o como la orientación sur.

-Planta con proporciones de volumen básico entre los lados de relación 1:1,3 y 1:1,6

-Inclusión de un patio interior, preferiblemente en orientación norte.

-Evitar asoleo excesivo, especialmente durante el verano.

-Volumen compacto y con el menor desarrollo en altura posible.

- Menor superficie de fachada posible.

-Colores de fachadas fríos y claros.

\section{REGIÓN CÁLIDA HÚMEDA}

-Orientación de la fachada principal de los entre los 5o oeste, y los 150 este, de azimut, considerando 0 o como la orientación sur.

-Planta con proporciones de volumen básico entre los lados de relación 1:1,7 y 1:3

-Inclusión de cubiertas protectoras de la irradiación solar.

- Evitar asoleo excesivo.

-Volumen preferiblemente abierto o fragmentado, y permeable al viento, siempre que este se encuentre cubierto.

-Fachadas protegidas de la irradiación solar.

-Colores de fachada de medios a claros. ${ }^{42}$

-Respuesta 1: El centro comercial no concuerda en ningún aspecto con las características formales estipuladas para esa zona climática, esta respuesta puntúa como +0

-Respuesta 2: El centro comercial concuerda de manera parcial con las características formales estipuladas para esa zona climática, esta respuesta puntúa como +1

-Respuesta 3: El centro comercial concuerda en la mayoría de los aspectos con las características formales estipuladas para su clima de acuerdo a Olgyay, esta respuesta puntúa como +2

A3.2.- ¿El estado de los cerramientos responde de manera correcta a las exigencias del clima en el que se asienta?.

El cerramiento de un edificio es el principal elemento encargado de mantener las condiciones de confort en su interior, ya que éste impide la transmitancia de energía entre el interior y el exterior en mayor o menor medida.

Dentro de los cerramientos, cabe remarcar la importancia de los huecos, los cuales además de suponer pérdida de energía, también pueden suponer ganancias. De este modo, es un asunto de importancia para la presente tesis doctoral, el estudio del cerramiento en su totalidad a efectos de adaptación a las exigencias del clima.

Para este estudio, van a recopilarse los datos de la simulación referidos a las demandas de calefacción y refrigeración, buscándose una demanda media de energía cuya calificación en baremo de la $\mathrm{A}$ a la $\mathrm{G}$, será el dato que se utilizará para ponderar los resultados.

\footnotetext{
${ }^{42}$ Olgyay, Victor (Edición de 2008, original:1963), "Arquitectura y Clima". Barcelona, Editorial Gustavo Gili. ISBN: 978-84-252-1488-2.
} 
-Respuesta 1: La media de demanda de energía del centro comercial entre calefacción y refrigeración está dentro de una calificación energética desfavorable a efectos de consumo de energía (F-G). La respuesta puntúa con +0

-Respuesta 2: La media de demanda de energía del centro comercial entre calefacción y refrigeración está dentro de una calificación energética media-baja a efectos de consumo de energía (E). La respuesta puntúa con +1

-Respuesta 2: La media de demanda de energía del centro comercial entre calefacción y refrigeración está dentro de una calificación energética media a efectos de consumo de energía (D). La respuesta puntúa con +2

-Respuesta 3: La media de demanda de energía del centro comercial entre calefacción y refrigeración está dentro de una calificación energética favorable a efectos de consumo de energía $(B-C)$. La respuesta puntúa con +3

-Respuesta 4: La media de demanda de energía del centro comercial entre calefacción y refrigeración está dentro de una calificación máxima en emisiones (A). La respuesta puntúa con un +4

A3.3.- ¿Qué porcentaje de los espacios del centro cuentan con iluminación natural?.

La luz es un elemento necesario en los interiores del edificio, debido a que esta es necesaria para la percepción por parte de los humanos. Por consiguiente cualquier espacio transitable dentro de un edificio, va a buscar unas condiciones de iluminación de acuerdo a su función. De este modo, la búsqueda de las condiciones lumínicas anteriormente mencionadas, puede hacerse mediante medios mecánicos, siendo una opción a considerar el uso de la luz natural derivada de la irradiación solar. Para esta tesis, el uso de la luz natural para la iluminación del espacio interior en la medida de lo posible, siempre va a ser un elemento favorable a efectos de sostenibilidad, debido al hecho de que esta luz puede obtenerse sin coste energético.

Para esta cuestión, se considerarán los espacios del centro comercial, que cuenten con iluminación natural en superficie. Este dato va a establecerse en forma de porcentaje, respecto al total de la superficie del centro.

-Respuesta 1: Menos del 20\% de los espacios del centro comercial cuentan con luz natural. Puntúa como +0.

-Respuesta 2: Entre el 20 y el 60\% de la superficie del centro, cuenta con luz natural. Puntúa con +1 .

-Respuesta 3: Más del 60\% de la superficie del centro comercial cuenta con luz natural. Puntúa con +2 . 
A3.4.- Los espacios del centro, están adaptados a lo estipulado por el Diagrama de Givoni de su respectivo clima?

El contenido de esta pregunta está referido a la adaptación pasiva de los espacios del centro comercial en sí, en referencia a las exigencias del diagrama de Givoni para alcanzar la temperatura de confort sin recurrir a sistemas automatizados de acondicionamiento. La importancia de esta pregunta, radica en el hecho de que la adaptación de los espacios a las características del diagrama anteriormente mencionado, es una de las bases de la arquitectura bioclimática, y de este modo, cualquier espacio que considere las medidas propuestas por el diagrama de Givoni, va a suponer un importante ahorro energético para el edificio.

Para esta pregunta, van a considerarse los espacios tanto interiores, como exteriores del centro comercial a estudiar, los cuales van ser comparados con las áreas del diagrama de Givoni correspondientes a las zonas: 3 (Masa térmica), 4 (enfriamiento evaporativo), 5 (ventilación natural permanente), 6 (ventilación natural nocturna), 7 (ganancias internas) y 8 (sistemas solares pasivos). Se comprobará que los espacios más importantes del centro comercial dispongan de una o varias de estas medidas para puntuar esta pregunta en positivo.

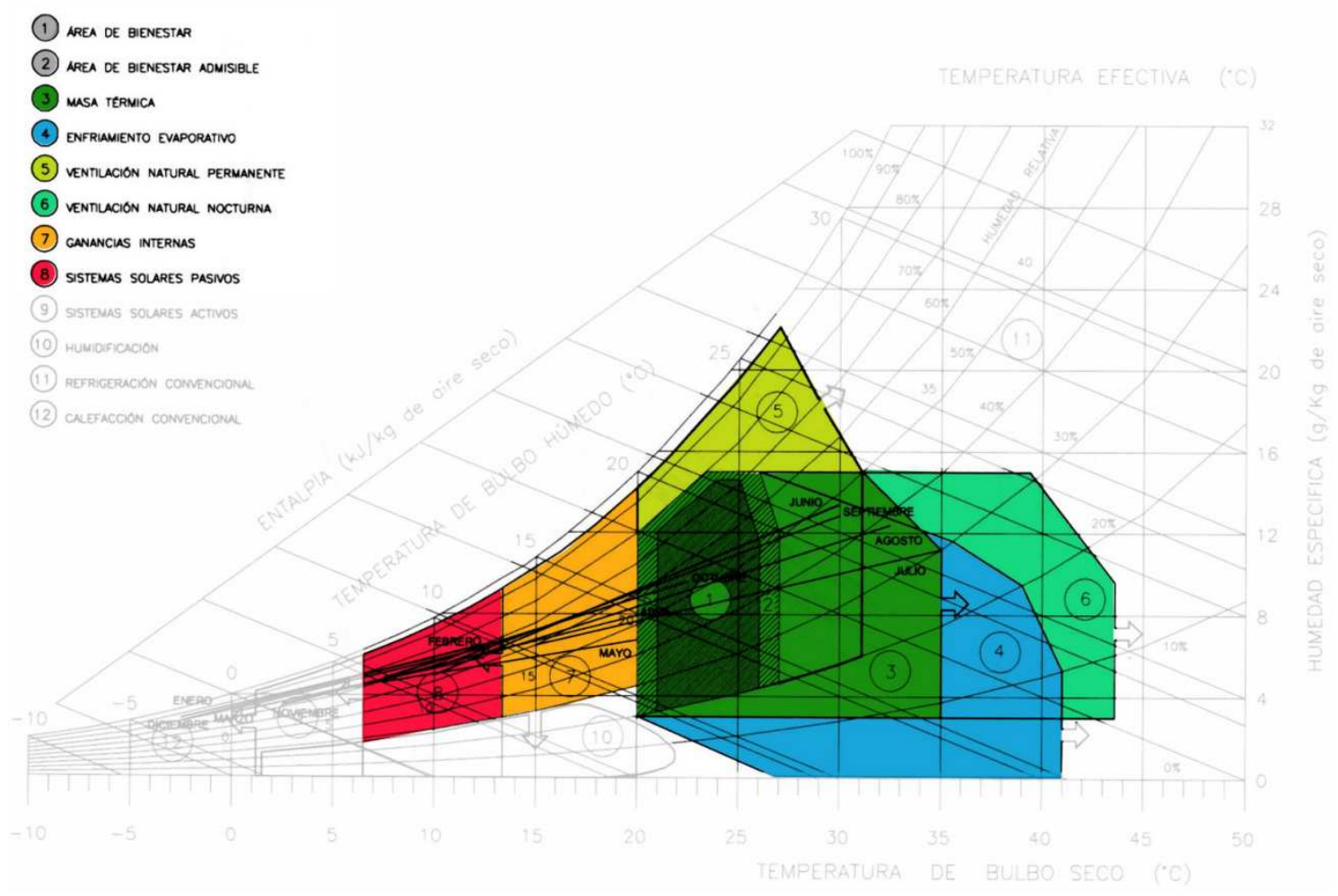

Figura 4.9.3: Áreas del diagrama de Givoni concernientes a este apartado. Fuente: Javier Neila, Ester Higueras.

-Respuesta 1: Ninguno de los espacios del centro comercial está adaptado a los condicionantes del diagrama de Givoni para su respectivo clima. Puntúa con +0 .

-Respuesta 2: En el centro existen espacios dentro del centro comercial, que están concebidos o cuentan con algunas de las medidas establecidas en el diagrama de Givoni. Puntúa con +1 
-Respuesta 3: La mayoría de los espacios del centro comercial están adaptados o cuentan con las medidas establecidas por el diagrama de Givoni. Puntúa con +2

\section{B.- REHABILITACIÓN MEDIOAMBIENTAL:}

Este campo de medidas de rehabilitación, va a comprender el estudio del comportamiento medioambiental del centro comercial sobre el entorno y el medio ambiente(aire, agua, suelo y temperatura), estando centrada cada una de las medidas de rehabilitación en la consecución de un centro comercial cuyo funcionamiento resulte más benigno de cara a los cuatro ámbitos anteriormente mencionados, considerando la inclusión de elementos que favorezcan este fin.

De este modo, las medidas de este campo de la rehabilitación, van a estar centradas en los ámbitos de la mejora de la calidad del aire mediante la inclusión las superficies verdes, la asimilación y recuperación del agua por parte del suelo, y el comportamiento benigno del centro comercial de cara a la mitigación del efecto de isla de calor.

\section{B1.- Rehabilitación mediante zonas verdes:}

Las zonas verdes dentro de un área urbana son de gran importancia, debido a la capacidad de asimilación que estas tienen de cara a lo que es la reducción de los gases de efecto invernadero y otros componentes nocivos presentes en la atmósfera de la ciudad. Además, las zonas verdes juegan un papel fundamental en el tema los usos urbanos, teniendo un efecto positivo para los habitantes de la ciudad, como decoración, o área de ocio.

En este apartado va a estudiarse lo que es el área urbana circundante al centro comercial, además de lo que es el centro comercial en sí y su parcela, analizando la cantidad de zona verde que hay presente. Se ponderará si esta va a resultar suficiente o no, de acuerdo a la naturaleza de la cuestión.

Cuestión B1.1.- ¿En el área urbana hay suficiente zona verde en el área en relación a sus habitantes?.

En esta pregunta va a estudiarse exclusivamente la superficie de zona verde que hay en el área urbana circundante al centro exclusivamente. La justificación de esta cuestión es ver si es necesario o va a resultar viable incluir áreas verdes en lo que es el centro comercial en sí. El baremo mínimo para este análisis va a ser de 10 metros cuadrados por habitante (deseable 20), dictado por el Plan Especial de Indicadores de Sostenibilidad Ambiental de la Actividad Urbanística de Sevilla. ${ }^{43}$

-Respuesta 1: La superficie verde por habitante en el área de análisis es inferior a $10 m^{2}$ por habitante. Puntúa con +0 .

\footnotetext{
${ }^{43}$ Ayuntamiento de Sevilla, Agencia de Ecología Urbana de Barcelona, Rueda, Salvador (2008) Plan Especial de Indicadores de Sostenibilidad Ambiental de la Actividad Urbanística de Sevilla.
} 
-Respuesta 2: La superficie verde por habitante en el área de análisis está entre $10 \mathrm{y} 20 \mathrm{~m}^{2}$ por habitante. Puntúa con +1.

-Respuesta 2: La superficie verde por habitante en el área de análisis es mayor a $20 m^{2}$ por habitante. Puntúa con +2 .

Cuestión B1.2.- ¿Las zonas verdes dentro del centro comercial pueden dar lugar a una área verde de uso cotidiano?.

Como primer acercamiento al dimensionamiento de las áreas de un centro comercial, el primer paso es establecer si hay suficiente zona verde dentro del mismo, de acuerdo al número de clientes que éste tiene asignado. Debido a que la superficie de un centro comercial está muy limitada, resulta inviable aplicar el baremo dictado en la anterior cuestión, de manera que para éste se establecerá una dimensión mínima, que será el del área de uso cotidiano establecida por Salvador Rueda $\left(1000 \mathrm{~m}^{2}\right.$ ) (Figura 3.9.4), ya que ésta instalación va a jugar el papel de ser un parque de jerarquía inferior, debido a la limitación de espacio mencionada anteriormente. Este factor, es más determinante y relevante en centros comerciales ubicados en áreas urbanas céntricas de gran densidad, en las que el espacio verde escasea. Para esta cuestión no se computarán las medianas de aparcamientos o las jardineras, ya que aunque son elementos verdes, no están pensados como espacios estancia.

-Respuesta 1: La superficie verde del centro comercial es inferior a $1000 m^{2}$. Puntúa con +0.

-Respuesta 2: La superficie verde del centro comercial es igual o superior $1000 m^{2}$. Puntúa con +1 .

Cuestión B1.3.- ¿La vegetación en el área (incluyendo el edificio del centro), en que porcentaje es capaz de asimilar las emisiones de la misma área urbana?.

El área urbana del centro comercial, genera emisiones de de gases nocivos que deben de ser asimilados debido a los efectos perniciosos que estos tienen sobre la atmósfera. Estando éstos presentes en lo que es el medio urbano. De este modo se ponderará si la vegetación del área urbana del área es suficiente para asimilar las emisiones de la misma área en mayor o menor medida.

-Respuesta 1: La capacidad de asimilación de dióxido de carbono de las zonas verdes del área urbana, es inferior a un $10 \%$ de la huella de carbono del área urbana, esta respuesta puntúa como +0

-Respuesta 2: La capacidad de asimilación de dióxido de carbono de las zonas verdes del área urbana, está entre un 10 y un $40 \%$ de la huella de carbono del área, esta respuesta puntúa como +1 
-Respuesta 3: La capacidad de asimilación de dióxido de carbono de las zonas verdes del área urbana, está entre un 40 y un $70 \%$ de la huella de carbono del área, esta respuesta puntúa como +2

-Respuesta 4: La capacidad de asimilación de dióxido de carbono de las zonas verdes del área urbana, es superior a un $70 \%$ de la huella de carbono del área, esta respuesta puntúa como +3

Cuestión B1.4.- ¿La vegetación en el centro comercial y su parcela, en que porcentaje es capaz de asimilar las emisiones del centro comercial?.

Como paso adelante de la anterior cuestión, a efectos de asimilación de gases, es deseable que el edificio del centro comercial posea las instalaciones para llevar a cabo este fin, y así lograr que esta instalación a escala global urbana tenga la menor huella de carbono posible. No obstante, en esta cuestión el baremo va a ser más reducido, debido a las limitaciones en la presencia de vegetación.

-Respuesta 1: La capacidad de asimilación de dióxido de carbono de las zonas verdes del centro comercial, es inferior a un $10 \%$ de la huella de carbono del centro, esta respuesta puntúa como $+0$

-Respuesta 2: La capacidad de asimilación de dióxido de carbono de las zonas verdes del centro comercial, está entre un 10 y un 30\% de la huella de carbono del centro, esta respuesta puntúa como +1

-Respuesta 3: La capacidad de asimilación de dióxido de carbono de las zonas verdes del centro comercial, está entre un 30 y un 50\% de la huella de carbono del centro, esta respuesta puntúa como +2

-Respuesta 4: La capacidad de asimilación de dióxido de carbono de las zonas verdes del centro comercial, es superior a un $50 \%$ de la huella de carbono del centro, esta respuesta puntúa como +3

Cuestión B1.5.- ¿La distancia media entre espacios verdes dentro del área es inferior a los 400 metros?

Salvador Rueda en el Plan de Indicadores de Sevilla, establece unas jerarquías de espacios verdes en referencia a su superficie, además de unas distancias mínimas entre éstos espacios verdes $^{2}$, (Figura 3.9.4) 


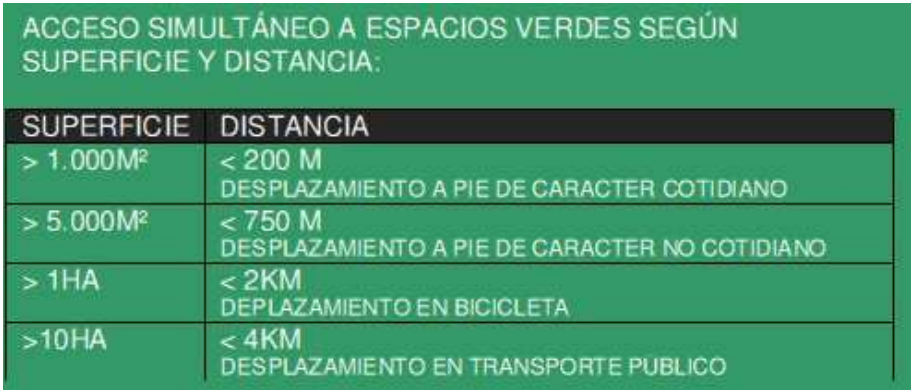

Figura 4.9.4: Jerarquías de espacios verdes de acuerdo a su superficie, y distancias. Fuente: S. Rueda.

Para establecer el criterio de valoración a esta cuestión, el primer paso es establecer la jerarquía en la que va a ubicarse un espacio verde que pudiera generarse en la unidad urbanística del centro comercial, y considerando la limitación de espacio en el mismo, éste espacio verde estaría dentro de la jerarquía más primaria (Hasta 1000 metros cuadrados), siendo la distancia entre estos espacios de $\mathbf{4 0 0}$ metros, ya que la distancia de 200 metros de Salvador Rueda, está referida a un punto intermedio entre áreas verdes.

De este modo para esta cuestión, van a localizarse los espacios verdes en el área de influencia del centro, considerando las distancias entre los mismos, se puntuará como positiva esta cuestión, si la distancia media entre estos espacios es inferior a los 400 metros.

-Respuesta 1: La distancia media entre espacios verdes dentro del área, es superior a los 400 metros, esta respuesta puntúa como +0

-Respuesta 2: La distancia media entre espacios verdes dentro del área, es inferior a los 400 metros, esta respuesta puntúa como +1

B2.- Rehabilitación mediante inserción de superficie asimiladora de agua:

El agua es una de las componentes fundamentales para el sustento de cualquier ser vivo del planeta, y un recurso escaso que debe de ser utilizado de manera correcta. De este modo toda rehabilitación medioambiental enfocada sobre cualquier centro comercial u otro tipo de edificio, deberá de considerar la correcta gestión y captación del agua, especialmente en climas propensos a la sequía.

En el caso de los centros comerciales, esto es un tema de gran importancia, debido a que estos cuentan con una gran cantidad de superficies impermeables tanto en el propio edificio, como en sus alrededores.

Cuestión B2.1.- ¿El clima en el que está el centro corresponde a un clima árido o semiárido?

Es importante considerar la rehabilitación de cara a la captación de aguas en cualquier tipo de clima, especialmente en los que el régimen de lluvias es escaso. En la presente tesis, van a considerarse como zonas con escasez de lluvias, tanto las zonas áridas del planeta, como las semiáridas. Para ver si una zona es árida, puede considerarse el índice de aridez de Martonne, que relaciona las precipitaciones con la temperatura media anual. 
Índice de aridez de Martonne $=(\mathrm{Pma} /(\mathrm{Tma}+10))$.

Siendo Pma, las precipitaciones medias anuales en milímetros, y Tma, la temperatura media

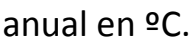

Éste índice define éstas zonas:

-0 - 5 Desiertos (Hiperárido).

- 5 - 10 Semidesierto (Árido).

-10 - 20 Semiárido de tipo mediterráneo.

-20 - 30 Subhúmeda.

-30 - 60 Húmeda.

-> 60 Perhúmeda. ${ }^{44}$

De este modo, la respuesta a esta pregunta va a depender del índice de Martonne para el clima del centro comercial.

-Respuesta 1: El centro se ubica en un clima desfavorable tendente a árido o semiárido (Índice de Martonne $<20$ ), esta respuesta puntúa como +0

-Respuesta 2: El centro no se ubica en un clima desfavorable tendente a árido o semiárido (Índice de Martonne $>20$ ), esta respuesta puntúa como +1

Cuestión B2.2.- ¿En qué porcentaje, la superficie absorbente de agua en el área urbana, es en relación a la impermeable?

El primer paso para acometer un proyecto medioambiental a efectos de absorción de agua, sobre un entorno urbano de nueva planta o consolidado, es considerar las capacidades absorbentes del terreno, y las de los diferentes pavimentos ya existentes, o los que fueran a considerarse para el proyecto.

De este modo, para esta tesis, se va a hacer necesario analizar los rasgos del pavimento presente en el área urbana próxima al centro comercial, y la misma parcela del mismo, realizándose un conteo aproximado que establecerá dos categorías que van a ser: permeable o impermeable. Se considerará como favorable para esta pregunta, el mayor porcentaje de superficie permeable en el área urbana.

-Respuesta 1: La superficie permeable del área urbana es inferior al 5\% de la superficie total, esta respuesta puntúa como +0

-Respuesta 2: La superficie permeable del área urbana está entre el 5 y el 20\% de la superficie total, esta respuesta puntúa como +1

\footnotetext{
${ }^{44}$ Fuente: De Martonne Emmanuel. Almorox Alonso Javier (2004). Climatología Aplicada Al Medio Ambiente y Agricultura. Madrid, Universidad Politécnica de Madrid, ISBN 978-84-7401-179-1. Recoge la fórmula de Emmanuel de Martonne.
} 
-Respuesta 3: La superficie permeable del área urbana está entre el 20 y el $40 \%$ de la superficie total, esta respuesta puntúa como +2

-Respuesta 4: La superficie permeable del área urbana está entre el 40 y el 60\% de la superficie total, esta respuesta puntúa como +3

-Respuesta 5: La superficie permeable del área urbana es superior al 60\% de la superficie total, esta respuesta puntúa como +4

Cuestión B2.3.- ¿El centro comercial posee sistemas para el aprovechamiento del agua?

El centro comercial al ser un edificio, su materialización va a impermeabilizar el suelo en el que está asentado, teniendo este edificio un elevado consumo de agua. De este modo es necesario ver si el centro comercial va a contar con alguno de los sistemas especificados a continuación:

-Pavimentos permeables en la parcela

-Aljibes subterráneos o en cubierta

-Instalaciones adaptadas al ahorro de agua

-Respuesta 1: El centro comercial no cuenta con ninguno de estos tres sistemas, esta respuesta puntúa como +0

-Respuesta 2: El centro comercial cuenta uno de estos tres sistemas, esta respuesta puntúa como +1

-Respuesta 3: El centro comercial cuenta con dos de estos sistemas, esta respuesta puntúa como +2

-Respuesta 3: El centro comercial cuenta con todos estos sistemas, esta respuesta puntúa como $+3$

Cuestión B2.4- ¿El consumo de agua del centro es en litros por visita?

El consumo de agua de un centro comercial es un factor de importancia a considerar, debido al hecho de que es preciso considerar el consumo responsable de agua a la hora de acometer una rehabilitación medioambiental en el propio edificio.

La normativa de Estados Unidos de América, considera una cantidad de 50 I por metro cuadrado y día, consumo que es a todas luces excesivo en comparación con lo establecido por las normativas de Perú: 25 litros metro cuadrado y día, o Venezuela que lo estima en 10 litros.

De este modo, considerando las dimensiones de un centro comercial de 36.000 metros cuadrados, visitado por una media de 10.714 personas al día. (Shopping Light de Sao Paulo), nos sale aproximadamente para Estados Unidos: 168 litros por visita, 84 litros por visita para Perú y para Venezuela Aproximadamente 33,6 litros por visita. Consumos de agua que son excesivos, y utilizados para el dimensionado de instalaciones. 
Como caso de correcta gestión de agua, tenemos el caso de los centros comerciales de la empresa Sonae Sierra ${ }^{t m}$, que tienen un consumo medio de 2,3 litros por visita, producto de la reducción de agua que estos han experimentado en los últimos años. De este modo, el caso de Sonae Sierra ${ }^{t m}$, va a considerarse como el límite más favorable, buscando en cada centro comercial el consumo de agua por visitante.

-Respuesta 1: El consumo de agua del centro comercial es superior a 50 litros por visita y día, esta respuesta puntúa como +0

-Respuesta 2: El consumo de agua del centro comercial está entre 20 y 50 litros por visita y día, esta respuesta puntúa como +1

-Respuesta 3: El consumo de agua del centro comercial es inferior a 20 litros por visita y día, esta respuesta puntúa como +2

B3.- Rehabilitación de tratamiento de isla de calor:

La isla de calor es una anomalía en la temperatura, debida a factores no naturales presentes en un área urbana (superficies acumuladores de calor en la ciudad, instalaciones de los diferentes edificios). De este modo, es importante considerar este factor a la hora de acometer una reforma hacia el edificio ecoeficiente, debido a que la isla de calor puede tener efectos negativos en el consumo energético de los edificios.

Cuestión B3.1.- ¿El clima en el que está el centro comercial tiene una temperatura media más o menos elevada?.

La justificación de esta cuestión, se basa en establecer si el centro va a ubicarse en un clima más o menos propenso a la isla de calor, debido a las temperaturas. Para este análisis se establecieron dos temperaturas límite, que fueron 14ㅇ o más como caso más desfavorable (Climas mediterráneos y más calurosos) y 8 grados o menos como límite menos favorable debido a la menor propensión a la generación de la isla de calor. (climas frescos o fríos).

-Respuesta 1: El centro se ubica en un clima cálido o habitualmente propenso a condiciones de calor extremo (Temperatura media superior a 14ㅇ), esta respuesta puntúa como +0

-Respuesta 2: El centro se ubica en un clima templado, moderadamente propenso a condiciones de calor extremo (Temperatura media entre 8 y y 14ㅇ), esta respuesta puntúa como $+1$

-Respuesta 3: El centro se ubica en un clima frío, nada propenso a condiciones de calor extremo (Temperatura media menor a 8), esta respuesta puntúa como +2 
Cuestión B3.2.- ¿En el clima en el que está ubicado en centro hay olas de calor frecuentes o en intervalo temporal menor?.

Para esta cuestión, se va a considerar si en el clima en el que está ubicado el centro, son frecuentes o no las olas de calor. La justificación de esta pregunta se debe a que éstas olas de calor van a agravar la isla térmica, acarreando esto consigo un mayor consumo. De este modo, van a analizarse fuentes climáticas de diversa naturaleza, analizándose la frecuencia anual de las olas de calor en la ciudad en la que se ubica el centro.

-Respuesta 1: En el área o clima en el que está ubicado el centro hay olas de calor frecuentes (una por año o más). Esta respuesta puntúa con +0 .

-Respuesta 2: En el área o clima en el que está ubicado el centro no hay olas de calor frecuentes (una por año o más). Esta respuesta puntúa con +1 .

Cuestión B3.3.- ¿El centro está en un área en el cual la diferencia de temperatura respecto a la normal es de?.

Para este análisis, va a estudiarse el mapa de la isla de calor de la ciudad, o en el caso de que este no existiera, se puede elaborar uno a escala media, mediante el uso de varios programas de simulación, considerando la zona de influencia del centro de manera total o parcial. Se va a considerar la posición del centro comercial, respecto al mapa de isla de calor general de la ciudad o local, indicando en que área se ubica, respecto al gradiente de temperatura.

-Respuesta 1: El centro se ubica en un área en la que la diferencia de temperatura respecto a la temperatura estándar es de 4 o superior. Esta respuesta puntúa con +0 .

-Respuesta 2: El centro se ubica en un área en la que la diferencia de temperatura respecto a la temperatura estándar es de 2 a 4․ Esta respuesta puntúa con +1 .

-Respuesta 3: El centro se ubica en un área en la que la diferencia de temperatura respecto a la temperatura estándar es de 0 a 2‥ Esta respuesta puntúa con +2 .

-Respuesta 4: El centro se ubica en un área en la que la diferencia de temperatura respecto a la temperatura estándar es de 0 o (no existe isla de calor). Esta respuesta puntúa con +3 .

Cuestión B3.4.- ¿La suma de superficies que contribuyen a la isla de calor en la parcela y el edificio del centro es superior a un porcentaje de la superficie total?.

En esta cuestión, va a realizarse un conteo de las superficies de la parcela, y la cubierta del centro comercial, clasificándose las mismas como propensas o no a la isla de calor. Las superficies que se considerarán como propensas a la isla de calor, serán todas aquellas que absorban energía solar fácilmente (Materiales pétreos o térreos, materiales de colores oscuros, asfaltos y materiales de mortero, o materiales metálicos). Mientras que las superficies que no 
tengan capacidades absorbentes de energía solar, serán consideradas como las no propensas a la isla de calor (Superficies vegetales, o superficies de materiales claros).

Se considerará para puntuar en esta pregunta el porcentaje de superficie absorbente Considerando esta tabla para climas cálidos o templados.

-Respuesta 1: Las superficies que contribuyen a la isla de calor, en la parcela y la cubierta del centro, son superiores al $80 \%$ del total. Esta respuesta puntúa con +0 .

-Respuesta 2: Las superficies que contribuyen a la isla de calor, en la parcela y la cubierta del centro, están entre el 60 y el $80 \%$ del total. Esta respuesta puntúa con +1.

-Respuesta 3: Las superficies que contribuyen a la isla de calor, en la parcela y la cubierta del centro, están entre el 40 y el $60 \%$ del total. Esta respuesta puntúa con +2 .

-Respuesta 4: Las superficies que contribuyen a la isla de calor, en la parcela y la cubierta del centro, están entre el 20 y el $40 \%$ del total. Esta respuesta puntúa con +3.

-Respuesta 5: Las superficies que contribuyen a la isla de calor, en la parcela y la cubierta del centro, son inferiores al $20 \%$ del total. Esta respuesta puntúa con +4 .

\section{C.- REHABILITACIÓN DOTACIONAL O DE USOS:}

La importancia del estudio de este campo de medidas de rehabilitación, se debe a que un centro comercial desempeña un papel urbano de gran importancia, ya que desde su primer momento fue concebido como una pieza centralizadora de la actividad urbana; ya sea con el papel de centro social proyectado por Gruen, o con el papel de absorber un volumen de negocio relativo a un nicho de mercado centrado en la provisión, venta y adquisición de género.

La Rehabilitación por usos de los centros comerciales y su viabilidad, debe de fundamentarse en un estudio de los usos del contexto urbano, debido al hecho de que esta instalación siempre va a complementar las necesidades dotacionales ligadas al comercio y la adquisición de bienes de la población presente en un área urbana de mayor o menor tamaño.

Respecto a la escala de los edificios del centro comercial, al estar este apartado de la presente tesis fundamentado en la inclusión, o redistribución de los usos del centro comercial enfocados hacia los clientes, para este análisis se excluirán las galerías pensadas como espacio de tránsito, los aparcamientos, los usos y servicios técnicos, los aseos y las oficinas de la empresa gestora. No obstante, en el posible proyecto de rehabilitación del centro éstos usos deben de ser considerados, debido a que son de mucha importancia para el funcionamiento del centro.

Este modelo de rehabilitación, es la base fundamental de las intervenciones y proyectos del movimiento del New Urbanism, ligados a la reconversión urbanística y arquitectónica de tipologías edificatorias basadas en la zonificación y la baja densidad. 
Para el análisis de la rehabilitación por usos, se va a considerar un baremo de usos en base a porcentajes, basados en diversos ejemplos de ciudades complejas y consolidadas o ecobarrios.

\section{C1.- Uso residencial.}

El uso residencial es de gran importancia para el centro comercial, ya que es el que está referenciado a las viviendas de los posibles compradores, va a resultar positivo de cara al centro comercial, que las viviendas estén próximas al mismo, o que dispongan de conexiones que garanticen el flujo de compradores.

Cuestión C1.1.- ¿El centro comercial posee usos residenciales u hoteleros dentro de su unidad catastral?.

A efectos de sostenibilidad urbanística, va a resultar favorable la presencia de instalaciones residenciales, tanto permanentes como temporales, debido a que esta va a favorecer la mezcla de usos de manera opuesta a la zonificación, propiciándose de esta manera un modelo de ciudad más seguro y sostenible, debido a la actividad constante, y a la reducción de desplazamientos motorizados. De este modo, el análisis del uso residencial en la zona de influencia del centro, a diferentes escalas, es fundamental para acometer una reforma adecuada en el campo de los usos. Para esta pregunta se va a considerar la superficie residencial del centro, y cuántas personas puede alojar. Se considerará un espacio de 20 metros cuadrados por persona. Comparándose este dato con la población asignada a centro comercial, para de esta manera obtener un porcentaje.

-Respuesta 1: La superficie residencial del centro comercial puede alojar a menos del $10 \%$ de la población asignada al centro comercial, esta respuesta puntúa con +0 .

-Respuesta 2: La superficie residencial del centro comercial puede alojar a un intervalo entre el 10 y el 15\% de la población asignada al centro comercial, esta respuesta puntúa con +1 .

-Respuesta 3: La superficie residencial del centro comercial puede alojar a más del 15\% de la población asignada al centro comercial. Esta respuesta puntúa con +2 .

Cuestión C1.2.- ¿Las parcelas próximas al centro comercial posen usos residenciales u hoteleros?

La relación urbana más directa del centro comercial con su entorno urbano, va a realizarse en sus manzanas anejas. De este modo, va a resultar favorable para la sostenibilidad urbana, la presencia de inmuebles residenciales; debido a que estos al tener relación directa con el centro, van a generar de esta relación un espacio dinámico. A todo esto hay que considerar que los residentes de estos inmuebles, van a demandar menos medios motorizados de transporte para ir al centro comercial. IMPORTANTE: En el caso de que el centro comercial poseyera una superficie de residencial considerable (mayor a $10.000 \mathrm{~m}^{2}$ ), se sumará la superficie residencial del centro comercial, a los metros cuadrados residenciales del área 
urbana próxima, y el porcentaje de uso se estimará dividiendo esta suma de superficies residenciales, entre la suma total de la superficie construida de las manzanas próximas, más la superficie construida del centro comercial.

-Respuesta 1: La superficie residencial en las manzanas próximas al centro es inferior al 10\% de la superficie útil total . Esta respuesta puntúa con +0 .

-Respuesta 2: La superficie residencial en las manzanas próximas al centro está en el intervalo entre el $10 \%$ y el $30 \%$ de la superficie útil total. Esta respuesta puntúa con +1 .

-Respuesta 3: La superficie residencial en las manzanas próximas al centro está en el intervalo entre el $30 \%$ y el $50 \%$ de la superficie útil total. Esta respuesta puntúa con +2 .

-Respuesta 4: La superficie residencial en las manzanas próximas al centro es superior al 50\% de la superficie útil total. Esta respuesta puntúa con +3 .

Cuestión C1.3.- ¿Dentro del área de influencia del centro comercial, que porcentaje de la superficie de uso total es de tipo residencial?

El centro comercial, está destinado a un número $\mathrm{x}$ de compradores, que son los que van a marcar el área de influencia. Para considerar una rehabilitación de un centro comercial de cara a la inserción de usos residenciales, es necesario el estudio de la cantidad de superficie residencial en la zona de influencia, para ver si hay superávit o déficit. Para este apartado, se va a considerar la media global de los porcentajes de superficie residencial, estimados en 1I-1J.

-Respuesta 1: La superficie residencial del área urbana es inferior al 10\% de la superficie útil total. Esta respuesta puntúa con +0 .

-Respuesta 2: La superficie residencial del área urbana está en el intervalo entre el $10 \%$ y el $20 \%$ de la superficie útil total. Esta respuesta puntúa con +1 .

-Respuesta 3: La superficie residencial del área urbana está en el intervalo entre el $20 \%$ y el $40 \%$ de la superficie útil total. Esta respuesta puntúa con +2 .

-Respuesta 4: La superficie residencial del área urbana está en el intervalo entre el $40 \%$ y el $50 \%$ de la superficie útil total. Esta respuesta puntúa con +3 .

-Respuesta 5: La superficie residencial del área urbana está en el intervalo entre el $50 \%$ y el $70 \%$ de la superficie útil total. Esta respuesta puntúa con +4 .

-Respuesta 6: La superficie residencial del área urbana es superior al 70\% de la superficie útil total. Esta respuesta puntúa con +5 .

C2.- Uso de actividades productivas. 
Las actividades productivas son necesarias para el desarrollo económico de la ciudad, ya que aunque estas no influyen directamente en su creación, son las encargadas de localizar los empleos de una ciudad. De este modo la presencia de este tipo de actividades va a generar tanto interacción urbana, como dinamismo, derivado de las interacciones entre estos usos y otros presentes en la ciudad. Como usos de actividades productivas para esta tesis, van a considerarse tanto las actividades industriales, como las actividades terciarias de oficinas no asistenciales y cerradas al público. Para este análisis se va a considerar dentro del bloque de actividades no residenciales, exclusivamente el uso no residencial de tipo productivo.

Cuestión C2.1.- ¿El centro comercial posee usos productivos no comerciales dentro de su unidad catastral?

La presencia de actividades productivas no comerciales, puede ser un incentivo para la actividad del centro comercial, además de dar al centro un grado mayor o menor de complejidad urbana. No se considerarán en este apartado como superficie de uso no residencial productivo, ni las oficinas de la empresa gestora, ni los talleres $u$ otras dotaciones de tipo terciario asistenciales o comerciales.

-Respuesta 1: El centro comercial no posee usos productivos no comerciales, esta respuesta puntúa con +0 .

-Respuesta 2: El centro comercial posee usos productivos no comerciales, esta respuesta puntúa con +1 .

Cuestión C2.2.- ¿Las parcelas próximas al centro comercial posen usos productivos no comerciales?

La importancia de esta cuestión, reside en el hecho de que la presencia de usos productivos en las proximidades del centro, puede ser una actividad complementaria, que dé lugar a un entorno urbano más dinámico y complejo. Se va a considerar la superficie de uso no residencial, productivo en las manzanas anejas al centro comercial. IMPORTANTE: En el caso de que el centro comercial poseyera una superficie de terciario no comercial o uso productivo considerable (mayor a $2000 \mathrm{~m}^{2}$ excluyendo siempre del conteo las oficinas de la gestora), se sumará la superficie de oficinas del centro comercial exclusivamente a los metros cuadrados de oficinas del área urbana próxima, y el porcentaje de uso se estimará dividiendo esta suma de superficies productivas, entre la suma total de la superficie construida de las manzanas próximas, más la superficie construida del centro comercial.

-Respuesta 1: La superficie de usos productivos no comerciales en las manzanas próximas al centro es inferior al 1\%. Esta respuesta puntúa con +0 .

-Respuesta 2: La superficie de usos productivos no comerciales en las manzanas próximas al centro está en el intervalo entre el $1 \%$ y el $5 \%$ de la superficie útil total de las mismas. Esta respuesta puntúa con +1 . 
-Respuesta 3: La superficie de usos productivos no comerciales en las manzanas próximas al centro está en el intervalo entre el $5 \%$ y el $10 \%$ de la superficie útil total de las mismas. Esta respuesta puntúa con +2 .

-Respuesta 4: La superficie de usos productivos no comerciales en las manzanas próximas al centro es superior al $10 \%$ de la superficie útil total de las mismas. Esta respuesta puntúa con +3 .

Cuestión C2.3.- ¿Dentro del área de influencia del centro comercial, que porcentaje de la superficie de uso total es de tipo productivo no comercial?

Para considerar la inclusión de actividades productivas en la rehabilitación de un centro comercial, es necesario considerar la presencia de las mismas en la zona urbana de influencia en su totalidad, para de esta manera ver la viabilidad en la inclusión de este tipo de instalaciones. Se va a considerar la superficie de uso productivo no comercial dentro del área de influencia en su totalidad. IMPORTANTE: En el caso de que el centro comercial poseyera una superficie de terciario no comercial o uso productivo considerable (mayor a $1000 \mathrm{~m}^{2}$ excluyendo siempre del conteo las oficinas de la gestora), se sumará la superficie de oficinas del centro comercial exclusivamente a los metros cuadrados de oficinas del área urbana global, y a partir de ello se estimarán los nuevos porcentajes de uso.

-Respuesta 1: La superficie de usos productivos no comerciales del área urbana es inferior al $2 \%$. Esta respuesta puntúa con +0 .

-Respuesta 2: La superficie de usos productivos no comerciales del área urbana está entre el 2\% y el $8 \%$ de la superficie útil total. Esta respuesta puntúa con +1 .

-Respuesta 3: La superficie de usos productivos no comerciales del área urbana está entre el 8\% y el $12 \%$ de la superficie útil total. Esta respuesta puntúa con +2 .

-Respuesta 4: La superficie de usos productivos no comerciales del área urbana está en el intervalo entre el $12 \%$ y el $18 \%$ de la superficie útil total. Esta respuesta puntúa con +3 .

-Respuesta 5: La superficie de usos productivos no comerciales del área urbana está en el intervalo entre el $18 \%$ y el $24 \%$ de la superficie útil total. Esta respuesta puntúa con +4 .

-Respuesta 6: La superficie de usos productivos no comerciales del área urbana está en el intervalo entre el 24 y el $30 \%$ de la superficie útil total. Esta respuesta puntúa con +5 .

-Respuesta 7: La superficie de usos productivos no comerciales del área urbana es superior al $30 \%$ de la superficie útil total. Esta respuesta puntúa con +6

C3.- Uso dotacional o de actividades asistenciales. 
Para este apartado, va a considerarse el conteo de todas las instalaciones de titularidad pública, que tengan como finalidad el ofrecimiento de cualquier tipo de servicio asistencial que no sea comercial, ni que esté relacionado con el trabajo o el ocio. En este apartado van a computarse las actividades relacionadas con la administración, la educación o la asistencia social de cualquier tipo. Las actividades educativas privadas de cualquier naturaleza van a ser consideradas dentro de este apartado.

La justificación de este estudio, se debe a que las actividades de tipo asistencial, resultan ser de interés para el planeamiento urbano, ya que son necesarias para el funcionamiento de la ciudad, y su presencia va a contribuir en la mezcla de usos y la complejidad urbana, además de generar flujos e interacción.

Cuestión C3-1.- ¿El centro comercial posee usos dotacionales dentro de su unidad catastral?

La presencia de actividades asistenciales o dotacionales, puede ser un incentivo para la actividad del centro comercial, además de dar al centro un grado mayor o menor de complejidad urbana.

-Respuesta 1: El centro comercial no posee usos asistenciales, esta respuesta puntúa con +0 .

-Respuesta 2: El centro comercial posee usos asistenciales, esta respuesta puntúa con +1 .

Cuestión C3.2.- ¿Las parcelas próximas al centro comercial posen usos dotacionales?

La importancia de esta cuestión, reside en el hecho de que la presencia de usos asistenciales en las proximidades del centro, puede ser una actividad complementaria, que dé lugar a un entorno urbano más dinámico y complejo, que además ayudará a contribuir de cara a las interacciones del centro comercial con el entorno urbano cercano. Se considerará la presencia de instalaciones dotacionales en las parcelas anejas al centro de la siguiente manera:

-Respuesta 1: En las manzanas próximas al centro comercial no hay instalación dotacional o asistencial alguna. Esta respuesta puntúa con +0 .

-Respuesta 2: En las manzanas próximas al centro hay alguna o varias instalaciones asistenciales, que son raramente concurridas o reciben visitas esporádicas. Esta respuesta puntúa con +1 .

-Respuesta 3: En las manzanas próximas al centro hay una o más instalaciones que son concurridas ocasionalmente (su servicio se limita al área de influencia del centro). Esta respuesta puntúa con +2 .

-Respuesta 4: En las manzanas próximas al centro hay una instalación asistencial que es concurrida de forma habitual. Esta respuesta puntúa con +3 . 
-Respuesta 5: En las manzanas próximas al centro hay por lo menos una instalación asistencial de primera jerarquía que recibe diariamente un gran número de visitantes. Esta respuesta puntúa con +4 .

Cuestión C3.3.- ¿A un kilómetro del centro comercial hay usos dotacionales?

Para considerar la inclusión de actividades dotacionales o asistenciales en la rehabilitación de un centro comercial, es necesario considerar la presencia de las mismas en la zona urbana de influencia en su totalidad, viéndose así la viabilidad en la inclusión de este tipo de instalaciones. No obstante, el centro comercial deberá de considerar este tipo de instalaciones, si hay déficit de las mismas en el entorno urbano. Se considerará el número de dotaciones establecido en área de dotaciones (1 kilómetro) que corresponde a una distancia a pie de 20 minutos caminando.

-Respuesta 1: En el área de dotaciones $(1 \mathrm{~km})$ no hay instalación dotacional o asistencial alguna. Esta respuesta puntúa con +0 .

-Respuesta 2: En el área de dotaciones (1 km) hay alguna o varias instalaciones asistenciales, que son raramente concurridas o reciben visitas esporádicas. Esta respuesta puntúa con +1 .

-Respuesta 3: En el área de dotaciones $(1 \mathrm{~km})$ hay una o más instalaciones que son concurridas ocasionalmente. (su servicio se limita al área de influencia del centro). Esta respuesta puntúa con +2 .

-Respuesta 4: En el área de dotaciones (1 km) hay una instalación asistencial que es concurrida de forma habitual. Esta respuesta puntúa con +3 .

-Respuesta 5: En el área de dotaciones $(1 \mathrm{~km})$ hay por lo menos una instalación asistencial de primera jerarquía que recibe diariamente un gran número de visitantes, pero son conocidas a nivel municipal o de barrio. Esta respuesta puntúa con +4 .

-Respuesta 6: En el área urbana del centro comercial hay una o varias varias instalaciones asistenciales que son concurridas por un gran número de personas, y que son muy conocidas, $o$ de gran importancia a nivel nacional. IMPORTANTE: Si el área del centro comercial posee varias dotaciones muy concurridas a escala local en lugar de una de gran jerarquía, hay que considerar este estado como una gran dotación, debido al movimiento de personas total que estas instalaciones generan. Esta respuesta puntúa con +5

\section{D.- REHABILITACIÓN EN ENTORNO URBANO:}

Este campo de medidas de rehabilitación, va a centrarse en el estudio de las características del entorno urbano, además de la analítica del modelo de transporte y la paseabilidad. La importancia de este estudio, reside en el hecho de que esta tesis tiene una fuerte componente 
de analítica urbana, siendo el análisis del entorno urbano, la base para la consideración de la ciudad como ecoeficiente o sostenible.

No obstante, se debe de considerar en todo momento, que las medidas de rehabilitación, se van a centrar en una escala mucho más amplia que lo que es el centro comercial en sí, de manera que las operaciones de rehabilitación ligadas a este campo, van a aplicarse sobre lo que es el espacio urbano, tanto el que está ligado al centro comercial, cómo el ajeno al mismo.

De este modo, un déficit en cualquier medida dentro del campo de la rehabilitación del entorno urbano, no va a resolverse de manera directa interviniendo sobre el edificio del centro comercial de manera exclusiva, sino que se van a requerir de planes de actuación urbanística que comprendan la escala de la ciudad en su totalidad.

\section{D1.- Transporte eficiente}

El transporte es un ámbito de consideración fundamental a la hora de planificar cualquier tipo de entorno urbano, siendo aún de mayor importancia a la hora de planear una ciudad que pudiera resultar eficaz en su consumo de energía, y benigna respecto al medio ambiente. Esto es debido, a que el transporte es lo que garantiza la movilidad y las relaciones entre los elementos urbanos. Siendo fundamental a día de hoy la consideración de medios mecanizados debido a las largas distancias presentes en las ciudades.

Los medios mecanizados, a día de hoy de manera directa o indirecta, además de consumir recursos y energía, son generadores de emisiones que empeoran la calidad del aire debido a sus componentes nocivos. Este problema puede llegar a ser muy crítico, si en la ciudad, el modelo de transporte predominante está basado en el uso masivo de vehículos particulares, derivando esto en un alto ratio de emisiones por desplazamiento, además de problemas de congestión en las vías. Como contraste a esto, el uso de medios de transporte mecanizados de tipo colectivo puede ayudar a reducir el ratio de emisiones y uso de energía por desplazamiento, siendo estos una opción viable para un modelo de transporte eficaz. Es además un aliciente en la creación del modelo de transporte sostenible y eficaz, todo intento por eliminar los desplazamientos innecesarios.

Cuestión D1.1.- ¿El centro dispone en sus inmediaciones de alguna parada de transporte público?

La presencia de una parada de transporte público en las inmediaciones del centro comercial, es una condición indispensable para asegurar el transporte eficiente en las comunicaciones entre el centro comercial y la ciudad. Para esta cuestión, se cogerá un radio de 200 metros desde el lindero de la parcela del centro comercial, valorándose como positivo la presencia de una parada de cualquier línea de transporte público, sin importar la naturaleza de la misma. También para esta cuestión, se considerará como positivo si la parada en las inmediaciones del centro comercial, corresponde a una instalación de importante jerarquía en la red de transporte público de la ciudad. (Paradas de metro, tren o autobús con mucha frecuencia de paso, trasbordos importantes o intercambiadores de transporte o paradas ubicadas en las 
partes centrales de su correspondiente línea). Es importante, que estas paradas comuniquen con áreas lejanas de la ciudad, No se considerarán las paradas asociadas a líneas de transporte de escala muy local que den servicio a instalaciones muy concretas.

-Respuesta 1: El centro no dispone de parada de transporte público en sus inmediaciones (200 metros), esta respuesta puntúa con +0

-Respuesta 2: El centro dispone de parada de transporte público en sus inmediaciones (200 metros), esta respuesta puntúa con +1

Cuestión D1.2.- ¿¿El tiempo de llegada al centro mediante transporte público supera al tiempo de llegada en vehículo particular?

Para que el transporte público resulte ser una opción atractiva o viable de transporte para ir al centro comercial, es deseable que el uso del mismo no suponga para el visitante una pérdida de tiempo excesiva, de lo contrario, el visitante optará por el uso del vehículo particular para su desplazamiento.

Para esta cuestión, van a analizarse los resultados del estudio sobre plano en los diversos recorridos establecidos en el apartado $2 \mathrm{E}$, sacándose una media de los mismos de acuerdo a la siguiente fórmula:

Tdtp1 /Tdvp1+ Tdtp2/Tdvp2 + .. Tdtpn/Tdvpn

Siendo:

Tdtp: tiempo del desplazamiento en transporte público del recorrido.

Tdvp: tiempo del desplazamiento en vehículo particular del recorrido.

El resultado de esta operación, será el índice de eficacia del transporte público, que se comparará para ver la puntuación de la cuestión.

-Respuesta 1: El índice de eficacia del transporte público es superior a 2 (el tiempo de desplazamiento en transporte público es el doble o más que en vehículo particular). Esta respuesta puntúa con +0 .

-Respuesta 2: El índice de eficacia del transporte público está en el intervalo entre 1,5 y 2 (el tiempo de desplazamiento en transporte público es moderadamente mayor que en vehículo particular). Esta respuesta puntúa con +1 .

-Respuesta 3: El índice de eficacia del transporte público es está en el intervalo entre 1,2 y 1,5 (el tiempo de desplazamiento en transporte público es ligeramente mayor al invertido en el desplazamiento usando un vehículo particular). Esta respuesta puntúa con +2 .

-Respuesta 4: El índice de eficacia del transporte público es menor a 1,2 (el tiempo de desplazamiento en transporte público es similar o menor al invertido en el desplazamiento usando un vehículo particular). Esta respuesta puntúa con +3 . 
Cuestión D1.3.- ¿El área urbana del centro comercial está cubierta de forma adecuada por la infraestructura de transporte público?

Para que el transporte público resulte viable en un área urbana determinada, es necesario que la mayor área de la misma este cubierta por instalaciones de transporte público. Para esta cuestión, dentro de lo que es el área urbana, se marcarán las diferentes líneas y paradas de transporte público, estableciéndose un área circular de 200 metros a partir de cada una de ellas. La cobertura del área urbana por estas zonas marcadas a partir de las líneas de transporte, será el dato que nos permitirá puntuar esta cuestión.

-Respuesta 1: Menos del 50\% del área urbana está cubierta por las áreas de influencia del transporte público. Esta respuesta puntúa con +0 .

-Respuesta 2: Menos entre un 50 y un 70\% del área urbana está cubierta por las áreas de influencia del transporte público. Esta respuesta puntúa con +1 .

-Respuesta 3: Más de un 70\% del área urbana está cubierta por las áreas de influencia del transporte público. Esta respuesta puntúa con +2 .

Cuestión D1.4.- ¿̇Los usos en la zona están mezclados o zonificados?

Aunque la mezcla de usos en el entorno urbano parezca a primera a primera vista un tema dispar con respecto al tema del transporte eficiente, a efectos prácticos este tema es clave en la consecución del mismo, ya que en una ciudad en la que los usos están mezclados, el número de desplazamientos motorizados va a ser menor, debido a la cercanía entre dotaciones y usos. Por el contrario, una ciudad en la que los usos estén muy zonificados en áreas, va a contribuir en menor o mayor medida a los desplazamientos motorizados (según el tamaño de las áreas) debido a la mayor lejanía entre usos.

Para responder a esta cuestión, se va a considerar el índice global de mezcla de usos, hallado en el apartado $1 \mathrm{~K}$, en base al siguiente baremo de puntuación:

-Respuesta 1: La zona es poco compleja respecto a mezcla de usos (el índice global de mezcla de usos es inferior a 0,4). Esta respuesta puntúa con +0 .

-Respuesta 2: En la zona hay una mezcla de usos esporádica (el índice global de mezcla de usos está entre 0,4 y 0,7). Esta respuesta puntúa con +1 .

-Respuesta 3: En la zona hay una mezcla de usos generalizada (el índice global de mezcla de usos es superior a 0,7). Esta respuesta puntúa con +2 .

Cuestión D1.5.- ¿El centro comercial y el área urbana próxima al centro cuenta con instalaciones enfocadas en la movilidad sostenible? 
En el tema de la movilidad sostenible, como elemento complementario al transporte público, también hay que destacar otras formas de movilidad que tienen una huella de carbono nula o muy reducida (bicicletas o vehículos eléctricos).

De este modo, se evaluará de manera positiva la presencia de medios e instalaciones que favorezcan el uso de estas formas de movilidad, tanto dentro del centro comercial, cómo en las parcelas anejas al mismo, siendo los que se remarcarán en la presente tesis:

-Carriles bici o instalaciones adaptadas a ciclos.

-Instalaciones de alquiler y mantenimiento de vehículos eléctricos o de bajas emisiones.

-Respuesta 1: En el área urbana la presencia de instalaciones enfocadas en la movilidad sostenible es inexistente. Esta respuesta puntúa con +0 .

-Respuesta 2: En el área urbana hay una presencia esporádica de instalaciones enfocadas en la movilidad sostenible. Esta respuesta puntúa con +1 .

-Respuesta 3: En el área urbana hay una fuerte presencia de instalaciones enfocadas en la movilidad sostenible. Esta respuesta puntúa con +2 .

\section{D2.- Densidad}

La densidad, es un factor a analizar de cara a la eficiencia ecológica de una ciudad, debido a que para que haya actividad en un entorno urbano, además de mezcla de usos, se requiere una densidad mínima de población por hectárea.

No obstante, es necesario no caer en la ingenuidad de que la mayor densidad de población va a ser más beneficiosa para el entorno urbano a efectos medioambientales, ya que esta acarrea consigo problemas derivados de la congestión urbana y la superpoblación, tales como problemas de salubridad o congestión.

Cuestión D2.1.- ¿La densidad de población en el área del centro está en el intervalo entre h/ha?

La densidad de población, y su estudio, es básico para la analítica de la sostenibilidad urbana. Para esta cuestión, va a compararse la densidad general del área urbana de influencia del centro comercial (U2), con un baremo establecido en base a una serie de umbrales que son los siguientes, en el caso de que la densidad coincida con el umbral se redondeará a la baja:

-Respuesta 1: Menos de 0,004 habitantes por metro cuadrado. Densidad muy baja, puntúa con $+0$

-Respuesta 2: Entre 0,004 y 0,008 habitantes por metro cuadrado. Densidad baja, puntúa con $+1$

-Respuesta 3: Entre 0,008 y 0,012 habitantes por metro cuadrado. Densidad media baja, puntúa con +2 
-Respuesta 4: Entre 0,012 y 0,016 habitantes por metro cuadrado. Densidad media, por debajo del óptimo puntúa con +3

-Respuesta 5: Entre 0,016 y 0,02 habitantes por metro cuadrado. Densidad óptima, puntúa con $+4$

-Respuesta 6: Entre a 0,02 y 0,06 habitantes por metro cuadrado. Densidad alta, van a haber problemas de congestión de leves a severos, puntúa con +3

-Respuesta 7: Más de 0,06 habitantes por metro cuadrado. Densidad muy alta, van a haber problemas de congestión de severos a críticos, puntúa con +2

Cuestión D2.2.- ¿A efectos de densidad de edificación, el tejido mayoritario es favorable o desfavorable de cara a la sostenibilidad?.

Además de la densidad de población, también es importante de cara al estudio de la sostenibilidad, la configuración de los tejidos urbanos a efectos de densidad de edificación y compacidad de la misma. Para responder a esta cuestión, se va a considerar el índice global de densidad urbana, que se resume en la siguiente fórmula:

(1* \% tejido poco denso en área $+2 * \%$ tejido densidad media en área $+3 * \%$ tejido denso en área), y dependiendo del resultado de la ecuación, se dará la siguiente puntuación

-Respuesta 1: El índice va de 1 a 1,25, puntúa con +0

-Respuesta 2: El índice va de 1,25 a 1,5, puntúa con +1

-Respuesta 3: El índice va de 1,5 a 2, puntúa con +2

-Respuesta 4: El índice va de 2 a 2,75, puntúa con +3

-Respuesta 5: El índice es mayor a 2,75 puntúa con +2, por problemas de congestión.

Cuestión D2.3.- ¿ ¿a cantidad de espacio ocupado en el área está en el intervalo entre...?

Esta cuestión, busca la analítica de la compacidad del tejido urbano en planta, considerando el porcentaje de superficie ocupada media en el área urbana de influencia del centro comercial en su totalidad. El análisis de la compacidad del tejido resulta ser de interés, debido a que determinadas compacidades de tejido pueden mitigar o agravar ciertos efectos urbanos derivados de la densidad. Para esta cuestión, se considerará la compacidad global del tejido urbano, que se hallará multiplicando los porcentajes de ocupación de cada zona homogénea hallados en 1D, por lo que ocupa cada una de estas zonas respecto del área urbana total establecida.

(\% ocup Z1* \%Z1 respecto al total área analizada $+\%$ ocup Z2* \%Z2 respecto al total área analizada $+\ldots \%$ ocup $\mathrm{Zn} *$ \% $\mathrm{Zn}$ respecto al total área analizada), y dependiendo del resultado de la ecuación, se dará la siguiente puntuación: 
-Respuesta 1: Menor a un 10\%, esta respuesta puntúa con +0

-Respuesta 2: Entre 10 y 30\%, esta respuesta puntúa con +1

-Respuesta 3: Entre 30 y 50\%, esta respuesta puntúa con +2

-Respuesta 4: Mayor al 50\%, esta respuesta puntúa con +3

\section{D3.- Seguridad y paseabilidad}

Para el establecimiento o proyección de un área urbana compleja que potencie la actividad, es necesario garantizar la seguridad en las calles, además de otros conceptos tales como el atractivo de cara al peatón o la accesibilidad, para de esta manera generar un espacio que potencie el uso por parte de los peatones. Un espacio que resulte inseguro o poco accesible para los peatones, va a derivar en efectos no deseados y externalidades negativas de cara al objetivo de la consecución de la ciudad sostenible, tales como la falta de uso del mismo, la aparición de un nodo de inactividad, la aparición de actividades no deseadas o la potenciación del uso del vehículo particular frente a la movilidad peatonal.

Este análisis, va a ejecutarse tanto en la escala global del área de influencia del centro urbano, cómo en la escala cercana que considera las inmediaciones del centro comercial y su entorno urbano inmediato.

Cuestión D3.1.- ¿En el área de influencia o en sus proximidades hay elementos negativos de cara a la seguridad o a la salubridad del área?.

Las áreas urbanas que pudieran resultar insalubres o inseguras, siempre van a ser un elemento negativo a efectos de paseabilidad, accesibilidad y vitalidad urbana. Esto se debe al hecho de que éstas zonas van a actuar como elemento de repulsión de cara a la actividad peatonal.

Se van a marcar las zonas que cumplan estas características dentro del área general de influencia del centro comercial, siendo negativa su presencia de cara a la paseabilidad.

-Respuesta 1: En el área urbana hay elementos negativos de cara a la paseabilidad. Esta respuesta puntúa con +0

-Respuesta 2: En el área urbana no hay elementos negativos de cara a la paseabilidad. Esta respuesta puntúa con +1

Cuestión D3.2.- ¿El centro comercial se encuentra en una zona de puntos fríos de actividad durante el día?.

La ubicación del centro comercial en un punto frío del área urbana a analizar, es en cualquier caso un factor desfavorable de cara al establecimiento de una relación correcta entre éste y el entorno urbano, debido al hecho de que los puntos fríos son áreas en las cuales debido a 
factores inherentes al tejido o a los usos urbanos, la actividad en ellos es escasa o nula en el peor de los casos.

Para esta cuestión, van a marcarse los puntos fríos a efectos de uso diurno en el entorno urbano, puntuando como negativo si el centro comercial está ubicado en un punto frío diurno, o si hay uno en sus inmediaciones.

-Respuesta 1: El centro está ubicado en un área con puntos fríos durante el día, esta respuesta puntúa con +0 .

-Respuesta 2: El centro no está ubicado en un área con puntos fríos durante el día, esta respuesta puntúa con +1 .

Cuestión D3.3.- ¿El centro comercial se encuentra en una zona de puntos fríos durante la noche?

Al igual que en la anterior cuestión, Para ésta, van a marcarse los puntos fríos a efectos de uso nocturno en el entorno urbano, puntuando como negativo si el centro comercial está ubicado en un punto frío nocturno, o si hay uno en sus inmediaciones.

-Respuesta 1: El centro está ubicado en un área con puntos fríos durante la noche, esta respuesta puntúa con +0 .

-Respuesta 2: El centro no está ubicado en un área con puntos fríos durante la noche, esta respuesta puntúa con +1 .

Cuestión D3.4.- ¿El centro comercial se encuentra en una zona con áreas de difícil control visual o de contacto urbano?

Para potenciar un espacio público urbano que garantice el uso y la actividad peatonal, es necesario considerar la accesibilidad y el control visual como primordial, para de esta manera evitar los puntos inaccesibles, ocultos o muertos, que pudieran escapar a la vigilancia por parte de los peatones, derivando estos en focos de inseguridad o insalubridad (Incluir referencia de José Fariña). Esta pregunta va a puntuar de la siguiente manera:

-Respuesta 1: Si el área próxima al centro, cuenta con este tipo de áreas, esta respuesta puntúa con +0 .

-Respuesta 2: Si el espacio urbano próximo al centro es perfectamente accesible y controlable a nivel visual, esta respuesta puntúa con +1 .

Cuestión D3.5.- ¿La sensación de seguridad por parte de los ciudadanos de la zona es positiva o negativa? 
La inseguridad en el espacio urbano, siempre va a ser un factor negativo de cara a la vitalidad urbana; esto se debe al efecto de repulsa que ésta genera en los habitantes o usuarios del mismo, los cuales como medida de protección contra el entorno hostil, van a evitar transitarlo, quedando éste abandonado. Si la inseguridad no se soluciona, este problema a la larga tendrá consecuencias perniciosas para el espacio urbano (Cierre del mismo por parte de los habitantes, abandono de los inmuebles...). Para responder a esta cuestión, pueden analizarse fuentes diversas relacionadas con la seguridad urbana (encuestas, datos criminológicos...) para obtener una visión global. Esta pregunta se puntuará de la siguiente manera:

-Respuesta 1: La sensación en el área, es de inseguridad por parte de sus habitantes, esta respuesta puntúa con +0 .

-Respuesta 2: La sensación en el área, es de relativa seguridad por parte de sus habitantes, esta respuesta puntúa con +1 .

Cuestión D3.6.- ¿La zona próxima al centro comercial tiene un porcentaje de fachadas activas?

Las fachadas activas siempre van a ser un factor positivo para la actividad y la vitalidad urbana, debido a que estas son un elemento de actividad atrayente para los habitantes de la zona, que va a acarrear consigo movimiento en el espacio público y actividad derivada de su presencia. Para este análisis, van a analizarse las calles próximas al centro en su totalidad, comprobando si van a haber en mayor o menor medida fachadas activas. Se estimará un porcentaje global para el cómputo de las calles próximas al centro en su totalidad, este porcentaje será el dato comparativo. La respuesta a esta pregunta puntuará de la siguiente manera.

-Respuesta 1: La zona del centro tiene un porcentaje menor en fachadas activas al 30\%, esta respuesta puntúa con +0 .

-Respuesta 2: La zona del centro tiene un porcentaje de fachadas activas del $30 \%$ al 50\%, esta respuesta puntúa con +1 .

-Respuesta 3: La zona del centro tiene un porcentaje de fachadas activas superior al 50\%, esta respuesta puntúa con +2 .

Cuestión D3.7.- ¿La distancia de la puerta del edificio del centro comercial al inmueble residencial cercano es superior a los 200 metros?

La lejanía de los accesos del centro comercial a los inmuebles residenciales más próximos, es un factor que va a favorecer la movilidad motorizada, siendo esto un problema de cara a la vitalidad urbana y la sostenibilidad, debido a que la tendencia en este tipo de desplazamientos se inclina hacia el uso del vehículo particular. Para esta cuestión se va a marcar la distancia desde la entrada al centro, al inmueble residencial más próximo, sin atender a limitaciones entre áreas. Esta cuestión puntúa de la siguiente manera.

-Respuesta 1: La distancia es mayor a 200 metros, esta respuesta puntúa con +0 
-Respuesta 2: La distancia es menor a 200 metros, esta respuesta puntúa con +1

Cuestión D3.8.- ¿La cantidad de espacio libre en el área va a resultar desfavorable de cara a la paseabilidad?

Aunque el espacio libre en muchos aspectos del urbanismo sostenible puede ser un factor favorable, para el caso de la paseabilidad se debe de establecer un intervalo. Esto es debido al hecho, de que el exceso de espacio libre dentro de un área urbana, puede desfavorecer la comodidad del espacio urbano para el peatón, debido al incremento de las distancias, y a la falta de uso. Esto tiene como efecto secundario el uso del vehículo particular, y la infrautilización del espacio público. Para esta cuestión, va a considerarse la cantidad de espacio libre del área de influencia del centro comercial en su totalidad; y esta se hallará restando a 1, el porcentaje global medio de ocupación hallado en D2.3.

-Respuesta 1: El espacio libre en el área de influencia del centro es superior al 70\%, esta respuesta puntúa con +0 .

-Respuesta 2: El espacio libre en el área de influencia del centro es inferior al 70\%, esta respuesta puntúa con +1 .

Cuestión D3.9.- ¿̇Los usos en la zona están mezclados o zonificados?

Esta cuestión es repetida en el análisis de esta medida de rehabilitación. La razón de esto, es debida a que a efectos de sostenibilidad urbana, paseabilidad, habitabilidad del espacio público y proyección de ciudades eficientes y benignas para el medio ambiente; la mezcla de usos es un factor favorable. Esto se debe al hecho, de que la falta de mezcla de usos, o la excesiva zonificación, además de suponer un incremento entre las distancias, va a conllevar la aparición de puntos fríos en la zona, como efecto secundario del enfoque exclusivo de los usos urbanos de cara al espacio anejo. Además, la generalización de la zonificación de usos, puede propiciar el uso del vehículo particular por el incremento de la distancia, espacialmente si el área urbana está formada por grandes extensiones edificadas enfocadas hacia un solo uso.

Para este análisis, se van a considerar el índice de mezcla de usos, hallado con anterioridad en el apartado 1J, y utilizado para la cuestión D1.4.

-Respuesta 1: La zona es poco compleja respecto a mezcla de usos (el índice global de mezcla de usos es inferior a 0,4). Esta respuesta puntúa con +0.

-Respuesta 2: En la zona hay una mezcla de usos esporádica o generalizada (el índice global de mezcla de usos es mayor a 0,4). Esta respuesta puntúa con +1 .

4E.- CUESTIONES RELACIONADAS CON LA ACTIVIDAD DEL CENTRO Y SUS INPLICACIONES A NIVEL URBANO: 
Este apartado, es el que está relacionado con otras cuestiones de importancia, que afectan a uno o varios campos de la rehabilitación, y que su estudio está relacionado e influido por algunas de las cuestiones anteriores y modelos de rehabilitación.

Cuestión E1: ¿La actividad del centro comercial, va a penalizar o a favorecer la sostenibilidad del entorno urbano?

El centro comercial al ser un elemento de gran importancia urbana, va a producir actividad en su entorno, siendo de importancia establecer como base, el número de personas que lo visitan en relación con el número de habitantes la zona de influencia. No obstante, la favorabilidad de la actividad, va a depender de la configuración urbana del área, así como del transporte.

De este modo, para esta cuestión va a elaborarse una tabla, en función del índice de capacidad de atracción del centro (C6), y el resultado del campo de rehabilitación D1 (Transporte eficiente). Y en función de la extrapolación de los factores de entrada, diferentes operaciones de rehabilitación van a ser favorecidas o penalizadas (Figura 4.9.5).

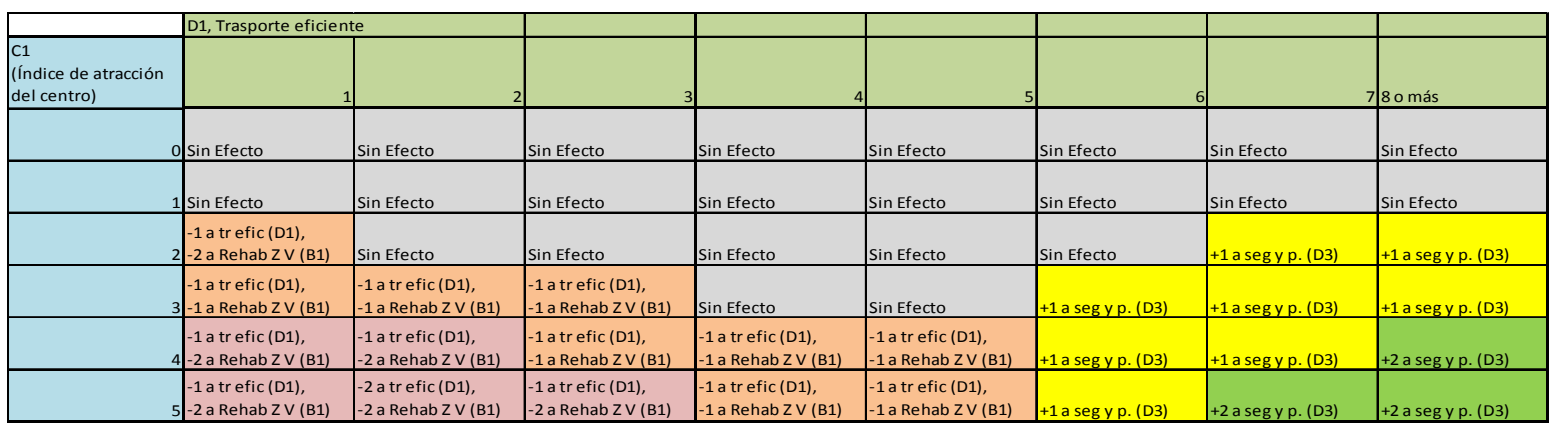

Figura 4.9.5. Tabla de ponderación en base a la actividad del centro comercial y el transporte. Fuente: Elaboración propia.

\subsection{0.- QUCK REFFERENCE GUIDE TO METHODOLOGY}

This chapter has the aim of resuming the working of the methodology of the current thesis, in addition to establish a guide to use it.

\subsection{1.- Methodology basics}

The methodology of analysis is based on four retrofitting means.

The first step of the methodology is to establish a quantitative criteria, to evaluate the efficacy and necessity of the means of retrofitting chosen. A scale of ten points was established, being the less score, the most harmful a shopping center is towards the sustainability in the field related the retrofitting mean analyzed. Three thresholds were established into the chard.

-Minimum threshold: If any retrofitting measure scores less than 2 points, this means the shopping mall is far from being sustainable related to environment and urban efficiency.

-Optimum Threshold: If a retrofitting mean scores up or more than 8 points, this mean the shopping mall comply with the requirements of urban and environmental sustainability ruling the retrofitting mean. 
-Green paradigm: If a retrofitting measure scores up to 10 points this means the shopping center complies more than successfully with the requirement of urban sustainability assigned for the retrofitting mean. Furthermore, retrofitting works in this mean have no sense.

Once the score and the quantitative criteria established, next step was to insert in the chard the means of retrofitting to be of application for the shopping mall to analyze.

-Related to the sustainability pillar of environment, the retrofitting means of application to the shopping mall established were the following ones: The facts to be analyzed within the retrofitting means, are shown in the (Annex 1).

A.- Eco efficiency and energy focused retrofitting: The means applied and studied within, are aimed to achieve a reduction of energy consumption in the shopping mall building, in addition to the bioclimatic adaptation of it. Related to ecological efficiency, three means of retrofitting were considered. However, was impossible to make an exhaustive analysis due to the lack of data concerning energy consumption and carbon dioxin emissions.

A1.- Installation of Low emission installations. Current status and consumption of installations were analyzed.

A2.- Installation of Active energetic systems. Availability of solar active systems and necessity were analyzed.

A3.- Passive measures. Bioclimatic adaptation of the mall building and availability of passive solar systems were analyzed.

B.- Green and environmental retrofitting: The objective is related in the partial recuperation of the environmental capabilities in the built area, such as green areas, water absorption by the terrain and greenhouse gas assimilation. Three means were considered.

B1.- Insertion of green areas. Amount of green areas in shopping mall and urban area, as well as carbon dioxin absorption.

B2.- Water saving and absorption retrofitting. Relative percentage of waterproof surface was analyzed, in addition to climate rain and the availability of water save devices in shopping mall.

B3.- Heat island treatment. The effects and presence of heat island effect was considered, as well as climate temperatures and clear surfaces in both shopping center and urban area.

C.- Retrofitting by the insertion of uses: The means of retrofitting, were focused in the addition of non commercial uses in the shopping mall. Three uses were considered.

C1.- Insertion of residential use. Residential surface in shopping mall and urban area were considered.

C2.- Insertion of non commercial business, or productive uses. Productive use surface in shopping mall and urban area were considered. Commercial surface was excluded. 
C3.- Insertion of public or social uses. Number of facilities aimed to social uses were considered in mall and urban area.

D.- Retrofitting in urban areas, Because of the paper the city planning has in urban environment, as well as the importance of the interaction of it with the shopping mall, three retrofitting measures of application in the urban area surrounding the shopping mall were considered. Is important to consider that any retrofitting operation on the shopping center is not going to solve the problems in the urban area.

D1.- Retrofitting aimed to efficient transportation means. Availability of mass transit in urban area, and efficacy of it related to private transportation were analyzed.

D2.- Retrofitting aimed to density. Density in urban area was considered, as well as urban tissue structure and percentages of surface occupied by buildings.

D3.- Improvement of Walkability and security. Complexity in urban area was analyzed, in addition to urban tissue structure.

The addition of these measures of retrofitting results in the Sustainable Retrofitting Rose graph. (Figure 3.10.1).

(A) ECO EFFICIENT RETROFITTING FAMILY
(A1) Low Emissive installations
(A2) Active measures
(A3) Passive measures

2 points: Minimum threshold 2 points: Minimum threshold
8 points: Optimal threshols 8 points: Optimal threshols

\section{(C) USES AND}

AMENITIES INSERTION

(C1) Residential use

(C2) Productive use

(C3) Services and amenities

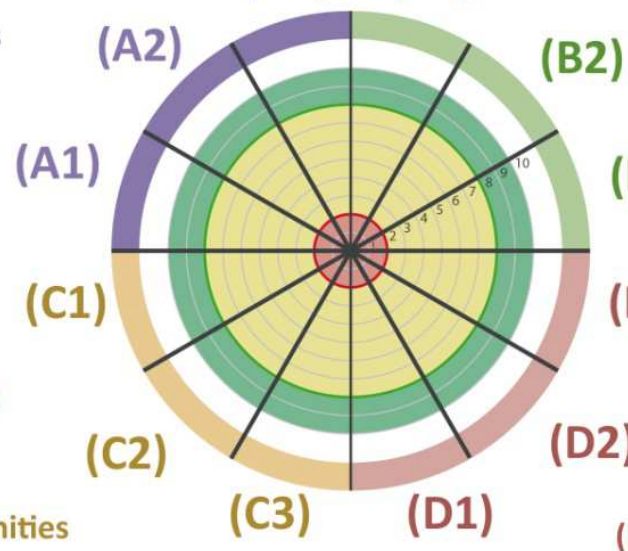

(B) ENVIRONMENTAL RETROFITTING FAMILY

(B1) Insertion of green areas (B2) Water assimilative surfaces (B3) Heat island treatment

Figure 4.10.1.- Retrofitting Rose Graph. Own's source.

To establish the scores in the Retrofitting Rose Graph, the next facts of the shopping mall building and urban area are going to be considered ${ }^{45}$ :

\subsection{2.- Shopping mall data Analytics}

PHASE 0: CUANTITATIVE DATA REPORT.

OC.- SHOPPING MALL DATA.

\footnotetext{
${ }^{45}$ CARRETERO, JORGE; HIGUERAS ESTER. "Included in the paper The Suitability Of Sustainable Retrofitting Means For Shopping Malls, In An Environmental And Urban Background. A Resume Of The Methodology".
} 
in this phase the quantitative data of the shopping mall is going to be considered, as the base for later calculation, the data to consider is:

C1: Shopping mall surface $\left(\mathrm{m}^{2}\right)$. Total built up surface of the shopping mall,

C2: Shopping mall plot surface $\left(\mathrm{m}^{2}\right)$. Surface in plan of the complete plot of the shopping mall.

C3: Plan Surface of the shopping mall $\left(\mathrm{m}^{2}\right)$. Surface covered by the shopping mall in the plot

C4: Weekly visitors (People). The weekly visitor data can be provided by the shopping mall, if not, the following criteria will be applied to calculate it, related to the surface of the mall, and presence in the city:

Monday-Friday: 1 visitor/m2; Saturday: 0,83 visitor/m2; Sunday: 0,27 visitor/m2.

Being the result multiplied later by

$x 1$,5: Fist grade shopping mall; $x 1$ : Important shopping mall; $x 0,8$ : average hierarchy shopping mall; $x 0,5$ : low hierarchy shopping mall; $x 0,05$ : decayed shopping mall, almost dead.

C5: Attraction index of the shopping mall: According to the weekly visitors, the shopping mall will be rated with the following index:

Index 0: < weekly visitors.

Index 1: 1000 - 5000 weekly visitors.

Index 2: $5000-20.000$ weekly visitors.

Index 3: de 20.000 - 150.000 weekly visitors.

Index 4: de 150.000 - 300.000 weekly visitors.

Index 5: > 300.000 weekly visitors.

C6: Residential surface in mall: $\left(\mathrm{m}^{2}\right)$ all the residential or hotel surface will be included in this account.

C7: Productive use surface in mall: $\left(\mathrm{m}^{2}\right)$ Non commercial tertiary - secondary use surface, management offices are excluded.

C8: Amenities or public uses in mall: ( $n$ o of dwellings) All non commercial services/amenities open to public.

\section{OU.- URBAN ENVIRONMENT DATA.}

In this index, the data concerning the urban environment is going to be considered, as the base of the analysis of the urban area of influence.

U1: Population of the urban area of analysis: (people) will be obtained by dividing the built up mall surface/2, according to Victor Gruen criteria to dimension shopping malls.

U2: Population density of the urban area: (People $\left./ \mathrm{m}^{2}\right)$

U3: Primal surface of the urban area: $\left(\mathrm{m}^{2}\right)$ will be obtained by multiplying the index U1 (people of the urban area), by the U2 index (Population density) 


\section{PHASE 1: ANALYSIS OF THE URBAN AREA.}

This analysis is aimed in the study of the different facts of the urban area of analysis, considering quantitative and qualitative methods. Is important to consider the surfaces, and the analysis of different sub areas into the urban area of analysis, established according to the features of the urban tissue.

1A.- Establishment of the influence area of the shopping mall: As a previous step of the delimitation of the urban area of analysis, a radius will be traced from the plot of the shopping mall, the length of this ration will follow this formula: . Radius $=V^{-}$(U3(primal surface urban area)/ $\pi$ ).

1B.- Delimitation of the urban area of influence (graphical analysis): in this graphical analysis, the urban area will be traced within the circumference, considering the shapes and the configuration of the urban structure.

IMPORTANT: The surface of this established area will be measured again, being obtained the definitive surface of the urban area of analysis.

1C.- Division of the urban area of influence in homogeneous areas: (graphical analysis, $\mathrm{m}^{2}$ ) The urban area of influence (1B) is going to be divided according to urban tissue features, considering homogeneous surfaces, which will be also measured in square meters. Is important to establish the percentage the homogeneous area copes in plan surface, according to the complete area of analysis.

1D.- Rate of coverage of homogeneous areas in urban area of influence: (graphical analysis, \%) The rate of coverage of each homogeneous area established in $1 \mathrm{C}$ will be obtained. by analyzing the occupied surfaces in a typological square sized representative area.
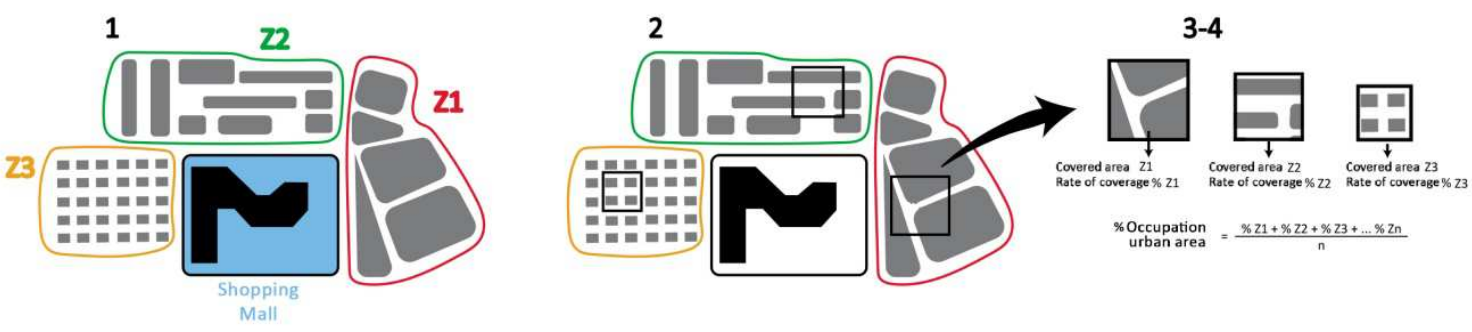

Figure 4.10.2.- Analysis of built surfaces in homogeneous areas Own's source.

1E.- Built surface in plan of homogeneous areas: (graphical analysis, $\mathrm{m}^{2}$ ). In this analysis, for each homogeneous area established in $1 \mathrm{C}$, the rate of coverage will be multiplied by the total surface, to obtain the built surface in plan.

1F.- Establishment of the typologies of urban tissue considering the density: (quantitative analysis). According to the features of each urban homogeneous tissue, the homogeneous areas will be qualified by density ranks according the following table (4.11.3): 


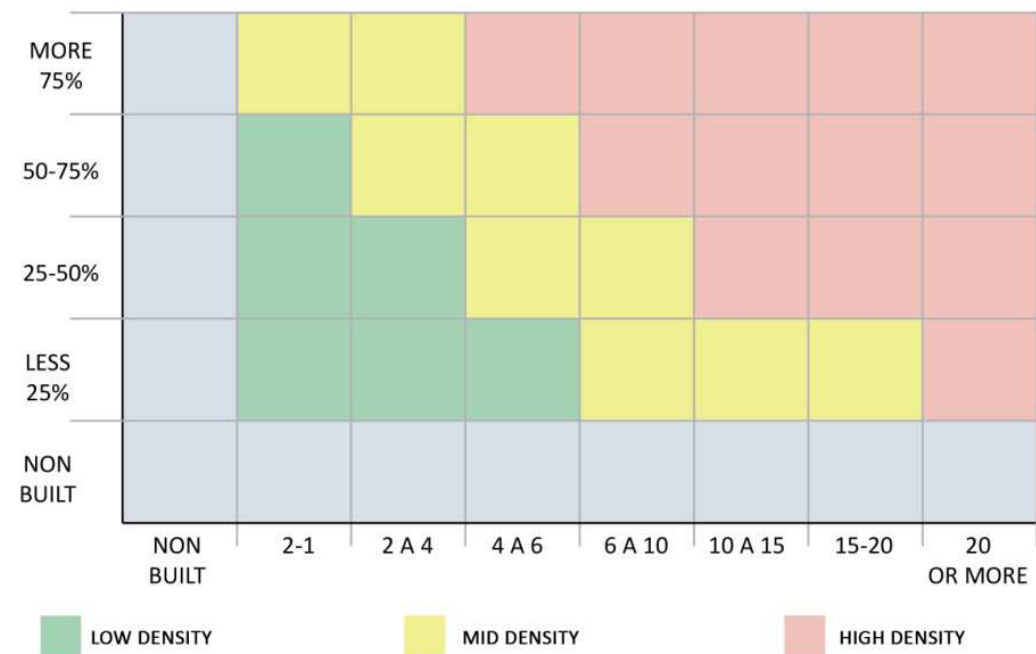

Figure 4.10.3.- Density qualification of homogeneous areas: Kevin Lynch, own's source.

1G.- Global density index: According to the qualification formerly done in $1 \mathrm{~F}$, each homogeneous area will have a density index considering the following criteria:

Low Density area: 1; Mid density area: 2; Low density area: 3.

To establish the global density index of the shopping mall area of influence, the following formula will be applied:

(1* \% of Hom. areas with low density, according to total surface of urban influence area + 2* \% Hom. areas with mid density, according to total surface of urban influence area $+3 * \%$ Hom. areas with high density, according to total surface of urban influence area).

$1 \mathrm{H}$.- Built up surface of each homogeneous area $\left(\mathrm{m}^{2}\right)$ : The covered surface obtained per homogeneous area will be multiplies by the average number of stories, being obtained the total built up area.

11.- Establishment of percentages of use in the area (\%): The built up surfaces of each homogeneous area will be divided in percentages considering the uses within. The following uses will be considered: residential, productive non commercial, and commercial.

11.- Surfaces of use of the urban area $\left(\mathrm{m}^{2}\right)$ : the percentages established formerly will be multiplies by the built up surface of each homogeneous area to obtain the surfaces of each use considered. This will be done too for the complete urban area of analysis by adding all the surfaces per use of the different homogeneous areas established.

1K.- Global index of use mixture: For each homogeneous area established will be considered an index of use mixture according the following criteria:

The percentages of commercial and productive uses (1I) will be added, to establish the non residential uses percentage. This will be compared with the residential use percentage according to the following statement: 
If the residential or non residential use supposes more than the $80 \%$ of the built up area, the index of use mixture will be 0 points. if not, the index will be of 1 point.

Later, once the indexes of uses mixture are calculated to each homogeneous area, to obtain the global index of uses mixture for the whole urban area of analysis, the following formula will be considered:

(mix of uses index of homogeneous area $1 * \%$ of homogeneous area $1+$ mix of uses index of homogeneous area $2 * \%$ of homogeneous area $2+\ldots .+$ mix of uses index of homogeneous area $n * \%$ of homogeneous area $n$ ).

1L.- Number of amenities in nearby urban area: ( $\mathrm{n}$ - of amenities): For this analysis, a radius of 1000 meters will be plotted form the limits of the shopping mall plot. in this area the following amenities will be located according to their hierarchies.

1M.- Positive and negative points in urban area: In the urban area of analysis established in $1 \mathrm{C}$, the positive and negative points related to urban vitality or security will be placed.

1 N.- Activity points: In the urban area of analysis established in $1 \mathrm{C}$, the daytime and night time hot and cold spots of activity are going to be placed.

10.- Green surfaces in urban areas $\left(\mathrm{m}^{2}\right): \ln$ this analysis, the green surfaces in the urban area are going to be located. Is important to consider the green surface in plan, as well are the different layers of vegetation within in square meters. (Prairies, Extensive vegetation or low height bushes, intensive vegetation or large size bushes, caduceus forest, perennial forest, or other layers to consider)

1P.- Paths to shopping mall in the urban area: In this analysis, on a plan different parts throughout the urban area will be plotted. These paths will start in the border of the urban area, and will end in any entrance of the shopping mall.

1Q.- Carbon footprint of the urban area: (Yearly Tons of CO2). This data can be obtained by multiplying the emissions per capita of the country or city where the shopping mall is located, by the people of the urban area of analysis (U1).

1R.- Carbon dioxin absorption of the green areas of urban environment: (Yearly Tons of $\mathrm{CO} 2$ assimilated). To obtain this index, all the layers of vegetation established in 10 , will be multiplied by the following rates of carbon dioxin assimilation:

-Prairies: 0,0013 T CO2 $/ \mathrm{m}^{2}$ per year.

-Extensive vegetation or low height bushes : 0,002 T CO2 $/ \mathrm{m}^{2}$ per year.

-Intensive green areas or big size bushes: 0,035 T CO2 $/ \mathrm{m}^{2}$ per year.

-Caduceus forest: $0,15 \mathrm{~T} \mathrm{CO} 2 / \mathrm{m}^{2}$ per year.

-Perennial forest: $2,25 \mathrm{~T} \mathrm{CO} 2 / \mathrm{m}^{2}$ per year.

1S: Areas according to water assimilation $\left(\mathrm{m}^{2}\right)$ : In this analysis of surfaces, the areas to be considered are going to be the green areas as well as the ones paved with permeable materials.

PHASE 2: ANALYSIS OF RELATIONS BETWEEN THE SHOPPING MALL AND URBAN AREA. 
2A.- Delimitation of nearby area: In this analysis, the surrounding plots of the shopping mall are going to be marked, these will compound the nearby area of the mall.

2B.- Built up surface in nearby area: $\left(\mathrm{m}^{2}\right)$. The built up surfaces of the surrounding plots nearby the shopping mall will be calculated. The covered areas in these plots will be obtained, and later they will be multiplied by their respective number of stories.

2C.- Uses in nearby area: $\left(\%, \mathrm{~m}^{2}\right)$. As it was done in $1 \mathrm{l}$ and $1 \mathrm{~J}$ for the urban area, the percentages of residential, commercial and productive uses will be established, in addition to the and the surfaces of them in the nearby plots.

2D.- active facades in nearby area $(\mathrm{m})$. In this analysis, the facades that has interaction with the street (active facades) in the nearby area, will be marked and measured, being of importance to calculate the percentage they suppose, related to the total length of facade of the nearby area.

2E.- Arrival time to the shopping mall by the usage of mass transit or public transport: (minutes of displacement). The times of displacement expended to cover the paths established in $1 \mathrm{P}$, by the use of mass transit are going to be estimated.

2F.- Arrival time to the shopping mall by the usage of private vehicle: (minutes of displacement). The times of displacement expended to cover the paths established in 1P by the use of a private vehicle are going to be estimated.

2G.- Covered areas by mass transit in urban area of analysis. $\left(\mathrm{m}^{2}\right)$. $\ln$ this analysis the whole urban area is going to be considered (1B). All the stops of mass transit are going to be located, establishing from each of them a circumference of 200 meters. The addition of these circular surfaces will compound the area covered with presence of mass transit. Is important to consider too the percentage this area occupies according the whole urban area of analysis (1C).

\section{PHASE 3: ANALYSIS OF THE SHOPPING MALL BUILDING.}

All of the analysis done in this chapter, re going to be related only to the plot and the building of the shopping mall analyzed, different facts are going to be considered according to the features of the building itself.

3A.- Delimitation of the areas according to water assimilation $\left(\mathrm{m}^{2}, \%\right)$. The surfaces in the shopping mall plot are going to be analyzed according to the water absorption. Both permeable and waterproof surfaces will be marked, obtaining their surfaces in square meters, and their percentages according to the surface of the plot.

3B.- Uses in the mall building (\%). the surfaces and percentages of residential and productive uses $(\mathrm{C} 6, \mathrm{C} 7)$ are going to be established in percentages, related to the total built surface of the shopping mall.

3C.- Green areas in shopping mall. $\left(\mathrm{m}^{2}\right)$. In this analysis, the green surfaces in the shopping mall plot are going to be located. Is important to consider the green surface in plan, as well are the different layers of vegetation within in square meters. (Prairies, Extensive vegetation or 
low height bushes, intensive vegetation or large size bushes, caduceus forest, perennial forest, or other layers to consider)

3D.- Carbon dioxin assimilation of the green areas in shopping mall. (Yearly Tons of $\mathrm{CO} 2$ assimilated). To obtain this index, all the layers of vegetation established in 3C, will be multiplied by the following rates of carbon dioxin assimilation:

-Prairies: 0,0013 T CO2 $/ \mathrm{m}^{2}$ per year.

-Extensive vegetation or low height bushes : 0,002 T CO2 $/ \mathrm{m}^{2}$ per year. -Intensive green areas or big size bushes: 0,035 T CO2 $/ \mathrm{m}^{2}$ per year.

-Caduceus forest: $0,15 \mathrm{~T} \mathrm{CO} 2 / \mathrm{m}^{2}$ per year.

-Perennial forest: $2,25 \mathrm{~T} \mathrm{CO} 2 / \mathrm{m}^{2}$ per year.

3E.- Givoni analysis of the shopping mall building: Both the shopping mall building features and its installations, are going to be put in the Givoni chard corresponding to its climate.

3F.- Energetic and emissions qualification of the shopping mall: An energetic analysis of the shopping mall is going to be done, with the aim of obtaining the carbon dioxin emissions and energy consumption of the shopping mall building. The analytics of the current thesis considers the European scale (going from the A to the G rating).

3G.- Usage of clean energies: An estimation of the usage of clean energies by the shopping mall is going to be performed, is important to establish this rate in percentage, related to the total amount of energy used by the shopping mall.

3H.- Inner spaces with natural light $\left(\mathrm{m}^{2}, \%\right)$ : In this analysis, the surfaces of the inner spaces with natural light in the shopping mall building, are going to be analyzed. This analysis will consider the following criteria: the surface of spaces mostly of fully illuminated with natural light will be multiplied by 1 , the surfaces of the spaces partially illuminated with natural light will be multiplied by 0,5 . Later, these surfaces will be added and compared with the total built surface of the shopping mall. Being finally established the percentage of spaces with natural light.

31.- Building shape and features: The features of the shopping mall building, Shapes, size, and main facade orientation, are going to be analyzed, according to the criteria of Olgyay related to climatic areas.

3J.- Pavements and surfaces according to irradiation reflection $\left(\mathrm{m}^{2}, \%\right)$ : For this analysis, both the shopping mall plot and surfaces, are going to be measures and classified according to their capacity to reflect the solar irradiation. Two categories of surfaces are going to be established, the reflective surfaces and the absorbent ones, being also considered the percentages they occupy respect to the plot surface.

\subsection{3.- Questionnaire of the retrofitting rose graph.}


all the features studied formerly related to shopping mall and urban area, are going to be considered for the questionnaire, that will define the score per retrofitting family in the retrofitting rose graph.

\section{A: ECO EFFICIENT RETROFITTING:}

A1: Low emission installations.

Question A1.1: Has the center unnecessary installations according to Givoni Chard?.

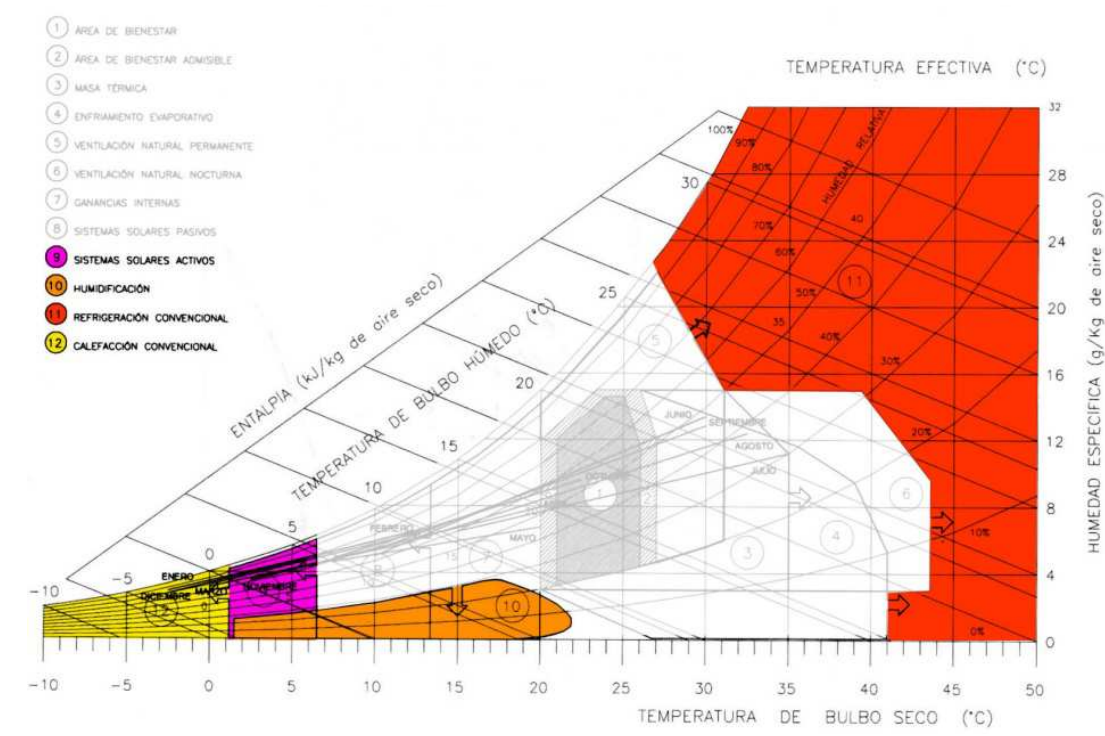

Figure 4.10.4.- Givoni chard related to installations (Givoni, Javier Neila, Ester Higueras)

-Shopping mall has unnecessary installations: +0 .

-Shopping mall has no unnecessary installations: +1

Question A1.2: Does the installations of the center emit a carbon dioxin amount bigger than the average?. (Energetic ranking European criteria)

$$
\begin{aligned}
& \text { - F-G ranking: +O } \\
& \text { - E ranking: }+1 \\
& \text { - D ranking: }+2 \\
& \text { - } B-C \text { ranking: }+3 \\
& \text { - A ranking: }+4
\end{aligned}
$$

Question A1.3: Are the installations of the center obsolete?.

-The installations have more than 15 years old, or they are obsolete: +0.

-The installations have less than 15 years old, or they are updated: +1 .

Question A1.4: Does the installations of the center consume more energy than the average? (Energetic ranking European criteria). 


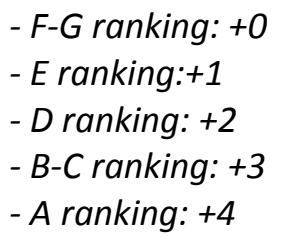

\section{A2: Active solar measures.}

Question A2.1: Which percentage of the necessary calories is obtained by the usage of active systems, in order to get the comfort temperature?
- None: +0
$-10 \%:+1$
$-30 \%:+2$
$-50 \%:+3$
$-70 \%$ or more: +4

Question A2.2: Which percentage of the energy is obtained by the usage of renewable energies?

-None: +0

$-10 \%:+1$

$-30 \%:+2$

$-50 \%:+3$

$-70 \%$ or more: +4

Question A2.3: Concerning active solar systems, does the center requires them according to the Givoni Chard?

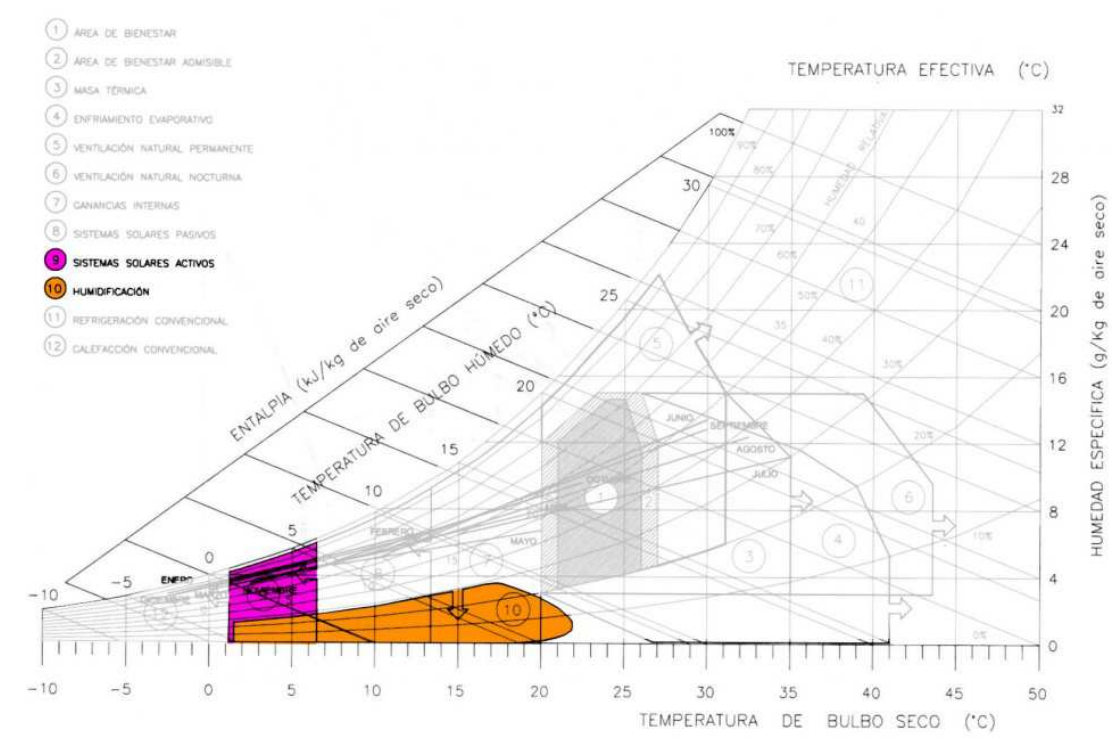

Figure 4.10.5.- Givoni chard related to active solar systems. Source: Givoni, Javier Neila, Ester Higueras 
- No active solar systems: +0

- Some active solar systems: +1

-All active solar systems required: +2

A3: Passive solar measures.

Question A3.1: Is the shape of the Shopping center building correct according to its climatic area? (Olgyay analysis of shape and climatic conditions).

-The mall building does not comply with Olgyay bioclimatic requirements +0

-The mall building complies partially with Olgyay bioclimatic requirements +1

- The mall building complies satisfactorily with Olgyay bioclimatic requirements +2

Question A3.2: Does the building enclosure responds efficiently according to its climate?. (Energetic ranking European criteria according to energetic consumption).

\section{- F-G ranking: +0 \\ - E ranking: +1 \\ - $D$ ranking: +2 \\ - B-C ranking: +3 \\ - A ranking: +4}

Question A3.3: Which is the percentage of the inner space of the shopping center, illuminated with natural light?.

\section{- Less than 20\%: +0 \\ - 20-60\%:+1 \\ - More than 60\%: +2}

Question A3.3: Is adapted the inner space of the center, or has features recommended by the Givoni Chard?.

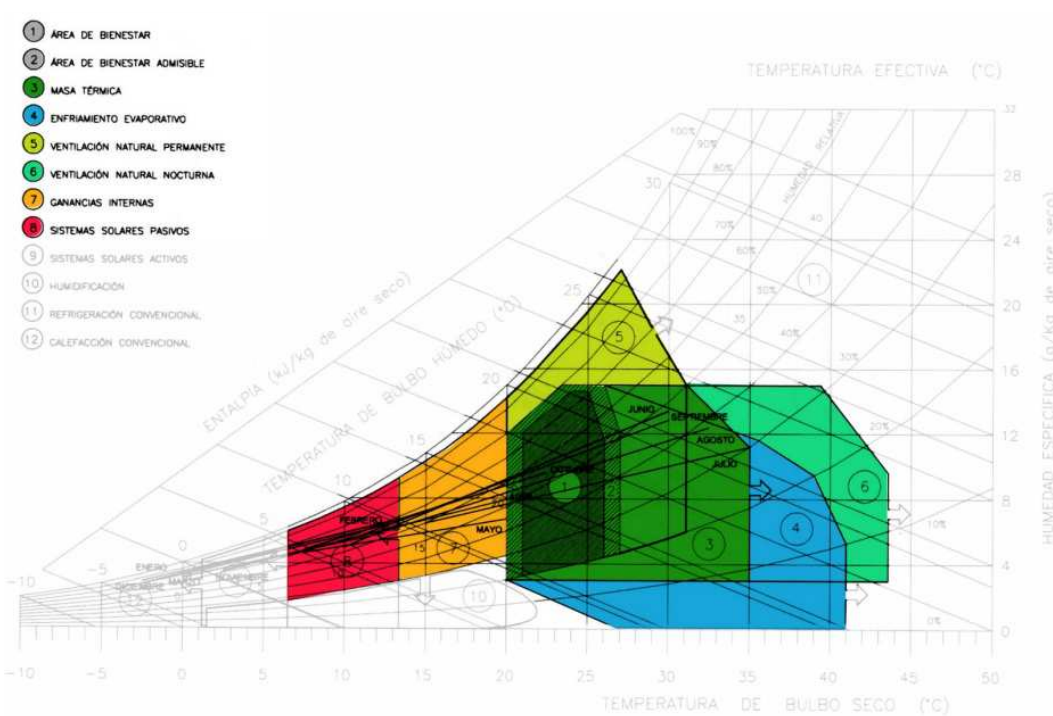


Figure 4.10.6.- Givoni chard related to passive measures (Givoni, Javier Neila, Ester Higueras)

-The inner space of the mall does not comply with Givonni requirements +0

-The inner space of the mall complies partially with Givonni requirements +1

- The inner space of the mall complies satisfactorily with Givonni requirements +2

\section{B: ENVIRONMENTAL RETROFITTING:}

B1: Green areas retrofitting.

Question B1.1.- Is there in the urban area enough green spaces according to its population? (Salvador Rueda Thresholds).

-Less than $10 m^{2}$ per inhabitant: +0 .

$-10-20 m^{2}$ per inhabitant: +1 .

-More than $20 \mathrm{~m}^{2}$ per inhabitant: +2 .

Question B1.2.- Are the green areas within the shopping center, enough for its visitors?.

-Shopping mall has less than $1000 \mathrm{~m}^{2}$ of green areas: +0 .

- Shopping mall has more than $1000 \mathrm{~m}^{2}$ of green areas: +1 .

Question B1.3.- Which amount of the carbon dioxin emissions produced by the urban area, can be assimilated by the green areas within?.

- Less than $10 \%:+0$

$-10-40 \%:+1$

$-40-70 \%:+2$

- More than $70 \%:+3$

Question B1.4.- Which amount of the carbon dioxin emissions produced by the mall, can be assimilated by the green areas within?.

- Less than $10 \%:+0$

$-10-30 \%:+1$

$-30-50 \%:+2$

- More than $50 \%:+3$

Question B1.5.- is the distance between green spaces in area less than 200 meters?.

- Yes, distances are more than $200 \mathrm{~m}:+0$

- No, distances are less than $200 \mathrm{~m}:+1$

B2.- Water assimilative surface retrofitting. 
Question B2.1.- is arid or semi arid, the climate where the center is located?. (Martonne qualification)

-Yes, Martonne index <20: +0

- No, Martonne index $>20:+0$

Question B2.2.- In which percentage, are the water permeable surfaces in relationship with waterproof ones?.

\section{- Less than $5 \%:+0$ \\ $-5-20 \%:+1$ \\ $-20-40 \%:+2$ \\ $-40-60 \%:+3$ \\ - More than 60\%: +4}

Question B2.3.- Has the Shopping center adapted installations for water saving, or facilities for water storage?. Three systems are going to be considered: Permeable pavements, reservoirs and Installations adapted to water savings.

- Shopping mall has none of these systems: +0

- Shopping mall has one of these systems: +1

- Shopping mall has two of these systems: +2

- Shopping mall has all of these systems: +3

Question B2.4.- in how many liters per visit, is defined the water consumption of the shopping center?.

- More than 501 per visit and day: +0

- 20-50l per visit and day: +1

- Less than 501 per visit and day: +2

B3.- Heat Island treatment.

Question B3.1.- Is The Shopping center located in a more or less hot climate?.

- Yearly average temperature of $14^{\circ} \mathrm{C}$ or more: +0

- Yearly average temperature of $8-14^{\circ} \mathrm{C}:+1$

- Yearly average temperature minor than $8 \stackrel{\circ}{ } \mathrm{C}:+1$

Question B3.2.- In the climate where shopping center is located. Can happen extreme heat conditions?.

- Yes: +0

- No: +1 
Question B3.3.- Is The shopping center located in an area with a difference of temperature of?.

- Heat island effect of $+4{ }^{\circ} \mathrm{C}$ or more: +0 .

- Heat Island effect of +2 to $+4 \%:+1$.

- Heat Island Effect of +0 to $+2 \%:+2$.

-No Heat island effect: +3 .

Question B3.4.- In the shopping mall roof and plot, Which is the percentage of the surfaces that contribute to heat island effect?.

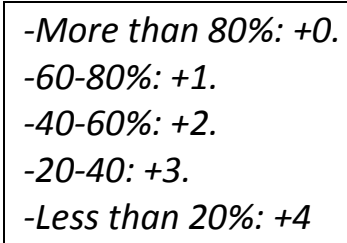

\section{C: USES RETROFITTING:}

C1.- Residential use.

Question C1.1.- Has The shopping center residential or lodging uses within?. (is going to be divided the residential surface in the mall by twenty, and compared with the population of urban area).

-The shopping mall residential use can lodge less than $10 \%$ of the area population: +0 .

-The shopping mall residential use can lodge $10-15 \%$ of the area population: +1 .

-The shopping mall residential use can lodge more than $15 \%$ of the area population +2 .

Question C1.2.- Have the plots nearby the shopping center residential use within?.

-The plots nearby the mall have less than a $10 \%$ of residential use: +0 .

- The plots nearby the mall have $10-30 \%$ of residential use: +1 .

- The plots nearby the mall have $30-50 \%$ of residential use +2 .

- The plots nearby the mall have more than a $50 \%$ of residential use +3 .

Question C1.3.- Which is the amount of residential use surface in the shopping mall influence urban area?.

-The urban area of influence has less than a $10 \%$ of residential use: +0.

- The urban area of influence has a 10-20\% of residential use: +1 .

- The urban area of influence has $20-40 \%$ of residential use +2 .

- The urban area of influence has $40-50 \%$ of residential use +3 .

- The urban area of influence has $50-70 \%$ of residential use +4 .

- The urban area of influence has more than a $70 \%$ of residential use +5 . 
C2.- Productive or workspace use.

Question C2.1.- Has The shopping center productive use within?.

- No: +0 .

- Yes: +1 .

Question C2.2.- Have the lots nearby the shopping center productive use within?.

-The plots nearby the mall have less than a $1 \%$ of productive use: +0 .

-The plots nearby the mall have 1-5\% of productive use: +1 .

- The plots nearby the mall have $5-10 \%$ of productive use +2 .

- The plots nearby the mall have more than a $10 \%$ of productive use +3 .

Question C2.3.- Which is the amount of productive use surface in the shopping mall influence urban area?.

- The urban area of influence has less than a $2 \%$ of productive use: +0 .

- The urban area of influence has a $2-8 \%$ of productive use: +1 .

- The urban area of influence has $8-12 \%$ of productive use +2 .

- The urban area of influence has $12-18 \%$ of productive use +3 .

- The urban area of influence has $18-24 \%$ of productive use +4 .

- The urban area of influence has $24-30 \%$ of productive use +5 .

- The urban area of influence has more than a $30 \%$ of productive use +6 .

C3.- Amenities or public uses.

Question C3.1.- Has The shopping center amenities within?.

- No: +0 .

- Yes: +1 .

Question C3.2.- Have the lots nearby the shopping center amenities or public uses?.

-The nearby plots have no amenities or public uses: +0 .

-The nearby plots have a scarcely visited amenity: +1 .

-The nearby plots have more than one amenities of scarce visit: +1 .

- In the nearby plots there is an amenity that is visited usually: +3 .

- In the nearby plots there are more than one amenity, which are visited usually: +4 .

Question C3.3.- In the area related to amenities ( $1 \mathrm{~km}$ from shopping mall) are there amenities?.

-In the area related to amenities there are none: +0 .

- In the area related to amenities, there are some scarcely visited amenities: +1 .

- In the area related to amenities, there are some occasionally visited amenities: +2 . 
- In the area related to amenities, there is one amenity that is visited usually: +3 .

- In the area related to amenities there are some amenities which are visited usually, or there is one that serves the whole urban area or district where the mall is located: +4 .

- In the area related to amenities there is more than one first hierarchy amenity that serves the whole urban area or district where the mall is located, or one that is related to the scale the whole city or the country where the mall is located +5

\section{D: RETROFITTING IN URBAN ENVIRONMENT.}

\section{D1.- Efficient transportation means}

Question D1.1.- Has the shopping center a mass transit system station nearby?.

- No: +0 .

- Yes: +1 .

Question D1.2.- Is more the time of arrival to the shopping center by the usage of mass transit, than by the usage of private transportation means?. (The efficacy index of the public transportation will be obtained by dividing the arrival time by public transportation by the private per path established, being later done the average among all the efficacy indexes)

-The average efficacy index of the public transportation is 2 or more: +0 .

-The average efficacy index of the public transportation is 1,5-2: +1 .

- The average efficacy index of the public transportation is 1,2-1,5: +2 .

- The average efficacy index of the public transportation is less than 1,2: +3 .

Question D1.3.-Which percentage of surface of the urban area is covered by mass transit?.

-Less than $50 \%:+0$.

$-50-70 \%:+1$.

-More than $70 \%:+2$.

Question D1.4.-Are the uses in the urban area of influence mixed?. (Mixture of uses index)

-Non complex urban area: (Mixture of uses index less than 0,4): +0 .

- Scarcely complex urban area: (Mixture of uses index in 0,4-0,7): +1

- Complex urban area: (Mixture of uses index in 0,7-1): +1

Question D1.5.- Have the surroundings of the shopping center, facilities aimed to sustainable mobility?.

-There are no facilities of sustainable mobility in the surroundings of the shopping mall: +0 .

- There is one facility of sustainable mobility in the surroundings of the shopping mall: +1

- There are some facilities of sustainable mobility in the surroundings of the shopping mall:+21 


\section{D2.- Density}

Question D1.1.-Is the population density index among...?.

-Less than 0,004 inhabitants $/ \mathrm{m}^{2}$, very low density: +0

$-0,004-0,008$ inhabitants $/ \mathrm{m}^{2}$, low density: +1

$-0,008-0,012$ inhabitants $/ \mathrm{m}^{2}$ low middle density: +2

$-0,012-0,016$ inhabitants $/ \mathrm{m}^{2}$, middle density +3

$-0,016-0,02$ inhabitants $/ \mathrm{m}^{2}$. optimal density: +4

$-0,02-0,06$ inhabitants $/ m^{2}$, high density, congestion problems: +3

-More than 0,06 inhabitants $/ \mathrm{m}^{2}$, very high density, severe congestion problems: +2

Question D1.2.-Is the density of urban tissues favorable toward sustainability...?.

-Density index in $1-1,25:+0$

- Density index in 1,25 - 1,5: +1

- Density index in 1,5 a $2:+2$

- Density index in $2-2,75:+3$

- Density index in more than 2,75: +2 because of congestion.

Question D1.3.-Is the occupied space of the urban area among...?.

- Less than $10 \%$ of total surface: +0

$-10-30 \%$ of total surface +1

$-30-50 \%$, of total surface +2

-More than $50 \%$, of total surface +3

D3.- Security and walkability

Question D3.1.- Are there negative elements towards the security or walkability in the urban area?.

- Yes: +0 .

- No: +1 .

Question D3.2.- Is the shopping mall building located in a daytime cold activity spot in the urban area?.

- Yes: +0 .

- No: +1 .

Question D3.3.- Is the shopping mall building located in a night time cold activity spot in the urban area?.

- Yes: +0 .

- No: +1 . 
Question D3.4.- Are nearby the shopping mall building, urban areas with harsh visual or urban control?.

- Yes: +0 .

- No: +1 .

Question D3.5.- Is the urban area considered among its inhabitants to be safe?.

- No: +0 .

- Yes: +1 .

Question D3.6.- Have the surroundings of the shopping center a percentage of active facades?.

- Less than 30\%: +0 .

- 30-50\%: +1 .

-More than 50\%: +2

Question D3.7.- Is the distance from the shopping mall gate, to the nearest residential building less than 200 meters?.

- No: +0

- Yes: +1

Question D3.8.- The amount of unoccupied space, is going to be a handicap towards urban walkability?.

- The unoccupied space by buildings in urban area is a $70 \%$ or more of the total surface: +0 .

- The unoccupied space by buildings in urban area is less than a $70 \%$ of the total surface: +1

Question D3.9.-Are the uses in the urban area mixed?.

- Non complex urban area: (Mixture of uses index less than 0,4): +0 .

- Complex urban area: (Mixture of uses index in more than 0,4):+1

E.- Questions related with more than one sorts of retrofitting.

Question E1.- The activity of the shopping center is going to be favorable or a handicap towards urban sustainability?.

The attraction index of the shopping mall (C5) And the last score in D1 questionnaire, are going to be compared according the following table, considering the effects included within. 


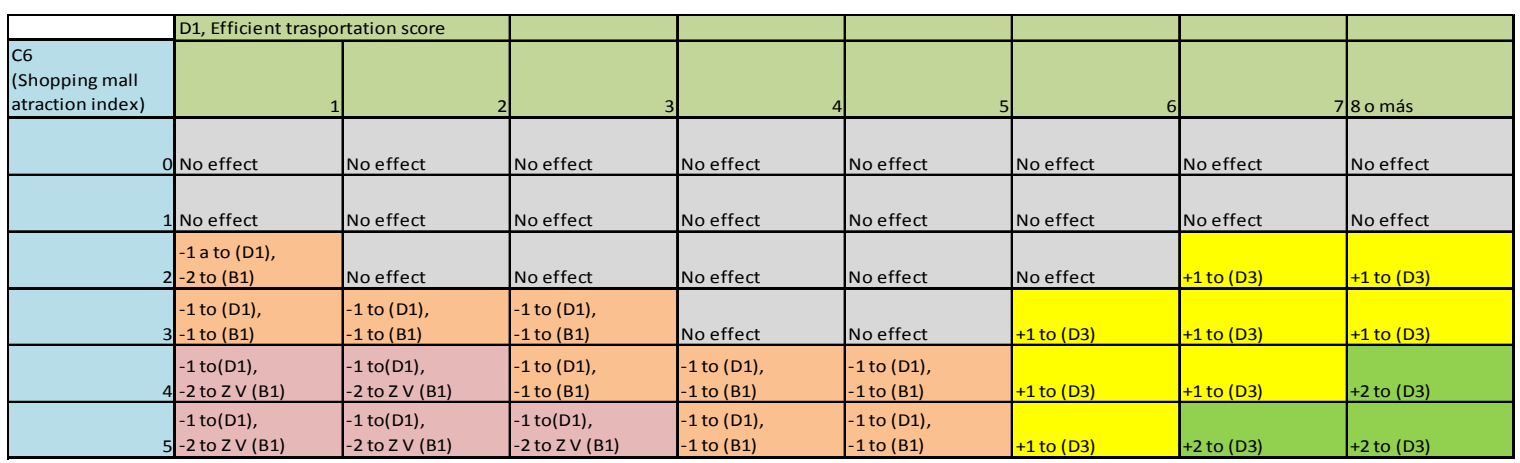

Figure 4.10.7: Analysis table of the factors relating attraction index and efficient transport rate. Own's source.

\subsection{1.- THE OPTIMAL CASE OF RETROFITTING.}

Being the methodology is aimed in the analysis of the retrofitting of shopping malls, is important to establish a case related to the objectives of environmental retrofitting for shopping malls.

As said in former chapters, there are two scales of positive scoring in the graph of analysis. One is the Optimal Score, related to the desired objectives, and the other is the Green Paradigm, far over them.

However, this chapter is focused in the explanation of the case concerning the scale of Optimal score. The reason behind this, is because this case is more reliable, environmentally friendly; as well as easier to get than the Green Paradigm when retrofitting a shopping mall.

The optimal case, is a fictional case of shopping mall, whose scoring in all the facts and questions of analysis within the methodology. Has the same score of the Optimal level, (8 points in all retrofitting method).

By this way, this optimal case is going to be explained in all of the facts of analysis corresponding to the phases 3.5 to 3.8. However this optimal case is not the only one, because is possible to obtain the score of 8 points, by scoring with other factors. To establish the scores of the optimal case, the guide and reference is the questions chard (3.9).

\section{OPTIMAL CASE (8 POINTS SCORE).}

\section{A: ECO EFFICIENT RETROFITTING:}

\section{A1: Low emission installations.}

Question A1.1: Has the mall unnecessary installations according to Givoni Chard?.

The optimal case, has no unnecessary installations according to Climate Givoni Chard. In the areas related to active solar systems, humidification systems, cooling and heating. (1 Point)

Question A1.2: Does the installations of the center emit a carbon dioxin amount bigger than the average?. 
To get the optimal case, This question is expected to be responded at least with a mark of B or $C$ related to emissions of the installations, (European energy certifying ranking) in the carbon dioxin simulation. (3 Points)

Question A1.3: Are the installations of the mall obsolete?.

The response of this question, must be negative, installations of the optimal case cannot be obsolete.

Question A1.4: Does the installations of the center consume more energy than the average?.

To get the optimal case, This question is expected to be responded at least with a mark of B or $C$ related to energy consumption of the installations, (European energy certifying ranking) in the energy consumption simulation. (3 Points).

A2: Active solar measures.

Question A2.1: Which percentage of the necessary calories is obtained by the usage of active systems, in order to get the comfort temperature?

In the optimal case, at least a $50 \%$ of the calories required to get the comfort temperature, are supplied by solar active systems. (3 Points).

Question A2.2: Which percentage of the energy is obtained by the usage of renewable energies?

In the optimal case, at least a $50 \%$ of the energy demand of the shopping center, is supplied by renewable energies. (3 Points).

Question A2.3: Concerning active solar systems, does the center requires them according to the Givoni Chard?

In this question, the center has every sort of active systems installations according to its concerning Givoni Chard, (See active measures area, and humidification). (2 Points).

A3: Passive solar measures.

Question A2.1: Is the shape of the shopping mall building correct according to its climatic area?.

The optimal case is required to comply partially with the optimal shape established for each climate area in the current thesis. (1 Point).

Question A2.2: Does the building enclosure responds efficiently according to its climate?.

To get the optimal case, This question is expected to be responded at least with a mark of B or $\mathrm{C}$, related to the average of both refrigeration and heating energy consumption, (European energy certifying ranking). (3 Points).

Question A2.3: Which is the percentage of the inner space of the shopping center, having natural light?. 
The optimal case, is required to have at least a $60 \%$ of the inner space with natural light. (2 points).

Question A2.3: Is adapted the inner space of the center, or has features recommended by the Givoni Chard?.

In this question, the inner space of the center must be mostly adapted to Givoni Chard requirements. The areas of analysis are the ones related to thermal mass, evaporative cooling, ventilation, night ventilation, internal gains and passive solar systems. (2 Points).

\section{B: ENVIRONMENTAL RETROFITTING:}

B1: Green areas retrofitting.

Question B1.1.- Is there in the urban area enough green spaces according to its population?.

The amount of green space per habitant of the urban area must be at least $20 \mathrm{~m}^{2}$. (2 Points).

Question B1.2.- Are the green areas within the shopping center, enough to house an everyday green area?.

In the optimal case, the surface of green areas in the shopping center must be at least: 1000 $\mathrm{m}^{2}$. (1 Point).

Question B1.3.- Which amount of the carbon dioxin emissions produced by the urban area, can be assimilated by the green areas within?.

The green areas in the urban area, must assimilate at least a $40 \%$ of the total footprint of the population of the urban area. ( 2 points).

Question B1.4.- Which amount of the carbon dioxin emissions produced by the center, can be assimilated by the green areas within?.

The green areas in the shopping center, must assimilate at least a $30 \%$ of the total footprint of the shopping center. ( 2 points).

Question B1.5.- is the distance between green spaces in area less than 200 meters?.

In the optimal case, the distance between areas must be less than 200 meters. (1 point).

B2.- Water assimilative surface retrofitting.

Question B2.1.- is arid or semi arid, the climate where the center is located?.

The correct working of the shopping center building towards water storage does not have relationship with the features of the climate. This question has no requirements.

Question B2.2.- In which percentage, are the water absorbing surfaces in relationship with waterproof ones?. 
The optimal case is required to have water absorbing surfaces at least in a $40 \%$ of the total surface (Including both lot and roof). (3 points)

Question B2.3.- Has the Shopping center installations or facilities for water storage?.

The optimal case of environmentally friendly shopping center, must have all sorts of water storage installations defined in the current thesis (Water absorbent surfaces in lot, cisterns for water storage, and installations adapted to water savings). ( 3 points)

Question B2.4.- in how many liters per visit, is defined the water consumption of the shopping center?.

The water consumption of the shopping center per visit, to get the optimal case, must be less than 50 liters per visit ( 2 points)

B3.- Heat Island treatment.

Because having much relation with the climate, The score for the optimal case in this retrofitting mean is going to be established in seven points.

Question B3.1.- Is The Shopping center located in a more or less hot climate?.

The correct working of the shopping center building towards heat island does not have relationship with any feature of the climate. This question has no requirements.

Question B3.2.- In the climate where shopping center is located. Can happen extreme heat conditions?.

The correct working of the shopping center building towards heat island does not have relationship with any feature of the climate. This question has no requirements.

Question B3.3.- Is The shopping center located in an area with a difference of temperature of?.

Despite this question has no relationship with the shopping center building exclusively. The optimal case, is required to be in an area where heat island is inexistent, (difference of 0 degrees from the average temperature in the city). (3 points).

Question B3.4.- In the shopping center, Which is the percentage of the surfaces that contribute to heat island effect?.

The optimal case of shopping center building is required to have less than the $20 \%$ of surfaces contributing heat island effect (roofs and floors of the lot). (4 points)

\section{C: USES RETROFITTING:}

C1.- Residential use.

Question C1.1.- Has The shopping center residential or lodging use within?.

The optimal case of shopping center is required to have at least lodging for a $10 \%$ of the population assigned to the influence area of the shopping center. ( 2 points). 
Question C1.2.- Have the lots nearby the shopping center residential use within?.

The lots nearby the shopping center, are required to have at least a $30 \%$ of their surface, aimed to residential uses. ( 2 points)

Question C1.3.- Which is the amount of residential use surface in the shopping mall influence urban area?.

The urban area of the optimal case, is required to have at least residential use in more than the $50 \%$ of the built area. (4 points).

C2.- Productive or workspace use.

Question C2.1.- Has The shopping center productive use within?.

The optimal case of shopping center, is required to have productive use within. (1 point).

Question C2.2.- Have the lots nearby the shopping center productive use within?.

The lots nearby the shopping center, are required to have at least a $10 \%$ of their surface, aimed to productive use. ( 3 points)

Question C2.3.- Which is the amount of productive use surface in the shopping mall influence urban area?.

The urban area of the optimal case, is required to have at least residential use in more than the $15 \%$ of the built area. (4 points).

C3.- Public or amenities use.

Question C3.1.- Has the shopping center amenities or public uses within?.

The optimal case of shopping center, is required to have public facilities use within. (1 point).

Question C3.2.- Have the plots nearby the shopping center productive use within?.

The plots nearby the shopping center, (or the shopping center), are required to have at least one public facility of first hierarchy. (3 points)

Question C3.3.- Which is the amount of productive use surface in the shopping mall influence urban area?.

The urban area of the optimal case, is required to have at least one public facility of first hierarchy. (3 points).

D: RETROFITTING IN URBAN ENVIRONMENT.

D1.- Efficient transportation means

Question D1.1.- Has the shopping center a mass transit system station nearby?.

The optimal case is required to have one station of mass transit nearby . (1 point). 
Question D1.2.- Is more the time of arrival to the shopping center by the usage of mass transit, than by the usage of private transportation means?

The index of relationship among mass transit time, between private transportation time, is required to be no more than 1.5 ( 2 points).

Question D1.3.-Is the urban area covered correctly by mass transit?.

In the optimal case urban area, the area must be covered by mass transit in at least a $70 \%$ (2 points).

Question D1.4.-Are the uses in the area mixed?.

The optimal case urban area, must have the urban uses mixed, this implies that a single use must not occupy more than $80 \%$ (1 point).

Question D1.5.-Have the surroundings of the shopping center facilities aimed to sustainable mobility?.

In the surrounding plots, or within the center, is required a strong presence of facilities aimed to the sustainable mobility (at least two). ( 2 points).

D2.- Density

Question D1.1.-Is the population density index among...?.

The urban area of the optimal case must have a density among 120 to 160 inhabitants per hectare. (3 points).

Question D1.2.-Is the density of urban tissues favorable toward sustainability...?.

The urban area of the optimal case must have a density tissue index above 1.5. (2 points).

Question D1.3.-Is the occupied space of the urban area among...?.

The urban area of the optimal case must have a building occupation index more than $50 \%$. (3 points).

D3.- Security and walkability

Question D3.1.- Are there negative elements towards the security or walkability in the urban area?.

Negative elements are sometimes hard to remove from the urban area, and its solution requires measures that not concerns the shopping center management. It is desirable not to have them, but because the reason explained formerly, the response for this question is not requesting to get the optimal case. (0 points).

Question D3.2.- Is the shopping mall building located in a daytime cold activity spot in the urban area?. 
The optimal case is required to have the shopping mall building not located in a daytime cold spots area, (1 point).

Question D3.3.- Is the shopping mall building located in a night time cold activity spot in the urban area?.

The optimal case is required to have the shopping mall building not located in a night time cold spots area, (1 point).

Question D3.4.- Are nearby the shopping mall building, urban areas with harsh visual or urban control?.

In the optimal case, is mandatory the surrounding plots of the shopping mall building not to have any sort of space with harsh visual or urban control. (1 point).

Question D3.5.- Is the urban area considered among its inhabitants to be safe?.

In the optimal case, The urban area must be considered to be safe, because this promotes the urban activity within. (1 point).

Question D3.6.- Have the surroundings of the shopping center a percentage of active facades?.

Is required for this question, to have at least a percentage of $30 \%$ of active facades, in the surroundings of the shopping center, to get the score of the optimal case. (1 point).

Question D3.7.- Is the distance from the shopping mall gate, to the nearest residential building less than 200 meters?.

In the optimal case of shopping center, The distance from gate to the nearest residential building, is mandatory to be less than 200 meters. (1 point).

Question D3.8.- The amount of unoccupied space, is going to be a handicap towards urban walkability?.

In this question, the amount of unoccupied space becomes a handicap being more than $70 \%$ of the total area. In the optimal case, this amount of non built space must be less than $70 \%$. (1 point).

Question D3.9.-Are the uses in the area mixed?.

The optimal case urban area, must have the urban uses mixed, this implies that a single use must not occupy more than $80 \%$ ( 1 point). This question is repeated in this retrofitting mean, because mix of uses helps the urban walkability.

E.- Questions related with more than one sorts of retrofitting.

Question E1.- The activity of the shopping center is going to be favorable or a handicap towards urban sustainability?. 
This question, depending on various facts to be considered, generally is not going to penalty the score of the optimal case, because related to efficient transport, the score required is 8 or more, and in the column of the analysis table, the scores are neutral or favorable. (Figure 3.10.1)

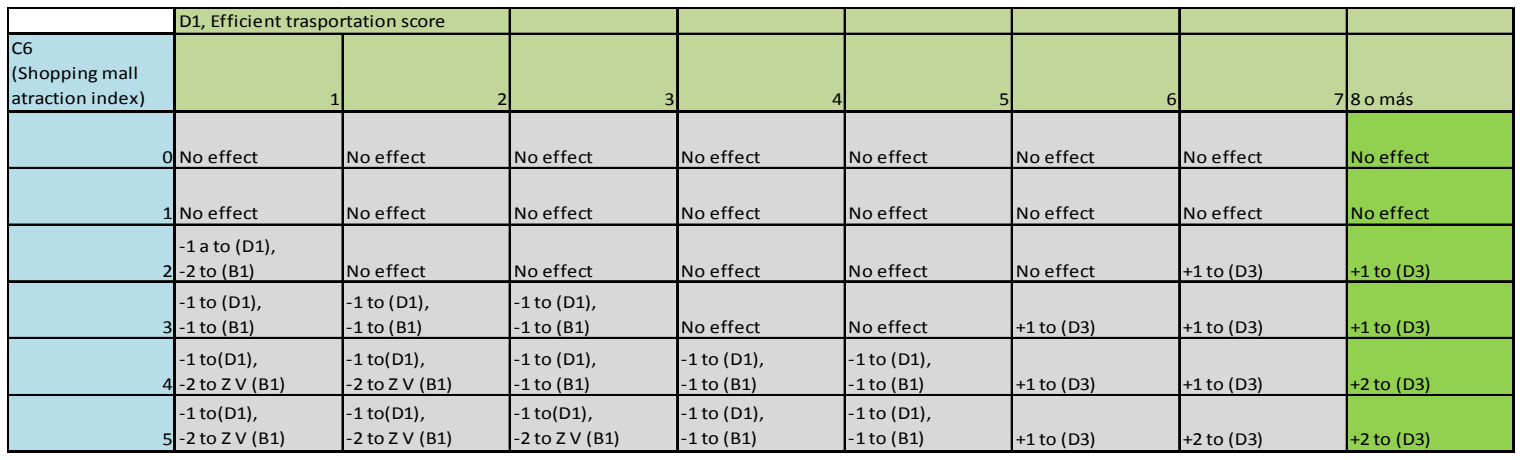

Figure 4.11.1: Analysis table of the factors relating attraction index and efficient transport rate. Own's source. Optimal case scores are shaded in green.

Once Methodology is established, the next step is the case study related to the application of it to respond the questions of the thesis.

\subsection{2.- INTRODUCCIÓN AL ESTUDIO DE CASOS}

\subsection{1.-Centros comerciales globales, estado actual}

Una vez establecida y resumida la metodología de la tesis, este capítulo buscará dar una visión global del estado actual de los centros comerciales en el mundo, enunciando los casos más relevantes por zona continental a escala global.

Se debe de considerar en todo momento, que cada centro comercial que aparecerá en el listado, va a tener diferente puntuación en la metodología, lo que supone que cada caso va a requerir de una rehabilitación diferente.

Para establecer un estudio de casos que pudiera resultar eficaz, el primer tema es el establecimiento de un criterio de selección que pudiera ser de aplicación para los casos de centro comercial que van a ser estudiados en el presente trabajo. De entrada, los casos se categorizarán en base a los siguientes factores intrínsecos y extrínsecos a lo que es el edificio del centro comercial en sí, durante este proceso de selección, se va a llevar a cabo la realización de un análisis somero, que nos va a resultar ser de interés como paso introductorio al análisis de casos que se llevará a cabo a posteriori más a fondo.

Resulta de especial relevancia, la realización de un análisis comparativo en profundidad para consolidar la metodología, escogiendo más adelante ocho casos de centros comerciales en los que se hará especial hincapié. Los casos que van a ser estudiados en profundidad más adelante van a corresponder a centros comerciales ubicados en las ciudades de São Paulo, Madrid, y varios casos ubicados en periferias de ciudades estadounidenses. 
Para la elaboración de la lista de centros comerciales a escala global se consideraron los siguientes factores.

1: FACTORES EXTRÍNSECOS: Están relacionados con alguna variable ajena a lo que es el edificio del centro comercial en sí. Estos tienen que ver más con el entorno o con la ubicación geográfica. De este modo, los factores extrínsecos que se considerarán sobre el caso van a ser:

A: Región Geográfica: Hace referencia a la región del mundo en el que está ubicado, respondiendo a criterios que tienen que ver en parte con zonas que comparten características comunes sociales y económicas. En nuestro caso las regiones van a ser Europa, Norteamérica, América Latina, Oriente Medio, Asia, Oceanía y África.

B: Clima: Hace referencia al clima en el que estamos ubicados, en este ámbito Olgyay divide el planeta en cuatro regiones climáticas, que son la fría, la templada, la cálida húmeda y cálida seca. (Ver Figura).

C: Contexto urbano: Esta caracterización hace referencia al contexto urbano en el que está ubicado el edificio del centro comercial, En el presente trabajo se definirá como contexto urbano, todo el contexto comprendido en el radio de un kilómetro desde la fachada del centro comercial. Tras realizar un estudio de tipologías de barrio en torno a los edificios de los centros mediante el análisis de fotos aéreas, (Google, Bing...) la pauta de caracterización primaria por contexto urbano se dividió en tres tipologías: céntrica, entro expandido o periferia próxima y periferia, cuya caracterización el este sentido va a ser cualitativa, estando establecida por la localización del centro en la planta de la ciudad a analizar, y las regiones administrativas. Esto va a considerarse para los casos de Madrid y Sao Paulo, siendo caracterizado el entorno de la América suburbana como periférico en todos los casos debido a las bajas densidades.

2: FACTORES INTRÍNSECOS: Estos factores de categorización están relacionados con las características del edificio del centro comercial y la parcela en la que está situado el inmueble. Los datos relacionados con este análisis van a ser extraídos de diferentes fuentes de internet en relación con los centros comerciales a analizar, tales como las páginas web de los mismos centros, o de asociaciones y organismos inmobiliarios cercanos al tema del centro comercial (ICSC, Emporis, Aguirre Newman...)

A: Apertura: El año de apertura de un centro comercial, nos puede dar una idea acerca de su estado actual, tanto a efectos de edificación como en relación a la curva del ciclo de vida.

B: Rehabilitación o reventa: Considerar si el centro ha sido rehabilitado o ha cambiado de dueño, este dato nos ayudará a establecer la posición del centro dentro de lo que es la curva del ciclo de vida.

C: Superficie edificada total: Hace referencia a la superficie construida bruta del centro comercial al completo. Esta categorización aunque puede dar una pauta acerca del tamaño, No obstante a la hora de aplicar este factor hay que considerar que hay muchos centros comerciales cuya superficie se distribuye en varias plantas, entre los que están incluidos los casos de mayor tamaño o importancia del mundo (que van a ser estudiados en esta tesis). 
Este punto va a establecer una pauta respecto a la superficie de los centros comerciales para el presente trabajo. Nos valdremos de la caracterización por superficie para centros comerciales establecida por el ICSC, International Council of Shopping Centers. (Organización Internacional de Centros Comerciales). que es la siguiente:

-Centro comercial muy grande: Mayor a 79.999m2.

-Centro comercial grande: 40.000-79.999m2.

-Centro comercial mediano: $20.000-39.999 \mathrm{~m} 2$.

-Centro comercial pequeño: 5.000-19.999m2.

D: Superficie Alquilable: Este dato hace referencia a la superficie neta alquilable del centro desarrollada en tiendas y otro tipo de negocios. Aunque este dato a efectos de rehabilitación no nos va a ser de gran utilidad, ya que esta superficie no se corresponde con la edificada total del edificio, si que nos va a dar unas pautas base para el análisis del consumo del centro comercial en sí, a la hora de tantear la relevancia de la intervención de rehabilitación una vez definida mas a posteriori.

E: Número de alturas: hace referencia al número de plantas del edificio del centro comercial.

De este modo, estos factores se aplicarán sobre diversos centros comerciales del mundo, estableciéndose una lista de 39 casos (Figura 4.12.1): 


\begin{tabular}{|l|}
\hline \\
\hline CENTRO \\
\hline Metro Center (Reino Unido) \\
\hline Colombo (Portugal) \\
\hline Parque Corredor (España) \\
\hline Parquesur (España) \\
\hline La Vaguada (España) \\
\hline ABC Serrano (España) \\
\hline Baricentro \\
\hline Paunsdorf Center (Alemania) \\
\hline Aeroville (Francia) \\
\hline Shopping City Sud (Austria) \\
\hline Puerto Venecia (España) \\
\hline Trafford Center (Reino Unido) \\
\hline \\
\hline Cehavir Mall (Turquía) \\
\hline Mega Belaya Dacha (Rusia) \\
\hline Mega Khimki (Rusia) \\
\hline Golden Babylon Rostokino (Rusia) \\
\hline Arkadia (Polonia) \\
\hline \\
\hline New South China Mall (China) \\
\hline Golden Resources (China) \\
\hline SM Megamall (Filipinas) \\
\hline Central World (Tailandia) \\
\hline Utama (Malasia) \\
\hline Mid Valley (Malasia) \\
\hline Jamuna Future Park (Bangladesh) \\
\hline Mall of Asia (Filipinas) \\
\hline SM City North EDSA (Filipinas) \\
\hline Berjaya Times Square (Malasia) \\
\hline AEON Lake Town Center (Japón) \\
\hline \\
\hline Dubai Mall (Emiratos) \\
\hline Persian Gulf complex (Irán) \\
\hline Isfahan City Center (Irán) \\
\hline \\
\hline Mall of America (EEUU) \\
\hline West Edonton Mall (Canada) \\
\hline King Of Prussia Mall (EEUU) \\
\hline Southdale Mall (EEUU) \\
\hline South Coast Plaza (EEUU) \\
\hline Belmar (EEUU) \\
\hline \\
\hline Centro Comercial Santa Fe (Colombia) \\
\hline Aricanduva (Brasil) \\
\hline Shopping Eldorado (Brasil) \\
\hline Shopping Light (Brasil) \\
\hline Costanera Center (Chile) \\
\hline Quicentro sur (Ecuador) \\
\hline \\
\hline Chadstone Shopping (Australia) \\
\hline Mall of Arabia (Egipto) \\
\hline
\end{tabular}

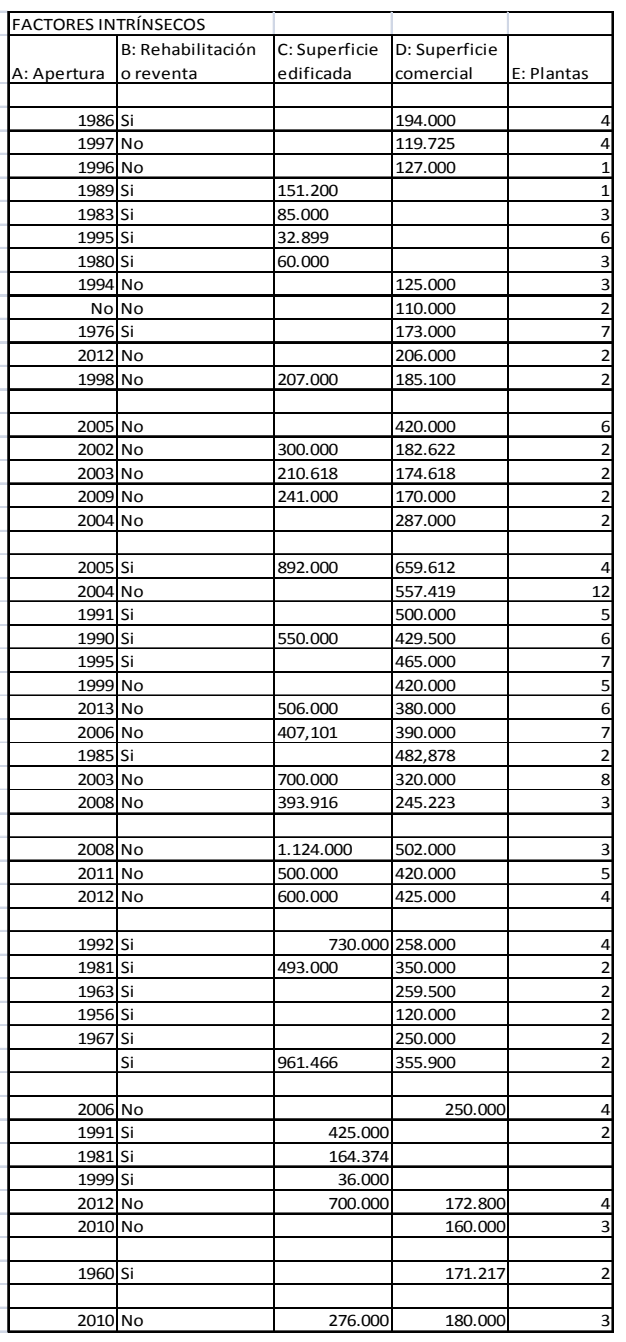

Figura 4.12.1 Tabla de centros comerciales de relevancia para el posterior estudio de casos. Fuente: elaboración propia.

No obstante, es de importancia remarcar el hecho de que los casos de esta lista sirven para dar una visión global del estado actual de los grandes centros comerciales, y que la aplicación de la metodología se va a considerar exclusivamente sobre ocho casos de relevancia ubicados en tres regiones muy concretas, pero distantes, que son las áreas urbanas de Madrid, Sao Paulo y las periferias de las ciudades estadounidenses. La aplicación de la metodología en profundidad sobre los casos de centros comerciales, será la base de las conclusiones de la tesis, las cuales de manera aproximada podrán extrapolarse a los centros de la lista.

\subsection{3.- SELECCIÓN DE CASOS DE ESTUDIO PROFUNDIZADO MADRID-SAO PAULO- NORTEAMÉRICA}

Para la presente tesis doctoral, y la consolidación de la metodología, se va a realizar un estudio de casos relacionado con tres realidades urbanas ubicadas en zonas geográficas y climáticas muy diferenciadas. Las cuales tienen condiciones urbanísticas y tamaños diferentes. Estas realidades urbanas van a ser São Paulo, Madrid y la Norteamérica suburbana descrita por dos casos de centros comerciales ubicados en las periferias de las ciudades de Denver y 
Minneapolis. Dentro de estas realidades urbanas se van a elegir diferentes contextos, los cuales van a ser relacionadas con un caso de estudio de centro comercial:

-Contexto céntrico: este contexto va a hacer referencia a las áreas urbanas consolidadas de las ciudades, y a las áreas céntricas de moderada a elevada densidad tanto edificatoria como poblacional dentro de las mismas, son entornos urbanos complejos.

-Contexto de centro expandido: este contexto va a estar referido a las áreas urbanas producidas de las expansiones urbanas cercanas a los centros de las ciudades, las cuales a pesar de su relativamente reciente consolidación, ya están integradas dentro del centro de las ciudades. Son entornos urbanos complejos con densidades moderadas.

-Contexto de periferia: Este va a estar referido a las áreas periféricas de las ciudades, ajenas a lo que es el centro, pero dentro de lo que podría considerarse la región metropolitana de la misma, la densidad en esta áreas puede variar de una región a otra, al igual que la complejidad.

De este modo, el estudio comparativo de los centros comerciales en profundidad, que nos va a permitir la comprobación de la presente metodología, se va a realizar sobre dos realidades urbanas que son la de la ciudad de Madrid en Europa, y la de la ciudad de São Paulo en América. Los motivos por los cuales se realizó esta elección de casos, fueron los siguientes:

\subsection{1.- Justificación de la elección de São Paulo.}

El caso de la ciudad de São Paulo fue elegido debido a las siguientes razones: en primer lugar, es porque se trata de una ciudad de gran volumen económico a escala mundial, la cual tiene una jerarquía urbana a escala continental. En segundo lugar, es porque São Paulo es sin duda un caso ejemplarizante de ciudad en la que se ha producido un crecimiento de escasa densidad y gran superficie, además de unos fenómenos urbanísticos que sin duda van a condicionar la aplicación de la actual metodología. A todo esto hay que añadir que Brasil es un mercado emergente en lo relacionado con el tema de los centros comerciales.

São Paulo, con aproximadamente veinte millones de habitantes, es con diferencia la mayor ciudad de América del Sur, y una de las más grandes del mundo. En la actualidad, São Paulo es una ciudad con mucho poder económico, y ahora está experimentando un crecimiento. A todo ello, se debe de considerar que la realidad urbana de la ciudad de São Paulo es muy compleja, debido a que es una ciudad de un tamaño exageradamente grande en superficie, la cual se ha desarrollado en los últimos cien años, además de la gran variedad de tipologías de áreas urbanas que se encuentra en su interior. Respecto a centros comerciales, São Paulo tiene dentro de sus límites, ejemplares de gran tamaño, debido a que la actividad económica de los mismos en Brasil se encuentra en la fase de crecimiento de la curva de ciclo de vida. También São Paulo, está ubicada en la zona cálida húmeda de la Tierra, siendo esta diferencia de clima también de importancia para la metodología a la hora de plantear soluciones.

Para el contexto de São Paulo, se eligieron los siguientes centros comerciales:

SHOPPING LIGHT, este centro fue escogido como caso ubicado en un entorno urbano céntrico y denso. La justificación en la elección de este edificio, se debe a que Shopping Light resulta ser 
un perfecto arquetipo de centro comercial en altura, el cual centra su influencia en la actividad peatonal presente en la zona. Los alrededores de este centro están dentro de los barrios más antiguos de São Paulo, que a su vez es una de las áreas más representativas de la ciudad. Resulta también de importancia para el estudio de este centro, la ausencia de instalaciones de aparcamiento del mismo, además de la fuerte competencia comercial en la zona, siendo de espacial interés, la presencia de instalaciones comerciales que tienen una mayor jerarquía y volumen de negocio que Shopping Light. (Rua 25 de Março). El centro comercial de Shopping Light, ocupa el edificio histórico de la compañía eléctrica.
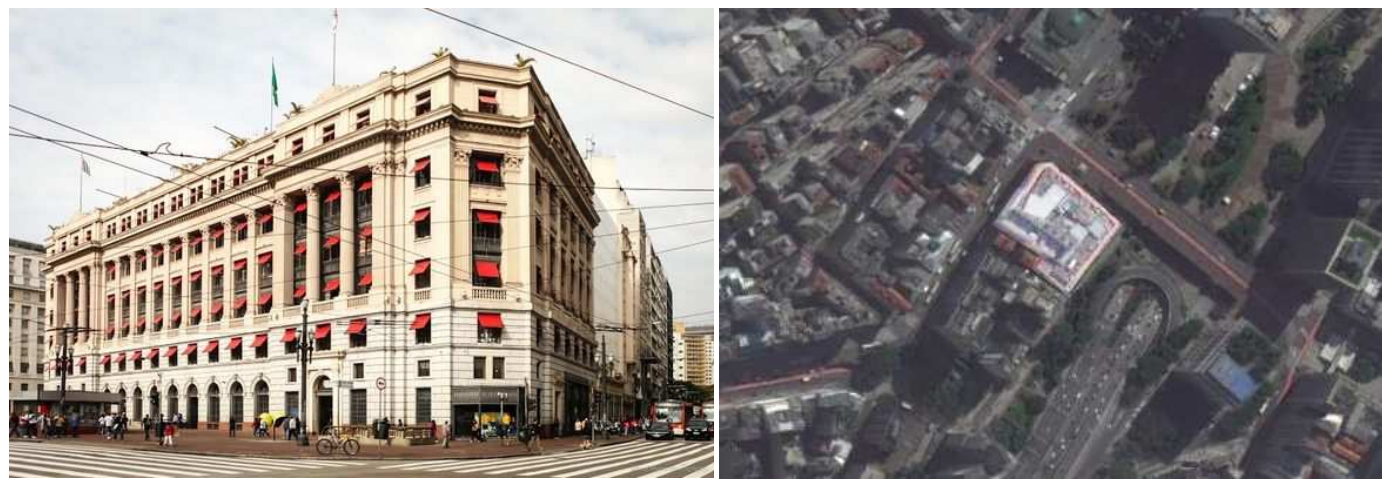

Figura 4.13.1 Shopping Light Fuente: Google

SHOPPING ELDORADO, como caso de centro ubicado en un entorno de centro expandido de la ciudad. El Centro Expandido de São Paulo, es sin duda una zona de gran importancia para la ciudad, teniendo esta área una configuración muy representativa. El centro comercial de Shopping Eldorado, además está ubicado en un punto muy estratégico entre vías urbanas de primera jerarquía (Marginal Pinheiros y Vía Rebouças), sirviendo como parada de tránsito para las personas que se desplazan de sus casas a sus trabajos. Teniendo estas vías anteriormente mencionadas, conexión con las áreas de la ciudad dónde se concentran los empleos. También es importante destacar el hecho de que en la cubierta del centro comercial de Shopping Eldorado, se ha instalado un huerto urbano que suministra productos vegetales a los empleados de la instalación comercial.
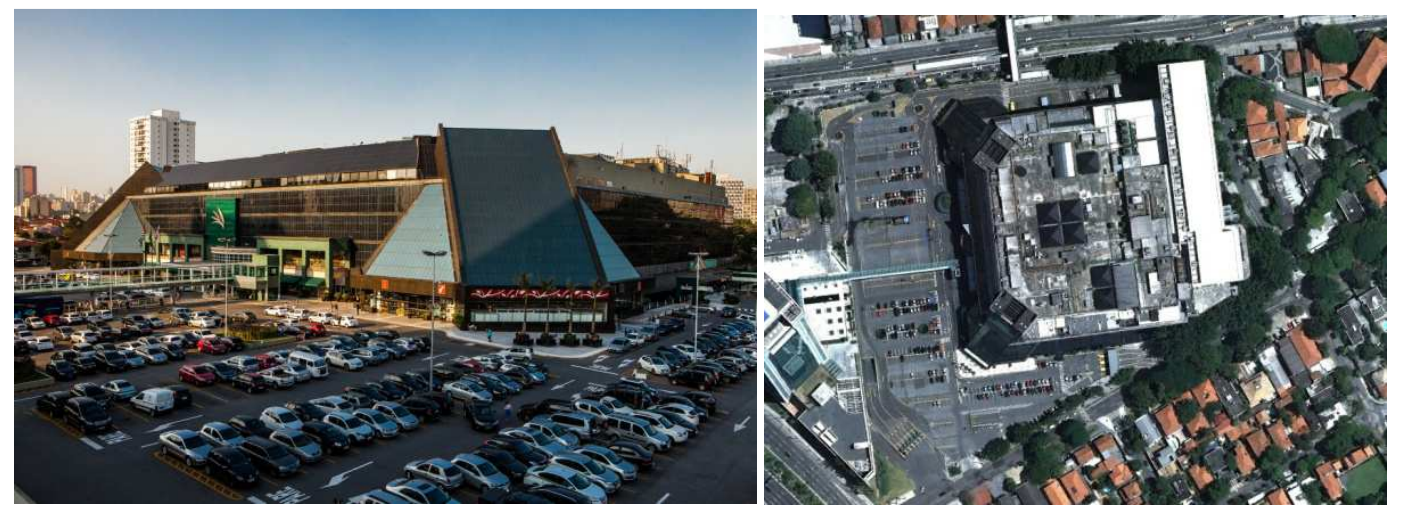

Figura 4.13.2 Shopping Eldorado Fuente: Guía da Semana, Google

SHOPPING ARICANDUVA, como caso de centro comercial de periferia. La importancia de este caso, radica no solamente en que es con diferencia el mayor de São Paulo, y uno de los mayores de América Latina en tamaño, sino que además resulta ser un modelo representativo 
de centralización comercial a gran escala, con mecanismos de funcionamiento urbano, similares al barrio de baja densidad en el que se encuentra, el cual forma parte de la periferia de São Paulo. Shopping Aricanduva debido a su enorme tamaño, tiene una gran área de influencia en los barrios circundantes, siendo además un aliciente, el hecho de que tanto el centro como su parcela, ocupan una enorme superficie, y esto sería sin duda una gran oportunidad de rehabilitación. El centro comercial Aricanduva es un complejo de cuatro edificios comerciales de gran superficie y tamaño, y poco desarrollo en altura.

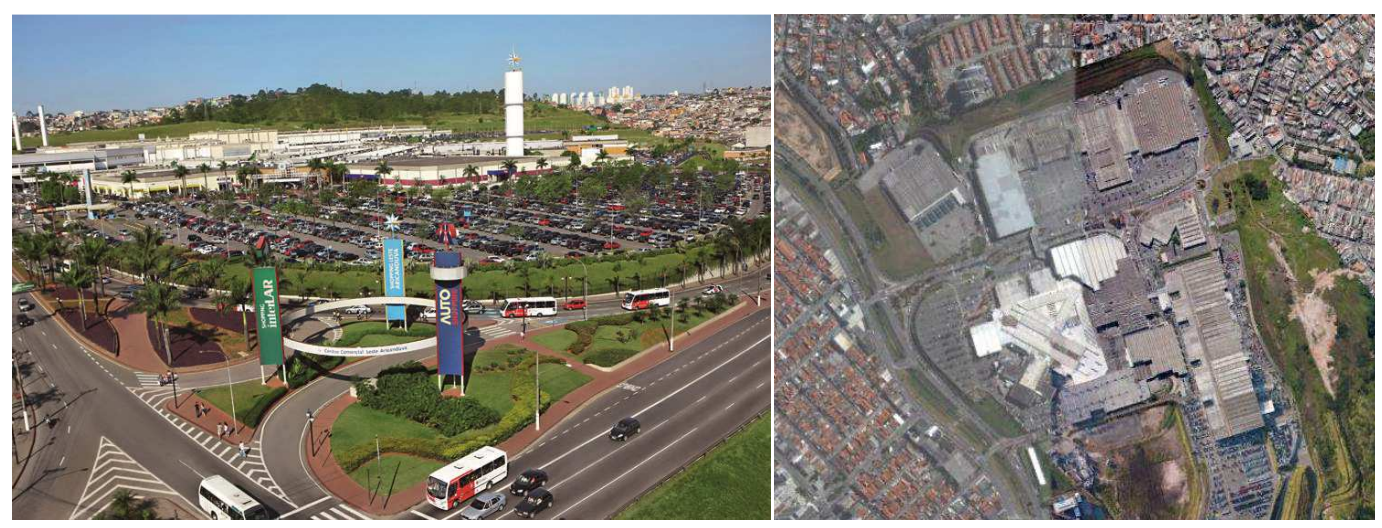

Figura 4.13.3 Shopping Aricanduva Fuente: Veja Sao Paulo, Google

\subsection{2.- Justificación de la elección de Madrid, y casos a considerar.}

Se eligió el caso de Madrid, debido a que se trata de una ciudad europea, en la cual hay una gran cantidad de tipologías de entornos urbanos, debido por una parte a su fuerte carácter de ciudad mediterránea compacta, y por otra parte al crecimiento que ha experimentado esta ciudad en los últimos años. Aún Así, también se debe considerar, que Madrid es un mercado en relación con los centros comerciales, que se sitúa en la parte de madurez prolongada de la curva del ciclo de vida. Y de este modo, en el contexto de la ciudad de Madrid, muchos centros comerciales están comenzando a entrar en estado de abandono debido a la gran oferta.

la ciudad de Madrid ha experimentado un crecimiento bastante considerable en superficie en los años anteriores a la crisis, propiciado en parte por la fiebre de la burbuja inmobiliaria. En las operaciones inmobiliarias ligadas a este crecimiento, han jugado un papel de gran importancia los centros comerciales, especialmente en las áreas periféricas. En la actualidad (2014), el mercado español de los centros comerciales está en recesión, y algunos ejemplares de centros están cayendo en desuso, siendo propiciado esto en parte por la saturación del mercado y la recesión económica. De este modo, se propicia la toma de medidas en relación a la revitalización de una actividad económica, que en el caso de Madrid ya se encuentra en fase de madurez avanzada.

De este modo, los casos que van a ser estudiados para Madrid van a ser:

-ABC SERRANO, como caso de centro comercial ubicado en contexto céntrico. Este centro, que se encuentra en una zona de alto poder adquisitivo de Madrid, y a similitud de Shopping Light en São Paulo, también se encuentra en el centro consolidado de la misma ciudad, siendo el 
presente centro comercial, el resultado de la rehabilitación de la sede histórica del periódico $A B C$.
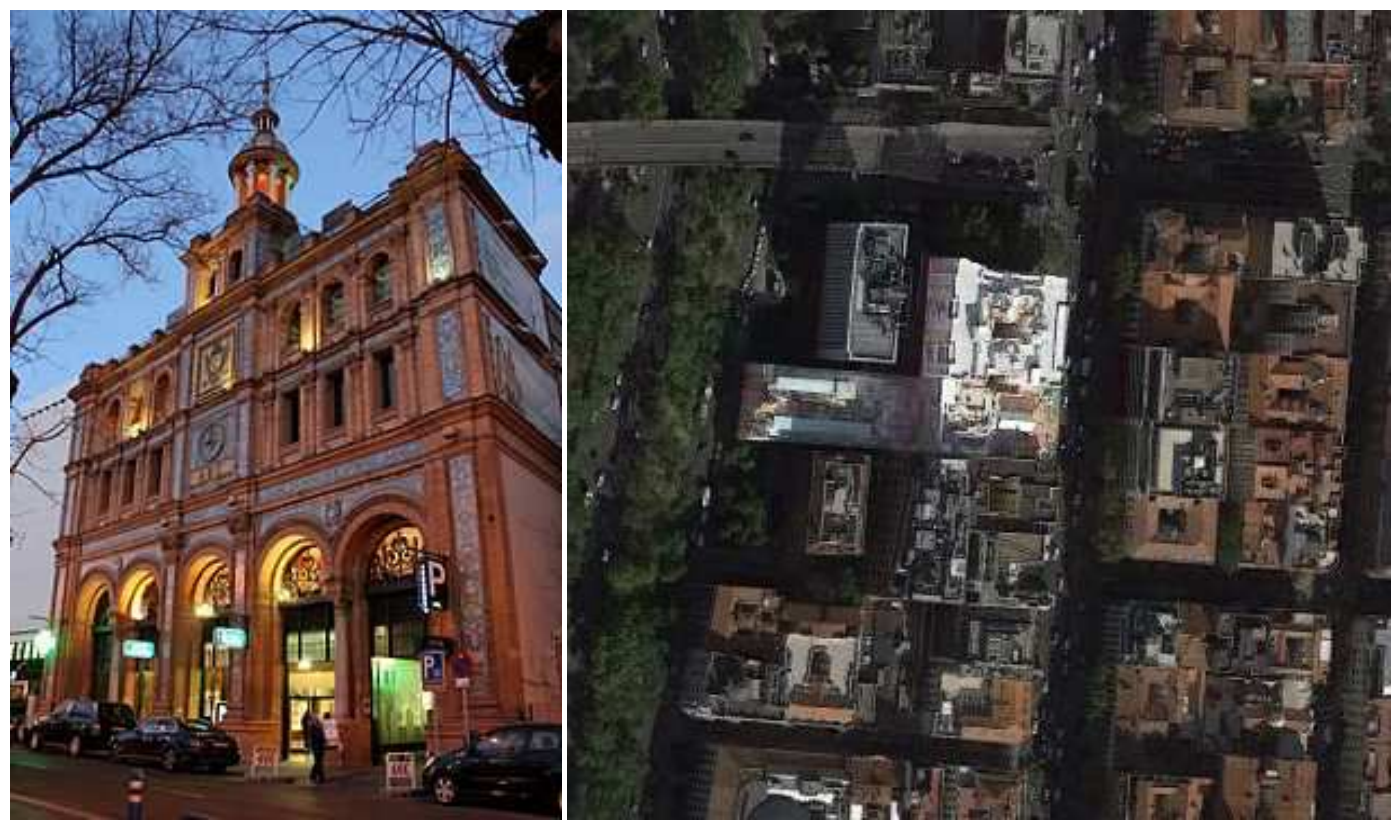

Figura 4.13.4.- ABC Serrano. Fuente: Wikipedia, Google

-LA VAGUADA, como caso de centro comercial ubicado en un contexto de periferia próxima. La importancia de este centro comercial, reside en que además de ser de gran importancia tanto para el centro como la periferia de Madrid. Tiene la característica de que es pionero en la aplicación de tecnologías de energía limpia sobre su superficie, además de la aplicación de criterios bioclimáticos en el proyecto de sus instalaciones. A todo esto hay que añadir la fuerte presencia del mismo en las proximidades de vías de primera jerarquía para la ciudad de Madrid (Avenida de la llustración y M30), Además de su protagonismo como instalación comercial a nivel de barrio. Es de especial interés, que el centro comercial de La Vaguada, tiene en su interior una de las mayores instalaciones de aparcamiento de la ciudad de Madrid.

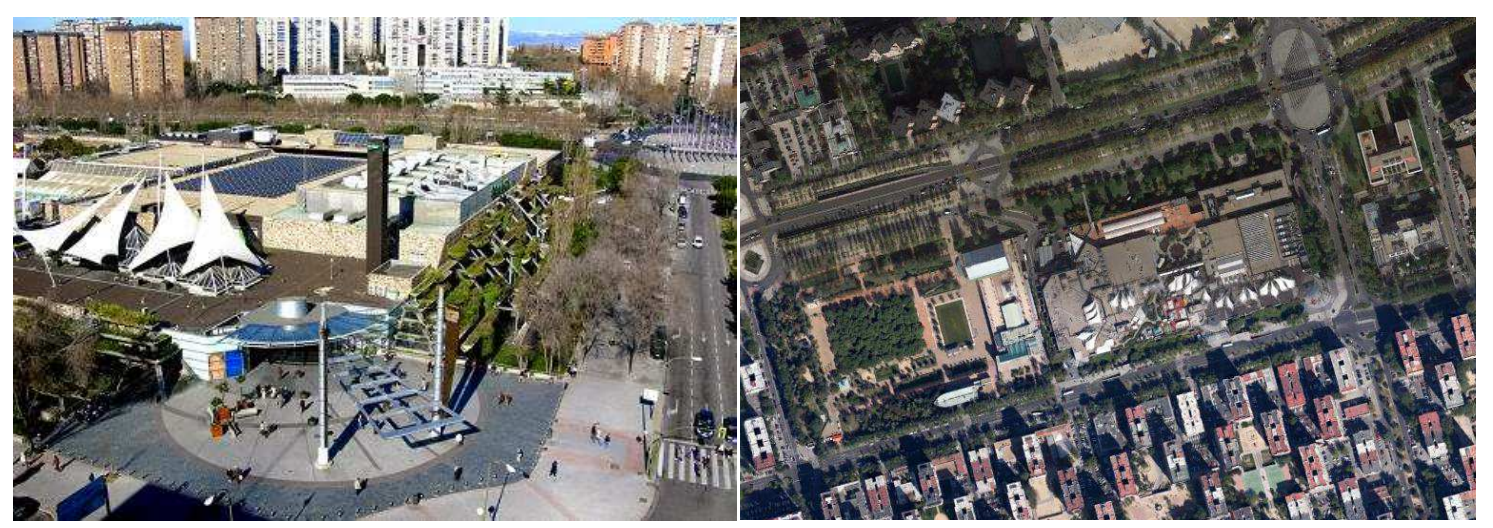

Figura 4.13.5. La Vaguada Fuente: Google

-PARQUESUR, como caso ubicado en zona periférica metropolitana en Madrid. Este centro da servicio a una amplia zona de la periferia sur de Madrid, la cual está muy poblada. Parquesur forma parte de un enorme conjunto de instalaciones comerciales y de ocio de primera 
categoría, siendo con diferencia el mayor centro comercial en superficie de la comunidad de Madrid, y uno de los mayores de España (El tercero tras Puerto Venecia en Zaragoza, y Marineda City en La Coruña.) (Fuente Urbanity.es, Cecilio Galdón, 18/03/2013). Parquesur, además cuenta en sus proximidades con la presencia de grandes infraestructuras, tanto en transporte público, como en transporte particular, estando además ubicado en la zona limítrofe de un barrio, como foco atrayente del mismo. Este centro tiene gran superficie tanto de aparcamiento, como edificada.
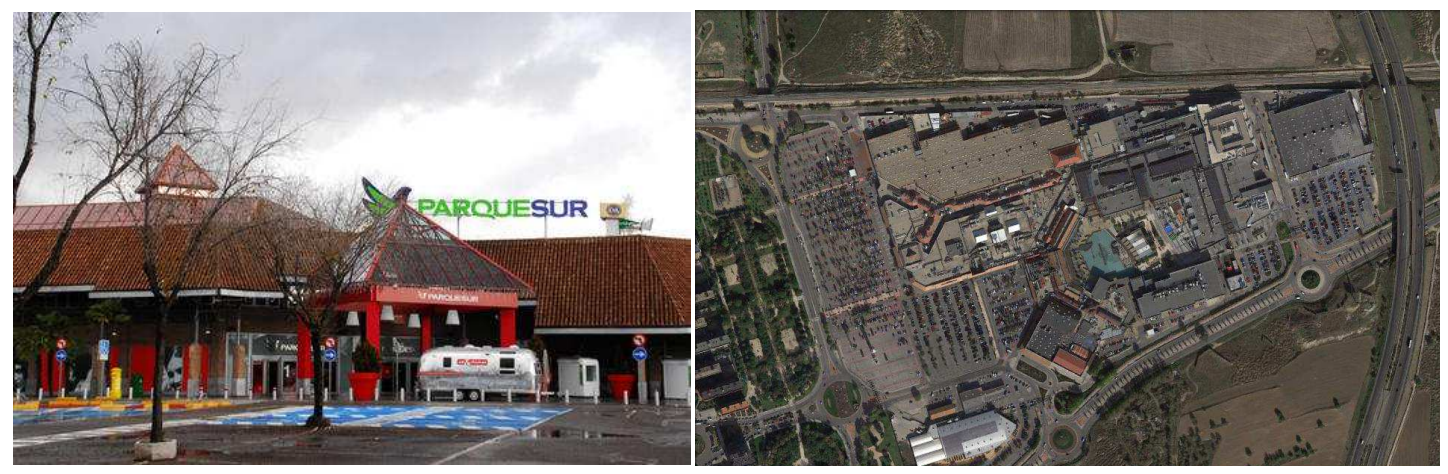

Figura 4.13.6.- Parquesur. Fuente:Turismo España, Google

\subsection{3.- Justificación de la elección de la Norteamérica suburbana, y casos a considerar.}

La Norteamérica suburbana, fue el caldo de cultivo para la aparición de los centros comerciales de la mano de Victor Gruen (ver capítulo génesis). Siendo actualmente a su vez el escenario de la reciente decadencia de algunos casos de centros. Por consiguiente, el análisis de casos ubicados en este entorno urbano, es sin duda de gran importancia para la presente tesis doctoral, ya que se van a presentar problemas derivados de un entorno de baja complejidad y alto impacto medioambiental, en el cual el centro comercial realmente tiene la función de nodo central para un amplia área urbana; de modo similar a lo que Victor Gruen proyectó. A su vez, con el análisis del contexto de la Norteamérica suburbana, se incluirá en la presente tesis un análisis de los modos de rehabilitación de la corriente del New Urbanism sobre los centros comerciales, y lo que estas intervenciones han supuesto de cara a una renovación a efectos de sostenibilidad, dándole a su vez a la tesis un campo más amplio. El contexto de la Norteamérica suburbana, es dónde los centros comerciales están experimentando su mayor caída debido a la madurez de su actividad, y por ello, es importante la propuesta de medidas de rehabilitación que pudieran resultar eficaces.

De este modo, los casos que van a elegirse para el análisis relacionado con la Norteamérica suburbana, van a ser casos de relevancia, que van a marcar a líneas generales la situación urbana de los centros comerciales, antes y después de las nuevas corrientes de rehabilitación. Por una parte se va a escoger un caso reformado de centro comercial, que siguiendo la corriente del New Urbanism, tras su abandono, reventa y reestructuración urbana, trata de ser el centro de actividad de un amplia área de poca densidad. Como contraste a esto se elegirá, otro caso de centro comercial boyante, encuadrado en un contexto suburbano aislado, cuya actividad se basa en la función de nodo aislado, y la presencia de grandes infraestructuras de transporte. Elementos primordiales en la planificación de grandes áreas urbanas extensivas. 
De este modo, los casos que van a ser estudiados para la Norteamérica suburbana van a ser:

BELMAR (Lakewood, Denver). Se escogió este caso de centro comercial ubicado en la periferia de la ciudad de Denver, por ser una respuesta de rehabilitación urbana frente a su situación previa de decadencia. El estado actual del complejo Belmar, es el resultado de una serie de actuaciones urbanísticas y arquitectónicas, proyectadas y realizadas por varios equipos de urbanistas norteamericanos cercanos a la corriente del New Urbanism. La intención del proyecto de reestructuración urbana de Belmar, era la de crear un área urbana compleja y activa en el centro de una zona suburbana de gran extensión y poca densidad, consiguiéndose resultados más o menos satisfactorios. De este modo este quizá sea uno de los casos más interesantes para la tesis, ya que es un caso de rehabilitación llevado a cabo, del cual se pueden obtener resultados que nos ayuden a valorar ese tipo de actuaciones, y las mejoras que estas pudieran suponer.
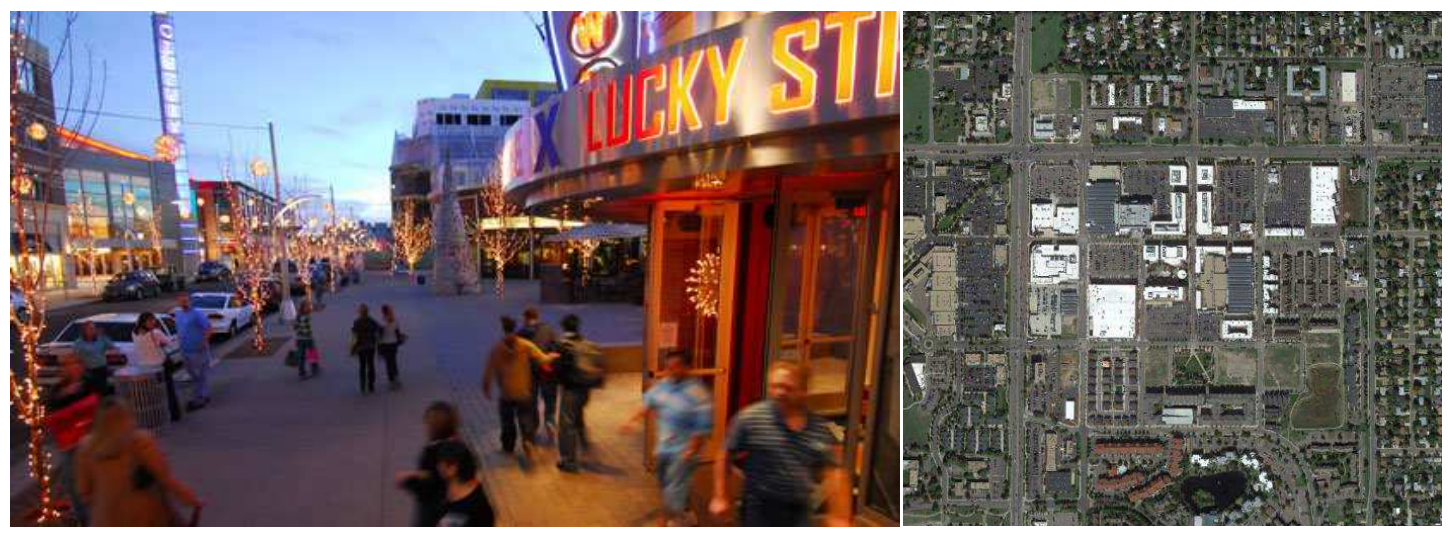

Figura 4.13.7.- Belmar. Fuente: J Kent Staffing, Google

MALL OF AMERICA (Bloomington, Minneapolis) Se escogió esta instalación comercial para su análisis por la metodología de la presente tesis, ya que además de estar ubicado en una zona climática fría de la región de Norteamérica, este centro comercial es el más visitado del planeta (40 millones de visitantes al año), en un mercado que se ve en un estado de madurez, para el tema del centro comercial de gran tamaño. A todo esto hay que añadir, que el comportamiento urbano del centro comercial, se basa en la negación parcial de las relaciones con el entorno próximo, buscando la relación con las grandes infraestructuras de transporte que están presentes en la zona. De este modo, en torno a Mall of America se consolida un área urbana con gran capacidad para la recepción y gestión de grandes cantidades de vehículos. Estando presente además una línea de transporte que une el centro con el aeropuerto de Minneapolis.

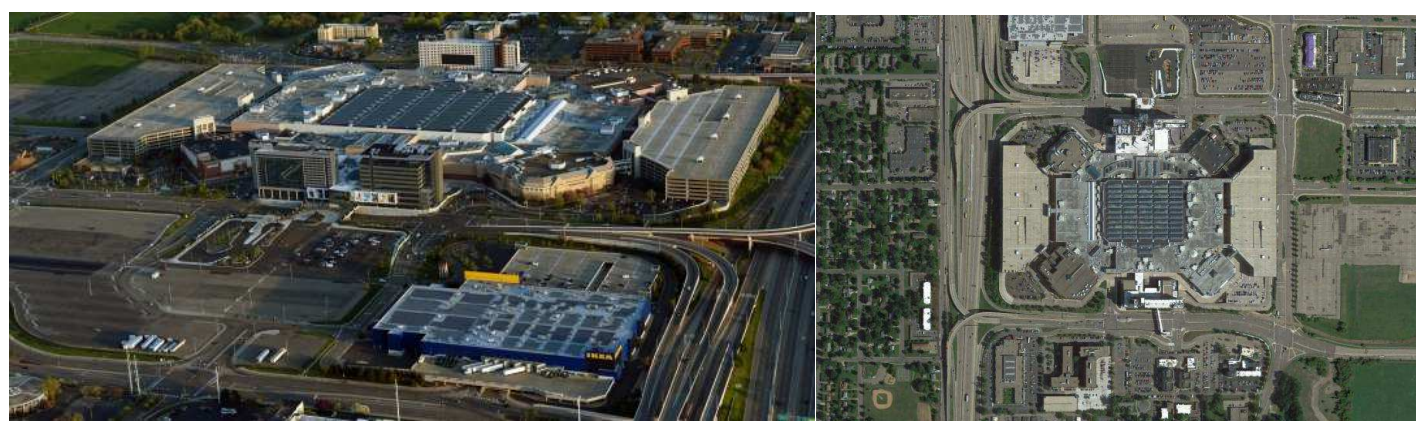


Figura 4.13.8.- Mall of America. Fuente: Google

Una vez justificada la elección de los casos, el siguiente paso es el análisis de los mismos aplicando la metodología. No obstante, como paso previo a este análisis más exhaustivo, se van a sintetizar de manera gráfica las relaciones entre los centros y su entorno urbano inmediato, para de este modo comprender el funcionamiento de los mismos, antes de realizar el análisis más a fondo de los mismos.
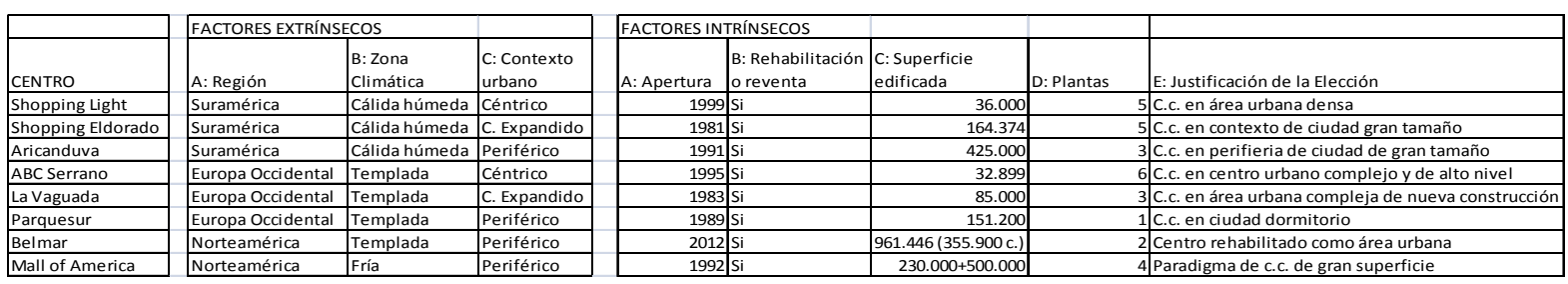

Figura 4.13.9.- Tabla resumen de datos de casos a elegir en profundidad. Fuente: Elaboración propia.

\subsection{4.- RELACIONES URBANAS ENTRE LOS CENTROS Y SU ENTORNO INMEDIATO, PRIMER ACERCAMIENTO A LA REALIDAD DE LOS CASOS DE ESTUDIO.}

Antes de comenzar el análisis de los ocho casos de centros comerciales ubicados en Madrid, Sao Paulo y Norteamérica a través de la metodología de la tesis, se hará necesaria la comprensión a grandes rasgos del funcionamiento de los mismos, estableciéndose de ese modo un acercamiento a la realidad que se está tratando.

Para este primer análisis, fue considerada la forma del centro, a la vez que los accesos, y la realidad urbana en la que se asientan, buscándose la configuración de las relaciones. De este modo, será necesario un estudio cualitativo tanto del centro comercial, como del entorno urbano, la ubicación del mismo y las instalaciones cercanas que pudiera haber.

\section{SHOPPING LIGHT}

El entorno que rodea el centro comercial Shopping Light, es un entorno céntrico de gran actividad, debido a la presencia de instalaciones dotacionales de (Teatro, Ayuntamiento y varias dotaciones institucionales de gran tamaño) e hitos turísticos primer orden (Edificio Copán, Valle de Anhangabau, Catedral de Sé, Plaza de la República, Patéo do Colégio...) en el cual es relevante la presencia de comercios de tamaños diversos. (Es importante considerar la cercanía de la Rua 25 de Março, la cual es el principal núcleo de actividad comercial en el área). Por consiguiente, Shopping Light al estar ubicado en un área con una fuerte competencia, centra su modelo económico en los productos de clase media o media alta. Shopping Light ocupa la sede histórica de la compañía eléctrica de Sao Paulo, con lo que a su vez es un edificio histórico.

De este modo, la relación de Shopping Light con su entorno urbano, se resume en ser un nodo de actividad dentro de la zona, el cual se abre a los numerosos tránsitos peatonales presentes, generados por los nodos de actividad enunciados anteriormente. A su vez, está muy próximo a 
grandes nodos de transporte público, y la zona del centro comercial goza de buenas instalaciones en este ámbito. Por consiguiente, el acceso e interacción urbana de Shopping Light se centra en la captación del tránsito peatonal entre las instalaciones y comercios anteriormente mencionados presentándose el centro comercial como un elemento exclusivo, careciendo el mismo de aparcamiento, u otra instalación para vehículos privados. (Figura 4.14.1)

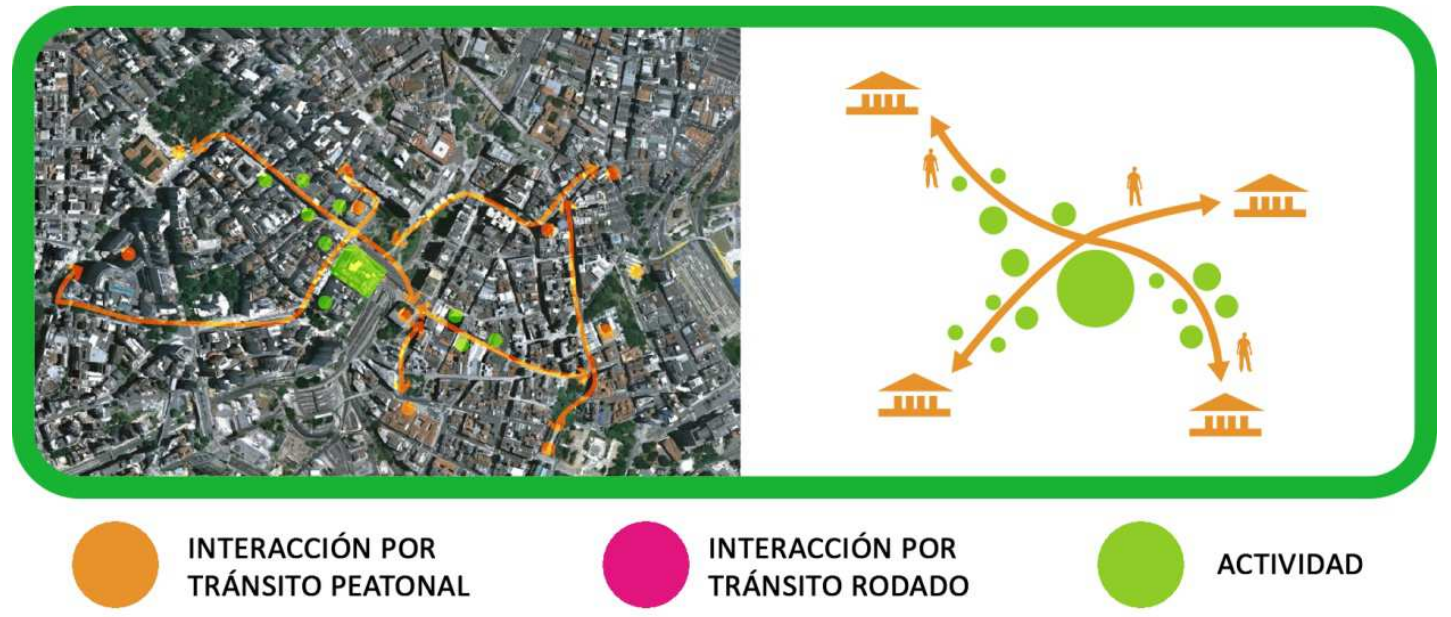

Figura 4.14.1.- Gráfico de relaciones urbanas de Shopping Light. Fuente: Elaboración propia

\section{SHOPPING ELDORADO}

Este centro está ubicado en un área periférica del centro de Sao Paulo, en lo que se conoce como el centro expandido. El centro se ubica muy próximo a un cruce entre vías rodadas de primera jerarquía, haciendo éstas a su vez el papel de una importante barrera entre lo que es el centro y las zonas circundantes. La actividad urbana en el área está ubicada en calles muy focalizadas. (Faria Lima, Theodoro Sampaio, Rua Butanta). Los locales predominantes son oficinas, restaurantes, tiendas de conveniencia y talleres. Dentro de la zona de influencia, hay inmuebles de alto nivel adquisitivo.

A todo ello, cabe destacar, que este centro al ubicarse en un entorno de gran actividad comercial hay competidores en sus inmediaciones, tales como Shopping Iguatemí, y los comercios de la avenida de Faria Lima.

De este modo, la faceta configuradora de las relaciones entre Shopping Eldorado y su entorno urbano, es la apertura al tránsito de vehículos de las vías de gran jerarquía, ubicándose el centro en un punto estratégico entre las mismas. (Cruce entre la Marginal Pinheiros y la Vía Eusebio Matoso). De este modo, Shopping Eldorado es perfectamente accesible desde estas vías, siendo el centro un punto de adquisición de bienes de consumo para los usuarios de esas vías.

A pesar de que el centro comercial de Shopping Eldorado, se ubica en las proximidades de la estación de tren de Pinheiros, habiendo además una parada de autobús exclusiva para el centro; el centro comercial no contribuye de ningún modo a la actividad peatonal en el área. Este se debe, a que el edificio del centro se ubica en el interior de una parcela cerrada a la calle, 
por la cual se accede desde puntos muy concretos, que son las dos entradas de vehículos de las que dispone, y la parada de autobús del propio centro. De manera ajena al centro, también muchos inmuebles se disponen dentro de parcelas cerradas, quedando las calles principales al mero papel de ser elementos de tránsito para una gran cantidad de vehículos. El resultado es un entorno urbano en el que predomina el vehículo privado. La densidad del entorno urbano es muy variable en el área. (Figura 4.14.2)

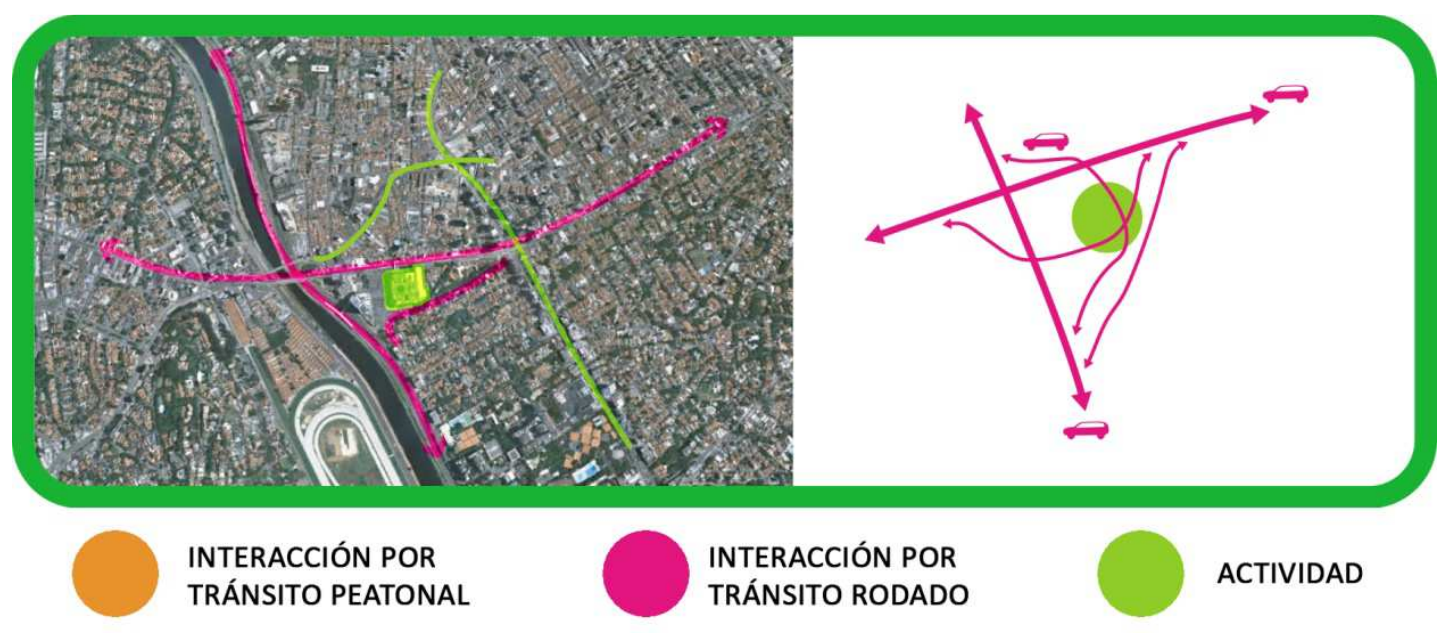

Figura 4.14.2: Gráfico de relaciones urbanas de Shopping Eldorado. Fuente: Elaboración propia

\section{SHOPPING ARICANDUVA}

El centro comercial de Aricanduva, es un caso de gran tamaño. Cuya función es la de ser un gran nodo comercial de primera jerarquía, para una extensa área urbana. De este modo, el centro comercial, trata de aglomerar en su interior el mayor número de comercios posible, ofertando el mayor número de productos.

De este modo, las relaciones urbanas entre el centro comercial Aricanduva y su entorno próximo, se basan en la idea anteriormente mencionada del nodo de actividad centralizado. Esto hace del centro comercial Aricanduva, el punto de convergencia de una gran cantidad de recorridos que cubre un área urbana muy amplia. Por consiguiente, es previsible que el centro comercial, se abra a las vías de mayor jerarquía posible, existiendo además líneas de transporte público que lo conectan con los nodos de transportes de mayor jerarquía más cercanos.

En el entorno urbano que rodea al centro comercial Aricnduva, hay una esporádica mezcla de actividades urbanas, siendo generalmente de baja densidad a pesar de la alta tasa de ocupación del terreno. La presencia de barreras es muy fuerte en las inmediaciones del centro (avenidas y ríos), y éste se ubica dentro de un recinto cerrado con accesos muy delimitados. De este modo, el centro comercial no genera actividad peatonal en el entorno próximo, Siendo la accesibilidad peatonal al mismo muy complicada debido a la presencia de vallas, calles muy transitadas en las que los vehículos van relativamente deprisa, estando los accesos al edificio de centro comercial, muy alejados de las calles. De este modo, la accesibilidad a Aricanduva, se 
basa en el vehículo privado, siendo buena prueba de ello, la ingente superficie de aparcamientos, tanto en superficie, como subterráneos que posee el centro. (Figura 4.14.3)

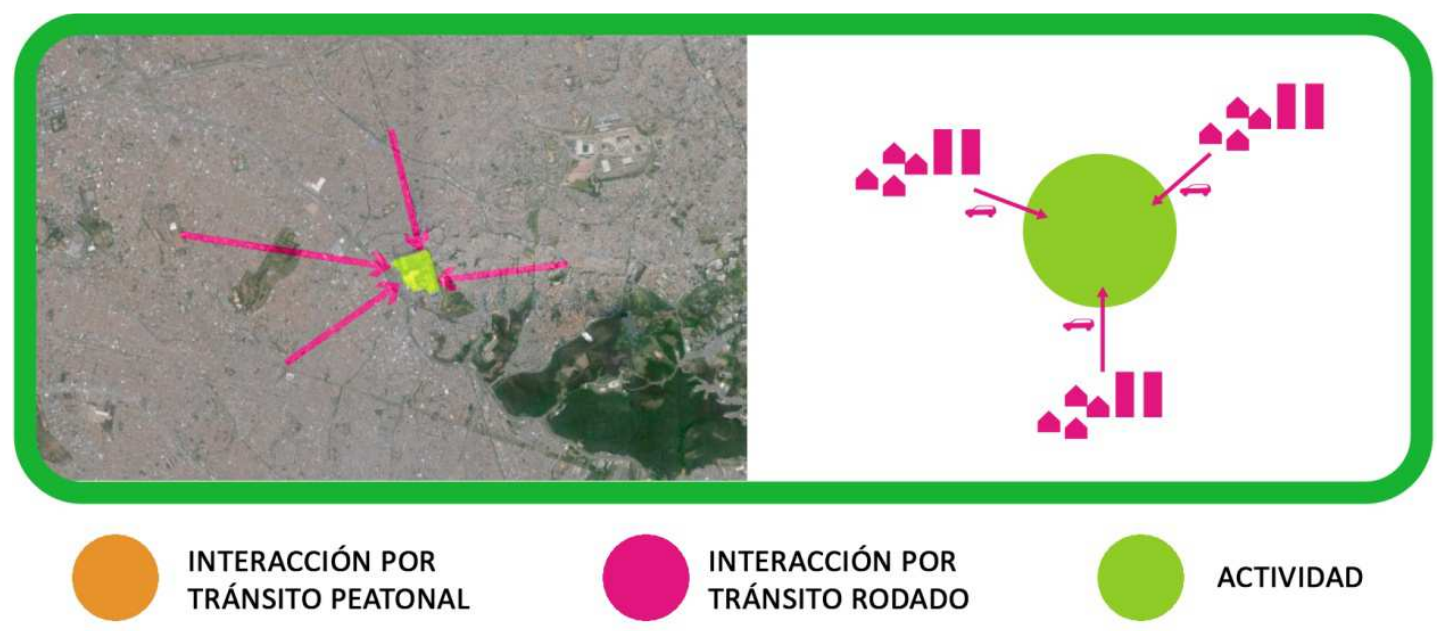

Figura 4.14.3.- Gráfico de relaciones urbanas de Shopping Aricanduva. Fuente: Elaboración propia

\section{ABC SERRANO}

Este centro comercial se ubica en una zona de gran actividad en el centro de Madrid, la cual se caracteriza por tener una gran presencia de comercios de alto nivel económico, además de una tasa de mezcla de usos muy elevada.

De este modo, el centro comercial ABC Serrano, trata de ubicarse de manera estratégica entre dos ejes de gran importancia en la ciudad de Madrid, ambos con gran capacidad de vehículos y peatones (La Castellana y la Calle Serrano) abriéndose a ambos. El centro busca ser un nodo de actividad de mayor jerarquía que los comercios colindantes, sin serlo de manera muy relevante. La apertura del centro a las vías y su fácil accesibilidad a pie de calle, genera actividad en las calles a las que se abre.

El área urbana próxima al centro comercial, posee instalaciones de transporte público en las inmediaciones, habiendo además un aparcamiento subterráneo. De este modo, ABC Serrano capta la actividad tanto de los recorridos peatonales a escala más próxima, cómo de los recorridos relacionados con distancias mayores dentro de Madrid. (Figura 4.14.4) 


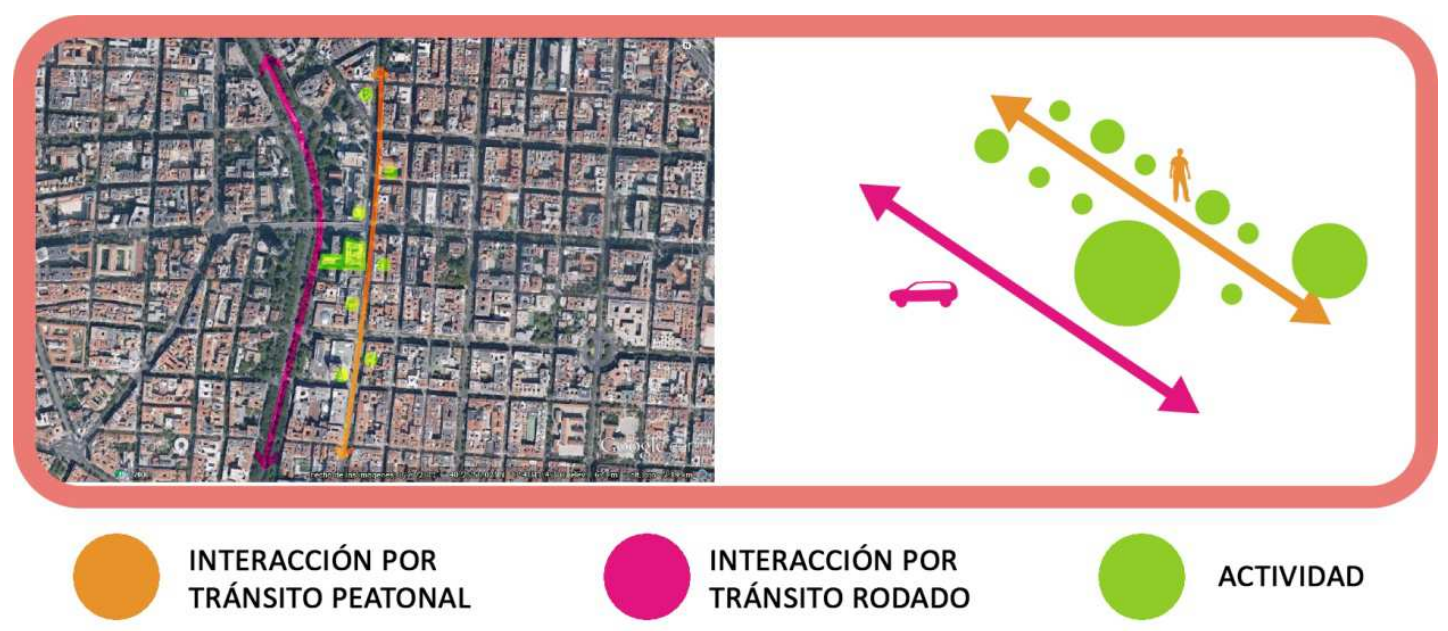

Figura 4.14.4.- Gráfico de relaciones urbanas de ABC Serrano. Fuente: Elaboración propia

\section{LA VAGUADA}

Este centro comercial de primera jerarquía, ubicado en la periferia del centro de Madrid, es una instalación comercial de gran tamaño que genera un importante nodo de actividad, cuya influencia puede abarcar toda la ciudad de Madrid.

La Vaguada, se ubica en las inmediaciones de un eje muy transitado, que rodea la ciudad de Madrid (M30 en la Avenida de la llustración). Por consiguiente la relación urbana entre el centro comercial y su entorno próximo también se basa en el aprovechamiento de los tránsitos del eje de la Avenida de la llustración, y la fácil accesibilidad, tanto para vehículos particulares cómo para peatones. De hecho, La Vaguada posee un aparcamiento subterráneo de gran capacidad, y aunque las entradas peatonales están muy localizadas, el centro genera de cara a la calle una fuerte actividad, que se ve reforzada por la complejidad y la mezcla de usos en las manzanas colindantes. Como conclusión, las relaciones urbanas entre el centro comercial de la Vaguada y su entorno próximo, se basan en el aprvechamiento de los tránsitos, además de la creación de un gran nodo de actividad dentro de un entorno urbano activo, estando el centro comercial bien comunicado con el resto de la ciudad, tanto por transporte público, como por viario para vehículos particulares. (Figura 4.14.5)

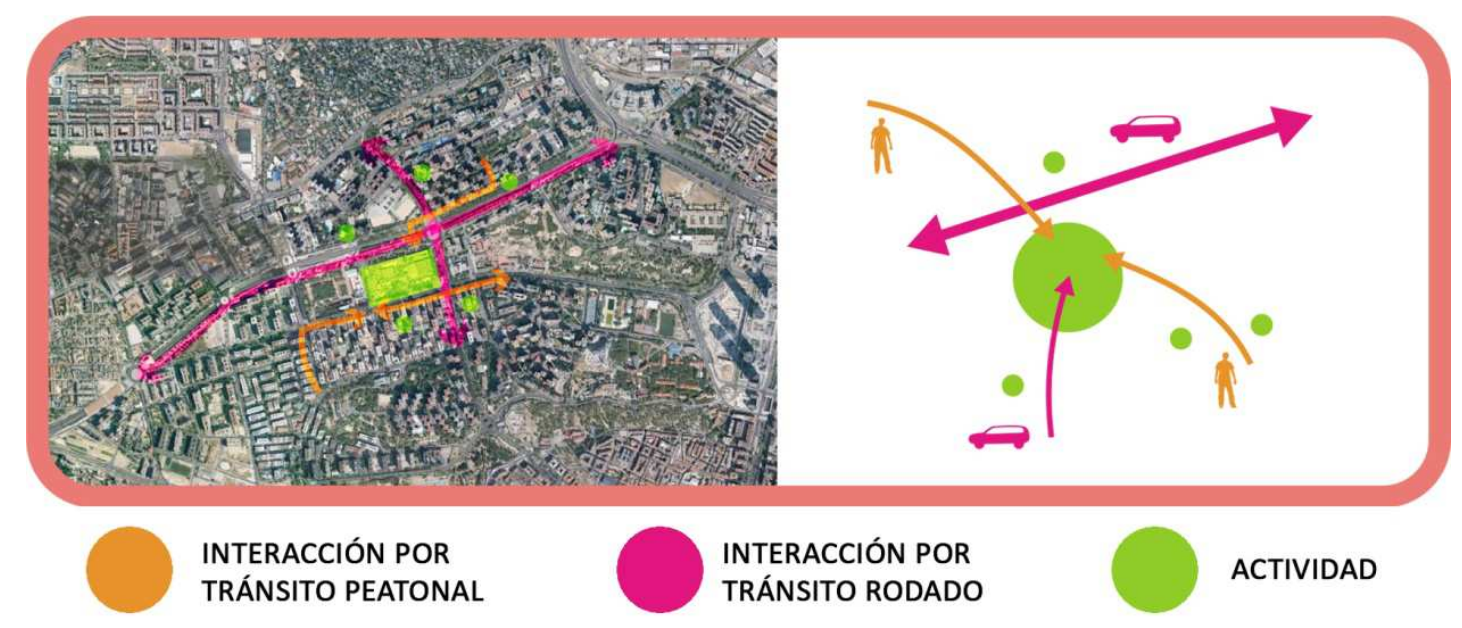

Figura 4.14.5.- Gráfico de relaciones urbanas de La Vaguada. Fuente: Elaboración propia 


\section{PARQUESUR}

El centro comercial de Parquesur, es un centro de gran superficie que se ubica en las afueras de una ciudad satélite de Madrid, generando un importante nodo de actividad.

A pesar de que el entorno urbano próximo posee un grado importante de mezcla de usos, la accesibilidad a este centro se basa principalmente en el uso del vehículo particular, ubicándose el centro entre vías interurbanas de gran capacidad. Sin embargo, es importante considerar a su vez, que el centro comercial Parquesur es relativamente accesible de cara al peatón, y que hay paradas de transporte público en sus inmediaciones.

No obstante, el centro de cara a la calle no genera actividad, ya que se ubica en el interior de un recinto cerrado con entradas localizadas, y los accesos al edificio del centro están alejados de la vía pública, habiendo aparcamientos abiertos entre medias.

También es importante destacar que el centro comercial de Parquesur, se ubica en el extremo este de su área de influencia urbana, creando recorridos e interacciones direccionales hacia el centro. Aún así, el centro está separado de su contexto urbano por parques y avenidas de gran tránsito, lo que dificulta aún más la accesibilidad peatonal debido a las distancias. (Figura 4.14.6)

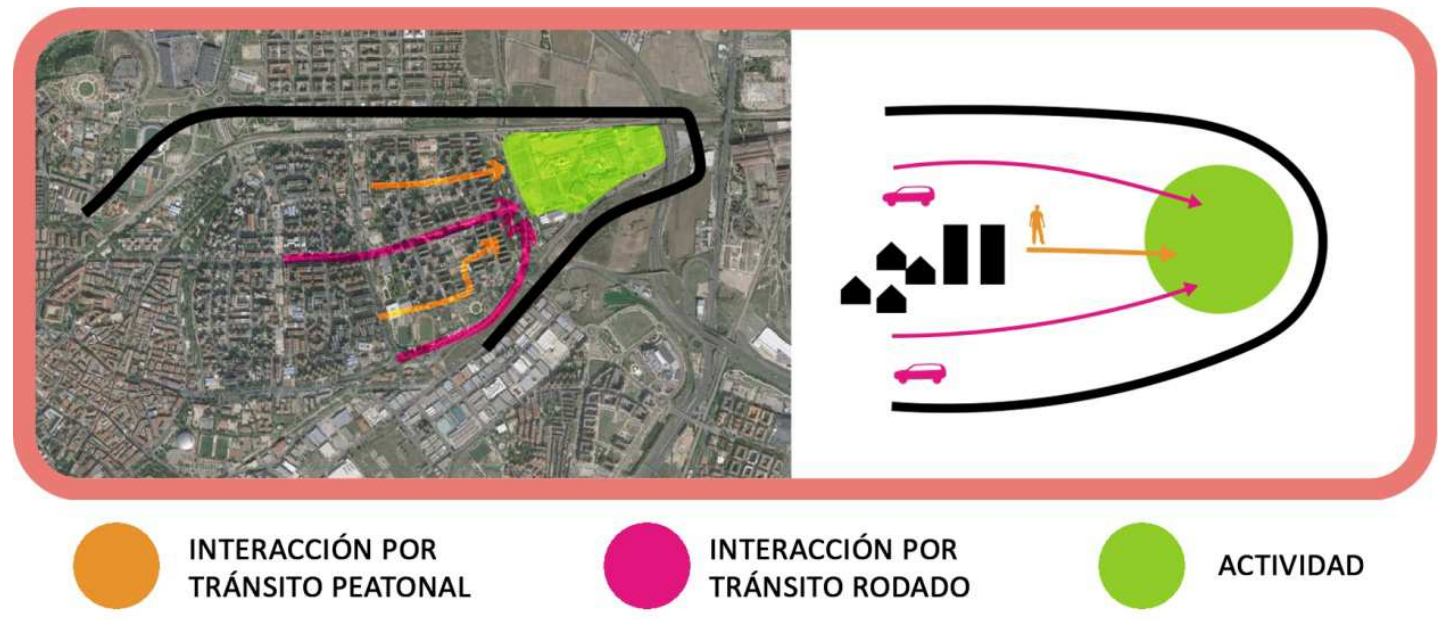

Figura 4.14.6.- Gráfico de relaciones urbanas de Parquesur. Fuente: Elaboración propia.

\section{BELMAR}

El complejo de Belmar, es un núcleo de actividad, dentro de un entorno urbano de suburb norteamericano, caracterizado generalmente por la poca densidad y la zonificación de los usos urbanos.

Concebido como un área urbana compleja en la que estuviera presente la mezcla de usos, En la actualidad Belmar asume el papel de ser el centro urbano de actividad del distrito de Lakewood ubicado en las afueras de Denver. Por consiguiente es previsible que las relaciones 
urbanas entre el complejo Belmar y su entorno urbano, se basen en la centralización de los usos, convergiendo en el mismo un gran número de recorridos.

A efectos de accesibilidad, el complejo, se ubica entre vías de gran capacidad, existiendo a su vez en las inmediaciones paradas de transporte público, y se ha intentado promocionar la accesibilidad peatonal. Sin embargo, el principal medio de accesibilidad al complejo Belmar sigue siendo el vehículo privado, habiendo dentro del complejo, grandes aparcamientos tanto en superficie como subterráneos.

Dentro de Belmar no hay dentro recintos cerrados que rodeen los edificios, existiendo además comercios a pie de calle, lo que hace que haya una presente actividad dentro del centro. Sin embargo, a pesar de que el complejo Belmar está abierto completamente a su entorno urbano colindante, la actividad que éste genera no repercute en el entorno urbano colindante, debido a las barreras, y al incremento de las distancias peatonales que supone la presencia de las amplias avenidas que rodean el centro. (Figura 4.14.7)

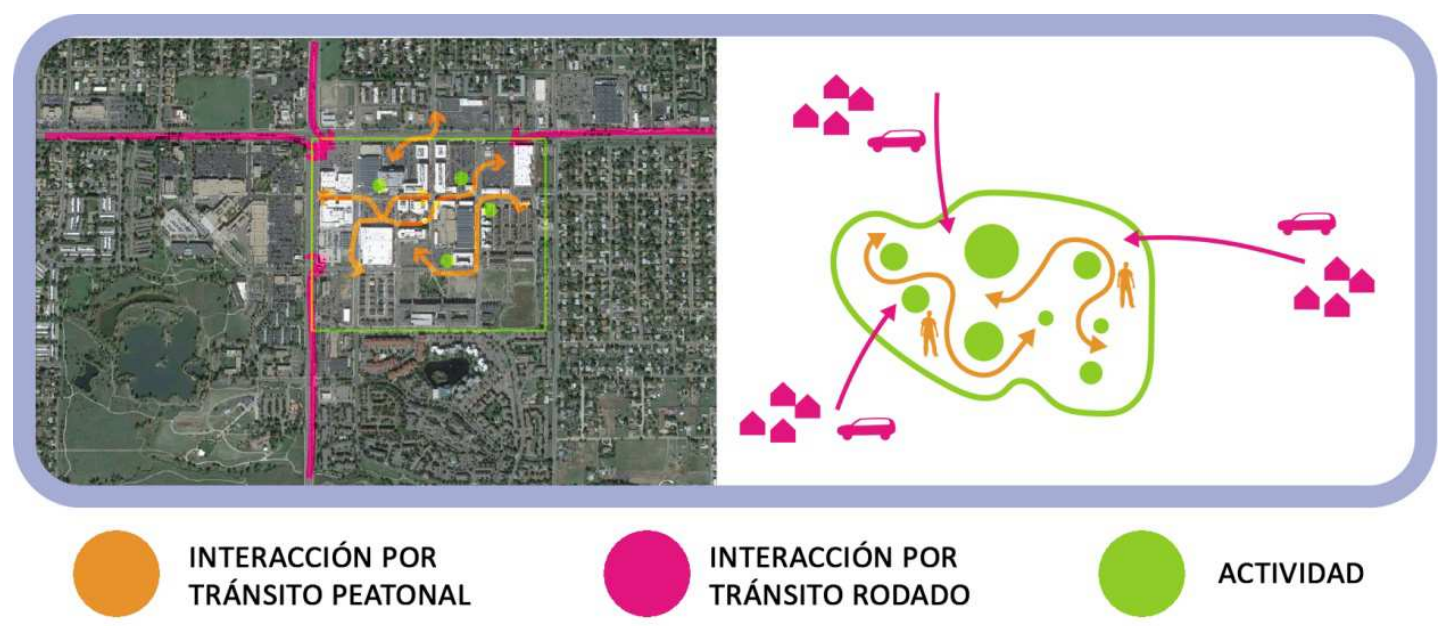

Figura 4.14.7.- Gráfico de relaciones urbanas de Belmar. Fuente:Elaboración propia

\section{MALL OF AMERICA}

El centro comercial Mall of America, es una instalación de gran superficie ubicada en un entorno de poca densidad y baja mezcla de usos. No obstante, esta gran instalación comercial está ubicada entre grandes infraestructuras de transporte privado, de las cuales va a haber acceso al centro comercial. No obstante, es importante remarcar el hecho de que estas grandes vías generan una barrera prácticamente intransitable por peatones, entre lo que es el Mall of America y su entorno urbano. De modo que la accesibilidad va a estar basada en el uso del vehículo particular.

A efectos de transporte público, el Mall of America cuenta con varias paradas de autobús en sus proximidades, siendo destacable la línea de monorraíl que conecta el centro comercial con el aeropuerto de Minneapolis exclusivamente.

De este modo, a efectos de relaciones urbanas, el Mall of America se abre prioritariamente a las grandes infraestructuras, que dan servicio a áreas territoriales que van más allá de la propia 
Minneapolis. (Ramificaciones de autopistas interestatales, o aeropuertos), de modo que aunque este centro tenga asignada un área de influencia próxima para el análisis en la presente tesis, las relaciones con ésta área van a ser algo secundario, estando basadas las relaciones urbanas del centro, con la infraestructura que transporta personas desde otros puntos y áreas cercanas de Estados Unidos. (Figura 4.14.8)

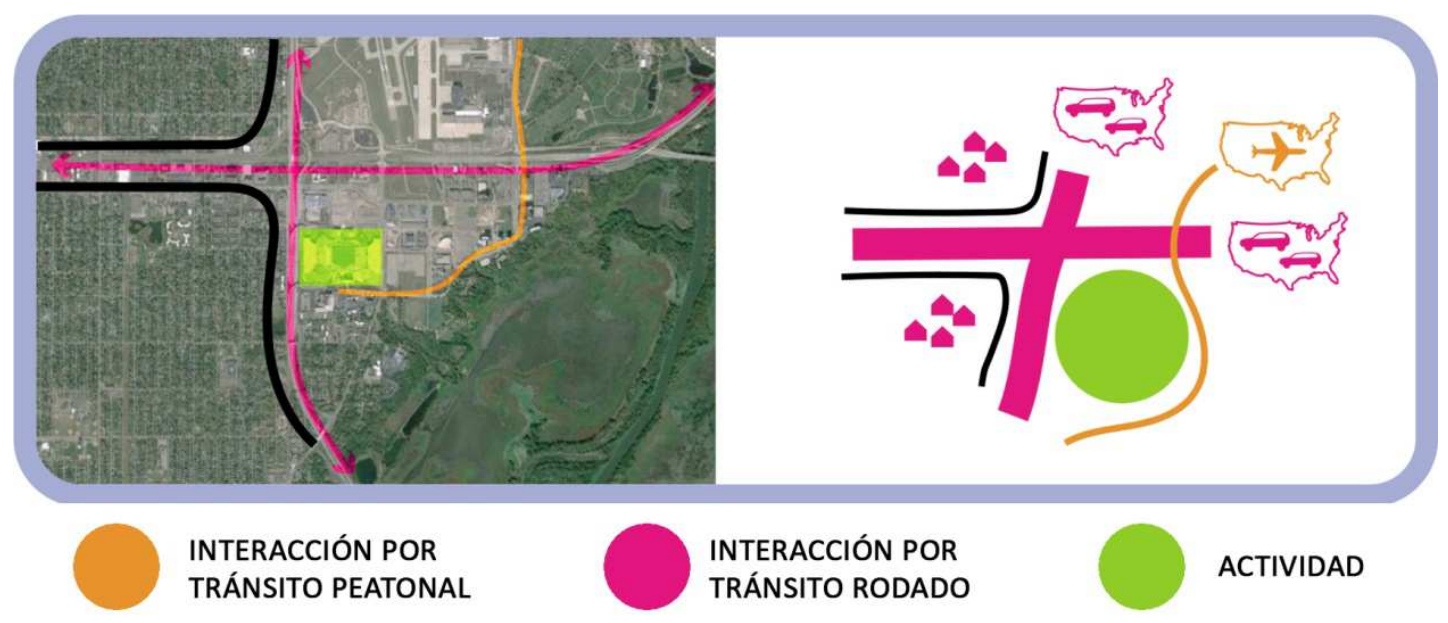

Figura 4.14.8.- Gráfico de relaciones urbanas de Mall of America. Fuente: Elaboración propia.

De este modo una vez explicadas las relaciones de los centros comerciales, se elaboró el siguiente gráfico conclusivo de acuerdo a las variables accesibilidad-actividad urbana, ubicando dentro del mismo los casos de estudio anteriormente descritos. (Figura 4.14.9) El criterio considerado es estimativo, y fue realizado en base a análisis cualitativos en los que se consideró para la accesibilidad, la ubicación del centro en la ciudad, y las características de la infraestructura cercana al centro, tanto de transporte público como de transporte privado. En lo referente al contexto urbano, se valoró la actividad en el mismo y la aparente mezcla de usos. Esto fue valorado en base al análisis de modelos urbanos similares a los de los centros, y visitas que el autor realizó a algunos de los centros analizados.

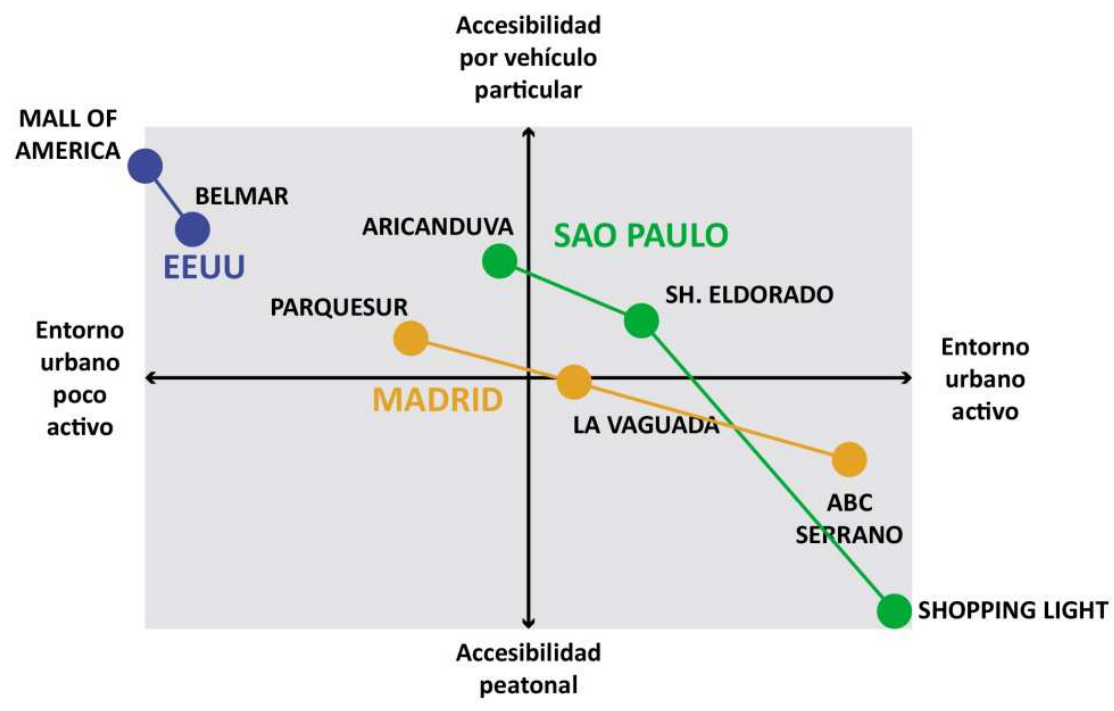


Figura 4.14.9: Disposición de los casos de estudio respecto a la accesibilidad y la actividad urbana Fuente: Elaboración Propia.

Como primer acercamiento a la realidad de los centros a analizar, se puede afirmar, que los casos de Madrid y Sao Paulo, están en entornos urbanos similares, disminuyendo la actividad urbana a medida que nos alejamos del centro. De la misma manera que prima la accesibilidad por vehículo particular. En la América suburbana, los casos de estudio se encuadran en un entorno poco activo, en el cual prima de forma drástica la accesibilidad por vehículo particular.

Este capítulo, ha servido para dar una visión general de los entornos urbanos de los centros y su configuración. El siguiente paso va a ser el análisis exhaustivo de los mismos, y el estudio de casos, de acuerdo a las pautas de la metodología explicadas en el capítulo 3 de la presente tesis.

\subsection{5.- FUENTES A CONSIDERAR PARA EL ESTUDIO DE CASOS.}

Antes de elaborar el estudio de casos de los centros comerciales para la presente tesis, es de interés mencionar y explicar las fuentes que fueron consideradas, así como las dificultades que pudieran. En la presente tesis fueron considerados varios tipos de análisis para el análisis de cada centro comercial.

\subsection{1.- Análisis y recogida de datos cuantitativos.}

Este análisis es el que está centrado en la recogida de datos numéricos cuantitativos descriptivos de la realidad, que pudieran ser de utilidad para el análisis del centro comercial y el entorno urbano en la metodología. Este análisis, aunque va a ser constante durante el estudio de casos, va a tener la mayor relevancia en las fases iniciales de la aplicación de la metodología, con la intención de sentar las bases de posteriores análisis que pudieran ser realizados, bien con otros datos también cuantitativos, bien comparando, o bien mediante simulación. Para esta fase de la investigación los datos que van a ser considerados, van a estar referidos a recogidas anteriores de datos estadísticos o numéricos, bien sean concretos o bien sean aproximados. Para la recogida de datos cuantitativos van a considerarse las siguientes fuentes:

-Páginas web de las autoridades urbanísticas, nomenclátores oficiales, o bases de datos oficiales y extraoficiales, que van a estar relacionadas con el estudio de las cualidades demográficas de las ciudades de Sao Paulo, Madrid, Leganés, Denver y Minneapolis. De estas fuentes, van a conseguirse en la medida de lo posible, todos los datos cuantitativos relativos a poblaciones, densidades, áreas, ratios y superficies de usos residencial, comercial y productivo industrial y terciario no comercial. Así como otros datos descriptivos ligados a características urbanísticas que fueran convenientes en relación al estudio del área urbana del centro comercial. 
-Páginas web y bases de datos, que estén ligados a las gerencias de los centros comerciales a analizar (Shopping Light, Shopping Eldorado, Aricanduva, ABC Serrano, La Vaguada, Parquesur, Belmar y Mall of America), o bien trabajos estadísticos relacionados con asociaciones de centros comerciales y otras autoridades educativas científicas o empresariales, que hayan trabajado con estos centros, o con casos similares. De estas fuentes, van a conseguirse datos relacionados con lo que es el centro comercial en sí de cara a la metodología: superficies de centros comerciales, número de visitantes diario, semanal, mensual o anual, consumos energéticos, calificaciones energéticas, ratios de emisiones, superficies de parcela o unidad catastral, superficies de usos residenciales o productivos terciarios no comerciales o industriales dentro del centro comercial.

\subsection{2.- Estudios cuantitativos y cualitativos sobre plano.}

El análisis sobre plano va a resultar fundamental en esta tesis doctoral. Esto se debe a que va a ser muy importante por una parte ubicar en el espacio las cualidades estudiadas en el análisis cuantitativo. Por otra parte, el análisis sobre plano va a resultar ser un medio eficaz, de cara a la obtención de datos que no pudieron obtenerse en el análisis cuantitativo. Todos los datos derivados del análisis sobre plano van a estar relacionados con áreas, superficies, distancias y longitudes. Para el análisis sobre plano se considerarán las diferentes fuentes:

-Plantas, fotos aéreas y parcelarios oficiales relacionados con el área urbana del centro, y el centro comercial en cuestión. El análisis de estas fuentes gráficas va a ser fundamental para la aplicación de la metodología, ya sea para delimitar u obtener datos cuantitativos de áreas determinadas, longitudes o distancias. Los datos que van a obtenerse de estas fuentes van a estar relacionados con superficies libres y ocupadas por la edificación, áreas verdes, superficies asimiladoras de agua por parte del suelo, distancias entre el centro comercial y puntos concretos del área urbana, superficies de áreas homogéneas dentro del área urbana de análisis en base a características urbanísticas, longitudes de fachadas y áreas edificadas en parcelas concretas para el análisis de las parcelas cercanas al centro comercial. También se van a marcar en los planos, apuntes y elementos cualitativos que pudieran resultar de interés.

\subsection{6- JUSTIFICATION OF THE CASES TO BE STUDIED, RESUME OF THE UNIT.}

Once the methodology was established, the next analysis, is the selection of the cases to be studied:

In this unit, an analysis was performed of a list of important cases of shopping malls in the world, being selected lately eight cases to be studied deeply. However the application of the methodology of the thesis was proposed to be universal for every shopping mall.

The urban backgrounds to be studied where the urban areas of Sao Paulo, Madrid, and the Suburban USA. 
The justification of the choosing of Sao Paulo, is because is the largest city in the American continent. In addition, in that urban background there is a rich variety of urban scenarios, such as the high dense downtown, or even the extremely large and low density sprawls. In addition Sao Paulo is located in an emergent economic situation related to shopping mall activity.

The cases chosen for the urban background of Sao Paulo were Shopping Light related to the dense Center of Sao Paulo, Shopping Eldorado in the Expanded City Center, and Shopping Aricanduva related to the sprawled outskirts of the city.

-Shopping light was chosen as an example of compact shopping developed in height, placed in a dense urban area. In addition this mall is inside a representative building. Being the area surrounding the mall one of the most active ones in the city of Sao Paulo. The urban background where this shopping mall is located is featured as being an important part of the administrative core of the city of Sao Paulo. To make an appointment, this area occupies part of the Sao Paulo initial footprint, corresponding to the Vila de Sao de Piratininga founded in 1554. O Edifício Alexandre Mackenzie ou Prédio da Light was built in 1926, when the city started a slight grow. Since this date, the whole area have experienced a lot of changes concerning both the urban structure and infrastructure. The most relevant changes happened in the second half of 20th century, when Sao Paulo experienced the largest grow. Planning politics considered the grow in height of buildings, as well as the density, as being the area one of the most relevant in the whole city of Sao Paulo. Currently, the area is features for the low income economic condition of their inhabitants, being some occupied buildings or Cortijos within. This happens in a frame where the tertiary activity is growing, being the services and touristic activity the engine of the economics in the area, in addition to the end or transportation link, of a large number of commuting movements.

-Shopping Eldorado was chosen as a case of analysis framed in the intermediate scenario of the expanded city center. This shopping mall is located nearby high capacity infrastructures, being this mall focused on the people with middle-high incomes. In addition, Shopping Eldorado management, have considered the insertion of an urban orchard on its roof. The district where this shopping mall is located (Pinheiros), is part of the development Sao Paulo city experienced when grew during the second half of 20th Century. Nearby the shopping mall there is the Avenue of Faria Lima, which was conceived as an economical core of the high level tertiary activity, when founded in 1968, being nowadays an important core of activity, The planning politics favored the growing of the buildings in height for offices and middle class dwellings, as well as the development in low density for the high class residential areas. The economical situation of the inhabitants, vary from medium incomes, to high incomes.

-Shopping Aricanduva was chosen as a case of study related to the frame of Sao Paulo nearby outskirts. This large commercial facility is one of the biggest in the American continent, being projected as a strong commercial centrality. This case, as being projected with extremely large built surfaces, can be a good opportunity to perform a sustainable retrofitting. The urban tissue of this area, is the consequence of the fast growing of the city of Sao Paulo, in the second half of 20th century. The lack of concrete urban planning politics, and the high increase have ended in a tissue featured by the low height of the buildings and the high rate of 
coverage. The wages of the population vary from medium to very low, Being in the area some favelas.

The justification of the choosing of Madrid background, is to perform a parallel analysis to Sao Paulo urban background. Madrid, is a city with a relatively compact urban tissue, being this one surrounded by dense bedroom towns. Madrid is an area in the world, in which the economy of the shopping mall is in a mature status in the life cycle curve. The cases chosen to analyze the urban reality of Madrid were ABC Serrano, La Vaguada and Parquesur.

$A B C$ Serrano was chosen as a parallel case to Shopping Light, as being located in a dense urban area, being the mall building a historical one too. The area surrounding the shopping mall has a very powerful economy. As a consequence of this, is currently considered as one of the richest in Madrid. The wages and incomes of the inhabitants overcomes the high rates. The urban tissue, is part of the Castro Plan started in 1846 to enlarge the urban surface of Madrid as a consequence of the increase in population happened in 19th century. In the last years the area have experienced a strong gentrification process, being favored by the local authorities. This supposed a lot of residential dwellings to be turned into high income tertiary activities.

La Vaguada was chosen, as a parallel study case to Shopping Eldorado. This large surface mall, is located in the outer city center of Madrid, next to a high capacity avenue, is known also to be a bright example of efficient and environmental energy management. The district where this mall is located is El Pilar, a new construction district of the northern area of Madrid, the construction of that area started in the second half of the 20th century. The urban policy for its development was based on the construction of hi rise residential buildings. The development of the amenities within, was a slow process, expanded in the time, and the construction of La Vaguada mall is included in these programs. Despite on its beginnings El Pilar was conceived for low income people, the integration of the district in the center of Madrid, as well as the insertion of amenities have supposed an increase of the land value. Currently the district is inhabited by middle class people

Parquesur, was chosen to be a parallel example to Aricanduva. This mall is an example of large surface commercial centrality located in a high density bedroom town of the outskirts of Madrid (Leganés). This mall is the biggest one in the Madrid Province, and the third in Spain. Have been also considered as a good example of energetic management towards eco efficiency. The district where this shopping mall is located was developed in the 1980's. Considering for the planning policies of this district the construction of hi rise residential buildings, and green areas, having a high rate of density. Is important to consider Parquesur mall as being the biggest amenity projected in the district, and probably the most important agent for the development of the economy in the district. The wages of the inhabitants of the district vary from the middle low incomes to the middle ones.

The urban frame of the suburban USA was important to be considered for this thesis. The justification of this, is because the suburban sprawl of these areas have been considered as a city with serious problems towards sustainability and environment. In addition, in this urban 
frame, the modern typology of shopping mall was conceived, and nowadays these are the urban areas in where the shopping mall activity is decaying. So is the background of the urban retrofitting programs aimed to refurbish these dead malls. The cases chosen to be studied in this urban background were Belmar and Mall of America.

Belmar was chosen for this thesis, as being the result of an urban retrofitting of a dead mall located in the Denver suburbs. The interest of this case for the thesis, is because is an example aimed to the evaluation of a large scale retrofitting operation, whose aim was to create a complex and vivid urban area. Belmar is located in a suburban area of Denver sprawl, concretely in the satellite town of Lakewood. As other suburban areas in the U.S.A. Lakewood planning policies considered as primal the low density, the predominance of the residential use and the availability of high capacity infrastructure for private vehicles. To make an important appointment, Lakewood was considered to have no downtown area within. Furthermore, the interest of the construction of the Belmar complex, is the creation of a downtown for Lakewood. The income level of Lakewood vary from middle class to upper middle class, being the people living there employed in the tertiary activities and services.

Mall of America was chosen as being the paradigm of the super regional suburban shopping mall. This large surface case, is the most visited commercial facility in the world. In addition, the urban environment surrounding this facility, is a low density suburban area, being the mall located nearby first grade infrastructures. The area surrounding Mall of America (Bloomington), is planned according to the activity the Minneapolis Airport and the nearby highways can generate or demand. As being located in an strategic location, the surroundings of Mall of America are composed by middle/hi rise, tertiary/commercial buildings, whose connectivity by motorized means with other buildings or infrastructure is primal for the working of the activities in the area. The residential areas are located in the west of the highway, and all the developments there are zoned per use. The economy in Bloomington is very strong, being this town the house of important private companies, and providing by this way more than 100.000 jobs to the Minneapolis Sprawl. this happens because of the strategic location of the city nearby the airport, or other important transport links. In this background, Mall of America is the agent that generates the major number of employs in the city (about 13.000), the hotel activity related to businesses and airport linkage is very strong too. The income level of the population is middle.

To sum up, once the cases have been chosen, the next step is to apply the methodology on them to analyze the efficacy of the means of sustainability. 


\section{5.- ESTUDIO DE CASOS}

\section{1.- CASO 1: SHOPPING LIGHT}

Una vez establecida la metodología, esta va a ser aplicada sobre el caso de centro comercial de Shopping Light, ubicado en la zona céntrica de Sao Paulo en Brasil, este caso de centro para la presente tesis, fue considerado como un caso para entornos urbanos de gran densidad. Por consiguiente, éste capítulo se centra en el análisis de Shopping Light aplicando la metodología de la tesis paso a paso, explicando en cada uno de los epígrafes, la fuente de dato, y cómo fue calculado o hallado, todo ello de acuerdo a lo establecido en el capítulo 3.

\section{FASE 0: RECOGIDA DE DATOS CUANTITATIVOS.}

En esta fase, se realiza la recogida de datos cuantitativos oficiales del centro comercial Shopping Light y su entorno urbano. Estos se hallarán bien a partir de fuentes oficiales del propio centro, las autoridades urbanas de Sao Paulo, o bien midiendo sobre plano. La justificación de esto, es establecer unos datos de partida que nos sentarán las bases de posteriores análisis más particularizados e exhaustivos relacionados con el centro o con el entorno urbano. Se considerarán los siguientes datos, que serán de utilidad para posteriores análisis. A modo de resumen se mostrará una tabla de resultados de este análisis previo. (Figura 5.1.1)

\begin{tabular}{|l|l|}
\hline \multicolumn{2}{|c|}{ SHOPPING LIGHT } \\
\multicolumn{2}{|c|}{ FASE 0, RECOGIDA DE DATOS CUANTITATIVOS } \\
\hline OC.- TABLA DE DATOS CENTRO & Valor \\
\hline OC1: Superficie centro comercial (m2) & 36.000 \\
\hline OC2: Superficie de parcela o ud. Catastral (m2) & 4899 \\
\hline OC3: Superficie en planta (m2) & 4899 \\
\hline OC4: Número de visitantes semanal (pe/sem) & 75.000 \\
\hline OC5: Índice de Atracción ( $\mathrm{n}$-) & 3 \\
\hline OC6: Superficie de tipo residencial (m2) & 0 \\
\hline OC7: Superficie de uso productivo (m2) & 400 \\
\hline OC8: Número de instalaciones dotacionales $(\mathrm{n}$-) & 1 \\
\hline OU.- TABLA DE DATOS ENTORNO URBANO & Valor \\
\hline OU1: Población asignada a centro (pe) & 18.000 \\
\hline OU2: Densidad de población (hab/m2) & 0,024 \\
\hline U03: Superficie partida de entorno urbano $(\mathrm{m} 2)$ & 750.000 \\
\hline
\end{tabular}

Figura 5.1.1: Tabla de Datos Shopping Light Fuente: Elaboración propia.

OC.- TABLA DE DATOS DEL CENTRO COMERCIAL (C).

OC1: SUPERFICIE CENTRO COMERCIAL TOTAL: Este dato fue obtenido de fuentes oficiales de parte de la gerencia propio centro comercial, mediante una encuesta que el autor de la tesis realizó a un técnico representante del centro comercial en noviembre de 2014. La superficie edificada de Shopping Light es de $36000 \mathrm{~m}^{2}$

OC2: SUPERFICIE TOTAL DE LA PARCELA DEL CENTRO: Para la obtención de este dato se midió la superficie de la parcela, en un parcelario de la ciudad de Sao Paulo, que fue obtenido de la página web de la gerencia de urbanismo de la Prefeitura de Sao Paulo, en el cuarto trimestre de 2014. la superficie de la parcela es de $4899 \mathrm{~m}^{2}$ 
OC3: SUPERFICIE EN PLANTA DEL EDIFICIO DEL CENTRO COMERCIAL. Para obtener este dato se midió sobre plano en el parcelario mencionado con anterioridad, analizándose los volúmenes que componen el edificio. La parcela del centro comercial Shopping Light está ocupada al $100 \%$ de su superficie, a pesar de la existencia de patios interiores. La superficie en planta es de 4899 $\mathrm{m}^{2}$, siendo esta superficie el equivalente a la superficie de cubiertas para posteriores análisis.

OC4: NÚMERO DE VISITANTES SEMANAL. Este dato fue dado por la gerencia del centro comercial, en una entrevista entre el autor de la tesis y un representante técnico de la gerencia del centro comercial en noviembre de 2014. El centro comercial Shopping Light posee un aparato medidor de las visitas en los accesos al centro comercial, el cual realizó un conteo estimativo de las visitas.

De lunes a viernes: 35000 personas.

Sábado: 30000 personas.

Domingo: 10000 personas.

De este modo, el número de visitantes semanal de Shopping Light es de 75.000 personas/semana.

OC5: ÍNDICE DE ATRACCIÓN DEL CENTRO. En función al número de visitantes del centro, y considerando el baremo establecido en el ÍNDICE C5 del capítulo 3.5, A Shopping Light le corresponde un índice de 3 (de 20.000 a 150.000 visitantes semanales).

OC6: SUPERFICIE DE USO EN EL CENTRO DE TIPO RESIDENCIAL. Shopping Light no posee superficie residencial dentro de su unidad catastral, esto se halló a partir de visitas al centro, y estudiando la página web oficial del centro comercial ${ }^{46}$.

OC7: SUPERFICIE DE USO EN EL CENTRO DE TIPO PRODUCTIVO: De las visitas al centro que fueron realizadas por el presente autor de la tesis, se consideró como superficie de tipo productivo la oficina de hacienda (Receita Federal) que está dentro del centro comercial, esta mide aproximadamente $400 \mathrm{~m}^{2}$ establecidos a partir de una tanteo aproximado medido sobre plano, ya que no fue posible obtener datos acerca de sus medidas exactas. Las oficinas de la gerencia y gestora del centro comercial, no fueron incluidas en este conteo, ya que aunque son espacio productivo, su acceso no está permitido a personas, agentes o empresas ajenas a la gestora del centro comercial.

OC8: NÚMERO DE INSTALACIONES EN EL CENTRO DE TIPO DOTACIONAL O ASISTENCIAL: En el centro comercial Shopping Light, hay 1 local de uso asistencial, que es la oficina de hacienda anteriormente mencionada (Receita Federal), este dato se extrajo del análisis de la planta, del análisis de la página web y la visita al centro en noviembre de 2014.

\section{OU.- TABLA DE DATOS DEL ENTORNO URBANO (U).}

OU1: POBLACIÓN DE ÁREA URBANA ASIGNADA A CENTRO COMERCIAL: Dividiendo la superficie del centro comercial entre 2, todo ello de acuerdo al baremo de Victor Gruen (1957) $\left(2 \mathrm{~m}^{2}\right.$ de edificio por comprador) salió una población asignada de 18.000 personas.

\footnotetext{
${ }^{46} \mathrm{http}: / /$ shoppinglight.com.br/
} 
OU2: DENSIDAD DE POBLACIÓN EN EL DISTRITO DEL CENTRO COMERCIAL: Para el análisis urbano, se cogió la densidad de población del distrito de República en Sao Paulo, que es dónde está ubicado el centro comercial, la densidad se estableció en $0,024 \mathrm{hab} / \mathrm{m}^{2}$ a partir de los datos oficiales del ayuntamiento de Sao Paulo, para 2010. Esto dato va a ser de interés, tanto para dimensionar el área de análisis, cómo para estudiar la densidad de cara a la adecuación de las medidas de rehabilitación del entorno urbano.

OU3: SUPERFICIE DE PARTIDA DEL ENTORNO URBANO: La superficie del entrono urbano a analizar, se sacó de los datos de población asignada al centro (18.000 personas), la cual fue dividida entre la densidad del área $\left(0,024 \mathrm{hab} / \mathrm{m}^{2}\right)$, la superficie de partida para el establecimiento del área de análisis es de $750.000 \mathrm{~m}^{2}$. Esa superficie podrá ser modificada en base a las características del entorno. No obstante para conteos poblacionales se usará el dato de población asignada al centro establecido en el apartado U1.

\section{FASE 1: ANÁLISIS DEL CONTEXTO URBANO.}

Este análisis se realiza generalmente en base a mediciones sobre plano del área del centro comercial Shopping Light. Se trabajarán diferentes escalas, siendo predominante la escala urbana amplia de toda la zona de influencia del centro comercial, que va a establecerse en este apartado. Para este análisis resultará fundamental el uso de los datos referentes a la configuración del entorno urbano del centro de Sao Paulo, establecidos en el apartado anterior. Estos datos van a ser ponderados con la información que pudiera sacarse del análisis sobre plano, y de este análisis, el objetivo será hallar y establecer las pautas urbanísticas para el cuestionario de rehabilitación del centro comercial, se considerarán aspectos relacionados con configuraciones de volumen urbano, densidades, usos, áreas verdes y medio ambiente urbano.

1A: ESTABLECIMIENTO DEL ÁREA DE INFLUENCIA DEL CENTRO COMERCIAL : En base a la superficie del área, hallada anteriormente, se estableció para el área de análisis del centro comercial Shopping Light, una distancia de aproximadamente 488 metros a partir del lindero de la parcela del centro. Este dato fue hallado considerando la superficie de partida (OU3) cómo el área de un círculo sobre el contexto urbano, aplicando la siguiente fórmula:

Radio $=\sqrt{ }(750.000 / \pi)=489 \mathrm{~m}$. Este dato es el verdaderamente relevante para establecer la superficie del área de análisis. (Figura 5.1.2)

1B: DELIMITACIÓN SOBRE PLANO DEL ÁREA DE INFLUENCIA: Para la delimitación del área de influencia, se trazó una circunferencia del radio anteriormente establecido $(489 \mathrm{~m})$, a partir del lindero de la parcela del centro, luego a partir del trazado de ese círculo, se estableció el borde del área urbana de análisis considerando en la trazada la configuración del tejido (parcelas, viario y áreas verdes), fue necesario añadir algunas parcelas, y descontar algunos espacios libres, quedando el área de análisis de la siguiente manera. (Figura 5.1.2). Se marcaron los límites en varias avenidas y plazas relevantes. LA SUPERFICIE DEL ÁREA URBANA FINAL DE ANÁLISIS PARA SHOPPING LIGHT ES DE $679.822 \mathrm{~m}^{2}$. Este dato será el que se utilice para cualquier conteo relacionado con el área urbana. 
1C: SUBDIVISIÓN DEL ÁREA DE INFLUENCIA EN ÁREAS HOMOGÉNEAS Y DELIMITACIÓN DE ZONAS VERDES. Para este análisis, el área urbana anteriormente asignada, va a dividirse en zonas homogéneas de acuerdo a la configuración de su tejido urbano, marcándose a su vez la superficie de zonas verdes. El área, al ser de un tamaño relativamente pequeño debido a la alta densidad, y muy similar en configuración urbana en toda su superficie, se estableció una única tipología de zona homogénea (Z1). Descontando los espacios verdes y sin edificar en el área, esta zona tiene aproximadamente $504.000 \mathrm{~m}^{2}$ brutos, que fueron medidos sobre plano. (Figura 5.1.2)

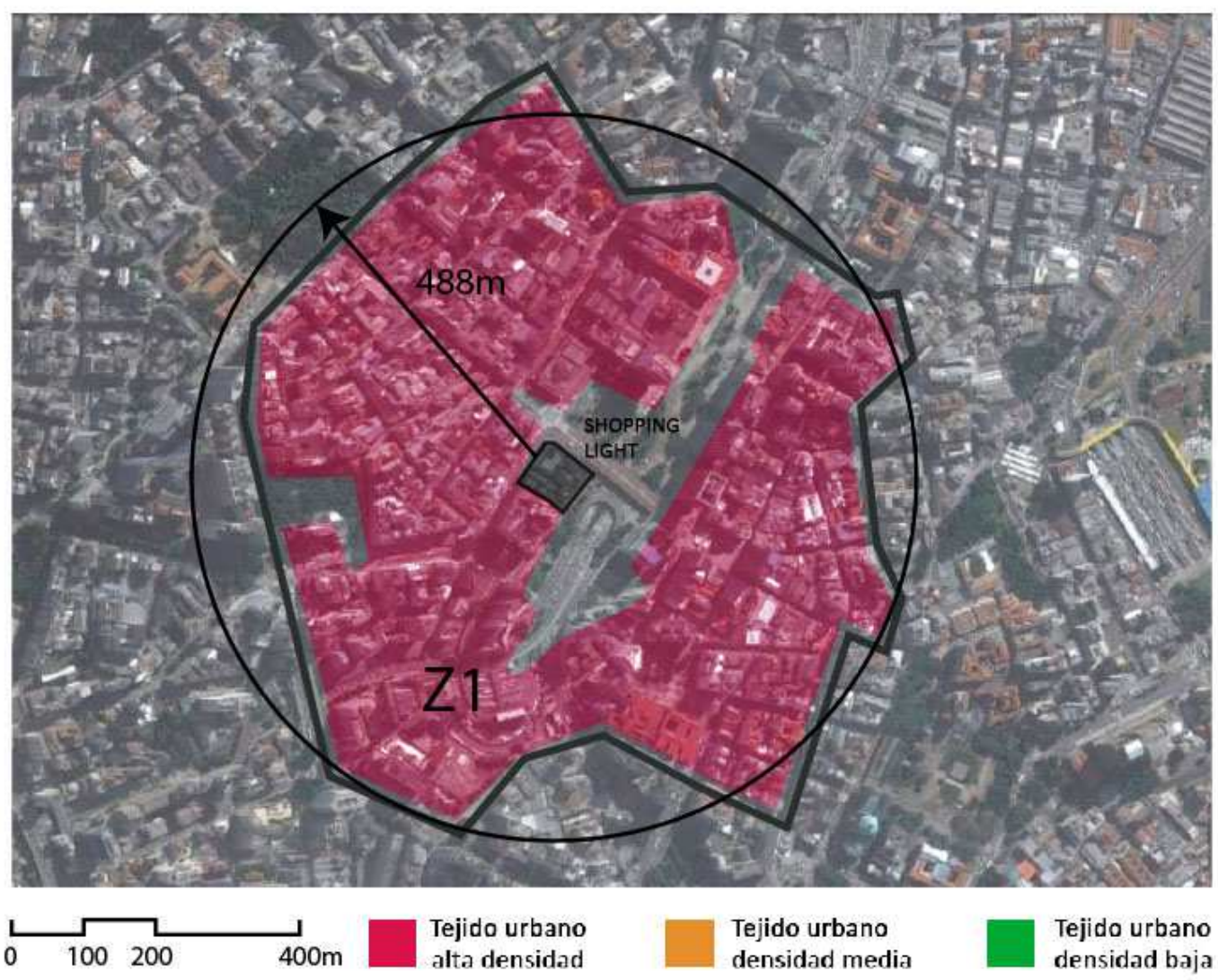

Figura 5.1.2: Área de Shopping Light y subdivisión por zonas homogéneas. Fuente: Elaboración propia.

1D: PORCENTAJE DE OCUPACIÓN DE LA EDIFICACIÓN Y ÁREA OCUPADA: A partir del análisis de un área tipo de $200 \times 200 \mathrm{~m}^{2}$ sobre un parcelario oficial de la ciudad de Sao Paulo, (Figura 5.1.3) contándose dentro de la misma el espacio libre y ocupado, para establecer un porcentaje. El porcentaje de ocupación de la edificación de la única zona homogénea establecida para el área de influencia de Shopping Light es del 67\%. Aplicando este porcentaje sobre la superficie de zona hallada anteriormente $\left(504.000 \mathrm{~m}^{2}\right)$ se puede obtener en el área urbana de Shopping Light una superficie ocupada de $337.680 \mathrm{~m}^{2}$. 


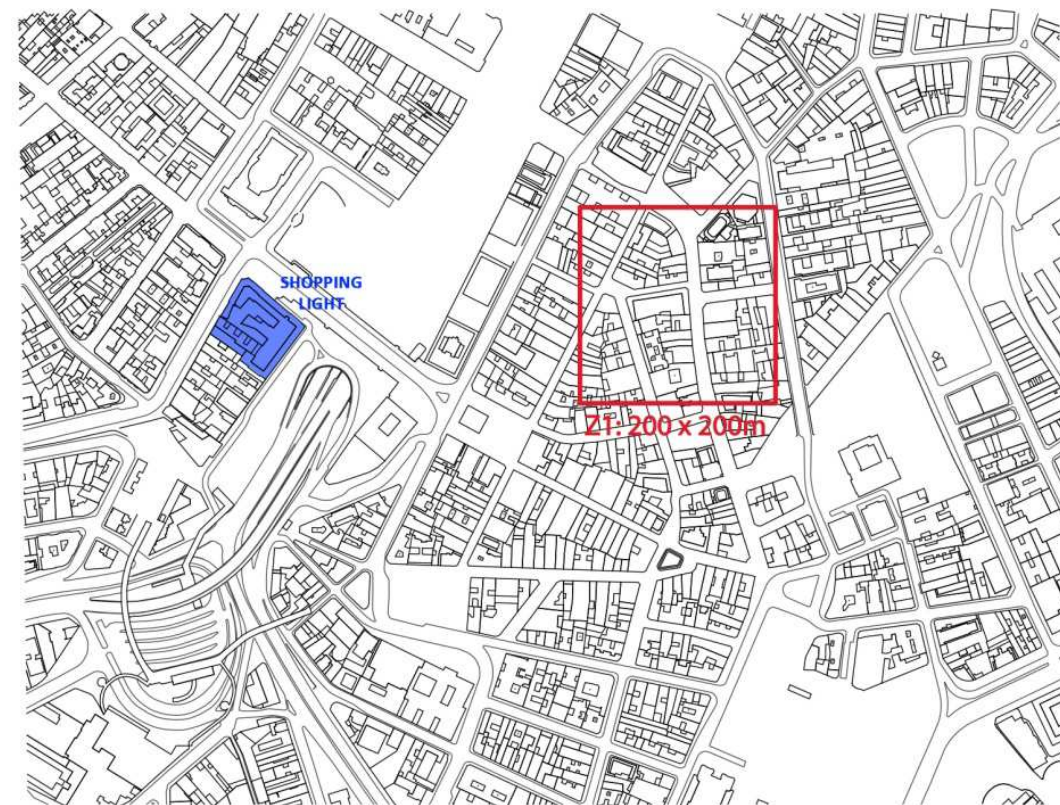

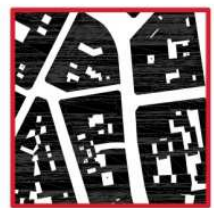

ÁREA TIPO Z1 $(40.000 \mathrm{~m} 2)$ $26977 \mathrm{~m} 2$ ocupados $(67 \%)$.

Figura 5.1.3: Análisis de ocupación sobre parcelario. Fuente: Prefeitura de Sao Paulo, FAU USP

1E: ALTURAS DE LA EDIFCACIÓN POR ÁREA HOMOGÉNEA: Al Haber un área homogénea en la zona, la altura de la edificación se estableció en 12 plantas, a partir de un análisis visual del área realizado de visitas a la misma, y de Google Street View.

1F: ESTABLECIMIENTO DE LAS TIPOLOGÍAS DE TEJIDO EN BASE A LA MORFOLOGÍA URBANA POR ÁREA HOMOGÉNEA: Con una ocupación de la edificación de un 67\% y una altura de 12 plantas, el área de influencia de Shopping Light es un tejido denso de acuerdo al cuadro respectivo a la cuestión $1 \mathrm{~F}$ del apartado en el capítulo 3.6 de la metodología.

1G.- ÍNDICE GLOBAL DE DENSIDAD. Al haber solo una tipología de tejido en el área de Shopping Light (ocupa el $100 \%$ de la zona analizada) de tipo denso, el índice global de densidad quedó establecido con una puntuación de 3, que corresponde a una zona urbana densa. Este dato va a resultar de gran interés, debido a que es la base para la analítica de la densidad urbana.

1H: SUPERFICIE EDIFICADA TOTAL DE CADA ÁREA HOMOGÉNEA. Para la superficie edificada total, se multiplicó la superficie ocupada en planta anteriormente hallada $\left(337.680 \mathrm{~m}^{2}\right)$ por el número medio de plantas (12). De este modo, la superficie total edificada bruta aproximada es de $4.389 .840 \mathrm{~m}^{2}$. Dato de gran relevancia para el análisis de los usos en el área urbana.

1l: ESTABLECIMIENTO DE PORCENTAJES DE USO DENTRO DE LAS ZONAS HOMOGÉNEAS ESTABLECIDAS: El área de Shopping Light corresponde a un entorno complejo en el que hay edificios tanto residenciales como comerciales y administrativos. Al no haber datos objetivos sobre los usos predominantes en la zona, se consideraron los siguientes porcentajes a partir de un análisis visual de los edificios presentes en el área.

Z1: Uso residencial: $40 \%$. Uso productivo: $30 \%$. Uso comercial: $30 \%$ 
1J: CONTEO DE LOS USOS DENTRO DEL CONTEXTO URBANO. Una vez se establecieron los porcentajes de uso en el apartado anterior, el siguiente paso es la obtención de los metros cuadrados absolutos de uso, para ello, se multiplicaron por separado los porcentajes de 1l por la superficie edificada total de $1 \mathrm{H}\left(4.389 .840 \mathrm{~m}^{2}\right)$, quedando establecidos los metros cuadrados de usos, para el área urbana de Shopping Light de la siguiente manera:

Z1: Uso residencial: $\left(40 \%\right.$ de $\left.4.389 .840 \mathrm{~m}^{2}\right) 1755936 \mathrm{~m}^{2}$. Uso productivo: (30\% de $4.389 .840 \mathrm{~m}^{2}$ ) 1.316.952m². Uso comercial: (30\% de $\left.4.389 .840 \mathrm{~m}^{2}\right) 1.316 .952 \mathrm{~m}^{2}$.

1K: ÍNDICE GLOBAL DE MEZCLA DE USOS. Para el índice global de mezcla de usos, se recogió por un lado el porcentaje de uso residencial del apartado $1 \mathrm{l}$, y por otro lado sumaron los porcentajes de uso productivo y comercial para hallar el porcentaje de uso no residencial, quedando la base para el análisis de mezcla de usos de la siguiente manera:

Z1: Uso residencial: $40 \%$. Uso no residencial: $60 \%$.

De este modo, a Z1 se le asignó un índice de mezcla de usos de 1 al no superar ninguno de los usos el límite de $80 \%$ establecido en el apartado $1 \mathrm{~K}$, para considerar un área como no compleja a efectos de mezcla de usos. Al ser la zona homogénea Z1 la única que se analizó en el área urbana de Shopping Light, a ésta se le asignó un índice de mezcla de usos de 1, que corresponde a un área muy compleja a efectos de usos.

1L: CONTEO DEL NÚMERO DE DOTACIONES DENTRO DEL CONTEXTO URBANO, DENTRO DEL ÁREA DE DOTACIONES Se estableció un área de un 1 kilómetro a partir del lindero del centro, y dentro de la misma, a través del análisis mediante visita al área, y planos de localización de usos de tipo Google Maps, se marcaron y localizaron las siguientes dotaciones de acceso público: 3 dotaciones de visita esporádica, 3 dotaciones de visita habitual, y 2 dos grandes dotaciones muy visitadas. (Figura 5.1.4) Este análisis va a ser determinante de cara al análisis del uso dotacional.

1M: PRESENCIA E INFLUENCIA DE ELEMENTOS POSITIVOS Y NEGATIVOS: En base a visitas que fueron realizadas al área, y fuentes de noticias, se marcaron los elementos positivos y negativos para la actividad del centro comercial. Como elementos positivos, cabe destacar la presencia en el área del Teatro, el ayuntamiento, y el edificio Altino Arantes, que son elementos turísticos para la ciudad de Sao Paulo, que van a atraer personas al centro, cómo se explicó en el gráfico del capítulo 3.3. No obstante en el área también hay inmuebles que pueden suponer un aumento de la inseguridad o la aparición de actividades no deseadas. (Figura 5.1.4)

1N: ZONAS DE ACTIVIDAD: De cara a la actividad urbana en las proximidades del centro comercial, los desniveles del Vale de Anhangabau, y las áreas difícilmente accesibles y pasos subterráneos, son causa de la aparición de puntos fríos de baja actividad durante la noche, quedando agravado este problema por el cierre de los numerosos edificios de oficinas, comerciales e institucionales. Como contraste a esto, de día la zona es muy activa y no hay puntos fríos, esto se dedujo a partir de visitas que se hicieron en la zona, tanto de día como de noche. (Figura 5.1.4) 


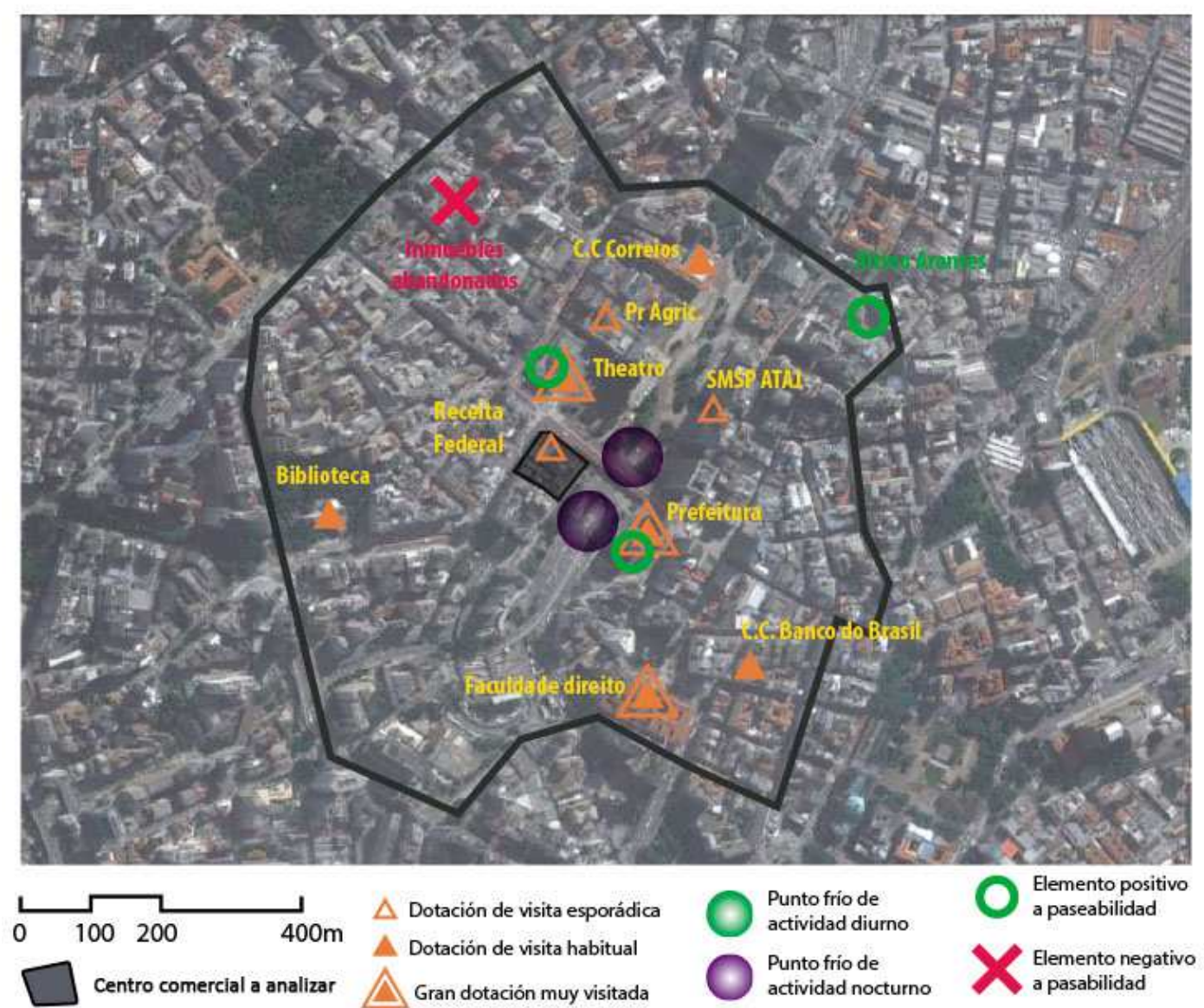

Figura 5.1.4: Área de Shopping Light, dotaciones, puntos fríos y elementos positivos y negativos. Fuente: Elaboración propia

10: ÁREAS ARBOLADAS Y VERDES, DENTRO DEL ÁREA URBANA DEL CENTRO: Dentro del área de shopping Light, se consideraron midiendo sobre plano las siguientes áreas verdes con sus respectivos metros cuadrados de superficie (Figura 5.1.5). Considerando las áreas netas de superficie verde, y los metros cuadrados de vegetación que poseen. El área urbana asignada a Shopping Light posee un área verde neta en planta de $35118 \mathrm{~m}^{2}$, que se desglosa en las siguientes superficies de vegetación, las cuales fueron estimadas a partir de las visitas al área del centro comercial, y a fotografías de las calles del área urbana de Shopping Light. 

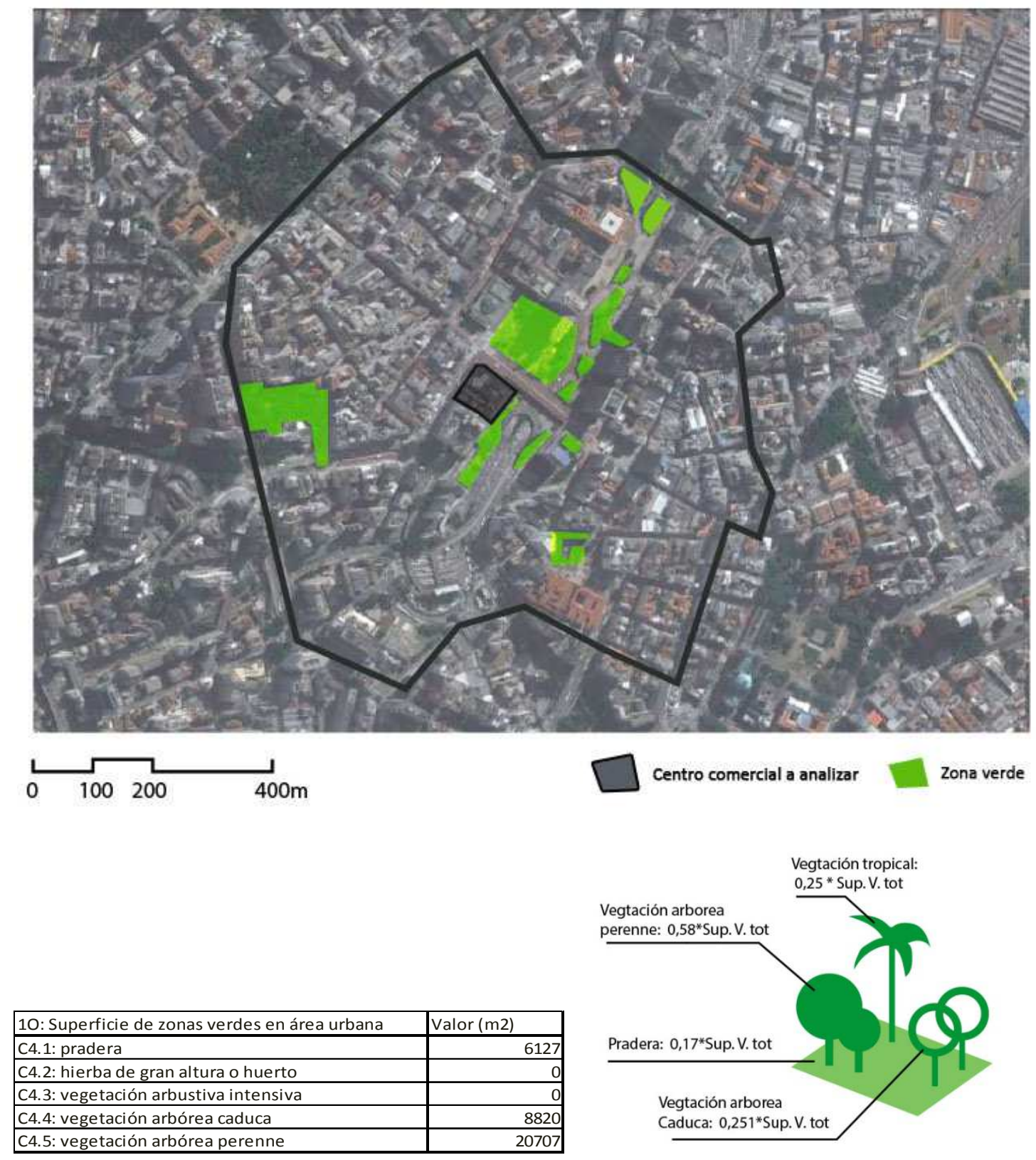

Figura 5.1.5: Área de Shopping Light, zonas verdes y capas de vegetación. Fuente: Elaboración propia.

1P.- DELIMITACIÓN DE RECORRIDOS A CENTRO, DENTRO DEL ÁREA URBANA: Para este análisis, fueron establecidos tres recorridos desde diferentes puntos del borde e interior del área urbana de análisis de Shopping Light, considerando la estructura urbana. Estos recorridos se muestran en el apartado 2E, (Figura 5.1.6), y se analizarán los tiempos de llegada tanto en transporte público, cómo en vehículo particular, para de esta manera ponderar la eficacia del transporte público. 


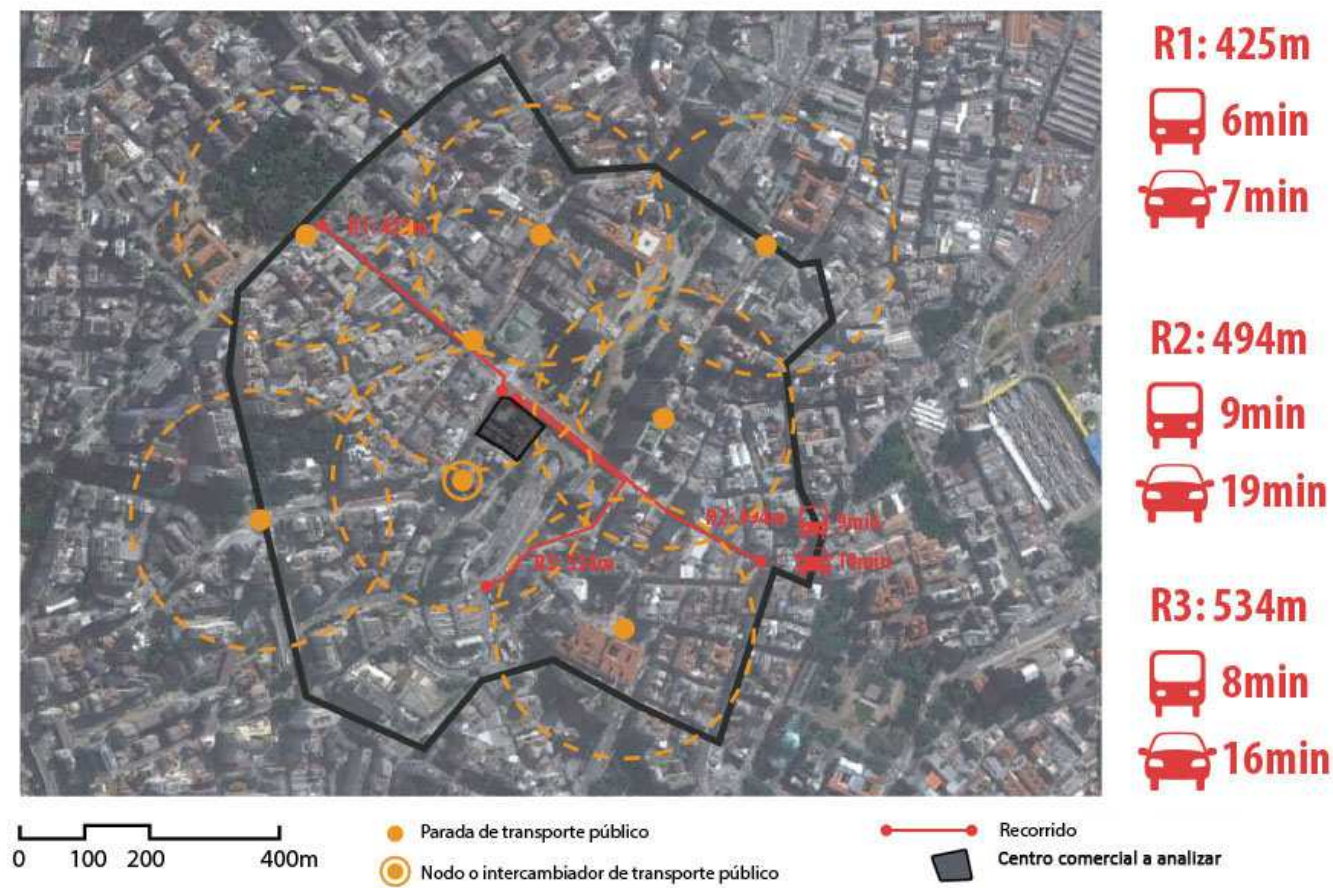

Figura 5.1.6: Recorridos, tiempos de llegada y zonas cubiertas por el transporte público. Fuente: Elaboración propia a partir de datos de Google

1Q.- HUELLA DE CARBONO DEL ÁREA URBANA: La huella de carbono base de Brasil de 2,1 ${ }^{47}$ toneladas anuales de dióxido de carbono por persona (esta fuente se extrajo a partir de datos de Trading Economics para 2008). No obstante, debido a que esta huella es media para todo el país, puede ser imprecisa ya que considera áreas con poco desarrollo industrial. Por consiguiente, se ponderó esta huella al alza, por estar relacionada con un área urbana desarrollada para el estándar de Brasil, que corresponde al centro de Sao Paulo. De este modo, para un habitante del área de Shopping Light, se estableció una huella de carbono estimada por persona de 3,9 toneladas anuales de dióxido de carbono, multiplicando este dato por la población asignada al centro (18.000 p), sale que la huella de carbono del área urbana de Shopping Light es de 70200 Toneladas de dióxido de carbono anuales estimadas.

1R.- CAPACIDAD ABSORCIÓN DE LOS ELEMENTOS VERDES EN ÁREA URBANA: En base a los datos de superficies verdes obtenidos en el apartado 10, se calculó la absorción total de las áreas verdes en base a la capacidad de absorción por metro cuadrado de las superficies vegetales estudiadas en el apartado $1 \mathrm{R}$ del capítulo 3.6, (figura 5.1.7.) Siendo la capacidad absorbente total en el área de 7421,71 Toneladas de dióxido de carbono anuales.

\begin{tabular}{|l|r|r|r|r|r|r|r|}
\hline 1 R: C.absorción elementos verdes en área & \multicolumn{1}{|l|}{ Pradera } & V.arb ext & V. A. Int. & H. Caduca & H. Perenne & Otro & TOTAL \\
\hline Superficie total & 6127,0000 & & & 0,0000 & 2707,0000 & 8820,0000 \\
\hline Tasa absorción TCo2/m2 año & 0,0013 & 0,0020 & 0,0350 & 0,1500 & 2,2500 & 0,1500 \\
\hline Absorción dióxido carbono TCo2 & 7,9651 & 0,0000 & 0,0000 & 0,0000 & 6090,7500 & 1323,0000 & $\mathbf{7 4 2 1 , 7 1 5 1}$ \\
\hline
\end{tabular}

Figura 5.1.7: Absorción de dióxido de carbono de las zonas verdes en área urbana. (Elaboración propia)

1S: DELIMITACIÓN DE ÁREAS EN FUNCIÓN DE LA RECUPERACIÓN DE AGUAS EN ÁREA URBANA. Para este análisis, se consideraron como zonas permeables al agua de lluvia, asimilables por el suelo para la recuperación de los acuíferos, las zonas verdes presentes en el área urbana, ya

\footnotetext{
${ }^{47}$ http://www.tradingeconomics.com/brazil/co2-emissions-metric-tons-per-capita-wb-data.html
} 
que estas no se encuentran pavimentadas por materiales impermeables (Figura 5.1.5). De este modo, la superficie absorbente del área de Shopping Light es de 35.118 m2.

\section{FASE 2: ANÁLISIS DE RELACIONES ENTRE CENTRO COMERCIAL Y ENTORNO URBANO.}

Este análisis es muy similar en búsqueda de datos y función con respecto al anteriormente analizado sobre el área urbana general. La particularidad de este análisis está en que su ámbito está limitado a las parcelas que directamente lindan con el centro comercial. El objetivo es cuantificar las relaciones urbanas entre el centro y el entorno próximo, ya sea mediante usos, relaciones entre dotaciones, y accesibilidad o transporte, en este análisis va a primar el estudio sobre plano, aunque también se harán análisis cuantitativos de superficies, y cualitativos.

2A: DELIMITACIÓN DE ÁREA PRÓXIMA: De cara al análisis del área próxima se escogieron las manzanas próximas al centro, marcándose sobre plano las superficies de las mismas, y las fachadas activas. Que para la presente tesis es cualquier fachada de edificio, en la cual en la cota del espacio público hay uno o varios locales o dotaciones que ejercen actividad, atracción o interacción sobre los flujos urbanos, debido a las personas que asisten a estas dotaciones. Los comercios comunes o las dotaciones asistenciales contribuyen a la aparición de fachadas activas debido a las visitas que generan. (Figura 5.1.8).
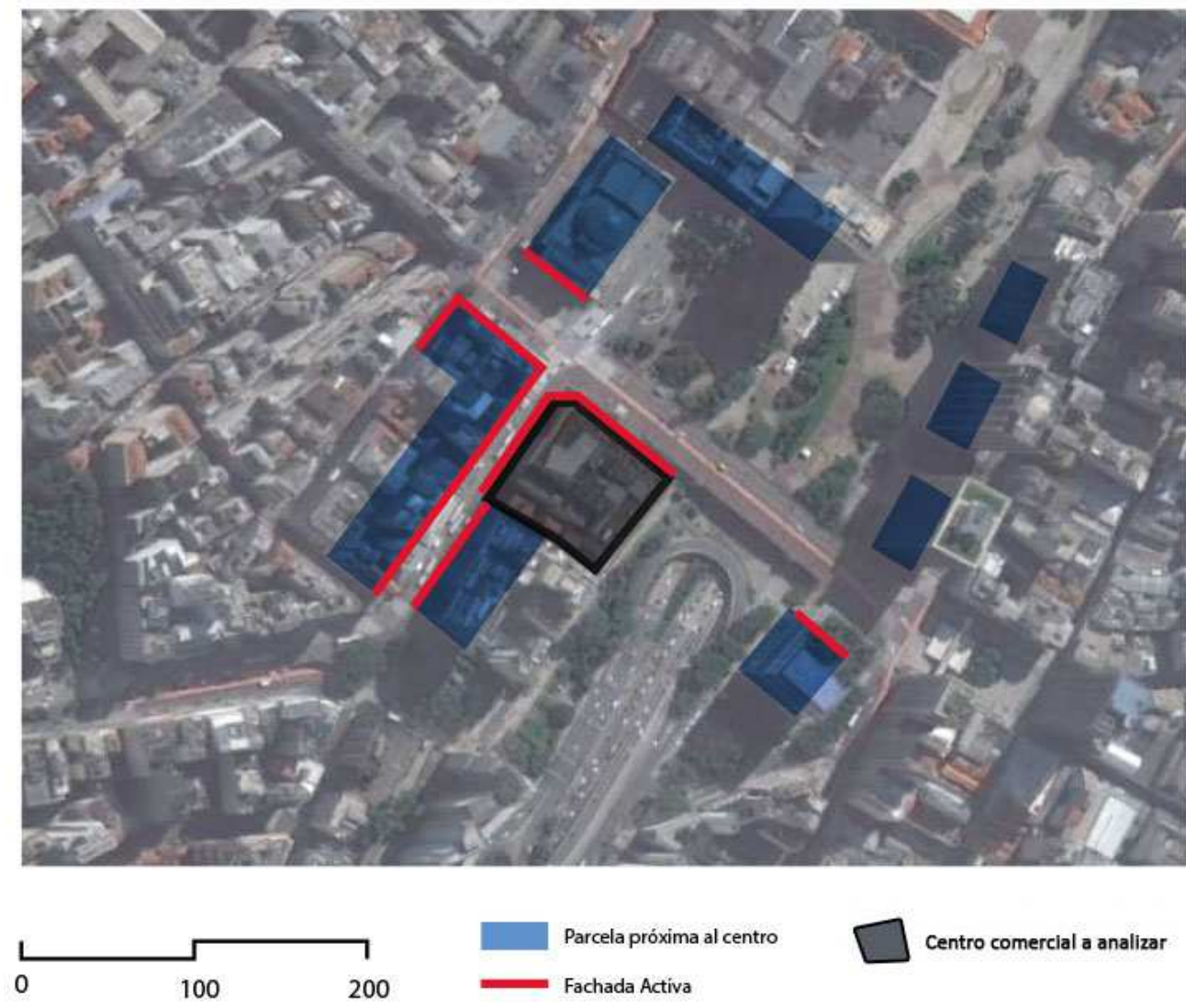

Figura 5.1.8: Análisis de parcelas próximas al centro. Fuente: Elaboración propia a partir de datos de Google. 
2B: SUPERFICIE TOTAL EDIFICADA EN ÁREA PRÓXIMA: Para el conteo de la superficie total estimada de las manzanas próximas al centro, se midió sobre un parcelario la superficie en planta de las mismas, que es de $29.452 \mathrm{~m}^{2}$, la cual fue multiplicada por el número de plantas medio de los edificios de susodichas manzanas, que para el caso de Shopping Light, se estableció en 15 plantas, en base a visitas realizadas al lugar y a vistas de fotografías. De este modo, la superficie construida de las manzanas próximas al centro es de $441.780 \mathrm{~m}^{2}$.

2C: USOS EN ÁREA PRÓXIMA: Aunque no es posible obtener datos concretos acerca de las superficies de uso en las manzanas contiguas al centro comercial, en base a conteos estimativos y visitas para la presente tesis se dedujo que los edificios próximos poseen una configuración de usos en la que predominan los edificios dotacionales o de oficinas, frente a los usos residenciales. De este modo, para este análisis se establecieron los siguientes porcentajes:

Uso residencial: $30 \%$. Uso productivo: $60 \%$. Uso comercial: $10 \%$.

Quedando estas superficies a partir de la multiplicación de los porcentajes establecidos anteriormente por el área total construida de las manzanas $\left(441.780 \mathrm{~m}^{2}\right)$ del apartado 2B:

Uso residencial: $132534 \mathrm{~m}^{2}$. Uso productivo: $265068 \mathrm{~m}^{2}$. Uso comercial: $44178 \mathrm{~m}^{2}$.

2D: FACHADAS ACTIVAS EN ÁREA PRÓXIMA Para este análisis, las fachadas activas en manzanas próximas se marcaron sobre plano, y se midieron en metros lineales, este análisis se obtuvo a partir de visitas al área y análisis de fotos de la zona de Google Maps. Por otra parte se obtuvo de manera paralela la longitud de fachada total midiendo directamente sobre un parcelario, que se obtuvo de la Prefeitura de Sao Paulo y de la Universidad de Sao Paulo. La longitud de fachada activa es de $753 \mathrm{~m}$ siendo la longitud de fachada total de $1522 \mathrm{~m}$ incluyendo las fachadas activas. El porcentaje de fachadas activas para el área es del $49 \%$.

2E: TIEMPOS DE LLEGADA DESDE LOS PUNTOS EN ÁREA A CENTRO COMERCIAL MEDIANTE TRANSPORTE PÚBLICO: Para la estimación de los tiempos de llegada en transporte público, fueron considerados los recorridos establecidos en 1P, y se utilizó la base de datos de Google Maps para establecer los tiempos de llegada, en transporte público, considerándose dentro de los mismos para algunos casos el recorrido a pie, en caso de no haber transporte. (Figura 5.1.6)

En este análisis, varios de los recorridos en transporte público se han considerado como desplazamientos a pie, al ser una zona muy transitada, la frecuencia entre vehículos es muy elevada (tiempos de espera medios de 3-5 minutos) y hay carriles vacíos destinados a los autobuses. Aún así hay que considerar que los desplazamientos en transporte particular para este centro se han considerado de forma muy favorable, eliminándose los problemas de tráfico. No obstante, la realidad es que el centro de Sao Paulo es un área con unos problemas de tráfico muy críticos. los cuales pueden incrementar los tiempos de llegada en 10-15 minutos, si el medio de transporte utilizado es un coche particular.

2F: TIEMPOS DE LLEGADA DESDE LOS PUNTOS EN ÁREA A CENTRO COMERCIAL MEDIANTE TRANSPORTE PRIVADO: Para la estimación de los tiempos de llegada en transporte público, fueron considerados los recorridos establecidos en 1P, y se utilizó la base de datos de Google 
Maps para establecer los tiempos de llegada, debemos de considerar, que al no existir aparcamiento en el centro comercial, se consideró para el desplazamiento un tiempo adicional de 15 minutos, que hace referencia a las esperas en aparcar, más el desplazamiento desde el aparcamiento al centro. De este modo, los tiempos establecidos para los medios de transporte son los siguientes para cada recorrido (Figura 5.1.6).

\section{FASE 3: ANÁLISIS DEL EDIFICIO DEL CENTRO COMERCIAL.}

Una vez analizado el entorno urbano en sus diferentes escalas, cuantificándose de cara al cuestionario de rehabilitación todas las facetas del mismo, a la par que las relaciones urbanas; el último campo de análisis es el estudio concreto de lo que es el edificio del centro comercial Shopping Light. De este modo a partir de los datos de los que se pudieron disponer del centro comercial, van a cuantificarse los rasgos del edificio de Shopping Light en relación a las facetas de usos, sostenibilidad y comportamiento bioclimático. Serán de importancia el conteo de superficies en base a la faceta a analizar, las simulaciones y la comparativa de las características formales para dar los datos necesarios para el cuestionario de rehabilitación.

3A: DELIMITACIÓN DE ÁREAS EN FUNCIÓN DE LA RECUPERACIÓN DE AGUAS: Sobre la planta de cubiertas del centro comercial, se delimitaron las áreas tanto permeables como impermeables del centro, de acuerdo a los estipulado en la metodología (apartado 3A del capítulo 3.8). Shopping Light, no posee superficie permeable alguna que ayude a regenerar el terreno o reducir el consumo de aguas.

3B: USOS DENTRO DEL EDIFICIO DEL CENTRO: Para los usos, se consideraron los diferentes locales dentro del centro comercial, buscándose los metros cuadrados de espacio productivo, y las dotaciones asistenciales dentro del mismo. Para el caso de Shopping Light, se localizó una instalación asistencial, que es la oficina de hacienda (Receita Federal), que se contó como aproximadamente $\mathbf{4 0 0}$ metros de superficie productiva, al desconocerse su superficie real. Con esto, pudieron averiguarse los porcentajes de superficies para el centro, dividiendo los correspondientes metros cuadrados entre la superficie total del centro, quedando los porcentajes divididos de la siguiente manera:

Superficie comercial $97,18 \%$

Superficie residencial $0 \%$

Superficie Productiva no comercial 2,82\%

3C: DELIMITACIÓN DE ÁREAS VERDES EN CENTRO COMERCIAL. La única área verde presente en el centro comercial Shopping Light, es la hilera de jardineras que hay en la terraza. Considerando éstas hileras cómo área verde, ésta no llega a los 30 metros cuadrados, de aproximadamente $4899 \mathrm{~m}^{2}$ de superficie de cubierta que se computaron como la superficie en planta del edificio total (C3). De modo que esta superficie es despreciable a efectos de análisis de zonas verdes y asimilación de dióxido de carbono.

3D: ABSORCIÓN DE LAS ÁREAS VERDES EN CENTRO COMERCIAL. Los 30 metros cuadrados de jardinera asimilan a lo sumo una tonelada de dióxido de carbono anual, (considerando los 
datos de absorción del capítulo 3.6) dato despreciable frente a la huella de carbono anual del centro (4715 T Co2 anuales) y el área urbana (70830 T Co2 anuales).

3E: ANÁLISIS BIOCLIMÁTICO DEL CENTRO COMERCIAL RESPECTO A CLIMA, DIAGRAMA DE GIVONI.

El Diagrama de Givoni para Sao Paulo es el siguiente (Figura 5.1.9), estos datos climáticos fueron obtenidos del programa Climaticus del LABAUT de la Universidad de Sao Paulo, y dispuestos en un diagrama de Givoni.

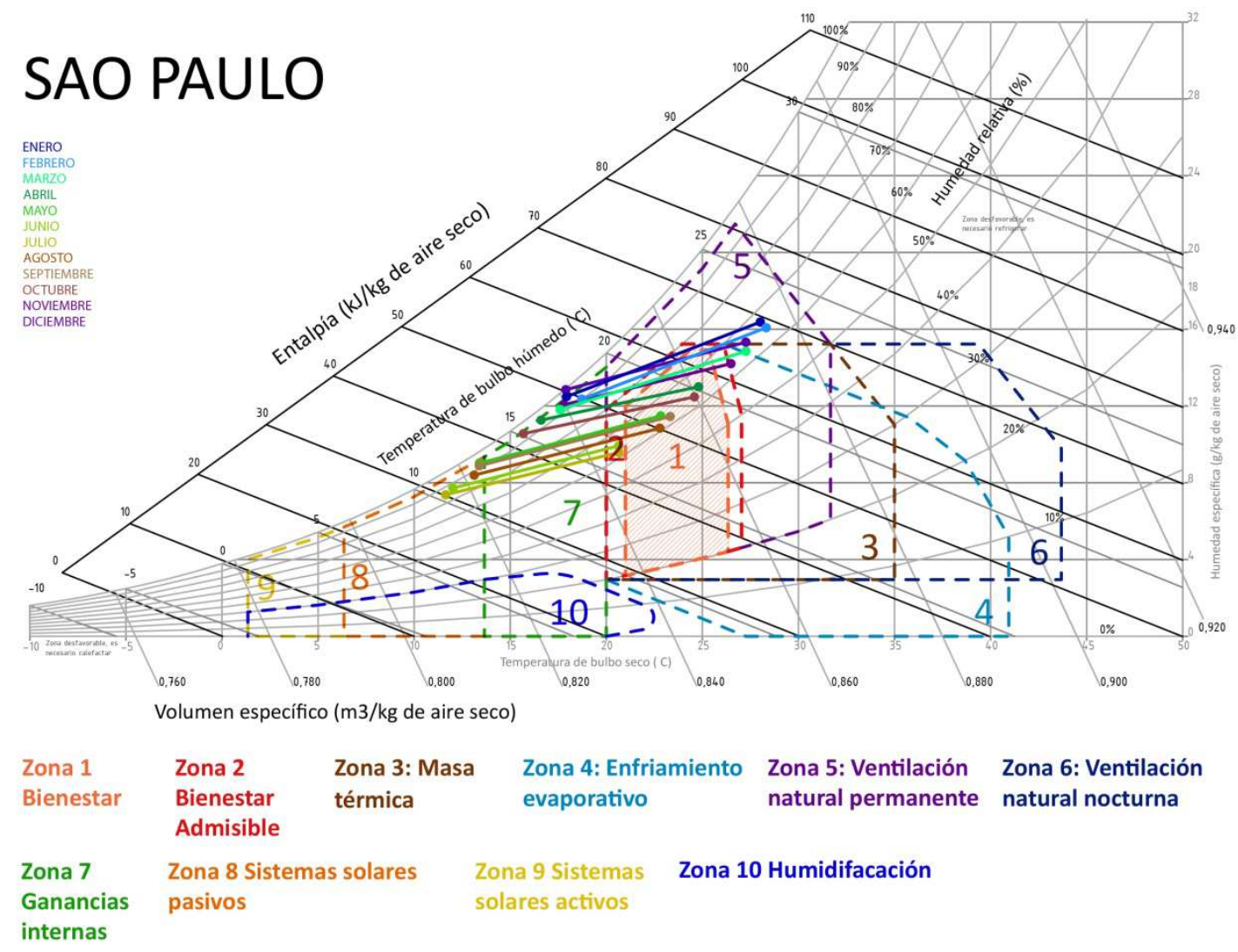

Figura 5.1.9: Diagrama de Givoni de Sao Paulo. Fuente: Elaboración propia a partir de datos de Givoni, Climaticus, LABAUT FAU USP.

A primera vista, el clima de Sao Paulo, tiene una gran porción de horas dentro de la zona de confort, y durante la mayoría de las horas que están fuera de esta área, se podría lograr la temperatura de confort mediante el uso de las cargas caloríficas internas (maquinaria o personas). Respecto a las condiciones extremas, cualquier edificio de Sao Paulo, de acuerdo al diagrama, necesitaría durante los meses más fríos sistemas solares pasivos para lograr la temperatura de confort durante las horas más frías. Siendo necesario en los meses más cálidos que el edificio posea ventilación natural permanente. Los medios de aclimatación mecánicos no son necesarios ni para refrigeración ni para calefacción. No obstante se debe de considerar que las horas más frías corresponden a un fragmento del día en el que el centro se encuentra cerrado (Primeras horas de madrugada), siendo realmente problemáticas las horas cálidas, ya que se corresponden a unas horas en las que el centro tiene mucha ocupación (primeras horas de la tarde). 
Por consiguiente, para lograr un acondicionamiento bioclimático del centro de Shopping Light, se precisaría del uso de cargas internas, además de garantizar la ventilación en todo el centro en las horas más cálidas, evitando las ganancias de calor. Sería también beneficioso para el centro, la consideración de medidas pasivas adaptadas a las condiciones solares de las primeras horas de luz.

El centro comercial Shopping Light, posee una envolvente de material masivo de gran densidad (Piedra y hormigón en masa) que le da al centro la capacidad de aclimatarse por masa térmica, y puede valerse de las cargas internas para acondicionarse en el caso de frío, debido al espacio interior relativamente pequeño. Además el centro posee patios que podrían garantizar el flujo de aire interno para ayudar en la ventilación. Sin embargo como contraste a esto, el centro comercial se encuentra completamente cerrado, sin que se considere la ventilación natural, y para calentar, ventilar o refrigerar el espacio interior, se usan sistemas mecanizados. estos sistemas también están pensados para controlar la humedad.

Respecto a la humedad, el clima de Sao Paulo, posee valores muy elevados, superando a veces los valores establecidos para las estrategias de proyecto. No obstante, el tiempo diario en el cual esto ocurre es corto, pudiéndose controlar fácilmente la humedad con las estrategias de proyecto pasivas relacionadas con la ventilación, y sistemas mecanizados de deshumidificación de poca potencia.

\section{F: CALIFICACIÓN ENERGÉTICA DEL CENTRO COMERCIAL.}

Al no haber datos acerca del consumo primario de energía o las emisiones generadas por el centro Shopping Light, se tuvo que realizar una estimación con el programa CE3X de las volumetrías, fachadas y huecos, de lo más relevante del edificio del centro comercial, considerando el clima de Santa Cruz de Tenerife, que en temperaturas es similar al de Sao Paulo, (1-2o más alto el de Santa Cruz) (Figura 5.1.10). Se readaptarán las orientaciones de las fachadas a los condicionantes del programa (las fachadas norte pasaron a considerarse como fachadas sur), y de cara al análisis térmico se consideró para cerramientos un muro masivo de piedra y hormigón sin aislante, para las cubiertas una cámara caliente sin aislante, y para el suelo, un forjado sanitario, habiendo muros en contacto con el terreno. Las ventanas fueron consideradas de acero sin rotura de puente térmico con vidrio sencillo. A efectos de instalaciones, no hay datos acerca de las mismas, de modo que para el análisis se consideraron sistemas de aire acondicionado, ventilación forzada y agua caliente por bomba de calor, los tres con un rendimiento aproximado del $250 \%$. 


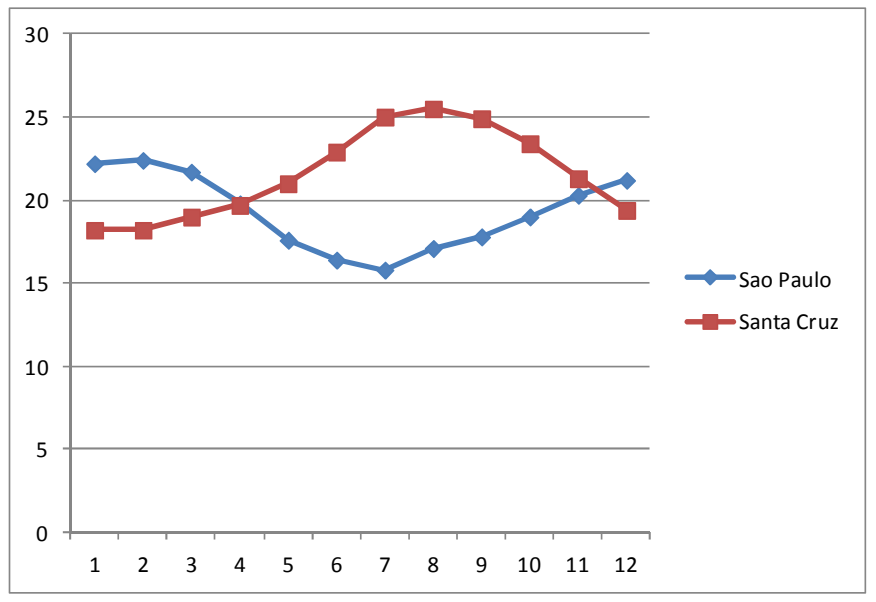

Figura 5.1.10: Comparativa de temperaturas entre Sao Paulo y Santa Cruz de Tenerife. Fuente: Elaboración propia a partir de datos del INM, LABAUT FAU USP

De este modo Shopping Light en el análisis con CE3X, obtuvo estas calificaciones, que aunque probablemente no sean las correspondientes en la realidad, sirvieron para estimar los consumos energéticos y de emisiones de Shopping Light..

Consumo de energía: $450 \mathrm{Kwh} / \mathrm{m}^{2}$ año. (C)

Emisiones anuales: $0,131 \mathrm{~T} / \mathrm{m}^{2}$ año. (C)

\section{G: USO DE FUENTES DE ENERGÍA LIMPIAS.}

En base a análisis visuales y visitas, se comprobó que el centro Shopping Light no posee sistemas de generación de energías limpias en el edificio. No obstante, es importante considerar el hecho de que la ciudad de Sao Paulo suple aproximadamente el $90 \%$ de su demanda energética con energías renovables ${ }^{48}$. según un análisis de la Agencia Internacional de Energías Renovables. No obstante, para el posterior estudio en el cuestionario, esto se considerará como parcialmente positivo, ya que lo que se busca es que el centro comercial tenga el menor impacto energético posible, y pueda generar su propia energía.

3H: FORMA DE LA EDIFICACIÓN: El centro comercial Shopping Light, es un volumen ortogonal con cierta fragmentación de cara al lindero sur, que es principalmente una medianería. Aproximadamente la relación entre el lado mayor y el menor es de 1,2, siendo la orientación de la fachada principal unos 40 este, respecto de la orientación norte, que es el azimut cero para el caso del hemisferio sur. El centro a su vez cuenta con una fachada de materiales de alta masa y densidad con relativamente pocas aperturas, con un espesor estimado de $40-50 \mathrm{~cm}$, y la mayoría de los huecos están retranqueados aproximadamente un metro respecto del lindero. El volumen del edificio es compacto y cerrado, y aunque hay patios interiores, estos están cerrados. (Figura 5.1.11)

\footnotetext{
${ }^{48}$ ICLEI- International Renewable Energy Agency, (2012). Renewable Energy Policy in Cities: Selected Case Studies, Sao Paulo.
} 


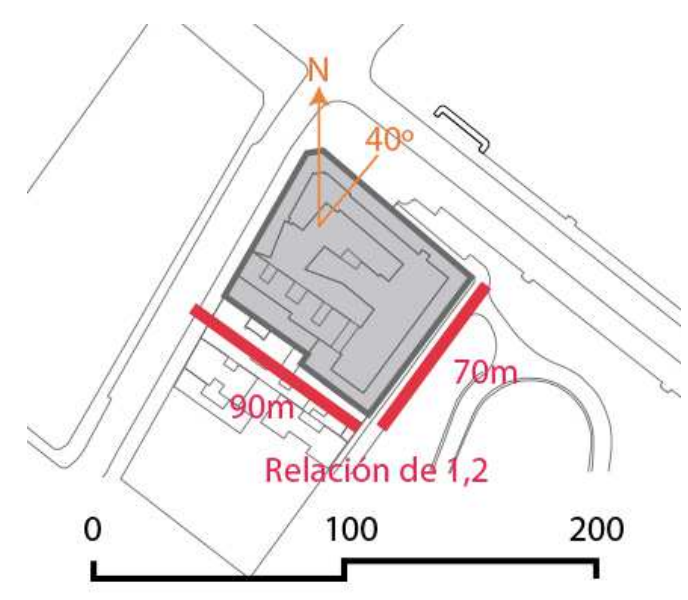

Figura 5.1.11: Análisis forma edificación Shopping Light. Fuente: Elaboración propia

31: ESPACIOS CON LUZ NATURAL Para medir esta superficie se consideraron de manera aproximada los espacios iluminados del centro comercial Shopping Light, que generalmente corresponden a las estancias cercanas a las fachadas $\left(1000 \mathrm{~m}^{2} \sim 7 \%\right)$, y en menor medida los patios interiores cuyos alrededores fueron considerados como espacios que cuentan con luz natural al $50 \%\left(6000 \mathrm{~m}^{2} / 2=3000 \mathrm{~m}^{2}\right)$. Estas últimas superficies fueron computadas a la mitad para establecer el porcentaje, ya que van a necesitar, aunque en menor medida, de sistemas eléctricos para iluminar correctamente el espacio. De este modo, la superficie con luz natural total es de aproximadamente de $4000 \mathrm{~m}^{2}$. Que comparado con los $36.000 \mathrm{~m}^{2}$ de superficie construida total del centro, en Shopping Light el espacio que cuenta con luz natural es aproximadamente el $11,1 \%$ de su superficie.

3J: PAVIMENTOS Y CUBIERTAS EN RELACIÓN A LA INCIDENCIA DE LA IRRADIACIÓN SOLAR. Sobre la planta de cubiertas se midieron las superficies de colores claros, en base a una medición directa sobre una ortofoto de la planta del centro comercial. Shopping Light tiene aproximadamente un $8 \%$ de su superficie de cubierta repelente de cara a la irradiación solar debido al tratamiento con colores claros. siendo el $92 \%$ restante, absorbente de cara a la irradiación solar.

\section{FASE 4: CUESTIONARIOS DE LA METODOLOGÍA, APLICACIÓN DE INDICADORES Y BAREMOS.}

Una vez fueron hallados los datos cuantitativos, de cara a la fase final de la aplicación de la metodología, y con el objetivo de establecer las medida de rehabilitación más adecuadas en el gráfico de la rosa de rehabilitación sostenible (3.3.2) los datos hallados fueron comparados en base a los umbrales y baremos establecidos en el cuestionario de la metodología (3.10).

\section{A.- REHABILITACIÓN ECOEFICIENTE.}

A1.- Cuestionario referenciado a rehabilitación hacia instalaciones poco emisivas.

Cuestión A1.1.- ¿El centro cuenta con instalaciones que no son necesarias de acuerdo a lo estipulado en el diagrama de Givoni?: Aunque no hay datos objetivos acerca de las instalaciones de Shopping Light, de visitas al centro se dedujo que se trata de un espacio 
completamente cerrado y aclimatado, que posee instalaciones mecánicas de refrigeración, las cuales Mirando el diagrama de Givoni para Sao Paulo (Figura 5.1.8), se ve que no son necesarias en principio para el clima de Sao Paulo, a este centro le corresponde una nota de +0 en esta cuestión.

Cuestión A1.2.- ¿Las instalaciones del centro generan unas emisiones de dióxido de carbono superiores a la media?. Aunque esta cuestión para la presente tesis no puede ser constatada con una respuesta objetiva, en el estudio energético estimativo realizado con CE3X (apartado 3F), Shopping Light ha obtenido en la calificación energética a efectos de emisiones relacionadas con las instalaciones una nota de $\mathrm{C}$, eso corresponde a una nota de +3

Cuestión A1.3.- ¿Las instalaciones del centro se encuentran en un estado de obsolescencia?. Respecto esta cuestión, el autor desconoce el estado de las instalaciones del centro. No obstante, para este análisis, éstas se estimaron con un estado de obsolescencia eligiendo el escenario más desfavorable a efectos de eficiencia energética, con lo que se puntuó esta cuestión con una nota de +0 .

Cuestión A1.4.- ¿Las instalaciones del centro tienen un consumo energético superior a la media?. En el estudio energético estimativo con CE3X, Shopping Light ha obtenido en la calificación energética de consumo de energía primaria una nota de $C$, que es un consumo energético medio tirando a bajo, eso corresponde a una nota de +3

\section{EN RELACIÓN A INSTALACIONES POCO EMISIVAS, SHOPPING LIGHT HA OBTENIDO UNA PUNTUACIÓN DE 6 (10).}

A2.- Cuestionario referenciado a inserción de medidas activas.

Cuestión A2.1.- ¿Qué porcentaje de las calorías necesarias para lograr la temperatura de confort se logra mediante sistemas activos?. El centro de Shopping Light, no posee medidas solares activas, o de cualquier tipo de energía renovable para lograr la temperatura de confort. No obstante, analizando el diagrama de Givoni para Sao Paulo (Figura 5.1.8) aunque cierto es que pueden ayudar en la reducción del consumo energético, éstos sistemas no son necesarios. Esta cuestión puntúa con +2 .

Cuestión A2.2.- ¿Qué porcentaje de la demanda energética se logra a partir de fuentes de energía renovable?: A pesar de que la ciudad de Sao Paulo, suple el $90 \%$ de su demanda de energía con energías renovables, el mérito medioambiental relacionado con esta cuestión reside en el hecho de que el centro posea este tipo de dispositivos en la medida de lo posible, para contribuir en la reducción del gasto energético, y lograr una menor dependencia en fuentes externas de energía. Esta cuestión fue puntuada como parcialmente positiva, con una puntuación de +3 .

Cuestión A2.3.- ¿El centro cuenta con las medidas y dispositivos necesarios para su aclimatación de acuerdo a lo estipulado en el diagrama de Givoni para sistemas solares activos?: Analizando el diagrama de Givoni de Sao Paulo (Figura 5.1.8), se puede considerar que el centro comercial Shopping Light, no necesita sistemas solares activos para una correcta aclimatación, no obstante, estos sistemas se van a hacer necesarios para deshumidificar o 
mitigar los efectos de las cargas internas derivadas del funcionamiento de la maquinaria. Esta cuestión puntúa con +1 .

EN RELACIÓN A MEDIDAS ACTIVAS, SHOPPING LIGHT HA OBTENIDO UNA PUNTUACIÓN DE 6 (10).

A3.- Cuestionario referenciado a inserción de medidas Pasivas.

A3.1.- ¿El centro comercial tiene una forma adecuada en volumen a las condiciones climáticas?: Shopping Light se encuentra en una zona climática cálida húmeda de acuerdo a la calificación de Olgyay, en el análisis anteriormente realizado en el punto 3l, Shopping Light no cumple los requisitos de proporción de planta, y aunque el retranqueo de los huecos evita el asoleo excesivo, el edificio es un volumen compacto, nada fragmentado, y las fachadas no están protegidas de la irradiación solar proveniente del norte. Shopping Light tiene su fachada principal orientada 400 al este, lejos de los $15 \circ$ máximos requeridos por Olgyay. De este modo, Shopping Light cumple de manera parcial los requisitos de forma de Olgyay, le corresponde una puntuación de +1 .

A3.2.- $\dot{\text { El }}$ estado de los cerramientos responde de manera correcta a las exigencias del clima en el que se asienta?: La calificación energética de Shopping Light a efectos de consumo global de energía es de $C$ (favorable a efectos de consumo), esto significa que los cerramientos responden de manera correcta a las inclemencias del clima de Sao Paulo. A este centro en esta cuestión le corresponde una puntuación de +3 .

A3.3.- ¿Qué porcentaje de los espacios del centro cuentan con iluminación natural?: En base al conteo de superficies total y parcial respecto a la iluminación realizado en el apartado $3 \mathrm{H}$ de este capítulo, Shopping Light posee un total del $28 \%$ del espacio interior iluminado con luz natural. Le corresponde de este modo una puntuación de +1 .

A3.4.- Los espacios del centro, están adaptados a lo estipulado por el Diagrama de Givoni de su respectivo clima?: Shopping Light, puede valerse de la ventilación natural permanente para aclimatar, al poseer patios y numerosas aperturas, no obstante el espacio interior del centro no se encuentra adaptado al uso de estos dispositivos pasivos de aclimatación, ya que tanto los lucernarios de los patios, cómo las ventanas que dan al espacio exterior son fijas e impracticables. Sin embargo, para calefactar, el centro puede utilizar las cargas internas provenientes de las instalaciones, la iluminación o las personas que lo transitan. Como medida adicional, también puede aprovecharse para aclimatar, la inercia térmica que poseen los muros masivos del edificio. De este modo, se cumple de manera parcial lo requerido por Givoni para el edificio de centro. A Shopping Light le corresponde una calificación de +1

EN RELACIÓN A MEDIDAS PASIVAS, SHOPPING LIGHT HA OBTENIDO UNA PUNTUACIÓN DE 6 (10).

4B.- REHABILITACIÓN MEDIOAMBIENTAL.

B1.- Cuestionario referenciado a rehabilitación mediante zonas verdes. 
Cuestión B1.1.- ¿En el área urbana hay suficiente zona verde en el área en relación a sus habitantes?: El área urbana de Shopping Light posee aproximadamente $35118 \mathrm{~m}^{2}$ de superficie verde en planta, que entre los 18000 habitantes que la habitan, hacen un ratio de $1,9 \mathrm{~m}^{2}$ de superficie verde por habitante, superficie que es a todas luces escasa e insuficiente para los mínimos establecidos en esta tesis $\left(10 \mathrm{~m}^{2}\right.$ por habitante). Le corresponde una puntuación de +0 .

Cuestión B1.2.- ¿Las zonas verdes dentro del centro comercial pueden dar lugar a una área verde de uso cotidiano?: Shopping Light no posee superficie verde alguna en su parcela o unidad catastral, de manera que le corresponde una puntuación de +0 a esta cuestión.

Cuestión B1.3.- ¿ ¿a vegetación en el área (incluyendo el edificio del centro), en que porcentaje es capaz de asimilar las emisiones de la misma área urbana?: Sumando las capacidades de asimilación de las superficies de vegetación establecidas en el apartado $1 \mathrm{R}$ del presente caso de estudio, tenemos una capacidad de asimilación de 7421,71 Toneladas de dióxido de carbono anuales, esto es aproximadamente un $10 \%$ de la huella de carbono del área, (70830 Toneladas de dióxido de carbono anuales). Esta cuestión puntuará con +1 .

Cuestión B1.4.- ¿La vegetación en el centro comercial y su parcela, en que porcentaje es capaz de asimilar las emisiones del centro comercial?: Las jardineras del centro comercial, asimilan a lo sumo una tonelada de dióxido de carbono anual, que es menos de un $0,5 \%$ de la huella de carbono anual del centro (4715 T Co2 anuales), a esta cuestión le corresponde una puntuación de +0

Cuestión B1.5.- ¿La distancia media entre espacios verdes dentro del área es inferior a los 400 metros?: Aunque hay escasos espacios verdes en al área de Shopping Light, del análisis sobre plano, la distancia que se midió entre los mismos está a una media de 300 metros unos de otros, a esta cuestión le corresponde una puntuación de +1 .

EN RELACIÓN A ZONAS VERDES, SHOPPING LIGHT HA OBTENIDO UNA PUNTUACIÓN DE 2 (10).

B2.- Cuestionario referenciado a inserción de superficie asimiladora de agua.

Cuestión B2.1.- ¿El clima en el que está el centro corresponde a un clima árido o semiárido?: El clima de Sao Paulo, con unas precipitaciones medias anuales de $1441,1 \mathrm{~mm}$, y una temperatura media anual de 19,3ㅜ, y de acuerdo a la aplicación de la fórmula de Martonne (Pma/(Tma+10)) $(1411,1 / 19,3+10)$, sale un índice de Martonne de 49,18. Éste corresponde a una zona húmeda a efectos de clima. A Shopping Light le corresponde una calificación de +1 a esta cuestión, ya que las precipitaciones no van a escasear de manera general, a pesar de que pudieran producirse sequías.

Cuestión B2.2.- ¿En qué porcentaje, la superficie absorbente de agua, en el área urbana, es en relación a la impermeable?: En esta cuestión, se consideró como superficie permeable las áreas verdes presentes en la zona $\left(35118 \mathrm{~m}^{2}\right)$, que respecto a la superficie urbana total del área a analizar, corresponden aproximadamente a un 2,6\% de los $679.822 \mathrm{~m}^{2}$ totales del área urbana. Al ser esta superficie escasa para el baremo de la tesis, esta cuestión puntúa con +0 . 
Cuestión B2.3.- ¿El centro comercial posee sistemas para el aprovechamiento del agua?: El centro comercial Shopping Light, en su edificio no posee sistema alguno para el aprovechamiento o el almacenamiento del agua, le corresponde una puntuación de +0 .

Cuestión B2.4- ¿El consumo de agua del centro es en litros por visita?: a pesar de que no hay datos del centro relativos a este apartado ya que no pudieron ser obtenidos, al centro comercial Shopping Light, se le estimó un consumo aproximado de agua de 30 litros por visita, en un baremo medio. A esto le corresponde a una puntuación de +1 .

\section{EN RELACIÓN A SUPERFICIE ASIMILADORA DE AGUA, SHOPPING LIGHT HA OBTENIDO UNA PUNTUACIÓN DE 2 (10).}

B3.- Cuestionario referenciado a tratamiento de isla de calor.

Cuestión B3.1.- ¿ ¿l clima en el que está el centro comercial tiene una temperatura media más o menos elevada?. El clima de Sao Paulo tiene una temperatura media anual de 19,3으, esto, a efectos de la presente tesis significa que es un clima cálido propenso a altas temperaturas, lo que resulta desfavorable de cara al tratamiento de la isla de calor. Esta pregunta puntúa con $+0$

Cuestión B3.2.- ¿En el clima en el que está ubicado en centro hay olas de calor frecuentes o en intervalo temporal menor?. De cara al análisis de noticias acerca del tiempo, se dedujo que el clima de Sao Paulo, aunque puede tener olas de calor, estas no suelen ser muy frecuentes, esta cuestión puntúa con un +1 .

Cuestión B3.3.- ¿El centro está en un área en el cual la diferencia de temperatura respecto a la normal es de?. Analizando la isla de calor de Sao Paulo (Figura 5.1.12), nos encontramos con el hecho de que Shopping Light se encuentra en un área con 4을 más de media de temperatura respecto de la temperatura natural, esto supone una zona con severos problemas de isla de calor que van a agravar el uso de la refrigeración automatizada. Esta cuestión puntúa con un +0 .

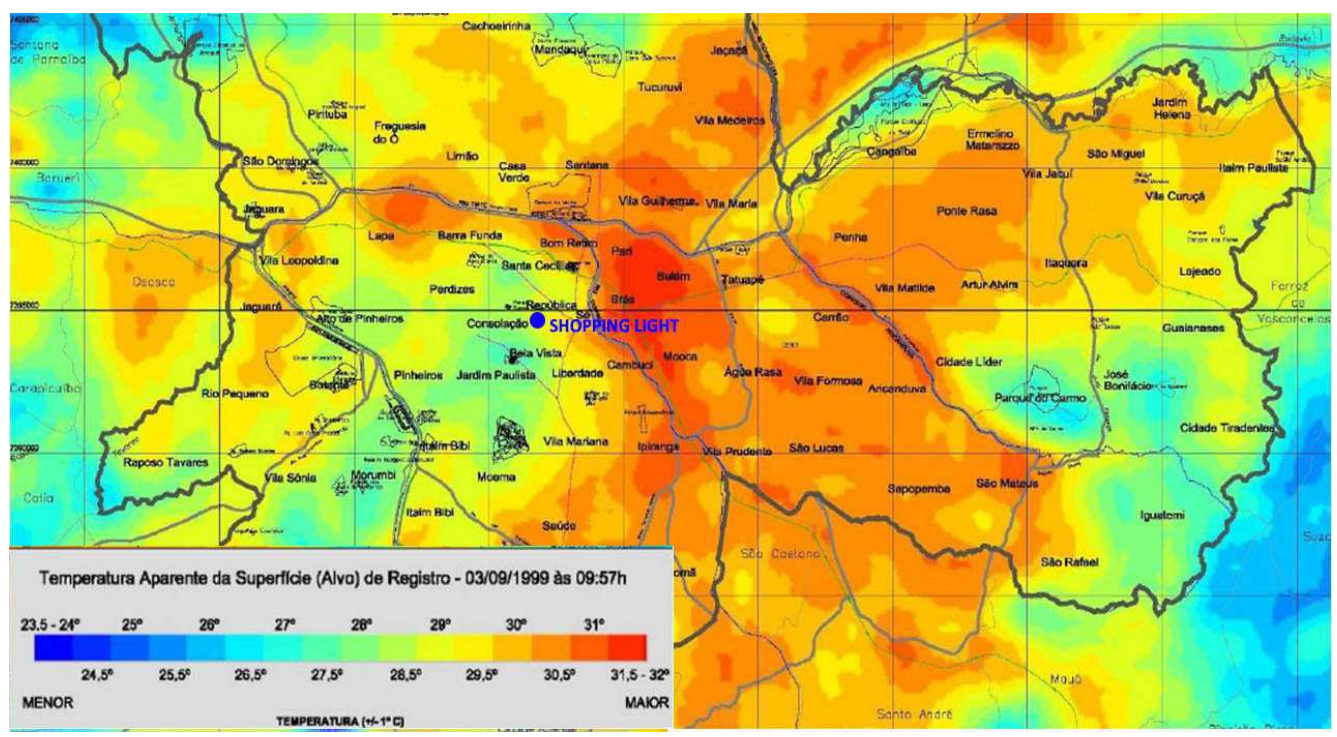

Figura 5.1.12.- Isla de calor para Shopping Light. Fuente: Atlas Ambiental de São Paulo - Prefeitura de São Paulo 2002. 
Cuestión B3.4.- ¿La suma de superficies que contribuyen a la isla de calor en la parcela y el edificio del centro es superior a un porcentaje de la superficie total?. De acuerdo al análisis de superficies a efectos de absorción de calor realizado en el apartado $3 \mathrm{~J}$ de este caso de estudio, la superficie absorbente de irradiación de Shopping Light es del $92 \%$, lo que va a suponer que el centro va a contribuir de manera crítica al efecto de isla de calor. A esta cuestión, le corresponde una puntuación de +0 .

EN RELACIÓN A TRATAMIENTO DE ISLA DE CALOR, SHOPPING LIGHT HA OBTENIDO UNA PUNTUACIÓN DE 1 (10).

\section{C.- REHABILITACIÓN POR USOS.}

C1.- Cuestionario referenciado a inserción de uso residencial.

Cuestión C1.1.- ¿El centro comercial posee usos residenciales u hoteleros dentro de su unidad catastral?. Shopping Light no posee dentro de su parcela usos hoteleros o residenciales, esta cuestión puntúa con +0 .

Cuestión C1.2.- ¿Las parcelas próximas al centro comercial posen usos residenciales u hoteleros?: El uso residencial en las parcelas colindantes al centro comercial fue estimado en un $30 \%$ de la superficie construida total, debido a la presencia de una gran cantidad de edificios terciarios o administrativos. Lo que le corresponde una puntuación de +2 .

Cuestión C1.3.- ¿Dentro del área de influencia del centro comercial, que porcentaje de la superficie de uso total es de tipo residencial?: en el área de influencia de Shopping Light, se estableció aproximadamente un $40 \%$ de uso residencial, que se encuadra en una zona compleja a efectos de usos en el centro de Sao Paulo, lo que le corresponde una puntuación de $+3$

EN RELACIÓN A USO RESIDENCIAL, SHOPPING LIGHT HA OBTENIDO UNA PUNTUACIÓN DE 5 (10).

C2.- Cuestionario referenciado a inserción de usos productivos, y terciarios no comerciales.

Cuestión C2.1.- ¿El centro comercial posee usos productivos no comerciales dentro de su unidad catastral?: Shopping Light posee las oficinas de la Receita Federal, que es un espacio terciario productivo de tipo administrativo abierto al público, esta cuestión puntúa con +1 .

Cuestión C2.2.- ¿Las parcelas próximas al centro comercial posen usos productivos no comerciales?: Las parcelas próximas al centro comercial, poseen una amplia oferta de instalaciones terciarias de oficinas y administrativas, que se computaron en aproximadamente un $60 \%$ de la superficie total, al tratarse de un centro administrativo de Sao Paulo. Esta cuestión puntúa con un +3 .

Cuestión C2.3.- ¿Dentro del área de influencia del centro comercial, que porcentaje de la superficie de uso total es de tipo productivo no comercial?: En el área urbana de influencia del centro comercial Shopping Light, se estimó un $30 \%$ de la superficie edificada total, como instalaciones terciarias no comerciales, éstas corresponden generalmente a los edificios de 
gran altura presentes en las inmediaciones del centro. A esta cuestión le corresponde una puntuación de +5 .

EN RELACIÓN A USO PRODUCTIVO, SHOPPING LIGHT HA OBTENIDO UNA PUNTUACIÓN DE 9 (10).

C3.- Cuestionario referenciado a inserción de instalaciones dotacionales y asistenciales.

Cuestión C3-1.- ¿El centro comercial posee usos dotacionales dentro de su unidad catastral?: El centro comercial Shopping Light, posee una oficina gubernamental de la Receita Federal. Al existir una dotación pública en el centro, se aumenta la complejidad de uso, lo que esta cuestión puntúa con un +1 .

Cuestión C3.2.- ¿Las parcelas próximas al centro comercial posen usos dotacionales?: En las inmediaciones del centro comercial Shopping Light hay varias instalaciones públicas concurridas de importancia para lo que es la ciudad de Sao Paulo. No obstante, éstas aunque no son de visita habitual (instalaciones institucionales principalmente) generan el movimiento de una gran cantidad de visitantes. Esta pregunta puntúa con un +4 .

Cuestión C3.3.- ¿A un kilómetro del centro comercial hay usos dotacionales?: En el área de dotaciones correspondiente a lo que es el centro comercial de Shopping Light $(1 \mathrm{~km}$ a la redonda), hay una gran cantidad de dotaciones de diversa capacidad y jerarquía, habiendo incluso más de una muy concurridas de primera jerarquía a escala territorial. Esta cuestión puntúa con +5 .

EN RELACIÓN A DOTACIONES, SHOPPING LIGHT HA OBTENIDO UNA PUNTUACIÓN DE 10 (10).

\section{D.- REHABILITACIÓN DE ENTORNO URBANO.}

C1.- Cuestionario referenciado a la inserción de medios de transporte eficientes.

Cuestión D1.1.- ¿El centro dispone en sus inmediaciones de alguna parada de transporte público?: El centro comercial Shopping Light, posee instalaciones de transporte público en las inmediaciones de sus parcelas, siendo algunas, estaciones de tránsito, finales de líneas confluyentes, o transbordos de gran importancia en la red de transporte de Sao Paulo. La puntuación que le corresponde a esta cuestión es de +1 .

Cuestión D1.2.- ¿¿El tiempo de llegada al centro mediante transporte público supera al tiempo de llegada en vehículo particular?, Comparando los datos obtenidos de los apartados $2 \mathrm{E}$ y $2 \mathrm{~F}$, (dividiendo el tiempo de llegada en transporte público, entre el tiempo de llegada en transporte privado o particular), se estableció que el tiempo de llegada en transporte público entre los recorridos, es de media 0,61 veces el tiempo de llegada en vehículo particular (Figura 5.1.13). Esta cuestión puntúa con +3 .

\begin{tabular}{|l|r|r|r|}
\hline Comparación tiempos de recorrido & Recorrido 1 & Recorrido 2 & Recorrido 3 \\
\hline Total tiempo desplazamiento t. público & 6 & 8 & 9 \\
\hline Total tiempo desplazamiento t. particular & 7 & 16 & 19 \\
\hline Relación entre tiempos desplazamiento & 0,857142857 & 0,5 & 0,473684211 \\
\hline Media tiempo desplazamiento & & & 0,610275689 \\
\hline
\end{tabular}


Figura 5.1.13: comparación entre tiempos de llegada. Fuente: Elaboración propia.

Cuestión D1.3.- ¿El área urbana del centro comercial está cubierta de forma adecuada por la infraestructura de transporte público?. Localizando las paradas de transporte público en el área de manera estimada, y trazando en todas ellas un radio de 200 metros, se pudo establecer que el área urbana de Shopping Light, está cubierta en un 96\% aproximadamente por la infraestructura de transporte público (Figura 5.1.7). Lo que la cuestión puntúa con un +2 .

Cuestión D1.4.- ¿Los usos en la zona están mezclados o zonificados?: De acuerdo al análisis de mezclas de usos realizado en $1 \mathrm{~K}$, en el área de Shopping Light, el índice Global de Mezcla de usos es de 1 (Zona de gran complejidad urbana), esto le corresponde una puntuación de +2 .

Cuestión D1.5.- ¿El centro comercial y el área urbana próxima al centro cuenta con instalaciones enfocadas en la movilidad sostenible?: De visitas al centro comercial se comprobó que el centro comercial Shopping Light no posee sistemas adaptados a la movilidad sostenible, al igual que el área próxima tampoco está adaptada a este tipo de sistemas de movilidad, esta cuestión obtiene una puntuación de +0.

EN RELACIÓN A TRANSPORTE EFICIENTE, SHOPPING LIGHT HA OBTENIDO UNA PUNTUACIÓN DE 8 (10).

C2.- Cuestionario referenciado a la rehabilitación por corrección de la densidad en área urbana.

Cuestión D2.1.- ¿La densidad de población en el área del centro está en el intervalo entre $\mathrm{h} / \mathrm{ha}$ ?, La densidad de población del área de Shopping Light es la del distrito República $(0,024$ $\mathrm{hab} / \mathrm{m}^{2}$ ), que corresponde a una densidad moderadamente elevada. Aunque a efectos de vitalidad urbana esto puede ser favorable, a esta cuestión le corresponde una puntuación de +3 , ya que hay en la zona problemas de congestión.

Cuestión D2.2.- ¿A efectos de densidad, el tejido mayoritario es favorable o desfavorable de cara a la sostenibilidad?. De acuerdo al análisis El índice global de densidad del área de Shopping Light es de 3, lo que es un entorno muy denso de acuerdo al apartado $1 \mathrm{~F}$ del capítulo 3.6. A esta cuestión le corresponde una puntuación de +2 , habiendo problemas de congestión.

Cuestión D2.3.- ¿La cantidad de espacio ocupado en el área está en el intervalo? El espacio ocupado en el área de Shopping Light, es de un 67\%, lo que corresponde a una puntuación de +3 .

EN RELACIÓN A DENSIDAD, SHOPPING LIGHT HA OBTENIDO UNA PUNTUACIÓN DE 8 (10).

C3.- Cuestionario referenciado a mejora de la seguridad y la paseabilidad en el área urbana.

Cuestión D3.1.- ¿En el área de influencia o en sus proximidades hay elementos negativos de cara a la seguridad o a la salubridad del área?: En el área cercana a Shopping Light, hay desniveles, pasos subterráneos y zonas marginales, que pueden ser peligrosos en las horas de escasa actividad debido a la falta de control del espacio urbano. Esta cuestión puntúa con +0.

Cuestión D3.2.- ¿El centro comercial se encuentra en una zona de puntos fríos de actividad durante el día?. El área de Shopping Light, debido a la gran cantidad de dotaciones con horario 
diurno, no tiene puntos fríos durante el día, siendo este área muy transitada. Esta cuestión puntúa con +1 .

Cuestión D3.3.- ¿El centro comercial se encuentra en una zona de puntos fríos durante la noche?, debido a los desniveles, y el cierre de los edificios dotaciones durante la noche que supone un decrecimiento de la actividad urbana, en la zona del centro comercial Shopping Light van a haber puntos fríos durante la noche, centrados en las áreas peatonales del valle de Anhangabau, esta cuestión puntúa con +0 .

Cuestión D3.4.- ¿El centro comercial se encuentra en una zona con áreas de difícil control visual o de contacto urbano?. El valle de Anhangabau, genera desniveles en el área de Shopping Light, los cuales son difíciles de controlar visualmente debido a su configuración en varios niveles, en el área hay además pasos subterráneos oscuros e intrincados. Esta cuestión puntúa con +0

Cuestión D3.5.- ¿ ¿La sensación de seguridad por parte de los ciudadanos de la zona es positiva o negativa?: En el centro de Sao Paulo, la sensación de inseguridad permanente está muy arraigada entre los ciudadanos. La puntuación a esta cuestión es de +0 .

Cuestión D3.6.- ¿La zona próxima al centro comercial tiene un porcentaje de fachadas activas?: En las manzanas próximas al centro comercial, de acuerdo a la medición sobre plano del apartado $2 \mathrm{D}$, hay un $49 \%$ de fachadas activas, lo que le corresponde una puntuación de +1 .

Cuestión D3.7.- ¿La distancia de la puerta del edificio del centro comercial al inmueble residencial cercano es superior a los 200 metros?: En base a medidas sobre plano, el inmueble residencial más cercano a Shopping Light, se encuentra a 80 metros, esta cuestión puntúa con +1 .

Cuestión D3.8.- ¿La cantidad de espacio libre en el área va a resultar desfavorable de cara a la paseabilidad?: El espacio libre en el área de Shopping light es de aproximadamente un 33\%, lo que supone que el área está muy ocupada por la edificación, y la distancia entre edificios no va a suponer un problema de cara a la complejidad y vitalidad urbana. Esta cuestión va a puntuar con un +1 .

Cuestión D3.9.- ¿ ¿Los usos en la zona están mezclados o zonificados? El índice global de mezcla de usos hallado en $1 \mathrm{~K}$ es de 1 , lo que supone un entorno muy complejo a efectos de usos. Esta cuestión puntúa con +1 .

EN RELACIÓN A PASEABILIDAD, SHOPPING LIGHT HA OBTENIDO UNA PUNTUACIÓN DE 5 (10).

\section{E.- CUESTIONARIO RELACIONADO CON LA ACTIVIDAD DEL CENTRO Y SUS CONSECUENCIAS URBANAS.}

Cuestión E1: ¿La actividad del centro comercial, va a penalizar o a favorecer la sostenibilidad del entorno urbano?: Shopping Light tiene un índice de atracción de 3, y la puntuación total en el cuestionario relacionado con el transporte eficiente es de 8 , de este modo, consultando la tabla del apartado 3.10, 4E. El efecto de la actividad corresponde a un incremento de +1 a la seguridad y paseabilidad (C3), quedando finalmente este cuestionario en una puntuación de 6. 
Esto se debe a que la actividad que va a generar el centro, va a favorecer la vitalidad urbana en la zona, sin llegar a producir congestión de tráfico debido a la fuerte presencia del transporte público en la zona.

\section{FASE FINAL: GRÁFICO DE LA ROSA DE REHABILITACIÓN SOSTENIBLE.}

Las puntuaciones obtenidas en el anterior cuestionario, fueron colocadas en el gráfico de la rosa de rehabilitación sostenible, obteniendo el siguiente resultado (Figura 5.1.14):

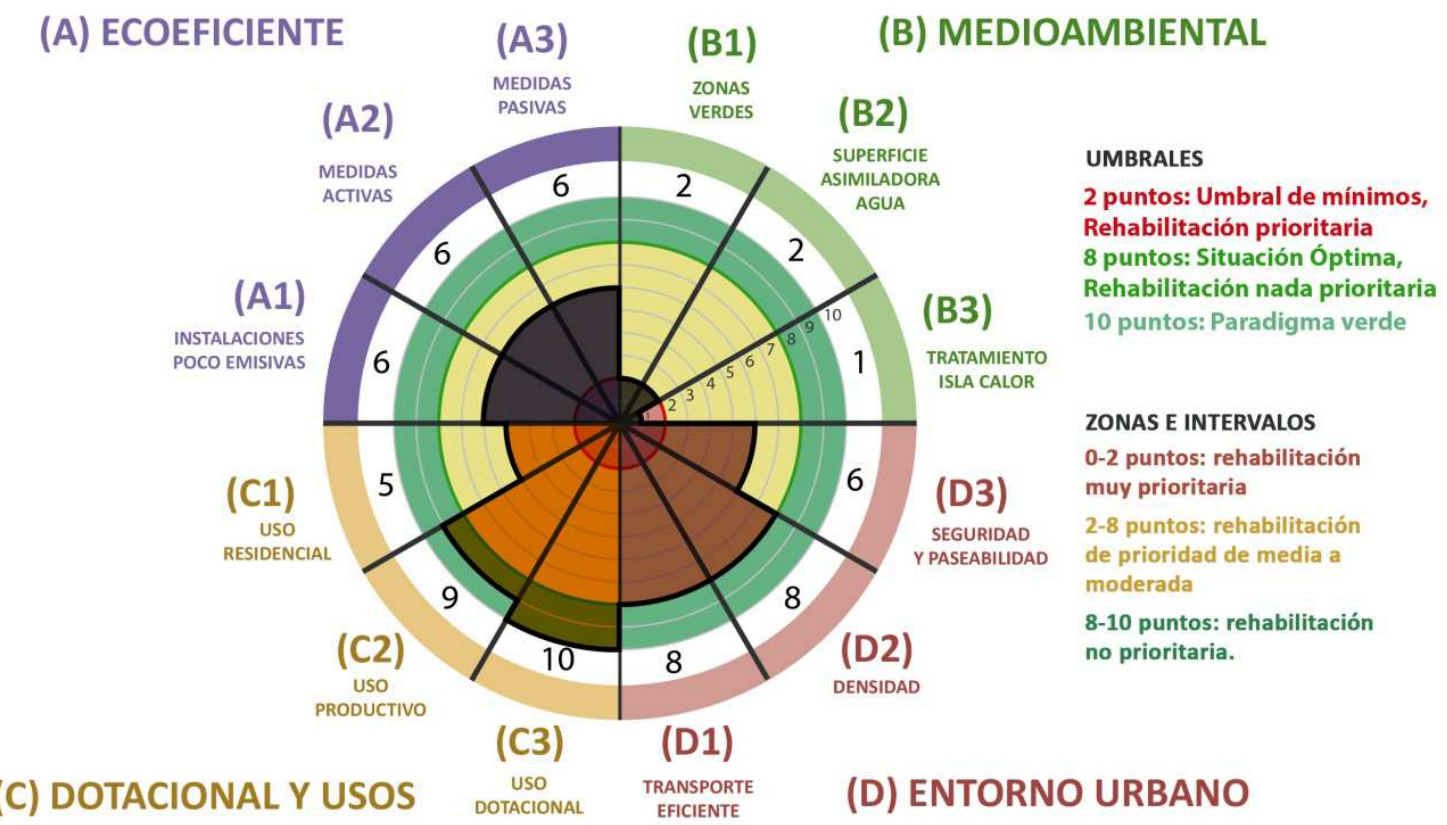

Figura 5.1.14: Gráfico de rosa de rehabilitación sostenible para Shopping Light. Fuente: Elaboración propia.

De este modo, de acuerdo al gráfico, Shopping Light es un caso de centro comercial que se ubica en un área urbana compleja y activa, en la cual el transporte público es bastante eficaz para la movilidad, y no resulta conveniente para acometer una rehabilitación, ni la densificación del entorno urbano, ni la inserción de usos dentro del centro comercial. El edificio del centro tiene un comportamiento bioclimático relativamente adecuado a las condiciones climáticas de Sao Paulo, no siendo necesarias las medidas pasivas para lograr la temperatura de confort. No obstante, este centro y su área urbana tienen unas serias carencias de cara a lo que es la calidad medioambiental tanto a efectos de isla de calor, como de emisiones, zonas verdes y agua y suelo. Esto se debe a la configuración urbana altamente densificada y edificada del entorno urbano de Shopping Light, que corresponde a un centro de una ciudad de gran tamaño y población como es Sao Paulo. De este modo, las rehabilitaciones que resultarían más eficaces de cara a la mejora de la sostenibilidad urbana, deberían de estar centradas en el tema medioambiental, para regenerar las cualidades del entorno respecto a lo anteriormente mencionado, cobrando importancia lo que es la mitigación de la isla de calor. Todo ello dentro de las posibilidades constructivas y urbanísticas, que pudiera ofrecer un entorno urbano de alta densidad. 


\section{2.- CASO 2: SHOPPING ELDORADO}

Shopping Eldorado, fue considerado como caso de estudio para el entorno urbano de lo que es el Centro Expandido de la ciudad de Sao Paulo, este centro comercial de gran tamaño, se ubica estratégicamente entre vías de jerarquía primaria, además de estar ubicado en las relativamente próximo a barrios de clase alta (Morumbi y Jardim Europa). A través de las vías anteriormente mencionadas, el centro tiene conexión directa a centros de negocios de primera categoría (Vila Olimpia y Faria Lima), y su ubicación entre las vías anteriormente mencionadas, hace que el centro pueda contar en sus proximidades con paradas importantes del transporte público. Éste capítulo se centra en el análisis de Shopping Eldorado aplicando la metodología de la tesis paso a paso, explicando en cada uno de los epígrafes, la fuente de dato, y cómo fue calculado o hallado, todo ello de acuerdo a lo establecido en el capítulo 3.

\section{FASE 0: RECOGIDA DE DATOS CUANTITATIVOS.}

En esta fase, se va a realizar una recogida de datos numéricos y cuantitativos oficiales del centro comercial Shopping Eldorado y su entorno urbano. Estos se hallarán bien a partir de fuentes oficiales del propio centro, las autoridades urbanas de Sao Paulo, o bien midiendo sobre plano. La justificación de esto, es establecer unos datos de partida que nos sentarán las bases de posteriores análisis más particularizados e exhaustivos relacionados con el centro o con el entorno urbano. Se considerarán los siguientes datos, que serán de utilidad para posteriores análisis. Los resultados se muestran en la siguiente tabla (Figura 5.2.1)

\begin{tabular}{|l|l|}
\hline \multicolumn{2}{|c|}{ SHOPPING ELDORADO } \\
FASE 0, RECOGIDA DE DATOS CUANTITATIVOS \\
\hline OC.- TABLA DE DATOS CENTRO & Valor \\
\hline OC1: Superficie centro comercial (m2) & 164.734 \\
\hline OC2: Superficie de parcela o ud. Catastral (m2) & 57.000 \\
\hline OC3: Superficie en planta (m2) & 25.057 \\
\hline OC4: Número de visitantes semanal (pe/sem) & 126.000 \\
\hline OC5: Índice de Atracción ( $\mathrm{n}$ ) & 3 \\
\hline OC6: Superficie de tipo residencial (m2) & 0 \\
\hline OC7: Superficie de uso productivo (m2) & 250 \\
\hline OC8: Número de instalaciones dotacionales (no) & 1 \\
\hline OU.- TABLA DE DATOS ENTORNO URBANO & Valor \\
\hline OU1: Población asignada a centro (pe) & 82.367 \\
\hline OU2: Densidad de población (hab/m2) & 0,0081 \\
\hline U03: Superficie partida de entorno urbano (m2) & 10.168 .765 \\
\hline
\end{tabular}

Figura 5.2.1: Tabla de datos Shopping Eldorado. Fuente: Elaboración Propia

\section{OC.- TABLA DE DATOS DEL CENTRO COMERCIAL.}

OC1: SUPERFICIE CENTRO COMERCIAL TOTAL: Este dato fue obtenido de fuentes oficiales, obtenidas de parte de la gerencia propio centro comercial, a través de una entrevista que tuvo el autor de la tesis con un representante de la misma en octubre de 2014. La superficie edificada de Shopping Eldorado es de $164.734 \mathrm{~m}^{2}$ 
OC2: SUPERFICIE TOTAL DE LA PARCELA DEL CENTRO: Para la obtención de este dato se midió en un parcelario de la ciudad de Sao Paulo, obtenido de la prefeitura de Sao Paulo en 2014, la superficie de la parcela o unidad catastral correspondiente al centro comercial, es de $57.000 \mathrm{~m}^{2}$

OC3: SUPERFICIE EN PLANTA DEL EDIFICIO DEL CENTRO COMERCIAL. La superficie en planta del centro del centro comercial, fue medida sobre plano en el parcelario de Sao Paulo, obteniendo como superficie unos $25.057 \mathrm{~m}^{2}$, dividiendo esta superficie obtenida entre la superficie total de parcela $\left(57.000 \mathrm{~m}^{2}\right)$, se obtiene que la parcela del centro comercial Shopping Eldorado está ocupada al $44 \%$ de su superficie.

OC4: NÚMERO DE VISITANTES SEMANAL. Al no poder obtenerse datos del número de visitantes del centro comercial Shopping Eldorado, se realizó un conteo estimativo de las visitas tomando como base los datos de Shopping Light del apartado $\mathrm{C} 4$, considerándose a su vez un coeficiente de ponderación de 0,8 , debido a la localización relativamente apartada de este centro comercial respecto del centro de Sao Paulo. Para Shopping Eldorado tenemos este número de visitas:

De lunes a viernes: 750.000 personas.

Sábado: 62.250 personas.

Domingo: 20.250 personas.

De este modo, el número de visitantes semanal de Shopping Eldorado es de 126.000 personas.

OC5: ÍNDICE DE ATRACCIÓN DEL CENTRO. En función al número de visitantes del centro, considerando el baremo establecido en el ÍNDICE C5 del capítulo 3.5, A Shopping Eldorado le corresponde un índice de 3 (de 20.000 a 150.000).

OC6: SUPERFICIE DE USO EN EL CENTRO DE TIPO RESIDENCIAL. De visitas al centro, se comprobó y de datos de Google Maps, se consideró que Shopping Eldorado no posee superficie residencial dentro de su unidad catastral.

OC7: SUPERFICIE DE USO EN EL CENTRO DE TIPO PRODUCTIVO: Se considerará como superficie de tipo productivo las oficinas de la policía federal que están dentro del centro comercial, esta mide aproximadamente $250 \mathrm{~m}^{2}$. Este dato pudo establecerse de manera aproximada, a partir de visitas al centro y midiendo sobre un plano de usos y locales recogido en Google Maps, de manera estimativa.

OC8: NÚMERO DE INSTALACIONES EN EL CENTRO DE TIPO DOTACIONAL O ASISTENCIAL: En Shopping Eldorado hay 1 local de uso asistencial, que es la comisaría anteriormente mencionada, este dato se extrajo del análisis de la planta y la visita al centro, cómo se mencionó anteriormente.

\section{OU.- TABLA DE DATOS DEL ENTORNO URBANO.}

OU1: POBLACIÓN DE ÁREA URBANA ASIGNADA A CENTRO COMERCIAL: De acuerdo a lo establecido en la metodología para este apartado $\left(2 \mathrm{~m}^{2}\right.$ de superficie edificada por persona), se dividió la superficie del centro comercial entre 2 , obteniendo una población asignada de 82.367 personas. 
OU2: DENSIDAD DE POBLACIÓN EN EL DISTRITO DEL CENTRO COMERCIAL: Cómo base para el análisis urbano, se cogió la densidad de población del distrito de Pinheiros en Sao Paulo, que es dónde está ubicado el centro comercial. La densidad de este distrito se estableció en 0,0081 $\mathrm{hab} / \mathrm{m}^{2}$, siendo la fuente, los datos oficiales poblacionales y de densidad del ayuntamiento de Sao Paulo, en el censo de 2010.

OU3: SUPERFICIE DEL ENTORNO URBANO: La superficie del entrono urbano a analizar, se obtuvo a partir de los datos de población asignada al centro hallados en U1 (82.367 personas), la cual fue dividida entre la densidad de población del distrito de Pinheiros (0,0081 hab/m2). De este modo se halló la superficie de partida para el área de análisis del centro comercial es de $10.168 .765 \mathrm{~m}^{2}$. No obstante, este área fue reducida en superficie, debido a las limitaciones en los bordes, y a la presencia de amplias áreas sin edificar en la zona. Siendo el área escogida, suficiente para acometer un análisis riguroso del entorno urbano del centro.

\section{FASE 1: ANÁLISIS DEL CONTEXTO URBANO.}

Este análisis se realizará generalmente en base a mediciones sobre plano de diferentes facetas en el área del centro comercial Shopping Eldorado. Se trabajarán diferentes escalas, siendo predominante la escala urbana amplia de toda la zona de influencia del centro comercial, que va a establecerse en este apartado. Para este análisis resultará fundamental el uso de los datos referentes a la configuración del entorno urbano del Centro Expandido de Sao Paulo, establecidos en el apartado anterior. Estos datos van a ser ponderados con la información que pudiera sacarse del análisis sobre plano, y de este análisis, el objetivo será hallar y establecer las pautas urbanísticas para el cuestionario de rehabilitación del centro comercial, se considerarán aspectos relacionados con configuraciones de volumen urbano, densidades, usos, áreas verdes y medio ambiente urbano.

1A: ESTABLECIMIENTO DEL ÁREA DE INFLUENCIA DEL CENTRO COMERCIAL : En base a la superficie del área, hallada anteriormente, se estableció para el área de análisis del centro comercial Shopping Eldorado, un radio de aproximadamente 1800 metros a partir del lindero de la parcela del centro. Este dato fue hallado considerando la superficie de partida cómo el área de un círculo aplicado la siguiente fórmula:

Radio $=\sqrt{ }(10.178 .765 / \pi)=1800 \mathrm{~m}$. Este dato es el verdaderamente relevante para establecer la superficie del área de análisis. (Figura 5.2.2)

1B: DELIMITACIÓN SOBRE PLANO DEL ÁREA DE INFLUENCIA: En base al radio anteriormente establecido $(1800 \mathrm{~m})$, y considerando la configuración del entorno urbano, se estableció la siguiente área (Figura 5.1.2). Se debe de considerar la presencia del río Pinheiros, y las avenidas, que van a expandir o delimitar el entorno, debido a que dentro de esas áreas no puede haber actividad. EL ÁREA DE ANÁLISIS FINAL PARA SHOPPING ELDORADO, QUEDÓ ESTABLECIDA EN 4665.934m² TRAS LA OPERACIÓN DE DELIMITACIÓN. Siendo éste el dato relevante para el análisis urbano. 
1C: SUBDIVISIÓN DEL ÁREA DE INFLUENCIA EN ÁREAS HOMOGÉNEAS Y DELIMITACIÓN DE ZONAS VERDES Para este análisis, el área urbana anteriormente asignada en superficie y límites, va a dividirse en zonas homogéneas de acuerdo a la configuración de los diferentes tejidos urbanos. (Figura 5.2.2) En este análisis van a marcarse también las superficies de zonas verdes dentro del área. Como resultado de este análisis, y caracterizando los tejidos en base a su configuración de altura, tipología de edificación y ocupación estimada de suelo. Se establecieron cuatro tipologías de zona homogénea, descontando los espacios verdes y sin edificar en el área, este análisis se realizó a partir de visitas al área, y del análisis de fotos aéreas. Las superficies medidas sobre plano de las diferentes zonas homogéneas son las siguientes: (Figura 5.2.2)

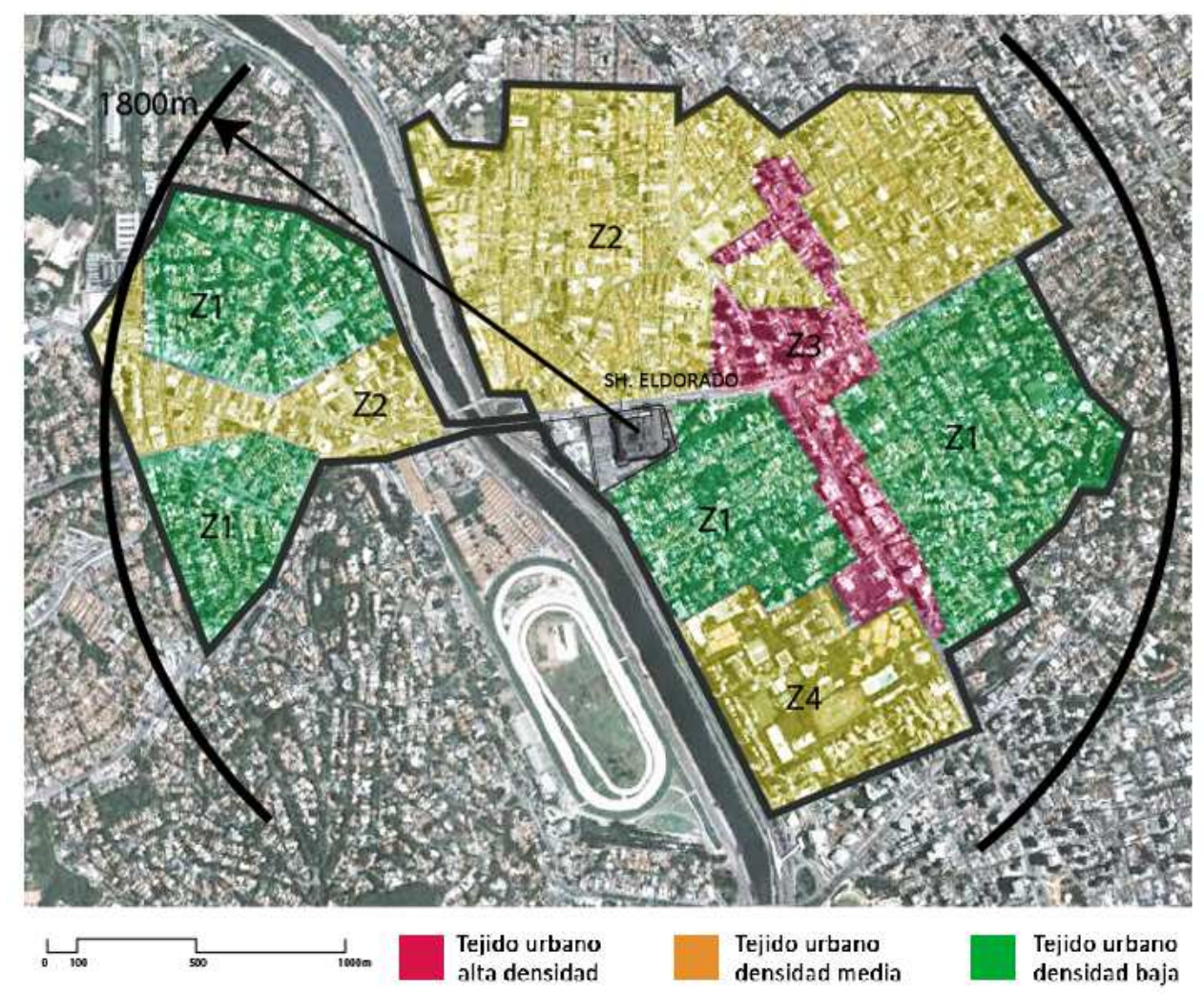

Figura 5.2.2: Área de Shopping Eldorado y subdivisión por zonas homogéneas. Fuente: Google, Elaboración Propia.

Quedando las zonas homogéneas con las siguientes superficies en planta:

Z1: $1787922 \mathrm{~m}^{2}$ brutos.

Z2: $1828839 \mathrm{~m}^{2}$ brutos.

Z3: $428716 \mathrm{~m}^{2}$ brutos.

Z4: $498785 \mathrm{~m}^{2}$ brutos

1D: PORCENTAJE DE OCUPACIÓN DE LA EDIFICACIÓN Y ÁREA OCUPADA: De acuerdo a lo estipulado por el apartado correspondiente en el capítulo 3.6, se realizará el análisis de la ocupación de las diferentes zonas homogéneas a partir del análisis de un área tipo de 200×200 $\mathrm{m}^{2}$ sobre parcelarios oficiales de la ciudad de Sao Paulo. En base a este análisis, pudieron establecerse los porcentajes, midiendo sobre plano el área ocupada por la edificación dentro del cuadrado de $200 \times 200$ metros, que será dividida entre el área de $40.000 \mathrm{~m}^{2}$ de éste área tipo 
de análisis. Los porcentajes de ocupación resultaron ser los siguientes para cada zona homogénea. (Figura 5.2.3)

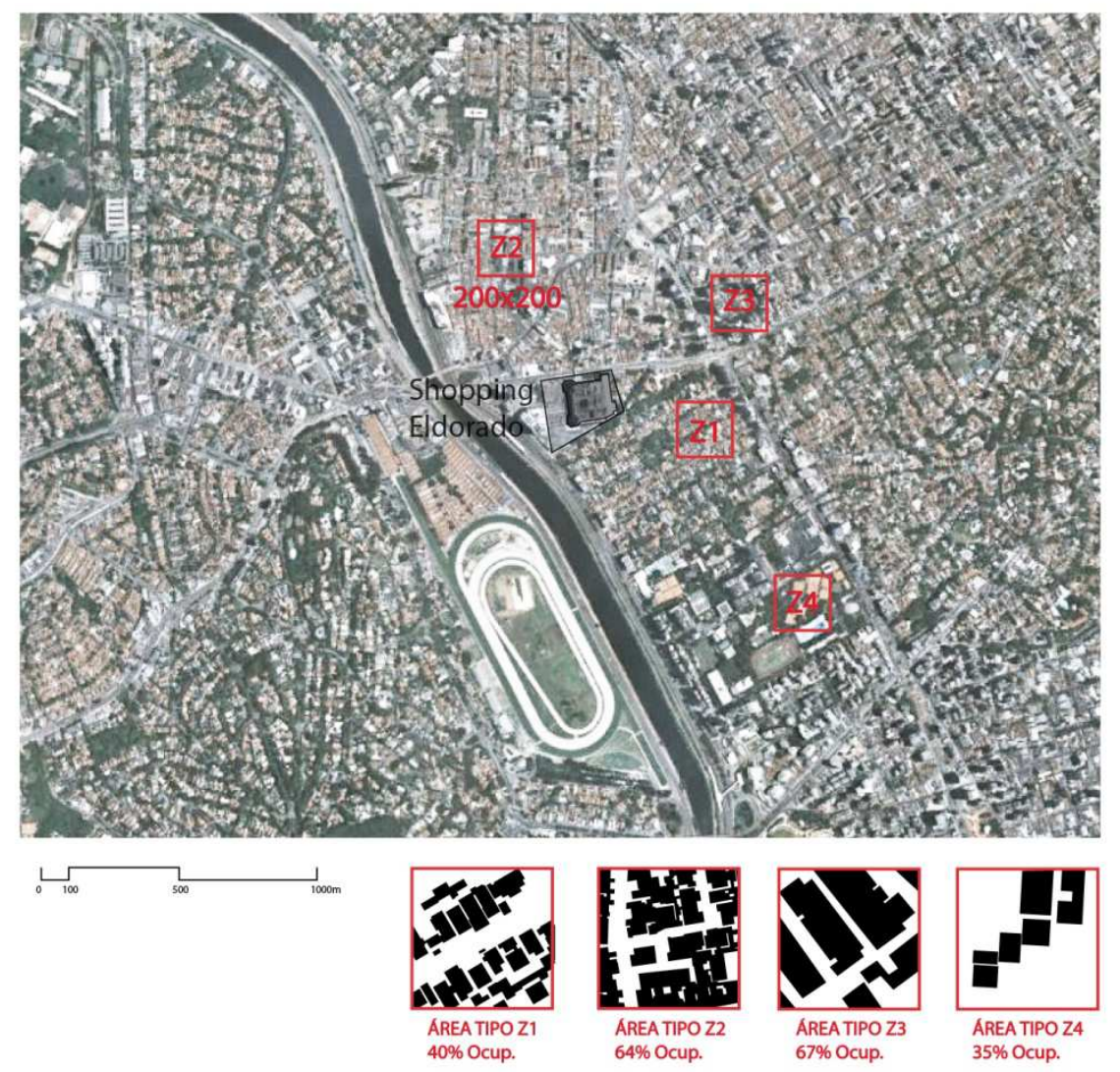

Figura 5.2.3.- Análisis de ocupación sobre parcelario. Fuente: Elaboración Propia a partir de datos de Google.

Estos porcentajes del análisis de tejidos serán aplicados a las superficies de área total, hallándose de esta forma la superficie ocupada en planta neta total de cada zona homogénea establecida.

Z1: $40 \%$ de superficie ocupada. Superficie ocupada $715.169 \mathrm{~m}^{2}$. Z2: $64 \%$ de superficie ocupada. Superficie ocupada $1.170 .457 \mathrm{~m}^{2}$. Z3: $66 \%$ de superficie ocupada. Superficie ocupada $282.953 \mathrm{~m}^{2}$. Z4: $35 \%$ de superficie ocupada. Superficie ocupada $174.575 \mathrm{~m}^{2}$.

1E: ALTURAS DE LA EDIFCACIÓN POR ÁREA HOMOGÉNEA: Para las diferentes áreas homogéneas de Shopping Eldorado establecidas con anterioridad, se consideraron las siguientes alturas medias de edificación, esto fue realizado de manera estimativa a partir de visitas al área y análisis de fotos de calles de Google Maps.

Z1: 2 alturas. Z2: 3 alturas. Z3: 10 alturas. Z4: 10 alturas.

1F: ESTABLECIMIENTO DE LAS TIPOLOGÍAS DE TEJIDO EN BASE A LA MORFOLOGÍA URBANA POR ÁREA HOMOGÉNEA: A partir de las ocupaciones y los números de plantas anteriormente considerados para cada zona homogénea, y considerando el baremo de la tabla correspondiente a densidades del presente apartado en el capítulo 3.6, cada área de Shopping Eldorado tiene estas densidades. 
Z1: Zona poco densa. Z2: Zona de densidad media. Z3: zona densa. Z4: 10 zona de densidad media.

1G.- ÍNDICE GLOBAL DE DENSIDAD. En base a las densidades establecidas anteriormente de acuerdo al apartado anterior, se pudo establecer el índice de densidad para cada zona. Es importante considerar la superficie que ocupa cada zona homogénea (Z1: $1787922 \mathrm{~m}^{2}$; Z2: $1828839 \mathrm{~m}^{2}$; Z3: $428716 \mathrm{~m}^{2}$; Z4: $498785 \mathrm{~m}^{2}$ brutos), las cuales fueron divididas respecto al área total de la zona $\left(4665934 \mathrm{~m}^{2}\right)$, para de esta manera hallar los porcentajes que ocupa cada zona. Multiplicando cada índice de densidad correspondiente a cada zona homogénea, por el porcentaje que ocupa cada una, y luego sumando los resultados, se pudo hallar el índice global de densidad.

Z1: Índice de 1, representa el 39,3\% de la superficie total, suma al índice global 0,39 puntos. Z2: Índice de 2, representa el $40,3 \%$ de la superficie total, suma al índice global 0,8 puntos. Z3: Índice de 3, representa el 9,4\% de la superficie total, suma al índice global 0,28 puntos. Z4: Índice de 2, representa el $11 \%$ de la superficie total, suma al índice global 0,22 puntos.

De este modo el índice global de densidad es de 1,7 puntos, lo que corresponde una zona de densidad media baja.

1H: SUPERFICIE EDIFICADA TOTAL DE CADA ÁREA HOMOGÉNEA. Para hallar la superficie edificada total de cada zona homogénea, se multiplicó la superficie ocupada de la edificación en planta, anteriormente hallada en el apartado 1D, por el número medio de plantas asignado a cada zona por separado en el apartado 1E. De este modo, la superficie total edificada aproximada por área es de:

Z1 $715.169 \mathrm{~m}^{2} \times 2 \mathrm{p}=1.430 .338 \mathrm{~m}^{2}$

$\mathrm{Z2}: 1.170 .457 \mathrm{~m}^{2} \times 3 \mathrm{p}=3.511 .371 \mathrm{~m}^{2}$

Z3: $282.952,6 \mathrm{~m}^{2} \times 10 \mathrm{p}=2.829 .526 \mathrm{~m}^{2}$

Z4: $174.575,7 \mathrm{~m}^{2} \times 10 \mathrm{p}=1.745 .748 \mathrm{~m}^{2}$

Siendo la superficie edificada total en el área urbana de análisis de $9.516 .982 \mathrm{~m} 2$

11: ESTABLECIMIENTO DE PORCENTAJES DE USO DENTRO DE LAS ZONAS HOMOGÉNEAS ESTABLECIDAS: El área de Shopping Eldorado corresponde a un entorno complejo en el que hay edificios tanto residenciales como comerciales y administrativos. Al no haber datos objetivos sobre los usos predominantes en la zona, se consideraron los siguientes porcentajes de manera estimativa, en base a visitas al área y estimaciones de superficies a partir de los tipos de edificios presentes en cada zona homogénea.

Z1: $90 \%$ residencial, $5 \%$ productivo, $5 \%$ comercial.

Z2: $50 \%$ residencial, $20 \%$ productivo, $30 \%$ comercial.

Z3: $10 \%$ residencial, $70 \%$ productivo, $20 \%$ comercial.

Z4: $90 \%$ residencial, $5 \%$ productivo, $5 \%$ comercial.

1J: CONTEO DE LOS USOS DENTRO DEL CONTEXTO URBANO: Una vez se establecieron los porcentajes en el apartado anterior, para obtener los metros cuadrados netos de uso, se multiplicarán éstos porcentajes hallados anteriormente por las superficies edificadas totales 
hallada en el apartado $1 \mathrm{H}$ de cada zona homogénea por separado, quedando establecidos los usos del área urbana relativa a Shopping Eldorado de la siguiente manera:

Z1: $1287304 \mathrm{~m}^{2}$ residencial, $71517 \mathrm{~m}^{2}$ productivo, $71517 \mathrm{~m}^{2}$ comercial.

Z2: $1755685 \mathrm{~m}^{2}$ residencial, $702274 \mathrm{~m}^{2}$ productivo, $1980668 \mathrm{~m}^{2}$ comercial.

Z3: $282953 \mathrm{~m}^{2}$ residencial, $1980668 \mathrm{~m}^{2}$ productivo, $565905 \mathrm{~m}^{2}$ comercial.

Z4: $1571173 \mathrm{~m}^{2}$ residencial, $87287 \mathrm{~m}^{2}$ productivo, $87287 \mathrm{~m}^{2}$ comercial.

1K: ÍNDICE GLOBAL DE MEZCLA DE USOS. Para el índice global de mezcla de usos, se consideró el baremo establecido en el apartado $1 \mathrm{~K}$ del capítulo 3.6, utilizando para ello los porcentajes de uso establecidos en 11 . Se sumará para cada zona homogénea el porcentaje de uso comercial más el productivo, calculándose el uso no residencial, éste será comparado en paralelo con el porcentaje de uso residencial, de este modo, queda establecido el índice de mezcla de usos, en base a si un uso supera o no el $80 \%$ de la superficie construida total.

Z1: $90 \%$ uso residencial, $10 \%$ uso no residencial, índice mezcla usos de 0

Z2: $50 \%$ uso residencial, $50 \%$ uso no residencial, índice mezcla usos de 1

Z3: $10 \%$ uso residencial, $90 \%$ uso no residencial, índice mezcla usos de 0

Z4: $90 \%$ uso residencial, $10 \%$ uso no residencial, índice mezcla usos de 0

De este modo, se multiplicarán los índices de uso, por los porcentajes que ocupa cada zona homogénea respecto al área urbana total, obteniendo estos resultados:

Z1: Índice de 0, representa el 39,3\% de la superficie total, suma al índice de mezcla de usos 0 puntos.

Z2: Índice de 1, representa el 40,3\% de la superficie total, suma al índice de mezcla de usos 0,4 puntos.

Z3: Índice de 0, representa el 9,4\% de la superficie total, suma al índice de mezcla de usos 0 puntos.

Z4: Índice de 0, representa el $11 \%$ de la superficie total, suma al índice de mezcla de usos 0 puntos.

Sumando los resultados, se saca que el área de Shopping Eldorado tiene un índice de mezcla de usos de 0,4 . Que corresponde a un área urbana poco compleja a efectos de usos.

1L: CONTEO DEL NÚMERO DE DOTACIONES DENTRO DEL CONTEXTO URBANO, DENTRO DEL ÁREA DE DOTACIONES Se estableció un área de un 1 kilómetro a partir del lindero del centro, y dentro del mismo se marcaron las siguientes dotaciones, cuya localización se halló a partir de visitas al área, y mediante la utilización de localización de actividades de Google Maps, en el área de dotaciones de Shopping Eldorado se marcaron: 2 dotaciones de visita esporádica, 5 dotaciones de visita habitual, y ninguna dotación muy visitada o de gran jerarquía. (Figura 5.2.4). 


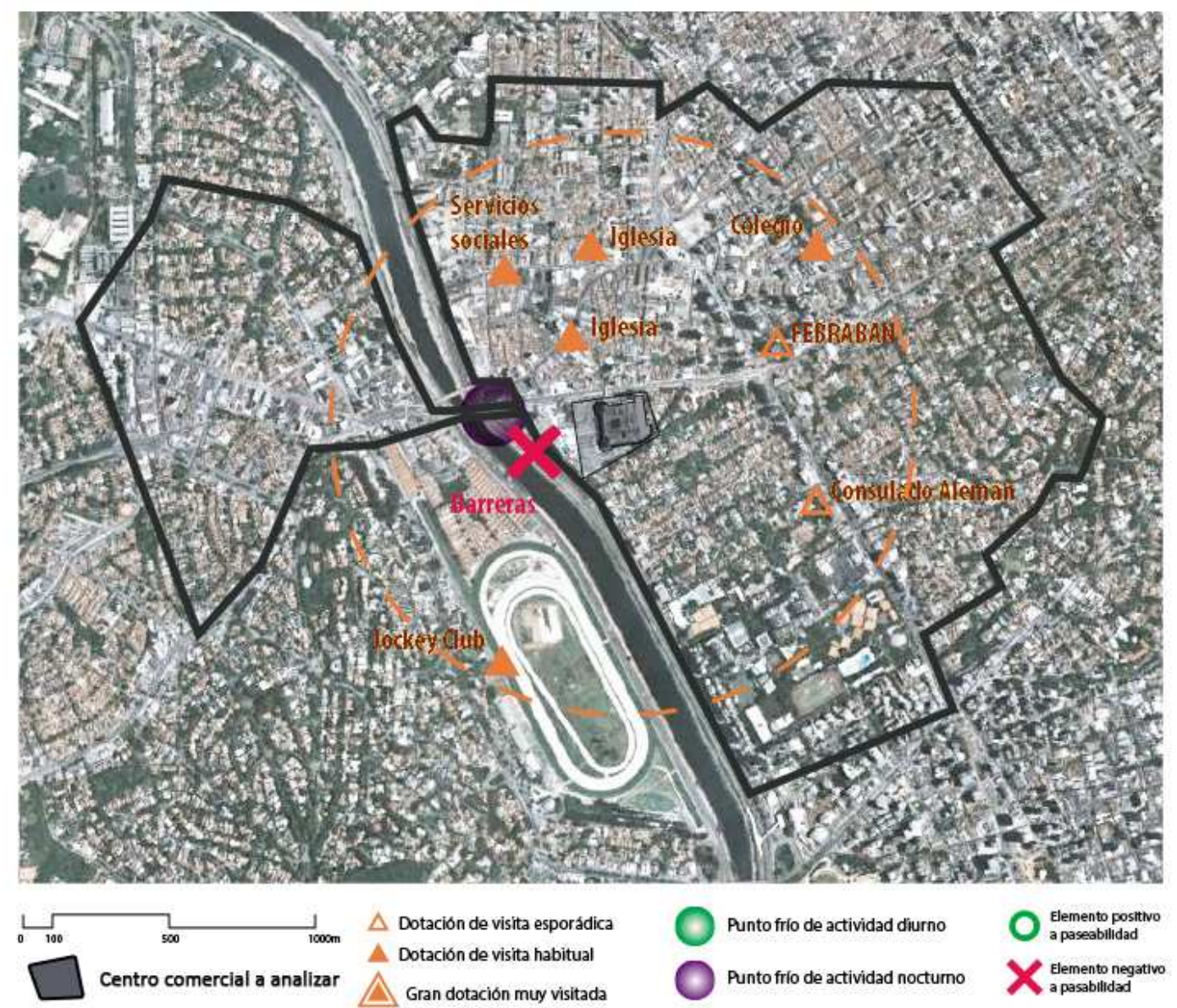

Figura 5.2.4: Análisis de dotaciones y actividad en área de Shopping Eldorado. Fuente: Elaboración Propia a partir de datos de Google.

1M: PRESENCIA E INFLUENCIA DE ELEMENTOS POSITIVOS Y NEGATIVOS:

En el área de Shopping Eldorado, no hay elementos negativos o peligrosos que pudieran ejercer efecto de repulsión de cara a los compradores. En cambio, los parques empresariales cercanos de Faria Lima y Pinheiros pueden funcionar como elementos atrayentes, al igual que la proximidad del centro con la Universidad de Sao Paulo.

1N: ZONAS DE ACTIVIDAD: El área en la que se encuentra Shopping Eldorado, es relativamente poco activa, ya que aunque tiene avenidas muy transitadas con mezcla de usos, éstas se ubican en puntos localizados, siendo el espacio urbano fuera de estas avenidas una zona con mezcla de usos casi nula, y por consiguiente una escasa actividad, que se agrava con la presencia de numerosos inmuebles ubicados en parcelas cerradas a la calle (uno de ellos el propio centro comercial). Hay que añadir también que muchos de los edificios del área limitan su actividad al horario de oficina. Además de esto, también hay puntos fríos de actividad, en lo que es el puente de la avenida Eusébio Matoso con el río Pinheiros y la autopista. Esto es debido a la larga distancia que separa los barrios ubicados a los lados del mismo, y a la presencia de las barreras anteriormente mencionadas. Esta análisis se realizó de manera cualitativa, a partir de varias visitas al área, y mediante la analítica de la localización de las diferentes tipologías edificatorias. (Figura 5.2.5) 


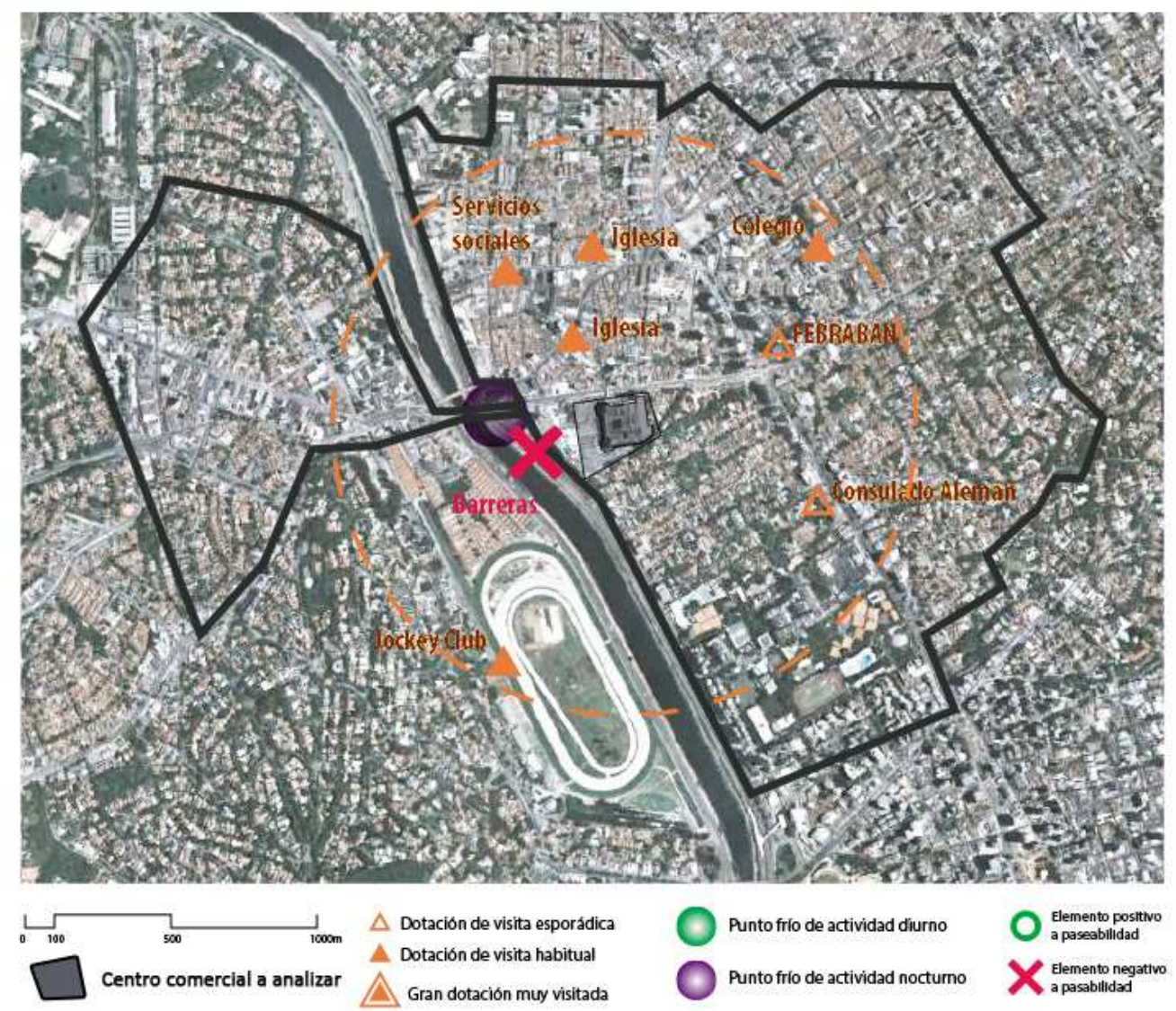

Figura 5.2.5: Área de Shopping Eldorado, Dotaciones, puntos fríos y elementos positivos y negativos Fuente: Elaboración Propia.

10: ÁREAS ARBOLADAS Y VERDES, DENTRO DEL ÁREA URBANA DEL CENTRO: Dentro del área de shopping Eldorado, se consideraron midiendo sobre plano las siguientes áreas verdes con sus respectivos metros cuadrados de superficie (Figura 5.2.5). Se considerarán para el análisis tanto las superficie verdes netas en planta, como los metros cuadrados de vegetación que poseen. El área urbana asignada a Shopping Eldorado posee un área verde neta en planta aproximada de $158.000 \mathrm{~m}^{2}$, que se desglosa en las siguientes superficies de capas vegetación. 

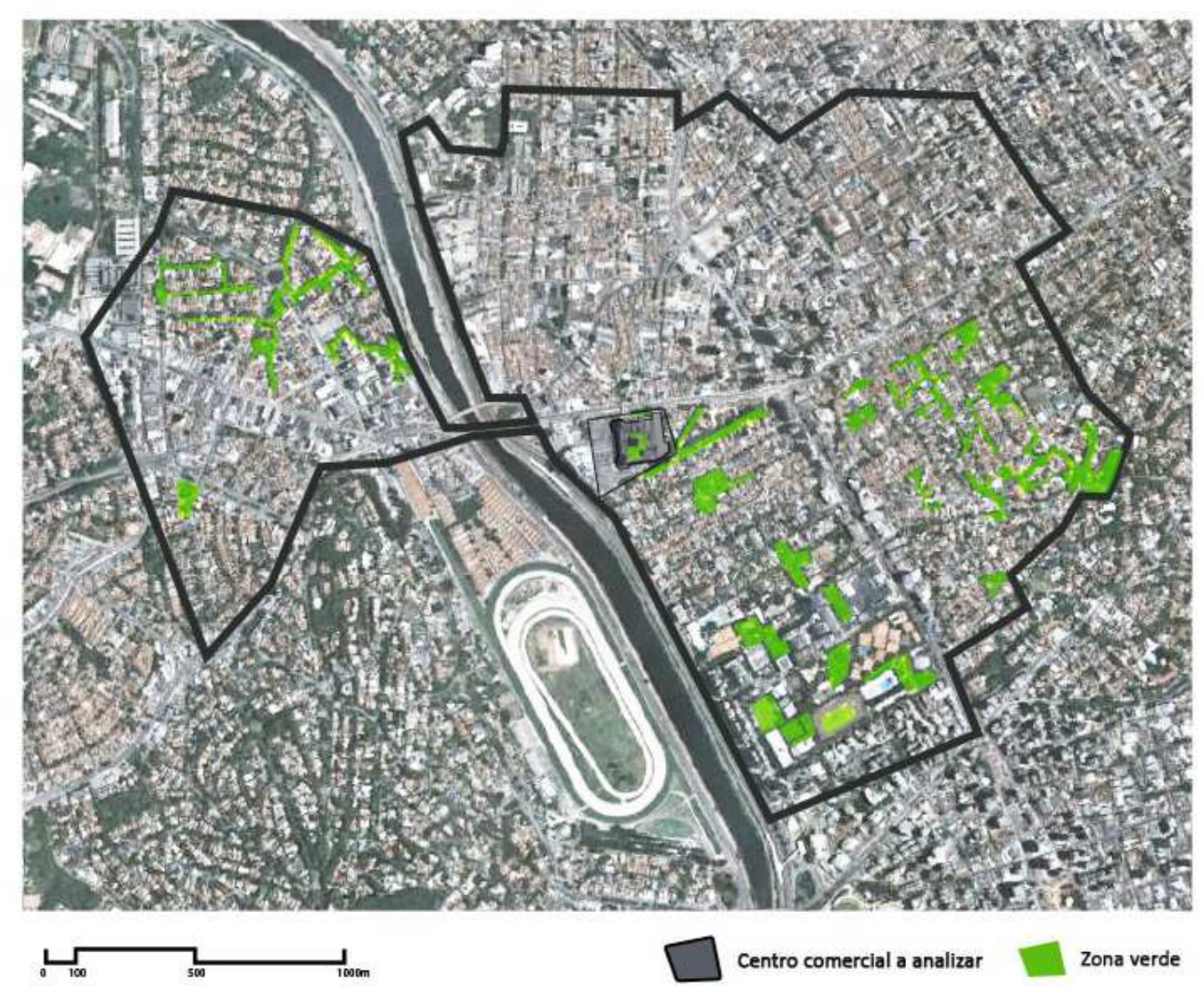

Centro comercial a analizar

Zona verde

\begin{tabular}{|l|r|}
\hline 10: Superficie de zonas verdes en área urbana & Valor \\
\hline C4.1: pradera & 17804 \\
\hline C4.2: hierba de gran altura o huerto & 0 \\
\hline C4.3: vegetación arbustiva intensiva & 0 \\
\hline C4.4: vegetación arbórea caduca & 140102 \\
\hline C4.5: vegetación arbórea perenne & 157906 \\
\hline TOTAL & \\
\hline
\end{tabular}

Vegtación arborea

perenne: $0,56 *$ Sup. V. tot

Figura 5.2.6: Área de Shopping Eldorado, Zonas verdes y capas de vegetación Fuente: Elaboración Propia a partir de datos de Google.

1P.- DELIMITACIÓN DE RECORRIDOS A CENTRO, DENTRO DEL ÁREA URBANA: Para este análisis, fueros establecidos tres recorridos desde diferentes puntos del borde e interior del área urbana de análisis establecida para Shopping Eldorado (figura 5.2.6), los tiempos de llegada analizarán a posteriori, considerando tanto el uso del transporte público (apartado 2E) cómo del vehículo particular (Apartado 2F). 


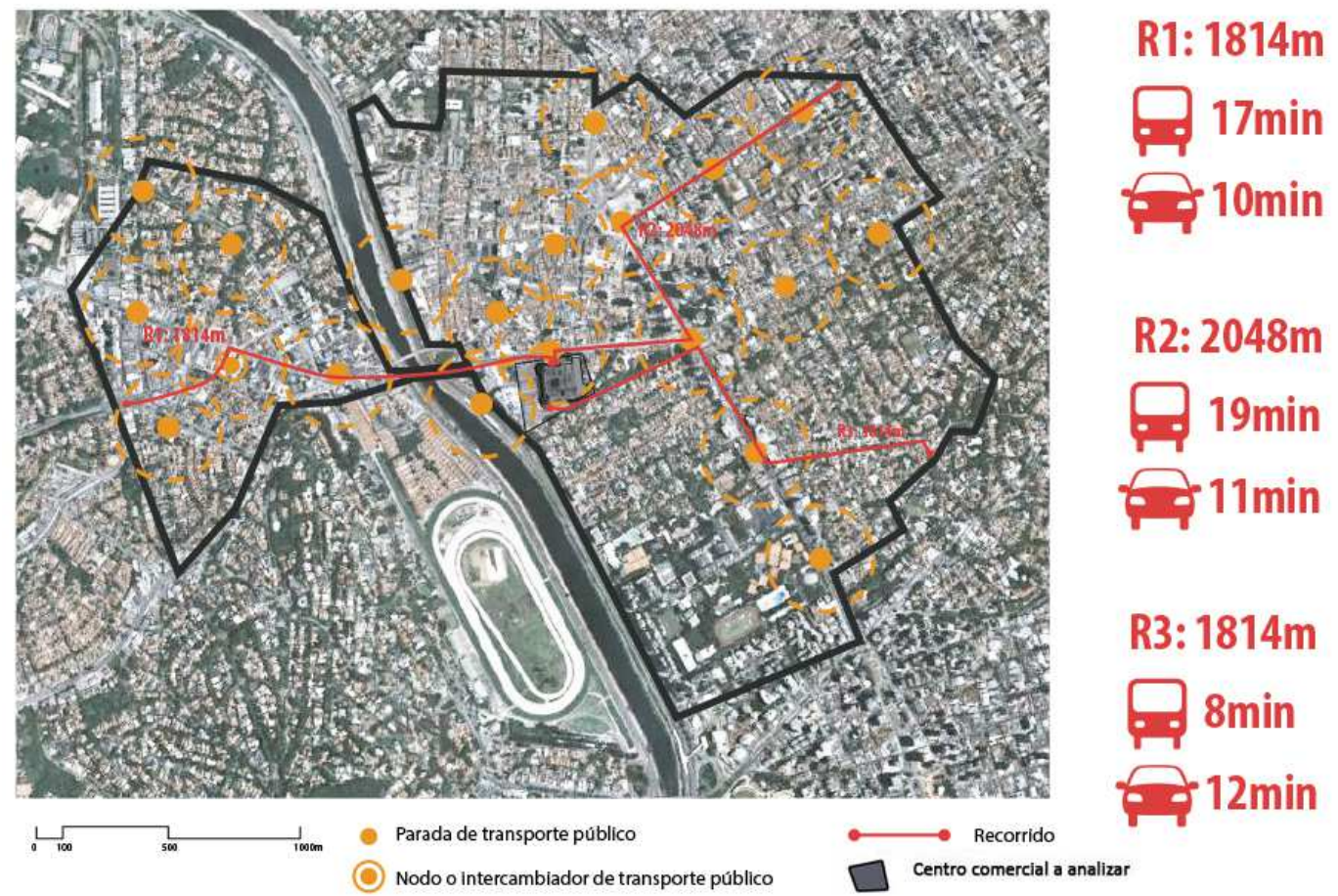

Figura 5.2.7: Recorridos, tiempos de llegada y zonas cubiertas por el transporte público. Fuente: Elaboración Propia a partir de datos de Google.

1Q.- HUELLA DE CARBONO DEL ÁREA URBANA: La huella de carbono base de Brasil de 2,1 ${ }^{49}$ toneladas anuales de dióxido de carbono por persona (esta fuente se extrajo a partir de datos de Trading Economics para 2008). No obstante, debido a que esta huella es media para todo el país, puede ser imprecisa ya que considera áreas con poco desarrollo industrial. Por consiguiente, se ponderó esta huella muy al alza, por estar relacionada con un área urbana desarrollada, y con presencia de viviendas e inmuebles de alto poder adquisitivo en comparación a otras áreas de Brasil, similar incluso al de algunos países del Primer Mundo. Para un habitante del área de Shopping Eldorado, se estableció una huella de carbono por persona de 7,28 toneladas anuales de dióxido de carbono por persona, siendo la huella de carbono del área urbana de Shopping Eldorado de 600000 Toneladas de dióxido de carbono anuales.

1R.- CAPACIDAD ABSORCIÓN DE LOS ELEMENTOS VERDES EN ÁREA URBANA: En base a los datos de superficies verdes obtenidos en el apartado 10, se calculó la absorción total de las áreas verdes, en base a la capacidad de absorción por metro cuadrado de las superficies de las diversas especies vegetales. (figura 5.1.7.) Siendo la capacidad absorbente total en el área de 315290 Toneladas de dióxido de carbono anuales.

\begin{tabular}{|l|r|r|r|r|r|r|}
\hline 1R: C.absorción elementos verdes en área & \multicolumn{1}{|l|}{ Pradera } & V.arb ext & V. A. Int. & H. Caduca & H. Perenne & Otro \\
\hline Superficie total & 17804,0000 & & 1094,0000 & & 140102,0000 & \\
\hline Tasa absorción TCo2/m2 año & 0,0013 & 0,0020 & 0,0350 & 0,1500 & 2,2500 & 0,0000 \\
\hline Absorción dióxido carbono TCo2 & 23,1452 & 0,0000 & 38,2900 & 0,0000 & 315229,5000 & 0,0000 \\
\hline
\end{tabular}

Figura 5.2.8: Absorción de las zonas verdes del área urbana de Shopping Eldorado. Fuente: Elaboración Propia

\footnotetext{
${ }^{49} \mathrm{http}: / /$ www.tradingeconomics.com/brazil/co2-emissions-metric-tons-per-capita-wb-data.html
} 
1S: DELIMITACIÓN DE ÁREAS EN FUNCIÓN DE LA RECUPERACIÓN DE AGUAS EN ÁREA URBANA. Para este análisis, se consideraron como zonas permeables al agua de lluvia, asimilables por el suelo para la recuperación de los acuíferos, las zonas verdes presentes en el área urbana, ya que estas no se encuentran pavimentadas por materiales impermeables (Figura 5.2.3). De este modo, la superficie absorbente del área de Shopping Eldorado es de 158000 m2

\section{FASE 2: ANÁLISIS DE RELACIONES ENTRE CENTRO COMERCIAL Y ENTORNO URBANO.}

Este análisis en muy similar en búsqueda de datos y función con respecto al anteriormente analizado sobre el área urbana general. La particularidad de este análisis está en que su ámbito está limitado a las parcelas que directamente lindan con la unidad catastral de Shopping Eldorado. El objetivo es cuantificar las relaciones urbanas entre el centro y el entorno próximo, ya sea mediante usos, relaciones entre dotaciones, y accesibilidad o transporte, en este análisis va a primar el estudio sobre plano, aunque también se harán análisis cuantitativos de superficies, y cualitativos.

2A: DELIMITACIÓN DE ÁREA PRÓXIMA: De cara al análisis del área próxima se escogieron las siguientes manzanas aledañas al centro, marcándose en el plano las superficies de manzana, y las fachadas activas. Las cuales para la presente tesis, son las que cuentan con locales abiertos a las vías urbanas, ejerciendo estos atracción o interacción sobre los viandantes. (Figura 5.2.8).

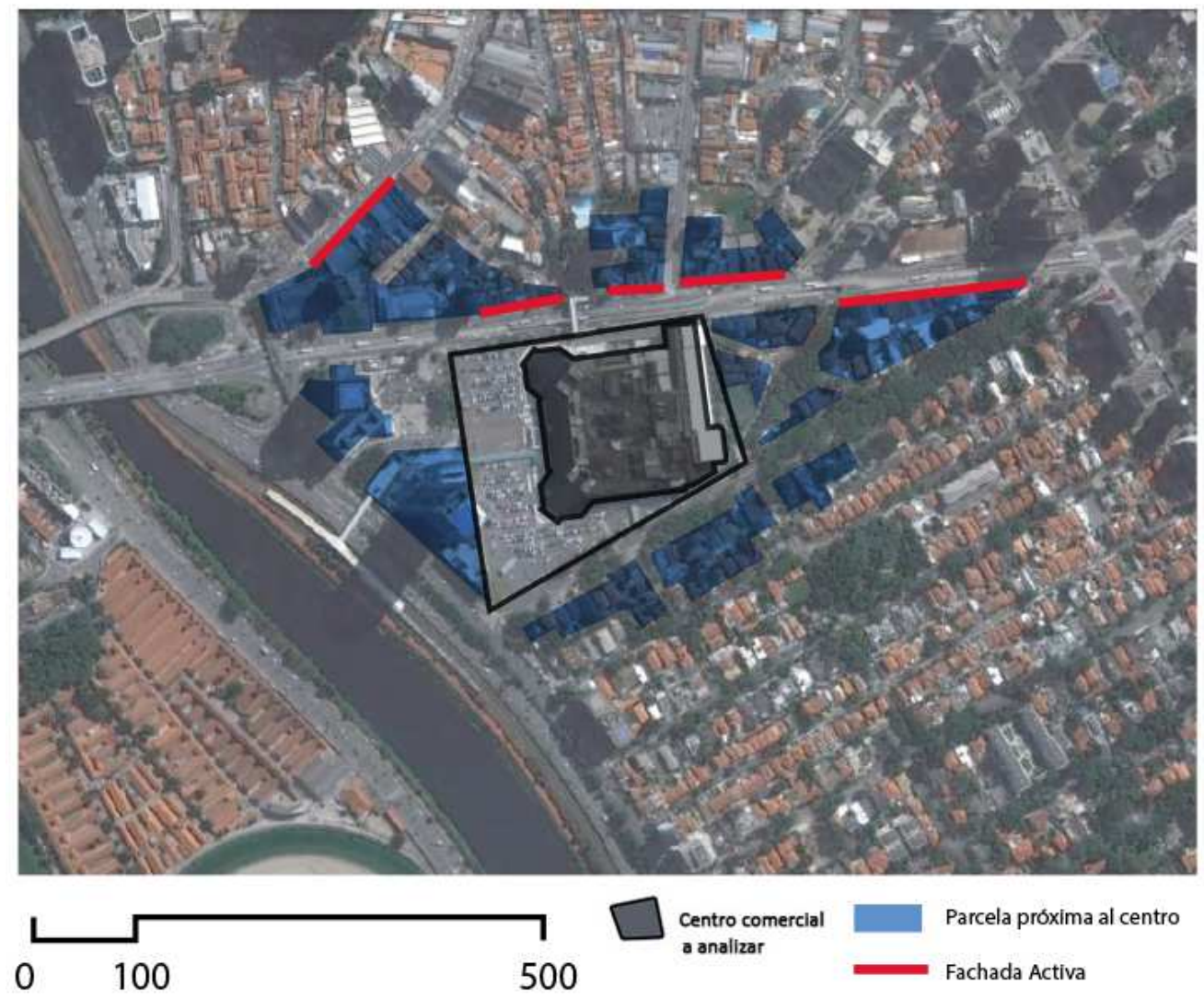

Figura 5.2.9: Análisis de parcelas próximas al centro. Fuente: Elaboración Propia a partir de datos de Google 
2B: SUPERFICIE TOTAL EDIFICADA EN ÁREA PRÓXIMA: Para el conteo de la superficie total estimada de las manzanas próximas al centro, se midió sobre un parcelario de Sao Paulo de la zona del centro, la superficie en planta de las mismas, que es de $31.500 \mathrm{~m}^{2}$, la cual fue multiplicada por el número de plantas medio de los edificios de susodichas manzanas, que en base a visitas al área, y fotos de calles, para el caso de Shopping Eldorado, se estableció en 5 plantas. De este modo, multiplicando la superficie medida en planta por el número de alturas, sale una superficie construida de $157.500 \mathrm{~m}^{2}$ en las manzanas próximas al centro.

2C: USOS EN ÁREA PRÓXIMA: Aunque no es posible obtener datos concretos acerca de las superficies de uso en las manzanas contiguas al centro comercial, en base a conteos estimativos y visitas para la presente tesis se dedujo que las manzanas próximas al centro comercial, poseen una configuración de usos en la que predominan los edificios de oficinas o de comercio, siendo los edificios residenciales generalmente de poca altura. De este modo, para este análisis se establecieron los siguientes porcentajes:

Uso residencial: $15 \%$. Uso productivo: $60 \%$. Uso comercial: $25 \%$.

Quedando estas superficies a partir de la multiplicación de los porcentajes establecidos anteriormente por el área total construida de las manzanas $\left(157.500 \mathrm{~m}^{2}\right)$ del apartado $2 \mathrm{~B}$ :

Uso residencial: $23625 \mathrm{~m}^{2}$. Uso productivo: $94500 \mathrm{~m}^{2}$. Uso comercial: $39375 \mathrm{~m}^{2}$.

2D: FACHADAS ACTIVAS EN ÁREA PRÓXIMA Para este análisis, las fachadas activas en manzanas próximas se marcaron sobre plano (Figura 5.2.8), y se midieron en metros lineales, este análisis se obtuvo a partir de visitas al área y análisis de fotos de la zona de Google Maps. Por otra parte se obtuvo de manera paralela la longitud de fachada total midiendo directamente sobre un parcelario, que se obtuvo de la Prefeitura de Sao Paulo y de la Universidad de Sao Paulo. La longitud de fachada activa (cuenta con locales que ejercen interacción sobre los usuarios del espacio urbano) es de $479 \mathrm{~m}$ siendo la longitud de fachada total de $1549,2 \mathrm{~m}$ incluyendo las fachadas activas y no activas. El porcentaje de fachadas activas para el área es del 31\%.

2E: TIEMPOS DE LLEGADA DESDE LOS PUNTOS EN ÁREA A CENTRO COMERCIAL MEDIANTE TRANSPORTE PÚBLICO: Para la estimación de los tiempos de llegada en transporte público, fueron considerados los recorridos establecidos confluyentes en Shopping Eldorado en $1 \mathrm{P}$, y se utilizó la base de datos de Google Maps para establecer los tiempos de llegada, en transporte público, considerándose dentro de los mismos para algunos casos el recorrido a pie, en caso de no haber transporte. (Figura 5.2.6).

2F: TIEMPOS DE LLEGADA DESDE LOS PUNTOS EN ÁREA A CENTRO COMERCIAL MEDIANTE TRANSPORTE PRIVADO: Para la estimación de los tiempos de llegada en transporte privado, fueron considerados los recorridos establecidos en $1 \mathrm{P}$, y se utilizó la base de datos de Google Maps para establecer los tiempos de llegada. El centro posee aparcamiento dentro de su unidad catastral; aún así, se añadió al tiempo de llegada unos tres minutos adicionales de maniobra y trayecto de llegada desde el vehículo al centro. De este modo, los tiempos establecidos para los medios de transporte son los siguientes para cada recorrido. (Figura 5.2.6). 
El transporte público en esta zona está basado en el uso de autobuses, habiendo en las avenidas carriles destinados exclusivamente a los mismos. La frecuencia entre autobuses en la zona es de 10 minutos, siendo la manera más viable de alcanzar el centro desde los puntos analizados, en varios casos parte de estos recorridos son realizados a pie. Respecto al transporte privado, la llegada al centro puede complicarse debido a los problemas de tráfico, pudiendo verse incrementados los tiempos de llegada en una media de 8-10 minutos, si se utiliza un coche. En algunos tramos de los recorridos, estos tiempos de llegada también pueden afectar al transporte público.

\section{FASE 3: ANÁLISIS DEL EDIFICIO DEL CENTRO COMERCIAL.}

Una vez analizado el entorno urbano en sus diferentes escalas, cuantificándose de cara al cuestionario de rehabilitación todas las facetas del mismo, a la par que las relaciones urbanas; el último campo de análisis es el estudio concreto de lo que es el edificio del centro comercial Shopping Eldorado. De este modo a partir de los datos de los que se pudieron disponer del centro comercial, van a cuantificarse los rasgos del edificio de Shopping Eldorado en relación a las facetas de usos, sostenibilidad y comportamiento bioclimático, de cara al cuestionario de la Rosa de sostenibilidad. Serán de importancia el conteo de superficies en base a la faceta a analizar, las simulaciones y la comparativa de las características formales para dar los datos necesarios para el cuestionario de rehabilitación.

3A: DELIMITACIÓN DE ÁREAS EN FUNCIÓN DE LA RECUPERACIÓN DE AGUAS: Sobre la planta de cubiertas y unidad catastral del centro comercial Shopping Eldorado, se delimitaron y midieron sobre plano las áreas tanto permeables como impermeables del centro comercial, de acuerdo a los estipulado en la metodología (apartado 3A del capítulo 3.8). Como áreas permeables a la recuperación de aguas, Shopping Eldorado posee espacios arbolados en su periferia; siendo destacable la presencia de un huerto urbano en su cubierta, que se consideró como superficie permeable ya que el agua de lluvia es aprovechada en el mismo. Las superficies permeables de shopping el Dorado suman $3038 \mathrm{~m}^{2}$.

3B: USOS DENTRO DEL EDIFICIO DEL CENTRO: Para los usos, se consideraron los diferentes locales dentro del centro comercial, buscándose los metros cuadrados de espacio productivo, y las dotaciones asistenciales dentro del mismo. Para el caso de Shopping Eldorado, se localizó una instalación asistencial, que es la oficina de policía, que se contó como aproximadamente 250 metros de superficie productiva. Con esto, pudieron averiguarse los porcentajes de superficies para el centro, dividiendo sus superficies netas de usos entre la superficie construida total del centro. De este modo, los usos se dividen de la siguiente manera:

Superficie comercial $99.63 \%$

Superficie residencial $0 \%$

Superficie Productiva no comercial 0,33\%

3C: DELIMITACIÓN DE ÁREAS VERDES EN CENTRO COMERCIAL. El centro comercial Shopping Eldorado, posee áreas verdes arboladas, además de un huerto urbano en su cubierta, establecidos a partir de un conteo de áreas verdes sobre plano. Sumando éstas dos superficies en total hay $3038 \mathrm{~m}^{2}$ de superficie verde neta, desglosada de la siguiente manera en las siguientes capas de vegetación (figura 5.2.9): 


\begin{tabular}{|l|r|}
\hline 3C: S. de zonas verdes en centro comercial & Valor \\
\hline C4.1: pradera & 1500 \\
\hline C4.2: hierba de gran altura o huerto & 0 \\
\hline C4.3: vegetación arbustiva intensiva & 0 \\
\hline C4.4: vegetación arbórea caduca & 1538 \\
\hline C4.5: vegetación arbórea perenne & 3038 \\
\hline TOTAL & \\
\hline
\end{tabular}
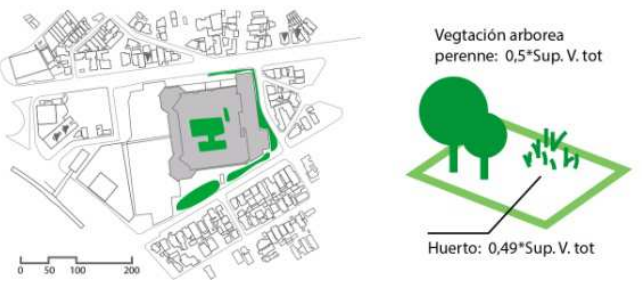

Figura 5.2.10: Áreas verdes y capas de vegetación Shopping Eldorado. Fuente: Elaboración Propia.

3D: ABSORCIÓN DE LAS ÁREAS VERDES EN CENTRO COMERCIAL. Los metros cuadrados de superficie verde de Shopping Eldorado, entre áreas arboladas y huerto, son capaces de asimilar aproximadamente unas 3463 toneladas de dióxido de carbono, partiendo de la base de las capacidades absorbentes de las especies vegetales, establecida para la presente tesis. Esto es aproximadamente un $21 \%$ de las emisiones del centro (16473,4 T Co2 anuales), y un $0,58 \%$ respecto de las emisiones del área urbana (600000 T Co2 anuales). (5.2.10)

\begin{tabular}{|l|r|r|r|r|r|r|}
\hline 3D: C.absorción elementos verdes en centro & \multicolumn{1}{|l|}{ Pradera } & V.arb ext & V. A. Int. & H. Caduca & H. Perenne & Ottro \\
\hline Superficie total & 0,0000 & 1500,0000 & 0,0000 & 0,0000 & 1538,0000 & 0,0000 \\
\hline Tasa absorción TCo2/m2 año & 0,0013 & 0,0020 & 0,0350 & 0,1500 & 2,2500 & 0,000 \\
\hline Absorción dióxido carbono TCo2 & 0,0000 & 3,0000 & 0,0000 & 0,0000 & 3460,5000 & 0,0000 \\
\hline
\end{tabular}

Figura 5.2.11: Absorción elementos vegetales Shopping Eldorado. Fuente: Elaboración Propia.

3E: ANÁLISIS BIOCLIMÁTICO DEL CENTRO COMERCIAL RESPECTO A CLIMA, DIAGRAMA DE GIVONI.

Los requisitos bioclimáticos de acuerdo a Givoni para el caso de Shopping Eldorado, son los referenciados al clima de Sao Paulo, y estos fueron desarrollados y explicados en el apartado 3E del capítulo de caso de estudio de Shopping Light (Capítulo 5.1). (5.2.11)

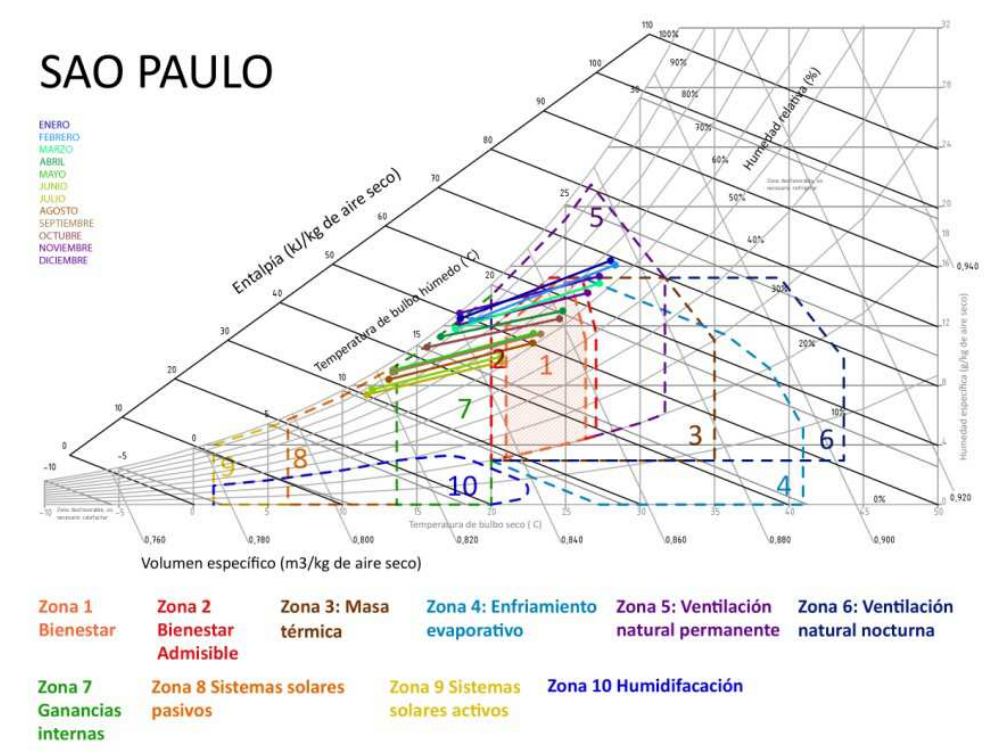

Figura 5.2.12: Diagrama de Givoni de Sao Paulo (Givoni, Climaticus, LABAUT FAU USP, Elaboración Propia)

El centro comercial Shopping Eldorado, posee una envolvente de hormigón que no tiene mucha masa térmica. No obstante, las cargas internas dentro de él son muy elevadas (Luz, maquinaria y personas), y puede valerse de las mismas para acondicionarse en el caso de frío, 
no obstante los espacios interiores tienen un tamaño muy grande, lo que complica la aclimatación utilizando este método. El centro está completamente cerrado, y es un volumen compacto, que no posee sistemas de ventilación natural. Para ventilar, calefactar o refrigerar se usan sistemas mecanizados. Las altas humedades se controlan mediante este tipo de sistemas mecanizados, aunque pueden controlarse también con ventilación y ganancias de energía internas.

\section{F: CALIFICACIÓN ENERGÉTICA DEL CENTRO COMERCIAL.}

Al no haber datos objetivos acerca del consumo primario de energía o las emisiones generadas por el centro Shopping Eldorado, se tuvo que realizar una estimación con el programa CE3X, considerando el clima de Santa Cruz de Tenerife, (ver apartado 3F de capítulo de análisis de Shopping Light, 5.1) que en temperaturas es similar al de Sao Paulo, readaptándose las orientaciones de las fachadas a los condicionantes del programa. Los cerramientos del centro comercial shopping Eldorado fueron establecidos cómo un muro multicapa de placa de hormigón ligero, sin aislante, y con revestimiento interior de ladrillo, se consideraron grandes huecos en la fachada de vidrio sencillo y carpintería de aluminio. Las cubiertas fueron consideradas cómo cubiertas planas sin aislante, y el suelo está en contacto con el garaje. A efectos de instalaciones, no hay datos acerca de las mismas, a si que para el análisis se consideraron sistemas de aire acondicionado, ventilación forzada y agua caliente por bomba de calor, los tres con un rendimiento aproximado del $250 \%$.

De este modo, Shopping Eldorado en el análisis obtuvo estas calificaciones.

Consumo de energía: $336,87 \mathrm{Kwh} / \mathrm{m}^{2}$ año. (C)

Emisiones anuales: $0,1 \mathrm{~T} / \mathrm{m}^{2}$ año. (C)

\section{G: USO DE FUENTES DE ENERGÍA LIMPIAS.}

En base a análisis visuales y visitas, se comprobó que el centro Shopping Eldorado no posee sistemas de generación de energías limpias en el edificio. No obstante, es importante considerar el hecho de que la ciudad de Sao Paulo suple aproximadamente el $90 \%$ de su demanda energética con energías renovables ${ }^{50}$, según un análisis de la Agencia Internacional de Energías Renovables. No obstante, para el posterior estudio en el cuestionario, esto se considerará como parcialmente positivo, ya que lo que se busca es que el centro comercial tenga el menor impacto energético posible, y pueda generar su propia energía.

3H: FORMA DE LA EDIFICACIÓN: Analizando las características formales del centro de cara al análisis de Olgyay, se puede comprobar que el centro comercial Shopping Eldorado, es un volumen compacto y poco fragmentado. Aproximadamente la relación entre el lado mayor $(164 \mathrm{~m})$ y el menor $(140 \mathrm{~m})$ es de 1,17 , siendo la orientación de la fachada principal unos 97,3 은 oeste, respecto de la orientación norte, que es el azimut cero para el caso del hemisferio sur. El centro comercial posee grandes cristaleras de colores oscuros que no cuentan con protección alguna frente a la irradiancia solar, y están inclinadas, con lo que el factor de

\footnotetext{
${ }^{50}$ ICLEI- International Renewable Energy Agency, (2012). Renewable Energy Policy in Cities: Selected Case Studies, Sao Paulo.
} 
exposición a la irradiación se agrava. El espacio interior del edificio está completamente cerrado, y los espacios principales miran al exterior. (Figura 5.2.12)

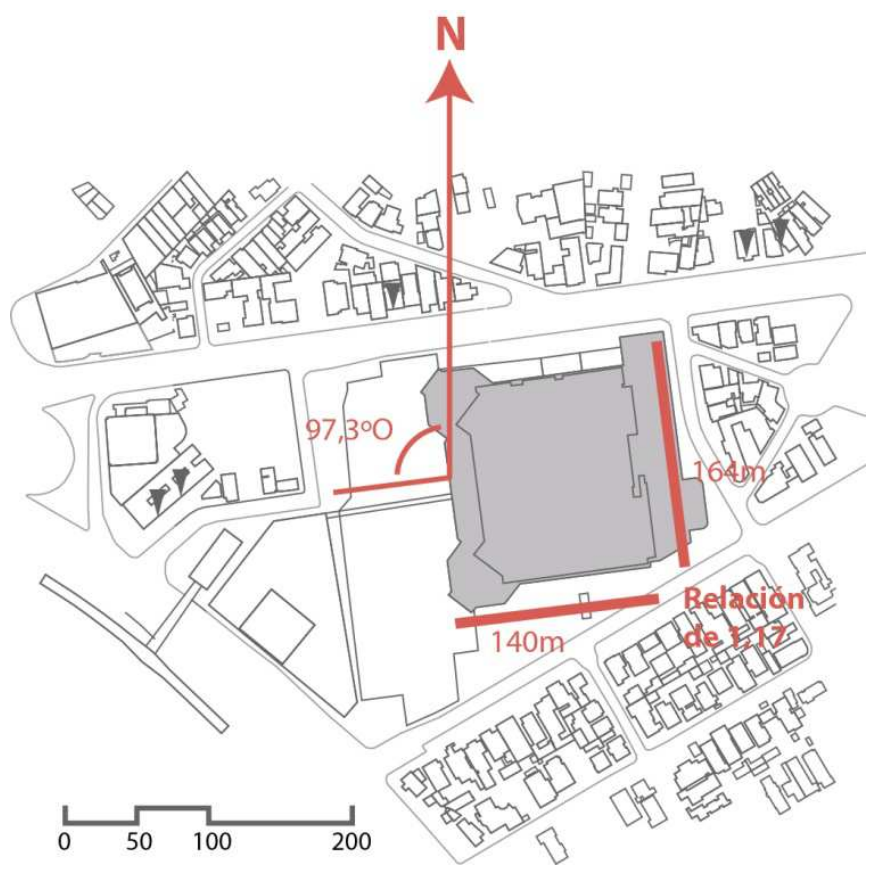

Figura 5.2.13: Análisis forma edificación Shopping Eldorado. Fuente: Elaboración Propia.

31: ESPACIOS CON LUZ NATURAL Para medir esta superficie se consideraron de manera aproximada los espacios iluminados del centro comercial Shopping Eldorado, en una medición sobre plano, considerando todas las plantas. Los espacios con luz natural generalmente corresponden a las estancias de las grandes cristaleras de entrada ubicadas a oeste, y los espacios anejos a las fachadas de la última planta $\left(8092 \mathrm{~m}^{2}\right)$. El hall de esa planta también fue considerado como superficie iluminada de manera parcial, debido a la presencia de lucernarios que contribuyen a alcanzar el nivel de iluminación requerido, este espacio a efectos de superficie total iluminada, computa a la mitad de acuerdo a las bases de la metodología $\left(8162 \mathrm{~m}^{2} / 2=4081 \mathrm{~m}^{2}\right)$. Computando los espacios anteriormente mencionados, y dividiendo esta superficie entre la superficie total del centro $(8092+4081) / 75000$, En Shopping Eldorado el espacio que cuenta con luz natural es aproximadamente el $16 \%$ de su superficie total.

3J: PAVIMENTOS Y CUBIERTAS EN RELACIÓN A LA INCIDENCIA DE LA IRRADIACIÓN SOLAR. Sobre la planta de cubiertas se midieron las superficies de colores claros, y se computó el huerto urbano como superficie repelente de cara a la irradiación solar, ya que las hojas de vegetación van a ejercer sombra, y la tierra no pavimentada tiene menor tasa de absorción del calor que la superficie pavimentada. Las superficies repelentes de calor suman $9388 \mathrm{~m}^{2}$, lo que suponen aproximadamente un $16 \%$ de la superficie de cubierta y parcela no ocupada, de tipo repelente de cara a la irradiación solar. El $84 \%$ restante, es absorbente de cara a la irradiación solar.

FASE 4: CUESTIONARIOS DE LA METODOLOGÍA, APLICACIÓN DE INDICADORES Y BAREMOS. 
Una vez fueron hallados los datos cuantitativos, de cara a la fase final de la aplicación de la metodología, y con el objetivo de establecer las medida de rehabilitación más adecuadas en el gráfico de la rosa de rehabilitación sostenible para Shopping Eldorado (figura 3.3.2, en capítulo 3.3) los datos hallados fueron comparados y aplicados en base a los umbrales y baremos establecidos en el cuestionario de la metodología (capítulo 3.10).

\section{A.- REHABILITACIÓN ECOEFICIENTE.}

A1.- Cuestionario referenciado a rehabilitación hacia instalaciones poco emisivas.

Cuestión A1.1.- ¿El centro cuenta con instalaciones que no son necesarias de acuerdo a lo estipulado en el diagrama de Givoni?: Aunque no hay datos objetivos acerca de las instalaciones de Shopping Eldorado, de visitas al centro se dedujo que se trata de un espacio completamente cerrado y aclimatado, que posee instalaciones mecánicas de refrigeración, las cuales Mirando el diagrama de Givoni, se ve que no son necesarias en principio para el clima de Sao Paulo, a este centro le corresponde una puntuación de +0 en esta cuestión

Cuestión A1.2.- ¿Las instalaciones del centro generan unas emisiones de dióxido de carbono superiores a la media?. En el estudio estimativo de calificación energética con CE3X (apartado $3 F$ ), shopping Eldorado ha obtenido en la calificación energética emisiones de las instalaciones una nota de $C$, lo que significa que la tasa de emisiones de dióxido de carbono es moderadamente baja. Eso corresponde a una puntuación de +3

Cuestión A1.3.- ¿Las instalaciones del centro se encuentran en un estado de obsolescencia?. Respecto esta cuestión, el autor desconoce el estado de las instalaciones del centro. No obstante, estas se estimaron con un estado de obsolescencia, eligiendo el escenario más desfavorable, con lo que se puntuó esta cuestión con una puntuación de +0 .

Cuestión A1.4.- ¿Las instalaciones del centro tienen un consumo energético superior a la media?. En el estudio energético estimativo con CE3X, shopping Eldorado ha obtenido en la calificación energética de consumo de energía primaria una nota de $C$, eso significa que las instalaciones tienen un consumo energético moderadamente bajo, esto corresponde a una puntuación de +3

EN RELACIÓN A INSTALACIONES POCO EMISIVAS, SHOPPING ELDORADO HA OBTENIDO UNA PUNTUACIÓN DE 6 (10).

A2.- Cuestionario referenciado a inserción de medidas activas.

Cuestión A2.1.- ¿Qué porcentaje de las calorías necesarias para lograr la temperatura de confort se logra mediante sistemas activos? De visitas de campo, páginas web oficiales e información de la dirección del centro, se estableció que el centro de Shopping Eldorado, no posee medidas activas, o de energías renovables para lograr la temperatura de confort. No obstante, analizando el diagrama de Givonni para Sao Paulo en el capítulo de Shopping Light (capítulo 5.1, apartado 3E, Figura 5.1.7), aunque cierto es que pueden ayudar en la reducción del consumo energético, éstos no son necesarios. Esta cuestión puntúa con +2 . 
Cuestión A2.2.- ¿Qué porcentaje de la demanda energética se logra a partir de fuentes de energía renovable?: A pesar de que la ciudad de Sao Paulo, suple el $90 \%$ de su demanda de energía con renovables de tipo hidroeléctrico, el mérito de esta cuestión reside en que el centro posea este tipo de dispositivos en la medida de lo posible, para de esta manera reducir la dependencia en fuentes de energía externas. Esta cuestión fue puntuada con un +3 .

Cuestión A2.3.- ¿El centro cuenta con las medidas y dispositivos necesarios para su aclimatación de acuerdo a lo estipulado en el diagrama de Givoni para sistemas solares activos?: Analizando el diagrama de Givoni de Sao Paulo (capítulo 5.1, apartado 3E, Figura 5.1.7) se puede sacar en conclusión que el centro comercial Shopping Eldorado, no precisa de sistemas activos para una correcta aclimatación. No obstante, estos sistemas, se van a hacer necesarios para mitigar ligeramente las calorías de las cargas internas cuando se alcance la temperatura de confort, o para mitigar la humedad. Esta cuestión puntúa con +1.

EN RELACIÓN A MEDIDAS ACTIVAS, SHOPPING ELDORADO HA OBTENIDO UNA PUNTUACIÓN DE 6 (10).

A3.- Cuestionario referenciado a inserción de medidas Pasivas.

A3.1.- ¿El centro comercial tiene una forma adecuada en volumen a las condiciones climáticas?: Shopping Eldorado se encuentra en una zona climática cálida húmeda de acuerdo a la calificación de Olgyay, en el análisis anteriormente realizado en el punto 31, Shopping Eldorado no cumple los requisitos de proporción de planta (1/17 lejos de los $1 / 3$ requeridos), y los huecos están expuestos a la irradiación solar siendo los mismos de colores oscuros. El edificio es un volumen compacto, nada fragmentado, y las fachadas no están protegidas de la irradiación solar proveniente del norte. A todo esto, Shopping Eldorado tiene su fachada principal orientada 97,30 al oeste, lejos de los 15ㅇ máximos requeridos por Olgyay. De este modo, Shopping Eldorado no cumple con ninguno de los requisitos de forma dictados por Olgyay, le corresponde una puntuación de +0 .

A3.2.- ¿El estado de los cerramientos responde de manera correcta a las exigencias del clima en el que se asienta?: La calificación energética estimada de Shopping Eldorado a efectos de consumo global de energía es de $C$, (favorable a efectos de consumo), esto significa que los cerramientos responden de una manera correcta respecto al clima. A este centro le corresponde una puntuación de +3 .

A3.3.- ¿Qué porcentaje de los espacios del centro cuentan con iluminación natural?: En base al conteo de superficies total y parcial respecto a la iluminación realizado en el apartado $3 \mathrm{H}$ de este capítulo, Shopping Eldorado posee un $16 \%$ del espacio interior iluminado con luz natural. Le corresponde de este modo una puntuación de +0 .

A3.4.- Los espacios interiores del centro, están adaptados a lo estipulado por el Diagrama de Givoni de su respectivo clima?: Shopping Eldorado, no tiene los espacios interiores adaptados a lo dictado por Givonni, debido a su gran tamaño y grandes alturas, lo que hace que sea complicado calefactar usando las cargas internas en invierno. A efectos de cerramientos, los muros no tienen mucha masa térmica al abundar las superficies acristaladas y las ventanas no pueden abrirse, lo que hace que la ventilación natural del centro no sea posible. De este modo, 
no se cumple lo requerido por Givoni para el edificio del centro comercial. A Shopping Eldorado le corresponde una calificación de +0

EN RELACIÓN A MEDIDAS PASIVAS, SHOPPING ELDORADO HA OBTENIDO UNA PUNTUACIÓN DE 3 (10).

\section{B.- REHABILITACIÓN MEDIOAMBIENTAL.}

B1.- Cuestionario referenciado a rehabilitación mediante zonas verdes.

Cuestión B1.1.- ¿En el área urbana hay suficiente zona verde en el área en relación a sus habitantes?: En base a el conteo de superficie verde neta en área urbana sobre plano (10), se llegó a la conclusión de que el área urbana de análisis de Shopping Eldorado en su totalidad posee aproximadamente $159.000 \mathrm{~m}^{2}$ de superficie verde en planta. Esta superficie, se dividirá entre los 82367 habitantes hallados para el área urbana a partir de la densidad, quedando establecido de este modo un ratio de $1,93 \mathrm{~m}^{2}$ de superficie verde por habitante. Esta superficie es insuficiente para el baremo mínimo establecido para la presente tesis $\left(10 \mathrm{~m}^{2}\right)$ por habitante. A esta cuestión le corresponde una puntuación de +0 .

Cuestión B1.2.- ¿Las zonas verdes dentro del centro comercial pueden dar lugar a una área verde de uso cotidiano?: Shopping Eldorado, aunque posee $3038 \mathrm{~m}^{2}$ de superficie verde en su parcela, como se estableció en el conteo realizado en el apartado 3D del presente capítulo. Estas zonas verdes corresponden a medianas entre calles, y el huerto urbano que posee, no está abierto al público, de modo que a este centro le corresponde una puntuación de +0 a esta cuestión.

Cuestión B1.3.- ¿La vegetación en el área (incluyendo el edificio del centro), en que porcentaje es capaz de asimilar las emisiones de la misma área urbana?: Sumando las capacidades de asimilación de las superficies de vegetación establecidas en 3D, tenemos una capacidad de asimilación de 315290,9352 Toneladas de dióxido de carbono anuales asimiladas, dividiendo esta cantidad entre la huella de carbono del área, (600000 Toneladas de dióxido de carbono anuales), el resultado es que las zonas verdes presentes en el área son capaces de asimilar aproximadamente un 53\% de la huella de carbono generada por la misma área asignada al centro comercial. De acuerdo al baremo establecido para esta cuestión ésta puntuará con +2 .

Cuestión B1.4.- ¿La vegetación en el centro comercial y su parcela, en que porcentaje es capaz de asimilar las emisiones del centro comercial?: Los espacios verdes del centro comercial, asimilan aproximadamente 3463 T Co2 anuales cómo se calculó en el apartado 3D. Este dato, en comparación con la huella de carbono del centro estimada en el análisis de CE3X (16473,4 T Co2 anuales), sale como resultado que las zonas verdes del centro comercial son capaces de asimilar un $21 \%$ de la huella de carbono anual del centro, a esta cuestión le corresponde una puntuación de +1

Cuestión B1.5.- ¿La distancia media entre espacios verdes dentro del área es inferior a los 400 metros?: Aunque hay espacios verdes en al área de Shopping Eldorado, en el análisis sobre plano se midieron las distancias medias entre los mismos, quedando como resultado, que los mismos están ubicados a una distancia media que supera los 500 metros; más de los 400 
metros máximos requeridos de distancia entre zonas verdes para la presente tesis. A esta cuestión le corresponde una puntuación de +0.

EN RELACIÓN A ZONAS VERDES, SHOPPING ELDORADO HA OBTENIDO UNA PUNTUACIÓN DE 3 (10).

B2.- Cuestionario referenciado a inserción de superficie asimiladora de agua.

Cuestión B2.1.- ¿El clima en el que está el centro corresponde a un clima árido o semiárido?: De acuerdo al análisis realizado en la misma cuestión para el centro comercial Shopping Light, aplicando la fórmula de Martonne (Pma/(Tma+10)), se obtuvo que El clima de Sao Paulo tiene un índice de Martonne de 49,18, corresponde a una zona húmeda. A Shopping Eldorado le corresponde una calificación de +1 a esta cuestión.

Cuestión B2.2.- ¿En qué porcentaje, la superficie absorbente de agua, en el área urbana, es en relación a la impermeable?: En esta cuestión, se consideraron como superficies permeables las áreas verdes presentes en la zona, al no tener tratamiento de pavimentación $\left(159000 \mathrm{~m}^{2}\right.$ netos), que divididos entre la superficie total del área, resultaron ser aproximadamente un 3\% de los $4665934 \mathrm{~m}^{2}$ totales del área urbana. Esta cuestión puntúa con +0 .

Cuestión B2.3.- ¿El centro comercial posee sistemas para el aprovechamiento del agua?: El centro comercial Shopping Eldorado, salvo las jardineras que conforman el huerto urbano, no posee sistemas avanzados para el aprovechamiento del agua, o el almacenamiento de pluviales. El autor desconoce el estado de las instalaciones debido a la falta de datos sobre las mismas, de manera que no es posible saber si están adaptadas al ahorro de agua, para considerar esta cuestión se consideró la ausencia de las mismas, eligiendo el escenario más desfavorable. A shopping Eldorado le corresponde una puntuación de +0 .

Cuestión B2.4- ¿El consumo de agua del centro es en litros por visita?: a pesar de que no hay datos del centro en este sentido, para el centro comercial Shopping Eldorado, el autor estimó un consumo de agua de 30 litros por visita, que es un consumo medio tirando a moderado, esta nota relativa a esta cuestión corresponde a una puntuación de +1 .

EN RELACIÓN A SUPERFICIE ASIMILADORA DE AGUA, SHOPPING ELDORADO HA OBTENIDO UNA PUNTUACIÓN DE 2 (10).

B3.- Cuestionario referenciado a tratamiento de isla de calor.

Cuestión B3.1.- ¿ ¿El clima en el que está el centro comercial tiene una temperatura media más o menos elevada?. El clima de Sao Paulo tiene una temperatura media anual de 19,3․ De acuerdo al baremo de la presente tesis, esto significa que es un clima cálido propenso a altas temperaturas. Esta pregunta puntúa con +0

Cuestión B3.2.- ¿En el clima en el que está ubicado en centro hay olas de calor frecuentes o en intervalo temporal menor?. De cara al análisis de noticias relacionadas con el tema de las islas de calor, el clima de Sao Paulo, aunque puede tener olas de calor, estas no suelen ser muy frecuentes, esta cuestión puntúa con un +1 . 
Cuestión B3.3.- ¿El centro está en un área en el cual la diferencia de temperatura respecto a la normal es de?. Analizando la isla de calor de Sao Paulo (Figura), nos encontramos con el hecho de que Shopping Eldorado se encuentra en un área con 40 de temperatura respecto de lo normal, esto resulta desfavorable para el centro, debido a que esta isla va acarrear un consumo adicional de energía. De este modo esta cuestión puntúa con un +0. (Figura 5.2.13)

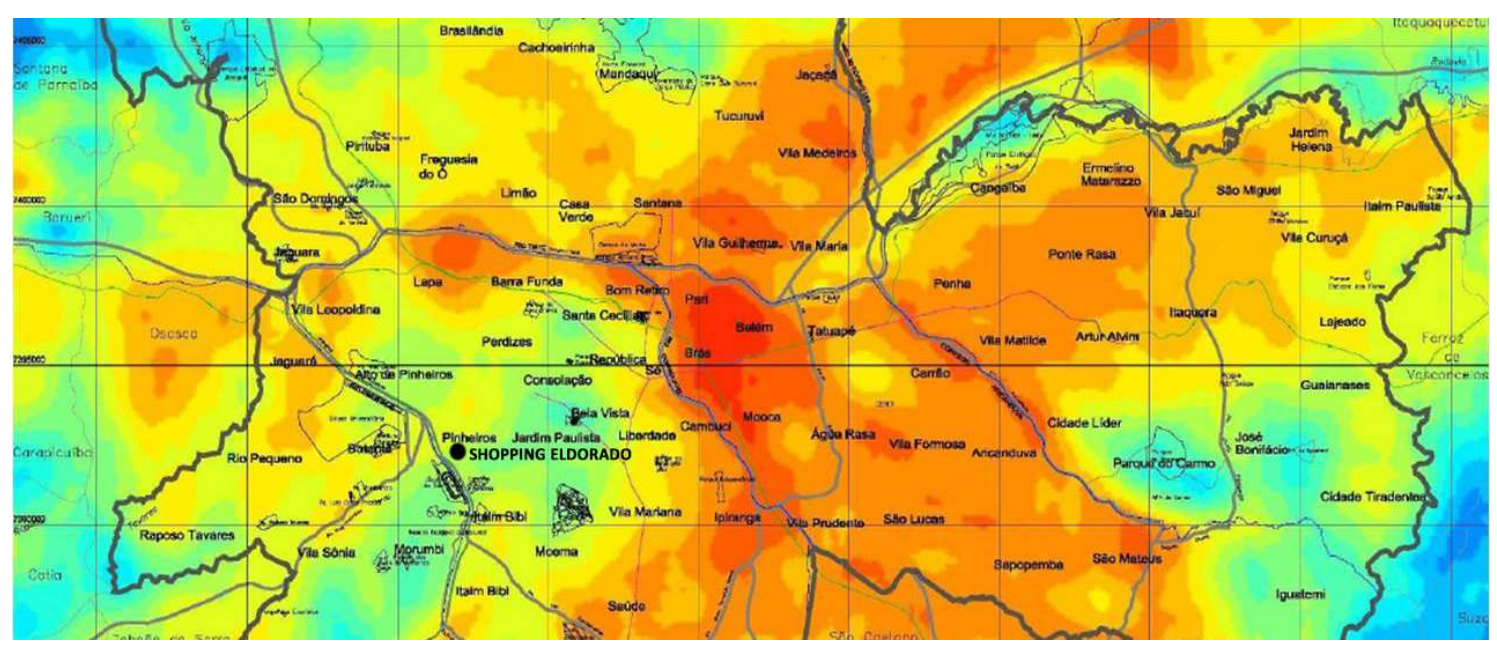

Figura 5.2.14: Isla de calor de Sao Paulo con la ubicación de Shopping Eldorado. Fuente: Elaboración Propia a partir de datos de la Prefeitura de Sao Paulo.

Cuestión B3.4.- ¿La suma de superficies que contribuyen a la isla de calor en la parcela y el edificio del centro es superior a un porcentaje de la superficie total?. De acuerdo al análisis de superficies a efectos de absorción de calor realizado en el apartado $3 \mathrm{~J}$ de este caso de estudio, la superficie absorbente de irradiación de Shopping Eldorado es del 83\%, lo que le corresponde una puntuación de +0 .

EN RELACIÓN A TRATAMIENTO DE ISLA DE CALOR, SHOPPING ELDORADO HA OBTENIDO UNA PUNTUACIÓN DE 1 (10).

\section{C.- REHABILITACIÓN POR USOS.}

C1.- Cuestionario referenciado a inserción de uso residencial.

Cuestión C1.1.- ¿El centro comercial posee usos residenciales u hoteleros dentro de su unidad catastral?. De visitas al centro, y del análisis, Shopping Eldorado no posee usos hoteleros o residenciales, esta cuestión puntúa con +0 .

Cuestión C1.2.- ¿Las parcelas próximas al centro comercial posen usos residenciales u hoteleros?: El uso residencial en las parcelas colindantes al centro comercial fue estimado en un $15 \%$, a partir de mediciones de las parcelas, y considerando los usos de visitas. Lo que le corresponde una puntuación de +1 .

Cuestión C1.3.- ¿Dentro del área de influencia del centro comercial, que porcentaje de la superficie de uso total es de tipo residencial?: Considerando las superficies establecidas para cada zona tipológica, estas fueron sumadas, obteniendo una superficie residencial total $\left(4897115 \mathrm{~m}^{2}\right)$ que fue comparada con la superficie total construida $\left(9516982 \mathrm{~m}^{2}\right)$. De este modo, 
la superficie de uso residencial en el área de Shopping Eldorado, se estableció aproximadamente en un $51 \%$ de la superficie edificada total, lo que le corresponde una puntuación de +4

EN RELACIÓN A USO RESIDENCIAL, SHOPPING ELDORADO HA OBTENIDO UNA PUNTUACIÓN DE 5 (10).

C2.- Cuestionario referenciado a inserción de usos productivos, y terciarios no comerciales.

Cuestión C2.1.- ¿El centro comercial posee usos productivos no comerciales dentro de su unidad catastral?: Shopping Eldorado posee unas oficinas de la policía federal, lo que puede ser considerado como uso productivo. Esta cuestión puntúa con +1 .

Cuestión C2.2.- ¿Las parcelas próximas al centro comercial posen usos productivos no comerciales?: Las parcelas próximas al centro comercial, poseen una amplia oferta de instalaciones terciarias de oficinas y administrativas, que se computaron en aproximadamente un $60 \%$ de la superficie total construida en las parcelas próximas, esta cuestión puntúa con un +3 .

Cuestión C2.3.- ¿Dentro del área de influencia del centro comercial, que porcentaje de la superficie de uso total es de tipo productivo no comercial?: Considerando las superficies productivas establecidas para cada zona tipológica, estas fueron sumadas obteniendo una superficie productiva total $\left(2841746 \mathrm{~m}^{2}\right)$ que fue comparada con la superficie total construida $\left(9516982 \mathrm{~m}^{2}\right)$. De este modo, la superficie de uso productivo en el área de Shopping Eldorado, se estableció aproximadamente en un $29,86 \%$ de la superficie edificada total. A esta cuestión le corresponde una puntuación de +5 .

EN RELACIÓN A USO PRODUCTIVO, SHOPPING ELDORADO HA OBTENIDO UNA PUNTUACIÓN DE 9 (10).

C3.- Cuestionario referenciado a inserción de instalaciones dotacionales y asistenciales.

Cuestión C3-1.- ¿El centro comercial posee usos dotacionales dentro de su unidad catastral?: El centro comercial Shopping Eldorado, posee unas oficinas de la policía federal, pero al no ser una instalación concurrida de forma habitual, esta cuestión puntúa con un +0 .

Cuestión C3.2.- ¿Las parcelas próximas al centro comercial posen usos dotacionales?: En las parcelas próximas del centro comercial Shopping Eldorado no hay instalaciones dotacionales de ningún tipo. Esta pregunta puntúa con un +0 .

Cuestión C3.3.- ¿A un kilómetro del centro comercial hay usos dotacionales?: En el área de dotaciones correspondiente a lo que es el centro comercial de Shopping Eldorado, hay una gran cantidad de dotaciones de diversa capacidad, habiendo algunas muy concurridas. Aunque no hay grandes dotaciones a nivel nacional, si hay un gran número de dotaciones muy concurridas a nivel local (colegios e iglesias). Esta cuestión puntúa con +5 .

EN RELACIÓN A DOTACIONES, SHOPPING ELDORADO HA OBTENIDO UNA PUNTUACIÓN DE 5 (10). 


\section{D.- REHABILITACIÓN DE ENTORNO URBANO.}

D1.- Cuestionario referenciado a la inserción de medios de transporte eficientes.

Cuestión D1.1.- ¿El centro dispone en sus inmediaciones de alguna parada de transporte público?: El centro comercial Shopping Eldorado, posee instalaciones de transporte público en las inmediaciones de sus parcelas, siendo algunas estaciones de tránsito transbordos de gran importancia (Estación de Pinheiros, y parada del autobús en Eusebio Matoso). la puntuación es de +1 .

Cuestión D1.2.- ¿El tiempo de llegada al centro mediante transporte público supera al tiempo de llegada en vehículo particular?, Comparando los datos obtenidos de los apartados $2 \mathrm{E}$ y $2 \mathrm{~F}$, (dividiendo el tiempo de llegada en transporte público, entre el tiempo de llegada en transporte privado) el tiempo de llegada medio en transporte público es ligeramente mayor que el empleado usando un vehículo particular (1,36 veces mayor, considerando tiempos de aparcamiento del vehículo particular), esta cuestión puntúa con +2. (Figura 5.2.14)

\begin{tabular}{|l|r|r|r|}
\hline Comparación tiempos recorrido & Recorrido 1 & Recorrido 2 & Recorrido 3 \\
\hline Total tiempo desplazamiento t. publico & 17 & 19 & 8 \\
\hline Total tiempo desplazamiento t. particular & 10 & 11 & 12 \\
\hline Relación entre tiempos desplazamiento & 1,7 & 1,727272727 & 0,666666667 \\
\hline Media tiempo desplazamiento & & & 1,364646465 \\
\hline
\end{tabular}

Figura 5.2.15: Comparación tiempos de llegada. Fuente: Elaboración Propia

Cuestión D1.3.- ¿El área urbana del centro comercial está cubierta de forma adecuada por la infraestructura de transporte público?. A partir de mediciones sobre plano de los radios de influencia de las paradas de transporte público, se pudo establecer que el área urbana de Shopping Eldorado, está cubierta en un 52\% aproximadamente por la infraestructura de transporte público. Lo que la cuestión puntúa con un +1 .

Cuestión D1.4.- ¿ ¿Los usos en la zona están mezclados o zonificados?: Cómo se estudió en $1 \mathrm{~K}$ en el área de Shopping Eldorado, el índice Global de Mezcla de usos es de 0,4 (Zona de complejidad urbana media), esto le corresponde una puntuación de +1 .

Cuestión D1.5.- ¿El centro comercial y el área urbana próxima al centro cuenta con instalaciones enfocadas en la movilidad sostenible?: De visitas al centro se comprobó que el centro comercial Shopping Eldorado no posee sistemas adaptados a la movilidad sostenible, al igual que tampoco las posee el área próxima al mismo. Esta cuestión obtiene una puntuación de +0 .

EN RELACIÓN A TRANSPORTE EFICIENTE, SHOPPING ELDORADO HA OBTENIDO UNA PUNTUACIÓN DE 5 (10).

D2.- Cuestionario referenciado a la rehabilitación por corrección de la densidad en área urbana.

Cuestión D2.1.- ¿La densidad de población en el área del centro está en el intervalo entre h/ha?, La densidad de población del área de Shopping Eldorado es la del distrito Pinheiros $\left(0,0081 \mathrm{hab} / \mathrm{m}^{2}\right)$, lo que corresponde a una densidad media, esta cuestión le corresponde una puntuación de +2 . 
Cuestión D2.2.- ¿A efectos de densidad, el tejido mayoritario es favorable o desfavorable de cara a la sostenibilidad?. El índice global de densidad del área de Shopping Eldorado es de 1,7, lo que es un entorno de densidad media, a esta cuestión le corresponde una puntuación de +2 .

Cuestión D2.3.- ¿La cantidad de espacio ocupado en el área está en el intervalo? El espacio medio ocupado por la edificación en el área de análisis total de Shopping Eldorado, se halló multiplicando cada porcentaje de ocupación de la zona por el porcentaje que esta ocupa respecto del total $(40 * 39,34+64 * 40,25+66 * 9,43+35 * 10,98) \%$, lo que corresponde a un $51,56 \%$ de la superficie respecto de la superficie total. A este estado le corresponde a una puntuación de +3 .

EN RELACIÓN A DENSIDAD, SHOPPING ELDORADO HA OBTENIDO UNA PUNTUACIÓN DE 7 (10).

D3.- Cuestionario referenciado a mejora de la seguridad y la pasibilidad en el área urbana.

Cuestión D3.1.- ¿En el área de influencia o en sus proximidades hay elementos negativos de cara a la seguridad o a la salubridad del área?: En el área cercana a Shopping Eldorado, hay enormes áreas sin uso, bloqueadas y divididas, debido a la presencia del río, y a las grandes vías de tránsito. Esto aumenta la lejanía entre puntos concretos y se propicia la aparición de espacios urbanos sin uso. Esta cuestión puntúa con +0.

Cuestión D3.2.- ¿El centro comercial se encuentra en una zona de puntos fríos de actividad durante el día?. El área de Shopping Eldorado, no tiene puntos fríos durante el día debido a la presencia de avenidas con gran tránsito urbano, habiendo además una gran cantidad de dotaciones e instalaciones con horario de uso diurno, esta cuestión puntúa con +1.

Cuestión D3.3.- ¿El centro comercial se encuentra en una zona de puntos fríos durante la noche?. Como consecuencia de las largas distancias que supone el cruce del río, y el cierre nocturno de los edificios de oficinas, en la zona del centro comercial Shopping Eldorado van a haber puntos fríos durante la noche. Estos puntos van a estar centrados en las áreas cercanas a los centros financieros y las orillas del río, esta cuestión puntúa con +0 .

Cuestión D3.4.- ¿El centro comercial se encuentra en una zona con áreas de difícil control visual o de contacto urbano?. El área urbana de Shopping Eldorado, a pesar de que tiene elementos de barrera en los puentes del río y las infraestructuras de gran capacidad que lo flanquean, no hay desniveles ni construcciones que dificulten la visibilidad urbana. Esta cuestión puntúa con +1

Cuestión D3.5.- ¿La sensación de seguridad por parte de los ciudadanos de la zona es positiva o negativa?. Aun no siendo tan severa como en el centro o en la periferia, en el centro expandido de Sao Paulo, la sensación de inseguridad permanente está muy arraigada entre los ciudadanos. La puntuación a esta cuestión es de +0 .

Cuestión D3.6.- ¿La zona próxima al centro comercial tiene un porcentaje de fachadas activas?: En las manzanas anejas al centro comercial, hay un $31 \%$ de fachadas activas relacionadas con locales concurridos, lo que le corresponde una puntuación de +1 . 
Cuestión D3.7.- ¿La distancia de la puerta del edificio del centro comercial al inmueble residencial cercano es superior a los 200 metros?: El inmueble residencial más cercano a Shopping Eldorado, se encuentra a 20 metros en una acera aneja, siendo este parte de un complejo de viviendas unifamiliares de clase alta, esta cuestión puntúa con +1 .

Cuestión D3.8.- ¿La cantidad de espacio libre en el área va a resultar desfavorable de cara a la paseabilidad?: El espacio libre de media en el área de Shopping Eldorado, se calculó restando a 1 el porcentaje medio de espacio ocupado de D2.3. El espacio ocupado medio en la zona, es de aproximadamente un $51,56 \%$, lo que supone que el espacio libre es de un $48,44 \%$. Esto corresponde a un área que no es escasa densidad edificada, en la que la lejanía entre edificios desfavorezca el uso del espacio urbano. Esta cuestión va a puntuar con un +1 .

Cuestión D3.9.- ¿Los usos en la zona están mezclados o zonificados? El índice global de mezcla de usos es de 0,4 en el área urbana de Shopping Eldorado. Se puede deducir de este modo, que aunque hay mezcla de usos, ésta resulta escasa como para propiciar una actividad urbana constante e intensa. Esta cuestión puntúa con +0.

EN RELACIÓN A PASEABILIDAD, SHOPPING ELDORADO HA OBTENIDO UNA PUNTUACIÓN DE 5 (10).

\section{E.- CUESTIONARIO RELACIONADO CON LA ACTIVIDAD DEL CENTRO Y SUS CONSECUENCIAS URBANAS.}

Cuestión E1: ¿La actividad del centro comercial, va a penalizar o a favorecer la sostenibilidad del entorno urbano?: Shopping Eldorado tiene un índice de atracción de 3 de acuerdo al apartado $\mathrm{C5}$, y la puntuación total en el cuestionario relacionado con el transporte eficiente (D1) es de 5. De este modo, consultando la tabla del apartado 3.10, 4E, se comprueba que el efecto de la actividad que ejerce el centro sobre el área urbana, no es suficiente para alterar los procesos de actividad urbana anteriormente estudiados. De este modo, las puntuaciones de los cuestionarios anteriormente desarrollados, se mantienen sin experimentar cambios de puntuación.

\section{FASE FINAL: GRÁFICO DE LA ROSA DE REHABILITACIÓN SOSTENIBLE.}

Las puntuaciones obtenidas en el anterior cuestionario, fueron colocadas en el gráfico de la rosa de rehabilitación sostenible, obteniendo el siguiente resultado (Figura 5.1.15): 


\section{(A) ECOEFICIENTE}

(B1)

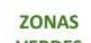

VERDES

\section{MEDIDAS}

(A3)

PASIVAS
(A2)

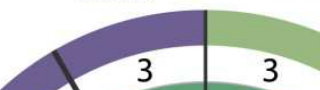

(A1)

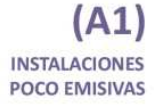

Activas

3

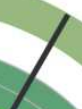

ASIMILADORA
AGUA

(B) MEDIOAMBIENTAL

\section{(B2)}

UMBRALES

2 puntos: Umbral de mínimos,

Rehabilitación prioritaria

8 puntos: Situación Óptima,

(B3)

TRATAMIENTO

ISLA CALOR

da prioritaria

10 puntos: Paradigma verde

ZONAS E INTERVALOS

0-2 puntos: rehabilitación

muy prioritaria

(D3)

SEGURIDAD

2-8 puntos: rehabilitación

de prioridad de media a

moderada

8-10 puntos: rehabilitación

no prioritaria.

(D2)

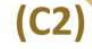

uso
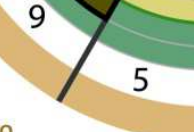

5

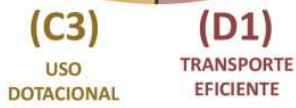

FICIENTE

(D) ENTORNO URBANO

Figura 5.2.16: Gráfico de la rosa de la rehabilitación sostenible para Shopping Eldorado. Fuente: Elaboración Propia.

De este modo, de acuerdo al gráfico, Shopping Eldorado es un caso de centro comercial que se ubica en un área urbana de la periferia próxima con ciertas carencias en lo referente a complejidad y actividad, en la cual el transporte público es medianamente eficaz para la movilidad. El edificio del centro tiene un comportamiento bioclimático poco adecuado a las condiciones climáticas de Sao Paulo, siendo prioritarias las medidas pasivas y la adaptación del edificio al clima para el ahorro energético. No obstante, este centro y su área urbana, aunque son áreas moderadamente complejas a efectos de actividad urbana, presentan unas serias carencias de cara a lo que es la calidad medioambiental tanto a efectos de isla de calor, como de emisiones, zonas verdes y agua y suelo; aun habiendo zonas verdes en el área y en el centro. De este modo, las rehabilitaciones que resultarían más eficaces de cara a la mejora de la sostenibilidad urbana, deberían de estar centradas en el tema medioambiental, cobrando importancia lo que es la mitigación de la isla de calor y la superficie permeable. También resultaría viable en segundo plano para la rehabilitación, la mejora de los medios de movilidad sostenible y la paseabilidad, así como una tímida densificación en las partes del entorno urbano de baja densidad, considerando el uso residencial o dotacional. En tercer lugar se considerará la mejora de las instalaciones, y la inserción de medidas solares activas.

\section{3.- CASO 3: SHOPPING ARICANDUVA}

El caso de Shopping Aricanduva es un caso de gran superficie ubicado en la periferia de la ciudad de Sao Paulo, siendo este centro el superficie el mayor de la ciudad, y uno de los más grandes de América del Sur. Este caso fue de importancia para la presente tesis, debido a que corresponde a una centralidad comercial que ocupa una gran superficie, la cual se encuentra ubicada en un área en la que la densidad de población es relativamente escasa, y da servicio a un área urbana de gran amplitud. De este modo, en este capítulo se va a analizar el centro comercial Aricanduva y su área urbana asignada de acuerdo a la metodología. 


\section{FASE 0: RECOGIDA DE DATOS CUANTITATIVOS.}

En esta fase, se va a realizar una recogida de datos cuantitativos oficiales del centro comercial Aricanduva y su entorno urbano dentro del distrito de Aricanduva, en la zona periférica de Sao Paulo. Estos se hallarán bien a partir de fuentes oficiales del propio centro, las autoridades urbanas, o bien midiendo sobre plano. La justificación de esto, es establecer los datos cuantitativos de partida que nos sentarán las bases de posteriores análisis más particularizados e exhaustivos relacionados con la metodología de análisis. (Figura 5.3.1)

\begin{tabular}{|l|l|}
\hline \multicolumn{2}{|c|}{ SHOPPING ARICANDUVA } \\
FASE 0, RECOGIDA DE DATOS CUANTITATIVOS \\
\hline OC.- TABLA DE DATOS CENTRO & Valor \\
\hline OC1: Superficie centro comercial (m2) & 425.000 \\
\hline OC2: Superficie de parcela o ud. Catastral (m2) & 497.450 \\
\hline OC3: Superficie en planta (m2) & 216.000 \\
\hline OC4: Número de visitantes semanal (pe/sem) & 716.000 \\
\hline OC5: Índice de Atracción ( $\mathrm{n}$ ) & 5 \\
\hline OC6: Superficie de tipo residencial (m2) & 0 \\
\hline OC7: Superficie de uso productivo (m2) & 175 \\
\hline OC8: Número de instalaciones dotacionales ( $\mathrm{n}$-) & 1 \\
\hline OU.- TABLA DE DATOS ENTORNO URBANO & Valor \\
\hline OU1: Población asignada a centro (pe) & 212.500 \\
\hline OU2: Densidad de población (hab/m2) & 0,012 \\
\hline U03: Superficie partida de entorno urbano (m2) & 17.708 .333 \\
\hline
\end{tabular}

Figura 5.3.1: Tabla de Datos Shopping Aricanduva. Fuente: Elaboración propia

\section{OC.- TABLA DE DATOS DEL CENTRO COMERCIAL.}

C1: SUPERFICIE CENTRO COMERCIAL TOTAL: Este dato fue obtenido de fuentes relacionadas con el centro disponibles en internet, ya que no pudieron obtenerse datos oficiales de la gerencia de este centro. La superficie edificada de Shopping Aricanduva es de $425.000 \mathrm{~m}^{2}$ aproximadamente.

C2: SUPERFICIE TOTAL DE LA PARCELA DEL CENTRO: Para la obtención de este dato se midió la superficie de la parcela directamente, en un parcelario de la ciudad de Sao Paulo correspondiente al área del centro, que se obtuvo de parte de la Prefeitura de Sao Paulo. La superficie de la parcela es de $497.450 \mathrm{~m}^{2}$

C3: SUPERFICIE EN PLANTA DEL EDIFICIO DEL CENTRO COMERCIAL. Midiendo en el parcelario obtenido anteriormente, se obtuvo que la superficie edificada de Shopping Aricanduva es de $216.000 \mathrm{~m}^{2}$. Dividiendo esta superficie entre la total de parcela del centro comercial establecida anteriormente (C2), se obtuvo una ocupación en planta del $43 \%$ de su superficie total.

C4: NÚMERO DE VISITANTES SEMANAL. Al no poder obtenerse datos del número de visitantes del centro comercial Shopping Aricanduva, se realizó un conteo estimativo de las visitas tomando como base los datos de Shopping Light del apartado C4 de la metodología, considerándose a su vez un coeficiente de ponderación de 1 debido al gran tamaño de este centro comercial, y a su importancia en la ciudad de Sao Paulo. De este modo, para Shopping Aricanduva tenemos este número de visitas semanal: 
De lunes a viernes: 341000 personas.

Sábado: 283030 personas.

Domingo: 92070 personas.

De este modo, el número de visitantes semanal de Shopping Aricanduva es de 716.100 personas, de acuerdo al método estipulado, siendo el mensual de 3,4 millones aproximadamente. Hay fuentes que estiman las visitas mensuales de Shopping Aricanduva en 4,5 millones de personas.

C5: ÍNDICE DE ATRACCIÓN DEL CENTRO. En función al número de visitantes del centro, y al baremo del capítulo C5 de la metodología. A Shopping Aricanduva le corresponde un índice de 5 (Más de 300.000 visitantes por semana).

C6: SUPERFICIE DE USO EN EL CENTRO DE TIPO RESIDENCIAL. De visitas al centro y análisis de planos oficiales y páginas web relacionadas, se estableció que Shopping Aricanduva no posee superficie residencial dentro de su unidad catastral.

C7: SUPERFICIE DE USO EN EL CENTRO DE TIPO PRODUCTIVO: En base a las visitas que el autor realizó al centro, se consideró como superficie de tipo productivo las oficinas de la policía militar que están dentro del recinto del centro comercial, estas miden aproximadamente 175 $m^{2}$.

C8: NÚMERO DE INSTALACIONES EN EL CENTRO DE TIPO DOTACIONAL O ASISTENCIAL: En Aricanduva hay 1 local de uso asistencial, que es la comisaría anteriormente mencionada, este dato se extrajo del análisis de la planta y la visita al centro.

OU.- TABLA DE DATOS DEL ENTORNO URBANO.

U1: POBLACIÓN DE ÁREA URBANA ASIGNADA A CENTRO COMERCIAL: De acuerdo a la metodología, dividiendo la superficie del centro comercial $\left(425.000 \mathrm{~m}^{2}\right)$ entre 2 , salió una población asignada de 212.500 personas.

U2: DENSIDAD DE POBLACIÓN EN EL DISTRITO DEL CENTRO COMERCIAL: Para el análisis urbano, se cogió la densidad de población del distrito de Aricanduva en Sao Paulo, que es dónde está ubicado el centro comercial, la densidad se estableció en $0,012 \mathrm{hab} / \mathrm{m}^{2}$ a partir de los datos oficiales del Ayuntamiento de Sao Paulo para 2010.

U3: SUPERFICIE DEL ENTORNO URBANO: La superficie del entrono urbano a analizar, se sacó de los datos de población asignada al centro en el apartado U1 (212.500p), la cual fue dividida entre la densidad del área urbana establecida en U2 $\left(0,012 \mathrm{hab} / \mathrm{m}^{2}\right)$. La superficie de partida es de $17.708 .333 \mathrm{~m}^{2}$ considerándose los bordes urbanos para delimitar su contorno.

\section{FASE 1: ANÁLISIS DEL CONTEXTO URBANO.}

Este análisis se realizarán mediciones sobre plano de diferentes facetas presentes en la extensa área urbana correspondiente al análisis del centro comercial Shopping Aricanduva. Se trabajarán diferentes escalas, siendo predominante la escala urbana amplia de toda la zona de influencia del centro comercial, en este apartado se establecerá el área de influencia total, y 
sus sub áreas, tanto homogéneas cómo verdes. Para este análisis resultará fundamental el uso de los datos referentes a la configuración del entorno urbano de la periferia de Sao Paulo, establecidos en el apartado anterior. Estos datos van a ser ponderados con la información que pudiera sacarse del análisis sobre plano, y de este análisis, el objetivo será hallar y establecer las pautas urbanísticas para el cuestionario de rehabilitación del centro comercial. Se considerarán aspectos relacionados con configuraciones de volumen urbano, densidades, usos, áreas verdes y medio ambiente urbano.

1A: ESTABLECIMIENTO DEL ÁREA DE INFLUENCIA DEL CENTRO COMERCIAL: En base a la superficie del área, hallada anteriormente por la superficie construida del centro comercial, y la densidad de población del distrito Aricanduva. Se estableció para el área de análisis del centro comercial Shopping Aricanduva, mediante la siguiente fórmula:

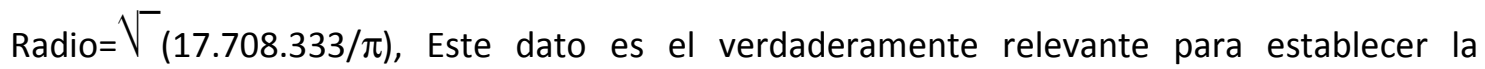
superficie del área de análisis. (Figura 5.3.2) Siendo el resultado de la fórmula, un radio de aproximadamente 2374 metros a partir del lindero de la parcela del centro.

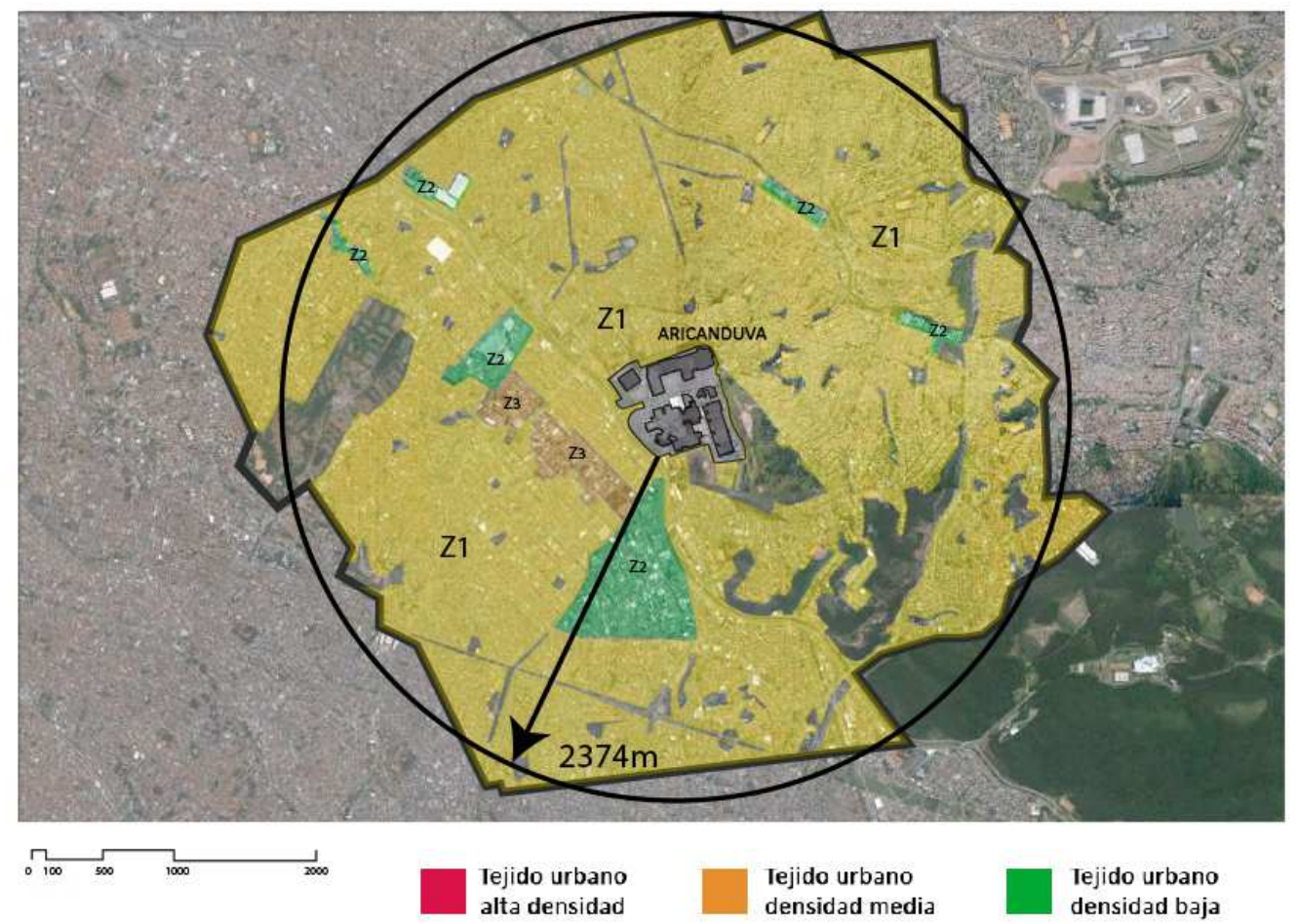

Figura 5.3.2: Área de Shopping Aricanduva y subdivisión por zonas homogéneas. Fuente:Elaboración Propia a partir de datos de Google.

1B: DELIMITACIÓN SOBRE PLANO DEL ÁREA DE INFLUENCIA: En base al radio anteriormente establecido, y considerando la configuración del entorno urbano, se estableció la siguiente área, considerando las vías importantes y las áreas verdes (Figura 5.2.2). EL ÁREA DE ANÁLISIS FINAL PARA SHOPPING ARICANDUVA, QUEDÓ ESTABLECIDA EN $23.373 .686 \mathrm{~m}^{2}$ TRAS LA OPERACIÓN DE DELIMITACIÓN. Ésta área se estableció mayor que la superficie de partida, debido a los espacios verdes, y a la fuerte influencia que este centro tiene sobre una gran área de la ciudad de Sao Paulo. 
1C: SUBDIVISIÓN DEL ÁREA DE INFLUENCIA EN ÁREAS HOMOGÉNEAS Y DELIMITACIÓN DE ZONAS VERDES Para este análisis, el área urbana anteriormente asignada, va a dividirse en zonas homogéneas de acuerdo a la naturaleza edificada de su tejido urbano, (Figura 5.2.2) marcándose a su vez la superficie de zonas verdes. En el área de este centro comercial, debido a su gran tamaño se establecieron tres tipologías de zona homogénea, descontando los espacios verdes y sin edificar en el área. Cada zona tiene aproximadamente:

Z1: $18.599 .107 \mathrm{~m}^{2}$ brutos.

Z2: $974.000 \mathrm{~m}^{2}$ brutos.

Z3: $367.100 \mathrm{~m}^{2}$ brutos.

La suma total de las zonas edificadas es de $20.433 .247 \mathrm{~m} 2$.

1D: PORCENTAJE DE OCUPACIÓN DE LA EDIFICACIÓN Y ÁREA OCUPADA: A partir del análisis de unas áreas tipo de $200 \times 200 \mathrm{~m}^{2}$ sobre parcelarios oficiales de la ciudad de Sao Paulo, El porcentaje de ocupación de la edificación de las zonas homogéneas establecida para las áreas de influencia de Shopping Aricanduva son: (Figura 5.3.3)
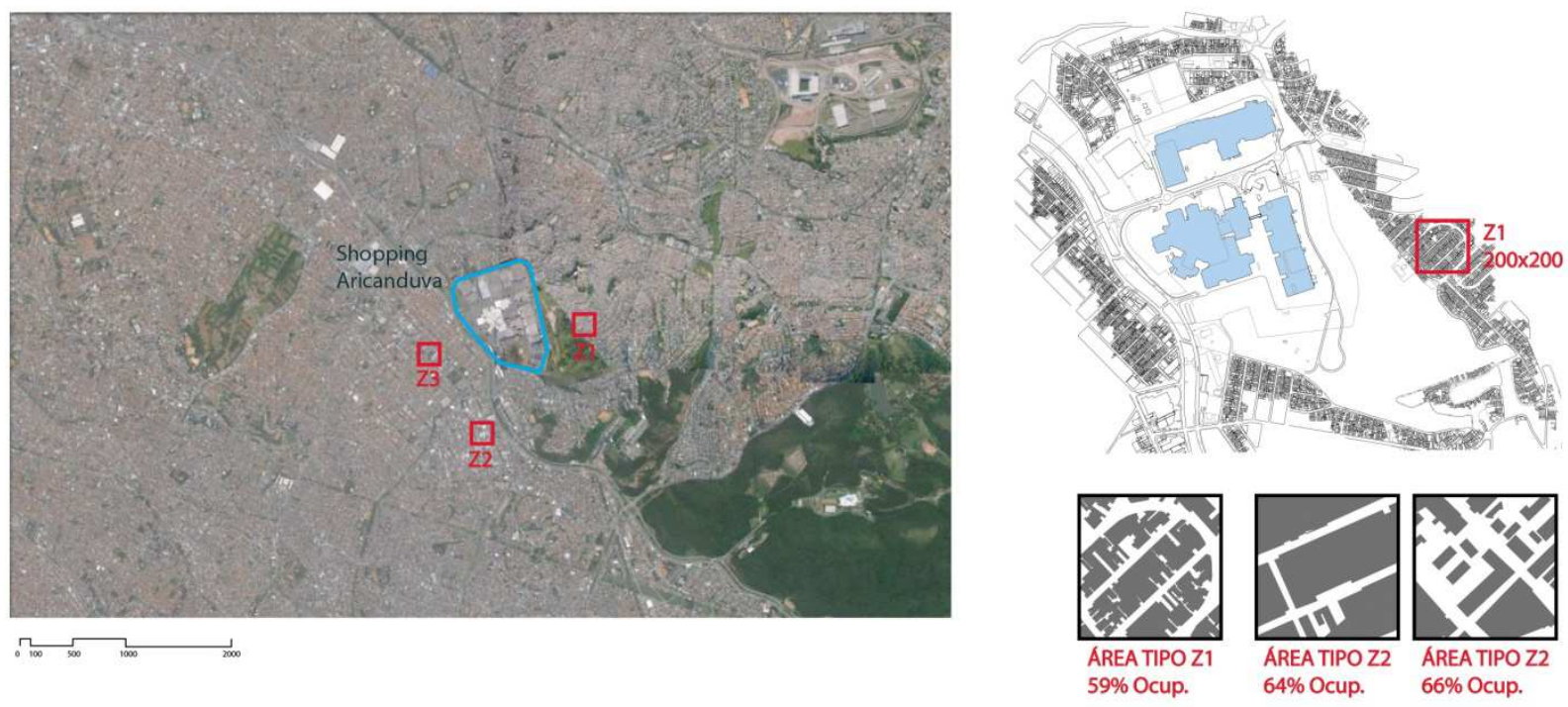

Figura 5.3.3: Análisis de ocupación sobre parcelario Fuente: Elaboración Propia a partir de datos de Google y la Pr. Sao Paulo.

Estos porcentajes del análisis de tejidos serán aplicados a las superficies de área total, hallándose de esta forma la superficie ocupada en planta neta total de cada zona homogénea establecida.

Z1: $59 \%$ de superficie ocupada. Superficie ocupada $10.973 .473 \mathrm{~m}^{2}$.

Z2: $64 \%$ de superficie ocupada. Superficie ocupada $711.020 \mathrm{~m}^{2}$.

Z3: $66 \%$ de superficie ocupada. Superficie ocupada $172.537 \mathrm{~m}^{2}$.

1E: ALTURAS DE LA EDIFCACIÓN POR ÁREA HOMOGÉNEA: Para las diferentes áreas homogéneas de Shopping Aricanduva, se establecieron las siguientes alturas de edificación. Esto fue realizado de manera estimativa a partir de visitas al área y análisis de fotos de calles de Google Maps.

Z1: 2 alturas. Z2: 1 altura. Z3: 6 alturas. 
1F: ESTABLECIMIENTO DE LAS TIPOLOGÍAS DE TEJIDO EN BASE A LA MORFOLOGÍA URBANA POR ÁREA HOMOGÉNEA: con las ocupaciones y números de plantas anteriormente estudiados, y considerando el baremo de la tabla correspondiente a densidades del presente apartado en el capítulo 3.6, a cada área de Shopping Aricanduva le corresponden estas densidades.

Z1: Zona de densidad media. Z2: Zona poco densa. Z3: zona de densidad media.

1G.- ÍNDICE GLOBAL DE DENSIDAD. Considerando los diferentes criterios de densidad anteriormente establecidos, y el porcentaje que ocupan las mismas respecto de la superficie total, tenemos este índice global de densidad.

Z1: Índice de 2, representa el 93,27\% de la superficie total, suma al índice global 1,87 puntos. Z2: Índice de 1, representa el 4,88\% de la superficie total, suma al índice global 0,05 puntos. Z3: Índice de 2, representa el $1,84 \%$ de la superficie total, suma al índice global 0,04 puntos.

De este modo el índice global de densidad es de 1,95 puntos, lo que corresponde una zona de densidad media.

1H: SUPERFICIE EDIFICADA TOTAL DE CADA ÁREA HOMOGÉNEA. Para la superficie edificada total, se multiplicó la superficie en planta anteriormente hallada, por el número medio de plantas. De este modo, la superficie total edificada aproximada por área es de:

$\mathrm{Z1:} 10.973 .473 \mathrm{~m}^{2} \times 2 \mathrm{pl}=21.946 .946 \mathrm{~m}^{2}$.

$\mathrm{Z2:} 711.020 \mathrm{~m}^{2} \times 1 \mathrm{pl}=711.020 \mathrm{~m}^{2}$.

Z3: $172.537 \mathrm{~m}^{2} . \times 6 \mathrm{pl}=1.035 .222 \mathrm{~m}^{2}$.

Siendo la superficie edificada total del área urbana de análisis de $23.693 .188 \mathrm{~m} 2$

11: ESTABLECIMIENTO DE PORCENTAJES DE USO DENTRO DE LAS ZONAS HOMOGÉNEAS ESTABLECIDAS: El área de Shopping Aricanduva corresponde a un entorno complejo en el que hay edificios tanto residenciales como comerciales y administrativos. Al no haber datos objetivos sobre los usos predominantes en la zona, se consideraron los siguientes porcentajes a partir de estimaciones analizando las tipologías de edificio y vistas de campo:

Z1: $85 \%$ residencial, $5 \%$ productivo, $10 \%$ comercial.

Z2: $0 \%$ residencial, $90 \%$ productivo, $10 \%$ comercial.

Z3: $10 \%$ residencial, $70 \%$ productivo, $20 \%$ comercial.

1J: CONTEO DE LOS USOS DENTRO DEL CONTEXTO URBANO. Una vez se establecieron los porcentajes, para obtener los metros cuadrados de uso, éstos fueron multiplicados por la superficie edificada total de cada zona homogénea $(1 \mathrm{H})$, quedando establecidos los usos para Shopping Aricanduva de la siguiente manera:

Z1: $18654904 \mathrm{~m}^{2}$ residencial, $1097347 \mathrm{~m}^{2}$ productivo, $2194695 \mathrm{~m}^{2}$ comercial.

Z2: $0 \mathrm{~m}^{2}$ residencial, $639918 \mathrm{~m}^{2}$ productivo, $71102 \mathrm{~m}^{2}$ comercial.

Z3: $724655 \mathrm{~m}^{2}$ residencial, $103522 \mathrm{~m}^{2}$ productivo, $207044 \mathrm{~m}^{2}$ comercial.

1K: ÍNDICE GLOBAL DE MEZCLA DE USOS. Para el índice global de mezcla de usos, se sumaron los porcentajes, quedando los del análisis de la siguiente manera, se sumaron los porcentajes 
de uso comercial y productivo hallados en $1 \mathrm{l}$, para hallar el uso no residencial, en base a la división de los porcentajes, se pudo hallar el índice de mezcla de usos.

Z1: $85 \%$ uso residencial, $15 \%$ uso no residencial, índice mezcla usos de 0

Z2: $0 \%$ uso residencial, $100 \%$ uso no residencial, índice mezcla usos de 0

Z3: 70\% uso residencial, 30\% uso no residencial, índice mezcla usos de 1

De este modo, multiplicando los índices de uso, por los porcentajes de cada zona homogénea, y sumando los resultados,

Z1: Índice de 0, representa el 93,27\% de la superficie total, suma al índice de mezcla de usos 0 puntos.

Z2: Índice de 0, representa el $4,88 \%$ de la superficie total, suma al índice de mezcla de usos 0 puntos.

Z3: Índice de 1, representa el 1,84\% de la superficie total, suma al índice de mezcla de usos 0,018 puntos.

Tras la suma de los índices finales, se saca que el área de Shopping Aricanduva tiene un índice de mezcla de usos de 0,018. Que corresponde a un área poco compleja a efectos de usos.

1L: CONTEO DEL NÚMERO DE DOTACIONES DENTRO DEL CONTEXTO URBANO, DENTRO DEL ÁREA DE DOTACIONES Se estableció un área circular de un 1 kilómetro de radio a partir del lindero del centro, y dentro del mismo se marcaron las siguientes dotaciones: 1 dotaciones de visita esporádica, 9 dotaciones de visita habitual, y ninguna gran dotación muy visitada. (Figura 5.3.4) Este análisis va a ser determinante de cara al análisis del uso dotacional.

\section{M: PRESENCIA E INFLUENCIA DE ELEMENTOS POSITIVOS Y NEGATIVOS:}

Como elemento a destacar en este análisis, se comprobó que en el lindero noroeste de Shopping Aricanduva hay una favela (Jardím Ipanema, Cidade Líder). Aunque esto de antemano no tiene por qué suponer un impacto negativo, ya hay que hay favelas pacíficas; en la presente tesis se indagó sobre esa favela en particular. Se encontró en varios noticiarios de Sao Paulo (Sao Paulo Agora) (http://www1.folha.uol.com.br/agora/policia/pl3101200701.htm). Las noticias de que esa favela fue un escenario de tiroteos hacia el recinto del centro comercial, habiendo en ella a su vez problemas de fabricación y tráfico de drogas. (G1 Sao Paulo, 17/04/2012) (http://g1.globo.com/sao-paulo/noticia/2012/04/policia-prende-irmaossuspeitos-de-trafico-na-zona-leste-de-sp.html). Por consiguiente, esa favela fue considerada como un elemento de impacto negativo de cara a la paseabilidad en el área próxima al centro comercial.

1N: ZONAS DE ACTIVIDAD: El área en la que se encuentra Shopping Aricanduva, es poco activa por lo general, ya que los usos no residenciales se ubican en calles y avenidas muy localizadas. Hay fuertes puntos fríos tanto diurnos como nocturnos, especialmente en las inmediaciones del centro. Esto último se debe a la presencia de grandes espacios libres sin edificar y o parcelas de fondo de saco, que se configuran como consecuencia de las tapias del recinto del centro comercial. Esto incrementa las distancias entre el entorno urbano y la entrada del 
centro, siendo relevante también la presencia de las barreras generadas por el río y las avenidas. (Figura 5.3.4)

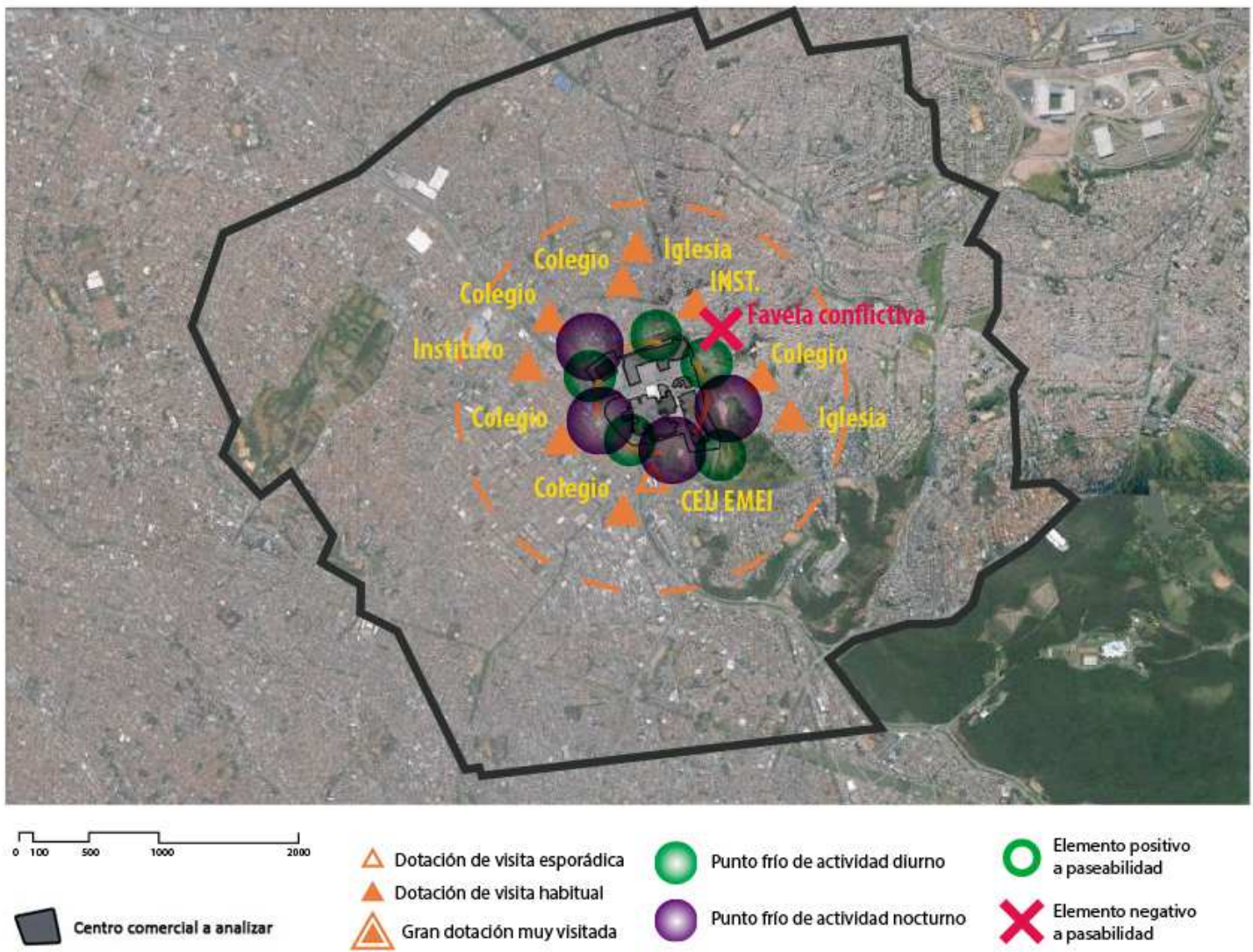

Figura 5.3.4: Área de Shopping Aricanduva, Dotaciones, puntos fríos y elementos positivos y negativos Fuente: Elaboración Propia a partir de datos de Google.

10: ÁREAS ARBOLADAS Y VERDES, DENTRO DEL ÁREA URBANA DEL CENTRO: Dentro del área de shopping Aricanduva, se consideraron las siguientes áreas verdes con sus respectivos metros cuadrados de superficie (Figura 5.3.5). considerando las áreas netas de superficie verde, y los metros cuadrados de vegetación que poseen. El área urbana asignada a Shopping Aricanduva posee un área verde neta en planta aproximada de $2.863 .070 \mathrm{~m}^{2}$, que se desglosa en las siguientes superficies de vegetación. 


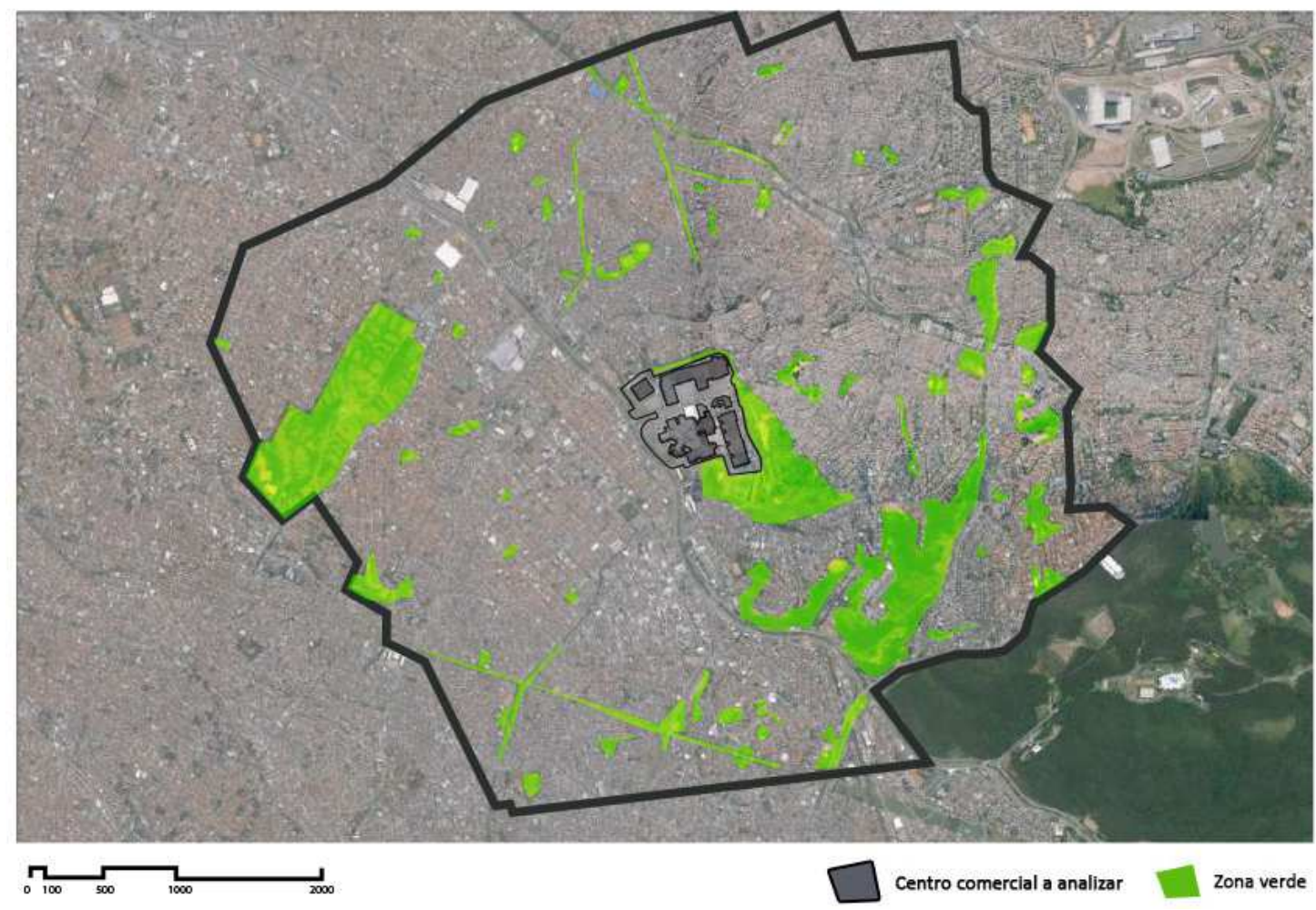

\begin{tabular}{|l|r|}
\hline 10: Superficie de zonas verdes en área urbana & Valor \\
\hline C4.1: pradera & 2000000,0000 \\
\hline C4.2: hierba de gran altura o huerto & 800000,0000 \\
\hline C4.3: vegetación arbustiva intensiva & 800000,0000 \\
\hline C4.4: vegetación arbórea caduca & 0 \\
\hline C4.5: vegetación arbórea perenne & 286400,0000 \\
\hline
\end{tabular}

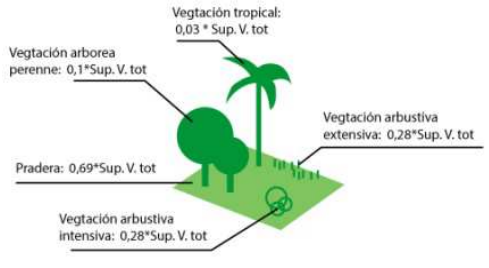

Figura 5.3.5: Área de Shopping Aricanduva, Zonas verdes y capas de vegetación. Fuente: Elaboración Propia a partir de datos de Google.

1P.- DELIMITACIÓN DE RECORRIDOS A CENTRO, DENTRO DEL ÁREA URBANA: Para este análisis, fueros establecidos tres recorridos desde diferentes puntos del borde e interior del área urbana de análisis de Shopping Aricanduva, estos recorridos se describen en el apartado 2E (Figura 5.3.6). Los tiempos de llegada, tanto en vehículo particular, como en transporte público se analizarán a posteriori. 


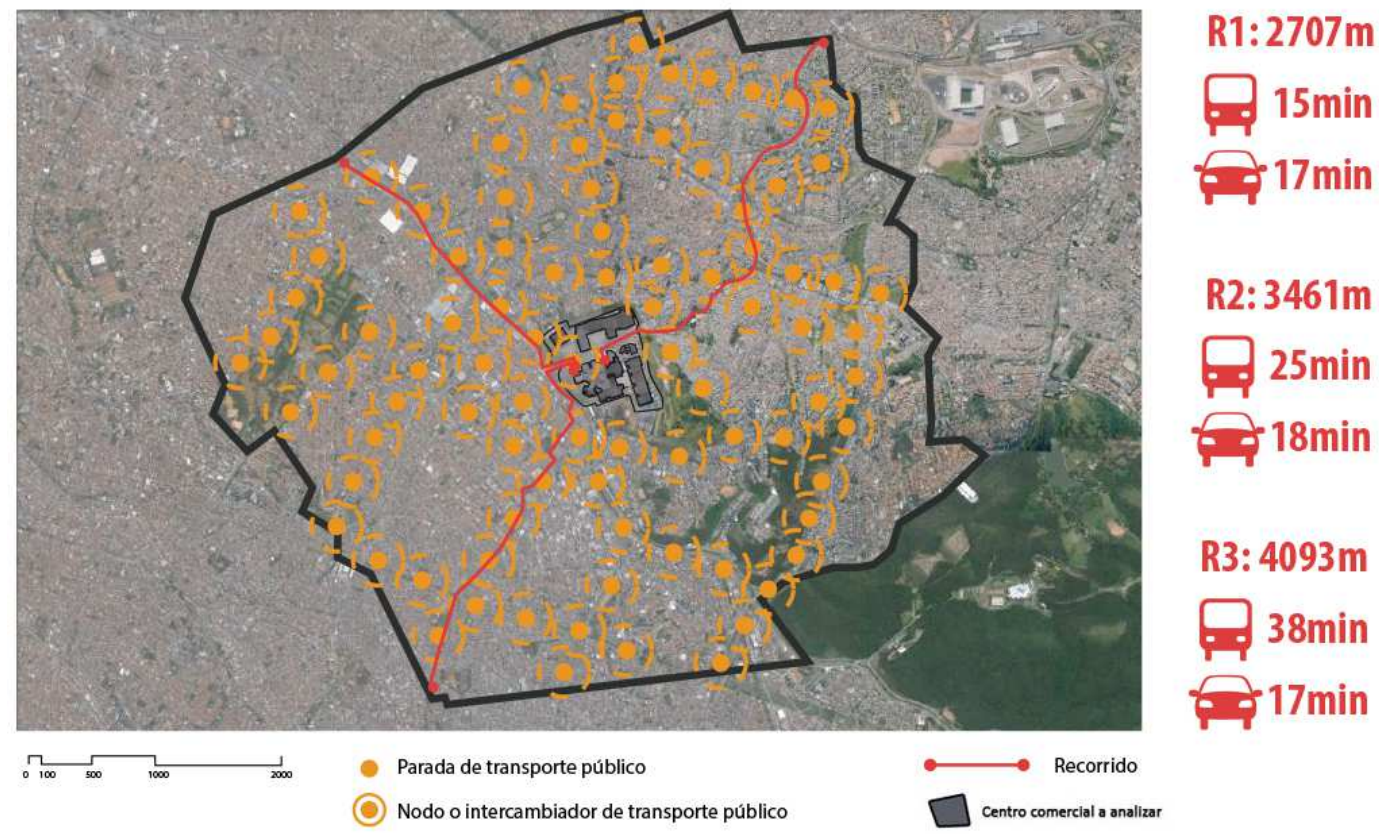

Figura 5.3.6: Recorridos, tiempos de llegada y zonas cubiertas por el transporte público. Fuente: Elaboración Propia a partir de datos de Google.

1Q.- HUELLA DE CARBONO DEL ÁREA URBANA: Siendo la huella de carbono de Brasil de 2,1 toneladas anuales de dióxido de carbono por persona. Se ponderó esta huella al alza, por estar relacionada con un área urbana desarrollada para el estándar de Brasil. De este modo, para un habitante del área de Shopping Aricanduva, se estableció una huella de carbono por persona de 6 toneladas anuales de dióxido de carbono por persona, ya que el centro está relacionado con un área de clase media para el estándar brasileño. Por consiguiente la huella de carbono del área urbana de Shopping Aricanduva es de 1023000 Toneladas de dióxido de carbono anuales.

1R.- CAPACIDAD ABSORCIÓN DE LOS ELEMENTOS VERDES EN ÁREA URBANA: En base a los datos de superficies verdes obtenidos en el apartado 10, se calculó la absorción total de las áreas verdes en base a la capacidad de absorción por metro cuadrado de las superficies vegetales. (figura 5.3.7.) Siendo la capacidad absorbente total en el área de 756600 Toneladas de dióxido de carbono anuales.

\begin{tabular}{|l|r|r|r|r|r|r|r|}
\hline 1R: C.absorción elementos verdes en área & \multicolumn{1}{|l|}{ Pradera } & \multicolumn{1}{l|}{ V.arb ext } & V. A. Int. & H. Caduca & H. Perenne & Otro (tropical) & TOTAL \\
\hline Superficie total & 2000000,0000 & 800000,0000 & 800000,0000 & & 286400,0000 & 100000,0000 \\
\hline Tasa absorción TCo2/m2 año & 0,0013 & 0,0020 & 0,0350 & 0,1500 & 2,2500 & 0,8000 \\
\hline Absorción dióxido carbono TCo2 & 2600,0000 & 1600,0000 & 28000,0000 & 0,0000 & 644400,0000 & 80000,0000 & 756600,0000 \\
\hline
\end{tabular}

Figura 5.3.7: Absorción de las zonas verdes del área urbana de Shopping Aricanduva. Fuente: Elaboración Propia

1S: DELIMITACIÓN DE ÁREAS EN FUNCIÓN DE LA RECUPERACIÓN DE AGUAS EN ÁREA URBANA. Para este análisis, se consideraron como zonas permeables al agua, las zonas verdes presentes en el área urbana, al no estar cubiertas de pavimento impermeable. De este modo, la superficie permeable del área de Shopping Aricanduva es de $3.886 .400 \mathrm{~m}^{2}$ 
Este análisis en muy similar en búsqueda de datos y función con respecto al anteriormente analizado sobre el área urbana general. La particularidad de este análisis está en que su ámbito está limitado a las parcelas que directamente lindan con la unidad catastral de Shopping Aricanduva aproximadamente. El objetivo es cuantificar las relaciones urbanas entre el centro y el entorno próximo, ya sea mediante usos, relaciones entre dotaciones, y accesibilidad o transporte, en este análisis va a primar el estudio sobre plano, aunque también se harán análisis cuantitativos de superficies, y cualitativos.

2A: DELIMITACIÓN DE ÁREA PRÓXIMA: De cara al análisis del área próxima se escogieron las manzanas próximas al centro (Figura 5.3.8). Se descartaron la áreas verdes próximas al centro comercial, al no tener éstas influencia alguna. Se marcaron sobre el plano las fachadas activas, que son las que poseen locales de actividad no residencial, a pie de calle y que ejercen interacción sobre el flujo urbano.

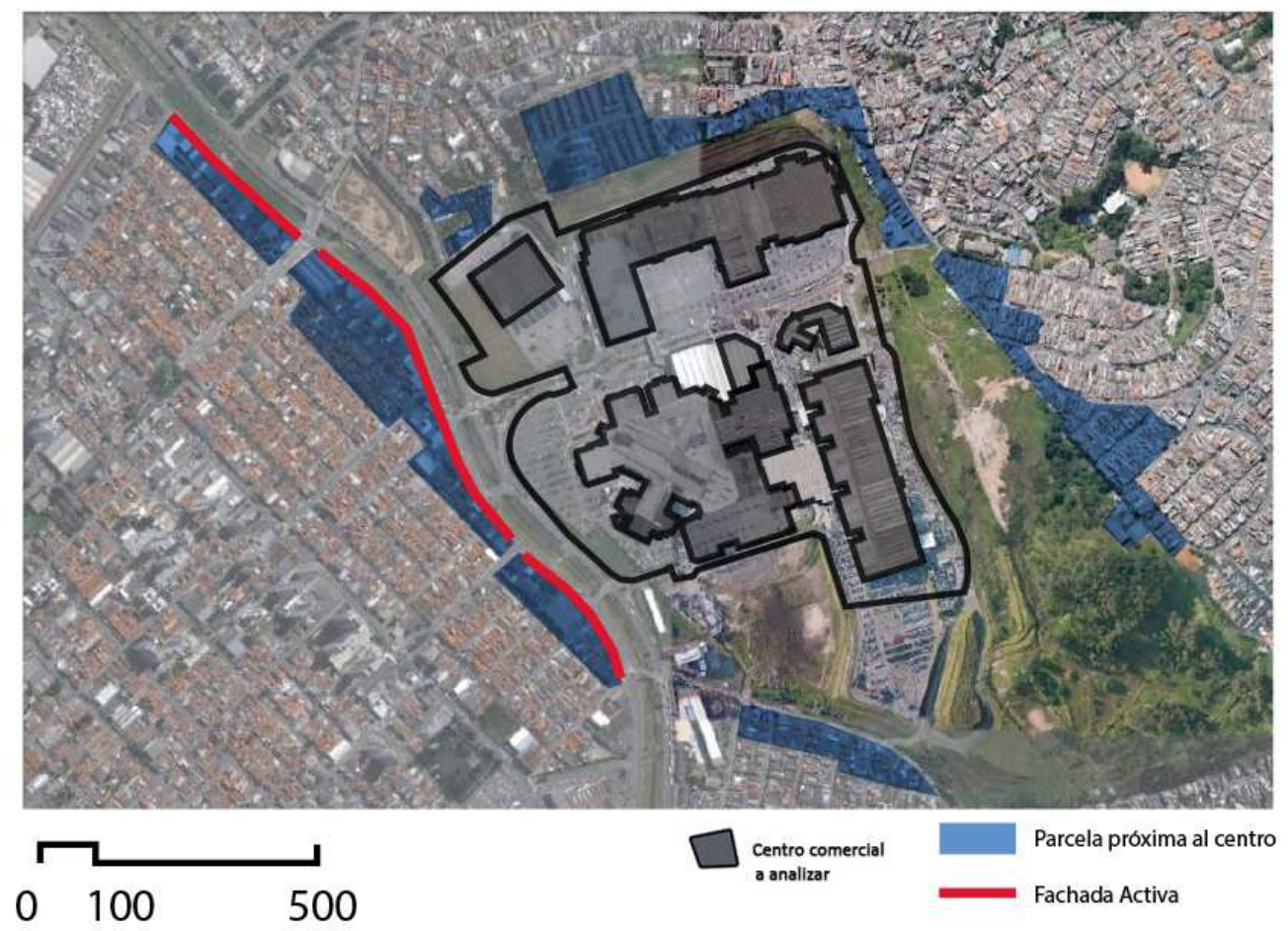

Figura 5.3.8: Análisis de parcelas próximas al centro. Fuente: Elaboración Propia a partir de datos de Google.

2B: SUPERFICIE TOTAL EDIFICADA EN ÁREA PRÓXIMA: Para el conteo de la superficie total estimada de las manzanas próximas al centro, se midió sobre un parcelario la superficie en planta de las mismas, que es de $136252 \mathrm{~m}^{2}$, la cual fue multiplicada por el número de plantas medio de los edificios de susodichas manzanas, que para el caso de Shopping Aricanduva, se estableció en 2 plantas. De este modo, la superficie construida de las manzanas próximas al centro es de $272504 \mathrm{~m}^{2}$.

2C: USOS EN ÁREA PRÓXIMA: Las manzanas próximas al centro comercial, poseen una configuración de usos en la que predominan los edificios residenciales o de comercio, de poca altura y poca mezcla de usos. De este modo, para este análisis se establecieron los siguientes porcentajes: 
Uso residencial: $85 \%$. Uso productivo: $10 \%$. Uso comercial: $5 \%$.

Quedando estas superficies de uso en las manzanas próximas a partir de la multiplicación de los porcentajes establecidos anteriormente, por el área total construida de manzana $\left(272504 \mathrm{~m}^{2}\right)$ :

Uso residencial: $231628 \mathrm{~m}^{2}$. Uso productivo: $27250 \mathrm{~m}^{2}$. Uso comercial: $13625 \mathrm{~m}^{2}$.

2D: FACHADAS ACTIVAS EN ÁREA PRÓXIMA Para este análisis, las fachadas activas en manzanas próximas se marcaron sobre plano (Figura 5.2.8), y se midieron en metros lineales, este análisis se obtuvo a partir de visitas al área y análisis de fotos de la zona de Google Maps. Por otra parte se obtuvo de manera paralela la longitud de fachada total midiendo directamente sobre un parcelario, que se obtuvo de la Prefeitura de Sao Paulo y de la Universidad de Sao Paulo. La longitud de fachada activa (cuenta con locales que ejercen interacción sobre los usuarios del espacio urbano) es de $319 \mathrm{~m}$ siendo la longitud de fachada total de $1948 \mathrm{~m}$ incluyendo las fachadas activas y no activas. El porcentaje de fachadas activas para el área es del $16 \%$.

2E: TIEMPOS DE LLEGADA DESDE LOS PUNTOS EN ÁREA A CENTRO COMERCIAL MEDIANTE TRANSPORTE PÚBLICO: Para la estimación de los tiempos de llegada en transporte público, fueron considerados los recorridos establecidos confluyentes en Shopping Aricanduva en 1P, y se utilizó la base de datos de Google Maps para establecer los tiempos de llegada, en transporte público, considerándose dentro de los mismos para algunos casos el recorrido a pie, en caso de no haber transporte. (Figura 5.3.6).

2F: TIEMPOS DE LLEGADA DESDE LOS PUNTOS EN ÁREA A CENTRO COMERCIAL MEDIANTE TRANSPORTE PRIVADO: Para la estimación de los tiempos de llegada en transporte privado a Shopping Aricanduva, fueron considerados los recorridos establecidos en 1P, y se utilizó la base de datos de Google Maps para establecer los tiempos de llegada. El centro posee aparcamiento dentro de su unidad catastral; aún así, se añadió al tiempo de llegada unos tres minutos adicionales de maniobra y trayecto de llegada desde el vehículo al centro. De este modo, los tiempos establecidos para los medios de transporte son los siguientes para cada recorrido. (Figura 5.3.6).

A efectos de transporte, la accesibilidad al centro mediante transporte público desde la ciudad es complicada. Las Estaciones de Carrao y Penha, son los principales puntos de trasbordo, si se accede en metro. desde el centro de la ciudad. no obstante para acercarse al centro, es necesario acceder mediante autobús, no habiendo en los recorridos establecidos carriles exclusivos, de manera que las condiciones de tráfico si se complican en la zona, van a afectar en la eficacia del transporte público, causando demoras serias en el mismo. Los tiempos de frecuencia de llegada de los autobuses que pasan por las inmediaciones del centro, son moderadamente altos (10 minutos de media), lo que no supone en principio problema alguno. efectos de accesibilidad mediante transporte. A efectos de accesibilidad mediante transporte privado, las vías pueden congestionarse durante las horas punta en algunos tramos, no obstante, al tratarse de una zona periférica, de relativa baja densidad, no hay generalmente problemas de acceso mediante el uso de vehículo particular. 


\section{FASE 3: ANÁLISIS DEL EDIFICIO DEL CENTRO COMERCIAL.}

Una vez analizado el entorno urbano en sus diferentes escalas, cuantificándose de cara al cuestionario de rehabilitación todas las facetas del mismo, a la par que las relaciones urbanas; el último campo de análisis es el estudio concreto de lo que es el edificio del centro comercial Shopping Aricanduva. De este modo a partir de los datos de los que se pudieron disponer del centro comercial, van a cuantificarse los rasgos del edificio de Shopping Aricanduva en relación a las facetas de usos, sostenibilidad y comportamiento bioclimático, de cara al cuestionario de la Rosa de Sostenibilidad. Serán de importancia el conteo de superficies en base a la faceta a analizar, las simulaciones y la comparativa de las características formales para dar los datos necesarios para el cuestionario de rehabilitación.

3A: DELIMITACIÓN DE ÁREAS EN FUNCIÓN DE LA RECUPERACIÓN DE AGUAS: Sobre la planta de cubiertas del centro comercial, se delimitaron las áreas tanto permeables como impermeables del centro, de acuerdo a los estipulado en la metodología. Como áreas permeables a la recuperación de aguas, Shopping Aricanduva, posee espacios verdes en su periferia. Las superficies permeables de shopping Aricanduva suman $30730 \mathrm{~m}^{2}$, que son aproximadamente el $6 \%$ de los $497450 \mathrm{~m}^{2}$ totales de parcela.

3B: USOS DENTRO DEL EDIFICIO DEL CENTRO: Para los usos, se consideraron los diferentes locales dentro del centro comercial, buscándose los metros cuadrados de espacio productivo, y las dotaciones asistenciales dentro del mismo. Para el caso de Shopping Aricanduva, se localizó una instalación asistencial, que es la oficina de policía, que se contó como aproximadamente $175 \mathrm{~m}^{2}$ de superficie productiva. Con esto, pudieron averiguarse los porcentajes de superficies para el centro, que se dividen de la siguiente manera:

Superficie comercial $99.95 \%$

Superficie residencial $0 \%$

Superficie Productiva no comercial 0,05\%

3C: DELIMITACIÓN DE ÁREAS VERDES EN CENTRO COMERCIAL. (Análisis sobre plano y cuantitativo, unidad: metros cuadrados). El centro comercial Shopping Aricanduva, posee áreas verdes en su periferia con apenas vegetación. En total hay $30800 \mathrm{~m}^{2}$ de superficie verde, desglosada de la siguiente manera (figura 5.3.9):

\begin{tabular}{|l|l|}
\hline 3C: S. de zonas verdes en centro comercial & Valor \\
\hline C4.1: pradera & 30800 \\
\hline C4.2: hierba de gran altura o huerto & \\
\hline C4.3: vegetación arbustiva intensiva & \\
\hline C4.4: vegetación arbórea caduca & \\
\hline C4.5: vegetación arbórea perenne & \\
\hline
\end{tabular}

Figura 5.3.9: Áreas verdes en el centro Aricanduva y localización de las mismas . Fuente: Elaboración Propia a partir de datos de Google.

3D: ABSORCIÓN DE LAS ÁREAS VERDES EN CENTRO COMERCIAL. Los metros cuadrados de superficie de Shopping Aricanduva, son capaces de asimilar aproximadamente unas 40,04 
toneladas de dióxido de carbono, que son aproximadamente un 0,34\% de las emisiones del centro (11935 T Co2 anuales), y un 0,004\% respecto de las emisiones del área urbana (1023000 T Co2 anuales). (5.3.10)

\begin{tabular}{|l|r|r|r|r|r|r|}
\hline 3D: C.absorción elementos verdes en área & \multicolumn{1}{|l|}{ Pradera } & V.arb ext & V. A. Int. & H. Caduca & H. Perenne & Otro \\
\hline Superficie total & 30800,0000 & & & & & \\
\hline Tasa absorción TCo2/m2 año & 0,0013 & 0,0020 & 0,0350 & 0,1500 & 2,2500 & 0,0000 \\
\hline Absorción dióxido carbono TCo2 & 40,0400 & 0,0000 & 0,0000 & 0,0000 & 0,0000 & 0,0000 \\
\hline
\end{tabular}

Figura 5.3.10: Absorción de áreas verdes en el centro Aricanduva. Fuente: Elaboración Propia.

3E: ANÁLISIS BIOCLIMÁTICO DEL CENTRO COMERCIAL RESPECTO A CLIMA, DIAGRAMA DE GIVONI.

El Diagrama de Givoni para Sao Paulo es el siguiente.

Los requisitos bioclimáticos de acuerdo a Givoni para el caso de Shopping Aricanduva, son los referenciados al clima de Sao Paulo, y estos fueron desarrollados y explicados en el apartado 3E del capítulo de caso de estudio de Shopping Light (Capítulo 5.1). (5.2.11)

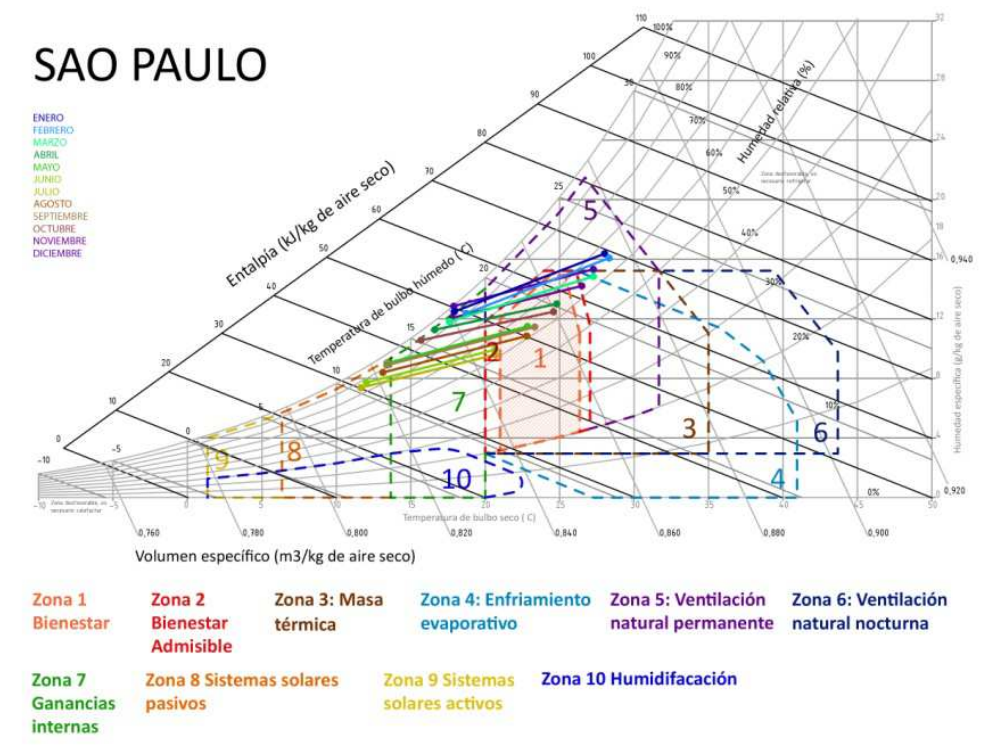

Figura 5.3.11: Diagrama de Givoni de Sao Paulo. Fuente: Elaboración propia a partir de datos de Givoni, Climaticus, LABAUT FAU USP,

El centro comercial Shopping Aricanduva, posee una envolvente de hormigón que no tiene mucha masa térmica. No obstante, las cargas internas dentro de él son muy elevadas (Luz, maquinaria y personas), y puede valerse de las mismas para acondicionarse en el caso de frío, no obstante los espacios interiores son de gran tamaño, lo que complica la aclimatación utilizando este método. El centro está completamente cerrado, y es un volumen compacto, que no posee sistemas de ventilación natural. Para ventilar, calefactar o refrigerar se usan sistemas mecanizados. El centro se desarrolla en superficie

\section{F: CALIFICACIÓN ENERGÉTICA DEL CENTRO COMERCIAL.}

Al no haber datos objetivos acerca del consumo primario de energía o las emisiones generadas por el centro Shopping Aricanduva, se tuvo que realizar una estimación con el programa CE3X, 
considerando el clima de Santa Cruz de Tenerife, que en temperaturas es similar al de Sao Paulo, readaptándose las orientaciones de las fachadas a los condicionantes del programa. Se consideraron para el análisis muros de hormigón prefabricado sin aislante y con trasdosado de ladrillo, a la vez que una cubierta plana también sin aislante. Para los huecos se consideraron ventanas de aluminio sencillo a la vez que sistemas de aire acondicionado, ventilación forzada y agua caliente por bomba de calor.

De este modo Shopping Aricanduva en el análisis obtuvo estas calificaciones.

Consumo de energía: $104,16 \mathrm{Kwh} / \mathrm{m}^{2}$ año. (C)

Emisiones anuales: $0,03 \mathrm{~T} / \mathrm{m}^{2}$ año. (C)

3G: USO DE FUENTES DE ENERGÍA LIMPIAS. El centro Shopping Aricanduva no posee sistemas de generación de energías limpias. No obstante, la ciudad de Sao Paulo suple aproximadamente el $90 \%$ de su demanda energética con energías renovables ${ }^{51}$. Para el presente estudio, esto se considerará como parcialmente positivo, ya que lo que se busca es que el centro comercial tenga el menor impacto energético posible.

3H: FORMA DE LA EDIFICACIÓN: Todos los edificios que conforman el centro comercial Shopping Aricanduva, son volúmenes muy extendidos en superficie, con cierta fragmentación en todas las orientaciones. Aproximadamente la relación entre el lado mayor y el menor del edificio principal Aricanduva es de 1,17, siendo la orientación de la fachada principal unos 1070 oeste, respecto de la orientación norte, que es el azimut cero para el caso del hemisferio sur. El centro comercial posee lucernarios de pequeño tamaño, y las escasas aperturas cuentan con parasoles. El volumen del edificio es fragmentado, pero compacto e impermeable. El edificio de Auto Shopping tiene una proporción de 3 entre el lado mayor y el menor, y su fachada principal es de 1070 oeste respecto al norte. El Edificio de Interlar tiene una proporción de 2,88, siendo su orientación de fachada de 162,70 este respecto al norte. Y Makro tiene una proporción de lados de 1,16, y su orientación es de 145,7 este respecto al norte. (Figura 5.3.12)

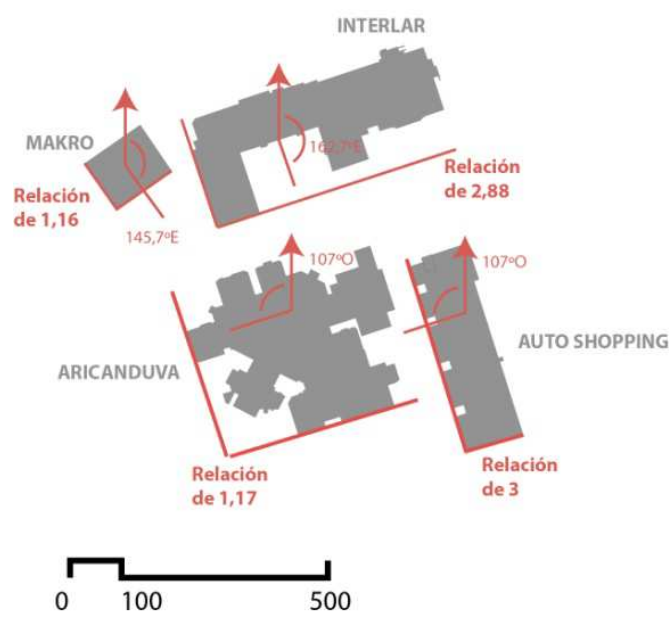

\footnotetext{
${ }^{51}$ ICLEI- International Renewable Energy Agency, (2012). Renewable Energy Policy in Cities: Selected Case Studies, Sao Paulo.
} 
Figura 5.3.12: Proporciones y orientación de Aricanduva. Fuente: Elaboración Propia

31: ESPACIOS CON LUZ NATURAL Para medir esta superficie se consideraron de manera aproximada los espacios iluminados del centro comercial Shopping Aricanduva, que generalmente corresponden a las galerías centrales, que cuentan con lucernarios, el hall de triple altura entre Aricanduva y Autoshopping y algunos locales, que generalmente son restaurantes. los edificios de Auto Shopping, Makro e Interlar apenas tienen espacios iluminados con luz natural. En total, Shopping Aricanduva el espacio que cuenta con luz natural es aproximadamente el $1,44 \%$ de su superficie.

3J: PAVIMENTOS Y CUBIERTAS EN RELACIÓN A LA INCIDENCIA DE LA IRRADIACIÓN SOLAR. Sobre la planta de cubiertas se midieron las superficies de colores claros. Shopping Aricanduva tiene aproximadamente un $15 \%$ de su superficie de cubierta repelente de cara a la irradiación solar, siendo el $85 \%$ restante, absorbente de cara a la irradiación solar.

FASE 4: CUESTIONARIOS DE LA METODOLOGÍA, APLICACIÓN DE INDICADORES Y BAREMOS.

\section{A.- REHABILITACIÓN ECOEFICIENTE.}

A1.- Cuestionario referenciado a rehabilitación hacia instalaciones poco emisivas.

Cuestión A1.1.- ¿El centro cuenta con instalaciones que no son necesarias de acuerdo a lo estipulado en el diagrama de Givoni?: Aunque no hay datos objetivos acerca de las instalaciones de Shopping Aricanduva, de visitas al centro se dedujo que se trata de un espacio completamente cerrado y aclimatado, que posee instalaciones mecánicas de refrigeración, las cuales mirando el diagrama de Givoni, se ve que no son necesarias en principio para el clima de Sao Paulo, a este centro le corresponde una nota de + 0 en esta cuestión

Cuestión A1.2.- ¿Las instalaciones del centro generan unas emisiones de dióxido de carbono superiores a la media?. En el estudio energético, Shopping Aricanduva ha obtenido en la calificación energética de emisiones de las instalaciones una nota de $C$, eso corresponde a una nota de +3

Cuestión A1.3.- ¿Las instalaciones del centro se encuentran en un estado de obsolescencia?. Respecto esta cuestión, el autor desconoce el estado de las instalaciones del centro. No obstante, estas se estimaron con un estado de cierta obsolescencia, eligiendo el escenario más desfavorable, con lo que se puntuó esta cuestión con una nota de +0 .

Cuestión A1.4.- ¿Las instalaciones del centro tienen un consumo energético superior a la media?. En el estudio energético, shopping Aricanduva ha obtenido en la calificación energética de consumo de energía primaria una nota de $C$, eso corresponde a una nota de +3

EN RELACIÓN A INSTALACIONES POCO EMISIVAS, SHOPPING ARICANDUVA HA OBTENIDO UNA PUNTUACIÓN DE 6 (10).

A2.- Cuestionario referenciado a inserción de medidas activas. 
Cuestión A2.1.- ¿Qué porcentaje de las calorías necesarias para lograr la temperatura de confort se logra mediante sistemas activos?: El centro de Shopping Aricanduva, no posee medidas activas para lograr la temperatura de confort, no obstante, aunque cierto es que pueden ayudar en la reducción del consumo energético, éstos no son necesarios para la temperatura, pero sí para controlar la humedad. Esta cuestión puntúa con +2 .

Cuestión A2.2.- ¿Qué porcentaje de la demanda energética se logra a partir de fuentes de energía renovable?: A pesar de que la ciudad de Sao Paulo, suple el $90 \%$ de su demanda de energía con renovables de tipo hidroeléctrico, el mérito en esta cuestión reside en que el centro posea este tipo de dispositivos en la medida de lo posible, para reducir su dependencia de fuentes externas. Esta cuestión fue puntuada con un +3 .

Cuestión A2.3.- ¿El centro cuenta con las medidas y dispositivos necesarios para su aclimatación de acuerdo a lo estipulado en el diagrama de Givoni para sistemas solares activos?: El centro comercial Shopping Aricanduva, no precisa de sistemas activos para una correcta aclimatación, salvo los relacionadas exclusivamente con la humedad, pero sólo en caso extremos. esta cuestión puntúa con +2 .

EN RELACIÓN A MEDIDAS ACTIVAS, SHOPPING ARICANDUVA HA OBTENIDO UNA PUNTUACIÓN DE 7 (10).

A3.- Cuestionario referenciado a inserción de medidas Pasivas.

A3.1.- ¿El centro comercial tiene una forma adecuada en volumen a las condiciones climáticas?: Shopping Aricanduva se encuentra en una zona climática cálida húmeda de acuerdo a la calificación de Olgyay, de acuerdo al análisis anteriormente realizado en el punto 31, ninguno de los edificios de Shopping Aricanduva cumplen los requisitos de proporción de planta, u orientación. Los huecos, están expuestos a la irradiación solar parcialmente. EI edificio es un volumen compacto, fragmentado, y las fachadas no están protegidas de la irradiación solar proveniente del norte. De este modo, aunque Shopping Aricanduva cumple con el requisito del volumen fragmentado, y hay huecos protegidos por parasoles, está muy lejos de ser un edificio adaptado al clima cálido húmedo de Sao Paulo (según Olgyay). Le corresponde una puntuación de +0 .

A3.2.- ¿El estado de los cerramientos responde de manera correcta a las exigencias del clima en el que se asienta?: La calificación energética de Shopping Aricanduva a efectos de consumo global de energía es de $C$, esto significa que los cerramientos responden de una manera correcta respecto al clima. A este centro le corresponde una puntuación de +3.

A3.3.- ¿Qué porcentaje de los espacios del centro cuentan con iluminación natural?: Shopping Aricanduva posee un $1,14 \%$ del espacio interior iluminado con luz natural (apartado $3 \mathrm{H}$ ). Le corresponde de este modo una puntuación de +0 .

A3.4.- Los espacios del centro, están adaptados a lo estipulado por el Diagrama de Givoni de su respectivo clima?: Shopping Aricanduva, no tiene los espacios interiores adaptados a lo dictado por Givoni, ya que los muros no tienen masa térmica, y el gran tamaño de los espacios interiores, hace que no sea viable calefactar usando las cargas internas. De este modo, no se 
cumple lo requerido para el edificio de centro. A Shopping Aricanduva le corresponde una calificación de +0

EN RELACIÓN A MEDIDAS PASIVAS, SHOPPING ARICANDUVA HA OBTENIDO UNA PUNTUACIÓN DE 3 (10).

\section{B.- REHABILITACIÓN MEDIOAMBIENTAL.}

B1.- Cuestionario referenciado a rehabilitación mediante zonas verdes.

Cuestión B1.1.- ¿En el área urbana hay suficiente zona verde en el área en relación a sus habitantes?: El área urbana de Shopping Aricanduva posee aproximadamente $2863070 \mathrm{~m}^{2}$ de superficie verde en planta, que entre 212.500 habitantes, sale un ratio de $13,47 \mathrm{~m}^{2}$ de superficie verde por habitante. Le corresponde una puntuación de +1 .

Cuestión B1.2.- ¿Las zonas verdes dentro del centro comercial pueden dar lugar a una área verde de uso cotidiano?: Shopping Aricanduva, posee $30800 \mathrm{~m}^{2}$ de superficie verde en los linderos de su parcela. Esta superficie aunque no tiene las características de un espacio estancia, puede ser tratada como tal de forma viable debido al tamaño de las parcelas y su facilidad para ser abierta al público, ya que está a pie de calle. Para esta cuestión, Aricanduva supera el baremo mínimo de $1000 \mathrm{~m}^{2}$, le corresponde una puntuación de +1 a esta cuestión.

Cuestión B1.3.- ¿La vegetación en el área (incluyendo el edificio del centro), en que porcentaje es capaz de asimilar las emisiones de la misma área urbana?: Sumando las capacidades de asimilación de las superficies de vegetación establecidas en las áreas verdes del área urbana de influencia del centro, tenemos una capacidad de asimilación de 756640 Toneladas de dióxido de carbono anuales, esto es aproximadamente un $73 \%$ de la huella de carbono del área, (1023000 Toneladas de dióxido de carbono anuales). Esta cuestión puntuará con +3.

Cuestión B1.4.- ¿La vegetación en el centro comercial y su parcela, en que porcentaje es capaz de asimilar las emisiones del centro comercial?: Los espacios verdes de la parcela del centro comercial, asimilan aproximadamente 3463 T CO2 anuales, que es un $21 \%$ de la huella de carbono anual del centro (16473,4 T CO2 anuales), a esta cuestión le corresponde una puntuación de +1 .

Cuestión B1.5.- ¿La distancia media entre espacios verdes dentro del área es inferior a los 400 metros?: Aunque hay espacios verdes en al área de Shopping Aricanduva, la distancia entre los mismos está a una distancia media que supera los 400 metros, a esta cuestión le corresponde una puntuación de +0 .

EN RELACIÓN A ZONAS VERDES, SHOPPING ARICANDUVA HA OBTENIDO UNA PUNTUACIÓN DE $6(10)$.

B2.- Cuestionario referenciado a inserción de superficie asimiladora de agua.

Cuestión B2.1.- ¿El clima en el que está el centro corresponde a un clima árido o semiárido?: El clima de Sao Paulo tiene un índice de Martonne de 49,18, corresponde a una zona húmeda. A Shopping Aricanduva le corresponde una calificación de +1 a esta cuestión. 
Cuestión B2.2.- ¿En qué porcentaje, la superficie absorbente de agua, en el área urbana, es en relación a la impermeable?: En esta cuestión, se consideró como superficie permeable las áreas verdes presentes en la zona $\left(2863070 \mathrm{~m}^{2}\right)$, que son aproximadamente un $12 \%$ de los $23.373 .686 \mathrm{~m} 2$ totales del área urbana. esta cuestión puntúa con +1 .

Cuestión B2.3.- ¿El centro comercial posee sistemas para el aprovechamiento del agua?: Aunque el autor de la tesis desconoce el estado de las instalaciones de Aricanduva debido a la falta de datos, se consideró a la desfavorable, que el centro comercial Shopping Aricanduva, no posee sistemas para el aprovechamiento del agua, le corresponde una puntuación de +0 .

Cuestión B2.4- ¿ ¿l consumo de agua del centro es en litros por visita?: a pesar de que no hay datos del centro en este sentido, al centro comercial Shopping Aricanduva, se le estimó un consumo de agua de 30 litros por visita, que corresponde a una puntuación de +1 .

\section{EN RELACIÓN A SUPERFICIE ASIMILADORA DE AGUA, SHOPPING ARICANDUVA HA OBTENIDO UNA PUNTUACIÓN DE 3 (10).}

B3.- Cuestionario referenciado a tratamiento de isla de calor.

Cuestión B3.1.- ¿El clima en el que está el centro comercial tiene una temperatura media más o menos elevada?. El clima de Sao Paulo tiene una temperatura media anual de 19,30, esto significa que es un clima cálido propenso a altas temperaturas. Esta pregunta puntúa con +0

Cuestión B3.2.- ¿En el clima en el que está ubicado en centro hay olas de calor frecuentes o en intervalo temporal menor?. El clima de Sao Paulo, aunque puede tener olas de calor, estas no suelen ser muy frecuentes, esta cuestión puntúa con un +1 .

Cuestión B3.3.- ¿El centro está en un área en el cual la diferencia de temperatura respecto a la normal es de?. Analizando la isla de calor de Sao Paulo (Figura 5.3.13), nos encontramos con el hecho de que Shopping Aricanduva se encuentra en un área con 4 을 de temperatura respecto de lo normal, de este modo esta cuestión puntúa con un +0 .

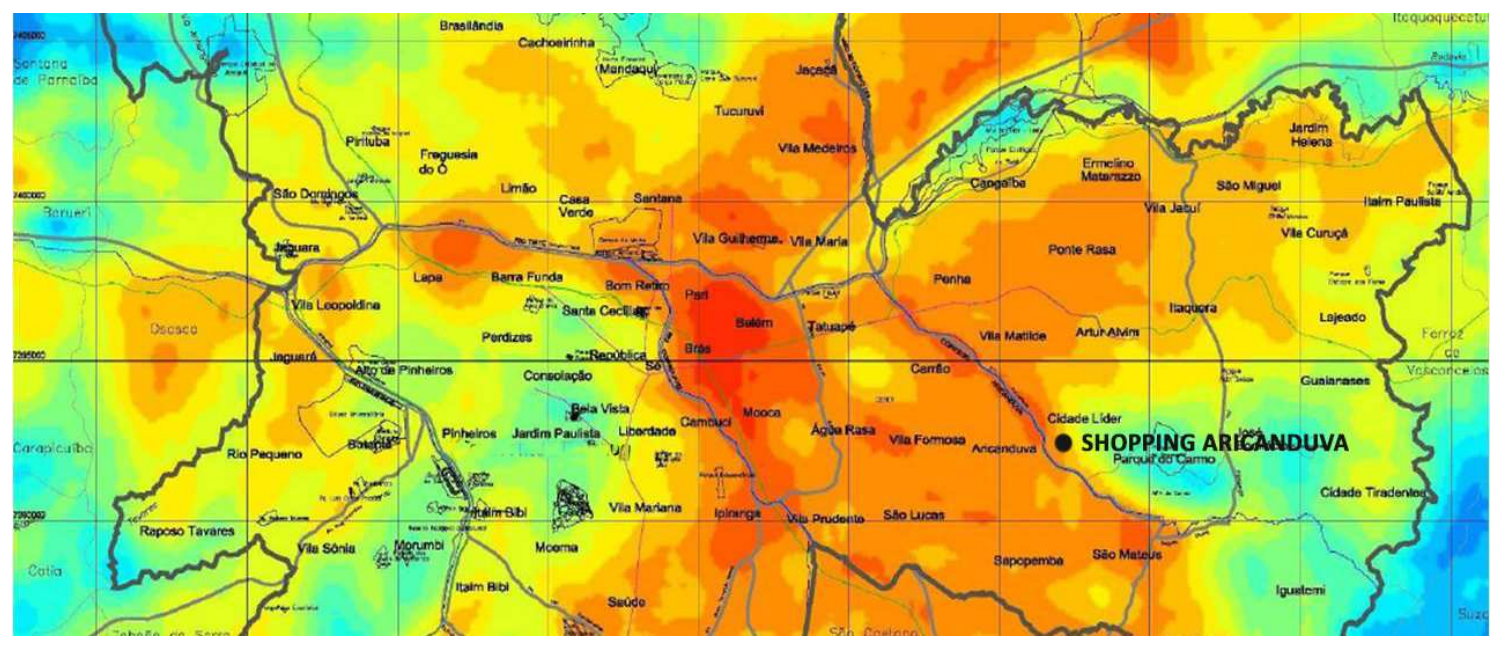

Figura 5.3.13: Isla de calor de Sao Paulo con la ubicación de Shopping Eldorado Fuente: Elaboración Propia, Prefeitura de Sao Paulo. 
Cuestión B3.4.- ¿La suma de superficies que contribuyen a la isla de calor en la parcela y el edificio del centro es superior a un porcentaje de la superficie total?. La superficie absorbente de irradiación de Shopping Aricanduva es del 84\%, lo que le corresponde una puntuación de +0 .

EN RELACIÓN A TRATAMIENTO DE ISLA DE CALOR, SHOPPING ARICANDUVA HA OBTENIDO UNA PUNTUACIÓN DE 1 (10).

\section{C.- REHABILITACIÓN POR USOS.}

C1.- Cuestionario referenciado a inserción de uso residencial.

Cuestión C1.1.- ¿El centro comercial posee usos residenciales u hoteleros dentro de su unidad catastral?. Shopping Aricanduva no posee usos hoteleros o residenciales, esta cuestión puntúa con +0 .

Cuestión C1.2.- ¿Las parcelas próximas al centro comercial posen usos residenciales u hoteleros?: El uso residencial en las parcelas colindantes al centro comercial fue estimado en un $85 \%$ en el análisis de parcelas próximas, lo que le corresponde una puntuación de +3 .

Cuestión C1.3.- ¿Dentro del área de influencia del centro comercial, que porcentaje de la superficie de uso total es de tipo residencial?: Considerando las superficies establecidas para cada zona tipológica, estas fueron sumadas, obteniendo una superficie residencial total $\left(19379560 \mathrm{~m}^{2}\right)$ que fue comparada con la superficie total construida $\left(23693188 \mathrm{~m}^{2}\right)$. De este modo, la superficie de uso residencial en el área de Shopping Aricanduva, se estableció aproximadamente en un $81 \%$ de la superficie edificada total, lo que le corresponde una puntuación de +5

\section{EN RELACIÓN A USO RESIDENCIAL, SHOPPING ARICANDUVA HA OBTENIDO UNA PUNTUACIÓN} DE 8 (10).

C2.- Cuestionario referenciado a inserción de usos productivos, y terciarios no comerciales.

Cuestión C2.1.- ¿El centro comercial posee usos productivos no comerciales dentro de su unidad catastral?: Shopping Aricanduva posee unas oficinas de la policía militar, esta cuestión puntúa con +1 .

Cuestión C2.2.- ¿Las parcelas próximas al centro comercial posen usos productivos no comerciales?: Las parcelas próximas al centro comercial, poseen una amplia oferta de instalaciones terciarias de oficinas y administrativas, que se computaron en aproximadamente un $10 \%$ de la superficie total, esta cuestión puntúa con un +2 .

Cuestión C2.3.- ¿Dentro del área de influencia del centro comercial, que porcentaje de la superficie de uso total es de tipo productivo no comercial?: Considerando las superficies productivas establecidas para cada zona tipológica, estas fueron sumadas obteniendo una superficie productiva total $\left(1840788 \mathrm{~m}^{2}\right)$ que fue comparada con la superficie total construida $\left(23693188 \mathrm{~m}^{2}\right)$. De este modo, la superficie de uso productivo en el área de Shopping Aricanduva, se estableció aproximadamente en un $7,77 \%$ de la superficie edificada total. A esta cuestión le corresponde una puntuación de +1 . 
EN RELACIÓN A USO PRODUCTIVO, SHOPPING ARICANDUVA HA OBTENIDO UNA PUNTUACIÓN DE 4 (10).

C3.- Cuestionario referenciado a inserción de instalaciones dotacionales y asistenciales.

Cuestión C3-1.- ¿ ¿El centro comercial posee usos dotacionales dentro de su unidad catastral?: El centro comercial Shopping Aricanduva, posee unas oficinas de la policía militar, pero al no ser una instalación concurrida, esta cuestión puntúa con un +0 .

Cuestión C3.2.- ¿Las parcelas próximas al centro comercial posen usos dotacionales?: En las inmediaciones del centro comercial Shopping Aricanduva no hay instalaciones dotacionales de ningún tipo. No obstante está en sus cercanías las instalaciones del CEU EMEl, que es una instalación no muy concurrida y a una distancia algo alejada. Esta pregunta puntúa con un +1 .

Cuestión C3.3.- ¿A un kilómetro del centro comercial hay usos dotacionales?: En el área de dotaciones correspondiente a lo que es el centro comercial de Shopping Aricanduva, hay una gran cantidad de dotaciones de diversa capacidad, habiendo algunas muy concurridas. Aunque no hay grandes dotaciones a nivel nacional si hay un gran número de dotaciones muy concurridas a nivel local (colegios e iglesias). Esta cuestión puntúa con +5 .

EN RELACIÓN A DOTACIONES, SHOPPING ARICANDUVA HA OBTENIDO UNA PUNTUACIÓN DE 6 (10).

\section{D.- REHABILITACIÓN DE ENTORNO URBANO.}

D1.- Cuestionario referenciado a la inserción de medios de transporte eficientes.

Cuestión D1.1.- ¿El centro dispone en sus inmediaciones de alguna parada de transporte público?: El centro comercial Shopping Aricanduva, posee instalaciones de transporte público en las inmediaciones de sus parcelas. Aún así, este centro está muy alejado de cualquier intercambiador de transporte de gran relevancia. la puntuación es de +1 .

Cuestión D1.2.- ¿El tiempo de llegada al centro mediante transporte público supera al tiempo de llegada en vehículo particular?, Comparando los datos obtenidos de los apartados $2 E$ y $2 F$, (dividiendo el tiempo de llegada en transporte público, entre el tiempo de llegada en transporte privado), se comprobó que el tiempo de llegada medio en transporte público es moderadamente mayor que el empleado usando un vehículo privado, (1,5 veces mayor, considerando tiempos de aparcamiento del vehículo particular), esta cuestión puntúa con +1 . (Figura 5.3.14)

\begin{tabular}{|l|r|r|r|}
\hline Comparación tiempos de recorrido & Recorrido 1 & Recorrido 2 & Recorrido 3 \\
\hline Total tiempo desplazamiento t. público & 15 & 25 & 38 \\
\hline Total tiempo desplazamiento t. particular & 17 & 18 & 17 \\
\hline Relación entre tiempos desplazamiento & 0,882352941 & 1,388888889 & 2,235294118 \\
\hline Media tiempo desplazamiento & & & 1,502178649 \\
\hline
\end{tabular}

Figura 5.3.14: Comparación tiempos de llegada. Fuente: Elaboración Propia.

Cuestión D1.3.- ¿El área urbana del centro comercial está cubierta de forma adecuada por la infraestructura de transporte público?. El área urbana de Shopping Aricanduva, está cubierta 
en un 50\% aproximadamente por la infraestructura de transporte público (Figura 5.3.7). Lo que la cuestión puntúa con un +1 .

Cuestión D1.4.- ¿Los usos en la zona están mezclados o zonificados?: En el área de Shopping Aricanduva, el índice Global de Mezcla de usos es de 0,02 (Zona de poca complejidad urbana), esto le corresponde una puntuación de +0 .

Cuestión D1.5.- ¿El centro comercial y el área urbana próxima al centro cuenta con instalaciones enfocadas en la movilidad sostenible?: El centro comercial Shopping Aricanduva no posee sistemas adaptados a la movilidad sostenible, al igual que tampoco hay en las parcelas próximas; esta cuestión obtiene una puntuación de +0 .

EN RELACIÓN A TRANSPORTE EFICIENTE, SHOPPING ARICANDUVA HA OBTENIDO UNA PUNTUACIÓN DE 3 (10).

D2.- Cuestionario referenciado a la rehabilitación por corrección de la densidad en área urbana.

Cuestión D2.1.- ¿La densidad de población en el área del centro está en el intervalo entre h/ha?, La densidad de población del área de Shopping Aricanduva es la del distrito Aricanduva $\left(0,012 \mathrm{hab} / \mathrm{m}^{2}\right)$, a esta cuestión le corresponde una puntuación de +2 .

Cuestión D2.2.- ¿A efectos de densidad, el tejido mayoritario es favorable o desfavorable de cara a la sostenibilidad?. El índice global de densidad del área de Shopping Aricanduva es de 1,95 , lo que es un entorno de densidad media alta, a esta cuestión le corresponde una puntuación de +2 .

Cuestión D2.3.- ¿La cantidad de espacio ocupado en el área está en el intervalo? El espacio ocupado medio en el área de Shopping Aricanduva se calculó multiplicando cada porcentaje de ocupación de cada zona homogénea, por lo que ocupa cada zona respecto al total. $(59 * 0,93+73 * 0,04+47 * 0,018)$, saliendo un resultado de $59,43 \%$, lo que corresponde a una puntuación de +3 .

EN RELACIÓN A DENSIDAD, SHOPPING ARICANDUVA HA OBTENIDO UNA PUNTUACIÓN DE 7 (10).

D3.- Cuestionario referenciado a mejora de la seguridad y la paseabilidad en el área urbana.

Cuestión D3.1.- ¿En el área de influencia o en sus proximidades hay elementos negativos de cara a la seguridad o a la salubridad del área?: En el área cercana a Shopping Aricanduva, hay una favela que ha resultado a veces ser problemática para el centro y el entorno. Esta cuestión puntúa con +0 .

Cuestión D3.2.- ¿El centro comercial se encuentra en una zona de puntos fríos de actividad durante el día?. El recinto de Shopping Aricanduva, está rodeado de puntos fríos durante el día debido a su concepción como recinto cerrado, y a las barreras arquitectónicas presentes formadas por las avenidas y el río, esta cuestión puntúa con un +0.

Cuestión D3.3.- ¿El centro comercial se encuentra en una zona de puntos fríos durante la noche?, el efecto de punto frío que está presente durante el día en las inmediaciones de 
Aricanduva, por las barreras y distancias, va a agravarse durante la noche debido al cierre del recinto del centro comercial. Esto se debe a que las áreas circundantes son zonas sin actividad, esta cuestión puntúa con +0 .

Cuestión D3.4.- ¿El centro comercial se encuentra en una zona con áreas de difícil control visual o de contacto urbano?. En torno al centro comercial hay desniveles y tapias de gran altura que van a dificultar la visibilidad y el control del espacio. Esta cuestión puntúa con +0

Cuestión D3.5.- ¿ ¿a sensación de seguridad por parte de los ciudadanos de la zona es positiva o negativa?: En la periferia de Sao Paulo, la sensación de inseguridad permanente está muy arraigada entre los ciudadanos, estando agravada por la presencia de una favela conflictiva. La puntuación a esta cuestión es de +0 .

Cuestión D3.6.- ¿La zona próxima al centro comercial tiene un porcentaje de fachadas activas?: En las manzanas próximas al centro comercial, hay un $16 \%$ de fachadas activas, lo que le corresponde una puntuación de +0 .

Cuestión D3.7.- ¿La distancia de la puerta del edificio del centro comercial al inmueble residencial cercano es superior a los 200 metros?: El inmueble residencial más cercano a Shopping Aricanduva, se encuentra a 500 metros, esta cuestión puntúa con +0.

Cuestión D3.8.- ¿La cantidad de espacio libre en el área va a resultar desfavorable de cara a la paseabilidad?: El espacio ocupado en el área de Shopping Aricanduva se calculó multiplicando cada porcentaje de ocupación de cada zona homogénea, por lo que ocupa cada zona respecto al total. $(59 * 0,93+73 * 0,04+47 * 0,018)$ el resultado es que la media de área ocupada es de aproximadamente un $59,43 \%$, y el porcentaje de área libre de un $40,57 \%$ de modo que esta cuestión va a puntuar con un +1 .

Cuestión D3.9.- ¿Los usos en la zona están mezclados o zonificados? El índice global de mezcla de usos es de 0,02, el ratio de mezcla de usos en el entorno urbano es muy bajo. Esta cuestión puntúa con +0 .

EN RELACIÓN A PASEABILIDAD, SHOPPING ARICANDUVA HA OBTENIDO UNA PUNTUACIÓN DE 1.

\section{E.- CUESTIONARIO RELACIONADO CON LA ACTIVIDAD DEL CENTRO Y SUS CONSECUENCIAS URBANAS.}

Cuestión E1: ¿La actividad del centro comercial, va a penalizar o a favorecer la sostenibilidad del entorno urbano?: Shopping Aricanduva tiene un índice de atracción de 5, y la puntuación total en el cuestionario relacionado con el transporte eficiente es de 3 . De este modo, consultando la tabla del apartado $3.10,4 \mathrm{E}$. se comprueba que el efecto de la actividad que ejerce el centro sobre el área urbana, va a ser severo a efectos de transporte, y va a suponer un impacto ambiental sobre el aire. Todo ello derivado de los desplazamientos en medios de transporte poco eficientes. Se penaliza la puntuación de TRANSPORTE EFICIENTE (D1) en un -1, quedando finalmente en 2, y Se penaliza la puntuación de REHABILITACIÓN DE ZONAS VERDES (B1) en un -2, quedando en 4. 


\section{FASE FINAL: GRÁFICO DE LA ROSA DE REHABILITACIÓN SOSTENIBLE.}

Las puntuaciones obtenidas en el anterior cuestionario, fueron colocadas en el gráfico de la rosa de rehabilitación sostenible, obteniendo el siguiente resultado (Figura 5.3.15):

\section{(A) ECOEFICIENTE

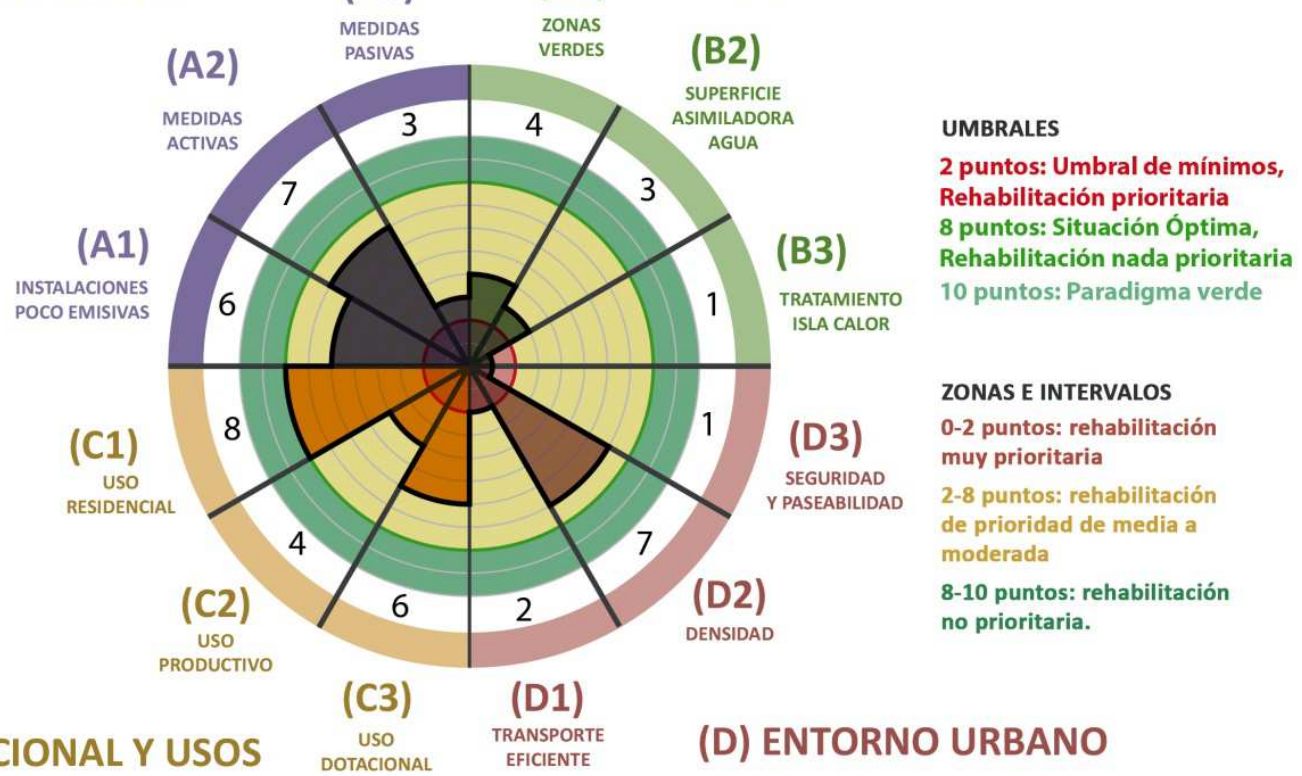

Figura 5.3.15: Gráfico de la rosa de la rehabilitación sostenible para Shopping Aricanduva. Fuente: Elaboración Propia.

De acuerdo al gráfico de rosa obtenido, las rehabilitaciones en Aricanduva deberían de focalizarse en el tema medioambiental (vegetación, asimilación de agua, e isla de calor) especialmente en lo relacionado al último concepto. de este modo, podría ser conveniente tratar las grandes superficies pavimentadas que posee el centro comercial en su periferia más próxima de cara a la recuperación de las cualidades del terreno. A su vez, el entorno urbano del centro, muestra carencias muy críticas, especialmente en lo relacionado con la seguridad y paseabilidad, a la par que con la eficacia del transporte público, problemas que están íntegramente relacionados entre sí, debido a la priorización del vehículo privado en el planeamiento de la zona y la accesibilidad al centro principalmente de esta manera. Como contraste a esto, la zona del centro Aricanduva tiene una densidad adecuada, y los usos están compensados. De cara a la ecoeficiencia, el centro puede presentar carencias de cara a la sostenibilidad en lo relativo a medidas pasivas de energía y acondicionamiento, pero esta reforma no se ve prioritaria.

\section{4.- CASO 4: ABC SERRANO}

El caso de centro comercial ABC Serrano, fie establecido para la presente tesis, como un análogo a Shopping Light (Caso 1, 5.1) en la ciudad de Madrid. Este centro comercial, que a similitud con Shopping Light, también ocupa un edificio histórico, está ubicado en la zona céntrica de la ciudad de Madrid en España. El presente capítulo se centra en el análisis de $A B C$ 
Serrano aplicando la metodología de la tesis paso a paso, explicando en cada uno de los epígrafes, la fuente de dato, y cómo fue calculado o hallado, todo ello de acuerdo a lo establecido en el capítulo 3.

FASE 0: RECOGIDA DE DATOS CUANTITATIVOS.

En esta fase, se realiza la recogida de datos cuantitativos oficiales del centro comercial $A B C$ Serrano y su entorno urbano. Estos se hallarán bien a partir de fuentes oficiales del propio centro, las autoridades urbanas del Ayuntamiento de Madrid, o bien midiendo sobre plano. La justificación de esto, es establecer unos datos de partida que nos sentarán las bases de posteriores análisis más particularizados e exhaustivos relacionados con el centro o con el entorno urbano. Se considerarán los siguientes datos, que serán de utilidad para posteriores análisis. A modo de resumen se mostrará una tabla de resultados de este análisis previo. (Figura 5.4.1)

\begin{tabular}{|l|l|}
\hline \multicolumn{2}{|c|}{ ABC SERRANO } \\
\multicolumn{2}{|c|}{ FASE 0, RECOGIDA DE DATOS CUANTITATIVOS } \\
\hline OC.- TABLA DE DATOS CENTRO & Valor \\
\hline OC1: Superficie centro comercial (m2) & 32.899 \\
\hline OC2: Superficie de parcela o ud. Catastral (m2) & 4106 \\
\hline OC3: Superficie en planta (m2) & 3891 \\
\hline OC4: Número de visitantes semanal (pe/sem) & 69.087 \\
\hline OC5: Índice de Atracción ( $\mathrm{n}$ ) & 3 \\
\hline OC6: Superficie de tipo residencial (m2) & 0 \\
\hline OC7: Superficie de uso productivo (m2) & 0 \\
\hline OC8: Número de instalaciones dotacionales ( $\mathrm{n}-$ ) & 0 \\
\hline OU.- TABLA DE DATOS ENTORNO URBANO & Valor \\
\hline OU1: Población asignada a centro (pe) & 16.450 \\
\hline OU2: Densidad de población (hab/m2) & 0,026 \\
\hline U03: Superficie partida de entorno urbano (m2) & 632.692 \\
\hline
\end{tabular}

Figura 5.4.1: Tabla de Datos ABC Serrano. Fuente:Elaboración propia

\section{OC.- TABLA DE DATOS DEL CENTRO COMERCIAL. (Figura 5.4.1)}

OC1: SUPERFICIE CENTRO COMERCIAL TOTAL: Este dato fue obtenido a partir de de fuentes oficiales, proporcionadas por parte de la gerencia propio centro comercial. La superficie edificada de ABC Serrano es de $32899 \mathrm{~m}^{2}$ totales construidos.

OC2: SUPERFICIE TOTAL DE LA PARCELA DEL CENTRO: Para la obtención de este dato se midió la superficie de la parcela, en un parcelario de la ciudad de Madrid del año 2002, obtenido en la página web del Ayuntamiento. La superficie de la parcela es de $3891 \mathrm{~m}^{2}$

OC3: SUPERFICIE EN PLANTA DEL EDIFICIO DEL CENTRO COMERCIAL. De mediciones, análisis y visitas de campo, se dedujo que la parcela del centro comercial ABC Serrano está ocupada al $100 \%$ de su superficie. La superficie en planta es de $3891 \mathrm{~m}^{2}$ 
OC4: NÚMERO DE VISITANTES SEMANAL. Al no poder obtenerse datos del número de visitantes del centro comercial $A B C$ Serrano, se realizó un conteo estimativo de las visitas tomando como base los datos de Shopping Light del apartado 0C4, considerándose a su vez un coeficiente de ponderación de 1 , debido a la localización céntrica de este centro comercial dentro del área urbana de Madrid, concretamente en un área de gran actividad.

De lunes a viernes: 32899 personas.

Sábado: 27306 personas.

Domingo: 8882 personas.

De este modo, el número de visitantes semanal de $A B C$ Serrano, se estimó en 69087 personas.

OC5: ÍNDICE DE ATRACCIÓN DEL CENTRO. En función al número de visitantes del centro, y de acuerdo al baremo establecido en el apartado C5, a ABC Serrano le corresponde un índice de atracción de 3 (de 20.000 a 150.000).

OC6: SUPERFICIE DE USO EN EL CENTRO DE TIPO RESIDENCIAL. De visitas al centro y consultas en su página web, se dedujo que $A B C$ Serrano no posee superficie residencial dentro de su unidad catastral.

OC7: SUPERFICIE DE USO EN EL CENTRO DE TIPO PRODUCTIVO: De visitas al centro y consultas en su página web, se dedujo que $A B C$ Serrano, no posee superficie de tipo productivo.

OC8: NÚMERO DE INSTALACIONES EN EL CENTRO DE TIPO DOTACIONAL O ASISTENCIAL: De visitas al centro y consultas en su página web, se dedujo que dentro del centro, no hay locales de tipo asistencial.

\section{OU.- TABLA DE DATOS DEL ENTORNO URBANO.}

OU1: POBLACIÓN DE ÁREA URBANA ASIGNADA A CENTRO COMERCIAL: Dividiendo la superficie del centro comercial entre 2, de acuerdo a lo establecido en el baremo de la metodología general, salió una población asignada de 16450 personas.

OU2: DENSIDAD DE POBLACIÓN EN EL DISTRITO DEL CENTRO COMERCIAL: Para el análisis urbano, se cogió la densidad de población del distrito de Salamanca en Madrid, que es dónde está ubicado el centro comercial, esta densidad es de $0,026 \mathrm{hab} / \mathrm{m}^{2}$ de acuerdo a los datos oficiales del ayuntamiento de Madrid de 2015. Esto dato va a ser de interés, tanto para dimensionar el área de análisis, cómo para estudiar la densidad de cara a la adecuación de las medidas de rehabilitación del entorno urbano. No obstante, se debe de considerar que este barrio tiene una compacidad de edificación mucho mayor que el Barrio del Pilar que va a ser estudiado en el caso del centro comercial La Vaguada, el descenso en este dato de población, se debe a los procesos de gentrificación y terciarización acontecidos en el Barrio Salamanca en las últimas décadas. (Jaime Taurrell, 2002) ${ }^{52}$

OU3: SUPERFICIE DE PARTIDA DEL ENTORNO URBANO: La superficie del entrono urbano a analizar, se halló a partir de los datos de población asignada al centro, la cual fue dividida entre la densidad del área urbana de análisis establecida (0,026 hab/m2, Distrito Salamanca, 2015), la superficie de partida para el área urbana de ABC Serrano es de $632692 \mathrm{~m}^{2}$

\footnotetext{
${ }^{52}$ http://www.elmundo.es/suvivienda/2002/242/1014912996.html, Título: Vivir en el distrito de Salamanca, se paga, Marzo 2002.
} 


\section{FASE 1: ANÁLISIS DEL CONTEXTO URBANO.}

Este análisis se realiza generalmente en base a mediciones sobre plano del área del centro comercial ABC Serrano. Se trabajarán diferentes escalas dentro de los planos y parcelarios de Madrid, siendo predominante la escala urbana amplia de toda la zona de influencia del centro comercial, la cual va a ser establecida en las primeras fases de este apartado. Para este análisis resultará fundamental el uso de los datos referentes a la configuración del entorno urbano del barrio de Salamanca en Madrid, siendo estos ponderados con la información que pudiera sacarse del análisis sobre plano. El objetivo será hallar y establecer las pautas urbanísticas para el cuestionario de rehabilitación del centro comercial, y se considerarán aspectos relacionados con configuraciones de volumen urbano, densidades, usos, áreas verdes y medio ambiente urbano.

1A: ESTABLECIMIENTO DEL ÁREA DE INFLUENCIA DEL CENTRO COMERCIAL: En base a la superficie de partida del área, hallada anteriormente, se estableció para el área de análisis del centro comercial ABC Serrano, un radio de aproximadamente 450 metros a partir del lindero de la parcela del centro. Este dato fue hallado considerando la superficie de partida (OU3) cómo el área de un círculo sobre el contexto urbano, aplicando la siguiente fórmula:

Radio $=\sqrt{ }(632692 / \pi)=450 \mathrm{~m}$. Este dato es el verdaderamente relevante para establecer la superficie del área de análisis. (Figura 5.4.2)

1B: DELIMITACIÓN SOBRE PLANO DEL ÁREA DE INFLUENCIA: Para la delimitación del área de influencia, se trazó una circunferencia del radio anteriormente establecido $(450 \mathrm{~m})$, a partir del lindero de la parcela del centro. Luego a partir del trazado de ese círculo, se estableció el borde del área urbana de análisis considerando en la trazada la configuración del tejido (parcelas, viario y áreas verdes), fue necesario añadir algunas parcelas, y descontar algunos espacios libres, quedando el área de análisis de la siguiente manera. (Figura 5.4.2). Se marcaron los límites en varias avenidas y plazas relevantes. LA SUPERFICIE DEL ÁREA URBANA FINAL DE ANÁLISIS PARA ABC SERRANO ES DE $798.318 \mathrm{~m}^{2}$. Este dato será el que se utilice para cualquier conteo relacionado con el área urbana.

1C: SUBDIVISIÓN DEL ÁREA DE INFLUENCIA EN ÁREAS HOMOGÉNEAS Y DELIMITACIÓN DE ZONAS VERDES. Para este análisis, el área urbana anteriormente asignada, va a dividirse en zonas homogéneas de acuerdo a la configuración de su tejido urbano, marcándose a su vez la superficie de zonas verdes sobre plano. El área, al ser de un tamaño relativamente pequeño debido a la alta densidad, y muy similar en configuración urbana en toda su superficie, se estableció una única tipología de zona homogénea (Z1). Descontando los espacios verdes y sin edificar en el área, esta zona tiene aproximadamente $689.591 \mathrm{~m}^{2}$ brutos, que fueron medidos sobre plano. (Figura 5.4.2) 

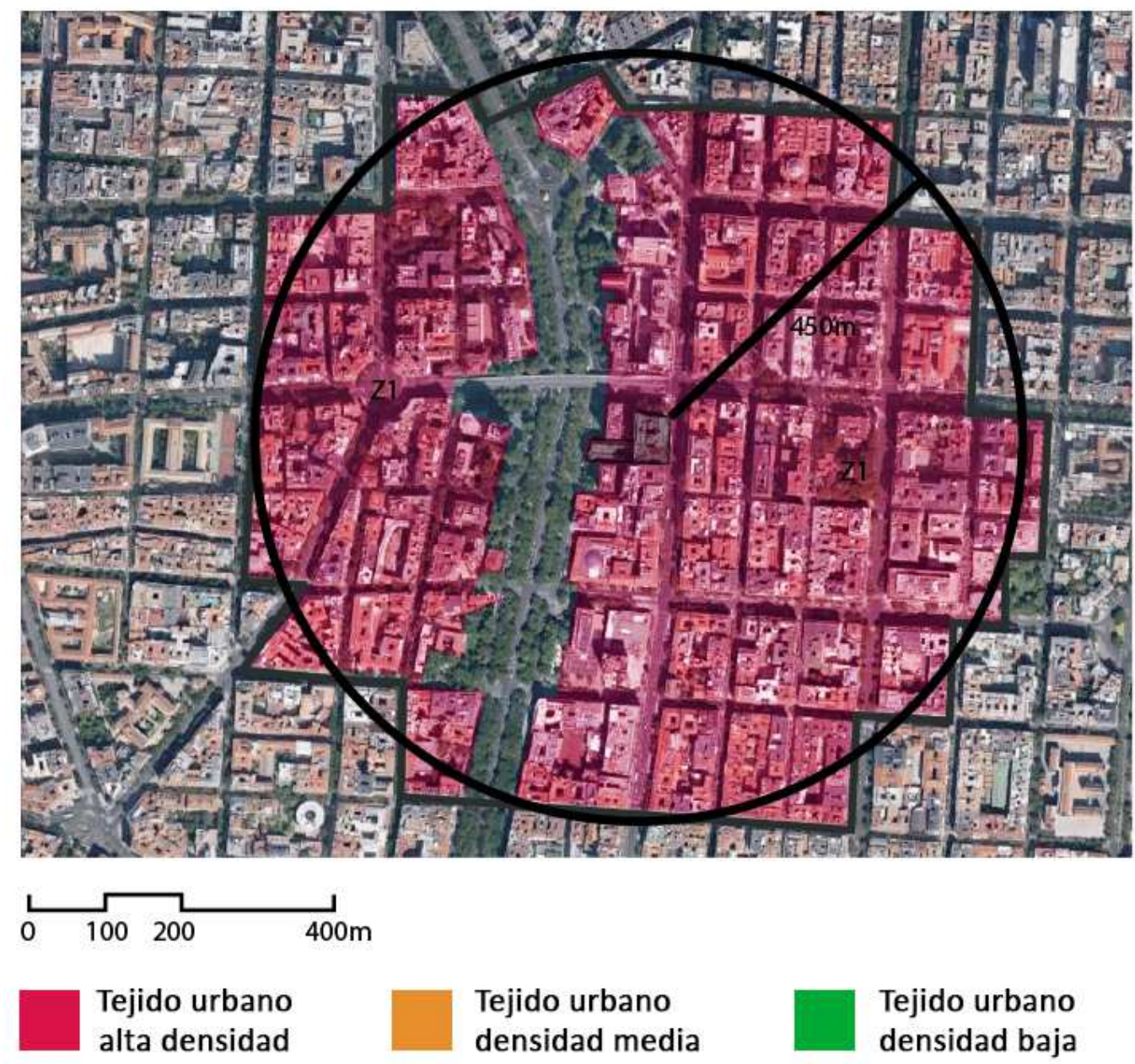

Tejido urbano
densidad baja

Figura 5.4.2: Área urbana de ABC Serrano y subdivisión por zonas homogéneas. Fuente: Elaboración propia a partir de datos de Google.

1D: PORCENTAJE DE OCUPACIÓN DE LA EDIFICACIÓN Y ÁREA OCUPADA: A partir del análisis de un área tipo de $150 \times 150 \mathrm{~m}^{2}$ sobre un parcelario oficial de la ciudad de Madrid, (Figura 5.4.3) contándose dentro de la misma el espacio libre y ocupado, para establecer un porcentaje. EI tamaño de la zona tipo fue reducido en este análisis, debido a que este tamaño más, siendo el tamaño del área irrelevante. El porcentaje de ocupación de la edificación de la única zona homogénea establecida para el área de influencia de $A B C$ Serrano es del $61 \%$. Aplicando este porcentaje sobre la superficie de zona total establecida anteriormente $\left(689.591 \mathrm{~m}^{2}\right)$ se puede obtener en el área urbana de ABC Serrano una superficie ocupada de $420.651 \mathrm{~m} 2$. 


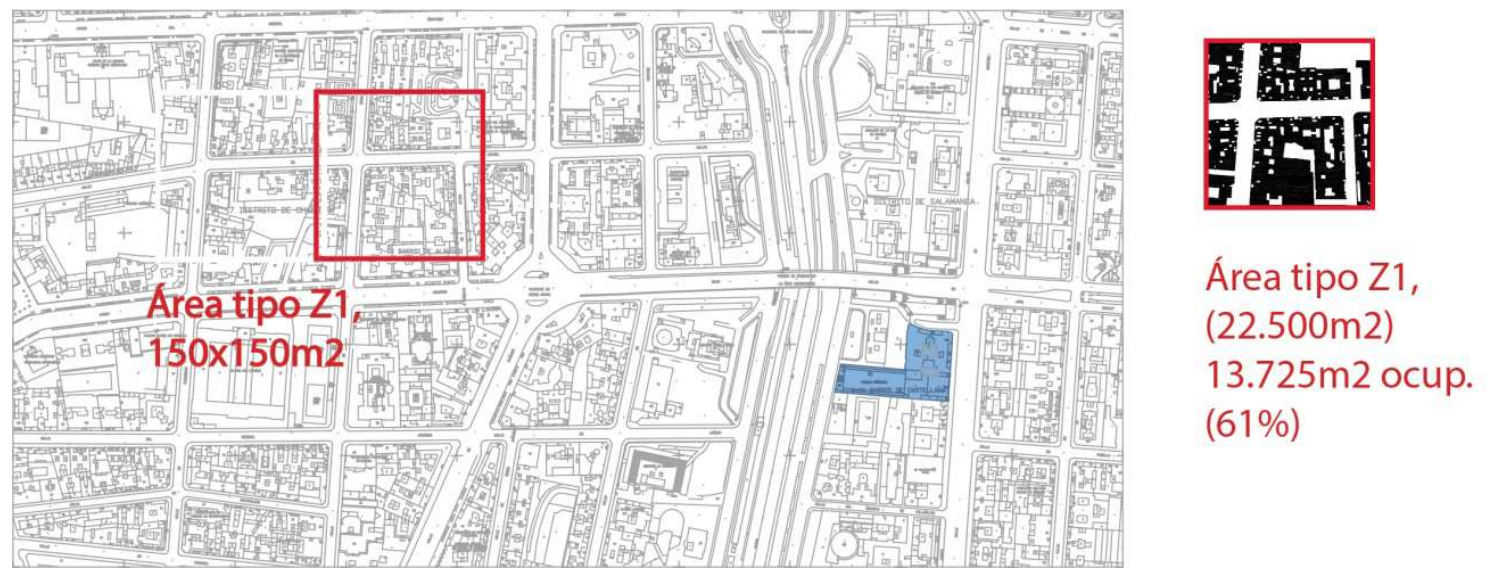

Figura 5.4.3: Análisis de ocupación sobre parcelario, $A B C$ de Serrano va marcado en azul. Fuente: Elaboración propia a partir de datos de I Ayuntamiento de Madrid.

1E: ALTURAS DE LA EDIFCACIÓN POR ÁREA HOMOGÉNEA: Al Haber un área homogénea en la zona, la altura de la edificación se estableció en 7 plantas, a partir de un análisis visual del área realizado de visitas a la misma, y de Google Street View.

1F: ESTABLECIMIENTO DE LAS TIPOLOGÍAS DE TEJIDO EN BASE A LA MORFOLOGÍA URBANA POR ÁREA HOMOGÉNEA: Con una ocupación de la edificación de un 67\% y una altura de 12 plantas, el área de influencia de $A B C$ Serrano es un tejido denso de acuerdo al cuadro respectivo a la cuestión $1 \mathrm{~F}$ del apartado en el capítulo 3.6 de la metodología.

1G.- ÍNDICE GLOBAL DE DENSIDAD. Al haber solo una tipología de tejido en el área de $A B C$ Serrano (ocupa el $100 \%$ de la zona analizada) de tipo denso, el índice global de densidad quedó establecido con una puntuación de 3, que corresponde a una zona urbana densa. Este dato va a resultar de gran interés, debido a que es la base para la analítica de la densidad urbana.

1H: SUPERFICIE EDIFICADA TOTAL DE CADA ÁREA HOMOGÉNEA. Para la superficie edificada total, se multiplicó la superficie ocupada en planta anteriormente hallada $\left(420.561 \mathrm{~m}^{2}\right)$ por el número medio de plantas (7). De este modo, la superficie total edificada bruta aproximada es de $2.944 .554 \mathrm{~m}^{2}$. Dato de gran relevancia para el análisis de los usos en el área urbana.

1I: ESTABLECIMIENTO DE PORCENTAJES DE USO DENTRO DE LAS ZONAS HOMOGÉNEAS ESTABLECIDAS: El área de $A B C$ Serrano corresponde a un entorno complejo en el que hay edificios tanto residenciales, como comerciales y administrativos. Al no haber datos objetivos sobre los usos predominantes en la zona, se consideraron los siguientes porcentajes.

Z1: Uso residencial: $50 \%$. Uso productivo: $30 \%$. Uso comercial: $20 \%$

1J: CONTEO DE LOS USOS DENTRO DEL CONTEXTO URBANO. Una vez se establecieron los porcentajes, para obtener los metros cuadrados de uso, éstos fueron multiplicados por separado, por la superficie edificada total de la única zona homogénea en el área de $A B C$ Serrano $\left(2.944 .554 \mathrm{~m}^{2}\right)$, quedando establecidos los usos para $A B C$ Serrano de la siguiente manera:

Z1: Uso residencial: $1472277 \mathrm{~m}^{2}$. Uso productivo: $883366 \mathrm{~m}^{2}$. Uso comercial: $588911 \mathrm{~m}^{2}$. 
1K: ÍNDICE GLOBAL DE MEZCLA DE USOS. Para el índice global de mezcla de usos, se sumaron los porcentajes de uso productivo y comercial para obtener el porcentaje de uso no residencial, el cual fue comparado con el uso residencial:

Z1: Uso residencial: 50\%. Uso no residencial: $50 \%$.

En base a estos porcentajes, y actuando de acurdo al baremo de este análisis establecido en las pautas de la metodología, a Z1 se le asignó un índice de mezcla de usos de 1, ocupando la zona el $100 \%$ de la superficie urbana analizada (una zona homogénea). El área de ABC Serrano tiene un índice de mezcla de usos de 1 de 1 , que corresponde a un área muy compleja a efectos de usos.

1L: CONTEO DEL NÚMERO DE DOTACIONES DENTRO DEL CONTEXTO URBANO, DENTRO DEL ÁREA DE DOTACIONES: Para el análisis de dotaciones, al estar comprendida el área de $A B C$ Serrano dentro del área de un 1 kilómetro a partir del lindero del centro, se consideró como área de dotaciones la misma área, se marcaron las siguientes dotaciones: 8 dotaciones de visita esporádica, 4 dotaciones de visita habitual, y ninguna gran dotación muy visitada. (Figura 5.4.4)

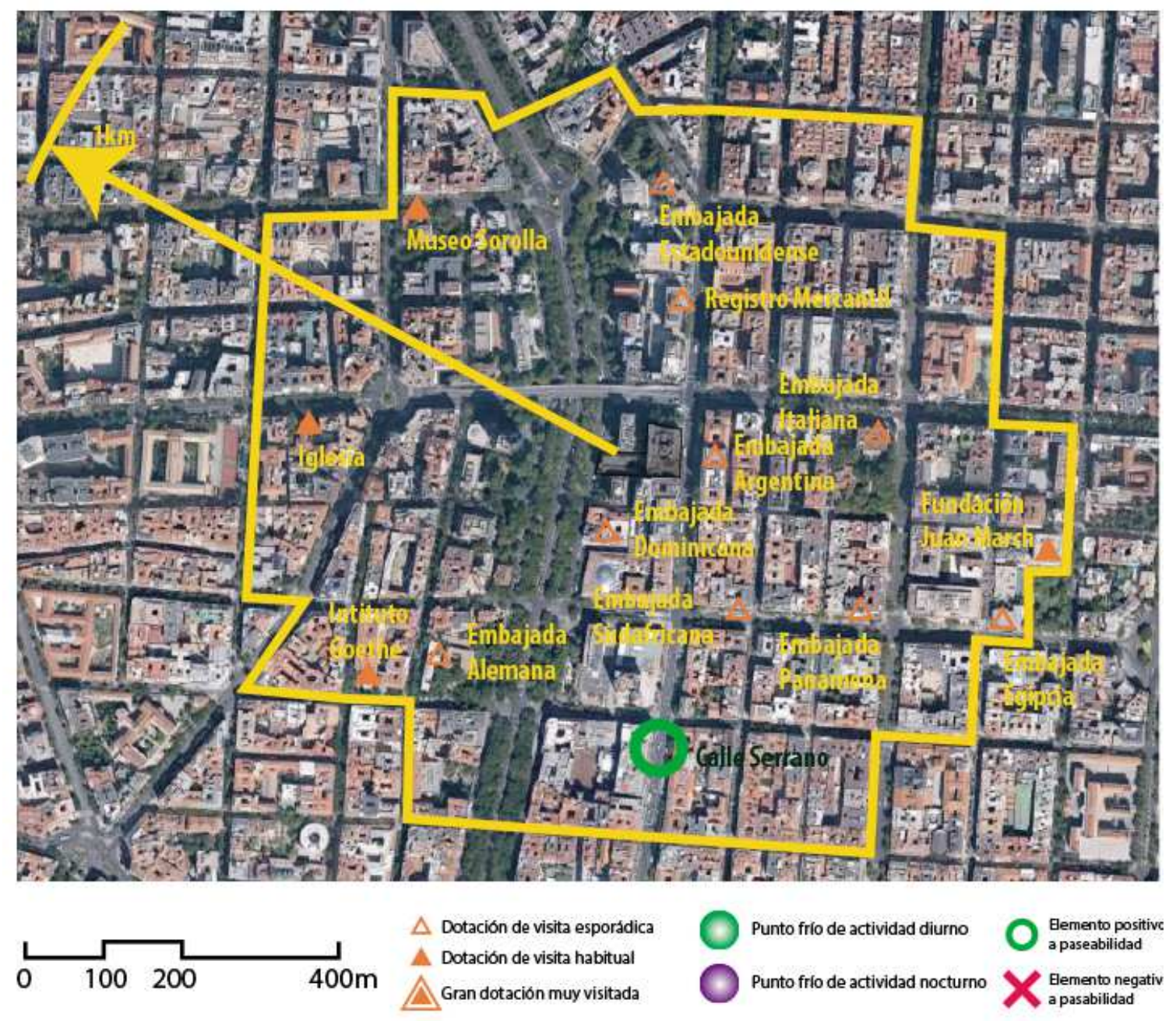

Figura 5.4.4: Análisis de dotaciones. Fuente: Elaboración propia a partir de datos de Google. 
1M: PRESENCIA E INFLUENCIA DE ELEMENTOS POSITIVOS Y NEGATIVOS: Como elementos positivos, cabe destacar la presencia del área comercial de la calle serrano, que atraerá clientela al centro. A pesar de la gran cantidad de dotaciones en la zona, no hay hitos turísticos de primer orden. En el área no hay elementos negativos que afecten a la paseabilidad (Figura 5.4.4).

1N: ZONAS DE ACTIVIDAD: Aunque hay desniveles en el área, debido a la configuración del terreno, al estar en un eje de gran concurrencia (Paseo de la Castellana y Serrano entre otros), la zona es muy activa tanto de día como de noche.

10: ÁREAS ARBOLADAS Y VERDES, DENTRO DEL ÁREA URBANA DEL CENTRO: Dentro del área de $A B C$ Serrano, se consideraron las siguientes áreas verdes con sus respectivos metros cuadrados de superficie (Figura 5.4.5). considerando las áreas netas de superficie verde, y los metros cuadrados de vegetación que poseen. El área urbana asignada a $A B C$ Serrano posee un área verde neta en planta de $37278 \mathrm{~m}^{2}$, que se desglosa en las siguientes superficies de vegetación.

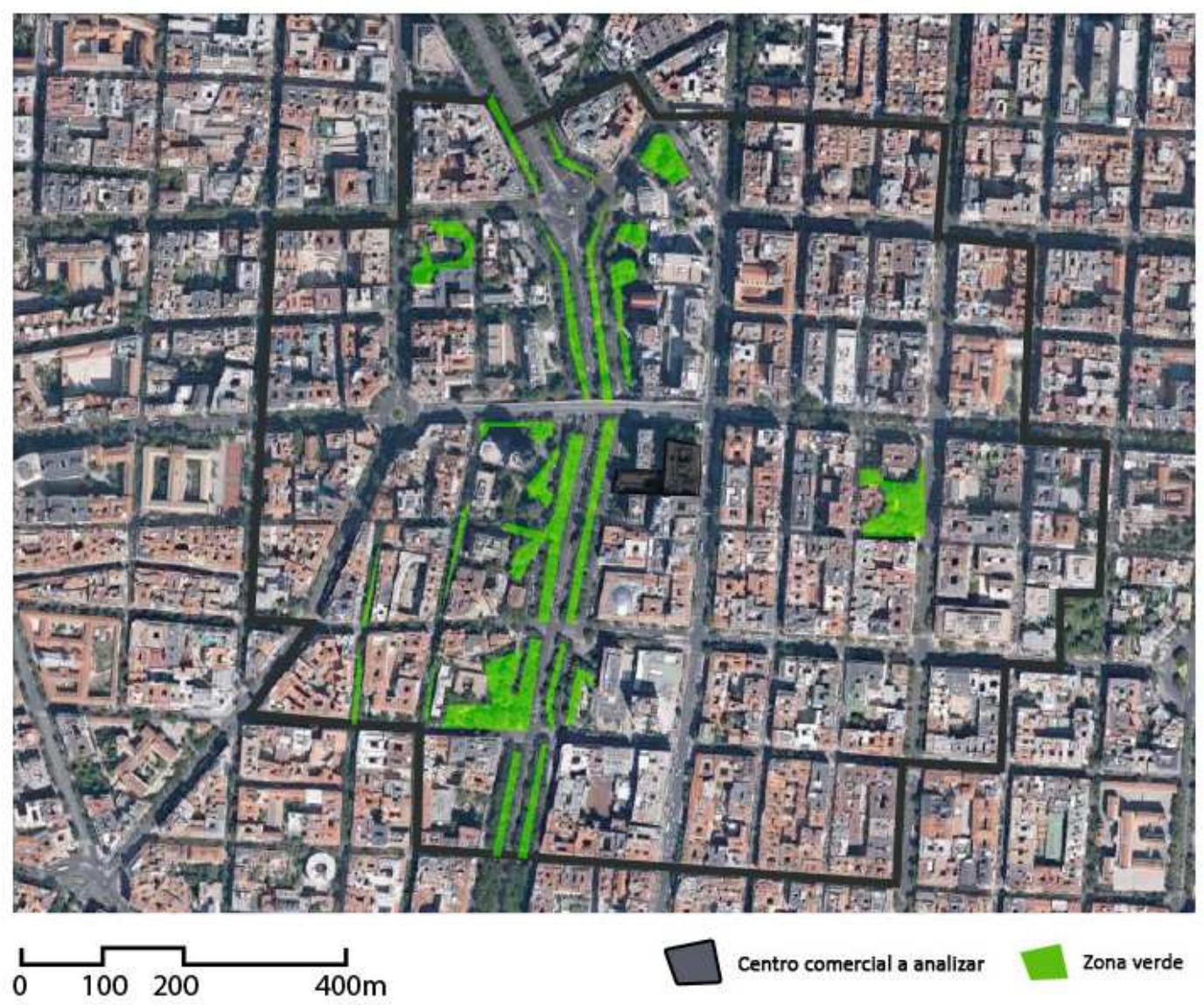

\begin{tabular}{|l|r|}
\hline 10: Superficie de zonas verdes en área urbana & Valor \\
\hline C4.1: pradera & 1000,0000 \\
\hline C4.2: hierba de gran altura o huerto & 1000,0000 \\
\hline C4.3: vegetación arbustiva intensiva & 1000,0000 \\
\hline C4.4: vegetación arbórea caduca & 37278 \\
\hline C4.5: vegetación arbórea perenne & 0,0000 \\
\hline
\end{tabular}

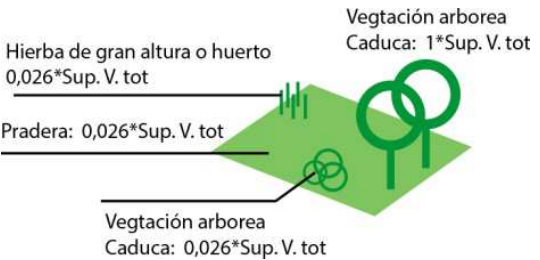


Figura 5.4.5: Análisis de dotaciones. Fuente: Elaboración propia a partir de datos de Google

1P.- DELIMITACIÓN DE RECORRIDOS A CENTRO, DENTRO DEL ÁREA URBANA: Para este análisis, fueros establecidos tres recorridos desde diferentes puntos del borde e interior del área urbana de análisis de ABC Serrano, de acuerdo a lo distado en la metodología. Los tiempos de llegada se muestran en la imagen de acuerdo a los resultados del posterior apartado $2 \mathrm{E}$, al igual que las paradas de transporte público, y su radio de influencia de 200m (Figura 5.4.6).

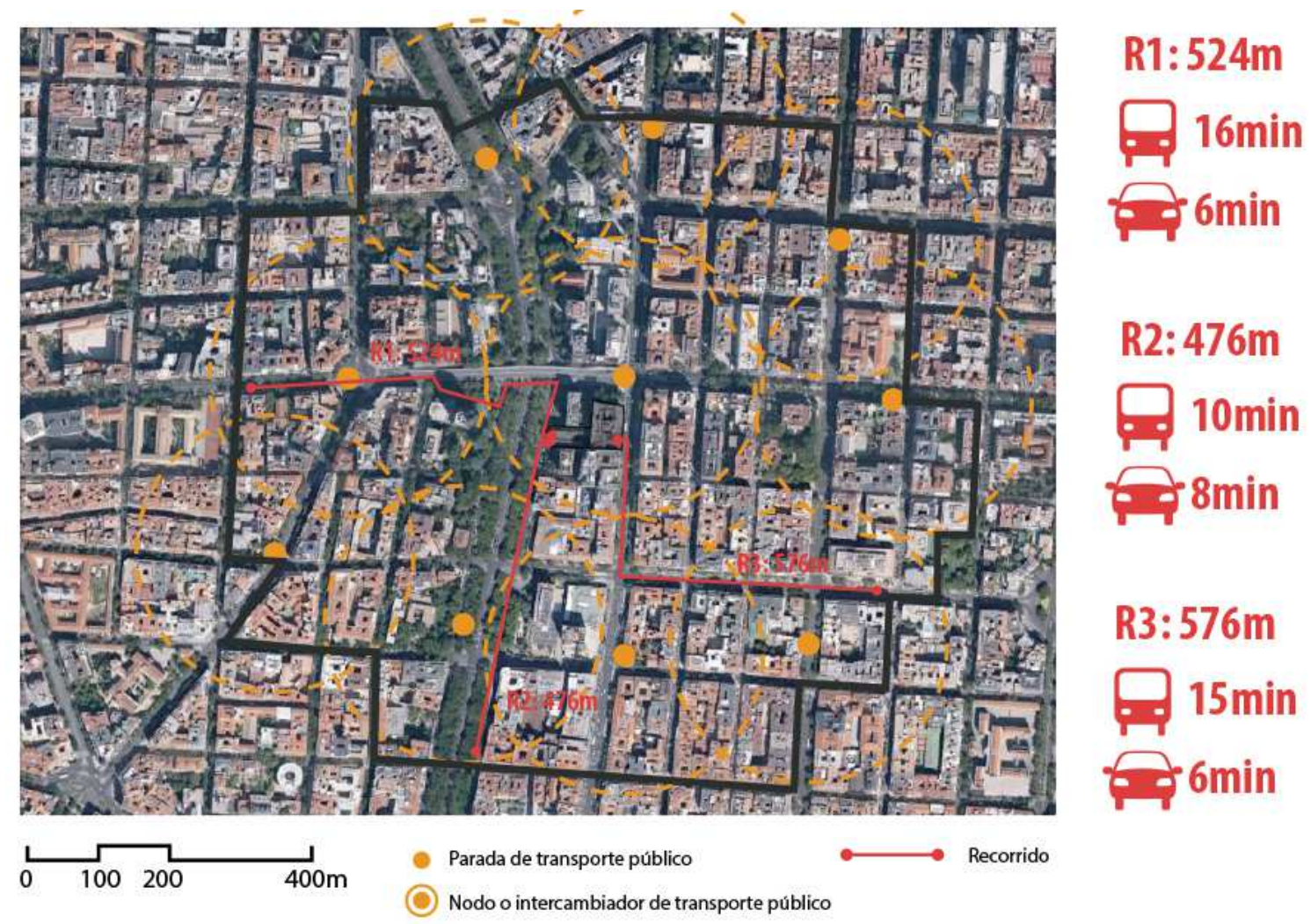

Figura 5.4.6: Recorridos, tiempos de llegada, y zonas cubiertas por el transporte público. Fuente: Elaboración propia a partir de datos de Google.

1Q.- HUELLA DE CARBONO DEL ÁREA URBANA: Siendo la huella de carbono de España de 5,083 toneladas anuales de dióxido de carbono per cápita (toneladas por habitante), de acuerdo al Banco Mundial para $2013^{53}$. Para hallar la huella de carbono del área urbana de ABC Serrano, se multiplicó este dato por la población total del área de ABC Serrano, (16.450 personas), saliendo una huella de 83.895 Toneladas de dióxido de carbono anuales.

1R.- CAPACIDAD ABSORCIÓN DE LOS ELEMENTOS VERDES EN ÁREA URBANA: En base a los datos de superficies verdes obtenidos en el apartado 10, se calculó la absorción total de las áreas verdes en base a la capacidad de absorción por metro cuadrado de las superficies vegetales consideradas. (figura 5.4.7.) Siendo la capacidad absorbente total en el área de 5630 Toneladas de dióxido de carbono anuales.

\footnotetext{
${ }^{53} \mathrm{http}: / /$ datos.bancomundial.org/indicador/EN.ATM.CO2E.PC?locations=ES
} 


\begin{tabular}{|c|c|c|c|c|c|c|}
\hline 1R: C.absorción elementos verdes en área & Pradera & V.arb ext & V. A. Int. & H. Caduca & H. Perenne & Otro \\
\hline Superficie total & 1000,0000 & 1000,0000 & 1000,0000 & 37278,0000 & 0,0000 & \\
\hline Tasa absorción TCo $2 / \mathrm{m} 2$ año & 0,0013 & 0,0020 & 0,0350 & 0,1500 & 2,2500 & 0,8000 \\
\hline Absorción dióxido carbono TCo2 & 1,3000 & 2,0000 & 35,0000 & 5591,7000 & 0,0000 & 0,0000 \\
\hline
\end{tabular}

Figura 5.4.7: Capacidad de absorción de dióxido de carbono de las especies vegetales en ABC Serrano. Fuente: Elaboración propia.

1S: DELIMITACIÓN DE ÁREAS EN FUNCIÓN DE LA RECUPERACIÓN DE AGUAS EN ÁREA URBANA. Para este análisis, se consideraron como zonas permeables al agua de lluvia en el terreno, las zonas verdes presentes en el área urbana asignadas en el apartado 10. De este modo, la superficie permeable del área urbana de ABC Serrano es de 37278 m2

\section{FASE 2: ANÁLISIS DE RELACIONES ENTRE CENTRO COMERCIAL Y ENTORNO URBANO.}

Este análisis es muy similar en búsqueda de datos y función con respecto al anteriormente analizado sobre el área urbana general. La particularidad de este análisis está en que su ámbito está limitado a las parcelas que directamente lindan con el centro comercial ABC Serrano. EI objetivo es cuantificar las relaciones urbanas entre el centro y el entorno próximo, ya sea mediante usos, relaciones entre dotaciones, y accesibilidad o transporte, en este análisis va a primar el estudio sobre plano, aunque también se harán análisis cuantitativos de superficies, y cualitativos.

2A: DELIMITACIÓN DE ÁREA PRÓXIMA: De cara al análisis del área próxima se escogieron para este análisis las manzanas próximas al centro (Figura 5.4.8).

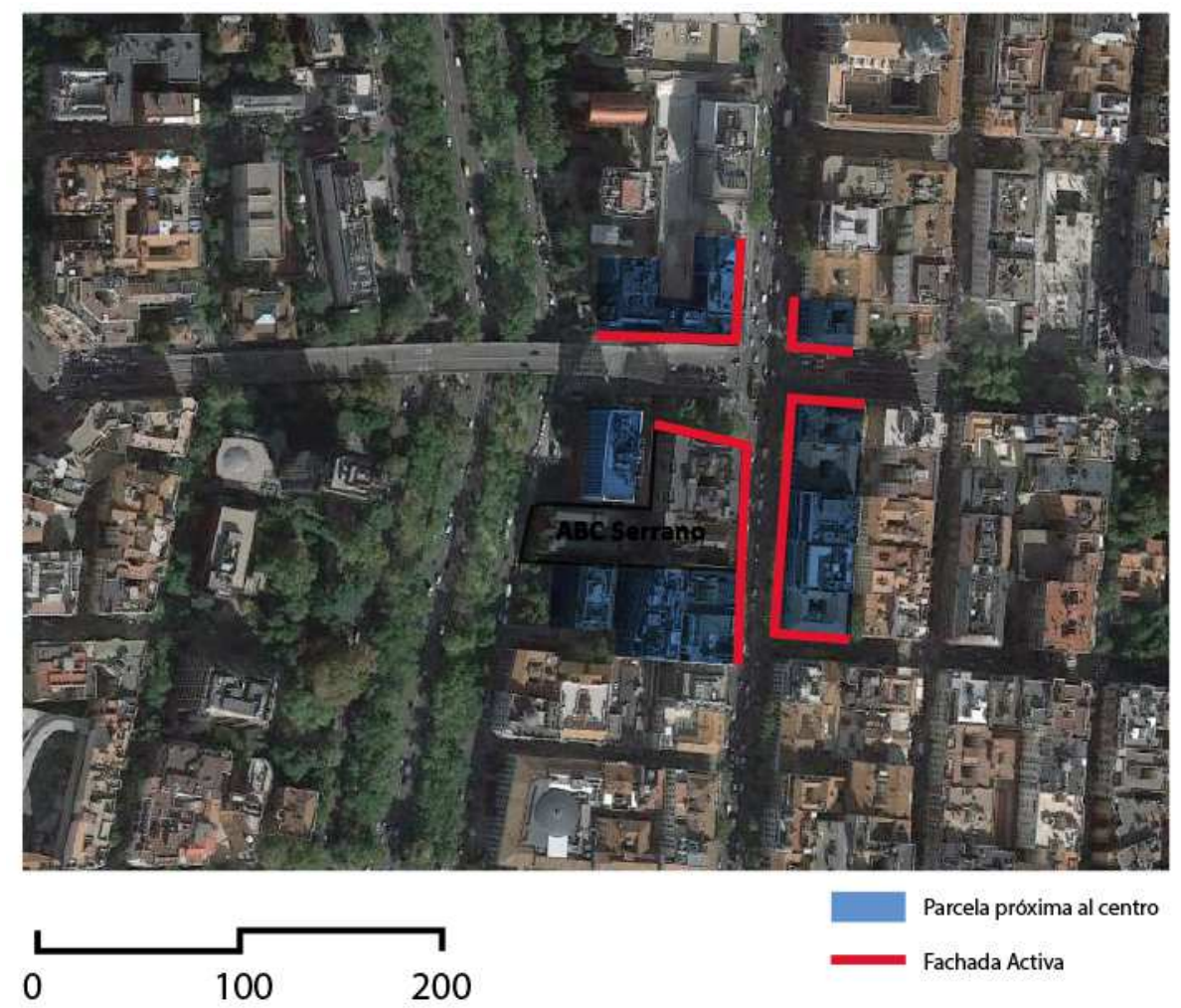

Figura 5.4.8: Análisis de parcelas próximas al centro. Fuente: Elaboración propia a partir de datos de Google. 
2B: SUPERFICIE TOTAL EDIFICADA EN ÁREA PRÓXIMA: Para el conteo de la superficie total estimada de las manzanas próximas al centro, se midió sobre un parcelario la superficie en planta de las mismas, que es de $24806 \mathrm{~m}^{2}$. A posteriori, para hallar la superficie edificada total del análisis de usos, ésta superficie en planta fue multiplicada por el número de plantas medio de los edificios de susodichas manzanas; para el caso de ABC Serrano, la altura media se estableció en 7 plantas, ya que éste se encuentra dentro de la zona homogénea Z1, establecida en 1C. De este modo, la superficie construida de las manzanas próximas al centro es de $173642 \mathrm{~m}^{2}$.

2C: USOS EN ÁREA PRÓXIMA: Las manzanas próximas al centro comercial, poseen una configuración de usos en la que predominan los edificios dotacionales o de oficinas, frente a los residenciales. Al haber una falta de datos sobre la distribución de los usos en las parcelas colindantes al centro, los porcentajes a establecer son los de la zona Z1, analizados en el apartado $1 \mathrm{~J}$.

Uso residencial: $50 \%$. Uso productivo: $30 \%$. Uso comercial: $20 \%$.

Estas superficies fueron multiplicadas por la superficie construida, quedando estas superficies de uso:

Uso residencial: $86821 \mathrm{~m}^{2}$. Uso productivo: $52093 \mathrm{~m}^{2}$. Uso comercial: $34728 \mathrm{~m}^{2}$.

2D: FACHADAS ACTIVAS EN ÁREA PRÓXIMA Para este análisis, las fachadas activas en manzanas próximas se marcaron en el plano (Figura 5.4.8), y se midieron en metros lineales. Para hacer una comparación, se hallará además la longitud de fachada total. La longitud de fachada activa es de $1054 \mathrm{~m}$ siendo la longitud de fachada total de $1818 \mathrm{~m}$, incluyendo las fachadas activas. De este modo, el porcentaje de fachada activa es del $58 \%$ en las parcelas colindantes al centro, incluyendo el propio centro que actúa como fachada activa en este caso.

2E: TIEMPOS DE LLEGADA DESDE LOS PUNTOS EN ÁREA A CENTRO COMERCIAL MEDIANTE TRANSPORTE PÚBLICO: Para la estimación de los tiempos de llegada en transporte público, fueron considerados los recorridos establecidos en $1 \mathrm{P}$, y se utilizó la base de datos de Google Maps para establecer los tiempos de llegada. (Figura 5.4.6)

2F: TIEMPOS DE LLEGADA DESDE LOS PUNTOS EN ÁREA A CENTRO COMERCIAL MEDIANTE TRANSPORTE PRIVADO: Para la estimación de los tiempos de llegada en transporte público, fueron considerados los recorridos establecidos en 1P, y se utilizó la base de datos de Google Maps para establecer los tiempos de llegada, El centro posee aparcamiento, aún así, se añadió al trayecto unos dos minutos adicionales de maniobra y trayecto de llegada al centro. De este modo, los tiempos establecidos para los medios de transporte son los siguientes para cada recorrido. (Figura 5.4.6)

Este centro está ubicado en un área muy concurrida de la ciudad de Madrid, la accesibilidad al mismo mediante transporte público es bastante sencilla, siendo además eficaz cubrir los recorridos establecidos en el análisis a pie. La frecuencia de autobuses en la zona, es de aproximadamente cinco minutos, habiendo carriles bus en las calles, que le dan eficacia a este medio de transporte en sus desplazamientos. No obstante, esta zona al ser un centro 
consolidado con una gran actividad de oficinas, va a ser el punto final de muchos desplazamientos a los lugares de trabajo, y pueden aparecer problemas de tráfico en las vías. En este sentido, el transporte particular, es el que va a verse más afectado por esto, pudiendo demorarse los tiempos de llegada en una media de 5 minutos.

\section{FASE 3: ANÁLISIS DEL EDIFICIO DEL CENTRO COMERCIAL.}

Una vez analizado el entorno urbano en sus diferentes escalas, cuantificándose de cara al cuestionario de rehabilitación todas las facetas del mismo, a la par que las relaciones urbanas; el último campo de análisis es el estudio concreto de lo que es el edificio del centro comercial $A B C$ Serrano. De este modo a partir de los datos de los que se pudieron disponer del centro comercial, van a cuantificarse los rasgos del edificio del centro en relación a las facetas de usos, sostenibilidad y comportamiento bioclimático. Serán de importancia el conteo de superficies en base a la faceta a analizar, las simulaciones y la comparativa de las características formales para dar los datos necesarios para el cuestionario de rehabilitación.

3A: DELIMITACIÓN DE ÁREAS EN FUNCIÓN DE LA RECUPERACIÓN DE AGUAS: Sobre la planta de cubiertas del centro comercial, se delimitaron las áreas tanto permeables como impermeables del centro, de acuerdo a los estipulado en la metodología, para el caso de $A B C$ Serrano, no hay datos sobre la posesión de sistemas de aprovechamiento de agua de lluvia, de manera que de cara al escenario más desfavorable, se consideró que el centro no posee superficie permeable alguna que ayude a regenerar el terreno o reducir el consumo de aguas.

3B: USOS DENTRO DEL EDIFICIO DEL CENTRO: Para los usos, se consideraron los diferentes locales dentro del centro comercial, buscándose los metros cuadrados de espacio productivo, y las dotaciones asistenciales dentro del mismo. En ABC Serrano, no se computaron para esta tesis usos productivos no comerciales, ni residenciales. (Las oficinas de gestión NO computan como espacio productivo, ya que generalmente no son accesibles por personas ajenas al centro comercial). Analizando plantas del centro y los locales presentes, se consideró que $A B C$ Serrano, no posee superficie ni residencial ni dotacional/asistencia alguna.

3C: DELIMITACIÓN DE ÁREAS VERDES EN CENTRO COMERCIAL. La única área verde presente en el centro comercial $A B C$ Serrano, es el conjunto de jardineras que hay en la terraza. Considerando esto cómo área verde, se comprobó que en superficie no llega a los 20 metros cuadrados, de aproximadamente $4106 \mathrm{~m}^{2}$ de cubierta. De modo que esta superficie es despreciable a efectos de análisis de zonas verdes en centro y asimilación de dióxido de carbono.

3D: ABSORCIÓN DE LAS ÁREAS VERDES EN CENTRO COMERCIAL. Los 20 metros cuadrados de jardinera asimilan a lo sumo media tonelada de dióxido de carbono anual, dato despreciable frente a la huella de carbono anual del centro (1644,95 T Co2 anuales) y el área urbana (83895 T Co2 anuales).

3E: ANÁLISIS BIOCLIMÁTICO DEL CENTRO COMERCIAL RESPECTO A CLIMA, DIAGRAMA DE GIVONI. 
El Diagrama de Givoni para Madrid es el siguiente (Figura) estos datos fueron tomados del Instituto nacional de Meteorología, considerando la metodología del Análisis de Givoni sobre una carta psicrométrica (Figura 5.4.9).

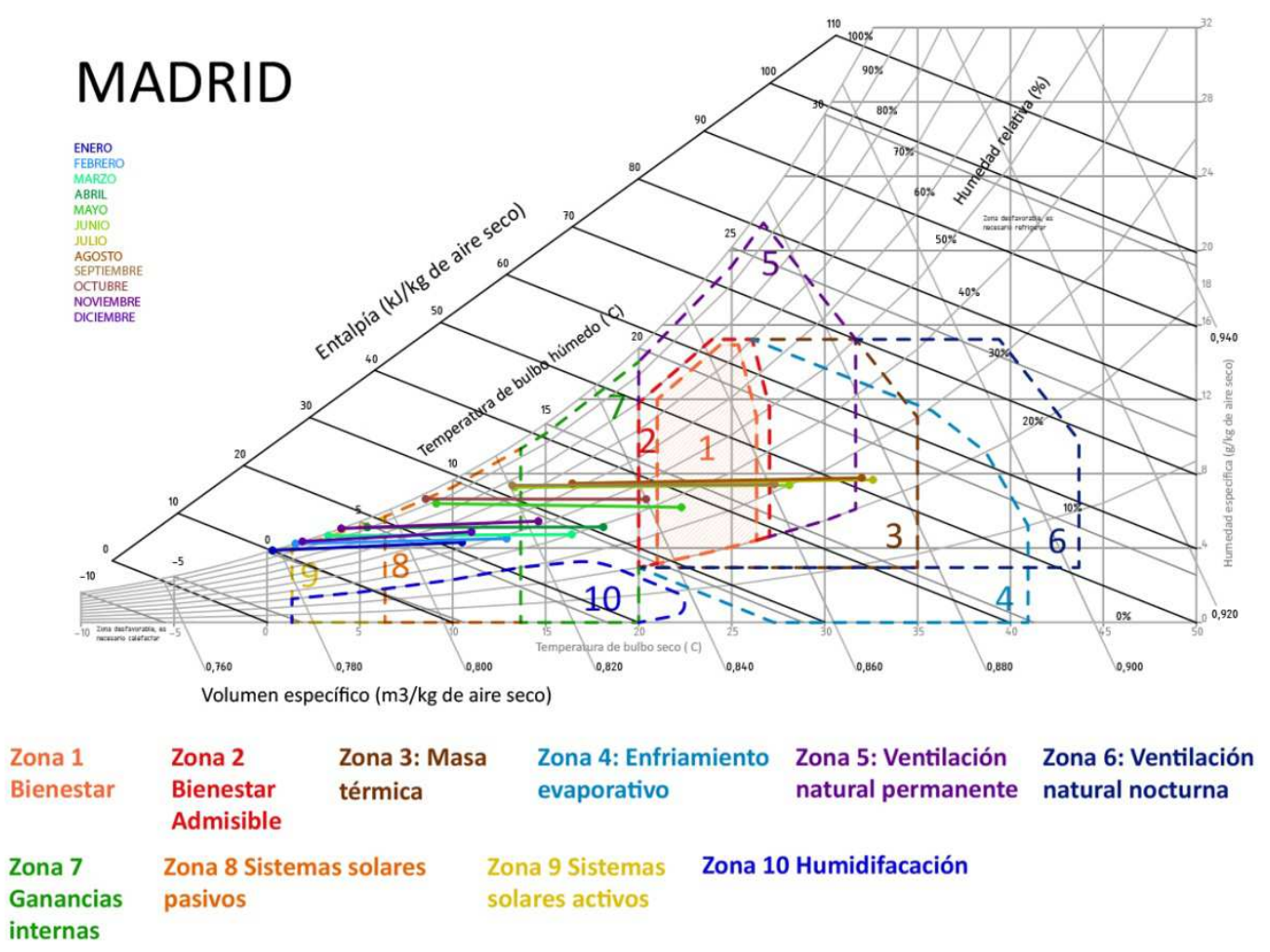

Figura 5.4.9: Diagrama de Givoni de Madrid. Fuente: Elaboración propia a partir de datos de Givoni y AEMET.

A primera vista, el clima de Madrid, durante los meses de verano, hay horas del día dentro de la zona de confort, habiendo también gran parte de las mismas fuera, debido al exceso o defecto de calor. En otoño y primavera, las temperaturas no alcanzan casi nunca la zona de confort, y en invierno se encuentran muy alejadas de la misma debido a las bajas temperaturas.

Cualquier edificio de Madrid, de acuerdo al diagrama de Givoni, necesitaría durante los meses más fríos, valerse de todo tipo de sistemas solares, tanto activos como pasivos, llegando incluso a necesitar de manera marginal sistemas mecánicos de calefacción para lograr la temperatura de confort durante las horas más frías del mes de enero. En las horas más cálidas de los meses de verano, durante el día el edificio puede recurrir bien a la ventilación natural tanto nocturna como permanente por una parte, o al enfriamiento evaporativo por otra, ya que en esos meses la humedad tiende a encontrarse en valores bajos; la masa térmica también puede ser una opción a considerar. Lo que debe de tenerse en cuenta, es que no van a necesitarse en ningún momento sistemas mecanizados de refrigeración. En las horas más frías de los meses de verano, así como en la primavera o en el otoño, una combinación que considere el uso de las cargas internas, junto con los sistemas solares pasivos, será suficiente para lograr la temperatura de confort. 
Por consiguiente, para lograr un acondicionamiento bioclimático del centro de ABC Serrano, se precisaría del uso de cargas internas, y todo tipo de sistemas solares, tanto activos como pasivos, durante la mayor parte del año. Siendo fundamental o bien garantizar la ventilación en todo el centro, o bien disponer de sistemas no mecanizados que humidifiquen el ambiente, sin descartar como opción el uso de sistemas constructivos masivos. Se debe de evitar a toda costa las ganancias de calor en las horas más cálidas.

El centro comercial ABC Serrano, posee una envolvente masiva que le da al centro la capacidad de aclimatarse por masa térmica, y puede valerse de las cargas internas para acondicionarse en el caso de frío, solo en el espacio de las tiendas. El centro aunque posee todo tipo de huecos y aperturas, éstas están completamente cerradas, sin que se considere la ventilación natural, y para calentar, ventilar o refrigerar el espacio interior, se usan sistemas mecanizados. El centro no posee además ningún tipo de sistema de acondicionamiento solar.

\section{F: CALIFICACIÓN ENERGÉTICA DEL CENTRO COMERCIAL.}

Al no haber datos objetivos acerca del consumo primario de energía o las emisiones generadas por el centro ABC Serrano, se tuvo que realizar una estimación con el programa CE3X en el clima de Madrid, además de realizarse una ponderación comparativa de las emisiones y el consumo, con otros centros comerciales de los que se disponen datos de calificación energética (Parquesur, Los Arcos, Planetocio). Se consideraron sistemas de aire acondicionado, ventilación forzada y agua caliente por bomba de calor.

De este modo ABC Serrano en el análisis obtuvo estas calificaciones.

De cara al análisis térmico se consideró para cerramientos un muro masivo de piedra y hormigón con aislante, las cubiertas fueron consideradas como parte de tipo plano, parte con cámara caliente, ambos con aislante, y para el suelo, un forjado aislando en contacto con un garaje, habiendo muros en contacto con el terreno. Las ventanas fueron consideradas de aluminio con rotura de puente térmico con vidrio doble. A efectos de instalaciones, no hay datos acerca de las mismas, de modo que para el análisis se consideraron sistemas de aire acondicionado, ventilación forzada y agua caliente por bomba de calor, los tres con un rendimiento aproximado del $250 \%$.

Consumo de energía: $196,8 \mathrm{Kwh} / \mathrm{m}^{2}$ año. (C) Emisiones anuales: $0,33 \mathrm{~T} / \mathrm{m}^{2}$ año. (C)

\section{G: USO DE FUENTES DE ENERGÍA LIMPIAS.}

Aunque la directiva del centro comercial no dio datos acerca de este tema, para el centro $A B C$ Serrano se consideró la ausencia de posee sistemas de generación de energías limpias. La base para esta consideración fue el análisis en páginas web del centro, y búsquedas del tema en fuentes variadas y artículos, no apareciendo el centro como case relacionado con la implantación de energías renovables.

3H: ESPACIOS CON LUZ NATURAL Para medir esta superficie, se consideraron de manera aproximada los espacios iluminados con luz natural del centro comercial $A B C$ Serrano, que 
generalmente corresponden a las estancias cercanas a las fachadas, y al gran vestíbulo interior, que tras la última reforma, culminada en septiembre de 2016, se considerará como un espacio que cuenta con luz natural al $100 \%$, considerando además las galerías anejas al mismo como tal. En ABC Serrano el espacio que cuenta con luz natural es aproximadamente el $22 \%$ de su superficie $\left(7309 \mathrm{~m}^{2}\right.$ de $\left.32899 \mathrm{~m}^{2}\right)$.

31: FORMA DE LA EDIFICACIÓN: El centro comercial ABC Serrano, es un volumen fragmentado, cuyo lado sur da a espacios medianeros, estando las fachadas principales en orientaciones este y oeste. Cabe destacar a la vez, el gran desarrollo longitudinal, siendo las fachadas norte y sur, principalmente medianeras y fachadas ciegas. Aproximadamente la relación entre el lado mayor y el menor es de 0,25 . Siendo la orientación de la fachada principal unos $102^{\circ}$ este, respecto de la orientación sur. El centro a su vez cuenta con una fachada masiva, y la mayoría de los huecos están retranqueados. El volumen del edificio es compacto, sin considerar la superficie que se ubica a norte, ya que esta sólo se desarrolla en una planta sobre rasante en el centro hay fachadas y cubiertas por las que no hay pérdidas de calor. (Figura 5.4.10)

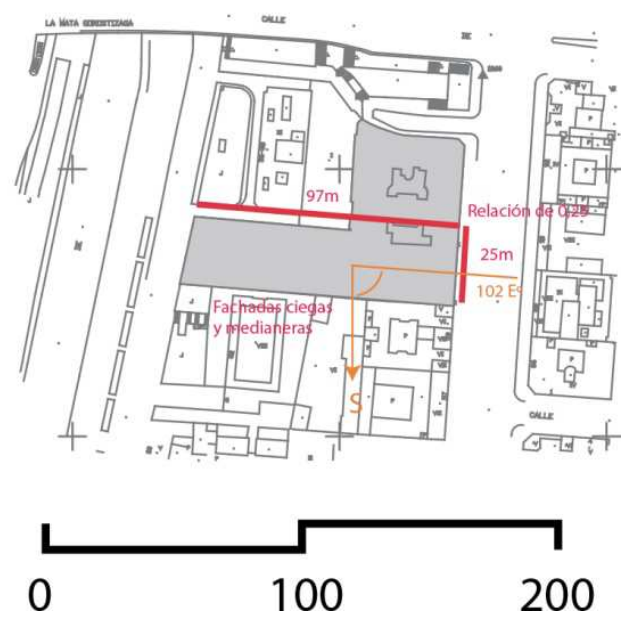

Figura 5.4.10: Análisis forma edificación ABC Serrano. Fuente: Elaboración propia.

3J: PAVIMENTOS Y CUBIERTAS EN RELACIÓN A LA INCIDENCIA DE LA IRRADIACIÓN SOLAR. Sobre la planta de cubiertas se midieron las superficies de colores claros. ABC Serrano tiene aproximadamente un $8 \%$ de su superficie de cubierta repelente de cara a la irradiación solar. siendo el $92 \%$ restante, absorbente de cara a la irradiación solar.

FASE 4: CUESTIONARIOS DE LA METODOLOGÍA, APLICACIÓN DE INDICADORES Y BAREMOS.

\section{A.- REHABILITACIÓN ECOEFICIENTE.}

A1.- Cuestionario referenciado a rehabilitación hacia instalaciones poco emisivas.

Cuestión A1.1.- ¿El centro cuenta con instalaciones que no son necesarias de acuerdo a lo estipulado en el diagrama de Givoni?: Aunque no hay datos objetivos acerca de las instalaciones de $A B C$ Serrano, de visitas al centro se dedujo que se trata de un espacio completamente cerrado y aclimatado, que posee instalaciones mecánicas de refrigeración y calefacción. Mirando el diagrama de Givoni de Madrid (Figura 5.4.9), se puede deducir que las 
instalaciones de calefacción si son necesarias, pero en las horas más frías de los días de Diciembre, Enero, y Febrero (hora solar 5:00-6:00, hora oficial 6:00-7:00), las cuales corresponden a horas en las que el centro comercial no tiene prácticamente actividad. Por otra parte, las instalaciones de refrigeración no lo son no son necesarias en principio para el clima de Madrid, siendo suficiente con medidas bioclimáticas pasivas para acondicionar la temperatura de confort. Como resultado de este análisis, A este centro le corresponde una nota de +0 en esta cuestión.

Cuestión A1.2.- ¿Las instalaciones del centro generan unas emisiones de dióxido de carbono superiores a la media?. En el estudio energético estimativo realizado con el programa CE3X, EI centro comercial $A B C$ Serrano ha obtenido en la calificación energética de emisiones de las instalaciones, una calificación de $\mathrm{C}$, eso corresponde a una nota de +3 .

Cuestión A1.3.- ¿Las instalaciones del centro se encuentran en un estado de obsolescencia?. Respecto esta cuestión, el autor desconoce el estado de las instalaciones del centro. No obstante, de acuerdo a fuentes periodísticas recientes, el centro comercial ABC Serrano, concluyó una obra de renovación, no obstante, no está claro, si se actualizaron las instalaciones. De este modo, eligiendo el escenario más desfavorable, se puntuó esta cuestión con una nota de +0 .

Cuestión A1.4.- ¿Las instalaciones del centro tienen un consumo energético superior a la media?. En el estudio energético, $A B C$ Serrano ha obtenido en la calificación energética de consumo de energía primaria una nota de $\mathrm{C}$, eso corresponde a una nota de +3

EN RELACIÓN A INSTALACIONES POCO EMISIVAS, ABC SERRANO HA OBTENIDO UNA PUNTUACIÓN DE 6 (10).

A2.- Cuestionario referenciado a inserción de medidas activas.

Cuestión A2.1.- ¿Qué porcentaje de las calorías necesarias para lograr la temperatura de confort se logra mediante sistemas activos?: De investigaciones realizadas acerca del centro comercial en fuentes oficiales y externas, se concluyó que el centro de ABC Serrano, no posee medidas activas para lograr la temperatura de confort. Esta cuestión puntúa con +0 .

Cuestión A2.2.- ¿Qué porcentaje de la demanda energética se logra a partir de fuentes de energía renovable?: De investigaciones realizadas acerca del centro comercial en fuentes oficiales y externas se comprobó que ABC Serrano no posee sistemas de energías renovables, de modo que esta cuestión puntúa con +0 .

Cuestión A2.3.- ¿El centro cuenta con las medidas y dispositivos necesarios para su aclimatación de acuerdo a lo estipulado en el diagrama de Givoni para sistemas solares activos?: De investigaciones realizadas acerca del centro comercial en fuentes oficiales y externas se comprobó que El centro comercial ABC Serrano, no posee sistemas solares activos. Esta cuestión puntúa con +0 .

EN RELACIÓN A MEDIDAS ACTIVAS, ABC SERRANO HA OBTENIDO UNA PUNTUACIÓN DE 0 (10).

A3.- Cuestionario referenciado a inserción de medidas Pasivas. 
A3.1.- ¿El centro comercial tiene una forma adecuada en volumen a las condiciones climáticas?: $A B C$ Serrano se encuentra en una zona climática templada de acuerdo a la calificación de Olgyay, de acuerdo al análisis anteriormente realizado en el punto $3 \mathrm{I}, \mathrm{ABC}$ Serrano no cumple los requisitos de proporción de planta, aunque los huecos están retranqueados en la fachada oeste, y hay obstáculos que evitan el asoleo excesivo en las fachadas sur y oeste. El edificio es un volumen fragmentado, pero hay áreas en contacto con medianeras, en las cuales no van a haber pérdidas. ABC Serrano tiene su fachada principal orientada 102 a al este, lejos de los 15 máximos requeridos por Olgyay. No obstante, de cara a norte, el edificio del centro está protegido de los vientos por otros edificios. Los colores de fachada son de medios a claros. De este modo, ABC Serrano cumple de manera parcial los requisitos de forma de Olgyay, le corresponde una puntuación de +1 .

A3.2.- ¿ ¿El estado de los cerramientos responde de manera correcta a las exigencias del clima en el que se asienta?: En el resultado del análisis estimativo energético con CE3X, se comprobó que la calificación energética de ABC Serrano, a efectos de consumo global de energía es de $C$, esto significa que los cerramientos responden de una manera correcta respecto al clima. A este centro le corresponde una puntuación de +3 .

A3.3.- ¿Qué porcentaje de los espacios del centro cuentan con iluminación natural?: En el análisis de luz natural, se comprobó que $A B C$ Serrano tras su renovación posee un $22 \%$ del espacio interior iluminado con luz natural. Le corresponde de este modo una puntuación de +1 .

A3.4.- Los espacios del centro, están adaptados a lo estipulado por el Diagrama de Givoni de su respectivo clima?: El edificio de $A B C$ Serrano, aunque puede valerse de la ventilación natural permanente en verano, esto no es posible debido a que los huecos de las ventanas, y los espacios interiores no son adecuados para generar ventilación. No obstante en invierno el centro puede valerse de las cargas internas y la masa térmica en invierno para aclimatar. De este modo se cumple de manera parcial lo requerido por Givoni para el edificio de centro comercial. A ABC Serrano le corresponde una puntuación de +1

EN RELACIÓN A MEDIDAS PASIVAS, ABC SERRANO HA OBTENIDO UNA PUNTUACIÓN DE 6 (10).

4B.- REHABILITACIÓN MEDIOAMBIENTAL.

B1.- Cuestionario referenciado a rehabilitación mediante zonas verdes.

Cuestión B1.1.- ¿En el área urbana hay suficiente zona verde en el área en relación a sus habitantes?: El área urbana de $A B C$ Serrano posee aproximadamente $35118 \mathrm{~m}^{2}$ de superficie verde en planta, que entre 18000 habitantes, el ratio es de $2,26 \mathrm{~m}^{2}$ de superficie verde por habitante, lejos del mínimo de $10 \mathrm{~m}^{2}$ establecido por Salvador Rueda. Le corresponde una puntuación de +0 .

Cuestión B1.2.- ¿Las zonas verdes dentro del centro comercial pueden dar lugar a una área verde de uso cotidiano?: $A B C$ Serrano, no posee superficie verde alguna en su parcela, con lo que esta pregunta no puede ser puntuada, le corresponde una puntuación de +0 a esta cuestión. 
Cuestión B1.3.- ¿La vegetación en el área (incluyendo el edificio del centro), en que porcentaje es capaz de asimilar las emisiones de la misma área urbana?: Sumando las capacidades de asimilación de las superficies de vegetación establecidas, tenemos una capacidad de asimilación de 5630 Toneladas de dióxido de carbono anuales, esto es aproximadamente un $7 \%$ de la huella de carbono del área, (83.895 Toneladas de dióxido de carbono anuales). Esta cuestión puntuará con +0 .

Cuestión B1.4.- ¿La vegetación en el centro comercial y su parcela, en que porcentaje es capaz de asimilar las emisiones del centro comercial?: Las jardineras del centro comercial, asimilan a lo sumo una tonelada de dióxido de carbono anual, que es menos de un $0,5 \%$ de la huella de carbono anual del centro (1644,9 T Co2 anuales), a esta cuestión le corresponde una puntuación de +0

Cuestión B1.5.- ¿ ¿a distancia media entre espacios verdes dentro del área es inferior a los 400 metros?: Aunque hay espacios verdes en al área de $A B C$ Serrano, la distancia entre los mismos está a una media algo menor a los 400 metros unos de otros, contando el bulevar de la Castellano como zona verde (aproximadamente a 380 metros unos de otros) a esta cuestión le corresponde una puntuación de +1 .

EN RELACIÓN A ZONAS VERDES, ABC SERRANO HA OBTENIDO UNA PUNTUACIÓN DE 1 (10).

B2.- Cuestionario referenciado a inserción de superficie asimiladora de agua.

Cuestión B2.1.- ¿El clima en el que está el centro corresponde a un clima árido o semiárido?: El clima de Madrid, con unas precipitaciones medias anuales de $420,9 \mathrm{~mm}$, y una temperatura media anual de 150, tiene un índice de Martonne de 16,83, éste corresponde a una zona semiárida. De acuerdo a lo establecido en el baremo, A ABC Serrano le corresponde una calificación de +0 a esta cuestión.

Cuestión B2.2.- ¿En qué porcentaje, la superficie absorbente de agua, en el área urbana, es en relación a la impermeable?: En esta cuestión, se consideró como superficie permeable la superficie neta verdes presente en la zona $\left(37.278 \mathrm{~m}^{2}\right)$, que es aproximadamente un $5 \%$ de los $798318 \mathrm{~m}^{2}$ totales del área urbana. esta cuestión puntúa con +0 .

Cuestión B2.3.- ¿El centro comercial posee sistemas para el aprovechamiento del agua?: De investigaciones acerca de las instalaciones del centro, y visitas, se concluyó que el centro comercial ABC Serrano, no posee sistemas para el aprovechamiento del agua, le corresponde una puntuación de +0 .

Cuestión B2.4- ¿El consumo de agua del centro es en litros por visita?: a pesar de que no hay datos del centro en este sentido, al centro comercial $A B C$ Serrano, se le estimó un consumo de agua de 30 litros por visita, que corresponde a una puntuación de +1 .

EN RELACIÓN A SUPERFICIE ASIMILADORA DE AGUA, ABC SERRANO HA OBTENIDO UNA PUNTUACIÓN DE 1 (10).

B3.- Cuestionario referenciado a tratamiento de isla de calor. 
Cuestión B3.1.- ¿El clima en el que está el centro comercial tiene una temperatura media más o menos elevada?. El clima de Madrid tiene una temperatura media anual de 15o, esto significa que es un clima templado propenso a altas temperaturas. Esta pregunta puntúa con $+0$

Cuestión B3.2.- ¿En el clima en el que está ubicado en centro hay olas de calor frecuentes o en intervalo temporal menor?. En Madrid generalmente acontecen varias olas de calor al año, sobre todo durante los meses más cálidos del verano, esta cuestión puntúa con un +0.

Cuestión B3.3.- ¿El centro está en un área en el cual la diferencia de temperatura respecto a la normal es de?. Analizando la isla de calor de Madrid (Figura 5.4.12), nos encontramos con el hecho de que $A B C$ Serrano se encuentra en un área con 9o de temperatura respecto de lo normal, estando este centro en el área de isla de calor más crítica de Madrid. De este modo esta cuestión puntúa con un +0 .

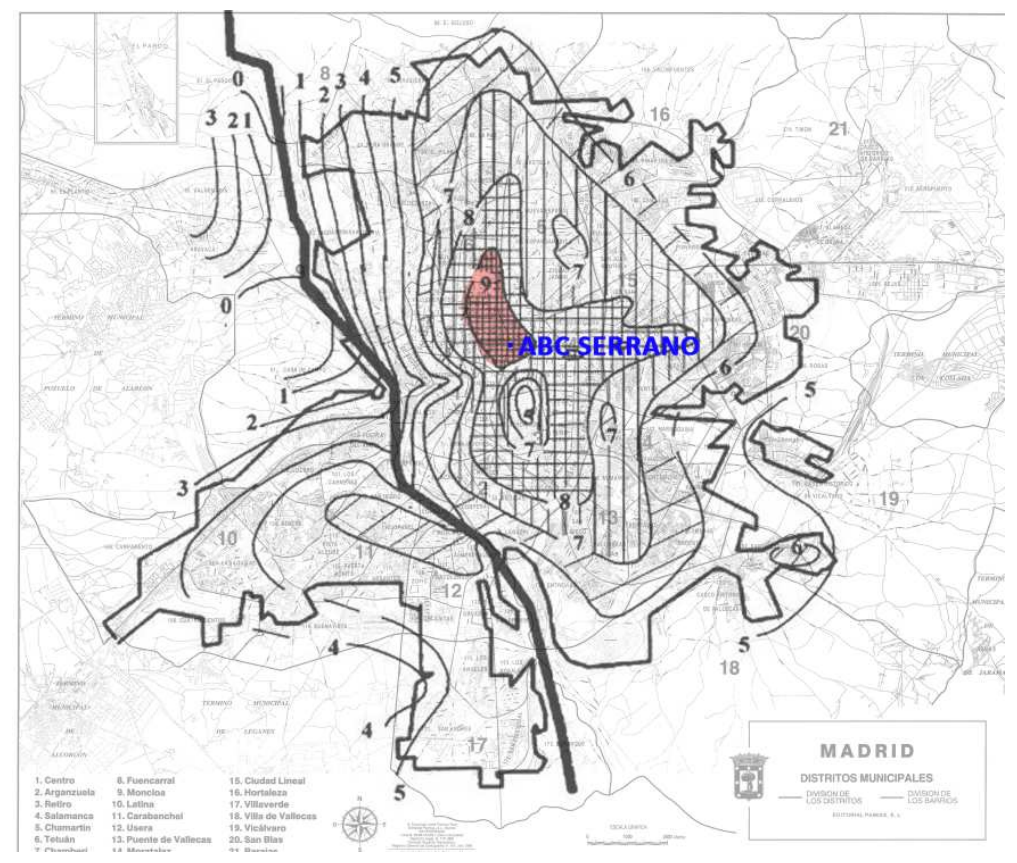

Figura 5.4.11: Isla de calor de Madrid con la ubicación de ABC Serrano. Fuente: Elaboración propia a partir de datos del Ayuntamiento de Madrid y la Universidad Politécnica de Madrid.

Cuestión B3.4.- ¿La suma de superficies que contribuyen a la isla de calor en la parcela y el edificio del centro es superior a un porcentaje de la superficie total?. La superficie absorbente de irradiación de ABC Serrano es del 45,96\%, lo que le corresponde una puntuación de +2 .

EN RELACIÓN A TRATAMIENTO DE ISLA DE CALOR, ABC SERRANO HA OBTENIDO UNA PUNTUACIÓN DE 2 (10).

4C.- REHABILITACIÓN POR USOS.

C1.- Cuestionario referenciado a inserción de uso residencial. 
Cuestión C1.1.- ¿El centro comercial posee usos residenciales u hoteleros dentro de su unidad catastral?. De visitas al centro, y de la página web del mismo se dedujo que ABC Serrano no posee usos hoteleros o residenciales, esta cuestión puntúa con +0 .

Cuestión C1.2.- ¿Las parcelas próximas al centro comercial posen usos residenciales u hoteleros?: El uso residencial en las parcelas colindantes al centro comercial fue estimado en un $50 \%$, de acuerdo a la distribución de los usos de las parcelas colindantes establecida. Lo que corresponde una puntuación de +2 .

Cuestión C1.3.- ¿Dentro del área de influencia urbana del centro comercial, que porcentaje de la superficie de uso total es de tipo residencial?: en el área de influencia de ABC Serrano, se estableció aproximadamente un 50\% de uso residencial, lo que le corresponde una puntuación de +3

EN RELACIÓN A USO RESIDENCIAL, ABC SERRANO HA OBTENIDO UNA PUNTUACIÓN DE 5 (10).

C2.- Cuestionario referenciado a inserción de usos productivos, y terciarios no comerciales.

Cuestión C2.1.- ¿El centro comercial posee usos productivos no comerciales dentro de su unidad catastral?: Descontando las oficinas de la gestora, que no computan para este análisis, de visitas al centro y análisis de la página web, pudo concluirse que $A B C$ Serrano no posee usos terciarios productivos en su interior, esta cuestión puntúa con +0 .

Cuestión C2.2.- ¿Las parcelas próximas al centro comercial posen usos productivos no comerciales?: Las parcelas próximas al centro comercial, poseen una amplia oferta de instalaciones terciarias de oficinas y administrativas, que se computaron en aproximadamente un $30 \%$ de la superficie total de acuerdo a la distribución de usos establecida en las parcelas próximas, esta cuestión puntúa con un +3 .

Cuestión C2.3.- ¿Dentro del área de influencia del centro comercial, que porcentaje de la superficie de uso total es de tipo productivo no comercial?: En el área urbana de influencia del centro comercial $A B C$ Serrano, se estimó un $30 \%$ de la superficie edificada total, como instalaciones terciarias no comerciales, éstas corresponden a edificios de oficinas. A esta cuestión le corresponde una puntuación de +5 .

EN RELACIÓN A USO PRODUCTIVO, ABC SERRANO HA OBTENIDO UNA PUNTUACIÓN DE 8 (10).

C3.- Cuestionario referenciado a inserción de instalaciones dotacionales y asistenciales.

Cuestión C3-1.- ¿El centro comercial posee usos dotacionales dentro de su unidad catastral?: De visitas al centro y análisis de la página web, pudo concluirse que el centro comercial $A B C$ Serrano no posee dotaciones asistenciales, esta cuestión puntúa con un +0 .

Cuestión C3.2.- ¿Las parcelas próximas al centro comercial posen usos dotacionales?: En las inmediaciones del centro comercial ABC Serrano, aunque hay una gran cantidad de instalaciones dotacionales, la mayoría corresponden a embajadas, que son lugares no muy concurridos. Esta pregunta puntúa con un +2 . 
Cuestión C3.3.- ¿A un kilómetro del centro comercial hay usos dotacionales?: En el área de dotaciones correspondiente a lo que es el centro comercial de $A B C$ Serrano, hay una gran cantidad de dotaciones de diversa capacidad, generalmente de visita esporádica y recurrente. No hay grandes dotaciones recurrentes de primera jerarquía. Esta cuestión puntúa con +5 .

\section{EN RELACIÓN A DOTACIONES, ABC SERRANO HA OBTENIDO UNA PUNTUACIÓN DE 7.}

\section{D.- REHABILITACIÓN DE ENTORNO URBANO.}

D1.- Cuestionario referenciado a la inserción de medios de transporte eficientes.

Cuestión D1.1.- ¿El centro dispone en sus inmediaciones de alguna parada de transporte público?: El centro comercial $A B C$ Serrano, posee instalaciones de transporte público en las inmediaciones de su parcela, estando algunas en vías muy transitadas de la ciudad de Madrid. La puntuación a esta cuestión es de +1 .

Cuestión D1.2.- ¿El tiempo de llegada al centro mediante transporte público supera al tiempo de llegada en vehículo particular?, Comparando los datos obtenidos de los apartados $2 \mathrm{E}$ y $2 \mathrm{~F}$, (dividiendo el tiempo de llegada en transporte público, entre el tiempo de llegada en transporte privado o particular) se estimó que el tiempo de llegada medio en transporte público desde los puntos asignados en el área, es de 2,13 veces de media más que en vehículo privado (Figura 5.1.12), esta cuestión puntúa con +0 .

\begin{tabular}{|l|r|r|r|}
\hline Comparación tiempos de recorrido & Recorrido 1 & Recorrido 2 & Recorrido 3 \\
\hline Total tiempo desplazamiento t. público & 16 & 10 & 15 \\
\hline Total tiempo desplazamiento t. particular & 6 & 8 & 6 \\
\hline Relación entre tiempos desplazamiento & 2,666666667 & 1,25 & 2,5 \\
\hline Media tiempo desplazamiento & & & 2,138888889 \\
\hline
\end{tabular}

Figura 5.4.12: Comparación entre tiempos de llegada. Fuente: Elaboración propia

Cuestión D1.3.- ¿El área urbana del centro comercial está cubierta de forma adecuada por la infraestructura de transporte público?. El área urbana de $A B C$ Serrano, está cubierta en un $72 \%$ aproximadamente por la infraestructura de transporte público como se estableció en el análisis relacionado con la cobertura del transporte público (Figura 5.4.6). Lo que la cuestión puntúa con un +2 .

Cuestión D1.4.- ¿Los usos en la zona están mezclados o zonificados?: En el área de ABC Serrano, el índice Global de Mezcla de usos, es el de la única zona homogénea que hay en el área, que es de 1 cómo se estableció en el apartado $1 \mathrm{~K}$ (Zona de gran complejidad urbana), esto le corresponde una puntuación de +2 .

Cuestión D1.5.- ¿El centro comercial y el área urbana próxima al centro cuenta con instalaciones enfocadas en la movilidad sostenible?: A pesar de que el centro comercial $A B C$ Serrano no posee sistemas adaptados a la movilidad sostenible, de visitas al área, pudo comprobarse que hay instalaciones de transporte sostenible, tales como alquileres $o$ aparcamientos de bicicletas. Esta cuestión obtiene una puntuación de +1 . 
EN RELACIÓN A TRANSPORTE EFICIENTE, ABC SERRANO HA OBTENIDO UNA PUNTUACIÓN DE 6 (10).

D2.- Cuestionario referenciado a la rehabilitación por corrección de la densidad en área urbana.

Cuestión D2.1.- ¿La densidad de población en el área del centro está en el intervalo entre $\mathrm{h} / \mathrm{ha}$ ?, La densidad de población del área de $A B C$ Serrano es la del distrito de Salamanca $(0,026$ $\mathrm{hab} / \mathrm{m}^{2}$ ), a esta cuestión le corresponde una puntuación de +3 , habiendo problemas de congestión en la zona.

Cuestión D2.2.- ¿A efectos de densidad, el tejido mayoritario es favorable o desfavorable de cara a la sostenibilidad?. El índice global de densidad del área de $A B C$ Serrano es de 3, lo que es un entorno muy denso a efectos de edificación y tejido urbano, a esta cuestión le corresponde una puntuación de +2 , habiendo problemas de congestión.

Cuestión D2.3.- ¿La cantidad de espacio ocupado en el área está en el intervalo entre...? El espacio ocupado en el área de $A B C$ Serrano, es de un 67\%, lo que corresponde a una ocupación media alta, que no va a favorecer el aislamiento de las edificaciones por las distancias entre las mismas. A esta cuestión le corresponde una puntuación de +3 .

EN RELACIÓN A DENSIDAD, ABC SERRANO HA OBTENIDO UNA PUNTUACIÓN DE 8 (10).

D3.- Cuestionario referenciado a mejora de la seguridad y la paseabilidad en el área urbana.

Cuestión D3.1.- ¿En el área de influencia o en sus proximidades hay elementos negativos de cara a la seguridad o a la salubridad del área?: En el área cercana a $A B C$ Serrano, no hay elementos que pudieran resultar negativos de cara a la seguridad o el control urbano, a pesar de los desniveles en la zona. Esta cuestión puntúa con +1 .

Cuestión D3.2.- ¿El centro comercial se encuentra en una zona de puntos fríos de actividad durante el día?. El área de $A B C$ Serrano, debido a la gran cantidad de dotaciones, servicios y locales con horario diurno, no tiene puntos fríos durante el día, esta cuestión puntúa con +1 .

Cuestión D3.3.- ¿El centro comercial se encuentra en una zona de puntos fríos durante la noche?, El área de $A B C$ Serrano es una zona con actividad durante la noche debido a la mezcla de usos y a su ubicación céntrica dentro de Madrid, no van a haber puntos fríos durante la noche, esta cuestión puntúa con +1 .

Cuestión D3.4.- ¿El centro comercial se encuentra en una zona con áreas de difícil control visual o de contacto urbano?. Aunque los desniveles y el paso elevado ubicado en las inmediaciones, pueden en parte dificultar el control visual, el centro se ubica anejo a vías muy transitadas. Esta cuestión puntúa con +1 .

Cuestión D3.5.- ¿La sensación de seguridad por parte de los ciudadanos de la zona es positiva o negativa?: El área de $A B C$ Serrano, es un área segura de Madrid, ubicada en un distrito marcado por el alto poder adquisitivo de sus habitantes. La puntuación a esta cuestión es de +1 . 
Cuestión D3.6.- ¿La zona próxima al centro comercial tiene un porcentaje de fachadas activas?: En las manzanas próximas al centro comercial, hay un $57,98 \%$ \% de fachadas activas, lo que le corresponde a una zona con gran actividad a pie de calle una puntuación de +2 .

Cuestión D3.7.- ¿La distancia de la puerta del edificio del centro comercial al inmueble residencial cercano es superior a los 200 metros?: De visitas al área, se pudo comprobar que el inmueble residencial más cercano a $A B C$ Serrano, se encuentra a 100 metros, esta cuestión puntúa con +1 .

Cuestión D3.8.- ¿La cantidad de espacio libre en el área va a resultar desfavorable de cara a la paseabilidad?: El espacio libre en el área de $A B C$ Serrano es de aproximadamente un $50 \%$, de modo que no se va a desfavorecer la mezcla de usos en base a las distancias. Esta cuestión va a puntuar con un +1 .

Cuestión D3.9.- ¿Los usos en la zona están mezclados o zonificados? En el análisis de $1 \mathrm{~K}$, se comprobó que el índice global de mezcla de usos es de 1, esta cuestión puntúa con +1 .

EN RELACIÓN A PASEABILIDAD, ABC SERRANO HA OBTENIDO UNA PUNTUACIÓN DE 10 (10).

\section{E.- CUESTIONARIO RELACIONADO CON LA ACTIVIDAD DEL CENTRO Y SUS CONSECUENCIAS URBANAS.}

Cuestión E1: ¿La actividad del centro comercial, va a penalizar o a favorecer la sostenibilidad del entorno urbano?: De lo establecido en el apartado OC5, ABC Serrano tiene un índice de atracción de 3. Por otra parte, la puntuación total en el cuestionario relacionado con el transporte eficiente (D1) es de 6. De este modo, consultando la tabla del apartado 3.10, (4E). Se comprobó que el efecto de la actividad de $A B C$ Serrano, supone un incremento de +1 a la puntuación seguridad y paseabilidad (C3), quedando finalmente este cuestionario en una puntuación de 11 .

FASE FINAL, GRÁFICO DE LA ROSA DE REHABILITACIÓN SOSTENIBLE.

Las puntuaciones obtenidas en el anterior cuestionario, fueron colocadas en el gráfico de la rosa de rehabilitación sostenible, obteniendo el siguiente resultado (Figura 5.4.13): 


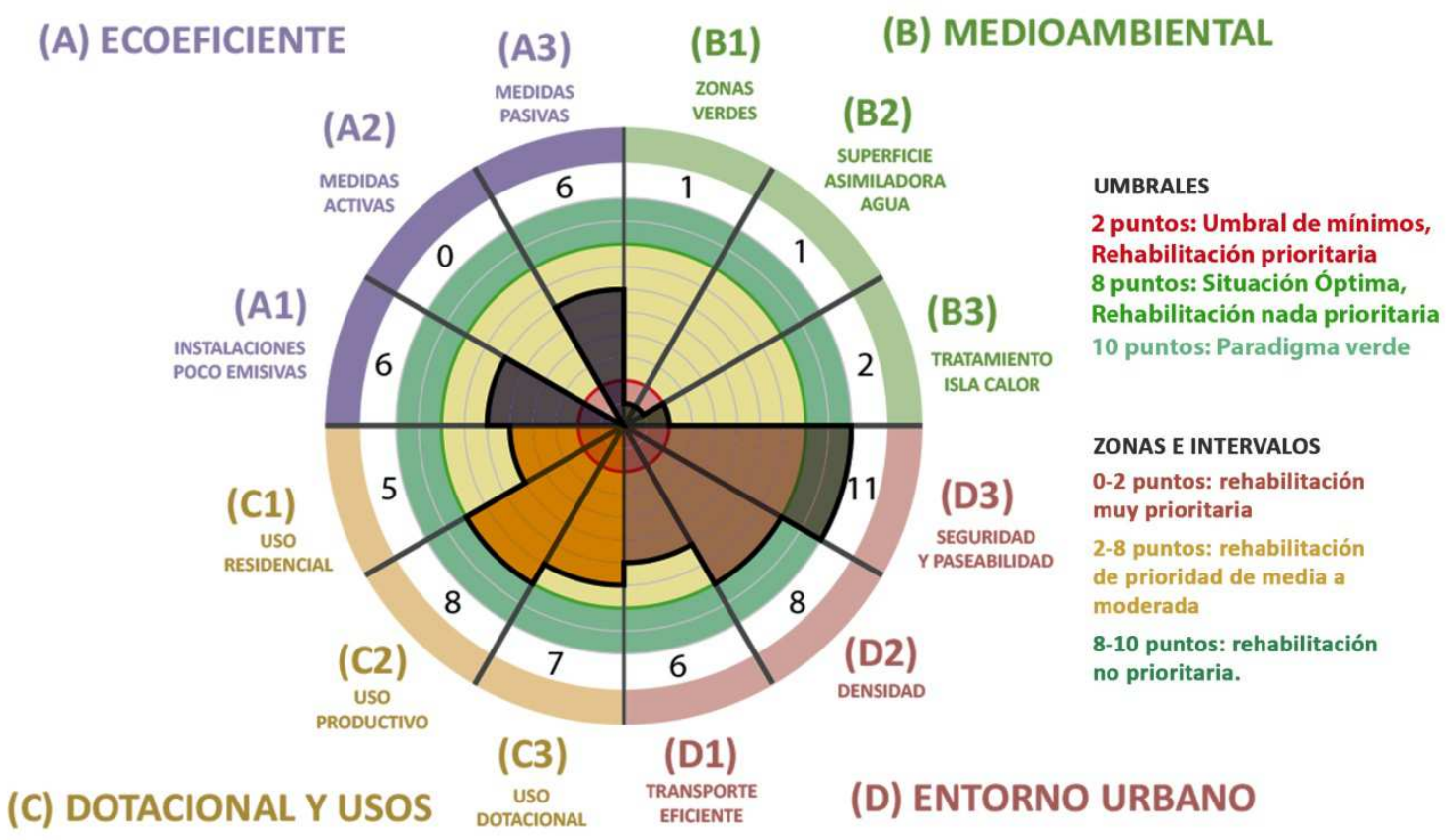

Figura 5.4.13: Gráfico de rosa de rehabilitación sostenible para ABC Serrano. Fuente: Elaboración propia

De acuerdo al gráfico, $A B C$ Serrano es un caso de centro comercial que se ubica en un área urbana compleja y activa, en la cual el transporte público es bastante eficaz para la movilidad, y no resulta conveniente intervenir en el mismo para acometer una rehabilitación. Tampoco, va a resultar eficaz a efectos de rehabilitación urbana sostenible, la densificación o rehabilitación del entorno urbano de cara a la actividad, la complejidad o la seguridad y paseabilidad. Tampoco es eficaz la inserción, o el cambio de usos dentro del centro comercial, debido a la mezcla que hay en el mismo. El edificio del centro comercial tiene un comportamiento bioclimático relativamente adecuado a las condiciones climáticas de Madrid, y las instalaciones y cerramientos parecen estar relativamente actualizados a efectos eficiencia energética. Sin embargo, el centro comercial carece en absoluto de medidas energéticas activas que pudieran ayudar a mejorar la eficiencia energética, siendo una opción adecuada para acometer una rehabilitación en el tema de lo energético, la inserción de medidas solares activas y el uso de energías renovables. Por otra parte, este centro comercial y su área urbana tienen unas carencias críticas de cara a lo que es la calidad medioambiental del entorno, esto se ve en la carencia de áreas verdes en la zona, la casi nulidad de las capacidades del terreno para regenerar agua, a la par que los problemas críticos con la isla de calor. Esto se debe a la configuración urbana altamente densificada y edificada del entorno urbano de ABC Serrano. De este modo, las rehabilitaciones que resultarían más eficaces de cara a la mejora de la sostenibilidad urbana y o medioambiental, deberían de estar centradas en el tema medioambiental, para regenerar las cualidades del entorno respecto a lo anteriormente mencionado. De este modo cualquier rehabilitación de ABC Serrano debería de estar centrada en la mitigación de la isla de calor, la inserción de sistemas de recuperación de agua en el centro, e inserción de superficies verdes. Todo ello dentro de las posibilidades constructivas y urbanísticas, que pudiera ofrecer un entorno urbano de alta densidad. 


\section{5.- CASO 5: LA VAGUADA}

La Vaguada, fue considerado como caso de estudio para lo que es la periferia próxima de Madrid, La Vaguada es un centro comercial que se ubica en el Barrio del Pilar, que de forma similar a Shopping Eldorado, se ubica en el lindero de una vía transitada, que es la Avenida de la llustración (Prolongación de la autopista de circunvalación M30). La Vaguada, es un caso de estudio a considerar para esta tesis, debido a las similitudes con Shopping Eldorado respecto a ubicación e interacción con la ciudad. No obstante siendo quizás la razón más relevante en la elección de la Vaguada como caso de estudio es la ambiciosa reforma que este centro acometió en las últimas décadas centrada en la inserción de energías renovables y optimización del consumo energético. Siendo a su vez este centro, un ejemplo de gestión medioambiental en diversos medios relacionados con los centros comerciales. La vaguada, además fue el primer centro comercial abierto en Madrid ${ }^{54}$.

\section{FASE 0: RECOGIDA DE DATOS CUANTITATIVOS.}

En esta fase, se va a realizar una recogida de datos numéricos y cuantitativos oficiales del centro comercial la Vaguada y su entorno urbano. Estos se hallarán bien a partir de fuentes oficiales del propio centro, las autoridades urbanas de Madrid, fuentes de internet, o bien midiendo sobre plano. La justificación de esto, es establecer unos datos de partida que nos sentarán las bases de posteriores análisis más particularizados e exhaustivos relacionados con el centro o con el entorno urbano. Se considerarán los siguientes datos, que serán de utilidad para posteriores análisis. Los resultados se muestran en la siguiente tabla (Figura 5.2.1)

\begin{tabular}{|l|l|}
\hline \multicolumn{2}{|c|}{ LA VAGUADA } \\
\hline \multicolumn{2}{|c|}{ FASE 0, RECOGIDA DE DATOS CUANTITATIVOS } \\
\hline OC.- TABLA DE DATOS CENTRO & Valor \\
\hline OC1: Superficie centro comercial (m2) & 85.000 \\
\hline OC2: Superficie de parcela o ud. Catastral (m2) & 61.692 \\
\hline OC3: Superficie en planta (m2) & 44.780 \\
\hline OC4: Número de visitantes semanal (pe/sem) & 179.550 \\
\hline OC5: Índice de Atracción ( $\mathrm{n}$ ) & 4 \\
\hline OC6: Superficie de tipo residencial (m2) & 0 \\
\hline OC7: Superficie de uso productivo (m2) & 400 \\
\hline OC8: Número de instalaciones dotacionales (no) & 1 \\
\hline OU.- TABLA DE DATOS ENTORNO URBANO & Valor \\
\hline OU1: Población asignada a centro (pe) & 42.750 \\
\hline OU2: Densidad de población (hab/m2) & 0,035 \\
\hline U03: Superficie partida de entorno urbano (m2) & 1.276 .119 \\
\hline
\end{tabular}

Figura 5.5.1: Tabla de datos Shopping Eldorado Fuente: Elaboración Propia

OC.- TABLA DE DATOS DEL CENTRO COMERCIAL. (Figura 5.5.1)

\footnotetext{
54 Tamayo, Gloria (1992). Nuevas Formas Comerciales de gran superficie en la Comunidad de Madrid. Madrid: Universidad Complutense de Madrid
} 
C1: SUPERFICIE CENTRO COMERCIAL TOTAL: Este dato fue obtenido de fuentes de internet, y de la página web del propio centro comercial ${ }^{55}$. La superficie edificada de La Vaguada es de $85.500 \mathrm{~m}^{2}$

C2: SUPERFICIE TOTAL DE LA PARCELA DEL CENTRO: Para la obtención de este dato se midió la superficie de la parcela, en un parcelario de la ciudad de Madrid, la superficie de la parcela es de $61.692 \mathrm{~m}^{2}$

C3: SUPERFICIE EN PLANTA DEL EDIFICIO DEL CENTRO COMERCIAL. De mediciones sobre parcelario, se concluyó que la parcela del centro comercial La Vaguada está ocupada al $72 \%$ de su superficie, la superficie en planta es de $44.780 \mathrm{~m}^{2}$

C4: NÚMERO DE VISITANTES SEMANAL. Al no poder obtenerse datos del número de visitantes del centro comercial la Vaguada, se realizó un conteo estimativo de las visitas tomando como base los datos de Shopping Light del apartado 5.1.C4, considerándose a su vez un coeficiente de ponderación de 1 , debido a la localización céntrica de este centro comercial dentro del área urbana de Madrid, y a su posición como referente.

De lunes a viernes: 85.500 personas.

Sábado: 70.965 personas.

Domingo: 23.085 personas.

De este modo, el número de visitantes semanal de La Vaguada es de 179.550 personas.

C5: ÍNDICE DE ATRACCIÓN DEL CENTRO. En función al número de visitantes del centro, A La Vaguada le corresponde un índice de 4 (de 150.000 a 300.000 visitas).

C6: SUPERFICIE DE USO EN EL CENTRO DE TIPO RESIDENCIAL. La Vaguada no posee superficie residencial dentro de su unidad catastral.

C7: SUPERFICIE DE USO EN EL CENTRO DE TIPO PRODUCTIVO: La Vaguada, posee una oficina de correos que fue considerada como superficie de tipo productivo, ésta mide $400 \mathrm{~m}^{2}$

C8: NÚMERO DE INSTALACIONES EN EL CENTRO DE TIPO DOTACIONAL O ASISTENCIAL: Dentro del centro, está la anteriormente mencionada oficina de correos, que se computó como 1 instalación dotacional.

\section{OU.- TABLA DE DATOS DEL ENTORNO URBANO.}

U1: POBLACIÓN DE ÁREA URBANA ASIGNADA A CENTRO COMERCIAL: Dividiendo la superficie del centro comercial entre 2 , de acuerdo al baremo establecido en la metodología. salió una población asignada de 42.750 personas.

U2: DENSIDAD DE POBLACIÓN EN EL DISTRITO DEL CENTRO COMERCIAL: Para el análisis urbano, se cogió la densidad de población del Barrio del Pilar en Madrid, que es dónde está ubicado el centro comercial, la densidad se estableció en $0,0335 \mathrm{hab} / \mathrm{m}^{2}$ a partir de los datos oficiales del ayuntamiento de Madrid, para susodicho barrio en el 1 de enero de 2015.

\footnotetext{
${ }^{55} \mathrm{http}: / /$ enlavaguada.com/la-vaguada/
} 
U3: SUPERFICIE DEL ENTORNO URBANO: La superficie del entrono urbano a analizar, se sacó de los datos de población asignada al centro, la cual fue dividida entre la densidad del área, la superficie de partida para el análisis urbano es de $1.276 .119 \mathrm{~m}^{2}$

\section{FASE 1: ANÁLISIS DEL CONTEXTO URBANO.}

La segunda fase del análisis de La Vaguada, se realizará generalmente en base a mediciones sobre plano de diferentes facetas en el área que tuviesen relación con el centro comercial La Vaguada. Se trabajarán diferentes escalas, siendo predominante la escala urbana amplia de toda la zona de influencia del centro comercial, que va a establecerse en este apartado. Para este análisis, resultará fundamental el uso de datos referentes a la configuración del entorno urbano de Madrid, concretamente los del Barrio del Pilar, establecidos en el apartado anterior. se ponderará la información del análisis sobre plano, y el objetivo será hallar y establecer las pautas urbanísticas para el cuestionario de rehabilitación del centro comercial. Para acometer dicha tarea, se considerarán aspectos relacionados con configuraciones de volumen urbano, densidades, usos, áreas verdes y medio ambiente urbano.

1A: ESTABLECIMIENTO DEL ÁREA DE INFLUENCIA DEL CENTRO COMERCIAL : En base a la superficie de partida del área hallada anteriormente en el apartado U3, se estableció para el área de análisis del centro comercial La Vaguada, un radio de partida de acuerdo a la siguiente

fórmula: Radio $=\sqrt{ }\left(1.276 .119 \mathrm{~m}^{2} / \pi\right)=637 \mathrm{~m}$. Este dato es el verdaderamente relevante para establecer la superficie del área de análisis. La cual fue fijada en aproximadamente 637 metros a partir del lindero del centro comercial.

1B: DELIMITACIÓN SOBRE PLANO DEL ÁREA DE INFLUENCIA: En base al radio anteriormente establecido, y considerando la configuración del entorno urbano, se estableció la siguiente área (Figura 5.5.2). El trazado de la misma, se consideró a partir del círculo trazado. El cual una vez descrito, se marcaron los límites considerando la estructura urbana del área. El área final de análisis para el caso del centro comercial de La Vaguada es de $1.258 .153 \mathrm{~m}^{2}$

1C: SUBDIVISIÓN DEL ÁREA DE INFLUENCIA EN ÁREAS HOMOGÉNEAS Y DELIMITACIÓN DE ZONAS VERDES Para este análisis, el área urbana anteriormente asignada, va a dividirse en zonas homogéneas de acuerdo a la configuración de su tejido urbano, (Figura 5.5.2) marcándose a su vez la superficie de zonas verdes. Se establecieron dos tipologías de zona homogénea, descontando los espacios verdes y sin edificar en el área, además de la parcela del centro. Cada zona tiene aproximadamente:

Z1: $371.503 \mathrm{~m}^{2}$ brutos.

Z2: $439.489 \mathrm{~m}^{2}$ brutos. 


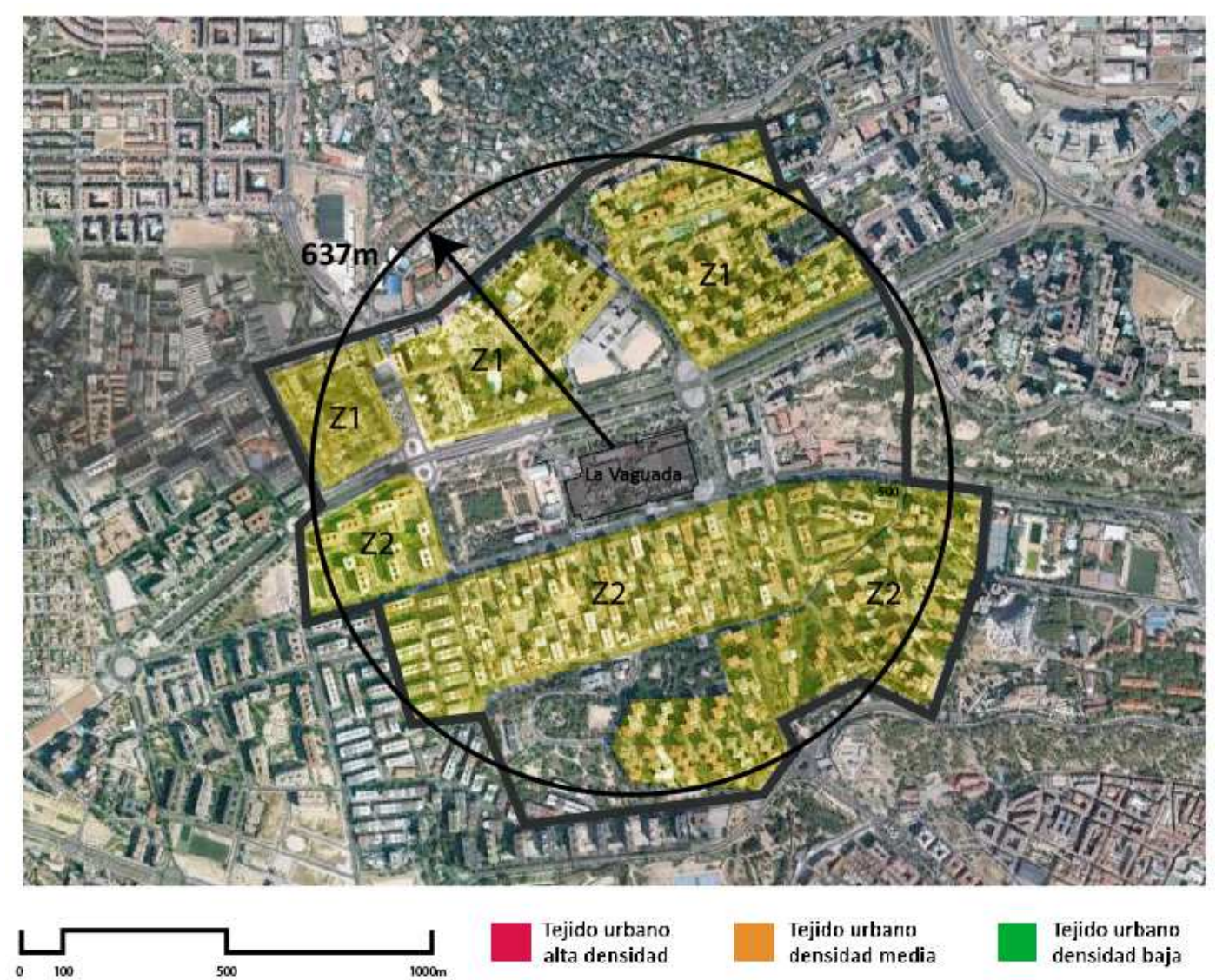

Figura 5.5.2: Área de Shopping Eldorado y subdivisión por zonas homogéneas. Fuente: Elaboración Propia a partir de datos de Google.

1D: PORCENTAJE DE OCUPACIÓN DE LA EDIFICACIÓN Y ÁREA OCUPADA: De acuerdo a lo estipulado por el apartado correspondiente en el capítulo 3.6, se realizará el análisis de la ocupación de las diferentes zonas homogéneas a partir del análisis de un área tipo de 200×200 $\mathrm{m}^{2}$ sobre parcelarios oficiales de la ciudad de Madrid. En base a este análisis, pudieron establecerse los porcentajes, midiendo sobre plano el área ocupada por la edificación dentro del área tipo, que para hallar el porcentaje será dividida entre el área total de la zona tipo. Los porcentajes de ocupación resultaron ser los siguientes para cada zona homogénea. (Figura 5.5.3) 


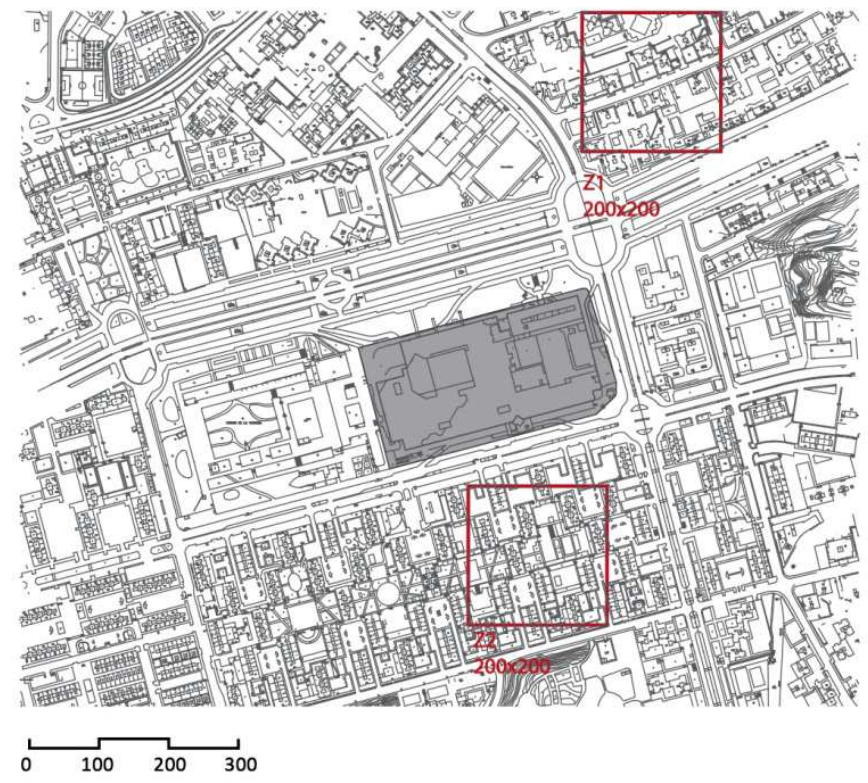

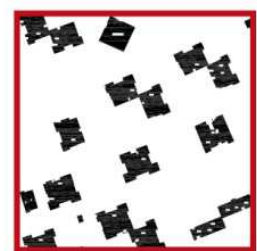

ÁREATIPO Z1 $19 \%$ Ocup.

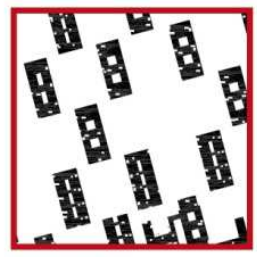

ÁREA TIPOZ2 $25 \%$ Ocup.

Figura 5.5.3: Análisis de ocupación sobre parcelario. Fuente: Elaboración Propia a partir de datos del Ayuntamiento de Madrid.

Estos porcentajes del análisis de tejidos serán aplicados a las superficies de área total, hallándose de esta forma la superficie ocupada en planta neta total de cada zona homogénea establecida.

Z1: $19 \%$ de superficie ocupada. Superficie ocupada $70.586 \mathrm{~m}^{2}$.

Z2: $25 \%$ de superficie ocupada. Superficie ocupada $109.872 \mathrm{~m}^{2}$.

1E: ALTURAS DE LA EDIFCACIÓN POR ÁREA HOMOGÉNEA: Para las diferentes áreas homogéneas de Shopping Eldorado establecidas con anterioridad, se consideraron las siguientes alturas medias de edificación, esto fue realizado de manera estimativa a partir de visitas al área y análisis de fotos de calles de Google Maps.

\section{Z1: 14 alturas. Z2: 13 alturas.}

1F: ESTABLECIMIENTO DE LAS TIPOLOGÍAS DE TEJIDO EN BASE A LA MORFOLOGÍA URBANA POR ÁREA HOMOGÉNEA: A partir de las ocupaciones y los números de plantas anteriormente considerados para cada zona homogénea, y considerando el baremo de la tabla correspondiente a densidades del presente apartado en el capítulo 3.6, cada área de Shopping Eldorado tiene estas densidades.

Z1: Zona de densidad media. Z2: Zona de densidad media.

1G.- ÍNDICE GLOBAL DE DENSIDAD: En base a las densidades establecidas anteriormente de acuerdo al apartado anterior, se pudo establecer el índice de densidad para cada zona. Es importante considerar la superficie que ocupa cada zona homogénea (Z1: $371.503 \mathrm{~m}^{2}$; Z2: $439.489 \mathrm{~m}^{2}$ brutos), las cuales fueron divididas respecto al área total de la zona $\left(1.258 .153 \mathrm{~m}^{2}\right)$, para de esta manera hallar los porcentajes que ocupa cada zona. Multiplicando cada índice de densidad correspondiente a cada zona homogénea, por el porcentaje que ocupa cada una, y luego sumando los resultados, se pudo hallar el índice global de densidad 
.Z1: Índice de 2, representa el $45,81 \%$ de la superficie total, suma al índice global 0,92 puntos. Z2: Índice de 2, representa el 54,19\% de la superficie total, suma al índice global 1,08 puntos.

De este modo el índice global de densidad es de 2 puntos, lo que corresponde una zona de densidad media de acuerdo al baremo del presente apartado.

1H: SUPERFICIE EDIFICADA TOTAL DE CADA ÁREA HOMOGÉNEA: Para hallar la superficie edificada total de cada zona homogénea, se multiplicó la superficie ocupada de la edificación en planta, anteriormente hallada en el apartado 1D, por el número medio de plantas asignado a cada zona por separado en el apartado 1E. De este modo, la superficie total edificada aproximada por área es la siguiente:

Z1 988.198m². Z2: 1.428.339m².

11: ESTABLECIMIENTO DE PORCENTAJES DE USO DENTRO DE LAS ZONAS HOMOGÉNEAS ESTABLECIDAS: El área de La Vaguada, corresponde a un entorno complejo en el que hay edificios tanto residenciales como comerciales y administrativos. Al no haber datos objetivos sobre los usos predominantes en la zona, se consideraron los siguientes porcentajes de manera estimativa, en base a visitas al área y estimaciones de superficies a partir de los tipos de edificios presentes en cada zona homogénea.

Z1: $80 \%$ residencial, $12 \%$ productivo, $8 \%$ comercial.

Z2: $80 \%$ residencial, $10 \%$ productivo, $10 \%$ comercial.

1J: CONTEO DE LOS USOS DENTRO DEL CONTEXTO URBANO. Una vez se establecieron los porcentajes en el apartado anterior, para obtener los metros cuadrados netos de uso, se multiplicarán éstos porcentajes hallados anteriormente por las superficies edificadas totales hallada en el apartado $1 \mathrm{H}$ de cada zona homogénea por separado, quedando establecidos los usos del área urbana relativa a Shopping Eldorado de la siguiente manera:

Z1: $790.558 \mathrm{~m}^{2}$ residencial, $118.584 \mathrm{~m}^{2}$ productivo, $79.056 \mathrm{~m}^{2}$ comercial.

Z2: $1.142 .671 \mathrm{~m}^{2}$ residencial, $142.834 \mathrm{~m}^{2}$ productivo, $142.834 \mathrm{~m}^{2}$ comercial.

1K: ÍNDICE GLOBAL DE MEZCLA DE USOS. Para el índice global de mezcla de usos, se consideró el baremo establecido en el apartado $1 \mathrm{~K}$ del capítulo 3.6, utilizando para ello los porcentajes de uso establecidos en 11 . Se sumará para cada zona homogénea el porcentaje de uso comercial más el productivo, calculándose el uso no residencial, éste será comparado en paralelo con el porcentaje de uso residencial, de este modo, queda establecido el índice de mezcla de usos, en base a si un uso supera o no el $80 \%$ de la superficie construida total.

Z1: $80 \%$ uso residencial, $20 \%$ uso no residencial, índice mezcla usos de 1

Z2: $80 \%$ uso residencial, $20 \%$ uso no residencial, índice mezcla usos de 1

De este modo, se multiplicarán los índices de uso, por los porcentajes que ocupa cada zona homogénea respecto al área urbana total, obteniendo estos resultados:

Z1: Índice de 0, representa el 39,3\% de la superficie total, suma al índice de mezcla de usos 0 puntos. 
Z2: Índice de 1, representa el 40,3\% de la superficie total, suma al índice de mezcla de usos 0,4 puntos.

Z3: Índice de 0, representa el 9,4\% de la superficie total, suma al índice de mezcla de usos 0 puntos.

Z4: Índice de 0, representa el $11 \%$ de la superficie total, suma al índice de mezcla de usos 0 puntos.

Como conclusión a la suma de los porcentajes parciales, La Vaguada tiene un índice de mezcla de usos de 1. Que corresponde a un área compleja a efectos de usos.

1L: CONTEO DEL NÚMERO DE DOTACIONES DENTRO DEL CONTEXTO URBANO, DENTRO DEL ÁREA DE DOTACIONES: Se estableció un área de un 1 kilómetro a partir del lindero del centro, y dentro del mismo se marcaron las siguientes dotaciones, cuya localización se halló a partir de visitas al área, y mediante la utilización de localización de actividades de Google Maps, en el área de dotaciones de Shopping Eldorado se marcaron: 1 dotación de visita esporádica, y 8 dotaciones de visita habitual. (Figura 5.5.3)

1M: PRESENCIA E INFLUENCIA DE ELEMENTOS POSITIVOS Y NEGATIVOS: En el área de la Vaguada no hay ni elementos positivos, ni negativos.

1N: ZONAS DE ACTIVIDAD: En el área de la Vaguada, durante el día hay una fuerte actividad en las avenidas y calles principales, No obstante, al tratarse de un área relativamente alejada del centro de Madrid, aunque incluida en el mismo, la actividad urbana, en parte va a remitir durante la noche. Debido a la configuración en planta de las edificaciones, y a la presencia de vías de gran anchura hay espacios urbanos que tienen un cierto grado de aislamiento con respecto a las vías y flujos principales del barrio. A efectos de actividad, durante el día esto no supone ningún problema ya que la zona es activa. Pero en cambio durante la noche pueden aparecer puntos fríos en estas zonas. (Figura 5.5.3) 

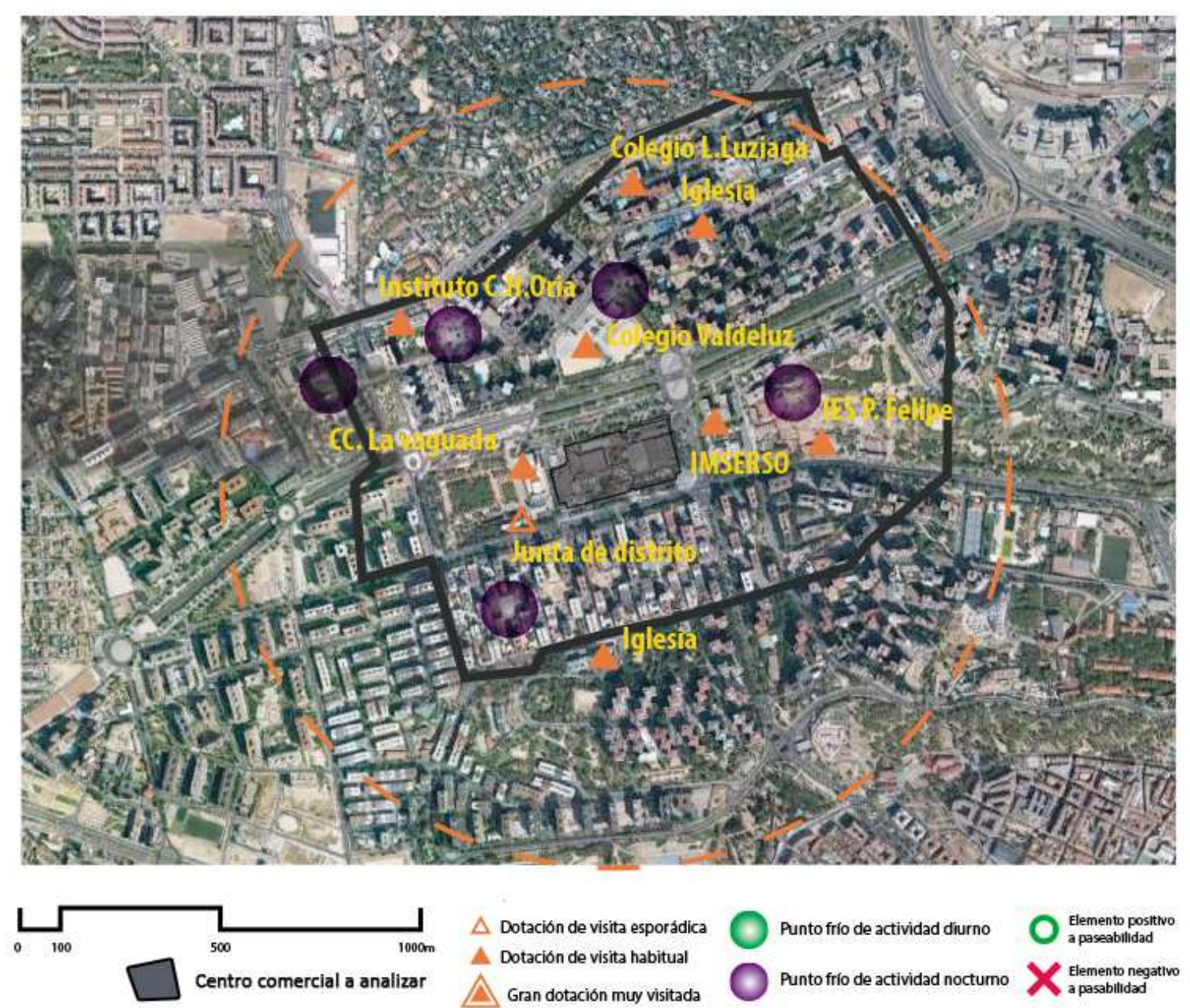

Figura 5.5.4: Área de La Vaguada, Dotaciones, puntos fríos y elementos positivos y negativos. Fuente: Elaboración Propia a partir de datos de Google.

10: ÁREAS ARBOLADAS Y VERDES, DENTRO DEL ÁREA URBANA DEL CENTRO: Dentro del área de La Vaguada, se consideraron las siguientes áreas verdes con sus respectivos metros cuadrados de superficie (Figura 5.5.5). El área urbana asignada a La Vaguada posee un área verde neta en planta de $49.885 \mathrm{~m}^{2}$, que se desglosa en las siguientes capas de vegetación superpuestas en relación a porcentajes estimados. 


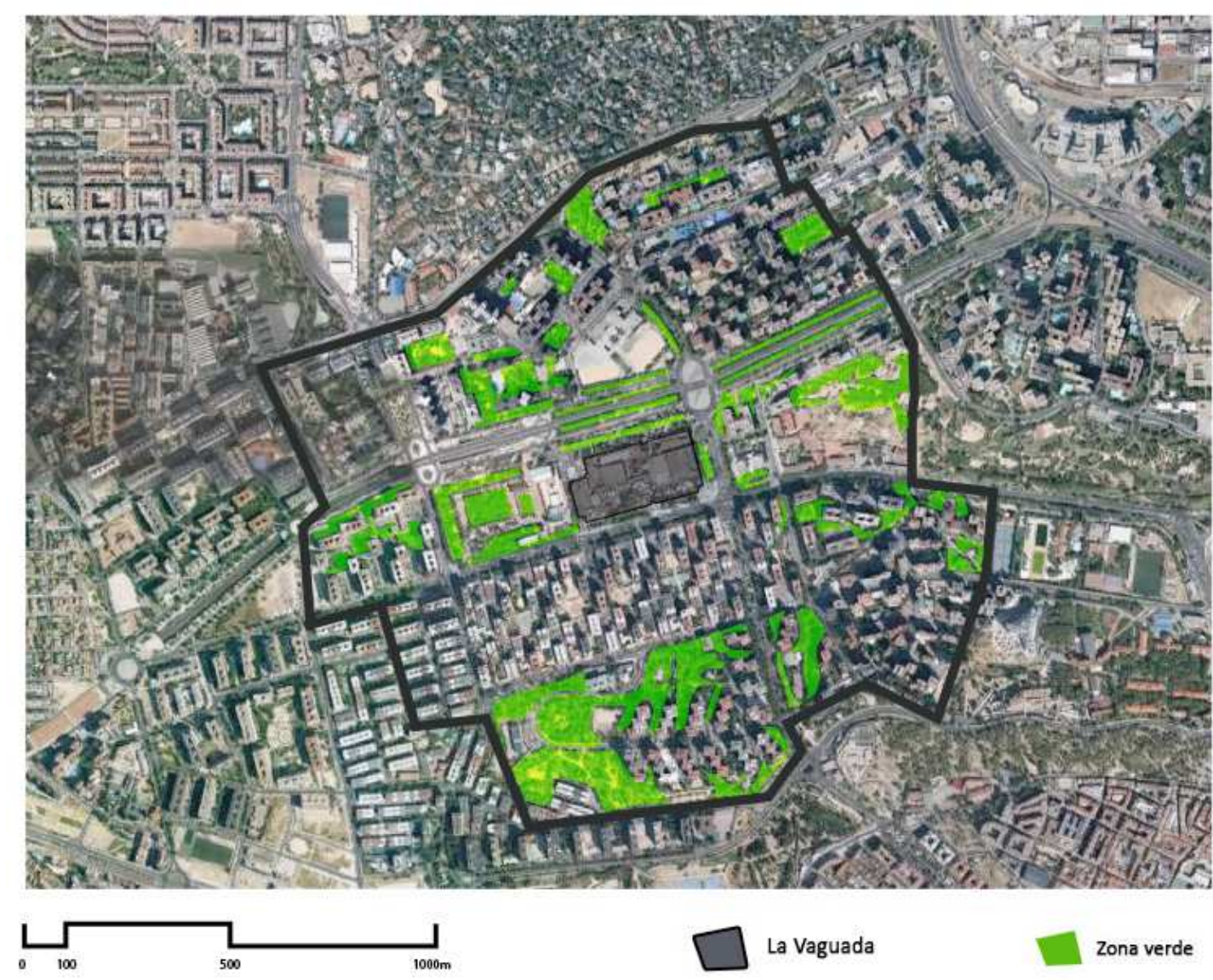

\begin{tabular}{|l|r|}
\hline 10: Superficie de zonas verdes en área urbana & Valor \\
\hline C4.1: pradera & 33051,0000 \\
\hline C4.2: hierba de gran altura o huerto & 0,0000 \\
\hline C4.3: vegetación arbustiva intensiva & 13220,0000 \\
\hline C4.4: vegetación arbórea caduca & 26441 \\
\hline C4.5: vegetación arbórea perenne & 6610,0000 \\
\hline
\end{tabular}

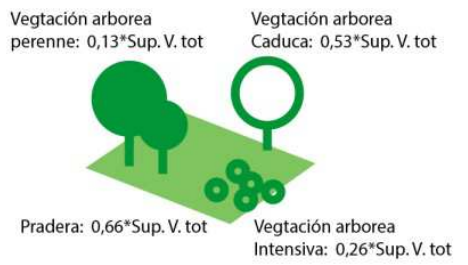

Figura 5.5.5: Área de La Vaguada, Zonas verdes y capas de vegetación. Fuente: Elaboración Propia a partir de datos de Google.

1P.- DELIMITACIÓN DE RECORRIDOS A CENTRO, DENTRO DEL ÁREA URBANA: Para este análisis, fueros establecidos tres recorridos desde diferentes puntos del borde e interior del área urbana de análisis de La Vaguada, los tiempos de llegada analizarán a posteriori. (figura 5.5.6.) 


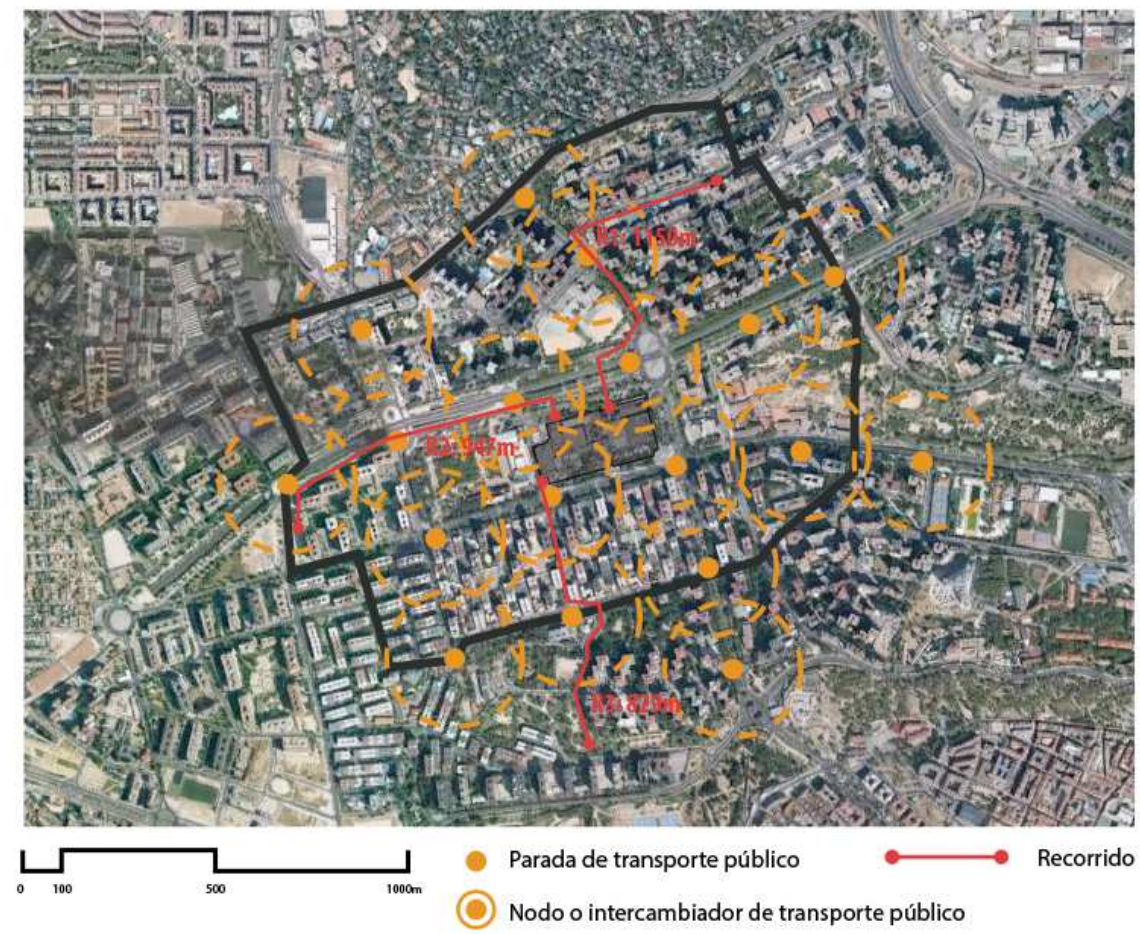

R1: $1150 \mathrm{~m}$

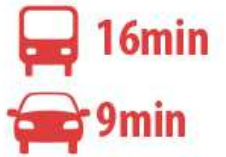

R2: $947 m$

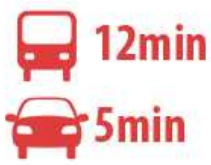

R3:829m

$15 \mathrm{~min}$

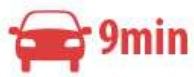

Figura 5.5.6: Recorridos, tiempos de llegada y zonas cubiertas por el transporte público. Fuente: Elaboración Propia a partir de datos de Google.

1Q.- HUELLA DE CARBONO DEL ÁREA URBANA: Siendo la huella de carbono de España de 5,083 toneladas anuales de dióxido de carbono per cápita (toneladas por habitante), de acuerdo al Banco Mundial para $2013^{56}$. Para hallar la huella de carbono del área urbana de La Vaguada, se multiplicó este dato por la población total del área asignada a La Vaguada, (42.750 personas), saliendo una huella de 214.605 Toneladas de dióxido de carbono anuales.

1R.- CAPACIDAD ABSORCIÓN DE LOS ELEMENTOS VERDES EN ÁREA URBANA: En base a los datos de superficies verdes obtenidos en el apartado 10, se calculó la absorción total de las áreas verdes en base a la capacidad de absorción por metro cuadrado de las superficies vegetales. (figura 5.5.7.) Siendo la capacidad absorbente total en el área de 19.344 Toneladas de dióxido de carbono anuales.

\begin{tabular}{|l|r|r|r|r|r|r|}
\hline 1R: C.absorción elementos verdes en área & \multicolumn{1}{|l|}{ Pradera } & V.arb ext & V. A. Int. & H. Caduca & H. Perenne & Otro \\
\hline Superficie total & 33051,0000 & 0,0000 & 13220,0000 & 26441,0000 & 6610,0000 & 0,0000 \\
\hline Tasa absorción TCo2/m2 año & 0,0013 & 0,0020 & 0,0350 & 0,1500 & 2,2500 & 0,8000 \\
\hline Absorción dióxido carbono TCo2 & 42,9663 & 0,0000 & 462,7000 & 3966,1500 & 14872,5000 & 0,0000 \\
\hline
\end{tabular}

Figura 5.5.7: Absorción de las zonas verdes del área urbana de La Vaguada. Fuente:Elaboración Propia

1S: DELIMITACIÓN DE ÁREAS EN FUNCIÓN DE LA RECUPERACIÓN DE AGUAS EN ÁREA URBANA. Para este análisis, se consideraron como zonas permeables al agua, las zonas verdes presentes en el área urbana. De este modo, la superficie permeable del área de La Vaguada es de $49.885 \mathrm{~m}^{2}$

FASE 2: ANÁLISIS DE RELACIONES ENTRE CENTRO COMERCIAL Y ENTORNO URBANO.

\footnotetext{
${ }^{56} \mathrm{http}: / /$ datos.bancomundial.org/indicador/EN.ATM.CO2E.PC?locations=ES
} 
Este análisis en muy similar en búsqueda de datos y función con respecto al anteriormente analizado sobre el área urbana general. La particularidad de este análisis está en que su ámbito está limitado a las parcelas que directamente lindan con la unidad catastral de La Vaguada. El objetivo es cuantificar las relaciones urbanas entre el centro y el entorno próximo, ya sea mediante usos, relaciones entre dotaciones, y accesibilidad o transporte. En este análisis va a primar el estudio sobre plano, aunque también se harán análisis cuantitativos de superficies, y cualitativos.

2A: DELIMITACIÓN DE ÁREA PRÓXIMA: De cara al análisis del área próxima se escogieron las manzanas próximas al centro (Figura 5.5.8).

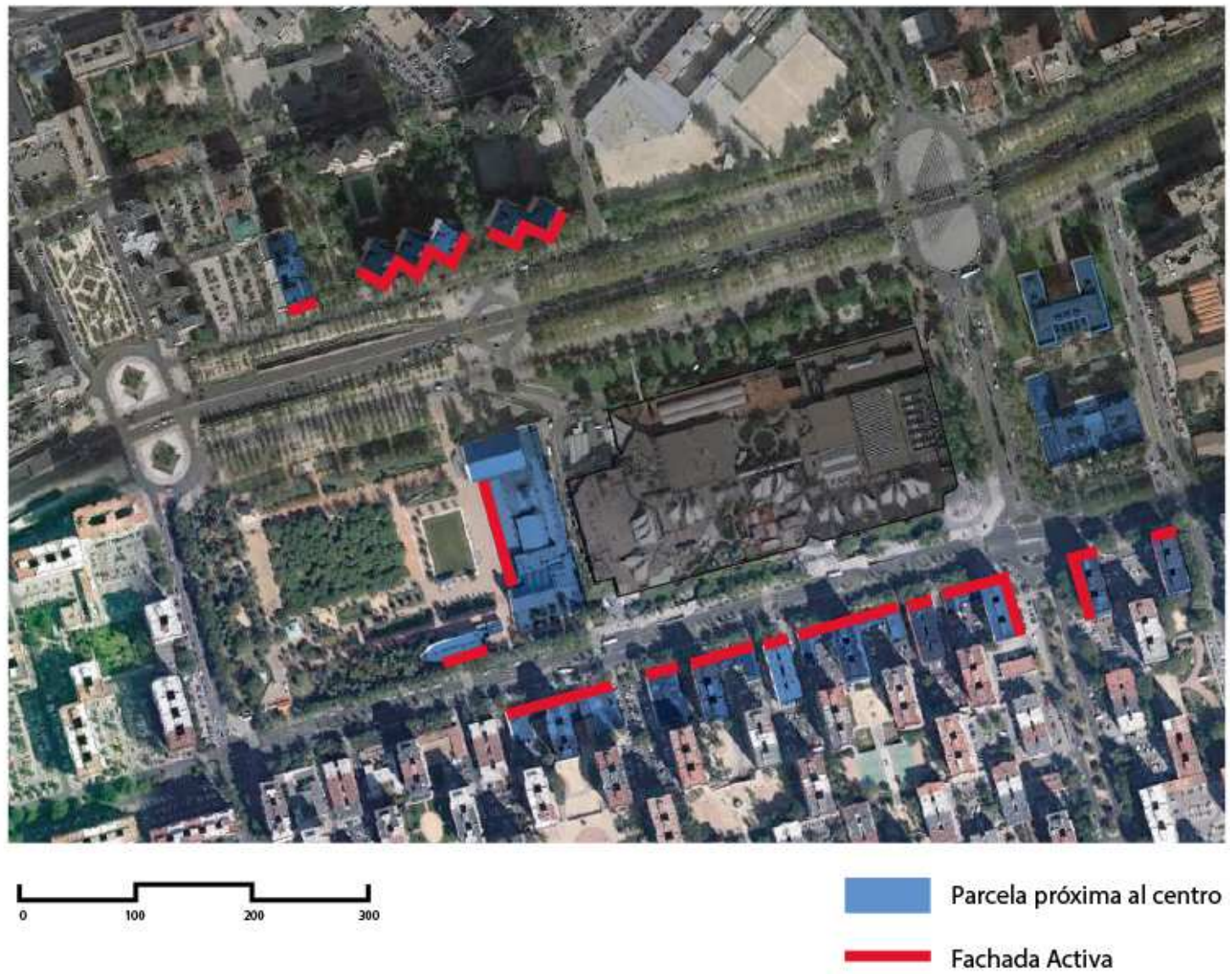

Figura 5.5.8: Análisis de parcelas próximas al centro. Fuente: Elaboración Propia a partir de datos de Google.

2B: SUPERFICIE TOTAL EDIFICADA EN ÁREA PRÓXIMA: Para el conteo de la superficie total estimada de las manzanas próximas al centro, se midió sobre un parcelario la superficie en planta de las mismas, que es de $28979 \mathrm{~m}^{2}$, la cual fue multiplicada por el número de plantas medio de los edificios de susodichas manzanas, que de análisis de parcelarios y visitas, se estableció en 12 plantas. De este modo, la superficie construida de las manzanas próximas al centro es de $347748 \mathrm{~m}^{2}$.

2C: USOS EN ÁREA PRÓXIMA: Las manzanas próximas al centro comercial, poseen una configuración de usos en la que predominan los edificios dotacionales o de oficinas, frente a los residenciales. De este modo, y de forma similar al análisis de usos del entorno urbano a escala amplia, se establecieron los siguientes porcentajes: 
Uso residencial: $50 \%$. Uso productivo: $30 \%$. Uso comercial: $20 \%$.

Quedando estas superficies a partir de la multiplicación de los porcentajes establecidos anteriormente, por el área total construida de manzana $\left(347748 \mathrm{~m}^{2}\right)$ :

Uso residencial: $173874 \mathrm{~m}^{2}$. Uso productivo: $104324 \mathrm{~m}^{2}$. Uso comercial: $69550 \mathrm{~m}^{2}$.

2D: FACHADAS ACTIVAS EN ÁREA PRÓXIMA Para este análisis, las fachadas activas (fachadas que cuentan con locales que ejercen interacción sobre los usuarios del espacio urbano) en manzanas próximas se marcaron en el plano, y se midieron en metros lineales, junto con la longitud de fachada total. la longitud de fachada activa es de $1155 \mathrm{~m}$ siendo la longitud de fachada total de $3653 \mathrm{~m}$ incluyendo las fachadas activas. el porcentaje es del $32 \%$.

2E: TIEMPOS DE LLEGADA DESDE LOS PUNTOS EN ÁREA A CENTRO COMERCIAL MEDIANTE TRANSPORTE PÚBLICO: Para la estimación de los tiempos de llegada en transporte público, fueron considerados los recorridos establecidos en $1 \mathrm{P}$, y se utilizó la base de datos de Google Maps para establecer los tiempos de llegada. (Figura 5.5.6)

2F: TIEMPOS DE LLEGADA DESDE LOS PUNTOS EN ÁREA A CENTRO COMERCIAL MEDIANTE TRANSPORTE PRIVADO: Para la estimación de los tiempos de llegada en transporte público, fueron considerados los recorridos establecidos en $1 \mathrm{P}$, y se utilizó la base de datos de Google Maps para establecer los tiempos de llegada, El centro comercial, aunque posee aparcamiento, se añadió al trayecto unos dos minutos adicionales de maniobra y trayecto de llegada a pie. De este modo, los tiempos establecidos para los medios de transporte son los siguientes para cada recorrido (Figura 5.5.6).

El centro comercial de La Vaguada, se encuentra en una zona de la periferia del centro de Madrid. A efectos de transporte público, aunque la zona está relativamente bien cubierta por las paradas, cabe destacar que debido a la ubicación excéntrica del centro comercial, las estaciones de metro cercanas se encuentran próximas a los finales de línea (Av. Ilustración y Barrio del Pilar), y lo mismo pasa con algunas líneas de autobús cercanas. De este modo, en esta zona el transporte público no es tan eficaz para cubrir los recorridos asignados, cómo pudiera serlo en el centro de Madrid. Cómo agravente de este hecho, los tiempos de frecuencia de autobuses son moderadamente altos (7 minutos). A efectos de transporte privado, el centro comercial de la vagua se encunetra próximo a grandes avenidas y arterias de circulación de Madrid. No obstante estas vías son promiscuas a congestionerse durante las horas puntas, de manera que los recorridos en vehículo privado van a prolongarse de manera significativa.

\section{FASE 3: ANÁLISIS DEL EDIFICIO DEL CENTRO COMERCIAL.}

Una vez analizado el entorno urbano en sus diferentes escalas, cuantificándose de cara al cuestionario de rehabilitación todas las facetas del mismo, a la par que las relaciones urbanas; el último campo de análisis es el estudio concreto de lo que es el edificio del centro comercial La Vaguada. De este modo, a partir de los datos de los que se pudieron disponer del centro comercial, van a cuantificarse los rasgos del edificio de La Vaguada en relación a las facetas de usos, sostenibilidad y comportamiento bioclimático, de cara al cuestionario de la Rosa de 
Sostenibilidad. Serán de importancia el conteo de superficies en base a la faceta a analizar, las simulaciones y la comparativa de las características formales para dar los datos necesarios para el cuestionario de rehabilitación.

3A: DELIMITACIÓN DE ÁREAS EN FUNCIÓN DE LA RECUPERACIÓN DE AGUAS: Sobre la planta de cubiertas del centro comercial, se delimitaron las áreas tanto permeables como impermeables del centro, de acuerdo a los estipulado en la metodología, para el caso de La Vaguada, se consideraron como superficies permeables las cubiertas verdes y las jardinerías de las fachadas (Apartado 3C)(Figura 5.5.9), que suman $7276 \mathrm{~m}^{2}$, siendo esta superficie un $12 \%$ de la superficie total de cubierta y parcela $\left(61.692 \mathrm{~m}^{2}\right)$

3B: USOS DENTRO DEL EDIFICIO DEL CENTRO: Para los usos, se consideraron los diferentes locales dentro del centro comercial, buscándose los metros cuadrados de espacio productivo, y las dotaciones asistenciales dentro del mismo. En La Vaguada, se computaron para esta tesis como usos productivos, la oficina de correos presente en el centro comercial, éstas suman unos $400 \mathrm{~m}^{2}$, que son un $0,47 \%$ de la superficie total del centro. (Las oficinas de gestión NO computan como espacio productivo, ya que generalmente no son accesibles por personas ajenas al centro comercial).

3C: DELIMITACIÓN DE ÁREAS VERDES EN CENTRO COMERCIAL. La Vaguada posee cubiertas verdes y jardineras en las fachadas, que suman $7276 \mathrm{~m}^{2}$, las cuales se desglosan en las siguientes capas de vegetación (figura 5.5.9):

\begin{tabular}{|l|r|}
\hline 3C: S. de zonas verdes en centro comercial & Valor \\
\hline C4.1: pradera & 0 \\
\hline C4.2: hierba de gran altura o huerto & 0 \\
\hline C4.3: vegetación arbustiva intensiva & 6776 \\
\hline C4.4: vegetación arbórea caduca & 500 \\
\hline C4.5: vegetación arbórea perenne & 0 \\
\hline
\end{tabular}

\section{Vegtación arborea} Caduca: $0,07 *$ Sup. V. tot
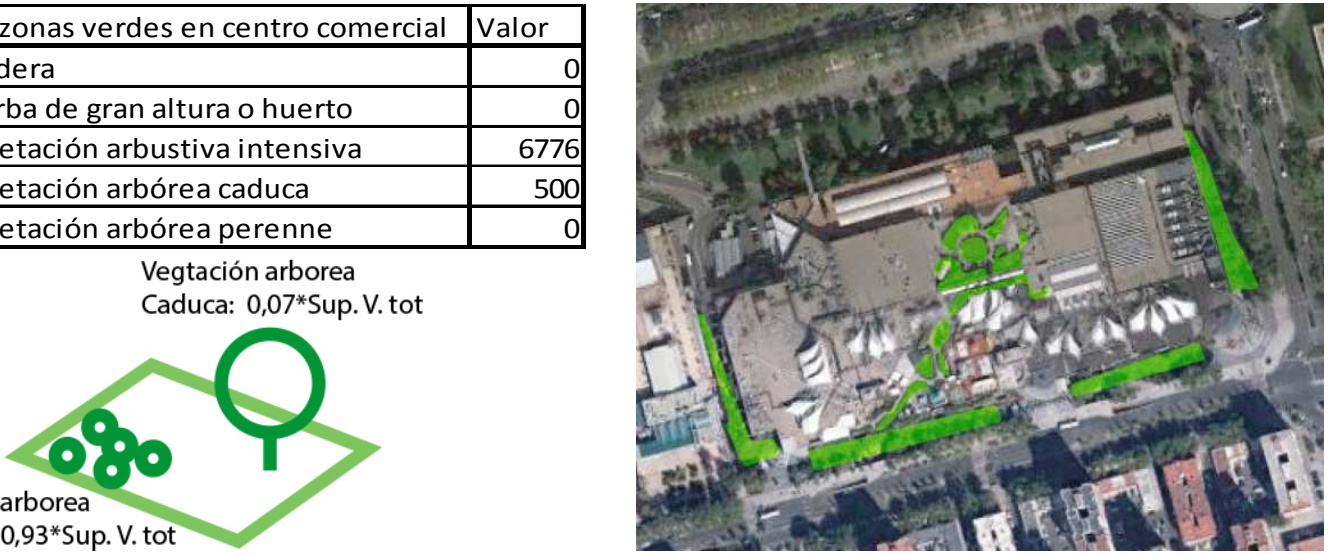

Vegtación arborea
Intensiva: $0,93 *$ Sup. V. tot

Figura 5.5.9: Áreas verdes y capas de vegetación La Vaguada, Fuente: Elaboración Propia.

3D: ABSORCIÓN DE LAS ÁREAS VERDES EN CENTRO COMERCIAL. Los las jardineras y zonas verdes del centro son capaces de asimilar hasta 312 toneladas anuales de dióxido de carbono, aproximadamente un $36 \%$ de la huella de carbono anual del centro (estimada en 850 T Co2 anuales, a partir de los cálculos realizados en 3F: 0,01 × 85.000 ) y un 1\% de la huella del área urbana (330.030 T Co2 anuales). (Figura 5.5.10)

\begin{tabular}{|l|r|r|r|r|r|r|}
\hline 3D: C.absorción elementos verdes en área & \multicolumn{1}{|l|}{ Pradera } & V.arb ext & V. A. Int. & H. Caduca & H. Perenne & Otro \\
\hline Superficie total & & & 6776,0000 & 500,0000 & & \\
\hline Tasa absorción TCo2/m2 año & 0,0013 & 0,0020 & 0,0350 & 0,1500 & 2,2500 & 0,0000 \\
\hline Absorción dióxido carbono TCo2 & 0,0000 & 0,0000 & 237,1600 & 75,0000 & 0,0000 & 0,0000 \\
\hline
\end{tabular}

Figura 5.5.10: Absorción elementos vegetales en La Vaguada. Fuente: Elaboración Propia. 
3E: ANÁLISIS BIOCLIMÁTICO DEL CENTRO COMERCIAL RESPECTO A CLIMA, DIAGRAMA DE GIVONI.

Los requisitos bioclimáticos de acuerdo a Givoni para el caso de La Vaguada, son los referenciados al clima de Madrid, y estos fueron desarrollados y explicados en el apartado $3 \mathrm{E}$ del capítulo de caso de estudio de ABC Serrano (Capítulo 5.4, Figura 5.4.9).

La Vaguada es un edificio que posee una envolvente de cierta masa térmica, en algunas fachadas hay jardineras, y aunque son habituales las superficies acristaladas algunas de ellas están cubiertas y protegidas de la irradiación solar. La Vaguada posee sistemas solares activos en la cubierta, y los espacios, aunque son de gran tamaño pueden valerse de las cargas térmicas para calefactarse. El centro comercial posee sistemas de calefacción y refrigeración convencionales, siendo el espacio interior generalmente cerrado y estanco.

\section{F: CALIFICACIÓN ENERGÉTICA DEL CENTRO COMERCIAL.}

Al no haber datos objetivos acerca del consumo primario de energía o las emisiones generadas por el centro La Vaguada, se tuvo que realizar una estimación con el programa CE3X, además de realizarse una ponderación comparativa de las emisiones y el consumo, con otros centros comerciales de los que se disponen datos de calificación energética, (los Arcos en Sevilla entre otros).

César Rey, que considera la Vaguada como un caso de éxito de gestión medioambiental, estipula que susodicho centro comercial en 2010 consumió $3.080 .410 \mathrm{kWh}^{57}$ en climatización, lo que supone un consumo de $36,02 \mathrm{kWh} / \mathrm{m}^{2}$, lo que en la escala definida en CE3X supone una calificación de $B$, de este modo, esta calificación fue también extrapolada, de manera supuesta a las emisiones, para el estudio en la presente tesis, pudiendo ser esto no cierto, debido a que el autor carece de este dato. De este modo las calificaciones energéticas para la Vaguada se establecieron en estos valores. (figura 5.5.11)

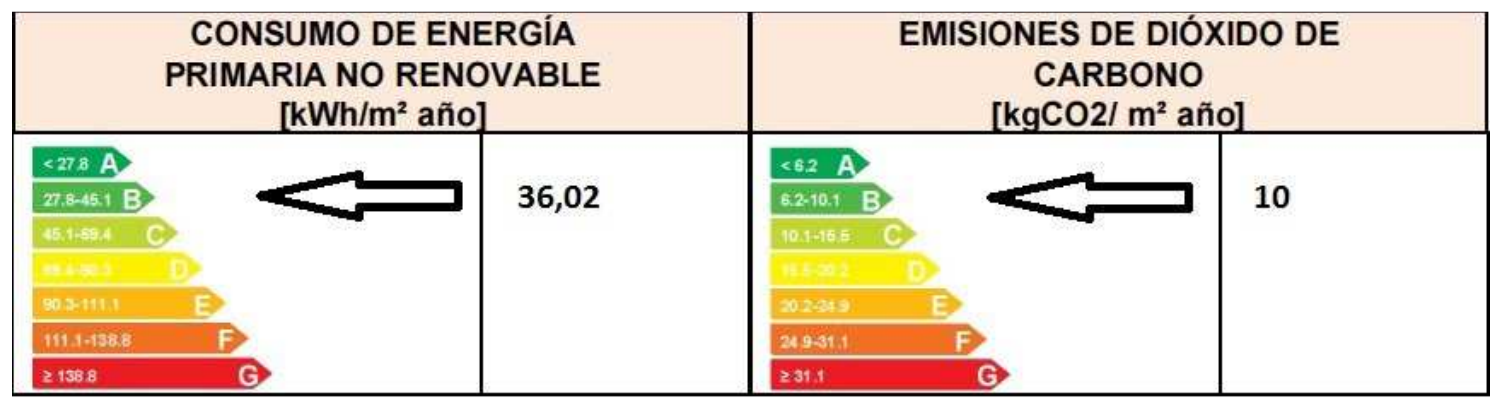

Figura 5.5.11: Escala de calificaciones CE3X, con las calificaciones de La Vaguada. Fuente: Elaboración propia a partir de datos del IDAE.

Consumo de energía: $36,02 \mathrm{Kwh} / \mathrm{m}^{2}$ año. (B)

Emisiones anuales: $10 \mathrm{~kg} / \mathrm{m}^{2}$ año; $0,01 \mathrm{~T} / \mathrm{m}^{2}$ año. (B)

3G: USO DE FUENTES DE ENERGÍA LIMPIAS.

\footnotetext{
${ }^{57}$ César Rey, Ponencia realizada en Sevilla en 2010, Centro comercial los Arcos, Efirenova.
} 
La Vaguada, posee sistemas de generación de energías limpias en forma de paneles fotovoltaicos. El centro posee $750 \mathrm{~m}^{2}$ de paneles, que generan anualmente unos $140.000 \mathrm{kWh}$ ${ }^{58}$. Este dato, será comparado en relación con los $3.080 .410 \mathrm{kWh}$ que el centro consume en un año ${ }^{1}$. Dando como conclusión que un $4 \%$ del consumo energético del centro se suple con energías limpias.

3H: ESPACIOS CON LUZ NATURAL Para medir esta superficie se consideraron de manera aproximada las superficies de los espacios iluminados del centro comercial La Vaguada, que generalmente corresponden a las estancias cercanas a los accesos, las plantas superiores y las plazas y galerías, que cuentan con lucernarios. En La Vaguada el espacio que cuenta con luz natural es aproximadamente el $23,39 \%$ de su superficie.

31: FORMA DE LA EDIFICACIÓN: El centro comercial La Vaguada, es un volumen ortogonal con cierta fragmentación de cara al lindero sur, que es principalmente una medianería. Aproximadamente la relación entre el lado mayor y el menor es de 2,13, siendo la orientación de la fachada principal unos 15 o este, respecto de la orientación sur. El centro a su vez cuenta con una fachada masiva, protegida en muchos casos por capas de vegetación en la fachada, y parasoles en los huecos, además de cubriciones en los lucernarios. El volumen del edificio, aunque tiene patios interiores abiertos, y algunos retranqueos, a grandes rasgos es compacto $\mathrm{y}$ cerrado. (Figura 5.5.12)

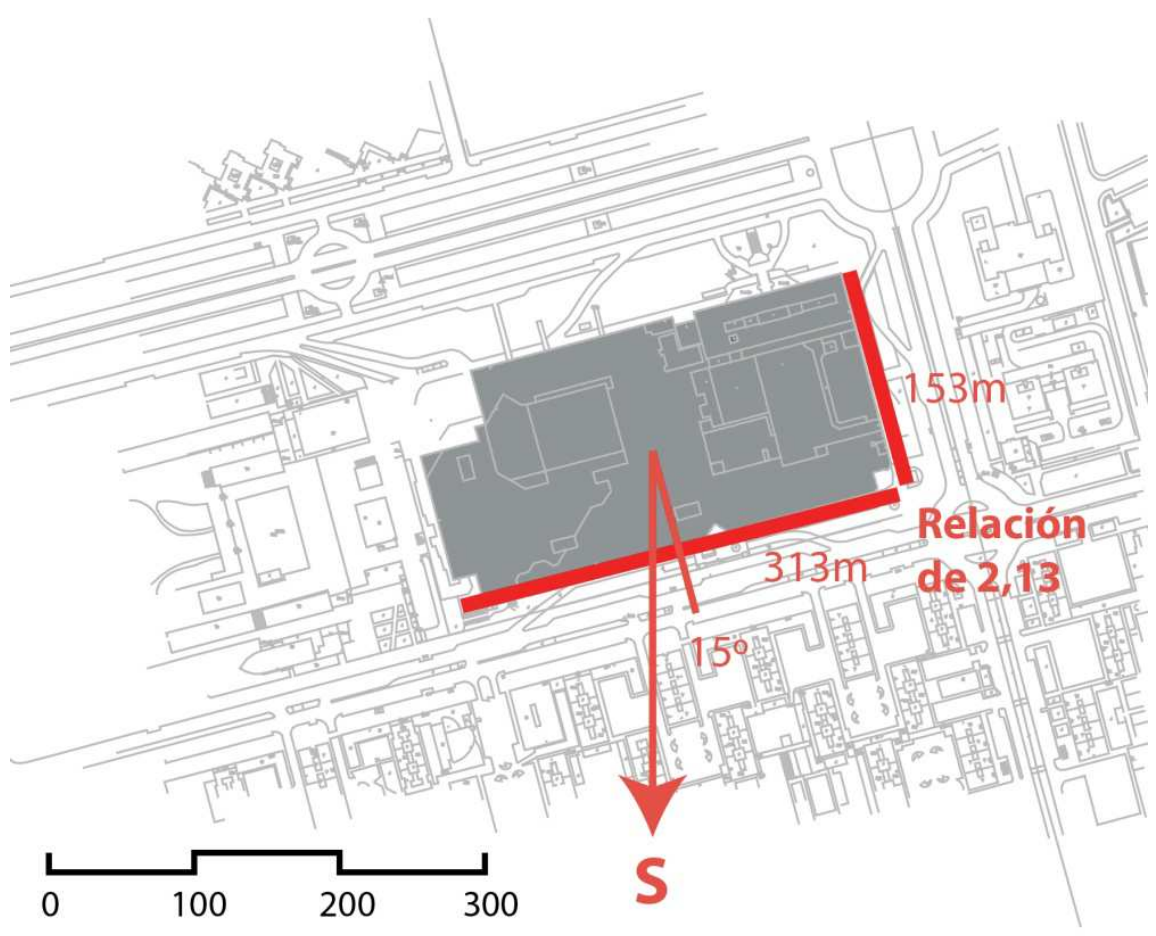

Figura 5.5.12: Análisis de forma de la edificación, La Vaguada. Fuente: Elaboración propia

3J: PAVIMENTOS Y CUBIERTAS EN RELACIÓN A LA INCIDENCIA DE LA IRRADIACIÓN SOLAR. Sobre la planta de cubiertas se midieron las superficies de colores claros. La Vaguada tiene

\footnotetext{
${ }^{58}$ Referencia en: http://www.eleconomista.es/desarrollo-sostenible/noticias/226912/06/07/Centroscomerciales-con-paneles-solares-La-Vaguada-estrena-el-suyo.html (2007)
} 
aproximadamente un $91,28 \%$ de su superficie de cubierta repelente de cara a la irradiación solar. siendo el 8,72\% restante, absorbente de cara a la irradiación solar. Esto se debe, al tratamiento de los patios con áreas ajardinadas, y a la presencia de superficies de colores claros en las cubiertas, además de las cubriciones de los lucernarios.

FASE 4: CUESTIONARIOS DE LA METODOLOGÍA, APLICACIÓN DE INDICADORES Y BAREMOS.

\section{A.- REHABILITACIÓN ECOEFICIENTE.}

A1.- Cuestionario referenciado a rehabilitación hacia instalaciones poco emisivas.

Cuestión A1.1.- ¿El centro cuenta con instalaciones que no son necesarias de acuerdo a lo estipulado en el diagrama de Givoni?: Aunque no hay datos objetivos acerca de las instalaciones de La Vaguada, de visitas al centro se dedujo que se trata de un espacio completamente cerrado y aclimatado, que posee instalaciones mecánicas de refrigeración y calefacción, las cuales mirando el diagrama de Givoni (figura 5.4.9 del capítulo del caso 4, ABC Serrano, 5.4), se ve que aunque las de calefacción son necesarias, las de refrigeración no lo son, no obstante, este centro decanta su política energética hacia la eficiencia, buscando el menor consumo posible. A este centro le corresponde una nota de +1 en esta cuestión.

Cuestión A1.2.- ¿Las instalaciones del centro generan unas emisiones de dióxido de carbono superiores a la media?. En el estudio energético, se supuso para el caso a estudiar, una calificación de $B$ en las emisiones de las instalaciones, eso corresponde a una nota de +3

Cuestión A1.3.- ¿Las instalaciones del centro se encuentran en un estado de obsolescencia?. Respecto esta cuestión, el autor desconoce el estado de las instalaciones del centro. No obstante, la Vaguada es considerada como un caso de éxito en gestión energética, como se explicó en el apartado 3F con lo que se puntuó esta cuestión con una nota de +1 .

Cuestión A1.4.- ¿Las instalaciones del centro tienen un consumo energético superior a la media?. El centro comercial la Vaguada, En base a lo estipulado en el análisis energético (3F) se consideró una calificación de $\mathrm{B}$, (bajo consumo) eso corresponde a una nota de +3

EN RELACIÓN A INSTALACIONES POCO EMISIVAS, LA VAGUADA HA OBTENIDO UNA PUNTUACIÓN DE 8 (10).

A2.- Cuestionario referenciado a inserción de medidas activas.

Cuestión A2.1.- ¿Qué porcentaje de las calorías necesarias para lograr la temperatura de confort se logra mediante sistemas activos?: Aunque el autor de la tesis desconoce la configuración de las instalaciones de la Vaguada, para este caso se supuso que el centro comercial de La Vaguada, aunque no posee sistemas solares activos de cara a la temperatura de confort, al ser un caso de éxito medioambiental, puede poseer otro tipo de sistemas activos que puedan suplir hasta el $10 \%$ de la energía necesaria para la temperatura de confort. Esta cuestión puntúa con +1 .

Cuestión A2.2.- ¿Qué porcentaje de la demanda energética se logra a partir de fuentes de energía renovable?: En los estudios de casos anteriores, se consideró que la instalación de 
paneles fotovoltaicos de la Vaguada, suple un $4 \%$ del consumo energético, esta cuestión fue puntuada con un +1 .

Cuestión A2.3.- ¿El centro cuenta con las medidas y dispositivos necesarios para su aclimatación de acuerdo a lo estipulado en el diagrama de Givoni para sistemas solares activos?: Aunque el autor de la tesis desconoce la configuración de las instalaciones de la Vaguada, al ser una caso de gestión correcta de la energía, se supuso la existencia de medidas activas de acurdo al diagrama de Givoni, esta cuestión puntúa con +1 .

EN RELACIÓN A MEDIDAS ACTIVAS, LA VAGUADA HA OBTENIDO UNA PUNTUACIÓN DE 3(10).

A3.- Cuestionario referenciado a inserción de medidas Pasivas.

A3.1.- ¿El centro comercial tiene una forma adecuada en volumen a las condiciones climáticas?: La Vaguada se encuentra en una zona climática templada de acuerdo a la calificación de Olgyay. De acuerdo al análisis anteriormente realizado en el punto 3l, La Vaguada cumple los requisitos de proporción de planta y de orientación de fachada principal, teniendo los huecos más importantes en la orientación sur, en fachada norte el edificio no está protegido contra vientos, pero apenas hay huecos en esta orientación. El edificio es un volumen compacto, algo fragmentado en las plantas superiores, que busca tener la menor superficie de fachada posible, al igual que y las fachadas y huecos cuentan con protecciones solares. El color de la fachada es de tonos que van de medios a oscuros. De este modo, La Vaguada cumple en muchos puntos con los requisitos de forma de Olgyay, le corresponde una puntuación de +2 .

A3.2.- ¿El estado de los cerramientos responde de manera correcta a las exigencias del clima en el que se asienta?: En lo relacionado con el estudio energético (3F), se concluyó que la calificación energética de La Vaguada a efectos de consumo global de energía es de B, esto significa que los cerramientos responden de una manera correcta respecto al clima. A este centro le corresponde una puntuación de +3 .

A3.3.- ¿Qué porcentaje de los espacios del centro cuentan con iluminación natural?: De acuerdo al apartado $3 \mathrm{H}$, La Vaguada posee un $23,39 \%$ del espacio interior iluminado con luz natural. Le corresponde de este modo una puntuación de +1 .

A3.4.- Los espacios del centro, están adaptados a lo estipulado por el Diagrama de Givoni de su respectivo clima?: La Vaguada, puede valerse de la ventilación natural permanente para aclimatar en caso de calor, debido a la presencia de numerosos lucernarios y galerías, no obstante el centro no se encuentra adaptado al uso de las mismas, pero las fachadas al ser masivas puede garantizar el uso de la masa térmica. Para calefactar, el centro puede utilizar las ganancias internas en los espacios de menor tamaño. De este modo se cumplen de manera parcial lo requerido por Givoni para el edificio de centro. A La Vaguada le corresponde una calificación de +1

EN RELACIÓN A MEDIDAS PASIVAS, LA VAGUADA HA OBTENIDO UNA PUNTUACIÓN DE 7 (10). 4B.- REHABILITACIÓN MEDIOAMBIENTAL. 
B1.- Cuestionario referenciado a rehabilitación mediante zonas verdes.

Cuestión B1.1.- ¿En el área urbana hay suficiente zona verde en el área en relación a sus habitantes?: El área urbana de La Vaguada posee aproximadamente $49.885 \mathrm{~m}^{2}$ de superficie verde en planta, que entre 42.750 habitantes, el ratio es de $1,16 \mathrm{~m}^{2}$ de superficie verde por habitante. Le corresponde una puntuación de +0 .

Cuestión B1.2.- ¿Las zonas verdes dentro del centro comercial pueden dar lugar a una área verde de uso cotidiano?: La Vaguada, posee aproximadamente $7276 \mathrm{~m}^{2}$ de superficie verde en su parcela. Supera el umbral mínimo de $1000 \mathrm{~m}^{2}$ impuesto por Salvador Rueda para áreas verdes de uso cotidiano, le corresponde una puntuación de +1 a esta cuestión.

Cuestión B1.3.- ¿La vegetación en el área (incluyendo el edificio del centro), en que porcentaje es capaz de asimilar las emisiones de la misma área urbana?: Sumando las capacidades de asimilación de las superficies de vegetación establecidas, tenemos una capacidad de asimilación de 19.472 Toneladas de dióxido de carbono anuales, esto es aproximadamente un 9\% de la huella de carbono del área, (214.605 Toneladas de dióxido de carbono anuales). Esta cuestión puntuará con +0 .

Cuestión B1.4.- ¿La vegetación en el centro comercial y su parcela, en que porcentaje es capaz de asimilar las emisiones del centro comercial?: Las áreas verdes del centro comercial, asimilan a lo sumo 312 toneladas de dióxido de carbono anuales, que es aproximadamente el $36 \%$ de la huella de carbono anual del centro ( 855 T Co2 anuales), a esta cuestión le corresponde una puntuación de +2

Cuestión B1.5.- ¿La distancia media entre espacios verdes dentro del área es inferior a los 200 metros?: Aunque hay espacios verdes en al área de La Vaguada, la distancia entre los mismos está a una media de $\mathbf{2 0 0}$ metros unos de otros, a esta cuestión le corresponde una puntuación de +1 .

\section{EN RELACIÓN A ZONAS VERDES, LA VAGUADA HA OBTENIDO UNA PUNTUACIÓN DE 4 (10).}

B2.- Cuestionario referenciado a inserción de superficie asimiladora de agua.

Cuestión B2.1.- ¿ ¿ El clima en el que está el centro corresponde a un clima árido o semiárido?: El índice de Martonne del clima de Madrid es de 16,83. A La Vaguada le corresponde una calificación de +0 a esta cuestión.

Cuestión B2.2.- ¿En qué porcentaje, la superficie absorbente de agua, en el área urbana, es en relación a la impermeable?: En esta cuestión, se consideró como superficie permeable las áreas verdes presentes en la zona $\left(49.885 \mathrm{~m}^{2}\right)$, que son aproximadamente un $4 \%$ de los 1.258.153 $\mathrm{m}^{2}$ totales del área urbana. esta cuestión puntúa con +0 .

Cuestión B2.3.- ¿El centro comercial posee sistemas para el aprovechamiento del agua?: Aunque el autor de la tesis desconoce el estado de las instalaciones de la Vaguada, se supuso que el centro comercial posee instalaciones para el aprovechamiento del agua, y una amplia superficie de jardineras. Le corresponde una puntuación de +2 . 
Cuestión B2.4- ¿El consumo de agua del centro es en litros por visita?: a pesar de que no hay datos del centro en este sentido, al centro comercial La Vaguada, al ser reconocido como un caso de correcta gestión medioambiental, se le estimó un consumo de agua de 20 litros por visita o menos, que corresponde a una puntuación de +2 .

EN RELACIÓN A SUPERFICIE ASIMILADORA DE AGUA, LA VAGUADA HA OBTENIDO UNA PUNTUACIÓN DE 4 (10).

\section{B3.- Cuestionario referenciado a tratamiento de isla de calor.}

Cuestión B3.1.- ¿ ¿El clima en el que está el centro comercial tiene una temperatura media más o menos elevada?. El clima de Madrid tiene una temperatura media anual de 150, esto significa que es un clima propenso a altas temperaturas. Esta pregunta puntúa con +0

Cuestión B3.2.- ¿En el clima en el que está ubicado en centro hay olas de calor frecuentes o en intervalo temporal menor?. En Madrid generalmente acontecen varias olas de calor al año, esta cuestión puntúa con un +0 .

Cuestión B3.3.- ¿El centro está en un área en el cual la diferencia de temperatura respecto a la normal es de?. Analizando la isla de calor de Madrid (Figura 5.5.13), nos encontramos con el hecho de que La Vaguada se encuentra en un área con 50 de temperatura respecto de lo normal, de este modo esta cuestión puntúa con un +0.

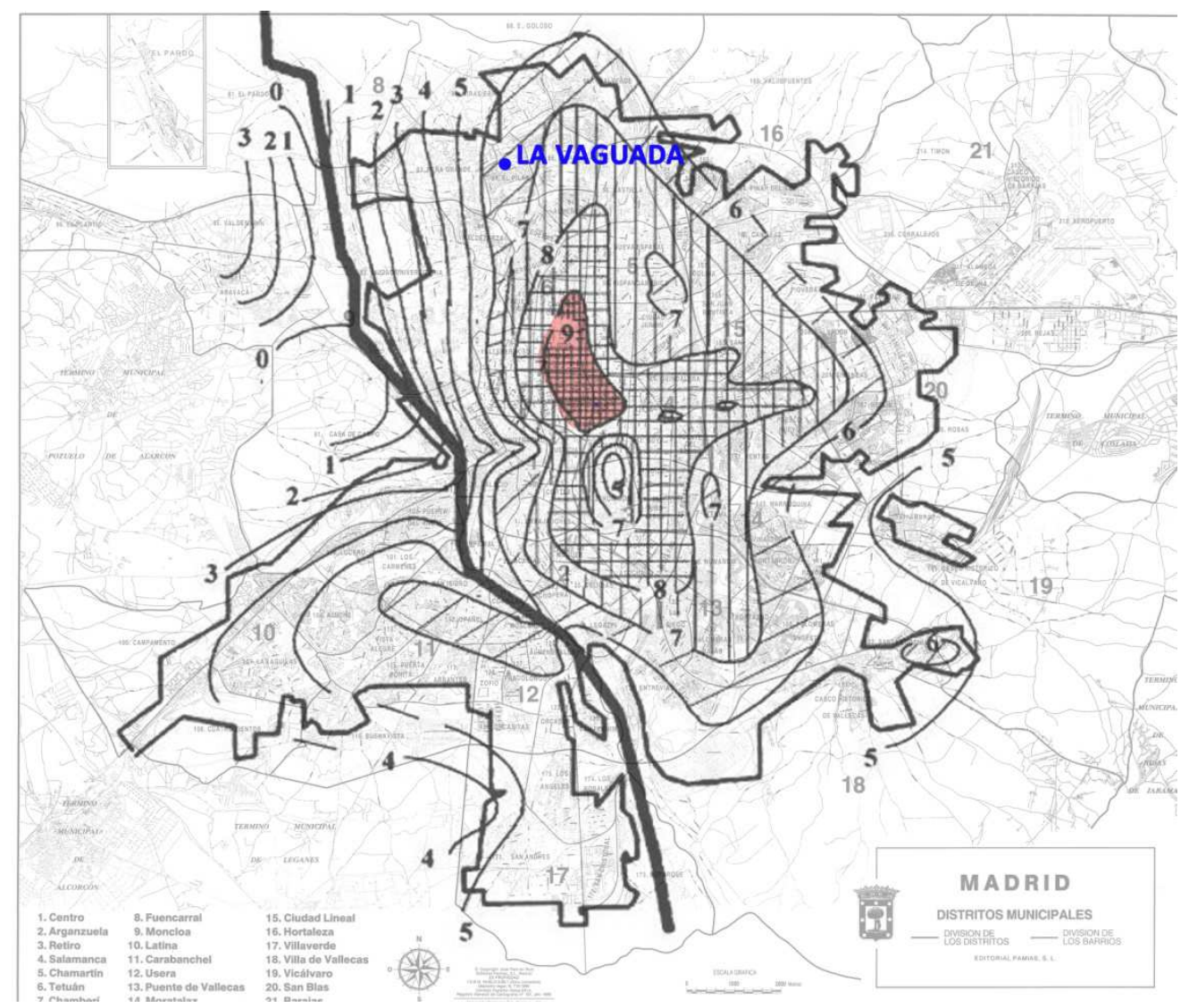

Figura 5.5.13: Isla de calor de Madrid con la ubicación de La Vaguada. Elaboración propia a partir de datos del Ayuntamiento de Madrid. 
Cuestión B3.4.- ¿La suma de superficies que contribuyen a la isla de calor en la parcela y el edificio del centro es superior a un porcentaje de la superficie total?. De acuerdo al apartado 3J, La superficie absorbente de irradiación en la parcela y edificio de La Vaguada es del 8,72\%, lo que le corresponde una puntuación de +4 .

EN RELACIÓN A TRATAMIENTO DE ISLA DE CALOR, LA VAGUADA HA OBTENIDO UNA PUNTUACIÓN DE 4 (10).

4C.- REHABILITACIÓN POR USOS.

C1.- Cuestionario referenciado a inserción de uso residencial.

Cuestión C1.1.- ¿El centro comercial posee usos residenciales u hoteleros dentro de su unidad catastral?. La Vaguada no posee usos hoteleros o residenciales, esta cuestión puntúa con +0 .

Cuestión C1.2.- ¿Las parcelas próximas al centro comercial posen usos residenciales u hoteleros?: El uso residencial en las parcelas colindantes al centro comercial fue estimado en un $50 \%$, de acuerdo al análisis del apartado $2 \mathrm{C}$, lo que le corresponde una puntuación de +2 .

Cuestión C1.3.- ¿Dentro del área de influencia del centro comercial, que porcentaje de la superficie de uso total es de tipo residencial?: De acuerdo a lo analizado en 11, en el área de influencia de La Vaguada, se estableció aproximadamente un $80 \%$ de uso residencial, lo que le corresponde una puntuación de +5

EN RELACIÓN A USO RESIDENCIAL, LA VAGUADA HA OBTENIDO UNA PUNTUACIÓN DE 7 (10).

C2.- Cuestionario referenciado a inserción de usos productivos, y terciarios no comerciales.

Cuestión C2.1.- ¿El centro comercial posee usos productivos no comerciales dentro de su unidad catastral?: La Vaguada posee unos $400 \mathrm{~m} 2$, de espacio terciario productivo de tipo administrativo (oficina de correos) que ocupa un $0,47 \%$ de la superficie total del centro, esta cuestión puntúa con +1 .

Cuestión C2.2.- ¿Las parcelas próximas al centro comercial posen usos productivos no comerciales?: Las parcelas próximas al centro comercial, poseen cierta oferta de instalaciones terciarias de oficinas y administrativas, que se computaron en aproximadamente un $30 \%$ de la superficie total (2C), esta cuestión puntúa con un +3 .

Cuestión C2.3.- ¿Dentro del área de influencia del centro comercial, que porcentaje de la superficie de uso total es de tipo productivo no comercial?: De acuerdo a lo analizado en 1 , en el área urbana de influencia del centro comercial La Vaguada, se estimó un 10,82\% de la superficie edificada total, como instalaciones terciarias no comerciales. A esta cuestión le corresponde una puntuación de +2 .

EN RELACIÓN A USO PRODUCTIVO, LA VAGUADA HA OBTENIDO UNA PUNTUACIÓN DE 6 (10).

C3.- Cuestionario referenciado a inserción de instalaciones dotacionales y asistenciales. 
Cuestión C3-1.- ¿El centro comercial posee usos dotacionales dentro de su unidad catastral?: El centro comercial La Vaguada, posee una oficina de correos, esta cuestión puntúa con un +1 .

Cuestión C3.2.- ¿Las parcelas próximas al centro comercial posen usos dotacionales?: En las inmediaciones del centro comercial La Vaguada, (apartado 1L, Figura 5.5.3) hay varias instalaciones concurridas de importancia local, siendo algunas de ámbito nacional, aunque no muy visitadas (oficinas del IMSERSO). Esta pregunta puntúa con un +3.

Cuestión C3.3.- ¿A un kilómetro del centro comercial hay usos dotacionales?: En el área de dotaciones correspondiente a lo que es el centro comercial de La Vaguada, hay 1 dotación de visita esporádica, y 8 de visita habitual de cierta importancia local (apartado 1L, Figura 5.5.3). Esta cuestión puntúa con +5 .

EN RELACIÓN A DOTACIONES, LA VAGUADA HA OBTENIDO UNA PUNTUACIÓN DE 9 (10).

4D.- REHABILITACIÓN DE ENTORNO URBANO.

D1.- Cuestionario referenciado a la inserción de medios de transporte eficientes.

Cuestión D1.1.- ¿El centro dispone en sus inmediaciones de alguna parada de transporte público?: El centro comercial La Vaguada, posee instalaciones de transporte público en las inmediaciones de sus parcelas, como se recoge en la figura 5.5.6. La puntuación es de +1 .

Cuestión D1.2.- ¿El tiempo de llegada al centro mediante transporte público supera al tiempo de llegada en vehículo particular?, A partir del análisis del apartado $2 \mathrm{~F}$, el tiempo de llegada medio en transporte público desde los puntos asignados en el área, es de 1,95 veces de media más que en vehículo privado, (Figura 5.5.14) esta cuestión puntúa con +1.

\begin{tabular}{|l|r|r|r|}
\hline 2E.- Tiempos de recorrido transporte público & Recorrido 1 & Recorrido 2 & Recorrido 3 \\
\hline Total tiempo desplazamiento tte público & 16 & 12 & 15 \\
\hline Total tiempo desplazamiento tte privado & 9 & 5 & 9 \\
\hline Relación entre tiempos desplazamiento & 1,777777778 & 2,4 & 1,666666667 \\
\hline Media tiempo desplazamiento & & & 1,948148148 \\
\hline
\end{tabular}

Figura 5.5.14: Comparación de recorridos a La Vaguada. Fuente: Elaboración propia

Cuestión D1.3.- ¿El área urbana del centro comercial está cubierta de forma adecuada por la infraestructura de transporte público?. El área urbana de La Vaguada, está cubierta en un $86 \%$ aproximadamente por la infraestructura de transporte público. Lo que la cuestión puntúa con un +2 .

Cuestión D1.4.- ¿ Los usos en la zona están mezclados o zonificados?: En el área de La Vaguada, el índice Global de Mezcla de usos es de 1 (Zona de gran complejidad urbana), esto le corresponde una puntuación de +2 .

Cuestión D1.5.- ¿El centro comercial y el área urbana próxima al centro cuenta con instalaciones enfocadas en la movilidad sostenible?: El centro comercial La Vaguada posee sistemas e instalaciones centradas en la movilidad sostenible, siendo algunas de ellas los puntos de recarga de coches eléctricos. Esta cuestión obtiene una puntuación de +2 . 
EN RELACIÓN A TRANSPORTE EFICIENTE, LA VAGUADA HA OBTENIDO UNA PUNTUACIÓN DE 8 (10).

D2.- Cuestionario referenciado a la rehabilitación por corrección de la densidad en área urbana.

Cuestión D2.1.- ¿La densidad de población en el área del centro está en el intervalo entre $\mathrm{h} / \mathrm{ha}$ ?, La densidad de población del área de La Vaguada es la del Barrio del Pilar (0,035 $\mathrm{hab} / \mathrm{m}^{2}$ ), establecida en el apartado 0 de este capítulo. De acuerdo al baremo establecido, a esta cuestión le corresponde una puntuación de +3 , habiendo problemas de congestión.

Cuestión D2.2.- ¿A efectos de densidad, el tejido mayoritario es favorable o desfavorable de cara a la sostenibilidad?. El índice global de densidad del área de La Vaguada es de 2, de acuerdo a lo estudiado en el apartado $1 \mathrm{G}$ lo que es un entorno de densidad media, a esta cuestión le corresponde una puntuación de +3 .

Cuestión D2.3.- ¿La cantidad de espacio ocupado en el área está en el intervalo...? Para calcular la media de espacio ocupado, se multiplicó el porcentaje de ocupación de cada zona, por el porcentaje que ocupa la zona respecto al área total. $\left(19 * 0,45+25^{*} 0,54\right)$. el resultado de esta operación, es que el espacio ocupado por la edificación en el área de La Vaguada, es de media un $22 \%$, lo que corresponde a una puntuación de +1 .

EN RELACIÓN A DENSIDAD, LA VAGUADA HA OBTENIDO UNA PUNTUACIÓN DE 7 (10).

D3.- Cuestionario referenciado a mejora de la seguridad y la paseabilidad en el área urbana.

Cuestión D3.1.- ¿En el área de influencia o en sus proximidades hay elementos negativos de cara a la seguridad o a la salubridad del área?: En el área cercana a La Vaguada, no hay áreas o elementos que pudieran influir negativamente de cara a la paseabilidad. Esta cuestión puntúa con +1 .

Cuestión D3.2.- ¿El centro comercial se encuentra en una zona de puntos fríos de actividad durante el día?. El área de La Vaguada, debido a la gran cantidad de dotaciones con horario diurno e intensa actividad, no tiene puntos fríos durante el día, esta cuestión puntúa con +1.

Cuestión D3.3.- ¿El centro comercial se encuentra en una zona de puntos fríos durante la noche?, En el área de la vaguada, pueden aparecer puntos fríos, espacialmente en los parques interiores de los complejos de viviendas y en las grandes avenidas. Esta cuestión puntúa con +0 .

Cuestión D3.4.- ¿El centro comercial se encuentra en una zona con áreas de difícil control visual o de contacto urbano?. En el área de La Vaguada, a pesar de los parques interiores, los desniveles existentes y algunos edificios que hacen un poco función de tapón, no hay áreas de difícil control visual. Esta cuestión puntúa con +1

Cuestión D3.5.- ¿La sensación de seguridad por parte de los ciudadanos de la zona es positiva o negativa?: El área de La Vaguada, es un área relativamente segura de Madrid. La puntuación a esta cuestión es de +1 . 
Cuestión D3.6.- ¿La zona próxima al centro comercial tiene un porcentaje de fachadas activas?: En las manzanas próximas al centro comercial, hay un $32 \%$ de fachadas activas, lo que le corresponde una puntuación de +1 .

Cuestión D3.7.- ¿La distancia de la puerta del edificio del centro comercial al inmueble residencial cercano es superior a los 200 metros?: El inmueble residencial más cercano a La Vaguada, se encuentra a 90 metros, esta cuestión puntúa con +1 .

Cuestión D3.8.- ¿La cantidad de espacio libre en el área va a resultar desfavorable de cara a la paseabilidad?: Siendo el porcentaje de ocupación global del área de un 22\%, El espacio libre en el área de La Vaguada es de aproximadamente un $78 \%$, lo que supone que los espacios libres van a alejar los usos unos de otros. Esta cuestión va a puntuar con un +0 .

Cuestión D3.9.- ¿Los usos en la zona están mezclados o zonificados? El índice global de mezcla de usos hallado es de 1 , esta cuestión puntúa con +1 .

EN RELACIÓN A PASEABILIDAD, LA VAGUADA HA OBTENIDO UNA PUNTUACIÓN DE 7 (10).

4E.- CUESTIONARIO RELACIONADO CON LA ACTIVIDAD DEL CENTRO Y SUS CONSECUENCIAS URBANAS.

Cuestión E1: ¿La actividad del centro comercial, va a penalizar o a favorecer la sostenibilidad del entorno urbano?: De acuerdo a lo establecido en el apartado 0 de este estudio, La Vaguada tiene un índice de atracción de 4 , y la puntuación total en el cuestionario relacionado con el transporte eficiente es de 8 , de este modo, consultando la tabla del apartado 3.10, 4E. El efecto de la actividad corresponde a un incremento de +2 a la seguridad y paseabilidad (D3), quedando finalmente este cuestionario en una puntuación de 9.

FASE FINAL: GRÁFICO DE LA ROSA DE REHABILITACIÓN SOSTENIBLE.

Las puntuaciones obtenidas en el anterior cuestionario, fueron colocadas en el gráfico de la rosa de rehabilitación sostenible, obteniendo el siguiente resultado (Figura 5.5.15): 


\section{(A) ECOEFICIENTE}

\section{(A3)}

MEDIDAS

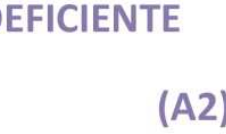

(A2)
MEDIDAS
ACTIVAS

(A1)

INSTALACIONES
POCO EMISIVAS

(n)

(C1)

USO
RESIDENCIAL.

MEDIDAS
ACTIVAS

PASIVAS

(B1)
ZONAS

ZONAS
VERDES

VERDES

(B2)

SUPERFICIE

ASIMILADORA AGUA

(B) MEDIOAMBIENTAL

UMBRALES

2 puntos: Umbral de mínimos, Rehabilitación prioritaria

8 puntos: Situación Óptima,

Rehabilitación nada prioritaria

(B3)

TRATAMIENTO

ISLA CALOR

10 puntos: Paradigma verde

\section{ZONAS E INTERVALOS}

0-2 puntos: rehabilitación muy prioritaria

2-8 puntos: rehabilitación

de prioridad de media a

moderada

8-10 puntos: rehabilitación

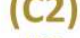

uso PRODUCTIVO
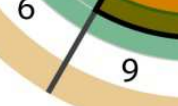

8

(D2)

SEGURIDAD

no prioritaria.

DENSIDAD

\section{(C) DOTACIONAL Y USOS}

(C3)

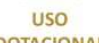

USO
DOTACIONAL
(D1)

TRANSPORTE
EFICIENTE

\section{(D) ENTORNO URBANO}

Figura 5.5.15: Gráfico de rosa de rehabilitación sostenible para La Vaguada. Fuente: Elaboración propia

A primera vista, se puede comprobar de acuerdo al gráfico que tanto el área urbana de la vaguada, cómo el centro comercial en sí, no tienen carencias graves de cara a la sostenibilidad. No obstante, las condiciones del centro comercial de cara a la sostenibilidad todavía pueden ser mejoradas, especialmente en lo que relata a superficies verdes y absorción de agua en el área urbana, así como la inserción de medidas solares activas de aclimatación y energía de tipo avanzado. De este modo, cualquier operación de rehabilitación sostenible que se realice en el centro comercial La vaguada o en su zona urbana, irá encaminada a dar el siguiente paso en rehabilitación sostenible de edificios establecido para esta tesis, que será transformar el centro y el área urbana en un paradigma verde.

\section{6.- CASO 6: PARQUESUR}

Parquesur es un centro comercial de gran superficie, y extensión en planta, que se ubica en Leganés, una ciudad de la periferia de Madrid. Este centro fue estudiado como homólogo al caso de Aricanduva en Sao Paulo. Parquesur actualmente es el tercer centro comercial de España en superficie (Según el ranking del Informe anual de la Asociación Española de Centros y Parques Comerciales, a partir de 2012, recogido en el siguiente enlace ${ }^{59}$ ). Siendo un caso de estudio de gran interés debido a

FASE 0: RECOGIDA DE DATOS CUANTITATIVOS.

OC.- TABLA DE DATOS DEL CENTRO COMERCIAL. (Figura 5.6.1)

\footnotetext{
${ }^{59}$ http://www.galapagar-info.net/ocio/centros-comerciales/los-10-centros-comerciales-mas-grandesde-espana/
} 


\begin{tabular}{|l|l|}
\hline \multicolumn{2}{|c|}{ PARQUESUR } \\
\hline \multicolumn{2}{|c|}{ FASE 0, RECOGIDA DE DATOS CUANTITATIVOS } \\
\hline OC.- TABLA DE DATOS CENTRO & Valor \\
\hline OC1: Superficie centro comercial (m2) & 151.200 \\
\hline OC2: Superficie de parcela o ud. Catastral (m2) & 296.205 \\
\hline OC3: Superficie en planta (m2) & 135.765 \\
\hline OC4: Número de visitantes semanal (pe/sem) & 254.016 \\
\hline OC5: Índice de Atracción ( $\mathrm{n}$-) & 4 \\
\hline OC6: Superficie de tipo residencial (m2) & 6000 \\
\hline OC7: Superficie de uso productivo (m2) & 0 \\
\hline OC8: Número de instalaciones dotacionales ( $\mathrm{n}$ o) & 0 \\
\hline OU.- TABLA DE DATOS ENTORNO URBANO & Valor \\
\hline OU1: Población asignada a centro (pe) & 75.600 \\
\hline OU2: Densidad de población (hab/m2) & 0,041 \\
\hline U03: Superficie partida de entorno urbano (m2) & $1.843 .902,439$ \\
\hline
\end{tabular}

Figura 5.6.1: Tabla de datos Parquesur. Fuente: Elaboración Propia.

C1: SUPERFICIE CENTRO COMERCIAL TOTAL: Este dato fue obtenido de fuentes oficiales de parte de la Asociación Española de Centros y Parques Comerciales. La superficie edificada de Parquesur es de $151.200 \mathrm{~m}^{2}$, siendo este dato comprobado sobre un parcelario de la ciudad de Leganés.

C2: SUPERFICIE TOTAL DE LA PARCELA DEL CENTRO: Para la obtención de este dato se midió la superficie de la parcela catastral de Parquesur, en un parcelario de la ciudad de Leganés, la superficie de la parcela obtenida es de $296.205 \mathrm{~m}^{2}$

C3: SUPERFICIE EN PLANTA DEL EDIFICIO DEL CENTRO COMERCIAL. De mediciones sobre plano en el parcelario de Leganés, se obtuvo que la planta del edificio de Parquesur tiene una superficie estimada en planta de $135.765 \mathrm{~m}^{2}$, comparando este dato con la superficie total de parcela, se obtiene que la parcela del centro comercial Parquesur está ocupada al $72 \%$ de su superficie.

C4: NÚMERO DE VISITANTES SEMANAL. Al no poder obtenerse datos del número de visitantes del centro comercial Shopping Eldorado, se realizó un conteo estimativo de las visitas tomando como base los datos de Shopping Light del apartado C4, considerándose a su vez un coeficiente de ponderación de 0,8 debido a la localización periférica de este centro comercial dentro del área urbana de Madrid.

De lunes a viernes: 120.960 personas.

Sábado: 100.397 personas.

Domingo: 32.659 personas.

De este modo, el número de visitantes semanal de Parquesur es de 254.016 personas.

C5: ÍNDICE DE ATRACCIÓN DEL CENTRO. En función al número de visitantes del centro, A Parquesur le corresponde un índice de 4 (de 150.000 a 300.000 visitas semanales). 
C6: SUPERFICIE DE USO EN EL CENTRO DE TIPO RESIDENCIAL. De visitas al centro y mediciones en planta, se obtuvo que Parquesur posee un hotel que se estimó en 6000 metros cuadrados.

C7: SUPERFICIE DE USO EN EL CENTRO DE TIPO PRODUCTIVO: De visitas al centro y mediciones en planta, se obtuvo que Parquesur no posee superficie productiva no comercial o de servicios asistenciales dentro de su unidad catastral.

C8: NÚMERO DE INSTALACIONES EN EL CENTRO DE TIPO DOTACIONAL O ASISTENCIAL: De visitas al centro y mediciones en planta, pudo obtenerse que en Parquesur no hay instalaciones asistenciales.

\section{OU.- TABLA DE DATOS DEL ENTORNO URBANO. (Figura 5.6.1)}

U1: POBLACIÓN DE ÁREA URBANA ASIGNADA A CENTRO COMERCIAL: En base al baremo establecido para la tesis, dividiendo la superficie obtenida del centro comercial en C1 entre 2, salió una población asignada para Parquesur de 75.600 personas.

U2: DENSIDAD DE POBLACIÓN EN EL DISTRITO DEL CENTRO COMERCIAL: Al ser los datos oficiales de densidad de Leganés poco viables para el análisis, ya que consideran áreas muy extensas sin edificar. Para el análisis urbano, se cogió la población del barrio de el Carrascal, (31.000 hab) que es el área urbana dónde está ubicado el centro comercial, y se dividió entre su superficie edificada estimada $\left(0,75 \mathrm{~km}^{2}\right.$ aproximadamente). De este modo, la densidad corregida de El Carrascal es de aproximadamente $41.000 \mathrm{hab} / \mathrm{Km}^{2}$. La densidad se estableció en $0,041 \mathrm{hab} / \mathrm{m}^{2}$. Estos datos fueron obtenidos del Instituto de Estadística de la Comunidad de Madrid de 2015, para el municipio de Leganés.

U3: SUPERFICIE DEL ENTORNO URBANO: La superficie de partida del entrono urbano a analizar, se sacó de los datos de población asignada al centro (75.600 personas), la cual fue dividida entre la densidad del área establecida para este caso de estudio $\left(0,041 \mathrm{hab} / \mathrm{m}^{2}\right)$, la superficie de partida es de $1.843 .902,439 \mathrm{~m}^{2}$, que puede no corresponderse con la superficie final para el análisis.

\section{FASE 1: ANÁLISIS DEL CONTEXTO URBANO.}

1A: ESTABLECIMIENTO DEL ÁREA DE INFLUENCIA DEL CENTRO COMERCIAL : En base a la superficie de partida del área, hallada anteriormente, a Parquesur, le corresponde un radio de aproximadamente 748 metros a partir del lindero de la parcela del centro, no obstante hay que considerar que el centro comercial está en un borde urbano, de modo que se va a escoger un área de aproximadamente la superficie de partida hallada, más centrada en lo que es la ciudad de Leganés. Para la delimitación de la misma, se consideraron las principales infraestructuras, y de esta manera el área de análisis de Parquesur quedó establecida en los barrios del Carrascal y Zarzaquemada dentro de Leganés, quedando el centro comercial ubicado en un extremo de la misma (Figura 5.6.2).

1B: DELIMITACIÓN SOBRE PLANO DEL ÁREA DE INFLUENCIA: En base al radio anteriormente establecido, y considerando la configuración del entorno urbano, se estableció la siguiente área (Figura 5.6.2). Se marcaron los límites, considerando la estructura urbana anteriormente mencionada. Este área mide 2.539.764,8651 m2. 
1C: SUBDIVISIÓN DEL ÁREA DE INFLUENCIA EN ÁREAS HOMOGÉNEAS Y DELIMITACIÓN DE ZONAS VERDES Para este análisis, el área urbana anteriormente asignada, va a dividirse en zonas homogéneas de acuerdo a su tejido urbano, (Figura 5.6.2) marcándose a su vez la superficie de zonas verdes. Se establecieron dos tipologías de zona homogénea, descontando las grandes avenidas, los grandes espacios verdes, y la parcela del centro. Cada zona homogénea tiene aproximadamente:

$\mathrm{Z1:} 716.600 \mathrm{~m}^{2}$ brutos.

Z2: $1.068 .500 \mathrm{~m}^{2}$ brutos.

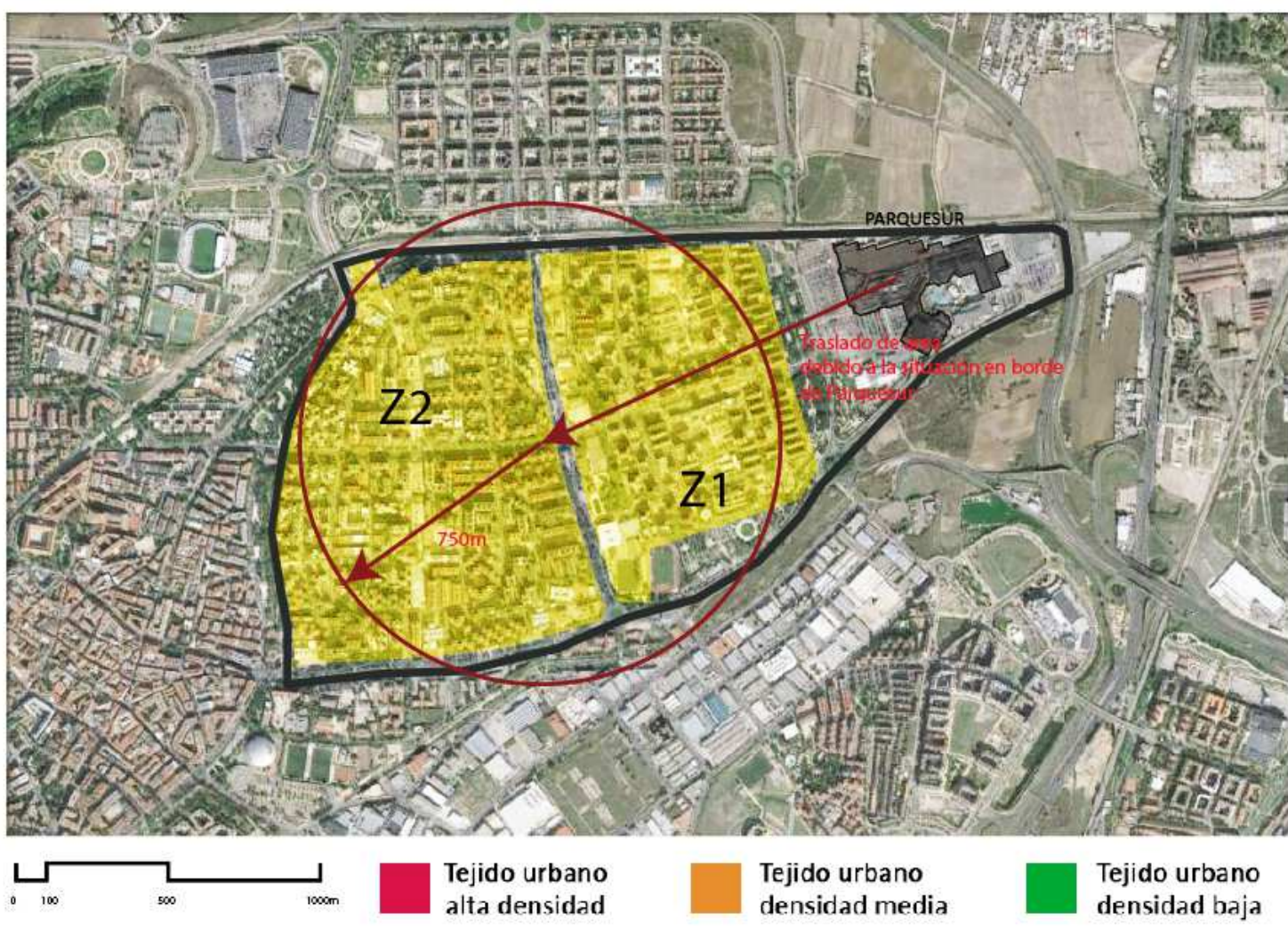

Figura 5.6.2: Área de Parquesur y subdivisión por zonas homogéneas. Fuente: Elaboración Propia a partir de datos de Google.

1D: PORCENTAJE DE OCUPACIÓN DE LA EDIFICACIÓN Y ÁREA OCUPADA: De acuerdo a lo estipulado por el apartado correspondiente en el capítulo 3.6, se realizará el análisis de la ocupación de las diferentes zonas homogéneas a partir del análisis de un área tipo de 100×100 $\mathrm{m}^{2}$ sobre parcelarios oficiales de la ciudad de Leganés. En base a este análisis, pudieron establecerse los porcentajes, midiendo sobre plano el área ocupada por la edificación dentro del cuadrado de 100×100 metros, que será dividida entre el área de $40.000 \mathrm{~m}^{2}$ de éste área tipo de análisis. Los porcentajes de ocupación resultaron ser los siguientes para cada zona homogénea (Figura 5.6.3) 


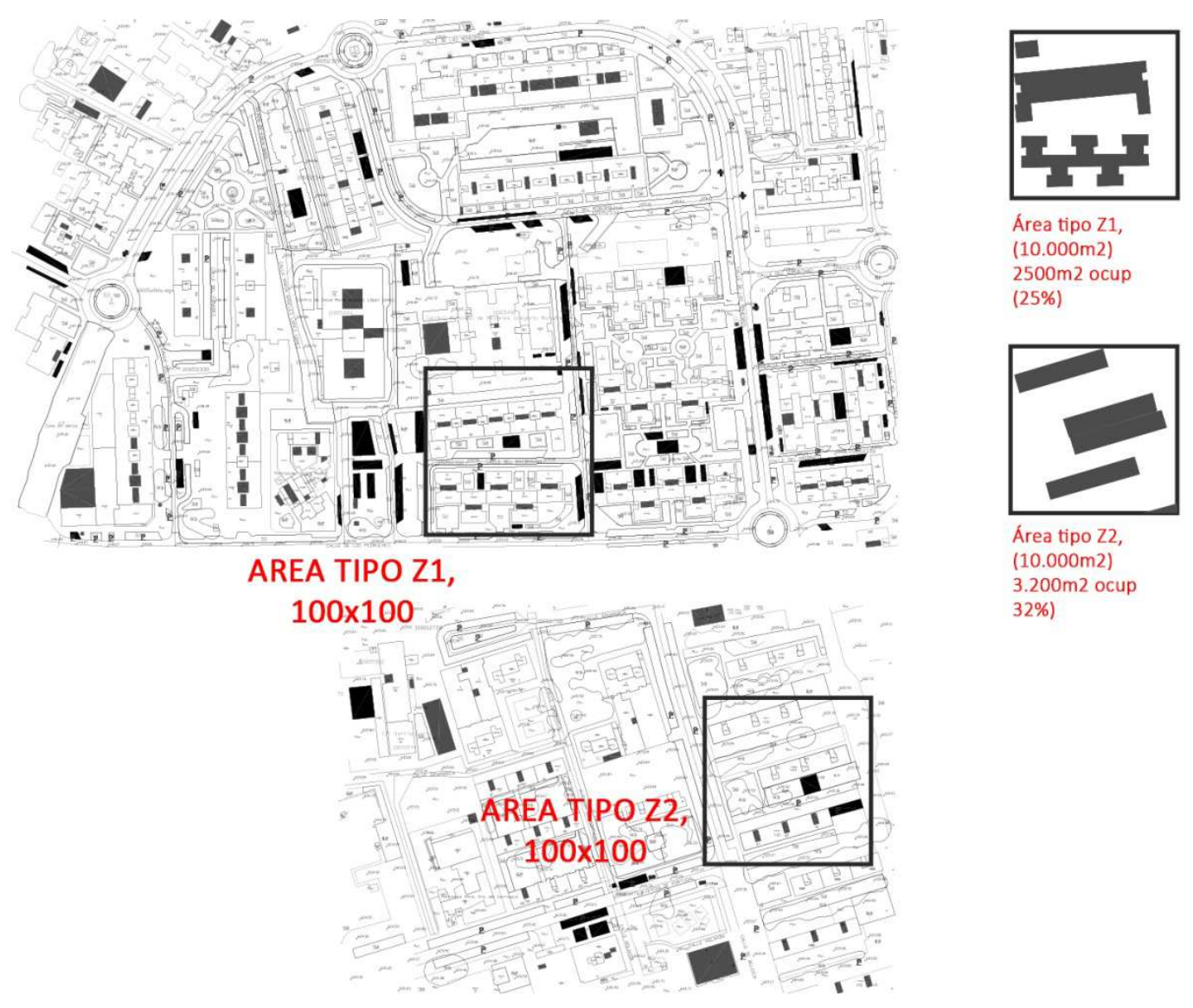

Figura 5.6.3: Análisis de ocupación sobre parcelario. Fuente: Elaboración Propia.

Estos porcentajes del análisis de tejidos serán aplicados a las superficies de área total, hallándose de esta forma la superficie ocupada en planta neta total de cada zona homogénea establecida.

Z1: $25 \%$ de superficie ocupada. Superficie ocupada $179.150 \mathrm{~m}^{2}$.

Z2: $32 \%$ de superficie ocupada. Superficie ocupada $341.920 \mathrm{~m}^{2}$.

1E: ALTURAS DE LA EDIFCACIÓN POR ÁREA HOMOGÉNEA: Para las diferentes áreas homogéneas de Parquesur establecidas con anterioridad, se consideraron las siguientes alturas medias de edificación, esto fue realizado de manera estimativa a partir de visitas al área y análisis de fotos de calles de Google Maps.

Z1: 8 alturas. Z2: 8 alturas.

1F: ESTABLECIMIENTO DE LAS TIPOLOGÍAS DE TEJIDO EN BASE A LA MORFOLOGÍA URBANA POR ÁREA HOMOGÉNEA: A partir de las ocupaciones y los números de plantas anteriormente considerados para cada zona homogénea, y considerando el baremo de la tabla correspondiente a densidades del presente apartado en el capítulo 3.6, cada área de Parquesur tiene estas densidades.

Z1: Zona de densidad media. Z2: Zona de densidad media. 
1G.- ÍNDICE GLOBAL DE DENSIDAD. En base a las densidades establecidas anteriormente de acuerdo al apartado anterior, se pudo establecer el índice de densidad para cada zona. Es importante considerar la superficie que ocupa cada zona homogénea (Z1: $716.600 \mathrm{~m}^{2}$; Z2: $1.068 .500 \mathrm{~m}^{2}$ brutos) las cuales fueron divididas respecto al área total de la zona $\left(2.539 .764 \mathrm{~m}^{2}\right)$, para de esta manera hallar los porcentajes que ocupa cada zona. Multiplicando cada índice de densidad correspondiente a cada zona homogénea, por el porcentaje que ocupa cada una, y luego sumando los resultados, se pudo hallar el índice global de densidad.

Z1: Índice de 2, representa el $40,14 \%$ de la superficie total, suma al índice global 0,8 puntos.

Z2: Índice de 2, representa el $59,86 \%$ de la superficie total, suma al índice global 1,2 puntos.

De este modo el índice global de densidad es de 2 puntos, lo que corresponde una zona de densidad media.

1H: SUPERFICIE EDIFICADA TOTAL DE CADA ÁREA HOMOGÉNEA. Para hallar la superficie edificada total de cada zona homogénea, se multiplicó la superficie ocupada de la edificación en planta, anteriormente hallada en el apartado 1D, por el número medio de plantas asignado a cada zona por separado en el apartado 1E. De este modo, la superficie total edificada aproximada por área es de:

Z1: $179.150 \mathrm{~m}^{2} * 8=1.433 .200 \mathrm{~m}^{2}$.

Z2: $341.920 \mathrm{~m}^{2} * 8=2.735 .360 \mathrm{~m}^{2}$.

Siendo la superficie edificada total en el área urbana de análisis de 4.168.560m2

11: ESTABLECIMIENTO DE TIPOLOGÍAS DE TEJIDO DENTRO DEL ÁREA URBANA EN REFERENCIA A LOS USOS: El área de Parquesur corresponde a un entorno relativamente complejo, complejo en el que aunque predominan los edificios residenciales, hay edificios comerciales y dotacionales en puntos localizados. Al no haber datos objetivos sobre los usos predominantes en la zona, se consideraron los siguientes porcentajes de manera estimativa, en base a visitas al área y estimaciones de superficies a partir de los tipos de edificios presentes en cada zona homogénea.

Z1: $65 \%$ residencial, $20 \%$ productivo, $15 \%$ comercial.

Z2: $70 \%$ residencial, $15 \%$ productivo, $15 \%$ comercial.

1J: CONTEO DE LOS USOS DENTRO DEL CONTEXTO URBANO. Una vez se establecieron los porcentajes en el apartado anterior, para obtener los metros cuadrados netos de uso, se multiplicarán éstos porcentajes hallados anteriormente por las superficies edificadas totales hallada en el apartado $1 \mathrm{H}$ de cada zona homogénea por separado, quedando establecidos los usos del área urbana relativa a Parquesur de la siguiente manera:

Z1: $931.580 \mathrm{~m}^{2}$ residencial, $286.640 \mathrm{~m}^{2}$ productivo, $214.980 \mathrm{~m}^{2}$ comercial.

Z2: $1.914 .752 \mathrm{~m}^{2}$ residencial, $410.304 \mathrm{~m}^{2}$ productivo, $410.304 \mathrm{~m}^{2}$ comercial.

1K: ÍNDICE GLOBAL DE MEZCLA DE USOS. Para el índice global de mezcla de usos, se consideró el baremo establecido en el apartado $1 \mathrm{~K}$ del capítulo 3.6, utilizando para ello los porcentajes de uso establecidos en 11 . Se sumará para cada zona homogénea el porcentaje de uso comercial más el productivo, calculándose el uso no residencial, éste será comparado en 
paralelo con el porcentaje de uso residencial, se establecerá el índice de mezcla de usos, en base a si un uso supera o no el $80 \%$ de la superficie construida total.

Z1: $65 \%$ uso residencial, $35 \%$ uso no residencial, índice mezcla usos de 1 Z2: 70\% uso residencial, 30\% uso no residencial, índice mezcla usos de 1

En el siguiente paso, se multiplicarán los índices de uso, por los porcentajes que ocupa cada zona homogénea respecto al área urbana total, obteniendo estos resultados:

Z1: Índice de 1, representa el $40,14 \%$ de la superficie total, suma al índice de mezcla de usos 0,4 puntos.

Z2: Índice de 1, representa el 59,86\% de la superficie total, suma al índice de mezcla de usos 0,6 puntos.

1L: CONTEO DEL NÚMERO DE DOTACIONES DENTRO DEL CONTEXTO URBANO, DENTRO DEL ÁREA DE DOTACIONES Se estableció un área de un 1 kilómetro a partir del lindero del centro, y dentro del mismo se marcaron las siguientes dotaciones, cuya localización se halló a partir de visitas al área, y mediante la utilización de localización de actividades de Google Maps, en el área de dotaciones de Parquesur se marcaron: 4 dotaciones de visita habitual, no habiendo ni de visita esporádica, ni grandes dotaciones. (Figura 5.6.4).

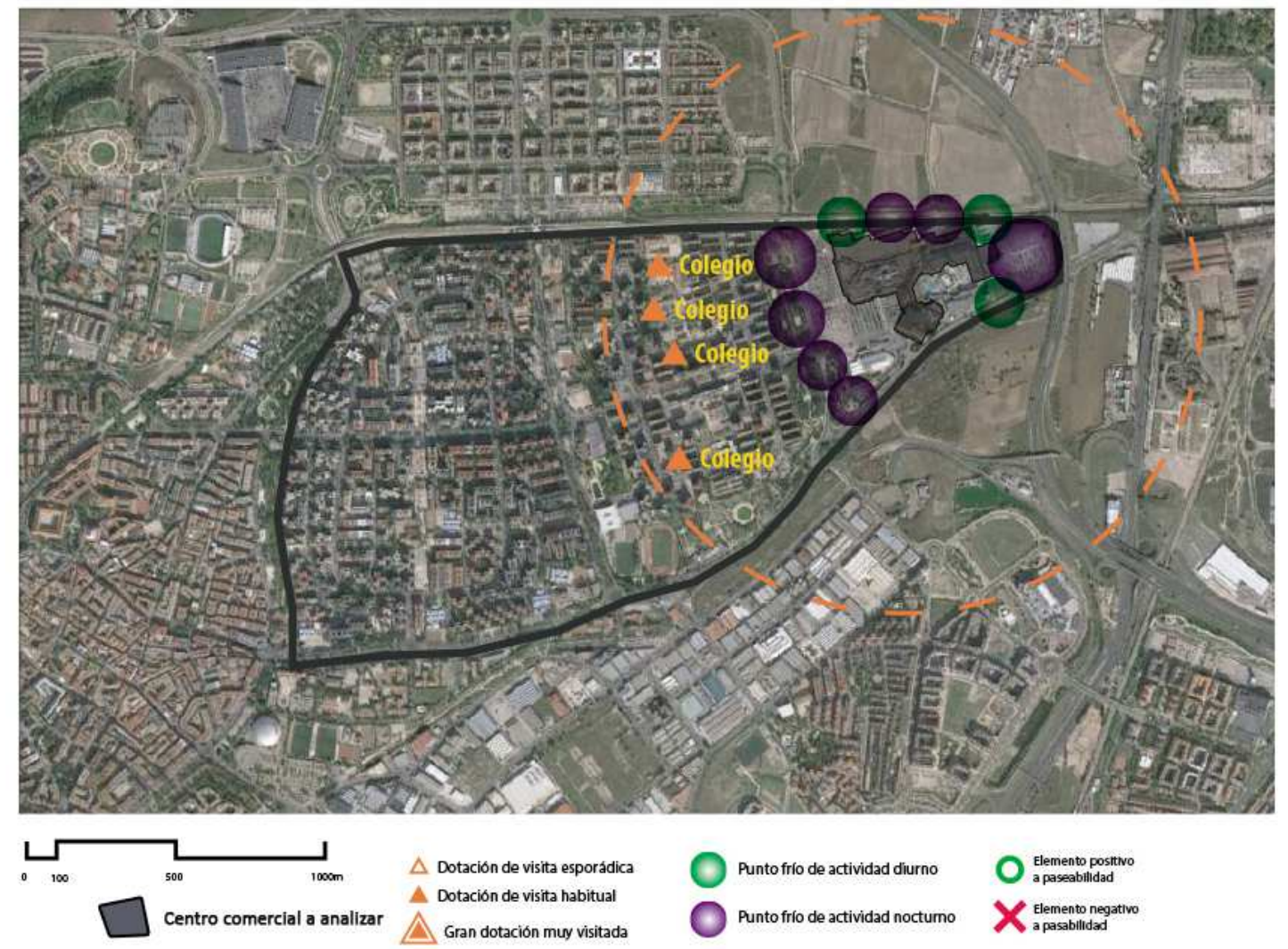

Figura 5.6.4: Área de Parquesur, Dotaciones, puntos fríos y elementos positivos y negativos. Fuente: Elaboración Propia a partir de datos de Google. 
1M: PRESENCIA E INFLUENCIA DE ELEMENTOS POSITIVOS Y NEGATIVOS: En el área de Parquesur no hay ni elementos positivos, ni negativos de cara a la actividad comercial o peatonal.

1N: ZONAS DE ACTIVIDAD: En el área de Parquesur, se van a dar puntos fríos tanto nocturnos como diurnos en los bordes de la parcela del centro, ya que este está entre infraestructuras que generan barrera. También cabe considerar la actividad en el parque próximo al centro, debido a que en base a su localización entre la ciudad y el centro comercial; es propenso a que la actividad en el mismo se produzca generalmente durante las horas de apertura del centro. Durante las horas en las que el centro permanece cerrado, (franja nocturna del día) en el parque puede producirse una carencia de actividad urbana, debido a que no hay nodo alguno que genere interacción alguna a través del mismo. Este problema se agrava, debido a las parcelas cerradas de los edificios circundantes, que suponen una barrera entre la ciudad y el parque. (Figura 5.6.4).

10: ÁREAS ARBOLADAS Y VERDES, DENTRO DEL ÁREA URBANA DEL CENTRO: Dentro del área de Parquesur, se consideraron las siguientes áreas verdes con sus respectivos metros cuadrados de superficie (Figura 5.6.4). considerando las áreas netas de superficie verde, y los metros cuadrados de vegetación que poseen. El área urbana asignada a Parquesur posee un área verde neta en planta de $428.052 \mathrm{~m}^{2}$, que se desglosa en las siguientes superficies de vegetación. No obstante, de cara a la analítica de la absorción de dióxido de carbono exclusivamente, van a añadirse aproximadamente unos 931.600 metros cuadrados de pradera, y unos $280.880 \mathrm{~m}^{2}$ de hierba de gran altura, que corresponden a las superficies verdes no edificadas de borde que rodean Parquesur.

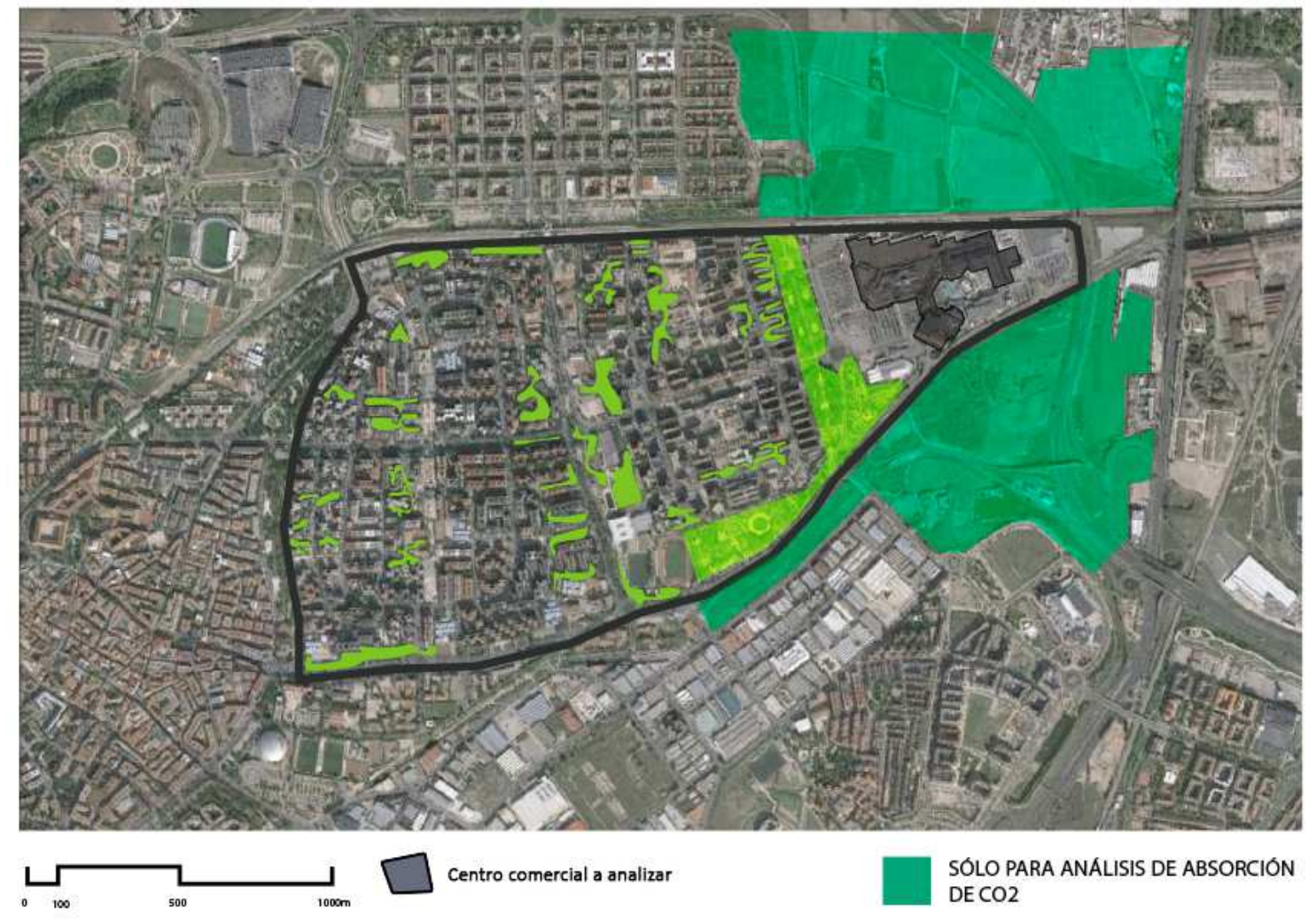




\begin{tabular}{|l|l|l|}
\hline 1O: Superficie de zonas verdes en área urbana & Valor & \\
\hline C4.1: pradera & 428052 & +931671 \\
\hline C4.2: hierba de gran altura o huerto & 10000 & +280.880 \\
\hline C4.3: vegetación arbustiva intensiva & 14014 & \\
\hline C4.4: vegetación arbórea caduca & 140146 & \\
\hline C4.5: vegetación arbórea perenne & 28029 & \\
\hline
\end{tabular}

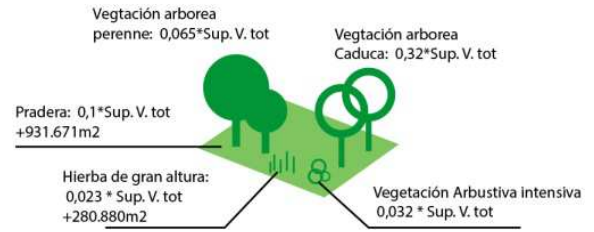

Figura 5.6.5: Área de Parquesur, Zonas verdes y capas de vegetación. Fuente: Elaboración Propia a aprtir de datos de Google.

1P.- DELIMITACIÓN DE RECORRIDOS A CENTRO, DENTRO DEL ÁREA URBANA: Para este análisis, fueros establecidos tres recorridos desde diferentes puntos del borde e interior del área urbana de análisis de Shopping Aricanduva, estos recorridos se describen en el apartado 2E (Figura 5.6.6). Los tiempos de llegada, tanto en vehículo particular, como en transporte público se analizarán a posteriori.

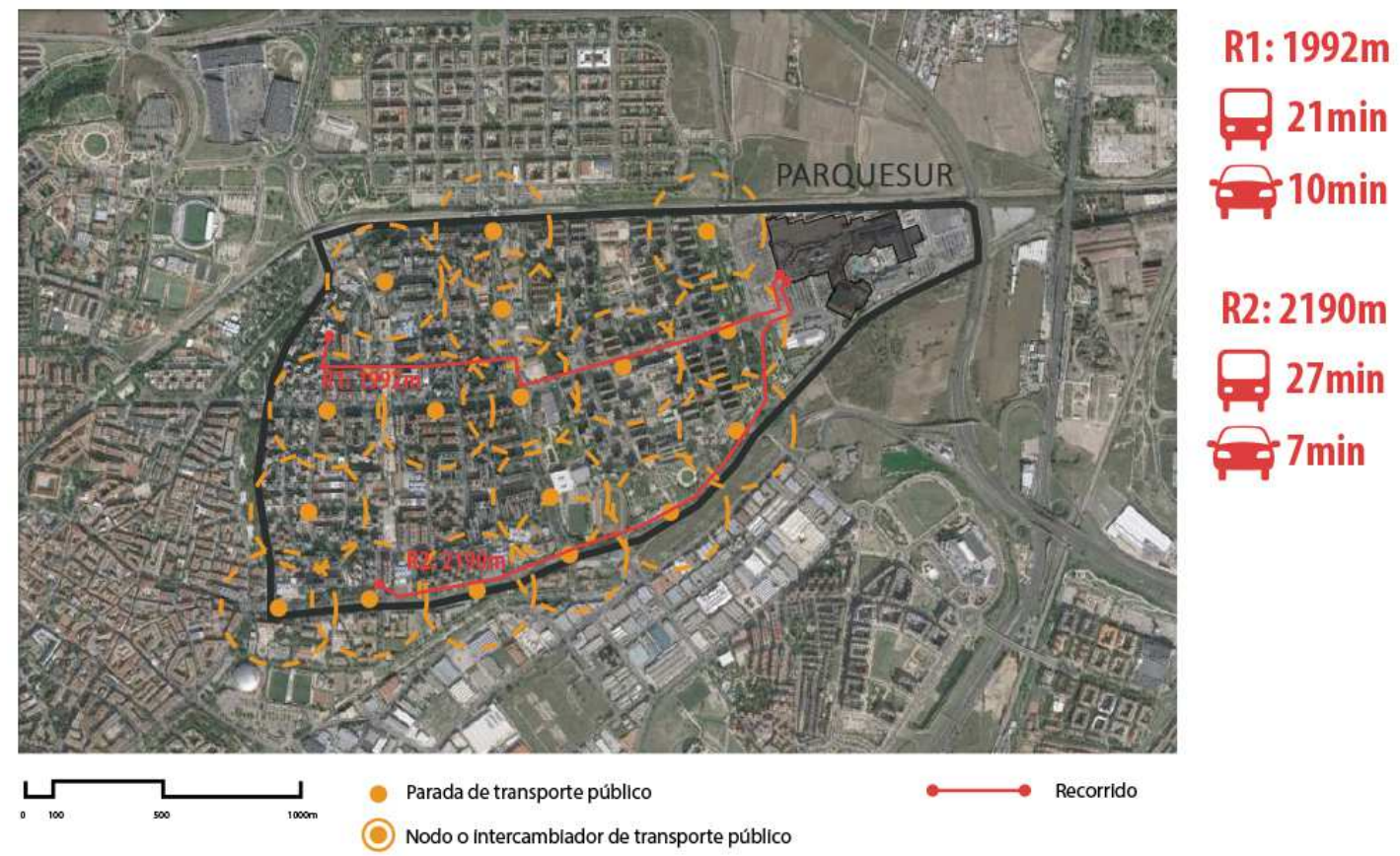

Figura 5.6.6: Recorridos, tiempos de llegada y zonas cubiertas por el transporte público. Fuente: Elaboración Propia a aprtir de datos de Google.

1Q.- HUELLA DE CARBONO DEL ÁREA URBANA: Siendo la huella de carbono de España de 5,083 toneladas anuales de dióxido de carbono per cápita (toneladas por habitante), de acuerdo al Banco Mundial para $2013^{60}$. Para hallar la huella de carbono del área urbana de Parquesur, se multiplicó este dato por la población total del área asignada, (75.600 personas), saliendo una huella de 384.274 Toneladas de dióxido de carbono anuales.

1R.- CAPACIDAD ABSORCIÓN DE LOS ELEMENTOS VERDES EN ÁREA URBANA: En base a los datos de superficies verdes obtenidos en el apartado 10, se calculó la absorción total de las áreas verdes en base a la capacidad de absorción por metro cuadrado de las superficies vegetales. Para este análisis, se consideraron las superficies vegetales de pradera que se

${ }^{60} \mathrm{http}: / /$ datos.bancomundial.org/indicador/EN.ATM.CO2E.PC?locations=ES 
ubican al otro lado de las barreras urbanas, debido a que éstas, aunque no son accesibles de manera directa, van a tener presencia en la zona asimilando dióxido de carbono, añadiendo al conteo anteriormente realizado de capas de superficie verde(10), unos $931.671 \mathrm{~m}^{2}$ de pradera, y unos $280.880 \mathrm{~m}^{2}$ de hierba de gran altura. (figura 5.6.7.) De este modo la capacidad absorbente total en el área es de 86.927 Toneladas de dióxido de carbono anuales incluyendo estas áreas.

\begin{tabular}{|c|c|c|c|c|c|c|}
\hline 1Q: C.absorción elementos verdes en área & Pradera & V.arb ext & V. A. Int. & H. Caduca & H. Perenne & Otro \\
\hline Superficie total & 1359723,0000 & 290880,0000 & 14014,0000 & 140146 & 28029,0000 & 0,0000 \\
\hline Tasa absorción TCo2/m2 año & 0,0013 & 0,0020 & 0,0350 & 0,1500 & 2,2500 & 0,8000 \\
\hline Absorción dióxido carbono TCo2 & 1767,6399 & 581,7600 & 490,4900 & 21021,9000 & 63065,2500 & 0,0000 \\
\hline
\end{tabular}

Figura 5.6.7: Absorción de las zonas verdes del área urbana de Parquesur. Fuente: Elaboración Propia

1S: DELIMITACIÓN DE ÁREAS EN FUNCIÓN DE LA RECUPERACIÓN DE AGUAS EN ÁREA URBANA. Para este análisis, se consideraron como zonas permeables al agua, las zonas verdes presentes en el área urbana (no considerando las áreas verdes periféricas del análisis de absorción de CO2). De este modo, la superficie permeable del área de Parquesur es de $428.052 \mathrm{~m} 2$.

\section{FASE 2: ANÁLISIS DE RELACIONES ENTRE CENTRO COMERCIAL Y ENTORNO URBANO.}

Este análisis en muy similar en búsqueda de datos y función con respecto al anteriormente analizado sobre el área urbana general. La particularidad de este análisis está en que su ámbito está limitado a las parcelas que directamente lindan con la unidad catastral de Parquesur. EI objetivo es cuantificar las relaciones urbanas entre el centro y el entorno próximo, ya sea mediante usos, relaciones entre dotaciones, y accesibilidad o transporte, en este análisis va a primar el estudio sobre plano, aunque también se harán análisis cuantitativos de superficies, y cualitativos.

2A: DELIMITACIÓN DE ÁREA PRÓXIMA: De cara al análisis del área próxima se escogieron las manzanas próximas al centro, siendo incluido en el conteo el parque cercano (Figura 5.6.8). 


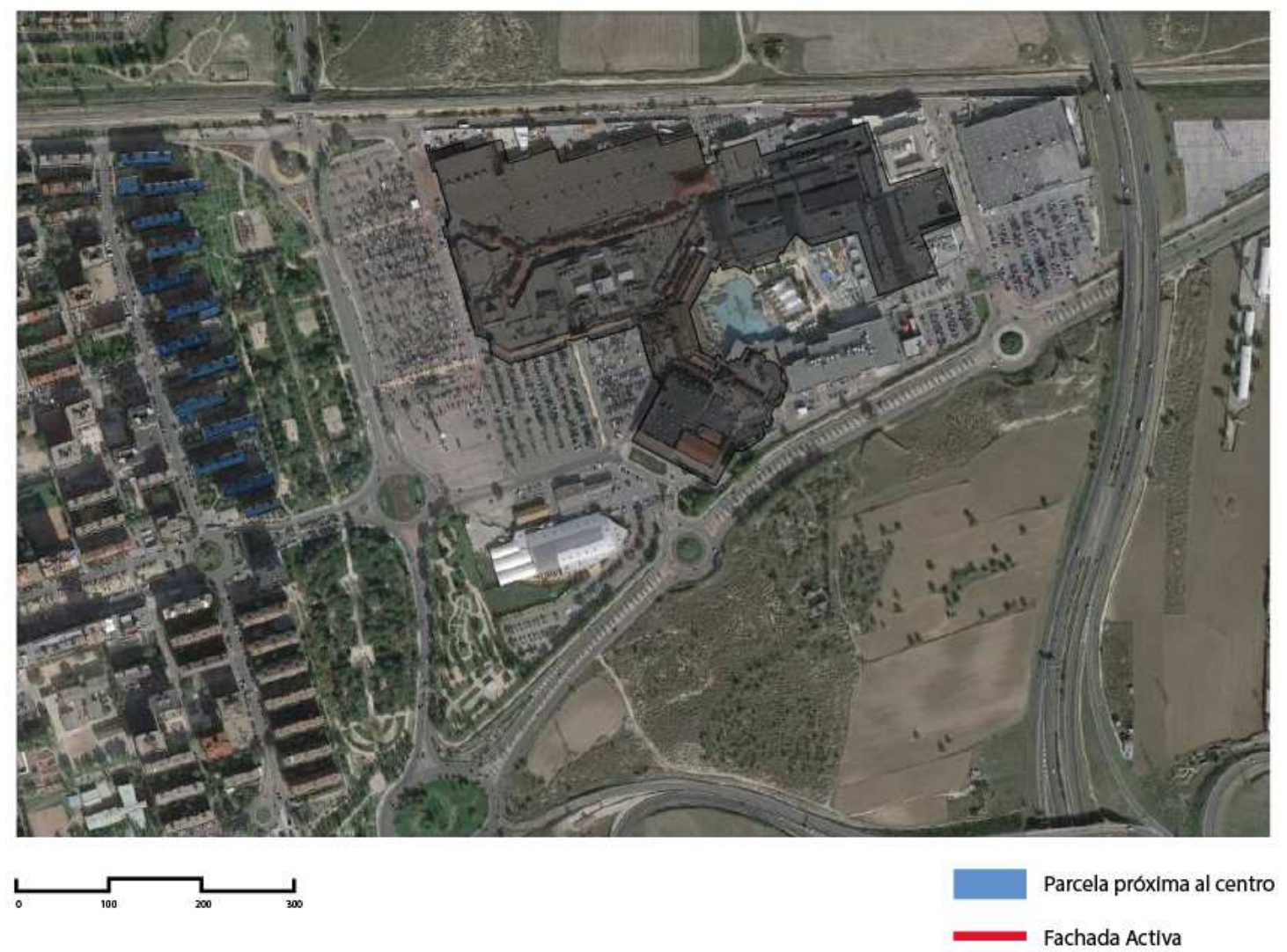

Figura 5.6.8: Análisis de parcelas próximas al centro. Fuente: Elaboración Propia a partir de datos de Google.

2B: SUPERFICIE TOTAL EDIFICADA EN ÁREA PRÓXIMA: Para el conteo de la superficie total estimada de las manzanas próximas al centro, se midió sobre un parcelario la superficie en planta de las mismas, que es de $12213 \mathrm{~m}^{2}$ de superficie, la cual fue multiplicada por el número de plantas medio de los edificios de susodichas manzanas, que para el caso de Parquesur, se estableció en 8 plantas en base a visitas a la zona y análisis de parcelarios. De este modo, la superficie construida total de las manzanas próximas al centro es de $97704 \mathrm{~m}^{2}$.

2C: USOS EN ÁREA PRÓXIMA: Las manzanas próximas al centro comercial, poseen una configuración de usos en la que predominan los edificios residenciales, los cuales copan prácticamente toda la superficie de uso. De este modo, para este análisis se establecieron los siguientes porcentajes:

Uso residencial: $94 \%$. Uso productivo: $1 \%$. Uso comercial: $5 \%$.

Quedando estas superficies de uso totales a partir de la multiplicación de los porcentajes establecidos anteriormente, por el área total construida de manzana $\left(97704 \mathrm{~m}^{2}\right)$ :

Uso residencial: $91.842 \mathrm{~m}^{2}$. Uso productivo: $977 \mathrm{~m}^{2}$. Uso comercial: $4885 \mathrm{~m}^{2}$.

2D: FACHADAS ACTIVAS EN ÁREA PRÓXIMA Para este análisis, las fachadas activas (fachadas que cuentan con locales que ejercen interacción sobre los usuarios del espacio urbano), en manzanas próximas (Figura 5.6.8) se marcaron en el plano, y se midieron en metros lineales, junto con la longitud de fachada total. En total La longitud de fachada activa es de 105 metros, 
siendo la longitud de fachada total de 2814 metros, (incluyendo las fachadas activas). El porcentaje es del $3,73 \%$.

2E: TIEMPOS DE LLEGADA DESDE LOS PUNTOS EN ÁREA A CENTRO COMERCIAL MEDIANTE TRANSPORTE PÚBLICO: Para la estimación de los tiempos de llegada en transporte público, fueron considerados los recorridos establecidos en 1P, y se utilizó la base de datos de Google Maps para establecer los tiempos de llegada. (Figura 5.6.6)

2F: TIEMPOS DE LLEGADA DESDE LOS PUNTOS EN ÁREA A CENTRO COMERCIAL MEDIANTE TRANSPORTE PRIVADO: Para la estimación de los tiempos de llegada en transporte público, fueron considerados los recorridos establecidos en $1 \mathrm{P}$, y se utilizó la base de datos de Google Maps para establecer los tiempos de llegada. El centro comercial Parquesur, aunque posee aparcamiento, se le añadieron al trayecto unos dos minutos adicionales de maniobra y llegada. De este modo, los tiempos establecidos de llegada de los dos recorridos mediante transporte particular están recogidos en la Figura 5.6.6.

En el área de Parquesur, aunque hay instalaciones de transporte público cercanas, (una de ellas una estación de Metrosur, y del tren de cercanías), prima el transporte particular en la accesibilidad al centro comercial. En esta zona, la disponibilidad de opciones de transporte público para acceder al centro es adecuada, siendo los tiempos de espera moderadamente altos (8 minutos). A efectos de transporte privado, aunque pueden darse situaciones de congestión en las vías, estas suelen estar centradas en las horas puntas, y los accesos y salidas de las autopistas cercanas. Dentro de los barrios cercanos a Parquesur no suelen haber problemas de circulación.

\section{FASE 3: ANÁLISIS DEL EDIFICIO DEL CENTRO COMERCIAL.}

Una vez analizado el entorno urbano en sus diferentes escalas, cuantificándose de cara al cuestionario de rehabilitación todas las facetas del mismo, a la par que las relaciones urbanas; el último campo de análisis es el estudio concreto de lo que es el edificio del centro comercial Parquesur. De este modo a partir de los datos de los que se pudieron disponer del centro comercial, van a cuantificarse los rasgos del edificio de Parquesur en relación a las facetas de usos, sostenibilidad y comportamiento bioclimático, de cara al cuestionario de la Rosa de sostenibilidad. Serán de importancia el conteo de superficies en base a la faceta a analizar, las simulaciones y la comparativa de las características formales para dar los datos necesarios para el cuestionario de rehabilitación.

3A: DELIMITACIÓN DE ÁREAS EN FUNCIÓN DE LA RECUPERACIÓN DE AGUAS: Sobre la planta de cubiertas del centro comercial, se delimitaron las áreas tanto permeables como impermeables del centro, de acuerdo a los estipulado en la metodología, para el caso de Parquesur, se consideraron como superficies permeables, las áreas verdes sin tratar de la periferia de la parcela, que suman $16827 \mathrm{~m}^{2}$, siendo esta superficie un $5 \%$ de la superficie total de cubierta y parcela $\left(296.205 \mathrm{~m}^{2}\right)$ 
3B: USOS DENTRO DEL EDIFICIO DEL CENTRO: Para los usos dentro de Parquesur, se consideraron los diferentes locales dentro del centro comercial, buscándose los metros cuadrados de espacio productivo no comercial, y las dotaciones asistenciales dentro del mismo. En Parquesur, no hay espacios de usos productivos o dotacionales, salvo las oficinas de gestión del centro, las cuales para esta tesis no computan como espacio productivo, ya que generalmente no son accesibles por personas ajenas al centro comercial. En uso residencial, Parquesur posee un hotel de aproximadamente 6000 metros, que corresponde a un $4 \%$ aproximadamente de la superficie total del centro.

3C: DELIMITACIÓN DE ÁREAS VERDES EN CENTRO COMERCIAL. El espacio verde de Parquesur son las zonas sin edificar de los bordes, las cuales suman $4827 \mathrm{~m}^{2}$, y un pequeño parque de aproximadamente $12.000 \mathrm{~m}^{2}$. El total de área verde es de $16.827 \mathrm{~m}^{2}$ estas superficies se desglosan en las siguientes capas de vegetación. (Figura 5.6.9).
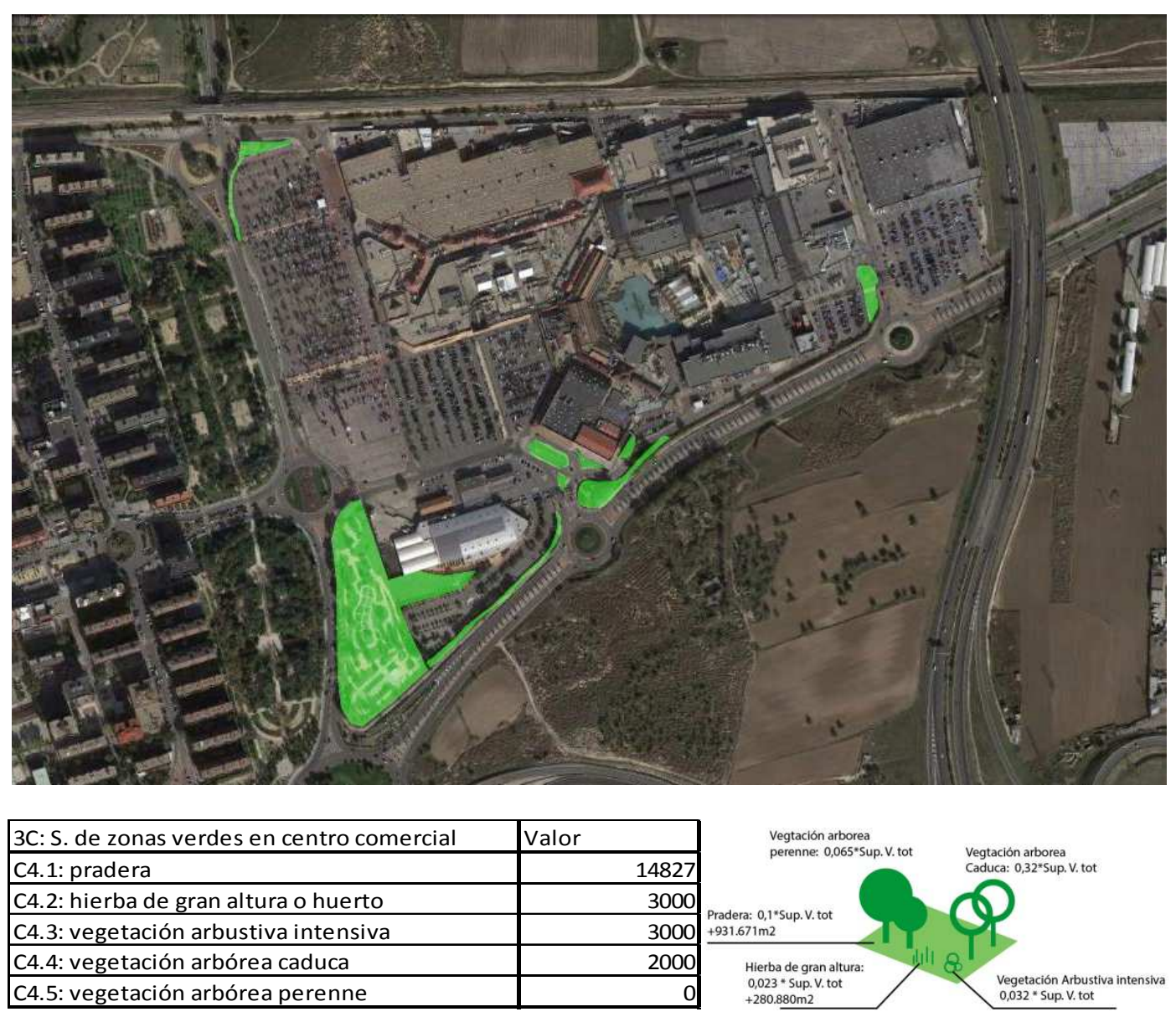

Figura 5.6.9: Áreas verdes y capas de vegetación en Parquesur Fuente: Elaboración Propia a partir de datos de Google.

3D: ABSORCIÓN DE LAS ÁREAS VERDES EN CENTRO COMERCIAL. Las jardineras del centro comercial y el parque anexo son capaces de asimilar hasta 430 toneladas anuales de dióxido de carbono, aproximadamente un $28 \%$ de la huella de carbono anual del centro estimada en $3 \mathrm{~F}$, (1512 T. Co2 anuales) y un 0,1\% de la huella del área urbana (384.274 T Co2 anuales). (Figura 5.6.10) 


\begin{tabular}{|l|r|r|r|r|r|r|}
\hline 3D: C.absorción elementos verdes en área & \multicolumn{1}{|l|}{ Pradera } & V.arb ext & V. A. Int. & H. Caduca & H. Perenne & Otro \\
\hline Superficie total & 14827,0000 & 3000,0000 & 3000,0000 & 2000,0000 & & \\
\hline Tasa absorción TCo2/m2 año & 0,0013 & 0,0020 & 0,0350 & 0,1500 & 2,2500 & 0,0000 \\
\hline Absorción dióxido carbono TCo2 & 19,2751 & 6,0000 & 105,0000 & 300,0000 & 0,0000 & 0,0000 \\
\hline
\end{tabular}

Figura 5.6.10: Absorción de las áreas verdes en Parquesur. Fuente: Elaboración Propia

3E: ANÁLISIS BIOCLIMÁTICO DEL CENTRO COMERCIAL RESPECTO A CLIMA, DIAGRAMA DE GIVONI. Los requisitos bioclimáticos de acuerdo a Givoni para el caso de Parquesur, son los referenciados al clima de Madrid, y estos fueron desarrollados y explicados en el apartado $3 \mathrm{E}$ del capítulo de caso de estudio de ABC Serrano (Capítulo 5.4, Figura 5.4.9).

Parquesur es un edificio que posee una envolvente de cierta masa térmica, que no posee protección alguna en las fachadas, en la cubierta hay algunas superficies acristaladas, Respecto a instalaciones, posee sistemas solares activos en la cubierta, y los espacios, aunque son de gran tamaño pueden valerse de las cargas térmicas para calefactarse. El centro comercial posee sistemas de calefacción y refrigeración convencionales, siendo el espacio interior generalmente cerrado y estanco.

3F: CALIFICACIÓN ENERGÉTICA DEL CENTRO COMERCIAL. Al no haber datos objetivos acerca del consumo primario de energía o las emisiones generadas por el centro Parquesur, se tuvo que realizar una estimación con el programa CE3X, además de realizarse una ponderación comparativa de las emisiones y el consumo, con otros centros comerciales de los que se disponen datos de calificación energética.

Al igual que La Vaguada y el centro comercial los Arcos, César Rey, considera Parquesur como un caso de éxito de gestión medioambiental, estipula que susodicho centro comercial en 2009 consumió $2.351 .759 \mathrm{kWh}^{61}$ en climatización, lo que dividido entre la superficie del centro, supone un consumo de $15,55 \mathrm{kWh} / \mathrm{m}^{2}$, lo que supone una calificación de $\mathrm{A}$, esta calificación fue también extrapolada, de manera supuesta a las emisiones para el estudio en la presente tesis de manera desfavorable, pudiendo ser esto no cierto, debido a que el autor carece de este dato. se eligió como ratio de emisiones unitarias, el mismo que el de La Vaguada (10 $\mathrm{Kg} / \mathrm{m}^{2}$ anuales), debido a las similitudes entre los dos centros de acuerdo al estudio de Cesar Rey. De este modo las calificaciones energéticas para la Vaguada se establecieron en estos valores. (Figura 5.5.11)

\begin{tabular}{|c|c|c|c|}
\hline \multicolumn{2}{|c|}{$\begin{array}{l}\text { CONSUMO DE ENERGÍA } \\
\text { PRIMARIA NO RENOVABLE } \\
{\left[\mathrm{kWh} / \mathrm{m}^{2} \text { año] }\right.}\end{array}$} & \multicolumn{2}{|c|}{$\begin{array}{c}\text { EMISIONES DE DIÓXIDO DE } \\
\text { CARBONO } \\
{\left[\mathrm{kgCO} 2 / \mathrm{m}^{2} \text { año] }\right.}\end{array}$} \\
\hline 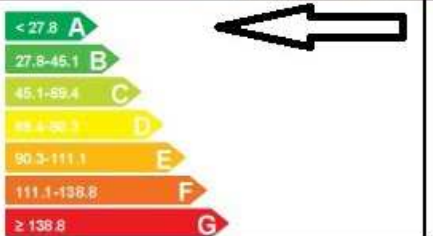 & 15,55 & $\begin{array}{lll}262 \mathrm{~A} \\
62.10 . \mathrm{B}\end{array}$ & 10 \\
\hline
\end{tabular}

Figura 5.6.11: Escala de calificaciones CE3X, con las supuestas calificaciones de Parquesur. Fuente: Elaboración propia a partir de datos de IDAE.

\footnotetext{
${ }^{61}$ César Rey, Ponencia realizada en Sevilla en 2010, Centro comercial los Arcos, Efirenova.
} 
Consumo de energía: $15,55 \mathrm{Kwh} / \mathrm{m}^{2}$ año. (A)

Emisiones anuales: $10 \mathrm{Kg} / \mathrm{m}^{2}$ anuales, $0,010 \mathrm{~T} / \mathrm{m}^{2}$ año. (B)

las emisiones totales del centro son de 1512 toneladas de CO2 anuales.

3G: USO DE FUENTES DE ENERGÍA LIMPIAS. El centro Parquesur, posee sistemas de generación de energías limpias en forma de paneles fotovoltaicos. cubriendo estos una superficie de $3557 \mathrm{~m}^{2}{ }^{62}$. Se estimó que estos paneles generan anualmente unos $133.000 \mathrm{kWh}$. Y en relación con los $2.351 .759 \mathrm{kw} / \mathrm{h}$ que el centro utiliza en un año ${ }^{1}$. El uso de energías renovables es capaz de cubrir la demanda de energía en un 5,6\% del consumo energético anual del centro.

3H: ESPACIOS CON LUZ NATURAL Para medir esta superficie se consideraron de manera aproximada las superficies de los espacios iluminados del centro comercial Parquesur, que generalmente corresponden a las galerías que cuentan con lucernarios, y los locales de la fachada oeste. En Parquesur el espacio que cuenta con luz natural es aproximadamente el $26,13 \%$ de su superficie.

31: FORMA DE LA EDIFICACIÓN: El centro comercial Parquesur, es un volumen fragmentado. Aproximadamente la relación en la envolvente entre el lado mayor (919 metros aproximadamente) y el menor (430 metros) es de 2,13 siendo la orientación de la fachada principal unos $17^{\circ}$ este, respecto de la orientación sur. El centro a su vez cuenta con una fachada masiva, protegida en las orientaciones sur y suroeste sur por cubiertas que hacen la función de voladizo. (Figura 5.6.12)

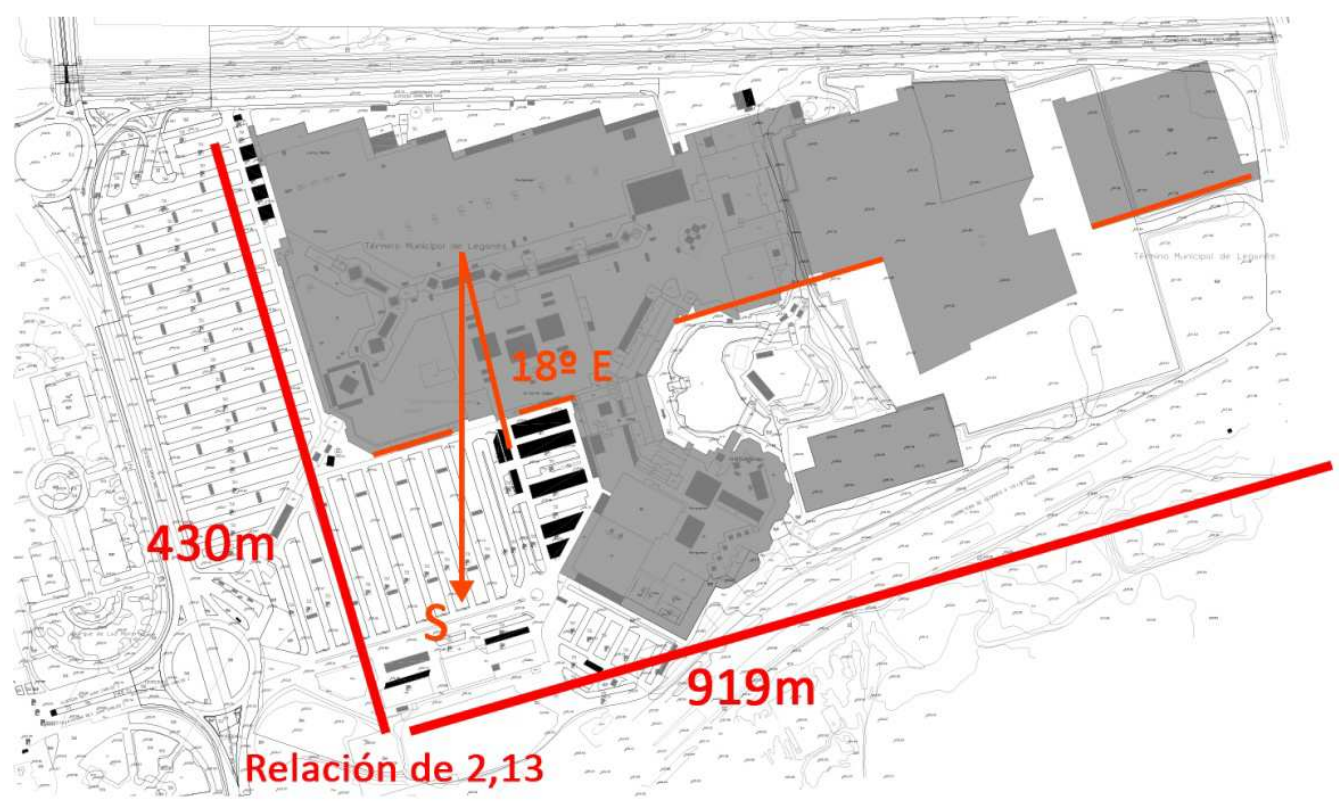

Figura 5.6.12: Análisis de forma de la edificación, Parquesur. Fuente: Elaboración propia

3J: PAVIMENTOS Y CUBIERTAS EN RELACIÓN A LA INCIDENCIA DE LA IRRADIACIÓN SOLAR. Sobre la planta de la parcela, se midieron las superficies de colores claros contándose las

\footnotetext{
${ }^{62}$ Referencia en: http://energium.es/el-centro-comercial-parquesur-inaugura-su-instalacionfotovoltaica-con-mas-de-3500-m2/
} 
superficies verdes. Parquesur tiene aproximadamente un $7,43 \%$ de su superficie de cubierta repelente de cara a la irradiación solar. Siendo el 92,57\% restante de la superficie de unidad catastral absorbente de cara a la irradiación solar.

FASE 4: CUESTIONARIOS DE LA METODOLOGÍA, APLICACIÓN DE INDICADORES Y BAREMOS.

\section{A.- REHABILITACIÓN ECOEFICIENTE.}

A1.- Cuestionario referenciado a rehabilitación hacia instalaciones poco emisivas.

Cuestión A1.1.- ¿El centro cuenta con instalaciones que no son necesarias de acuerdo a lo estipulado en el diagrama de Givoni?: Aunque no hay datos objetivos acerca de las instalaciones de Parquesur, de visitas al centro se dedujo que se trata de un espacio completamente cerrado y aclimatado, que posee instalaciones mecánicas de refrigeración y calefacción, las cuales mirando el diagrama de Givoni, se ve que aunque las de calefacción son necesarias, las de refrigeración no lo son, no obstante, este centro decanta su política energética hacia la eficiencia, buscando el menor consumo posible. A este centro le corresponde una nota de +1 en esta cuestión.

Cuestión A1.2.- ¿Las instalaciones del centro generan unas emisiones de dióxido de carbono superiores a la media?. Aunque el autor desconoce la calificación energética del centro, En el estudio energético estimativo, Parquesur ha obtenido en la calificación energética emisiones de las instalaciones una calificación de $B$, eso corresponde a una nota de +3

Cuestión A1.3.- ¿Las instalaciones del centro se encuentran en un estado de obsolescencia?. Respecto esta cuestión, el autor desconoce el estado de las instalaciones del centro. No obstante, Parquesur es considerada como un caso de éxito en gestión energética, con lo que se puntuó esta cuestión con una nota de +1 .

Cuestión A1.4.- ¿Las instalaciones del centro tienen un consumo energético superior a la media?. En el estudio energético, Parquesur ha obtenido en la calificación energética de consumo de energía primaria una nota de $\mathrm{C}$, eso corresponde a una nota de +3

EN RELACIÓN A INSTALACIONES POCO EMISIVAS, PARQUESUR HA OBTENIDO UNA PUNTUACIÓN DE 8 (10).

A2.- Cuestionario referenciado a inserción de medidas activas.

Cuestión A2.1.- ¿Qué porcentaje de las calorías necesarias para lograr la temperatura de confort se logra mediante sistemas activos?: Aunque el autor de la tesis desconoce la configuración de las instalaciones de Parquesur, para este caso, se supuso que el centro comercial, aunque no posee sistemas solares activos de cara a la temperatura de confort, al ser un caso de correcta gestión energética, puede poseer otro tipo de sistemas que pueden suplir una parte de la energía necesaria para la temperatura de confort. Esta cuestión puntúa con +1 .

Cuestión A2.2.- ¿Qué porcentaje de la demanda energética se logra a partir de fuentes de energía renovable?: De acuerdo al apartado 3G, la instalación de paneles fotovoltaicos de 
Parquesur suple un 5,6\% del consumo energético establecido, esta cuestión fue puntuada con un +1 .

Cuestión A2.3.- ¿El centro cuenta con las medidas y dispositivos necesarios para su aclimatación de acuerdo a lo estipulado en el diagrama de Givoni para sistemas solares activos?: Aunque el autor de la tesis desconoce la configuración de las instalaciones de Parquesur, al ser una caso de gestión correcta de la energía, se supuso la existencia de ciertas medidas activas de acuerdo al diagrama de Givoni, esta cuestión puntúa con +1.

EN RELACIÓN A MEDIDAS ACTIVAS, PARQUESUR HA OBTENIDO UNA PUNTUACIÓN DE 3 (10).

A3.- Cuestionario referenciado a inserción de medidas Pasivas.

A3.1.- ¿El centro comercial tiene una forma adecuada en volumen a las condiciones climáticas?: Parquesur se encuentra en una zona templada húmeda de acuerdo a la calificación de Olgyay, de acuerdo al análisis anteriormente realizado en el punto 3I, Parquesur cumple los requisitos de orientación de fachada, y de manera somera los requisitos de proporción de planta. El centro, y sus huecos están expuesto a la irradiación solar durante el invierno, existiendo voladizos en la orientación sur y oeste. No obstante, el edificio es un volumen muy fragmentado y distendido, con gran superficie de fachada y cubierta, además de estar expuesto a los vientos de norte. De este modo, Parquesur cumple de manera parcial los requisitos de forma de Olgyay, le corresponde una puntuación de +1 .

A3.2.- ¿El estado de los cerramientos responde de manera correcta a las exigencias del clima en el que se asienta?: La calificación energética de Parquesur a efectos de consumo global de energía es de $B$, esto significa que los cerramientos responden de manera correcta respecto al clima. A este centro le corresponde una puntuación de +3 .

A3.3.- ¿Qué porcentaje de los espacios del centro cuentan con iluminación natural?: Parquesur posee un $26,13 \%$ del espacio interior iluminado con luz natural. Le corresponde de este modo una puntuación de +1 .

A3.4.- Los espacios del centro, están adaptados a lo estipulado por el Diagrama de Givoni de su respectivo clima?: Parquesur, tiene escasas aperturas para garantizar una ventilación natural en caso de calor y las fachadas, aunque son relativamente masivas, no son lo suficiente para garantizar el uso de la masa térmica. Para calefactar, el centro puede utilizar las ganancias internas, ya que muchos de los espacios interiores del mismo son de un tamaño fácilmente controlable. De este modo se cumplen de manera parcial lo requerido por Givoni para el edificio de centro. A Parquesur le corresponde una calificación de +1 .

EN RELACIÓN A MEDIDAS PASIVAS, PARQUESUR HA OBTENIDO UNA PUNTUACIÓN DE 6(10).

4B.- REHABILITACIÓN MEDIOAMBIENTAL.

B1.- Cuestionario referenciado a rehabilitación mediante zonas verdes.

Cuestión B1.1.- ¿En el área urbana hay suficiente zona verde en el área en relación a sus habitantes?: El área urbana de Parquesur posee aproximadamente $428.052 \mathrm{~m}^{2}$ de superficie 
verde en planta, que entre 75600 habitantes, el ratio es de 5,66 de superficie verde por habitante, inferior al mínimo de $10 \mathrm{~m}^{2}$ establecido en el baremo mínimo. Le corresponde una puntuación de +0 .

Cuestión B1.2.- ¿Las zonas verdes dentro del centro comercial pueden dar lugar a una área verde de uso cotidiano?: Descontando para este baremo, los espacios verdes de bordes y rotondas, ya que no pueden ser utilizados para el disfrute de las personas del centro Parquesur, posee un parque de aproximadamente $12.000 \mathrm{~m}^{2}$ de superficie verde en su parcela, superando el baremo mínimo de Salvador Rueda de $1000 \mathrm{~m}^{2}$ para espacios verdes cotidianos, le corresponde una puntuación de +1 a esta cuestión.

Cuestión B1.3.- ¿La vegetación en el área (incluyendo el edificio del centro), en que porcentaje es capaz de asimilar las emisiones de la misma área urbana?: Sumando las capacidades de asimilación de las superficies de vegetación establecidas, tenemos una capacidad de asimilación de 86.927 Toneladas de dióxido de carbono anuales, esto es aproximadamente un $22 \%$ de la huella de carbono del área, (384.274 Toneladas de dióxido de carbono anuales). Esta cuestión puntuará con +1 .

Cuestión B1.4.- ¿La vegetación en el centro comercial y su parcela, en que porcentaje es capaz de asimilar las emisiones del centro comercial?: Las zonas verdes de Parquesur, asimilan 430 toneladas de dióxido de carbono anuales, que es aproximadamente un $28 \%$ de la huella de carbono anual del centro (1512 toneladas de $\mathrm{CO} 2$ anuales). A esta cuestión le corresponde una puntuación de +1

Cuestión B1.5.- ¿La distancia media entre espacios verdes dentro del área es inferior a los 400 metros?: Aunque hay espacios verdes en al área de Parquesur, la distancia entre los mismos está a una media de 380 metros unos de otros, a esta cuestión le corresponde una puntuación de +1 .

\section{EN RELACIÓN A ZONAS VERDES, PARQUESUR HA OBTENIDO UNA PUNTUACIÓN DE 4(10).}

B2.- Cuestionario referenciado a inserción de superficie asimiladora de agua.

Cuestión B2.1.- ¿El clima en el que está el centro corresponde a un clima árido o semiárido?: El clima de Leganés, es el mismo que el de Madrid, analizado en los casos de ABC Serrano y La Vaguada, con unas precipitaciones medias anuales de $420,9 \mathrm{~mm}$, y una temperatura media anual de 15‥ Le corresponde un índice de Martonne de 16,83, que es una zona semiárida. A Parquesur le corresponde una calificación de +0 a esta cuestión.

Cuestión B2.2.- ¿En qué porcentaje, la superficie absorbente de agua en el área urbana, es en relación a la impermeable?: En esta cuestión, se consideró como superficie permeable las áreas verdes presentes en la zona, incluyendo las del centro comercial, $\left(428.052 \mathrm{~m}^{2}\right)$, que son aproximadamente un $17 \%$ de los $2.539 .764 \mathrm{~m}^{2}$ totales del área urbana. esta cuestión puntúa con +1 .

Cuestión B2.3.- ¿El centro comercial posee sistemas para el aprovechamiento del agua?: Aunque no ha sido posible obtener datos oficiales en este aspecto, al ser considerado como un 
caso de éxito en gestión ambiental, el centro comercial Parquesur, se consideró con instalaciones adaptadas consumo de agua, no habiendo apenas superficies permeables ni aljibes, le corresponde una puntuación de +1 .

Cuestión B2.4- ¿El consumo de agua del centro es en litros por visita?: a pesar de que no hay datos del centro en este sentido, al centro comercial Parquesur, al ser reconocido como un caso de correcta gestión medioambiental, se le estimó un consumo de agua de 20 litros por visita o menos; que corresponde a una puntuación de +2 .

EN RELACIÓN A SUPERFICIE ASIMILADORA DE AGUA, PARQUESUR HA OBTENIDO UNA PUNTUACIÓN DE 4 (10).

B3.- Cuestionario referenciado a tratamiento de isla de calor.

Cuestión B3.1.- ¿El clima en el que está el centro comercial tiene una temperatura media más o menos elevada?. El clima de Leganés, es el mismo que el de Madrid, y éste tiene una temperatura media anual de 15 o, lo que significa que es un clima templado propenso a altas temperaturas. Esta pregunta puntúa con +0

Cuestión B3.2.- ¿En el clima en el que está ubicado en centro hay olas de calor frecuentes o en intervalo temporal menor?. En Madrid generalmente acontecen varias olas de calor al año, esta cuestión puntúa con un +0 .

Cuestión B3.3.- ¿El centro está en un área en el cual la diferencia de temperatura respecto a la normal es de?. Analizando la isla de calor de la Comunidad de Madrid (Figura 5.6.13) ${ }^{63}$, nos encontramos con el hecho de que Parquesur se encuentra en un área desfavorable a efectos de isla de calor (se estimó en $+2 \circ$ de temperatura respecto de lo normal, al tratarse de una zona periférica), de este modo, esta cuestión puntúa con un +1 .

\footnotetext{
${ }^{63}$ Moreno, Antonio; et al. (2003) "La distribución espacial de la renta en la Comunidad de Madrid. Análisis y aplicaciones". Madrid: Instituto de Estadística de la Comunidad de Madrid.
} 


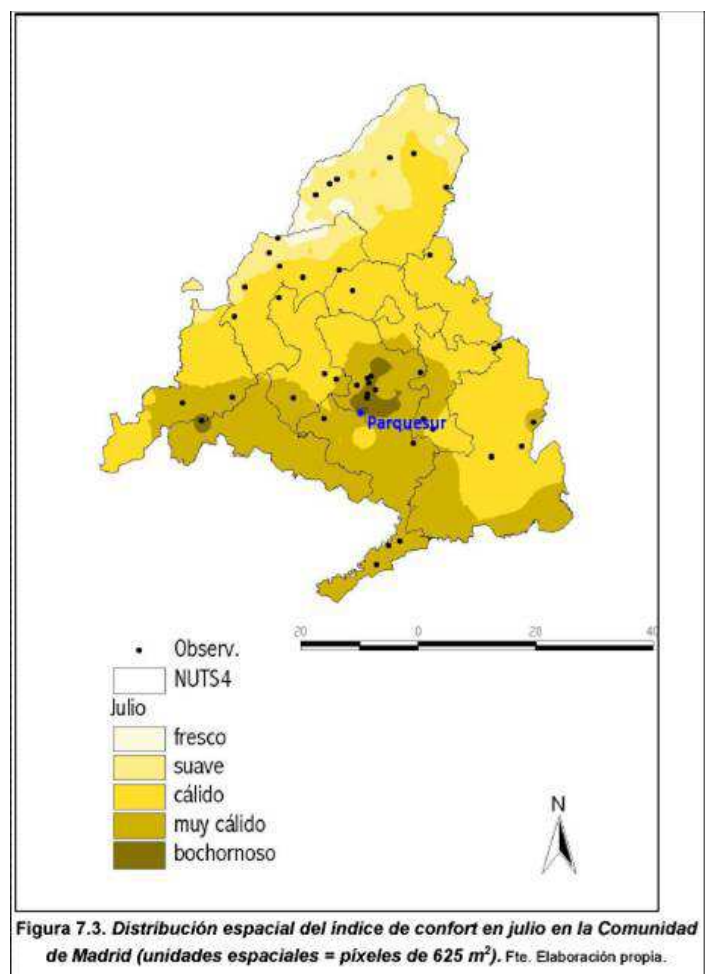

Figura 5.6.13: Rasgos de la Isla de calor de la Comunidad de Madrid. Fuente: Antonio Moreno, et al. Comunidad de Madrid.

Cuestión B3.4.- ¿La suma de superficies que contribuyen a la isla de calor en la parcela y el edificio del centro es superior a un porcentaje de la superficie total?. La superficie absorbente de irradiación de Parquesur es del 92,57\%, lo que le corresponde una puntuación de +0 .

EN RELACIÓN A TRATAMIENTO DE ISLA DE CALOR, PARQUESUR HA OBTENIDO UNA PUNTUACIÓN DE 1 (10).

4C.- REHABILITACIÓN POR USOS.

C1.- Cuestionario referenciado a inserción de uso residencial.

Cuestión C1.1.- ¿El centro comercial posee usos residenciales u hoteleros dentro de su unidad catastral?. Parquesur posee un hotel dentro de su unidad catastral de 6000 metros aproximadamente. este hotel, de acuerdo al baremo de la tesis, puede alojar a un máximo de 300 personas, las cuales son aproximadamente un $0,4 \%$ de la población total del área urbana, esta cuestión puntúa con +0 .

Cuestión C1.2.- ¿Las parcelas próximas al centro comercial posen usos residenciales $u$ hoteleros?: El uso residencial en las parcelas colindantes al centro comercial fue estimado en un $94 \%$, lo que le corresponde una puntuación de +3 .

Cuestión C1.3.- ¿Dentro del área de influencia del centro comercial, que porcentaje de la superficie de uso total es de tipo residencial?: en el área de influencia de Parquesur al completo, se estableció aproximadamente un $68,28 \%$ de uso residencial, lo que le corresponde una puntuación de +4

EN RELACIÓN A USO RESIDENCIAL, PARQUESUR HA OBTENIDO UNA PUNTUACIÓN DE 7 (10). 
C2.- Cuestionario referenciado a inserción de usos productivos, y terciarios no comerciales.

Cuestión C2.1.- ¿El centro comercial posee usos productivos no comerciales dentro de su unidad catastral?: Parquesur no posee espacio terciario productivo o de tipo terciario oficinas, salvo la gestora, que no computa para este apartado, esta cuestión puntúa con +1 .

Cuestión C2.2.- ¿Las parcelas próximas al centro comercial posen usos productivos no comerciales?: Las parcelas próximas al centro comercial, poseen una escasa oferta de instalaciones terciarias de oficinas o productivas, que se computaron en aproximadamente un $1 \%$ de la superficie total, esta cuestión puntúa con un +0 .

Cuestión C2.3.- ¿Dentro del área de influencia del centro comercial, que porcentaje de la superficie de uso total es de tipo productivo no comercial?: En el área urbana de influencia del centro comercial Parquesur, se estimó un $16,72 \%$ de la superficie edificada total, como instalaciones terciarias no comerciales, éstas corresponden a edificios de gran altura. A esta cuestión le corresponde una puntuación de +1 .

EN RELACIÓN A USO PRODUCTIVO, PARQUESUR HA OBTENIDO UNA PUNTUACIÓN DE 2 (10).

C3.- Cuestionario referenciado a inserción de instalaciones dotacionales y asistenciales.

Cuestión C3-1.- ¿El centro comercial posee usos dotacionales dentro de su unidad catastral?: El centro comercial Parquesur, no posee usos dotacionales en su interior, esta cuestión puntúa con un +0 .

Cuestión C3.2.- ¿Las parcelas próximas al centro comercial posen usos dotacionales?: En las parcelas inmediatas al centro comercial Parquesur no hay dotaciones, estando la más cercana a 500 metros. Esta cuestión puntúa con +0.

Cuestión C3.3.- ¿A un kilómetro del centro comercial hay usos dotacionales?: En el área de dotaciones correspondiente a lo que es el centro comercial de Parquesur ( $1 \mathrm{~km}$ desde el lindero del centro), hay varias dotaciones de visita habitual que están limitadas a escala local. Esta cuestión puntúa con +4 .

EN RELACIÓN A DOTACIONES, PARQUESUR HA OBTENIDO UNA PUNTUACIÓN DE 4 (10).

4D.- REHABILITACIÓN DE ENTORNO URBANO.

D1.- Cuestionario referenciado a la inserción de medios de transporte eficientes.

Cuestión D1.1.- ¿El centro dispone en sus inmediaciones de alguna parada de transporte público?: El centro comercial Parquesur, posee instalaciones de transporte público en las inmediaciones de su parcela, además de varios tipos de medios de transporte. La puntuación es de +1 .

Cuestión D1.2.- ¿El tiempo de llegada al centro mediante transporte público supera al tiempo de llegada en vehículo particular?, A partir del análisis del apartado $2 \mathrm{~F}$, y ponderando los recorridos medios por trayecto el tiempo de llegada medio en transporte público desde los 
puntos asignados en el área a las puertas del centro comercial, es casi 3 veces que en vehículo privado (Figura 5.6.14), esta cuestión puntúa con +0 .

\begin{tabular}{|l|r|r|}
\hline Comparación de tiempos de recorrido & Recorrido 1 & Recorrido 2 \\
\hline Total tiempo desplazamiento tte público & 21 & 27 \\
\hline Total tiempo desplazamiento tte privado & 10 & 7 \\
\hline Relación entre tiempos desplazamiento & 2,1 & 3,857142857 \\
\hline Media tiempo desplazamiento & & 2,978571429 \\
\hline
\end{tabular}

Figura 5.6.14: Comparación de recorridos a Parquesur. Fuente: Elaboración propia

Cuestión D1.3.- ¿El área urbana del centro comercial está cubierta de forma adecuada por la infraestructura de transporte público?. El área urbana de Parquesur, está cubierta en un más de un $70 \%$ de su superficie, aproximadamente por la infraestructura de transporte público (Figura 5.6.6). Lo que la cuestión puntúa con un +2 .

Cuestión D1.4.- ¿Los usos en la zona están mezclados o zonificados?: De acuerdo al análisis de 1K En el área de Parquesur, el índice Global de Mezcla de usos es de 1 (Zona de gran complejidad urbana), esto le corresponde una puntuación de +2 .

Cuestión D1.5.- ¿El centro comercial y el área urbana próxima al centro cuenta con instalaciones enfocadas en la movilidad sostenible?: El centro comercial Parquesur tiene varios sistemas adaptados a la movilidad sostenible, (aparcamientos de bicicletas y puntos de recarga de coches eléctricos) esta cuestión obtiene una puntuación de +2 .

EN RELACIÓN A TRANSPORTE EFICIENTE, PARQUESUR HA OBTENIDO UNA PUNTUACIÓN DE 7 (10).

D2.- Cuestionario referenciado a la rehabilitación por corrección de la densidad en área urbana.

Cuestión D2.1.- ¿La densidad de población en el área del centro está en el intervalo entre h/ha?, La densidad de población del área de Parquesur es la del barrio del Carrascal (0,041 $\left.\mathrm{hab} / \mathrm{m}^{2}\right)$, a esta cuestión le corresponde una puntuación de +3 , habiendo en el área problemas de congestión.

Cuestión D2.2.- ¿A efectos de densidad, el tejido mayoritario es favorable o desfavorable de cara a la sostenibilidad?. de acuerdo al análisis de 1G, El índice global de densidad del área de Parquesur es de 2, lo que es un entorno de densidad media. A esta cuestión le corresponde una puntuación de +3 , no siendo necesario densificar más el área.

Cuestión D2.3.- ¿La cantidad de espacio ocupado en el área está en el intervalo? El espacio ocupado en el área urbana total de Parquesur, es de un $28 \%$ de la superficie, lo que corresponde a una puntuación de +1 .

EN RELACIÓN A DENSIDAD, PARQUESUR HA OBTENIDO UNA PUNTUACIÓN DE 7 (10).

D3.- Cuestionario referenciado a mejora de la seguridad y la paseabilidad en el área urbana.

Cuestión D3.1.- ¿En el área de influencia o en sus proximidades hay elementos negativos de cara a la seguridad o a la salubridad del área?: En el área cercana a Parquesur, hay partes del 
borde urbano, que se encuentran un tanto descuidadas y aisladas de la actividad debido a que son linderos de infraestructuras de gran capacidad. Esta cuestión puntúa con +0 .

Cuestión D3.2.- ¿El centro comercial se encuentra en una zona de puntos fríos de actividad durante el día?. El centro comercial, debido a su gran tamaño en si mismo actúa como un nodo, a pesar de ubicarse en un extremo urbano rodeado de barreras. Esta cuestión puntúa con +1 .

Cuestión D3.3.- ¿El centro comercial se encuentra en una zona de puntos fríos durante la noche?, Cuando cesa la actividad del centro comercial, la parcela del centro y el parque de sus inmediaciones pasan a ser un fondo de saco urbano debido a las barreras que lo rodean, esta cuestión puntúa con +0 .

Cuestión D3.4.- ¿El centro comercial se encuentra en una zona con áreas de difícil control visual o de contacto urbano?. En el área de Parquesur no hay zonas en las que puedan darse situaciones de difícil control visual. Esta cuestión puntúa con +1

Cuestión D3.5.- ¿La sensación de seguridad por parte de los ciudadanos de la zona es positiva o negativa?: Aunque Leganés no es una de las zonas más seguras de Madrid, la sensación por parte de los habitantes es generalmente positiva. La puntuación a esta cuestión es de +1 .

Cuestión D3.6.- ¿La zona próxima al centro comercial tiene un porcentaje de fachadas activas?: En las manzanas próximas al centro comercial, hay un 3,73\% de fachadas activas, respecto a la longitud de fachada total, esto es un porcentaje escaso, que le corresponde una puntuación de +0 .

Cuestión D3.7.- ¿La distancia de la puerta del edificio del centro comercial al inmueble residencial cercano es superior a los 200 metros?: El inmueble residencial más cercano a Parquesur, se encuentra a alrededor de $\mathbf{3 5 0}$ metros desde la entrada del centro comercial, esta cuestión puntúa con +0 .

Cuestión D3.8.- ¿La cantidad de espacio libre en el área va a resultar desfavorable de cara a la paseabilidad?: El espacio libre en el área de Parquesur es de aproximadamente un $71,5 \%$, un porcentaje elevado que va a favorecer la aparición de grandes espacios urbanos sin control. de modo que esta cuestión va a puntuar con un +0 .

Cuestión D3.9.- ¿Los usos en la zona están mezclados o zonificados? El índice global de mezcla de usos es de 1, esta cuestión puntúa con +1 .

EN RELACIÓN A PASEABILIDAD, PARQUESUR HA OBTENIDO UNA PUNTUACIÓN DE 4 (10).

\section{E.- CUESTIONARIO RELACIONADO CON LA ACTIVIDAD DEL CENTRO Y SUS CONSECUENCIAS URBANAS.}

Cuestión E1: ¿La actividad del centro comercial, va a penalizar o a favorecer la sostenibilidad del entorno urbano?:De acuerdo a la tabla de datos del apartado OC, El centro comercial Parquesur tiene un índice de atracción de 4. A su vez, la puntuación total en el cuestionario relacionado con el transporte eficiente (D1) es de 7 , de este modo, consultando la tabla del 
apartado 3.10, 4E. El efecto de la actividad corresponde a un bonificador de +1 a seguridad y paseabilidad (D4), quedando finalmente este cuestionario en una puntuación de 5.

FASE FINAL: GRÁFICO DE LA ROSA DE REHABILITACIÓN SOSTENIBLE.

Las puntuaciones obtenidas en el anterior cuestionario, fueron colocadas en el gráfico de la rosa de rehabilitación sostenible, obteniendo el siguiente resultado (Figura 5.6.15):

\section{(A) ECOEFICIENTE}

\section{( $\mathrm{A} 3)$}

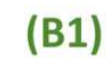

\section{(B) MEDIOAMBIENTAL}

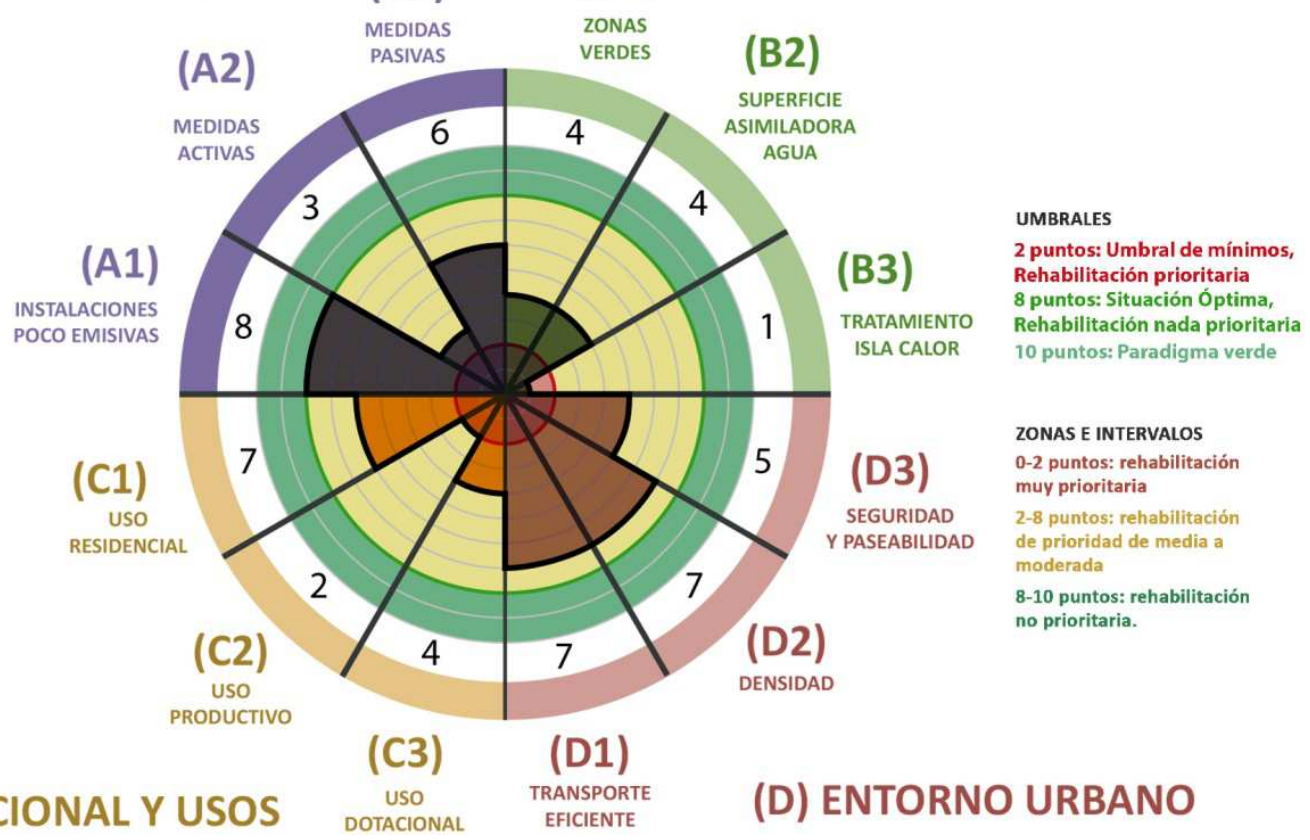

Figura 5.6.15: Gráfico de rosa de rehabilitación sostenible para Parquesur. Fuente: Elaboración propia.

A primera vista, se puede comprobar de acuerdo al gráfico que tanto el área urbana de Parquesur, cómo el centro comercial en sí, tiene carencias graves de cara a la sostenibilidad, en lo relativo al tratamiento de la isla de calor en el centro comercial y área. debido a la presencia de grandes superficies pavimentadas, y su presencia en un área de altas temperaturas dentro de la Comunidad de Madrid. No obstante, en otros aspectos, Parquesur no tiene carencias graves, a pesar de que las condiciones del centro comercial de cara a la sostenibilidad todavía pueden ser mejoradas, sobre todo a efectos de superficies verdes y absorción de agua en el área urbana, así como la inserción de medidas solares activas de aclimatación y energía de tipo avanzado. De este modo, cualquier operación de rehabilitación sostenible que se realice en el centro comercial Parquesur o en su zona urbana, irá encaminada en primer lugar a mitigar la isla de calor, siendo prioridad secundaria la mejora de otras facetas.

\section{7.- CASO 7: BELMAR}

Este caso de estudio de centralidad comercial ubicado en las afueras de Denver, en lugar de ser un centro comercial al uso, consiste en un complejo urbano con una relativa variedad de edificaciones. El causante del estado actual, es el resultado de la demolición de un anterior 
centro comercial de gran tamaño llamado Villa Italia, seguido de la replanificación de la parcela, y la disposición de edificios comerciales, de oficinas y residenciales en la zona. El interés de este caso de estudio reside en que resulta ser el resultado de una ambiciosa rehabilitación urbana, con la intención de transformar una pieza de gran tamaño en planta y un solo uso, en un área urbana compleja y relativamente densa. Siendo de esta manera este caso un caso comparativo.

\section{FASE 0: RECOGIDA DE DATOS CUANTITATIVOS.}

En esta fase, se va a realizar una recogida de datos cuantitativos oficiales del complejo urbano de Belmar y su entorno. Estos se hallarán bien a partir de fuentes oficiales, de las autoridades urbanas de Lakewood, o bien midiendo sobre plano. Se considerarán los siguientes datos que serán de utilidad para posteriores análisis. Debido a que Belmar es una zona con relativa mezcla de usos, en la que hay grandes superficies de zona residencial, los análisis de área e índice de atracción, van a considerarse en base a la superficie comercial dentro del complejo, ya que es la que ejerce interacción.

OC.- TABLA DE DATOS DEL CENTRO COMERCIAL. (Figura 5.7.1)

\begin{tabular}{|l|l|}
\hline \multicolumn{2}{|c|}{ BELMAR } \\
\hline \multicolumn{2}{|c|}{ FASE 0, RECOGIDA DE DATOS CUANTITATIVOS } \\
\hline OC.- TABLA DE DATOS CENTRO & Valor \\
\hline OC1: Superficie centro comercial (m2) & 961.446 (355.900 c.) \\
\hline OC2: Superficie de parcela o ud. Catastral (m2) & 1.848 .190 \\
\hline OC3: Superficie en planta (m2) & 480.700 \\
\hline OC4: Número de visitantes semanal (pe/sem) & 421.741 \\
\hline OC5: Índice de Atracción ( $\mathrm{n}$-) & 5 \\
\hline OC6: Superficie de tipo residencial (m2) & 429.378 \\
\hline OC7: Superficie de uso productivo (m2) & 176.168 \\
\hline OC8: Número de instalaciones dotacionales ( $\mathrm{n}$ - $)$ & 3 \\
\hline OU.- TABLA DE DATOS ENTORNO URBANO & Valor \\
\hline OU1: Población asignada a centro (pe) & 177.950 \\
\hline OU2: Densidad de población (hab/m2) & 0,0015 \\
\hline U03: Superficie partida de entorno urbano $(\mathrm{m} 2)$ & $118.633 .333,3 \mathrm{~m}^{2}$ \\
\hline
\end{tabular}

Figura 5.7.1: Tabla de datos Belmar. Fuente: Elaboración Propia.

C1: SUPERFICIE CENTRO COMERCIAL TOTAL: Ya que no pudieron obtenerse datos oficiales de la gerencia de este centro. Las superficies fueron medidas sobre plano. La superficie edificada de Belmar es de $961.446 \mathrm{~m}^{2}$ de los cuales hay una superficie comercial de $355.900 \mathrm{~m}^{2}$, que nos servirá para dimensionar el área de estudio y realizar el análisis.

C2: SUPERFICIE TOTAL DE LA PARCELA DEL CENTRO: Para la obtención de este dato se midió la superficie de la parcela sobre una foto aérea del complejo, la superficie de la parcela de Belmar es de $1.848 .190 \mathrm{~m}^{2}$ 
C3: SUPERFICIE EN PLANTA DEL EDIFICIO DEL CENTRO COMERCIAL. De las mediciones sobre plano, se obtuvo que la parcela del complejo Belmar está ocupada al $26 \%$ de su superficie. la superficie en planta de Belmar es de $480.700 \mathrm{~m}^{2}$

C4: NÚMERO DE VISITANTES SEMANAL. Al no poder obtenerse datos del número de visitantes de Belmar, se realizó un conteo estimativo de las visitas tomando como base los datos de Shopping Light del apartado $C 4$, considerándose a su vez un coeficiente de ponderación de 0,5, debido a la localización periférica de este complejo. No obstante, para este caso, va a considerarse exclusivamente la superficie comercial.

De este modo, para Belmar tenemos este número de visitas:

De lunes a viernes: 177.950 personas.

Sábado: 147.698 personas.

Domingo: 96.093 personas.

El número de visitantes semanal de Belmar es de 421.741 personas.

C5: ÍNDICE DE ATRACCIÓN DEL CENTRO. En función al número de visitantes del centro, A Belmar le corresponde un índice de 5, (Más de 300.000 visitantes por semana). Es justificable esta calificación, debido al inmenso tamaño del centro comercial anteriormente construido, así como la concepción de este complejo como el centro urbano de un área de gran tamaño.

C6: SUPERFICIE DE USO EN EL CENTRO DE TIPO RESIDENCIAL. Belmar posee edificios de viviendas de varios tipos, que al cómputo suman aproximadamente $429.378 \mathrm{~m} 2$ de uso residencial dentro de la unidad catastral.

C7: SUPERFICIE DE USO EN EL CENTRO DE TIPO PRODUCTIVO: Dentro de la unidad catastral de Belmar, hay superficie de tipo productivo y terciario no comercial repartida en edificios de oficinas. Este uso engloba $176168 \mathrm{~m}^{2}$.

C8: NÚMERO DE INSTALACIONES EN EL CENTRO DE TIPO DOTACIONAL O ASISTENCIAL: En Belmar, hay 3 instalaciones de tipo asistencial abiertas al público, de marcado carácter privado. Una es una asociación de arte con galerías, la otra un centro de estudios y la otra una clínica asistencial privada.

OU.- TABLA DE DATOS DEL ENTORNO URBANO.

U1: POBLACIÓN DE ÁREA URBANA ASIGNADA A CENTRO COMERCIAL: Debido a que Belmar es una zona compleja que incluye edificios residenciales y dotacionales, el análisis del área para este caso, tuvo que realizarse en base a la superficie comercial presente dentro del complejo, ya que es la que ejerce poder de atracción. Dividiendo la superficie comercial en el complejo entre 2 , salió una población asignada de 177.950 personas.

U2: DENSIDAD DE POBLACIÓN EN EL DISTRITO DEL CENTRO COMERCIAL: Para el análisis urbano, se cogió la densidad de población del distrito de Lakewood en Denver, la cual fue ponderada para adaptarse a la realidad suburbana dónde está ubicado el centro comercial, la densidad se estableció en $0,0015 \mathrm{hab} / \mathrm{m}^{2}$. 
U3: SUPERFICIE DEL ENTORNO URBANO: La superficie del entrono urbano a analizar, se sacó de los datos de población asignada al centro, la cual fue dividida entre la densidad del área, la superficie de partida es de $118.633 .333,3 \mathrm{~m}^{2}$.

\section{FASE 1: ANÁLISIS DEL CONTEXTO URBANO.}

La segunda fase del análisis de Belmar, se realizará generalmente en base a mediciones sobre plano de diferentes facetas en el área que tuviesen relación con el complejo. Se trabajarán diferentes escalas, siendo predominante la escala urbana amplia de toda la zona de influencia, que va a establecerse en este apartado. Para este análisis, resultará fundamental el uso de datos referentes a la configuración del entorno urbano de Lakewood, establecidos en el apartado anterior. Se ponderará la información del análisis sobre plano, y el objetivo será hallar y establecer las pautas urbanísticas para el cuestionario de rehabilitación del centro comercial. Para acometer dicha tarea, se considerarán aspectos relacionados con configuraciones de volumen urbano, densidades, usos, áreas verdes y medio ambiente urbano.

1A: ESTABLECIMIENTO DEL ÁREA DE INFLUENCIA DEL CENTRO COMERCIAL: En base a la superficie del área, hallada anteriormente, al área de análisis del centro comercial Belmar, le corresponde un radio de aproximadamente 6,1 kilómetros a partir del lindero de la parcela del centro, no obstante, debido al gran tamaño de este área, para el análisis, se escogió como límite aproximado para la circunferencia de análisis los límites del municipio de Lakewood. De este modo, el área de análisis de Belmar se redujo a una circunferencia de 3900 metros a partir del lindero del complejo. (Figura 5.7.2)

1B: DELIMITACIÓN SOBRE PLANO DEL ÁREA DE INFLUENCIA: En base a las consideraciones citadas en el anterior capítulo, se estableció el área de análisis de Belmar sobre el plano, el área de la misma es de aproximadamente $50.300 .000 \mathrm{~m}^{2}$ (Figura 5.7.2).

1C: SUBDIVISIÓN DEL ÁREA DE INFLUENCIA EN ÁREAS HOMOGÉNEAS Y DELIMITACIÓN DE ZONAS VERDES Para este análisis, el área urbana anteriormente asignada, va a dividirse en zonas homogéneas de acuerdo a su tejido urbano, (Figura 5.7.2) marcándose a su vez la superficie de zonas verdes. Se establecieron dos tipologías de zona homogénea, descontando los espacios verdes y sin edificar en el área, cada zona tiene aproximadamente:

Z1: $44.104 .072 \mathrm{~m}^{2}$ brutos.

Z2: $5.537 .832 \mathrm{~m}^{2}$ brutos.

La suma total de las zonas edificadas es de $11503628 \mathrm{~m} 2$. 


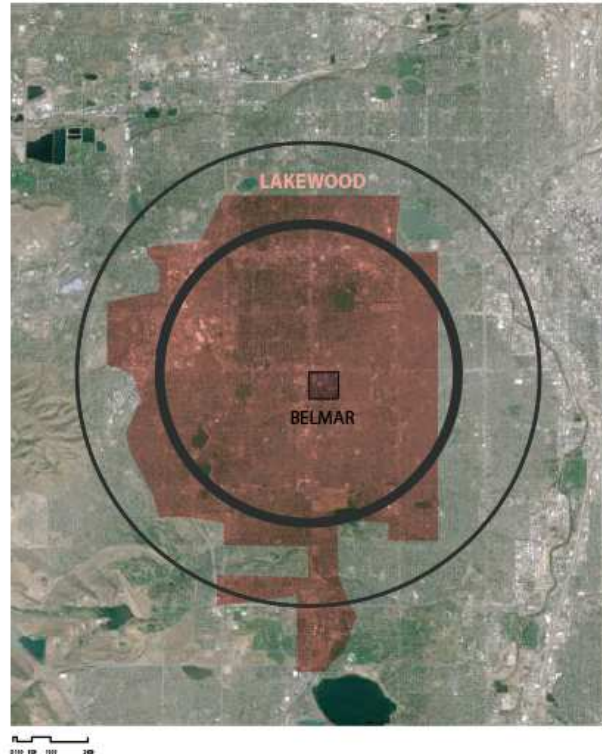

$$
\text { intin }
$$

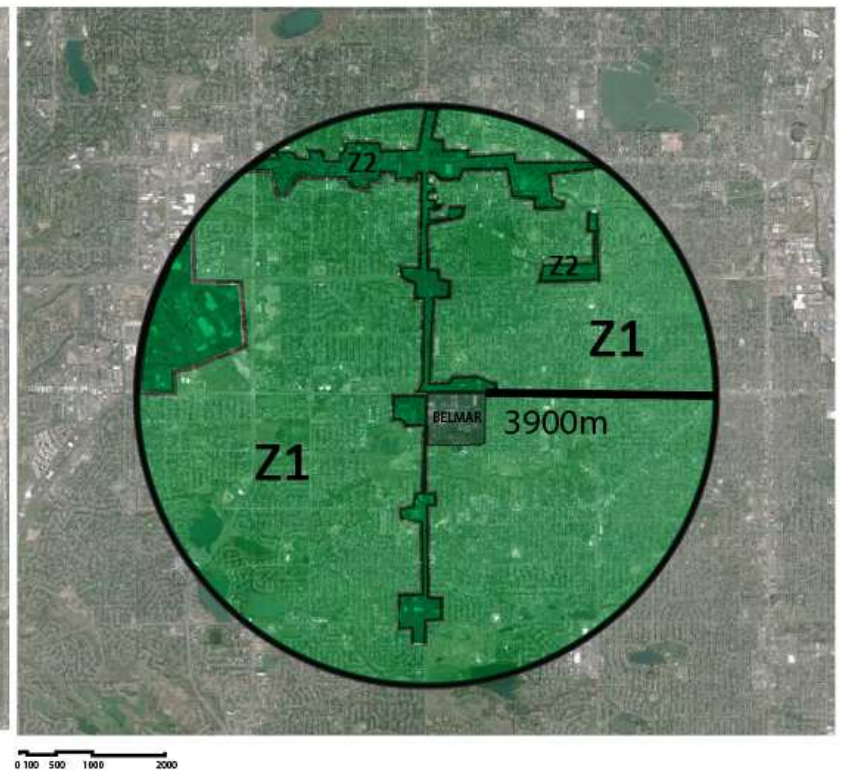

ग1000 500

Tejido urbano densidad media
Tejido urbano

densidad baja

Figura 5.7.2: Área de Belmar y subdivisión por zonas homogéneas. Fuente: Elaboración Propia a partir de datos de Google.

1D: PORCENTAJE DE OCUPACIÓN DE LA EDIFICACIÓN Y ÁREA OCUPADA: A partir del análisis de un área tipo de $200 \times 200 \mathrm{~m}^{2}$ sobre parcelarios interpretados a partir de planos de la ciudad de Denver, El porcentaje de ocupación de la edificación de la única zona homogénea establecida para las áreas de influencia de Belmar son: (Figura 5.7.3)

Z1: $15 \%$ de superficie ocupada. Superficie ocupada $6.615 .611 \mathrm{~m}^{2}$. Z2: $27 \%$ de superficie ocupada. Superficie ocupada $1.495 .215 \mathrm{~m}^{2}$.
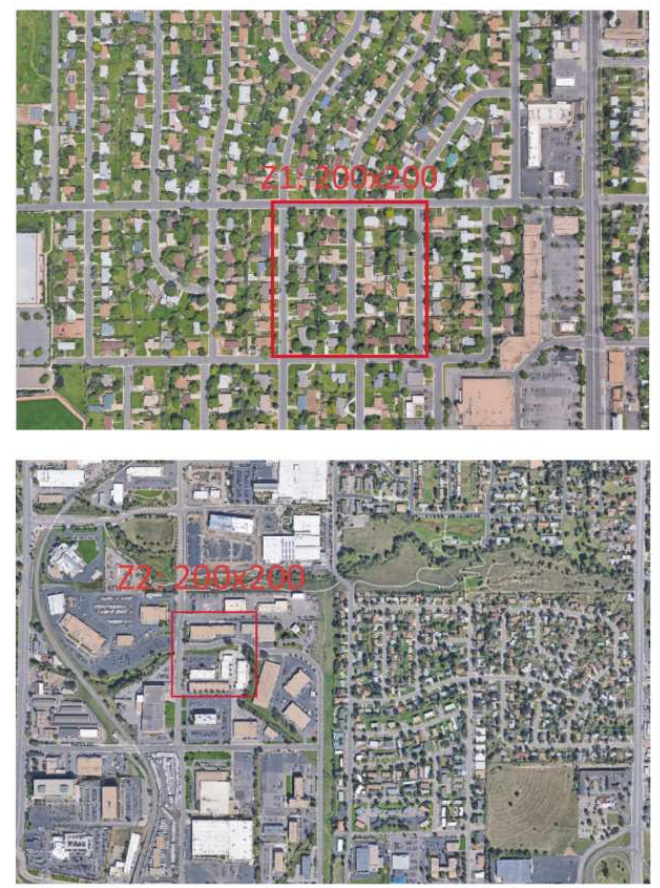

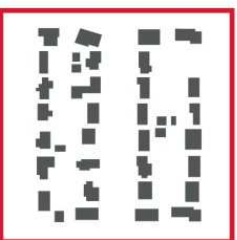

ÁREA TIPO Z1 $15 \%$ ocup.

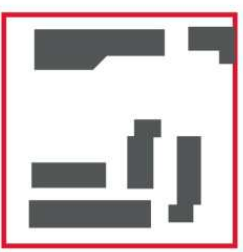

ÁREA TIPO Z2

$27 \%$ ocup.

Figura 5.7.3: Análisis Tejidos Belmar. Fuente: Elaboración Propia a partir de datos de Google. 
1E: ALTURAS DE LA EDIFCACIÓN POR ÁREA HOMOGÉNEA: Para las diferentes áreas homogéneas de Belmar, se establecieron las siguientes alturas de edificación. Esto fue realizado en base al estudio de áreas similares y fotos de calle:

Z1: 1 altura. Z2: 2 alturas.

1F: ESTABLECIMIENTO DE LAS TIPOLOGÍAS DE TEJIDO EN BASE A LA MORFOLOGÍA URBANA POR ÁREA HOMOGÉNEA: con las ocupaciones y números de plantas anteriormente estudiados, de acuerdo al baremo establecido de la tabla correspondiente a densidades del presente apartado en el capítulo 3.6, a cada área de Belmar le corresponden estas densidades.

Z1: Zona poco densa. Z2: Zona poco densa.

1G.- ÍNDICE GLOBAL DE DENSIDAD. Considerando los diferentes criterios de densidad anteriormente establecidos, y el porcentaje que ocupan las mismas respecto de la superficie total, tenemos este índice global de densidad.

Z1: Índice de 1, representa el $88,84 \%$ de la superficie total, suma al índice global 0,89 puntos.

Z2: Índice de 1, representa el 11,16\% de la superficie total, suma al índice global 0,11 puntos.

De este modo el índice global de densidad en Belmar es de 1 punto, lo que corresponde una zona de densidad baja.

1H: SUPERFICIE EDIFICADA TOTAL DE CADA ÁREA HOMOGÉNEA. Para la superficie edificada total, se multiplicó la superficie en planta anteriormente hallada por el número medio de plantas por zonas. De este modo, la superficie total edificada aproximada por área es de:

Z1: $6.615 .611 \mathrm{~m}^{2} \times 1=6.615 .611 \mathrm{~m}^{2}$.

Z2: $1.495 .215 \mathrm{~m}^{2} \times 2=2.990 .429 \mathrm{~m}^{2}$.

Siendo de este modo la superficie edificada total de $9.606 .040 \mathrm{~m} 2$

1I: ESTABLECIMIENTO DE TIPOLOGÍAS DE TEJIDO DENTRO DEL ÁREA URBANA EN REFERENCIA A LOS USOS: El área de Belmar corresponde a un entorno nada complejo, con usos zonificados en el que predomina un tipo de edificio por zona homogénea. Al no haber datos objetivos sobre los usos predominantes en la zona, se consideraron los siguientes porcentajes:

Z1: $90 \%$ residencial, $2 \%$ productivo, $8 \%$ comercial.

Z2: $0 \%$ residencial, $40 \%$ productivo, $60 \%$ comercial.

1J: CONTEO DE LOS USOS DENTRO DEL CONTEXTO URBANO. Una vez se establecieron los porcentajes, para obtener los metros cuadrados netos de uso, éstos fueron multiplicados por la superficie edificada total de cada zona homogénea $(1 \mathrm{H})$, quedando establecidos los usos para el área urbana circundante de Belmar de la siguiente manera:

Z1: $5954050 \mathrm{~m}^{2}$ residencial, $132312 \mathrm{~m}^{2}$ productivo, $529249 \mathrm{~m}^{2}$ comercial.

Z2: Om² residencial, $1196172 \mathrm{~m}^{2}$ productivo, $1794258 \mathrm{~m}^{2}$ comercial. 
1K: ÍNDICE GLOBAL DE MEZCLA DE USOS. Para el índice global de mezcla de usos, se establecieron los porcentajes de uso residencial y no residencial, estableciéndose a su vez la comparativa de acuerdo al apartado, para definir los índices de uso de la siguiente manera:

Z1: $90 \%$ uso residencial, $10 \%$ uso no residencial, índice mezcla usos de 0

Z2: $0 \%$ uso residencial, $100 \%$ uso no residencial, índice mezcla usos de 0

De este modo, multiplicando los índices de uso, por los porcentajes de cada zona homogénea, y sumando los resultados, se saca que el área de Belmar tiene un índice de mezcla de usos de 0. Que corresponde a un área nada compleja a efectos de usos.

1L: CONTEO DEL NÚMERO DE DOTACIONES DENTRO DEL CONTEXTO URBANO, DENTRO DEL ÁREA DE DOTACIONES: Se establecerá un área de un 1 kilómetro a partir del lindero del centro, y dentro del mismo se marcaron las siguientes dotaciones: 2 dotaciones de visita esporádica y 4 dotaciones de visita habitual, dos dentro del propio centro. (Figura 5.7.4)

1M: PRESENCIA E INFLUENCIA DE ELEMENTOS POSITIVOS Y NEGATIVOS: De acuerdo a fuentes periodísticas y análisis de fotos, En el área del centro comercial Belmar, no hay elementos negativos de cara a la paseabilidad, seguridad o actividad del área. (Figura 5.7.4)

1N: ZONAS DE ACTIVIDAD: El área en la que se encuentra Belmar, es muy poco activa por lo general, ya que todos los usos se encuentran muy zonificados y agrupados por parcelas. A todo esto hay que añadir que los usos no residenciales se ubican en calles y avenidas muy localizadas, siendo la excepción el complejo de Belmar, que posee una cierta mezcla de usos dentro de sus límites. Esto va a suponer la aparición de puntos fríos tanto diurnos como nocturnos en el área, incluso dentro del propio complejo, que van a corresponder a las enormes parcelas de aparcamiento. (Figura 5.7.4) 


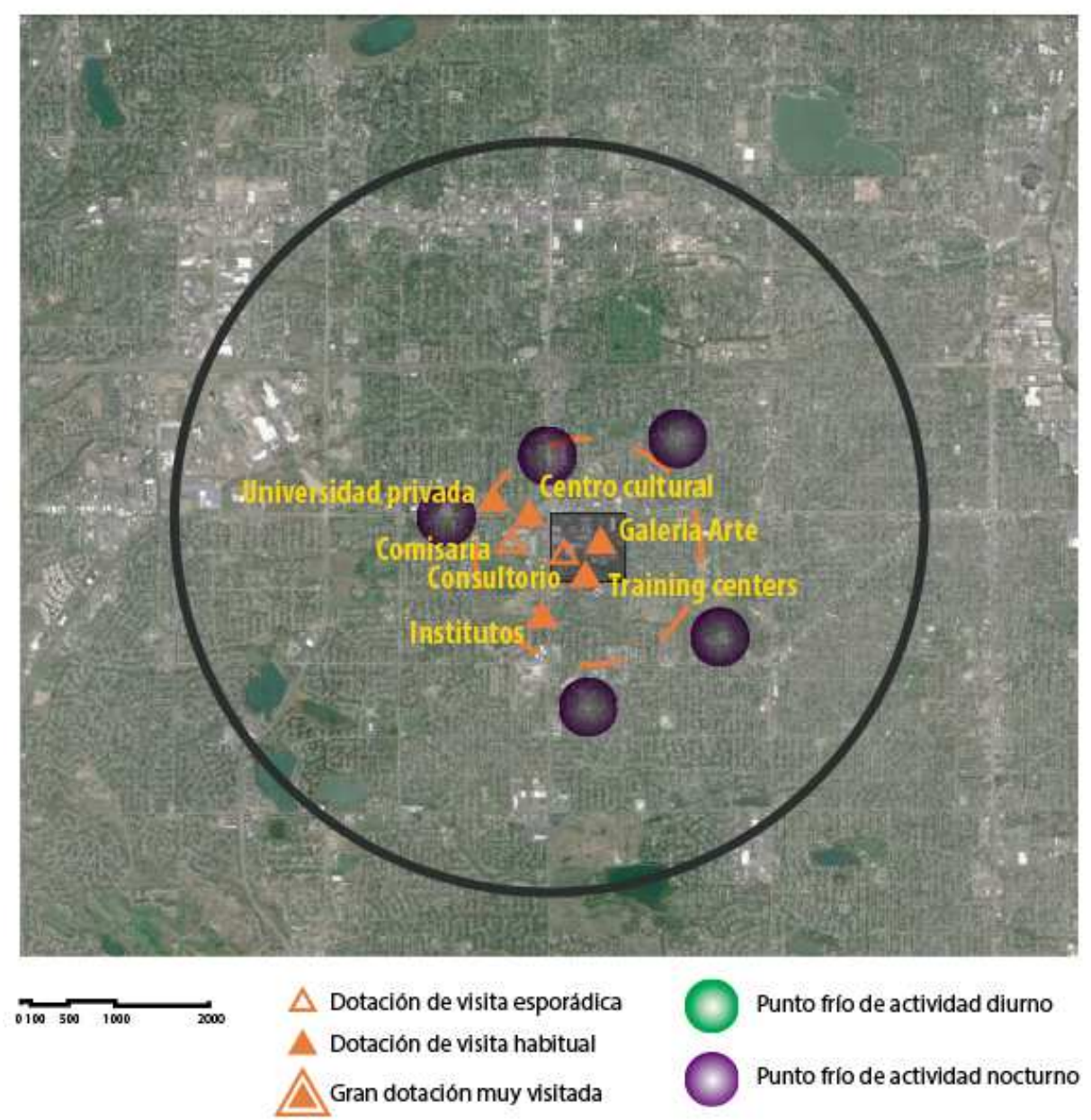

Figura 5.7.4: Análisis de dotaciones y actividad del área de Belmar. Fuente: Elaboración Propia a partir de datos de Google.

10: ÁREAS ARBOLADAS Y VERDES, DENTRO DEL ÁREA URBANA DEL CENTRO: Dentro del área de Belmar, se consideró como superficie verde neta un $54 \%$ del área total de influencia del centro, debido a que el tejido urbano es muy disperso y de poca densidad. De este modo la superficie neta total verde en el área de Belmar es de $27.016 .226 \mathrm{~m}^{2}$. que se desglosa en las siguientes superficies y capas de vegetación. (Figura 5.7.5) 

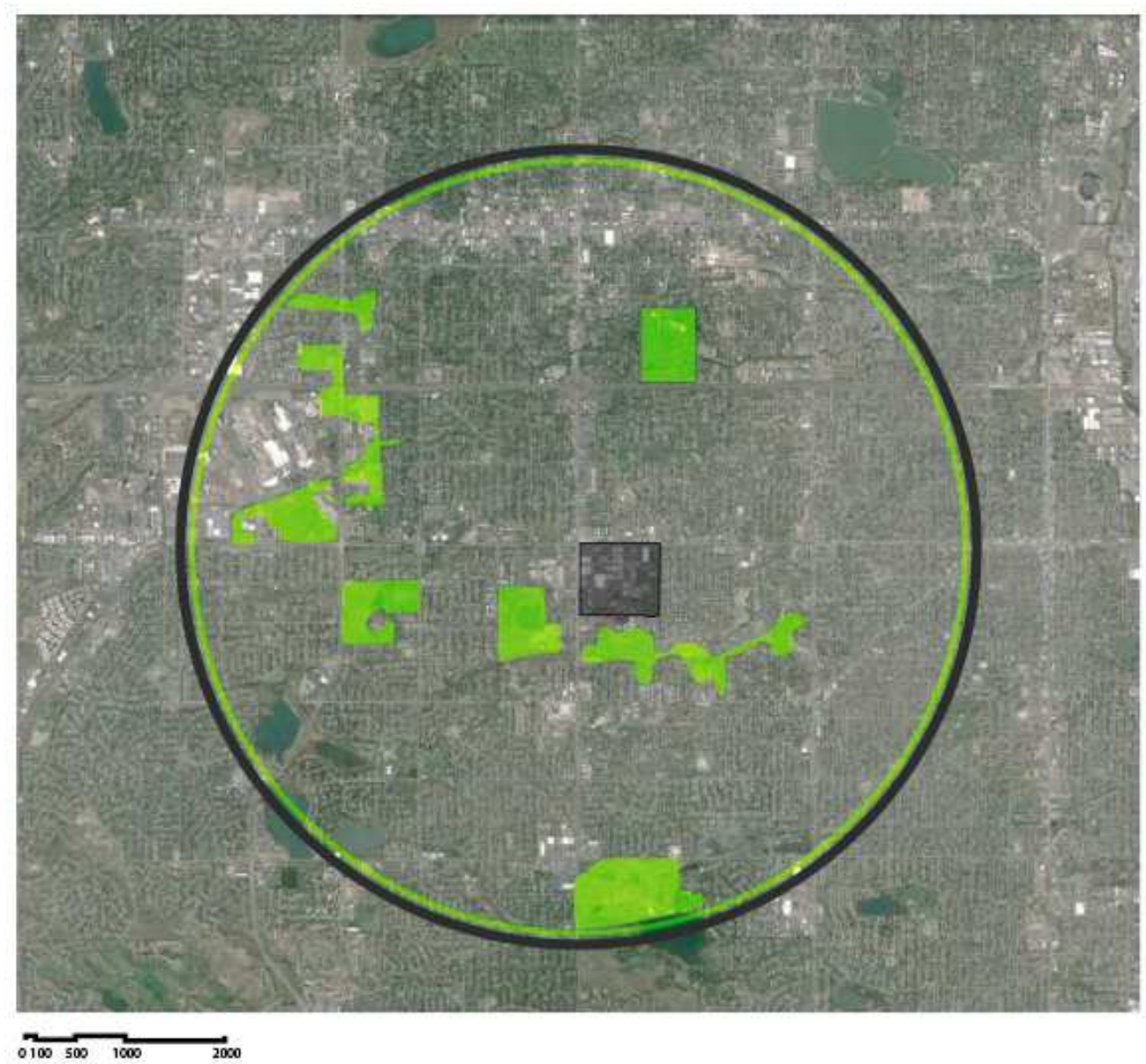

\begin{tabular}{|l|r|}
\hline 1O: Superficie de zonas verdes en área urbana & Valor \\
\hline C4.1: pradera & 17016226,4000 \\
\hline C4.2: hierba de gran altura o huerto & 4410407,0000 \\
\hline C4.3: vegetación arbustiva intensiva & 4687298,6000 \\
\hline C4.4: vegetación arbórea caduca & 4508113,2000 \\
\hline C4.5: vegetación arbórea perenne & 2410407,0000 \\
\hline
\end{tabular}

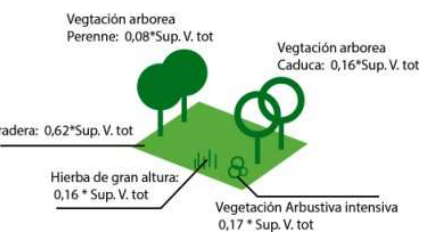

Figura 5.7.5: Área de Belmar, Zonas verdes y capas de vegetación. Fuente: Elaboración Propia a partir de datos de Google.

1P.- DELIMITACIÓN DE RECORRIDOS A CENTRO, DENTRO DEL ÁREA URBANA: Para este análisis, fueros establecidos tres recorridos desde diferentes puntos del borde e interior del área urbana de análisis de Belmar, los tiempos de llegada al complejo se analizarán a posteriori (figura 5.7.6). 


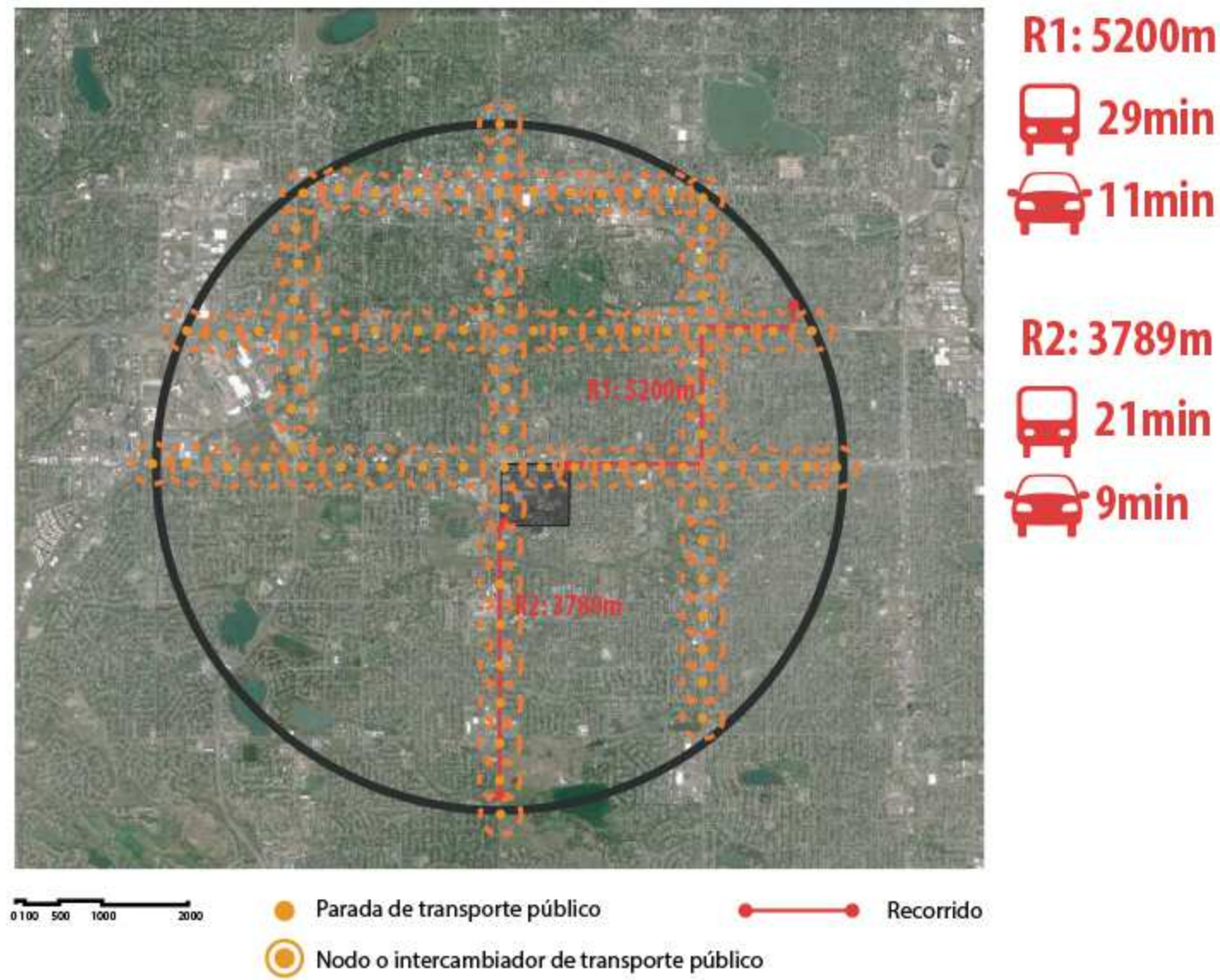

Figura 5.7.6: Recorridos, tiempos de llegada y zonas cubiertas por el transporte público en el área de Belmar. Fuente: Elaboración Propia a partir de datos de Google.

1Q.- HUELLA DE CARBONO DEL ÁREA URBANA: Siendo la huella de carbono de Estados Unidos de 17,2 toneladas anuales por persona (Banco Mundial, año $2009^{64}$ ), aunque esta cantidad en los últimos años ha bajado a las 16,38 Toneladas por habitante (2013), este análisis fue realizado en un escenario desfavorable. Siendo el número de habitantes del área de Belmar de 177950 personas, la huella de carbono del área es de, 1.360 .800 Toneladas de dióxido de carbono anuales.

1R.- CAPACIDAD ABSORCIÓN DE LOS ELEMENTOS VERDES EN ÁREA URBANA: En base a los datos de superficies verdes obtenidos en el apartado 10, se calculó la absorción total de las áreas verdes en base a la capacidad de absorción por metro cuadrado de las superficies vegetales. (figura 5.7.7.) Siendo la capacidad absorbente total en el área de 6.307.630 Toneladas de dióxido de carbono anuales.

\begin{tabular}{|l|r|r|r|r|r|r|}
\hline 1Q: C.absorción elementos verdes en área & \multicolumn{1}{l|}{ Pradera } & V.arb ext & V. A. Int. & H. Caduca & H. Perenne & Otro \\
\hline Superficie total & 17016226,4000 & 4410407,0000 & 4687298,6000 & 4508113,2000 & 2410407,0000 & 0,0000 \\
\hline Tasa absorción TCo2/m2 año & 0,0013 & 0,0020 & 0,0350 & 0,1500 & 2,2500 & 0,8000 \\
\hline Absorción dióxido carbono TCo2 & 22121,0943 & 8820,8140 & 164055,4510 & 676216,9800 & 5423415,7500 & 0,0000 \\
\hline
\end{tabular}

Figura 5.7.7: Absorción de las zonas verdes del área urbana de Belmar. Fuente: Elaboración Propia.

${ }^{64}$ http://datos.bancomundial.org/indicador/EN.ATM.CO2E.PC?locations=US 
1S: DELIMITACIÓN DE ÁREAS EN FUNCIÓN DE LA RECUPERACIÓN DE AGUAS EN ÁREA URBANA. Para este análisis, se consideraron como zonas permeables al agua, las zonas verdes netas presentes en el área urbana. De este modo, la superficie permeable del área de Belmar es de 27.016.226 $\mathrm{m}^{2}$

\section{FASE 2: ANÁLISIS DE RELACIONES ENTRE CENTRO COMERCIAL Y ENTORNO URBANO.}

Este análisis en muy similar en búsqueda de datos y función con respecto al anteriormente analizado sobre el área urbana general. La particularidad de este análisis está en que su ámbito está limitado a las parcelas que directamente lindan con la unidad catastral de Parquesur. El objetivo es cuantificar las relaciones urbanas entre el centro y el entorno próximo, ya sea mediante usos, relaciones entre dotaciones, y accesibilidad o transporte, en este análisis va a primar el estudio sobre plano, aunque también se harán análisis cuantitativos de superficies, y cualitativos.

2A: DELIMITACIÓN DE ÁREA PRÓXIMA: De cara al análisis del área próxima se escogieron las manzanas próximas al centro, marcándose en el plano la superficie de fachada para posteriores análisis (Figura 5.3.5).

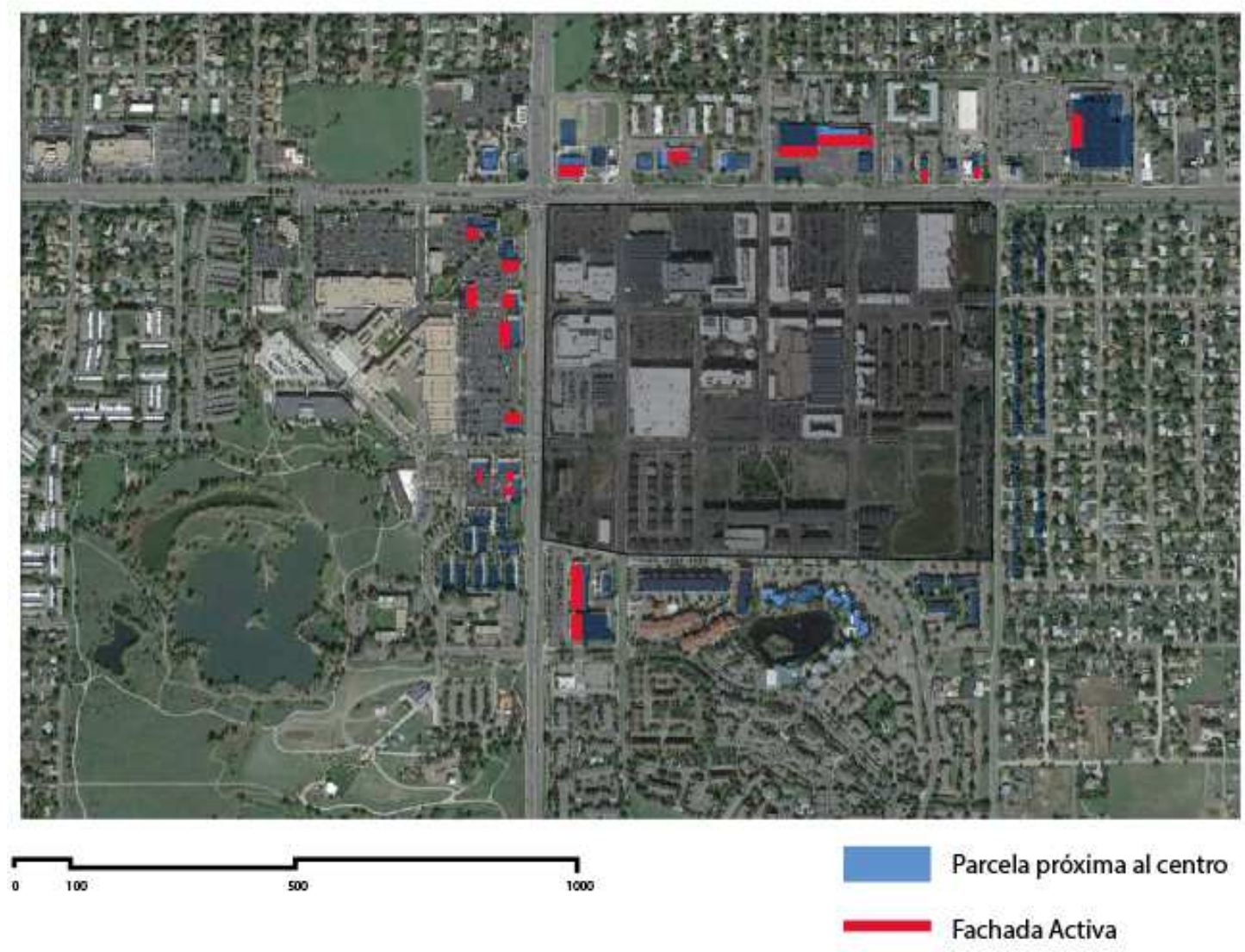

Figura 5.7.8: Análisis de parcelas próximas al centro. Fuente: Elaboración Propia a partir de datos de Google.

2B: SUPERFICIE TOTAL EDIFICADA EN ÁREA PRÓXIMA: Para el conteo de la superficie total estimada de las manzanas próximas al centro, se midió sobre un parcelario la superficie en planta de las mismas, que es de $282.255 \mathrm{~m}^{2}$. Luego, ésta fue multiplicada por el número de plantas medio de los edificios de susodichas manzanas, que para el caso de Shopping Belmar, 
se estableció en 1 planta en base al análisis de fotos del lugar. De este modo, la superficie construida de las manzanas próximas al centro es de $282.255 \mathrm{~m}^{2}$.

2C: USOS EN ÁREA PRÓXIMA: Las manzanas próximas al centro comercial, poseen una configuración de usos en la que predominan los edificios residenciales o de comercio, de poca altura en los cuales el uso es el mismo para todo el edificio. De este modo, para este análisis se establecieron los siguientes porcentajes:

Uso residencial: $80 \%$. Uso productivo: $8 \%$. Uso comercial: $12 \%$.

Quedando estas superficies:

Uso residencial: $225.804 \mathrm{~m}^{2}$. Uso productivo: $22580 \mathrm{~m}^{2}$. Uso comercial: $33871 \mathrm{~m}^{2}$.

2D: FACHADAS ACTIVAS EN ÁREA PRÓXIMA Para este análisis, las fachadas activas en manzanas próximas se marcaron en el plano, y se midieron en metros lineales, junto con la longitud de fachada total. la longitud de fachada activa es de 1710 metros siendo la longitud de fachada total de $21.480 \mathrm{~m}$ incluyendo las fachadas activas. el porcentaje es del $8 \%$.

2E: TIEMPOS DE LLEGADA DESDE LOS PUNTOS EN ÁREA A CENTRO COMERCIAL MEDIANTE TRANSPORTE PÚBLICO: Para la estimación de los tiempos de llegada en transporte público, fueron considerados los recorridos establecidos en 1P, y se utilizó la base de datos de Google Maps para establecer los tiempos de llegada. (Figura 5.7.6)

2F: TIEMPOS DE LLEGADA DESDE LOS PUNTOS EN ÁREA A CENTRO COMERCIAL MEDIANTE TRANSPORTE PRIVADO: Para la estimación de los tiempos de llegada en transporte público, fueron considerados los recorridos establecidos en 1P, y se utilizó la base de datos de Google Maps para establecer los tiempos de llegada, El centro, aunque posee aparcamientos, aún así, se añadió al trayecto unos dos minutos adicionales de maniobra y trayecto de llegada. De este modo, los tiempos establecidos para los medios de transporte son los siguientes para cada recorrido. (Figura 5.7.6)

El área que rodea el complejo de Belmar, está compuesta por las características relativas a una zona de baja densidad, no obstante al ser concebido el complejo como un centro urbano, existe cierta centralización de cara a la estructuración del transporte público. Belmar posee en sus inmediaciones paradas de autobús, siende este el único medio de accesibilidad. La frecuencia de paso entre vehículos es de aproximadamente 15 minutos de media, más el tiempo de llegada que no baja de 15 minutos para los recorridos establecidos. Por consiguiente en lo que es el complejo, prima la accebilidad por transporte particular, siendo los tiempos de llegada mucho más reducidos (8 minutos). Las vías al ser de gran capacidad, y de carácter secundario, no aparentan a primera vista tener problemas de tráfico, salvo que se den condiciones de tráfico muy elevado de cara a lo que es el nodo de interacción del propio centro.

FASE 3: ANÁLISIS DEL EDIFICIO DEL CENTRO COMERCIAL.

3A: DELIMITACIÓN DE ÁREAS EN FUNCIÓN DE LA RECUPERACIÓN DE AGUAS: Sobre la planta de cubiertas del complejo de Belmar, se delimitaron las áreas tanto permeables como 
impermeables, de acuerdo a los estipulado en la metodología. Como áreas permeables a la recuperación de aguas, Belmar, posee espacios verdes tanto en su centro, como en su periferia. Las superficies permeables de Belmar en total suman $200.000 \mathrm{~m}^{2}$, que son aproximadamente el $11 \%$ de los $1.862 .062 \mathrm{~m}^{2}$ totales de parcela.

3B: USOS DENTRO DEL EDIFICIO DEL CENTRO: Para los usos, se consideraron los diferentes locales dentro del centro comercial, buscándose los metros cuadrados de espacio productivo, y las dotaciones asistenciales dentro del mismo. Para el caso de Belmar, hay tres instalaciones dotacionales que se computaron, varios edificios de función terciaria no comercial y varios edificios residenciales dentro de la parcela del complejo. Los porcentajes de superficie en función al uso dentro de Belmar quedan distribuidas de la siguiente manera

Superficie comercial $37 \%\left(355.900 \mathrm{~m}^{2}\right)$

Superficie residencial $45 \%(429.378 \mathrm{~m} 2)$

Superficie Productiva no comercial 18\% (176.168m2)

3C: DELIMITACIÓN DE ÁREAS VERDES EN CENTRO COMERCIAL. (Análisis sobre plano y cuantitativo, unidad: metros cuadrados). El centro comercial Belmar, posee áreas verdes a su alrededor con vegetación. en total hay $200.000 \mathrm{~m}^{2}$ de superficie verde, desglosada de la siguiente manera:
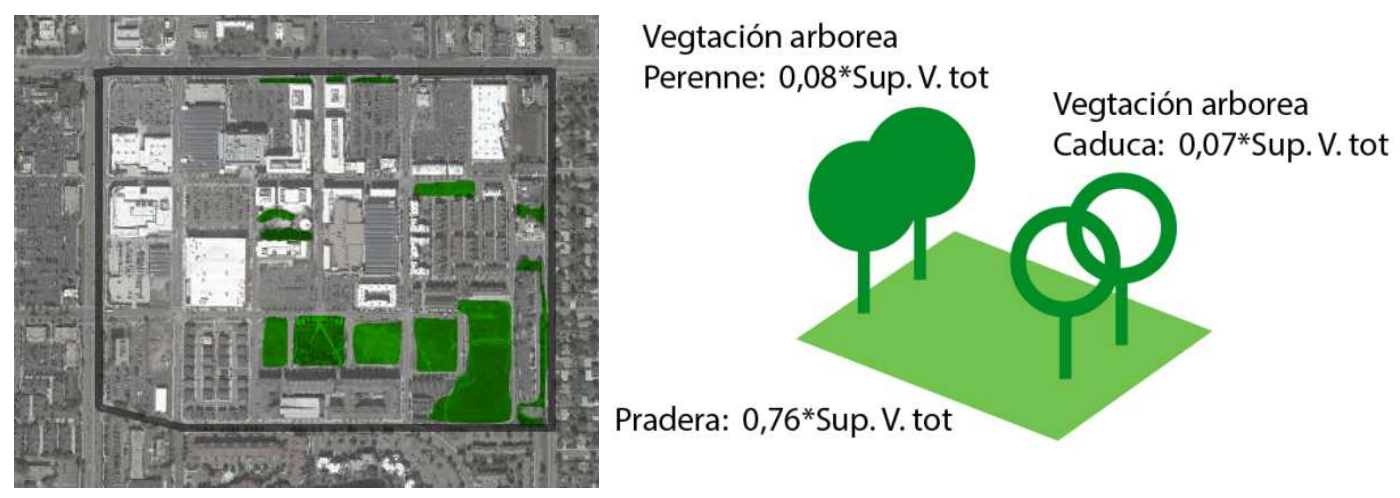

\begin{tabular}{|l|r|}
\hline 3C: S. de zonas verdes en centro comercial & Valor \\
\hline C4.1: pradera & 153215 \\
\hline C4.2: hierba de gran altura o huerto & 0 \\
\hline C4.3: vegetación arbustiva intensiva & 15321,5 \\
\hline C4.4: vegetación arbórea caduca & 1532 \\
\hline C4.5: vegetación arbórea perenne & \\
\hline
\end{tabular}

Figura 5.7.9: Áreas verdes y capas de vegetación en Belmar Fuente: Elaboración Propia a partir de datos de Google

3D: ABSORCIÓN DE LAS ÁREAS VERDES EN CENTRO COMERCIAL. Los metros cuadrados de superficie verde de Belmar, son capaces de asimilar aproximadamente unas 5944 toneladas de dióxido de carbono anuales, que son aproximadamente un $2 \%$ de las emisiones del centro (326891 T Co2 anuales), y un 0,4\% respecto de las emisiones del área urbana establecida (1360800 T Co2 anuales). (figura 5.7.10) 


\begin{tabular}{|l|r|r|r|r|r|r|}
\hline 3D: C.absorción elementos verdes en área & \multicolumn{1}{|l|}{ Pradera } & V.arb ext & V. A. Int. & H. Caduca & H. Perenne & Otro \\
\hline Superficie total & 153215,0000 & 0,0000 & 0,0000 & 15321,5000 & 1532,0000 & \\
\hline Tasa absorción TCo2/m2 año & 0,0013 & 0,0020 & 0,0350 & 0,1500 & 2,2500 & 0,0000 \\
\hline Absorción dióxido carbono TCo2 & 199,1795 & 0,0000 & 0,0000 & 2298,2250 & 3447,0000 & 0,0000 \\
\hline
\end{tabular}

Figura 5.7.10: Absorción de las áreas verdes en Belmar. Fuente: Elaboración Propia.

3E: ANÁLISIS BIOCLIMÁTICO DEL CENTRO COMERCIAL RESPECTO A CLIMA, DIAGRAMA DE GIVONI.

El Diagrama de Givoni para Denver es el siguiente (Figura 5.7.11).

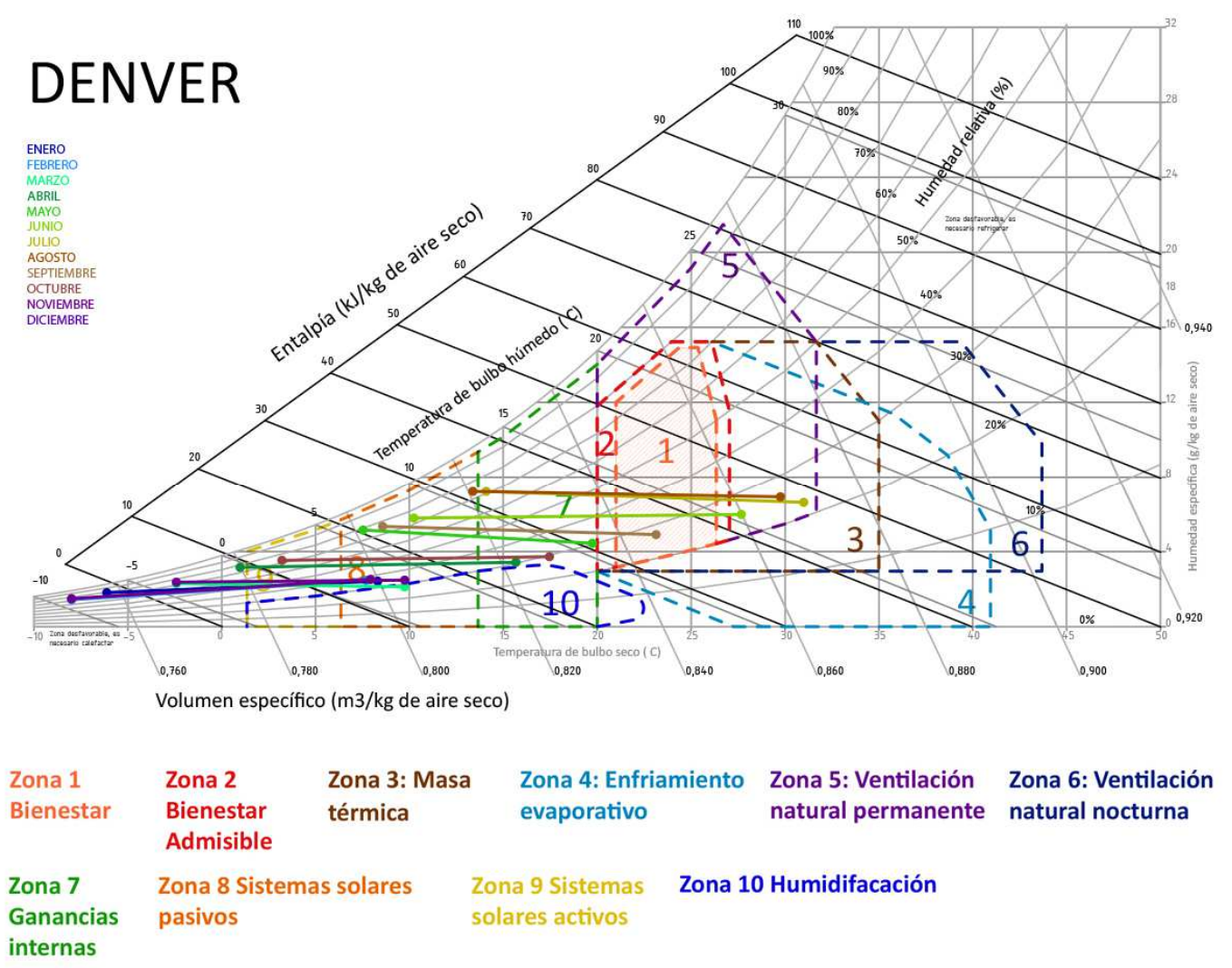

Figura 5.7.11: Diagrama de Givoni de Denver. Elaboración propia a partir de datos de Givoni y NOAA.

A primera vista, el clima de Denver, durante los meses de verano, hay horas del día dentro de la zona de confort, habiendo también gran parte de las mismas fuera, debido al exceso o defecto de calor. En otoño y primavera, las temperaturas no alcanzan casi nunca la zona de confort, y en invierno se encuentran muy alejadas de la misma debido a las bajas temperaturas, siendo necesarios sistemas de calefacción mecánicos.

Cualquier edificio de Denver, de acuerdo al diagrama de Givoni, necesitaría durante los meses más fríos, valerse de todo tipo de sistemas solares, además de necesitar medios mecánicos para calefactar, debido a las bajas temperaturas durante la mayoría de los días de invierno. En las horas más cálidas de los meses de verano, durante el día el edificio puede recurrir bien a la ventilación natural tanto nocturna como permanente por una parte, o al enfriamiento evaporativo por otra, ya que en esos meses la humedad tiende a encontrarse en valores bajos; 
la masa térmica también puede ser una opción a considerar. Lo que debe de tenerse en cuenta, es que no van a necesitarse en ningún momento sistemas mecanizados de refrigeración. En las horas más frías de los meses de verano, así como en la primavera o en el otoño, una combinación que considere el uso de las cargas internas, junto con los sistemas solares pasivos, será suficiente para lograr la temperatura de confort, siendo a veces necesario el uso de los sistemas de calefacción mecánicos, durante las horas más frías.

\section{F: CALIFICACIÓN ENERGÉTICA DEL CENTRO COMERCIAL.}

Respecto a la calificación energética del centro comercial Belmar, no fue posible encontrar datos, ni relativos al centro, ni relacionados con las instalaciones. De información de partida, se consideraron diferentes descripciones acerca del complejo, en el que se evidenciaba la presencia de varios edificios con categoría y homologación LEED ${ }^{65}$. Considerando que esta calificación está normalizada a escala internacional como muy favorable a efectos de impacto ambiental, consumo energético y emisiones; para la presente tesis, se consideró que los edificios con susodicha calificación tendrían una nota equivalente a una $A$ efectos de calificación energética europea. No obstante, en el complejo Belmar estos edificios se estimaron en aproximadamente un $50 \%$ de la superficie total; siendo el $50 \%$ de la superficie restante, edificios de un tipo más convencional con unas calificaciones energéticas y de emisiones más desfavorables. De este modo, para buscar una calificación media para Belmar, se interpolaron diferentes grados de calificación respecto a las superficies, considerando las siguientes calificaciones de partida. Se consideró un clima similar al de Madrid, pero con inviernos más rigurosos.

Edificios Leed:

Consumo de energía: $100 \mathrm{Kwh} / \mathrm{m}^{2}$ año. (A)

Emisiones anuales: $0,19 \mathrm{~T} / \mathrm{m}^{2}$ año. $(\mathrm{A})$

Edificios convencionales:

Consumo de energía: $300 \mathrm{Kwh} / \mathrm{m}^{2}$ año. (D)

Emisiones anuales: $0,5 \mathrm{~T} / \mathrm{m}^{2}$ año. (D)

De este modo, ponderando cada puntuación respecto a los porcentajes establecidos, a Belmar le corresponde esta calificación:

Consumo de energía: $200 \mathrm{Kwh} / \mathrm{m}^{2}$ año. (C)

Emisiones anuales: $0,34 \mathrm{~T} / \mathrm{m}^{2}$ año. (C)

3G: USO DE FUENTES DE ENERGÍA LIMPIAS. Algunos de los edificios de Belmar, poseen sistemas de generación de energías limpias, cuyas contribuciones energéticas se estimaron para la presente tesis en un 30\% aproximadamente para lograr la temperatura de confort mediante sistemas solares activos, y aproximadamente un $20 \%$ de la energía eléctrica requerida para otras funciones mediante aerogeneradores y paneles fotovoltaicos.

3H: ESPACIOS CON LUZ NATURAL Para medir esta superficie se consideraron de manera aproximada la superficie de los espacios iluminados de los edificios que componen el complejo

\footnotetext{
${ }^{65}$ DUNHAM Jones, Ellen; WILLIAMSON, June. 2011. Retrofitting Suburbia, Urban Solutions For Redesigning Suburbs.
} 
Belmar, se consideraron al completo los edificios residenciales, y de oficinas, considerándose como poco iluminados o de manera parcial los edificios comerciales más convencionales. En Belmar el espacio que cuenta con luz natural se estimó aproximadamente en el $83,53 \% \%$ de la superficie total.

3I: FORMA DE LA EDIFICACIÓN: Muchos de los edificios de Belmar, están adecuados a las condiciones climáticas de Denver, mientras que otros tienen formas más desfavorables. Aún así, entre los edificios del complejo, predominan las formas compactas y proporcionadas de los edificios, aunque no las orientaciones óptimas de las fachadas.

3J: PAVIMENTOS Y CUBIERTAS EN RELACIÓN A LA INCIDENCIA DE LA IRRADIACIÓN SOLAR. Sobre la planta de cubiertas se midieron las superficies de colores claros. Belmar tiene aproximadamente un $22,3 \%$ de su superficie de cubierta repelente de cara a la irradiación solar, siendo el $77,7 \%$ restante, absorbente de cara a la irradiación solar, debido a las extensas áreas de aparcamiento que posee.

FASE 4: CUESTIONARIOS DE LA METODOLOGÍA, APLICACIÓN DE INDICADORES Y BAREMOS.

\section{A.- REHABILITACIÓN ECOEFICIENTE.}

A1.- Cuestionario referenciado a rehabilitación hacia instalaciones poco emisivas.

Cuestión A1.1.- ¿El centro cuenta con instalaciones que no son necesarias de acuerdo a lo estipulado en el diagrama de Givoni?: Aunque no hay datos objetivos acerca de las instalaciones de Belmar, el complejo tiene edificios con calificación Leed, habiendo en el resto instalaciones que son necesarias de acuerdo a Givoni, a este caso de estudio le corresponde una nota de +1 en esta cuestión.

Cuestión A1.2.- ¿Las instalaciones del centro generan unas emisiones de dióxido de carbono superiores a la media?. En el estudio energético, se consideró al complejo Belmar, unas emisiones medias anuales de $0,34 \mathrm{~T} / \mathrm{m}^{2}$ año (C), eso corresponde a una nota de +3

Cuestión A1.3.- ¿Las instalaciones del centro se encuentran en un estado de obsolescencia?. Respecto esta cuestión, el autor desconoce el estado de las instalaciones del centro. No obstante, al ser un centro de reciente construcción, en el que se buscó la mayor eficiencia energética, se consideró el complejo Belmar con instalaciones en un estado de obsolescencia marginal; con lo que se puntuó esta cuestión con una nota de +1 .

Cuestión A1.4.- ¿Las instalaciones del centro tienen un consumo energético superior a la media?. En el estudio energético en el que se consideraron los dos tipos de edificios presentes en el complejo, Belmar ha obtenido en la calificación energética de consumo de energía primaria una nota de $\mathrm{C}$, eso corresponde a una nota de +3

EN RELACIÓN A INSTALACIONES POCO EMISIVAS, SHOPPING BELMAR HA OBTENIDO UNA PUNTUACIÓN DE 8 (10).

A2.- Cuestionario referenciado a inserción de medidas activas. 
Cuestión A2.1.- ¿Qué porcentaje de las calorías necesarias para lograr la temperatura de confort se logra mediante sistemas activos?. El complejo Belmar, posee medidas solares activas, que se estimaron que podrían subsanar hasta un $30 \%$ de la energía requerida para lograr la temperatura de confort (3G). Esta cuestión puntúa con +2 .

Cuestión A2.2.- ¿Qué porcentaje de la demanda energética se logra a partir de fuentes de energía renovable?: Belmar posee sistemas eléctricos fotovoltaicos que se estimaron que suplirían hasta un $20 \%$ de la demanda de energía eléctrica, esta cuestión fue puntuada con un +2 .

Cuestión A2.3.- ¿El centro cuenta con las medidas y dispositivos necesarios para su aclimatación de acuerdo a lo estipulado en el diagrama de Givoni para sistemas solares activos?: Aunque se desconocen de manera rigurosa las instalaciones de Belmar El complejo, posee sistemas solares activos, esta cuestión puntúa con +1 .

\section{EN RELACIÓN A MEDIDAS ACTIVAS, BELMAR HA OBTENIDO UNA PUNTUACIÓN DE 5 (10).}

A3.- Cuestionario referenciado a inserción de medidas Pasivas.

A3.1.- ¿El centro comercial tiene una forma adecuada en volumen a las condiciones climáticas?: Belmar se encuentra en una zona templada de acuerdo a la calificación de Olgyay, de acuerdo al análisis anteriormente realizado en el punto 3l, la mayoría de los edificios de Belmar cumplen los requisitos de proporción de planta, pero la mayoría no cumplen los de la orientación de la fachada principal. Los huecos, están expuestos a la irradiación solar parcialmente, estando protegidos en verano por parasoles o retranqueos. La mayoría de los edificios son volúmenes compactos algo fragmentados, los colores de fachada van de claros a medios. Le corresponde una puntuación de +1 .

A3.2.- ¿El estado de los cerramientos responde de manera correcta a las exigencias del clima en el que se asienta?: La calificación energética de Belmar a efectos de consumo global de energía es de $C$, esto significa que los cerramientos responden de una manera correcta respecto al clima. A este centro le corresponde una puntuación de +3 .

A3.3.- ¿Qué porcentaje de los espacios del centro cuentan con iluminación natural?: Belmar posee un $83,53 \% \%$ del espacio interior iluminado con luz natural. Le corresponde de este modo una puntuación de +2 .

A3.4.- Los espacios del centro, están adaptados a lo estipulado por el Diagrama de Givoni de su respectivo clima?: En Belmar, la mayoría de los edificios tiene los espacios interiores adaptados a lo dictado por Givoni, ya que los muros tienen masa térmica, y el tamaño controlado de los espacios interiores, hace que pueda ser viable calefactar usando las cargas internas, además en muchos edificios se puede utilizar la ventilación natural permanente, no obstante en el complejo hay varios edificios que no cumplen lo dictado por Givoni en espacios interiores ya sea por forma o cerramientos. De este modo, a Belmar le corresponde una calificación de +1

EN RELACIÓN A MEDIDAS PASIVAS, BELMAR HA OBTENIDO UNA PUNTUACIÓN DE 7 (10). 


\section{B.- REHABILITACIÓN MEDIOAMBIENTAL.}

B1.- Cuestionario referenciado a rehabilitación mediante zonas verdes.

Cuestión B1.1.- ¿En el área urbana hay suficiente zona verde en el área en relación a sus habitantes?: El área urbana de Belmar posee aproximadamente $17.016 .226 \mathrm{~m}^{2}$ de superficie verde en planta, que entre 177.950 habitantes, el ratio es de $95,62 \mathrm{~m}^{2}$ de superficie verde por habitante. Le corresponde una puntuación de +2 .

Cuestión B1.2.- ¿Las zonas verdes dentro del centro comercial pueden dar lugar a una área verde de uso cotidiano?: Shopping Belmar, posee $200.000 \mathrm{~m}^{2}$ de superficie verde en su parcela, superando el baremo mínimo de Salvador Rueda de $1000 \mathrm{~m}^{2}$ para espacios verdes cotidianos, le corresponde una puntuación de +1 a esta cuestión.

Cuestión B1.3.- ¿La vegetación en el área (incluyendo el edificio del centro), en que porcentaje es capaz de asimilar las emisiones de la misma área urbana?: Sumando las capacidades de asimilación de las superficies de vegetación establecidas, tenemos una capacidad de asimilación de 6.307.630 Toneladas de dióxido de carbono anuales, esto es aproximadamente algo más de un $400 \%$ de la huella de carbono del área, (1.023.000 Toneladas de dióxido de carbono anuales). Esta cuestión puntuará con +3 .

Cuestión B1.4.- ¿La vegetación en el centro comercial y su parcela, en que porcentaje es capaz de asimilar las emisiones del centro comercial?: Los espacios verdes del centro comercial, asimilan aproximadamente 5944,4 T Co2 anuales, que es un $18 \%$ de la huella de carbono anual del centro (326.891,6 T Co2 anuales), a esta cuestión le corresponde una puntuación de +1 .

Cuestión B1.5.- ¿La distancia media entre espacios verdes dentro del área es inferior a los 400 metros?: En el área de Belmar, hay una gran cantidad de espacios verdes, considerando tanto los públicos cómo los privados, siendo el resultado de ello que la distancia media entre los mismos es inferior a los 400 metros, a esta cuestión le corresponde una puntuación de +1 .

EN RELACIÓN A ZONAS VERDES, BELMAR HA OBTENIDO UNA PUNTUACIÓN DE 8 (10).

B2.- Cuestionario referenciado a inserción de superficie asimiladora de agua.

Cuestión B2.1.- ¿El clima en el que está el centro corresponde a un clima árido o semiárido?: El clima de Denver tiene una temperatura media anual de 10ㅇ, y una humedad relativa de 394,72mm, lo que corresponde un índice de Martonne de 19,73 que es de una zona semiárida. A Belmar le corresponde una calificación de +0 a esta cuestión.

Cuestión B2.2.- ¿En qué porcentaje, la superficie absorbente de agua, en el área urbana, es en relación a la impermeable?: En esta cuestión, se consideró como superficie permeable las áreas verdes presentes en la zona $\left(17.016 .226 \mathrm{~m}^{2}\right)$, que son aproximadamente un $33 \%$ de los $50.300 .000 \mathrm{~m} 2$ totales del área urbana. esta cuestión puntúa con +2 .

Cuestión B2.3.- ¿El centro comercial posee sistemas para el aprovechamiento del agua?: Aunque el autor desconoce el estado de las instalaciones de agua de Belmar, se supuso que los 
edificios de Belmar, buscar el menor impacto medioambiental, contarían con sistemas para el aprovechamiento del agua. A esta cuestión le corresponde una puntuación de +2 .

Cuestión B2.4- ¿El consumo de agua del centro es en litros por visita?: A pesar de que no hay datos del centro en este sentido, Al área de Belmar, se le estimó un consumo de agua de 30 litros por visita, que corresponde a una puntuación de +1 .

\section{EN RELACIÓN A SUPERFICIE ASIMILADORA DE AGUA, BELMAR HA OBTENIDO UNA PUNTUACIÓN DE 5 (10).}

B3.- Cuestionario referenciado a tratamiento de isla de calor.

Cuestión B3.1.- ¿El clima en el que está el centro comercial tiene una temperatura media más o menos elevada?. El clima Denver tiene una temperatura media anual de 10 , esto significa que es un clima templado algo propenso a altas temperaturas. Esta pregunta puntúa con +1

Cuestión B3.2.- ¿En el clima en el que está ubicado en centro hay olas de calor frecuentes o en intervalo temporal menor?. El clima de Denver, tiene olas de calor con cierta frecuencia, debido a su carácter semiárido y continental, esta cuestión puntúa con un +0.

Cuestión B3.3.- ¿El centro está en un área en el cual la diferencia de temperatura respecto a la normal es de?. Analizando la isla de calor de Denver (Figura 5.4.12), nos encontramos con el hecho de que Belmar se encuentra en un área muy periférica de la ciudad, en la que el efecto de isla de calor afecta de forma marginal (1ํ), de este modo esta cuestión puntúa con un +2 .

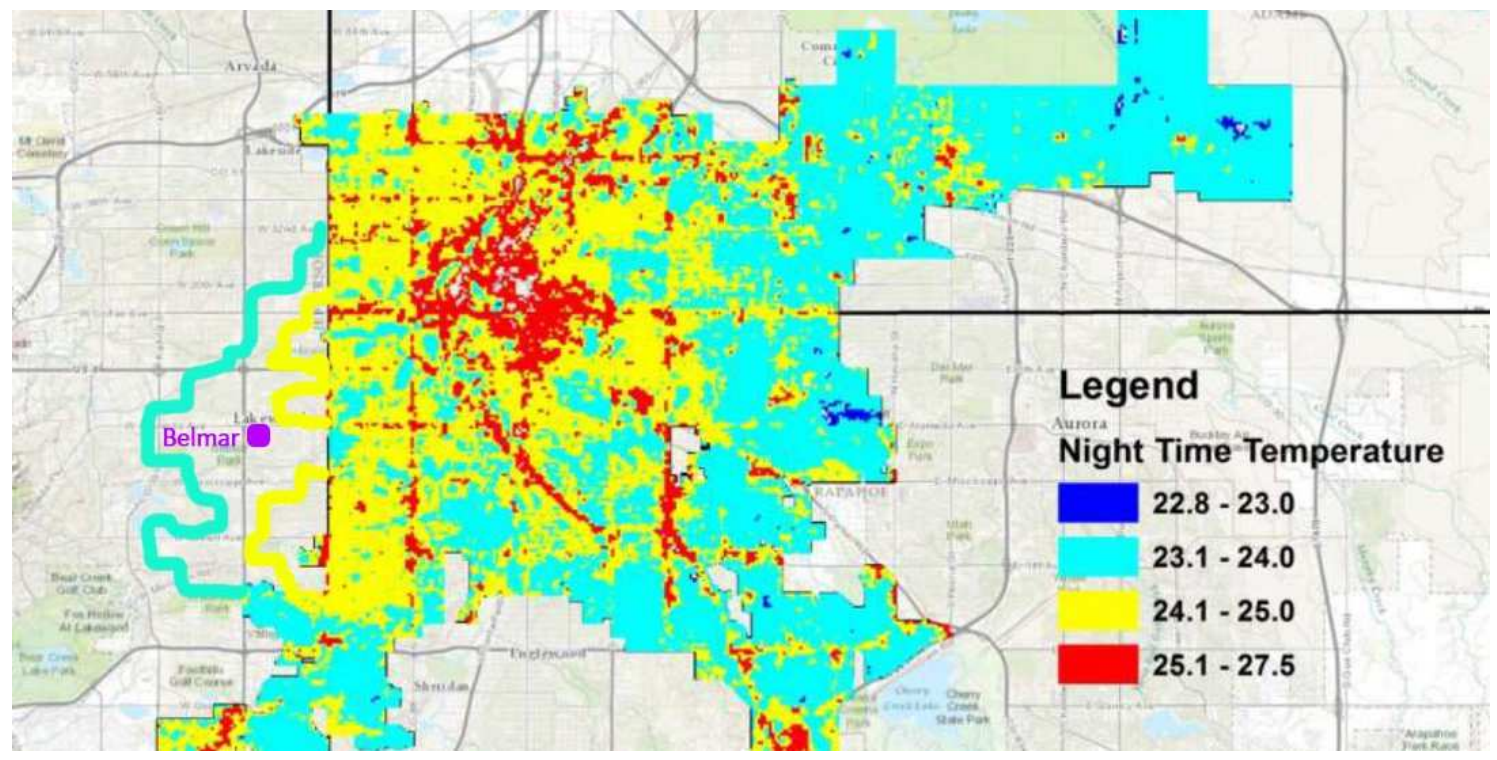

Figura 5.4.12: Isla de calor de Denver, se estimó en la zona de Lakewood en base a la configuración urbana. Fuente: www.deeproot.com.

Cuestión B3.4.- ¿La suma de superficies que contribuyen a la isla de calor en la parcela y el edificio del centro es superior a un porcentaje de la superficie total?. La superficie absorbente de irradiación de Belmar es del $77,70 \% \%$, lo que le corresponde una puntuación de +1 . 
EN RELACIÓN A TRATAMIENTO DE ISLA DE CALOR, BELMAR HA OBTENIDO UNA PUNTUACIÓN DE 4 (10).

4C.- REHABILITACIÓN POR USOS.

C1.- Cuestionario referenciado a inserción de uso residencial.

Cuestión C1.1.- ¿El centro comercial posee usos residenciales u hoteleros dentro de su unidad catastral?. Belmar posee aproximadamente $429500 \mathrm{~m}^{2}$ de uso residencial dentro de su unidad catastral, esta superficie puede alojar a lo sumo a 21475 personas, es decir, a un $12 \%$ de la población asignada al centro. Esta cuestión puntúa con +1 .

Cuestión C1.2.- ¿Las parcelas próximas al centro comercial posen usos residenciales $u$ hoteleros?: Al tener Belmar unos $429500 \mathrm{~m}^{2}$ de uso residencial, para este análisis se sumó esta superficie residencial, a la superficie residencial total de las parcelas próximas $(225804+429500=655304)$, cuyo resultado fue dividido entre la superficie edificada de las parcelas próximas, más la superficie construida del centro comercial $(282255+961446=$ 1243701). De este modo, el uso residencial copa el 52\% de en el área próxima al centro comercial, lo que le corresponde una puntuación de +3 .

Cuestión C1.3.- ¿Dentro del área de influencia del centro comercial, que porcentaje de la superficie de uso total es de tipo residencial?: Considerando las superficies establecidas para cada zona tipológica, estas fueron sumadas, obteniendo una superficie residencial total de $5.954 .050 \mathrm{~m}^{2}$ que fue dividida entre la superficie total construida para hallar el porcentaje $\left(9.606 .040 \mathrm{~m}^{2}\right)$. De este modo, la superficie de uso residencial en el área de influencia de Belmar, se estableció aproximadamente en un $62 \%$ de la superficie edificada total, lo que le corresponde una puntuación de +4

\section{EN RELACIÓN A USO RESIDENCIAL, BELMAR HA OBTENIDO UNA PUNTUACIÓN DE 8 (10).}

C2.- Cuestionario referenciado a inserción de usos productivos, y terciarios no comerciales.

Cuestión C2.1.- ¿El centro comercial posee usos productivos no comerciales dentro de su unidad catastral?: Belmar posee unos $176.046 \mathrm{~m}^{2}$ de superficie productiva no comercial, en forma de oficinas, esta cuestión puntúa con +1 .

Cuestión C2.2.- ¿Las parcelas próximas al centro comercial posen usos productivos no comerciales?: Al tener Belmar unos $176046 \mathrm{~m}^{2}$ de uso productivo, para este análisis se sumó esta superficie productiva, a la superficie productiva total de las parcelas próximas $(176.046+22.580=198.626)$, cuyo resultado fue dividido entre la superficie edificada de las parcelas próximas, más la superficie construida del centro comercial (282255+961446= 1243701). De este modo, el uso terciario no comercial copa el $16 \%$ de en el área próxima al centro comercial, lo que le corresponde una puntuación de +3 .

Cuestión C2.3.- ¿Dentro del área de influencia del centro comercial, que porcentaje de la superficie de uso total es de tipo productivo no comercial?: Considerando las superficies productivas establecidas para cada zona tipológica, estas fueron sumadas obteniendo una superficie productiva total $\left(1328484 \mathrm{~m}^{2}\right)$ que fue comparada con la superficie total construida 
$\left(23693188 \mathrm{~m}^{2}\right)$. De este modo, la superficie de uso productivo en el área de Belmar, se estableció aproximadamente en un $14 \%$ de la superficie edificada total. A esta cuestión le corresponde una puntuación de +3 .

EN RELACIÓN A USO PRODUCTIVO, SHOPPING BELMAR HA OBTENIDO UNA PUNTUACIÓN DE 7 (10).

C3.- Cuestionario referenciado a inserción de instalaciones dotacionales y asistenciales. (Figura 5.7.4)

Cuestión C3-1.- ¿El centro comercial posee usos dotacionales dentro de su unidad catastral?: De análisis de directorios del complejo y la información de Google Maps sobre los negocios en el complejo, se estableció que Belmar, posee tres instalaciones asistenciales, que son una clínica privada, un centro de oficios, y una galería museo privada. Esta cuestión puntúa con un +1 .

Cuestión C3.2.- ¿Las parcelas próximas al centro comercial posen usos dotacionales?: En las manzanas próximas, no hay dotaciones asistenciales. No obstante, el complejo Belmar al haber sido proyectado para albergar esta función, las instalaciones dotacionales fueron incluidas en el cómputo. Belmar posee 1 instalación de visita esporádica, y dos de visita habitual. Esta pregunta puntúa con un +4 .

Cuestión C3.3.- ¿A un kilómetro del centro comercial hay usos dotacionales?: En el área de dotaciones correspondiente a lo que es el centro comercial de Shopping Belmar, hay 2 dotaciones de visita esporádica y 4 dotaciones de visita habitual. Esta cuestión puntúa con +2 .

EN RELACIÓN A DOTACIONES, SHOPPING BELMAR HA OBTENIDO UNA PUNTUACIÓN DE 7 (10).

4D.- REHABILITACIÓN DE ENTORNO URBANO.

D1.- Cuestionario referenciado a la inserción de medios de transporte eficientes.

Cuestión D1.1.- ¿El centro dispone en sus inmediaciones de alguna parada de transporte público?: Belmar, posee instalaciones de transporte público en las inmediaciones de sus parcelas, buscando ser el complejo uno de los puntos de confluencia del transporte público local. La puntuación es de +1 .

Cuestión D1.2.- ¿̇El tiempo de llegada al centro mediante transporte público supera al tiempo de llegada en vehículo particular?, A partir del análisis del apartado $2 \mathrm{~F}$, el tiempo de llegada medio en transporte público es más que el doble que el empleado usando un vehículo privado, (2,5 veces mayor, considerando tiempos de aparcamiento del vehículo particular), esta cuestión puntúa con +0. (Figura 5.7.13)

\begin{tabular}{|l|r|r|}
\hline Comparación de tiempos de recorrido & Recorrido 1 & Recorrido 2 \\
\hline Total tiempo desplazamiento tte público & 29 & 21 \\
\hline Total tiempo desplazamiento tte privado & 11 & 9 \\
\hline Relación entre tiempos desplazamiento & 2,636363636 & 2,333333333 \\
\hline Media tiempo desplazamiento & & 2,484848485 \\
\hline
\end{tabular}

Figura 5.7.13: Comparación de recorridos a Belmar. Fuente: Elaboración propia. 
Cuestión D1.3.- ¿El área urbana del centro comercial está cubierta de forma adecuada por la infraestructura de transporte público?. Estudiando con Google Maps la localización de las paradas de transporte público, y ubicando sus correspondientes radios de 200 metros, se dedujo que el área urbana de Belmar, está cubierta en menos de un 50\% aproximadamente por la infraestructura de transporte público. Lo que la cuestión puntúa con un +0.

Cuestión D1.4.- ¿Los usos en la zona están mezclados o zonificados?: En el área de Shopping Belmar, el índice Global de Mezcla de usos es de 0 (Zona de muy poca complejidad urbana), esto le corresponde una puntuación de +0 .

Cuestión D1.5.- ¿El Área urbana próxima al centro cuenta con instalaciones enfocadas en la movilidad sostenible?: El centro comercial Shopping Belmar posee sistemas adaptados a la movilidad sostenible dentro del complejo, aunque estas son esporádicas. Esta cuestión obtiene una puntuación de +1 .

EN RELACIÓN A TRANSPORTE EFICIENTE, SHOPPING BELMAR HA OBTENIDO UNA PUNTUACIÓN DE 2 (10).

D2.- Cuestionario referenciado a la rehabilitación por corrección de la densidad en área urbana.

Cuestión D2.1.- ¿La densidad de población en el área del centro está en el intervalo entre h/ha?, La densidad de población del área de Belmar es la del distrito Lakewood $(0,0015$ $\left.\mathrm{hab} / \mathrm{m}^{2}\right)$, a esta cuestión le corresponde una puntuación de +0 .

Cuestión D2.2.- ¿A efectos de densidad, el tejido mayoritario es favorable o desfavorable de cara a la sostenibilidad?. El índice global de densidad del área de Shopping Belmar es de 1, lo que es un entorno de densidad baja, a esta cuestión le corresponde una puntuación de +0 .

Cuestión D2.3.- ¿La cantidad de espacio ocupado en el área está en el intervalo? El espacio ocupado en el área de Shopping Belmar, es de un 21\%, lo que corresponde a una puntuación de +1 .

EN RELACIÓN A DENSIDAD, SHOPPING BELMAR HA OBTENIDO UNA PUNTUACIÓN DE 1 (10).

D3.- Cuestionario referenciado a mejora de la seguridad y la paseabilidad en el área urbana.

Cuestión D3.1.- ¿En el área de influencia o en sus proximidades hay elementos negativos de cara a la seguridad o a la salubridad del área?: En el área cercana a Belmar, no hay elementos negativos Esta cuestión puntúa con +1 .

Cuestión D3.2.- ¿El centro comercial se encuentra en una zona de puntos fríos de actividad durante el día?. El área que rodea Belmar, es una zona poco compleja con avenidas de gran tamaño y poca densidad, van a haber puntos fríos durante el día. Esta cuestión puntúa con +0.

Cuestión D3.3.- ¿El centro comercial se encuentra en una zona de puntos fríos durante la noche?, debido a lo anteriormente mencionado, el problema de puntos fríos va a agravarse durante la noche, debido al cierre de numerosas instalaciones dotacionales y comerciales, tanto dentro de Belmar como en sus inmediaciones, esta cuestión puntúa con +0 . 
Cuestión D3.4.- ¿El centro comercial se encuentra en una zona con áreas de difícil control visual o de contacto urbano?. En torno a Belmar no hay elementos que dificulten el control urbano del espacio público. Esta cuestión puntúa con +1

Cuestión D3.5.- ¿ ¿La sensación de seguridad por parte de los ciudadanos de la zona es positiva o negativa?: En el área de Lakewood, la sensación por parte de los habitantes es generalmente positiva. La puntuación a esta cuestión es de +1 .

Cuestión D3.6.- ¿La zona próxima al centro comercial tiene un porcentaje de fachadas activas?: En las manzanas próximas al centro comercial, hay un $7,96 \%$ de fachadas activas, lo que le corresponde una puntuación de +0 .

Cuestión D3.7.- ¿La distancia de la puerta del edificio del centro comercial al inmueble residencial cercano es superior a los 200 metros?: Dentro de Belmar hay edificios residenciales esta cuestión puntúa con +1 .

Cuestión D3.8.- ¿La cantidad de espacio libre en el área va a resultar desfavorable de cara a la paseabilidad?: El espacio libre en el área de Shopping Belmar es de aproximadamente un 79\%, de modo que esta cuestión va a puntuar con un +0 .

Cuestión D3.9.- ¿Los usos en la zona están mezclados o zonificados? El índice global de mezcla de usos es de 0 , el ratio de mezcla de usos en el entorno urbano es casi nulo. Esta cuestión puntúa con +0 .

EN RELACIÓN A PASEABILIDAD, SHOPPING BELMAR HA OBTENIDO UNA PUNTUACIÓN DE 4 (10).

\section{E.- CUESTIONARIO RELACIONADO CON LA ACTIVIDAD DEL CENTRO Y SUS CONSECUENCIAS URBANAS.}

Cuestión E1: ¿La actividad del centro comercial, va a penalizar o a favorecer la sostenibilidad del entorno urbano?: Belmar tiene un índice de atracción de 3, y la puntuación total en el cuestionario relacionado con el transporte eficiente es de 2 . De este modo, consultando la tabla del apartado 3.10, 4E. se comprueba que el efecto de la actividad que ejerce el centro sobre el área urbana, va a ser moderado a efectos de transporte, y va a suponer un impacto ambiental sobre el aire, esto es consecuencia del uso generalizado de medios de transporte particulares, poco respetuosos con el medio ambiente. Por consiguiente se penaliza la puntuación de TRANSPORTE EFICIENTE (D1) en un -1, quedando finalmente en 1, y Se penaliza la puntuación de REHABILITACIÓN DE ZONAS VERDES (B1) en un -1, quedando en 7.

FASE FINAL: GRÁFICO DE LA ROSA DE REHABILITACIÓN SOSTENIBLE.

Las puntuaciones obtenidas en el anterior cuestionario, fueron colocadas en el gráfico de la rosa de rehabilitación sostenible, obteniendo el siguiente resultado (Figura 5.5.14): 


\section{(A) ECOEFICIENTE}

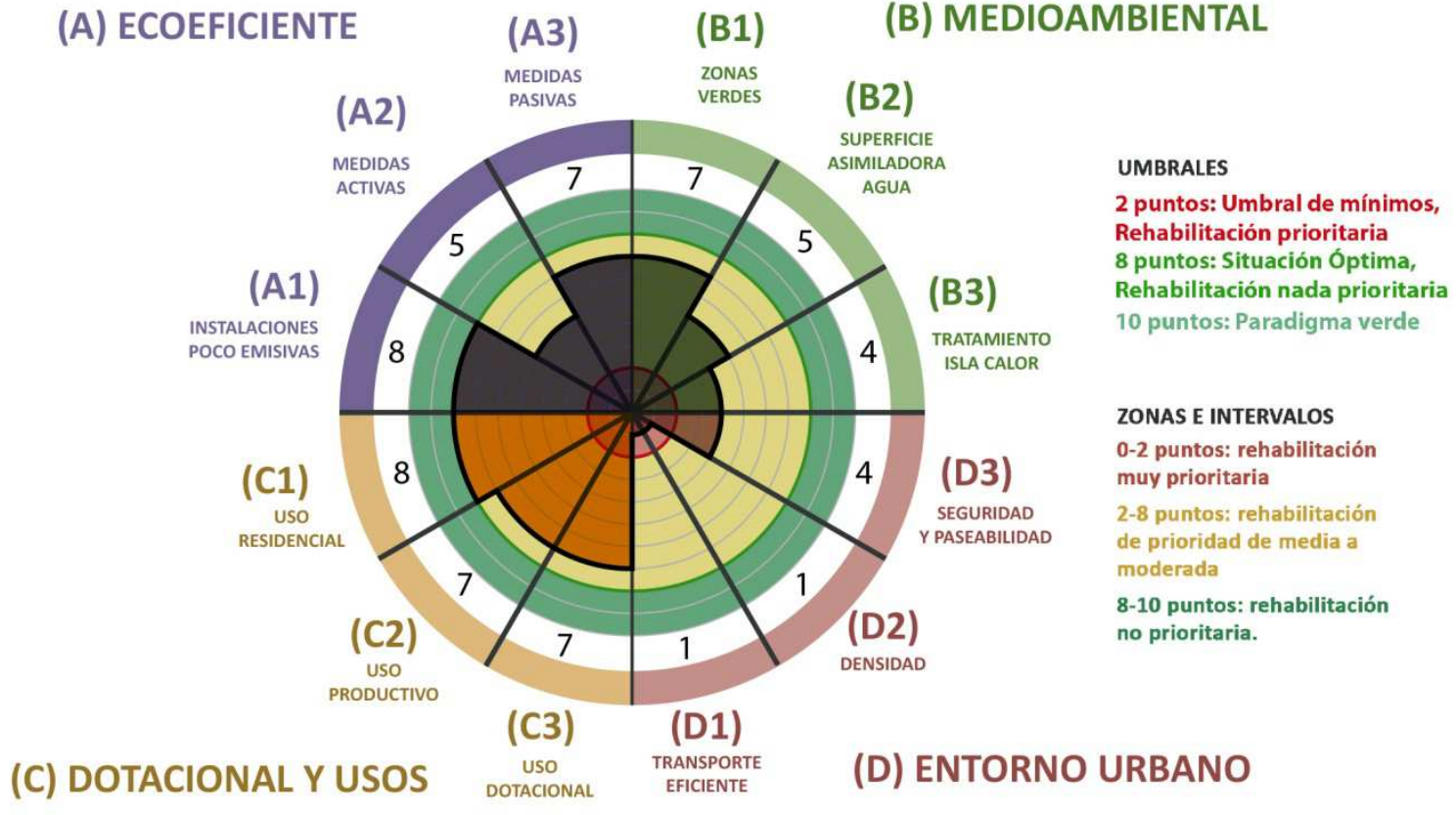

Figura 5.7.14: Gráfico de rosa de rehabilitación sostenible para Belmar. Fuente: Elaboración propia.

De acuerdo a lo mostrado en el gráfico anterior, Belmar al ser el resultado de una rehabilitación enfocada en la sostenibilidad urbana, sobre un centro comercial de gran superficie. Las puntuaciones en la rosa son favorables de cara a la eficiencia energética y al medio ambiente. Como aliciente, el complejo en el ámbito de dotaciones y usos, cumple de manera muy eficaz los requerimientos de sostenibilidad impuestos en esta tesis, estando en los tres campos de rehabilitación muy cerca de la situación óptima. Como contraste a esto, el entorno urbano de Belmar, tiene carencias muy graves de acuerdo a la sostenibilidad medioambiental, especialmente en lo relacionado con la baja densidad, y la generalización de los medios de transporte con severo impacto ecológico. De este modo se verifica lo dictado por Helen Dunham Jones en el libro de Retrofitting Suburbia, cuando considera que la infraestructura del complejo de Belmar todavía está pensada para los desplazamientos mediante vehículo particular, hecho que se agrava con la baja densidad del entorno suburbano de la zona en la que el centro está ubicado. Como apunte adicional, la necesaria disponibilidad de aparcamiento para los vehículos particulares, y la gran superficie pavimentada que esto requiere, es a su vez es la causa de que las puntuaciones de Belmar relacionadas con la superficie asimiladora de aguas y el tratamiento de isla de calor sean un tanto mediocres para lo que podría esperarse de una rehabilitación modélica de urbanismo sostenible en los Estados Unidos de América. Esto significa que para lograr la sostenibilidad medioambiental en este caso de estudio, las actividades de rehabilitación en Belmar, no deberían de ir encaminadas de manera inmediata hacia lo que es el complejo en sí, o los edificios que lo componen. Sino que es prioritario incrementar de manera paulatina la densidad del entorno urbano, a su vez que la inserción de usos no residenciales dentro del mismo, siendo esto aliciente para dar el siguiente paso que sería la inserción de medios de transporte más eficientes. No obstante la rehabilitación de este tipo de zonas urbanas es un tema muy complejo que no se va a tocar a fondo en esta tesis, ya que el campo de actuación de la misma está limitado a lo que es la parcela del centro comercial. En el caso de que se optase por operar dentro del complejo de 
Belmar, las rehabilitaciones deberían de centrarse en el incremento de la superficie permeable en las enormes superficies pavimentadas y la mitigación de la isla de calor.

\section{8.- CASO 8: MALL OF AMERICA}

Mall of America, es una caso de centro comercial de gran tamaño, ubicado en un entorno de densidades mínimas, caracterizado por la presencia de grandes infraestructuras para transporte privado. Este centro se ubica en una periferia apartada de Minneapolis (Bloomington) en las inmediaciones del aeropuerto de la ciudad. Este caso de centro para la presente tesis, fue considerado como un caso de gran tamaño y capacidad, que tiene un radio de influencia que abarca casi todo Estados Unidos, siendo un paradigma e icono de la tipología de centro comercial multifunción periférico. Este capítulo en su totalidad corresponde al análisis de Mall of America, aplicando la metodología de la tesis paso a paso, para establecer de este modo las medidas de rehabilitación más eficientes para este caso de centro comercial, en el gráfico de rosa de rehabilitación sostenible. Se explicarán en cada uno de los epígrafes, la fuente de dato, y cómo fue calculado o hallado, todo ello de acuerdo a lo establecido en el capítulo 3.

\section{FASE 0: RECOGIDA DE DATOS CUANTITATIVOS.}

En esta fase, se va a realizar una recogida de datos cuantitativos oficiales del centro comercial Mall of America y su entorno urbano. Estos se hallarán bien a partir de fuentes oficiales, de las autoridades urbanas de Bloomington, o bien midiendo sobre plano. Se considerarán los siguientes datos que serán de utilidad para posteriores análisis. (Figura 5.8.1)

\begin{tabular}{|l|l|}
\hline \multicolumn{2}{|c|}{ MALL OF AMERICA } \\
\hline \multicolumn{2}{|c|}{ FASE 0, RECOGIDA DE DATOS CUANTITATIVOS } \\
\hline OC.- TABLA DE DATOS CENTRO & Valor \\
\hline OC1: Superficie centro comercial (m2) & 730.000 \\
\hline OC2: Superficie de parcela o ud. Catastral (m2) & 307.690 \\
\hline OC3: Superficie en planta (m2) & 212.364 \\
\hline OC4: Número de visitantes semanal (pe/sem) & 762.000 \\
\hline OC5: Índice de Atracción ( $\mathrm{n}$ ) & 5 \\
\hline OC6: Superficie de tipo residencial (m2) & 60.918 \\
\hline OC7: Superficie de uso productivo (m2) & 0 \\
\hline OC8: Número de instalaciones dotacionales ( $\mathrm{n}$ ) & 0 \\
\hline OU.- TABLA DE DATOS ENTORNO URBANO & Valor \\
\hline OU1: Población asignada a centro (pe) & 365.000 \\
\hline OU2: Densidad de población (hab/m2) & 0,00092 \\
\hline U03: Superficie partida de entorno urbano (m2) & 396.739 .130 \\
\hline
\end{tabular}

Figura 5.8.1: Tabla de datos de Mall of America Fuente: Elaboración Propia

OC.- TABLA DE DATOS DEL CENTRO COMERCIAL. 
C1: SUPERFICIE CENTRO COMERCIAL TOTAL: Este dato fue obtenido de fuentes extraoficiales, ya que no pudieron obtenerse datos oficiales de la gerencia de este centro. La superficie edificada total de Mall of America es de $730.000 \mathrm{~m}^{2}$ aproximadamente, contando la superficie originaria del centro comercial $\left(230.000 \mathrm{~m}^{2}\right)$ con la ampliación prevista $\left(500.000 \mathrm{~m}^{2}\right)$, la cual está abierta parcialmente, y se prevé su apertura en los próximos años.

C2: SUPERFICIE TOTAL DE LA PARCELA DEL CENTRO: Para la obtención de este dato se midió la superficie de la parcela sobre una foto aérea del centro, la superficie de la parcela es de $307.690 \mathrm{~m}^{2}$

C3: SUPERFICIE EN PLANTA DEL EDIFICIO DEL CENTRO COMERCIAL. La parcela del centro comercial Shopping Mall of America está ocupada al $69 \%$ de su superficie, a partir de lo analizado sobre la planta. La superficie en planta de Shopping Mall of America es de 212.364 $\mathrm{m}^{2}$

C4: NÚMERO DE VISITANTES SEMANAL. Al no poder obtenerse datos del número de visitantes del centro comercial Shopping Mall of America, se realizó un conteo estimativo de las visitas tomando como referencia datos relacionados con las visitas anuales en la página web del centro comercial. Mall of América estima sus visitas anuales en aproximadamente 40 millones de personas. Considerando que en esta tesis un año tiene aproximadamente 52,14 semanas, para este centro comercial, se estimó el número de visitantes semanal en un ratio variable cercano a las 762.000 personas.

C5: ÍNDICE DE ATRACCIÓN DEL CENTRO. En función al número de visitantes del centro, A Mall of America le corresponde un índice de 5 (Más de 300.000 visitantes por semana), de acuerdo a lo establecido en el capítulo de la metodología relacionado con este apartado.

C6: SUPERFICIE DE USO EN EL CENTRO DE TIPO RESIDENCIAL. Mall of America posee un hotel de aproximadamente $60.918 \mathrm{~m}^{2}$ dentro de su unidad catastral, se prevé la apertura de otro hotel en la nueva ampliación.

C7: SUPERFICIE DE USO EN EL CENTRO DE TIPO PRODUCTIVO: Dentro de Mall of América no hay superficie de tipo productivo, ajena a las oficinas de la gerencia del centro comercial.

C8: NÚMERO DE INSTALACIONES EN EL CENTRO DE TIPO DOTACIONAL O ASISTENCIAL: En Mall of América no hay instalación alguna de tipo asistencial.

\section{OU.- TABLA DE DATOS DEL ENTORNO URBANO.}

U1: POBLACIÓN DE ÁREA URBANA ASIGNADA A CENTRO COMERCIAL: Dividiendo la superficie del centro comercial entre 2, salió una población asignada de 365.000 personas.

U2: DENSIDAD DE POBLACIÓN EN EL DISTRITO DEL CENTRO COMERCIAL: Para el análisis urbano, se cogió la densidad de población del distrito de Bloomington en Minneapolis, la cual fue ponderada para adaptarse a la realidad suburbana dónde está ubicado el centro comercial, la densidad se estableció en 0,00092 hab/ $\mathrm{m}^{2}$.

U3: SUPERFICIE DEL ENTORNO URBANO: La superficie del entrono urbano a analizar, se sacó de los datos de población asignada al centro, la cual fue dividida entre la densidad del área, la superficie de partida es de $396.739 .130,4 \mathrm{~m}^{2}$. 


\section{FASE 1: ANÁLISIS DEL CONTEXTO URBANO.}

1A: ESTABLECIMIENTO DEL ÁREA DE INFLUENCIA DEL CENTRO COMERCIAL: En base a la superficie del área, hallada anteriormente, al área de análisis del centro comercial Mall of America, le corresponde un radio de aproximadamente 11 kilómetros a partir del lindero de la parcela del centro, esta superficie para el análisis del entorno urbano del centro comercial, es poco rigurosa y demasiado compleja, ya que ocupa casi un tercio de la ciudad de Minneapolis e incluye dentro de sí misma extensas áreas interurbanas relacionadas con otros municipios, estando incluso dentro de esta zona el centro comercial Southdale. De este modo, el área de análisis de Mall of América se redujo a un recuadro de áreas tipo, cuyo lindero va a establecerse en $\mathbf{2 0 0 0}$ metros en paralelo a la planta del edificio del centro comercial. (Figura 5.8.2).

1B: DELIMITACIÓN SOBRE PLANO DEL ÁREA DE INFLUENCIA: En base a las consideraciones citadas en el anterior capítulo, se estableció el área de análisis de Mall of America sobre el plano, el área de la misma es de 20.047.119m² (Figura 5.8.2).

1C: SUBDIVISIÓN DEL ÁREA DE INFLUENCIA EN ÁREAS HOMOGÉNEAS Y DELIMITACIÓN DE ZONAS VERDES Para este análisis, el área urbana anteriormente asignada, va a dividirse en zonas homogéneas de acuerdo a su tejido urbano, (Figura 5.8.2) marcándose a su vez la superficie de zonas verdes. Se establecieron cuatro tipologías de zona homogénea, descontando los espacios verdes y sin edificar en el área, cada zona tiene aproximadamente:

Z1: $9.126 .822 \mathrm{~m}^{2}$ brutos.

Z2: $2.376 .806 \mathrm{~m}^{2}$ brutos.

La suma total de las zonas edificadas es de $11503628 \mathrm{~m} 2$.

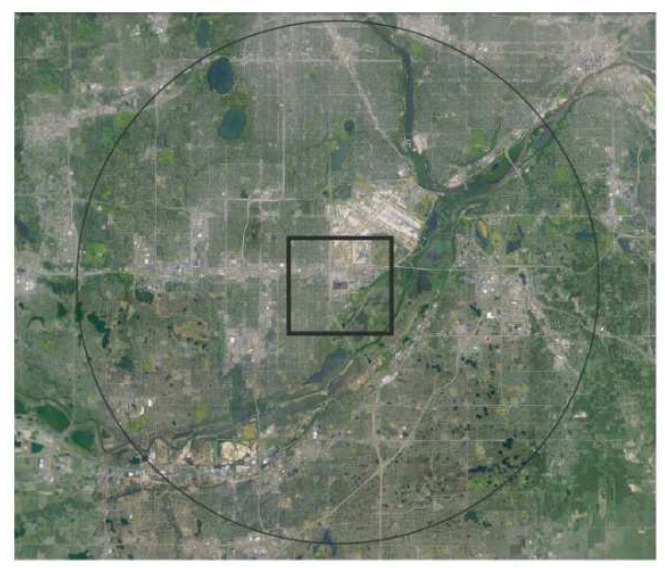

Tejido urbano alta densidad

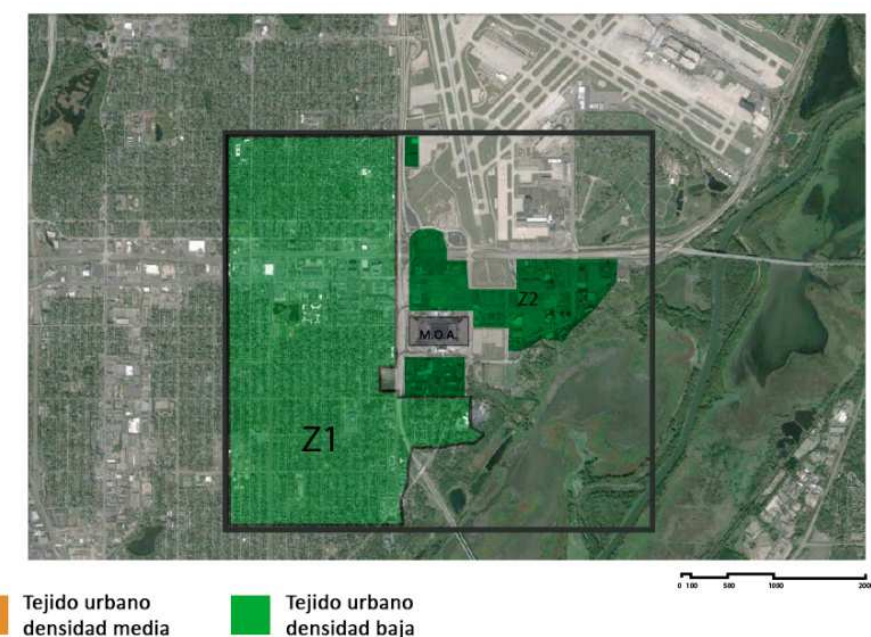

densidad media

densidad baja

Figura 5.8.2: Área de Mall of America, establecimiento y subdivisión por zonas homogéneas. Fuente: Elaboración propia a partir de datos de Google.

1D: PORCENTAJE DE OCUPACIÓN DE LA EDIFICACIÓN Y ÁREA OCUPADA: A partir del estudio formal de las zonas homogéneas de este caso de estudio, se pudo comprobar que su configuración y ocupación en planta es muy similar a la de las zonas homogéneas del área del caso de estudio de Belmar, que corresponden a las tipologías de tejido residencial y comercial 
de la Norteamérica suburbana. De este modo, los porcentajes de ocupación establecidos para el presente estudio, son los estudiados en el caso de Belmar.

Z1: $15 \%$ de superficie ocupada. Superficie ocupada $1387965 \mathrm{~m}^{2}$.

Z2: $27 \%$ de superficie ocupada. Superficie ocupada $607508 \mathrm{~m}^{2}$.

1E: ALTURAS DE LA EDIFCACIÓN POR ÁREA HOMOGÉNEA: Para las diferentes áreas homogéneas de Mall of America, se establecieron las siguientes alturas medias de edificación. Para obtener estos datos, se considerará la visualización de imágenes de calles de la zonas homogéneas:

Z1: 1 altura. Z2: 4 alturas.

1F: ESTABLECIMIENTO DE LAS TIPOLOGÍAS DE TEJIDO EN BASE A LA MORFOLOGÍA URBANA POR ÁREA HOMOGÉNEA: Con las ocupaciones y números de plantas anteriormente estudiados, a cada área de shopping Mall of America le corresponden estas densidades de acuerdo a la tabla de la metodología referente a este apartado en el capítulo 3.6.

Z1: Zona poco densa. Z2: Zona poco densa.

1G.- ÍNDICE GLOBAL DE DENSIDAD. Considerando los diferentes criterios de densidad anteriormente establecidos, y el porcentaje que ocupan las mismas respecto de la superficie total, tenemos este índice global de densidad. Estos índices fueron establecidos en base a las directrices correspondientes a este apartado en el capítulo 3.6.

Z1: Índice de 1, representa el $80,44 \%$ de la superficie total, suma al índice global 0,8 puntos. Z2: Índice de 1 , representa el $20 \%$ de la superficie total, suma al índice global 0,2 puntos.

De este modo el índice global de densidad es de 1 punto, lo que corresponde una zona de densidad baja.

1H: SUPERFICIE EDIFICADA TOTAL DE CADA ÁREA HOMOGÉNEA. Para la superficie edificada total, se multiplicó la superficie en planta anteriormente hallada por el número medio de plantas. De este modo, la superficie total edificada aproximada por área es de:

Z1 $1387965 \mathrm{~m}^{2}$. Z2: $2430031 \mathrm{~m}^{2}$. Siendo la superficie edificada total de $3.817 .996 \mathrm{~m} 2$

1I: ESTABLECIMIENTO DE PORCENTAJES DE USO DENTRO DE LAS ZONAS HOMOGÉNEAS ESTABLECIDAS: El área de Mall of America corresponde a un entorno de baja densidad y poca mezcla de usos en el que hay edificios tanto residenciales como comerciales y de oficinas, sin haber ningún tipo de mezcla de usos dentro de los mismos, ni interacción urbana. Al no haber datos objetivos sobre los usos predominantes en la zona, se consideraron los siguientes porcentajes.

Z1: $90 \%$ residencial, $2 \%$ productivo, $8 \%$ comercial.

Z2: $0 \%$ residencial, $70 \%$ productivo, $30 \%$ comercial.

1J: CONTEO DE LOS USOS DENTRO DEL CONTEXTO URBANO. Una vez se establecieron los porcentajes, para obtener los metros cuadrados de uso, éstos fueron multiplicados por la 
superficie edificada total de cada zona homogénea $(1 \mathrm{H})$, quedando establecidos los usos para Mall of America de la siguiente manera:

Z1: $1249168 \mathrm{~m}^{2}$ residencial, $27759 \mathrm{~m}^{2}$ productivo, $111037 \mathrm{~m}^{2}$ comercial. Z2: $0 \mathrm{~m}^{2}$ residencial, $1701022 \mathrm{~m}^{2}$ productivo, $729009 \mathrm{~m}^{2}$ comercial.

1K: ÍNDICE GLOBAL DE MEZCLA DE USOS. Para el índice global de mezcla de usos, se sumaron los porcentajes, quedando los del análisis de la siguiente manera, y se operó en base a lo estipulado en el capítulo de la 3.6 de la metodología:

Z1: $90 \%$ uso residencial, $10 \%$ uso no residencial, índice mezcla usos de 0

Z2: $0 \%$ uso residencial, $100 \%$ uso no residencial, índice mezcla usos de 0

De este modo, multiplicando los índices de uso, por los porcentajes de cada zona homogénea, y sumando los resultados, se saca que el área de Mall of America tiene un índice de mezcla de usos de 0 . Que corresponde a un área nada compleja a efectos de mezcla de usos.

1L: CONTEO DEL NÚMERO DE DOTACIONES DENTRO DEL CONTEXTO URBANO, DENTRO DEL ÁREA DE DOTACIONES Se estableció un área de un 1 kilómetro a partir del lindero del centro, y dentro del mismo se marcaron las siguientes dotaciones: 1 dotación de visita esporádica. (Figura 5.8.2)

\section{M: PRESENCIA E INFLUENCIA DE ELEMENTOS POSITIVOS Y NEGATIVOS:}

En el área del centro comercial Mall of America, no hay elementos negativos de cara a la paseabilidad, seguridad o actividad del área. (Figura 5.8.2)

1N: ZONAS DE ACTIVIDAD: El área en la que se encuentra Mall of America, es muy poco activa por lo general, ya que los usos no residenciales se ubican en calles y avenidas muy localizadas. Como agravante de esto, cabe destacar la configuración del área en base al uso masivo del vehículo particular, lo que se traduce en avenidas de gran tamaño y espacios libres entre edificios de enorme superficie, lo que propicia aún más el desuso del espacio público debido a la lejanía entre edificios. De este modo en el área hay fuertes puntos fríos tanto diurnos como nocturnos. Siendo relevante también la presencia de las barreras generadas por las avenidas anteriormente citadas y las autopistas que discurren en las inmediaciones del centro y dividen el área analizada, agravando los problemas relacionados con las distancias y el uso del vehículo particular. (Figura 5.8.2) 


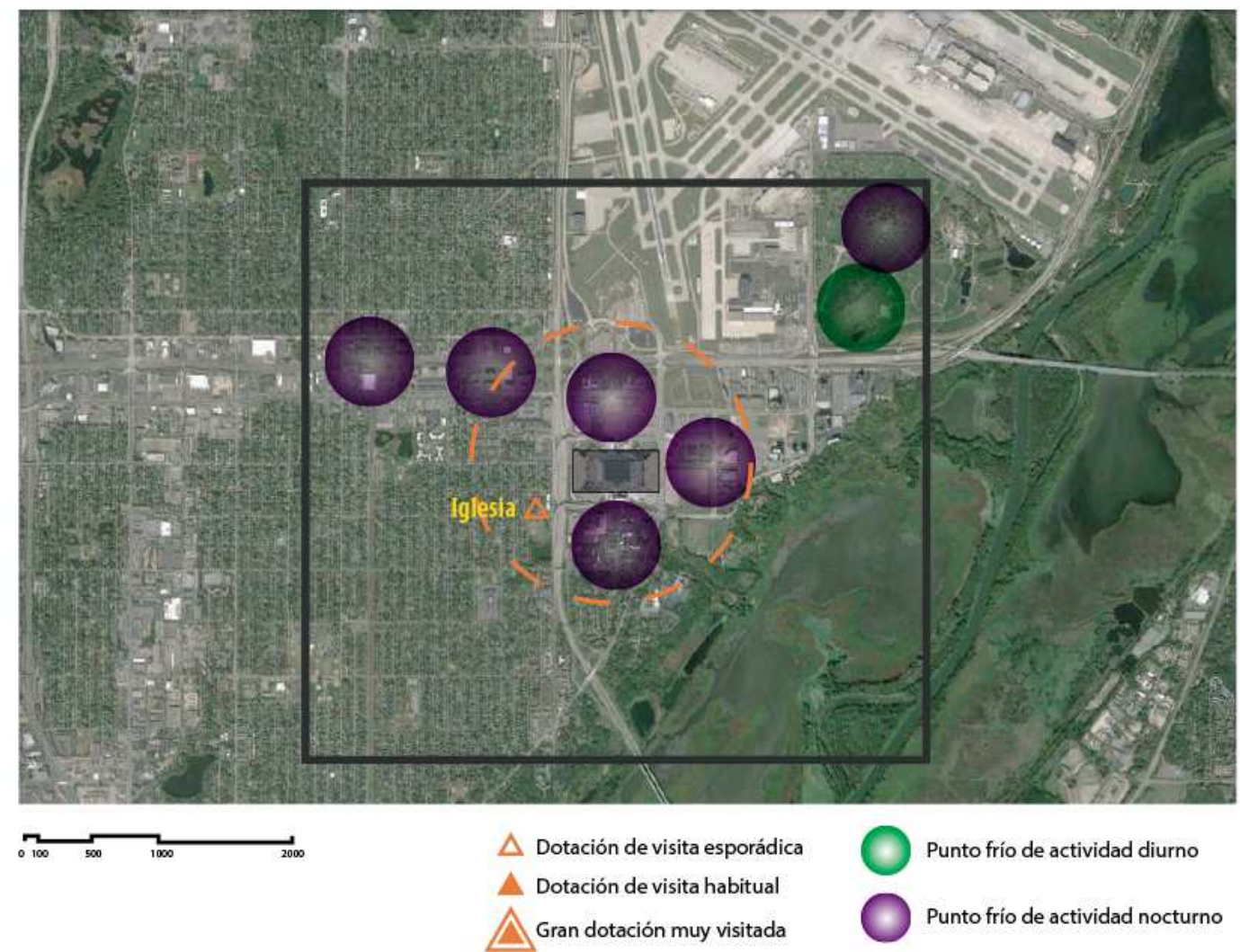

Figura 5.8.3: Área de Mall of America, dotaciones, puntos fríos y elementos positivos y negativos. Fuente: Elaboración propia a aprtir de datos de Google.

10: ÁREAS ARBOLADAS Y VERDES, DENTRO DEL ÁREA URBANA DEL CENTRO COMERCIAL: Dentro del área de Mall of America, se consideraron las siguientes áreas verdes con sus respectivos metros cuadrados de superficie (Figura 5.3.4). considerando las áreas netas de superficie verde, y los metros cuadrados de vegetación que poseen. El área urbana asignada a Mall of America posee un área verde neta en planta aproximada de $5567703 \mathrm{~m}^{2}$ en lo que es la rivera, considerándose además un $30 \%$ de la zona $1\left(2776000 \mathrm{~m}^{2}\right)$, y un $20 \%$ de la zona 2 $\left(450100 \mathrm{~m}^{2}\right)$, y un $20 \%$ de pradera en el aeropuerto $\left(543806 \mathrm{~m}^{2}\right)$ de este modo la superficie total verde es de $9.337 .609 \mathrm{~m}^{2}$, la cual se desglosa en las siguientes capas de vegetación. (Figura 5.8.3) 

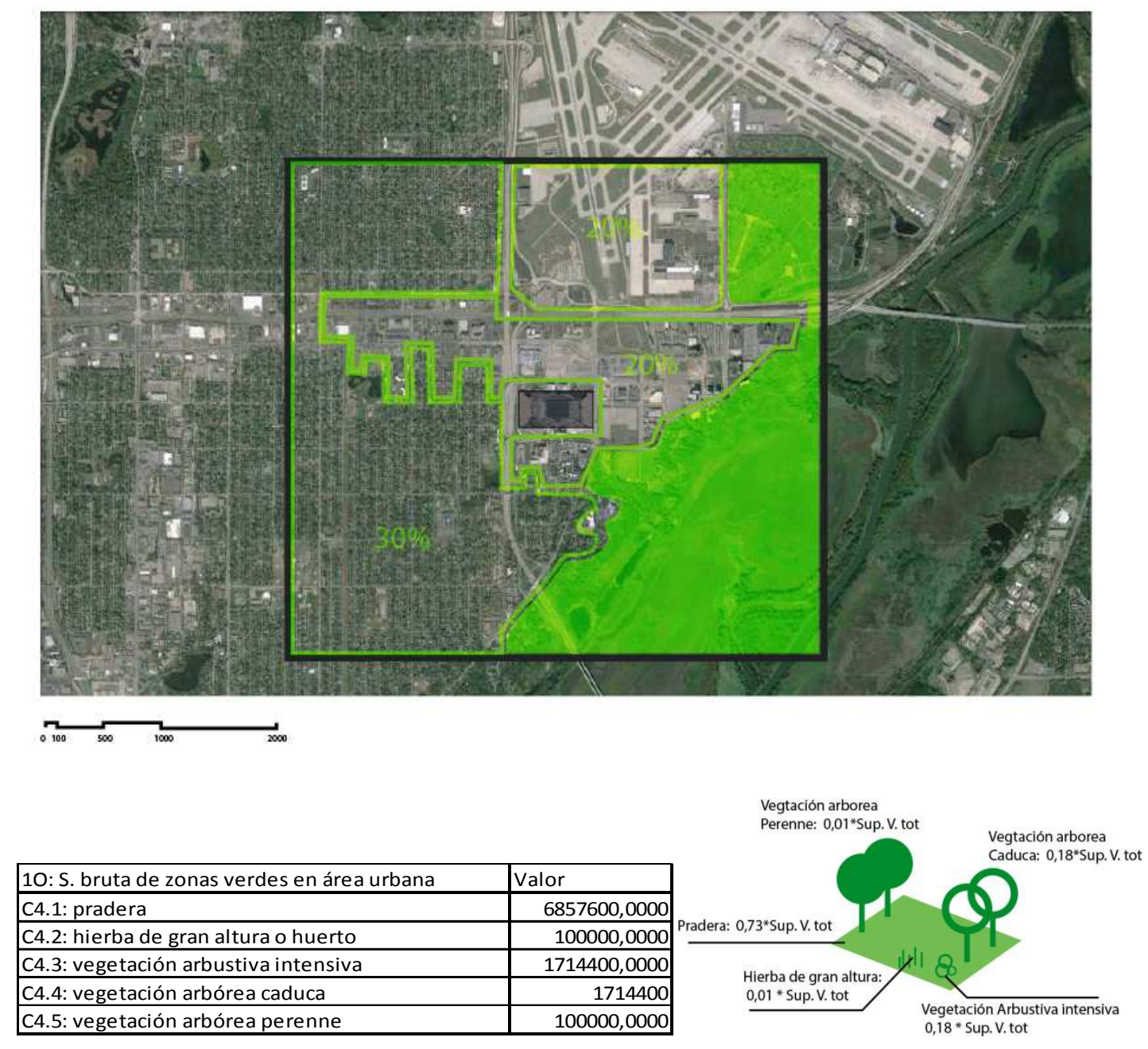

Figura 5.8.4: Área de Mall of America, zonas verdes y capas de vegetación. Fuente: Elaboración propia a aprtir de datos de Google.

1P.- DELIMITACIÓN DE RECORRIDOS A CENTRO, DENTRO DEL ÁREA URBANA: Para este análisis, fueros establecidos tres recorridos desde diferentes puntos del borde del área urbana de análisis de Mall of America, estos recorridos se muestran en el apartado 2E, (Figura 5.8.4), en el análisis de los tiempos de llegada. 


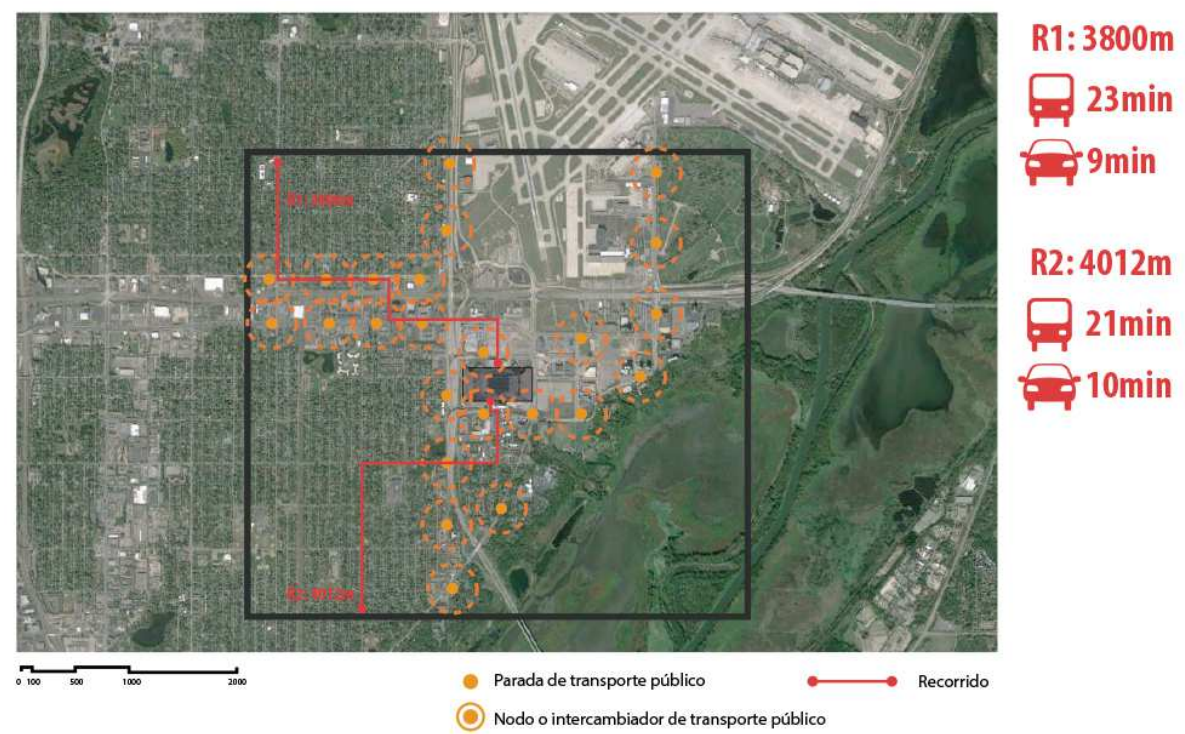

Figura 5.8.5: Recorridos, tiempos de llegada y zonas cubiertas por el transporte público. Fuente: Elaboración propia a aprtir de datos de Google.

10.- HUELLA DE CARBONO DEL ÁREA URBANA: Siendo la huella de carbono de Estados Unidos de 17,2 toneladas anuales por persona (Banco Mundial, año 2009). No obstante, es importante tener en consideración, que el área de análisis es mucho menor a la de partida, de modo que esto también debe de verse reflejado en la huella de carbono al contar con menor población. La huella de carbono del área de partida total es de 6.278 .000 toneladas anuales de $\mathrm{CO}$, pero el área asignada es aproximadamente un $5 \%$ del área total, de manera que la huella de carbono que va a ser analizada para este caso va a ser también de aproximadamente un $5 \%$ de la huella total, 313.900 Toneladas de dióxido de carbono anuales.

1R.- CAPACIDAD ABSORCIÓN DE LOS ELEMENTOS VERDES EN ÁREA URBANA: En base a los datos de superficies verdes obtenidos en el apartado 10, se calculó la absorción total de las áreas verdes en base a la capacidad de absorción por metro cuadrado de las superficies vegetales establecida para la presente tesis (apartado $1 \mathrm{R}$ del capítulo 3.6). (figura 5.8.5.) Siendo la capacidad absorbente total en el área de 554502 Toneladas de dióxido de carbono anuales.

\begin{tabular}{|l|r|r|r|r|r|r|}
\hline 1Q: C.absorción elementos verdes en área & \multicolumn{1}{|l|}{ Pradera } & V.arb ext & V. A. Int. & H. Caduca & H. Perenne & Otro \\
\hline Superficie total & 9337609 & 100000,0000 & 1714400,0000 & 1714400,0000 & 100000,0000 & 0,0000 \\
\hline Tasa absorción TCo2/m2 año & 0,0013 & 0,0020 & 0,0350 & 0,1500 & 2,2500 & 0,8000 \\
\hline Absorción dióxido carbono TCo2 & 12138,8917 & 200,0000 & 60004,0000 & 257160,0000 & 225000,0000 & 0,0000 \\
\hline
\end{tabular}

Figura 5.8.6: Absorción de dióxido de carbono de las zonas verdes en área urbana de Mall of America. Fuente: Elaboración propia

1S: DELIMITACIÓN DE ÁREAS EN FUNCIÓN DE LA RECUPERACIÓN DE AGUAS EN ÁREA URBANA. Para este análisis, se consideraron como zonas permeables al agua, las zonas verdes presentes en el área urbana. De este modo, la superficie permeable del área de Mall of America es de $9.337 .609 \mathrm{~m}^{2}$

FASE 2: ANÁLISIS DE RELACIONES ENTRE CENTRO COMERCIAL Y ENTORNO URBANO. 
Este análisis es muy similar en búsqueda de datos y función con respecto al anteriormente analizado sobre el área urbana general. La particularidad, está en que su ámbito está limitado a las parcelas que directamente lindan con el centro comercial, que en este caso van a estar bastante alejadas debido a los retranqueos y a las grandes infraestructuras. El objetivo en este apartado es cuantificar las relaciones urbanas entre el centro y el entorno próximo, ya sea mediante usos, relaciones entre dotaciones, y accesibilidad o transporte, en este análisis va a primar el estudio sobre plano.

2A: DELIMITACIÓN DE ÁREA PRÓXIMA: De cara al análisis del área próxima se escogieron las manzanas próximas al centro (Figura 5.8.6).

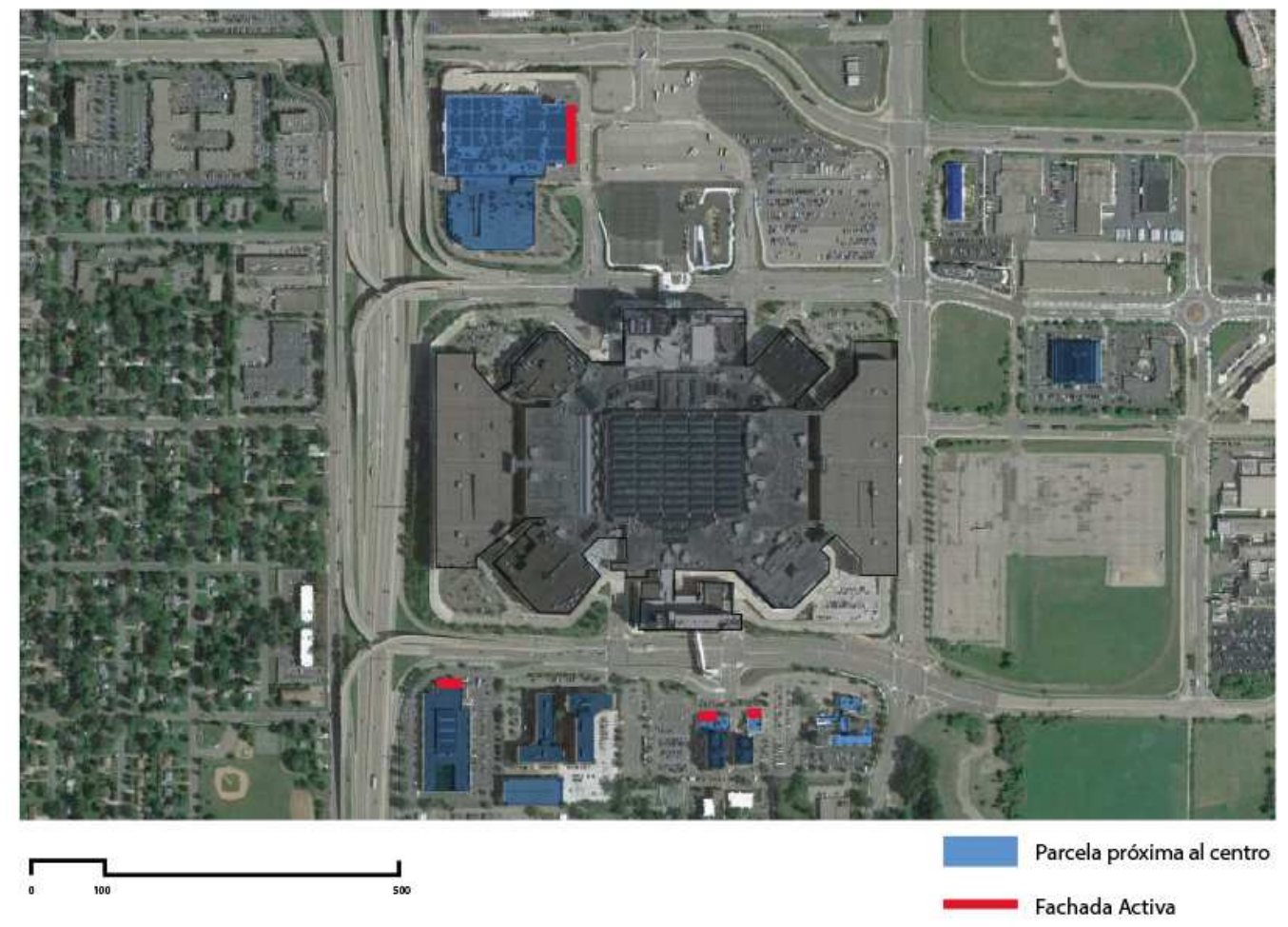

Figura 5.8.7: Análisis de parcelas próximas al centro Mall of América. Fuente: Elaboración propia a aprtir de datos de Google.

2B: SUPERFICIE TOTAL EDIFICADA EN ÁREA PRÓXIMA: Para el conteo de la superficie total estimada de las manzanas próximas al centro, se midió sobre un parcelario la superficie en planta de las mismas, que es de $70099 \mathrm{~m}^{2}$, la cual fue multiplicada por el número de plantas medio de los edificios de susodichas manzanas, que para el caso de Mall of America, se estableció en 2 plantas de media a partir de la visión de fotos de las calles. Esto se debe, a que aunque en la zona hay edificios de bastante altura 6-8 plantas, estos están muy focalizados y priman en estas manzanas los edificios de gran superficie en planta y 1 altura. De este modo, la superficie construida de las manzanas próximas al centro es de $140.198 \mathrm{~m}^{2}$.

2C: USOS EN ÁREA PRÓXIMA: Las manzanas próximas al centro comercial, poseen una configuración de usos en la que predominan los edificios residenciales o de comercio, de poca altura y poca mezcla de usos. De este modo, para este análisis se establecieron los siguientes porcentajes: 
Uso residencial: $4 \%$. Uso productivo: $20 \%$. Uso comercial: $76 \%$.

Quedando estas superficies:

Uso residencial: $5608 \mathrm{~m}^{2}$. Uso productivo: $28040 \mathrm{~m}^{2}$. Uso comercial: $106550 \mathrm{~m}^{2}$.

2D: FACHADAS ACTIVAS EN ÁREA PRÓXIMA Para este análisis, las fachadas activas en manzanas próximas se marcaron en el plano, y se midieron en metros lineales, junto con la longitud de fachada total. la longitud de fachada activa es de $1252 \mathrm{~m}$ siendo la longitud de fachada total de $5307 \mathrm{~m}$ incluyendo las fachadas activas. El porcentaje de fachada activa es del $23 \%$ de la longitud total de fachada.

2E: TIEMPOS DE LLEGADA DESDE LOS PUNTOS EN ÁREA A CENTRO COMERCIAL MEDIANTE TRANSPORTE PÚBLICO: Para la estimación de los tiempos de llegada en transporte público, fueron considerados los recorridos establecidos en 1P, y se utilizó la base de datos de Google Maps para establecer los tiempos de llegada. (Figura 5.8.6).

2F: TIEMPOS DE LLEGADA DESDE LOS PUNTOS EN ÁREA A CENTRO COMERCIAL MEDIANTE TRANSPORTE PRIVADO: Para la estimación de los tiempos de llegada en transporte público, fueron considerados los recorridos establecidos en 1P, y se utilizó la base de datos de Google Maps para establecer los tiempos de llegada, El centro posee aparcamiento, aún así, se añadió al trayecto unos dos minutos adicionales de maniobra y trayecto de llegada al centro. De este modo, los tiempos establecidos para los medios de transporte son los siguientes para cada recorrido. (Figura 5.8.4).

A efectos de transporte público, en Mall of America existen instalaciones de transporte colectivo que lo conectan con el aeropuerto de manera inmediata, y por su parcela pasan cerca líneas de autobús. No obstante, tos tiempos de frecuencia entre vehículos en este área son muy elevados (20-30 minutos de espera), y aunque el monorial tiene un tiempo de frecuencia mucho menor (10 minutos), su alcance se limita exclusivamente a las conexiones con el aeropuerto, y los cercanos paques empresariales que hay de camino. con lo que no es un medio de accesibilidad viable a la escala de la ciudad. Esto pone en evidencia, que la accesibilidad a Mall of America, se basa en el uso del vehículo privado, siendo los tiempos de desplazamiento muy cortos. A todo ello, el centro cuenta en sus inmediaciones con vías de gran capacidad, y los problemas de tráfico pueden darse en los accesos a las autopistas durante las horas punta, los autobuses discurren por calles secundarias, con lo que en principio no pueden verse afectados por los problemas de tráfico.

\section{FASE 3: ANÁLISIS DEL EDIFICIO DEL CENTRO COMERCIAL.}

3A: DELIMITACIÓN DE ÁREAS EN FUNCIÓN DE LA RECUPERACIÓN DE AGUAS: Sobre la planta de cubiertas del centro comercial, se delimitaron las áreas tanto permeables como impermeables del centro, de acuerdo a los estipulado en la metodología. Como áreas permeables a la recuperación de aguas, Mall of America, posee espacios verdes en su periferia. Las superficies permeables suman $16.288 \mathrm{~m}^{2}$, que son aproximadamente el $5 \%$ de los $307690 \mathrm{~m}^{2}$ totales de parcela. 
3B: USOS DENTRO DEL EDIFICIO DEL CENTRO: Para los usos, se consideraron los diferentes locales dentro del centro comercial, buscándose los metros cuadrados de espacio productivo, y las dotaciones asistenciales dentro del mismo. Para el caso de Mall of America, no hay instalaciones dotacionales, pero no obstante el centro cuenta dentro de sus fronteras con un hotel de $60.918 \mathrm{~m}^{2}$, quedando distribuidas las superficies de esta manera

Superficie comercial $91,66 \%$

Superficie residencial $8,34 \%$

Superficie Productiva no comercial 0,00\%

3C: DELIMITACIÓN DE ÁREAS VERDES EN CENTRO COMERCIAL. (Análisis sobre plano y cuantitativo, unidad: metros cuadrados). El centro comercial Mall of America, posee áreas verdes a su alrededor con vegetación. En total hay $16.288 \mathrm{~m}^{2}$ de superficie verde, desglosada de la siguiente manera (figura 5.8.7):
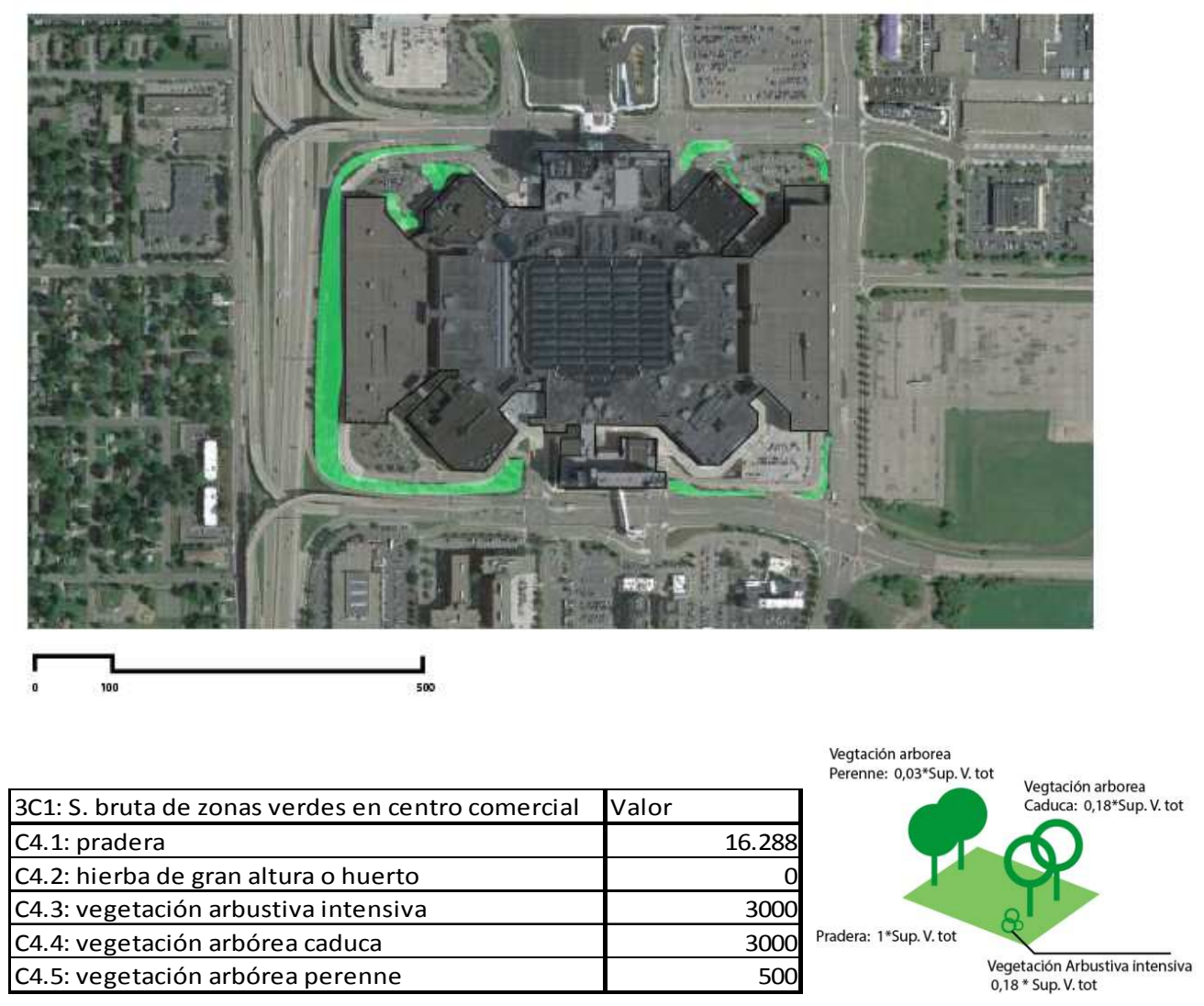

Figura 5.8.8: Áreas verdes del centro comercial Mall of America. Fuente: Elaboración propia a aprtir de datos de Google.

3D: ABSORCIÓN DE LAS ÁREAS VERDES EN CENTRO COMERCIAL. Los metros cuadrados de superficie de Mall of America, son capaces de asimilar aproximadamente unas 3142 toneladas de dióxido de carbono, que son aproximadamente un 3,5\% de las emisiones del centro $(87.600$ T Co2 anuales), y un 1\% respecto de las emisiones del área urbana establecida (313.900 T Co2 anuales). (Figura 5.8.8) 


\begin{tabular}{|l|r|r|r|r|r|r|}
\hline 3D: C.absorción elementos verdes en área & \multicolumn{1}{|l|}{ Pradera } & V.arb ext & V. A. Int. & H. Caduca & H. Perenne & Otro \\
\hline Superficie total & 17202,0000 & 0,0000 & 0,0000 & 8321,5000 & 832,0000 & \\
\hline Tasa absorción TCo2/m2 año & 0,0013 & 0,0020 & 0,0350 & 0,1500 & 2,2500 & 0,0000 \\
\hline Absorción dióxido carbono TCo2 & 22,3626 & 0,0000 & 0,0000 & 1248,2250 & 1872,0000 & 0,0000 \\
\hline
\end{tabular}

Figura 5.8.9: Absorción de las ,áreas verdes del centro comercial Mall of America. Fuente: Elaboración propia.

3E: ANÁLISIS BIOCLIMÁTICO DEL CENTRO COMERCIAL RESPECTO A CLIMA, DIAGRAMA DE GIVONI.

El Diagrama de Givoni para Minneapolis es el siguiente (Figura 5.8.9). Las temperaturas bajas durante los meses más fríos en Minneapolis, hacen que para cualquier edificio sean necesarios los sistemas mecánicos de calefacción. Durante los meses de primavera y otoño, deben de utilizarse tanto sistemas activos solares, cómo pasivos. En el clima de Minneapolis, la temperatura de confort sólo se da en los meses de verano, o al final de la primavera, y durante las horas más cálidas.

De este modo, cualquier edificio en Minneapolis, para lograr un acondicionamiento bioclimático debe de centrar sus instalaciones en lo que es la ganancia de energía solar, tanto con medidas pasivas como activas, para de este modo reducir en lo posible el impacto ambiental que va a suponer el uso de los sistemas mecánicos. En el caso de que se den condiciones de calor extremo, podrá utilizarse la ventilación natural o la masa térmica. El edificio va a necesitar sistemas mecánicos, pero solamente de calefacción.

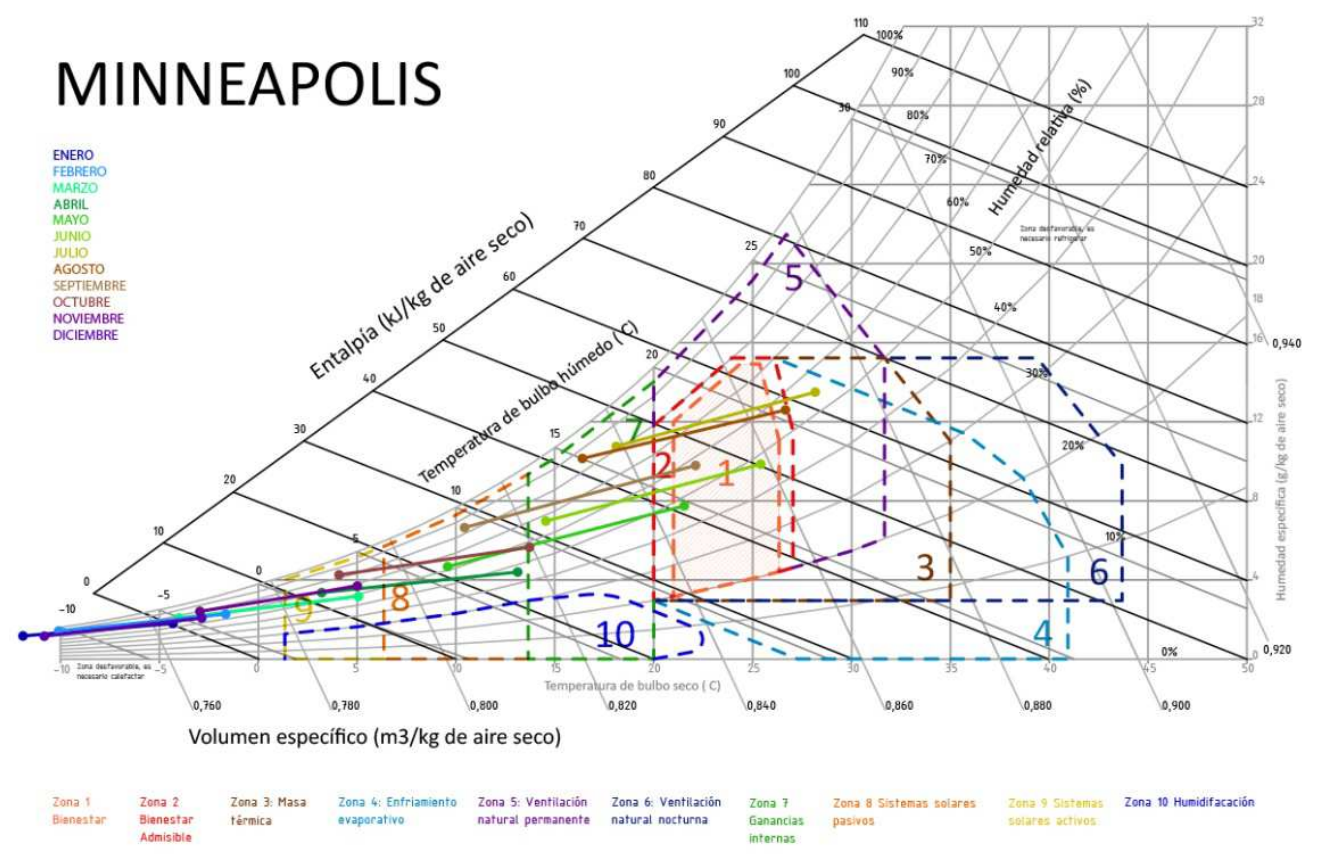

Figura 5.8.10: Diagrama de Givoni de Minneapolis. Fuente: Elaboración propia a partir de datos de Givoni y NOAA.

\section{F: CALIFICACIÓN ENERGÉTICA DEL CENTRO COMERCIAL.}

Respecto a la calificación energética del centro comercial Mall of America, no fue posible encontrar datos, ni relativos al centro, ni relacionados con las instalaciones. No obstante, a partir del análisis de las calificaciones de otros centros, y la realización de una simulación 
estimativa con CE3X del volumen, considerando el centro en una zona climática de E1-II, (zona climática fría), que dio las siguientes calificaciones: (Consumo de energía: 104,16 Kwh/m² año. (C), Emisiones anuales: 0,03 T/m ${ }^{2}$ año. (C)). No obstante, hay que tener en consideración, que este baremo está relacionado con el estándar español, y se debe de considerar, que Estados Unidos, es un país con una huella de carbono mucho mayor que la de España. Por consiguiente, a efectos de calificación energética, para el análisis de Mall of America se consideró un escenario desfavorable con las siguientes calificaciones:

Consumo de energía: 104,16 Kwh/m² año. (C)

Emisiones anuales: $0,12 \mathrm{~T} / \mathrm{m}^{2}$ año. (C)

3G: USO DE FUENTES DE ENERGÍA LIMPIAS. El centro Shopping Mall of America, aunque no posee sistemas de generación de energías limpias en su unidad catastral, suple aproximadamente un porcentaje que se estimó en un $10 \%$ de la demanda energética proveniente de fuentes de energía eólica de la red de Minneapolis (Programa Xcel Energy Minnesota Wind Source program). Esta energía se usa para dar energía a varias áreas del aparcamiento, y al parque de atracciones del atrio central. solares (MOA, Green Initiatives, página web del centro comercial Mall of América). No obstante, en el centro se están llevando a cabo proyectos para la mejora energética, y se prevé la inserción de sistemas solares.

3H: ESPACIOS CON LUZ NATURAL Para medir esta superficie se consideraron de manera aproximada los espacios iluminados del centro comercial Shopping Mall of America, que generalmente corresponden a las estancias de las grandes cristaleras de entrada ubicadas a norte y a sur, el invernadero central y sus espacios anejos. No obstante este centro comercial ha invertido en la inserción de luz natural en numerosas galerías y tiendas, Mall of America el espacio que cuenta con luz natural es aproximadamente el $33 \%$ de la superficie total.

31: FORMA DE LA EDIFICACIÓN: El Mall of America, tanto el edificio como el hotel, son volúmenes compactos algo fragmentados, relativamente extendidos en superficie. Aproximadamente la relación entre el lado mayor y el menor del edificio principal Mall of America es de 1,13, siendo la orientación de la fachada principal unos 3 o este, respecto de la orientación sur. El centro comercial posee lucernarios de pequeño tamaño sobre algunas galerías, y uno de gran tamaño que es la cubierta acristalada del atrio central. El volumen del edificio es relativamente compacto. (Figura 5.8.9)

3J: PAVIMENTOS Y CUBIERTAS EN RELACIÓN A LA INCIDENCIA DE LA IRRADIACIÓN SOLAR. Sobre la planta de cubiertas se midieron las superficies de colores claros. Mall of America tiene aproximadamente un $7,80 \%$ de su superficie de cubierta repelente de cara a la irradiación solar, siendo el $92,20 \%$ restante, absorbente de cara a la irradiación solar.

\section{FASE 4: CUESTIONARIOS DE LA METODOLOGÍA, APLICACIÓN DE INDICADORES Y BAREMOS.}

Una vez fueron hallados los datos cuantitativos, de cara a la fase final de la aplicación de la metodología, y con el objetivo de establecer las medida de rehabilitación más adecuadas en el gráfico de la rosa de rehabilitación sostenible (3.3.2) para Mall of America. Los datos hallados fueron comparados en base a los umbrales y baremos establecidos en el cuestionario de la metodología. 


\section{A.- REHABILITACIÓN ECOEFICIENTE.}

A1.- Cuestionario referenciado a rehabilitación hacia instalaciones poco emisivas.

Cuestión A1.1.- ¿El centro cuenta con instalaciones que no son necesarias de acuerdo a lo estipulado en el diagrama de Givoni?: Aunque no hay datos objetivos acerca de las instalaciones de Mall of America, Este centro posee todo tipo de instalaciones mecánicas, tanto de calefacción cómo de refrigeración. Las instalaciones de calefacción son necesarias, pero las de refrigeración no lo son para el clima de Minneapolis, a este centro le corresponde una nota de +1 en esta cuestión.

Cuestión A1.2.- ¿Las instalaciones del centro generan unas emisiones de dióxido de carbono superiores a la media?. En el estudio energético, Mall of America ha obtenido en la calificación energética de emisiones de las instalaciones una nota de $\mathbf{C}$, eso corresponde a una nota de +3

Cuestión A1.3.- ¿Las instalaciones del centro se encuentran en un estado de obsolescencia?. Respecto esta cuestión, el autor desconoce el estado de las instalaciones del centro. No obstante, de fuentes oficiales del centro comercial del año 2015 (Green initiatives, Página web del centro comercial), se pudo ver que Mall of America posee instalaciones actualizadas, habiendo en proyecto la instalación de mecanismos de bajo consumo energético. Con lo que se puntuó esta cuestión con una nota de +1 .

Cuestión A1.4.- ¿Las instalaciones del centro tienen un consumo energético superior a la media?. En el estudio energético, Mall of America ha obtenido en la calificación energética de consumo de energía primaria una nota de $\mathbf{C}$, eso corresponde a una nota de +3

EN RELACIÓN A INSTALACIONES POCO EMISIVAS, MALL OF AMERICA HA OBTENIDO UNA PUNTUACIÓN DE 8 (10).

A2.- Cuestionario referenciado a inserción de medidas activas.

Cuestión A2.1.- ¿Qué porcentaje de las calorías necesarias para lograr la temperatura de confort se logra mediante sistemas activos?: Mall of America, no posee medidas activas para lograr la temperatura de confort. No obstante, hay plan de acción para implantarlas. Esta cuestión puntúa con +0 .

Cuestión A2.2.- ¿Qué porcentaje de la demanda energética se logra a partir de fuentes de energía renovable?: Mall of America se estimó que suple hasta el $10 \%$ de la demanda energética con energías renovables, esta cuestión puntúa con +1 .

Cuestión A2.3.- ¿El centro cuenta con las medidas y dispositivos necesarios para su aclimatación de acuerdo a lo estipulado en el diagrama de Givoni para sistemas solares activos?: El centro comercial Mall of America, no posee ningún tipo de sistema activo para una correcta aclimatación, no obstante, hay un plan de acción para implantarlas. Esta cuestión puntúa con +0 .

EN RELACIÓN A MEDIDAS ACTIVAS, MALL OF AMERICA HA OBTENIDO UNA PUNTUACIÓN DE 1 (10). 
A3.- Cuestionario referenciado a inserción de medidas Pasivas.

A3.1.- ¿El centro comercial tiene una forma adecuada en volumen a las condiciones climáticas?: Mall of America se encuentra en una zona climática fría de acuerdo a la calificación de Olgyay, de acuerdo al análisis anteriormente realizado en el punto 31, Mall of America cumple los requisitos de orientación de fachada, y la proporción en planta (1:1,1). Los huecos, aunque están expuestos a la irradiación solar los de la orientación norte no están protegidos. El edificio es un volumen fragmentado, aunque relativamente compacto, y se intenta tener la menor superficie de fachada posible. A Mall Of America. Le corresponde una puntuación de +1 .

A3.2.- ¿El estado de los cerramientos responde de manera correcta a las exigencias del clima en el que se asienta?: La calificación energética de Shopping Mall of America a efectos de consumo global de energía es de $\mathrm{C}$, esto significa que los cerramientos responden de una manera correcta respecto al clima. A este centro le corresponde una puntuación de +3 .

A3.3.- ¿Qué porcentaje de los espacios del centro cuentan con iluminación natural?: Mall of America posee aproximadamente un $33 \%$ del espacio interior iluminado con luz natural. Le corresponde de este modo una puntuación de +1 .

A3.4.- Los espacios del centro, están adaptados a lo estipulado por el Diagrama de Givoni de su respectivo clima?: Aunque Mall of America, no tiene un espacio interior adaptado a lo dictado por Givoni, debido a su gran tamaño, de cara al verano, los muros tienen masa térmica, y se pueden usar los lucernarios para ventilar. De cara al invierno, Mall of America posee lucernarios habilitados para la ganancia de energía solar, y utiliza las cargas internas tanto de maquinaria como de personas para ayudar en la aclimatación de los espacios. A Mall of America le corresponde una calificación de +2

EN RELACIÓN A MEDIDAS PASIVAS, MALL OF AMERICA HA OBTENIDO UNA PUNTUACIÓN DE 7 (10).

\section{B.- REHABILITACIÓN MEDIOAMBIENTAL.}

B1.- Cuestionario referenciado a rehabilitación mediante zonas verdes.

Cuestión B1.1.- ¿En el área urbana hay suficiente zona verde en el área en relación a sus habitantes?: El área urbana de Mall of America posee aproximadamente $9337609 \mathrm{~m} 2$ de superficie verde en planta, en la zona analizada. No obstante, debido a que ésta corresponde a un área de grandes infraestructuras, este conteo va a realizarse sobre la población en el tejido residencial del área, que es la zona homogénea Z1, la cual en planta mide $9126822 \mathrm{~m}^{2}$. Utilizando la densidad de población de Bloomington $\left(0,00092 \mathrm{~h} / \mathrm{m}^{2}\right)$, nos sale que la población sobre la que se va a realizar el análisis es de 8397 habitantes, el ratio es de $1086 \mathrm{~m}^{2}$ de superficie verde por habitante. Le corresponde una puntuación de +2 .

Cuestión B1.2.- ¿Las zonas verdes dentro del centro comercial pueden dar lugar a una área verde de uso cotidiano?: Mall of America, posee $16.288 \mathrm{~m}^{2}$ netos de superficie verde en su parcela, no obstante, esta superficie corresponde a espacios verdes que son jardineras 
decorativas en grandes aparcamientos y medianeras entre calles, que aunque pueden ayudar en la reducción de dióxido de carbono, no podrían considerarse como espacios estancia. De este modo, a Mall of America le corresponde una puntuación de +0 a esta cuestión.

Cuestión B1.3.- ¿La vegetación en el área (incluyendo el edificio del centro), en que porcentaje es capaz de asimilar las emisiones de la misma área urbana?: Sumando las capacidades de asimilación de las superficies de vegetación establecidas, tenemos una capacidad de asimilación de 554503 Toneladas de dióxido de carbono anuales, esto es aproximadamente un 176\% de la huella de carbono del área, (313900 Toneladas de dióxido de carbono anuales). Esta cuestión puntuará con +3 .

Cuestión B1.4.- ¿La vegetación en el centro comercial y su parcela, en que porcentaje es capaz de asimilar las emisiones del centro comercial?: Los espacios verdes del centro comercial, asimilan aproximadamente 3142 T Co2 anuales, que es un 3,5\% de la huella de carbono anual del centro (87600T Co2 anuales), a esta cuestión le corresponde una puntuación de +0 .

Cuestión B1.5.- ¿La distancia media entre espacios verdes dentro del área es inferior a los 400 metros?: La distancia entre espacios verdes en Mall of America, es inferior a los 400 metros, debido a que la mayoría de las unidades catastrales, poseen espacios verdes. A esta cuestión le corresponde una puntuación de +1 .

EN RELACIÓN A ZONAS VERDES, MALL OF AMERICA HA OBTENIDO UNA PUNTUACIÓN DE 6 (10).

B2.- Cuestionario referenciado a inserción de superficie asimiladora de agua.

Cuestión B2.1.- ¿El clima en el que está el centro corresponde a un clima árido o semiárido?: El clima de Minneapolis, con una temperatura media anual de 70 y unas precipitaciones medias de $800 \mathrm{~mm}$ anuales, tiene un índice de Martonne de 47 , los que corresponde a una zona húmeda. A Mall of America le corresponde una calificación de +1 a esta cuestión.

Cuestión B2.2.- ¿En qué porcentaje, la superficie absorbente de agua, en el área urbana, es en relación a la impermeable?: En esta cuestión, se consideró como superficie permeable las áreas verdes presentes en la zona $\left(9126822 \mathrm{~m}^{2}\right)$, que son aproximadamente un $45 \%$ de los $20047119 m^{2}$ totales del área urbana. esta cuestión puntúa con +3 .

Cuestión B2.3.- ¿El centro comercial posee sistemas para el aprovechamiento del agua?: Aunque se desconocen datos sobre este aspecto, de fuentes del centro, se comprobó que Mall of America, posee instalaciones que buscan el menor consumo de agua. Le corresponde una puntuación de +1 .

Cuestión B2.4- ¿El consumo de agua del centro es en litros por visita?: a pesar de que no hay datos del centro en este sentido, al centro comercial Mall of America, se le estimó un consumo de agua de 30 litros por visita, que corresponde a una puntuación de +1 .

EN RELACIÓN A SUPERFICIE ASIMILADORA DE AGUA, MALL OF AMERICA HA OBTENIDO UNA PUNTUACIÓN DE 6 (10). 
B3.- Cuestionario referenciado a tratamiento de isla de calor.

Cuestión B3.1.- ¿El clima en el que está el centro comercial tiene una temperatura media más o menos elevada?. El clima de Minneapolis tiene una temperatura media anual de 70, esto significa que es un clima algo frío nada propenso a condiciones de calor extremo. Esta pregunta puntúa con +2

Cuestión B3.2.- ¿En el clima en el que está ubicado en centro hay olas de calor frecuentes o en intervalo temporal menor?. Aunque en Minneapolis puedan acontecer olas de calor, estas no son frecuentes, esta cuestión puntúa con un +1 .

Cuestión B3.3.- ¿El centro está en un área en el cual la diferencia de temperatura respecto a la normal es de?. Analizando la isla de calor de Minneapolis (Figura 5.8.10), nos encontramos con el hecho de que Mall of America se encuentra en un área con 4ํ de temperatura respecto de lo normal, de este modo esta cuestión puntúa con un +0 .

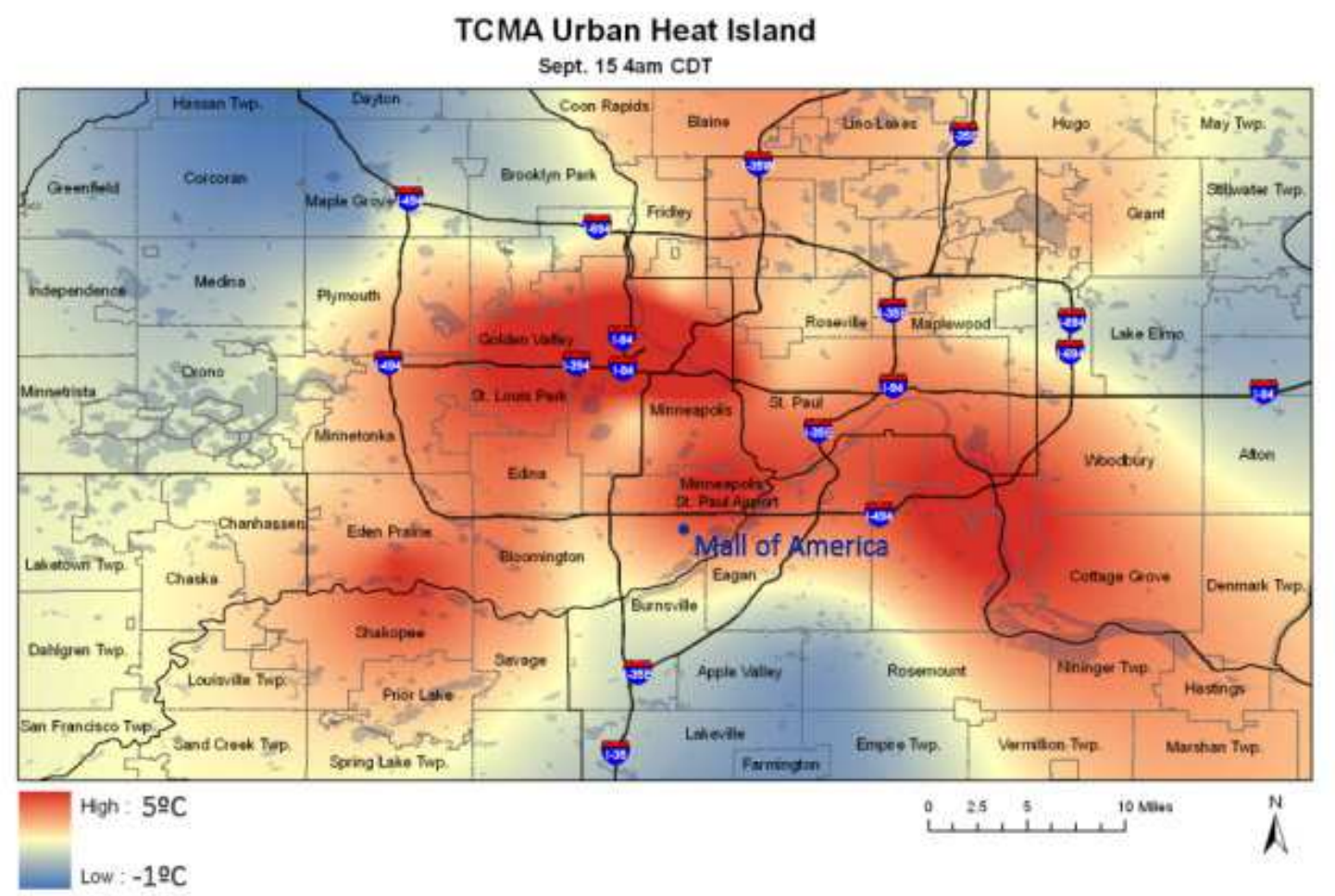

Figura 5.8.11: Isla de Calor de Minneapolis. Fuente: University of Minnesota, Peter Snyder, Tracy Twine.

Cuestión B3.4.- ¿La suma de superficies que contribuyen a la isla de calor en la parcela y el edificio del centro es superior a un porcentaje de la superficie total?. La superficie absorbente de irradiación de Mall of America es del 92,20\%, en superficies asfaltadas y hormigonadas de colores oscuros, lo que le corresponde una puntuación de +0 .

EN RELACIÓN A TRATAMIENTO DE ISLA DE CALOR, MALL OF AMERICA HA OBTENIDO UNA PUNTUACIÓN DE 3 (10).

4C.- REHABILITACIÓN POR USOS. 
C1.- Cuestionario referenciado a inserción de uso residencial.

Cuestión C1.1.- ¿El centro comercial posee usos residenciales u hoteleros dentro de su unidad catastral?. Mall of America posee aproximadamente un hotel de aproximadamente unos $60918 \mathrm{~m}^{2}$, considerando un baremo de $20 \mathrm{~m}^{2}$ por persona, este hotel tiene aproximadamente capacidad para 3000 personas, que son aproximadamente un $36 \%$ de la población del área de análisis. Esta cuestión puntúa con +2 .

Cuestión C1.2.- ¿Las parcelas próximas al centro comercial posen usos residenciales $u$ hoteleros?: El uso residencial en las parcelas colindantes fue estimado en un $4 \%$, no obstante, este centro al poseer una superficie residencial considerable, ésta va a ser computada para éste análisis $\left(5608+60918 \mathrm{~m}^{2}=66526 \mathrm{~m}^{2}\right)$, haciéndose el porcentaje respecto a la suma de superficies construidas de las manzanas colindantes y el centro $\left(870198 \mathrm{~m}^{2}\right)$. El resultado es un $7,6 \%$, lo que le corresponde una puntuación de +0 .

Cuestión C1.3.- ¿Dentro del área de influencia del centro comercial, que porcentaje de la superficie de uso total es de tipo residencial?: Considerando las superficies establecidas para cada zona tipológica, estas fueron sumadas, obteniendo una superficie residencial total $\left(1249168 \mathrm{~m}^{2}\right)$ que fue comparada con la superficie total construida $\left(3817996 \mathrm{~m}^{2}\right)$. De este modo, la superficie de uso residencial en el área de Mall of America, se estableció aproximadamente en un $33 \%$ de la superficie edificada total, lo que le corresponde una puntuación de +2

EN RELACIÓN A USO RESIDENCIAL, MALL OF AMERICA HA OBTENIDO UNA PUNTUACIÓN DE 4 (10).

C2.- Cuestionario referenciado a inserción de usos productivos, y terciarios no comerciales.

Cuestión C2.1.- ¿El centro comercial posee usos productivos no comerciales dentro de su unidad catastral?: Mall of America no posee usos productivos, salvo las oficinas de la gestora, que no fueron computadas para esta tesis, esta cuestión puntúa con +0 .

Cuestión C2.2.- ¿Las parcelas próximas al centro comercial posen usos productivos no comerciales?: Las parcelas próximas al centro comercial, poseen cierta oferta de instalaciones terciarias de oficinas y administrativas, que se computaron en aproximadamente un $20 \%$ de la superficie total, esta cuestión puntúa con un +3 .

Cuestión C2.3.- ¿Dentro del área de influencia del centro comercial, que porcentaje de la superficie de uso total es de tipo productivo no comercial?: Considerando las superficies productivas establecidas para cada zona tipológica, estas fueron sumadas obteniendo una superficie productiva total $\left(1728781 \mathrm{~m}^{2}\right)$ que fue comparada con la superficie total construida $\left(3817996 \mathrm{~m}^{2}\right)$. De este modo, la superficie de uso productivo en el área de Mall of America, se estableció aproximadamente en un $45,28 \%$ de la superficie edificada total. A esta cuestión le corresponde una puntuación de +6 .

EN RELACIÓN A USO PRODUCTIVO, MALL OF AMERICA HA OBTENIDO UNA PUNTUACIÓN DE 9 (10).

C3.- Cuestionario referenciado a inserción de instalaciones dotacionales y asistenciales. 
Cuestión C3-1.- ¿El centro comercial posee usos dotacionales dentro de su unidad catastral?: El centro comercial Mall of America, no posee instalaciones asistenciales en su unidad catastral, esta cuestión puntúa con un +0 .

Cuestión C3.2.- ¿Las parcelas próximas al centro comercial posen usos dotacionales?: En las inmediaciones de Mall of America no hay instalaciones dotacionales de ningún tipo. Esta pregunta puntúa con un +0 .

Cuestión C3.3.- ¿A un kilómetro del centro comercial hay usos dotacionales?: En el área de dotaciones correspondiente a Mall of America, se marcó solo una dotación de visita esporádica. Esta cuestión puntúa con +1 .

EN RELACIÓN A DOTACIONES, MALL OF AMERICA HA OBTENIDO UNA PUNTUACIÓN DE 1 (10).

\section{D.- REHABILITACIÓN DE ENTORNO URBANO.}

D1.- Cuestionario referenciado a la inserción de medios de transporte eficientes.

Cuestión D1.1.- ¿El centro dispone en sus inmediaciones de alguna parada de transporte público?: El centro comercial Mall of America, posee varias instalaciones de transporte público en las inmediaciones de sus parcelas, teniendo el centro una estación de monorraíl. No obstante, este medio de transporte tiene un alcance muy limitado, ya que sólo conecta con el aeropuerto y los parques empresariales de sus inmediaciones. La puntuación es de +1 .

Cuestión D1.2.- ¿El tiempo de llegada al centro mediante transporte público supera al tiempo de llegada en vehículo particular?, A partir del análisis del apartado $2 \mathrm{~F}$ se compararon los tiempos de llegada de transporte público y privado, estableciéndose para el centro, un tiempo de llegada en transporte público de 2,3 veces mayor que en transporte privado, considerando tiempos de aparcamiento del vehículo particular, lo que supone que hay que invertir más del doble de tiempo para acceder al centro en transporte público, que lo que se invertiría usando el vehículo particular(Figura 5.8.11). esta cuestión puntúa con +0 .

\begin{tabular}{|l|r|r|}
\hline 2E.- Tiempos de recorrido transporte público & Recorrido 1 & Recorrido 2 \\
\hline Total tiempo desplazamiento tte público & 23 & 21 \\
\hline Total tiempo desplazamiento tte privado & 9 & 10 \\
\hline Relación entre tiempos desplazamiento & 2,555555556 & 2,1 \\
\hline Media tiempo desplazamiento & & 2,327777778 \\
\hline
\end{tabular}

Figura 5.8.12: Comparación entre tiempos de llegada para Mall of America. Fuente: Elaboración propia

Cuestión D1.3.- ¿El área urbana del centro comercial está cubierta de forma adecuada por la infraestructura de transporte público?. El área urbana de Mall of America, está cubierta en un menos de un 50\% aproximadamente por la infraestructura de transporte público (Figura 5.8.6) . Lo que la cuestión puntúa con un +0.

Cuestión D1.4.- ¿Los usos en la zona están mezclados o zonificados?: En el área de Mall of America, el índice Global de Mezcla de usos es de 0,0 (Zona de complejidad urbana nula), esto le corresponde una puntuación de +0 . 
Cuestión D1.5.- ¿El Área urbana próxima al centro cuenta con instalaciones enfocadas en la movilidad sostenible?: El centro comercial Mall of America no posee sistemas adaptados a la movilidad sostenible, esta cuestión obtiene una puntuación de +0 .

EN RELACIÓN A TRANSPORTE EFICIENTE, SHOPPING MALL OF AMERICA HA OBTENIDO UNA PUNTUACIÓN DE 1 (10).

D2.- Cuestionario referenciado a la rehabilitación por corrección de la densidad en área urbana.

Cuestión D2.1.- ¿La densidad de población en el área del centro está en el intervalo entre h/ha?, La densidad de población del área de Mall of America es la del distrito de Bloomington para $2014\left(0,00092 \mathrm{hab} / \mathrm{m}^{2}\right)$, a esta cuestión le corresponde una puntuación de +0 .

Cuestión D2.2.- ¿A efectos de densidad, el tejido mayoritario es favorable o desfavorable de cara a la sostenibilidad?. El índice global de densidad del área de Shopping Mall of America es de 1 , lo que es un entorno de densidad baja, a esta cuestión le corresponde una puntuación de +0 .

Cuestión D2.3.- ¿La cantidad de espacio ocupado en el área está en el intervalo? El espacio ocupado en el área de Shopping Mall of America, es de un 21\%, lo que corresponde a una puntuación de +1 .

EN RELACIÓN A DENSIDAD, SHOPPING MALL OF AMERICA HA OBTENIDO UNA PUNTUACIÓN DE 1 (10).

D3.- Cuestionario referenciado a mejora de la seguridad y la paseabilidad en el área urbana.

Cuestión D3.1.- ¿En el área de influencia o en sus proximidades hay elementos negativos de cara a la seguridad o a la salubridad del área?: En el área cercana a Mall of America, no hay elementos ni zonas que pudieran afectar de manera negativa a la paseabilidad. Esta cuestión puntúa con +1 .

Cuestión D3.2.- ¿El centro comercial se encuentra en una zona de puntos fríos de actividad durante el día?. El recinto de Shopping Mall of America, está rodeado de puntos fríos durante el día debido al gran tamaño de las vías que lo rodean, esta cuestión puntúa con +0.

Cuestión D3.3.- ¿El centro comercial se encuentra en una zona de puntos fríos durante la noche?, el efecto de punto frío que está presente durante el día en las inmediaciones de Mall of America, por las barreras y distancias, va a agravarse durante la noche debido al cierre del centro comercial. Esto se debe a que las áreas circundantes son zonas sin actividad nocturna, esta cuestión puntúa con +0 .

Cuestión D3.4.- ¿El centro comercial se encuentra en una zona con áreas de difícil control visual o de contacto urbano?. En torno al centro comercial hay vías de gran tamaño y barreras difíciles de transitar como consecuencia de la formalización de éstas. Esta cuestión puntúa con $+0$ 
Cuestión D3.5.- ¿La sensación de seguridad por parte de los ciudadanos de la zona es positiva o negativa?: Aunque Minneapolis es una ciudad considerada algo peligrosa, la zona en la que se ubica el centro comercial no lo es. La puntuación a esta cuestión es de +1 .

Cuestión D3.6.- ¿La zona próxima al centro comercial tiene un porcentaje de fachadas activas?: En las manzanas próximas al centro comercial, hay un $23,59 \%$ de fachadas activas, lo que le corresponde una puntuación de +0 .

Cuestión D3.7.- ¿La distancia de la puerta del edificio del centro comercial al inmueble residencial cercano es superior a los 200 metros?: El inmueble residencial más cercano a Mall of America, es el hotel que se ubica en el propio centro, habiendo hoteles también en las manzanas próximas $(150 \mathrm{~m})$ e inmuebles residenciales a unos 300 metros. Esta cuestión puntúa con +1 .

Cuestión D3.8.- ¿La cantidad de espacio libre en el área va a resultar desfavorable de cara a la paseabilidad?: El espacio libre en el área de Mall of America es de aproximadamente un 79\%, de modo que esta cuestión va a puntuar con un +0 .

Cuestión D3.9.- ¿Los usos en la zona están mezclados o zonificados? El índice global de mezcla de usos es de 0,0, el ratio de mezcla de usos en el entorno urbano es nulo. Esta cuestión puntúa con +0 .

EN RELACIÓN A PASEABILIDAD, MALL OF AMERICA HA OBTENIDO UNA PUNTUACIÓN DE 3 (10).

4E.- CUESTIONARIO RELACIONADO CON LA ACTIVIDAD DEL CENTRO Y SUS CONSECUENCIAS URBANAS.

Cuestión E1: ¿La actividad del centro comercial, va a penalizar o a favorecer la sostenibilidad del entorno urbano?: Mall of America tiene un índice de atracción de 5, y la puntuación total en el cuestionario relacionado con el transporte eficiente es de 1 . De este modo, consultando la tabla del apartado 3.10, 4E. se comprueba que el efecto de la actividad que ejerce el centro sobre el área urbana, va a ser severo a efectos de transporte, y va a suponer un impacto ambiental sobre el aire. Todo ello derivado de los desplazamientos en medios de transporte poco eficientes. Se penaliza la puntuación de TRANSPORTE EFICIENTE (D1) en un -1, quedando finalmente en 0 , y Se penaliza la puntuación de REHABILITACIÓN DE ZONAS VERDES (B1) en un -2 , quedando en 4.

FASE FINAL: GRÁFICO DE LA ROSA DE REHABILITACIÓN SOSTENIBLE.

Las puntuaciones obtenidas en el anterior cuestionario relativo a Mall of America, fueron colocadas en el gráfico de la rosa de rehabilitación sostenible, obteniendo el siguiente resultado (Figura 5.8.12): 


\section{(A) ECOEFICIENTE}

\section{(A3)}

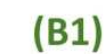
ZONAS (A2)

(A1)
INSTALACIONES
POCO EMISIVAS

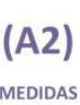
MEDIDAS VERDES MEDIDAS PASIVAS 4 (1)

(B2)

SUPERFICIE ASIMILADORA AGUA

(B) MEDIOAMBIENTAL

\section{(C1)} USO
RESIDENCIAL

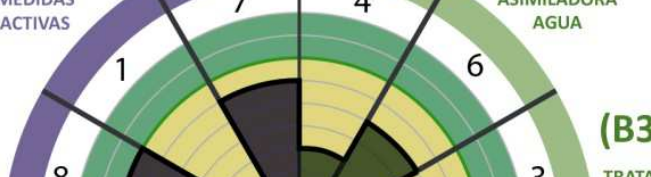
ISLA CALOR

\section{(D3)}

SEGURIDAD

Y PASEABILIDAD

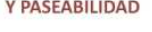

\section{(C2)}

uso

PRODUCTIVO

\section{(C) DOTACIONAL Y USOS}

UMBRALES

2 puntos: Umbral de mínimos, Rehabilitación prioritaria 8 puntos: Situación Óptima, Rehabilitación nada prioritaria 10 puntos: Paradigma verde

\section{ZONAS E INTERVALOS}

0-2 puntos: rehabilitación muy prioritaria

2-8 puntos: rehabilitación de prioridad de media a moderada

8-10 puntos: rehabilitación no prioritaria.

Figura 5.8.13: Gráfico de rosa de rehabilitación sostenible para Mall of America. Fuente: Elaboración propia.

De acuerdo al gráfico de la rosa de rehabilitación sostenible, el caso de Mall of América, aunque ha sacado buenas puntuaciones en instalaciones eficientes y aplicación de medidas pasivas, está lejos de ser un caso de centro comercial sostenible a efectos de medidas solares activas. Las puntuaciones del centro comercial y el área urbana respecto a medio ambiente, aunque superan el umbral de mínimos son generalmente mediocres, y la distribución de usos en el área urbana está muy focalizada hacia el uso productivo de terciario de oficinas, no habiendo prácticamente dotaciones asistenciales en la misma. No obstante, las mayores carencias que tiene este centro a efectos de sostenibilidad urbana, se dan generalmente en la configuración del entorno urbano, el cual está completamente zonificado y tiene muy poca densidad. De este modo, las operaciones de rehabilitación en este centro son importantes en todos los aspectos, siendo lo más viable enfocarse en las medidas solares activas, y la alimentación con energías renovables, ya que van a ser las medidas más viables de aplicación sobre el centro. De cara a una rehabilitación urbanística, las medidas deberán de enfocarse en la densificación, la inserción de usos y la mejora de la red de transporte público, aplicando todas estas medidas en el entorno urbano próximo. La inserción de usos residenciales o dotacionales y asistenciales en lo que es la parcela del centro, aunque va a contribuir en la generación de actividad urbana, debe de ser considerada como una medida complementaria a la densificación del entorno.

\section{9.- CASE STUDY CONCLUSSIONS}

Shopping malls cases where analyzed according to methodology. Next step is to relate the different retrofitting means described to each center, according to the typology and urban background. The objective to be achieved in this part of the research, is to give the case study analysis done before, a both simplified and universal view. However, is important to consider 
that this analysis is estimative. As a previous step of this unit, a resume of the scores obtained in the case study was done in the following table (figure 5.9.1):

\begin{tabular}{|c|c|c|c|c|c|c|}
\hline \multicolumn{2}{|c|}{ SHOPPING MALL CASES OF STUDY } & & C1. S.Light & C2. S. E.D. & C3.Aricanduva & C4. ABC. Serr. \\
\hline \multirow{14}{*}{$\begin{array}{c}\text { A } \\
\text { ECOEFFICIENT } \\
\text { RETROFITTING }\end{array}$} & \multirow{5}{*}{$\begin{array}{l}\text { A1.- LOW } \\
\text { EMISSIVE } \\
\text { INSTALLATIONS }\end{array}$} & A1.1 Givonni ch. adequacy & 0 (1) n. $a d q$ & $0(1)$ n. $a d q$ & 0 (1) n. adq & 0 (1) n. $a d q$ \\
\hline & & A1.2 CO2 emissions calification (Eur.Union) & $3(4) \mathrm{C}$ & $3(4) \mathrm{C}$ & $3(4) \mathrm{C}$ & $3(4) \mathrm{C}$ \\
\hline & & A1.3 Obsolescence & o (1) obsolete & o(1) obsolete & o(1) obsolete & o (1) obsolete \\
\hline & & A1.4 En. Consumption calification (Eur.Union) & $3(4) C$ & $3(4) C$ & $3(4) C$ & \\
\hline & & TOTAL SCORE & $6(10)$ & $6(10)$ & $6(10)$ & $6(10)$ \\
\hline & \multirow{4}{*}{$\begin{array}{l}\text { A2.- ACTIVE } \\
\text { SOLAR SYSTEMS }\end{array}$} & A2.1 Usage of act. s. syst. & 2 (4) adq. build. & 2 (4) adq. build. & 2 (4) adq. build. & 0 (4) none \\
\hline & & A2.2 Usage of $r$. energies (in mall) & 3 (4) r. e in city & $3(4)$ r. e in city & $3(4)$ r. e in city & 0 (4) none \\
\hline & & A2.3 Givonni ch. adequacy & 2 (2) non neces. & 2 (2) non neces. & 2 (2) non neces. & 0 (2) none \\
\hline & & TOTAL SCORE & $7(10)$ & $7(10)$ & $7(10)$ & $0(10)$ \\
\hline & \multirow{5}{*}{$\begin{array}{l}\text { A3.- PASSIVE } \\
\text { SOLAR SYSTEMS }\end{array}$} & A3.1 Bioclimatic adequacy (Olgyay) & 1(2) part. Adq & 0 (2) non. adq. & 0 (2) non. adq. & 1(2) Part. adq \\
\hline & & A3.2 Efficiency of coverages & 3 (4) efficient & 3 (4) efficient & 3 (4) efficient & 3 (4) efficient \\
\hline & & A3.3 Usage of natural light (\% of built up area) & $1(2) 28 \%$ & 0 (2) $16 \%$ & $0(2) 1,14 \%$ & 1 (2) $20 \%$ \\
\hline & & A3.4 Givonni ch. adequacy & 1(2) part. Adq & 0 (2) non adq. & 0 (2) non adq. & 1(2) part. Adq \\
\hline & & TOTALSCORE & $6(10)$ & $3(10)$ & $3(10)$ & $6(10)$ \\
\hline \multirow{16}{*}{$\begin{array}{c}\text { B } \\
\text { EVIRONMENTAL } \\
\text { RETROFITTING }\end{array}$} & \multirow{6}{*}{$\begin{array}{l}\text { B1.- GREEN } \\
\text { AREAS } \\
\text { RETROFITTING }\end{array}$} & & & & & \\
\hline & & $\begin{array}{l}\text { B1.1 Green areas in urban env. (m2 inhabitant) } \\
\text { B1.2 Green areas in mall }\end{array}$ & $\begin{array}{l}0(2) 1,9 \mathrm{~m} 2 \text { inh. } \\
0 \text { (1) no areas }\end{array}$ & $\begin{array}{l}0(2) 1,9 \mathrm{~m} 2 \text { inh. } \\
1(1) \text { no open areas }\end{array}$ & $\begin{array}{l}1(2) 13,47 \mathrm{~m} 2 \mathrm{i} . \\
1(1) 30800 \mathrm{~m} 2\end{array}$ & $\begin{array}{l}\text { o (2) } 2,3 \mathrm{~m} 2 \text { inh. } \\
0 \text { (1) no areas }\end{array}$ \\
\hline & & B1.3 CO2 Assimilation rate (urban env.) & 1(3) $10 \%$ & $2(3) 52 \%$ & 3(3) $73 \%$ & $0(3) 4,4 \%$ \\
\hline & & $\begin{array}{l}\text { b1.4 CO2 Assimilation rate (mall) } \\
\text { B1.) }\end{array}$ & $0(3) 0,5 \%$ & $1(3) 21 \%$ & $1(3) 21 \%$ & $0(3) 0,5 \%$ \\
\hline & & B1.5 Distance between green areas & $1(1) 300 m$ & 0 (1) $500 \mathrm{~m}$ & 0 (1) $400 \mathrm{~m}$ & $1(1) 380 \mathrm{~m}$ \\
\hline & & 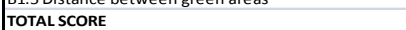 & $2(10)$ & $3(10)$ & $6(10) E->4(10)$ & 1(10) \\
\hline & \multirow{5}{*}{$\begin{array}{l}\text { B2.- WATER } \\
\text { ABSORBING } \\
\text { SURFACE }\end{array}$} & B2.1 Aridity of climate & 1 (1) non arid & 1 (1) non arid & 1(1) non arid & 0 (1) semi arid \\
\hline & & B2.2 Rate of absorbent paviment \% (ur. Env) & $0(4) 2,6 \%$ & $0(4) 3 \%$ & $1(4) 12 \%$ & $0(4) 9 \%$ \\
\hline & & $\begin{array}{l}\text { B2.3 Water saving installations } \\
\text { all }\end{array}$ & 0 (3) none & 0 (3) none & o(3) none & 0 (3) none \\
\hline & & B2.4 Water consumption per visit & 1 (2) 30 l visit & $\begin{array}{l}\text { 1(2) nolve } \\
\text { (2) visit }\end{array}$ & $\begin{array}{l}\text { 1(2) nolve } \\
\text { (2)isit }\end{array}$ & $\begin{array}{l}\text { (3) none } \\
1 \text { (2) 30l visit }\end{array}$ \\
\hline & & $\begin{array}{l}\text { TOTAL SCORE } \\
\end{array}$ & $2(10)$ & $2(10)$ & $3(10)$ & $1(10)$ \\
\hline & \multirow{5}{*}{\begin{tabular}{|c|} 
B3.- HEAT \\
ISLAND TREATMENT
\end{tabular}} & B3.1 Climate heat & 0 (2) hot $c l$. & 0 (2) hot $c l$. & $0(2)$ hot $c l$. & 0 (2) hot cl. \\
\hline & & & 1(1) no heat & & 1(1) no heat & 0 (1) heat cond. \\
\hline & & $\begin{array}{l}\text { B3.2Frequency ore extreme neat conations } \\
\text { B3.3 Heat island effect in the mall urb. area }\end{array}$ & $\begin{array}{l}\text { 1(1) no neat } \\
0 \text { (3) }+40 . i .\end{array}$ & $\begin{array}{l}\text { 1(1) no neat } \\
0 \text { (3) }+40 . i .\end{array}$ & $\begin{array}{l}\text { 1(1) no neat } \\
0 \text { (3) }+40 . i .\end{array}$ & 0. \\
\hline & & B3.4 Rate of heat expelling built surface & 0 (4) $8 \%$ & 0 (4) $17 \%$ & O(4) $16 \%$ & 2 (4) $45,96 \%$ \\
\hline & & TOTAL SCORE & $1(10)$ & $1(10)$ & $1(10)$ & $2(10)$ \\
\hline \multirow{13}{*}{$\begin{array}{c}\text { C } \\
\text { RETROFITTING } \\
\text { BY THE INSERTION } \\
\text { OF USES }\end{array}$} & \multirow{5}{*}{$\begin{array}{c}\text { C1.- } \\
\text { RESIDENTIAL USE }\end{array}$} & & & & & \\
\hline & & C1.1 Residential use in mall & o(2) none & 0 (2) none & 0 (2) none & 0 (2) none \\
\hline & & C1.2 Residential use in nearby plots & $2(3) 30 \%$ & $1(3) 15 \%$ & $3(3) 85 \%$ & $2(3) 50 \%$ \\
\hline & & C1.3 Residential use in urban area & $3(5) 40 \%$ & $4(5) 51 \%$ & $5(5) 81 \%$ & $3(5) 50 \%$ \\
\hline & & TOTALSCORE & $5(10)$ & $5(10)$ & $8(10)$ & $5(10)$ \\
\hline & \multirow{4}{*}{$\begin{array}{c}\text { C2.- } \\
\text { PRODUCTIVE USE }\end{array}$} & C2.1 Productive use in mall & 1(1) R.F. office & 1(1) Police box & 1(1) Police box & 0 (1) no uses \\
\hline & & C2.2 Productive use in nearby plots & $3(3) 60 \%$ & $3(3) 60 \%$ & 2 (3) $10 \%$ & 3 (3) $30 \%$ \\
\hline & & c2.3 Productive Use in urban area & $5(6) 30 \%$ & $5(6) 29,86 \%$ & $1(6) 7,77 \%$ & $5(6) 30 \%$ \\
\hline & & TOTALSCORE & $9(10)$ & $9(10)$ & $4(10)$ & $8(10)$ \\
\hline & & C3.1 Pressence of amenities in mall & 1(1) R.F. office & 0 (1) non visit. & $O(1)$ non visit. & 0 (1) none \\
\hline & $\begin{array}{c}\text { C3.- } \\
\text { C.- }\end{array}$ & C3.1 Amenities in nearby plots & 4(4) 1st rank. & 0 (4) none & 1(4) 3rd rank & 2 (4) 2nd rank \\
\hline & $\begin{array}{l}\text { AMENITIES } \\
\text { ARPUBSES }\end{array}$ & C3.3 Amenities in $1 \mathrm{~km}$. from mall & 5(5) 1st rank & 5 (5) 1st rank & 5 (5) 1st rank & 5 (5) 1st rank \\
\hline & & TOTALSCORE & $10(10)$ & $5(10)$ & $6(10)$ & $7(10)$ \\
\hline & & D1.1 Mass transit facility nearby mall & 1(1) yes & 1(1) yes & 1(1)yes & 1(1) yes \\
\hline & & $\begin{array}{l}\text { 11.1 Masss transit acaility nearby mall } \\
\text { D1.2 Efficacy of mass transit/private veh. }\end{array}$ & $\begin{array}{l}\text { 1(1) yes } \\
3(3) \text { high effic. }\end{array}$ & $\begin{array}{l}1 \text { (1) yes } \\
2 \text { (3) efficient }\end{array}$ & $\begin{array}{l}\text { 1(1) yes } \\
1(3) \text { poorly eff. }\end{array}$ & $\begin{array}{l}\text { 1) (1) yes } \\
0 \text { (3) non eff. }\end{array}$ \\
\hline & D1.- EFFICIENT & D1.3 Mass transit coverage in urban area & $2(2) 96 \%$ & $1(2) 52 \%$ & $1(2) 50 \%$ & $2(2) 72 \%$ \\
\hline & TRANSPORTATION & D1.4 Zonning rate & 2(2) no zonn. & 1(2) Avg. zonn. & $0(2)$ zonified & 2 (2) no zonn. \\
\hline & & D1.5 Sustainable movility facilities in mall & $\begin{array}{l}\text { o(2) none } \\
\text { (2) }\end{array}$ & o(2) none & 0 (2) none & 1 (2) some \\
\hline & & TOTAL SCORE & $8(10)$ & $5(10)$ & $3(10) E->2(10)$ & $6(10)$ \\
\hline & & D2.1 Optimal rate of population density & 3(4) str. dens. & 2 (4) sl. dense & 2 (4) sl. dense & 3 (4) str. dens. \\
\hline & & D2.2 Density of built up area & 2 (3) str. dens. & $2(3)$ avg dens. & $2(3)$ avg dens. & 2 (3) str. dens. \\
\hline & D2.- DENSITY & D2.3 Rate of building coverage (\%) & $3(3) 67 \%$ & 3 (3) $51 \%$ & $3(3) 69 \%$ & $3(3) 67 \%$ \\
\hline-5 & & TOTALSCORE & $8(10)$ & $7(10)$ & $7(10)$ & $8(10)$ \\
\hline RETROFITTING IN & & D3.1 Negative elements in area & 0 (1) yes & $0(1)$ yes & 0 (1) yes & 1(1) none \\
\hline URBAN AREA & & D3.2 Cold activity areas in daytime & 1(1) act. area & 1 (1) act. area & $0(1)$ non act. & 1(1) act. area \\
\hline & & D3.3 Cold activity areas at night & $0(1)$ non act. & $0(1)$ non act. & 0 (1) non act. & 1 (1) act. area \\
\hline & & D3.4 Areas with complicated visual control & 0 (1) yes & $1(1)$ no & 0 (1) yes & 1 (1) no \\
\hline & D3.- WALKABILITY & D3.5 Security feeling in people & 0 (1) non secure & 0 (1) non secure & 0 (1) non secure & 1(1) secure \\
\hline & AND SECURITY & D3.6 Active facades in nearby plots (\% facade lenght) & 1 (2) $49 \%$ f.lgt & 1 (2) $31 \%$ f.lgt & 0 (2) $16 \%$ & $2(2) 58 \%$ \\
\hline & & D3.7 Distance to nearest residential building & 1 (1) $80 \mathrm{~m}$ & 1 (1) $20 \mathrm{~m}$ & 0 (1) $500 \mathrm{~m}$ & 1(1) $100 \mathrm{~m}$ \\
\hline & & D3.8 Rate of free space in area & $1(1) 33 \%$ & 1(1) $51 \%$ & 1(1) $40 \%$ & $1(1) 50 \%$ \\
\hline & & D3.9 Rate of uses zonification & 1(1) mix. uses & o(1) no mix & 0 (1) no mix & 1 (1) mix. uses \\
\hline & & TOTALSCORE & $5(10) E->6(10)$ & $5(10)$ & $1(10)$ & $10(10) E->11(10)$ \\
\hline & $\bar{\Gamma}$ & E1 Attraction index of the mall & $3(5)$ & $3(5)$ & $5(5)$ & $3(5)$ \\
\hline & E & E2 Score in Efficient transportation & $8(10)$ & $5(10)$ & $3(10)$ & $7(10)$ \\
\hline SCORING RELA & TED TO ACTIVITY & 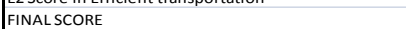 & +1 to $D 3$ & No Score & $-1>\mathrm{D} 1 ;-2>\mathrm{B} 1$ & +1 to $D 3$ \\
\hline
\end{tabular}




\begin{tabular}{|c|c|c|c|c|c|c|}
\hline \multicolumn{2}{|c|}{ SHOPPING MALL CASES OF STUDY } & & C5. L. Vaguda & C6. P.S. & C7. Belmar & C8. M.O.A. \\
\hline \multirow{14}{*}{$\begin{array}{c}\text { A } \\
\text { ECOEFFICIENT } \\
\text { RETROFITING }\end{array}$} & \multirow{5}{*}{$\begin{array}{c}\text { A1.- LOW } \\
\text { EMISSIVE } \\
\text { INSTALLATIONS }\end{array}$} & A1.1 Givonni ch. adequacy & 1(1) adequate & 1(1) adequate & 1(1) adequate & 1(1) adequate \\
\hline & & A1.2 $\mathrm{CO} 2$ emissions calification (Eur.Union) & 3 (4) $B$ & 3(4) $B$ & $3(4) C$ & $3(4) C$ \\
\hline & & A1.3 Obsolescence & 1 (1) non obs. & 1(1) non obs. & 1 (1) non obs. & 1(1) non obs. \\
\hline & & A1.4 En. Consumption calification (Eur.Union) & $3(4) C$ & $3(4) \mathrm{C}$ & $3(4) C$ & $3(4) C$ \\
\hline & & TOTAL SCORE & $8(10)$ & $8(10)$ & $8(10)$ & $8(10)$ \\
\hline & \multirow{4}{*}{$\begin{array}{c}\text { A2.- ACTIVE } \\
\text { SOLAR SYSTEMS }\end{array}$} & A2.1 Usage of act. s. syst. & $1(4) 10 \%$ & $1(4) 10 \%$ & $2(4) 30 \%$ & $0(4)$ no \\
\hline & & A2.2 Usage of r. energies (in mall) & $1(4) 4 \%$ & $1(4) 5,6 \%$ & $2(4) 20 \%$ & 1(4) $10 \%$ est. \\
\hline & & A2.3 Givonni ch. adequacy & 1(2) p. adeq. & 1 (2) p.adeq. & 1(2) p.adeq. & $0(2)$ none \\
\hline & & TOTAL SCORE & $3(10)$ & $3(10)$ & $5(10)$ & $1(10)$ \\
\hline & \multirow{5}{*}{$\begin{array}{l}\text { A3.- PASSIVE } \\
\text { SOLAR SYSTEMS }\end{array}$} & A3.1 Bioclimatic adequacy (Olgyay) & 2 (2) adeq. & 1(2) Part. adq & 1(2) Part. adq & 1(2) Part. adq \\
\hline & & A3.2 Efficiency of coverages & 3 (4) efficient & 3 (4) efficient & 3(4) efficient & 3(4) efficient \\
\hline & & A3.3 Usage of natural light (\% of built up area) & 1(2) $23,39 \%$ & 1(2) $26,13 \%$ & $2(2) 83,53 \%$ & $1(2) 33 \%$ \\
\hline & & A3.4 Givonni ch. adequacy & 1(2) part. Adq & 1(2) part. Adq & 1(2) part. Adq & 2(2) adequate \\
\hline & & TOTAL SCORE & $7(10)$ & $6(10)$ & $7(10)$ & $7(10)$ \\
\hline \multirow{16}{*}{$\begin{array}{c}\text { B } \\
\text { EVIRONMENTAL } \\
\text { RETROFITTING }\end{array}$} & \multirow{6}{*}{$\begin{array}{l}\text { B1.- GREEN } \\
\text { AREAS } \\
\text { RETROFITTING }\end{array}$} & B1.1 Green areas in urban env. (m2 inhabitant) & 0 (2) $1,16 \mathrm{~m} 2 \mathrm{inh}$ & $0(2) 5,6 m 2$ inh & 2 (2) $96 \mathrm{~m} 2 \mathrm{inh}$ & 2 (2) $1086 \mathrm{~m} 2 \mathrm{inh}$ \\
\hline & & B1.2 Green areas in mall & 1(1) $7276 \mathrm{~m} 2$ & 1 (1) $12000 \mathrm{~m} 2$ & 1 (1) $200000 \mathrm{~m} 2$ & $0(0) O m 2$ \\
\hline & & B1.3 CO2 Assimilation rate (urban env.) & $0(3) 6 \%$ & $1(3) 22 \%$ & 3 (3) $400 \%$ & $3(3) 176 \%$ \\
\hline & & B1.4 CO2 Assimilation rate (mall) & $2(3) 36 \%$ & 1 (3) $28 \%$ & $1(3) 18 \%$ & $0(3) 3,5 \%$ \\
\hline & & B1.5 Distance between green areas & $1(1) 200 \mathrm{~m}$ & 1(1) $380 \mathrm{~m} 2$ & $1(1) 200 \mathrm{~m}$ & 1 (1) $100 \mathrm{~m}$ \\
\hline & & TOTAL SCORE & $4(10)$ & $4(10)$ & $8(10) E->7(10)$ & $6(10) E->4(10)$ \\
\hline & \multirow{5}{*}{$\begin{array}{l}\text { B2.- WATER } \\
\text { ABSORBING } \\
\text { SURFACE }\end{array}$} & B2.1 Aridity of climate & 0 (1) semiarid & O(1) semiarid & O(1) semiarid & 1(1) humid \\
\hline & & B2.2 Rate of absorbent paviment \% (ur. Env) & $0(4) 4 \%$ & $1(4) 17 \%$ & $2(4) 33 \%$ & $3(4) 45 \%$ \\
\hline & & B2.3 Water saving installations & 2 (3) has some & 1 (3) has some & 2 (3) has some & 1 (3) has some \\
\hline & & B2.4 Water consumption per visit & 2 (2) 201 visit & 2 (2) 201 visit & 1 (2) 301 visit & 1 (2) 301 visit \\
\hline & & TOTAL SCORE & $4(10)$ & $4(10)$ & $5(10)$ & $6(10)$ \\
\hline & \multirow{5}{*}{$\begin{array}{c}\text { B3.- HEAT } \\
\text { ISLAND TREATMENT }\end{array}$} & B3.1 Climate heat & 0 (2) hot cl. & 0 (2) hot cl. & 1 (2) avg. Clim. & 2 (2) coolcl. \\
\hline & & B3.2 Frequency of extreme heat conditions & 0 (1) heat cond. & 0 (1) heat cond. & 0 (1) heat cond. & 1(1) no heat \\
\hline & & B3.3 Heat island effect in the mall urb. area & $0(3)+5=$ h.i. & $1(3)+20$ & $2(3)+10$ & $0(3)+40$ \\
\hline & & B3.4 Rate of heat expelling built surface & $4(4) 91,28 \%$ & $0(4) 3 \%$ & 1 (4) $23 \%$ & $0(4) 8 \%$ \\
\hline & & TOTAL SCORE & $4(10)$ & $1(10)$ & $4(10)$ & $3(10)$ \\
\hline \multirow{12}{*}{$\begin{array}{c}\text { C } \\
\text { RETROFITTING } \\
\text { BY THE INSERTION } \\
\text { OF USES }\end{array}$} & \multirow{4}{*}{$\begin{array}{c}\text { C1.- } \\
\text { RESIDENTIAL USE }\end{array}$} & C1.1 Residential use in mall & $0(2)$ none & $0(2)$ none & 1 (2) $15 \%$ visit. & 2 (2) $36 \%$ visit. \\
\hline & & C1.2 Residential use in nearby plots & $2(3) 50 \%$ & $3(3) 94 \%$ & $3(3) 52 \%$ & $0(3) 7,96 \%$ \\
\hline & & C1.3 Residential use in urban area & $5(5) 80 \%$ & $4(5) 68 \%$ & $4(5) 62 \%$ & $2(5) 33 \%$ \\
\hline & & TOTAL SCORE & $7(10)$ & $7(10)$ & $8(10)$ & $4(10)$ \\
\hline & \multirow{4}{*}{$\begin{array}{c}\text { C2.- } \\
\text { PRODUCTIVE USE }\end{array}$} & C2.1 Productive use in mall & 1(1) yes & 1(1) yes & 1(1) yes & $0(1)$ no uses \\
\hline & & C2.2 Productive use in nearby plots & $3(3) 30 \%$ & $0(3) 1 \%$ & $3(3) 16 \%$ & $3(3) 20 \%$ \\
\hline & & C2.3 Productive Use in urban area & $2(6) 10,82 \%$ & 1 (6) $16,72 \%$ & $3(6) 14 \%$ & $6(6) 45,2 \%$ \\
\hline & & TOTAL SCORE & $6(10)$ & $2(10)$ & $7(10)$ & $9(10)$ \\
\hline & \multirow{4}{*}{$\begin{array}{c}\text { C3.- } \\
\text { AMENITIES } \\
\text { OR PUBLIC USES }\end{array}$} & C3.1 Pressence of amenities in mall & 1(1) post office & 0 (1) none & 1 (1) some fac. & 0 (1) none \\
\hline & & C3.1 Amenities in nearby plots & 3 (4) 1st rank & $0(4)$ none & 4 (4) most visit. & $0(4)$ none \\
\hline & & C3.3 Amenities in $1 \mathrm{~km}$. from mall & 5 (5) 1st rank & 4 (5) local rank & 2 (5) local rank & 1 (5) one only \\
\hline & & TOTAL SCORE & $9(10)$ & $4(10)$ & $7(10)$ & $1(10)$ \\
\hline & & D1.1 Mass transit facility nearby mall & 1(1)yes & 1(1)yes & 1(1) yes & \\
\hline & & D1.2 Efficacy of mass transit/private veh. & 1 (3) poorly eff. & o (3) no effic. & 0 (3) no effic. & 0 (3) no effic. \\
\hline & D1.- EFFICIENT & D1.3 Mass transit coverage in urban area & $2(2) 86 \%$ & $2(2) 70 \%$ & 0 (2) less $50 \%$ & $0(2)$ less $50 \%$ \\
\hline & TRANSPORTATION & D1.4 Zonning rate & 2(2) no zonn. & 2(2) no zonn. & 0 (2) zonified & 0 (2) zonified \\
\hline & & D1.5 Sustainable movility facilities in mall & 2(2) yes & 2(2) yes & 1 (2) some & o(2) none \\
\hline & & TOTAL SCORE & $8(10)$ & $7(10)$ & $2(10) E->1(10)$ & $1(10) E->0(10)$ \\
\hline & & D2.1 Optimal rate of population density & 3 (4) str. dens. & 3 (4) str. dens. & 0 (4) low dens. & 0 (4) low dens. \\
\hline & D2.- DENSITY & D2.2 Density of built up area & 3 (3) optimald. & 3(3) optimald. & 0 (3) low dens. & 0 (3) low dens. \\
\hline & D2.- DENSITY & D2.3 Rate of building coverage (\%) & $1(3) 22 \%$ & 1 (3) $28 \%$ & 1 (3) $21 \%$ & 1 (3) $21 \%$ \\
\hline D & & TOTAL SCORE & $7(10)$ & $7(10)$ & $1(10)$ & $1(10)$ \\
\hline RETROFITTING IN & & D3.1 Negative elements in area & 1(1) none & $0(1)$ yes & 1 (1) none & 1(1) none \\
\hline URBAN AREA & & D3.2 Cold activity areas in daytime & 1(1) act. area & 1(1) act. area & 0 (1) non act. & 0 (1) non act. \\
\hline & & D3.3 Cold activity areas at night & 0 (1) non act. & 0 (1) non act. & 0 (1) non act. & 0 (1) non act. \\
\hline & & D3.4 Areas with complicated visual control & 1(1) no & 1(1) no & 1(1) no & $0(1)$ yes \\
\hline & D3.- WALKABILITY & D3.5 Security feeling in people & 1 (1) secure & 1(1) secure & 1(1) secure & 1(1) secure \\
\hline & AND SECURITY & D3.6 Active facades in nearby plots (\% facade lenght) & $1(2) 32 \%$ & $0(2) 3,73 \%$ & $0(2) 7,96 \%$ & $0(2) 23,59 \%$ \\
\hline & & D3.7 Distance to nearest residential building & 1(1) $90 \mathrm{~m}$ & 0 (1) $350 \mathrm{~m}$ & 1 (1) R. in mall & 1(1) $150 \mathrm{~m}$ \\
\hline & & D3.8 Rate of free space in area & 0 (1) $79 \%$ & $0(1) 71,5 \%$ & o(1) $79 \%$ & $0(1) 79 \%$ \\
\hline & & D3.9 Rate of uses zonification & 1 (1) mix. uses & 1(1) mix. uses & 0 (1) no mix & $0(1)$ no mix \\
\hline & & TOTAL SCORE & $7(10) E->9(10)$ & $4(10) E->5(10)$ & $4(10)$ & $3(10)$ \\
\hline & & & & $4(5)$ & $3(5)$ & $5(5)$ \\
\hline & $E$ & E2 Score in Efficient transportation & $8(10)$ & $7(10)$ & $2(10)$ & $1(10)$ \\
\hline SCORING RELA & TED TO ACTIVITY & FINALSCORE & +2 to $D 3$ & +1 to $D 3$ & $-1>\mathrm{D} 1 ;-1>\mathrm{B} 1$ & $-1>\mathrm{D} 1 ;-2>\mathrm{B} 1$ \\
\hline
\end{tabular}

Figure 5.9.1: Resumed table of the case study scores. Own's source.

To start with the analysis, the retrofitting rose graphs are going to be put in common (figure 5.9.2), looking for differences and similarities among each other. 
(A3) (B1)

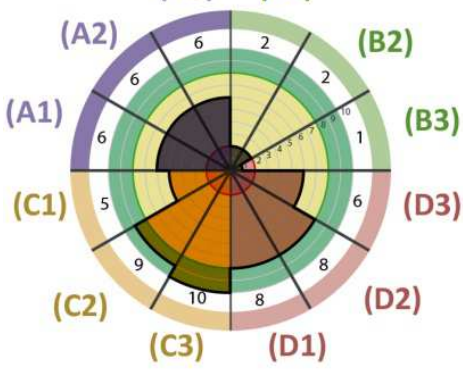

SHOPPING LIGHT

(A3) (B1)

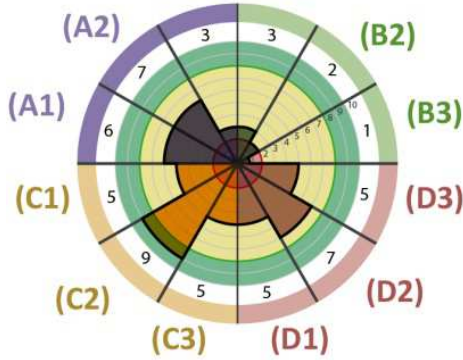

SHOPPING ELDORADO

(A3) (B1)

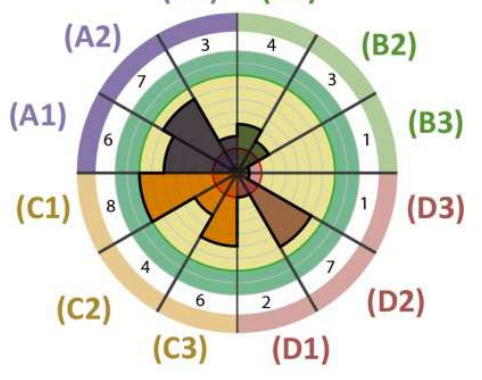

SHOPPING ARICANDUVA

(A3) (B1)

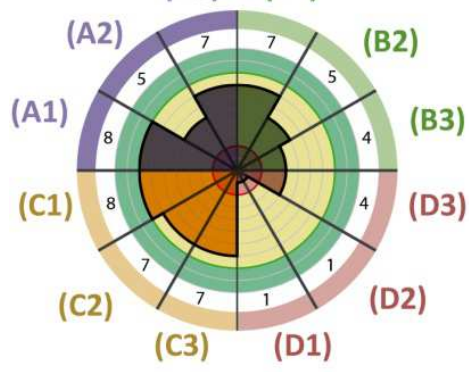

BELMAR
(A3) (B1)

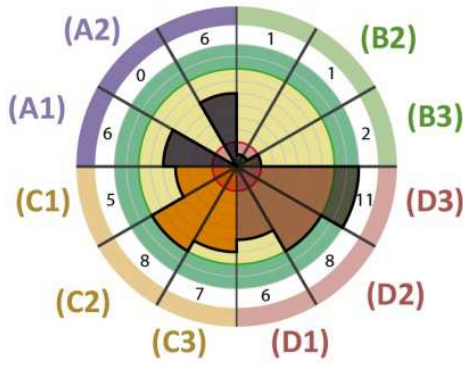

ABC SERRANO

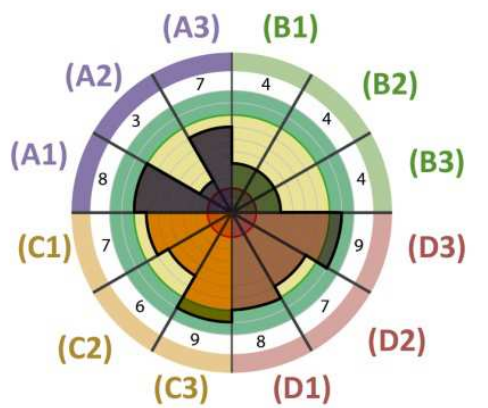

LA VAGUADA

(A3) (B1)

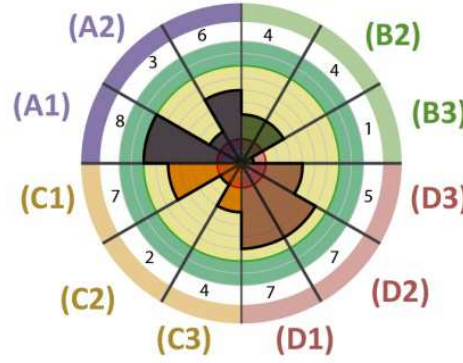

PARQUESUR

(A3) (B1)

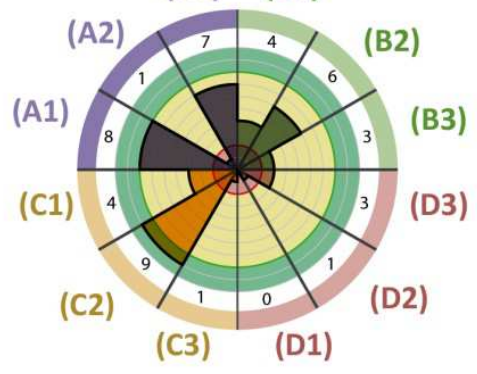

MALL OF AMERICA
(A) ECO EFFICIENT RETROFITTING FAMILY

(A1) Low Emissive installations

(A2) Active measures

(A3) Passive measures

(B) ENVIRONMENTAL RETROFITTING FAMILY

(B1) Insertion of green areas

(A2) Water assimilative surfaces

(A3) Heat island treatment

C) USES AND AMENITIES INSERTION

(C1) Residential use

(A2) Productive use

(A3) Services and amenities

(D) RETROFITTING OF URBAN AREAS

(D1) Sustainable transportation

(D2) Density

(A3) Security and urban interactions

\section{THRESHOLDS}

2 points: Minimum threshold

8 points: Optimal threshols

10 points: Green paradigm

\section{AREAS AND INTEVALS}

0-2 points: Highly prior retrofitting

mean

2-8 points: Averagely prior

retrofitting mean

8-10 points: No prior retrofitting mean

Figure 5.9.2: Graphs of the Sustainable Retrofitting Rose for each case. Own's source.

5.9.1.- Retrofitting measures of application criteria according to shopping mall urban background. 
In this chapter, that will conclude the case study, the cases are going to be compared according the features of their urban backgrounds. The aim is to establish one of the conclusions of this thesis, concretely the one related to the correct choose of retrofitting measures according to urban background.

To start with this analysis, the cases studied are going to be put in the Kevin Lynch Graph related for the urban background established for this thesis (Figure 5.9.3). This step will help us to group the most adequate retrofitting measures of application by urban background features.

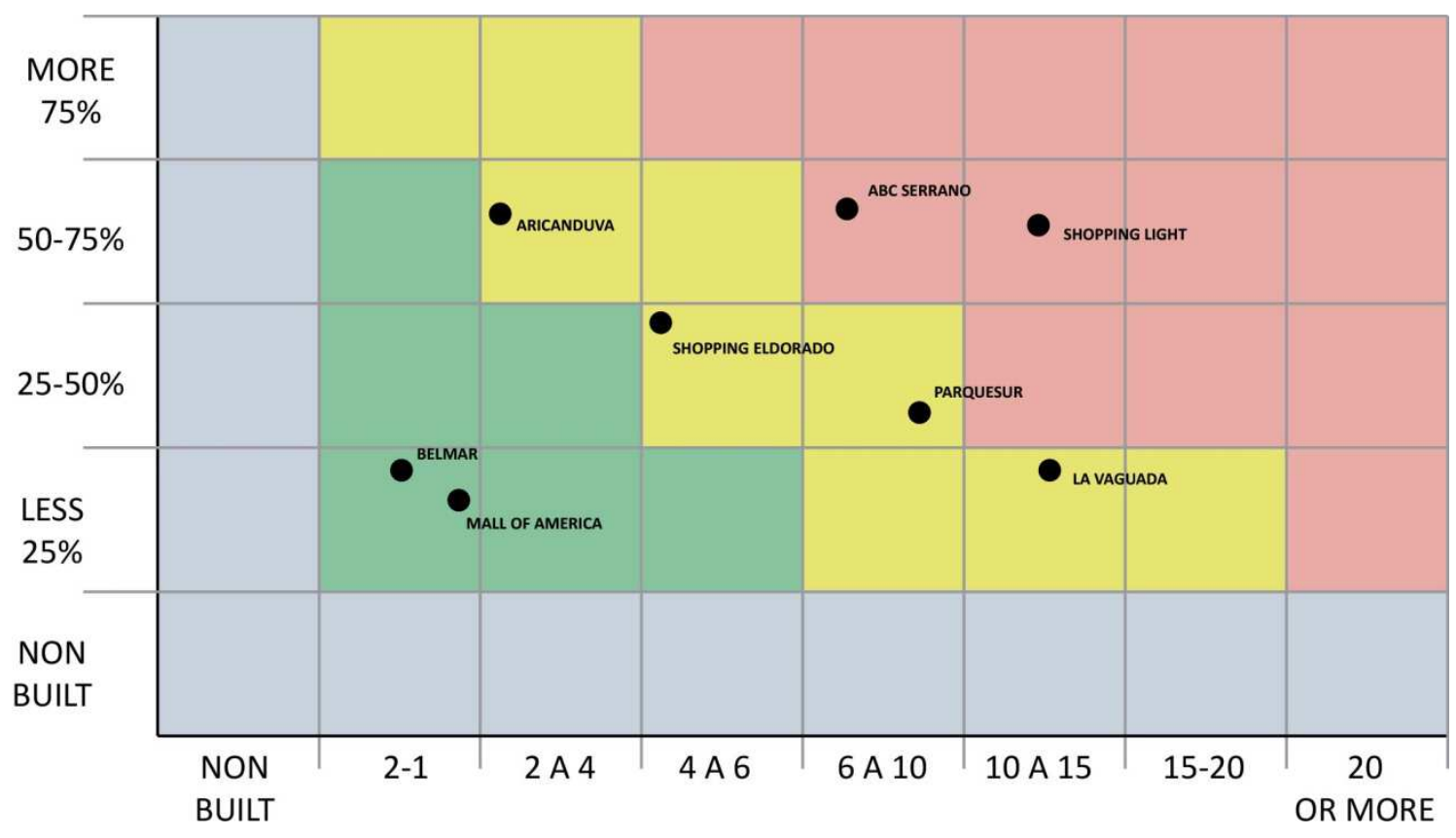

Figure 5.9.3: Kevin Lynch based analysis graph for cases urban areas. Own's source.

This analysis will establish the criteria of comparison among the shopping malls facing the final conclusions, The centers will be group in these pairs for this analysis:

In a general View, the cases located in dense urban areas such as Shopping Light and $A B C$ Serrano, have low scores in the Sustainable Retrofitting Rose. This means in the facts related to the environmental quality, a retrofitting is going to be required. The main cause of this is the high rate of built surfaces in the areas (97,4\% in Shopping Light and $91 \%$ in ABC Serrano Area) that implies a low rate carbon dioxin assimilation (SL:10\%, ABC: 4,4\%), a low rate of water absorption by the terrain, and critical problems related to heat island (more than 40 in both cases). Opposite to this, related to uses availability and complexity, in addition to urban vitality, both shopping malls have high scores. (Figure 5.9.4) 


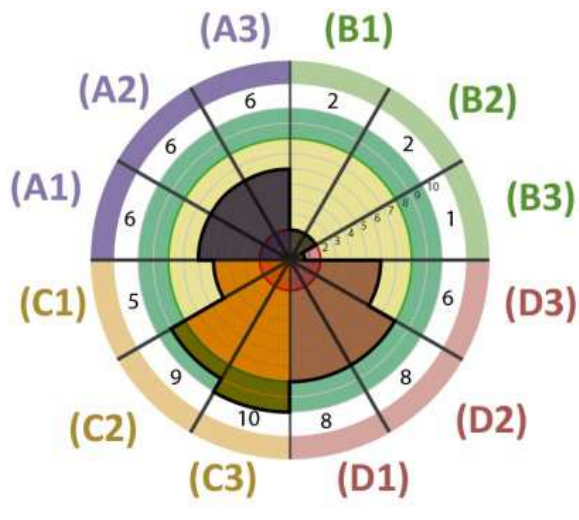

SHOPPING LIGHT

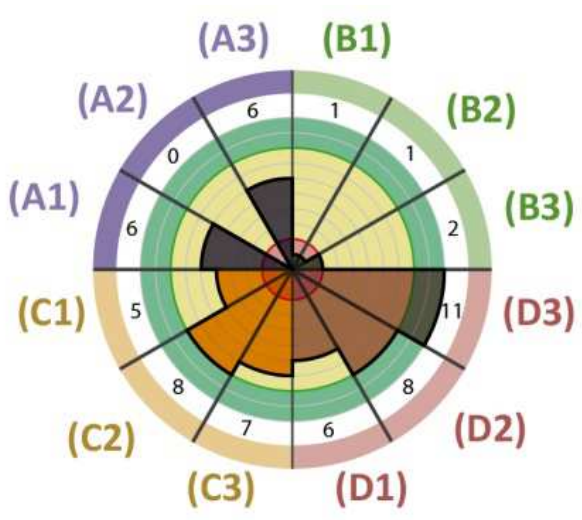

ABC SERRANO

Figure 5.9.4: Retrofitting roses of the cases located in dense urban areas. Own's source.

As the figure 5.9.3 shows, The density of the outskirts areas of Madrid, seems to be higher than the one of the urban areas of Sao Paulo, because of major building height, despite having a minor rate of coverage. The most efficient retrofitting for the cases located in middle density urban areas, (Shopping Eldorado, Aricanduva, La Vaguada and Parquesur) depends on the case, However the general trend for these four cases is the relatively low scores in the environmental quality.

Considering the cases located in the Expanded city centers of Sao Paulo and Madrid, (Shopping Eldorado and La Vaguada), both cases have related to environment, a slightly better condition than shopping malls located in dense urban areas. this happens because there are more green areas that implies a better rate in carbon dioxin absorption. For instance, the vegetation in the Shopping Eldorado urban area can assimilate about a $52 \%$ of its own emissions, and in the case of La Vaguada, despite this rate is low, (6\%) the vegetation in the shopping mall can assimilate about a $35 \%$ of the emissions of the shopping mall, being the green areas in urban surroundings better distributed. Related to uses, and urban activity, the area of la Vaguada is more complex than the one of Shopping Eldorado, having better coverage in mass transit (ED: $52 \%$; LV: $86 \%$ of the urban area) despite being the transportation more efficient for the case of Shopping Eldorado, because of the strategic location of the mall. In addition, the urban surroundings of La Vaguada, have a strong mix of uses, with high rank amenities nearby the shopping mall (complexity index of 1), Being this mixture of uses almost null in the urban surroundings of Shopping Eldorado, which are almost zonified. (Figure 5.9.4) 


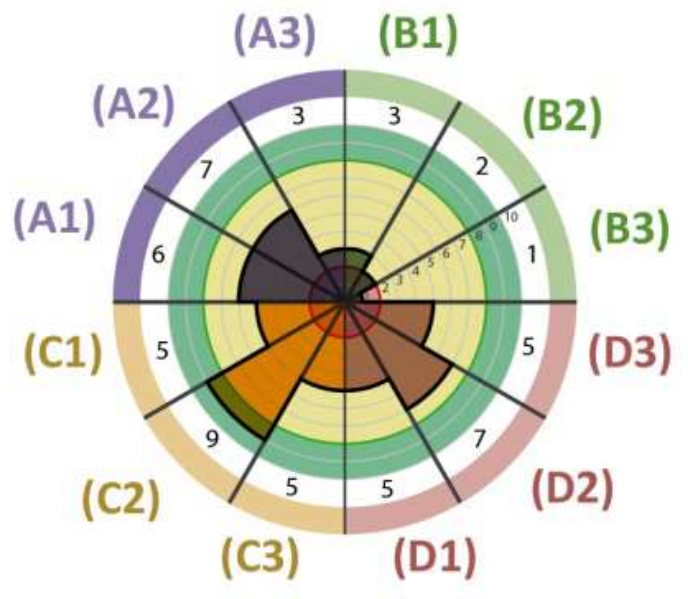

SHOPPING ELDORADO

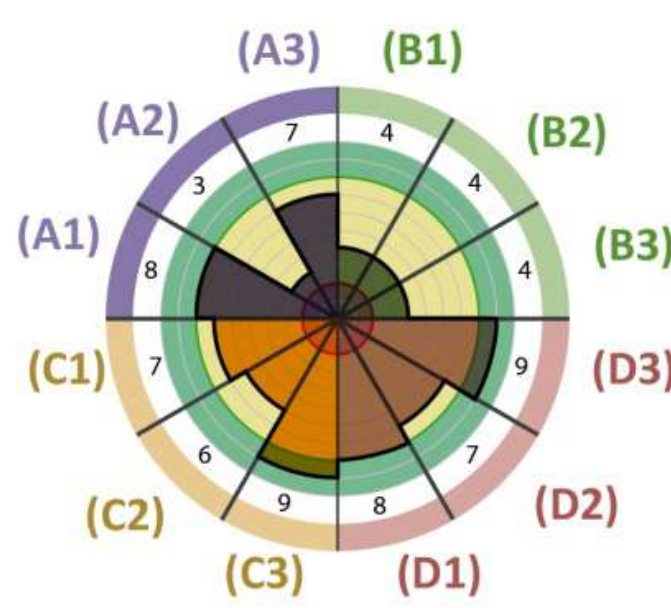

LA VAGUADA

Figure 5.9.5: Retrofitting roses of the cases located in expanded city centers. Own's source.

Related to the cases studied located in nearby outskirts (Aricanduva and Parquesur), the Rose Graph shows that in all retrofitting families, are both high scores and low scores. For both cases, the lowest scores are in the environmental retrofitting family; having the urban environment of these two malls, almost the same problems of the ones located in the expanded city center. However, the fact that penalties this family of retrofitting is the heat island treatment, and the cause of this is because both malls have large paved surfaces without heat reflection treatment (Ar:84\%-Ps:97\%). Related to uses, the urban areas surrounding these malls are more zoned, being predominant the residential use. (Ar: $81 \%$ Ps:68\%, but $98 \%$ in nearby plots). The problem of urban activity is critical in the urban area of Aricanduva, because of the almost none mix of uses, the long distances, and the insecurity. (Figure

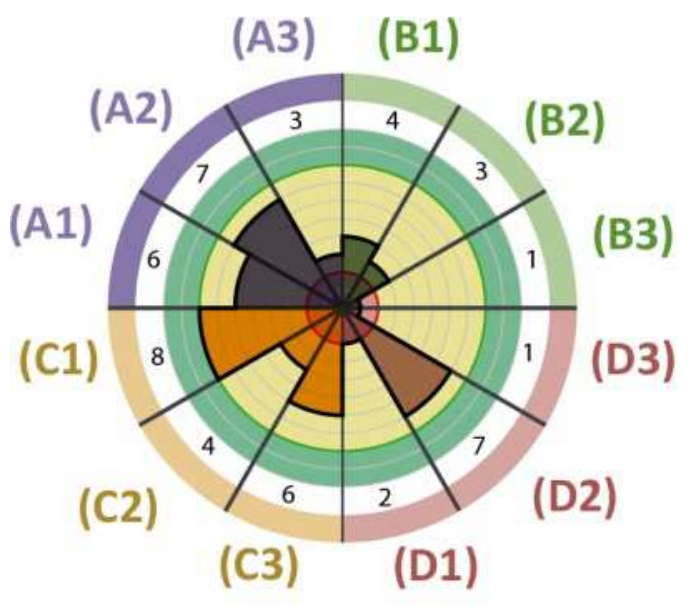

SHOPPING ARICANDUVA

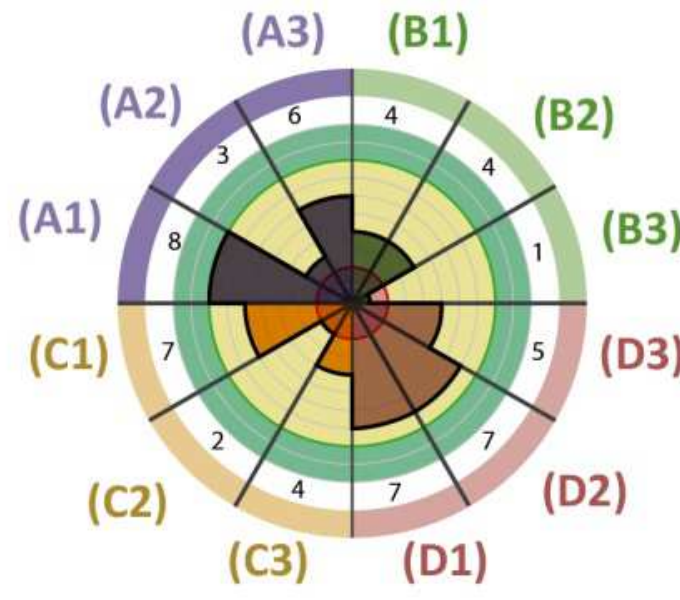

PARQUESUR

Figure 5.9.6: Retrofitting roses of the cases located in nearby outskirts. Own's source. 
The Last cases to compare, are the ones related to North American suburban areas (Belmar and Mall of America). Because both malls are located in low density, zoned, and sprawled urban areas, scores related to urban activity, density and mass transit are critically low (In both cases, density is minor to 20 inhabitants per hectare. The coverage of mass transit scarcely goes up to $30 \%$ of the urban area of analysis, the uses are zoned per use, and the rate of non built space is about a $79 \%$ of the total surface). However, the case of Belmar, as being the result of a retrofitting aimed to solve these problems, the mixture of uses in the complex is correct ( $52 \%$ of residential and $48 \%$ of non residential), and this generates urban activity in the nearby areas. Strengths in both cases though, are related to environmental quality. The reason of this, is because both urban areas have large green surfaces among the sprawled buildings, being even the rate of carbon dioxin absorption more than $100 \%$ of the carbon dioxin emissions the urban area generate for both cases (Be: $400 \%$ and MOA: 176\%).

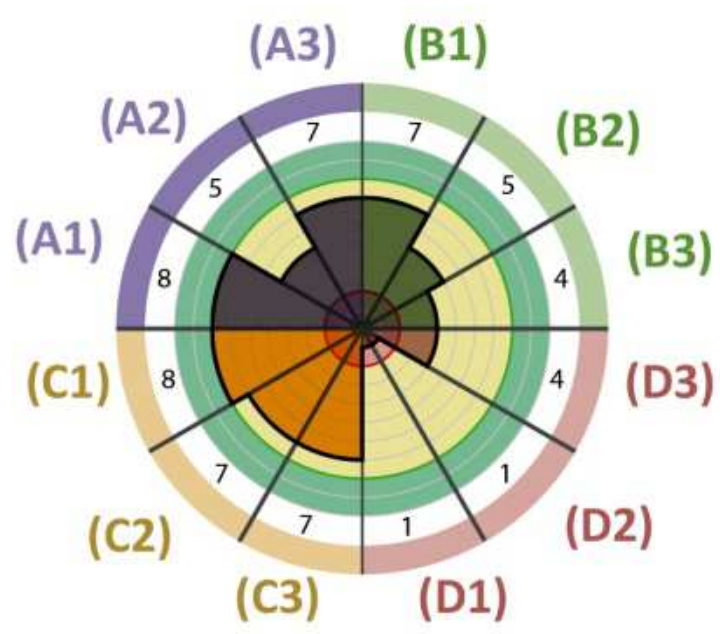

BELMAR

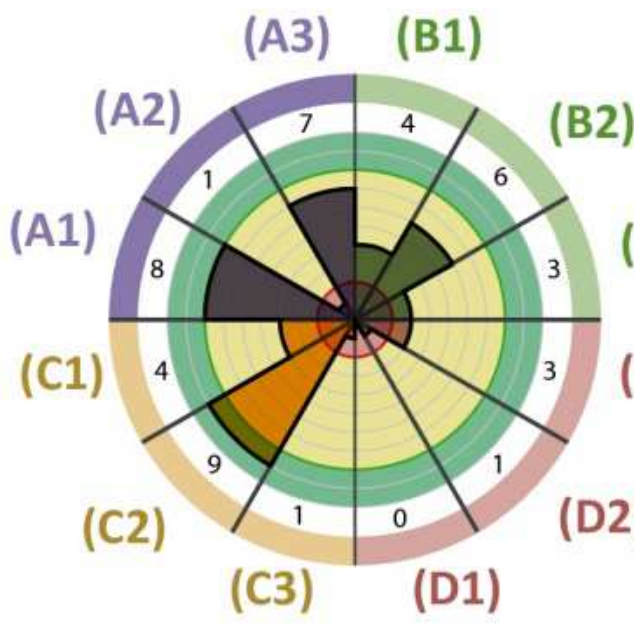

MALL OF AMERICA

Figure 5.9.7: Retrofitting roses of the cases located in the North American Suburban areas. Own's source.

To sum up with this chapter, the following graph was done, considering all the average scores of the retrofitting roses, the idea is to show which retrofitting are the most adequate according the urban background (Figure 5.9.8). 


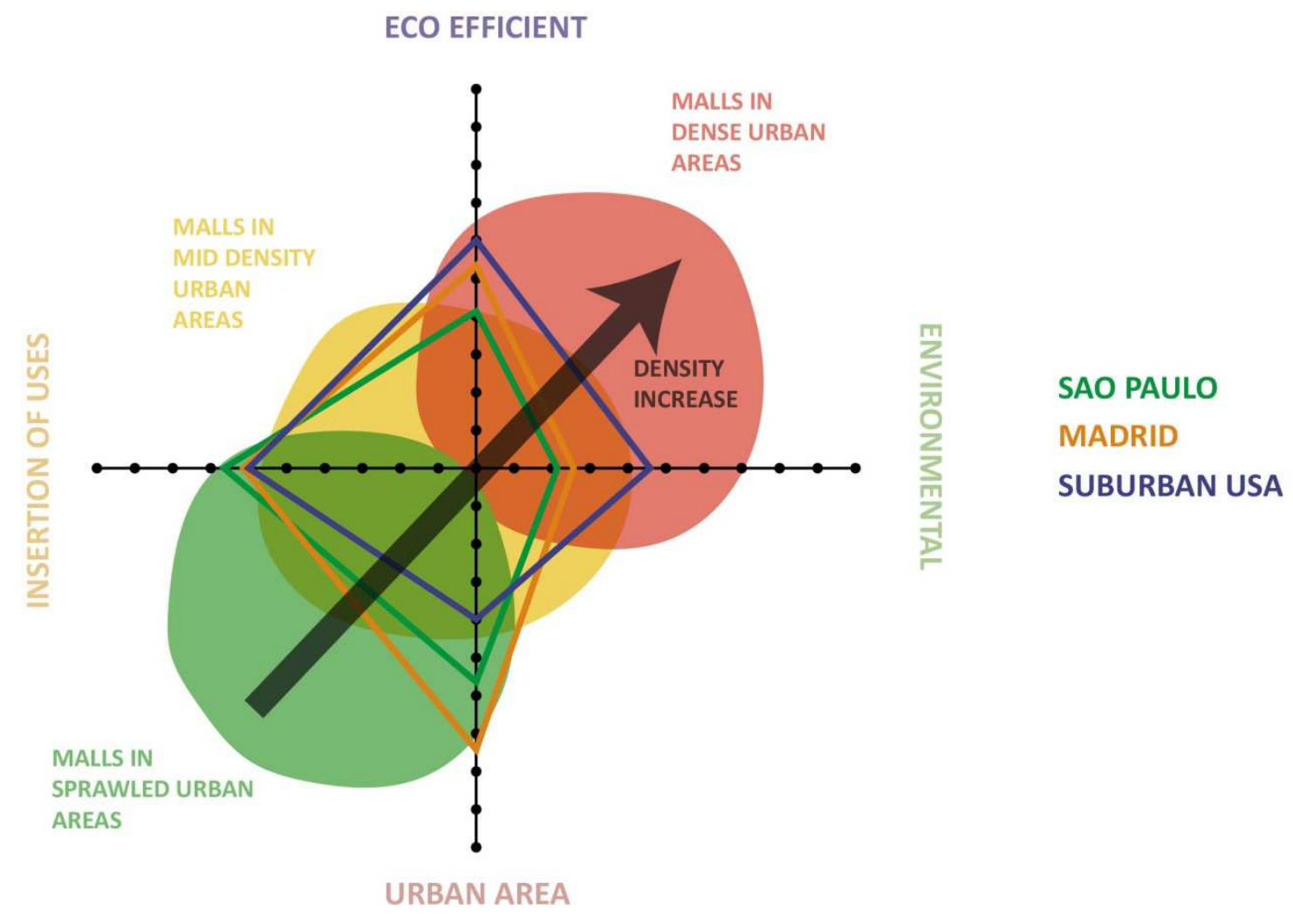

Figure 5.9.8: Retrofitting graph according to urban areas typologies and locations. Own's source.

By comparing the priorities towards the means of retrofitting, the following statements could be established as a conclusion. In complex cities with density, and mixture of uses (Sao Paulo and Madrid) the retrofitting means on shopping malls should be aimed in the insertion of green elements, Opposite, In the Suburban USA, the priorities in retrofitting must be aimed at improving the urban sustainability in the low density areas (a moderate increase of density, insertion of uses, insertion of mass transit or sustainable mobility devices...) applying these measures into the whole urban area, rather than a into a located shopping mall. This task is very complicated, and must be thought in very long term.

In addition, the graph shows the most dense the urban area surrounding the mall is, the most the retrofitting operations should be applied in the environment and eco efficiency, this happens because of the high carbon footprint the dense urban areas have, in addition to the lack of greenery of other elements to reduce it. Opposite, for the malls located in sprawled urban areas, the priorities in retrofitting should be aimed in the insertion of uses and the making of the urban surroundings moderately dense but complex, in order to guarantee the urban activity.

Once the situation of the malls related to environmental and urban sustainability have been developed, the last step is the reinforcement of the conclusions, by the study of theoretical retrofitting operations. 


\section{6.- CONCLUSSIONS}

\section{1.- INTRUDUCTION TO CONCLUSIVE COMPARATIVE ANALYSIS}

Once the retrofitting means of application were studied for all of the cases, the next step is to consider the effects of five supposed retrofitting operations on the shopping malls. This was done with the aim of studying the efficacy an environmental retrofitting program can suppose.

As a previous step, is important to consider, how the effects related to the retrofitting means can be considered as relevant. Because the aim, is to improve the current situation of the shopping mall, to make it less harmful towards environment, and more favorable towards the urban complexity and community engagement. The scale established for these thresholds is going to depends entirely on the current situation towards sustainability of the shopping mall.

Furthermore, the different operations of theoretical retrofitting means will be applied on each case of shopping mall, being studied the resulting effects.

To sum up, a retrofitting measure will be positive if any score in the Sustainable Rose Graph becomes altered in a positive way.

The final step of this chapter, and thesis, is the response to the questions and hypotheses established, to be positive or negative.

\subsection{1.- Establishment of the theoretical retrofitting operations to be applied for each center.}

Being this thesis aimed in the analysis of the efficacy of retrofitting means applied on shopping malls, the first step in the conclusions chapter, is to establish the theoretical retrofitting means of application on each case. The retrofitting means are related to the Sustainable Retrofitting Rose, being them applied separated or together according to their respective families.

\section{RA.- RETROFITTING OPEARTIONS AIMED ON ECOEFFCIENCY.}

The retrofitting operations described in this chapter are aimed in the improve of the eco efficiency of the shopping mall related to energetic and bioclimatic conditions, (Sector A of the Sustainable Retrofitting Rose Graph).

Due to the lack of concrete and rigorous data related to energy consumption or carbon dioxin emissions, was not possible to establish retrofitting measures aimed in the improve of installations, or the reduction of energy consumption and carbon dioxin emissions with mechanical means. This can be an issue for future research works.

RA1.- Optimal bioclimatic adaptation of the building, inner space and installations: This operation will be considered for the study, supposing the shopping mall have applied all sorts of operations that have turned it into a building completely adapted to the bioclimatic 
conditions. In addition, the mall is going to have only the necessary installations according to Givoni chards. The effects of this retrofitting operation will be considered as:

- The score in the question A.1.1 will be considered as +1

- The score in the question A.1.3 will be considered as +1

- The score in the question A.2.3 will be considered as +2

- The score in the question A.3.1 will be considered as +2

- The score in the question A.3.3 will be considered as +2

- The score in the question A.3.4 will be considered as +2

RB.- RETROFITTING OPERATIONS FOCUSED ON ECOLOGY.

The retrofitting operations described in this family are aimed in the improve of the ecological features of the shopping mall, (Sector B of the Sustainable Retrofitting Rose Graph)

RB1.- Green retrofitting: This retrofitting operation, will consist on the partial transformation of the roof and the plot into green areas, a minimum of surface without green aimed to installations or high capacity infrastructures is going to be considered. The green retrofitting operations will include the insertion of the following layers of vegetation.

- The $60 \%$ of the shopping center roof will be turned into an intensive green roof

- The $60 \%$ of the shopping center plot area (the non built area) will be turned into vegetal parking plots (prairie vegetation)

- About a $10 \%$ of the shopping center plot, will be turned into an area with perennial plants or others with high capacity of carbon dioxin assimilation.

RB2.- Waterproof surfaces retrofitting: This retrofitting operation is aimed in the insertion of all sorts of means to ensure the water absorption for the terrain. These devices will be put in both the roof and the non built areas of the shopping mall. The consideration of this retrofitting will have the following effects:

-The $100 \%$ of the surface of the shopping mall plot (including the built areas) will be turned into a water assimilative surface.

-All sorts of water savings devices are going to be put in the shopping mall, so the score in the question $\mathrm{B} 2.3$ will be considered as +3

-The water consumption per visit, due to the update of installations, is going to be reduced to minimum rates, the question $\mathrm{B} 2.4$ will be considered as +2

RB3.- Heat island surfaces retrofitting: Despite heat island effect depends on the configuration of the urban tissue at the scale of the whole city, the mall building can contribute to its 
reduction. In this operation, all the surface of the shopping mall will be turned into a reflective one, having this the following effect in the Sustainable Retrofitting Rose Graph score:

- The score of question B.3.4 will be scored as +4 for all the cases.

RC.- RETROFITTING OPERATIONS FOCUSED ON THE INSERTION OF USES.

The retrofitting operations described in this family are aimed in the insertion of uses in the shopping mall plot, in order to achieve an increase of urban complexity. (Sector $\mathrm{C}$ of the Sustainable Retrofitting Rose Graph).

Furthermore, to analyze this retrofitting operation, a theoretical enlargement of the shopping mall is going to be considered, concerning different percentages related to its built surface to be added:

-A $35 \%$ of the shopping mall built surface will be added as residential use.

-A $15 \%$ of the shopping mall built surface will be added as productive use.

- A scarce visited services amenity will be added in the shopping mall.

The commercial use was not considered for these cases, because the shopping mall is enough to cover the demand of this use.

This thesis, because focusing in the retrofitting of shopping mall buildings, no retrofitting on the urban environment is going to be considered. However is important to show the importance of this issue, in order to consolidate the final conclusions.

\subsection{2.- Parameters and thresholds of relevance.}

Once the retrofitting measures of application have been defined, the following step is to establish the criteria any theoretical retrofitting can be considered of relevance for the current thesis.

The performance of this study will be based in a second calculation of the Sustainable Retrofitting Rose scores, the effects of the theoretical retrofitting measures studied will be inserted in.

In addition, the relevance threshold needs to be defined, the criteria to be considered, will be based on the average scores per retrofitting family to be considered. This supposes all the retrofitting scores within the sectors A, B, and C, of the Sustainable Retrofitting Rose Graph will be added, being the result divided in 3 . Is important to define the averages per family for both the non retrofitted and retrofitted status of the shopping mall.

The average scores, is the base of the criteria of relevance. Any retrofitting operation, will be considered of relevance, if the average score per retrofitting family becomes increased in 1 point or more. 


\subsection{3.- The final conclusions establishment}

By analyzing the relevance of the retrofitting operations applied, the final step of this thesis will be established. A conclusive report of the results obtained will be done, explaining the efficacy of the retrofitting measures. This will end up in the clearance of the hypotheses and the final and conclusive responses to the research question established.

\section{2.- THE EFFECTS OF THE THEORETICAL RETROFITTING OPERATIONS.}

In this chapter, all the established in the introduction is going to be performed. This will be done with the aim of quantifying the effects of the retrofitting operations studied, in addition to the showing of the effects in the Sustainable Retrofitting Rose Graph, and the analysis of the efficacy of these means.

\subsection{1.- Calculus performed, and their results for each case.}

The application of the theoretical retrofitting operations, ended up in the following results per case, which are going to end up in new Sustainable Retrofitting Rose Graphs. This is the base of the analysis of the relevance of the retrofitting operations applied. (Figure 6.2.1). 


\begin{tabular}{|c|c|c|c|c|c|c|}
\hline \multicolumn{3}{|c|}{ RETROFITTING OPERATIONS BALANCE TABLE } & \multirow{2}{*}{$\frac{\mid \text { C1. S.Light }}{1(1)}$} & \multirow{2}{*}{$\begin{array}{l}\text { C2. S. E.D. } \\
1(1)\end{array}$} & \multirow{2}{*}{$\begin{array}{l}\text { C3.Aricanduva } \\
1(1)\end{array}$} & \multirow{2}{*}{$\begin{array}{l}\text { C4. ABC. Serr. } \\
1(1)\end{array}$} \\
\hline \multirow{14}{*}{$\begin{array}{c}\text { A } \\
\text { ECOEFFICIENT } \\
\text { RETROFITTING }\end{array}$} & & A1.1 Givonni ch. adequacy & & & & \\
\hline & \multirow{4}{*}{$\begin{array}{c}\text { A1.- LOW } \\
\text { EMISSIVE } \\
\text { INSTALLATIONS }\end{array}$} & A1.2 $\mathrm{CO} 2$ emissions calification (Eur.Union) & $3(4) \mathrm{C}$ & $3(4) C$ & $3(4) C$ & $3(4) \mathrm{C}$ \\
\hline & & A1.3 Obsolescence & $1(1)$ & $1(1)$ & $1(1)$ & $1(1)$ \\
\hline & & A1.4 En. Consumption calification (Eur.Union) & $3(4) C$ & $3(4) C$ & $3(4) C$ & $3(4) C$ \\
\hline & & TOTAL SCORE & $6(10)>8(10)$ & $6(10)>8(10)$ & $6(10)>8(10)$ & $6(10)>8(10)$ \\
\hline & \multirow{4}{*}{$\begin{array}{c}\text { A2.- ACTIVE } \\
\text { SOLAR SYSTEMS }\end{array}$} & A2.1 Usage of act. s. syst. & 2 (4) adq. build. & 2 (4) adq. build. & 2 (4) adq. build. & 0 (4) none \\
\hline & & A2.2 Usage of r. energies (in mall) & 3 (4) r. e in city & $3(4)$ r. e in city & 3 (4) r. e in city & 0 (4) none \\
\hline & & A2.3 Givonni ch. adequacy & 2 (2) non neces. & 2 (2) non neces. & 2 (2) non neces. & $2(2)$ \\
\hline & & TOTAL SCORE & $7(10)$ & $7(10)$ & $7(10)$ & $0(10)>2(10)$ \\
\hline & \multirow{5}{*}{$\begin{array}{c}\text { A3.- PASSIVE } \\
\text { SOLAR SYSTEMS }\end{array}$} & A3.1 Bioclimatic adequacy (Olgyay) & $2(2)$ & $2(2)$ & $2(2)$ & $2(2)$ \\
\hline & & A3.2 Efficiency of coverages & 3(4) efficient & 3 (4) efficient & 3(4) efficient & 3 (4) efficient \\
\hline & & A3.3 Usage of natural light (\% of built up area) & $2(2)$ & $2(2)$ & $2(2)$ & $2(2)$ \\
\hline & & A3.4 Givonni ch. adequacy & $2(2)$ & $2(2)$ & $2(2)$ & $2(2)$ \\
\hline & & TOTAL SCORE & $6(10)>9(10)$ & $3(10)>9(10)$ & $3(10)>9(10)$ & $4(10)>9(10)$ \\
\hline \multirow{16}{*}{$\begin{array}{c}\text { B } \\
\text { EVIRONMENTAL } \\
\text { RETROFITTING }\end{array}$} & \multirow{6}{*}{$\begin{array}{l}\text { B1.- GREEN } \\
\text { AREAS } \\
\text { RETROFITIING }\end{array}$} & B11 Gren areasin urban & $0(2) 19 \mathrm{~m} 2 \mathrm{inh}$ & $0(2) 19 \mathrm{~m} 2 \mathrm{inh}$ & $1(2) 15 m^{2 i}$ & $0(2) 24 m^{2} \mathrm{inh}$ \\
\hline & & B1.2 Green areas in mall & 1(1) $2939,4 \mathrm{~m} 2$ & 1(1) $40432 \mathrm{~m} 2$ & $1(1) 357415 \mathrm{~m} 2$ & 1(1) $2463 \mathrm{~m} 2$ \\
\hline & & B1.3 CO2 Assimilation rate (urban env.) & $2(3) 10,7 \%$ & $2(3) 53 \%$ & $3(3) 74,26 \%$ & $0(3) 6,83 \%$ \\
\hline & & B1.4 CO2 Assimilation rate (mall) & 0 (3) $0,87 \%$ & $3(3) 68 \%$ & $3(3) 570 \%$ & 0 (3) $6,25 \%$ \\
\hline & & B1.5 Distance between green areas & $1(1) 300 m$ & 0 (1) $500 \mathrm{~m}$ & 0 (1) $400 \mathrm{~m}$ & $1(1) 380 m$ \\
\hline & & TOTAL SCORE & $2(10)>4(10)$ & $4(10)>6(10)$ & $4(10)>6(10)(E)$ & $1(10)>2(10)$ \\
\hline & \multirow{5}{*}{$\begin{array}{l}\text { B2.- WATER } \\
\text { ABSORBING } \\
\text { SURFACE }\end{array}$} & B2.1 Aridity of climate & 1(1) non arid & 1(1) non arid & 1 (1) non arid & $0(1)$ semi arid \\
\hline & & B2.2 Rate of absorbent paviment \% (ur. Env) & 1(4) $5,9 \%$ & $0(4) 4,61 \%$ & 1 (4) $14,38 \%$ & $1(4) 5,18 \%$ \\
\hline & & B2.3 Water saving installations & 3 (3) all sorts & 3 (3) all sorts & 3 (3) all sorts & 3 (3) all sorts \\
\hline & & B2.4 Water consumption per visit & $2(2)<201$ visit & $2(2)<201$ visit & $2(2)<20$ l visit & $2(2)<20$ l visit \\
\hline & & TOTAL SCORE & $2(10)>7(10)$ & $2(10)>6(10)$ & $3(10)>6(10)$ & $1(10)>6(10)$ \\
\hline & & B3.1 Climate heat & o(2) hot cl. & 0 (2) hot cl. & 0 (2) hot cl. & 0 (2) hot cl. \\
\hline & B3.- HEAT & B3.2 Frequency of extreme heat conditions & 1(1) no heat & 1 (1) no heat & 1 (1) no heat & 0 (1) heat cond. \\
\hline & ISLAND & B3.3 Heat island effect in the mall urb. area & $0(3)+4 \%$ h.i. & $0(3)+4 o h . i$ & $0(3)+40 h . i$ & $0(3)+8$ o h.i. \\
\hline & TREATMENT & B3.4 Rate of heat expelling built surface & $4(4) 100 \%$ & $4(4) 100 \%$ & $4(4) 100 \%$ & $4(4) 100 \%$ \\
\hline & & TOTAL SCORE & $1(10)>5(10)$ & $1(10)>5(10)$ & $1(10)>5(10)$ & $2(10)>4(10)$ \\
\hline & & & & & & \\
\hline & & C1.1 Residential capacity of mall (\% of u. a. pop.) & $0(2) 3,5 \%$ & $0(2) 3,5 \%$ & $0(2) 3,5$ & $0(2) 3,5$ \\
\hline & C1.- & C1.2 Residential use in nearby plots & $2(3) 32 \%$ & $2(3) 33,89 \%$ & $3(3) 78,43 \%$ & 3 (3) $51,7 \%$ \\
\hline & RESIDENTIAL USE & C1.3 Residential use in urban area & $3(5) 40,12 \%$ & $3(5) 51,62 \%$ & $5(5) 81 \%$ & $3(5) 50,11 \%$ \\
\hline & & TOTAL SCORE & $5(10)$ & $5(10)$ & $8(10)$ & $5(10)>6(10)$ \\
\hline & & C2.1 Productive use in mall & 1(1) R.F. office & 1(1) Police box & 1 (1) Police box & 1(1) pr.u. added \\
\hline RETROFITTING & C2.- & C2.2 Productive use in nearby plots & $3(3) 58,24 \%$ & $3(3) 49,7 \%$ & $3(3) 18,76 \%$ & 3 (3) $30 \%$ \\
\hline BYTHE & PRODUCTIVE USE & C2.3 Productive Use in urban area & $5(6) 30 \%$ & 5 (6) $29,86 \%$ & $1(6) 7,97 \%$ & $5(6) 30 \%$ \\
\hline INSERTION OF & & TOTAL SCORE & $9(10)$ & $9(10)$ & $4(10)>5(10)$ & $8(10)>9(10)$ \\
\hline USES & & C3.1 Pressence of amenites in mall & 1(1) R.F. office & 1(1) act. Added & 1(1) act. Added & 1(1) act. Added \\
\hline & $\begin{array}{l}\text { C3.- } \\
\text { AMENUTIES }\end{array}$ & C3.1 Amenities in nearby plots & 4 (4) 1st rank. & 1(4) 3rd rank & 1(4) 3rd rank & 2 (4) 2nd rank \\
\hline & 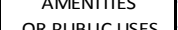 & C3.3 Amenities in $1 \mathrm{~km}$. from mall & 5 (5) 1st rank & 5 (5) 1st rank & 5 (5) 1st rank & 5 (5) 1st rank \\
\hline & & TOTAL SCORE & $10(10)$ & $5(10)>7(10)$ & $6(10)>7(10)$ & $7(10)>8(10)$ \\
\hline & & & & & & \\
\hline & & D1.1 Mass transit facility nearby mall & 1(1) yes & 1(1) yes & 1(1) yes & 1 (1) yes \\
\hline & & D1.2 Efficacy of mass transit/private veh. & 3(3) high effic. & 2(3) efficient & 1(3) poorly eff. & 0 (3) non eff. \\
\hline & D1.- EFFICIENT & D1.3 Mass transit coverage in urban area & $2(2) 96 \%$ & $1(2) 52 \%$ & $1(2) 50 \%$ & $2(2) 72 \%$ \\
\hline & TRANSPORTATION & D1.4 Zonning rate & 2 (2) no zonn. & 1 (2) Avg. zonn. & 0 (2) zonified & 2 (2) no zonn. \\
\hline & & D1.5 Sustainable movility facilities in mall & $0(2)$ none & $0(2)$ none & o(2) none & 1 (2) some \\
\hline & & TOTAL SCORE & $8(10)$ & $5(10)$ & $3(10) E->2(10)$ & $6(10)$ \\
\hline & & D2.1 Optimal rate of population density & 3(4) str. dens. & 2 (4) sl. dense & 2 (4) sl. dense & 3 (4) str. dens. \\
\hline & D2 DENSITY & D2.2 Density of built up area & 2 (3) str. dens. & 2 (3) avg dens. & 2 (3) avg dens. & 2 (3) str. dens. \\
\hline & D2.- DENSIIY & D2.3 Rate of building coverage (\%) & $3(3) 67 \%$ & $3(3) 51 \%$ & $3(3) 69 \%$ & $3(3) 67 \%$ \\
\hline & & TOTAL SCORE & $8(10)$ & $7(10)$ & $7(10)$ & $8(10)$ \\
\hline RETROFITTING IN & & D3.1 Negative elements in area & 0 (1) yes & $0(1)$ yes & 0 (1) yes & 1 (1) none \\
\hline URBAN AREA & & D3.2 Cold activity areas in daytime & 1 (1) act. area & 1 (1) act. area & 0 (1) non act. & 1 (1) act. area \\
\hline & & D3.3 Cold activity areas at night & $\mathrm{o}(1)$ non act. & 0 (1) non act. & 0 (1) non act. & 1 (1) act. area \\
\hline & & D3.4 Areas with complicated visual control & $0(1)$ yes & 1(1) no & $0(1)$ yes & 1 (1) no \\
\hline & D3.- WALKABILITY & D3.5 Security feeling in people & 0 (1) non secure & 0 (1) non secure & 0 (1) non secure & 1 (1) secure \\
\hline & AND SECURITY & D3.6 Active facades in nearby plots (\% facade lenght) & $1(2) 49 \% f . l g t$ & $1(2) 31 \% f . l g t$ & $0(2) 16 \%$ & $2(2) 58 \%$ \\
\hline & & D3.7 Distance to nearest residential building & 1(1) $80 \mathrm{~m}$ & 1 (1) $20 \mathrm{~m}$ & 0 (1) $500 \mathrm{~m}$ & $1(1) 100 m$ \\
\hline & & D3.8 Rate of free space in area & $1(1) 33 \%$ & $1(1) 51 \%$ & $1(1) 40 \%$ & $1(1) 50 \%$ \\
\hline & & D3.9 Rate of uses zonification & 1 (1) mix. uses & 1 (1) mix. uses & 1 (1) mix. uses & 1(1) mix. uses \\
\hline & & TOTAL SCORE & $5(10) E->6(10)$ & $5(10)>6(10)$ & $1(10)$ & $10(10) E->11(10)$ \\
\hline & ᄃ & E1 Attraction index of the mall & $3(5)$ & $3(5)$ & $5(5)$ & $3(5)$ \\
\hline & & E2 Score in Efficient transportation & $8(10)$ & $5(10)$ & $3(10)$ & $7(10)$ \\
\hline SCORING RELA & TED TO ACTIVITY & FINAL SCORE & +1 to $D 3$ & No Score & $-1>D 1 ;-2>B 1$ & +1 to $D 3$ \\
\hline
\end{tabular}




\begin{tabular}{|c|c|c|c|c|c|c|}
\hline \multicolumn{3}{|c|}{ RETROFITTING OPERATIONS BALANCE TABLE } & \multirow{2}{*}{$\frac{\mid \text { C5. L. Vaguda }}{1(1)}$} & \multirow{2}{*}{$\frac{\text { C6. P.S. }}{1(1)}$} & \multirow{2}{*}{$\frac{\text { C7. Belmar }}{1(1)}$} & \multirow{2}{*}{$\frac{\text { C8. M.O.A. }}{1(1)}$} \\
\hline \multirow{14}{*}{$\begin{array}{c}\boldsymbol{A}_{\text {ECOEFFICIENT }} \\
\text { RETROFITTING }\end{array}$} & & A1.1 Givonni ch. adequacy & & & & \\
\hline & A1.- LOW & A1.2 $\mathrm{CO} 2$ emissions calification (Eur.Union) & $3(4) B$ & $3(4) B$ & $3(4) C$ & $3(4) C$ \\
\hline & EMISSIVE & A1.3 Obsolescence & $1(1)$ & $1(1)$ & $1(1)$ & $1(1)$ \\
\hline & \multirow[t]{2}{*}{ INSTALLATIONS } & A1.4 En. Consumption calification (Eur.Union) & $3(4) C$ & $3(4) C$ & $3(4) C$ & $3(4) C$ \\
\hline & & TOTAL SCORE & $6(10)>8(10)$ & $6(10)>8(10)$ & $6(10)>8(10)$ & $6(10)>8(10)$ \\
\hline & \multirow{4}{*}{$\begin{array}{c}\text { A2.- ACTIVE } \\
\text { SOLAR SYSTEMS }\end{array}$} & A2.1 Usage of act. s. syst. & $1(4) 10 \%$ & $1(4) 10 \%$ & $2(4) 30 \%$ & $0(4)$ no \\
\hline & & A2.2 Usage of r. energies (in mall) & $1(4) 4 \%$ & $1(4) 5,6 \%$ & $2(4) 20 \%$ & 1 (4) $10 \%$ est. \\
\hline & & A2.3 Givonni ch. adequacy & $2(2)$ & $2(2)$ & $2(2)$ & $2(2)$ \\
\hline & & TOTAL SCORE & $3(10)>4(10)$ & $3(10)>4(10)$ & $5(10)>6(10)$ & $1(10)>3(10)$ \\
\hline & \multirow{5}{*}{$\begin{array}{l}\text { A3.- PASSIVE } \\
\text { SOLAR SYSTEMS }\end{array}$} & A3.1 Bioclimatic adequacy (Olgyay) & 2 (2) adeq. & $2(2)$ & $2(2)$ & $2(2)$ \\
\hline & & A3.2 Efficiency of coverages & 3 (4) efficient & 3 (4) efficient & 3 (4) efficient & 3 (4) efficient \\
\hline & & A3.3 Usage of natural light (\% of built up area) & $2(2)$ & $2(2)$ & $2(2) 83,53 \%$ & $2(2)$ \\
\hline & & A3.4 Givonni ch. adequacy & $2(2)$ & $2(2)$ & $2(2)$ & 2 (2) adequate \\
\hline & & TOTAL SCORE & $7(10)>9(10)$ & $5(10)>9(10)$ & $7(10)>9(10)$ & $7(10)>9(10)$ \\
\hline \multirow{16}{*}{$\begin{array}{c}\text { B } \\
\text { EVIRONMENTAL } \\
\text { RETROFITTING }\end{array}$} & \multirow{6}{*}{$\begin{array}{c}\text { B1.- GREEN } \\
\text { AREAS } \\
\text { RETROFITTING }\end{array}$} & B1.1 Green areas in urban env. (m2 inhabitant) & $0(2) 2 m 2 i n h$ & $0(2) 8,2 m 2 i n h$ & $2(2) 158 m 2 i n h$ & $2(2) 1135 \mathrm{~m} 2 \mathrm{inh}$ \\
\hline & & B1.2 Green areas in mall & 1 (1) $45982 \mathrm{~m} 2$ & 1 (1) $193767 \mathrm{~m} 2$ & 1 (1) $1445663 \mathrm{~m} 2$ & 1 (1) $210434 \mathrm{~m} 2$ \\
\hline & & B1.3 $\mathrm{CO} 2$ Assimilation rate (urban env.) & 1 (3) $11,23 \%$ & $1(3) 32,8 \%$ & 3 (3) $486 \%$ & 3 (3) $185 \%$ \\
\hline & & B1.4 CO2 Assimilation rate (mall) & $3(3) 596 \%$ & 3 (3) $2612,8 \%$ & $3(3) 99,36 \%$ & $2(3) 33,25 \%$ \\
\hline & & B1.5 Distance between green areas & $1(1) 200 m$ & 1 (1) $380 \mathrm{~m} 2$ & $1(1) 200 m$ & $1(1) 100 m$ \\
\hline & & TOTAL SCORE & $4(10)>5(10)$ & $3(10)>5(10)$ & $7(10)>8(10)(E)$ & $5(10)>7(10)(E)$ \\
\hline & \multirow{5}{*}{$\begin{array}{l}\text { B2.- WATER } \\
\text { ABSORBING } \\
\text { SURFACE }\end{array}$} & B2.1 Aridity of climate & 0 (1) semi arid & 0 (1) semiarid & 0 (1) semiarid & 1 (1) humid \\
\hline & & B2.2 Rate of absorbent paviment \% (ur. Env) & $1(4) 8,87 \%$ & 2 (4) $28,52 \%$ & $3(4) 57,38 \%$ & $3(4) 48,11 \%$ \\
\hline & & B2.3 Water saving installations & 3 (3) all sorts & 3 (3) all sorts & 3 (3) all sorts & 3 (3) all sorts \\
\hline & & B2.4 Water consumption per visit & $2(2)<201$ visit & $2(2)<201$ visit & $2(2)<20 l$ visit & $2(2)<201$ visit \\
\hline & & TOTAL SCORE & $4(10)>6(10)$ & $3(10)>7(10)$ & $5(10)>8(10)$ & $6(10)>8(10)$ \\
\hline & \multirow{5}{*}{$\begin{array}{l}\text { B3.- HEAT } \\
\text { ISLAND } \\
\text { TREATMENT }\end{array}$} & B3.1 Climate heat & $0(2)$ hot $c l$. & o(2) hot cl. & 1(2) avg. Clim. & 2 (2) cool cl. \\
\hline & & B3.2 Frequency of extreme heat conditions & 0 (1) heat cond. & 0 (1) heat cond. & 0 (1) heat cond. & 1 (1) no heat \\
\hline & & B3.3 Heat island effect in the mall urb. area & $0(3)+5 \circ h . i$. & $1(3)+2 o$ & $2(3)+19$ & $0(3)+4 \div$ \\
\hline & & B3.4 Rate of heat expelling built surface & $4(4) 100 \%$ & $4(4) 100 \%$ & $4(4) 100 \%$ & $4(4) 100 \%$ \\
\hline & & TOTAL SCORE & $4(10)$ & $1(10)>5(10)$ & $4(10)>6(10)$ & $3(10)>7(10)$ \\
\hline & & C1.1 Residential capacity of mall (\% of u. a. pop.) & $0(2) 3,5$ & $0(2) 3,9$ & $2(2) 21,5 \%$. & 2 (2) $188 \%$ visit. \\
\hline & & C1.2 Residential use in nearby plots & $3(3) 52,18 \%$ & $3(3) 83,53 \%$ & $3(3) 73,7 \%$ & 3 (3) $51,68 \%$ \\
\hline & RESIDENTIAL USE & C1.3 Residential use in urban area & $5(5) 79,83 \%$ & $4(5) 68,31 \%$ & $4(5) 69,32 \%$ & 2 (5) $35,97 \%$ \\
\hline & & TOTAL SCORE & $7(10)>8(10)$ & $7(10)$ & $8(10)>9(10)$ & $4(10)>7(10)$ \\
\hline & & C2.1 Productive use in mall & $1(1)$ yes & 1(1) yes & 1 (1) yes & 1 (1) pr.u. added \\
\hline RETROFITTING & C2.- & C2.2 Productive use in nearby plots & $3(3) 30 \%$ & $2(3) 13,65 \%$ & $3(3) 16 \%$ & 3 (3) $20 \%$ \\
\hline BY THE & PRODUCTIVE USE & C2.3 Productive Use in urban area & 2 (6) $11,15 \%$ & $3(6) 16,96 \%$ & $3(6) 14 \%$ & $6(6) 45,2 \%$ \\
\hline INSERTION OF & & TOTAL SCORE & $6(10)$ & $2(10)>7(10)$ & $7(10)$ & $9(10)>10(10)$ \\
\hline USES & & C3.1 Pressence of amenites in mall & 1(1) post office & 1 (1) act. Added & 1(1) some fac. & 1 (1) act. Added \\
\hline & C3.- & C3.1 Amenities in nearby plots & 3 (4) 1st rank & 1 (4) 3rd rank & 4 (4) most visit. & 1 (4) 3rd rank \\
\hline & ARIENIIES & C3.3 Amenities in $1 \mathrm{~km}$. from mall & 5 (5) 1st rank & 4 (5) local rank & 2 (5) local rank & 2 (5) local rank \\
\hline & & TOTAL SCORE & $9(10)$ & $4(10)>6(10)$ & $7(10)$ & $1(10)>4(10)$ \\
\hline & & D1.1 Mass transit facility nearby mall & 1(1) yes & 1(1) yes & 1(1) yes & 1 (1) yes \\
\hline & & D1.2 Efficacy of mass transit/private veh. & 1 (3) poorly eff. & o (3) no effic. & 0 (3) no effic. & 0 (3) no effic. \\
\hline & D1.- EFFICIENT & D1.3 Mass transit coverage in urban area & $2(2) 86 \%$ & $2(2) 70 \%$ & 0 (2) less $50 \%$ & 0 (2) less $50 \%$ \\
\hline & TRANSPORTATION & D1.4 Zonning rate & 2 (2) no zonn. & 2 (2) no zonn. & $0(2)$ zonified & $0(2)$ zonified \\
\hline & & D1.5 Sustainable movility facilities in mall & 2 (2) yes & 2 (2) yes & 1 (2) some & 0 (2) none \\
\hline & & TOTAL SCORE & $8(10)$ & $7(10)$ & $2(10) E->1(10)$ & $1(10) E->0(10)$ \\
\hline & & D2.1 Optimal rate of population density & 3(4) str. dens. & 3 (4) str. dens. & 0 (4) low dens. & 0 (4) low dens. \\
\hline & D DENGITY & D2.2 Density of built up area & 3 (3) optimald. & 3 (3) optimald. & 0 (3) low dens. & 0 (3) low dens. \\
\hline & D2.- DENSITY & D2.3 Rate of building coverage (\%) & $1(3) 22 \%$ & $1(3) 28 \%$ & 1 (3) $21 \%$ & 1 (3) $21 \%$ \\
\hline & & TOTAL SCORE & $7(10)$ & $7(10)$ & $1(10)$ & $1(10)$ \\
\hline RETROFITTING IN & & D3.1 Negative elements in area & 1 (1) none & 0 (1) yes & 1 (1) none & 1 (1) none \\
\hline URBAN AREA & & D3.2 Cold activity areas in daytime & 1 (1) act. area & 1 (1) act. area & 0 (1) non act. & 0 (1) non act. \\
\hline & & D3.3 Cold activity areas at night & 0 (1) non act. & 0 (1) non act. & 0 (1) non act. & 0 (1) non act. \\
\hline & & D3.4 Areas with complicated visual control & 1(1) no & 1(1) no & $1(1)$ no & 0 (1) yes \\
\hline & D3.- WALKABILITY & D3.5 Security feeling in people & 1 (1) secure & $1(1)$ secure & 1 (1) secure & $1(1)$ secure \\
\hline & AND SECURITY & D3.6 Active facades in nearby plots (\% facade lenght) & $1(2) 32 \%$ & $0(2) 3,73 \%$ & $0(2) 7,96 \%$ & $0(2) 23,59 \%$ \\
\hline & & D3.7 Distance to nearest residential building & 1 (1) $90 \mathrm{~m}$ & 0 (1) $350 m$ & 1 (1) R. in mall & 1 (1) $150 \mathrm{~m}$ \\
\hline & & D3.8 Rate of free space in area & $0(1) 79 \%$ & $0(1) 71,5 \%$ & $0(1) 79 \%$ & $0(1) 79 \%$ \\
\hline & & D3.9 Rate of uses zonification & 1 (1) mix. uses & 1 (1) mix. uses & 1 (1) mix. uses & 1 (1) mix. uses \\
\hline & & TOTAL SCORE & $7(10) E->9(10)$ & $4(10) E->5(10)$ & $4(10)>5(10)$ & $3(10)>4(10)$ \\
\hline & ᄃ & E1 Attraction index of the mall & $4(5)$ & $4(5)$ & $3(5)$ & $5(5)$ \\
\hline & $\mathbf{E}$ & E2 Score in Efficient transportation & $8(10)$ & $7(10)$ & $2(10)$ & $1(10)$ \\
\hline SCORING RELA & ITED TO ACTIVITY & FINALSCORE & +2 to $D 3$ & +1 to $D 3$ & $-1>\mathrm{D} 1 ;-1>\mathrm{B} 1$ & $-1>D 1 ;-2>B 1$ \\
\hline
\end{tabular}

Figure 6.2.1: Table with scores after retrofitting application. Own's source. All the raised scores resulting from the application of the theoretical measures are in the following table, shaded in grey. The total scores modified per retrofitting measure are shaded in green.

The resulting scores of the retrofitting operations, sum up in the following set of sustainable Rose Graphs (Figure 6.2.2). 
(A3) (B1)

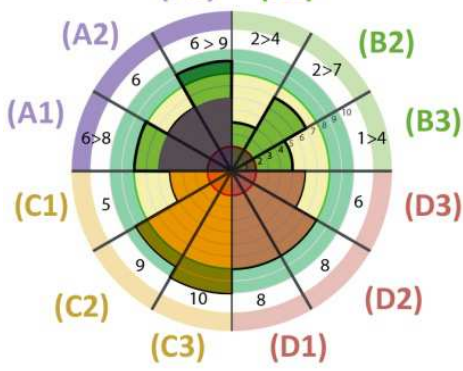

SHOPPING LIGHT

(A3) (B1)

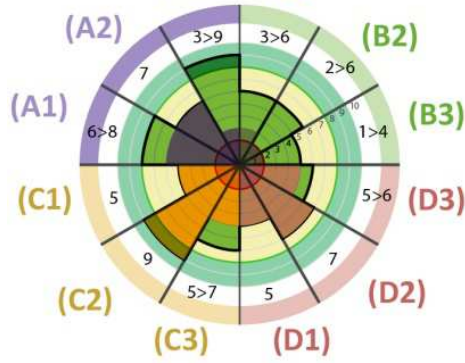

SHOPPING ELDORADO

(A3) (B1)

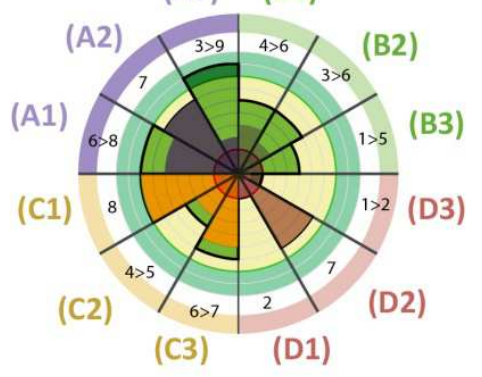

SHOPPING ARICANDUVA

(A3) (B1)

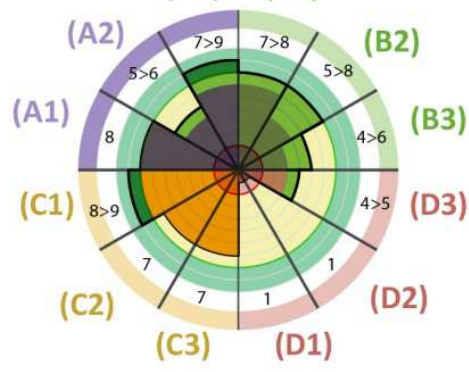

BELMAR
(A3) (B1)

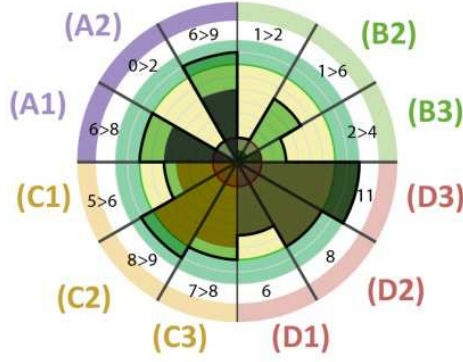

ABC SERRANO

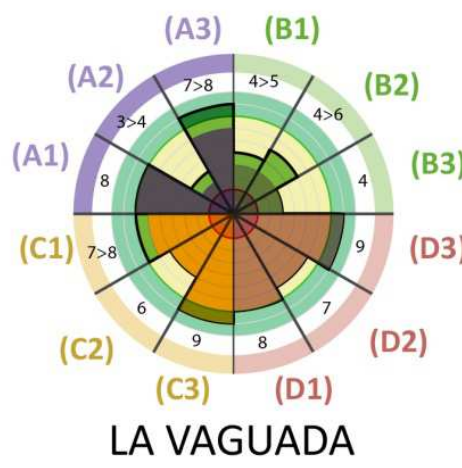

(A3) (B1)

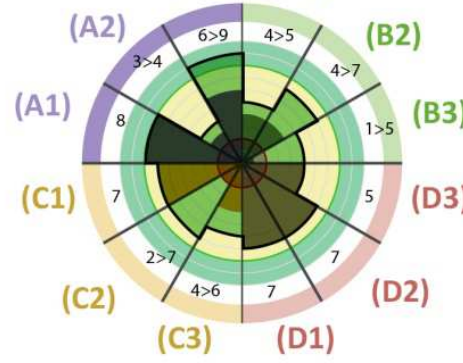

PARQUESUR

(A3) (B1)

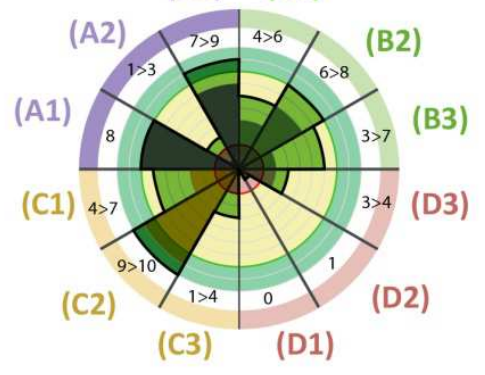

MALL OF AMERICA
(A) ECO EFFICIENT RETROFITTING FAMILY

(A1) Low Emissive installations

(A2) Active measures

(A3) Passive measures

(B) ENVIRONMENTAL RETROFITTING FAMILY

(B1) Insertion of green areas

(A2) Water assimilative surfaces

(A3) Heat island treatment

(C) USES AND AMENITIES INSERTION

(C1) Residential use

(A2) Productive use

(A3) Services and amenities

(D) RETROFITTING OF URBAN AREAS

(D1) Sustainable transportation

(D2) Density

(A3) Security and urban interactions

\section{THRESHOLDS}

2 points: Minimum threshold

8 points: Optimal threshols

10 points: Green paradigm

\section{AREAS AND INTEVALS}

0-2 points: Highly prior retrofitting

mean

2-8 points: Averagely prior

retrofitting mean

8-10 points: No prior retrofitting

mean 
the Rose Graph firstly. Being the next, the analysis of the measures together according to their respective retrofitting families.

\subsubsection{Analysis of the effects of retrofitting measures.}

the analysis of the final graphs is the previous step towards the conclusions of the thesis. The idea is to evaluate if any of the theoretical retrofitting measures have supposed a relevant improvement for all the cases of malls. As established in 6.1.2 The threshold established, is a raise of one point respect the average score of the mall per retrofitting family, respect the status before the application of the theoretical retrofitting.

\section{RA.- RESULTS OF THE RETROFITTING OPEARTIONS AIMED ON ECOEFFCIENCY}

RA1.- Optimal bioclimatic adaptation of the building, inner space and installations.

Considering that all of the facades and inner spaces of the shopping malls have been optimized according to the bioclimatic conditions; and all the installations have been updated searching the less consumption as possible. The results of this retrofitting operation are going to be studied considering the whole family of the Eco Efficiency (A). This is because its effects alter simultaneously the score of more than one sector.

As shown in the figure 6.2.2, the application of the pack of measures concerning this operation have been positive for all the shopping malls studied. The field in which the improvements are more evident is the one of the passive measures (A3). This happens because generally the buildings of the shopping malls studied were not projected with the aim of achieving a bioclimatic adaptation, nor including a program of passive conditioning measures. Furthermore the insertion of these measures have supposed for almost all the malls a drastic improvement towards sustainability, specially for the cases of Shopping Eldorado and Aricanduva.

The cases in which the effects of the bioclimatic adaptation retrofitting have been less effective are Belmar and La Vaguada. This happens because both commercial complexes have considered a correct criteria/program of energy savings as well as the adaptation of the inner spaces and facades. Belmar Complex has even LEED qualified buildings within.

Related to low emissive installations, La Vaguada, Parquesur, Belmar and Mall of America are the cases in which the theoretical retrofitting have resulted in no improvement at all. This is a consequence of the retrofitting programs these malls have performed in the last years, which allowed them to update their installations. For the other cases studied (Shopping Light, Eldorado, Aricanduva, and ABC Serrano) the retrofitting of installations have supposed a slight improvement towards sustainability (2 points).

\section{RB.- RETROFITTING OPERATIONS FOCUSED ON ECOLOGY.}

The retrofitting operations related to this family in the Retrofitting Rose Graph, were thought in a more concrete way, concerning one sector of the graph. In this chapter the measures are 
going to be studied at first separately, being later concluded with a comparison of the average scores of the family of retrofitting means focused on environment (B).

RB1.- Green retrofitting:

The retrofitting aimed in the increase of green areas have been generally positive. The cases in which this retrofitting have achieved the more relevant effects are Eldorado, and Aricanduva. This happens because their respective urban environments have scarce green areas, in addition to the large surfaces these shopping malls have in their roof and plot. In the rest of the cases, the variation have been scarce ( 1 or 2 points). This retrofitting operation though, have let the shopping malls located in dense urban areas with scarce greenery, to improve their conditions towards sustainability. For instance $A B C$ Serrano now comply with the minimum requirements, and the insertion of intensive greenery in Shopping Light can suppose an added value for both the shopping center and the center of the city of Sao Paulo, where the density is very high, and the green areas are scarce.

In the case of La Vaguada, both the shopping center and urban area have green areas within, despite the high density of the urban area. This way the retrofitting based in the addition of green areas is not efficient at all. Almost the same happens for the cases of Belmar and Mall of America, where the green spaces are abundant in the urban surroundings.

In contrast to this, the insertion of greenery in Aricanduva, La Vaguada and Parquesur, can turn these shopping malls to assimilate more than a 500\% the emissions they generate. This happens because these centers were considered to have a low rate of carbon dioxin emissions, being the large surfaces of theirs plots and the roofs an opportunity to create a green area in the city.

However, these high rates of carbon dioxin absorption, despite being very high related to the emissions of the mall itself. this improvement is not so high if compared with the emissions of the whole urban area of analysis.

RB2.- Waterproof surfaces retrofitting:

The theoretical retrofitting towards the recuperation of the terrain water capabilities, and the update of installations towards water savings; have been by far the one with the most positive results. All of the malls studied have environmental problems according to water and soil, as a consequence of the large paved surfaces that consolidates their buildings and parking plots surrounding them.

In this case, the shopping malls whose scores have been improved mostly, are the ones located in the dense urban areas (Shopping Light and ABC Serrano), and the ones located in areas with a large rate of paved surfaces (Aricanduva and Eldorado).

Related to the cases of Belmar, Parquesur, La Vaguada And Mall Of America, the effects of these retrofitting have been less effective. The reason is these centers are located in urban areas with minor rates of paved surface. In contrast to this, these shopping malls have still 
large paved surfaces in their plots and buildings, and the adaptation of them to water assimilation can suppose a moderate improvement towards ecological sustainability.

RB3.- Heat island surfaces retrofitting:

Despite the heat island effect depends mainly on the urban area where the shopping mall is located in, the treatment of the shopping mall building towards the mitigation of this effect by the insertion of reflective surfaces, can be of interest.

As a result, the application of reflective surfaces in the whole plot of the mall have resulted in relevant improvements for almost all the cases. The exception is the case of La Vaguada, for which this retrofitting operation looks useless and redundant. This happens because of the clear colors of some roof areas, as well as the coverage of the skylight gaps and the green areas on both the roof and the plot.

Disappointedly, most of the cases studied are located in areas with heat island problems going from moderate to critical. This means is going to necessary to treat the urban area with the aim of avoiding heat island problems.

RB.- Analysis of the three measures put together.

To conclude this chapter, is important to consider the effects of these measures put together in the family of environmental retrofitting. The reason of this, is because the retrofitting measures studied are perfectly compatible among each other, resulting the combination of them in even better improvements towards the environmental conditions.

After doing the average score of the environmental retrofitting family after the application of these operations, the result is that the threshold of relevance is accomplished in all the cases. having the major rise of the average score the cases of Eldorado, Aricanduva and ABC Serrano. This means, the combined solutions are the more effective ones for a retrofitting aimed in the regeneration of green capabilities. (Chapter 6.2.3)

\section{RC.- RETROFITTING OPERATIONS FOCUSED ON THE INSERTION OF USES.}

The insertion of uses is focused mainly in the making of the shopping mall into a complex urban area, following the retrofitting lines of New Urbanism. This retrofitting operation is going to be analyzed considering the whole family of the uses retrofitting $(C)$, because the aim is the complexity of uses, opposite to the zoned planning.

The results of the analysis vary depending on the mall, For the case of Shopping light, this operation have no effect due to the overcrowd of both the public and productive use in the urban surroundings. In addition the insertion of residential uses in Shopping Light is not enough to make a relevant change.

Related to the cases of Shopping Eldorado, Aricanduva, and La Vaguada, the insertion of uses have supposed a minimal improvement towards urban complexity, but not relevant. The reason is because these malls are located in complex urban areas. 
Belmar, despite being located in a nothing complex urban area, the insertion of uses has almost no effect, because in the complex there is a mix of uses that comply with the requirements related to urban complexity established. ABC Serrano is located in a complex urban area, and the insertion of uses will turn the shopping mall into an optimal case. This retrofitting despite having relevance, must be considered once other issues of importance have been considered.

The cases of Parquesur and Mall of America are the ones in which the retrofitting operation of insertion of uses have supposed the most drastic changes. This happens because the urban environment surrounding these malls is an area with almost no mix of uses. Being an appointment, there are serious lacks related to the surface a concrete use.

However, in a general view, the insertion of uses in the studied malls have turned the nearby urban environments of them to comply with the requirements established in this thesis according to urban complexity. (A mix of uses between residential an non residential uses of a $20-80 \%)$

\subsection{3.- Retrofitting means put in together, resume and dimension of the improvements achieved.}

This chapter has the aim of performing a resumed overview of the effects of the theoretical retrofitting operations applied for all the cases. The average scores of the Retrofitting Roses Graphs, are going to be compared, being chosen two scenarios: the first one is the status of the shopping mall without any retrofitting, being the second one the shopping mall, considering all the retrofitting operations formerly stated were applied together. This analysis is shown in the figure 6.2.3. 


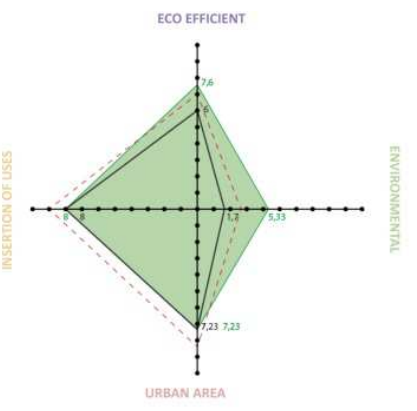

SHOPPING LIGHT

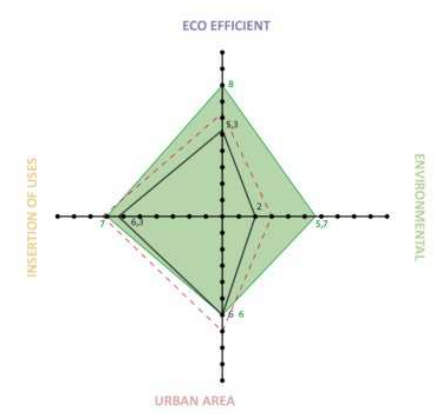

SHOPPING ELDORADO

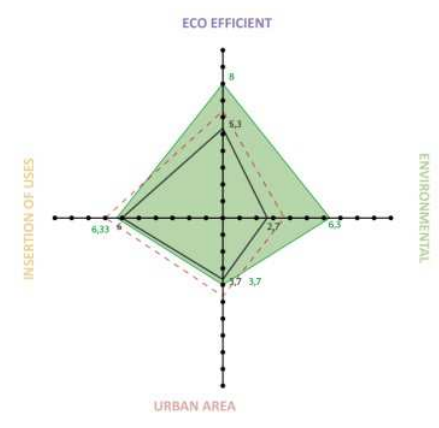

SHOPPING ARICANDUVA

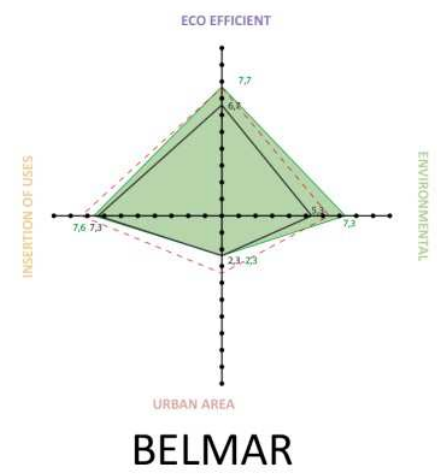

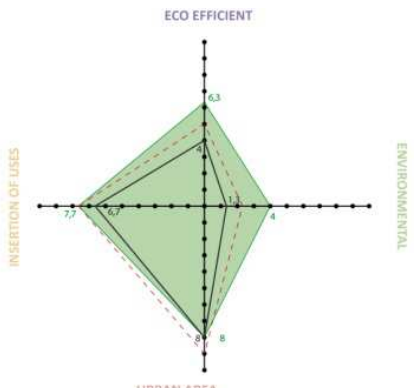

ABC SERRANO

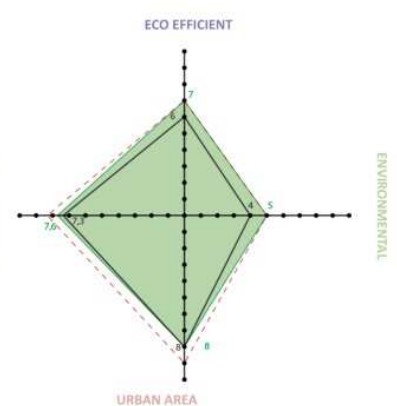

LA VAGUADA

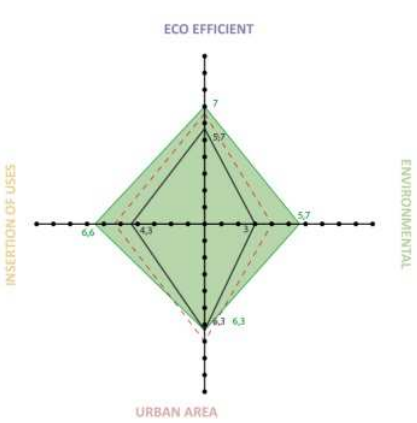

PARQUESUR

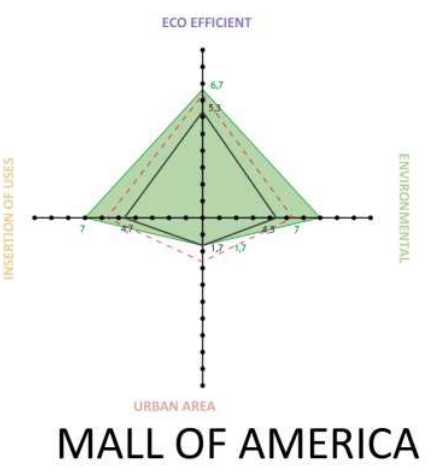


In a general view concerning the average scores, the cases in which the retrofitting measures have been more successful are Shopping Eldorado and Aricanduva, in these cases any of the retrofitting operations studied is going to be effective and successful. Opposite to this, the shopping malls in which retrofitting operations have supposed little changes are the cases of La Vaguada And Belmar. This happens because these malls have considered retrofitting programs, and by this way the effects of a theoretical retrofitting are not going to suppose a strong difference, being the retrofitting of them even useless in some facts.

\subsection{4.- Retrofitting results considering the cases by urban background.}

In the following chapter, the results of the retrofitting applied on the cases of shopping malls, are going to be put in common, considering the urban background of each case by pairs. For this study, is going to be supposed all the retrofitting operations considered have been applied. The idea is to show which retrofitting measure have been resulted more efficient according the urban background of the shopping mall.

For the cases located in dense urban backgrounds (Shopping Light and ABC Serrano), (Figure 6.2.4.) the results show that the most efficient retrofitting operations applied, are within the environmental family, the ones applied to water assimilative surfaces and heat island. The less efficient, are the ones related to uses and urban areas, this happens because both cases studied are located in dense and complex urban areas with strong activity.

Related to water assimilation and heat island reduction aimed retrofitting, the application of them on the shopping mall only, is enough to achieve a relevant improvement; but not enough, even applying all sorts of means that can reduce heat island or guarantee the water absorption and savings, to achieve the optimal scores. This happens because the shopping mall surface covers the $5,9 \%$ of the urban area of analysis. This way, the improvements related to water assimilative surface or heat island expelling surfaces are scarce in comparison with the wide paved surface a dense urban area carries out. Being scarce too the increase in carbon dioxin assimilation rate, if covered with greenery (No more than a $0,07 \%$ related to urban area emissions, and a $1 \%$ related to shopping mall ones.)

Related to eco efficiency, the consideration of the bioclimatic conditions for the shopping mall building can suppose a relevant improvement. If the building is not adapted to the climatic conditions, as are both the buildings of Shopping Light and ABC Serrano. 

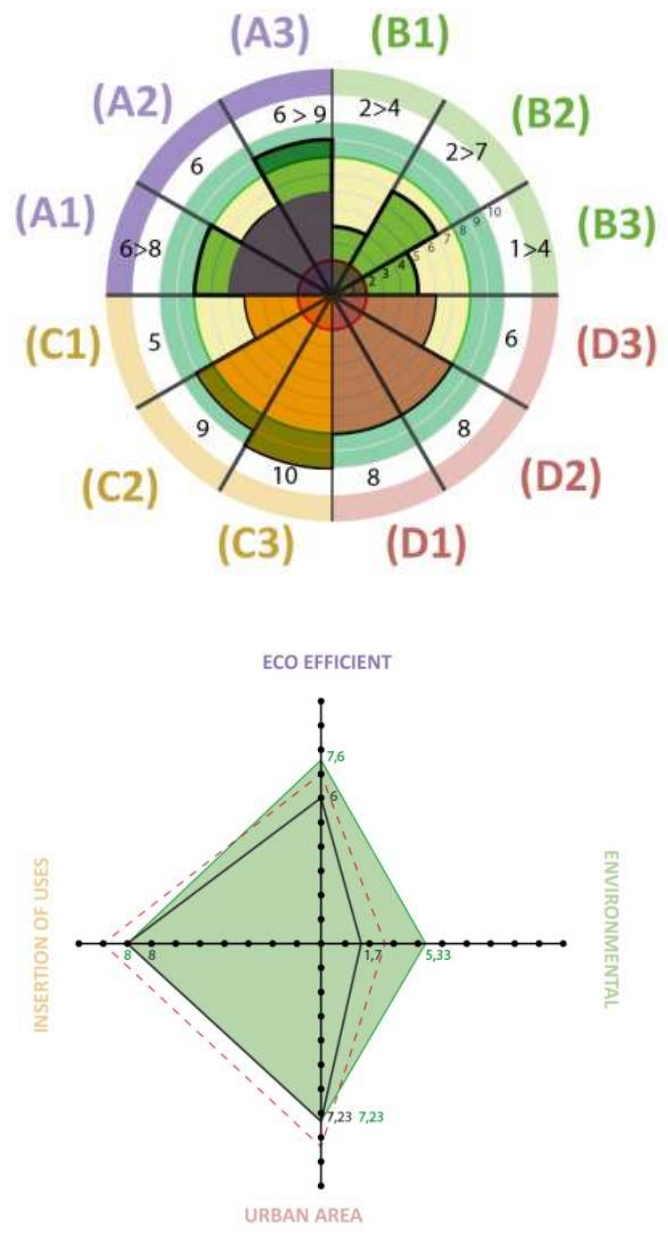

SHOPPING LIGHT
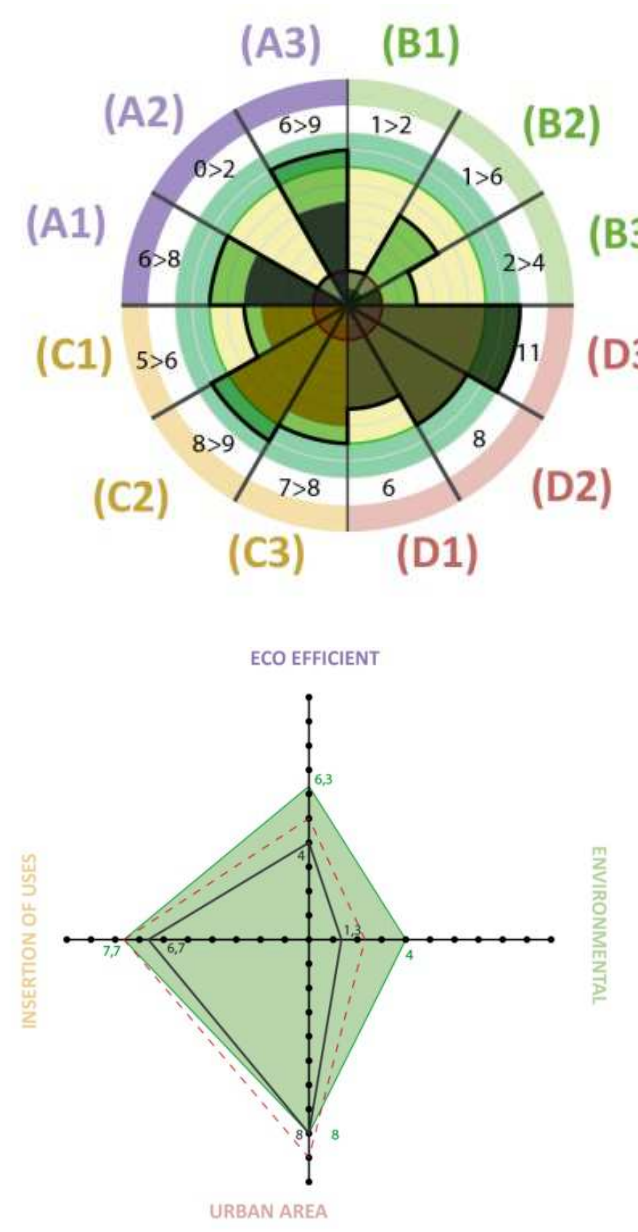

ABC SERRANO

Figure 6.2.4: Comparison of the retrofitting results for the cases of Shopping Light and ABC Serrano. Own's source.

Related to the cases in expanded city centers (Shopping Eldorado and La Vaguada) (Figure 6.2.5.) The most efficient retrofitting operations are the ones related to the environmental quality, as having the urban areas surrounding these shopping malls almost the same problems as the high density ones. However the malls studied have major roof and plot surfaces than the ones located in the dense urban downtowns, and this means, the insertion of greenery on their plots or roofs can create a carbon dioxin sink, aimed to assimilate a great part of the mall emissions, or even the ones of the nearby urban plots, if the shopping mall has a low rate. For instance, In Shopping Eldorado, the green retrofitting supposed an increase from $21 \%$ to $68 \%$ of the shopping mall emissions, and in la Vaguada the rate increased from a $36 \%$ to a $400 \%$ of the mall emissions. However, these increases are scarce considering the wide urban scale (at most a $2-3 \%)$.

Related to uses and urban activity, the retrofitting operations applied have been more efficient than in the cases located in dense urban areas. 

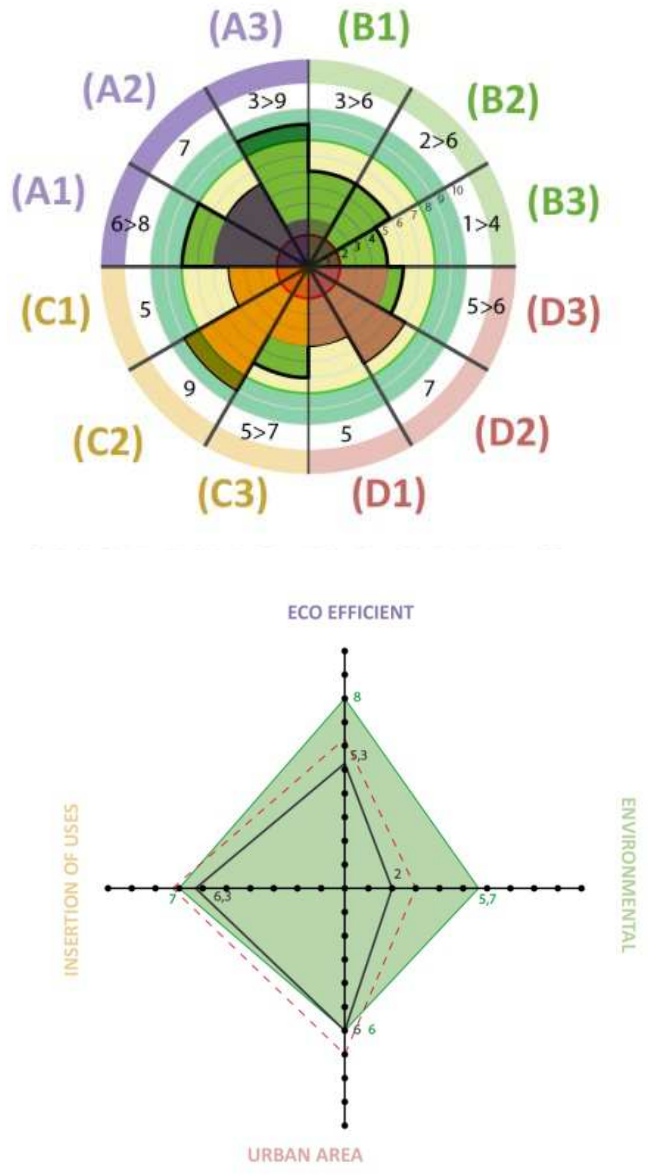

SHOPPING ELDORADO
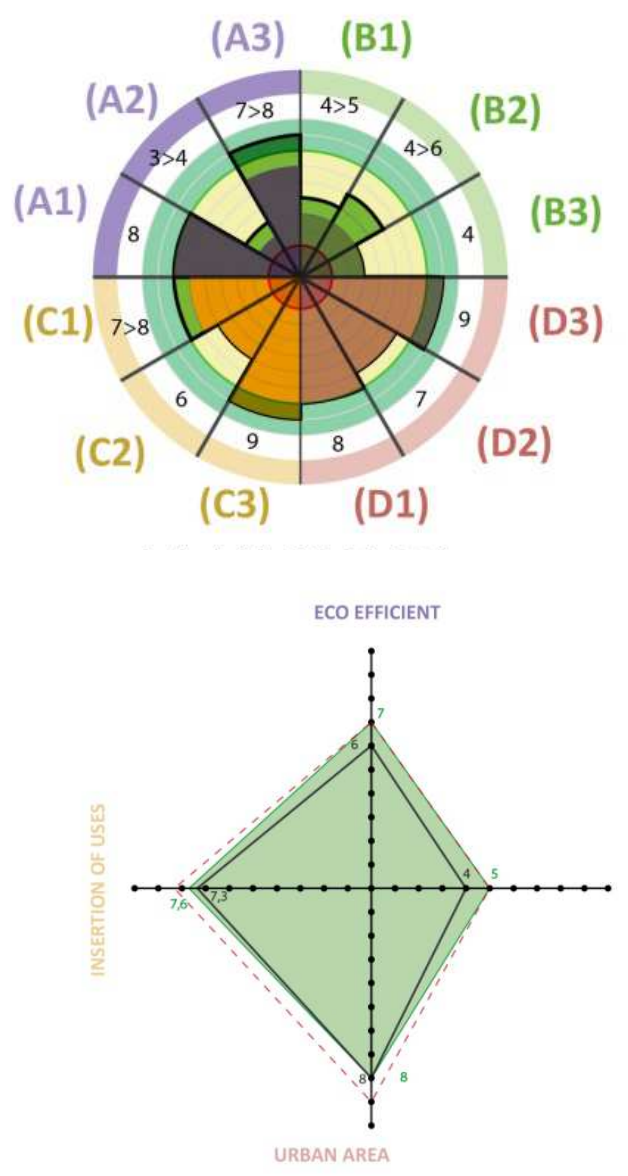

LA VAGUADA

Figure 6.2.5: Comparison of the retrofitting results for the cases for Shopping Eldorado and La Vaguada. Own's source.

In the cases located in nearby outskirts (Aricanduva and Parquesur) (Figure 6.2.6.) The results of the retrofitting operations applied are almost the same as the cases in expanded urban areas. However the retrofitting aimed in environmental quality, have resulted in better results, because both malls, have large surfaces of roof and plot. (the coverage of these shopping malls with greenery, can assimilate in more than the $500 \%$ their emissions, being also possible to assimilate more than a $70 \%$ of the emissions of their nearby urban area), In addition, the insertion of uses have been resulted effective, because in those areas the uses are slightly zoned. For instance, in Parquesur, the insertion of productive uses, have supposed an increase of the urban complexity, because of the lack of them in both the mall and surrounding plots. (from $1 \%$ to $13,65 \%$ ). 

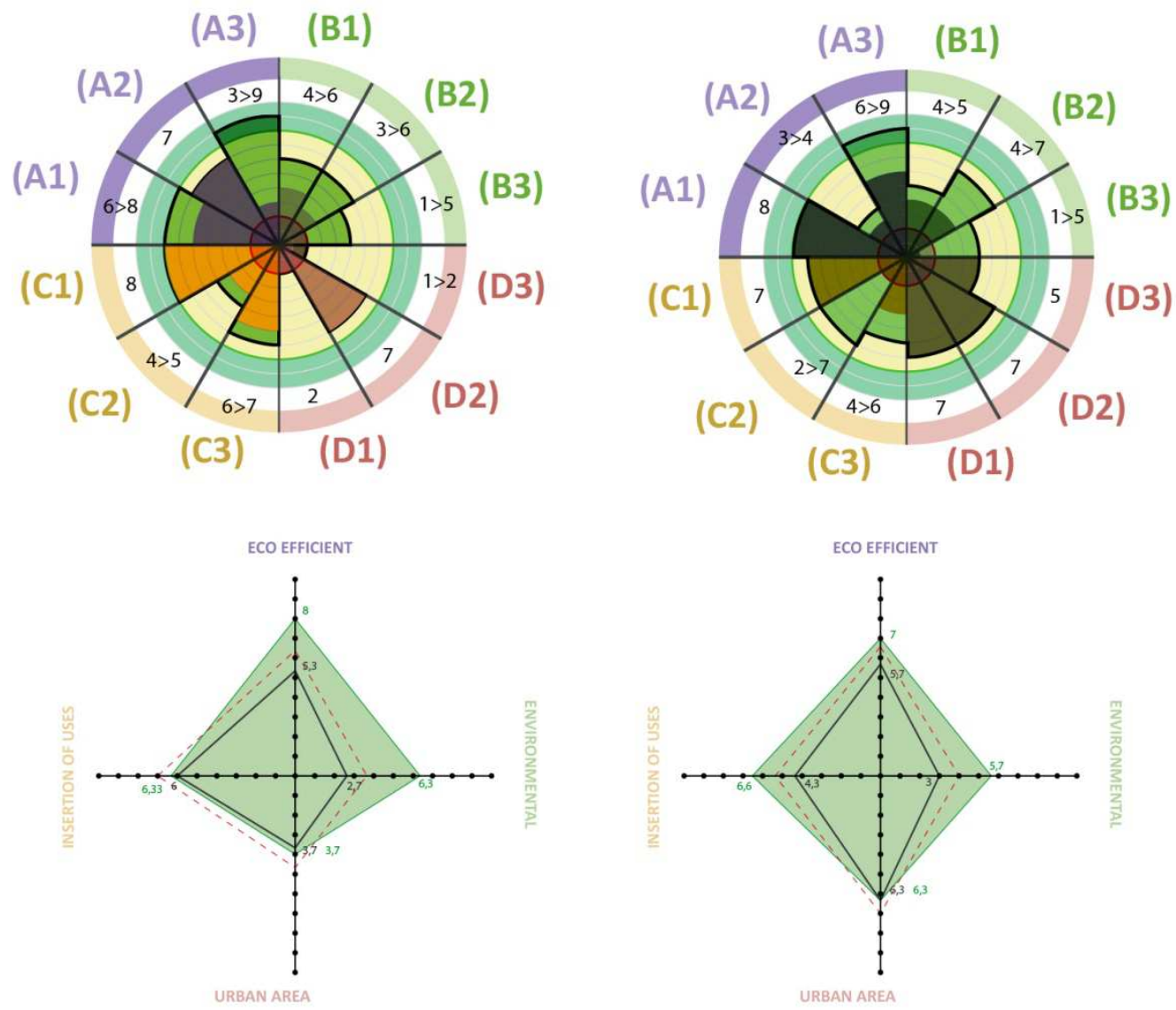

\section{SHOPPING ARICANDUVA}

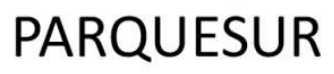

Figure 6.2.6: Comparison of the retrofitting results for the cases of Aricanduva and Parquesur. Own's source.

Related to Suburban USA, (Mall of America and Belmar) (Figure 6.2.7) the best resulting retrofitting operations, are the ones related to use insertions, if the mall is located in a zoned area with a predominant use. The insertion of greenery, turned these cases into optimal ones, because of both the large built surfaces of the mall buildings, and the high rates of greenery in urban area surrounding them.
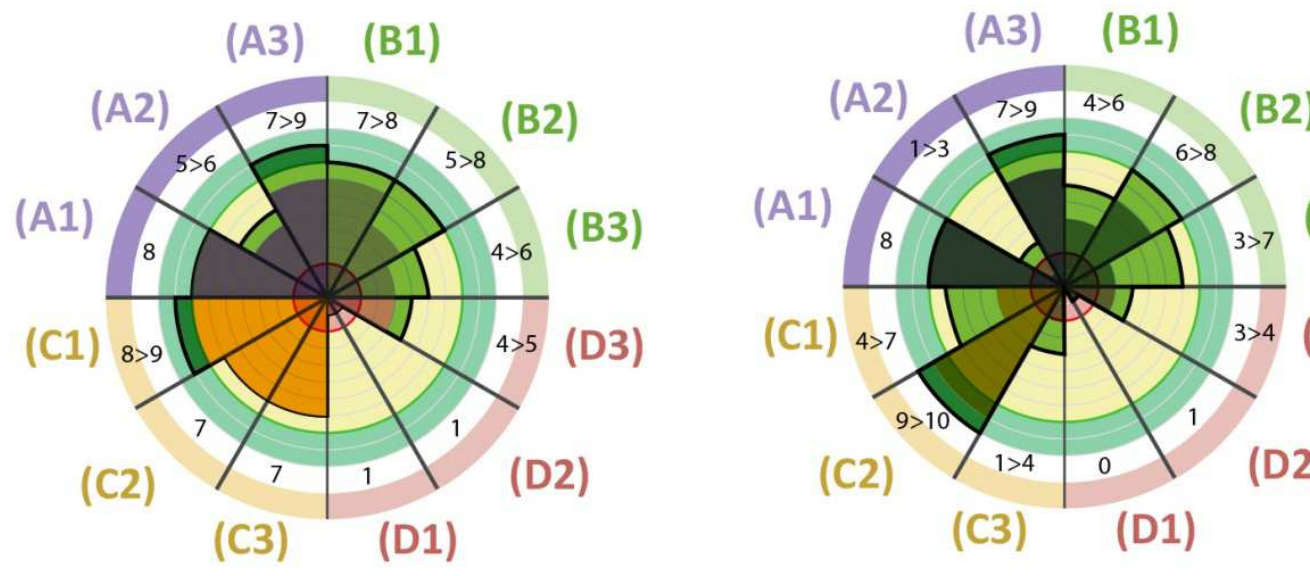


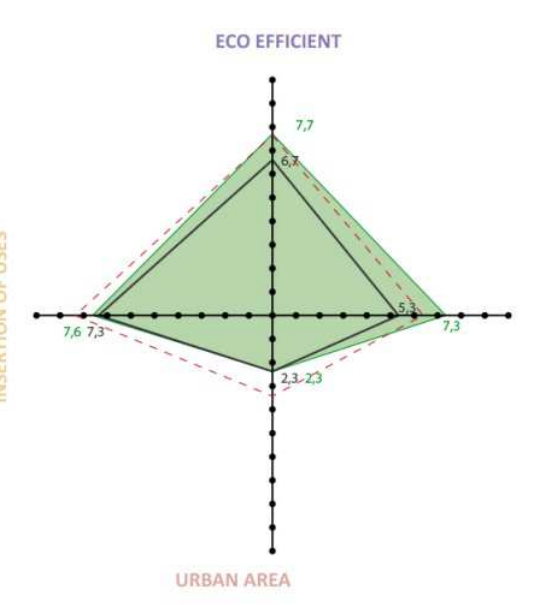

BELMAR

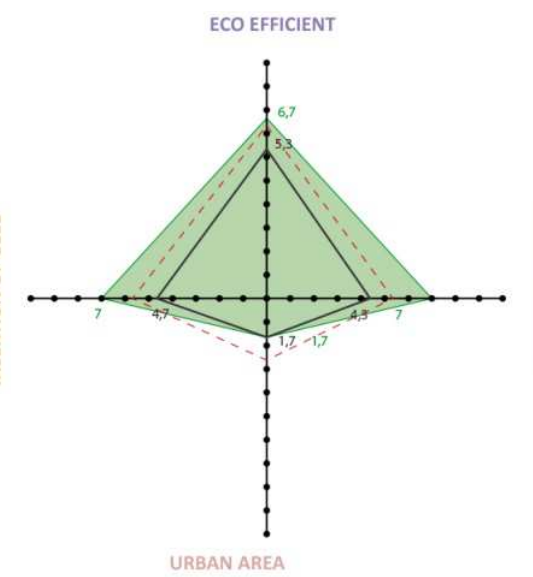

MALL OF AMERICA

Figure 6.2.7: Comparison of the retrofitting results for the cases of Mall of America and Belmar. Own's source.

The following graph sums up the chapter, showing which retrofitting operations have resulted more effective according the urban background, a biaxial graph is considered (Figure 6.2.8) :

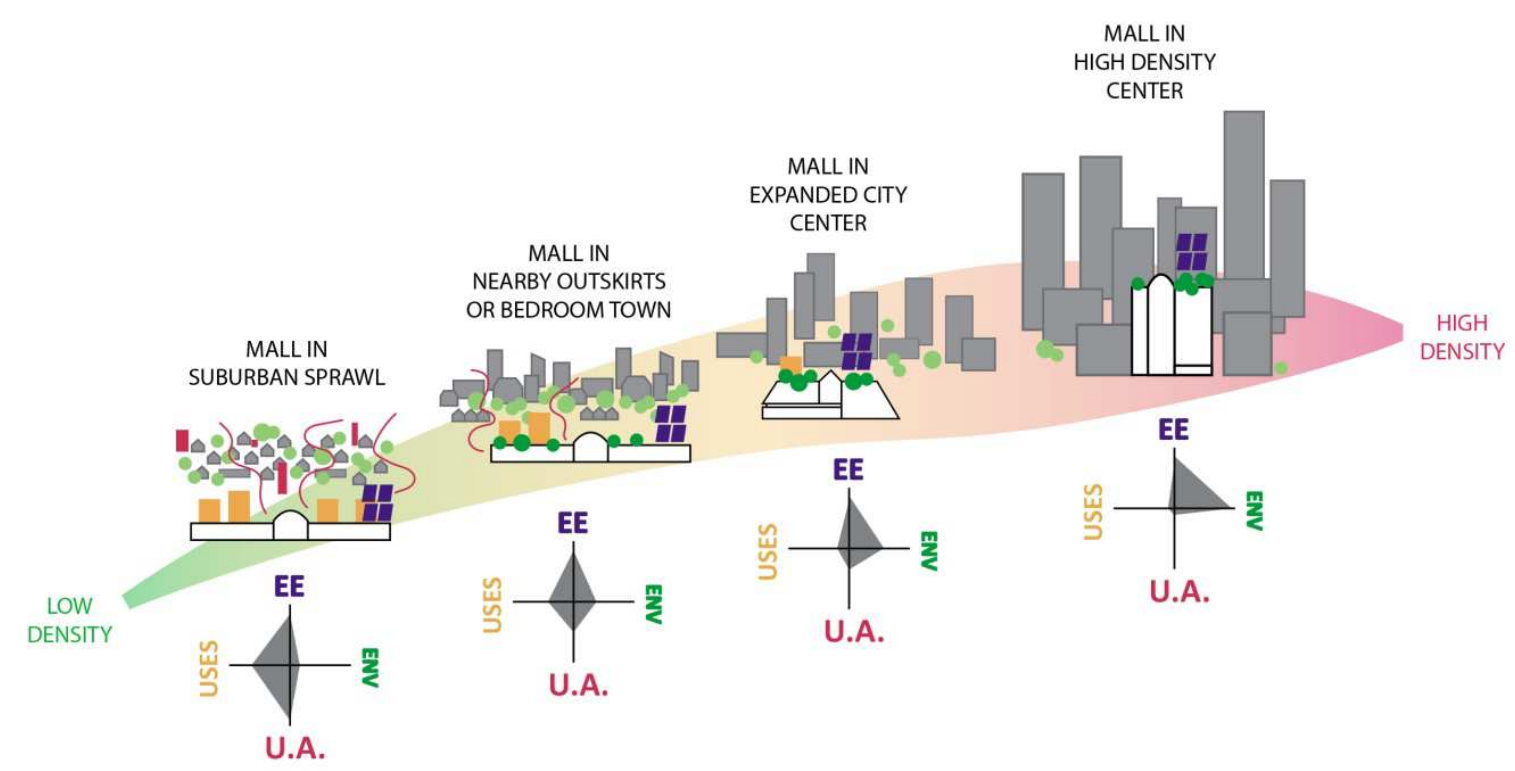

Figure 6.2.8: Efficacy of the retrofitting means related to urban background, conclusive graph. Own's source.

\section{3.- FINAL CONCLUSSIONS, RESPONSES TO HYPOTHESES AND RESERCH QUESTIONS.}

To sum up with this thesis, and to establish the final conclusions, the research question and the hypotheses are going to be responded, according to the analysis of the centers.

\subsection{1.- Response to the research question.}

Would the retrofitting of shopping malls carry on a relevant improvement towards urban environment and sustainability?. 
Despite the analysis of the retrofitting towards the aim of the urban sustainability is a complex issue, that does not depend on a particular building (shopping mall). It becomes clear that in some cases this architectural typology is an anomaly in the urban tissue. According to the comparative studies performed on last chapter, the sustainable retrofitting of a shopping mall, is going to suppose an improvement towards urban sustainability. However, the positive effects are limited to a concrete area in the city, concerning just some aspects of urban sustainability depending on the retrofitting applied.

Related to eco efficient retrofitting operation, its application on a shopping mall, can turn it a more respectful buildings towards environmental sustainability. Both the operations of bioclimatic adaptation, and the insertion of solar or efficient installations, have the aim of reducing the dependence on external energy sources, or even the usage of clean energies. In contrast to this, the energetic consumption reduction of a shopping mall does not supposes a relevant reduction of the energy consumption of the whole city.

The cases of Sao Paulo, have better scores related to eco efficiency, due to the predominance of the usage of hydroelectric energy in the city of Sao Paulo (about $90 \%$ according to ICLEI) this makes the malls of Sao Paulo ha have better scores in Active energetic measures, (6-7 points) than the cases of Madrid or USA, even after the application of the theoretical retrofitting. with the exception of Belmar, which after the theoretical retrofitting the scores raise as 6 , because of the LEED qualified buildings the complex has.

Related to green retrofitting, shopping malls, especially the ones with large surfaces can be an opportunity to create a green area for the urban background, In addition, in some cases the vegetation of these new green areas can assimilate the shopping mall emissions. This happens if the building has large surfaces to be retrofitted in plot or roof, and the carbon dioxin emissions are relatively low. (The cases of Aricanduva, La Vaguada and Parquesur, after the application of greenery, they turned up to assimilate more than the $500 \%$ of the shopping mall emissions). Being the new green areas of the shopping mall even enough to assimilate the emissions of the urban area, if it has low density and a lot of greenery within. For instance The new green areas of Belmar and Mall of America, have turned the urban area to assimilate more than the $100 \%$ of its emissions, (without considering transportation. that should rise exponentially the carbon footprint in the urban area). In contrast to this, the supposed new shopping mall green areas, are not going to assimilate all the emissions of a whole city; even being not possible to assimilate the ones expelled by the urban area of influence, if it has a little higher density rate than the one related to sprawled suburbs. (The new green areas applied on Shopping Aricanduva or Parquesur have raised the $\mathrm{CO} 2$ assimilation rate in the urban area from $7 \%$ to $74 \%$, and in Parquesur the raise have raised from $17 \%$ to $32 \%$, being in both cases this operation successful).

However, is important to consider the adaptation of the paved surface of the shopping mall to water absorption by the terrain. And the insertion of heat reflective surfaces to mitigate heat island effect. These operations should be applied too in the other buildings of the urban surroundings, to achieve a relevant improvement. 
To put an example, the theoretical retrofitting aimed to greenery or water absorption by the terrain, have supposed the best results in the cases in which the air environmental quality is better, and the paved surfaces are minimum, such as Mall Of America And Belmar (green surfaces in about the $33-45 \%$ of the urban area of analysis) in, contrast to the scarce $2,6 \%$ the area surrounding Shopping Light has. The retrofitting on these malls made those scores to rise from $6 / 7$ to 8 , that is the optimal case.

In no case, the insertion of reflective surfaces in the shopping mall is enough to mitigate the heat island, which is stronger in the areas with major rate of paved surface, (The most critical case is $A B C$ Serrano surrounding area with a difference of $+8{ }^{\circ} C$ and a paver surface of the $91 \%$, being the less critical one, the Belmar urban area with a heat island of $+1^{\circ}$ and a paved surface of about a $70 \%$ )

Related to the insertion of uses, this retrofitting operation can help to create in the nearby plots of the shopping mall, a complex urban area with activity if the mixture of activities is poor. For example, the refurbishment program Belmar have considered, supposes nowadays a mix of uses of a $52 \%$ of residential use, and a $48 \%$ of non residential use in nearby plots, in contrast with Mall of America area whose proportion of uses is an $8 \%$ of residential use, and a $92 \%$ of non residential use. Another relevant case is Parquesur, in which nearby plots, the retrofitting of uses have supposed the productive use to rise from $1 \%$ to $13 \%$. In larger scales though, this activity is not going to alter the configuration of the urban activity, if the urban area has a certain mixture of uses. This is related to $A B C$ Serrano or La Vaguada areas, in which the insertion of uses have supposed a scarce increase of a $2 \%$.

The exception of this affirmation are the suburban areas with low density and the predominance of a single use. In these conditions a change of uses in surfaces can produce a relevant change, such as the increase of the residential use in more than a 5-7\% in the urban areas of Belmar and Mall of America. Furthermore these change are going to suppose new urban interactions that need to be controlled.

To sum up, the retrofitting of a shopping mall is going to have effects. But they are going to be more relevant in the plot of the shopping mall, and its immediate surrounding plots. Considering larger urban scales, this retrofitting does not solve any problem related to urban environment, but can contribute. This means is going to be necessary to retrofit more buildings and urban areas, as well as the shopping malls, to achieve a relevant improvement towards urban sustainability, in the wide scale of the whole city.

\subsection{2.- Response to the hypothesis 1 .}

Is possible an improvement of the revitalization of a wide urban area, throughout the alteration of the shopping mall building and plot, considering different techniques of rezoning, and insertion of uses".

The response for this hypothesis is negative. As stated before in the research question, is true that the insertion of uses is going to improve the urban vitality in nearby plots (After the 
application of the theoretical uses retrofitting, relevant changes in the configuration of uses in the nearby plots surrounding Mall of America, Parquesur and Belmar were achieved). But this effect does not suppose the revitalization of the areas that are far from the shopping mall plot. To achieve a revitalization of a wide urban area by the insertion of uses, these operations should be applied too in another plots or buildings of the urban area, being of importance the optimization of the mass transit and sustainable mobility. This happens because the new retrofitted shopping mall is going to produce new interactions and displacements; being necessary the treatment of them to avoid serious problems related to urban mobility, with their subsequently environmental impact. For instance, according to the methodology, the lack of efficient mass transit as well as the high number of visits, have supposed a negative impact in the score related to green areas for the cases of Aricanduva, Belmar and Mall of America.

\subsection{3.- Response to the hypothesis 2 .}

The application of a single retrofitting mean is going to be insufficient to get a relevant improvement towards urban sustainability, is required the application of various means simultaneously.

The response for this hypothesis is positive depending on the case. The reason of this, is because as shown in the analysis of the average scores in the Retrofitting Rose, an improvement per single sector sometimes is not enough to result in a relevant improvement, or is enough to do it with a minimum raise in the average score per retrofitting family (1 point at most). However, if the shopping mall has critical lacks related to a single sector of the Retrofitting Rose, the variation is going to be bigger, even if the measures are aimed only in the correction of one fact (sector). For Instance, after the application of the retrofitting aimed in water savings and assimilation (B2), the scores in this sector of the Retrofitting Rose for $A B C$ Serrano, and Shopping Light have raised 5 points due. This is because of the serious lacks both the mall and urban area has towards water assimilation. Another examples are the cases of Shopping Eldorado or Aricanduva. In which the bioclimatic adaptation of the buildings, have supposed a great improvement in the eco efficiency related to passive measures. This happens because the planning of these buildings did not considered the bioclimatic conditions (zero punctuation in the questions related to Olgyay and Givonni adequacy of their buildings). Furthermore is more recommendable the mixed solutions, to cover the most fields as possible. This translates in better results, as shown in the average scores analysis.

\subsection{4.- Response to the hypotheses 3.}

The retrofitting of a shopping mall is not going to be enough to produce a reduction of the environmental impact in the scale of the whole city. This supposes is going to be necessary the retrofitting on a whole urban area.

The response for this hypothesis is true. Considering the wide urban scale, the retrofitting of the shopping mall only, is not enough to improve the environmental conditions and 
sustainability of a whole city. This is explained in the research question paragraph, and chapter 6.3.2. This supposes is going to be necessary the application of the retrofitting operations in the urban area to achieve this goal. To make an appointment, is even more important the retrofitting and the refurbishment of the urban background, rather than the mall building itself, especially if the urban area is characterized by the low density, the zoned uses, and the predominance of the private transportation. The evidence of this, is that the shopping malls whose urban surroundings comply partially, or totally with the requirements established towards sustainability by the methodology (uses and greenery), have reached the score of optimal case in some sectors, (8 points) once the retrofitting operations have been applied: Aricanduva in green areas, ABC Serrano in Public uses and amenities, La Vaguada in residential uses, Belmar in green areas and water assimilation and Mall of America in water assimilation.

\subsection{5.- Epilogue, final conclusion.}

The issue of the sustainable retrofitting of shopping malls, and their urban problems, where the parting point to develop a methodology to evaluate the retrofitting operations. The application of this methodology on different cases, evidenced that the retrofitting of shopping malls, can be an efficient measure towards sustainability to be considered. However cannot solve the environmental problems of a whole city. As shown in the state of the art chapter related to the process of project of a shopping mall, both the configuration and dimensions are based on the features of the nearby urban environment. And this means the operations of sustainable retrofitting to be applied on a shopping mall should be projected considering the features of both the shopping mall building and the configuration of the urban area of influence, as being any shopping mall a part of a complex urban environment.

\section{4.- CONCLUSIONES.}

Este capítulo resume los resultados del estudio de casos y las conclusiones, indicando los resultados más relevantes de los mismos.

\subsection{1.- Introducción a las conclusiones, las medidas de rehabilitación teóricas a analizar.}

De acuerdo a los resultados obtenidos en las rosas de rehabilitación sostenible, van a considerarse las siguientes operaciones teóricas de rehabilitación, que van a ser aplicadas sobre los casos de estudio anteriormente analizados.

Los resultados de esta operación van a concluir en nuevas puntuaciones en las gráficas de la Rosa de la Rehabilitación Sostenible. Estos nuevos resultados, van a ser la base que nos permitirá establecer las conclusiones ligadas a la pregunta de investigación y las hipótesis, siendo concluida de esta manera la presente tesis doctoral. 
De este modo, las operaciones de rehabilitación teóricas que van a ser consideradas van a ser las siguientes:

RA- Operaciones de rehabilitación centradas en la eficiencia energética del centro

Las operaciones descritas en este capítulo se centrarán en la mejora de la eco eficiencia del centro comercial, en relación con las instalaciones energéticamente eficientes y las condiciones bioclimáticas. no obstante, debido a la ausencia de datos rigurosos respecto al consumo energético, las operaciones a aplicar van a limitarse la adaptación total del centro a lo requerido por los diagramas de Givoni para instalaciones y espacios interiores y se adaptará el edificio a las condiciones bioclimáticas impuestas por Olgyay, además de considerarse una puesta al día de las instalaciones hacia la eficiencia energética.

RA1.- Adaptación del centro comercial a los condicionantes bioclimáticos

Para el cálculo de los resultados de esta operación de rehabilitación van a considerarse los siguientes efectos en el cuestionario de la Rosa de Rehabilitación sostenible, que corresponden a las cuestiones relacionadas con los gráficos de Olgyay y Givoni:

- La pregunta A.1.1 tendrá una puntuación de +1

- La pregunta A.1.3 tendrá una puntuación de +1

- La pregunta A.2.3 tendrá una puntuación de +2

- La pregunta A.3.1 tendrá una puntuación de +2

- La pregunta A.3.3 tendrá una puntuación de +2

- La pregunta A.3.4 tendrá una puntuación de +2

RB.- Operaciones de rehabilitación centradas en la calidad medioambiental.

Este bloque de operaciones de rehabilitación, está centrado en la mejora de las cualidades medioambientales del centro y la área urbana, mediante la inserción de elementos verdes, y otros dispositivos encaminados a la reducción del dióxido de carbono atmosférico, la asimilación de aguas por parte del terreno y la mitigación de la isla de calor. Se considerarán las siguientes operaciones de rehabilitación, las cuales van a ser aplicadas o bien por separado, o bien de forma simultánea.

RB1.- Rehabilitación verde: Esta operación de rehabilitación consistirá en la transformación parcial de la cubierta y la parcela del centro en zonas verdes. Un mínimo de zona sin rehabilitar va a considerarse para la infraestructura del centro comercial, esta rehabilitación incluye las siguientes capas de vegetación:

-El 60\% de la cubierta del centro pasará a ser una cubierta verde intensiva.

-El $60 \%$ de la parcela del centro comercial (áreas no edificadas) van a transformarse el aparcamientos vegetales (Pradera) 
El 10\% de la parcela del centro comercial (área sin edificar), va a transformarse en una zona destinada a la vegetación de alta capacidad absorbente.

RB2.- Rehabilitación de superficies impermeables: Esta operación de rehabilitación está enfocada en la permeabilización de las superficies construidas del centro comercial, o su adaptación para el almacenamiento de agua, con el fin de garantizar la absorción de la misma por el terreno. Esta operación considerará los siguientes efectos:

-El $100 \%$ de la superficie del centro comercial va a transformarse en una superficie asimiladora de aguas pluviales.

-Todo tipo de sistemas destinados al ahorro de agua van a ser implementados en el centro. La puntuación en la pregunta B.2.3 será considerada como +3 .

-Va a reducirse el consumo de agua por visita a mínimos. La puntuación en la pregunta B.2.4 será considerada como +2 .

RB3.- Rehabilitación de superficies de cara a la isla de calor: Aunque la isla de calor depende generalmente de la escala amplia urbana, el centro comercial va a adaptarse de cara a la mitigación de la misma en lo posible. De este modo, se va a considerar que toda la superficie construida del mismo va a tratarse con superficies reflectivas o de colores claros teniendo esto el siguiente efecto:

- La puntuación en la cuestión B.3.4 será considerada como +4 en todos los casos.

\section{RC.- REHABILITACIÓN MEDIANTE LA INSERCIÓN DE USOS}

Las operaciones de rehabilitación descritas, van a estar centradas en la inserción de usos en el centro comercial, para tratar de conseguir en el mismo una mezcla de usos que implique complejidad e interacción urbana. (Sector $\mathrm{C}$ del gráfico de la Rosa de Rehabilitación sostenible).

De este modo, para el consiguiente análisis, va a agrandarse el edificio del centro comercial, considerando los siguientes porcentajes de uso añadido respecto de su superficie construida total.

-Se añadirá un 35\% de uso residencial.

- Se añadirá un $15 \%$ de uso productivo no comercial.

- Se añadirá una dotación de carácter local o visita esporádica.

El uso comercial no será añadido, ya que el centro en sí cubre la demanda de una gran parte de este uso.

La presente tesis, al estar enfocada en la rehabilitación de los centros comerciales exclusivamente, quedando el campo de acción de la misma acotada al edificio en sí, el entorno urbano no va a ser considerado, ya que su rehabilitación requiere de otra metodología diferente. no obstante la importancia de rehabilitar el entorno urbano va a ponerse de manifiesto en las conclusiones. 


\subsection{2.- Parámetros y umbrales de relevancia.}

Para que los efectos de una operación de rehabilitación sean considerados como relevantes, es importante establecer un umbral de relevancia. Debido a que operaciones de rehabilitación van a suponer nuevas puntuaciones en los sectores de la Rosa de rehabilitación sostenible, el umbral de relevancia establecido, va a basarse en el incremento de las puntuaciones medias por sector, entre el estado sin rehabilitar del centro comercial, y el estado rehabilitado del mismo.

Para las medias, van a sumarse las puntuaciones de los tres sectores por familia de medidas de rehabilitación de la rosa (A, B y C) y van a ser divididos entre tres. Se va a realizar esta operación para la rosa del centro sin rehabilitar, y la rosa con las operaciones teóricas aplicadas. Estas medias van a compararse por sector.

De este modo, la operación de rehabilitación aplicada, se va a considerar con resultados relevantes, si se ha producido un incremento de la media en al menos un punto.

\subsection{3.- Aplicación de las medidas de rehabilitación sobre los casos analizados.}

La inserción de las medidas teóricas de rehabilitación, dieron lugar a los siguientes resultados (Figura 6.4.1): 


\begin{tabular}{|c|c|c|c|c|c|c|}
\hline \multicolumn{3}{|c|}{ RESULTADO OPERACIONES REHABILITACIÓN } & \multirow{2}{*}{$\frac{\mid \text { C1. S.Light }}{1(1)}$} & \multirow{2}{*}{$\begin{array}{l}\text { C2. S. E.D. } \\
1(1)\end{array}$} & \multirow{2}{*}{$\begin{array}{l}\text { C3.Aricanduva } \\
1(1)\end{array}$} & \multirow{2}{*}{$\begin{array}{l}\text { C4. ABC. Serr. } \\
1(1)\end{array}$} \\
\hline \multirow{14}{*}{$\begin{array}{c}\text { A } \\
\text { REHABILITACIÓN } \\
\text { ECOEFICIENTE }\end{array}$} & \multirow{5}{*}{$\begin{array}{c}\text { A1.- } \\
\text { INSTALACIONES } \\
\text { POCO EMISIVAS }\end{array}$} & A1.1 Adecuación a d. Givoni & & & & \\
\hline & & A1.2 Emisiones $\mathrm{CO} 2$ (Eur.Union) & $3(4) C$ & $3(4) C$ & $3(4) C$ & $3(4) \mathrm{C}$ \\
\hline & & A1.3 Obsolescencia & $1(1)$ & $1(1)$ & $1(1)$ & $1(1)$ \\
\hline & & A1.4 Consumo energético (Eur.Union) & $3(4) \mathrm{C}$ & $3(4) \mathrm{C}$ & $3(4) C$ & $3(4) C$ \\
\hline & & PUNTUACIÓN & $6(10)>8(10)$ & $6(10)>8(10)$ & $6(10)>8(10)$ & $6(10)>8(10)$ \\
\hline & \multirow{4}{*}{$\begin{array}{c}\text { A2.- SISTEMAS } \\
\text { SOLARES ACTIVOS }\end{array}$} & A2.1 Uso S. Activos & 2 (4) adq. const. & 2 (4) adq. const. & 2 (4) adq. const. & 0 (4) none \\
\hline & & A2.2 Iso energías renovables (centro) & 3 (4) e. r. en ciudad & 3 (4) e. r. en ciudad & 3 (4) e. r. en ciudad & 0 (4) none \\
\hline & & A2.3 Adecuación a d. Givoni & 2 (2) no neces. & 2 (2) no neces. & 2 (2) no neces. & $2(2)$ \\
\hline & & PUNTUACIÓN & $7(10)$ & $7(10)$ & $7(10)$ & $0(10)>2(10)$ \\
\hline & \multirow{5}{*}{$\begin{array}{c}\text { A3.- SISTEMAS } \\
\text { SOLARES PASIVOS }\end{array}$} & A3.1 Adecuación bioclimatica (Olgyay) & $2(2)$ & $2(2)$ & $2(2)$ & $2(2)$ \\
\hline & & A3.2 Efficiencia de cerramientos & 3 (4) eficiente & 3 (4) eficiente & 3 (4) eficiente & 3 (4) eficiente \\
\hline & & A3.3 Uso de luz natural (\% área edificada) & $2(2)$ & $2(2)$ & $2(2)$ & $2(2)$ \\
\hline & & A3.4 Adecuac. digrama Givoni & $2(2)$ & $2(2)$ & $2(2)$ & $2(2)$ \\
\hline & & PUNTUACIÓN & $6(10)>9(10)$ & $3(10)>9(10)$ & $3(10)>9(10)$ & $4(10)>9(10)$ \\
\hline & & & & & & \\
\hline \multirow{16}{*}{$\begin{array}{c}\text { B } \\
\text { REHABILITACIÓN } \\
\text { MEDIAOMBIETAL }\end{array}$} & \multirow{6}{*}{$\begin{array}{c}\text { B1.- } \\
\text { REHABILITACIÓN } \\
\text { DE ÁREAS VERDES }\end{array}$} & B1.1 Áreas verdes en entorno. ( $\mathrm{m} 2 \mathrm{hab})$. & $0(2) 1,9 m 2 h$ & $0(2) 1,9 m 2 h$. & $1(2) 15 \mathrm{~m} 2 \mathrm{~h}$. & $0(2) 2,4 m 2 h$. \\
\hline & & B1.2Áreas verdes en centro & 1 (1) $2939,4 \mathrm{~m} 2$ & $1(1) 40432 \mathrm{~m} 2$ & 1(1) $357415 \mathrm{~m} 2$ & 1 (1) $2463 \mathrm{~m} 2$ \\
\hline & & B1.3 Ratio asim. $\mathrm{CO} 2$ (e.u.) & 2 (3) $10,7 \%$ & $2(3) 53 \%$ & $3(3) 74,26 \%$ & 0 (3) $6,83 \%$ \\
\hline & & B1.4 Ratio Asim. CO2 (Ctro C.) & $0(3) 0,87 \%$ & $3(3) 68 \%$ & $3(3) 570 \%$ & $0(3) 6,25 \%$ \\
\hline & & B1.5 Distancia entre áreas verdes & 1 (1) $300 \mathrm{~m}$ & 0 (1) $500 \mathrm{~m}$ & $0(1) 400 \mathrm{~m}$ & 1 (1) $380 \mathrm{~m}$ \\
\hline & & PUNTUACIÓN & $2(10)>4(10)$ & $4(10)>6(10)$ & $4(10)>6(10)(E)$ & $1(10)>2(10)$ \\
\hline & & B2.1 Aridez del clima & 1 (1) no árido & 1 (1) no árido & 1(1) no árido & 0 (1) semiárido \\
\hline & REHABILITACIÓN & B2.2 Porcentaje de pav. absorbente $\%$ (ur. Env) & 1(4) $5,9 \%$ & $0(4) 4,61 \%$ & $1(4) 14,38 \%$ & 1(4) $5,18 \%$ \\
\hline & POR SUPERFICIE & B2.3 Instalaciones econ. Agua & 3 (3) todo tipo & 3 (3) todo tipo & 3 (3) todo tipo & 3 (3) todo tipo \\
\hline & ASIMILADORA & B2.4 Consumo agua visita & $2(2)<20$ l visit & $2(2)<201$ visit & $2(2)<201$ visit & $2(2)<20$ visit \\
\hline & AGUA & PUNTUACIÓN & $2(10)>7(10)$ & $2(10)>6(10)$ & $3(10)>6(10)$ & $1(10)>6(10)$ \\
\hline & & B3.1 Clima cálido & O (2) clima cálido & O (2) clima cálido & o (2) clima cálido & o (2) clima cálido \\
\hline & & B3.2 Frecuencia olas de calor & $1(1)$ no & 1(1) no & 1(1) no & 0 (1) si. \\
\hline & B3.-TRATAMIENTO & B3.3 Isla de calor en área del centro & $0(3)+4 \%$ i.c. & $0(3)+4^{\circ}$ i.c. & $0(3)+4^{\circ}$ i.c. & $0(3)+80_{i . c .}$ \\
\hline & & B3.4\% de superficie repelente de calor & 4 (4) $100 \%$ & $4(4) 100 \%$ & $4(4) 100 \%$ & $4(4) 100 \%$ \\
\hline & & PUNTUACIÓN & $1(10)>5(10)$ & $1(10)>5(10)$ & $1(10)>5(10)$ & $2(10)>4(10)$ \\
\hline & & & & & & \\
\hline & & C1.1 Cap. Residencial Ctro (\% of u. a. pop.) & $0(2) 3,5 \%$ & $0(2) 3,5 \%$ & $0(2) 3,5$ & $0(2) 3,5$ \\
\hline & C1.- & C1.2 Uso residencial en parcelas cercanas & 2 (3) $32 \%$ & $2(3) 33,89 \%$ & $3(3) 78,43 \%$ & 3 (3) $51,7 \%$ \\
\hline & USO RESIDENCIAL & C1.3 Uso residencial área urbana & $3(5) 40,12 \%$ & $3(5) 51,62 \%$ & $5(5) 81 \%$ & $3(5) 50,11 \%$ \\
\hline & & PUNTUACIÓN & $5(10)$ & $5(10)$ & $8(10)$ & $5(10)>6(10)$ \\
\hline & & C2.1 Uso productivo ctro & 1 (1) Oficinas R. F. & 1(1) comisaría & 1(1) comisaría & 1 (1) uso añadido \\
\hline & & C2.2 Uso productivo parcelas residenciales & 3 (3) $58,24 \%$ & $3(3) 49,7 \%$ & $3(3) 18,76 \%$ & $3(3) 30 \%$ \\
\hline REHABILITACIÓN POR & USO PRODUCTIVO & C2.3 Uso productivo área urbana & $5(6) 30 \%$ & $5(6) 29,86 \%$ & $1(6) 7,97 \%$ & $5(6) 30 \%$ \\
\hline INSERCIÓN DE USOS & & PUNTUACIÓN & $9(10)$ & $9(10)$ & $4(10)>5(10)$ & $8(10)>9(10)$ \\
\hline & & C3.1 Presencia de uso dotacional en centro & 1(1) Oficinas R. F. & 1(1) act. añadida & 1(1) act. Añadida & 1(1) act. Añadida \\
\hline & C3.- & C3.1 Presencia de uso dotacional en p. proximas & 4 (4) 1er rango. & 1(4) 3er rango & 1 (4) 3er rango & 2 (4) 20 rango \\
\hline & USO DOTACIONAL & C3.3 dotaciones a $1 \mathrm{~km}$ del centro & 5 (5) 1er rango & 5 (5) 1er rango & 5 (5) 1er rango & 5 (5) 1er rango \\
\hline & & PUNTUACIÓN & $10(10)$ & $5(10)>7(10)$ & $6(10)>7(10)$ & $7(10)>8(10)$ \\
\hline & & & & & & \\
\hline & & D1.1 Transporte público a centro & 1 (1) si & $1(1) s i$ & 1 (1) si & $1(1) \mathrm{si}$ \\
\hline & & D1.2 Eficacia tte público & 3 (3) alta. & 2 (3) media & 1 (3) baja. & o (3) nada. \\
\hline & D1.-TRANSPORTE & D1.3 Cobertura tte público en área & $2(2) 96 \%$ & $1(2) 52 \%$ & 1 (2) $50 \%$ & $2(2) 72 \%$ \\
\hline & EFICIENTE & D1.4 Zonificación de usos & 2 (2) ninguna. & $1(2)$ media & $\begin{array}{l}\text { o (2) usos zonificados } \\
\text { (n) }\end{array}$ & $\begin{array}{l}2 \text { (2) ninguna } \\
\text { ning }\end{array}$ \\
\hline & & D1.5 instalaciones mo. S. en ctro. & 0 (2) ninguna & 0 (2) ninguna & 0 (2) ninguna & 1 (2) algunas \\
\hline & & PUNTUACIÓN & $8(10)$ & $5(10)$ & $3(10) E->2(10)$ & $6(10)$ \\
\hline & & D2.1 Ratio óptimo de densidad población & 3 (4) alta densidad & 2 (4) densidad insuf. & 2 (4) densidad insuf. & 3 (4) alta densidad. \\
\hline & & D2.2 Densidad área construida & 2 (3) Alta & 2 (3) Media & 2 (3) Media & 2 (3) Media \\
\hline & D2.- DENSIDAD & D2.3 Ratio de cobertura de edificios (\%) & $3(3) 67 \%$ & $3(3) 51 \%$ & $3(3) 69 \%$ & $3(3) 67 \%$ \\
\hline$D$ & & PUNTUACIÓN & $8(10)$ & $7(10)$ & $7(10)$ & $8(10)$ \\
\hline REHABILITACIÓN EN & & D3.1 Elementos negativos en área & $0(1) s i$ & $0(1) s i$ & 0 (1) si & 1(1) no \\
\hline $\begin{array}{l}\text { ÁREA URBANA } \\
\text {. }\end{array}$ & & D3.2 Puntos fríos de día & $1(1)$ no & $1(1)$ no & 0 (1) si & $1(1)$ no \\
\hline & & D3.3 Puntos fríos de noche & $0(1)$ si & $\mathrm{o}(1)$ si & $\mathrm{o}(1)$ si & 1(1) no \\
\hline & & D3.4 Áreas $\sin$ coltrol visual & $\mathrm{o}(1) \mathrm{si}$ & 1(1) no & $\mathrm{o}(1) \mathrm{si}$ & $1(1)$ no \\
\hline & D3.- PASEABILIDAD & D3.5 Sensación de seguridad en área & $\mathrm{o}(1)$ no & $0(1)$ no & $\mathrm{o}(1)$ no & $1(1) s i$ \\
\hline & YSEGURIDAD & D3.6 Fachadas activas (\% long. fachada) & $1(2) 49 \%$ & $1(2) 31 \%$ & 0 (2) $16 \%$ & $2(2) 58 \%$ \\
\hline & & D3.7 Distancia a edificio resid. Cercano & 1 (1) $80 \mathrm{~m}$ & 1(1) $20 \mathrm{~m}$ & o (1) $500 \mathrm{~m}$ & $1(1) 100 m$ \\
\hline & & D3.8 Ratio espacio libre en área & $1(1) 33 \%$ & $1(1) 51 \%$ & $1(1) 40 \%$ & $1(1) 50 \%$ \\
\hline & & D3.9 Ratio de mezcla de usos & 1 (1) usos mezclados & 1 (1) usos mezclados & 1(1) usos mezclados & 1(1) usos mezclados \\
\hline & & $\begin{array}{l}\text { PUNTUACIÓN } \\
\text { PUTC }\end{array}$ & $5(10) E->6(10)$ & $5(10)>6(10)$ & $1(10)$ & $10(10) E->11(10)$ \\
\hline & & & & & & \\
\hline $\mathrm{E}$ & & $\begin{array}{l}\text { E1 Índice atracción ctro } \\
\text { E2 Puntuación en D1, transporte eficiente }\end{array}$ & $\begin{array}{l}3(5) \\
8(10)\end{array}$ & $\begin{array}{l}3(5) \\
5(10)\end{array}$ & $\begin{array}{l}5(5) \\
3(10)\end{array}$ & $\begin{array}{l}3(5) \\
7(10)\end{array}$ \\
\hline P. RELACIONADAC & CON ACTIVIDAD & PUNTUACIÓN & +1 a D3 & No & $-1>\mathrm{D} 1 ;-2>\mathrm{B} 1$ & +1 a D3 \\
\hline
\end{tabular}




\begin{tabular}{|c|c|c|c|c|c|c|}
\hline \multicolumn{3}{|c|}{ RESULTADO OPERACIONES REHABILITACIÓN } & \multirow{2}{*}{$\frac{\mid \text { C5. L. Vaguda }}{1(1)}$} & \multirow{2}{*}{$\begin{array}{l}\text { C6. P.S. } \\
1(1)\end{array}$} & \multirow{2}{*}{$\begin{array}{l}\text { C7. Belmar } \\
1(1)\end{array}$} & \multirow{2}{*}{$\begin{array}{l}\text { C8. M.O.A. } \\
1(1)\end{array}$} \\
\hline \multirow{14}{*}{$\begin{array}{c}\text { A } \\
\text { REHABILITACIÓN } \\
\text { ECOEFICIENTE }\end{array}$} & \multirow{5}{*}{$\begin{array}{c}\text { A1.- } \\
\text { INSTALACIONES } \\
\text { POCO EMISIVAS }\end{array}$} & A1.1 Adecuación a d. Givoni & & & & \\
\hline & & A1.2 Emisiones $\mathrm{CO} 2$ (Eur.Union) & 3 (4) $B$ & $3(4) B$ & $3(4) \mathrm{C}$ & $3(4) \mathrm{C}$ \\
\hline & & A1.3 Obsolescencia & $1(1)$ & $1(1)$ & $1(1)$ & $1(1)$ \\
\hline & & A1.4 Consumo energético (Eur.Union) & $3(4) \mathrm{C}$ & $3(4) \mathrm{C}$ & $3(4) C$ & $3(4) C$ \\
\hline & & PUNTUACIÓN & $6(10)>8(10)$ & $6(10)>8(10)$ & $6(10)>8(10)$ & $6(10)>8(10)$ \\
\hline & \multirow{4}{*}{$\begin{array}{c}\text { A2.- SISTEMAS } \\
\text { SOLARES ACTIVOS }\end{array}$} & A2.1 Uso S. Activos & $1(4) 10 \%$ & $1(4) 10 \%$ & $2(4) 30 \%$ & $0(4) n o$ \\
\hline & & A2.2 Iso energías renovables (centro) & $1(4) 4 \%$ & 1(4) $5,6 \%$ & $2(4) 20 \%$ & 1 (4) $10 \%$ est. \\
\hline & & A2.3 Adecuación a d. Givoni & $2(2)$ & $2(2)$ & $2(2)$ & $2(2)$ \\
\hline & & PUNTUACIÓN & $3(10)>4(10)$ & $3(10)>4(10)$ & $5(10)>6(10)$ & $1(10)>3(10)$ \\
\hline & \multirow{5}{*}{$\begin{array}{c}\text { A3.- SISTEMAS } \\
\text { SOLARES PASIVOS }\end{array}$} & A3.1 Adecuación bioclimatica (Olgyay) & 2 (2) adec. & $2(2)$ & $2(2)$ & $2(2)$ \\
\hline & & A3.2 Efficiencia de cerramientos & 3 (4) eficiente & 3 (4) eficiente & 3 (4) eficiente & 3 (4) eficiente \\
\hline & & A3.3 Uso de luz natural (\% área edificada) & $2(2)$ & $2(2)$ & $2(2) 83,53 \%$ & $2(2)$ \\
\hline & & A3.4 Adecuac. digrama Givoni & $2(2)$ & $2(2)$ & $2(2)$ & 2 (2) adecuado \\
\hline & & PUNTUACIÓN & $7(10)>9(10)$ & $5(10)>9(10)$ & $7(10)>9(10)$ & $7(10)>9(10)$ \\
\hline & & & & & & \\
\hline \multirow{10}{*}{$\begin{array}{c}\text { B } \\
\text { REHABILITACIÓN } \\
\text { MEDIAOMBIETAL }\end{array}$} & \multirow{5}{*}{\begin{tabular}{|c} 
B1.- \\
REHABILITACIÓN \\
DE ÁREAS VERDES
\end{tabular}} & B1.1 Áreas verdes en entorno. ( $\mathrm{m} 2 \mathrm{hab})$. & $0(2) 2 m 2 h$ & $0(2) 8,2 m 2 h$ & $2(2) 158 \mathrm{~m} 2 \mathrm{~h}$ & $2(2) 1135 \mathrm{~m} 2 \mathrm{~h}$ \\
\hline & & B1.2Áreas verdes en centro & $1(1) 45982 \mathrm{~m} 2$ & 1(1) $193767 \mathrm{~m} 2$ & 1(1) $1445663 \mathrm{~m} 2$ & 1 (1) $210434 \mathrm{~m} 2$ \\
\hline & & B1.3 Ratio asim. CO2 (e.u.) & $1(3) 11,23 \%$ & 1 (3) $32,8 \%$ & 3 (3) $486 \%$ & 3 (3) $185 \%$ \\
\hline & & B1.4 Ratio Asim. CO2 (Ctro C.) & 3 (3) $596 \%$ & 3 (3) $2612,8 \%$ & $3(3) 99,36 \%$ & 2(3) $33,25 \%$ \\
\hline & & B1.5 Distancia entre áreas verdes & 1 (1) $200 \mathrm{~m}$ & $1(1) 380 \mathrm{~m} 2$ & 1 (1) $200 \mathrm{~m}$ & 1 (1) $100 \mathrm{~m}$ \\
\hline & \multirow{5}{*}{$\begin{array}{l}\text { B3.-TRATAMIENTO } \\
\text { ISLA DE CALOR }\end{array}$} & B3.1 Clima cálido & 0 (2) cálido & 0 (2) cálido & 1 (2) moderado & 2 (2) fresco \\
\hline & & B3.2 Frecuencia olas de calor & 0 (1) si. & o(1) si. & $\mathrm{o}(1) \mathrm{si}$ & 1(1) no \\
\hline & & B3.3 Isla de calor en área del centro & $0(3)+50 h . i$. & $1(3)+29$ & $2(3)+10$ & $0(3)+49$ \\
\hline & & B3.4\% de superficie repelente de calor & 4 (4) $100 \%$ & $4(4) 100 \%$ & 4 (4) $100 \%$ & $4(4) 100 \%$ \\
\hline & & PUNTUACIÓN & $4(10)$ & $1(10)>5(10)$ & $4(10)>6(10)$ & $3(10)>7(10)$ \\
\hline & & & & & & \\
\hline & & C1.1 Cap. Residencial Ctro (\% of u. a. pop.) & $0(2) 3,5$ & $0(2) 3,9$ & 2 (2) $21,5 \%$. & 2 (2) $188 \%$ visit. \\
\hline & & C1. 2 Uso residencial en parcelas cercanas & 3 (3) $52,18 \%$ & 3 (3) $83,53 \%$ & $3(3) 73,7 \%$ & 3 (3) $51,68 \%$ \\
\hline & USO RESIDENCIAL & C1.3 Uso residencial área urbana & $5(5) 79,83 \%$ & $4(5) 68,31 \%$ & $4(5) 69,32 \%$ & $2(5) 35,97 \%$ \\
\hline & & PUNTUACIÓN & $7(10)>8(10)$ & $7(10)$ & $8(10)>9(10)$ & $4(10)>7(10)$ \\
\hline & & C2.1 Uso productivo ctro & 1 (1) si & $1(1) s i$ & 1 (1) si & 1 (1) uso p. añadido \\
\hline & C2.- & C2.2 Uso productivo parcelas residenciales & 3 (3) $30 \%$ & $2(3) 13,65 \%$ & $3(3) 16 \%$ & $3(3) 20 \%$ \\
\hline REHABILITACIÓN POR & USO PRODUCTIVO & C2.3 Uso productivo área urbana & $2(6) 11,15 \%$ & $3(6) 16,96 \%$ & $3(6) 14 \%$ & $6(6) 45,2 \%$ \\
\hline INSERCIÓN DE USOS & & PUNTUACIÓN & $6(10)$ & $2(10)>7(10)$ & $7(10)$ & $9(10)>10(10)$ \\
\hline & & c3.1 Presencia de uso dotacional en centro & $1(1)$ correos & 1(1) act. Añadida & 1 (1) algunas & 1(1) act. Añadida \\
\hline & C3.- & C3.1 Presencia de uso dotacional en p. proximas & 3 (4) 1er rango & 1(4) 3er rango & 4 (4) muy visitadas. & 1 (4) 3errango \\
\hline & USO DOTACIONAL & C3.3 dotaciones a $1 \mathrm{~km}$ del centro & $5(5)$ 1er rango & $4(5)$ rango local alto & 2 (5) rango local & 2 (5) rango local \\
\hline & & PUNTUACIÓN & $9(10)$ & $4(10)>6(10)$ & $7(10)$ & $1(10)>4(10)$ \\
\hline & & & & & & \\
\hline & & D1.1 Transporte público a centro & 1(1) si & 1(1) si & 1(1) si & 1(1) si \\
\hline & D1.-TRANSPORTE & $\begin{array}{l}\text { D1.2 Eficacia tte público } \\
\text { D1.3 Cobertura tte público en área }\end{array}$ & $\begin{array}{l}1 \text { (3) baja } \\
2 \text { (2) } 86 \%\end{array}$ & $\begin{array}{l}0 \text { (3) nada efic. } \\
2(2) 70 \%\end{array}$ & $\begin{array}{l}0 \text { (3) nada efic. } \\
0 \text { (2) less } 50 \%\end{array}$ & $\begin{array}{l}0 \text { (3) nada efic. } \\
0 \text { (2) less } 50 \%\end{array}$ \\
\hline & 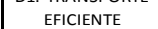 & D1.4 Zonificación de usos & $2(2)$ no. & $2(2)$ no & 0 (2) zonificados & 0 (2) zonificados \\
\hline & & D1.5 instalaciones mo. S. en ctro. & $2(2)$ si & $2(2) \mathrm{si}$ & 1 (2) algunas & 0 (2) ninguna \\
\hline & & PUNTUACIÓN & $8(10)$ & $7(10)$ & $2(10) E->1(10)$ & $1(10) E->0(10)$ \\
\hline & & D2.1 Ratio óptimo de densidad población & 3 (4) densidad alta. & 3 (4) densidad alta. & 0 (4) dens.muy baja & 0 (4) dens.muy baja \\
\hline & & D2.2 Densidad área construida & 3 (3) óptima. & 3 (3) óptima & o (3) baja & 0 (3) baja \\
\hline & D2.- DENSIDAD & D2.3 Ratio de cobertura de edificios (\%) & 1 (3) $22 \%$ & 1 (3) $28 \%$ & $1(3) 21 \%$ & 1 (3) $21 \%$ \\
\hline$D$ & & PUNTUACIÓN & $7(10)$ & $7(10)$ & $1(10)$ & $1(10)$ \\
\hline REHABILITACIÓN EN & & D3.1 Elementos negativos en área & 1 (1) no & $0(1) s i$ & 1 (1) no & $1(1)$ no \\
\hline ÁREA URBANA & & D3.2 Puntos fríos de día & 1 (1) no & 1(1) no & $0(1) s i$ & 0 (1) si. \\
\hline & & D3.3 Puntos fríos de noche & $0(1)$ si & $\mathrm{o}(1)$ si & $\mathrm{O}(1)$ si & o (1) si. \\
\hline & & D3.4 Áreas $\sin$ coltrol visual & 1(1) no & 1(1) no & 1(1) no & $0(1) s i$ \\
\hline & D3.- PASEABILIDAD & D3.5 Sensación de seguridad en área & $1(1)$ segura & $1(1)$ segura & $1(1)$ segura & 1(1) segura \\
\hline & YSEGURIDAD & D3.6 Fachadas activas (\% long. fachada) & $1(2) 32 \%$ & $0(2) 3,73 \%$ & $0(2) 7,96 \%$ & $0(2) 23,59 \%$ \\
\hline & & D3.7 Distancia a edificio resid. Cercano & $1(1) 90 \mathrm{~m}$ & $0(1) 350 m$ & 1 (1) $R$. in mall & 1(1) $150 \mathrm{~m}$ \\
\hline & & D3.8 Ratio espacio libre en área & $0(1) 79 \%$ & $0(1) 71,5 \%$ & $0(1) 79 \%$ & 0 (1) $79 \%$ \\
\hline & & D3.9 Ratio de mezcla de usos & 1(1) usos mezclados & 1(1) usos mezclados & 1(1) usos mezclados & 1(1) usos mezclados \\
\hline & & $\begin{array}{l}\text { PUNTUACIÓN } \\
\text { PUTC }\end{array}$ & $7(10) E->9(10)$ & $4(10) E->5(10)$ & $4(10)>5(10)$ & $3(10)>4(10)$ \\
\hline & & & & & & \\
\hline $\mathrm{E}$ & & $\begin{array}{l}\text { E1 Índice atracción ctro } \\
\text { E2 Puntuación en D1, transporte eficiente }\end{array}$ & $\begin{array}{l}4(5) \\
8(10)\end{array}$ & $\begin{array}{l}4(5) \\
7(10)\end{array}$ & $\begin{array}{l}3(5) \\
2(10)\end{array}$ & $\begin{array}{l}5(5) \\
1(10)\end{array}$ \\
\hline P. RELACIONADAC & CON ACTIVIDAD & PUNTUACIÓN & +2 to $D 3$ & +1 to $D 3$ & $-1>\mathrm{D} 1 ;-1>\mathrm{B} 1$ & $-1>D 1 ;-2>B 1$ \\
\hline
\end{tabular}

Figure 6.4.1: Tabla de puntuaciones después de las operaciones de rehabilitación Fuente: Elaboración propia. Todas las puntuaciones alteradas están marcadas en gris, las puntuaciones finales por sector, están marcadas en verde.

Los resultados de esta operación dieron lugar a los siguientes gráficos de rosas de rehabilitación (Figura 6.4.2): 
(A3) (B1)

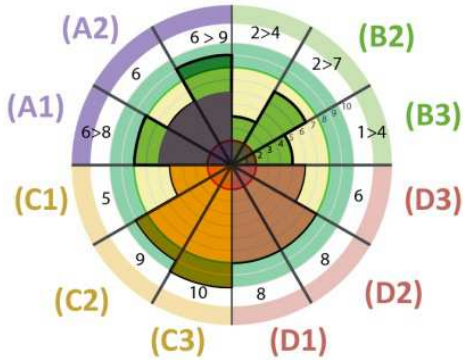

SHOPPING LIGHT

(A3) (B1)

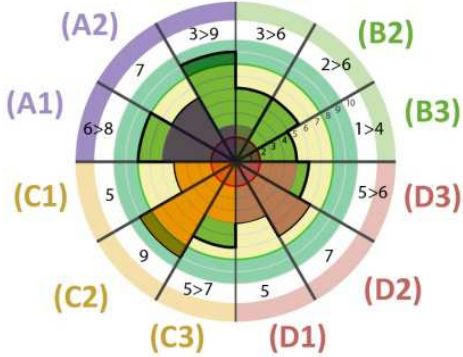

SHOPPING ELDORADO

(A3) (B1)

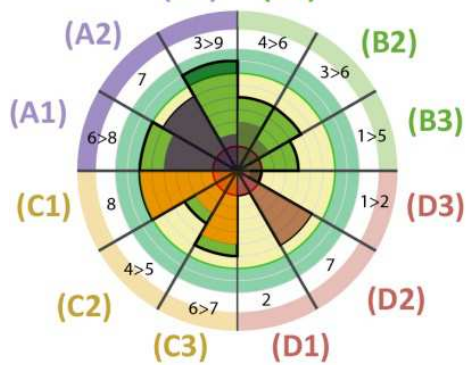

SHOPPING ARICANDUVA

(A3) (B1)

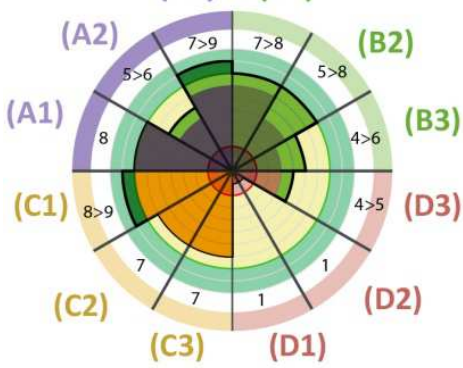

BELMAR
(A3) (B1)

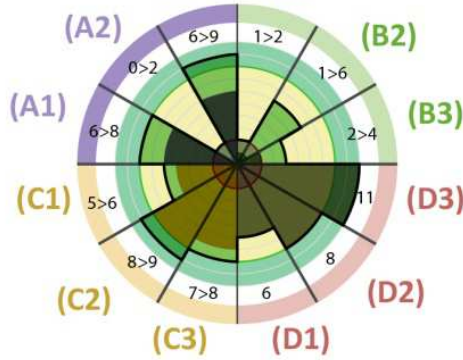

ABC SERRANO

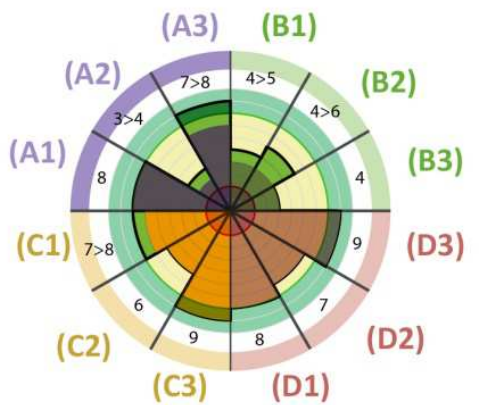

LA VAGUADA

(A3) (B1)

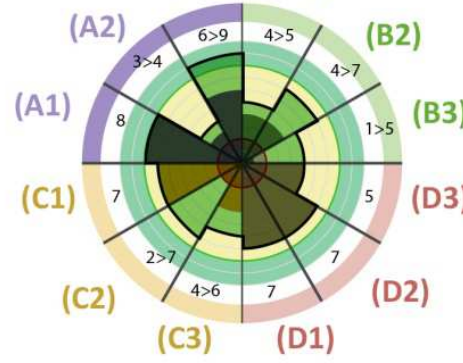

PARQUESUR

(A3) (B1)

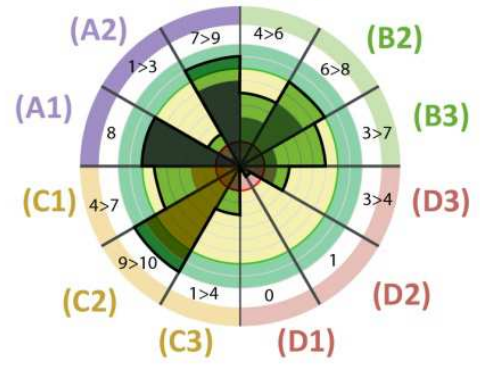

MALL OF AMERICA
(A) REHABILITACIÓN ECOEFICIENTE

(A1) Instalaciones poco emisivas

(A2) Medidas activas

(A3) Medidas pasivas

(B) REHABILITACIÓN MEDIAOMBIENTAL

(B1) Inserción de áreas verdes

(B2) Superficie asimiladora de agua

(B3) Tratamiento isla calor

(C) REHABILITACIÓN DE USOS Y DOTACIONES

(C1) Uso residencial

(C2) Uso productivo

(C3) Servicios y dotaciones

(D) REHABILITACIÓN DE ÁREAS URBANAS (D1) Transporte sosteible $y$ eficiente (D2) Densidad

(D3) Seguridad y paseabilidad

UMBRALES

2 puntos: Umbral de minimos,

Rehabilitación prioritaria

8 puntos: Situación Óptima

Rehabilitación nada prioritaria

10 puntos: Paradigma verde

ZONAS E INTERVALOS

0-2 puntos: rehabilitación

muy prioritaria

2-8 puntos: rehabilitación

de prioridad de media a

moderada

8-10 puntos: rehabilitación

no prioritaria.

Figura 6.4.2: Gráficos de rosas de rehabilitación sostenible tras las operaciones de rehabilitación. Fuente: Elaboración propia

De este modo, tenemos los siguientes resultados relacionados con las medidas de rehabilitación, los cuales van a ser desarrollados en base al contexto urbano de los centros comerciales. 
Para los casos relacionados con los centros ubicados en contextos urbanos de gran densidad (Shopping Light y ABC Serrano), las operaciones de rehabilitación más eficientes son las que están relacionadas con la mejora de la calidad medioambiental (B), esto se debe a las carencias medioambientales, derivadas de los entornos urbanos con grandes superficies pavimentadas, intensa actividad y carencias de zonas verdes, (falta de absorción de agua por parte del terreno, altas emisiones y baja capacidad de absorción de las mismas en la zona y problemas de isla de calor). En cambio las operaciones de rehabilitación en usos o entorno urbano son ineficientes debido a la mezcla de usos de ese tipo de zonas y las altas densidades que garantizan la viabilidad de medios de transporte energéticamente eficientes.

No obstante es necesario analizar las medidas de rehabilitación de forma pormenorizada. En relación con la asimilación de aguas y la mitigación de la isla de calor, la inserción de estas medidas exclusivamente en el centro comercial no es suficiente para producir un cambio drástico. Esto es debido a que, la superficie del centro comercial en sí cubre en los dos casos analizados como máximo un 5,9\% del área urbana analizada. Por consiguiente las mejoras medioambientales logradas mediante la rehabilitación del centro van a ser escasas, siendo también escasa la mejora en el ratio de emisiones (no más de un 0,07\% en relación a las emisiones del área urbana, y un $1 \%$ en relación a las emisiones del centro). Con lo que va a ser necesario la aplicación de las medidas de rehabilitación medioambiental a escala generalizada en el área urbana.

En relación con los casos ubicados en los centros expandidos (Shopping Eldorado y la Vaguada), las operaciones de rehabilitación que van a resultar más eficaces, son las relacionadas con la calidad medioambiental, ya que estas zonas tienen prácticamente los mismos problemas que los centros densos. Sin embargo, los centros comerciales analizados en este contexto tienen mayores superficies de cubierta y parcela, de modo que la inserción de elementos verdes puede llegar incluso a resultar en la creación de un sumidero de dióxido de carbono, si lo que es el centro comercial en sí, tiene un bajo ratio de emisiones. por ejemplo, la teórica rehabilitación verde sobre Shopping Eldorado, ha supuesto un incremento del 21 al 68\% en la asimilación de las emisiones generadas por el propio centro, y en el caso de La Vaguada, este ratio se ha incrementado del $36 \%$ al $400 \%$. No obstante, este ratio de emisiones, todavía es escaso respecto a las emisiones de área urbana, (se ha producido un incremento de un 2-3\% a lo sumo). Con lo que también es necesaria la aplicación de medidas de rehabilitación verde en el contexto urbano. Respecto a la rehabilitación de usos, o de contexto urbano para estos casos, éstas van a resultar ligeramente más eficaces que en los centros comerciales de entorno urbano denso, pero estas deben de plantearse como actuaciones de carácter secundario.

Para los casos localizados en las periferias próximas de las ciudades, o ciudades dormitorio (Aricanduva y Parquesur) Los resultados y efectos de las operaciones de rehabilitación, son idénticos a los obtenidos en el contexto del centro expandido. Sin embargo, las reformas aplicadas hacia la calidad medioambiental han tenido mejores resultados, debido a que ambos centros poseen grandes superficies de parcela y cubierta. Por ejemplo, la cobertura con elementos verdes de ambos centros analizados, ha sido capaz de aumentar el ratio de asimilación de dióxido de carbono en más de un 500\% respecto a las emisiones del centro comercial, siendo posible además asimilar hasta un $70 \%$ de las emisiones del área urbana 
cercana (no considerando el transporte). Además, la inserción de usos en estos contextos ha resultado ser efectiva, debido a la zonificación de los mismos, sobre todo en las parcelas adyacentes al centro. Por ejemplo, en el caso de Parquesur, la inserción de usos productivos ha supuesto un incremento de la complejidad urbana, debido a la ausencia de este uso tanto en el centro comercial como en las parcelas adyacentes. (del $1 \%$ al $13,65 \%$ ).

En relación con la Norteamérica suburbana, (Mall of America y Belmar) las operaciones mejor resultantes han sido las relacionadas con la inserción de usos en el centro comercial, sobre todo si el mismo está ubicado en una zona en la que predomina un único uso (alrededores de Mall of America). Sin embargo, la inserción de elementos verdes o reformas orientadas hacia la calidad medioambiental, aunque no ha sido especialmente relevante debido a la cantidad de áreas verdes en la zona, ha hecho que estos centros analizados obtengan la calificación de caso óptimo debido a las grandes superficies de estos centros, cuya reforma ha supuesto un incremento en el ratio de emisiones.

Sin embargo, en relación con las operaciones de rehabilitación enfocadas en la ecoeficiencia del edificio del centro, han resultado muy eficaces en todos los casos, independientemente del contexto urbano, haciendo incluso que centros con bajas puntuaciones en este aspecto (Shopping Eldorado, Aricanduva y Parquesur), hayan mejorado su ecoeficiencia de forma relevante (incrementos en el sector A3 de la rosa de hasta 6 puntos). Por consiguiente la rehabilitación en la ecoeficiencia del centro va a resultar eficaz, mientras el objetivo no implique temas de sostenibilidad urbana o medioambiental ajenos a la parcela del centro comercial.

\subsection{4.- Efectos de las medidas de reforma puestos en común, y relevancia de las mismas.}

Este capítulo, ofrece una vista resumida de los efectos de las operaciones teóricas de rehabilitación estudiadas anteriormente. Se analizarán los incrementos en las puntuaciones medias. (Figura 6.4.3). Se va a considerar la aplicación de todas las operaciones de rehabilitación de forma simultánea.

En una vista general relacionada con las puntuaciones medias, los casos que han mejorado de forma más considerable son Shopping Eldorado y Aricanduva, en estos casos cualquier operación planteada ha tenido resultados relevantes. Opuestamente a esto, los centros comerciales en los cuales las operaciones han sido menos eficaces, son los casos de La Vaguada y Belmar, los cuales corresponden a centros que han considerado programas de rehabilitación, y por consiguiente algunas de las medidas han resultado incluso ineficaces. Por consiguiente en estos casos va a ser más eficaz rehabilitar las deficiencias del entorno urbano, antes que el centro en sí.

No obstante, los centros que tienen serias deficiencias en algún ámbito, tales como Shopping Light, ABC Serrano, Aricanduva y Eldorado en asimilación de agua por el terreno, y tratamiento de isla de calor. Parquesur en lo relativo a uso productivo o Mall of America en uso residencial. 
Es fácil obtener una mejora relevante, incluso si se centran las operaciones de rehabilitación en el ámbito anteriormente mencionado.

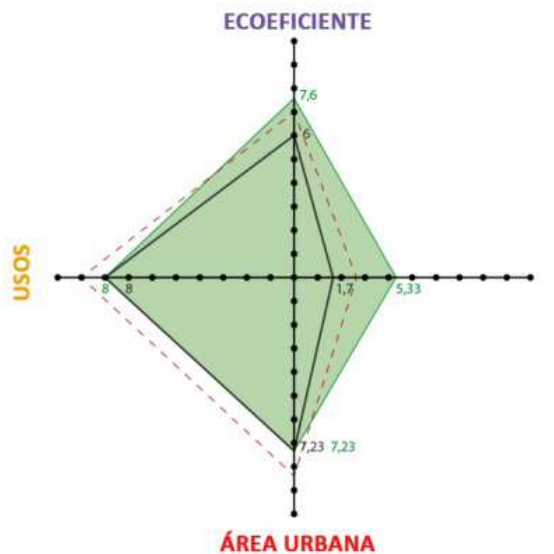

SHOPPING LIGHT

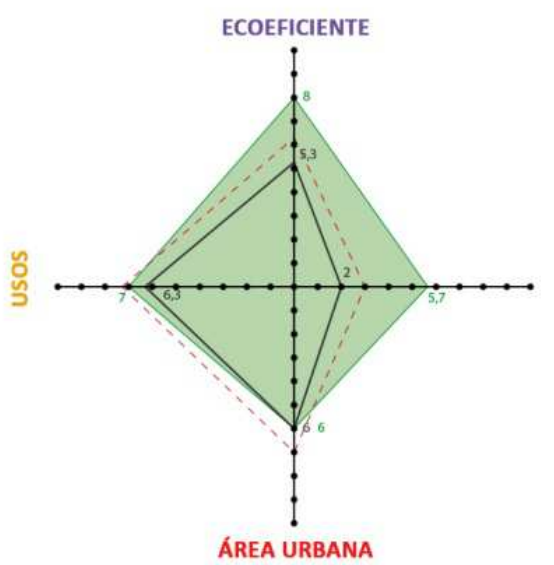

SHOPPING ELDORADO

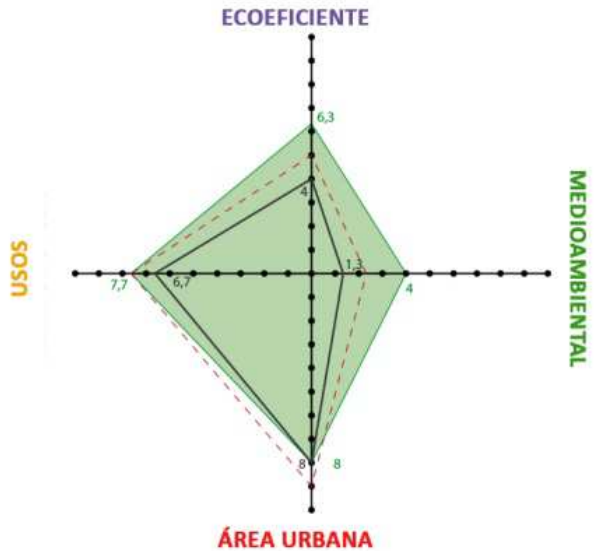

ABC SERRANO

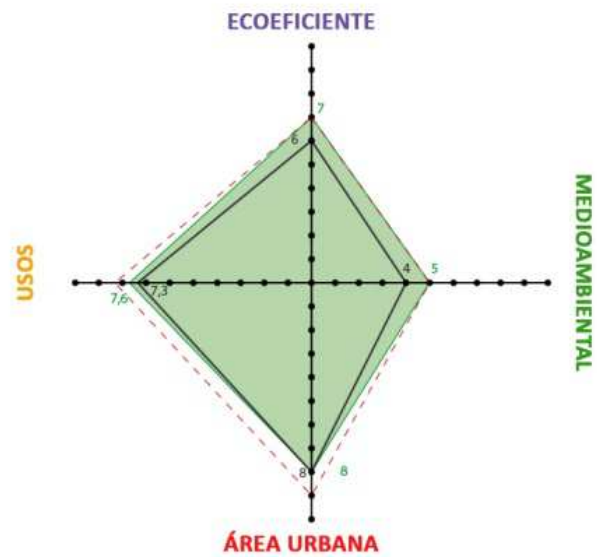

LA VAGUADA 


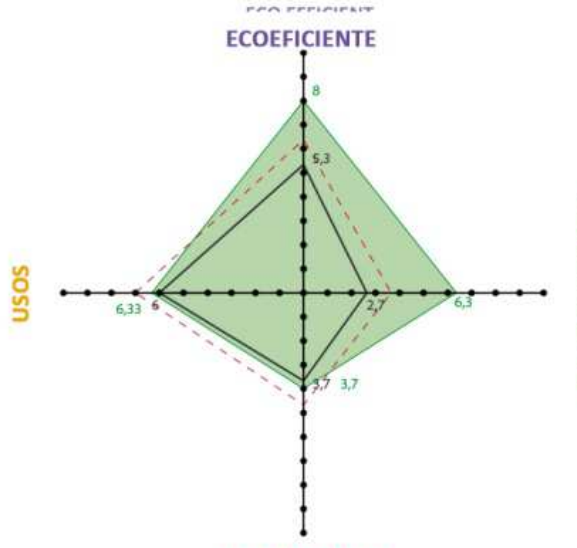

ÁREA URBANA

\section{SHOPPING ARICANDUVA}

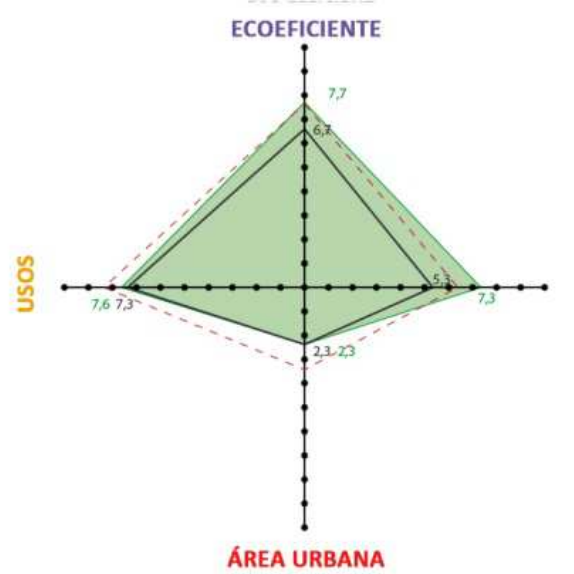

BELMAR

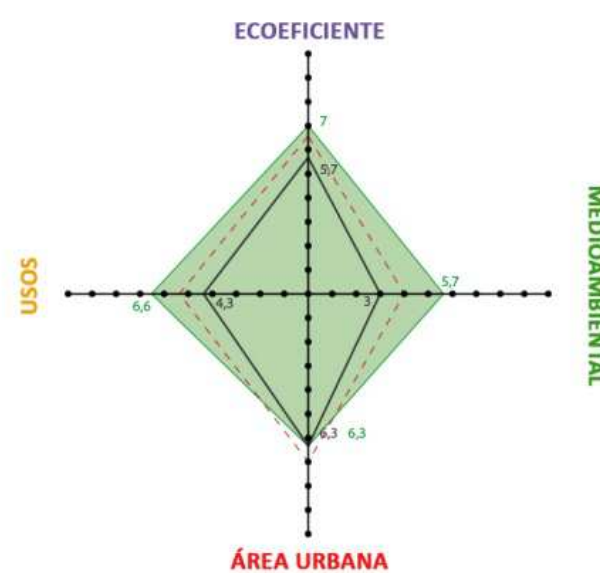

PARQUESUR

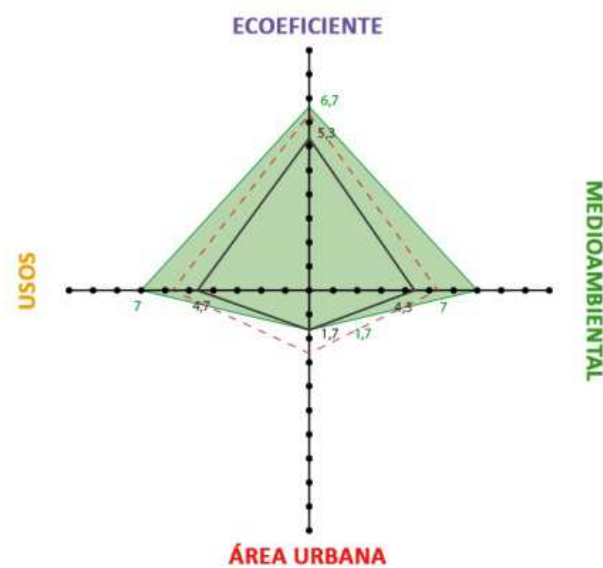

MALL OF AMERICA

PUNTUACIONES MEDIAS

CENTRO NO REHABILITADO

UMBRAL DE RELEVANCIA

PUNTUACIONES MEDIAS

CENTRO REHABILITADO

Figura 6.4.3: Comparación de las medias por familia de medios de rehabilitación, antes y después de las operaciones teóricas estudiadas. Fuente: Elaboración propia.

\section{5.- CONCLUSIONES FINALES, PREGUNTAS DE INVESTIGACIÓN E HIPÓTESIS.}

Para concluir la tesis, y establecer las conclusiones, las preguntas de investigación van a ser aclaradas de acuerdo a los resultados del análisis de centros comerciales. 


\subsection{1.- Respuesta a la pregunta de investigación.}

¿La rehabilitación de los centros comerciales, tanto en el ámbito urbanístico, como en el medioambiental, traería consigo una mejora relevante del medio ambiente urbano?.

A pesar de que el análisis de la rehabilitación urbana hacia la sostenibilidad es un asunto complejo, que no va a depender de un edificio en particular como es el centro comercial. No obstante, este tipo de edificios, en los casos no céntricos es una anomalía en el tejido urbano. Considerando los estudios comparativos considerados en el capítulo anterior, la rehabilitación sostenible de un centro comercial va a suponer en mayor o menor medida una mejora en la sostenibilidad urbana. No obstante estos efectos van a estar limitados a una parte muy concreta de la ciudad, y a ciertos aspectos de la sostenibilidad urbana dependiendo de las características del programa de rehabilitación.

Las medidas de rehabilitación basadas en la eco eficiencia del centro comercial, y la aplicación de energías activas y pasivas, tienen el objetivo de reducir la dependencia energética del centro en fuentes externas, llegando incluso al uso de energías renovables. No obstante, esta reducción no va a suponer un incremento considerable, si se considera la ciudad en su totalidad.

Los casos de Sao Paulo analizados, en lo referente a energías activas, tienen mejor calificación en el cuestionario (6-7 puntos), debido al uso generalizado de la energía hidroeléctrica en Sao Paulo, de acuerdo a la Agencia Internacional de la Energía ICLEI. Belmar también sobresale en este aspecto (6 puntos) debido a la presencia de edificios LEED.

En relación a la inserción de zonas verdes, los centros comerciales, especialmente los que tienen gran superficie, pueden ser una buena oportunidad para la inserción de zonas verdes que pudieran en mayor o menor medida mitigar las emisiones del centro principalmente. Los caso de Aricanduva, La Vaguada y Parquesur, tras la rehabilitación aplicada, se posicionaron con un ratio de absorción de emisiones mayor al 500\% respecto de las emisiones del centro. Si el área urbana tiene baja densidad y abundancia de zonas verdes, este efecto va a expandirse al área urbana (La rehabilitación verde de Belmar y Mall of America ha hecho que el área urbana pueda asimilar algo más del $100 \%$ de sus emisiones, (sin considerar el impacto del transporte). En contraste a esto, estas áreas verdes no están destinadas a asimilar las emisiones de una ciudad al completo, siendo en muchos casos incluso incapaces de asimilar las emisiones del área urbana, si esta tiene una densidad ligeramente mayor a la de los suburbs norteamericanos. (En este campo, los casos más satisfactorios, han sido Parquesur, cuyo ratio de absorción del entrono urbano ha ascendido del 17 al 32\%, y Aricanduva, cuyo ratio ha ascendido del 7 al 74\%, debido a que hay muchas áreas de baja densidad en su área de influencia).

Sin embargo, resulta de importancia considerar la adaptación del pavimento y las superficies edificadas, de cara a la absorción de agua por el terreno, además de la mitigación de la isla de calor. Pero estas operaciones deben de considerarse a la escala amplia de la ciudad, para que tengan un efecto considerable y beneficioso. por poner un ejemplo, la rehabilitación teórica relacionada con la inserción de zonas verdes o para la asimilación de aguas, ha tenido las 
mejores puntuaciones en los casos en los que la calidad del aire es mejor, y las superficies pavimentadas son mínimas, tales como los casos de área urbana de Mall of America y Belmar (33-45\% de la superficie del área urbana es verde) en contraste con el escaso $2,6 \%$ del área circundante a Shopping Light. En estos dos casos de centro comercial suburbano, la rehabilitación verde, ha supuesto que obtengan puntuaciones de caso óptimo (8 puntos).

Pero de ningún modo la inserción de superficies reflectantes en todo el centro comercial, va a resultar suficiente para mitigar la isla de calor, que es mayor según la zona está más edificada (El caso más crítico es ABC Serrano con una isla de calor de +8 y y una superficie pavimentada del $91 \%$, siendo el caso menos crítico Belmar con una isla de calor de +19 , y una superficie pavimentada de un $70 \%$ a lo sumo).

En relación a la inserción de usos, esta operación de rehabilitación puede ayudar a componer en las parcelas próximas al centro comercial, un entorno urbano complejo, si la mezcla de usos es pobre. Por ejemplo, la reforma de usos aplicada en Belmar, ha supuesto en las parcelas próximas una mezcla de usos con un $52 \%$ de residencial y un $48 \%$ de no residencial, en contraste con Mall of America, en cuyas parcelas próximas la proporción de uso es de un 8\% de residencial, y un $92 \%$ de no residencial. En este aspecto, otro caso relevante es Parquesur cuyas parcelas anejas la rehabilitación de usos aplicada ha supuesto un aumento del uso productivo del $1 \%$ al $13 \%$. No obstante en escalas más amplias, esta actividad no va a alterar la configuración de la actividad urbana si la zona posee una cierta mezcla de usos. Tal como el caso de ABC Serrano o La Vaguada, en los cuales la inserción de usos ha supuesto una ligera variación de un $2 \%$ a lo sumo.

La excepción en la anterior afirmación son las áreas suburbanas en las que hay baja densidad y predominio de un solo uso. Bajo estas condiciones un cambio de usos puede dar lugar a un cambio relevante, tal como el incremento de los porcentajes de uso residencial en más de un $5-7 \%$ en las extensas áreas urbanas de influencia de Belmar y Mall of America. Por consiguiente, estos cambios van a suponer nuevas interacciones que necesitan ser controladas.

Para concluir, la rehabilitación de un centro comercial va a tener efectos: pero van a ser más relevantes en la parcela del centro comercial, y su entorno más inmediato. Considerando escalas urbanas más extensas, esta rehabilitación no resuelve ningún problema, aunque puede ayudar en ello. Esto significa que va a ser necesario rehabilitar mas edificios y áreas urbanas, además del centro comercial, para lograr una mejora relevante de cara a la sostenibilidad en la escala amplia de la ciudad.

\subsection{2.- Respuesta a la hipótesis 1.}

Se puede lograr una mejora en la revitalización del área urbana amplia, a través de la alteración del centro comercial y su parcela, mediante diferentes técnicas de rezonificación, adición o alteración de usos.

La respuesta de esta hipótesis es negativa: Como se estableció en la pregunta de investigación, es verdad que la inserción de usos va a mejorar la vitalidad urbana, pero esta se va a limitar a 
la escala inmediata de las parcelas cercanas (Se lograron cambios relevantes en la configuración de usos de las parcelas próximas, en los casos de Mall of America, Parquesur y Belmar, tras la teórica rehabilitación de usos). No obstante, este efecto no implica la revitalización de las áreas que están algo alejas del centro comercial. Para lograr una revitalización a gran escala urbana mediante la inserción de usos, es necesario aplicar esto en otras edificaciones ajenas al centro comercial, siendo importante además la optimización del transporte público y la movilidad sostenible. El hecho, es que el centro comercial reformado con los nuevos usos va a producir nuevas interacciones y desplazamientos, la cuales si no están resueltos de forma adecuada, pueden derivar en problemas serios de movilidad urbana, con su consecuente impacto ambiental. Por ejemplo, los centros comerciales estudiados, que tienen un alto número de visitas, y una baja eficacia del transporte público (Aricanduva, Belmar y Mall of America), estos factores se han traducido en un impacto negativo para sus respectivas puntuaciones respecto a la calidad medioambiental.

\subsection{3.- Respuesta a la hipótesis 2}

La aplicación de una única técnica de rehabilitación resultará insuficiente para poder producir una reducción relevante del impacto ambiental. Se hará necesaria la aplicación de varias técnicas de manera simultánea.

La respuesta es positiva dependiendo del caso. La razón de esto, es que de acuerdo a lo mostrado en la Rosa de Rehabilitación Sostenible, la variación de una puntuación en un sector localizado a veces no va a suponer una mejora relevante, y si lo hace es con una puntuación mínima de relevancia (1 punto a lo sumo). Sin embargo si el centro comercial tiene carencia críticas en lo relativo a un sector de la Rosa de Rehabilitación, la variación va a ser relevante, incluso si la rehabilitación está exclusivamente enfocada en la mejora de susodicho. por ejemplo, la rehabilitación centrada en las condiciones de asimilación y ahorro de agua (B2) en los casos de ABC Serrano y Shopping Light, ha supuesto un incremento en las puntuaciones de este sector en el gráfico de la Rosa de Rehabilitación Sostenible. Esto es debido a las carencias que tanto el centro, como el área urbana tienen a efectos de asimilación de aguas. Otros ejemplos, son Shopping Eldorado y Aricanduva, en los cuales la adaptación bioclimática del edificio, ha supuesto una relevante mejora en la ecoeficiencia ligada a medidas pasivas. La razón de esto, es que ambos centros no consideraron en su proyecto los condicionantes bioclimático (obtuvieron en análisis puntuaciones de cero en los análisis de Olgyay y Givoni relacionados). Sin embargo, es más recomendable las soluciones mixtas, intentando cubrir los máximos campos que se puedan, esto va a suponer mejores resultados, como puede comprobarse en el análisis de puntuaciones medias realizado (6.4.4).

\subsection{4.- Respuesta a la hipótesis 3.}

La rehabilitación de un centro comercial no va a ser suficiente para lograr una reducción del impacto ambiental en la escala de la ciudad. Esto significa que va a ser necesario la rehabilitación en un área urbana al completo. 
La respuesta a esta hipótesis es cierta. Considerando la escala urbana amplia, la rehabilitación de un centro comercial exclusivamente, no es suficiente para lograr una mejora en las condiciones medioambientales de una ciudad completa. Esto es desarrollado también en los párrafos relacionados con la pregunta de investigación, y la primera hipótesis en este capítulo. Esto significa que va a ser necesario la aplicación de medidas de rehabilitación en el área urbana de cara a este reto. De hecho es incluso más importante actuar en el entorno urbano antes que en un edificio en concreto, como es un centro comercial, sobre todo si el área urbana se caracteriza por tener baja densidad, usos zonificados y predominio del transporte particular. La evidencia de esto, es que los centros comerciales estudiados, cuyo entorno urbano cumple de manera parcial con los requerimientos de sostenibilidad de la metodología (usos y verde urbano), han obtenido la puntuación de caso óptimo en algunos sectores de la Rosa de Rehabilitación, después de la aplicación de las operaciones teóricas de rehabilitación: Aricanduva en áreas verdes, $A B C$ Serrano en usos públicos y dotaciones, La Vaguada en uso residencial, Belmar en áreas verdes y asimilación de aguas y Mall of America en asimilación de agua.

\section{6.- ANÁLISIS RETROSPECTIVO, FORTALEZAS Y DEBILIDADES DE LA METODOLOGÍA Y DE LA INVESTIGACIÓN.}

La metodología que se ha creado para la presente tesis, se buscó con el objetivo de dar una fotografía actual del estado de los centros comerciales de cara a las posibles medidas de rehabilitación, con el objetivo de hacer la función de guía para el enfoque de rehabilitacion los mismos.

\subsection{1.- Limitaciones de la investigación:}

-Debido al enfoque relativo que se ha dado, valoración cuantitativa, absoluta y real de los efectos de las medidas de rehabilitación; la presente metodología no es capaz de dar unos resultados finales con precisión. Esto se ha visto propiciado por la falta de datos reales, y la complejidad en los cálculos para la obtención de estas valoraciones. Proceso que a veces incluso puede llegar a requerir abordar temas más cercanos al proyecto arquitectónico, que no era el objetivo final de esta investigacion.

-Aunque las medidas de rehabilitación poseen una caracterización relativa, la ponderación y valoración real de los efectos medioambientales entre las mismas, no pudo ser realizado debido a lo explicado en el párrafo anterior. Esto supone que las valoraciones de las medidas de rehabilitación estudiadas, en principio se tratan de manera independiente sin estudiarse los efectos reales de las mismas. No obstante de cara a las conclusiones se realiza una media aritmética sencilla entre las medidas de rehabilitación por ámbito, pero el alcance de este estudio se queda en lo meramente orientativo para ver la mayor o menor eficacia de los métodos de rehabilitación que se implementen en cada caso. 
-La ausencia de datos para los centros comerciales estudiados, obligó al autor de la tesis a interpolar con modelos reales, utilizando otros datos fiables. Esto significa que algunos datos concretos de los centros comerciales no pudieron valorarse de manera real y absoluta.

-La metodología no aborda el tema económico, que es de gran importancia, por la falta de conocimientos del autor para efectuar una rehabilitación económica fiable en un centro comercial.

\subsection{2.- Fortalezas del método empleado.}

-La metodología sintetiza de forma precisa una realidad muy compleja, los centros comerciales de gran superficie y su interaccion con su entorno urbano, ofreciendo una analítica fácil y accesible para cualquier persona interesada en el tema. Aunque enuncia constantemente el tema de la rehabilitación de centros comerciales en casos concretos, en ningún momento se llega al proyecto de rehabilitacion de los mismos.

-Al ser consideradas las valoraciones a través de un baremo relativo, los resultados obtenidos en la aplicación de la metodología son accesibles y comprensibles, viéndose esta cualidad reforzada a través del uso de gráficos que refuerzan esta comprensión. Se sintetizan en la analítica características cuantitativas y cualitativas, y se busca dar a los resultados un enfoque cualitativo y gráfico, que resulta más rápido, accesible y comprensible para el lector, que los datos numéricos puros, y condicirán a la toma de prioridades.

-La ausencia de datos presente en varios análisis pudo paliarse mediante interpolaciones de datos verificados. (Superficies de entornos urbanos y centros comerciales, características del entorno urbano, tiempos de transporte, población, huella de carbono del entorno urbano, isla de calor, datos climáticos y absorción de dióxido de carbono de zonas verdes). La investigación profundiza en estos ámbitos.

-El estudio abarca el mayor número posible de tipologías de centros comerciales, condicionantes climáticos y áreas urbanas existentes en el mundo. Los resultados obtenidos en el análisis comparativo pueden ser extrapolados en mayor o menor medida para otros casos similares, y constituye una aportacion metodologica adecuada para establecer las acciones sobre los mismos, bajo los criterios de sostenibilidad.

-Se pudo ponderar de manera relativa los efectos de diversos factores de cara a la elaboración de los cuestionarios relativos a las medidas de rehabilitación. Estos cuestionarios sintetizan una realidad muy compleja, y por ende resultan sencillos de responder para obtener las valoraciones en las medidas de rehabilitación de los centros.

\section{7.- FUTUROS TRABAJOS DE INVESTIGACIÓN A PARTIR DE LA PRESENTE TESIS}

Los trabajos de investigación que pudieran resultar a partir de la presente tesis podrían enfocarse en cubrir las lagunas de las mismas, concretar en lo estudiado con precisión o la 
elaboración y aplicación de la metodología para otros tipos de edificios. De este modo se plantean las siguientes líneas de investigación:

-Ampliación de la metodología expuesta en la tesis, hacia el ámbito de la recuperación económica de los centros comerciales. Esta faceta que resulta de gran importancia no pudo abordarse en la tesis debido a la falta de conocimiento del autor la compleja realidad económica que es la de los centros comerciales. Los temas y medidas de rehabilitación que podrían abordarse dentro del mismo podrían ser la potenciación del valor añadido, el programa comercial, el estudio del mercado y sus características, el estado del centro frente a la realidad de mercado, la obsolescencia del negocio, el programa de márketing...

-Ampliación de la metodología expuesta en la tesis hacia el ámbito del proyecto del centro comercial como tema proyectual artístico. El tema del centro comercial como espacio arquitectónico, y su valoración artística, es un tema de interés para lo que es el estudio de la arquitectura contemporánea, siendo necesaria la aplicación de medidas de rehabilitación para corregir en mayor o menor medida los efectos agresivos del centro comercial. Los temas a valorar en este ámbito podrían ser la Jerde Transfer, la Gruen Transfer, la complejidad en la estructuración de los recorridos, la agresividad de la imagen interior y exterior, el enfoque, la repetición de espacios y formas entre los diferentes casos de centros...

-Ampliación de la metodología expuesta en la tesis hacia la remodelación del centro como condensador social. El tema social siempre está vigente en el urbanismo, siendo de interés cuando un centro comercial pierde su potencial de nodo de actividad, y es necesario darle otra función cómo parte de la ciudad. La inserción de pautas relacionadas con el tema de la sociedad en un centro comercial puede ser un buen indicativo hacia el que guiar las posibles rehabilitaciones. Los temas a abordar en ese ámbito podrían ser el estudio de los modos de vida, el potencial atrayente dentro de la ciudad, la adaptación del centro y sus actividades a las características de la población y su poder adquisitivo y nivel cultural, el estudio de la transformación de los usos considerando la evolución prospectiva de la población en el área urbana, y sus cambios en los hábitos de vida...

-Establecimiento de baremos y coeficientes de ponderación entre las medidas establecidas para la tesis de forma real. Esta futura línea de investigación, viene propiciada por las debilidades de la propia tesis, el tema de establecer un baremo concreto para valorar el estado de las medidas de rehabilitación de cara a un único valor, es un tema interesante, pero complicado de abordar, ya que intervienen muchos factores, los cuales también se basan en cálculos relativos debido a la imprevisibilidad en el comportamiento de una ciudad. Como complicación adicional, probablemente los coeficienctes de ponderación entre las medidas de rehabilitación enunciadas en la metodología, vayan a ser completamente diferentes en cada caso analizado, ya que cada centro y entorno urbano funcionan de diferente manera. Esta investigación se recomienda ser abordada sobre un caso concreto de centro comercial, del que se dispongan todos los datos requeridos para la metodología de la tesis, y haya sufrido una reforma en el ámbito de la sostenibilidad para de esta manera reforzar los coeficientes de ponderación de forma precisa. 
-Adaptación de la metodología de la tesis hacia otras tipologías de edificios de gran superficie. La presente metodología estudiada para los centros comerciales puede ser adaptada a otros tipos de edificios, el condicionante es que posean una cantidad considerable de metros cuadrados construídos. De este modo sería tema de interés esta readaptación hacia los siguientes temas:

-Edificios de las grandes dotaciones urbanas en su conjunto: Los edificios de la administración ejercen un poder de atracción muy elevado dentro de la ciudad, siendo fundamentales para el funcionamiento de la misma. Algunos de los edificios a considerar para esta investigación, serían los hospitales universitarios de primera jeraquía, campus universitarios o educativos, terminales de aeropuertos, cocheras del transporte público, grandes estaciones de tren, grandes centros sociales.

-Edificios de gran altura: los rascacielos de las grandes ciudades pueden suponer una oportunidad para acometer medidas de rehabilitación urbana al ser edificios con gran potencial de atracción, grandes superficies construídas y baja huella en el terreno.

-Edificios industriales: La industria, aunque beneficiosa para el desarrollo de una ciudad, es una actividad con una huella de carbono muy elevada, especialmente en los países en vías de desarrollo. El interés de esta investigación, residiría en la posibilidad de reducción de las emisiones de la industria, y la transformación de los polígonos industriales insalubres, en zonas más respetuosas con el medio ambiente.

-Grandes edificios residenciales: Este tipo de edificios, aunque no son habituales, siempre están presentes en muchas ciudades del planeta. La rehabilitación de esta tipología de cara a la sostenibilidad es un tema de interés, siendo un factor motivador la estigmatización de este tipo de complejos residenciales en numerosos contextos urbanos, al estar a veces asociados con los problemas sociales.

-Adaptación de la metodología a conjuntos urbanos. La metodología expuesta en la presente tesis doctoral, centrada en la tipología concreta del centro comercial, también puede ser adaptada a un conjunto urbano en sí, formado por un mayor o menor conjunto de edificaciones. De este modo puede resultar muy interesante establecer una pauta analítica de valoración de la sostenibilidad, y para la rehabilitación de diferentes tipologías de barrios dentro de la ciudad. Estos barrios a estudiar pueden ser los centros históricos, los polígonos residenciales y PAUs, los centros financieros, los ensaches burgueses, los suburbs... incluso los llamados Power centers formados por un conjunto de hipermercados y centros comerciales.

\section{8.- EPÍLOGO}

El tema de la rehabilitación sostenible de los centros comerciales y sus problemas de sostenibilidad urbana, fueron el punto de partida para desarrollar una metodología para evaluar las medidas de rehabilitación existentes. La aplicación de esta metodología en diferentes casos de centros comerciales, puso en evidencia que la rehabilitación de los mismos puede ser una medida eficiente de cara a la sostenibilidad a ser considerada. No obstante esta 
no puede solucionar los problemas medioambientales de una ciudad al completo. Como se vio en el capítulo del estado de la cuestión relacionado con el proceso de proyecto de un centro comercial, tanto las dimensiones del mismo, como su configuración, van a depender de las facetas del entorno urbano. Esto significa, que las operaciones de rehabilitación sostenible a ser aplicadas en el centro, deberían de proyectarse considerando las facetas tanto del edificio del centro comercial, cómo del área urbana de influencia. Ya que el centro en sí forma parte de un entorno urbano complejo. 


\section{7.- BIBLIOGRAFÍA}

\section{1.- URBANISMO SOSTENIBLE Y REHABILITACIÓN URBANA}

libros.

A+T RESEARCH GROUP (2015) WHY DENSITY? Desmontando el mito de la sandía cúbica (Serie Densidad). Vitoria Gasteiz: A+T Architecture Publishers.

ÁREA DE VIVIENDA Y URBANISMO DEL AYUNTAMIENTO DE MADRID, AYUNTAMIENTO DE MADRID (2009): Buenas Prácticas En Arquitectura Y Urbanismo Para Madrid. Madrid. 197 Páginas

AYUNTAMIENTO DE SEVILLA, RUEDA SALVADOR. ET AL. (2006) Plan Especial de Indicadores de Sostenibilidad Ambiental de la Actividad Urbanística de Sevilla. Sevilla: Ayuntamiento de Sevilla.

CÁRDENAS JIRÓN LUZ ALICIA, HIGUERAS GARCÍA ESTER. (2015), El Barrio Solar. Madrid: Mairea Libros, Polytechnic University of Madrid. ISBN 978-84-944528-2-6.

DEL RÍO SÁNCHEZ, ROGER (1989) Curso De Urbanismo De Áreas Comerciales. Madrid: Colegio Oficial De Arquitectos de Madrid.

EMPRESA MUNICIPAL DE LA VIVIENDA (1999) Áreas de Rehabilitación Preferente, Intervenciones en el centro histórico y barrios periféricos de Madrid (España). Madrid: Ayuntamiento de Madrid. ISBN 978-84-935142-5-9.

EZQUIAGA DOMÍNGUEZ, JOSE MARÍA, GONZÁLEZ ALFAYA,LUCIANO. (2011) Transformaciones Urbanas Sostenibles. Madrid: Universidad Internacional Menéndez Pelayo. 275 páginas. ISBN: 9788493937706.

RED ESPAÑOLA DE CIUDADES POR EL CLIMA (2015) Medidas para la mitigación y la adaptación al cambio climático en el planeamiento urbano, Guía metodológica. Madrid: Federación Española de Municipios y Provincias. Dep. Legal M-17301-2015.

HERNÁNDEZ AJA, AGUSTín (1997) La Ciudad de los Ciudadanos. Madrid: Universidad politécnica de Madrid.

HIGUERAS, ESTER. (2007): Urbanismo Bioclimático. Barcelona: Gustavo Gili. 241 páginas. ISBN: 9788425220715

HIGUERAS GARCÍA ESTER, NEILA JAVIER (2012) Urbanismo Solar, manual de buenas prácticas para Vitoria Gasteiz. Vitoria: Council of Vitoria Gasteiz, Polytechnic University of Madrid.

HIGUERAS GARCÍA ESTER (2009) El Reto De La Ciudad Habitable Y Sostenible. Madrid: Editorial DAPP

HIGUERAS GARCÍA ESTER (2009) La Rehabilitación Ecológica Y Bioclimática De La Ciudad Consolidada. (Artículo resumen del anterior libro mencionado). 
J. STROMANN ANDERSEN; P.A.SATTRUP (2011) The urban canyon and building energy use: Urban density versus daylight and passive solar gains. Lyngby: Department of Civil Engineering, Technical University of Denmark.

JENKS, MICHAEL, JONES COLLINS (2010). "Dimensions of the Sustainable City". Londres y Nueva York. Springer Dordrecht Heidelberg. ISBN 978-1-4020-8646-5(HB) e-ISBN 978-1-4020-8647-2 ISBN 978-1-4020-8645-8(PB).

JORNET, SEBASTIÁ; ET AL. (2006) La Rehabilitación de la Ciudad Existente, El Plan Especial de Reforma y Reordenación del Barrio de La Mina y Documentos Complementarios. Barcelona, Consorcio del barrio de La Mina.

$\begin{array}{llll}\text { NEW } & \text { YORK } & \text { CITY } & \text { GOVERNMENT: }\end{array}$ http://www.nyc.gov/html/planyc/html/home/home.shtml.M.

PHILINE, GAFFRON; ET AL. (2008) Proyecto Ecocity, Manual para el Diseño de Ecociudades en Europa. Viena: Facultas Verlags- und Buchhandels AG

TUMINI, IRINA; ET AL. (2016) Urban microclimate and thermal comfort modeling: strategies for urban renovation. Published In The International Journal Of Sustainable Building Technology And Urban Development.

VÁZQUEZ ESPÍ MARIANO (2010) Reducción de la Insostenibilidad Mediante la Rehabilitación Urbana. Madrid: Biblioteca Ciudades Para un Futuro Más Sostenible. http://habitat.aq.upm.es/.

\section{Artículos.}

ALCOFORADO MARIA JOAO, ET AL. (2009). Application of Climatic Guidelines to Urban Planning. The example of Lisbon (Portugal). Research Gate.

FARIÑA TOJO, JOSÉ. (Octubre de 2000) Naturaleza Urbana. MADRID

FARIÑA TOJO, JOSÉ. (2013) Rehabilitación Arquitectónica y regeneración Urbana . Zaragoza: Monografías de la Revista Aragonesa de Administración Pública 26 ISSN 1133-4797, XV, pp. 15 26

SILVEIRA ,GUILHERME; ET AL. (2014) Definindo melhores práticas em projetos de Regeneração Urbana Sustentável. Guimarães: Universidade do Minho.

HERNÁNDEZ AJA, AGUSTÍN. (16 de octubre de 2000): La Ciudad Estructurada. Madrid HIGUERAS, ESTER. (Octubre de 1997) Urbanismo Bioclimático. Criterios Medioambientales En La Ordenación De Asentamientos.

JENKS MIKE, COLIN JONES (2010) Dimensions of the Sustainable City. New York, Springer Dordrecht Heidelberg London New York.

JIMÉNEZ ROMERA, CARLOS. (2007): Calidad De Vida. Madrid 
LÓPEZ RODRÍGUEZ, BORJA. (2007) Influencia de los estándares urbanísticos en los nuevos desarrollos residenciales. Madrid: Biblioteca Ciudades Para un Futuro Más Sostenible.

PORTILLA, GÓMEZ ET AL. (2014) La Regeneración Urbana Integrada, Una Respuesta a la Crisis Urbana. Santander: ETS Ingenieros de Caminos, Canales y Puertos, Universidad de Cantabria.

RUEDA PALENZUELA SALVADOR, (1999) Modelos E Indicadores Para Ciudades Mas Sostenibles. Rubí, Barcelona: Departament de Medi Ambient de la Generalitat de Catalunya, Fundació Fórum Ambiental.

RUEDA PALENZUELA SALVADOR, (1999?) Un nuevo urbanismo para una ciudad más sostenible. Barcelona: Consorci Universitat Internacional Menéndez Pelayo Barcelona.

RUEDA PALENZUELA SALVADOR, ET AL., (2009) Plan de Indicadores de Sostenibilidad Urbana de Vitoria-Gasteiz. Barcelona, Vitoria Gasteiz: Agencia de Ecología Urbana de Barcelona, Ayuntamiento de Vitoria Gasteiz.

VAZQUEZ ESPÍ, MARIANO (2010). "Reducción de la Insostenibilidad Mediante la Rehabilitación Urbana". Madrid, Biblioteca Ciudad Para un Futuro Más Sostenible

WILSON, JEFFREY S.; ET AL. (2002) Evaluating environmental influences of zoning in urban ecosystems with remote sensing. Indianapolis, Department of Geography, Indiana UniversityPurdue University, 425 University Boulevard. 01/2003; DOI: 10.1016/S0034-4257(03)00084-1.

XIAOSHAN, YANG; ET AL. (2012) An integrated simulation method for building energy performance assessment in urban environments. Guangzhou: South China University of Technology.

\section{Tesis Doctorales.}

CHISTINA MIANA ANNA, (2010) Adensamento e forma Urbana: Inserção de Parâmetros Ambientais no Processo de Projeto. São Paulo: Universidade de São Paulo.

\section{2.- PLANEAMIENTO URBANO Y TEORÍA DEL URBANISMO}

\section{Libros:}

BERTA, LILIANA; FRANCHINI, TERESA (1992) Planeamiento Urbano, procedimiento y Acción. Madrid: Dyckinson. ISBN 84-88030-27-4.

CHUECA GOITIA FERNADO (1968) Breve Historia del urbanismo. Madrid: Alianza Editorial, ISBN 84-206-3519-7.

LYNCH, KEVIN. (1985): LA BUENA FORMA DE LA CIUDAD. Barcelona: Gustavo Gili. 364 páginas. ISBN:8425212081. [Edición original: (1981) A Theory Of Good City Form. Cambridge, Massachusetts: Mit Press.] 
MOYA, LUIS. (2011): LA PRÁCTICA DEL URBANISMO. Madrid: Síntesis. 389 páginas. ISBN:9788497567305.

M R. PANERAI PHILLIPE, CASTEX JEAN, DEPAULE JEAN CHARLES. (1986): FORMAS URBANAS: DE LA MANZANA AL BLOQUE. Barcelona: Gustavo Gili. 209 páginas. ISBN: 842521291X.

SOLÁ MORALES, MANUEL. (2005): DIEZ LECCIONES SOBRE BARCELONA. Barcelona: Col Legi D’Arquitectes de Catalunya. 578 páginas. ISBN:9788496842243.

\section{Artículos.}

EWERTON, ROSA (2011): Shopping Centers e Condomínios Fechados: Fragmentação, Homogeneização e Hierarquização na Cidade Contemporânea, Published in the Page Urbanidades. http://urbanidades.arq.br/2011/09/shopping-centers-e-condominios-fechadosfragmentacao-homogeneizacao-e-hierarquizacao-na-cidade-contemporanea/

\section{3.- REHABILITACIÓN DE EDIFICIOS}

Libros.

ABRUDAN IOANNA, ET AL. (2009).The Life Cycle Of Shopping Centers And Possible Revitalization Strategies. Oradea: Facultatea de Stiinte Economice, Faculty of Economic Sciences.

ALCALDE PECERO, FRANCISCO. (2003): BANCO DE DETALLES ARQUITECTÓNICOS. Sevilla: Editorial Díaz de Santos. 368 páginas. ISBN: 8460738604.

K. WEILER, SUSAN, SCHOLZ-BARTH, KATRIN. (1986): GREEN ROOF SYSTEMS, A GUIDE TO THE PLANNING, DESIGN, AND CONSTRUCTION OF LANDSCAPES OVER STRUCTURE. Nueva York: John Willey and Sons Inc. 313 páginas. ISBN: 9780471674955.

MARTÍNEZ, ANDRÉS. (2005): HABITAR LA CUBIERTA, Dweling On The Roof. Barcelona: Gustavo Gili. 205 páginas. ISBN: 8425219892.

\section{Artículos.}

B. BASS, B. BASKARAN, (2003). Evaluating Rooftop and Vertical Gardens as an Adaptation Strategy for Urban Areas, Institute for Research and Construction, NRCC-46737, Project number A020, CCAF Report B1046, Ottawa, Canada, National Research Council.

CHUNG-YI CHUNG, PEI-LING CHUNG (2011) Assessment of Carbon Dioxide Reduction Efficiency Using the Regional Carbon Neutral Model-A Case Study in University Campus. Pingtung (Taiwan): Tajen University, Published in Scientific Research Publishing Inc, Taiwan 
E.A. EUMORFOPOULOU*, K.J. KONTOLEON (2009), Experimental approach to the contribution of plant-covered walls to the thermal behavior of building envelopes, Building and Environment Journal, vol. 44, pp. 1024-1038

GANDER, MARK (2013) Green Parking, Sustainable Urban Mobility and Placemaking. New York, AECOM.

GRAUS, RAMÓN (2005): La Cubierta Plana, Un Paseo Por Su Historia. Barcelona: Universidad Politécnica de Cataluña y Texsa. 12 páginas

J.C. DENARDO, ET AL., (2005). Stormwater mitigation and surface temperature reduction by green roofs. American Society of Agricultural Engineers 48, 1491-1496.

KIDD, JOSH. (2005): OPTIMUM GREEN ROOF FOR BRISBANE. BRISBANE: GREENROOFS.COM.

K.L. GETTER EA. Carbon Sequestration Potential Of Extensive Green Roofs

NYUK HIEN WONG, ET AL. (2009), Energy simulation of vertical greenery systems, Building and Environment Journal, vol. 41, pp. 1401-1408

THE GREEN ROOF RESEARCH CENTRE . improving air and water quality. Sheffield: University Of Sheffield

YAGÜE JOSE MARÍA (2010)Revitalización Vs Rehabilitación. Segovia, IE University.

\section{4.- URBANISMO DE PERIFERIAS DE BAJA DENSIDAD}

Libros.

BHATTA BASUDEB. (2010): Analysis of Urban Growth and Sprawl from Remote Sensing Data. New York: Springer International Publishing A.G. ISBN 978-3-642-05299-6.

BRACCO SERGIO. (1988): LOS SISTEMAS METROPOLITANOS DE LAS NUEVAS CIUDADES. Oikos Tau. 143 Páginas.

DUNHAM JONES, ELLEN; WILLIAMSON, JUNE. (2011). Retrofitting Suburbia, Urban Solutions For Redesigning Suburbs. Hobokey, New Jersey, U.S.: John Willey and Sons. ISBN 978-0-47093432-6.

HARRIS RICHARD (1999): Changing Suburbs, Foundation Form And Function. E y Fn Spon.280 Páginas

LÓPEZ DE LUCIO RAMÓN (1996). Cuadernos De Investigación Urbanística № 14: El Comercio En La Periferia Sur Metropolitana De Madrid: Soportes Urbanos Tradicionales Y Nuevas Centralidades. Madrid: Escuela Técnica Superior de Arquitectura de Madrid. 58 Páginas

7.4.2.-ARTÍCULOS: 
CONGRESS FOR THE NEW URBANISM, (2005) Malls Into Mainstreets. Published in the webpage of the Congress For the New Urbanism.

https://www.cnu.org/sites/files/mallsintomainstreets.pdf

CONGRESS FOR THE NEW URBANISM, (2008) Canons Of Sustainable Architecture And Urbanism A Companion To The Charter Of The New Urbanism. Published in the webpage of the Congress For the New Urbanism https://www.cnu.org/sites/default/files/Canons_0.pdf

CONGRESS FOR THE NEW URBANISM (2001) Greyfields Into Goldfields. San Francisco: Congress for the New Urbanism.

NAREDO, JOSÉ MANUEL. (30 Julio 1997): Sobre La Insostenibilidad De Las Actuales Conurbaciones Y EI Modo De Paliarla.

\section{5.- TEMAS Y CONCEPTOS DE PROYECTO}

Libros.

AUGÉ MARC (1992): "Los No Lugares, Espacios Del Anonimato". Gedisa. 125 Páginas

BENÉVOLO LEONARDO (2002) Historia de la Arquitectura Moderna, 8a edición Revisada y ampliada. Barcelona: Gustavo Gili.

HOWARD, EBENEZER, (1902) "Ciudades Jardín del Mañana". Londres.

KOOLHAS REM, HARVARD PROYECT ON THE CITY, ET AL. (2000). "Mutaciones" .Barcelona: Actar.

NAVASCUÉS, PALACIO PEDRO (1969). "La Ciudad Lineal de Arturo Soria". Madrid

NEUFERT ERNST, NEUFERT PETER (1991) Arte de Proyectar en Arquitectura (Trigesimotercera edición). Barcelona: Gustavo Gili

\section{Artículos}

BIANCHINNI F, WEISS SUSSEX G. (2006) Urban Mindscapes of Europe, European Studies № 23, Brill-Rodopi, Leyden; Netherlands.

UTZON, JORN. (1962): PLATAFORMAS Y MESETAS. Milán: Revista Zodiac nํ10,

\section{6.- EFICIENCIA MEDIOAMBIENTAL Y ENERGÉTICA}

Libros.

BREEAM INTERNATIONAL (2102) BREEAM Communities Technical Manual SD 202. United Kingdom. 
CONSEJERÍA DE OBRAS PÚBLICAS Y TRANSPORTE, DIRECCIÓN GENERAL DE ORDENACIÓN DEL TERRITORIO Y URBANISMO. (2001): ESTIMACIÓN DE LA HUELLA ECOLÓGICA EN ANDALUCÍA Y APLICACIÓN A LA AGLOMERACIÓN URBANA DE SEVILLA. Sevilla: Junta de Andalucía. 144 páginas. ISBN: 8480952709.

COMISIÓN EUROPEA (2011) Evaluación de la pobreza energética en Bélgica, España, Francia, Italia y Reino Unido. EPEE Project WP2- Deliverable 6.

D. MEADOWS, ET AL. (1972). "The Limits to Growth". Cambridge, Nueva York. MIT, Signet Books.

EUROPEAN UNION (1999) A Green Vitruvius. Principles and practice of sustainable architectural design.

FIGUEROA CLEMENTE, MANUEL ENRIQUE, SUÁREZ INCLÁN, LUIS MIGUEL. (2009): CIUDAD Y CAMBIO CLIMÁTICO, 707 MEDIDAS PARA LUCHAR CONTRA EL CAMBIO CLIMÁTICO DESDE LA CIUDAD. Sevilla: Universidad de Sevilla, Muñoz Moya Editores. 351 páginas. ISBN: 9788480101783.

FIGUEROA CLEMENTE, MANUEL ENRIQUE, SUÁREZ INCLÁN, LUIS MIGUEL. (2009): LOS SUMIDEROS NATURALES DE CO2: UNA ESTRATEGIA SOSTENIBLE ENTRE EL CAMBIO CLIMÁTICO $Y$ EL PROTOCOLO DE KYOTO DESDE LAS PERSPECTIVAS URBANA Y TERRITORIAL. Sevilla: Universidad de Sevilla, Muñoz Moya Editores. 218 páginas.

GREEN BUILDING COUNCIL ESPAÑA. Metodología VERDE. Madrid: GBCe

MINISTERIO DE FOMENTO (2010). 8 Catálogo Español de Buenas Prácticas Para Mejorar las Condiciones de Vida. Madrid: Gobierno de España. ISBN 978-84-498-0890-6.

MINISTERIO DE MEDIO AMBIENTE Y MEDIO RURAL Y MARINO. (2008): La Huella Ecológica De España. Madrid: Ministerio de Medio Ambiente y Medio Rural y Marino. 66 páginas. ISBN: 9788449109133.

OLGYAY VICTOR (1998): ARQUITECTURA Y CLIMA. Barcelona: Gustavo Gili, 1963. 201 Páginas.

U.S. GREEN BUILDING COUNCIL (1993) LEED Methodology. Washington DC: U.S. Green Building Council.

Tesis doctorales.

GÓMEZ DE PEROZO, NERSA (2012)Estrategias Para El Control Microclimático Del Espacio Entre Edificaciones En Clima Cálido Húmedo. Madrid: Universidad Politécnica de Madrid, Universidad de Zulia.

Artículos.

ALLEGRINI, JONAS; ET AL. (2012) Influence of the urban microclimate in street canyons on the energy demand for space cooling and heating of buildings. Dübendorf: Laboratory for Building 
Science and Technology, Swiss Federal Laboratories for Materials Science and Technology (Empa).

AYUNTAMIENTO DE MADRID. (2005): Diagnóstico De Sostenibilidad De La Ciudad De Madrid. Madrid

BUILDING AND CONSTRUCTION AUTHORITY, SINGAPORE. (2010) Existing Building Retrofit. Singapore, Building And Construction Authority, ISBN 978-981-08-5238-2

CARBAJAL, MICAELA. INVESTIGACIÓN SOBRE LA ABSORCIÓN DEL CO2 POR LOS CULTIVOS MÁS REPRESENTATIVOS DE LA REGIÓN DE MURCIA. Madrid: CSIC.

CENTRO DE ACTIVIDAD REGIONAL PARA LA PRODUCCIÓN DE LIMPIA, (2008) LAS EMISIONES DE GASES DE EFECTO INVERNADERO DESDE LA PERSPECTIVA DEL CONSUMO EN UNA ECONOMÍA GLOBAL, EXPERIENCIA PILOTO EN EL MEDITERRÁNEO.

GÓMEZ DE PEROZO NERSA, HIGUERAS ESTER. Microespacio Urbano Entre Edificaciones En Clima Calido-Humedo. Saarbrucken, Maracaibo: Publicia OmniScriptum GmbH \& Co, University of Zulia. ISBN-0: 3639556844 ISBN-13: 978-3639556841 (2014).

HERNÁNDEZ AJA, AGUSTÍN (Noviembre de 2003): INFORME SOBRE LOS INDICADORES LOCALES DE SOSTENIBILIDAD UTILIZADOS POR LOS MUNICIPIOS ESPAÑOLES FIRMANTES DE LA CARTA DE AALBORG. Madrid

JIMÉNEZ HERRERO LUIS M. MANUAL DE CÁLCULO Y REDUCCIÓN DE HUELLA DE CARBONO EN EL SECTOR DEL COMERCIO. Alcalá de Henares: Observatorio De La Sostenibilidad En España

JIMÉNEZ HERRERO LUIS M. MANUAL DE CÁLCULO Y REDUCCIÓN DE HUELLA DE CARBONO PARA ACTIVIDADES DE TRANSPORTE POR CARRETERA. Alcalá de Henares: Observatorio De La Sostenibilidad En España

OFICINA CATALANA DEL CAMBI CLIMATIC. (2011): GUÍA PRÁCTICA PARA EL CÁLCULO DE EMISIONES DE GASES DE EFECTO INVERNADERO. Barcelona: Generalitat De Catalunya

RIEZNIK LAMANA, NATALIA, HERNÁNDEZ AJA, AGUSTíN. (Julio de 2005): HUELLA ECOLÓGICA. Madrid

SOSTENIBILIDAD EN ESPAÑA (2009) Capítulo 22 Transporte, Página 372. (Autor Desconocido)

TREVILCOCK M. (2011) Percepción de Barreras a la Incorporación de Criterios de Eficiencia Energética en las Edificaciones. Revista de la Construcción, Volume 10, April 2011 p 4-14. http://dx.doi.org/10.4067/S0718-915X2011000100002.

\section{7.- ARQUITECTURA BIOCLIMÁTICA}

Libros. 
NEILA, JAVIER. (2004) ARQUITECTURA BIOCLIMÁTICA EN UN ENTORNO SOSTENIBLE. Madrid: Editorial Munilla Lería. 443 páginas. ISBN: 9788489150645.

Artículos.

DE LUXÁN GARCÍA DE DIEGO, MARGARITA. (1996): Arquitectura Integrada En El Medio Ambiente. Madrid.

DE LUXÁN GARCÍA DE DIEGO, MARGARITA. Posibilidades y resultados de la rehabilitación sostenible Valencia: Instituto Valenciano de la Edificación.

NEILA, JAVIER. (Octubre de 2000): Arquitectura Bioclimática En Un Entorno Sostenible: Buenas Prácticas Edificatorias. Madrid.

\section{8.- EDIFICIOS DE GRAN CONTENEDOR Y CENTROS COMERCIALES}

Libros.

CASARIEGO RAMÍREZ JOAQUÍN, LEY BOSCH PABLO (2006):LAS ÁREAS COMERCIALES COMPLEJAS. Las Palmas de Gran Canaria: Universidad de Las Palmas de Gran Canaria, 2006. 105 Páginas.

DE HEREDIA RAFAEL. (1981) ARQUITECTURA Y URBANISMO INDUSTRIAL, DISEÑO Y CONSTRUCCIÓN DE PLANTAS, EDIFICIOS Y POLÍGONOS INDUSTRIALES. Madrid: Escuela Técnica Superior de Ingenieros Industriales, Universidad Politécnica de Madrid. 490 páginas. ISBN: 847894-017-1.

DIRECCIÓN GENERAL DE INDUSTRIA, ENERGÍA Y MINAS DE LA COMUNIDAD DE MADRID (2010) Guía de Auditorías Energéticas en Centros Comerciales. Madrid: Fenercom, Consejerías de la Comunidad de Madrid.

DIRECCIÓN GENERAL DE INDUSTRIA, ENERGÍA Y MINAS DE LA COMUNIDAD DE MADRID (2010) Guía de Buenas prácticas Energéticas en galerías y Centros Comerciales. Madrid: Fenercom, Consejerías de la Comunidad de Madrid.

DURRY JOLYON. (1981) FACTORIES, PLANNING, DESIGN AND MODERNIZATION. Nueva York: Nichols Publishing Company ISBN 0-89397-113-8. Londres: The Architectural Press 253 páginas. ISBN: 0851393020.

FAJARDO JULIO (2009) MEGAMALLS, CENTROS COMERCIALES. Reditar Libros,2009. 215 páginas.

FERRIER JACKES. (1987) USINES. Paris: Editions du Moniteur. 119 páginas. ISBN: 2-281-19031-5. [Edición original: (1987). Milan Paris, Electa France. 
GRUEN VICTOR (1973) CENTERS FOR THE URBAN DEVELOPEMENT. Nueva York: Van Nostrand Reinhold Company, Victor Gruen Foundation for the environmental planning, Lilton Educational Publishing. 255 Páginas.

HILL JIM. (2005): CAR PARK DESIGNERS HANDBOOK. Londres: Thomas Telford Publishing. 211 páginas. ISBN: 0727734385.

JIM Mc CLUSKEY. (1990): PARKING, MANUAL DE DISEÑO AMBIENTAL. Versión castellana. Barcelona: Santiago Castán, Gustavo Gili. 279 páginas. ISBN:84-252-1425-4. [Edición original: (1987) Parking, a Handbook of Environmental Design. Londres, E\&FN.]

N. KEITH SCOTT (1989): SHOPPING CENTER DESIGN. Nueva York: Van Nostrand Reindhold, 1989. 216 Páginas

PETERS PAULHANS. (1974): ESTABLECIMIENTOS COMERCIALES. Barcelona: Gustavo Gili. 108 páginas. ISBN:84-252-0498-4. [Edición original: (1970) Bautentür das Verkaufen. Munich, D.W Callwey.]

REY, CÉSAR (2010): Servicios Energéticos, Centro Comercial Los Arcos. Madrid: Escuela de Organización Industrial

RODRÍGUEZ SÁNCHEZ, JESÚS MIGUEL (2009) Climatización De Un Centro Comercial En Puertollano. Madrid: Universidad Pontificia Comillas.

SILL OTTO. (1968): CONSTRUCCIÓN DE APARCAMIENTOS. Barcelona: Blume (1969). 271 páginas.[Edición original: Parkbauten. Berlin: Bauverlag GmbH Wiesbaden (1968).]

SULLIVAN BARRY JAMES. (1980): INDUSTRIALIZATION IN THE BUILDING INDUSTRY. Nueva York: Litton Educational Publishing, Van Nostrand Reinhold. 253 páginas. ISBN: 0-442-27941-8.

VAHÍ SERRANO, AMALIA (2007): LA PERSPECTIVA TERRITORIAL Y URBANA DE LOS GRANDES EQUIPAMIENTOS COMERCIALES EN ANDALUCÍA. Sevilla: Universidad de Sevilla, 314 Páginas

ZUKOWSKY, JOHN. (1996): BUILDING FOR AIR TRAVEL. Munich: Prestel Verlag, Chicago: The Art Institute of Chicago. 255 páginas. ISBN: 3-7913-1684-2.

\section{Artículos.}

BERTOLINI LUCA, ET AL. (2014) Metropolitan Transportation Planning, Case Study, Mall of America, Bloomington (MN, US). Amsterdam: University Van Amsterdam, Graduate School of Social Sciences MSC Urban and Regional Planning.

A. QUEIPO BLANCO, FRANCISCO (1992) Planificación, Análisis, Concepto, Centros Comerciales. Oviedo.

AGENCIA ANDALUZA DE LA ENERGÍA (2010?)Optimización del consumo energético en centro comercial. Ahorro y eficiencia energética en la instalación de climatización de Los Arcos, Sevilla. Sevilla: Junta de Andalucía. 
CASTELLOT, JESÚS ANDRÉS (2011) Sistemas de Alta Eficiencia Energética. Caso Práctico: Centro Comercial Parquesur. Madrid, Efirenova.

DEL RÍO ROGER, SÁNCHEZ (2013) Impacto Medioambiental de los Centros Comerciales: de Gran Vía a Xanadú. Madrid: Mercasa.

DEL RÍO ROGER, SÁNCHEZ (2010) Nuevos y clásicos entornos comerciales: una carrera global de éxitos y obstáculos no compartidos. Madrid: Mercasa.

DERRY, MARK (2009): DAWN OF THE DEAD MALL.

EQUIPO PLATAFORMA URBANA: (Agosto 2012) "La idea del mall cerrado cumple 60 años y prepara su jubilación" Publicado en la revista chilena de internet Plataforma Urbana. www.plataformaurbana.cl

FILIOND, PIERRE; HAMMOND, KAREN (2006). The Failure of Shopping Malls as a Tool of Downtown Revitalization in Mid-Size Urban Areas. Toronto: Published in the Journal "Plan Canada" winter edition, pp 49-52.

JONATHAN DENIS-JACOB (2011) Retrofitting Suburban Shopping Malls: A Step Towards Metropolitan Sustainability. Own Publishing

KENNETH CARLING; ET AL. Out-of-town shopping and its induced CO 2 -emissions. Falun: Dalarna University

MARASCHIN CLARICE, COMIN HELIANA. (2010). Shopping Centers e Seu Entorno Inmediato. Rio de Janeiro: ENANPARQ, Primeiro encontro da Associaçao Nacional de Pesquisa e Pos Graduaçao en Arquitetura e urbanismo.

OFICINA ECOSISTEMA URBANO: (June 2015). Reinventarse o Morir, la Transformación de los Centros Comerciales bajo el Nuevo Paradigma Económico/Urbano. Santiago: Published in the Chilean web journal "Plataforma Urbana". www.plataformaurbana.cl.

OSLO CENTER FOR URBAN AND LANDCAPE STUDIES. (2014). Rethinking Retail - A Case for Courtyard Shopping. Oslo: published in the webpage: http://www.oculs.no/news/rethinkingretail-case-courtyard-shopping/

PADILHA VALQUIRIA (2012), Shopping Center a Catedral das Mercadorias. São Paulo: Boitempo, ISBN: 978-857-559-077-5).

RICHARD A. FEINBERG, MEOLI JENNIFER (1991), A Brief History of the Mall, United States, Advances in Consumer Research. Volumen 18, eds. Rebecca H. Holman and Michael R. Solomon. Provo, UT : Association for Consumer Research, pp: 426-427.

SAMER ABU-GHAZALAH; ET AL. (2004) "The Impact Of Shopping Mall Upon the Future of Urban Planning in Greater Amman" ICSC.

SENA IZGI, ET AL. (2010). Negative Effects of Shopping Malls. 
TAMAYO D'OCON, GLORIA LORA; ET AL. Nuevas formas comerciales de gran superficie en la Comunidad de Madrid. Madrid: Universidad Complutense de Madrid.

WARD EWAN, (2005). El Diseño De Centros Comerciales En América. Pamplona: RA, Revista de Arquitectura, Año 2005, número 7.

WARREN, JONATHAN (2009): New South China Mall.

\section{9.- SOSTENIBILIDAD Y EFICIENCIA ENERGÉTICA}

Libros y tesis doctorales.

MARQUES MONTEIRO LEONARDO. (2008) Modelos Preditivos de Conforto Térmico: Quantificação de Relações entre Variáveis Microclimáticas e de Sensação Térmica para Avaliação e Projeto de Espaços Abertos. São Paulo, University of São Paulo.

Artículos.

BRUNTLAND, GRO HARLEM, UNITED NATIONS (1987). Our Common Future. New York: United Nations.

ESCORCIA O. , GARCÍA R. ,TREBILCOCK M. ,CELIS F. ,BRUSCATO U. (2012). Mejoramientos de envolvente para la eficiencia energética de viviendas en el centro-sur de Chile. Informes de la construcción, Volume 64, October-December 2012. ISSN: 0020-0883 eISSN: 1988-3234 doi: 10.3989/ic.11.143.

GARCÍA RAMIRO, ROBERTO (2013) Estudio de la Huella de Carbono de los hogares españoles: Evolución nacional (1998-2011) y por Comunidades Autónomas (2006-2011). Madrid: Universidad Politécnica de Madrid.

HIGUERAS ESTER, CAMAÑO ESTEFANIA (2011). Identificación Y Aprovechamiento del Potencial Solar a Través de Estrategias Locales, Polis Project, Madrid: ETSAM, Polytechnic University of Madrid, (IEE/08/603/SI2.529237).

HIGUERAS E. CARRETERO J. (2015) Environmental retrofitting of public buildings according to the objectives of the European Directive 20-20-20, case study of Iparralde civic center in Vitoria. Congreso Internacional de Construcción Sostenible y Soluciones Ecoeficientes. Sevilla, Universidad de Sevilla.

HIGUERAS ESTER, TUMINI IRINA, (2014) Use of Energy Simulation Tools For Studying the Urban Microclimate. Bilbao: Dyna.

JIMÉNEZ HERRERO LUIS M. (1999) Cambio Global, Desarrollo Sostenible y Coevolución. Barcelona, Revista SOStenible? no1. Universidad Politécnica de Cataluña. 
NAREDO JOSE MANUEL, (1997). Sobre el Origen, el uso y el contenido del término Sostenible. Madrid: Politechnical University of Madrid, "Biblioteca Ciudades Para un Futuro Más Sostenible".

SANTOS CRISTINA. ET AL. (2011). Otimização Do Consumo De Água Em Edifícios. Implementação De Sistemas De Aproveitamento De Águas Pluviais E Reutilização De Águas Cinzentas. Porto: Faculdade de Engenharia da Universidade do Porto. ISBN 978-989-95557-5-4.

VERDAGUER CARLOS, CÁRDENAS VIANA (2013) Cambio climático, sostenibilidad y urbanismo: un marco de referencia. Madrid: Universidad politécnica de Madrid, Escuela técnica Superior de Arquitectura.

\subsection{0.- OTRAS REFERENCIAS.}

ALMOROX ALONSO JAVIER (2004). Climatología Aplicada Al Medio Ambiente y Agricultura. Madrid: Universidad Politécnica de Madrid, ISBN 978-84-7401-179-1.

AYUNTAMIENTO DE MADRID (2000) Instrucción de Vía Pública.

E.A.P.E. DOMínGUEZ, SAMUEL (2010): "Curso De Patologías En La Edificación", Mérida, Sevilla: Junta de Extremadura, Universidad de Sevilla http://fomento.gobex.es/fomento/live/informacionciudadano/Arquitectura/Documentacion/patologiaclimatizacion.pdf ENERGY PERFORMANCE OF BUILDING DIRECTIVE (EPBD) (2002). EUROPEAN UNION (2007) Communication from the Commission to the European Council and the European Parliament of 10 January 2007, "An energy policy for Europe".

FERNÁNDEZ GÜELL, JOSÉ MIGUEL (1997) Planificación Estratégica de Ciudades. Barcelona: Reverté. ISBN 10: 84-291-2110-2.

ICLEI- IRENA (INTERNATIONAL RENEWABLE ENERGY AGENCY) (2012), Renewable Energy Policy in Cities: Selected Case Studies, Sao Paulo. Bonn: ICLEl; Abu Dhabi: Irena

MALL OF AMERICA GREEN INITIATIVES (2016) Mall of America Management, Bloomington.

MINISTERIO FEDERAL DE MEDIO AMBIENTE DE ALEMANIA, AGENCIA FEDERAL MEDIOAMBIENTAL DE ALEMANIA, IHOBE, S.A. GOBIERNO VASCO. (1999) Guía de Indicadores Medioambientales para la Empresa.

MINISTERIO DE FOMENTO, (2003): "Nota Metodológica de Construcción de Edificios", Madrid: Gobierno de España.

PLAN ESTATAL DE VIVIENDA Y REHABILITACIÓN (2009-2012), Ministerio de Vivienda.

PROGRAMA DE REDUCCIÓN DE AGUAS DE LA EMPRESA SONAE SIERRA PARA CENTROS COMERCIALES (2010): Sonae Sierra. referencias en: 
http://www.europapress.es/epsocial/responsables/noticia-sonae-sierra-reduce-consumomedio-agua-visitante-2011-20120604163205.html. https://www.certicalia.com/blog/sonaesierra-reduce-el-consumo-de-agua-y-energetico-durante-2011

PROSPERI MEYER, REGINA MARIA; ET AL (2004-2013) Sao Paulo Metropole. Sao Paulo: Editora da Universidade de Sao Paulo. ISBN 978-85-314-0803-8

PROYECTO REVITASUD DE LA INICIATIVA INTERREG III-A ESPAÑA-FRANCIA, (2003-2006).

REAL ACADEMIA ESPAÑOLA (2001) "Diccionario de la Lengua Española, Vigésima primera edición". Madrid: Real Academia Española de la Lengua.

SPHERE PROJECT. Minimum Standards In Shelter Settlement And Non Food Items.

UNITED NATIONS (2012). Climate Change Conference, Cop 18/Cmp8, Doha, QATAR.

UNIVERSIDADE FEDERAL DE SANTA CATARINA, CENTRO TECNOLÓGICO DEPARTAMENTO DE ENGENHARIA CIVIL (2010). Análise de Capacidade de Vias com base no HCM 2010. Florianopolis: Universidade Federal de Santa Catarina.

HOFFMAN LARKIN (2010) Environmental and Sustainability Issues to be covered at Big Green Conference. Bloomington MN. Mall of America.

\subsection{1.- PÁGINAS WEB DE CONSULTA}

ABC Serrano: http://abcserrano.com/

Asociación Española de centros comerciales: http://www.aedecc.com/

Ambialia Inginiería y Medio Ambiente: www.ambialia.es

Ayuntamiento de Madrid: http://www.madrid.es/portal/site/munimadrid

Ayuntamiento de Madrid: www.madrid.es

Belmar: https://www.belmarcolorado.com/

BREEAM certificado: http://www.breeam.es/

Compromiso para la Reducción de la Huella de Carbono: www.huellacarbono.es

Directgov, Climate change and protecting the environment: www.direct.gov.uk

Ecological Footprint Quiz by Center for Sustainable Economy www.myfootprint.org.

Encuesta de la energía, tu huella ecológica: www.tuhuellaecologica.org

Fundación Eroski, Erosky Consumer: www.consumer.es

Greenroofs.com, The Resource Portal for Green Roofs: www.greenroofs.com 
Green Building Council España: http://www.gbce.es/pagina/certificacion-verde

Green Certified Site: www.co2stats.com

Green Mat Systems: www.greenmatsystem.com

Google Maps.

IDAE, Instituto para la Diversificación y el Ahorro de la Energía: www.idae.es

Intemper: www.intemper.com

Instituto de estadística de la Comunidad de Madrid: http://www.madrid.org/iestadis/

Instituto Huella de Carbono: www.institutohuelladecarbono.com

Instituto Nacional de estadística: www.ine.es

International Council of Shopping Centers: https://www.icsc.org/

La Vaguada: http://enlavaguada.com/

LEED. Us. Green Building Council: http://www.usgbc.org/leed

Mall of America: http://es.mallofamerica.com/

Nomecalles - Nomenclator y Callejero de la Comunidad de Madrid:

www.madrid.org/nomecalles/

Observatorio de la Sostenibilidad en España: www.sostenibilidad-es.org

Parquesur: http://parquesur.com/

Página del UK Green Building Council: http://www.ukgbc.org/

Página web de AENOR: www.aenor.es

Prefeitura de Sao Paulo: http://capital.sp.gov.br/

Semper Green: www.sempergreen.com

Shopping Eldorado: http://www.shoppingeldorado.com.br/

Shopping Leste Aricanduva: http://www.aricanduva.com.br/

Shopping Light: http://shoppinglight.com.br/

Sonae Sierra: https://www.sonaesierra.com/spain/es-es

Tecta Green: www.greenroof.com

United States Environmental Protection Agency: www.epa.gov 
METODOLOGÍA PARA REHABILITACIÓN DE GRANDES CENTROS COMERCIALES, MEDIANTE EL ANÁLISIS DEL CONTEXTO Y LA SOSTENIBILIDAD URBANA.

\subsection{2.-AUDIOVISUAL}

GREENE GREGORY (2004) The End Of Suburbia Oil Depletion And The Collapse Of The American Dream 


\section{ANEXO 1.- GRÁFICOS RESUMEN ESTUDIO CASOS}

\begin{tabular}{|l|l|}
\hline \multicolumn{2}{|c|}{ SHOPPING LIGHT } \\
PHASE 0, CUANTITATVE DATA \\
\hline OC.- SHOPPING MALL DATA & Value \\
\hline OC1: Shopping mall surface (m2) & 36.000 \\
\hline OC2: Plot Surface (m2) & 4899 \\
\hline OC3: Plan Surface (m2) & 4899 \\
\hline OC4: Weeklyvisitors (pe/sem) & 75.000 \\
\hline OC5: Attraction index (no) & 3 \\
\hline OC6: Residential surface (m2) & 0 \\
\hline OC7: Productive Surface (m2) & 400 \\
\hline OC8: Amenities in mall (n-) & 1 \\
\hline OU.- URBAN AREA DATA & Value \\
\hline OU1: Population (pe) & 18.000 \\
\hline OU2: Population density (hab/m2) & 0,024 \\
\hline U03: Surface of urban area (m2) & 679.822 \\
\hline
\end{tabular}

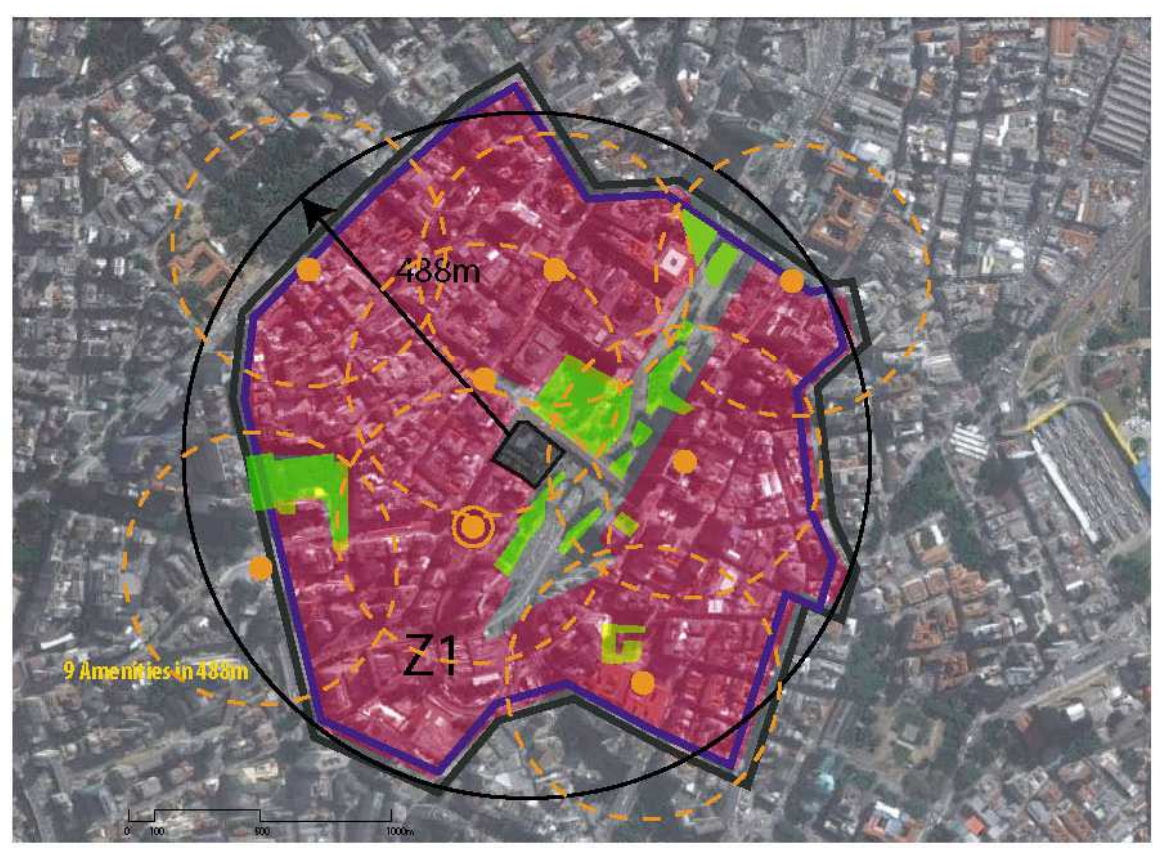

난

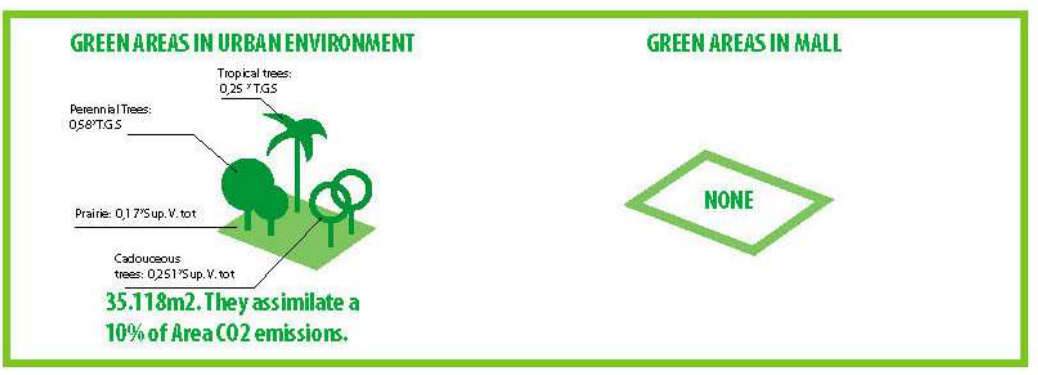

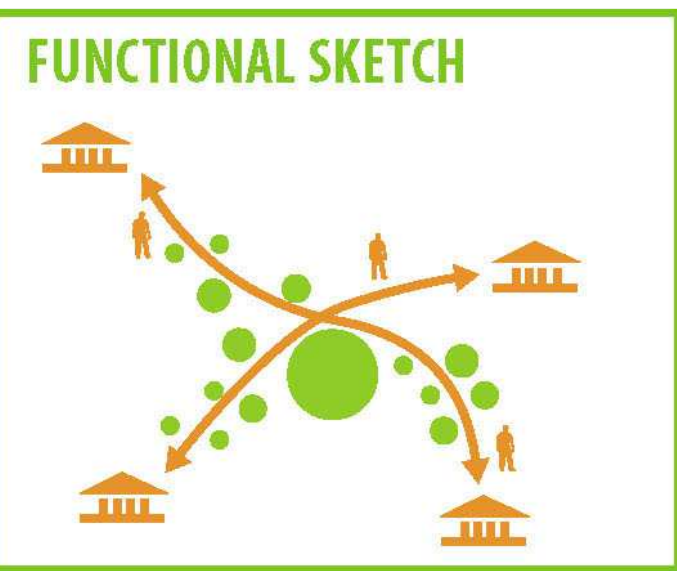

Average
Arrival time
A $96 \%$ of the
urban area is
covered by mass
transit

ACTIVITY IS IN THE WHOLE AREA.

Very high

urban complexity 


\begin{tabular}{|l|l|}
\multicolumn{2}{|c|}{ SHOPPING ELDORADO } \\
PHASE 0, CUANTITATIVE DATA \\
\hline OC.- SHOPPING MALI DATA & Value \\
\hline OC1: Shopping mall surface (m2) & 164.734 \\
\hline OC2: Plot Surface (m2) & 57.000 \\
\hline OC3: Plan Surface (m2) & 25.057 \\
\hline OC4: Weekly visitors (pe/sem) & 126.000 \\
\hline OC5: Attraction index (no) & 3 \\
\hline OC6: Residential surface (m2) & 0 \\
\hline OC7: Productive Surface (m2) & 250 \\
\hline OC8: Amenities in mall (no) & 1 \\
\hline OU.- URBAN AREA DATA & Value \\
\hline OU1: Population (pe) & 82.367 \\
\hline OU2: Population density (hab/m2) & 0,0081 \\
\hline U03: Surface of urban area (m2) & 4.665 .934 \\
\hline
\end{tabular}
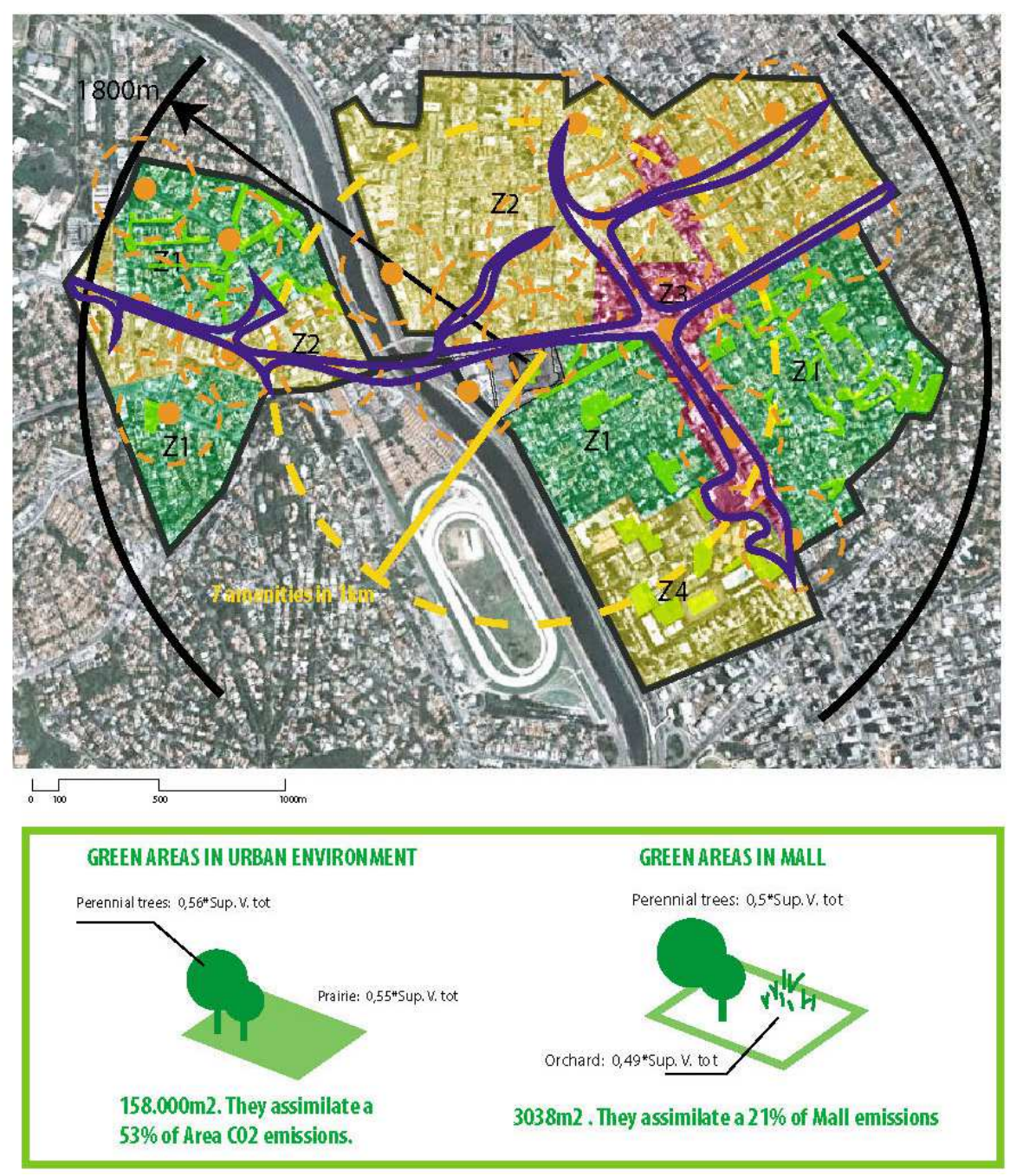
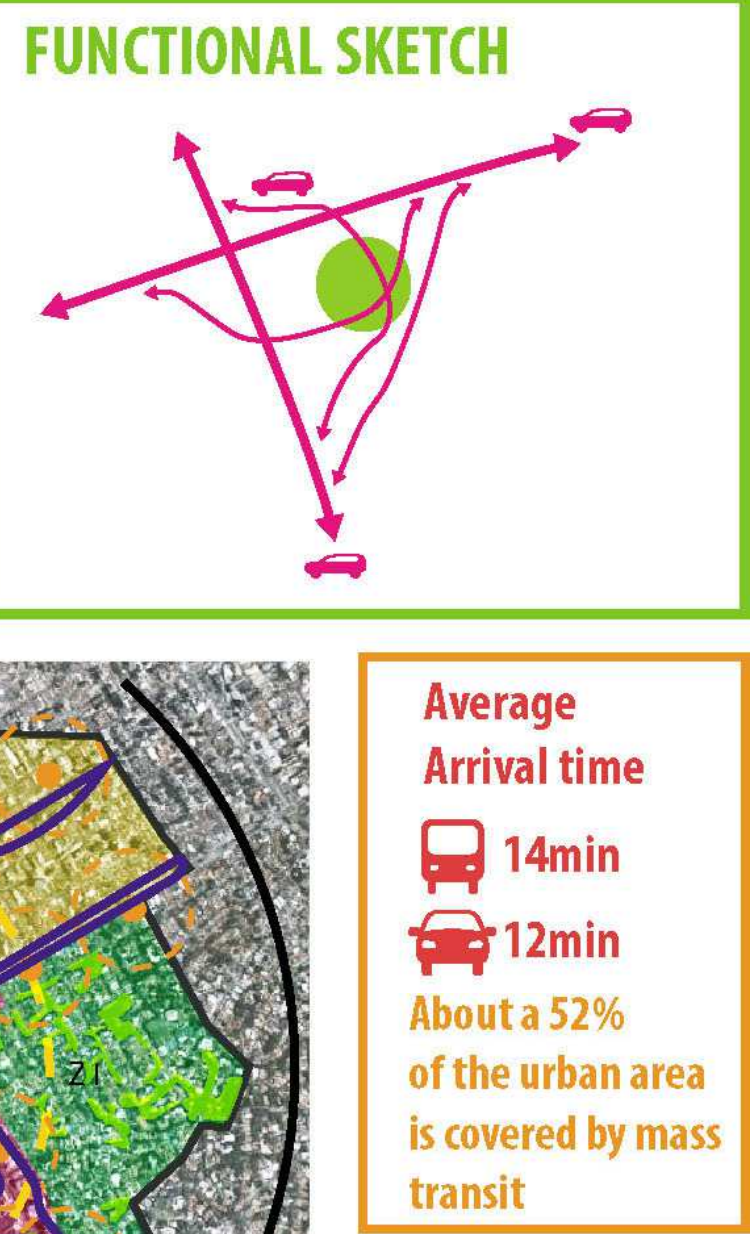

ACTIVITY IS CENTERED IN MAIN AVENUES. Average-high urban complexity

HIGH DENSITY TISSUE MID DENSITY TISSUE LOW DENSITY TISSUE

HI-RISE BUILDINGS AND AVERAGELY BUILT SURFACE 


\begin{tabular}{|c|c|}
\hline \multicolumn{2}{|c|}{$\begin{array}{l}\text { SHOPPING ARICANDUVA } \\
\text { PHASE 0, CUANTITATIVE DATA }\end{array}$} \\
\hline OC.- SHOPPING MALL DATA & Value \\
\hline OC1: Shopping mall surface $(\mathrm{m} 2)$ & 425.000 \\
\hline OC2: Plot Surface $(\mathrm{m} 2)$ & 497.450 \\
\hline OC3: Plan Surface (m2) & 216.000 \\
\hline OC4: Weekly visitors (pe/sem) & 716.000 \\
\hline OC5: Attraction index $(\mathrm{n} 9)$ & 5 \\
\hline 0C6: Residential surface (m2) & 0 \\
\hline OC7: Productive Surface $(\mathrm{m} 2)$ & 175 \\
\hline OC8: Amenities in mall $(n$ ) $)$ & 1 \\
\hline OU.- URBAN AREA DATA & Value \\
\hline OU1: Population (pe) & 212.500 \\
\hline OU2: Population density (hab/m2) & 0,012 \\
\hline U03: Surface of urban area $(\mathrm{m} 2)$ & 23.373 .68 \\
\hline
\end{tabular}

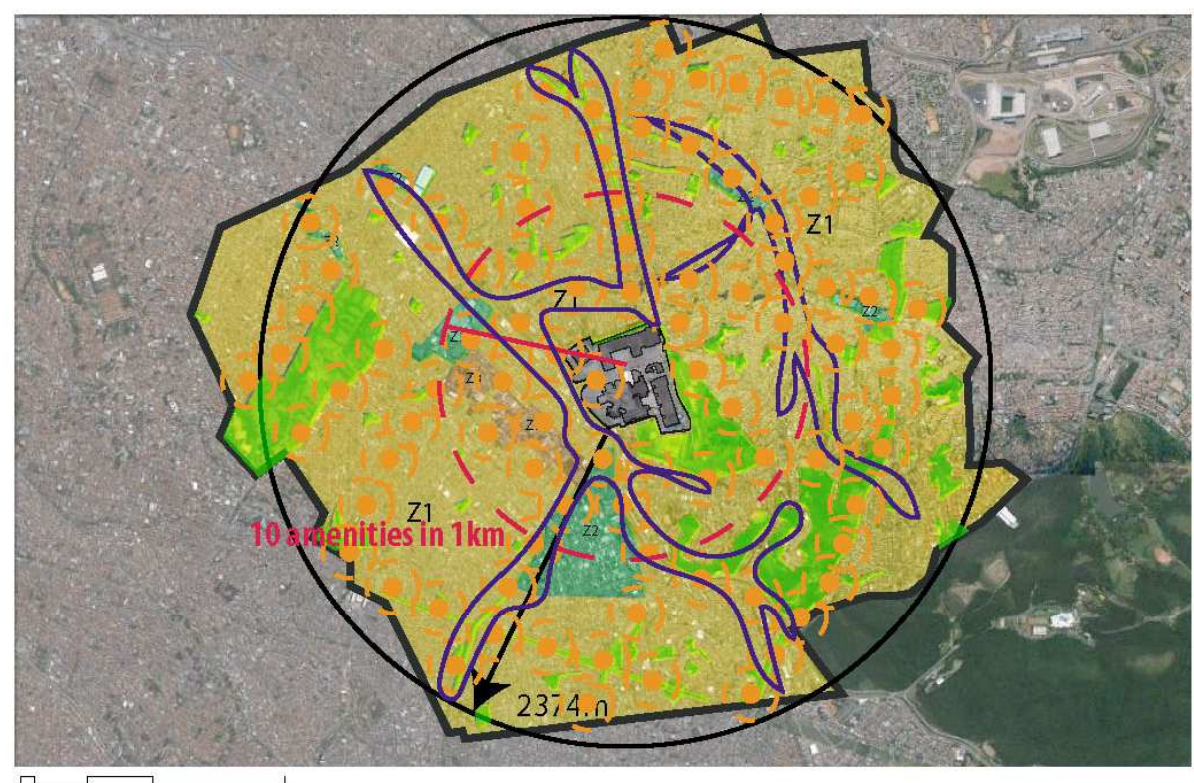

$\Gamma_{100}^{\longrightarrow} \underset{1000}{\longrightarrow} \underset{2000}{\longrightarrow}$

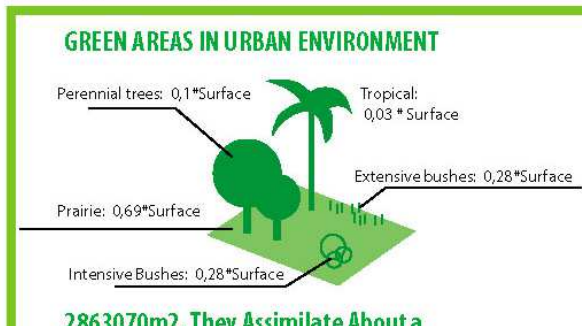

$2863070 \mathrm{~m} 2$. They Assimilate About a $73 \%$ of Area $\mathrm{C} 02$ emissions.
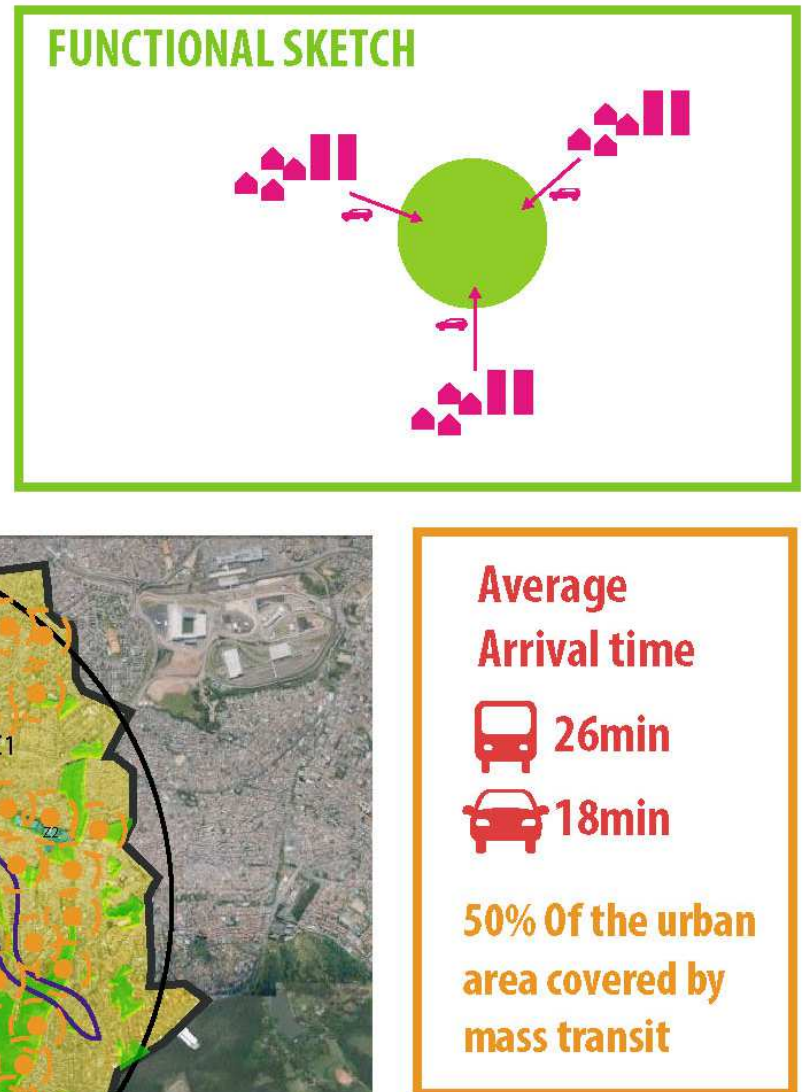

ACTIVITY IS CENTERED

IN MAIN AVENUES,

Scarce complexity

HIGH DENSITYTISSUE

MID DENSITYTISSUE

LOW DENSITY TISSUE

MID DENSITY, BUT

SPRAWLED URBANISM 


\begin{tabular}{|c|c|}
\hline \multicolumn{2}{|c|}{$\begin{array}{c}\text { ABC SERRANO } \\
\text { PHASE } 0 \text {, CUANTITATIVE DATA }\end{array}$} \\
\hline OC.- SHOPPING MALL DATA & Jvalue \\
\hline OC1: Shopping mall surface $(\mathrm{m} 2)$ & 32.899 \\
\hline OC2: Plot Surface $(\mathrm{m} 2)$ & 4106 \\
\hline OC3: Plan Surface (m2) & 3891 \\
\hline OC4: Weekly visitors (pe/sem) & 69.087 \\
\hline OC5: Attraction index (no) & 3 \\
\hline OC6: Residential surface (m2) & 0 \\
\hline OC7: Productive Surface $(\mathrm{m} 2)$ & 0 \\
\hline OC8: Amenities in mall ( $\mathrm{n}$-) & 0 \\
\hline OU.- URBAN AREA DATA & Value \\
\hline OU1: Population (pe) & 16.450 \\
\hline OU2: Population density (hab/m2) & 0,026 \\
\hline U03: Surface of urban area (m2) & 798.318 \\
\hline
\end{tabular}
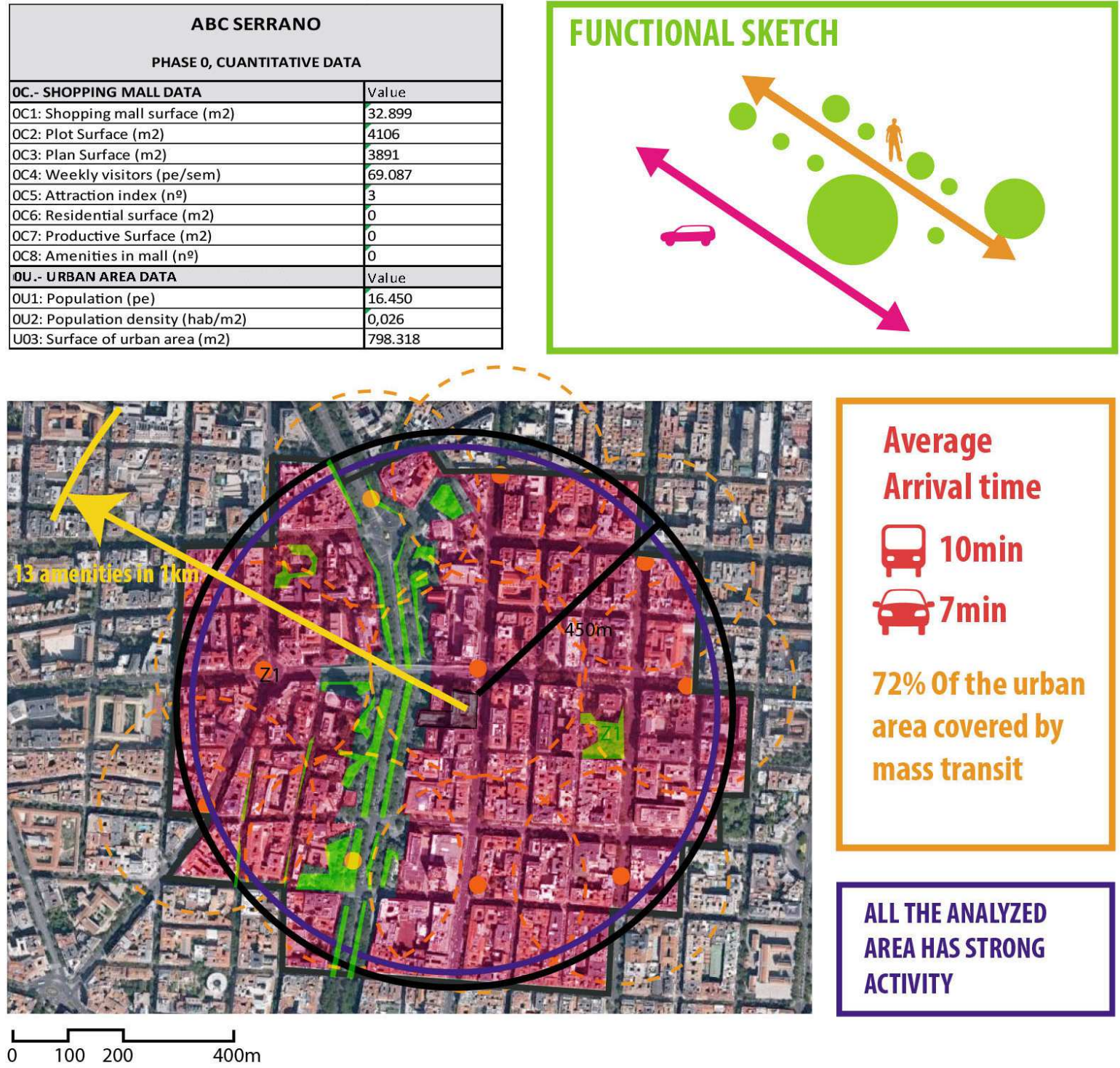

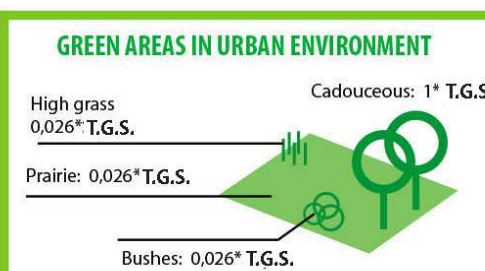

37.278m2. They Assimilate About a $7 \%$ of Area $\mathrm{CO} 2$ emissions.
GREEN AREAS IN MALL

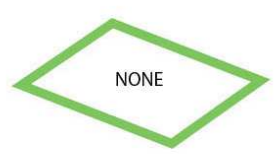

Om2. They Assimilate A 0\% of Mall emissions
HIGH DENSITY TISSUE

MID DENSITY TISSUE

LOW DENSITY TISSUE

DENSE AREA WITH

CONGESTION PROBLEMS 


\begin{tabular}{|l|l|}
\hline \multicolumn{2}{|c|}{ LA VAGUADA } \\
\multicolumn{2}{|c|}{ PHASE 0, CUANTTTATIVE DATA } \\
\hline OC. SHOPPING MALL DATA & Value \\
\hline OC1: Shopping mall surface (m2) & 85.000 \\
\hline OC2: Plot Surface (m2) & 61.692 \\
\hline OC3: Plan Surface (m2) & 44.780 \\
\hline OC4: Weekly visitors (pe/sem) & 179.550 \\
\hline OC5: Attraction index ( $\mathrm{n}$ ) & 4 \\
\hline OC6: Residential surface (m2) & 0 \\
\hline OC7: Productive Surface (m2) & 400 \\
\hline OC8: Amenities in mall ( $\mathrm{n} 9$ ) & 1 \\
\hline OU.- URBAN AREA DATA & Value \\
\hline OU1: Population (pe) & 42.750 \\
\hline OU2: Population density (hab/m2) & 0,035 \\
\hline U03: Surface of urban area (m2) & 1.258 .153 \\
\hline
\end{tabular}
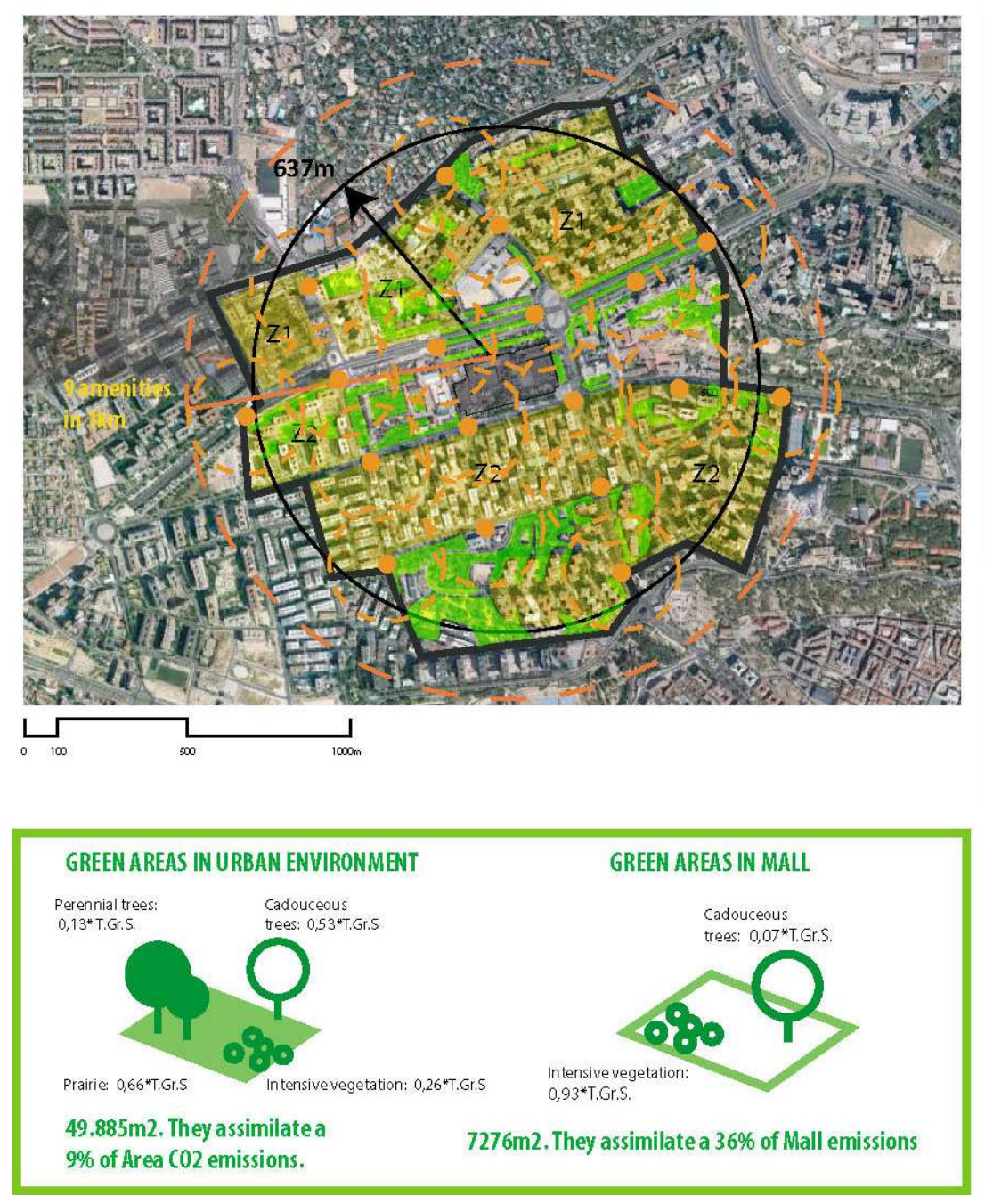

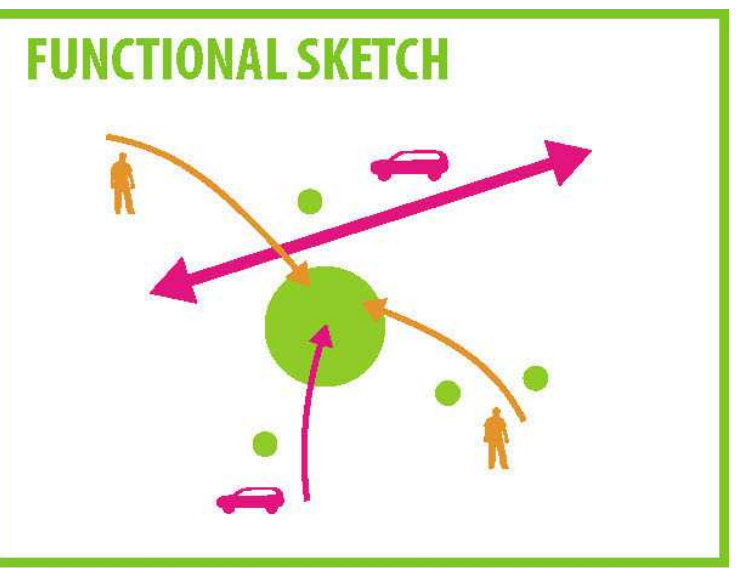

Average
Arrival time
A $86 \%$ of the urban
area covered
by mass transit

\section{ACTIVITY IS CENTERED}

IN ALL STREETS.

Average-high

urban complexity

HIGH DENSITYTISSUE

MID DENSITYTISSUE

LOW DENSITY TISSUE

HI-RISE BUILDINGS AND

SCARCELY BUILT

SURFACE 


\begin{tabular}{|c|c|}
\hline \multicolumn{2}{|c|}{$\begin{array}{c}\text { PARQUESUR } \\
\text { PHASE 0, CUANTITATIVE DATA }\end{array}$} \\
\hline OC.- SHOPPING MALL DATA & Value \\
\hline OC1: Shopping mall surface $(\mathrm{m} 2)$ & 151.200 \\
\hline OC2: Plot Surface (m2) & 296.205 \\
\hline 0C3: Plan Surface (m2) & 135.765 \\
\hline OC4: Weekly visitors (pe/sem) & 254.016 \\
\hline OC5: Attraction index $\left(\mathrm{n}^{\circ}\right)$ & 4 \\
\hline OC6: Residential surface (m2) & 0 \\
\hline OC7: Productive Surface $(\mathrm{m} 2)$ & 0 \\
\hline OC8: Amenities in mall $\left(n^{\circ}\right)$ & 0 \\
\hline IOU.- URBAN AREA DATA & Value \\
\hline 0U1: Population (pe) & 75.600 \\
\hline OU2: Population density (hab/m2) & 0,041 \\
\hline U03: Surface of urban area $(\mathrm{m} 2)$ & 2.539 .764 \\
\hline
\end{tabular}

\section{FUNCTIONAL SKETCH}
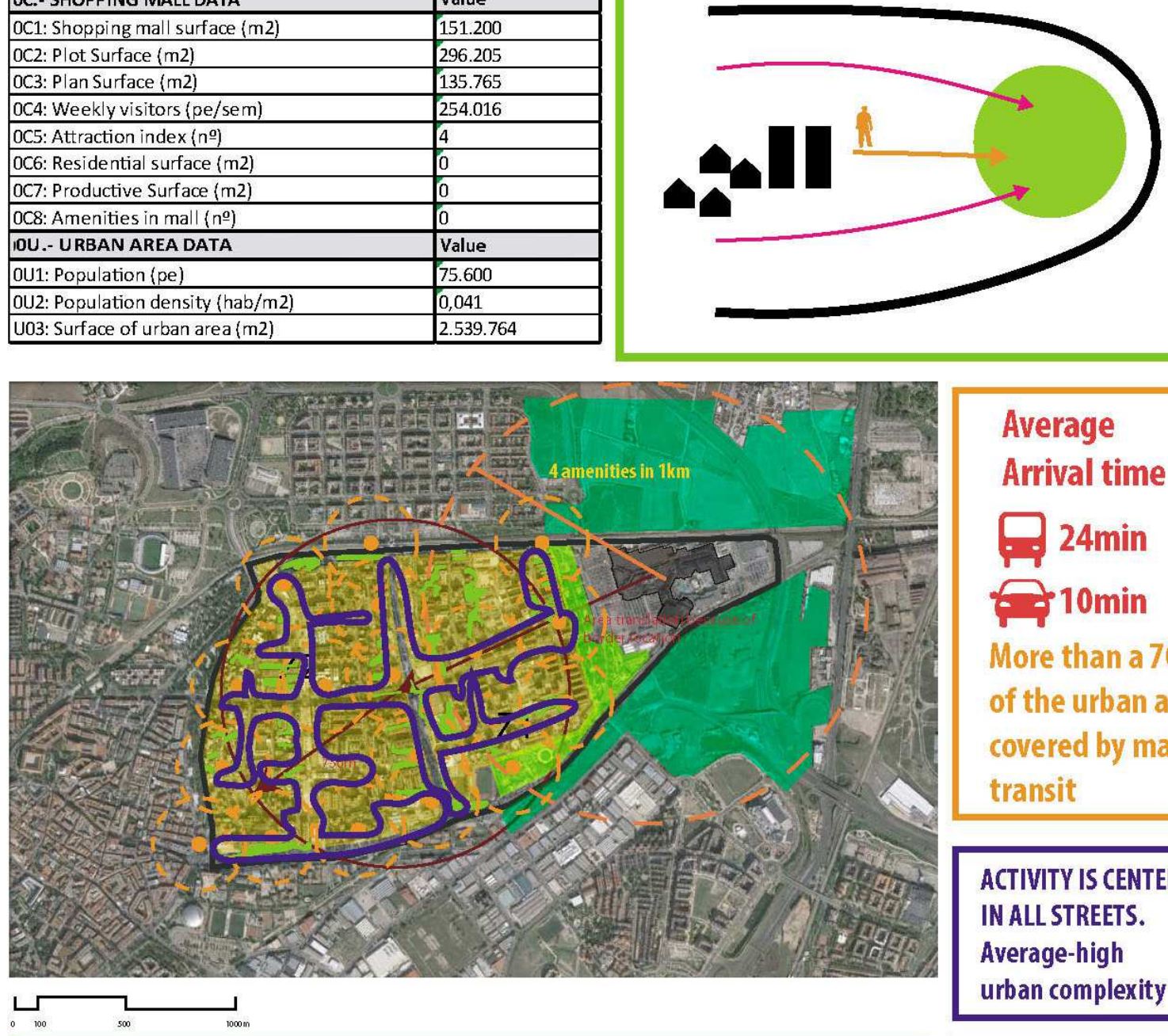

\section{GREEN AREASIN URBAN ENVIRONMENT}

Perennial trees:

Pririe: 0.1 .T. . S.

\begin{tabular}{l} 
Prairie: $0,17 . \mathrm{Ts}$ \\
$+931.671 \mathrm{~m} 2$ \\
\hline
\end{tabular}

High grass:
$0,023 *$ T.G.S.

$+280.880$

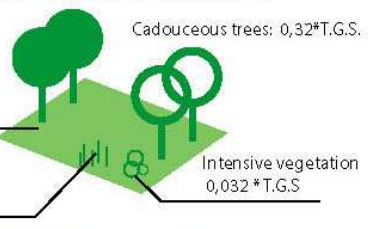

$428.052 \mathrm{~m} 2$. They assimilate a $22 \%$ of Area $\mathrm{C} 02$ emissions.
GREEN AREASIN MALL Cadouceous trees: 0,11*T.G.S.

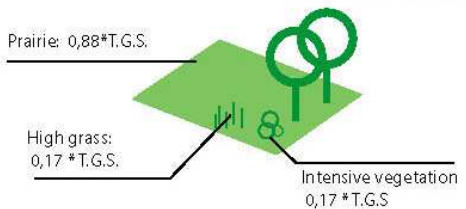

$16.827 \mathrm{~m} 2$. They assimilate a $28 \%$ of Mall emissions
Average

Arrival time

24min

F $10 \mathrm{~min}$

More than a 70\%

of the urban area

covered by mass

transit

ACTIVITY IS CENTERED

IN ALL STREETS.

Average-high

urban complexity

HIGH DENSITY TISSUE

MID DENSITYTISSUE

LOW DENSITY TISSUE

HI-RISE BUILDINGS AND

AVERAGELY BUILT

SURFACE 


\begin{tabular}{|l|l|}
\hline \multicolumn{2}{|c|}{ BELMAR } \\
\multicolumn{2}{|c|}{ PHASE 0, CUANTTTATIVE DATA } \\
\hline OC.- SHOPPING MALL DATA & Value \\
\hline OC1: Shopping mall surface (m2) & 961.446 (355.900 c.) \\
\hline OC2: Plot Surface (m2) & 1.848 .190 \\
\hline OC3: Plan Surface (m2) & 480.700 \\
\hline OC4: Weekly visitors (pe/sem) & 421.741 \\
\hline OC5: Attraction index ( $\mathrm{n}$-) & 5 \\
\hline OC6: Residential surface (m2) & 429.378 \\
\hline OC7: Productive Surface (m2) & 176.168 \\
\hline OC8: Amenities in mall ( $\mathrm{n}-$ ) & 3 \\
\hline OU.- URBAN AREA DATA & Value \\
\hline OU1: Population (pe) & 177.950 \\
\hline OU2: Population density (hab/m2) & 0,0015 \\
\hline U03: Surface of urban area (m2) & 50.300 .000 \\
\hline
\end{tabular}

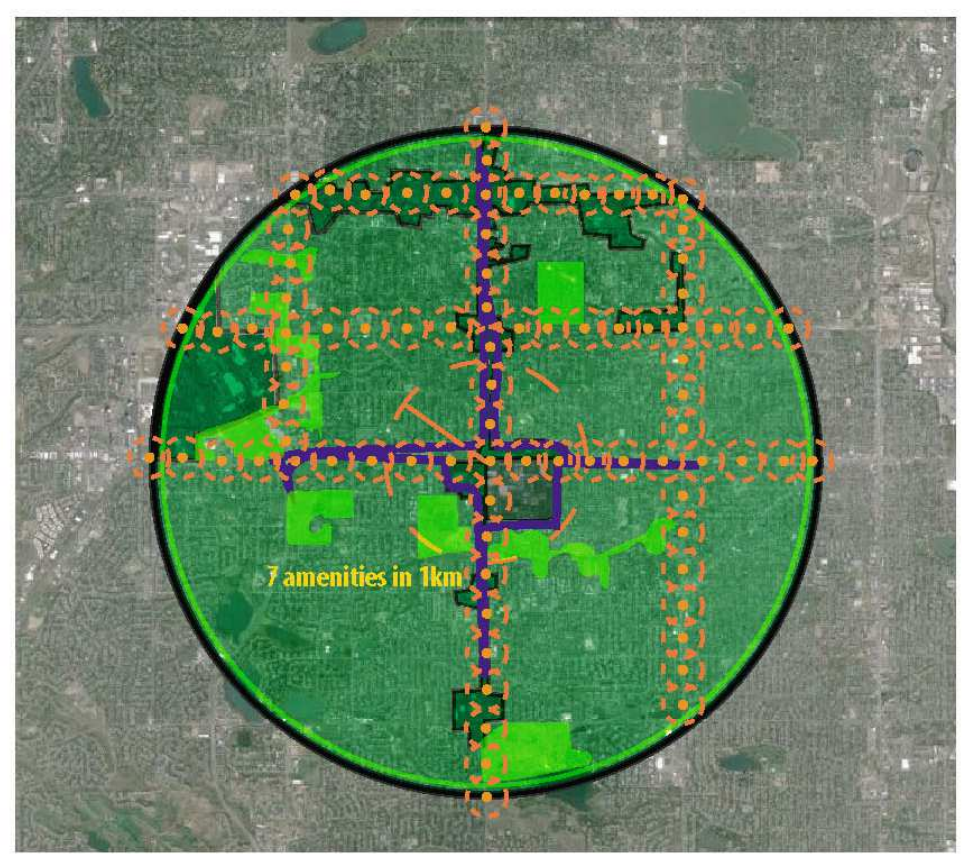

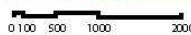

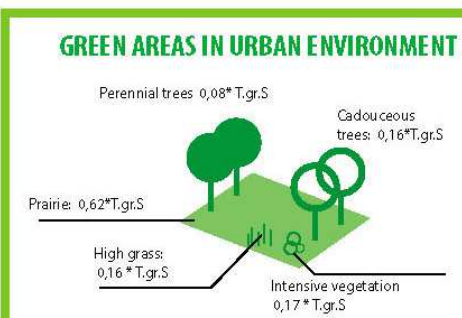

27.016.226 m2. They Assimilate About a $400 \%$ of Area $\mathrm{C} 02$ emissions.
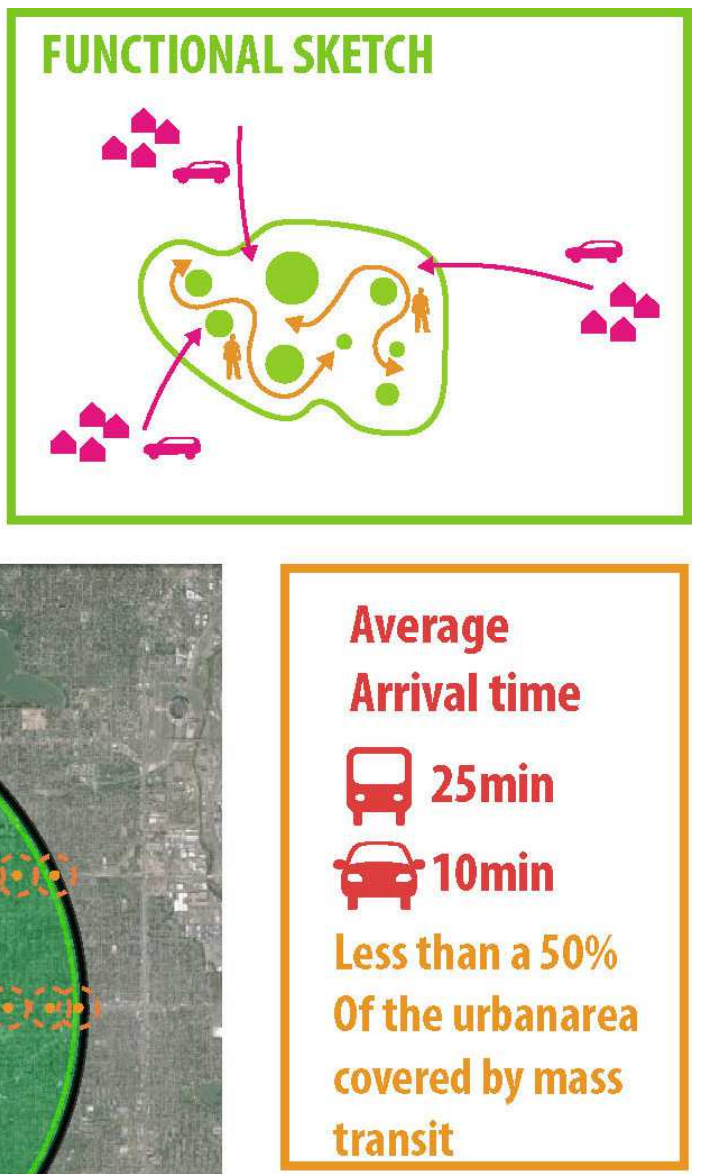

ACTIVITY IS CENTERED IN MAIN AVENUES, AND

MALL.

Scarce complexity

HIGH DENSITY TISSUE

MID DENSITY TISSUE

LOW DENSITY TISSUE

SPRAWLED TISSUE

WITH VERY LOW

DENSITY 


\begin{tabular}{|l|l|}
\hline \multicolumn{2}{|c|}{ MALL OF AMERICA } \\
\multicolumn{2}{|c|}{ PHASE 0, CUANTITATIVE DATA } \\
\hline OC.- SHOPPING MALL DATA & Value \\
\hline OC1: Shopping mal/ surface (m2) & 730.000 \\
\hline OC2: Plot Surface (m2) & 307.690 \\
\hline OC3: Plan Surface (m2) & 212.364 \\
\hline OC4: Weekly visitors (pe/sem) & 762.000 \\
\hline OC5: Attraction index ( $\mathrm{n}$ ) & 5 \\
\hline OC6: Residential surface $(\mathrm{m} 2)$ & 60.918 \\
\hline OC7: Productive Surface (m2) & 0 \\
\hline OC8: Amenities in mall ( $\mathrm{n}$ ) & 0 \\
\hline OU.- URBAN ENVIRONMENT DATA & Value \\
\hline OU1: Population (pe) & 365.000 \\
\hline OU2: Population density (hab/m2) & 0,00092 \\
\hline U03: Surface of urban area (m2) & 20.047 .119 \\
\hline
\end{tabular}
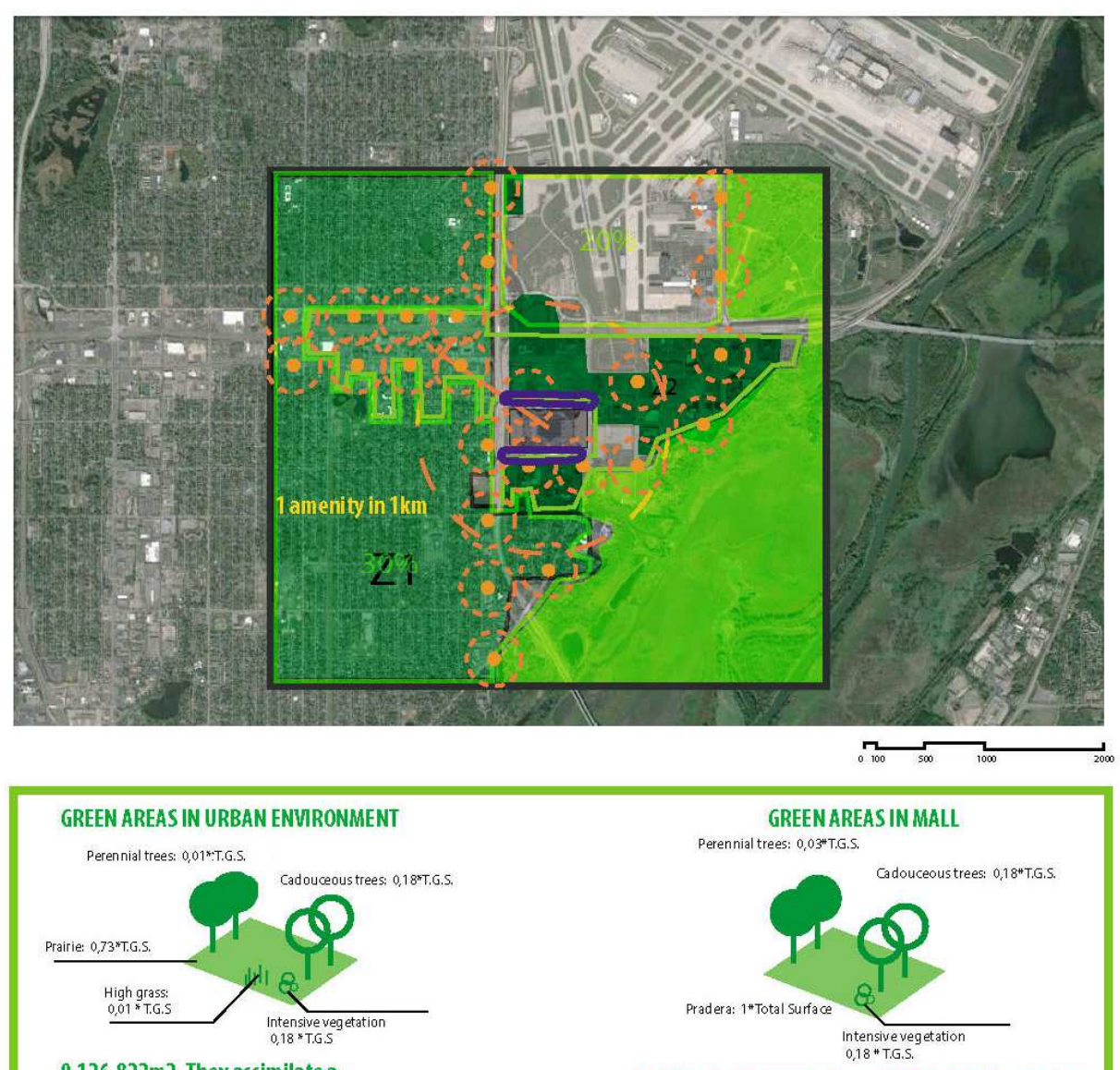

$9.126 .822 \mathrm{~m} 2$. They assimilate a $176 \%$ of Area $\mathrm{C} 02$ emissions. $\sqrt{700} 500$

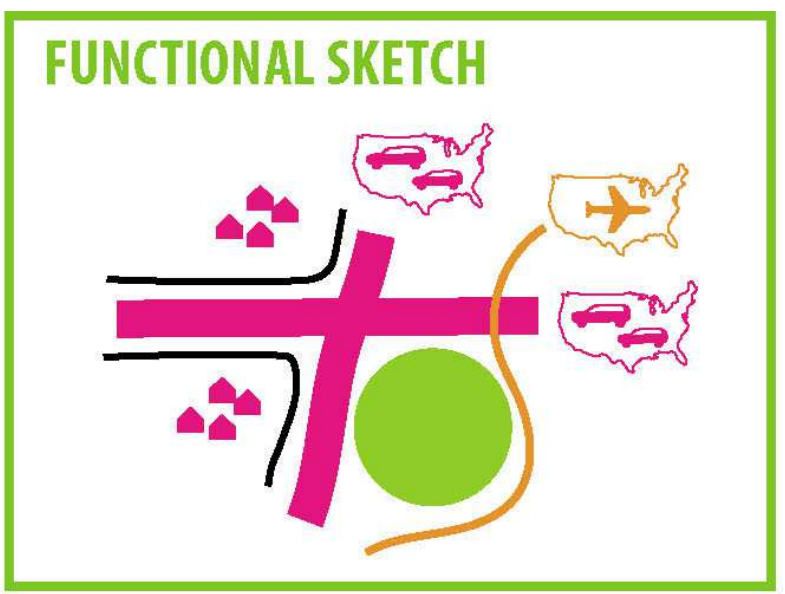

Average
Arrival time
$22 \mathrm{~min}$
Less than a $50 \%$
Of the urban area
covered by mass
transit

\section{ALMOST NOACTIVITY IN AREA. A BIT IN MALL FACADES. \\ No complexity}

HIGH DENSITY TISSUE

MID DENSITYTISSUE

LOW DENSITY TISSUE

SPRAWLED TISSUE WITH VERY LOW DENSITY 


\section{ANEXO 2.- ESTADO DEL ARTE EN METOdOLOGÍAS DE ANÁlISIS AMBIENTAL, FUNDAMENTOS Y TIPOS DE ANALÍTICA.}

Acerca de las metodologías de análisis, Luis Alberto García Leyton testifica que "Las características deseables en las metodologías que se adopten deben de comprender los siguientes aspectos:

1.- Deben de ser adecuados a las tareas que hay que realizar como la identificación de impactos o la comparación de opciones.

2.- Deben de ser lo suficientemente independientes de los puntos de vista personales del equipo evaluador y sus sesgos.

3.- Deben de ser económicos en términos de costes y requerimiento de datos, tiempo de aplicación, cantidad y tiempo de personal, equipo e instalaciones." 66

Este autor, también en el presente artículo, cita las limitaciones de las metodologías en general a la hora de resolver los interrogantes del problema, además del criterio científico y el conocimiento profesional, que el usuario de las mismas debe de tener para su uso correcto.

De este modo, en el ámbito de las metodologías de análisis medioambiental, cabe remarcar la existencia de una gran cantidad de métodos de analítica, que siguen diferentes pasos, y consideran diferentes factores.

Diferentes autores, (Warner, Brownley, Canter, Sadler...) han considerado estos métodos, calificándolos de acuerdo a su procedimiento.

Warner and Brownley en 1974, ordenaron las metodologías de investigación en cinco grandes grupos, esta es una de las primeras clasificaciones en el ámbito:

1: Métodos ad Hoc,

2: Técnicas gráficas mediante mapas y superposiciones.

3: Listas de chequeo.

4: Matrices.

5: Diagramas. ${ }^{67}$

Luis Alberto García Leyton, incluye esta clasificación en el escrito anteriormente citado.

Canter y Sadler recogen también en sus escritos una clasificación organizada en base a veintidós tipologías de metodología, de este modo tenemos los siguientes tipos de

\footnotetext{
${ }^{66}$ García Leyton L. A. (2004). Aplicación del Análisis Multicriterio en la Evaluación de Impactos Ambientales. Página 40.

${ }^{67}$ Warner and Brownley (1974). Esta calificación está incluida en la página 40 de la tesis doctoral Aplicación del Análisis Multicriterio en la evaluación de impactos ambientales. (2004). Página 40.
} 
metodologías, Luis Alberto García Leyton las recoge en el escrito Aplicación del Análisis Multicriterio en la Evaluación de Impactos Ambientales:

(1) Métodos Analógicos: Consiste en la realización de un análisis de casos, buscando información análoga y similar, que pudiera ser de aplicación para ponderar el impacto ecológico de un proyecto determinado, esta metodología se usa generalmente para el análisis de impacto medioambiental.

(2) Listas de chequeo: Este método consiste en el establecimiento de una serie de puntos y cuestiones a ser respondidas por el usuario del estudio de impacto, con el fin de establecer una base, hay muchas tipologías de listas de chequeo.

(3) Listas de chequeo enfocadas a decisiones: Este tipología sigue el mismo procedimiento que todos los fundamentados en listas de análisis, con la diferencia de que las cuestiones de la lista deben de estar enfocadas en las fases de síntesis, su concepción es un tema de gran complejidad.

(4) Análisis ambiental coste-beneficio: Consiste en un análisis coste-beneficio, centrado especificamente en los temas de consumo de recursos naturales e impacto ambiental, en la actualidad hay muchos métodos para abarcar estos tipos de análisis.

(5) Opinión de expertos: Consiste en la evaluación de expertos, sobre un tema de impacto ambiental, el fin de estas metodologías es la obtención de una opinión rigurosa y en profundidad sobre un aspecto concreto del análisis, (Método Delphi).

(6) Sistemas expertos: Consisten en la codificación de las opiniones de los expertos y la realidad en programas de análisis matemático o informático, para obtener un resultado concreto, conclusivo o parcial en el estudio.

(7) Índices e indicadores: Éste método consiste en la codificación numérica o abstracta de las diferentes realidades a analizar, buscando parámetros de la misma sin llegar a resultados concluyentes.

(8) Pruebas de laboratorio y modelos a escala: Consisten en el análisis práctico de diferentes factores medioambientales con medios científicos y tecnológicos, se utilizan para dar información cuantitativa al estudio de impacto ambiental.

(9) Evaluación de paisajes: Consiste en un análisis cualitativo basado en indicadores, que se fundamenta en criterios de imagen. Se busca ponderar el potencial o impacto visual de un proyecto.

(10) Revisión Bibliográfica: Este análisis es básicamente un estudio del estado del arte a efectos de impacto ambiental, en otros proyectos diferentes al que se está acometiendo más o menos similares. Este método puede resultar ser de utilidad para anticipar posibles impactos ambientales.

(11) Balance de materia: Este análisis se basa en procedimientos de química medioambiental, buscándose y ponderándose las alteraciones en la materia que el proyecto ha causado. Este 
tipo de análisis se utiliza para considerar el impacto ambiental de todo tipo de componentes químicos (dióxido de carbono, residuos...).

(12) Matrices de interacción: Consiste en la relación entre variables de forma matemática o relativa, de forma ordenada y metodológica, son de gran utilidad para caracterizar aspectos concretos.

(13) Monitorización: Consiste en la medición mediante sistemas, de la realidad ambiental, buscando posibles cambios o tendencias en sus características. Sirve para obtener datos en este aspecto.

(14) Estudios de campo: Consisten en la toma de datos a partir de la realidad de manera directa para sacar datos de la realidad, fin muy similar a la monitorización.

(15) Redes: Este estudio, está basado en el establecimiento de las relaciones entre los diferentes factores del estudio contenidos en la metodología, a través de diagramas de relación. A diferencia de las matrices, las redes no siguen un orden concreto, pero muchas veces pueden complementarse unas con otras (Figura A2.1).

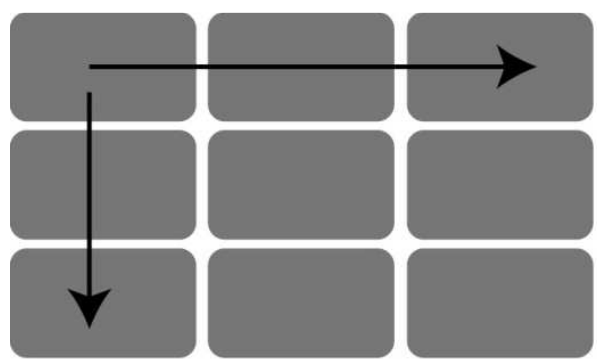

MATRIZ

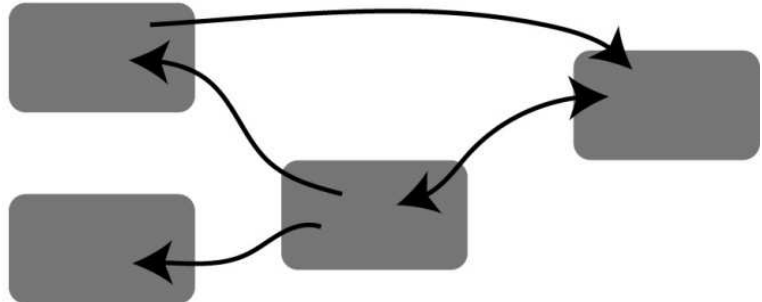

RED

Figura A2.1: Diagrama de funcionamiento de matrices y redes (Elaboración propia)

(16) Superposición de mapas: este análisis consiste en la adición y relación de mapas cartográficos o de análisis para establecer conclusiones del estudio de impacto medioambiental en relación a lugares geográficos. Este estudio es muy útil para establecer líneas de actuación en la zona ubicadas en puntos concretos, o remarcar elementos de interés, ambos asociados a lugares.

(17) Fotografías y fotomontajes: Básicamente consisten en la toma o manipulación de imágenes mediante superposición de las mismas u otros métodos. Este modelo de estudio está muy relacionado con la evaluación de paisajes antes citada,

(18) Modelización cualitativa: Este análisis consiste en la relación o analítica de varios factores, estableciendo vínculos o conclusiones de manera cualitativa, se busca el impacto de estos factores a partir de supuestos. las redes de trabajo explicadas anteriormente son ejemplos de modelización cualitativa. Este método es muy recurrido, ya que muchos factores que se manejan el estudio de impacto ambiental, son de carácter cualitativo.

(19) Modelización cuantitativa: Consiste en el establecimiento de datos y relaciones de manera cuantitativa, (datos numéricos y fórmulas matemáticas) entre los diferentes factores del 
estudio ambiental que pudieran ser abstraídos de la siguiente manera (gramos de gases procedentes de emisiones, litros de agua de lluvia recogidos, superficies de terrenos...)

(20) Evaluación de riesgo: Este estudio se centra en el análisis de los riesgos de impacto ambiental de un proyecto o actividad, ponderándose las acciones y las alteraciones que pudieran acontecer de cara a salud humana y hacia el medio ambiente, que impliquen riesgos en el mantenimiento o conservación de las mismas. Este análisis puede ser enfocando tanto cuantitativa, como cualitativamente.

(21) Construcción de escenarios: Consiste en dar una visión prospectiva de cara a acontecimientos, a partir de los factores y tendencias actuales.

(22) Extrapolación de tendencias: Este estudio, se basa en la recogida de factores de cambio tanto actuales como históricos, ligados en mayor o menor medida a tendencias constantes. Este estudio está muy ligado a la construcción de escenarios y la prospectiva ambiental en general. ${ }^{68}{ }^{1}$

No obstante, lo indicado anteriormente, son métodos de trabajo concretos destinados al estudio de partes concretas. Por consiguiente, un estudio ambiental completo, lo normal es que englobe muchas de estas tipologías de estudio asociadas a un paso en concreto en mayor o menor medida.

A continuación se muestran diferentes metodologías de análisis ambiental al completo, caracterizadas de acuerdo a su finalidad.

1: Metodologías de presentación, abstracción u obtención de datos: estas metodologías de análisis ambiental, tienen como fin último presentar, datos cualitativos o cuantitativos asociados a una realidad concreta. Sin embargo, a pesar de que no buscan conclusiones o hipótesis de manera directa, su grado de importancia es muy elevado, ya que muchos de estos estudios son una base fundamental o una importantísima fuente de información para otros estudios coetáneos o futuros. Algunos ejemplos de metodologías de presentación de datos asociadas al análisis medioambiental, son los estudios de indicadores o los mapas solares de las ciudades.

2: Metodologías de análisis científico: estas metodologías de análisis son las más básicas en cuanto a número de pasos se refiere, y su fin es el análisis de una realidad de manera científica y rigurosa a partir de datos científicos y empíricos que son insertados dentro de la metodología, para a posteriori realizar una síntesis en base a métodos de cálculo establecidos por la propia metodología, que va a dar otros datos científicos diferentes. El objetivo de estas metodologías es la abstracción científica de una realidad para dar datos acerca de la misma, que a posteriori pueden ser o no homologados, (metodologías de homologación). Ejemplos de metodologías

\footnotetext{
${ }^{68}$ Canter, L. and B. Sadler. (1997). A tool kit for effective EIA practice-Review of methods and perspectives on their application. A supplementary report of the international study of the effectiveness of environmental assessment. Oklahoma, Environmental and Ground Water Institute, Institute of Environmental Assessment. Reino Unido, International Association for Impact Assessment. http://www.eiatraining.com/A_Tool_Kit_for_Effective_EIA_Practice.pdf. 148 p.
} 
de análisis en el tema de la arquitectura y el urbanismo, son los programas informáticos de dimensionado de elementos arquitectónicos o los de analítica ambiental, entre otros.

3: Metodologías de homologación: Estas metodologías se basan el análisis cualitativo o cuantitativo de una realidad concreta en base a indicadores y factores, tomando como base una metodología de análisis científico o cualitativo; para a posteriori dar un resultado de acuerdo a un estándar homologado o certificación, el cual generalmente está reconocido de manera institucional. El objetivo de la obtención de esta certificación es mostrar una visión sintética de la realidad que se ha analizado. Generalmente, el resultado está dado y explicado mediante una notación establecida por la propia metodología, que está reconocida de manera oficial por las instituciones oficiales. Esta notación puede tomar como base bien otros estándares científicos (Toneladas de dióxido de carbono emitidas, energía consumida...) o bien un resultado derivado de la síntesis de los datos recogidos para el análisis de la realidad. En relación al urbanismo y a los temas de sostenibilidad, ejemplos de estas metodologías son BREEAM, LEED, Calener o Verde entre otras.

Dentro de estas metodologías, hay casos que tras establecer la certificación final para la realidad a analizar en sí, propongan medidas de mejora, que darán pie a una segunda aplicación de la metodología considerando también los datos introducidos al principio, dando a posteriori una nueva certificación centrada en la supuesta aplicación de las medidas de mejora. Varios ejemplos de estas metodologías en el campo de la arquitectura y el urbanismo son CE3, o CE3X.

4: Metodologías de estandarización y homologación: Estas metodologías tienen como base el establecimiento de unos estándares a ser cumplidos a la hora de materializar un objeto en cuestión, que bien puede ser una pieza de ingeniería, un edificio o un barrio. El cumplimiento total o parcial de las condiciones de estándares anteriormente mencionadas, será lo que hará que el objeto en cuestión una vez materializado pueda tener una certificación u homologación de acuerdo a las condiciones de la metodología en sí. En el campo de la arquitectura y el urbanismo, un ejemplo de metodología de estandarización es Passivhaus.

5: Metodologías de Análisis prospectivo: Estas metodologías tienen como base y finalidad, la presentación de una supuesta visión de futuro a corto, medio o largo plazo, basada en escenarios fundamentados por tendencias y factores de cambio tanto históricos como actuales, por lo que las conclusiones de estas metodologías generalmente son suposiciones que no se pueden garantizar con certeza, debido a la imprevisibilidad del futuro. Los planes estratégicos de los municipios y sus procedimientos, son ejemplos de metodologías de análisis prospectivo. 


\section{ANEXO 3.- ÍNDICE DE TABLAS Y FIGURAS.}

\section{CAPÍTULO 2}

Figura 2.1.1.- Renderizado de Mall of America y su futura ampliación, ejemplo de centro comercial de gran tamaño. Fuente: Star Tribune

Figura 2.1.2.- Imagen urbana en una galería comercial proyectada por Jon Jerde, y ejemplo de Jerde Transfer en el centro comercial de Las Rozas Village. Fuente: Friendsofsdarch, Secretos de Madrid

Figura 2.1.3.- Interior del centro comercial Southdale, y Mall of America. Fuente: Minnesota Hystorical Society, Getty images

Figura 2.2.1.- Ecuación de la sostenibilidad urbana en el tiempo, Izquierda, Evolución en la ciudad actual, Derecha evolución propuesta por Salvador Rueda. Fuente y autoría: Salvador Rueda, Un Nuevo Urbanismo para una ciudad más Sostenible

Figura 2.2.2.- Impacto medioambiental de la edificación en todas sus fases del ciclo de vida. Fuente y autoría: Margarita de Luxan

Figura 2.2.3.- Consumos relativos de combustibles de acuerdo al modelo de intervención sobre en entorno urbano edificado. Fuente y autoría: Mariano Vázquez Espí.

Figura 2.4.1.- Imagen Conceptual ligada al movimiento del New Urbanism. Fuente: hesisprep2014

Figura 2.4.2.- Imagen de una calle de Seaside Fuente: Ron Beitler

\section{CAPÍTULO 3}

Figura 3.1.1.- Imagen del mercado de Trajano y detalle de las tiendas. Se piensa que este complejo es el primer centro comercial integrado y abierto al público de la historia Fuente: Realm Of Hystory, Carole Raddato.

Figura 3.1.2.- Vista del Bazar de Estambul e Interior del Bazar de Teherán Fuente: Google, Iran Review

Figura 3.1.3.- Oxford Covered Market. Funte: Wikipedia, Wikimedia Commons

Figura 3.1.4.- Fachada y arcadas de Gostini Dvor. Fuente: saintpetersburg.com

Figura 3.1.5.- Interiores de Burlington y Westminster Arcade. Fuente: 
Figura 3.1.6.- Fachada e interior de la Galería Vittorio Emmanuelle.

Fuente: deviajeporitalia.com. Tecnaria

Figura 3.1.7.- Fachada e interior de Cleveland Arcade. Fuente:

theclevelandarcade.com, Cleveland Area History

Figura 3.1.8.- Roland Park y Lake View Store. Fuente: Wikipedia, Duluth Budgeteer

Figura 3.1.9.- Country Club Plaza. Fuente: Internet

Figura 3.1.10. Exterior e interior de Southdale, el primer centro comercial con concepto actual de la historia. Fuente: MNopedia, Minnesota Hystorical Society

Figura 3.1.11.- Mall of America y Dubai Mall. Fuente: Internet, Google

Figura 3.1.12.- New South China Mall y Rolling Acres, Ejemplos de centros comerciales en desuso o Dead Malls. Fuente: UberPickleMonkey, Caters News Agency.

Figura 3.1.13.- Media Markt Goya. Fuente: ABC, Zonaretiro.com

Figura 3.1.14.- Gráfico temporal de la evolución de los centros comerciales. Fuente: Elaboración propia

Figura 3.3.1. Desglose por ámbitos de los factores de análisis del proceso de proyecto del centro comercial realizados por el autor Francisco Queipo Blanco. Fuente: Elaboración propia a partir de datos de Francisco Queipo.

Figura 3.5.1.- Berjaya Times Square y Shopping Light, ejemplos de centros comerciales en altura. Fuente: (Internet: sonicsteamsauna, Eu Quero Trabalho

Figura 3.5.2.- West Edmonton y Aricanduva, ejemplos de centros comerciales en superficie Fuente: Internet: paNOW, SkyscraperCity.

Figura 3.5.3.- Ejemplo de big box retailer o hipermercado. Fuente: clevelandconstruction

Figura 3.5.5.- Mall of America, Ejemplo de shopping mall periférico Fuente: Pioneer Press

Figura 3.5.6.- Ejemplo de Shoppping Strip Fuente:

resources3.news.com.au

Figura 3.5.7.- El Carralero, Ejemplo de Power Center. Fuente: bing maps. 
Figura 3.6.1.- Curva de Ciclo de Vida. Elaboración propia a partir de datos de José Miguel Fernández Güell.

Figura 3.6.2.- Esquemas de potencial de mercado según geografía.

Figura 3.6.3.- Curva ciclo vida centros comerciales según localización geográfica Fuente: Elaboración propia a partir de datos de A.T. Kearney y Fernández Güell.

Figura 3.7.1.- Matriz certidumbre-impacto de los factores de cambio.

Fuente: Elaboración propia

Figura 3.7.2.- Análisis DAFO. Fuente: Elaboración propia.

Figura 3.8.1.- Rehabilitación ecoeficiente, ubicación en curva de ciclo de vida, y enfoque respecto a los tres pilares de la sostenibilidad y el urbanismo. Fuente: Elaboración Propia

Figura 3.8.2.- Rehabilitación económica, ubicación en curva de ciclo de vida, y enfoque respecto a los tres pilares de la sostenibilidad y el urbanismo. Fuente: Elaboración Propia

Figura 3.8.3.- Cambio de uso, ubicación en curva de ciclo de vida, y enfoque respecto a los tres pilares de la sostenibilidad y el urbanismo. Fuente: Elaboración Propia.

Figura 3.8.4.- Inserción de usos, ubicación en curva de ciclo de vida, y enfoque respecto a los tres pilares de la sostenibilidad y el urbanismo. Fuente: Elaboración Propia.

\section{CAPÍTULO 4}

Figura 4.2.1.- Relación entre métodos de estudio y fases, remarcando en las que se hace especial hincapié. Fuente: Elaboración propia a partir de datos de Canter y Sadler.

Figura 4.3.1.- Gráfico de la Rosa de Rehabilitación Sostenible. Fuente: Elaboración propia.

Figura 4.5.1.- Número de estimado personas visitantes de un centro comercial de acuerdo a la superficie del mismo, en referencia a los días. Fuente: Shopping Light, Elaboración Propia.

Figura 4.5.2.- Tabla de datos de partida Fuente: Elaboración Propia.

Figura 4.6.1.- Esquema de análisis de tejidos urbanos. Fuente:

Figura 4.6.2.- Clasificación de tejidos por densidad. Fuente: Elaboración Propia a partir de datos de Kevyn Lynch. 
Figura 4.6.3.- Capacidades absorción especies de plantas Micaela Carbajal.

Figura 4.9.1.- Áreas del diagrama de Givoni concernientes a este apartado. Fuente: Javier Neila, Ester Higueras.

Figura 4.9.2.- Áreas del diagrama de Givoni concernientes a este apartado. Fuente: Javier Neila, Ester Higueras.

Figura 4.9.3.- Áreas del diagrama de Givoni concernientes a este apartado. Fuente: Javier Neila, Ester Higueras.

Figura 4.9.4.- Jerarquías de espacios verdes de acuerdo a su superficie, y distancias. Fuente: S. Rueda.

Figura 4.9.5.- Tabla de ponderación en base a la actividad del centro comercial y el transporte. Fuente: Elaboración propia.

Figure 4.10.2.- Analysis of built surfaces in homogeneous areas. Own's source

Figure 4.10.3.- Density qualification of homogeneous areas: Kevin Lynch. Own's source.

Figure 4.10.4.- Givoni chard related to installations. Source: Givoni, Javier Neila, Ester Higueras.

Figure 4.10.5.- Givoni chard related to active solar systems. Source:

Givoni, Javier Neila, Ester Higueras.

Figure 4.10.6.- Givoni chard related to passive measures Source: Givoni, Javier Neila, Ester Higueras.

Figure 4.10.7.- Analysis table of the factors relating attraction index and efficient transport rate. Own's source.

Figure 4.11.1.- Analysis table of the factors relating attraction index and efficient transport rate. Own's source

Figura 4.12.1.- Tabla de centros comerciales de relevancia para el posterior estudio de casos. Fuente: Elaboración propia.

Figura 4.13.1.- Shopping Light. Fuente: Google

Figura 4.13.2.- Shopping Eldorado Fuente: Guía da Semana, Google 
Figura 4.13.9.- Tabla resumen de datos de casos a elegir en profundidad. Fuente: Elaboración propia.

Figura 4.14.1.- Gráfico de relaciones urbanas de Shopping Light. Fuente: Elaboración propia.

Figura 4.14.2: Gráfico de relaciones urbanas de Shopping Eldorado.

Figura 4.14.3.- Gráfico de relaciones urbanas de Shopping Aricanduva.

Figura 4.14.4: Gráfico de relaciones urbanas de ABC Serrano. Fuente:

Figura 4.14.5: Gráfico de relaciones urbanas de La Vaguada. Fuente:

Elaboración propia.

Figura 4.14.6: Gráfico de relaciones urbanas de Parquesur. Fuente:

Elaboración propia.

Figura 4.14.7: Gráfico de relaciones urbanas de Belmar. Fuente:

Elaboración propia.

Figura 4.14.8.- Gráfico de relaciones urbanas de Mall of America. Fuente:

Figura 4.14.9.- Disposición de los casos de estudio respecto a la accesibilidad y la actividad urbana Fuente: Elaboración Propia.

\section{CAPÍTULO 5}

Figura 5.1.1.- Tabla de Datos Shopping Light Fuente: Elaboración propia.

Figura 5.1.2.- Área de Shopping Light y subdivisión por zonas homogéneas. Fuente: Elaboración propia.

Figura 5.1.3.- Análisis de ocupación sobre parcelario. Fuente: Prefeitura de Sao Paulo, FAU USP 
Figura 5.1.4.- Área de Shopping Light, dotaciones, puntos fríos y elementos positivos y negativos. Fuente: Elaboración propia

Figura 5.1.5.- Área de Shopping Light, zonas verdes y capas de vegetación. Fuente: Elaboración propia.

Figura 5.1.6.- Recorridos, tiempos de llegada y zonas cubiertas por el transporte público. Fuente: Elaboración propia a partir de datos de Google

Figura 5.1.7.- Absorción de dióxido de carbono de las zonas verdes en área urbana. Fuente: Elaboración propia.

Figura 5.1.8.- Análisis de parcelas próximas al centro. Fuente:

Elaboración propia a partir de datos de Google.

Figura 5.1.9.- Diagrama de Givoni de Sao Paulo. Fuente: Elaboración propia a partir de datos de Givoni, Climaticus, LABAUT FAU USP.

Figura 5.1.10.- Comparativa de temperaturas entre Sao Paulo y Santa Cruz de Tenerife. Fuente: Elaboración propia a partir de datos del INM, LABAUT FAU USP

Figura 5.1.11: Análisis forma edificación Shopping Light. Fuente: Elaboración propia.

Figura 5.1.12.- Isla de calor para Shopping Light. Fuente: Atlas Ambiental de São Paulo - Prefeitura de São Paulo 2002.

Figura 5.1.13.- Comparación entre tiempos de llegada. Fuente:

Elaboración propia.

Figura 5.1.14.- Gráfico de rosa de rehabilitación sostenible para Shopping Light. Fuente: Elaboración propia.

Figura 5.2.1.- Tabla de datos Shopping Eldorado. Fuente: Elaboración Propia

Figura 5.2.2.- Área de Shopping Eldorado y subdivisión por zonas homogéneas. Fuente: Elaboración Propia a partir de datos de Google.

Figura 5.2.3.- Análisis de ocupación sobre parcelario. Fuente:

Elaboración Propia a partir de datos de Google.

Figura 5.2.4.- Análisis de dotaciones y actividad en área de Shopping Eldorado. Fuente: Elaboración Propia a partir de datos de Google.

Figura 5.2.5.- Área de Shopping Eldorado, Dotaciones, puntos fríos y elementos positivos y negativos Fuente: Elaboración Propia a partir de datos de Google. 
Figura 5.2.6.- Área de Shopping Eldorado, Zonas verdes y capas de vegetación Fuente: Elaboración Propia a partir de datos de Google

Figura 5.2.7.- Recorridos, tiempos de llegada y zonas cubiertas por el transporte público. Fuente: Elaboración Propia a partir de datos de Google.

Figura 5.2.8.- Absorción de las zonas verdes del área urbana de Shopping Eldorado. Fuente: Elaboración Propia

Figura 5.2.9.- Análisis de parcelas próximas al centro Elaboración Propia a partir de datos de Google.

Figura 5.2.10.- Áreas verdes y capas de vegetación Shopping Eldorado. Fuente: Elaboración Propia

Figura 5.2.11.- Absorción elementos vegetales Shopping Eldorado.

Figura 5.2.12.- Diagrama de Givoni de Sao Paulo. Fuente: Elaboración propia a partir de datos de Givoni, Climaticus, LABAUT FAU USP.

Figura 5.2.13.- Análisis forma edificación Shopping Eldorado. Fuente: Elaboración Propia.

Figura 5.2.14.- Isla de calor de Sao Paulo con la ubicación de Shopping Eldorado. Fuente: Elaboración Propia a partir de datos de la Prefeitura de Sao Paulo.

Figura 5.2.15.- Comparación tiempos de llegada. Fuente: Elaboración Propia

Figura 5.2.16.- Gráfico de la rosa de la rehabilitación sostenible para Shopping Eldorado. Fuente: Elaboración Propia.

Figura 5.3.1.- Tabla de Datos Shopping Aricanduva. Fuente: Elaboración propia

Figura 5.3.2.- Área de Shopping Aricanduva y subdivisión por zonas homogéneas. Fuente: Elaboración Propia a partir de datos de Google.

Figura 5.3.3.- Análisis de ocupación sobre parcelario Fuente: Elaboración Propia a partir de datos de Google y la Pr. Sao Paulo

Figura 5.3.4.- Área de Shopping Aricanduva, Dotaciones, puntos fríos y elementos positivos y negativos Fuente: Elaboración Propia a partir de datos de Google.

Figura 5.3.5.- Área de Shopping Aricanduva, Zonas verdes y capas de vegetación. Fuente: Elaboración Propia a partir de datos de Google. 
Figura 5.3.6.- Recorridos, tiempos de llegada y zonas cubiertas por el transporte público Fuente: Elaboración Propia a partir de datos de Google.

Figura 5.3.7.- Absorción de las zonas verdes del área urbana de Shopping Aricanduva. Fuente: Elaboración Propia

Figura 5.3.8.- Análisis de parcelas próximas al centro. Fuente:

Elaboración Propia a partir de datos de Google.

Figura 5.3.9.- Áreas verdes en el centro Aricanduva y localización de las mismas . Fuente: Elaboración Propia a partir de datos de Google.

Figura 5.3.10.- Absorción de áreas verdes en el centro Aricanduva. Fuente: Elaboración Propia.

Figura 5.3.11.- Diagrama de Givoni de Sao Paulo. Fuente: Elaboración propia a partir de datos de Givoni, Climaticus, LABAUT FAU USP,

Figura 5.3.12.- Proporciones y orientación de Aricanduva. Fuente: Elaboración Propia.

Figura 5.3.13.- Isla de calor de Sao Paulo con la ubicación de Shopping Eldorado Fuente: Elaboración Propia, Prefeitura de Sao Paulo.

Figura 5.3.14.- Comparación tiempos de llegada. Fuente: Elaboración Propia.

Figura 5.3.15.- Gráfico de la rosa de la rehabilitación sostenible para Shopping Aricanduva. Fuente: Elaboración Propia.

Figura 5.4.1.- Tabla de Datos ABC Serrano. Fuente: Elaboración propia

Figura 5.4.2.- Área urbana de ABC Serrano y subdivisión por zonas homogéneas. Fuente: Elaboración propia a partir de datos de Google.

Figura 5.4.3.- Análisis de ocupación sobre parcelario, $A B C$ de Serrano va marcado en azul. Fuente: Elaboración propia a partir de datos del Ayuntamiento de Madrid.

Figura 5.4.4.- Análisis de dotaciones. Fuente: Elaboración propia a partir de datos de Google.

Figura 5.4.5.- Análisis de dotaciones. Fuente: Elaboración propia a partir de datos de Google

Figura 5.4.6.- Recorridos, tiempos de llegada, y zonas cubiertas por el transporte público. Fuente: Elaboración propia a partir de datos de Google. 
Figura 5.4.7.- Capacidad de absorción de dióxido de carbono de las especies vegetales en ABC Serrano. Fuente: Elaboración propia.

Figura 5.4.8.- Análisis de parcelas próximas al centro. Fuente:

Elaboración propia a partir de datos de Google.

Figura 5.4.9.- Diagrama de Givoni de Madrid. Fuente: Elaboración propia a partir de datos de Givoni y AEMET.

Figura 5.4.10.- Análisis forma edificación ABC Serrano. Fuente:

Elaboración propia.

Figura 5.4.11.- Isla de calor de Madrid con la ubicación de ABC Serrano. Fuente: Elaboración propia a partir de datos del Ayuntamiento de Madrid y la Universidad Politécnica de Madrid.

Figura 5.4.12.- comparación entre tiempos de llegada. Fuente:

Elaboración propia

Figura 5.4.13.- Gráfico de rosa de rehabilitación sostenible para $A B C$ Serrano. Fuente: Elaboración propia

Figura 5.5.1.- Tabla de datos Shopping Eldorado Fuente: Elaboración Propia.

Figura 5.5.2.- Área de Shopping Eldorado y subdivisión por zonas homogéneas. Fuente: Elaboración Propia a partir de datos de Google.

Figura 5.5.3.- Análisis de ocupación sobre parcelario. Fuente:

Elaboración Propia a partir de datos del Ayuntamiento de Madrid.

Figura 5.5.4.- Área de La Vaguada, Dotaciones, puntos fríos y elementos positivos y negativos . Fuente: Elaboración Propia a partir de datos de Google.

Figura 5.5.5.- Área de La Vaguada, Zonas verdes y capas de vegetación. Fuente: Elaboración Propia a partir de datos de Google.

Figura 5.5.6.- Recorridos, tiempos de llegada y zonas cubiertas por el transporte público. Fuente: Elaboración Propia a partir de datos de Google.

Figura 5.5.7.- Absorción de las zonas verdes del área urbana de La Vaguada. Fuente: Elaboración Propia

Figura 5.5.8.- Análisis de parcelas próximas al centro. Fuente: Elaboración Propia a partir de datos de Google.

Figura 5.5.9.- Áreas verdes y capas de vegetación La Vaguada, Fuente: Elaboración Propia. 
Figura 5.5.10.- Absorción elementos vegetales en La Vaguada. Fuente:

Elaboración Propia.

Figura 5.5.11.- Escala de calificaciones CE3X, con las calificaciones de La Vaguada. Fuente: Elaboración propia a partir de datos del IDAE.

Figura 5.5.12.- Análisis de forma de la edificación, La Vaguada. Fuente:

Elaboración propia.

Figura 5.5.13.- Isla de calor de Madrid con la ubicación de La Vaguada. Elaboración propia a partir de datos del Ayuntamiento de Madrid.

Figura 5.5.14.- Comparación de recorridos a La Vaguada. Fuente:

Elaboración propia

Figura 5.5.15.- Gráfico de rosa de rehabilitación sostenible para La Vaguada. Fuente: Elaboración propia

Figura 5.6.1.- Tabla de datos Parquesur. Fuente: Elaboración Propia.

Figura 5.6.2.- Área de Parquesur y subdivisión por zonas homogéneas. Fuente: Elaboración Propia a partir de datos de Google.

Figura 5.6.3.- Análisis de ocupación sobre parcelario. Fuente:

Elaboración Propia.

Figura 5.6.4.- Área de Parquesur, Dotaciones, puntos fríos y elementos positivos y negativos. Fuente: Elaboración Propia a partir de datos de Google.

Figura 5.6.5.- Área de Parquesur, Zonas verdes y capas de vegetación. Fuente: Elaboración Propia a aprtir de datos de Google.

Figura 5.6.6.- Recorridos, tiempos de llegada y zonas cubiertas por el transporte público. Fuente: Elaboración Propia a aprtir de datos de Google.

Figura 5.6.7.- Absorción de las zonas verdes del área urbana de Parquesur. Fuente: Elaboración Propia

Figura 5.6.8.- Análisis de parcelas próximas al centro. Fuente:

Elaboración Propia a partir de datos de Google.

Figura 5.6.9.- Áreas verdes y capas de vegetación en Parquesur Fuente: Elaboración Propia a partir de datos de Google.

Figura 5.6.10.- Absorción de las áreas verdes en Parquesur. Fuente: 
Figura 5.6.11.- Escala de calificaciones CE3X, con las supuestas calificaciones de Parquesur. Fuente: Elaboración propia a partir de datos de IDAE.

Figura 5.6.12.- Análisis de forma de la edificación, Parquesur. Fuente:

Elaboración propia

Figura 5.6.13.- Rasgos de la Isla de calor de la Comunidad de Madrid.

Fuente: Antonio Moreno, et al. Comunidad de Madrid.

Figura 5.6.14.- Comparación de recorridos a Parquesur. Fuente:

Elaboración propia.

Figura 5.6.15.- Gráfico de rosa de rehabilitación sostenible para Parquesur. Fuente: Elaboración propia.

Figura 5.7.1.- Tabla de datos Belmar. Fuente: Elaboración Propia.

Figura 5.7.2.- Área de Belmar y subdivisión por zonas homogéneas. Fuente: Elaboración Propia a partir de datos de Google.

Figura 5.7.3.- Análisis Tejidos Belmar. Fuente: Elaboración Propia a partir de datos de Google.

Figura 5.7.4.- Análisis de dotaciones y actividad del área de Belmar. Fuente: Elaboración Propia a partir de datos de Google.

Figura 5.7.5.- Área de Belmar, Zonas verdes y capas de vegetación. Fuente: Elaboración Propia a partir de datos de Google.

Figura 5.7.6.- Recorridos, tiempos de llegada y zonas cubiertas por el transporte público en el área de Belmar Fuente: Elaboración Propia a partir de datos de Google.

Figura 5.7.7.- Absorción de las zonas verdes del área urbana de Belmar. Fuente: Elaboración Propia.

Figura 5.7.8.- Análisis de parcelas próximas al centro. Fuente:

Elaboración Propia a partir de datos de Google.

Figura 5.7.9.- Áreas verdes y capas de vegetación en Belmar Fuente: Elaboración Propia a partir de datos de Google.

Figura 5.7.10.- Absorción de las áreas verdes en Belmar. Fuente:

Figura 5.7.11: Diagrama de Givoni de Denver. Elaboración propia a partir de datos de Givoni y NOAA.

Figura 5.7.12.- Isla de calor de Denver, se estimó en la zona de Lakewood en base a la configuración urbana. Fuente: www.deeproot.com. 
Figura 5.7.13.- Comparación de recorridos a Belmar. Fuente: Elaboración propia.

Figura 5.7.14.- Gráfico de rosa de rehabilitación sostenible para Belmar.

Fuente: Elaboración propia.

Figura 5.8.1.- Tabla de datos de Mall of America Fuente: Elaboración Propia.

Figura 5.8.2.- Área de Mall of America, establecimiento y subdivisión por zonas homogéneas. Fuente: Elaboración propia a partir de datos de Google.

Figura 5.8.3.- Área de Mall of America, dotaciones, puntos fríos y elementos positivos y negativos. Fuente: Elaboración propia a aprtir de datos de Google.

Figura 5.8.4.- Área de Mall of America, zonas verdes y capas de vegetación. Fuente: Elaboración propia a aprtir de datos de Google.

Figura 5.8.5.- Recorridos, tiempos de llegada y zonas cubiertas por el transporte público. Fuente: Elaboración propia a aprtir de datos de Google.

Figura 5.8.6.- Absorción de dióxido de carbono de las zonas verdes en área urbana de Mall of America. Fuente: Elaboración propia

Figura 5.8.7.- Análisis de parcelas próximas al centro Mall of América. Fuente: Elaboración propia a aprtir de datos de Google.

Figura 5.8.8.- Áreas verdes del centro comercial Mall of America. Fuente: Elaboración propia a aprtir de datos de Google.

Figura 5.8.9.- Absorción de las ,áreas verdes del centro comercial Mall of America. Fuente: Elaboración propia.

Figura 5.8.10.- Diagrama de Givoni de Minneapolis. Fuente: Elaboración propia a partir de datos de Givoni y NOAA.

Figura 5.8.11.- Isla de Calor de Minneapolis. Fuente: University of Minnesota, Peter Snyder, Tracy Twine.

Figura 5.8.12.- Comparación entre tiempos de llegada para Mall of America. Fuente: Elaboración propia

Figura 5.1.13.- Gráfico de rosa de rehabilitación sostenible para Mall of America. Fuente: Elaboración propia 
Figure 5.9.2.- Graphs of the Sustainable Retrofitting Rose for each case.

Own's source.

Figure 5.9.3.- Kevin Lynch based analysis graph for cases urban areas.

Own's source.

Figure 5.9.4.- Retrofitting roses of the cases located in dense urban areas.

Own's source.

Figure 5.9.5.- Retrofitting roses of the cases located in expanded city

centers. Own's source.

Figure 5.9.6.- Retrofitting roses of the cases located in nearby outskirts.

Own's source.

Figure 5.9.7.- Retrofitting roses of the cases located in the North

American Suburban areas. Own's source.

Figure 5.9.8.- Retrofitting graph according to urban areas typologies and locations. Own's source.

\section{CAPÍTULO 6}

Figure 6.2.1.- Table with scores after retrofitting application. Own's source.

Figure 6.2.2.- Retrofitting Rose Graphs for the cases studied, after the application of the retrofitting operations. Own's source.

Figure 6.2.3.- Comparison of the average scores of the shopping malls before and after the theoretical retrofitting operations. Own's source.

Figure 6.2.4.- Comparison of the retrofitting results for the cases of Shopping Light and ABC Serrano. Own's source.

Figure 6.2.5.- Comparison of the retrofitting results for the cases for Shopping Eldorado and La Vaguada. Own's source.

Figure 6.2.6.- Comparison of the retrofitting results for the cases of Aricanduva and Parquesur. Own's source.

Figure 6.2.7.- Comparison of the retrofitting results for the cases of Mall of America and Belmar. Own's source.

Figure 6.2.8.- Efficacy of the retrofitting means related to urban background, conclusive graph. Own's source.

Figure 6.4.1.- Tabla de puntuaciones después de las operaciones de rehabilitación Fuente: Elaboración propia. 
Figura 6.4.2.- Gráficos de rosas de rehabilitación sostenible tras las operaciones de rehabilitación. Fuente: Elaboración propia

Figura 6.4.3: Comparación de las medias por familia de medios de rehabilitación, antes y después de las operaciones teóricas estudiadas. Fuente: Elaboración propia.

Figura A2.1: Diagrama de funcionamiento de matrices y redes (Elaboración propia) 


\section{Agradecimientos:}

A mi tutora y directora de tesis Ester Higueras García.

Al profesor Leonardo Monteiro de la Universidad de Sao Paulo, y James Buckley de la Unversidad de Oregón.

Al personal del departemento de Urbanismo y los componentes de los tribunales y mesas de expertos, en la corrección de la tesis.

A mis padres M. Ángeles y Joaquín.

A mi hermano Jaime y a Lara.

A a mis abuelos Joaquín y Carmen, a mis tíos Jose Luis, Rosalía y Antonia.

A las gerencias de Shopping Light y Shopping Eldorado por los datos otorgados.

A mis amigos: Moises, Ángel, Alberto, Alicia, Sara y sus primos Alex y Gonzalo, Jose, Nacho, Darío, Iván, y Adrián.

A mis amigos de Sao Paulo: Daniel, Thales y Katia. 